
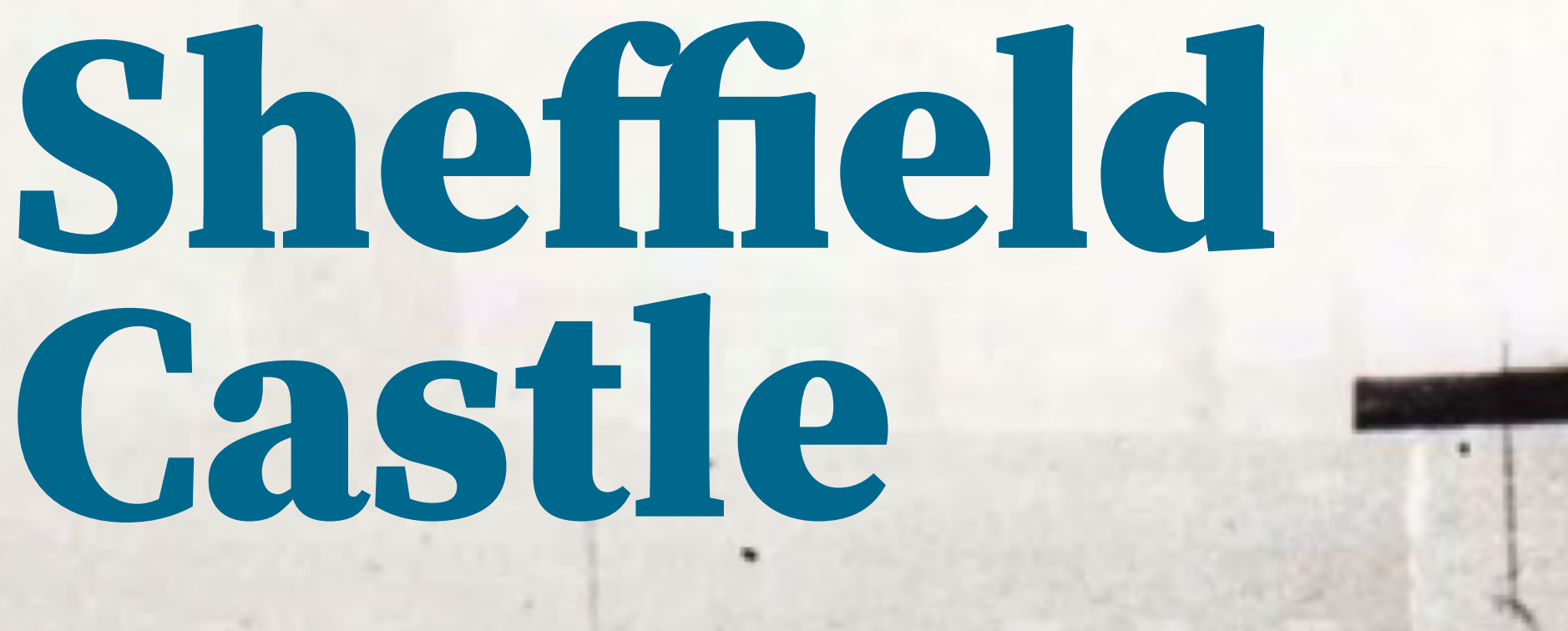


\title{
Sheffield Castle: Archaeology, Archives, Regeneration, 1927-2018
}

\author{
John Moreland and Dawn Hadley \\ with \\ Ashley Tuck and Milica Rajic
}

\begin{abstract}
and contributions by
Umberto Albarella, Lucy Allott, Phil Andrews, Rachel Askew, Ian Atkins, Mark Bateman, Pauline Beswick, Pippa Bradley, Alex Brown, Alan Bryson, Caitlin Buck, Andrea Burgess, Carolyn Butterworth, Nigel Cameron, Liz Chambers, Vicky Crewe, Chris Cumberpatch, Glyn Davies, Gareth Dean, Deborah Harlan, Chris Harrison, David Higgins, Glynis Jones, Matt Leach, Inés López-Dóriga, Erica Macey-Bracken, Rod Mackenzie, Steve Maddock, Lucy Marston, Lorraine Mepham, Alvaro Mora-Ottomano, Quita Mould, Nicky Mulhall, Richard Payne, Andrew Powell, Paul Rowland, Peter Ryder, Ellen Simmons, James Symonds, Ian Tyers, Susie White, John Whittaker, Morgan Windle, Jane Young
\end{abstract}

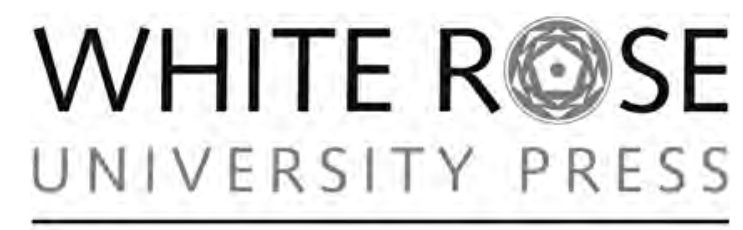

Universitles of Leeds, Sheffield \& York 
Published by

White Rose University Press

(Universities of Leeds, Sheffield and York)

University of York,

Heslington, York, UK, YO10 5DD

https://universitypress.whiterose.ac.uk

Sheffield Castle: archaeology, archives, regeneration, 1927-2018

Text (C) The Author(s) 2020

First published 2020

Front cover image: A photograph taken by Joseph Himsworth when he visited the building work on Castle Hill in October 1927.

Courtesy of Museums Sheffield.

Back cover image: The gatehouse of Sheffield Castle in a

Virtual Reality model. University of Sheffield.

Cover designed by Tom Grady, WRUP

ISBN (Hardback): 978-1-912482-28-3

ISBN (PDF): 978-1-912482-29-0

ISBN (EPUB): 978-1-912482-30-6

ISBN (MOBI): 978-1-912482-31-3

DOI (volume): https://doi.org/10.22599/SheffieldCastle

Reuse statement: Apart from exceptions, where specific copyright statements are given, this work is licensed under the Creative Commons Attribution Non-Commercial 4.0 International License (CC BY-NC 4.0). To view a copy of this license, visit https://creativecommons.org/licenses/by-nc/4.0 or send a letter to Creative Commons, PO Box 1866, Mountain View, California, 94042, USA. This license allows for sharing and adapting any part of the work for personal and non-commercial use, providing author attribution is clearly stated.

Example citation: Moreland, J. and Hadley, D. (with A. Tuck and M. Rajic). 2020. Sheffield Castle: archaeology, archives, regeneration, 1927-2018. York: White Rose University Press. DOI: https://doi.org/10.22599

/SheffieldCastle. CC BY-NC 4.0, https://creativecommons.org/licenses/by-nc/4.0

To access this work freely online via the White Rose University Press website, please scan this QR code or visit https://doi.org/10.22599/SheffieldCastle. 
For Pamela Staunton 1930-2014

Pam had an abiding interest in the archaeology and history of South Yorkshire (and north Derbyshire!) and was a mainstay of the Hunter Archaeological Society. Her generous bequest to the University of Sheffield made possible this book and its associated digital archive; without it our understanding of Sheffield's past would be immeasurably diminished. 



\section{Contents}

Foreword vii

Acknowledgements $\quad$ ix

Preface: Biography of a Castle $\quad$ xiii

Chapter 1: Sheffield and Its Castle 1

Chapter 2: Archaeological Practice in the Inter-War Years 29

$\begin{array}{lr}\text { Chapter 3: The Origins of Sheffield Castle } & 69\end{array}$

Chapter 4: Post-War Rebuilding: A New Battle for the Castle 105

Chapter 5: 'Long before Castles Were Thought of': Sheffield Castle and Deep History 135

$\begin{array}{ll}\text { Chapter 6: Pots, Pins and People } & 185\end{array}$

Chapter 7: Modern Excavation and Regeneration, 1999-2018 (Ashley Tuck and Milica Rajic) 215

$\begin{array}{ll}\text { Chapter 8: Beyond the Pale } & 251\end{array}$

Chapter 9: The Persistence of Place 289

Epilogue 333

Bibliography 341

$\begin{array}{ll}\text { Index } & 367\end{array}$ 



\section{Foreword}

The University of Sheffield is a truly civic university. Founded in 1905 on penny donations from local steel and factory workers and residents, the University has remained committed to putting the knowledge and research expertise of its academics to the service of the people of the city. When the City Council decided to move the Markets from Castlegate to the Moor, it became clear to me that this was an opportunity for us to work with the local authority to help effect the regeneration of this, now run-down, former heart of the city. The Castlegate Steering Group, which I established in 2013, comprised colleagues from the departments of Animal and Plant Sciences, Archaeology, Architecture, History, Landscape Design, Civil and Structural Engineering, and Town and Regional Planning, and was chaired by Prof. John Moreland, one of the authors of this book. The group worked closely with the City Council, advising, for example, on city-centre Masterplans, meanwhile uses for the site of the former markets, and funding applications. It also (along with Prof. Richard Jones, former ProVice Chancellor for Research and Innovation) commissioned the early analyses of the textual archives from Sheffield Castle from which this marvellous book ultimately grew.

Sheffield Castle lay buried under the Markets. For some it was a myth and a memory, for others it was an emblem of civic pride and identity - for most, it was forgotten. In a 21st-century context, however, it represented a tremendous resource - a vehicle through which the heritage-led regeneration of Castlegate could be delivered. But before that could begin, we had to understand the heritage of the site itself. The results of 20th-century excavations on the site lay buried in the archives, depriving both the people of Sheffield and potential developers of the site of the rich information they contain.

The authors, aided (again!) by a donation from a local resident, and in partnership with the City Council and Museums Sheffield, have therefore done a great service to the city and its people by bringing this material to publication. They have demonstrated the richness of the city's pre-industrial history, and have shown how, time and again, local people and local organisations were at the heart of efforts to rescue, preserve and protect that history. The medieval heritage of the Manor Estate was the focus of a community engagement project led by another of the authors of this book, Prof. Dawn Hadley (then of the University of Sheffield, now of the University of York), showing how urban regeneration can be informed by academic research. The 2018 excavations conducted by Wessex Archaeology continue this tradition of archaeological research conducted within the context of community engagement and urban regeneration debates. Through their highly innovative approach to the study of a medieval castle, the authors have provided the people of the City, its planners and developers, with a major resource - for shaping both identity in the present, and the city of the future. Through

\footnotetext{
How to cite this book chapter:

Moreland, J. and Hadley, D. (with A. Tuck and M. Rajic). 2020. Sheffield Castle: archaeology, archives, regeneration, 1927-2018, pp. vii-viii. York: White Rose University Press. DOI: https://doi.org/10.22599/SheffieldCastle.l. CC BY-NC 4.0, https://creativecommons.org/licenses/by-nc/4.0
} 
their partnership with local creative media companies, Human and Llama Digital, they are also leading the way in showing how this heritage asset can be used to inform people about the past so that they can take informed decisions about the future.

And, finally, I am delighted that it has been possible to make this publication available as an Open Access monograph, free to read online, and for this to be accompanied by a digital archive hosted by the Archaeology Data Service. The archives on which the book is based belong to the people of the city and now we are able to share them not only with the local community but globally, bringing new audiences to this famous place. I hope that readers will take the opportunity afforded by the digital archive to conduct their own research on the castle, and find their own stories in the archive. This ensures that Sheffield Castle will continue to fascinate and stimulate stories and ideas for generations to come.

Prof. Vanessa Toulmin Director of City and Cultural Engagement

University of Sheffield 


\section{Acknowledgements}

The authors of this book owe a huge debt of gratitude to friends and colleagues with whom we have worked over many years to bring to publication our study of Sheffield Castle. We would particularly like to thank Prof. Vanessa Toulmin (Director of City and Cultural Engagement, University of Sheffield) for spearheading the University of Sheffield's engagement with Castlegate (and the city more generally - she recognised earlier than most the value of heritage-led regeneration), and Prof. Richard Jones (former Pro-Vice Chancellor for Research and Innovation, University of Sheffield), who provided funding for analysis of the documentary sources, and our early work on the Museums Sheffield archives. A grant from the Arts \& Humanities Research Council to John Moreland (and Prof. Anthony Milton, Department of History, University of Sheffield) enabled this research to feed into a walking tour phone app of Sheffield in the 16th and 17th centuries, produced by Rachel Askew in collaboration with Llama Digital (https://situate.io/sheffieldlives). A grant from the Faculty of Arts and Humanities' Arts Enterprise Academic in Residence scheme permitted John Moreland to spend time working with the Friends of Sheffield Castle in 2017. Further grants from Research Services and from the Office of Partnerships and Regional Engagement allowed him to devote more time to writing this book. Time to complete the writing up of the book was provided to John Moreland by the Department of Archaeology, University of Sheffield, through study leave and teaching buy-out, and to Dawn Hadley by research leave from the Department of Archaeology, University of York. We are also grateful to Miles Stevenson (Director of Advancement) and Louise Shaw (Senior Development Manager) of Development, Alumni Relations and Events, University of Sheffield for their efforts to secure funding for the Castlegate Archives Project. The Society for Medieval Archaeology funded research on the shell-tempered pottery. The project would not, however, have been possible but for a bequest to the Department of Archaeology by Pamela (Pam) Staunton, a resident of Unstone (Derbs), member of the Hunter Archaeological Society and alumna of the University of Sheffield, which provided us with the resources to digitise the relevant archives and to research and write this book.

The book has benefitted immensely from the contributions of a range of specialists who wrote archive reports that underpinned several of the chapters. Dr Gareth Dean (now University of York), was Research Assistant for the Castlegate Archives Project (2017-18), liaised with finds specialists and coordinated their access to the Museums Sheffield archives, assisted Ashley Tuck with the digitisation of the archive, and produced an index to the archive of Leslie Butcher, which underpins the appendix to Chapter 5. Dr Rachel Askew and Dr Alan Bryson (both then University of Sheffield) produced archive reports on the unpublished written sources for

\footnotetext{
How to cite this book chapter:

Moreland, J. and Hadley, D. (with A. Tuck and M. Rajic). 2020. Sheffield Castle: archaeology, archives, regeneration, 1927-2018, pp. ix-xiii. York: White Rose University Press. DOI: https://doi.org/10.22599/SheffieldCastle.m. CC BY-NC 4.0, https://creativecommons.org/licenses/by-nc/4.0
} 
Sheffield Castle (2015-16), and in this we were advised by Prof. Anthony Milton. Analysis of the finds from the early and mid-20th-century excavations was undertaken by Dr Chris Cumberpatch and Jane Young (pottery), Quita Mould (leather) and Lorraine Mepham (Wessex Archaeology; all other small finds). Dr Mark Hall (Perth Museum and Art Gallery) kindly discussed with us the 'playing card' recovered by Leslie Armstrong. We would also like to thank the Archaeology Data Service at the University of York for hosting the digital archive, and particularly Dr Ray Moore for his advice on digitisation protocols.

Wessex Archaeology would like to thank Sheffield City Council for commissioning the 2018 archaeological evaluation, which is the basis of Chapter 7, especially Simon Ogden and Helen Leavers, who commissioned and managed the project, and Dinah Saich and Zac Nellist of South Yorkshire Archaeology Service, which monitored the project on behalf of the Council. They would like to thank Amy Derrick and Sam Birchall for their incredibly hard work on site and in the post-excavation process. The trial trench excavation was assisted by University of Sheffield students Isabelle Sherriff, Paul Harrison, Georgina Goodison and James Chapman, and important contributions on site were also made by Wessex Archaeology's staff Ciaran O'Neill, Jake Dyson, Stuart Pierson, Otis Gilbert, Rob Jones, Karen Austin and John Whitmore and University of Sheffield student Erina Mamenda. The borehole survey was undertaken by Richard Payne and Liz Chambers and was reported on by Alex Brown. The environmental samples were processed by Liz Chambers, Fiona Eaglesham, Morgan Windle, Chris Warburton, Gwen Naylor and Kate Fitzpatrick. Jack Fox-Laverick operated a drone. The illustrations were produced by Ian Atkins and Rob Goller. Wessex Archaeology are very grateful to all volunteers who participated in the project. Their sincere gratitude goes to Prof. John Moreland for his support, inspiration, help and friendship, and they are also grateful to Prof. Dawn Hadley, Dr Gareth Dean, Prof. Glynis Jones, Ellen Simmons, Prof. Mark Bateman and Prof. Caitlin Buck for their assistance. Thanks are due to Dr Samantha Stein, who at the time of the excavation was Assistant Science Advisor (Yorkshire) at Historic England, and to Dr Andrew Hammond (Science Advisor at Historic England) for his support. Westmoreland Plant Hire and HB Tunnelling provided plant and specialist deep excavation equipment and expertise.

The material from the 2018 Wessex Archaeology excavations was analysed by Dr Chris Cumberpatch and Jane Young (pottery), Dr Susie White and Dr David Higgins (clay tobacco pipes), Dr Rod Mackenzie (industrial material), Peter Ryder (architectural stone), Alvaro Mora-Ottomano (additional information about ceramic building material), Phil Andrews (slag), Dr Lucy Allott and Erica Macey-Bracken (wood), Prof. Umberto Albarella and Morgan Windle (animal bone), Lorraine Mepham (other finds), Ellen Simmons, Prof. Glynis Jones, Inés López-Dóriga and Nicky Mulhall (environmental samples), Liz Chambers (geoarchaeological evidence), Alex Brown (pollen), Prof. Mark Bateman (luminescence dating), Prof. Caitlin Buck and Inés LópezDóriga (statistical analysis), Dr Nigel Cameron (diatoms) and John Whittaker (ostracods). The excavations were written up by Ashley Tuck and Milica Rajic, who co-authored Chapter 7 of this book.

Research on the hunting lodge led by Dawn Hadley between 2009 and 2011 is the basis for Chapter 8 and this was funded by a grant from the Higher Education Innovation Fund. We are grateful to the supervisors of the excavations conducted at that time: Michael McCoy (ARCUS), Chris Harrison, Andrea Burgess (Wessex Archaeology), Alvaro Mora-Ottomano (then of Archaeological Research Services Ltd) and Dr Vicky Crewe (University of Sheffield), to the site assistants Charlie Hay, Dr Lauren McIntyre, Dr Charlotte Howsam, Dr Jenny Crangle, Dr Gareth Perry and Dr Letty ten Harkel, and the student and volunteer participants. Buildings recording was carried out by Lucy Marston (Wessex Archaeology), and post-excavation analysis of finds was supervised by Lorraine Mepham, Justin Wiles (Wessex Archaeology) and Dr Vicky Crewe. The excavation reports were written up by Lorraine Mepham, Andrew Powell, Andrea Burgess, Chris Harrison, Lucy Marston, Dr Rachel Askew and Dr Vicky Crewe, and illustrations were produced by Chris Swales, Kenneth Lymer (Wessex Archaeology) and Colin Merrony (University of Sheffield). Deborah Harlan (University of Sheffield) produced reports on the excavations conducted at the hunting lodge by Sheffield City Museum between 1968 and 1980, and the archival sources were studied by Dr Rachel Askew, who contributed to writing up the historical evidence discussed in Chapter 8.

We owe a particular debt of thanks to numerous people who helped to provide the figures for this book. New illustrations were prepared by Ian Atkins and Chris Swales (Wessex Archaeology). We are grateful to Pat Wagner for permission to reproduce images from the original diary of Joseph Himsworth, Paul Rowland for permission to reproduce his photograph of the 2018 excavations, and Aidan McRae Thomson for permission to reproduce his photograph of the tomb of the $4^{\text {th }}$ Earl of Shrewsbury. The National Portrait Gallery gave permission to reproduce paintings of Mary, Queen of Scots and Bess of Hardwick. Museums Sheffield 
were incredibly helpful in tracking down images for the book and for permission to reproduce them, and we are especially grateful to Leigh-Anne Baldridge (Collections Access Curator) and Sian Brown (Head of Collections). As the latter noted, it is important to be clear that, although permission for reproductions was given by Museums Sheffield, 'it is the city and the people of Sheffield who own the material'. Katherine Bishop and Lindsay Cooke, from the University of Sheffield Library provided access to maps. Ed Powell (the Co-operative Group) gave permission to reproduce the 1964 painting of Sheffield Castle by Kenneth Steel. Ruth Morgan and Tony Ball gave permission to reproduce images from the Transactions of the Hunter Archaeological Society. Pete Evans (Sheffield City Archives) was incredibly helpful in providing us with images from Picture Sheffield (www.picturesheffield.com) and Sheffield Archives. We are grateful to Nancy Fielder and Jane Salt for permission to reproduce images from Sheffield Newspapers Ltd. Reconstructions of the castle and hunting lodge were created by Marcus Abbott (then of ARCUS) and Dan Fleetwood and Michaela McKone (Human). Steve Pool took the picture (Figure vii) of the reconstructed castle projected on the wall of Exchange Place studios overlooking the site.

One of the real joys of the project was the opportunity to work with colleagues from across the University of Sheffield on aspects of it. Carolyn Butterworth runs the School of Architecture's Live Projects, in which students work on 'real projects, in real time with real people'. Castlegate has been home to several Live Projects, all of which have engaged with its heritage, the archaeology of Castle Hill, and the issue of regeneration. Carolyn also worked with two of us (John Moreland and Dawn Hadley), and Ralph Mackinder (School of Architecture), in the project to create Virtual Reality and Augmented Reality models of the castle, as well as a physical 3D model on which the latter was projected. This project was a collaboration with Dr Steve Maddock, Matt Leach (Department of Computer Science), and Nick Bax, Dan Fleetwood and Michaela McKone of the Sheffield creative organisation Human, which was funded by the Arts and Humanities Research Council and the Engineering and Physical Sciences Research Council (grant AH/R009392/1 to Dawn Hadley (PI), Steve Maddock and Carolyn Butterworth (Co-Is)). Also involved in preparing the digital model of the castle for display were students Kacper Pach (School of Architecture) and James Harvey (Department of Computer Science). Additional funding for this was received from the University of Sheffield's Festival of the Mind and Sheffield Undergraduate Research Experience scheme in 2018. We would also like to thank Dr Graham McElearney, Senior Learning Technologist (Academic Practice and Skills Development team) for his help and advice on our digital project.

During the period when the research for this book and the associated digital archive was conducted we received support and encouragement from a variety of individuals and organisations we would like to thank: Simon Ogden, Castlegate Programme Director, Sheffield City Council, for long-term support and collaboration in our joint efforts to secure heritage-led regeneration in Castlegate; members of the Castlegate Partnership, particularly Paul Houghton (chair), Valerie Bayliss (Friends of the Old Town Hall), and Kate Dore (Yorkshire Artspace); Martin Gorman and Ron Clayton (Friends of Sheffield Castle), who also provided feedback on Chapters 1 and 9 and the Epilogue; Andrew Norton (Regional Director of Wessex Archaeology North), for his continuous support and invaluable knowledge and advice, and sharing with us his experience of digging Oxford Castle; Anna Badcock (Peak District National Park Authority); Dr Glyn Davies (ArcHeritage); LeighAnne Baldridge, Martha Lawrence and Kim Streets (Museums Sheffield) who facilitated access to the archives of Leslie Armstrong, Joseph Himsworth and Leslie Butcher; Ed Dennison (Ed Dennison Archaeological Services Ltd) for providing us with archive reports; Ken Dash, who arranged access to the pottery from the castle on display at the Bishops' House Museum; Pauline Beswick, former Keeper of Antiquities at Sheffield City Museum, who advised us about her excavations at Sheffield Manor Lodge and recording of aspects of the castle archaeology in the 1970s, provided important information about the work of Leslie Butcher and John Bartlett, and read and commented on Chapter 4; Pat Wagner, who provided us with her unpublished biography of Joseph Himsworth and the original version of his diary; Prof. Tim Darvill (University of Bournemouth), who advised on archaeological practice in the early 20th century; Prof. Richard Hodges (President of the American University of Rome) for his insights into archaeology, heritage and placemaking; Kathryn Goulding, who assisted with organisation of the digitised archive; Jayne Burland, who provided bibliographical assistance at the start of our project; Katherine Onadeko (Architects Registration Board) for information on F. E. P. Edwards (Sheffield City Architect); Alistair McLean (President of the Sorby Natural History Society and Curator of Natural Sciences at Weston Park Museum) and Margaret Boulton (secretary of the Sorby Natural History Society) for information on Mr T. L. C. Bottomley, who studied botanical remains from the 1958-61 excavations; Dr Nick Butcher for information on his father's career and the recording of Sheffield Castle he undertook 
from 1958, and for feedback on a draft of Chapter 4; Steve Thompson, Principle 5 Yorkshire Co-operative Resource Centre, for information on the early history of the Co-op, the loan of the 1929 souvenir brochure and other documents; Dr David Clarke (Sheffield Hallam) for sharing with us his paper on Earl Waltheof; Dr Richard Nevell for providing us with a copy of his PhD thesis; Michael Clark for access to his University of Sheffield undergraduate dissertation on the 'afterlife' of Castle Hill; Kevin Booth (English Heritage) for supply of the unpublished report on the pottery from excavations at Conisbrough Castle; Lynn Dowding of Romsey, and former University of Sheffield Geology student, for her memories of, and bibliographical information on, Norton Hall; and Kate Petherbridge and Tom Grady from White Rose University Press for their help and support, as well as the anonymous reviewers who provided useful feedback both on the original book proposal and the final manuscript. A number of colleagues read drafts of this book and provided valuable feedback; in particular we would like to thank Prof. Julian D. Richards (University of York), Dr Jon Finch (University of York), Prof. Prue Chiles (University of Newcastle), Prof. Richard Hodges (American University of Rome) and Prof. Martin Carver (University of York).

John Moreland (University of Sheffield) and Dawn Hadley (University of York) Ashley Tuck and Milica Rajic (Wessex Archaeology) 


\title{
Preface
}

\section{Biography of a Castle}

\begin{abstract}
Passing on to Waingate we stand on classic ground, but it is a little foreign to the tenor of our usual conversations to go so far back as to try to conjure up an imaginary picture of what the old Castle used to be. The materials for such a picture are very scanty, and all that remains to us above ground is the name (Leader 1875, 218)

The uncovering of the castle remains and part of the River Sheaf will create a new focus for Castlegate which provides a direct link with the historic roots of Sheffield (Sheffield City Council Castlegate Masterplan, EDAW 2005, 9)
\end{abstract}

The northern English city of Sheffield is not well known for its medieval heritage. Rather, the 'Steel City' gained global fame in the 18th and 19th centuries for the products of its metalworking forges, and for innovations in manufacturing processes, including those involved in the production of crucible and stainless steel (Hey 1991; 2005; 2010, 86-94). In the early 18th century, the novelist Daniel Defoe commented on the features which were to make Sheffield famous across the world, describing it as 'very populous and large, the streets narrow and the houses dark and black, occasioned by the continued smoke from the forges, which are always at work' (Defoe 1724-27, III, letter 8, part 3), while towards the end of the 19th century John Daniel Leader (1872, 371), a Sheffield newspaper proprietor and antiquarian, lamented that the city had almost lost its connection with the romance of history and is known to fame only for its hardware and smoke. In more recent times, Sheffield has become internationally recognised for its vibrant creative arts scene, through bands such as ABC, Def Leppard, The Human League, Pulp and Arctic Monkeys, but, as elsewhere, this emerged in the context of economic hardship caused, in Sheffield's case, by government cuts and the demise of the steel industry. Nowadays, the city is at least as well known to international audiences through its portrayal in the film The Full Monty (1997), an affectionate tale but one in which the ravages of post-industrial decline provide the backdrop to the story of unemployed former steel workers who became male strippers. This book sets out to present a very different account of Sheffield from the one contained within this standard narrative of industrial colossus to post-industrial rustbelt (Hey 2010, 86-94). Its focus is Sheffield Castle, one of the largest medieval castles in northern England, which was ordered to be demolished at the end of the English Civil War in the mid-17th century but has remained a powerful, if largely hidden, presence in Sheffield's urban landscape through to the present day (Figure i). This book offers an original take on an urban castle, resurrecting from the archives a building that, for over 350 years, has resided only on the horizons of the imagination but which once made Sheffield a nexus of power in medieval England.

How to cite this book chapter:

Moreland, J. and Hadley, D. (with A. Tuck and M. Rajic). 2020. Sheffield Castle: archaeology, archives, regeneration, 1927-2018, pp. xiii-xxi. York: White Rose University Press. DOI: https://doi.org/10.22599/SheffieldCastle.n. CC BY-NC 4.0, https://creativecommons.org/licenses/by-nc/4.0 


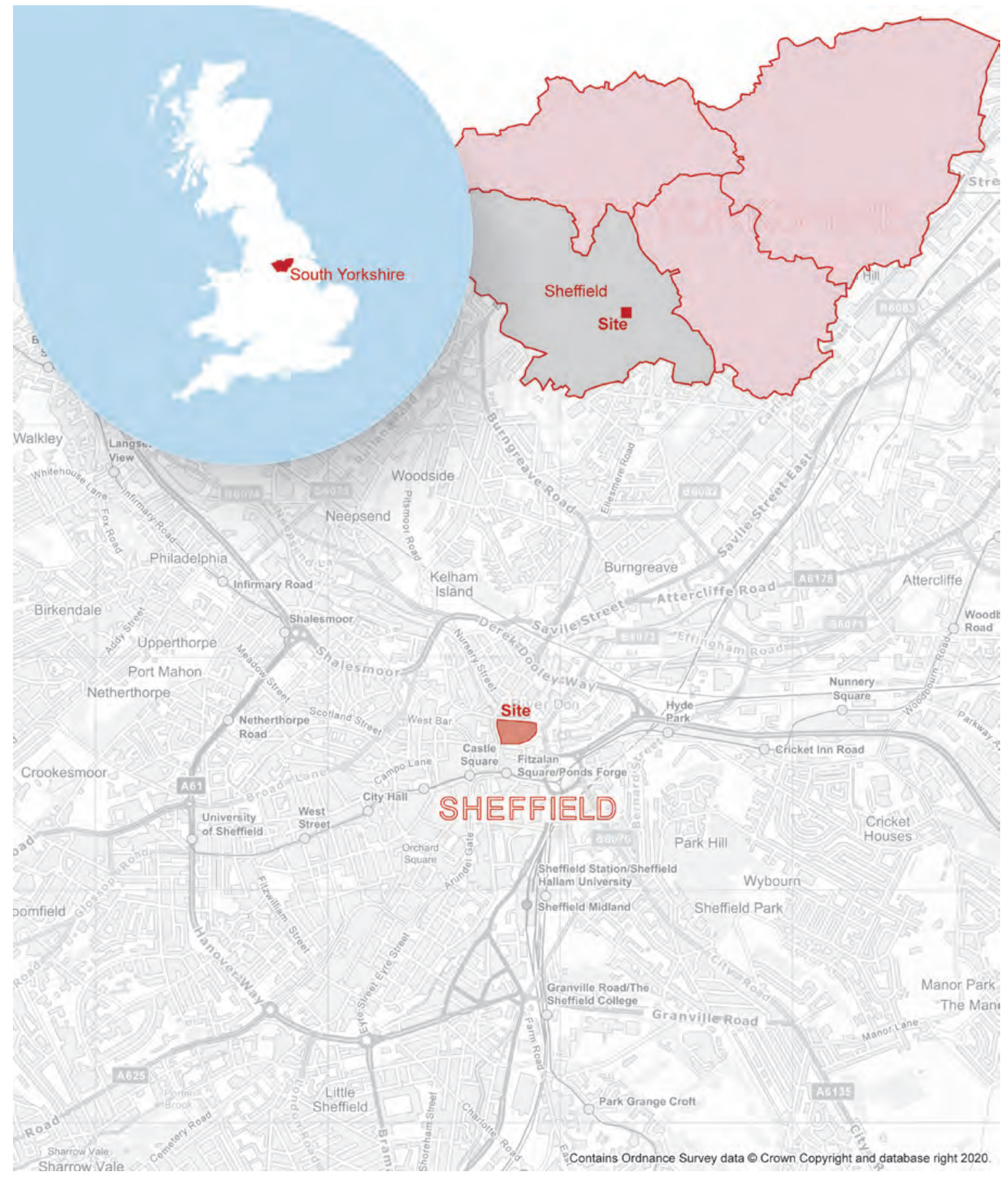

Figure i: Location maps. The location of Sheffield in Great Britain (left) and South Yorkshire (right), and the site of Sheffield Castle in the modern city centre. Wessex Archaeology.

\section{Aims of the book: the many battles for Sheffield Castle}

Since 1927, Sheffield Castle has been subject to several campaigns of archaeological recording, which have largely gone unpublished and unstudied. At the time of writing the site of the former castle stands empty and is the focus of intensive discussions about urban regeneration (EDAW 2005; Ogden 2018; University of Sheffield 2016; 2017; Figure ii). Efforts to develop the site and to attract investment into this district of Sheffield 
Wills 2016, 5-6; Darvill et al. 2019, 3-10, 289-90). Instead of relying, as had been the case since the introduction of the Ancient Monuments Protection Act in 1882, on limited legislation to protect specific monuments or (from 1979) 'archaeological areas', PPG16 sought to 'manage' the archaeological resource by embedding it within the planning system. PPG16 asserted that

archaeological remains ... are a material consideration in the planning process, and ... where it is a question of archaeological remains of national importance ... there should be a presumption in favour of their physical preservation in situ (Champion 1996, 56; also Bryant and Wills 2016, 6; Chapter 7).

One of the consequences of PPG16 within British archaeology is that an ethos of evaluation and assessment in advance of development prevails, and that the developer is responsible for paying for this.

Changes in political philosophy saw new, more community-focussed, guidance issued in 2010 called Planning Policy Statement 5: Planning and the Historic Environment. This was replaced by the National Planning Policy Framework in 2012, which simplified the guidance of PPG16 but placed the historic environment on an equal footing with economic, social and environmental considerations in planning and development decisions (Darvill et al. 2019, 288-9). There have also been attempts among archaeologists to change the management agenda from one that privileges preservation by record to an approach that enhances understanding of the past by placing 'emphasis on interpretation in addition to recording, and developing a historical narrative as the site is excavated' (Andrews et al. 2000); it is ironic that this is precisely the approach to excavation and recording that was adopted by the early and mid-20th-century excavators we shall discuss in this book. However, the well-established structures of developer funding and commercial archaeology remain (Schofield et al. 2011, 37), and such has been the success of PPG16 in creating this expectation that it is sometimes hard to remember that this is not always how it was - and we need to appreciate that difference if we are properly to understand the work of earlier generations of archaeologists, and the conclusions they drew from it.

We also have to recognise that, while PPG16 has privileged mitigation of damage to the archaeological record and an ethos of preservation by record, analysis of previous unpublished excavations falls outside of its purview. This has had profound consequences for places with long histories of unstudied archaeological investigations, especially where, as has happened for the site of Sheffield Castle, this has prevented local authorities from securing the funding required for regeneration. In 2014, a large-scale bid to the Heritage Lottery Fund was submitted by Sheffield City Council for funding to undertake 'analysis, conservation, display, interpretation and, where appropriate, reconstruction of the [castle] remains whilst revealing the larger story of Sheffield's pre-industrial evolution' as part of the regeneration strategy for Castlegate (Sheffield City Council 2014). It was unsuccessful in no small part because of 'the high risk associated with the ... unknown extent of the archaeological remains' (HLF 2014). It is clearly to be regretted that efforts to regenerate one of Sheffield's most impoverished districts have been impeded by the black cloud of an unstudied, and misunderstood, archive hanging over it. This book, therefore, not only tells the story of Sheffield Castle and its rediscovery; it also provides a crucial resource for those working to harness the city's heritage to secure urban regeneration.

\section{Structure of the book: from elite display to community regeneration}

We have structured this book to reflect the fact that it is not simply an account of a castle but rather a biography of a historic place, from its origins to its demise, and beyond into a place of myth making, memory and imagination. The book is largely framed around the excavation campaigns on the castle site, enabling us to interweave an account of the castle with those of both the excavation process of different eras and their contemporary regeneration agendas. In our aims and approach to writing this book, we set a new agenda for the study of castles as places integral to their urban communities, showing how, and why, their cultural construction continues into the 21st century. It is, in essence, an exposition of the longue durée of community engagement with a building, with important lessons for the current trend for community involvement in regeneration initiatives. Chapter 1 presents an outline history of Sheffield Castle and its elite residents, and examines its fate in the aftermath of the Civil War, based on our analysis of neglected and unpublished manuscript sources. We also reveal that more survived of the castle into the modern period than has hitherto been appreciated. The chapter introduces the various archaeological campaigns to record the remains of the castle since 1927 and summarises previous attempts to analyse and write up the unpublished records of those excavations. 
Discussions over the last 20 years about the significance of the unpublished excavations for the history and heritage of the city are also presented. Finally, we position our study within the wider context of recent archaeological research on castles.

No study of Sheffield Castle can ignore the legacy of Leslie Armstrong, better known as a prehistorian, who was living in Sheffield in the late 1920s and led the recording of the remains of the castle when they were exposed during construction work between 1927 and 1929. His paper, published in the Transactions of the Hunter Archaeological Society in 1930, has informed all subsequent accounts of the castle. As we will show in Chapter 2, however, his archive contains ample material enabling us to contextualise, and in some respects correct, this published account. Even more important is the archive of his collaborator Joseph B. Himsworth, which reveals much about the circumstances under which the remains of the castle were recorded, and presents us with a parallel narrative to that of Armstrong's published work, including information on aspects of what was seen of the castle that were not published at the time. Both were members of the local Hunter Archaeological Society, founded in 1912 and extremely influential in recording and - from 1914 through their Transactions - publishing the archaeological record of South Yorkshire and North Derbyshire. While Armstrong is the far better known figure, the archive of Himsworth takes us to the heart of historical and archaeological investigation in the inter-War years, and also reveals the considerable contributions to the recording, preservation and promotion of heritage made by local archaeological societies. Following their intervention, the remains of parts of the castle's gatehouse, courtyard buildings and other structures were preserved in brick-built chambers beneath the markets subsequently constructed on the castle site, and their work was important for placing the rediscovery of the castle in its social, cultural and intellectual context (Figure iii).

In Chapter 3, we offer a detailed analysis of what Armstrong and Himsworth saw, expanding considerably on what is known from Armstrong's published work, and examining the nature and quality of the interpretations they placed on their findings. What emerges from our study of the archives is a well-recorded insight into the castle, with an invaluable photographic record and important unpublished descriptions of what was found. However, we also reveal that caution needs to be exercised when accepting their interpretations, many of which evolved over time, owing as much to attempts to validate the contemporary written record as to the archaeological remains, and their over-enthusiastic engagement with public expectations of what the excavations would reveal. This chapter takes the form of a very detailed analysis of the archival sources, examining how Armstrong's published account came into being, what it omitted, and how the story of the castle they presented grew over the course of the investigations.

In Chapter 4 we introduce the work of Leslie Butcher, a geologist and surveyor by training, who worked in the Architect's Department of Sheffield City Council and was given the task of recording the remains of the castle uncovered during new building work from 1958 (Figure iv). While not well known outside Sheffield, he was an experienced and skilled member of the local archaeological community. He collaborated with the better-known John Bartlett, Deputy Director of Sheffield City Museum, but, aside from a brief note (Hurst 1959), none of this work was ever published. However, Butcher's extensive archive survives, comprising a hugely valuable drawn and photographic record, drafts of a paper (Butcher 1972a; 1972b; 1972c; 1972d) and the script of a lecture (Butcher 1961), which all provide crucial insights into analytical processes that differed significantly from those of Armstrong and Himsworth. His photographs and drawings provide considerable detail on what was uncovered, which, as we will see in Chapter 5, allows us to place many of the artefacts in their stratigraphic contexts. In turn, this enables us to refine and correct further some of the published claims made by Armstrong. As will become clear, the focus of Butcher's analysis was very different from that of Armstrong and Himsworth, with a greater emphasis on the topographical setting of the castle, including the manner in which it had been transformed by centuries of development on the site, and on the moat, both its form and how it was constructed to maintain water levels. In this chapter we therefore take a different approach to the archival material than that adopted for Armstrong's and Himsworth's records, as it lends itself to detailed discussion of archaeological contexts given the information available for individual excavated features (we provide that detail in an appendix to Chapter 5). This chapter also shows that recent concerns expressed that the castle remains are an impediment to regeneration of this site - because their scale and location are unknown - have been overstated, and have become part of a contemporary mythology that has emerged around the castle remains. Much of the material to assess the nature of the archaeological remains, especially relating to the moat, and to mitigate these factors in construction design, have been available all along, if largely unstudied, in the Butcher archive. As we will show, the castle remains, indeed the entire deep 


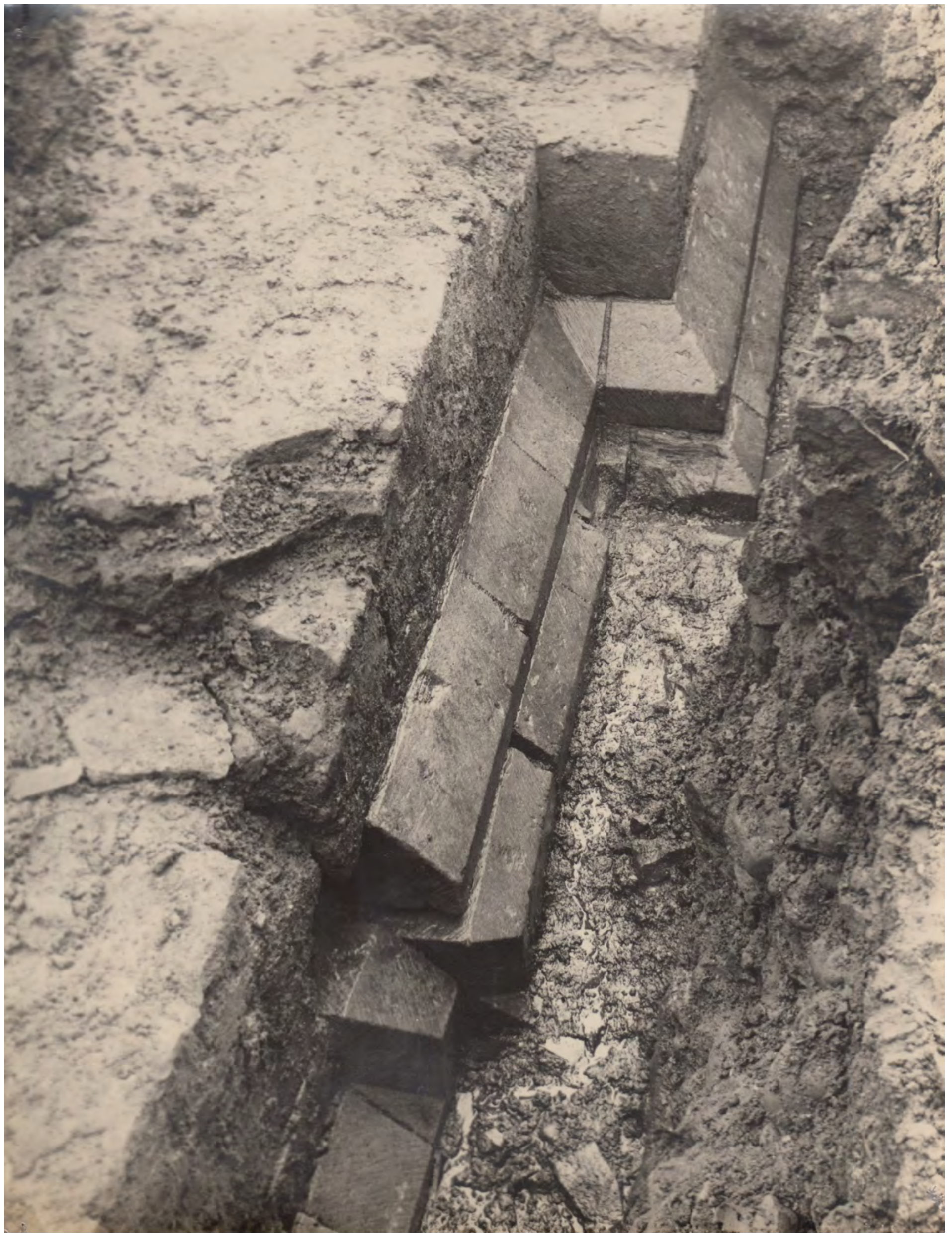

Figure iii: Part of the wall of a building in the courtyard of Sheffield Castle. Photographed by Leslie Armstrong, October 1928. Courtesy of Museums Sheffield. 


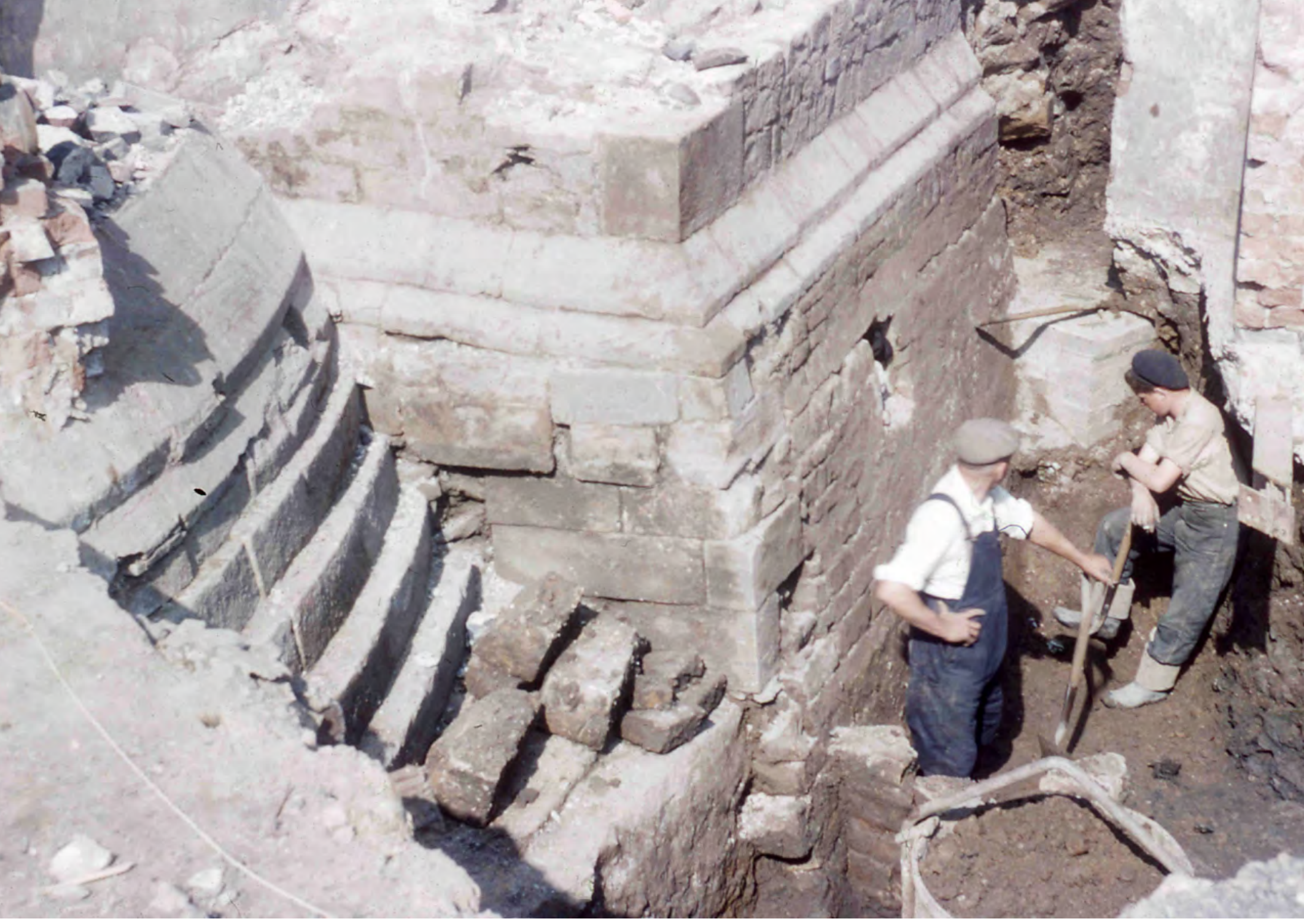

Figure iv: Construction workers digging a foundation trench next to the remains of the gatehouse of Sheffield Castle in the late 1950s. Courtesy of Museums Sheffield.

history of the site, captured in the records of Armstrong, Himsworth and Butcher, are a significant asset to an imaginative regeneration of the area.

During the research for this book we commissioned new analyses of the surviving artefacts recovered during the early and mid-20th-century investigations of the castle, as these had been subject to little or no previous examination. In Chapter 6 we report on the resultant findings and what they reveal of the household that resided in the castle across the later medieval and early post-medieval periods. We show that the material culture recovered during these excavations allows us to rebalance the historical perspective outlined in Chapter 1, which focussed on the aristocrats who periodically resided in the castle; Chapter 6, in contrast, focusses on the ordinary men and women who lived and worked there or whose craft skills and labour were critical to the maintenance of the castle, as well as to the social display of power. In this chapter, therefore, we present a narrative about castle life that scarcely features in castle studies, where it is repeatedly the elite occupants whose experiences, attitudes and contributions that are foregrounded in analyses.

In Chapter 7 we turn to the findings of the modern excavations undertaken in advance of development, including those conducted by ARCUS (Archaeological Research and Consultancy at the University of Sheffield) between 1998 and 2001 (Belford 1998; 1999; Davies 2000; Davies and Symonds 2002), which provided new insights into developments at the northern end of the site. In 2018, Sheffield City Council commissioned local company Wessex Archaeology to conduct an archaeological evaluation on the site of the 
castle to guide their plans for future development. This was the first large-scale, professional excavation across the whole of the site, and our research on the early to mid-20th-century archives informed the excavation strategy both in formal meetings with Wessex Archaeology and Sheffield City Council and on a day-to-day basis during the preparations for the excavation and as it was being conducted. Uniquely in the history of archaeological exploration of Castle Hill, this was not driven by, or indeed part of, its ongoing or imminent redevelopment. Rather, it was designed to enhance our knowledge of human activity there and to clarify the scale and degree of preservation of the archaeological remains, with a view to facilitating, and informing, the future regeneration of the area. In the discussions led by the City Council over the last 20 years about what to do with the site of the former castle, the archaeological remains have often been seen as a 'problem': a disincentive to development, and an impediment to securing the funding required to regenerate this part of the city centre. However, aided by the work undertaken for this book, and by projects led by colleagues in the School of Architecture at the University of Sheffield $(2015 ; 2016 ; 2017)$, the City Council was finally able to unlock regional government 'kickstart' funding to begin exploratory work in advance of development. It is this that directly led to the excavations undertaken by Wessex Archaeology (Ogden 2018), which have provided the first modern dating evidence for the castle and important insights into subsequent developments on the site. Together we then worked in collaboration to bring all of the excavations to publication, and to advance the momentum for regeneration.

The castle did not stand in isolation, and in Chapter 8 we explore its relationship to the lordly landscape of the medieval deer park and hunting lodge to the east. A deer park had been in existence since at least the late 13th century, with a hunting lodge sitting at one of its highest points. This chapter examines the standing remains of that lodge, which date to the 15th and 16th centuries, and draws on the archives of unpublished excavations conducted between 1968 and 1980 by Sheffield City Museum (Beswick 2002; Hadley and Harlan 2011), and the reports produced following more recent excavations by ARCUS (2007-08) (McCoy 2007a; 2007b; 2009) and Hadley for the University of Sheffield (2009-11) (Mepham and Powell 2010; Burgess et al. 2011; Crewe and Askew 2012). When integrated with the documentary evidence, this reveals the scale of the impact of the castle and its wider estate on Sheffield in the medieval period and beyond. The chapter also examines the fate of the seigneurial landscape as the lodge and park began to be dismantled in the 17th century, which has had significant consequences for the landscape of the city that continue to the present day.

In Chapter 9 we examine the legacy of the castle for the people and city of Sheffield. Although demolished over 350 years ago, traces of Sheffield's castle are perpetuated in local street names (Goodwin 1764, 157), and memories of the castle have persisted to be captured locally in art and architecture, not least in the design and decoration of the 19th- and 20th-century buildings constructed on and around its buried remains. The deer park has also had a significant impact on the development of Sheffield, as it remained open land until the 18th century, after which industrial activities began to impinge on it, although many parts of the park were not built on for housing until the 20th century. In this chapter we show how the archaeology of the castle and its wider landscape can be used to stimulate and inform the regeneration of an area that is now one of the most deprived wards in Sheffield but was once at its social, political and cultural heart. From the 1920s a substantial working-class social housing complex was built on much of the former deer park, and this estate has experienced considerable deprivation since then, being blighted by unemployment since the 1980s, with high levels of crime leading to the estate being dubbed in more recent times 'the worst in Britain' (McCaffrey 2007; Jackson 2016; Lee 2016). However, the sites of both the castle and its deer park and hunting lodge are now being used to inform regeneration (EDAW 2005) and the creation of new employment and social opportunities (Green Estate 2016), and these initiatives are detailed in this chapter, which also makes the case for the importance of researching and publishing the hidden heritage of urban communities, and the social and economic value of this into the 21 st century. This chapter also discusses recent work by University of Sheffield researchers from a diversity of disciplines to develop models for regeneration of the site of Sheffield Castle, in partnership with community group the Friends of Sheffield Castle (see Chapter 9), which are feeding into the City Council plans for the future. In an epilogue we show how we have succeeded in contributing a new dimension to the civic pride of Sheffield, and a new visual identity for ongoing regeneration debates through use of computer technology. This really matters in a city where a survey commissioned by the Council in 2013 from audience engagement consultancy Wafer Hadley revealed that $46 \%$ of the public were unaware that it had ever had a castle despite there being 60,000 visitors a week to the market hall on the site, the eponymous 
Castle Market! Such lack of public awareness has had profound consequences for the vitality and vibrancy of the city, as well as the identity and sense of place of its citizens. In this book, we respond to the challenges posed by an understudied and misunderstood urban archaeological site and show how the castle, as well as subsequent developments on the site, can be recovered from the archives and reimagined in placemaking in the 21 st century.

\section{Bibliography}

The full bibliography is available at the end of this volume, or at: https://doi.org/10.22599/SheffieldCastle.k. 



\title{
CHAPTER I
}

\section{Sheffield and Its Castle}

\begin{abstract}
Throughout the six centuries which preceded the Parliamentary Civil War, few of the baronial castles of England could boast a more intimate connection with outstanding men and national events than could the castle of Sheffield, and it is doubtful if since that time any has suffered such complete destruction or become more entirely forgotten than has the noble pile of buildings which once occupied the high ground at the junction of the River Sheaf with the River Don and towered above the little town of Sheffield (Armstrong 1930, 7)
\end{abstract}

In medieval Sheffield, as in most towns in the Middle Ages, the castle, along with the parish church, were the principal focal points. Sheffield Castle was a major regional centre in the north of England, and one of the largest aristocratic castles in Yorkshire, its elite occupants playing important parts in local, national and international affairs. The use of two castles as the symbol for Sheffield on the Gough Map of $c .1360$ may be a reflection of its significance (Lilley and Lloyd 2009, 7). While no contemporary depictions of the medieval castle survive, as David Hey $(2010,16)$ suggests, it is likely to have been on much the same scale as the castles Edward I built in north Wales, such as Conwy and Harlech. This much is evident from a description of the castle in John Harrison's 1637 'Exact and Perfect Survey and View of the Manor of Sheffield', which he produced for the Earls of Arundel and Surrey (later the Dukes of Norfolk) after they had acquired it:

ye scite of ye Mannor or Mansion house called Sheffeild Castle being fairely built with stone \& very spacious containeth divers buildings \& Lodgings about an Inward Court yard \& all offices thereto belonging having a Great Ditch about ye same ye Great River of Doun lying on ye north parte thereof \& ye Lesser River called ye Little Sheath on ye East parte thereof haveing on ye South an outward Court Yard or fould builded round with diverse houses of office as an armory a Granary, Barnes Stables \& divers Lodgeings all containeing by measure 4 acres 00 roods $302 / 5$ perches (Harrison 1637, fol. 44; Ronksley 1908, 47).

In this chapter we introduce the castle and the lords of the manor who built and rebuilt it, using it as a base from which to manage their estates and orchestrate their affairs, and leaving an indelible impression on Sheffield in its street names, civic landscape and buildings. The Civil War of the mid-17th century saw orders to

How to cite this book chapter:

Moreland, J. and Hadley, D. (with A. Tuck and M. Rajic). 2020. Sheffield Castle: archaeology, archives, regeneration, 1927-2018, pp. 1-27. York: White Rose University Press. DOI: https://doi.org/10.22599/SheffieldCastle.a. CC BY-NC 4.0, https://creativecommons.org/licenses/by-nc/4.0 
demolish the castle but, as we will reveal, more of it survived into at least the 19th century than has hitherto been recognised. We also introduce previous archaeological investigations of the castle, positioning our work in the context of castle studies more broadly. Construction work on the site in the early and mid-20th century exposed the remains of Sheffield Castle for archaeologists to record, but few of their findings have ever been published. Over the last 20 years there has been a growing recognition that the insights from these excavations would be extremely valuable to enhancing our knowledge of Sheffield Castle if they were fully studied, and that they also hold great significance for influencing the future regeneration of the castle site. This chapter sets the scene for the fulfilment of the first of these aspirations, and we are confident that this book will inform the latter.

\section{Elusive antecedents}

It has recently been argued that scholars should consider the possibility that some Norman castles in England were consciously constructed on the sites of prehistoric and Roman monuments, an 'appropriation of places which held significance for local populations', and an enhanced source of power and mechanism of control (Jamieson 2019, 340, 362; also Swallow 2016). On the basis of the available evidence, that case cannot, however, be made for Sheffield Castle. Leslie Armstrong $(1930,24)$ recorded the recovery of a Bronze Age scraper and a flint flake, and a few fragments of 'much worn' Roman pottery, during his excavations of the castle site, but there is nothing here, or in subsequent excavations, to suggest sustained prehistoric activity on the site. Certainly, there is nothing to support John Daniel Leader's (1897, ix) belief in the probability that at the junction of the Sheaf and the Don ... a small Roman castrum was placed. His brother Robert rightly dismissed that argument as based 'on the flimsiest of conjecture'.

There has also been much speculation that the castle was built on the site of an Anglo-Saxon hall, as Domesday Book records that Earl Waltheof had an aula, or hall, in Hallam before the Norman Conquest (Faull and Stinson 1986, fol. 320a). While the text does not specify precisely where this was located, it has been widely identified as Sheffield, which was part of the estate (or inland) of Hallam (Hey 2010, 12). Some antiquarians went further and assumed that Sheffield Castle would be located in the same place as Waltheof's aula, and that this was at the junction of the rivers Don and Sheaf (e.g. Holland 1824, 15-16; Leader 1897, ix, xx; Leader 1904a, 3-5; Drury 1929a, 177-8; Armstrong 1929b; 1930, 23; Himsworth n.d. (b), 5). This debate about the Anglo-Saxon origins of Sheffield, the location of any remains of this date, and their relationship to the castle is one of the major themes of this book (see, especially, Chapter 3).

\section{Sheffield Castle and its elite occupants}

After the execution of Waltheof, following his involvement in a revolt of the earls against William I (the Conqueror), his lands passed to his wife, Judith, and by 1086 her tenant was the Norman lord Roger de Busli, who had a castle at Tickhill (c.25km north-east of Sheffield) and held numerous manors across Yorkshire, Nottinghamshire, Derbyshire, Leicestershire and Devonshire (Faull and Stinson 1986, fol. 230c; Hunter 1819, 24). By the early 12th century the manor of Hallamshire had come to William de Lovetot, from a family which had been tenants of de Busli in Nottinghamshire, and it seems that de Lovetot held the manor from Maud, the daughter of Waltheof and Judith (Hey 2010, 15; Hunter 1819, 22-9). It has generally been assumed that Sheffield Castle was built for William (Hunter 1819, 26), although it is first documented only in 1183-4 in a Pipe Roll of Henry II, when Ralph Murdac, Sheriff of Nottinghamshire and Derbyshire, was recompensed for expenditure on fortifying it (National Archives E372/30). William de Lovetot held manors across large areas of Yorkshire, Huntingdonshire and Nottinghamshire, and also founded the important priory at Worksop (Notts) (Stacye 1874, 158-60; Hunter 1819, 25). The lack of a de Lovetot male heir in the late 12th century saw the castle pass by marriage, of William de Lovetot's great-granddaughter Maud (Matilda), to Gerard de Furnival (c.1175-1219) and it descended through this prominent family for over a century. De Furnival died on Crusade in Palestine, as did his son Thomas de Furnival (d. 1238) (Hunter 1819, 32-3; Hey 2010, 16). In 1270, the latter's son, also called Thomas (c.1231-91), received a licence 'that at his manor of Sheffield, co. 
York, he may build a stone castle and fortify and crenellate it' (Lyte 1913, 447). This has been widely regarded as representing the point at which the castle was rebuilt in stone (Drury 1929b, 180; McCoy and Stenton 2009, 12; Hey 2010, 16).

The male line of de Furnivals came to an end with the death of William de Furnival on $12^{\text {th }}$ April 1383, and the lordship of Hallamshire, and with it Sheffield Castle, passed to Sir Thomas Nevill, who had married William's daughter, Joan (Hunter 1819, 40). In 1386 he received confirmation of a grant previously made in 1296 under Edward I which allowed the holding of a market in Sheffield every Tuesday, and of a fair over the three days around the Feast of the Holy Trinity (Hunter 1819, 41; Hey 2010, 16). Thomas and Joan had no sons, and (sometime before $12^{\text {th }}$ March 1407) Maud their daughter and heir married John Talbot (1384-1453), and from this point onwards Sheffield Castle was in the hands of noble families of wide renown and influence; it was at the centre of regional and national affairs (Hey 2010, 27). Talbot, 'his name terrible to the French', was one of the great English commanders of the Hundred Years War (1337-1453), Lord Lieutenant of Ireland from 1414 to 1419, Knight of the Garter (1424), and ennobled as Earl of Shrewsbury in 1442 (Hunter 1819, 45). He was Shakespeare's 'valiant Lord Talbot, Earl of Shrewsbury, Created, for his rare success in arms' and 'the Frenchmen's only scourge' (1 Henry VI, Act IV, sc. vii, 11. 2294-6, 2311), and in 1592 the Elizabethan pamphleteer Thomas Nashe declared 'How would it have joyed brave Talbot, the terror of the French, to think that after he had lyen two hundred yeare in his toomb, he should triumph again on the stage' (cited in Hunter 1819, 46; see also Gatty 1873, 20-1; Drury 1929b, 183).

John, $2^{\text {nd }}$ Earl of Shrewsbury (c.1417-60), who was born in Sheffield Castle, served with his father in Ireland and in France, and was made Lord Treasurer of England in 1456. During the Wars of the Roses he fought on the Lancastrian side and was killed at the Battle of Northampton on $10^{\text {th }}$ July 1460 . His son John, the $3^{\text {rd }}$ Earl (1448-73), was less politically prominent ('more devoted to literature and the muses, than to politics and arms'; Hunter 1819, 47), but served as Commissioner of Oyer and Terminer in Yorkshire, Cumberland, Westmorland and the city of York (Hunter 1819, 46-8). George, the $4^{\text {th }}$ Earl (c.1468-1538), a Knight of the Garter and member of the Privy Council, was frequently involved in court ceremonies, and in 1502 was appointed Lord Steward of the royal household. He was involved in court diplomacy; in 1511 he helped to conclude a treaty between Henry VIII and Ferdinand of Aragon, and in June 1520 he was present at the 'summit' between Henry VIII and Francis I of France at the 'Field of the Cloth of Gold' (Pas-de-Calais). His loyalty to the Tudor dynasty was a major factor in the failure of the Pilgrimage of Grace (1536), a revolt against the king's break with Rome, which was prevented from moving any further south than Doncaster (South Yorks) as a result of the influence of the Earl in this area (Bernard 2012, 2).

George Talbot is best known in Sheffield for the construction of the Shrewsbury Chapel in the parish church of St Peter (now the cathedral of St Peter and St Paul; Figure 1.1) and, at roughly the same time, for the significant embellishment of the hunting lodge in the deer park to the east of the castle, now known as Sheffield Manor Lodge (see Chapter 8). It was there that, in 1530, he 'entertained' Cardinal Wolsey, Archbishop of York and former Lord Chancellor. This followed Wolsey's arrest for treason at Cawood Castle in north Yorkshire and was while he was on his way south towards London; Wolsey took ill at the lodge and died just two days after his departure (Hunter 1819, 49-54; Gatty 1873, 24-6). The $4^{\text {th }}$ Earl was buried in the Shrewsbury Chapel in March 1539, after a magnificent funeral ceremony attended by 'Many ho[nourable] men \& tall yomen', all dressed in black gowns and hoods, with thousands of bystanders looking on (Harley MS 2076, fol. 4v; LPL, MS 698, fol. 5). A monument to him was completed several decades later after the death of his second wife, Elizabeth Walden (Figure 1.2).

George Talbot's only surviving son by his first wife, Lady Anne Hastings, Francis, the $5^{\text {th }}$ Earl (1500-60), born in Sheffield Castle, also moved in the highest social and political circles. He was one of the 13 mourners at the funeral of Henry VIII and was chief mourner at that of his son Edward VI. He was 'favoured' at the court of Queen Mary and used his influence there to secure restoration to the Sheffield Church Burgesses of rents from lands sequestered under the Chantries Act of 1547 (Tolley 1999, 9-10). He was a privy councillor and Knight of the Garter, and in 1549 was described by the Imperial ambassador as 'one of the most powerful men in the kingdom' (Bernard 2004, 1-2). The splendour of his funeral, and of the great dinner afterwards in Sheffield Castle on $21^{\text {st }}$ October 1560, which was attended by the 'nobles and gentry of the surrounding district', including Sir Thomas Cockayne (Ashbourne, Derbs), Sir George Vernon (Haddon Hall, Derbs, known as 'King of the Peak'), and Sir Thomas Gargrave (Speaker of the House of Commons and 

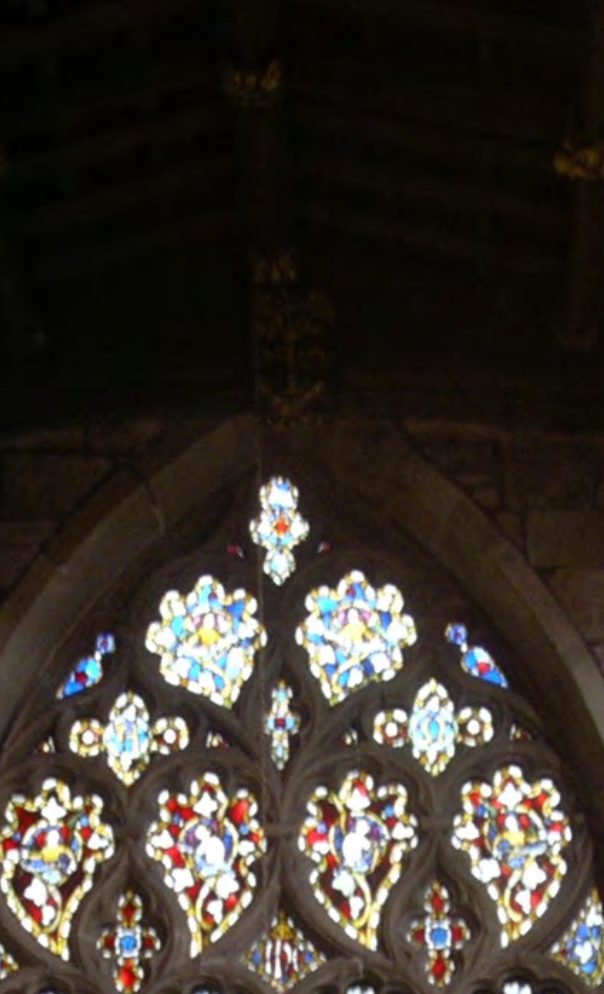

a.

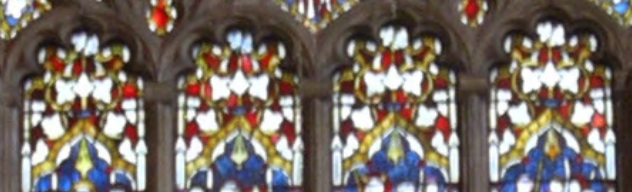

$8 \times 3$.

Por

(6) 2

Dis.

बत्डs

and

and

n.

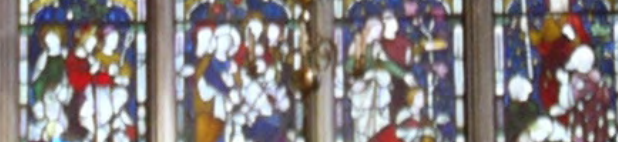

is

$\frac{1}{52 \times 1}$

$\frac{1}{15}-1$

$252 \pi$

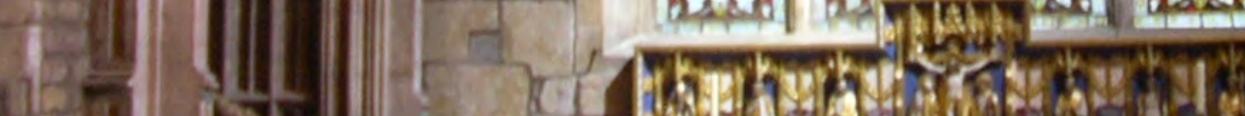

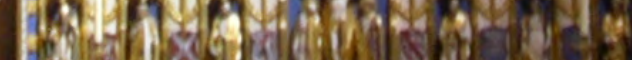
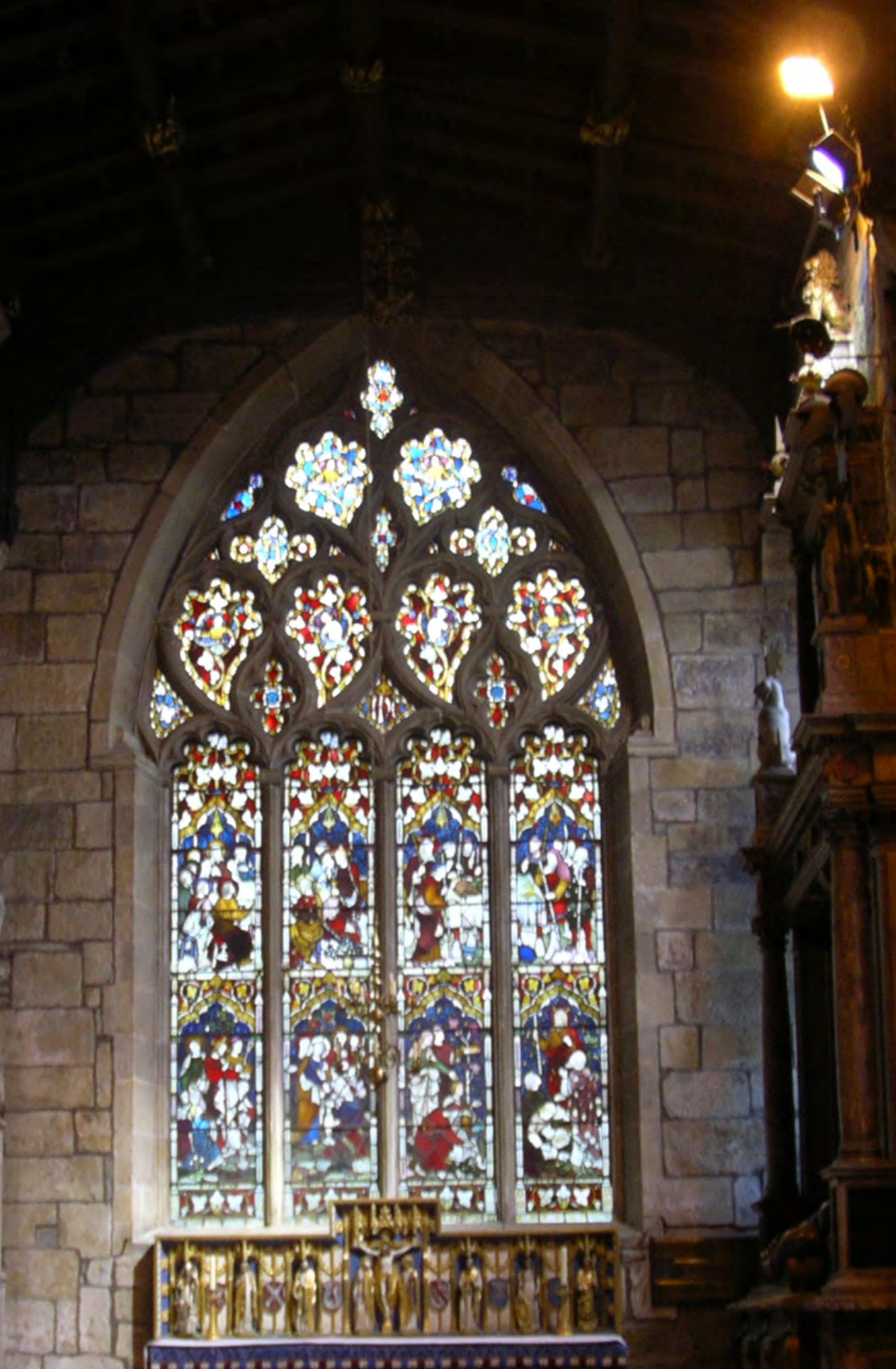

8

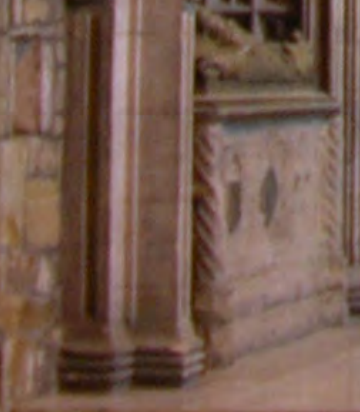




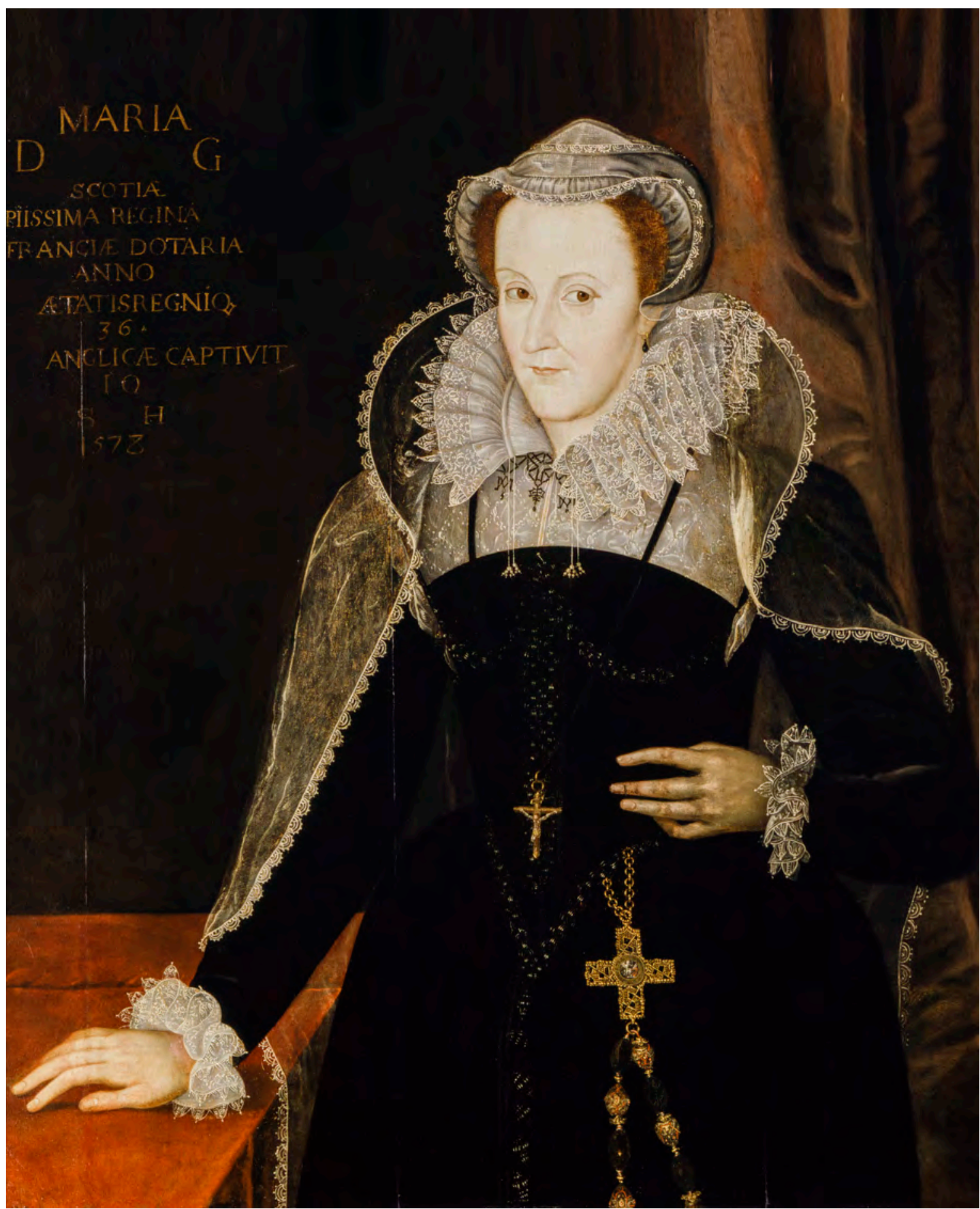

Figure 1.3: Portrait of Mary, Queen of Scots. After Nicholas Hilliard, oil on panel, inscribed 1578. (c) National Portrait Gallery, London.

(Drury 1929b, 186; also Hunter 1819, 64; Gatty 1873, 27; Figure 1.3). George was married first to Lady Gertrude Manners, daughter of the Earl of Rutland, and second to Elizabeth, Lady St Loe, better known to posterity as Bess of Hardwick (Figure 1.4). While castles are often gendered as masculine spaces (Gilchrist 1999, 109-45; Dempsey et al. 2019), Sheffield Castle is a rarity in being as strongly associated with two prominent 


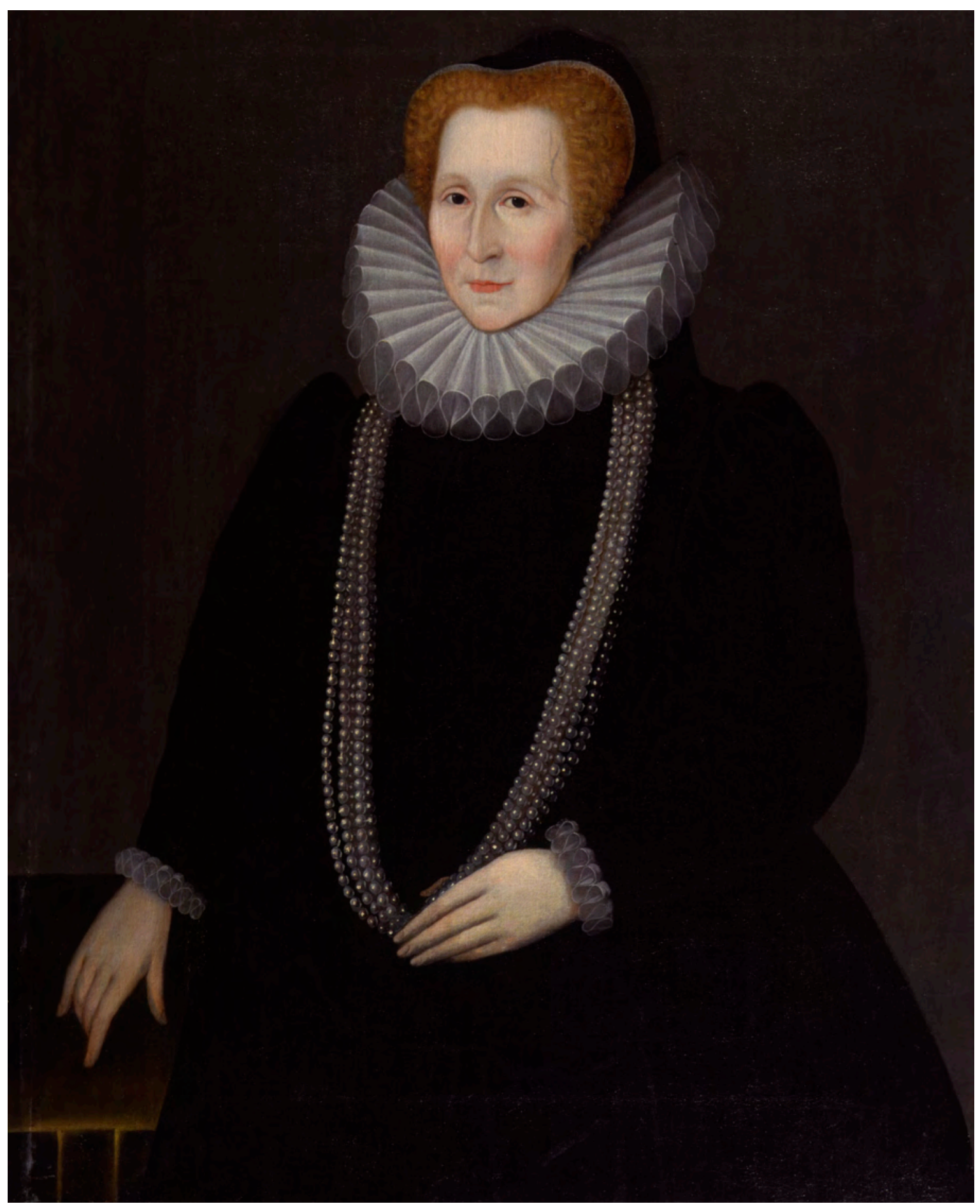

Figure 1.4: Elizabeth, Countess of Shrewsbury, popularly known as Bess of Hardwick. Painted by an unknown artist in the 17th century, in a portrait based on a painting of $c .1590$. ( ) National Portrait Gallery, London.

and powerful women - the doomed Scottish queen and the Earl's second wife - in both popular and scholarly works as it is with the elite men who passed through its gates.

The burial of George Talbot on $13^{\text {th }}$ January 1591 was just as impressive as that of his grandfather. After his death on $18^{\text {th }}$ November 1590, which occurred at the hunting lodge in the deer park, his servants organised 


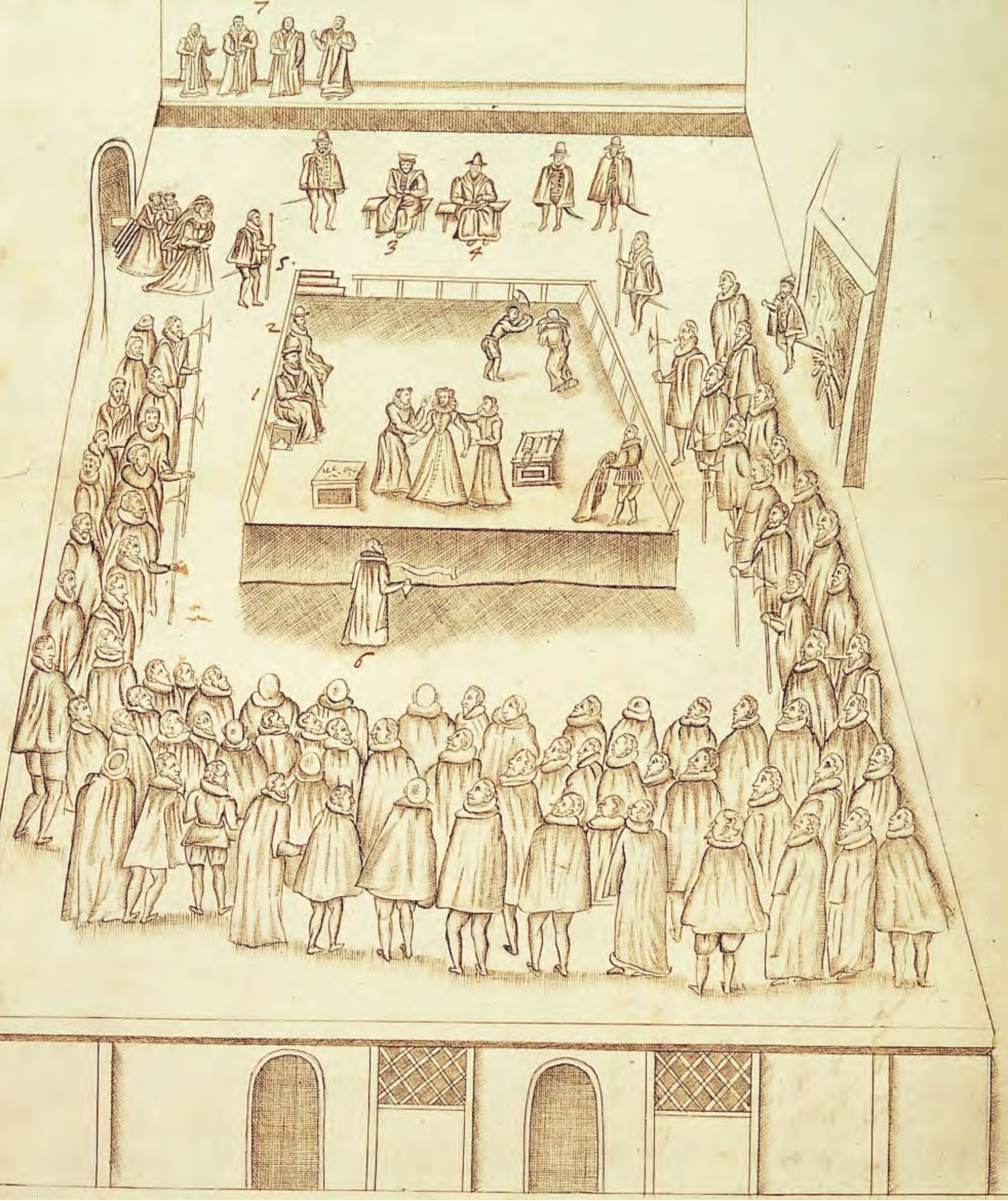

Figure 1.5: The execution of Mary, Queen of Scots at Fotheringhay Castle (Northants) on $8^{\text {th }}$ February 1587. Drawn by Robert Beale (1541-1601), the $6^{\text {th }}$ Earl of Shrewsbury, George Talbot, is seated to the left of the platform (numbered 1). Source: Wikimedia Commons, Public Domain. 
his funeral in collaboration with the College of Arms, discussing with Garter Principal King of Arms William Dethick whether to have the procession to the church on horseback from the lodge (as was usual for funerals of comital rank) or from the castle, which 'would be more convenient in respect of the lodging and dynner' (LPL, MS 3199, fol. 203). The latter was selected and thousands turned out for the funeral, which 'was then sumptuously done that was ever to any afore in these countrys', according to one eyewitness, the gentleman Arthur Mower of Woodseats in Derbyshire, 'and the assembly to see the same was marvellous both of nobility gentry and country folks and poor folks without number. Bonfires were lit, and trees were cut down in the deer park to warm the 600 beggars who attended, although three onlookers were killed by falling trees (BL, Additional MS 6671, fols 345-6; College of Arms RR 20/D intra 247-8; Hunter 1819, 73; Leader 1897, 60). No less a minister than John Piers, Archbishop of York, preached the sermon (LPL, MS 3200, fol. 100; Figure 1.5).

The $7^{\text {th }}$ Earl, Gilbert Talbot (1552-1616), son of George Talbot by his first marriage to Gertrude Manners, was one of the most significant iron masters in the country, and Sheffield was the most important centre of cutlery production in England at this time (LPL, MS 705, fol. 144; LPL, MS 710, fol. 70; LPL, MS 3205, fol. 95). His deputy, Sir John Bentley, recorded the impact of this industrial activity in Sheffield, commenting on its smokefilled streets in a letter to the Earl in October 1608 (LPL, MS 3203, fol. 540). Both the lordship of Hallamshire and the castle remained in Talbot hands until 1617, and the death of the $8^{\text {th }}$ Earl, Edward Talbot, who had been born in Sheffield and was the youngest son from the marriage of George Talbot and Gertrude Manners (Hunter $1819,41,98)$. Since Edward died without a surviving child, the lordship eventually passed through the marriage of Alethea Talbot, daughter of Gilbert, to Thomas Howard, Earl of Arundel and Surrey, and later $1^{\text {st }}$ Earl of Norfolk, whose descendants became the Dukes of Norfolk (Hunter 1819, 24-96; Gatty 1869, 22-128; Drury 1929b, 179-92; Hey 2010, 27-34). The dukes retained possession of the site of the castle even after its demolition and on into the late 19th century (see Chapter 9).

The manorial records of Sheffield provide some details of the form of the castle in which these lords and ladies periodically resided and from which they administered their estates. For example, Account Rolls of the 1440s reveal that it contained a Great Hall and Great Gate, with a stone and cinder path running between them, while the Hall led into the camera abstracta, or withdrawing-room, of the Earl. Also recorded are a chapel, kitchen, bakehouse, hospitium (a guest-house where lower-status visitors and workmen stayed), prison and three towers comprising a 'Great Tower', another 'next to the bakehouse', and a third adjacent to the chapel (Thomas 1920-24, 68, 70-2). Structures referred to as being 'outside the castle' included an Exchequer Chamber, where matters relating to wages, fines and other payments would have been dealt with, a grange, cowhouse and stables, adjacent to which was another tower (Thomas 1920-24, 68-72).

Seventeenth-century accounts provide further insights into the appearance of the castle. For example, an inventory of the goods inside, produced by George Lawson and dated $20^{\text {th }}$ December 1628, mentions a dining chamber and adjoining chamber, three further chambers said to be located over the kitchen, bakehouse and day chamber respectively, a hall, 'Mr Cookes chamber', a gallery and the 'next chamber', and a turret used as a bedchamber (Wilson MS 295/24 fol. 6). Records of estate disbursements detail some of the repairs undertaken on the castle, which also provide further insights into the range of buildings it comprised. For example, in 1633 a payment was made to George Adram 'for seelinge blacke Chamb[er] at Castle' (Wilson MS 295/223, Book 3 fol. 5), while a bill was paid for the replacement and repair of windows, including 669 feet of glass for 'the newe building' (Wilson MS 295/42, fol. 155). As we will see in more detail in Chapter 9, accounts relating to the demolition of the castle at the end of the Civil War record the sale of some of its fabric and in doing so mention a variety of rooms and buildings including the hall, old kitchen, little kitchen, sentry house, stable, old bakehouse, Nicholas Spadman's chamber, the Middleton chamber, the square and round towers, gatehouse, dungeon, and chapel (Wilson MSS 295/57; Askew 2017, 205-10). The castle is described as being surrounded by a deep water-filled moat in both a 1644 pamphlet on the siege of Sheffield Castle (Anon. 1644, 2) and an account of the Civil War and the virtues of Parliament called the Magnalia Dei Anglicana. Or, England's Parliamentary Chronicle, published in four parts between 1644 and 1646, by John Vicars $(1646,7)$, a puritan writer and schoolmaster. Sheffield Castle was clearly a substantial and complex set of buildings by the mid-17th century - as John Harrison described in his 1637 survey (Ronksley 1908, 47; Edwards 1930; see Chapter 3). Until the excavations undertaken in the 1920s, it was this written record that informed antiquarian knowledge of the castle, although, as we shall now see, traces of its fabric had survived above ground into the early 20th century, albeit largely overlooked by recent reviews of the available evidence. 


\section{The castle 'made untenable'}

Between 1642 and 1644, during the first phase of the English Civil War, Sheffield Castle was occupied consecutively by Parliamentarian and Royalist forces, before surrendering to Parliament in August 1644 (Hunter 1819, 103-12; Gatty 1873, 83-91; Winder 1910, 57-8; Hey 2010, 53-4; Askew 2017, 190-1). On 30 ${ }^{\text {th }}$ April 1646 the House of Commons passed a resolution that

the several Castles of Tickhill, Sheffield, Knaesborough, Cawood, Sandall, Boulton, Midlam, Hemesley, Mulgrave, and Crake, in the County of Yorke, being inland Castles, be made untenable; and no Garisons kept or maintained in them (Parliament. House of Commons 1646, 528).

They followed this up on $13^{\text {th }}$ July 1647 with a second resolution that that all the new Works about Sheffield Castle be dismantled and slighted; and the Castle disgarisoned' (Parliament. House of Commons 1647, 243; also Hunter 1819, 113; Askew 2017, 192). It seems, however, that little actual 'slighting' took place until a letter dated $16^{\text {th }}$ October 1648 from the County Committee of York ordered the castle's demolition (Askew 2017, 192). The sale of the castle fabric, including its slates, lead, timbers, furniture, and plasterwork followed and by the mid-1650s parts of the castle site had been turned over to cultivation (Hunter 1819, 113-16; Askew 2017, 202; see Chapter 9 for further discussion).

The 'destruction' of Sheffield Castle is well-documented in a set of demolition accounts which commence in January 1649 (Wilson MSS 295/57; Hunter 1819, 114-15). Only two other castles - Pontefract (West Yorks) and Montgomery (Powys) - have similar accounts, and only those from Pontefract have been extensively studied (Thompson 1987, 188-93; Roberts 2002, 421-2, 442-6; Rakoczy 2007, 219-57). The Sheffield accounts lay out in great detail not only the cost of destruction (a total of $£ 2088 \mathrm{~s}$. 8d.) but also the buildings demolished and the people involved. As such, they provide a fascinating, and rare, insight into the 'reduction' of one of Yorkshire's largest castles at the hands of its inhabitants, from the scaffolding employed 'to keepe up the Castle the walls beeing let doune' to the ditches filled in by the Earl of Norfolk's tenants (Wilson MSS, 295/57, fols 9, 12).

The repeated demands that Sheffield Castle be 'slighted', and its absence from the present cityscape, has contributed to the assumption that it was largely if not entirely erased at this time (Gatty 1873, 92; Winder 1910, 57; Bostwick 1985, 2; Belford 1998, 12; Richardson and Dennison 2014a, 19-20; but see Chapter 9). Certainly, some areas were quickly 'repurposed' by the townspeople; for example, Robert Shertcliffe rented a 'garden Spott in the Castle ditch' in 1655/6; later another was leased by Widow Butler (Wilson MSS 295/38, Book 4, fol. 6; Askew 2017, 202). Contemporary illustrations and maps suggest that by the mid-18th century the castle site had largely been levelled, and put to new uses (Armstrong 1930, 8, 14, 22). There are no signs of a castle in Ralph Gosling's 1736 Plan of Sheffield (Figure 1.6), Thomas Oughtibridge's 1737 North Perspective View of the Town of Sheffield (Figure 8.26) or Nathaniel Buck's 1745 East Prospect of Sheffield. In all of them a bowling green occupies part of the castle's inner court, with buildings and 'rectangular plots or enclosures' reminiscent of gardens or yards arranged over the rest of the site (Richardson and Dennison 2014a, 21). Notes, field sketches and plans made by the Fairbank family of surveyors and engineers, between the late 1760s and 1780s, also record the bowling green and surrounding buildings owned by the Duke of Norfolk, but sublet to various tenants (Belford 1998, 13 and fig. 7; Fairbank 1769; Hall 1932; Chapter 9). Although beyond the bounds of the castle proper, a notable indication of the changing character of the area is that its former nursery grounds, situated just across the River Don, were opened up as a 'public recreation ground' in 1781 (Leader 1901, 200; Banham 2011, 140-1).

Late 18th-century maps record steep slopes down to the Don and Sheaf on the north and east sides of the site, respectively, creating what on the north side was labelled 'the precipice' on a 1769 Fairbank plan of Castle Hill (see Figure 3.24; Belford 1998, 14; McCoy and Stenton 2009, 24). It is likely that this reflects a natural topography enhanced by 'made ground' and castle defences (see Chapter 5; Himsworth 1927-42), with the effect perhaps exaggerated by the ruination of the castle walls. Following an Act of Parliament in 1784 to regulate and improve Sheffield's marketplaces, the precipice was cut back and slaughterhouses were built along the south bank of the Don and the west bank of the Sheaf (Leader 1901, 163; Walton 1949, 143; Belford 1998, 15); the 


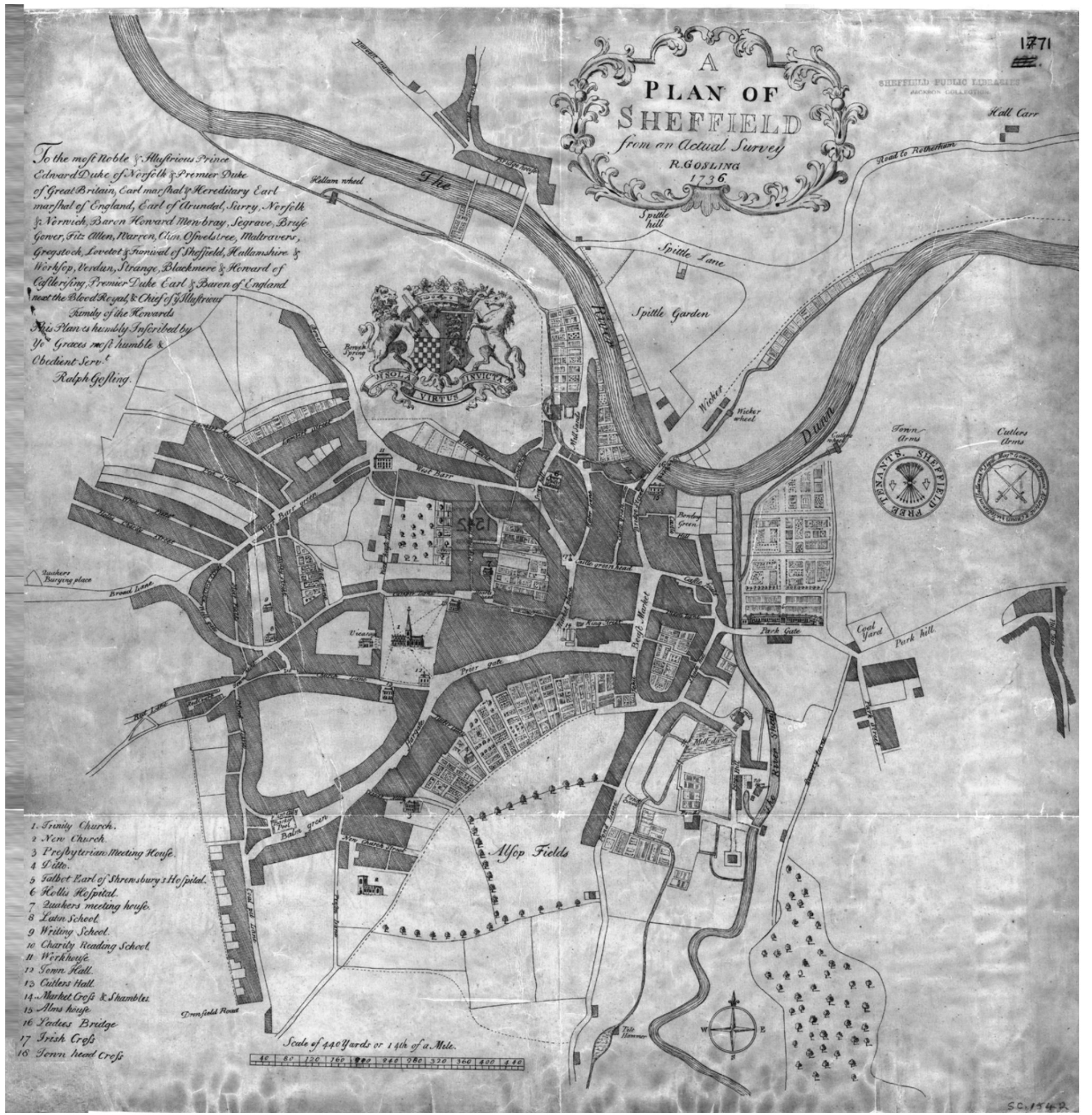

Figure 1.6: A Plan of Sheffield from an Actual Survey. Mapped by Ralph Gosling, 1736. Reproduced with permission from Sheffield City Council. 
slaughterhouses (the 'Killing Shambles') appear for the first time on Fairbank's 1797 map of the city (Figure 1.7; see also Figure 3.5). Further south, the presumed location of the castle's inner courtyard, great hall and chapel (and the later bowling green) were now occupied by tool and cutlery workshops, Thomas Clegg's cementation furnace, and the Reindeer Inn, on the corner of Waingate and Castle Folds (which would become Exchange Street), where the Brightside and Carbrook Co-operative Society would later build its city-centre store (Armstrong 1930, 8; Belford 1998, 14).

However, parts of the castle remained visible throughout the 18th century. A William Fairbank sketch of 1768 records a wall on the north-eastern side of the outcrop and a 1771 field notebook records a section of wall marked 'ruins of the castle', while a map of 1782 records two properties on the south-west of the site joined by a 'Castle Wall' (McCoy and Stenton 2009, 23-4; Belford 1998, 14). In addition, a report on the 'Natural History of Sheffield' in 1764 by the Reverend Edward Goodwin of Attercliffe (Sheffield) informs us that 'of the castle there are now very few vestiges remaining' - implying that there were some (Goodwin 1764, 157, emphasis added). We discuss the new archaeological evidence for the persistence of medieval structures into the 18th century in Chapter 7 (Figure 1.8).

Two hundred years ago, Joseph Hunter $(1819,115)$, author of Hallamshire: The History and Topography of the Parish of Sheffield and widely regarded as Sheffield's preeminent antiquarian (also Hunter 1828-31), lamented that 'the once proud castle of Sheffield was but a heap of shapeless ruins, every year doing something to complete the destruction which the axe of violence had begun. He was saddened that it had not survived for his contemporaries to appreciate, acknowledging that the reasons lay in competing demands for the space (Hunter 1819, 116). Nonetheless some traces of the castle, perhaps ever fewer and more reduced, persisted, as he acknowledges in his references to its 'shapeless ruins', the 'stone foundation work ... on Castle-hill', and the fact that 'a few vaults are all which now remain' (Hunter 1819, 17, 115-16; also Holland 1824, 15-16). Moreover, there is some evidence that traces of the castle remained visible into the early 20th century. For example, on Tuesday, $24^{\text {th }}$ November 1908, the Sheffield Daily Telegraph described photographs of 'the only remaining portion of the wall of the old Castle of Sheffield' and published one of a slaughterhouse door that 'tradition speaks of as the door of the Chapel in the castle' ('Sheffield Castle', 1908). In 1910 local historian Thomas Winder wrote that 'part of one of the angle-towers still remains by the White Cottage which can be seen from Castlefolds bridge situate $[s i c]$ where the moat left the river Sheaf' (Winder 1910, 58); this cottage is perhaps visible in a photograph taken in the early 20th century (Anon. 1900-19; Figure 5.25). Three photographs from 1918 depict sections of stone walls on the east side of the castle site, opposite the weir on the Sheaf. Accompanying notes in the Museums Sheffield archives claim these as remnants of the castle (Figures 1.9, 5.25; Richardson and Dennison 2014a, 28-9; though note that Leslie Armstrong $(1930,21)$ believed these walls had been rebuilt using material from the demolished castle; see also Chapter 5, Section: The morphology of the town plan). While traces of the castle did, then, remain, the trajectory of 19th-century development saw the site built on and obscured (Figure 1.10). In 1873 the Reverend Alfred Gatty $(1873,92)$ described the 'gradual reduction' of Sheffield Castle:

the dilapidated outer walls stood grimly for a while on Castle Hill - ghost of magnificence which had now passed away - and very soon the site was cleared of all encumbering traces of the old mansion, whilst buildings of a more practical kind were erected in its stead.

In 1898 the Lord Mayor of Sheffield wrote to the Duke of Norfolk expressing the view that the market rights should belong to the city of Sheffield, not to a private individual. The Duke, reluctantly, agreed to sell and in 1899 Sheffield Corporation purchased the markets and rights for $£ 526,000$ (Zasada 1996, 28; Short and Godfrey 2007, 55-6; Hey 2010, 223; Simmons 1997; see Chapter 9 for a longer-term perspective on this purchase). These acquisitions may also have been driven by the Corporation's desire to improve the infrastructure and hygiene of the area, although regeneration did not begin for many years. A plan from 1922 reveals their intentions for the site, and in 1928 the Shambles were demolished, and replaced in 1930 with a major road ('The New Road' - later called Castlegate), linking Lady's Bridge and Blonk Street, to the east (Armstrong 1930, 9; Belford 1998, 18-19; Richardson and Dennison 2014a, 34; 2014b, fig. 16; Figure 1.11). In 1927 the Brightside and Carbrook Co-op began the construction of the first phase of their new premises on a site at the corner of Exchange Street and Waingate, which they had purchased in 1914 (Figure 1.12). The following year 


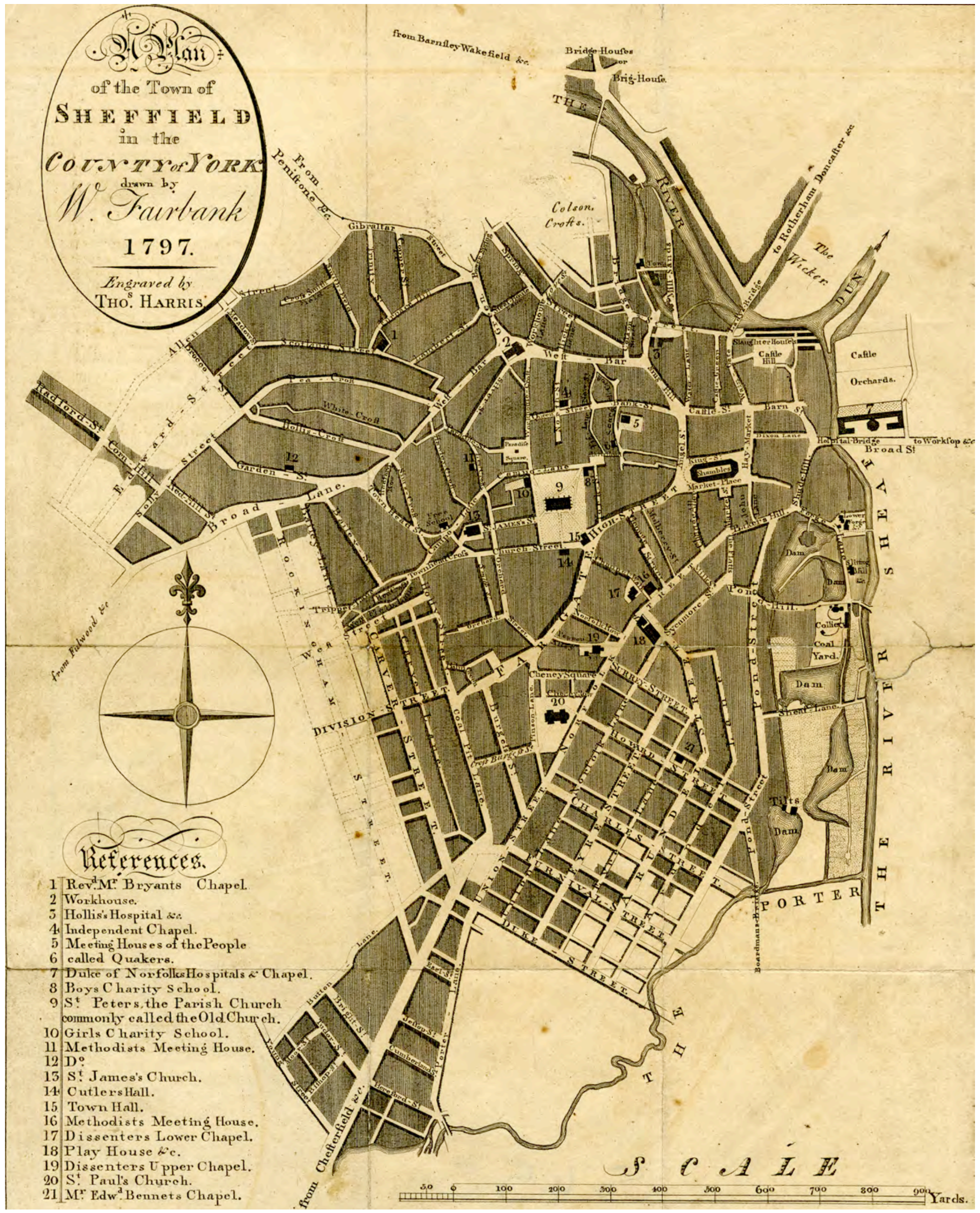

Figure 1.7: A Plan of the Town of Sheffield. Drawn by William Fairbank, 1797. Reproduced with permission from Sheffield City Council. 


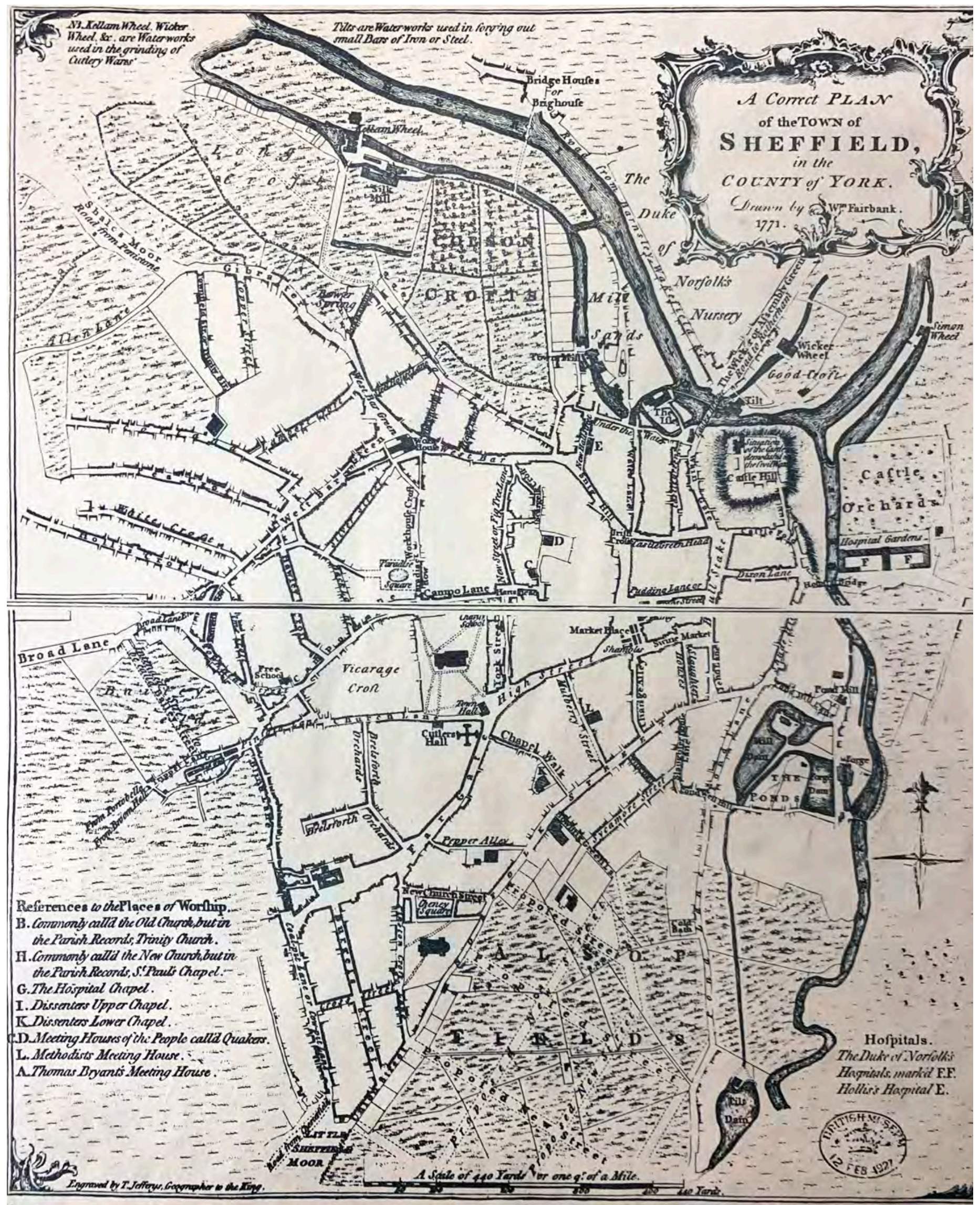

Figure 1.8: A Correct Plan of the Town of Sheffield. Drawn by William Fairbank, 1771. A copy is in the University of Sheffield Fairbank map collection; reproduced with permission from Sheffield City Council.

Figure 1.10 (page 15): Aerial photograph from 1921 of Castle Hill looking south. The slaughterhouses are visible above the Don, and behind them, and to the left of Waingate (on the right-hand side of the photograph), the densely packed 18th-and 19th-century buildings remain. Others had been cleared from the southern part of the site in preparation for redevelopment. () Historic England. 


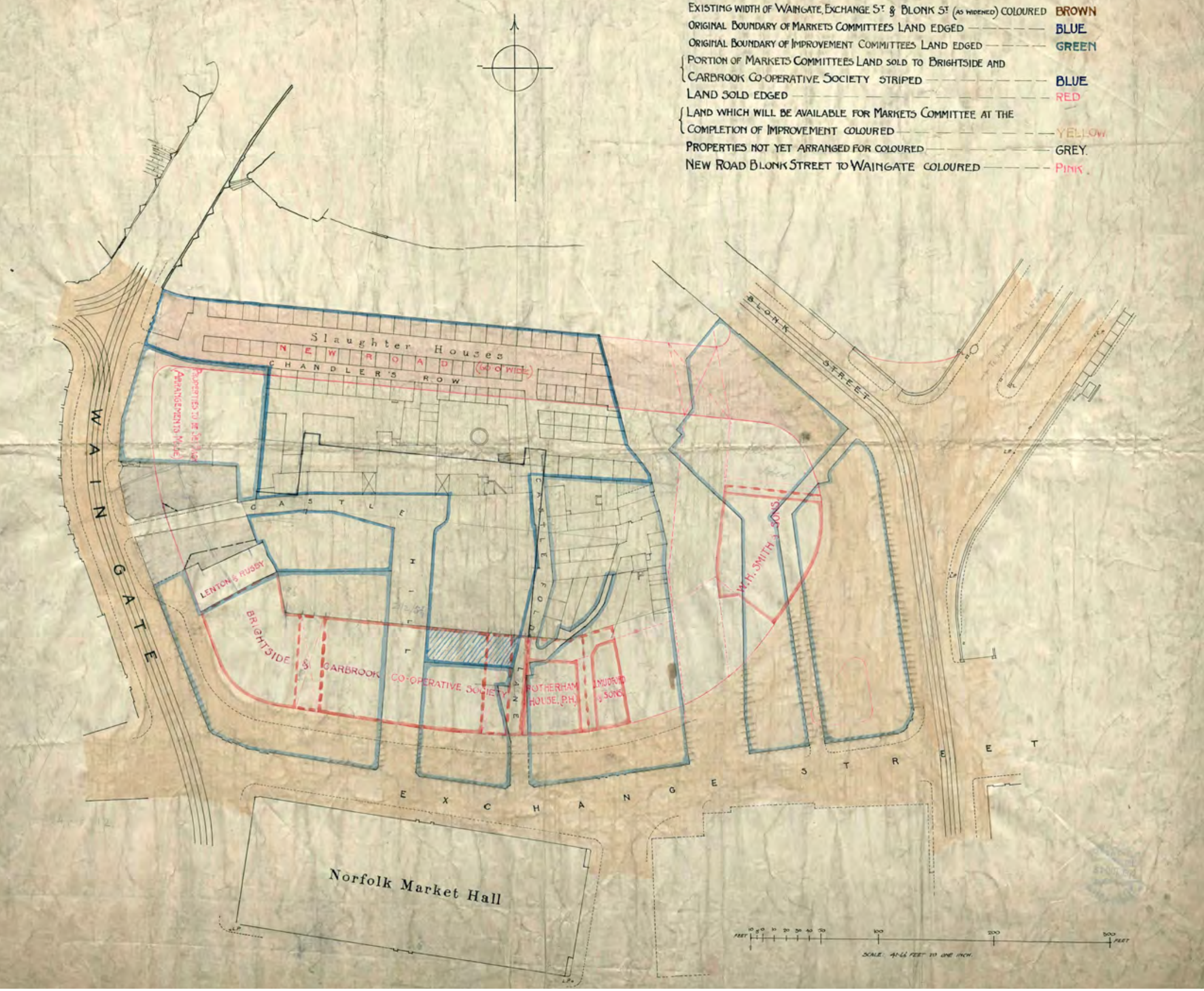

Figure 1.11: Sheffield Corporation plan of Castlegate, November 1922. This summary of the Corporation's proposals shows the land sold to the Brightside and Carbrook Co-operative Society for the construction of their new store (to the south), the line of the proposed new road (later known as Castlegate) from Blonk Street to Waingate (to the north), and 'the land which will be available for the Markets Committee' on which they built Castle Hill Market in 1928 (in the middle). Courtesy of Museums Sheffield.

the Corporation began the redevelopment of the area immediately north of these new Co-op Stores with the construction ofCastleHillMarket(Belford 1998, 19; McCoyandStenton2009,25-6; Figure 1.13). In the early 1930s Waingate was widened, and the buildings along the street front redeveloped (Belford 1998, 20). From that time the location of Sheffield Castle was home to the city's markets, until 2013, when they were rehoused at the bottom of the Moor, on the western side of the city centre, and the market buildings were demolished; the site of Sheffield Castle has lain derelict ever since. 



\section{Sheffield Castle rediscovered: 1927-2001}

Excavations at Sheffield Castle over the last 90 or so years have been piecemeal, mainly carried out in response to various phases of construction on the site. Very little about them has been published, even though the remains uncovered were substantial and their importance for our understanding of the Middle Ages, for the heritage of Sheffield and for the regeneration of this part of the city has been recognised since the 1920s. These excavations are introduced here to set the scene for detailed discussions in the ensuing chapters.

The plans for the construction of the Brightside and Carbrook Co-op store on the site at the corner of Exchange Street and Waingate, which commenced in 1927 (above), 'included a basement over the whole area' (Armstrong 1930, 9); and the foundation plan (c.1927) for the building shows the wall foundations as well as 40 'stanchion pits' each between $6 \mathrm{ft}(1.83 \mathrm{~m})$ and $9 \mathrm{ft}(2.74 \mathrm{~m})$ square (Johnson 1927a; 1927b; Richardson and Dennison 2014a, 30; also 2014b, fig. 17a; Figure 1.14). It was expected that there might be a significant impact on the remains of Sheffield Castle from the excavations required to deliver both this plan, and the building of the adjacent Castle Hill Market, which necessitated the creation of concrete bases for lines of steel stanchions as well as a grid of concrete piles, some sunk to a depth of $25 \mathrm{ft}$ (7.62m) (Anon. 1930a; Richardson and Dennison 2014a, 33; 2014b, figs 18a and 18b). Consequently, the Society of Antiquaries of London and the Hunter Archaeological Society appointed A. Leslie Armstrong to monitor the works and record the remains of the castle as they were exposed, including parts of a monumental gatehouse structure, sections of walls, and the moat. Armstrong's account of the castle excavations appeared first in the Antiquaries Journal in 1928 and then at greater length in the Transactions of the Hunter Archaeological Society in 1930. Surviving unpublished, and hitherto unstudied, material by Armstrong in the Museums Sheffield archive includes a site notebook, handwritten draft manuscripts of his work on the castle, sketches (some literally on the back of an envelope; Armstrong n.d. (a)), and various lecture notes.

Armstrong was aided in his work on the castle by Joseph B. Himsworth, cutler and silversmith by trade, who was also active in the Hunter Archaeological Society. The diary he kept during the excavations on the castle site survives, along with his many photographs, and the texts for lectures he gave locally in the 1930s and 1940s,

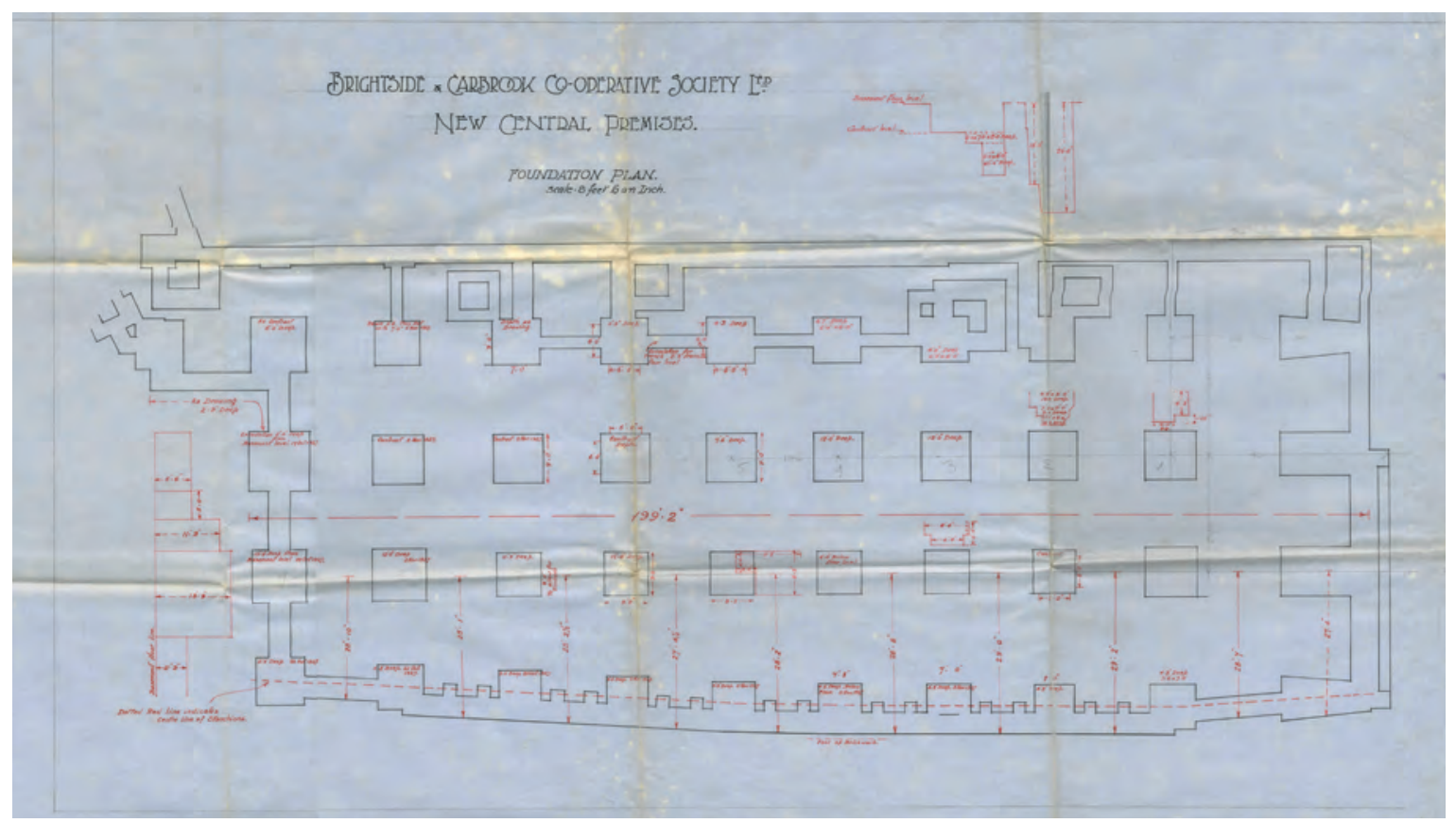

Figure 1.14: Foundation plan for the new Brightside and Carbrook Co-operative Society Building on Exchange Street. Courtesy of Museums Sheffield.

Figure 1.15 (page 19): Castle Market photographed in 2012. It was closed the following year and demolished in 2015. Copyright Stephen Richards; reproduced under a CC BY-SA 2.0 licence; geograph.org.uk /photo/3921121. 
as well as various letters he exchanged with Armstrong and others at the time of the excavations. As we will see in Chapter 2, the relationship between Armstrong and Himsworth, and their determination to record and preserve the remains as they were uncovered during construction work between 1927 and 1930, provided the crucial first steps in the rediscovery of Sheffield Castle. They set an agenda for interpretation that has cast a long shadow over subsequent work, and also initiated a debate about the significance of the castle for the modern development of the city of Sheffield, which continues to this day (see Chapter 9).

Work on the construction of a new market hall - Castle Market - commenced in 1958, and over the following decade or so a number of new buildings were constructed on the site of the castle (Figure 1.15). In places these developments re-exposed areas of the castle seen in the 1920s and 1930s, although they also uncovered parts not previously encountered. Leslie Butcher, from the City Architect's Department, recorded the remains of the castle from 1958, while John Bartlett, Deputy Director of the City Museum, recorded and conserved the finds, although his involvement was short-lived (see Chapter 4). Butcher produced detailed plans, sections and isometric drawings of excavated features, and an extensive photographic record also survives. His recording was meticulous, and he frequently drew multiple sections of individual holes and foundation shafts dug during construction (Richardson and Dennison 2014a, 4).

The only publication to emerge from this work was a brief note in the annual round-up of excavations across Britain and Ireland in the journal Medieval Archaeology in 1959 (Hurst 1959, 308). Yet, various handwritten notes detailing the remains of the castle that he recorded and a typed manuscript of $c .8,000$ words reveal that Butcher intended to publish his work more fully, although he died before these plans came to fruition. His archive was subsequently donated to Sheffield City Museum by his son Nicholas, but has not hitherto been

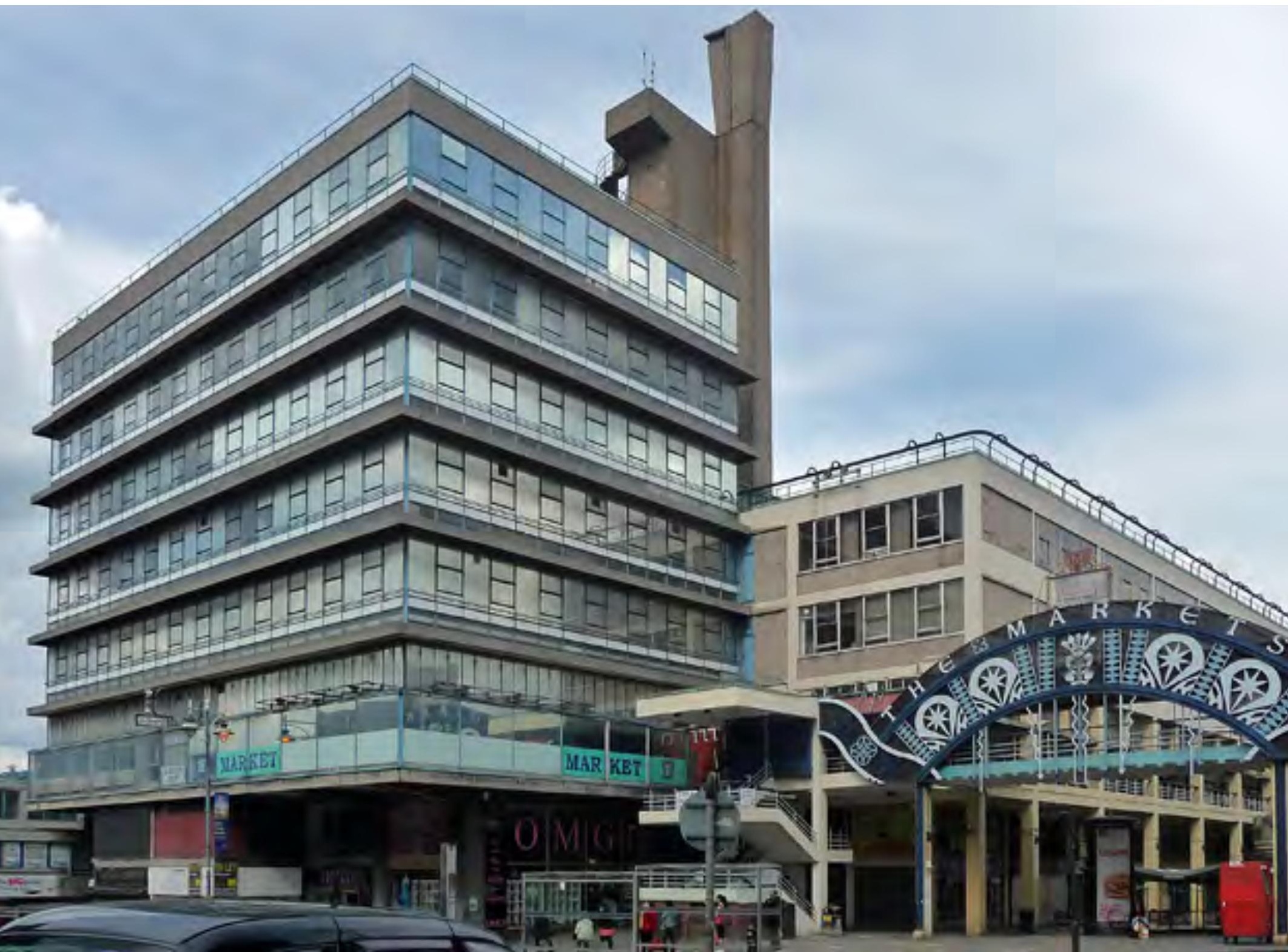


studied in detail (its contents were catalogued in Dennison 2014). As we will see, Butcher (1972a, 6-16) was able to refine some of the insights presented by Armstrong in his 1930 publication, particularly concerning the course and profile of the moat, the topography of Castle Hill, and the form of the gatehouse structures, and he also recorded sections of the curtain wall not noted by Armstrong, as well examining cartographic evidence for the place of the castle in the townscape.

There were many subsequent developments on the site of the castle during the 1960s and 1970s, but little recording seems to have taken place (Davies and Symonds 2002, 22; Davies and Willmott 2002, 7; Richardson and Dennison 2014a, 39). One exception was in 1972, when the paved surface that had been constructed in the 1930s to cover the sloping ground along Castlegate began to collapse, and the Council decided to replace it with a vertical concrete retaining wall. A section of stone wall of the castle was visible through the paved slope but collapsed during construction of the retaining wall (Richardson and Dennison 2014a, 62). However, Pauline Beswick, then Keeper of Antiquities at Sheffield City Museum, was able to record another section of stone wall (Beswick 1972d; Figure 1.16), and in 1990 she also produced a photographic record of the state of the gatehouse
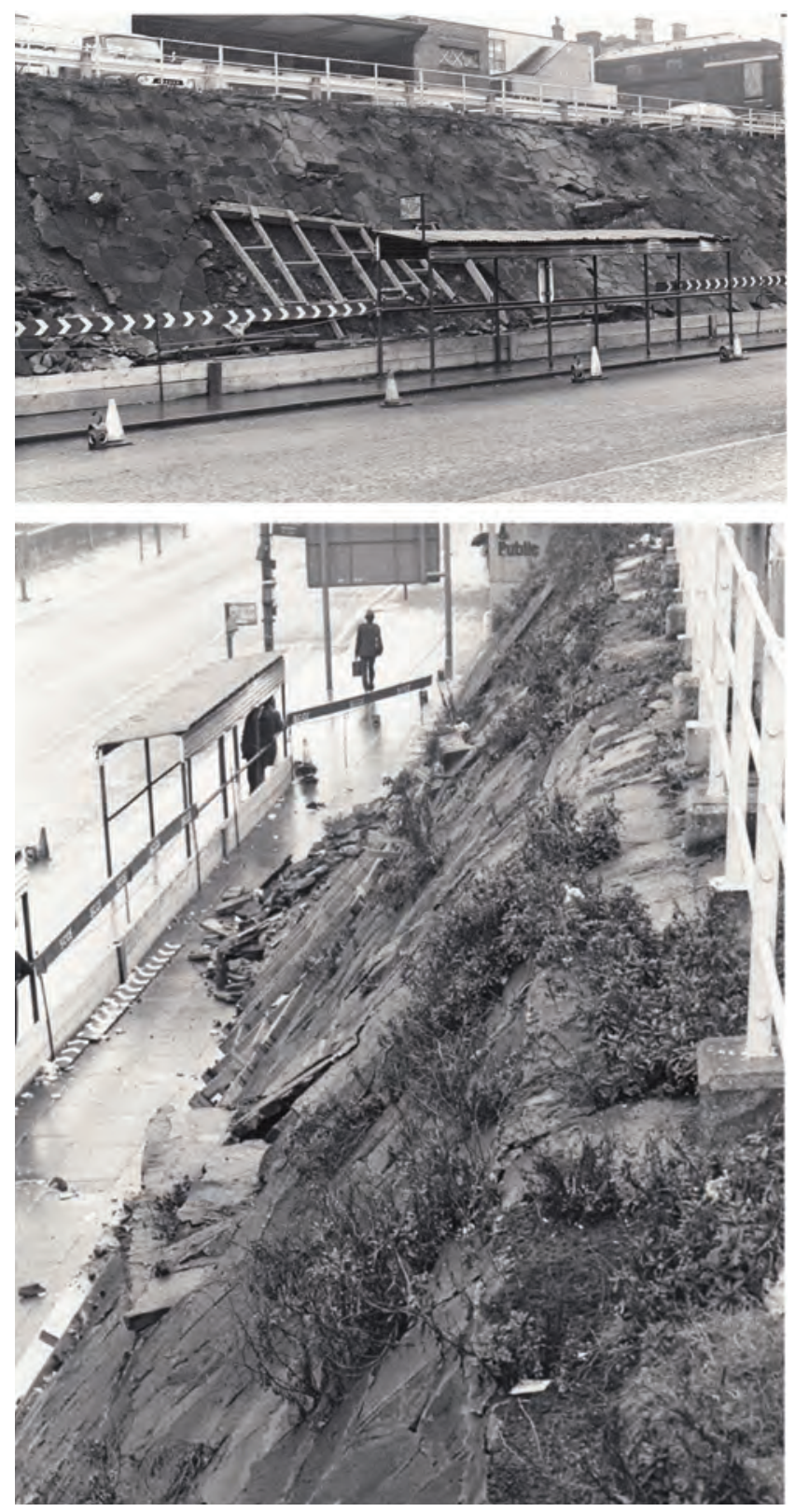

Figure 1.16: Collapse of the retaining wall above Castlegate in 1972. A section of castle wall is visible above the right-hand end of the bus stop (top) and another at the lower part of the slope (below). Recording of these exposed parts of the castle was undertaken by Pauline Beswick of Sheffield City Museum. Courtesy of Museums Sheffield. 


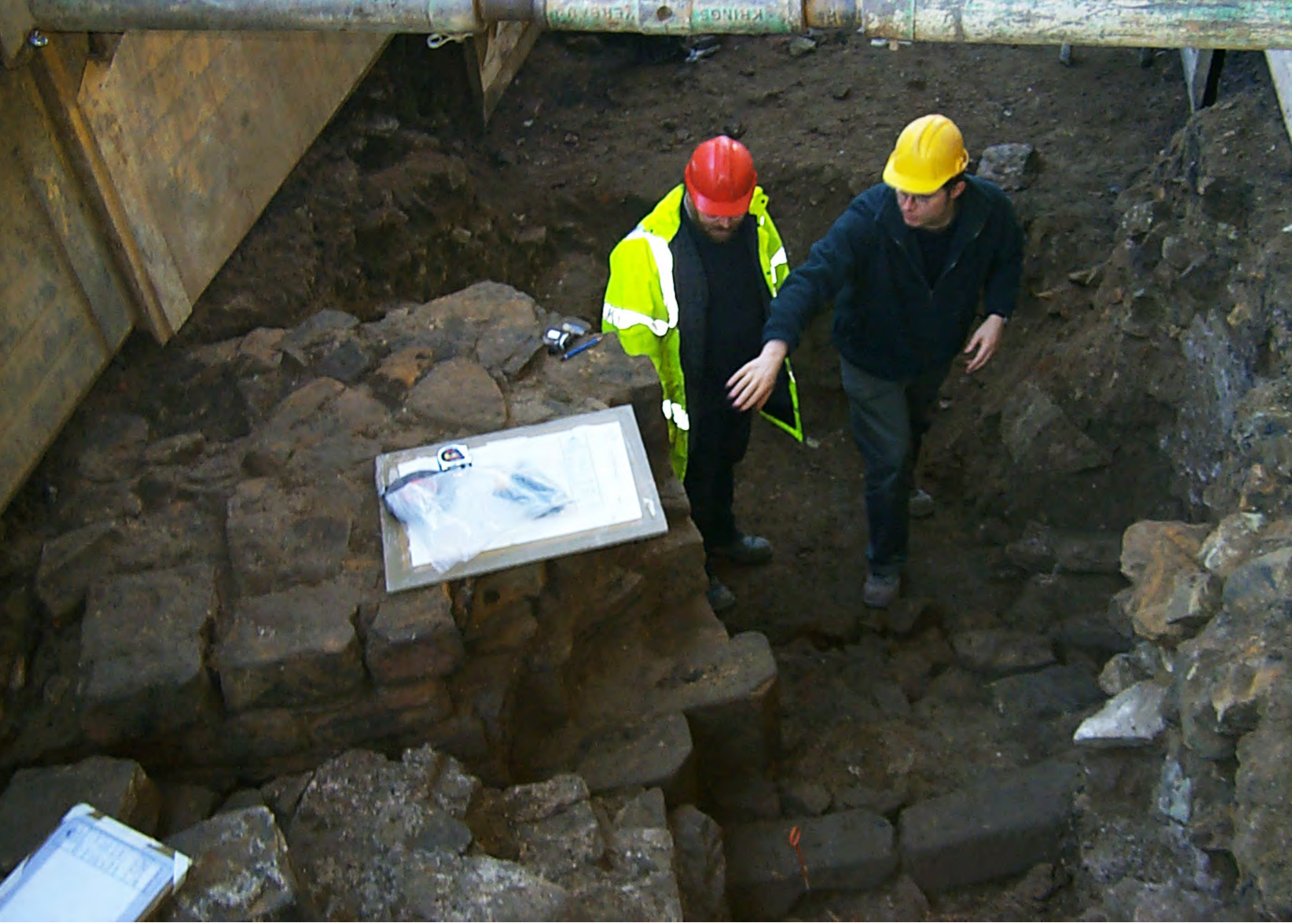

Figure 1.17: Remains of the castle's courtyard buildings. These were uncovered in excavations undertaken by ARCUS in 2001. University of Sheffield.

structure during repairs to the chamber in which it was housed (Beswick 1990). In 1994, the Sheffield Markets Department contracted South Yorkshire Archaeology Field and Research Unit to survey the remains of buildings from the castle's courtyard preserved in another chamber beneath the market buildings; this preceded work to improve presentation of them to the public (Latham and Atkinson 1994; Figure 3.21).

The first modern excavation on the site of Sheffield Castle was undertaken in 1998 by ARCUS, in preparation for the proposed redevelopment of the markets, and in line with the requirements of PPG16 (see Preface). Two trenches were opened on either side of the culverted River Sheaf, uncovering a medieval tanning pit, although the excavations mainly revealed that medieval levels in this part of the city centre had been extensively disturbed by early post-medieval development (Belford 1999; also Chapter 6). In the following year, work commenced in the area of the lower loading bay of Castle Market, which permitted investigation of the castle's eastern defences. The cut of the moat and a sequence of stratified fill deposits dating to between the late 11th and 17th centuries were recorded (Davies 2000). In 2001, two further trial trenches were dug in the area of the former upper loading bay, on the higher ground overlooking the River Don, which allowed further investigation of features first uncovered in the late 1920s and revealed additional structures (Davies and Symonds 2002; Figure 1.17; also Chapter 7). The artefact assessment reports produced by ARCUS following their three campaigns of excavation provided the first detailed sequence of activity on the site from stratified deposits, although this work did not produce tightly dated sequences, and the influence of the dating horizons of the published work of Leslie Armstrong is notable in the ARCUS phasing (e.g. Davies and Symonds 2002, 9). 
ARCUS produced well-illustrated 'grey literature' reports for these evaluation trenches, with stratigraphic sequences, site plans, sections and photographs (Belford 1999; Davies 2000; Davies and Symonds 2002). The work was never published, although the results were summarised a few years later by Neil Guy (2005) in the Castle Studies Group Bulletin. Significantly, these ARCUS reports had a major impact on the City Council's plans for the regeneration of the site, and indeed for the whole of Sheffield city centre (see EDAW 2005).

\section{The excavation archives and the city}

The potential for the archaeological record and the archives held by Museums Sheffield (which incorporates the former City Museum) to reveal important information about the castle has long been recognised, as has the potential of the castle for the city's heritage and regeneration. For example, in the late 1980s, when Sheffield City Council began to produce plans for the redevelopment of the city centre, Clive Hart (1989a, 8) of the City Museum prepared a report advocating the value of a study of the early history of Sheffield, including the castle: 'it is a common fallacy that the location of most archaeological sites and features is already known ... Sheffield's early history and archaeology is largely unknown because of insufficient study. It is critical that resources be deployed before the city loses more of its individual heritage.

In 1998, ARCUS was commissioned by the Council to undertake a desk-based assessment of the Castle Markets area, prior to possible redevelopment. The report, written by Paul Belford (1998), reviewed the history of development of the site to assess the likely character of the archaeological remains and to suggest mitigation strategies to protect them. This was mainly based on historical sources and Armstrong's published account of the archaeological remains. Belford (1998, 22-4) deemed it likely that many parts of the castle survived beyond the areas disturbed by 20 th-century building works, and also highlighted the potential for good organic preservation in the waterlogged areas of the moat. The subsequent ARCUS excavations confirmed both propositions (see above, and Chapter 7; Figure 1.18).

A more comprehensive review of the archaeological archives from the castle was undertaken by Glyn Davies and Hugh Willmott of ARCUS in 2002, funded by English Heritage. Their report included a summary of both the physical and paper archive held in Sheffield City Museum, and they highlighted the importance of Sheffield having one of the few castles in a large urban centre 'subject to well-recorded archaeological study, instead of large-scale unrecorded clearance' (Davies and Willmott 2002, 26). However, they also observed that the jumbled nature of the paper archive and lack of a finds catalogue were major impediments to future work. While recognising the importance of the archive, they highlighted the problem that PPG16 only required archaeological evaluation of remains that would be disturbed during development (Davies and Willmott 2002, 12). Therefore, the comprehensive study of the archives of earlier excavations fell outside of its remit, despite the historical significance of the site (Davies and Willmott 2002, 26). While also identifying the considerable public interest in the then recent ARCUS excavations, no funding was forthcoming to facilitate further work on the archive.

Awareness that the extent of the remains established by ARCUS, but also by Armstrong and Butcher, had implications for existing, and future, usage of the site found expression in the 2005 masterplan for the area commissioned from international architecture firm EDAW by Sheffield City Council: Castlegate - A New Vision. This 'vision document' considered how 'the original historic core of the City can redevelop to become one of the most interesting, diverse and vibrant parts of Sheffield' (EDAW 2005, 3; Minutes 2008, 1). In response to these developments, the Remains of the Sheffield Castle Working Group was set up in 2008 by Councillors Sylvia Dunkley and Arthur Dunworth 'to bring together all interested parties concerning the future of the remains of the Sheffield Castle and to formulate a policy for the Council and its partners to agree' (Minutes 2008). An inaugural meeting held on $18^{\text {th }}$ September heard, from a council representative, that the [ARCUS] dig had revealed significant remains of the Castle, which, if duplicated elsewhere, could prove a significant site and a major landmark for the City. This discovery had brought an end to plans to extend the market and that would now be relocated elsewhere' (Minutes 2008, 1). The regeneration of Castlegate was to be heritage-led; and this had wider implications, in the form of the relocated markets, for the whole city.

The Working Group inspired two reports intended to generate momentum for the development of the site and the uncovering and dissemination of its heritage. First, at the request of a city councillor, Clive Waddington of local archaeological unit Archaeological Research Services Ltd prepared a vision statement for how 


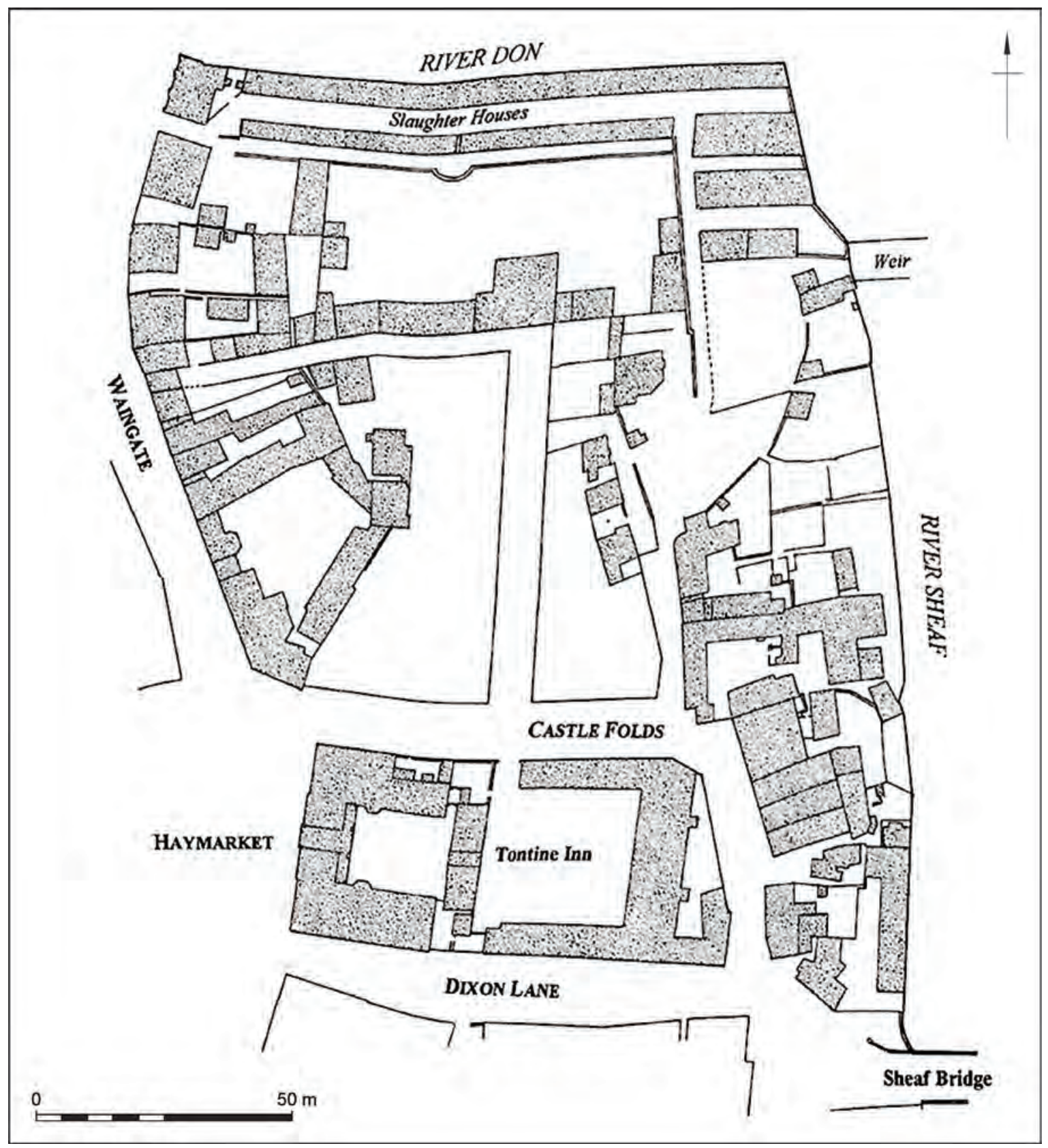

Figure 1.18: The site of Sheffield Castle in the 18th century. Based on Fairbank maps, this was produced by Paul Belford of ARCUS in 1998 during his review of the development of the site. Redrawn by Wessex Archaeology.

heritage-led regeneration might be achieved. Waddington $(2009,6)$ argued that '[r]ather than providing an impediment to development the Castle remains give Sheffield an enviable historic asset around which high grade new development could be designed and constructed. Second, the University of Sheffield funded ARCUS to undertake another review of the castle archive, and to produce a predictive model of the layout of Sheffield Castle to inform future development. The ensuing report by Michael McCoy and Mark Stenton (2009) contained a chronological outline of the development of the castle, integrating the known archaeological evidence with published written sources. They suggested where buildings mentioned in these written sources may have been located within the inner courtyard (Figure 1.19), and a 3D model of the gatehouse was created by Marcus Abbott (Figure 1.20). 


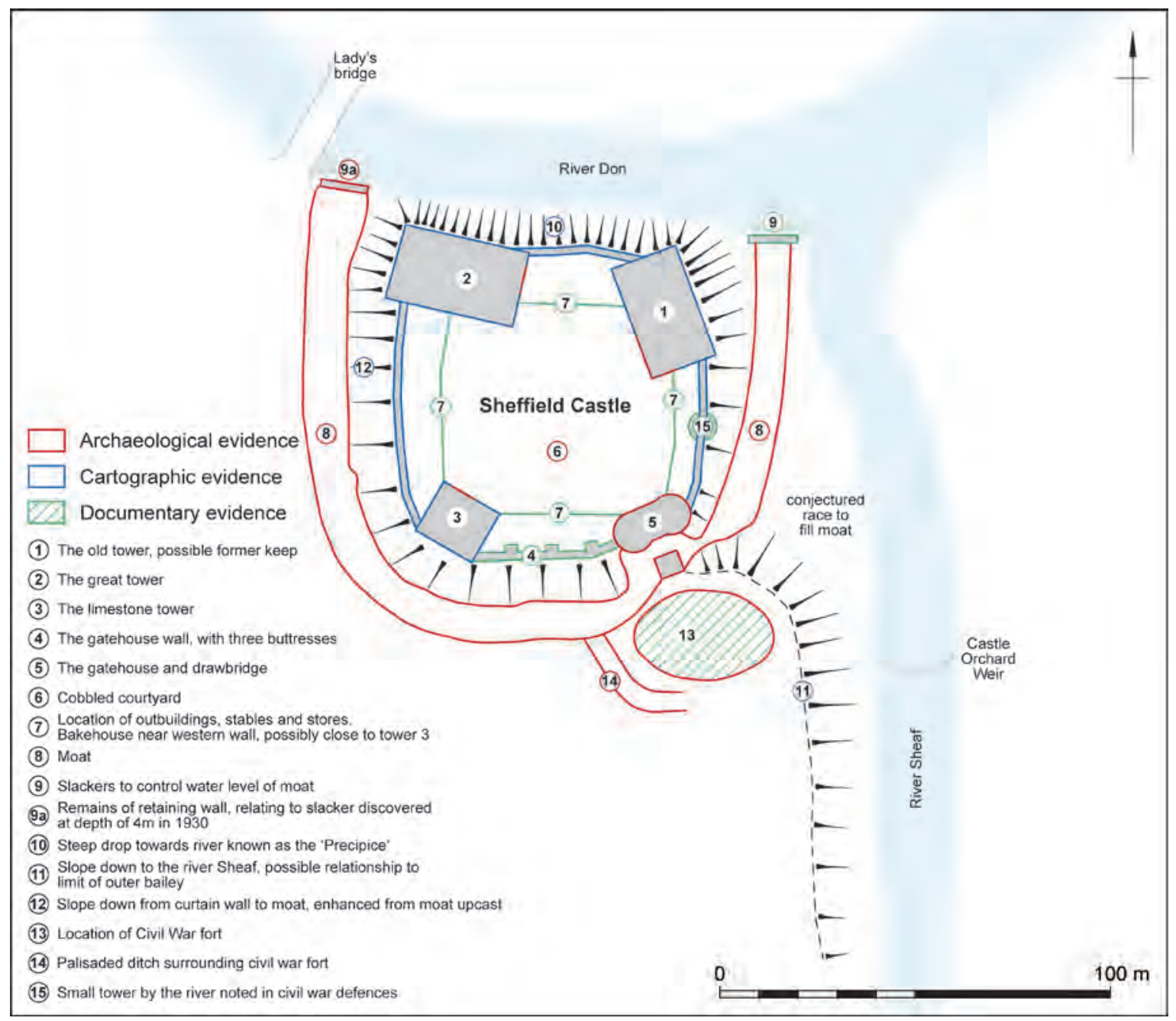

Figure 1.19: Conjectural plan of Sheffield Castle. Produced by Michael McCoy and Mark Stenton of ARCUS in 2009, suggesting where buildings and other features mentioned in the written sources might be located. Redrawn by Wessex Archaeology.

A detailed review of the paper archives was conducted in 2013 and 2014 by Ed Dennison and Shaun Richardson of Ed Dennison Archaeological Services Ltd, who also provided a catalogue of the physical archive (Dennison 2014). This was commissioned by the City Council to provide 'sufficient information about areas of archaeological potential on and within the Castle Markets site, so that they might be able to secure an appropriate and cost-effective archaeological evaluation of the complex' (Richardson and Dennison 2014a, 3). This review was intended to inform proposed archaeological work that would be required for redevelopment of the castle site following the demolition of the 1950s and 1960s market buildings and to support a bid to the Heritage Lottery Fund (Richardson and Dennison 2014a, 1; Sheffield City Council 2014), although, as we saw in the Preface, this bid was unsuccessful. The reports presented a detailed strategy for a future archaeological analysis of the castle site prior to development, including a specification of work required on the archive (Dennison 2014). They also provided an overview of the history of the castle and a summary of the previous excavations on the site, largely based on the earlier reviews by ARCUS, and suggested that detailed analysis of the unpublished material by Armstrong and Himsworth should be undertaken to see if 'any information that contrasts with Armstrong's published account emerged' (Dennison 2014, 11). For the first time the importance of the Leslie Butcher archive was identified (Richardson and Dennison 2014a, 57). Richardson and Dennison 


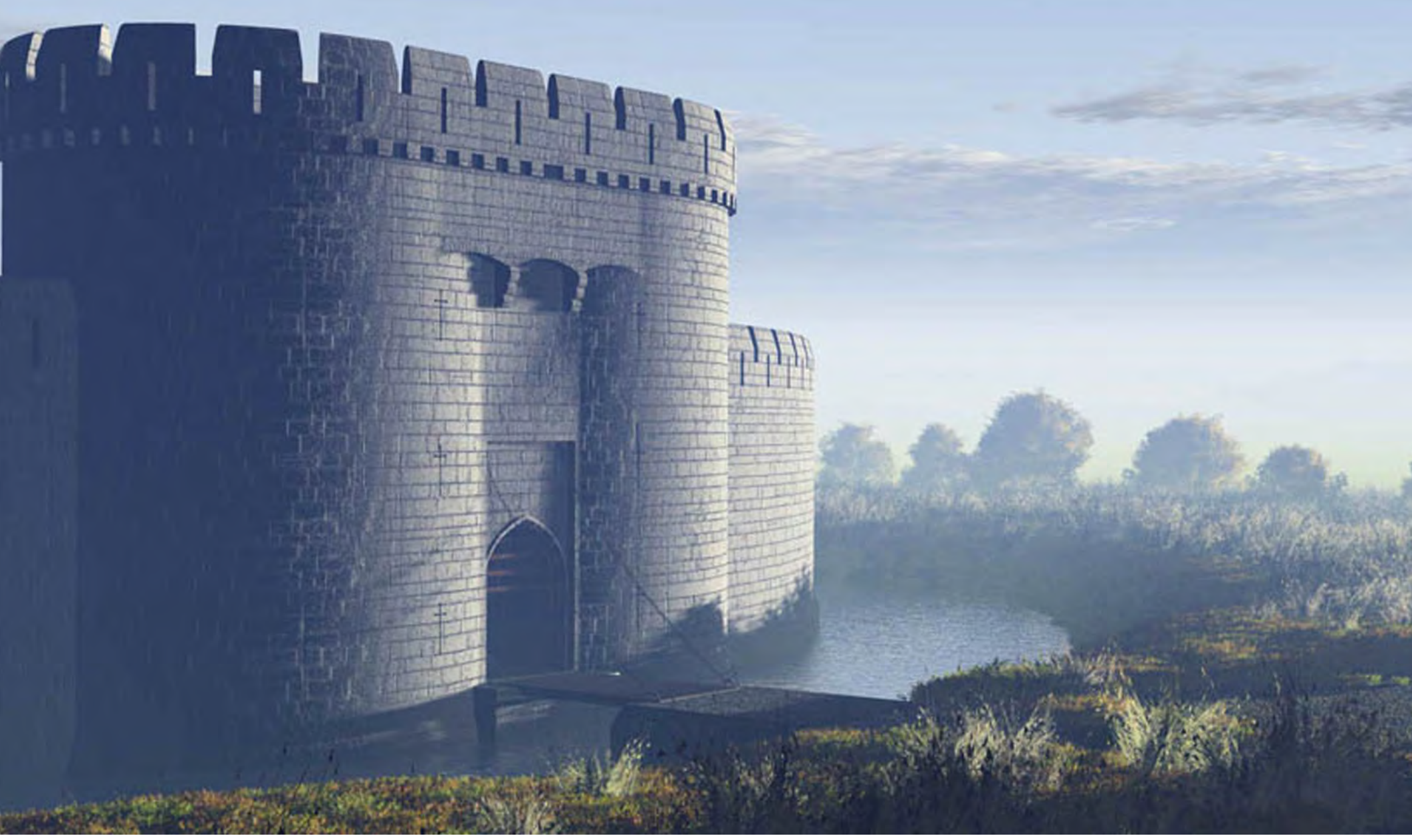

Figure 1.20: A 3D model of the gatehouse. Created by Marcus Abbott of ARCUS in 2009. University of Sheffield.

presented the first detailed assessment of the paper archives, intended 'to identify the potential for subsequent analysis of all or some of the material, not only in terms of its research value but also for its public interest and capacity to engage and involve non-professionals in the wider Castle project' (Dennison 2014, 1). The present volume finally enables these ambitions, expressed many times over the course of three decades, to come to fruition. Our research on the archives facilitated new archaeological work on the site of the castle (see Preface), which was carried out by Wessex Archaeology in 2018. The results of these investigations are incorporated into this book (especially Chapter 7), enabling us to bring our understanding of the castle, and the narrative of the manner in which urban excavation is conducted and its position in regeneration debates, up to the present day.

\section{Sheffield Castle in scholarly context}

In this book we have set about bringing to publication several campaigns of excavation on the site of the castle, and, as well as contextualising these within regeneration debates in the city, we position our analysis within the context of wider studies of castles. There have been many studies of the origins, form and architectural development of castles (Brown 1954; Platt 1982; Cathcart King 1983; 1988; Fradley 2015; Kenyon 1990; Liddiard 2002; 2016a; Shapland 2019), their social, ideological and political meanings (e.g. Austin 2007; Pounds 1990; Coulson 1979; 2003; Gilchrist 1999, 109-45; Johnson 2002; Swallow 2016), and the impact of castles on the medieval economy (e.g. Austin 1984) and landscape (Creighton 2002; Liddiard 2005; Creighton and Higham 2004). A great deal has also been written in the last 30 years or so about the apparent transition in castle architecture from an emphasis on military defensibility to domestic comfort and 'a retreat from the more warlike characteristics of a previous age, which derives from a shift in interpretative emphasis (Liddiard 2016b, 2-3). The notion that the later medieval centuries represented a 'decline' of the ideals of medieval castles has taken hold in castle studies, but has been a controversial proposition and widely opposed by some scholars who have preferred to focus instead on the continuous evolution of castles across the medieval period (Faulkner 1963; Coulson 2000; Liddiard 2016b, 5). At the same time as we situate our research within this broader scholarly 
context, our approach differs considerably from the tenor of this recent work, with its principal contribution being a study of the embeddedness of Sheffield Castle in urban life, especially its significance for the city in the centuries following its demolition. Our study is also unique in focussing on a castle that has almost entirely disappeared from the settlement in which it was located, in contrast to the focus of most castle studies on surviving fabric, architectural details and earthworks (e.g. see the range of papers in the two volumes compiled by Liddiard in 2002 and 2016; also Johnson 2017a).

Our book also contributes a new dimension to the discussion of castles as cultural phenomena. Much previous work has explored the imagined castles of medieval literature, the influence that medieval mythology had on castle architecture (e.g. Thompson 1997; Wheatley 2004; 2010; Swallow 2019), and the evidence from the landscape setting of castles that suggests that literary imagining 'of a castle magnificent in its setting was very much a medieval reality' (Liddiard 2016b, 16; Taylor 2000; see Chapter 8). In contrast, our analysis of Sheffield Castle presents a detailed examination of the way that even a castle that had disappeared from an urban landscape held a powerful pull on the imagination and on a sense of civic identity, and was subject to multiple reimaginings.

There have been a few recent studies integrating archaeological and historical evidence for the destruction, or slighting, of medieval castles during the English Civil War (e.g. Rakoczy 2007; Nevell 2020), but no study has previously examined the longer-term consequences of these acts of monumental destruction. Sheffield provides a rare opportunity to do that, with one of the most complete sets of demolition accounts, a rich, but largely untapped, archaeological record, and a long-running campaign of attempted regeneration of the castle site, to which the physical traces of the castle have been a perceived barrier but which we argue are, in fact, the potential key to unlocking the future. There have been other studies that have looked at the post-medieval fate of castles, as they were transformed into aristocratic country houses, repurposed as prisons (e.g. Munby et al. 2010), or became romantic follies in the designed landscapes of the 18th century and later (Johnson 2002; 2017b), but here we present a unique perspective on the afterlife of a medieval castle in an industrial and postindustrial urban landscape.

Our approach has been to write the biography of a historic place, interweaving three principal narratives: 1) the story of Sheffield Castle (its building phases, the people who lived and worked there etc.); 2) the story of the people who rediscovered the castle, inventing new histories for the place in the process; and 3) the story of the castle in its contemporary world from the place it occupied in medieval Sheffield to its role in the city today. These narratives are interspersed throughout the book with accounts of different historical actors (Waltheof, Leslie Armstrong, the de Lovetots, Joseph Himsworth, the de Furnivals, the Earls of Shrewsbury, Leslie Butcher, Mary, Queen of Scots, the Dukes of Norfolk, estate officials such as Geoffrey Botery the park keeper, and the labourers and craftworkers of the town, such as Henry Roworth and the Shore brothers) coming to the fore at different times, both in the past because of the historical sources we have but also across the last hundred years as the needs and agendas of successive eras have unfolded.

\section{Conclusion}

During their visit to Sheffield in 1903, members of the British Archaeological Association were presented with a bleak view of the heritage of the city by local historian Robert Eadon Leader (1904a, 12-13):

in Sheffield itself, there are but few objects of archaeological interest ... One stone, with chevron moulding, is the only proof of a Norman church. One mention alone is there of an early castle ... The old Hall in the Ponds is, in its decadence, the only remnant of the appurtenances of a castle whose materials were effectually utilised to rebuild a town of wood in stone ... Beyond these ... what have we got?

Traces of the city's medieval past had, admittedly, largely been obscured by industrialisation and urban expansion, and the situation has been compounded since Leader's day by the impact of the Luftwaffe during the Sheffield Blitz in December 1940, and the efforts of urban planners from the 1960s. Yet, as we shall see in this book, much more of the castle has survived than Leader's pessimistic assessment suggests, and, in the century or more since, much has been learned from excavation about the remains of the castle and its associated park and hunting lodge. While we began this chapter with an outline of the elites of Sheffield Castle, that is 
arguably the least interesting or important aspect of its history, and what unfolds in the book is an archaeological record that has more to say about the servants, craftworkers and ordinary men and women of Sheffield whose labour created, maintained and ultimately dismantled the castle, and an account of the efforts of community heritage enthusiasts, amateur and professional archaeologists, university researchers, museum staff and the City Council, who have saved, recorded and sought to promote the castle. Finally, this book demonstrates the extent to which the hidden heritage of Sheffield's castle has had a continued, profound impact on the development, opportunities and aspirations of the city, showing that even as it lies beneath an empty plot of land it is returning, once again, to its role at the heart of the urban landscape in the 21 st century.

\section{Bibliography}

The full bibliography is available at the end of this volume, or at: https://doi.org/10.22599/SheffieldCastle.k. 



\title{
Archaeological Practice in the Inter-War Years
}

\begin{abstract}
By the courtesy of the contractors and the officials of the Co-operative Society the writer has been privileged to watch the progress of the excavations, and during brief daily visits, to recover from the sludge, before it was carted away, a representative collection of objects and other interesting relics of mediceval days (Armstrong 1927b)
\end{abstract}

The rediscovery of Sheffield Castle commenced in earnest in 1927, with the construction of the new city-centre store of the Brightside and Carbrook Co-operative Society and (shortly afterwards) of Sheffield Corporation's Castle Hill Market just to the north. The paper Leslie Armstrong published in the Transactions of the Hunter Archaeological Society in 1930 was based on observations made during this construction work. This seminal paper has been the principal source for all subsequent understanding of Sheffield Castle (e.g. Walton 1949, 21-2; Fine 2003, 36, 41; Jones 2004, 27; Hey 2010, 15; Hallam 2015) but has been subject to little critical scrutiny, and few have considered the inevitable shortcomings of efforts to record the remains of the castle in the pressurised circumstances of commercial construction. Nor has the role and influence of Armstrong's collaborator Joseph Himsworth been adequately assessed or, indeed, acknowledged. In this chapter we use unpublished sources in the Museums Sheffield archive including correspondence, diaries, lecture notes and excavation records, as well as contemporary newspaper articles, to situate Armstrong and Himsworth's work (both on site and in publication) in the context of the personalities involved, the prevailing intellectual climate, archaeological practice, and understandings of the past and of its value in contemporary society. In this first part of the story of the uncovering of Sheffield Castle, it is the amateur enthusiasts, local heroes battling against the odds, who take centre stage, the man from the Inland Revenue supported, aptly for Sheffield, by the son of a cutler. In their work we see a narrative emerging around the castle, we feel the excitement and thrill of discovery that shines through the manuscript sources - and the myth making commences.

\section{Sheffield Castle: where the two rivers meet}

In his 1930 publication Leslie Armstrong gives a laconic account of the circumstances leading up to the first 20th-century archaeological investigation of Castle Hill. He reports that in $1915^{1}$ the Brightside and Carbrook Co-op bought part of the site with the intention of building a new city-centre store. Construction began

${ }^{1}$ Other sources say that the Co-op purchased the site in 1914 (Denton 1946; English Heritage 2009).

How to cite this book chapter:

Moreland, J. and Hadley, D. (with A. Tuck and M. Rajic). 2020. Sheffield Castle: archaeology, archives, regeneration, 1927-2018, pp. 29-67. York: White Rose University Press. DOI: https://doi.org/10.22599 /SheffieldCastle.b. CC BY-NC 4.0, https://creativecommons.org/licenses/by-nc/4.0 
in 1927, and as local secretary of the Society of Antiquaries Armstrong $(1930,9)$ was appointed to record this work and 'on its behalf also' by the Committee of the Hunter Archaeological Society. In a lecture to the Sheffield Trades Technical Society in 1935 Joseph Himsworth embellished this account, imbuing it with a sense of mystery and urgency. Thus, he reported that, although most 'expert opinion' favoured the land in 'the angle formed by the Junction of the Sheaf and the Don', 'considerable controversy' remained locally regarding the site of Sheffield Castle (reflecting the claim by Armstrong (1929b) in the handwritten draft of his partially completed book on the castle that, until his work, 'the actual position of the [castle] building remained a matter of conjecture'). Himsworth told the audience of a later lecture, on '500 Years of Sheffield Trade and Sheffield Castle', that when 'the city authorities cleared the area between Exchange Street, Waingate and the Don of what were chiefly $17^{\text {th }}$ and $18^{\text {th }}$ century buildings' (see Figure 1.10), and it became clear that the Brightside and Carbrook Co-op was going to build on part of that land, 'local antiquaries bestirred themselves'. Armstrong was appointed to 'watch' the excavations, in turn inviting Himsworth to assist (Himsworth 1937, 4-5; 1935, 5). In these compressed narratives, historians and archaeologists respond to an emerging threat/opportunity, and Armstrong and Himsworth end up recording the uncovering of Sheffield Castle. In fact, the process was more protracted, and the 'position' of the castle less mysterious, than all this implies.

The location of the castle was not a controversy for the Reverend Edward Goodwin, who wrote in 1764 that 'at the NE part of the town, where the two rivers meet, formerly stood a strong castle, which was demolished in the civil wars', but lived on in the names of 'the streets and places thereabouts ... Castle-hill, Castle-Fold, CastleGreen, Castle-Lathe etc.' (Goodwin 1764, 157). Nor was it a mystery to Thomas Winder (1910, 55), who told the British Association for the Advancement of Science in 1910 that 'Sheffield Castle was situate at the confluence of the rivers Don and Sheaf'. Not long afterwards 'archaeological traces' of the castle came to light (see Chapter 1, Section: The castle 'made untenable' for evidence that parts of the castle remained visible into the early 20th century; also Chapter 7, Section: Steel City). In a letter to the editor of the Sheffield Daily Telegraph, published on $1^{\text {st }}$ July 1914, 'W' (probably architect, local historian, and FRSA James Ragg Wigfull (Ball 2012)) reported that while walking along Exchange Street he had observed what he took to be official surveyors ... at work' on the site, following the 'demolition of the old buildings and the clearing of the ground. He hoped that these men were 'marking on their plans and making notes of anything ... which might eventually help to explain the lay of the Castle and its moat' ('Sheffield castle', 1914). A short note by Wigfull (1916, 239; also 'Sheffield's Streets', 1922) in the Transactions of the Hunter Archaeological Society reported on the ensuing discovery of 'some slight traces of the Castle of Sheffield', comprising 'fragments of a paved roadway' close to the Royal Hotel on Waingate, and 'the outline of a ditch' which seemed to run parallel with Exchange Street.

The construction of the Co-op's city-centre store, and other proposed developments in the area, were delayed by World War I, but, even before the first steps towards redevelopment were taken in that post-War period, there were calls for 'action' on the castle site - and from Joseph Himsworth, no less. On $1^{\text {st }}$ July 1924, he wrote to the editor of the Sheffield Daily Telegraph praising the results of recent excavations on the site of Beauchief Abbey, a 12th-century monastic foundation in what is now south-west Sheffield, and expressing the hope that 'Sheffield castle [will be] next. He argued that the position of the castle is well known 'within a few yards', that 'a few trial holes would cost very little for labour', and noted that 'offers of help for the purpose' had been made - all that was lacking was, he thought, 'the man to organise the effort' (Himsworth 1924, 6). That man was soon to appear - but he did so at the end of a long period of calls for action to understand and preserve the remains of Sheffield Castle, and an intermittent process of regeneration in the area, not as a result of the burst of activity in 1927 implied by Armstrong's paper.

The excavations overseen by Armstrong and Himsworth would finally settle whatever 'controversy' remained about the location of the castle. ${ }^{2}$ However, given the conditions under which they were conducted, and the character and intellectual background of those involved, much uncertainty remains - about, for example, the castle's origins, development, daily life and the manner and timescale of its demise - and Armstrong's publications offered problematic interpretations in this respect. To achieve the fullest understanding of what they saw we need to interrogate a much wider array of evidence than the 1930 paper. Our archival research provides fresh insights into the two men who oversaw the 'rediscovery' of Sheffield Castle in the course of the

\footnotetext{
2 That there was some controversy can be seen in the fact that an early newspaper report on the question of what to do with the remains is prefaced by the remark that 'It is a strange thing that the site of such a place as this, certainly the most important and imposing building in medieval Sheffield, should have passed out of record' (Sheffield Daily Telegraph, $13^{\text {th }}$ October 1927, under Current Topics).
} 
early 20th-century regeneration of the area, and we begin our discussion with an analysis of their interests, experiences and motivations.

\section{Albert Leslie Armstrong: more than just the 'gifted amateur'}

Albert Leslie Armstrong (known as Leslie) began his working life with a firm of architects and surveyors in his hometown of Harrogate (Yorks), and in 1912 moved to Sheffield to work for the Inland Revenue. During World War I he served as a lieutenant with the Royal Engineers (Burkitt 1963, xi). From an early age, however, archaeology was his 'guiding passion' (Allsworth-Jones 2014, 8), and, mentored by famed geologist and archaeologist Professor William Boyd Dawkins, he acquired considerable experience working on, and directing, archaeological projects, particularly at prehistoric sites including the Neolithic flint mines at Grimes Graves (Norf) between 1916 and 1939 (e.g. Armstrong 1924; also Russell 2000, 25, 37; Varndell 1991), the caves at Creswell Crags (Derbs) from the 1920s (Armstrong 1926a; 1929d; 1932;1956) and Palaeolithic and Mesolithic 'open sites' in Lincolnshire (e.g. Armstrong 1923). Armstrong was not a 'professional' archaeologist - they were still very rare in the 1920s and 1930s (Barker 2007, 383) - but he was undoubtedly a very experienced one. Although his work has not been without controversy - for example, the questionable 'authenticity' of some of the engraved and carved figures he found at Creswell and Grime's Graves (Burkitt 1963, xi-xii; Bahn and Pettitt 2009, 14; Hutton 1997) 3 - it is generally accepted that Armstrong was a 'highly capable and talented archaeologist' (Russell 2000, 41), whose 'records of his excavations in Pin Hole [cave] are far better than any others that exist for Creswell' (Bahn and Pettitt 2009, 14; also Burkitt 1963, xi-xiv; Allsworth-Jones 2012, 30).

Armstrong was one of the most respected practitioners in his field, advising and debating with some of the best-known prehistorians of the time - including Abbé Breuil (France), Raymond Dart (South Africa) and Louis Leakey (East Africa). He died ( $3^{\text {rd }}$ December 1958) at Johannesburg railway station while 'making his final visit to Professor Dart' (Kitching 1963, 2; Dart 1973, 424), while Leakey thanked 'my friend ... Mr Leslie Armstrong' for discussions that informed his The Stone Age Cultures of Kenya Colony (1931, xiii). Some of his interactions were not entirely 'harmonious', however. Brian Fagan (2001, 44-5) describes a meeting of the Prehistoric Society of East Anglia in 1932, where the 'venerable but troublesome' Armstrong lambasted a young Grahame Clark as 'you impudent puppy' after the latter had 'brashly' corrected his identification of a prehistoric flint. This marked the beginning of a brief feud with Clark (and Stuart Piggott) played out in the pages of the Proceedings of the Prehistoric Society (Russell 2000, 24-5).

By the time he oversaw the excavations at Sheffield Castle, Armstrong was one of the most influential archaeologists in the country - Roger Mercer $(2010,50)$ refers to him as one of those who 'controlled the levers of the profession'. In the 1920s the British Association for the Advancement of Science, in collaboration with the Royal Anthropological Institute, established a research Committee for the Exploration of Derbyshire Caves, appointing Armstrong as field archaeologist (Allsworth-Jones 2014, 10; White et al. 2009, 227). His early work at Grime's Graves was funded by the Percy Sladen Memorial Fund (administered by the Linnean Society) (Armstrong 1924, 182), and in 1938 he won a research grant from the Lord Leverhulme Fund to carry out research on the prehistoric archaeology of the Trent gravels (Armstrong 1942, 34). He published in what are still the leading journals in the field - including Man (e.g. 1925; 1936) and the Proceedings of the Prehistoric Society (e.g. 1924). As well as publishing numerous excavation reports, he used his knowledge, expertise and wide-ranging contacts to write broad overviews, comparing, for example, the Mesolithic cultures of East Yorkshire and Denmark, or the Mousterian industries in South Africa and Europe (e.g. Armstrong 1924; 1936; Dart 1973, 424). This is a long way from Sheffield's medieval castle, but to assess his work there it is essential to understand the experience and stature of a man for whom the phrase 'gifted amateur' (Burkitt 1963, xiii) does scarce justice. He was well connected, and, as well as being local secretary of the Society of Antiquaries, was President of the Sorby Natural History Society (1927), a founder member (in 1935) of the British Speleological

\footnotetext{
${ }^{3}$ Miles Russell $(2000,41,45)$ went so far as to accuse Armstrong of faking the 'flint crust engravings' from Grime's Graves, even suggesting that he may have been 'implicated in the manufacture' of the sculpture that became known as the Grime's Graves Goddess. His evidence is, however, hardly convincing, with the Grime's Graves engravings bearing little resemblance to the French examples on which they were supposedly based (see Russell 2000, figs 17 and 18). He cites the testimony of Ethel Rudkin (to Kevin Leahy), who was at Grime's Graves when the 'Goddess' was discovered, to cast doubt on Armstrong's behaviour, but neglects to tell us that 'in her conversation with Leahy [Mrs Rudkin] was adamant that Armstrong's figurine was genuine' (Varndell 1991, 104; 2005).
} 


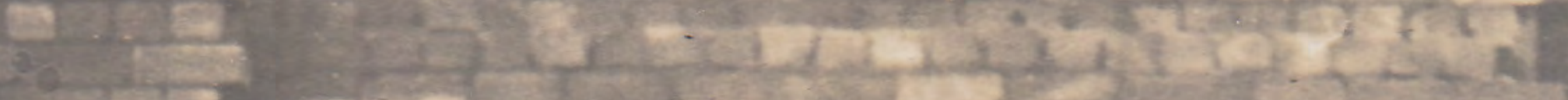

ancotistos $\mathrm{Stanc}$ cosing woon $\frac{x^{2 x}}{x^{2}}$

$\lim _{x \rightarrow 3}$

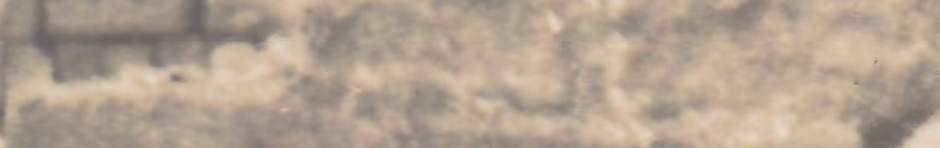

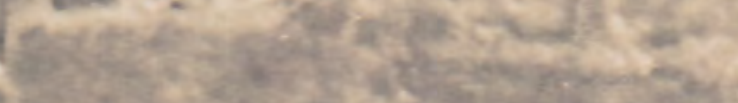

$\frac{4}{4}$

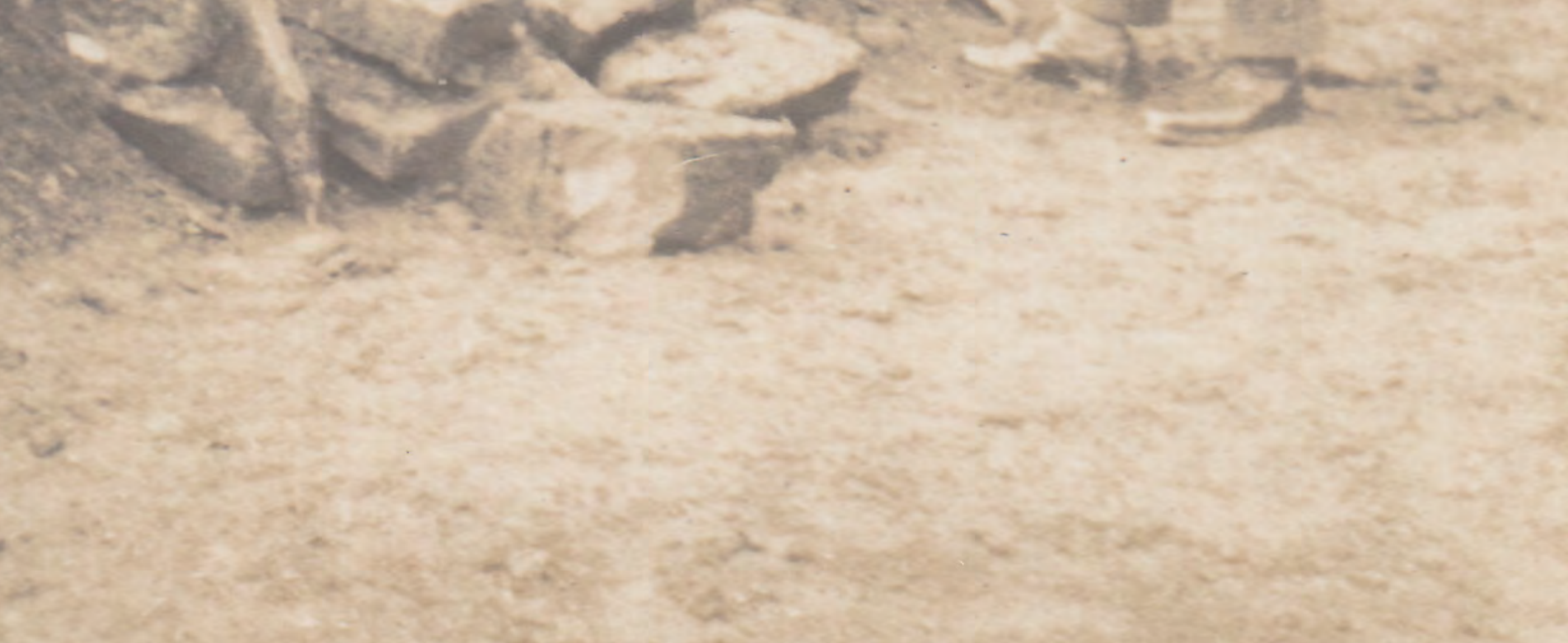


Association (Craven 2001, 100) and a very active member of both the British Association for the Advancement of Science and the Hunter Archaeological Society, and was Vice President of the latter for 27 years (AllsworthJones 2012, 30; Burkitt 1963, xiii).

Despite his considerable experience, Armstrong's work on Sheffield Castle was, nonetheless, a rare foray into the archaeological record of historical periods (Figure 2.1). ${ }^{4}$ In his lecture to the Hunter Archaeological Society on $11^{\text {th }}$ December 1928, he expressed some unease about that:

I appear before you tonight as a creature of circumstances. Mediaeval history is not really my forte. It is not 'my period'. I am more at home delving into the pre-history of mankind \& piecing together from scraps of bone \& tools of flint something of man's early story. In comparison with that, mediaeval history is an exact science (Armstrong 1928a).

Despite his international standing, he goes on to say that, in the presence of such 'well-known writers on local history' as Canon Odom, Charles Drury, Walter Hall, Wigfull and Himsworth, perhaps 'I am the wrong man to be on the platform tonight'. However, he admitted that he was 'not unwilling to watch the excavations made on the site of our ancient castle', stressing the value of his previous extensive experience in dealing with 'much more intricate \& difficult [archaeological] problems elsewhere' (Armstrong 1928a). The content of his lecture, and the quality of his later publication, make it clear that, despite his misgivings (are there hints of feigned modesty here?), he was the right man for the job (Figure 2.2).

However, we need to be clear that, unlike at Creswell or Grime's Graves, at Sheffield Castle Armstrong did not direct a programme of archaeological excavations; rather, he conducted what we would today call a 'watching brief'. This was a practice adopted at Aberystwyth Castle (Dyfed) by Harold Hughes (1904, 317-18), who, despite instigating the excavations, inspected work undertaken by the Borough Surveyor. Armstrong felt it was his 'bounden duty ... to describe ... as well and as lucidly as I am able, what has been found \& how far the discoveries made have advanced our knowledge of Sheffield's ancient Castle' (Armstrong 1928a) and to 'watch this work ... to secure a record of the various findings [and] to obtain every possible shred of evidence which was revealed' (Armstrong 1930, 9, emphasis added). He soon realised that deep deposits (between 4 and $11 \mathrm{~m}$ ) had accumulated over the remains of the castle (Armstrong 1930,14-15), and his archaeological efforts mainly consisted of inspecting the foundation shafts set out in a grid over the site and other holes dug through these deposits (Figure 2.3). This resulted in only partial glimpses of the castle, which, nonetheless, confirmed its imposing scale - "bastion" ${ }^{5}$ towers $(12.2 \mathrm{~m}$ in diameter) flanked the entrance on its south-eastern side, and the castle was surrounded by a deep moat, passage over which was facilitated by a drawbridge. While it is easy to lament this chequerboard view as one of the limitations consequent upon doing archaeology side-by-side with commercial development, when considered in the context of 1920s archaeology, and of Armstrong's work elsewhere, we can see that it was not, in the end, so different from normal contemporary practice (see Larkin 1927 for similar undertakings on the site of Liverpool Castle).

Contrary to received wisdom within the discipline - which imagines it to be an advance of the late 1950s and 1960s (Collis 2001, 11-16; Lucas 2001, 52) - open-area excavation was archaeological 'best practice' in the 1920s; as, in fact, it had been for Flinders Petrie $(1904,41-2)$ at the very beginning of the 20th century. The question was the means by which such excavation should be achieved. As both John Collis (2001, 3-16) and Gavin Lucas (2001, 36-47) have pointed out, these apparently simple methodological concerns were ultimately dictated by wider theoretical views on the forces driving the historical process. From the early 20th century,

${ }^{4}$ Although he had recorded Roman and medieval material in some of his cave excavations (e.g. Armstrong 1923, 413).

5 While the term 'bastion' was in common parlance in the early 20th century to describe circular towers projecting from a castle wall (e.g. Hughes 1904, 318; Barber 1931, 207), this use is inaccurate, as a bastion - an angular projection from a wall enabling projectiles to be fired along its face - is more usually associated with post-medieval fortifications rather than medieval castles. In Chapter 5 we will return to consider whether the towers were D-shaped rather than circular (as Armstrong supposed).

Figure 2.1 (page 32): Leslie Armstrong inspecting remains of Sheffield Castle in 1927. In his diary entry for $5^{\text {th }}$ December, Joseph Himsworth records that he had met Armstrong on site 'to view more masonry which is evidently a portion of a bastion ... Photographed it three courses high', and it is this visit that is captured in this photograph. Courtesy of Museums Sheffield. 


\section{CITY OF}

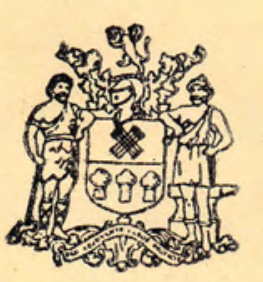

\section{SHEFFIELD.}

\section{MAPPIN ART GALLERY。}
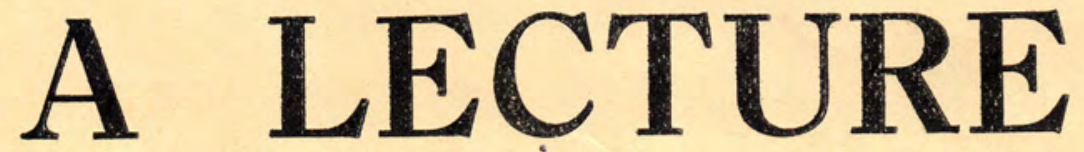

WILL BE DELIVERED IN THE

MAPPIN ART GALLERY, WESTON PARK,

ON

Thursday, March 7th, 1929, at 7-45 p.m.

BY

A. LESLIE ARMSTRONG, F.S.A.,

ON

\section{"The Story of Sheffield Castle."}

(RELICS from the site of Sheffield Castle are on

Exhibition in the Gallery.)

The Lecture will be delivered in the CENTRAL HALL, and will be Illustrated by LANTERN SLIDES.

\section{Chairman - - Councillor A. BARTON}

(Chairman of the Mappin Art Gallery and the Libraries and Museums Committees).

\section{ADMISSION FREE.}




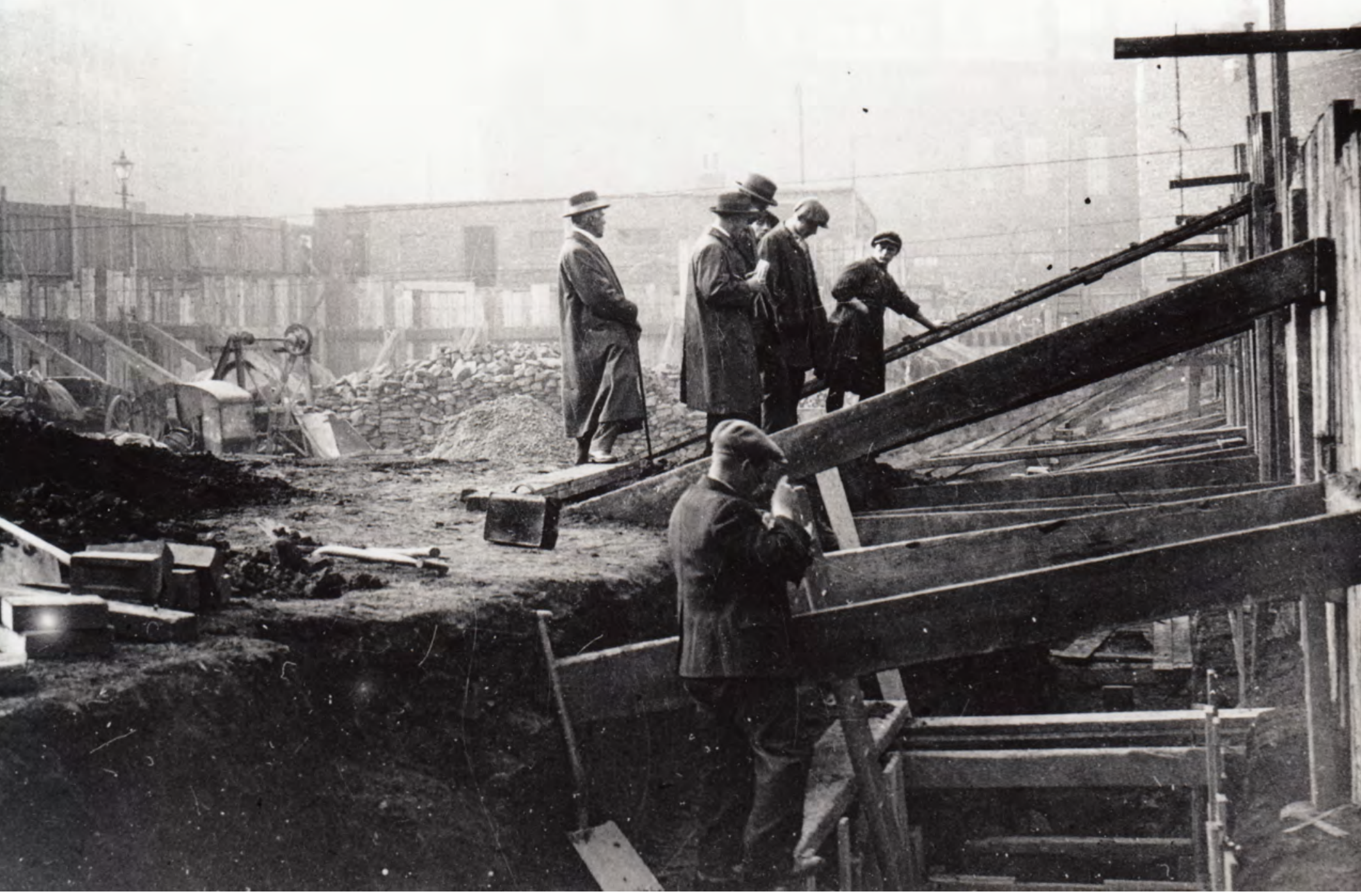

Figure 2.3: A photograph taken by Joseph Himsworth when he visited the building work on Castle Hill in October 1927. He was accompanied by Leslie Armstrong and J. R. Wigfull. A similar photograph also taken at this time is included in Himsworth's diary. Armstrong is second from the left in the group in the middle of the picture. Courtesy of Museums Sheffield.

archaeologists moved from describing the societies whose remains they encountered to trying to understand the 'dynamics' which led to change over time in, for example, burial traditions, settlement form and ceramic styles. Throughout much of Armstrong's archaeological career, explanations for change were framed within the culture-historical paradigm, in which such groupings of objects and traditions were seen as manifestations of 'culture-groups', themselves identified with the ancient 'peoples' named in the historical sources (Trigger 2006, 244-8). In an explanation that owed more to the emerging racial perspectives on past and present then coming to the fore in Europe than to anything that actually happened in the past, the catalyst for change, in culture groups/peoples, was located in 'external influence, usually in the form of invasions' (Collis 2001, 9; Trigger 2006, 237-8). This was also a framework in which archaeological explanation depended heavily on texts (Moreland 2010, 163).

Figure 2.2 (page 34): Handbill advertising a talk about Sheffield Castle. Given by Leslie Armstrong at the Mappin Art Gallery, Sheffield, on $7^{\text {th }}$ March 1929. Courtesy of Museums Sheffield. 


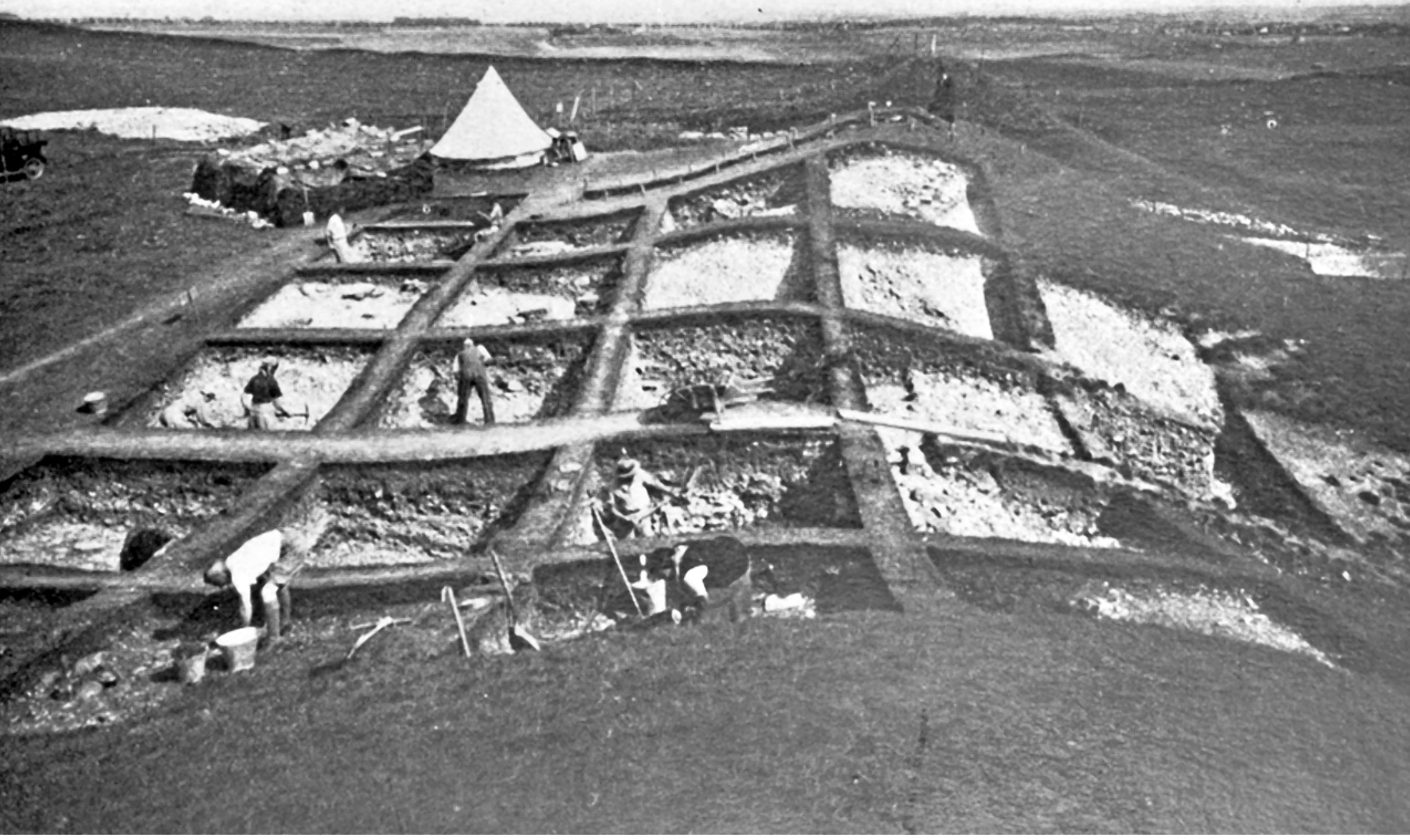

Figure 2.4: Mortimer Wheeler's excavations at the eastern entrance of Maiden Castle (Dorset). Here he was using the box grid system. By kind permission of the Society of Antiquaries of London.

The key point here, as John Collis $(2001,9)$ observes, is that within this explanatory framework 'the emphasis was on short-term changes, with [therefore] a need for precise dating. The result, as Wheeler (1927) set out, was a new focus on stratigraphy and on 'sections' in which the sequence of such changes was manifest with, in some (extreme) cases, layers being treated as if they 'stood for' peoples, and 'major discontinuities' in the section being 'read as major changes in culture groups' (Lucas 2001, 47; Lyman et al. 1997, 77). This was a theoretical perspective favouring excavation strategies which generated sections, exemplified in Mortimer Wheeler's 'box system' - 'a series of squares, a grid, dug so that a balk is left between each pair of adjacent squares' (Wheeler 1954, 64; Lucas 2001, 39; Figure 2.4).

The grid pattern of foundation shafts that formed the basis for Armstrong and Himsworth to view the archaeology of the castle site did not, therefore, differ in essence from that which would have resulted from the use of the ideal methods proposed in archaeological manuals from the 1920s onwards - although the 'baulks' were much wider than the ' 3 foot standard' proposed by Wheeler (1954, 65; Atkinson 1946, 50). We also know that Armstrong $(1931,245-6)$ himself deployed a version of the grid system during his excavations at Bambata Cave in Rhodesia (modern Zimbabwe) in June $1929 .{ }^{6}$ Driven by the demands of commercial construction, the process of excavating the grid of foundation shafts on the castle site certainly differed from that advocated by, for example, Kathleen Kenyon in her Beginning in Archaeology (1952, 77-80), but was perhaps similar to some of Armstrong's excavations at Grime's Graves, where, 'by the splendid energy of the workmen', a shaft $12 \mathrm{ft}$ 6in $(1.98 \mathrm{~m})$ deep and measuring $10 \mathrm{ft}(3.05 \mathrm{~m})$ by $9 \mathrm{ft}(2.74 \mathrm{~m})$ at the rim, was 'bottomed' in two

\footnotetext{
${ }^{6}$ Although here the concern seems to have been 'to ensure an accurate record of the position of important finds', and only one baulk was maintained through the middle of the excavation (see Armstrong 1931, fig. 3).
} 
days (Armstrong 1924, 119). He also excavated there a gridded system of 52 'trial holes' to obtain insights into the location and extent of buried 'primitive flint workings' and high-quality floorstone flint (Armstrong 1924, 191, fig. 4).

The focus on stratigraphy, manifest in 'Wheeler's pioneering work in the 1920s' (Lucas 2001, 52; also Piggott 1965), led to calls to refrain from digging in arbitrary depth lines, or spits (Wheeler 1954, 53-4) - but Armstrong seems to have persisted with 'traditional' methods. He certainly differentiated layers stratigraphically (by content, composition, texture etc.), and he did this both as the excavation was taking place and later by consulting the sections (e.g. 1924, 184; 1931, 244; 1956, 95) - but he also excavated in arbitrary spits. At Bambata Cave, for example, he dug in 'layers' of ' 6 inches ... for the top 18 inches and below that level layers of 12 inches were taken out' (Armstrong 1931, 244). Section drawings form an important interpretative element in his published work (from Creswell, Grime's Graves and Bambata), and, in keeping with the pervading cultural-historical perspective, he very often added 'cultural' labels to layer descriptions (e.g. Armstrong 1931, fig. 4; 1942, fig. 6). However, he did not blindly accept cultural-historical explanations for change - arguing, for example, that 'Clactonian' and 'Levalloisian' stone tools are more likely to represent technological adaptations to climate change rather than 'two different races of men, the one ... occupying a particular region when the rigours of climate had compelled the other ... to migrate' (Armstrong 1942, 42-3; Figure 2.5). On the other hand, it is important to recognise that, in the tradition of General Pitt-Rivers 40 years earlier, Armstrong frequently published 'typical' sections comprising schematic, but measured, representations of the sequences on an excavation (see, for example, Armstrong 1923, fig. 2; 1925, fig. 4; 1931, section 7; 1956, fig. 27; Lucas 2001, 23). This helps to explain an issue which Leslie Butcher later had with Armstrong's presentation of his findings

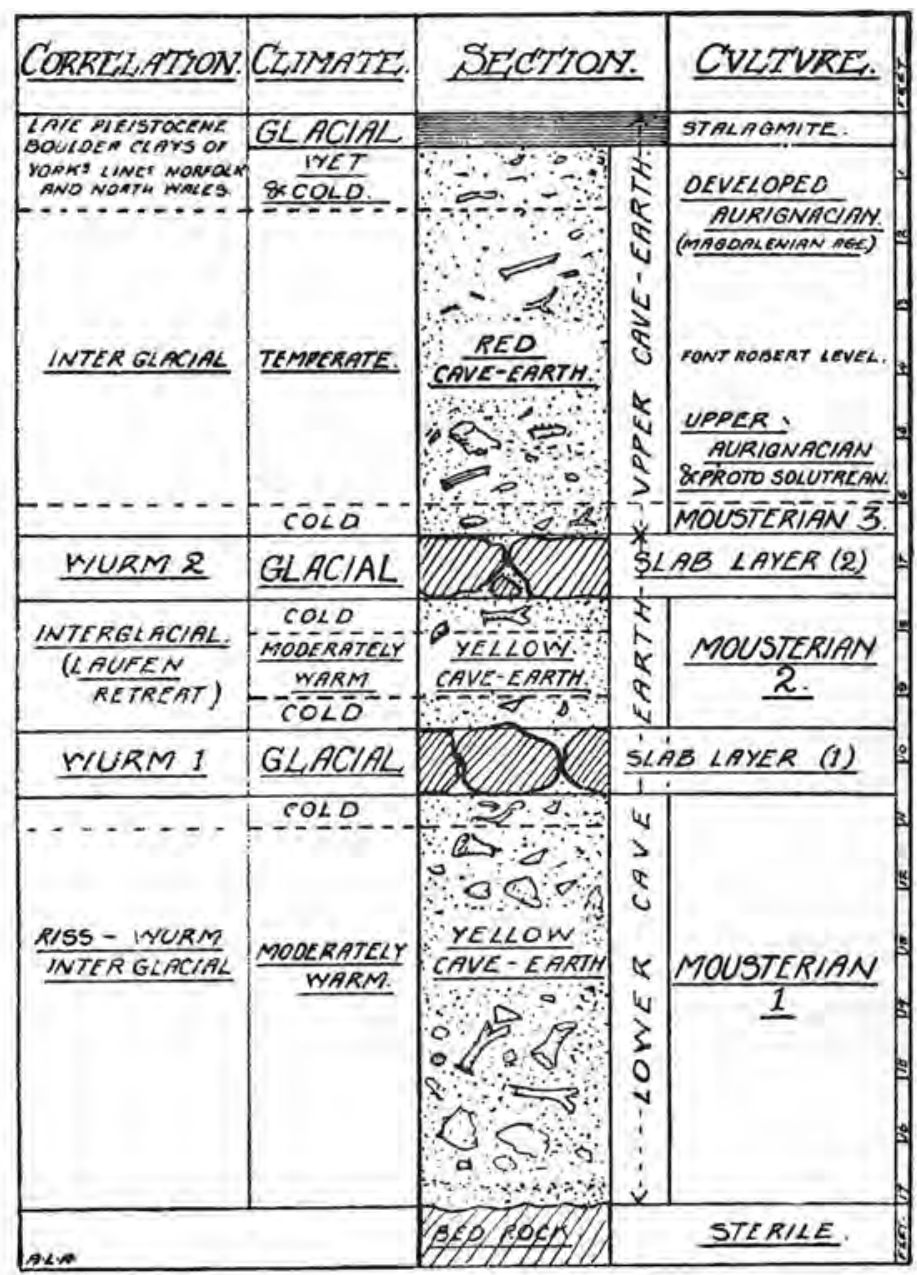

Typical section of the Pin Hole Cave, Creswell.
Figure 2.5: 'Typical' section drawing from Leslie Armstrong's excavations at Pinhole Cave, Creswell (Notts). Note the correlation between stratigraphy, culture type and 'the rigours of climate' (Armstrong 1942 , 42). Image reproduced by permission of the Derbyshire Archaeological Society. 
(Chapter 5, Section: The moat), and, along with the observation on his digging technique, it might well confirm Brian Fagan's $(2001,44)$ description of him as 'old school'.

The biggest difference between emerging archaeological best practice and the situation Armstrong and Himsworth encountered on the castle site in late 1927 is that the box grids of the former were only ever intended to be temporary. The ideal was open-area excavation; the box grid was seen as the best way to achieve this while the stratigraphy in the sections helped to retain tight chronological control (Kenyon 1952, 94; Wheeler 1954, 64; Lucas 2001, 39). Once that had been secured, Wheeler $(1954,65)$ proposed, 'the barriers between the squares can be removed without loss of vertical evidence and the whole plan laid bare' (see also Atkinson 1946, 50-1). This, of course, was never possible at Sheffield Castle, where the foundation shafts were to provide the permanent supports for the new buildings on the site (see Figure 1.14). While Armstrong did not always use the most 'up-to-date' methods, his archaeological expertise, and especially his ability to read stratigraphy as it appeared in deep sections (whether in the baulks of cave excavations, the shafts of flint mines, or the gravel workings at Hilton and Willington in the Trent Valley; White et al. 2009, 228), would have been invaluable assets as he sought to make sense of the archaeology being exposed in the course of redevelopment.

\section{Joseph Beeston Himsworth: cutler and artist}

As we noted in Chapter 1, the records that survive of Armstrong's work on the castle site, while vital, are limited. We are fortunate, therefore, to have a second archive, that of Joseph Himsworth, who worked with Armstrong $(1930,27)$ both in recording the excavation and producing his paper (Figure 2.6). This comprises his diary account of the uncovering of the castle, fragments of his personal site diary, correspondence, numerous photographs, and the texts of three lectures which drew upon the results of the excavations.

Himsworth (1953, vii) was a cutler and silversmith by trade, and proud to continue 'the family tradition of more than 220 years of active participation in the cutlery trade in the city of Sheffield'. His training in design and the use of fine materials at the Sheffield School of Art informed his craft and he was a keen artist, exhibiting his paintings in local art clubs ('Sheffield Art Society and Sketching Club', 1896). He was a member of the Sheffield Artcrafts Guild, founded by his friend and sculptor Charles Green in 1894, becoming Deputy Master (1926-28, 1930-31) and Master (1932-34; Conroy 2008, 47; Himsworth 1953, viii). In common with many in Sheffield at the time, Himsworth was inclined to the socialist ideas of William Morris, John Ruskin, Edward Carpenter 'and the early Bolsheviks' (Wagner 2012, 26; n.d., 4; Rose 2001, 190-2). Indeed, in 1934, with his wife Dora and daughter Joyce, he visited Moscow and Leningrad (Soviet Union), regarding it as 'the highlight on my experience in the whole of my life' (Himsworth 1936). Joseph Himsworth's (1964) characterisation of the Guild tells us much about himself and his worldview:

Over a long period all the chief designers in the Sheffield stove-grate firms, as well as in the silver and plate trade, were members. There were also a number of independent freelance men who testified to that independent spirit always so marked among those who disliked the restraint of factory life ... There was, at times, a Bohemian element in strong measure among the members, but it was largely kept in control by industrial demands with which they were in daily contact (cited in Conroy 2008, 48).

He was a Fellow of both the Royal Society for the Encouragement of Arts, Manufactures and Commerce and the Council for the Preservation of Rural England, President of the Trades Technical Preservation of Old Tools Society (1939-45) and a Freeman of the Company of Cutlers in Hallamshire (Himsworth 1953, viii; Wagner n.d., 4-5). Joyce went on to become an internationally renowned silversmith, and c. 1940 she designed and made a bracelet for her father with links epitomising some of the central concerns of his life - a stylised landscape, a cutler's grinding wheel ... and a spade and pick, almost certainly symbolising his passion for archaeology'

Figure 2.6 (page 39): Photograph of Joseph Himsworth as a young man. Unknown date but probably taken between 1910 and 1920. Courtesy of Museums Sheffield. 


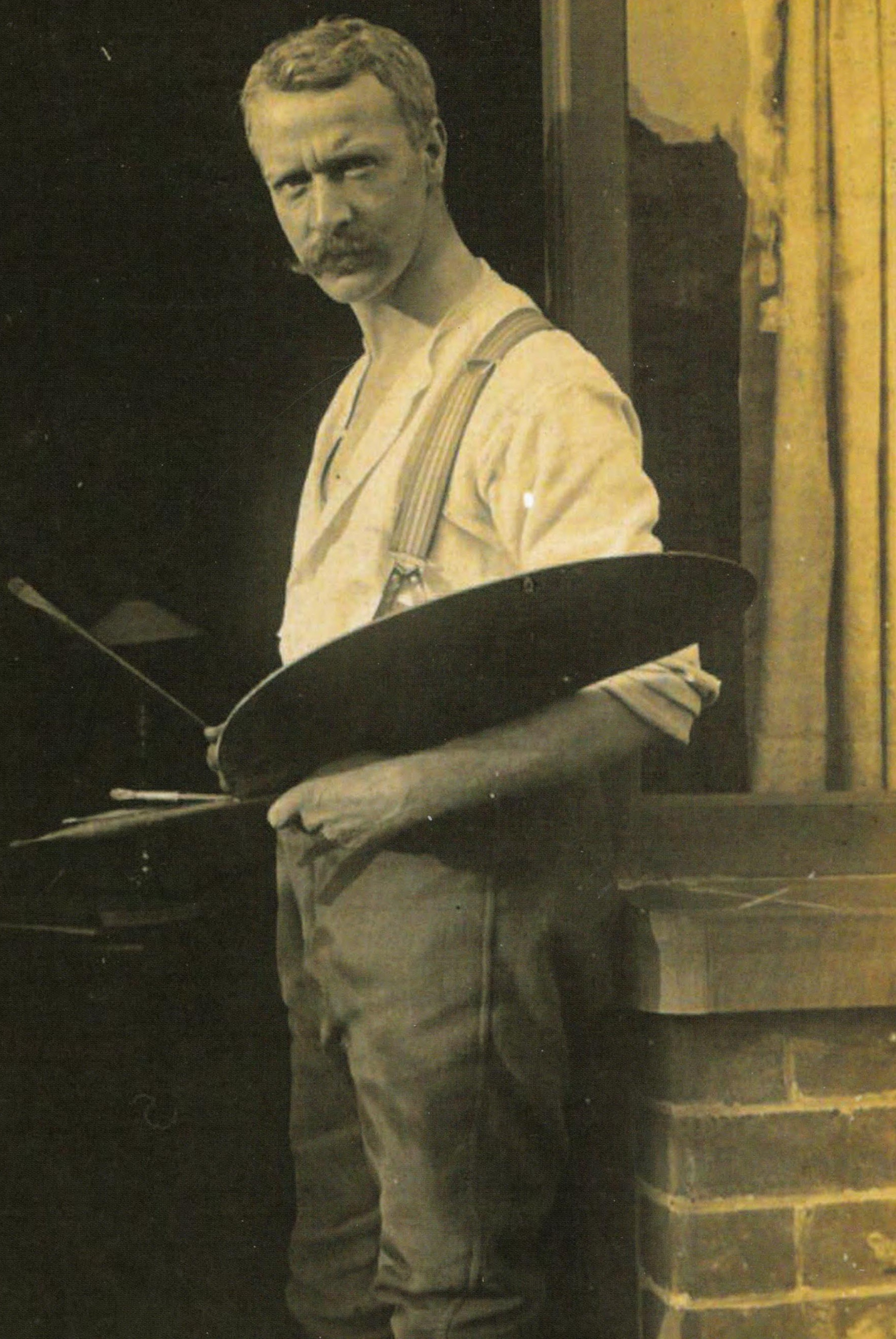


(Conroy 2008, 52). Himsworth's diary bookplate similarly contains a crossed spade and pick and a grinding wheel (Himsworth 1927-42; Figure 2.7).

There is no doubting Himsworth's passion for the archaeology and history of Sheffield. In his lecture to the Hunter Archaeological Society in December 1928, Armstrong described him as 'storing up facts and figures about Sheffield's past ... for years' - perhaps in the series of notebooks Himsworth (1944, 3-4) referred to in a lecture entitled 'Eye witnesses of Sheffield Castle'. Some of his interest may, in fact, have been stirred by Armstrong - he speaks of how the latter 'fanned the flame of interest in pre-history through the years', and he was clearly indebted to him (not least for some of the illustrations) for the opening sections of his famous The Story of Cutlery (1953, xii, 17-29). He seems to have been especially interested in Sheffield Castle. In a lecture to a section of the Sheffield Trades Technical Society in 1935 - entitled 'Some Old Sheffield Stories, Discoveries \& Art' - he recalled that as 'a youngster I used to like to think that a namesake of mine who was in Sheffield Castle when it surrended [surrendered] [to Parliamentarian forces, during the English Civil War] in August 1644, was a direct ancestor of mine' (Himsworth 1935, 1; also 1944, 2, and below, Section: Himsworth's historical perspective). Himsworth belonged to the Prehistoric Society (his aforementioned bookplate contains images of a stone axe and a barbed and tanged arrowhead) and was an active member of the Hunter Archaeological Society (President from 1958 to 1968) (Himsworth 1953, viii; Wagner 2012, 26).

The original version of Himsworth's diary (1927-30) is a handwritten account entitled 'THE UNCOVERING OF SHEFFIELD CASTLE SITE. It was discovered by Sheffield resident, and (like Himsworth) former President of the Hunter Archaeological Society, Pat Wagner (pers. comm.) in a second-hand book shop in Sheffield about 30 years ago, in another of the many acts of serendipity that has characterised the archaeological recording of Sheffield Castle. It comprises two physically distinct parts (Figure 2.8). Himsworth started it

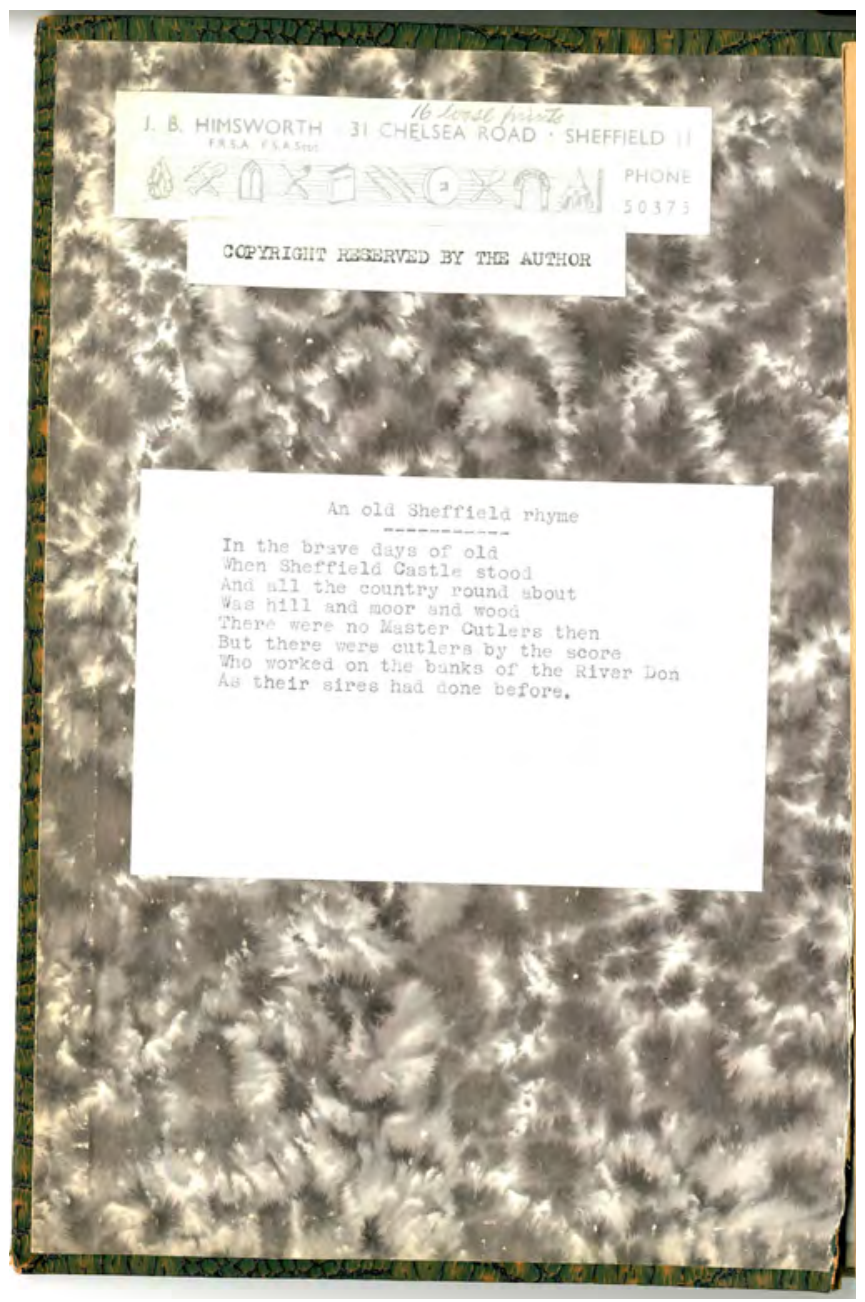

Figure 2.7: The inside cover of the diary of Joseph Himsworth typed by Harry Lea. The bookplate shows his interests in archaeology, Sheffield crafts, and ancient monuments, and beneath is 'An old Sheffield rhyme. Courtesy of Museums Sheffield. 
THE. UNCUVERIIVG. OF. SHEFFIELD. CASTLE. SITE.

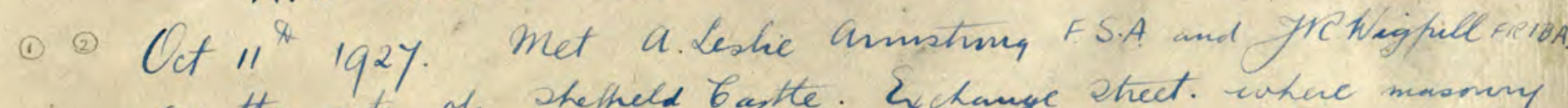
on the sute of sheffeld bastle. Exchange shect. whac masmy i.e. walking. toth. straight and sound en flan, hoth dechoss Laving a gond flinth, had hea moconced when a hench was

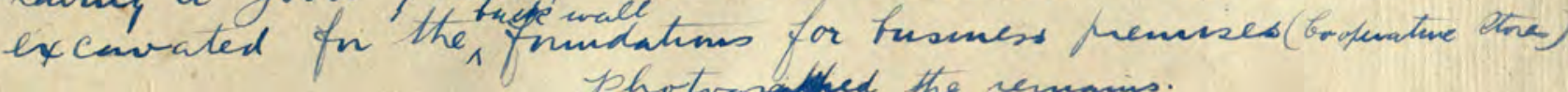
photrgrapied the remanis.

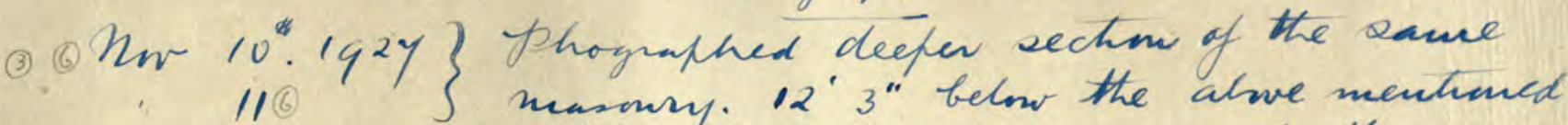
phisth. At the fosit undmabted evidence of the snvat

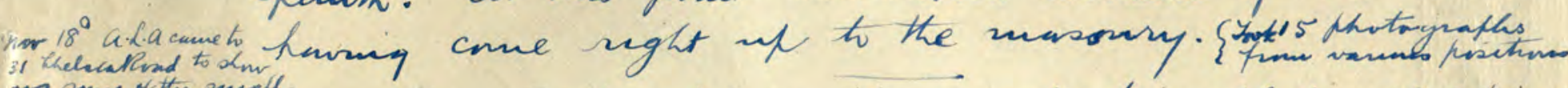

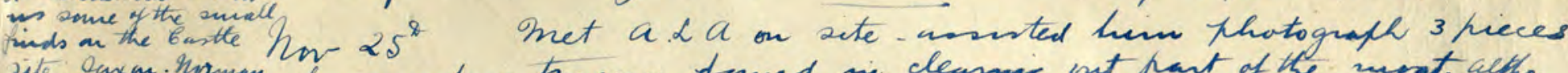
site. Oaxm. Homan of wondur hacery fand in clearnig sut prant of the werat. altho.

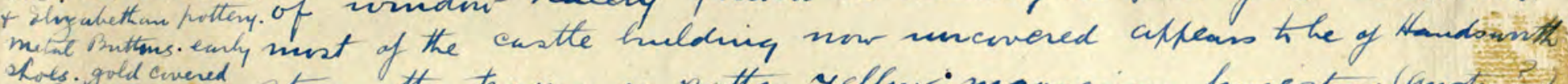

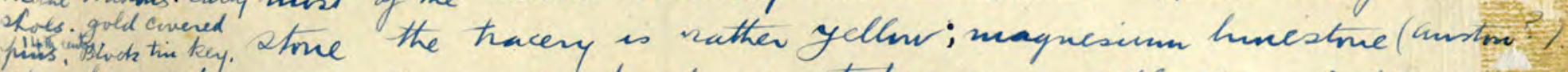
glass fingments.

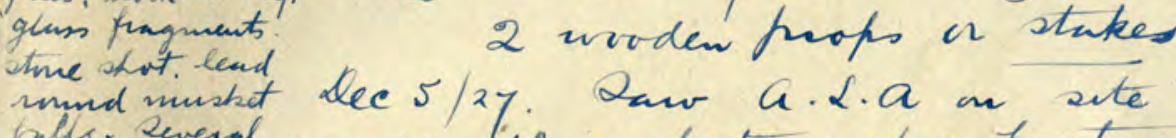

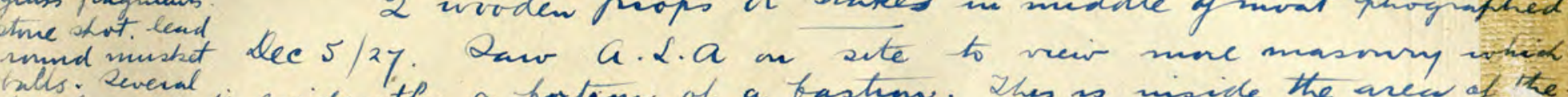
tratal medals is evidently a forteon of a bastum. Thes is miside the area of the

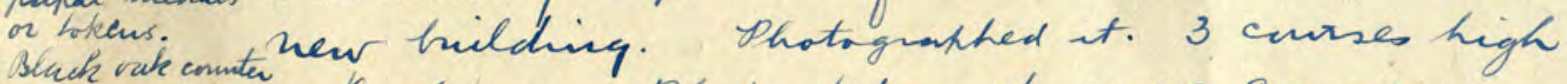

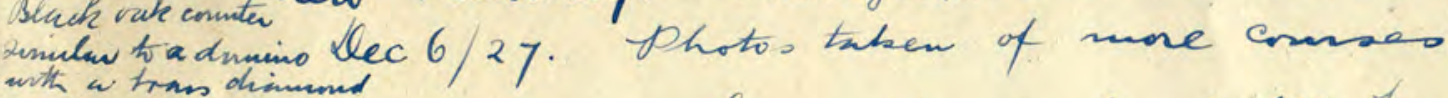

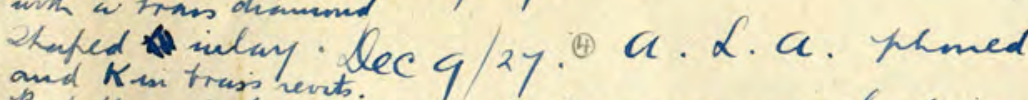

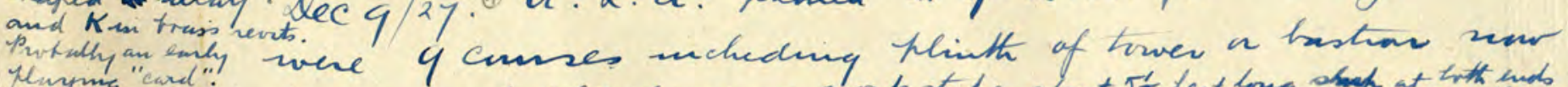

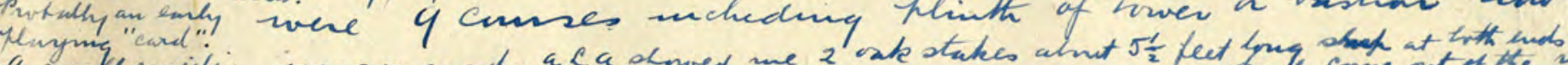

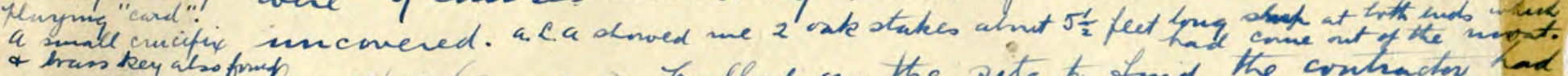

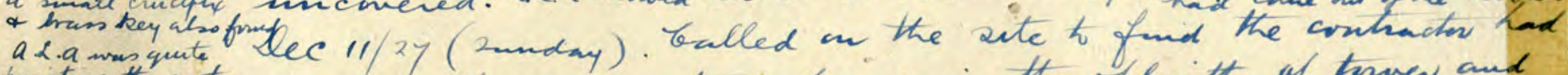

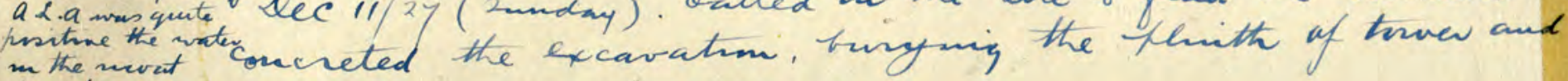
hadhem several cossses of masoms. ingmant.

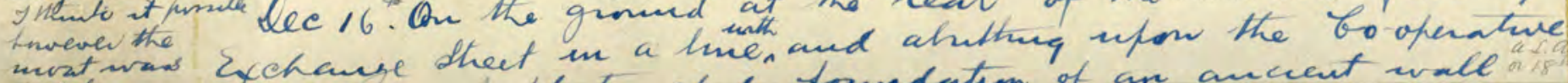

Figure 2.8: The opening sections of Joseph Himsworth's handwritten diary. The first entry is for $11^{\text {th }}$ October 1927 and records the discovery of the remains of Sheffield Castle. Courtesy of Pat Wagner.

in the back covers 'of my copy of Hunter's Hallamshire', thereby updating and developing (intentionally or not) some of the central concerns of the great antiquarian's account. Indeed, he continued to acknowledge his debt to Hunter, and in 1961 commissioned his daughter Joyce to make a plaque to commemorate the centenary of Hunter's death (Wagner 2012, 26; Figure 2.9). ${ }^{7}$ The last daily record in this section of the diary is for $20^{\text {th }}$ January 1928, and is followed by a reflective piece on the efforts being made to secure the preservation of the castle ruins, written two days later (we will return to these in Chapter 9). The second of the inside back covers contains seven photographs of the excavations by Himsworth, dated between $11^{\text {th }}$ October 1927 (his first day on site) and $18^{\text {th }}$ January 1928. Himsworth continued the diary (single-sided) on nine sheets of unlined paper, taped together and subsequently stuck between these back covers; the first dated entry is for $28^{\text {th }}$ September 1928. At the top of the first of these sheets, Himsworth wrote 'THESE NOTES ARE A CONTINUATION OF THOSE I HAVE WRITTEN IN MY COPY OF HUNTERS HALLAMSHIRE INSIDE THE BACK COVERS. J.B.H.' (Figure 2.10). Although Himsworth here refers to 'notes', he later calls his work a 'diary', and it does take the form of generally sequential dated entries.

7 The plaque was installed by the Hunter Archaeological Society while Himsworth was President in the Local Studies Library, Sheffield. 

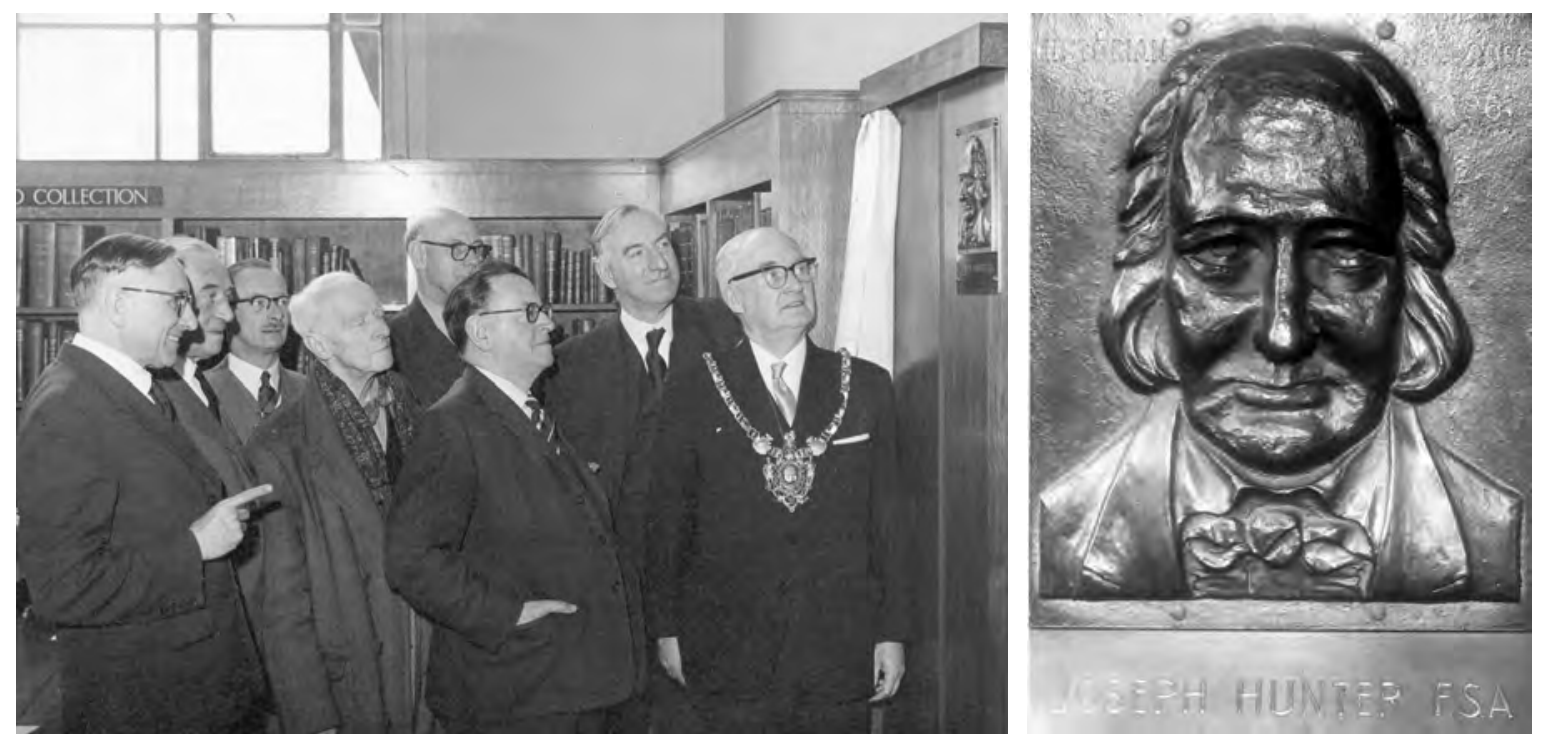

Figure 2.9: Joseph Himsworth, President of the Hunter Archaeological Society. Photographed (fourth from left) at the unveiling of a plaque in Sheffield Central Library to commemorate the centenary of the death of Joseph Hunter in 1961 (courtesy of Sheffield Newspapers Ltd (u08604)). This serves as a reminder of the powerful hold of the great antiquarian over studies of Sheffield's history (see also Figure 2.10). The plaque was made by Joyce Himsworth. With thanks to www.picturesheffield.com (s28138).

The second version of Himsworth's 'diary' is a typescript of the original, entitled 'Record by an eye-witness of the uncovering of SHEFFIELD CASTLE' (Himsworth 1927-42), contained within a green, fake crocodile skin binder (Figure 2.11). The inside cover bears 'An Old Sheffield rhyme', in the 'when Adam delved and Eve span' mode (Figure 2.7; see also below, Section: Himsworth's historical perspective), and on the following three pages are a copy of part of an inventory of the 'fitments and furnishings of the Castle at time of Mary, Queen of Scots' (from Tucker 1874), and two maps - one of the castle site as 'surveyed [in] 1889' at a scale of '41.66 feet to 1 inch', and one of the excavated area as depicted in plan I of Armstrong's 1930 excavation report. The text is accompanied by 49 illustrations, mostly Himsworth's photographs of the excavations and architectural fragments, but also sketches and section drawings. After the final typewritten entry, for $18^{\text {th }}$ February 1942, Himsworth $(1927-42,21)$ added the following handwritten note in blue ink:

As the whole of the Co-op building had perished in the blitz the large flat showcase full of small objects retrieved from the Castle site by excavation had disappeared. There were some of the objects also originally placed in Weston Park Museum.

J.B. Himsworth the compiler of this diary also has a few objects taken from the moat in his possession viz: an early shoe sole and several blades depicted by AL Armstrong in his report printed in the Hunter Archaeological Transactions (Figure 2.12).

At the bottom of the page he wrote, in black ink, a 'note of authentication', which, although undated, was probably written soon after the last entry: 'This typescript from my original daily notes and enlargements from my negatives are by courtesy of my friend C. H. Lea. JB Himsworth. Harry Lea was a Sheffield box manufacturer and, for a time, Honorary Treasurer of the Hunter Archaeological Society, well known for his photography skills, and may have introduced Himsworth to photography (Himsworth 1953, xi; Wagner n.d., 3). Himsworth travelled widely, and used the photographs he took to illustrate his public lectures - his talk to the Sheffield Artcrafts Guild on 'Personal Impressions of French Art Craftsmanship', for example, was described as 'splendidly illustrated, the photographs of cathedral and church architecture being exceptionally good' ('French art', 1922). As we will see, he put this expertise to good use as he recorded the uncovering of Sheffield Castle. 
THESE.NOTES.ARE.A.CONTINUATION. OF. THOSE.1. HAVE.

WRITTENY Sumi Reft. 1928. several motes affeared

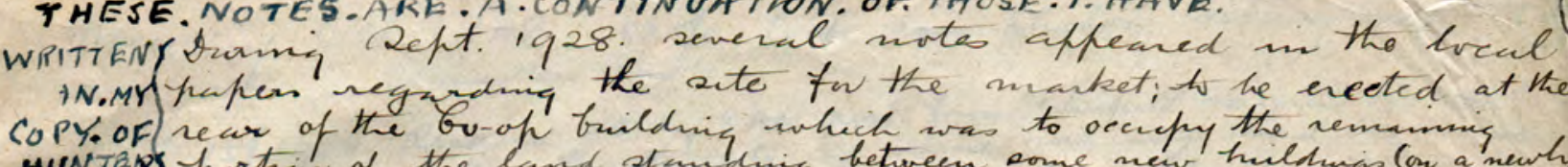

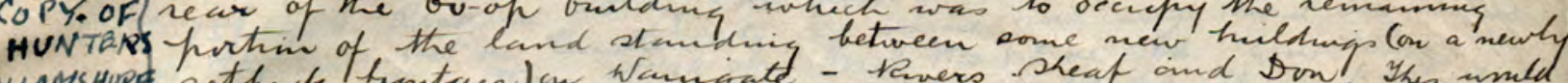

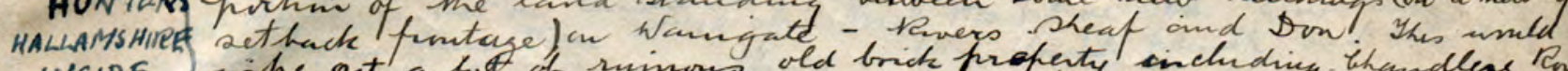
THEBACIS and a hive of Tilthy slanghter hivises fintury the tiver Don (a) J.B.It. all the renmider of bheffeld Gastle Qite. Fo ocme sunth

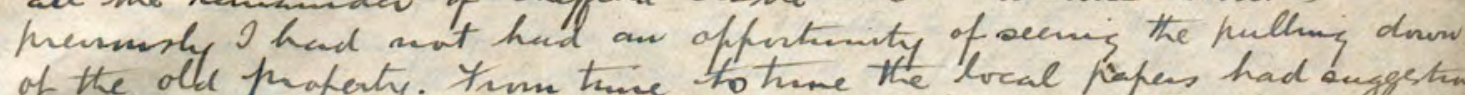
of the old proferty. Trme true to home the local kapess had augges

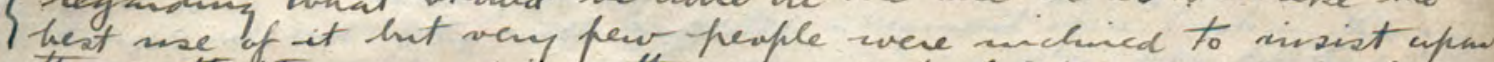

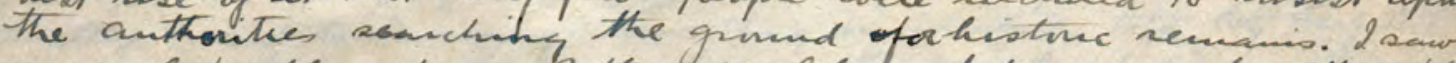

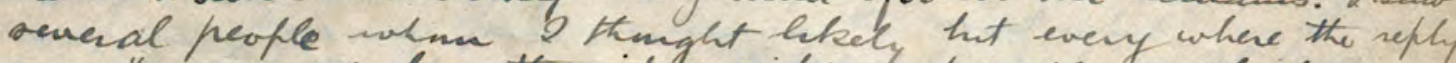
mas," we mist elewer the site quichly do fosuble and hild a matect cheaply. Guditions of tade are so bad we care meither

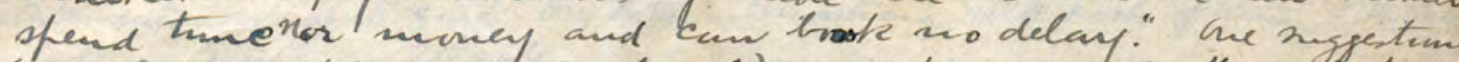
(and 2 hehure heans wore git ont) was to excentile the site to reveal the busthe hlan; hreserve what mas fornd in istur os a hasenent, purking place on what woti and hild the moket meshead an a level wht \& wange sheet. alust the moddle of rept a mote appeaved me the thers to the effect that Girmmoncit had graisted provers th the hral anttorities to ravie sumen for the hew hunket scheare, the site mas heviy clemed, and dikect habus uns to the enplenf ce, ie

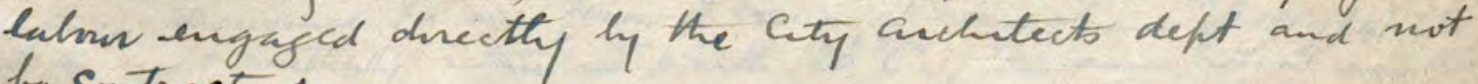
by entractors.

Sept. 28/28. Went dow mithe sete-finnd suat of the ald

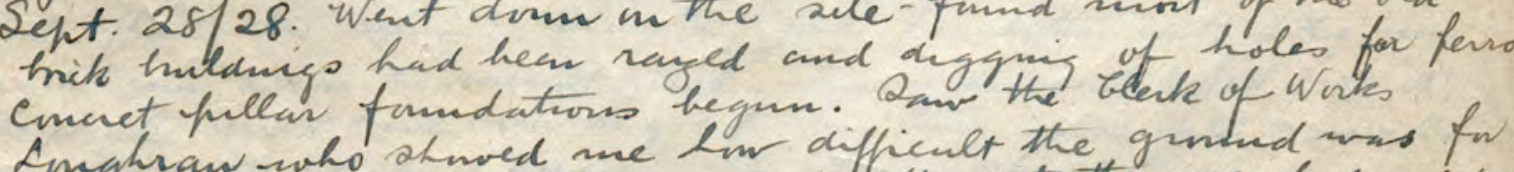
Ancret pullas forndations begun.

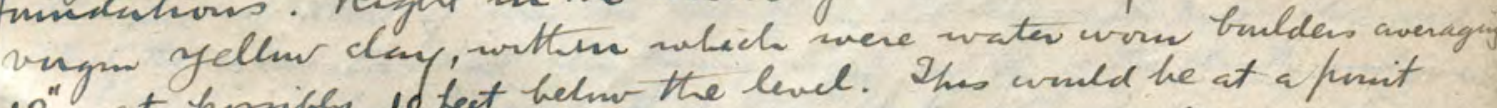

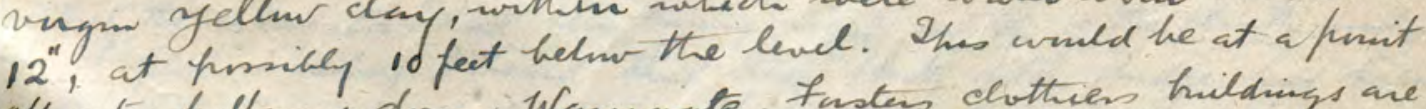

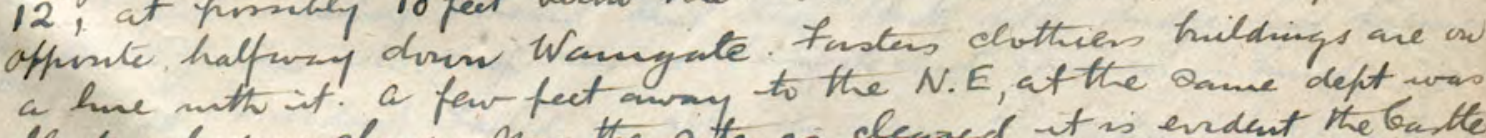

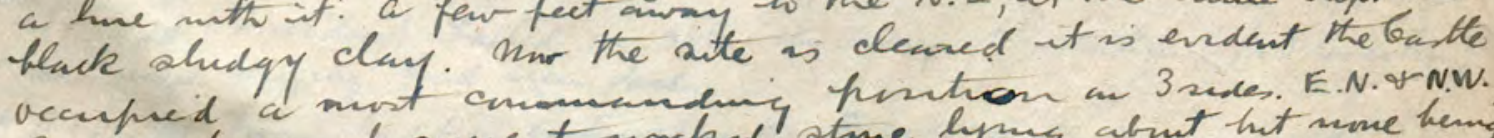
many preces of ancient racked stme hong abut hit move hering preserned. 2 photis of ramour stive steps at N.E. opsite ecading dom t sume shallur wanlted inch basements the flim of whlic rest

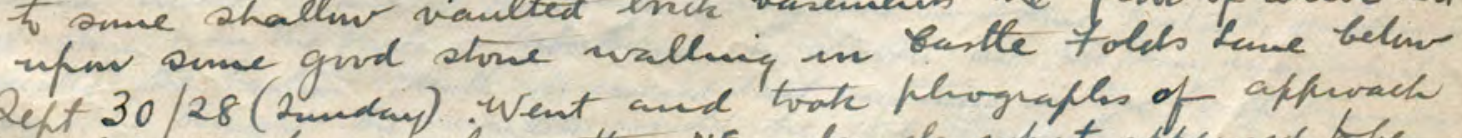
Lept $30 / 28$ (2undan) Went and took phograflas of apfurach

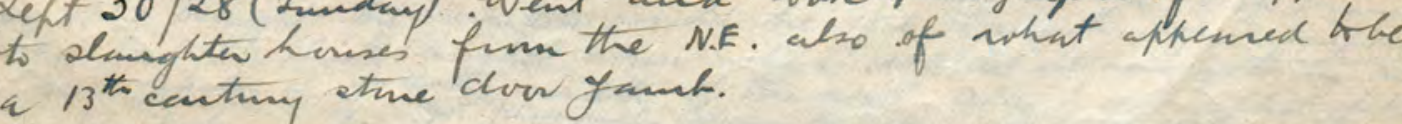

Figure 2.10: Himsworth's handwritten diary from $28^{\text {th }}$ September 1928. He records that 'These notes are a continuation of those I have written in my copy of Hunter's Hallamshire inside the back covers'. Courtesy of Pat Wagner. 

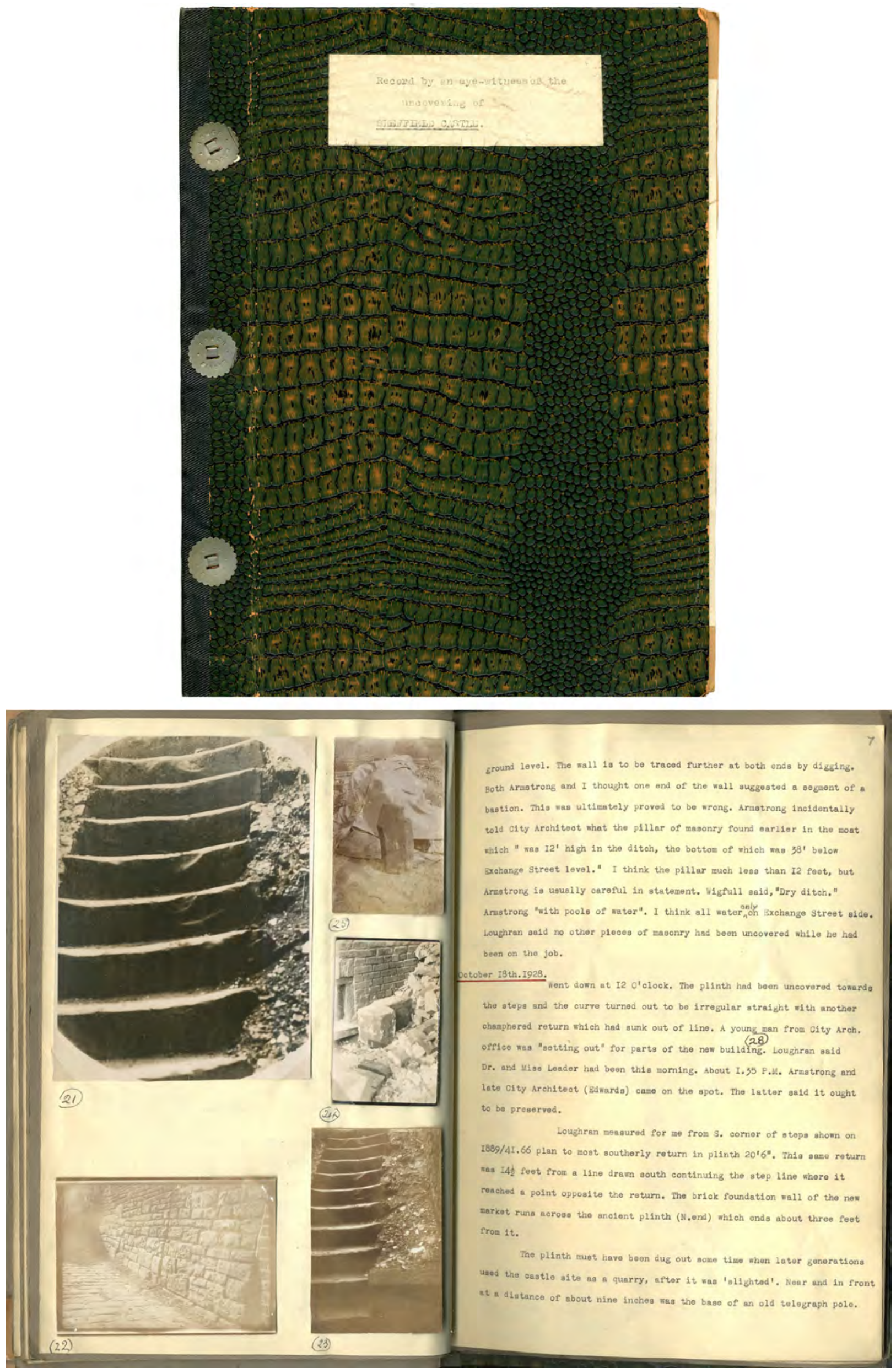

Figure 2.11: Record by an eye-witness of the uncovering of Sheffield Castle. Front cover of Himsworth's diary bound in fake crocodile skin (top); page of entries from 1928 and accompanying photographs facing (bottom). Courtesy of Museums Sheffield. 


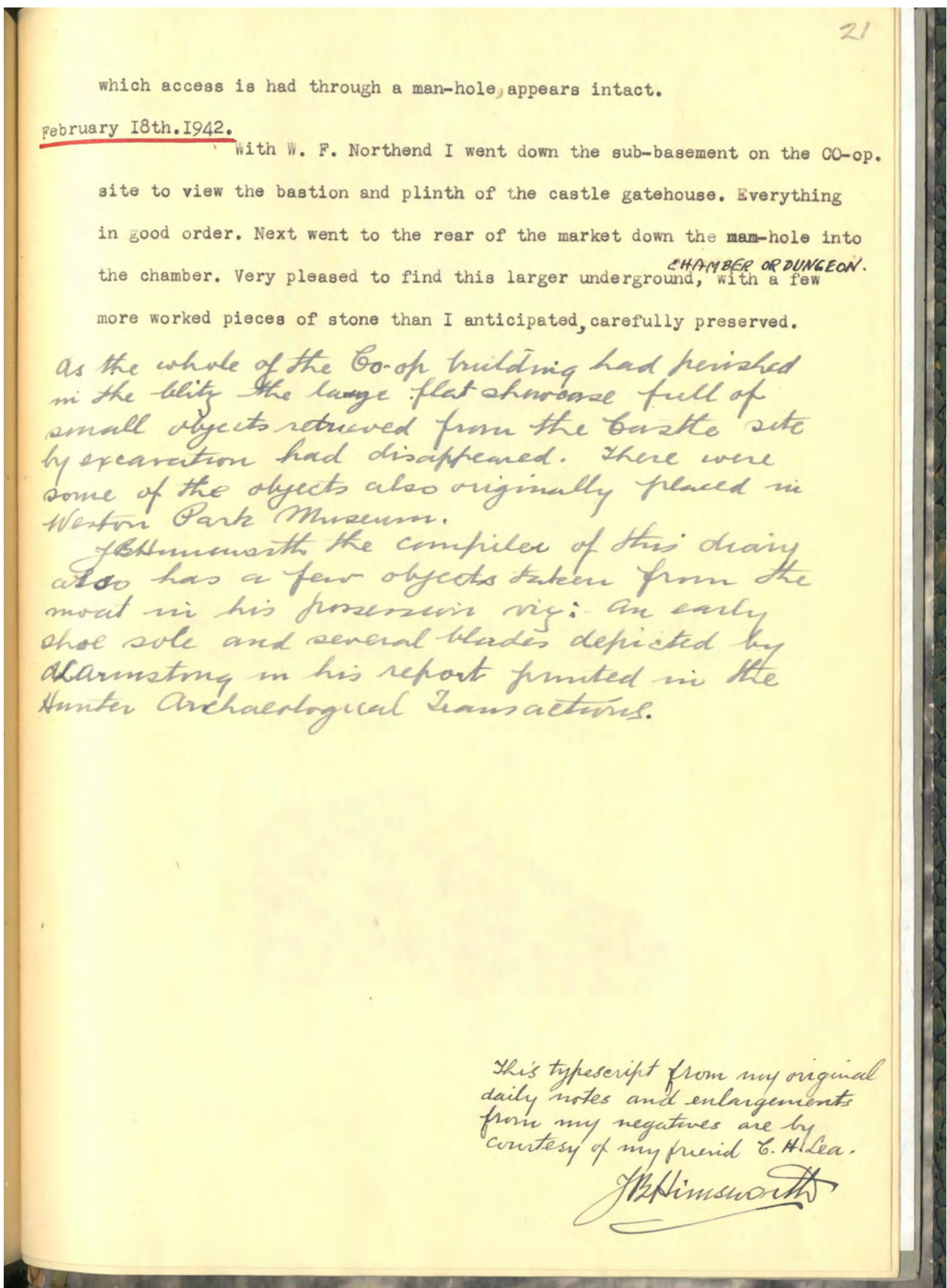

Figure 2.12: Last page of Himsworth's typed diary. A handwritten addition, reporting on the destruction of the Co-op building and the loss of some of the artefacts from the castle on display there. Himsworth notes that he has some items in his possession, and authenticates and signs this version of his diary. Courtesy of Museums Sheffield. 
Some editing took place in the process of turning the Himsworth manuscript into the typescript. For example, the manuscript entries for $21^{\text {st }}$ October 1928 ('(Sunday) Called on site on way to station (for S Leverton) but no more digging had been done') and $25^{\text {th }}$ October 1928 ('Called on the site - no developments') do not appear in the typescript, probably because they did not contain any significant information about progress at the castle. There are also some transcription errors; for example, $28^{\text {th }}$ December 1928 and $9^{\text {th }}$ September 1930 appear in the manuscript as, respectively, $8^{\text {th }}$ December 1928 and $4^{\text {th }}$ September 1930. Himsworth's final handwritten additions to the typescript are not found in the manuscript version, which also has a much more limited range of illustrations. For the most complete record we need both versions of the 'diary'. There is good evidence that the 'original' handwritten manuscript was not a day-by-day record. First, entries like that for $18^{\text {th }}$ November 1930 cannot have been contemporary - 'finishing the new road this week. It was later called Castle Gate' (Himsworth 1927-30, 1, emphasis added). Second, it has a very consistent and coherent feel - very cleanly presented and written in the same colour ink throughout the two main parts (blue for the part in Hunter's Hallamshire, and black for the continuation) - as if large sections were written in one go. This impression is reinforced by the correction of entries $-22^{\text {nd }}$ and $26^{\text {th }}$ February 1929 were changed to $22^{\text {nd }}$ and $26^{\text {th }}$ March - which might well occur if entries were being copied out from another source.

That the manuscript was not a continuously maintained, contemporary record of events is confirmed by the last entries, in which Himsworth returned to it after a gap of more than 10 years to record that on the night of $12^{\text {th }} / 13^{\text {th }}$ December 1940 'The Co-Operative Stores destroyed by blitz', by $13^{\text {th }}$ February 1942 'a good deal of the debris has been removed from the site, and on $18^{\text {th }}$ February 1942 he visited the excavated remains with W. F. Northend and found 'everything in good order'. Each of these entries is 'distinctive' - in terms of writing style or ink colour - and so stands in contrast to the general uniformity of the preceding entries. Further, the original Himsworth manuscript was accompanied by three pages of what looks to be his personal diary/ account book, covering $14^{\text {th }}$ July to $20^{\text {th }}$ August, and $30^{\text {th }}$ October to $5^{\text {th }}$ November 1930 . They contain only three daily entries, as well as two sketch sections. Of the daily entries, that for $19^{\text {th }}$ August is most illuminating - 'Demolishing retaining brick wall on castle site. 5 to 6 feet down comparatively recent filling only revealed' (Himsworth 1927-30; Figure 2.13). The relevant entries in both the manuscript and typescript diaries match (almost) perfectly: 'Today they are demolishing brick retaining wall under castle bank. 5 to 6 feet down recent filling only revealed' (Himsworth 1927-30; 1927-42, 17). Some of the sketches stuck into the manuscript were drawn on pages of what appears to be the same diary.

Himsworth recorded his work on the castle elsewhere too. The Museums Sheffield archive contains a single sheet of lined paper, embossed at the top with Himsworth's address, on which he wrote the following:
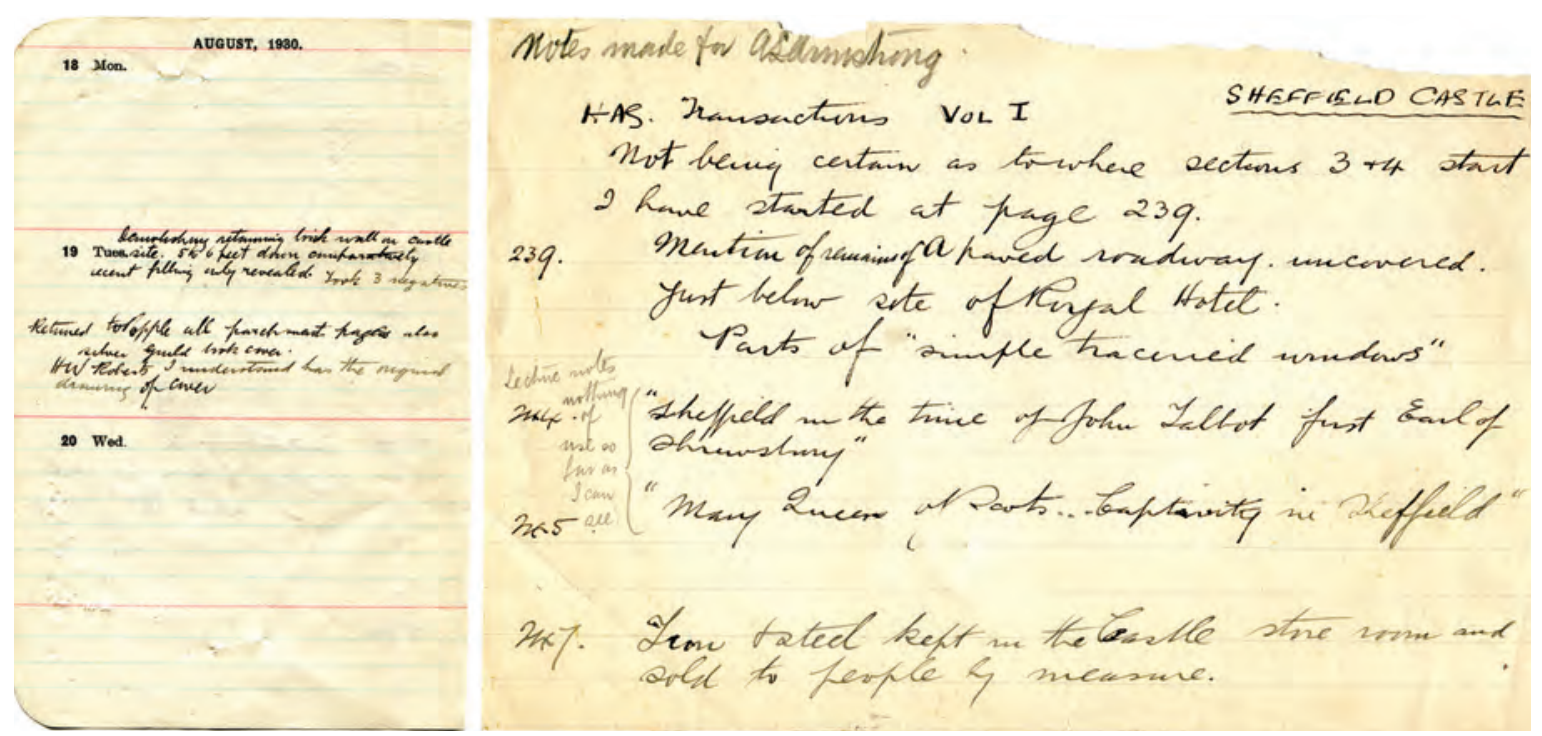

Figure 2.13: Joseph Himsworth's entry in an account book recording the demolition of the retaining wall above the Don in August 1930. This was subsequently copied into his diary (left). Notes on historical research (right), also by Himsworth. Courtesy of Pat Wagner. 
I met Mr Austin. Messrs. Bagshawe \& Bradbury were both out of town.

Friday

Concreting round the pier was starting while we were there at 12-30. today (Himsworth n.d. (d))

This note almost certainly served as an aide-memoire for the diary entry for Friday, $20^{\text {th }}$ January 1928 :

Met John Austen on the site ... Found the foundation of the pier had been cleared of sludge ... They were then putting concrete into the hole, the foreman remarking upon the fact that the splendid stonework of the pier was a good support for their concrete (Himsworth 1927-42, 3).

So, before Harry Lea typed up the 'Record by an eye-witness' 'from my original daily notes' (Himsworth 1927-42, 21, emphasis added), it seems that Himsworth first copied his personal diary entries and other notes into the manuscript we have now. We have taken some time to outline the origins and history of the diary as it is a crucial, largely untapped, resource and will play a significant part in detailing exactly what was found of Sheffield Castle between 1927 and 1930 in the next chapter.

\section{Armstrong's assistant?}

In his 1935 lecture to the Sheffield Trades Technical Society, Himsworth $(1935,5)$ told the audience that following his appointment by the Hunter Archaeological Society to 'watch the excavations ... Mr Armstrong very kindly allowed me to act as his assistant', and in another lecture stated that Armstrong 'was good enough to allow me to make myself conversant with all that occurred in detail' (Himsworth 1937, 5), perhaps because of the depth of his knowledge of local history, as there is no evidence that he had any significant archaeological experience. Whatever the case, our archival research has enabled us to determine something of Himsworth's remit as 'assistant', and to chart the process by which he came to assume increasing responsibility for overseeing the excavations.

Himsworth does not seem to have been involved on site from the very beginning. It was not until October 1927, when the first traces of what were believed to be Sheffield Castle were uncovered (Armstrong 1930, 14), that we have evidence of his involvement. The first entry in his 'Record by an eye-witness' account is dated $11^{\text {th }}$ October 1927 and Himsworth $(1927-42,1)$ tells us that he

met A. Leslie Armstrong and J.R. Wigfall [recte Wigfull] on the site of Sheffield Castle, Exchange Street, where masonry, i.e. walling, both straight and round in plan; both sections having a good plinth had been uncovered when a trench was excavated for the back wall foundations for business premises (Brightside and Carbrook Co-operative Society; Figure 2.8).

In his 1935 lecture Himsworth $(1935,6)$ conveys more of the excitement of the moment, telling his audience that 'on October 11th 1927 I got a message from Armstrong by phone to "come down at once a most astonishing discovery has been made". He also told them that he 'photographed daily' the uncovering of the drawbridge pier, thereby providing further insights into the depth of his involvement in the project and into some of his duties as 'assistant' to Armstrong. Although it was mainly the photographs of 'Mr Senior, of the Improvement Surveyor's department' that were used to illustrate the 1930 paper (see Armstrong 1930, 37; Himsworth 1927-42, 11), Himsworth's images, preserved in his 'Record by an eye-witness' and elsewhere in the Museums Sheffield archive, provide invaluable insights into both what was found, and under what circumstances - into how archaeology was done in the 1920s.

Another of Himsworth's duties as assistant was to carry out background research on the site and the castle. An undated slip of paper included with Himsworth's (1927-30) 'THE UNCOVERING OF SHEFFIELD CASTLE SITE' manuscript is headed 'Notes made for Armstrong', which derive from articles in volume 1 of the Transactions of the Hunter Archaeological Society (1914-18), and are directly referenced in Armstrong's $(1930,13)$ paper (Figure 2.13). Furthermore, Himsworth's (n.d. (a)) notes on Hunter's Hallamshire (Gatty's updated 1869 edition) seem to have informed Armstrong's $(1930,8)$ description of the castle $c .1646$. Here Himsworth was acting much as a modern-day 'research assistant', and Armstrong $(1930,27)$ acknowledged his 'help ... during the preparation of this report' - but he went on to become so much more than this. As Armstrong became preoccupied with the serious illness and death of his wife on $19^{\text {th }}$ January 1928 ('Deaths', 1928; Himsworth 1927-42, 3; Butcher 1961, 7), and then took a career shift away from Sheffield (below, 
Section: The enduring legacy of Leslie Armstrong), the diary suggests that Himsworth assumed more responsibility for observing the construction of Castle Hill Market and recording the archaeology brought to light (see also Butcher 1972a, 3).

The final 'daily' entry in the first part of the diary records that on $20^{\text {th }}$ January 1928 Himsworth was on site but 'Mrs. Armstrong had died and A.L.A. could not be present'. The break in the diary at this point might well be a product of Armstrong's tragic personal circumstances, combined with the fact that the digging of foundations for the construction of the Brightside and Carbrook building had been completed, and with that the need for an archaeological 'watching brief' had ended.

The diary resumes on $28^{\text {th }}$ September 1928 with an overview of the efforts in the preceding months to preserve and display the excavated remains. This probably coincides with the resumption of excavations associated with the construction of Castle Hill Market. From this point on Armstrong appears less frequently in the diary entries, and sometimes in a more 'passive' role, with Himsworth, by contrast, seeming to take a more active part, for example in discussions with Reg Loughran, the Clerk of Works. Thus, in a series of entries from mid-October 1928, we read of Loughran assisting Himsworth in measuring the site (1 ${ }^{\text {th }}$ October), showing him 'his plan upon which was indicated the bastion and plinth discovered last autumn' (23 ${ }^{\text {rd }}$ October) and deploying some of his workmen to help Himsworth explore parts of the site ( $31^{\text {st }}$ October). On $7^{\text {th }}$ December 1928, Himsworth 'phoned A.L.A. to come down' to see a newly uncovered section of the plinth 'in perfect state. A very handsome piece of masonry' (Figure 2.14). Armstrong said 'he would do so at 3-30'; Himsworth,
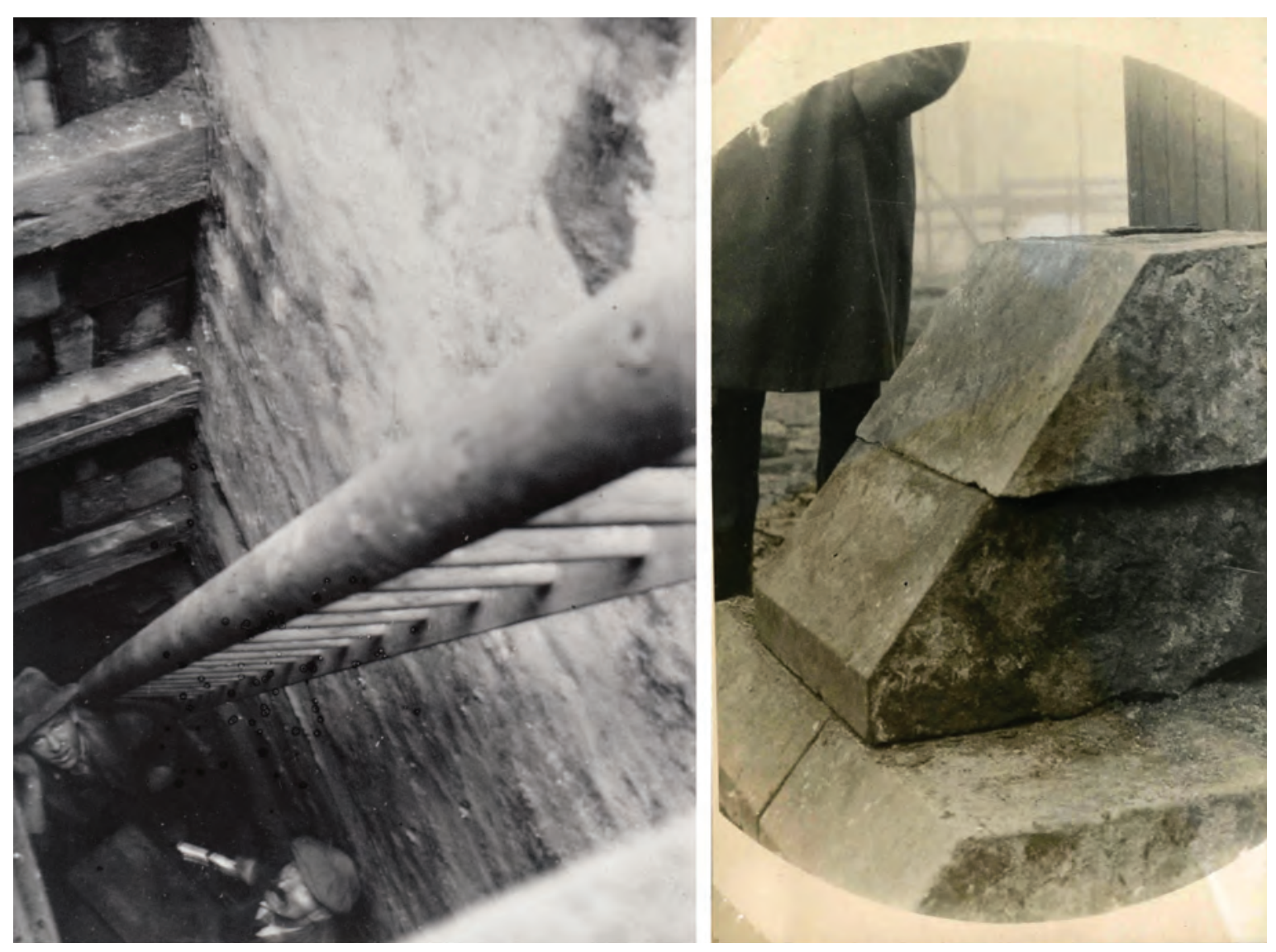

Figure 2.14: Photographs taken on $7^{\text {th }}$ December 1928 when a section of plinth was found in a foundation shaft. At the bottom of the shaft (left) are Joseph Himsworth and one of the construction workers, probably the Clerk of Works Reg Loughran since Himsworth $(1927-42,12)$ recorded that he 'went down the hole with him'. On the right is the plinth after it had been removed from the shaft. Courtesy of Museums Sheffield. 
meanwhile, 'went down the hole' with Loughran. Yet, Armstrong was still involved - on $20^{\text {th }}$ December 1928 Himsworth reports that 'A.L.A called and said he had seen in one of the holes got out for a pillar there were nine "occupation levels" in ten feet'. Indeed, Armstrong was clearly still in charge - when the editor of the Sheffield Independent Press called Himsworth on $28^{\text {th }}$ December 1928 to ask if he could use some of his photographs of the excavations, he 'referred him to A.L.A.' (Himsworth 1927-30, 3).

The diary breaks again on $4^{\text {th }}$ April 1929 , probably marking roughly the point after which no more excavations were necessary for the construction of Castle Hill Market. Armstrong left England with his son on $10^{\text {th }}$ May 1929 to lead the Rhodesian Archaeological Expedition to Southern Rhodesia, returning in September (Armstrong 1931, 239; Allsworth-Jones 2014). The only two entries between then and late June 1930 probably represent special visits to the site. In the first (12 ${ }^{\text {th }}$ August 1929), Loughran showed Himsworth how they had preserved various important features (see below) 'by making a basement' (subsequently referred to in the present volume as the chamber for the courtyard remains), and in the second ( ${ }^{\text {th }}$ September 1929) Himsworth photographed the area cleared for 'a new road' by the demolition of the slaughterhouses. From $24^{\text {th }}$ June to $18^{\text {th }}$ November 1930 he records features revealed during construction of this 'new road', which do not appear in Armstrong's publication, including the remains of what he thought were four towers on the northern curtain wall overlooking the Don, and decorative mouldings and tracery, at least some of which was 'probably Grenoside sandstone' (Himsworth 1927-42, 18-20; Figure 2.15; see also Chapter 7). He also recorded the digging of holes to be filled with concrete to 'stiffen the edge near the river bank' of the Don, which revealed the underlying
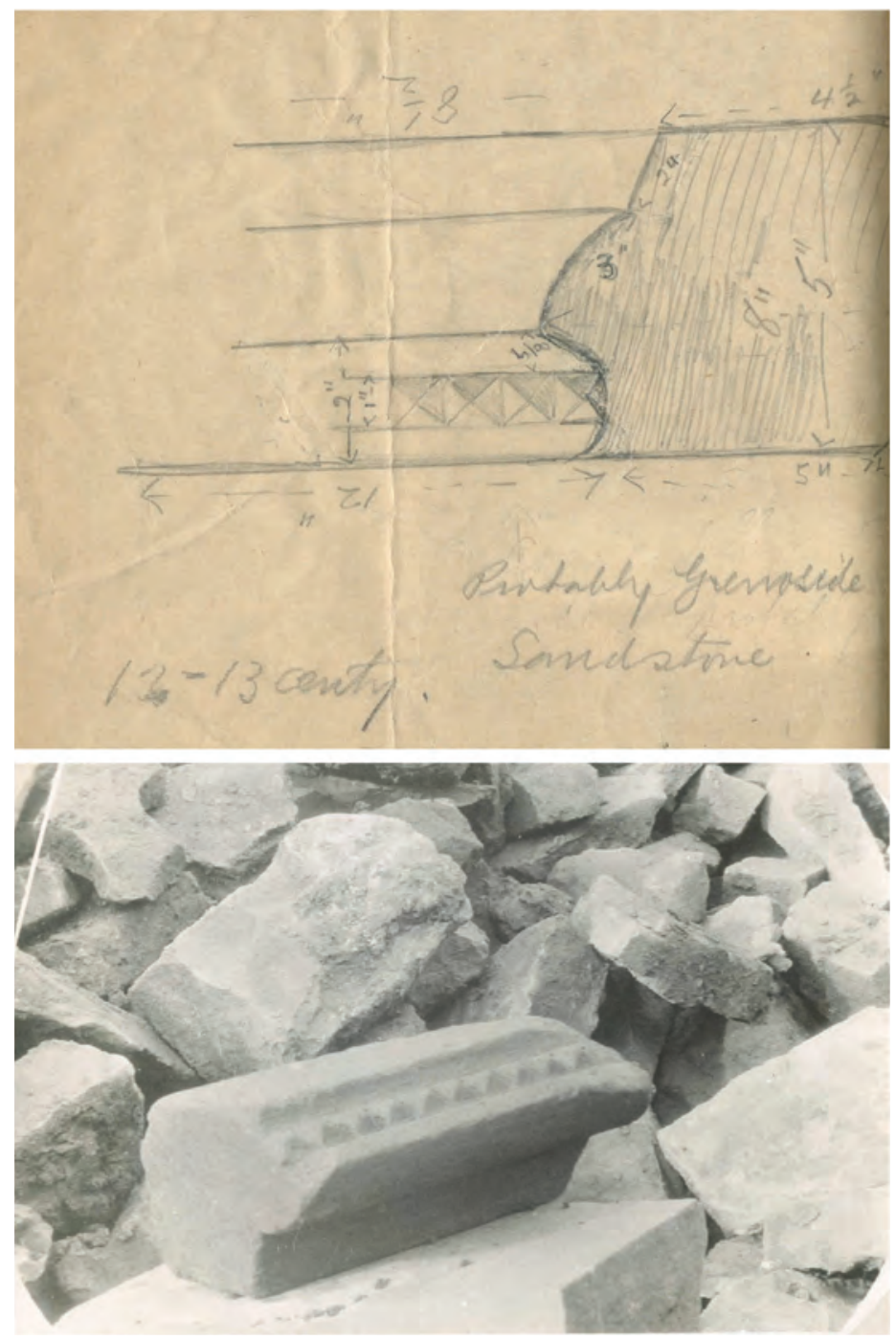

Figure 2.15: A piece of decorative moulding of Grenoside sandstone found on 17th October 1930. The sketch on the top is by Himsworth and was incorporated in the typed version of his diary. Courtesy of Museums Sheffield. 
geology (Himsworth 1927-42, 16-17; also Butcher 1972a, 4). The break in the diary after this point marks the end of construction. It seems that Himsworth had 'graduated' from being Armstrong's on-site assistant and had taken on responsibility for observing, and recording, the archaeology of Sheffield Castle. As Leslie Butcher (1972a, 4) later noted, Himsworth comes across as 'a dogged observer', endeavouring to record the remains of the castle 'on a site still encumbered with undemolished walls and slopes of rubble', the admiration evident in Butcher's remark probably a product of the fact that he himself had recently faced the same difficulties of 'doing archaeology' in a construction environment (see Chapter 4).

\section{Himsworth's historical perspective}

Himsworth's diary and lectures provide us with very personal insights into the archaeological interventions on the site of Sheffield Castle in the late 1920s. The lectures especially reveal the historical perspective through which he approached the past and read its evidence. His was a rather variegated, and subtle, philosophy of history, informed by intellectual perspectives perhaps drawn from, and certainly in harmony with, his social and political beliefs. The importance of the power of the past underpinned his historical understanding - 'what has happened in the past still shapes and influences what will be'. And for Himsworth those 'happenings' could take the form of natural processes as well as human actions: 'geological deposits, geographical position, climatic conditions have all helped to make our district what it is, and incidentally helped no doubt to produce that rather unusual type of individual "the Sheffielder"' (Himsworth 1937, 1; see also Armstrong 1942, 30 for a similar emphasis on the environment as a 'potent factor' in cultural evolution). 'Sheffields [Sheffield's] course', Himsworth went on to tell the audience attending his lecture on '500 Years of Sheffield Trade and Sheffield Castle', was shaped by 'Geographical position natural resources, and industry started by the monks locally' (the latter referring to the role of monastic institutions in initiating, and then developing, metalworking industries in the region; Himsworth 1937, 4). Reflecting on the relationship between long- and short-term history, between structure and event, Himsworth $(1937,4)$ argued that not only did the environment and past history of the region influence the character of the people of Sheffield and its castle, but in its turn that 'Castle and its occupants have, like destiny "shaped our ends rough hew them as we will"'. Himsworth is here quoting from Hamlet (Act V, sc. ii, 1l. 3659-60), but, given his inclination towards the ideals of the early Bolsheviks (Wagner n.d., 2), he might as easily have cited Marx's (1963, ch. 1) famous dictum that

Men make their own history, but they do not make it as they please; they do not make it under selfselected circumstances, but under circumstances existing already, given and transmitted from the past. The tradition of all dead generations weighs like a nightmare on the brains of the living.

In the same lecture, Himsworth $(1937,4)$ extended his thoughts on the relationship between past and present by comparing the Norman Conquest with 'the recent terrible [Italian] conquest of Abysinnia' (October 1935-May 1936). There are signs that he believed that 'historical imagination' might be used to bridge the gap between past and present and facilitate interpretation of the archaeological and historical records. This might take the form of imagining himself witnessing, and thus understanding, past events at Sheffield Castle. Reading Hunter's Hallamshire, for example, 'especially did I [he] feel sorry' for his namesake, Gabriel Hemsworth, one of those appointed to negotiate the surrender of the castle to its Parliamentarian besiegers in August 1644 (Wilson MSS 295/24 fol. 8):

The terms recorded were generous and I pictured him marching out as is permitted in the terms drawn up with 'the Governor and all the other officers, with their drums and colours, and each his own horse saddled; sword and pistol, to Pomfret [Pontefract] Castle or wheresoever they please' (Himsworth 1935, 1; see also Himsworth 1944, 2; Hunter 1819, 111).

As well as using a possible genealogical connection to imagine himself back into the colour and spectacle of that historical moment, ${ }^{8}$ Himsworth (certainly influenced by the craft tradition within which he worked)

8 'These references to ancestry are sometimes dangerous as you know - it just depends how far you push the matter' (Himsworth $1935,1)$. 
also used the objects, and the site itself, to enter into the immediacy of everyday life in the past. Having described the discovery and excavation of the castle moat, he then asked his 'Some Old Sheffield Stories' audience to

Just try to imagine what would be likely in times past to occur at this spot. Here with the gateway towers overlooking the moat what a handy place to throw all the rubbish. Antlers \& bones from the kitchen, broken knives \& keys, and other unmendable articles. Old shoes of several periods, hundreds of years old were discovered in quantities, some with a hole worn through the sole where the big toe had contacted the ground most strongly (Himsworth 1935, 6-7).

We get the same sense of entering the past through an engagement with the immediacy of its material remains at the beginning of his 'Eye Witnesses of Sheffield Castle' lecture. Explicitly setting to one side the perspective of 'owners', he found his 'eyewitnesses' in 'documents written by those who saw things in their settings for daily use' and in 'objects which may be seen and handled today' (Himsworth 1944, 1). He undoubtedly used his knowledge of both to imagine, and to sketch out a picture of, the life of the family of a 14th-century 'peasant cum-handicraft worker. They would have lived in a

crucks built house of huge beams divided in three sections and [would have carried out] the comparatively easy provision of food by growing on a small scale a little corn, some vegetables and keeping a pig or a cow ... each household trying to be as self supporting as possible (Himsworth 1937, 3a).

While this is clearly an idealised vision of a self-sufficient family (and community), it does reveal that, although Himsworth's historical understanding was framed by great men and events, his historical instinct was to seek out the 'common man'. What we might call his nostalgic egalitarianism is evident in the 'Old Sheffield Rhyme' recited to him by 'J. Wragg' (did he mean James Ragg Wigfull?), which he uses to preface his 'Record by an eyewitness' (Figure 2.7), and repeats at the end of its first section (Himsworth 1927-42,4) and at the beginning of the typescript of his 'Some Old Sheffield Stories' lecture $(1935,1)$.

Himsworth's historical method involved using empathy and imagination to link together and extract meaning from the 'facts' found in objects and texts. In this sense, his approach might be said to come close to that advocated, at roughly the same time, if in very different circumstances, by R. G. Collingwood (Waynflete Professor of Metaphysical Philosophy at the University of Oxford):

the historian's picture of his subject, whether that subject be a sequence of events or a past state of things, thus appears as a web of imaginative construction stretched between certain fixed points provided by the statements of his authorities; and if these points are frequent enough and the webs spun from each to the next are constructed with due care, always by the a priori imagination and never by merely arbitrary fancy, the whole picture is constantly verified by appeal to these data, and runs little risk of losing touch with the reality which it represents (Collingwood 1994, 242; also Johnson 1998, 79-90).

Joseph Himsworth was a craftsman and cutler, a skilled professional. But, like many people in the Sheffield in which he grew up who were influenced by Morris and Ruskin, he had strong political and historical sensibilities (see Rose 2001, 190-6). As we will see in the section that follows, this was a combination that would significantly advance the study and understanding of Sheffield Castle.

\section{Doing archaeology in Sheffield 1927-30}

As we have seen, neither Armstrong nor Himsworth was a professional archaeologist - although the former was the vastly more experienced of the two. They were, as Barri Jones $(1984,10)$ put it, amateurs who 'earned their daily bread elsewhere', which had a significant impact on the nature of their archaeological practice. Himsworth joined his father's cutlery firm of B. Worth \& Co. in 1888, initially 'to do office and warehouse work' (Himsworth 1965; Museums Sheffield 2019a), and Armstrong worked full-time for the Inland Revenue while monitoring the excavations on Castle Hill. They were working at a time where urban archaeology, if it 
existed at all, took the form of the exploration of the remains of the cities of Roman Britain - an extension onto home territory, Martin Carver $(1987,101-3)$ argues, of the archaeological 'pursuit of the lost Homeric and biblical cities of the eastern Mediterranean', exemplified at exactly the same time by Sir Leonard Woolley's excavations at Ur (Mesopotamia, modern Iraq). This was a time, Carver $(1987,102)$ continues, of wholesale destruction of archaeological deposits and buildings 'to which the blitz in many cases put the finishing touches': a time when, in many places, the physical fabric of past urban dwellers was considered 'nothing but a nuisance, to be got rid of at the first convenient opportunity' (W. T. Jones on the 'walls and towers of Durham' in 1923, cited by Carver 1987, 102). Armstrong and Himsworth were largely not in a position to do other than observe such destruction and to record the strata, objects and buildings it brought to light. And they owed this concession to 'the Directors and Mr. J. E. Forster, the Secretary, of the Brightside \& Carbrook Co-operative Society', who, as we have seen, granted 'permission to watch the excavations', and to 'Mr. W.G. Davies, F.R.I.B.A., the City Architect ... for assistance given and privileges accorded in relation to the excavations on the site of Castle Hill Market' (Armstrong 1930, 27).

Photographs taken on site at the time capture the energy and 'chaos' of an active construction site, revealing just what a difficult task Armstrong and Himsworth faced in attempting to record the archaeology of Castle Hill (Figure 2.16). In what must have been one of the first public announcements of what he had observed,
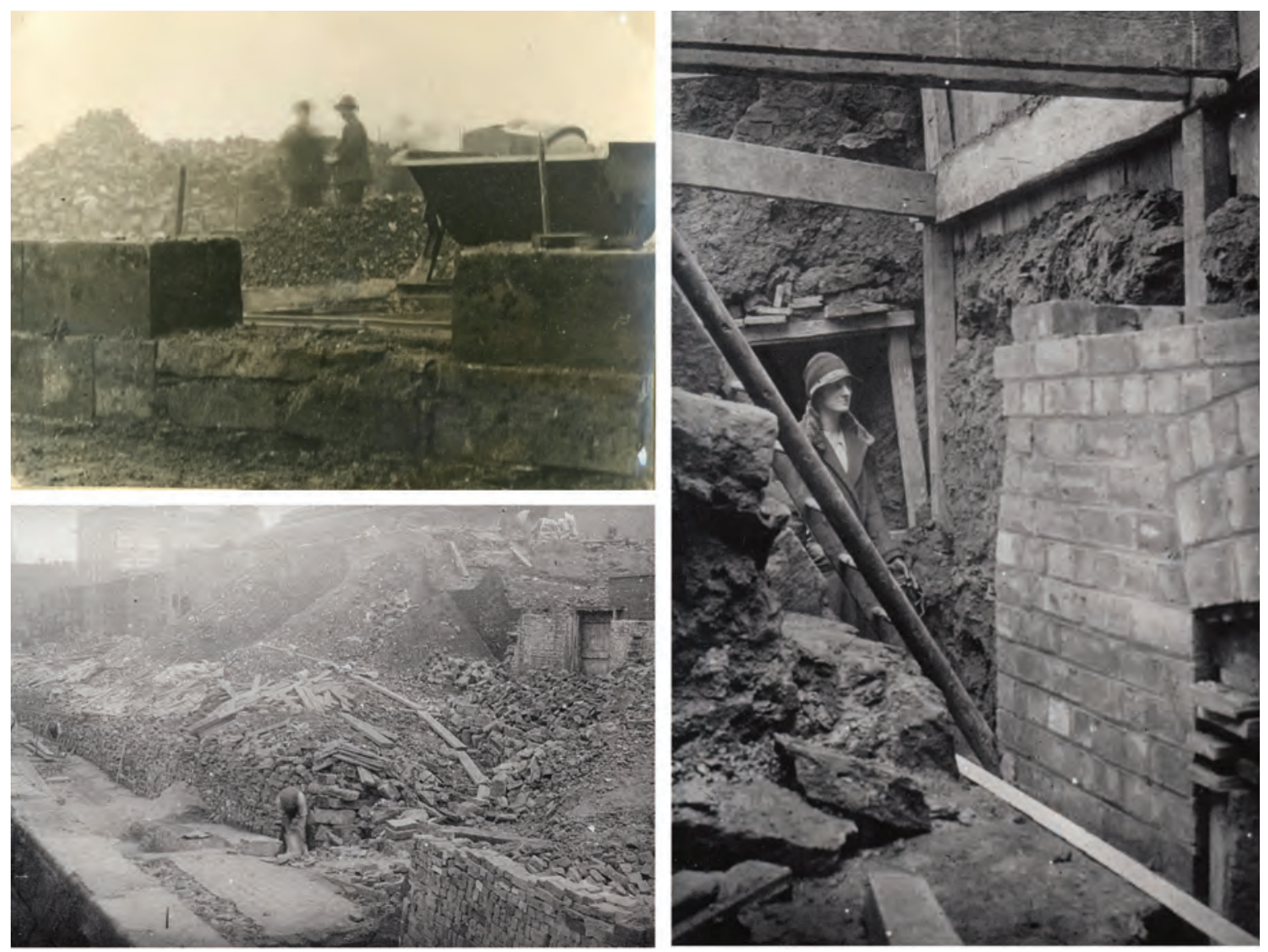

Figure 2.16: The site of Sheffield Castle during construction work 1927-30. Armstrong and Himsworth experienced considerable difficulty recording archaeology on an 'active' construction site. The right-hand photograph shows the wattlework believed to be Anglo-Saxon (next to the woman's hand), which is discussed in Chapter 3. This photograph appeared in Himsworth's diary along with the top left-hand photograph showing construction work near the courtyard buildings, with a planning frame placed on the walls of one of these buildings for a foundation shaft to be dug there (see also Figure 3.17). The bottom left photograph records building work in 1930 at the north of the site above the Don before Castlegate was built. Courtesy of Museums Sheffield. 
a report Armstrong (1927b) wrote for a local newspaper, The Star, in late October or early November 1927, makes clear how the presence of the castle remains affected the ongoing building work (Figure 2.17). Thus, he describes how the construction teams experienced 'considerable difficulty' finding a firm foundation for the wall of the new Co-op building, as their trial shaft just kept going down, 'deeper and deeper', through sticky black sludge. We now know, as Armstrong later concluded, that this was the fill of the moat - at the time he thought it could equally have been a rubbish pit (Armstrong 1927b). Early 19th-century construction on the site of Liverpool Castle faced a similar problem, and the builders 'having met with the filled in moat ... thought it necessary to excavate it to the bottom to obtain reliable foundations', resulting in basements reaching $23 \mathrm{ft}$ (7.01m) below street level (Larkin 1927, 183-4).

Both this 1927 newspaper report and his 1930 paper reveal Armstrong's irritation with the attitude of the construction workers, who were only minimally engaged with what he was trying to do (maybe they too thought him 'troublesome'!):

Though a bonus was offered for all finds, the men were not sufficiently keen to look out for objects of interest until stimulated by the finding of [a 'silver'] key ... near the bottom of the ditch. It is certain that

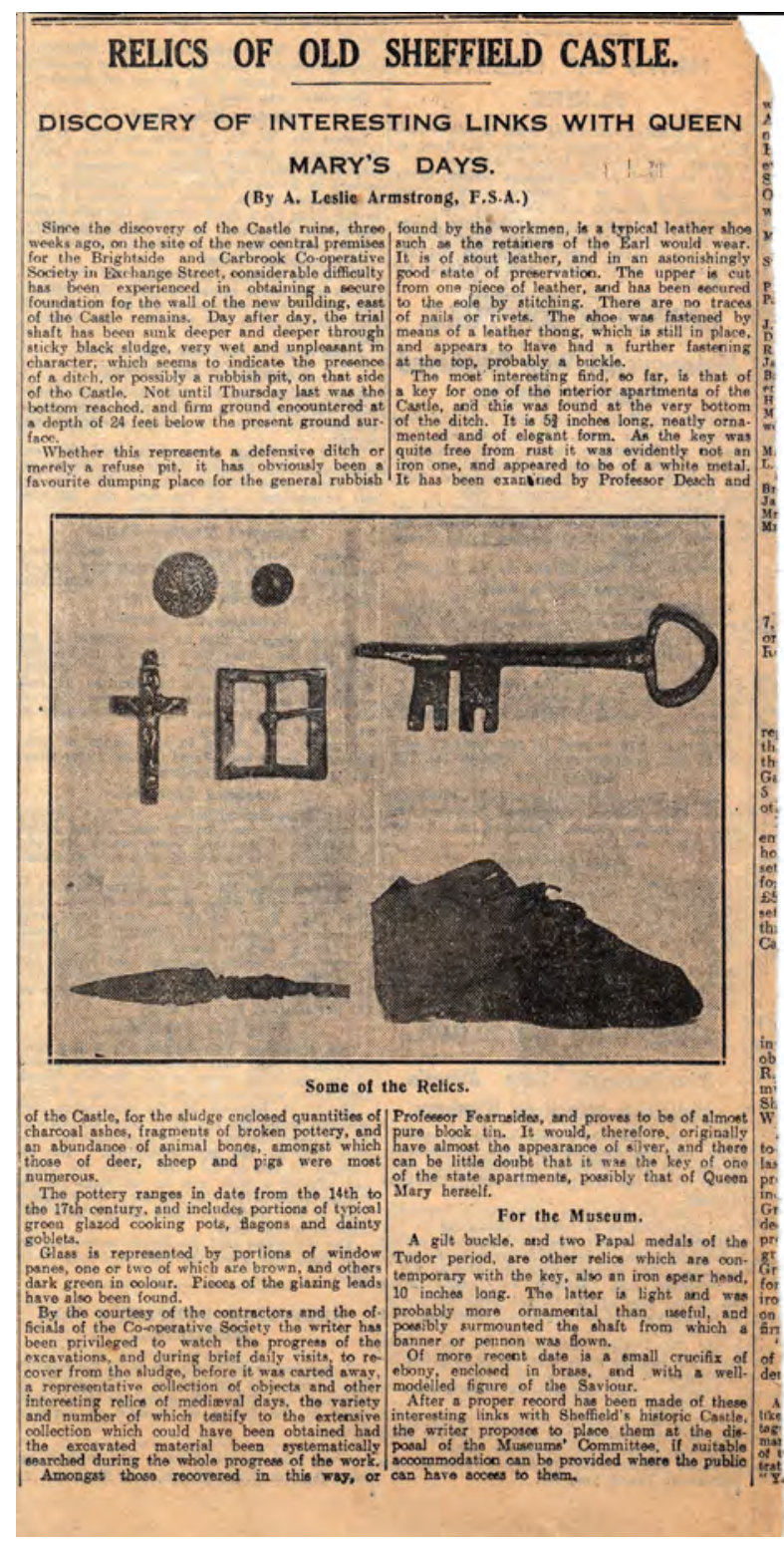

Figure 2.17: Newspaper article about the findings on Castle Hill from 1927. This was one of the first published accounts of the ongoing excavations. In his report Armstrong stressed the difficulty of the working conditions and also made the link with Mary, Queen of Scots. Here he was appealing to public interest in a well-known period in Sheffield's history, although he had little to say about the Queen in his published work and clearly knew that the key was not 'that of Queen Mary herself'. Courtesy of Museums Sheffield. 
this rich section would have yielded much more had it been possible to give the work constant supervision and to examine the whole of the material before it was carted away to the tip (Armstrong 1930, 15).

It is possible, such was Armstrong's frustration with the disengaged workmen, that, in his efforts to motivate them he was economical with the truth about this key. In his 1927 newspaper article he suggested that 'there can be little doubt that it was the key of the state apartments, possibly that of Queen Mary herself'. However, on the back of one of the original photographs he describes it as ' $14^{\text {th }}$ Cent. key of one of the state apartments' (Armstrong 1927a; also 1930, 25) - long predating, therefore, the incarceration of the tragic Queen of Scots (Moreland and Gorman 2019). Armstrong was not unusual in associating objects with a notable local figure; for example, in the same period at Knaresborough (North Yorks) a 13th-century cooking pot was embellished by public opinion which claimed it held 'the incinerated remains of the local Saint Robert' (Barber 1931, 202).

In his diary Joseph Himsworth appears even more frustrated than Armstrong with the apparent lack of concern for the archaeology of the site shown by the site foreman and labourers. For example, on $11^{\text {th }}$ December 1927 he 'called on the site to find the contractor had concreted the excavation, burying the plinth or tower and several courses of masonry' (Himsworth 1927-42, 2), and in January 1928 lamented that 'Up to the present there has been more destroyed or covered up with concrete than will ever be seen by the public' (Himsworth $1927-42,4)$. On $28^{\text {th }}$ September 1928 he noted that, although many pieces of 'ancient stone' were lying around, 'none [were] being preserved' (Himsworth 1927-42, 6). In December of that year, when architectural fragments were encountered during digging close to the north wall of the Co-op building, he remarked that Loughran 'was cursing the delay these finds were causing, in strong "Builders language" (Himsworth 1927-42, 12). The situation did not improve much over time. On $10^{\text {th }}$ October 1930 he records that he called at 2.15 in time to stop the men pulling to pieces masonry almost six feet by four feet high overlooking the Don and parallel with it'.

In another important entry, he wrote that on $31^{\text {st }}$ October 1928 'men were digging out the remains of a furnace, said by one of them to be the oldest in Sheffield' (Himsworth 1927-42, 9; JWM n.d.; Figure 2.18). The significance of this account is twofold. First, the men clearly knew something of the antiquity of the furnace, but demolished it anyway. And, second, this may have been the remains of a furnace whose partial destruction in 1915 had been recorded by the Sheffield Daily Telegraph and then by Wigfull in the pages of the Transac-

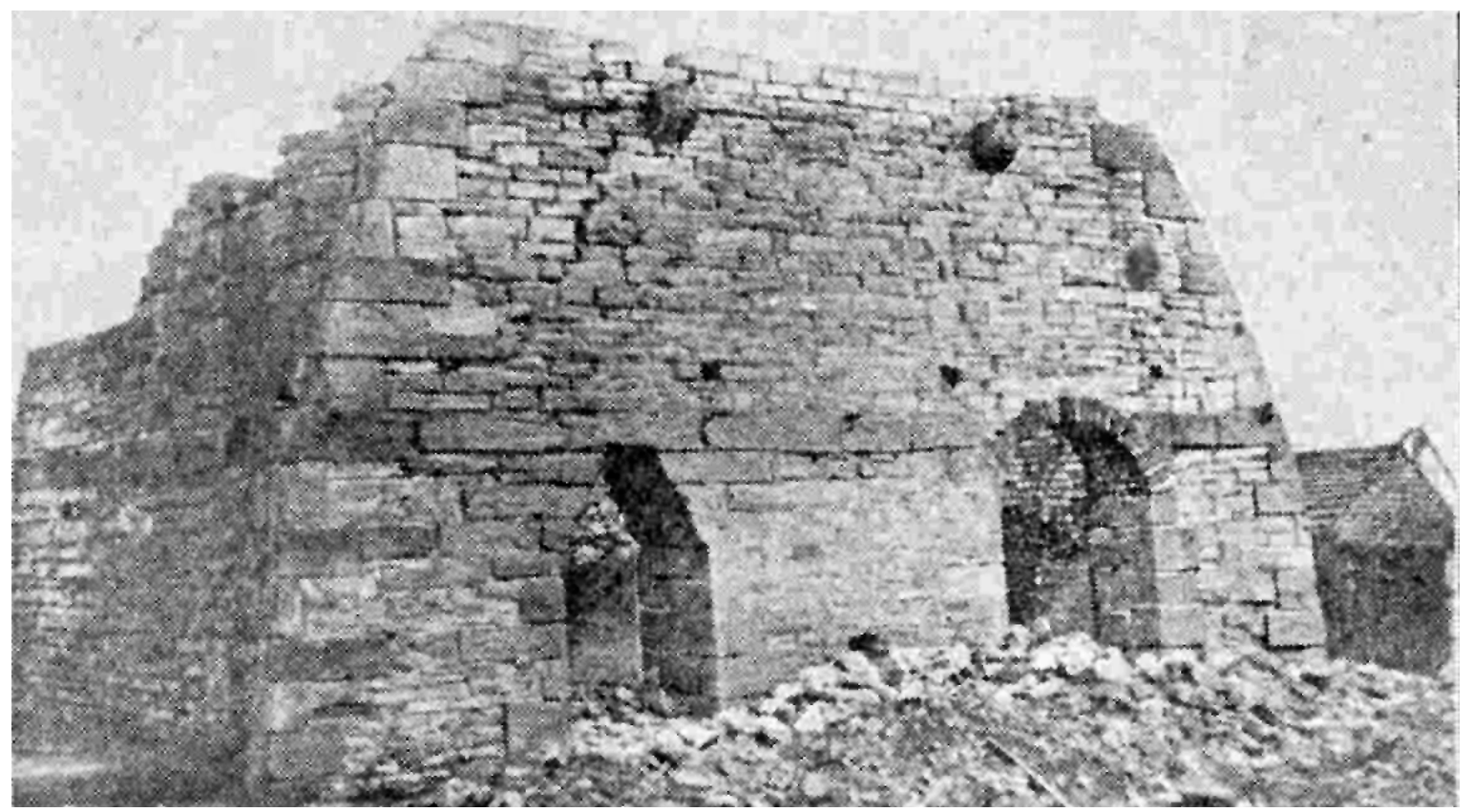

Figure 2.18: Ancient furnace on the site of Sheffield Castle. Reputed to be the oldest furnace in Sheffield, this early 20th-century photograph was included in Himsworth's typed diary. It had previously appeared in the Sheffield Daily Telegraph on $30^{\text {th }}$ March 1915. Courtesy of Museums Sheffield. 
tions of the Hunter Archaeological Society. This cupola furnace, we are told, was 'unearthed' on the castle site by 'Sheffield Corporation workmen engaged on the construction of the new road from the Great Central Station', also known as Victoria Station. It took the form of a 'square truncated mound', and was constructed from 'rubble stone with a strong course of heavy gritstone' incorporating 'slabs of the old stone from the castle' including 'portions of dressed stone and door moulds' ('Ancient furnace', 1915; Wigfull 1916, 239). A photograph of the structure published in the same issue of the Sheffield Daily Telegraph ('Sheffield's oldest furnace', 1915; and reproduced as fig. 32 in Himsworth 1927-42) shows it to have been a very substantial structure. If it had indeed been 'uncovered' during road construction, this image suggests that some significant excavation must subsequently have taken place. We are told that the furnace was located in the former premises of R\&J Smith, which are shown on the 1896 Goad Fire Insurance map of the area, with a 40in furnace cone marked in the north-east corner. This cone is not shown on the 1888 version of Goad's map, but 'part of the old castle' is noted in exactly the same place. The report in the Sheffield Daily Telegraph noted that the cone was visible in a sketch of Lady's Bridge (Winder 1907, 80); it can also be seen in an 1825 painting of the area (River Sheaf and the Shrewsbury Hospital, Sheffield; Figure 9.5). In demolishing this 'old cupola furnace' the workmen therefore erased traces of two important moments in Sheffield's history simultaneously (see Chapter 7 for how recent excavations may have recovered its traces). Wigfull (1916) ended his report by regretting the decision to abandon the scheme to cut the road through the castle site ('it is probable that some considerable remains would have been found, or even a complete plan of its arrangements laid bare') and instead to adopt one which 'involves a raising of the site rather than an excavation'. Might this be an early example where the archaeology of the site, the presence of the castle and later structures, influenced plans for development?

It was not only the workmen who were indifferent, at best, to the fragments of Sheffield's heritage being exposed, and sometimes destroyed, on Castle Hill. In September 1928, Himsworth reports that, even after substantial, visually striking, parts of the castle had been uncovered (the towers, gatehouse etc.), 'very few people were inclined to insist upon the authorities searching the ground for historic remains'. Even among those he 'thought likely' to be sympathetic, there was little appetite for recording or preserving further remains of the castle: 'everywhere the reply was, "we must clear the site quickly as possible and build a market cheaply. Conditions of trade are so bad we can neither spend time nor money and can brook no delay"' (Himsworth 1927-42, 5). In this sense, doing archaeology in Sheffield in the late 1920s was very different from today's practices, lacking the regulations that put archaeology at the heart of the planning process. Armstrong and Himsworth's presence on site seems to have been one of toleration, yet there is a great deal, perhaps a surprising amount, about their intervention on Castle Hill which finds strong echoes in contemporary, professional archaeological practice. While their records are impoverished by modern standards, they nonetheless used many of the same 'instruments' to preserve their observations - photographs, measured and sketched sections, and profiles. Himsworth's (1927-30) personal diary contains a roughly measured sketch north-south section across the site, defining and describing various layers and features ('virgin yellow clay and a few boulders - 3'6" deep'; 'remains of a tower - opp. Waingate back market entrance,' ' 9 " black occupation level', all fixed by distance from and measurement above/below the 'present road level' Figure 3.7). Armstrong's diary contains a sketch ( $18^{\text {th }}$ November 1927) of the relationship between five foundation pits and the Rotherham House Hotel, and measured sketch plans and sections of the sides of two of these 'holes' (Armstrong 1927-28, 3; Figure 2.19). In the end, Armstrong succeeded in masking the contingency that underpinned much of their work in a report that would not look entirely out of place in a modern context - an illustration of Gavin Lucas's $(2001,212)$ argument that by the 1920s and 1930s 'the standard site report was established and has changed little' since.

The quality of the recording and the 1930 publication might reasonably be explained as a product of Armstrong's considerable archaeological experience in the flint mines of Norfolk and in the caves of Derbyshire and Zimbabwe. However, a detailed study of the unpublished correspondence contained in the Museums Sheffield archive reveals it might also derive from another similarity between Armstrong's work on Sheffield Castle and modern archaeological practice. Archaeology today is very much a team effort, in terms of the numbers of professionals deployed on site and in the range of specialists called upon to plan the project and to analyse the material recovered. Although Armstrong could not rely on a team of on-site archaeologists, in developing the castle narrative, he too 'employed' a number of local specialists. Like Armstrong and Himsworth, these were men who earned their daily bread in other professions - and in many cases it was this professional expertise that Armstrong sought to exploit to enhance his understanding of the archaeology of Sheffield Castle. 

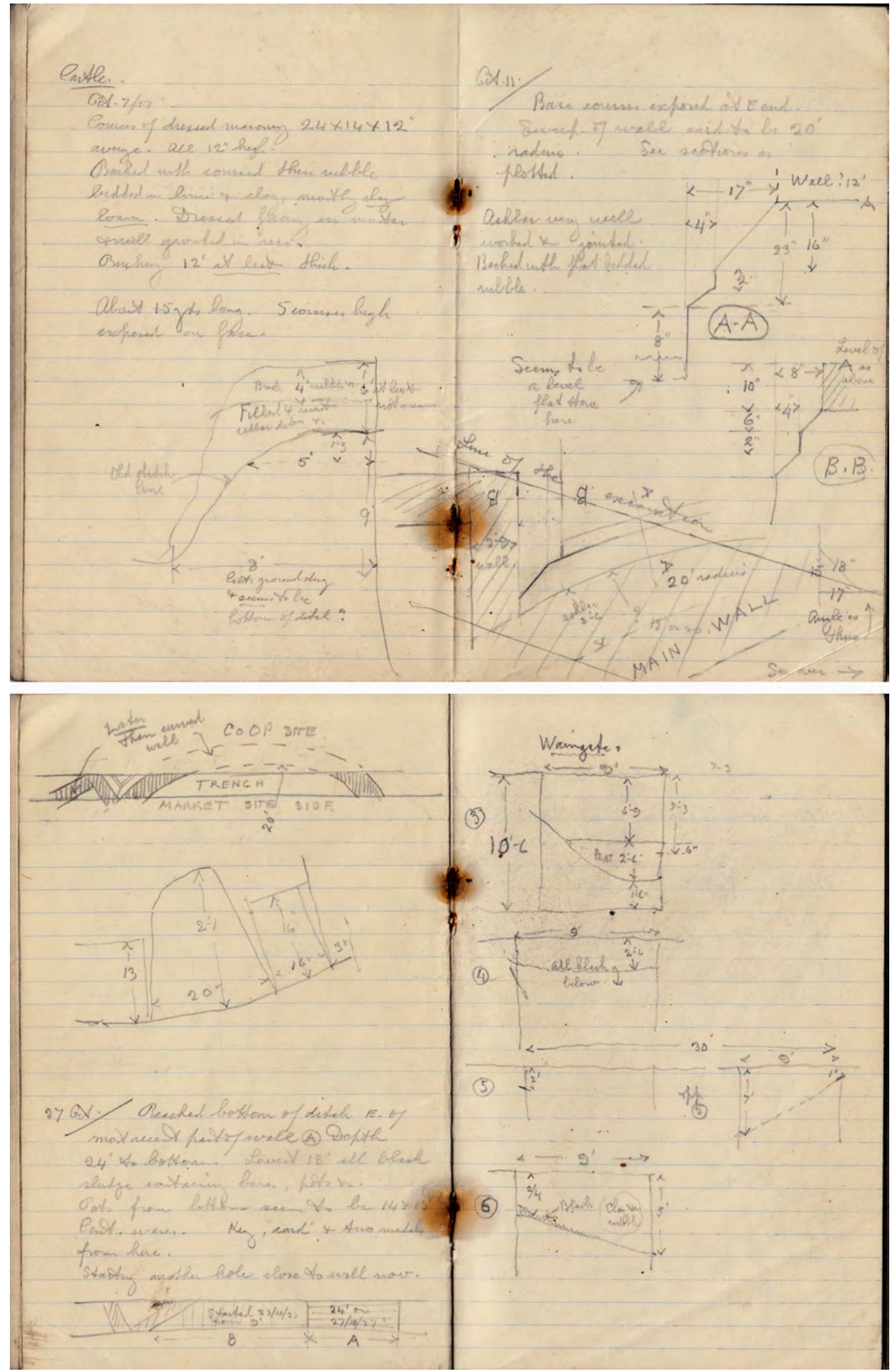

Figure 2.19: Sketch plans, profiles and excavation notes in Armstrong's on-site diary. Here he records the discovery of the monumental gatehouse and the bottoming of the moat, and provides sections through the moat as it passed Waingate. Courtesy of Museums Sheffield. 


\section{The finds specialists}

Joseph Baggaley was curator of Sheffield City Museum from 1928, and he seems to have had a very good working and (to judge from the tone and content of their correspondence) personal relationship with Armstrong. Although he also wrote on other aspects of the archaeology of the Sheffield region, particularly various Bronze Age finds (e.g. Baggaley 1938), Baggaley's specialism was in numismatics. On $9^{\text {th }}$ May 1930 he wrote to Armstrong to provide details (dates, denominations etc.) on the coins found at the castle, some of which were in the museum, having formed part of a 1929 exhibition entitled 'Old Sheffield', while others were at 'the Brightside \& Carbrook stores', perhaps in the 'cabinet of relics' on permanent view in the new premises on Exchange Street (Baggaley 1930a; Anon. 1969, 11). This information appears, almost verbatim, in Armstrong's 1930 publication, with the additional information that the Keeper of Coins at the British Museum had been able to identify 12 brass, coin-like, objects (presumably including the eight 'Elizabethan' brass counters referred to by Baggaley) as 'sixteenth century counters ... [eight of which] are inscribed in Tudor lettering "Ave Maria Gracia [sic - surely 'Gratia'] Plena", with the abacus in the centre. On the reverse are emblems of the Apostles, or a fleur-de-lys design' (Armstrong 1930, 25; Moreland and Gorman 2019; see Chapter 6 for further discussion).

Another of the specialists to whom Armstrong turned in pursuit of further detailed information from the castle finds was Frederick Bradbury, co-owner of Thomas Bradbury \& Sons, the famous Sheffield silversmiths and silver platers. Bradbury wrote to Armstrong on $11^{\text {th }}$ June 1930, returning ' 4 buttons' (although he goes on to talk about five; Figure 2.20). He had concluded that a pair of sterling silver buttons were 'in all probability' from 'the coat of some officer or gentleman' (Bradbury 1930a; nos 7, 8 on Armstrong's plate II; Figure 2.21), while a smaller one was 'probably used as a waistcoat button' (no. 10). Believing that they had been produced 'around the middle of the 17th century', he suggested to Armstrong that, given their composition, they 'would not have been thrown into the moat in a haphazard way along with various odds and ends of discarded garments' but rather 'may have belonged to some of the soldiers or civilians taking part in the fighting outside the castle' (Bradbury 1930a). The other two buttons (probably nos 6, 9) were bronze but, applying a social/military hierarchy to them, Bradbury could not determine if they were formerly on the coats of retainers ... as they bear no evidence of an heraldic design or any other form of ornament'. He was, however, able to date one to 'the Cromwellian period' (no. 6).

Bradbury was clearly puzzled by the discovery of three silver buttons in the fill of the castle moat (remember the 'sticky black sludge') and, having reflected on the matter, wrote to Armstrong again on $17^{\text {th }}$ June 1930 with the thought that ' 200 or 300 years ago people regarded silver with a good deal of respect, the price then being high. He went on to make the kind of offer that would horrify conservators today and which certainly reflects changed priorities in our approach to artefacts: 'I had thought of just polishing the top of one of those silver buttons for you, as there are a pair. Would you like me to do this? if so, kindly send one to me and I will have it done for you' (Bradbury 1930b)!

The depth of Bradbury's interest, and expertise, can be gauged from the fact that he returned to the buttons once again, getting them back from Armstrong and, as reported in a letter of $8^{\text {th }}$ July 1930, subjecting them to 'a longer and more exhaustive examination'. That examination involved the deployment of unspecified techniques to determine their metallurgical composition, with unfortunate consequences for the smallest of the buttons (presumably that which he had earlier identified as being from a waistcoat; Bradbury 1930c). He was able to determine that it was 'partly silver, possibly 50\%', but 'in taking the test' the button came apart, 'a small section having flown away which I failed to recover. He was also able to show that the other two buttons only had a silver content of between $25 \%$ and $50 \%$, and suggested that, as long as the finished object 'had a whitish hue they [people in the past] were not very particular concerning ingredients'. He went on to note that there was 'certainly no plating of any description'.

What especially interested him, however, were the six pins also sent to him by Armstrong, which 'are nearly pure gold, i.e. either 18 or 22 carat (a most interesting discovery)' (Bradbury 1930c). He returned at the end of this letter to say 'I wonder how you managed to acquire the tiny and interesting gold pins' - presumably considering the less-than-optimal conditions for archaeological recovery on the construction site. These are probably the pins illustrated as no. 7 on plate III of Armstrong's 1930 publication (Figure 2.22), and Armstrong, perhaps not sharing Bradbury's special interest, provides only the following additional information: 'Pins, of drawn gold, heads formed of coiled wire' (Armstrong 1930, 27). Some pins from the castle site survive in the Museums Sheffield (2019b) collection, but these are copper alloy (Chapter 6, Section: Domestic and personal items). Given his knowledge and experience, it is unlikely that these are the ones Bradbury described as 'nearly 


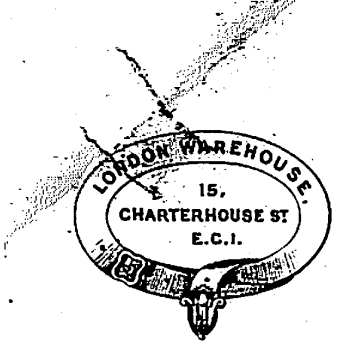

TELEGRAPHIC ADDRESSES: "BRADBURY, SHEFFIELD":

"SILVIUM LONDON."

TELEPHONES

SHEFFIELD 20514 LONDON,HOLBORN.1381

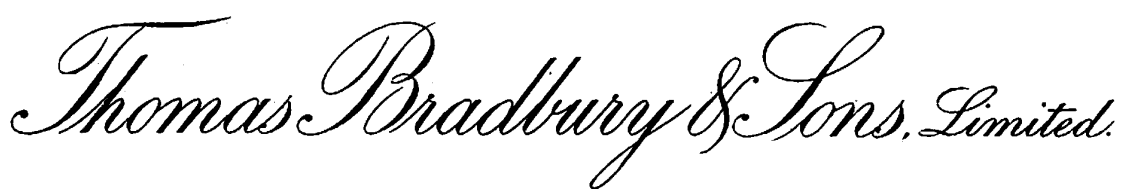

Direndel Coreet.

A. Iesile Armstrong Esq., 52, Warburton Street, Stockt on Heath,

Warringtor.

Dear Armstrong,

I return the 4 buttoss herewith.

Three of them aṛe of sterling silver. The pair $1^{n}$ across, one of which has the oje missing, were in all probability attached to the coat of some officer or gentleman of rank, I1kewise the other small specimen just under $\frac{g^{\prime \prime}}{4}$, this was probably used as a waistcoat button.

I take 1t, that being of precious metal they would not have been thrown into the moat in an haphazard way along wilh various other odds and ends of discarded gaments. It is just possible they may have belonged to some of the soldiers or c1filians taking part in the fighting outside the castle or in an attack.

I should ente these silver buttons as heving

been produced about the ildale of the $17 \mathrm{th}$ century.

of the other two, formerly a pair, these are composed of bronze.

contai.

Figure 2.20: Letter from Frederick Bradbury to Leslie Armstrong, $11^{\text {th }}$ June 1930 (page 1). Here Bradbury informs Armstrong about his analysis, and interpretation, of buttons found in the castle moat. Courtesy of Museums Sheffield. 


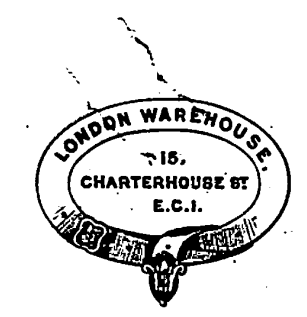

TELEORAPHIC ADDRESSES: BRADBURY, SHEFFIELD" "SILVIUM LONDON.

TELEPHONES SHEFFIELD,205! LONDON,HOLBORN.138T
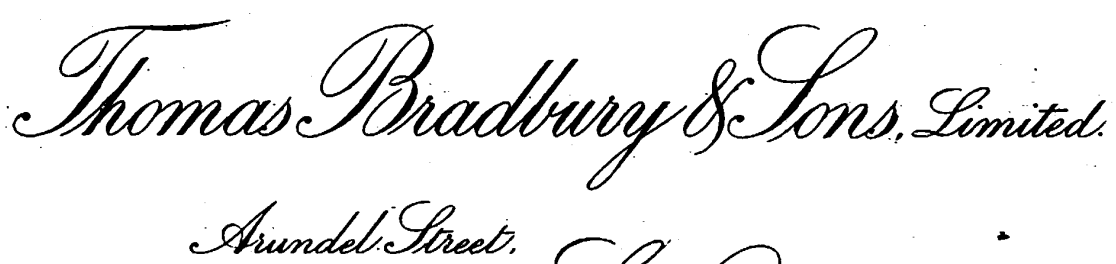

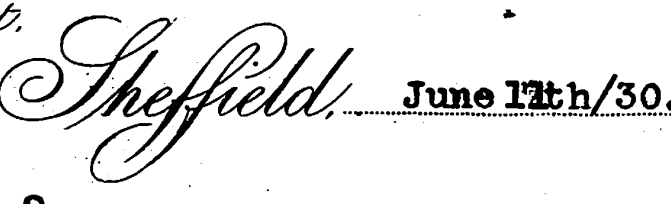

The one with decoration thereon consisting of

a round volute engraved centre ornament is typical of the Cromwellian period. Whether these two buttons were formerly on the coats of retainers or not it would be difficult to state, as they bear no ovidence either of an heraldic design or any other form of ormament, as would probably have been the case had they been used either on a military uniforn or hunting equipment.

$$
\text { Yours very tmuly, }{ }_{\text {bred }} \text { Bradbery }
$$

Figure 2.20 (continued): Letter from Frederick Bradbury to Leslie Armstrong, $11^{\text {th }}$ June 1930 (page 2). Courtesy of Museums Sheffield. 

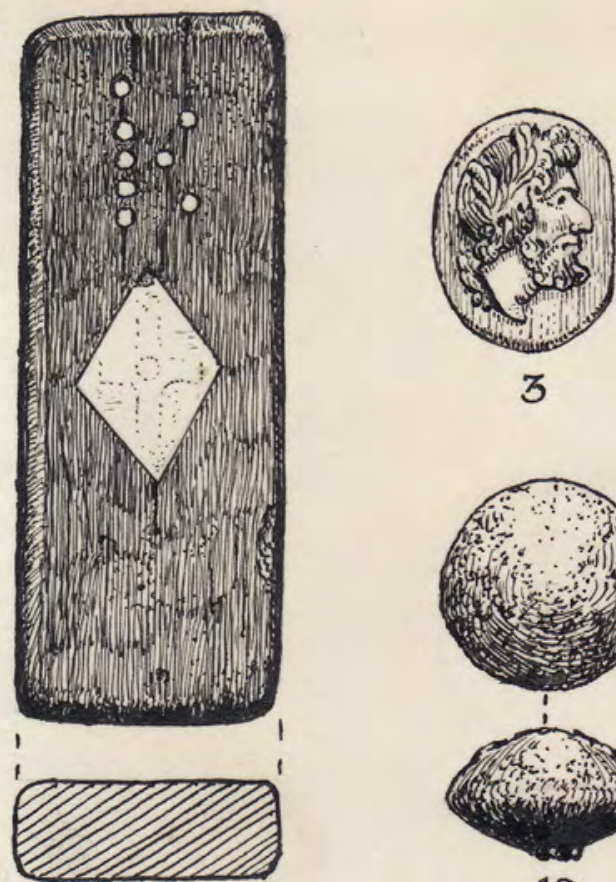

3

1
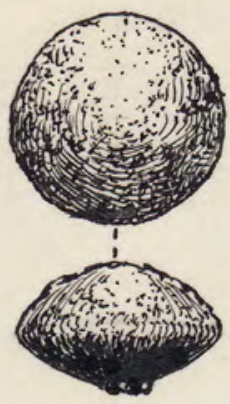

10

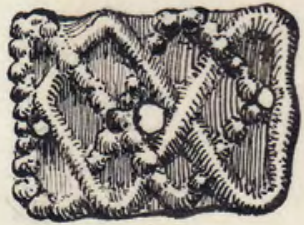

5
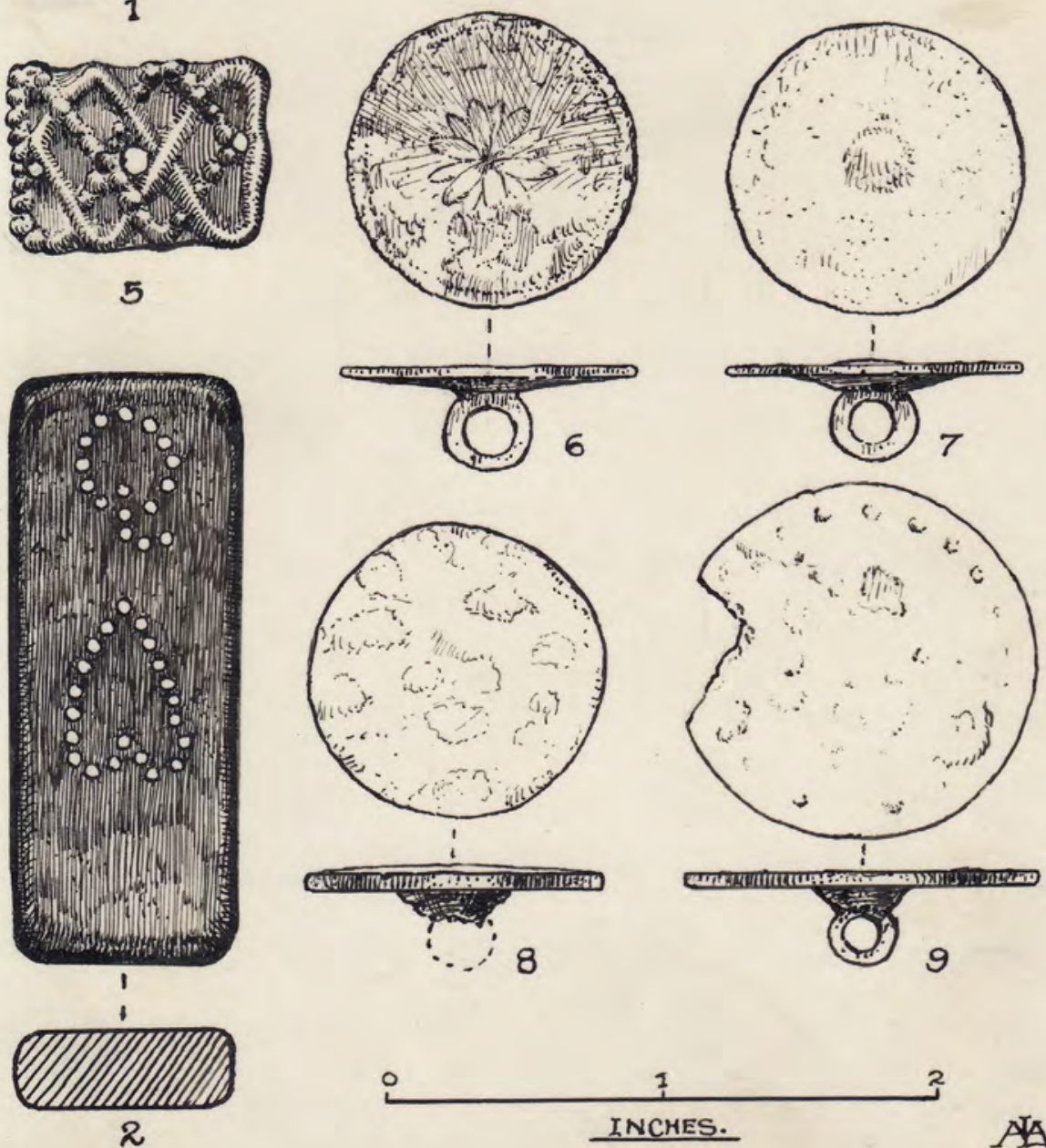

A

Figure 2.21: Plate II from Armstrong's 1930 paper on Sheffield Castle. This shows the 'playing card' he recovered from the moat (1) and a similar item shown to Armstrong by a local boy (2; see Chapter 6, Section: Domestic and personal items), a wooden/brass crucifix, a brooch mount, and various buttons examined by Frederick Bradbury (see also Figure 2.20). Hunter Archaeological Society. 


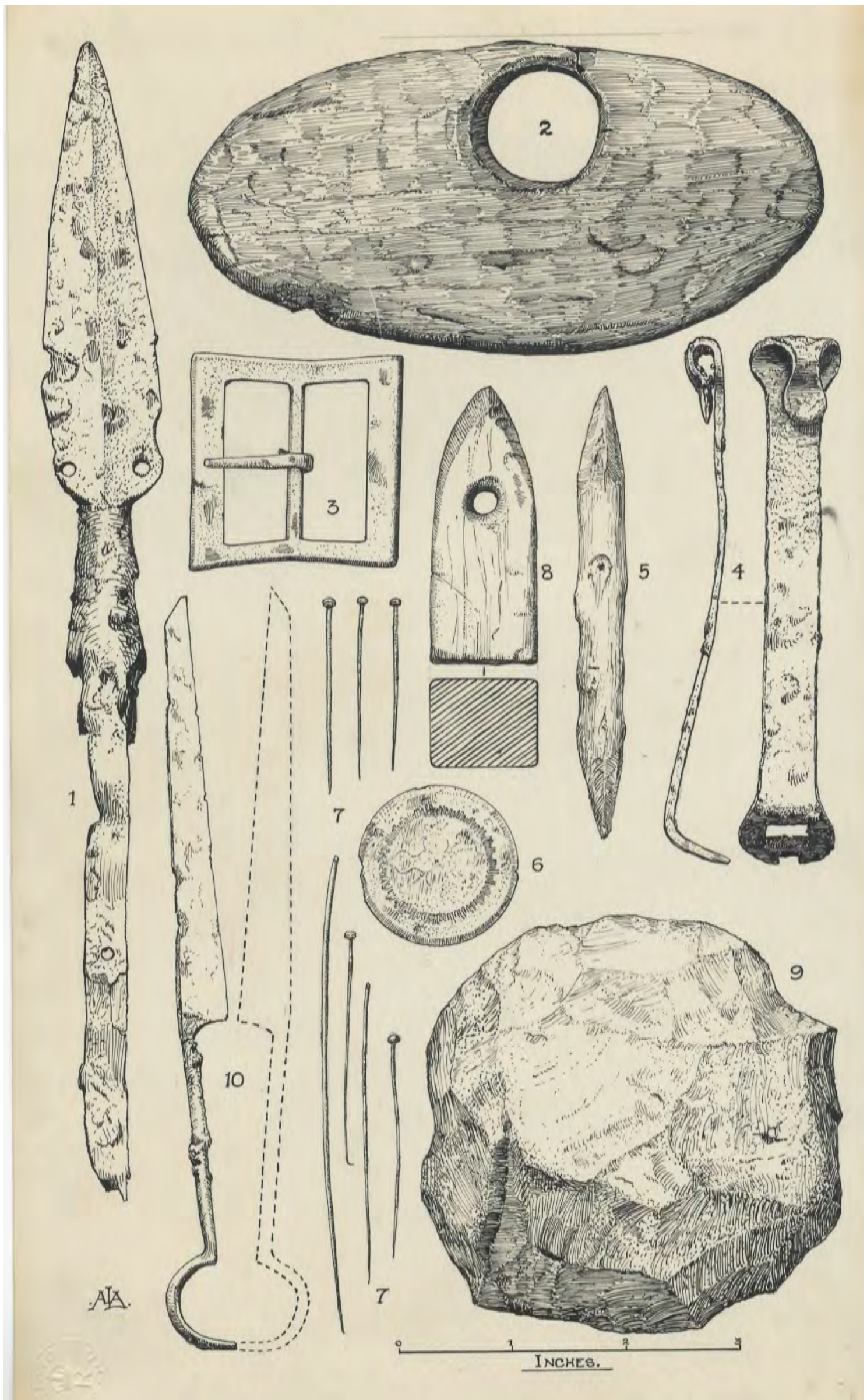

Figure 2.22: Plate III from Armstrong's 1930 paper on Sheffield Castle, illustrating a spearhead, saddler's palm guard, button, pins, buckle, shears, whetstone, textile-working implements and a padlock slide key, misidentified by Armstrong as a 'probable cheek piece from a horse's bit'. Hunter Archaeological Society. 
pure gold', and we should note that Armstrong provides another illustration of 'gold pins ... from the Ditch' (his fig. 16), some of which look more like those currently curated by Museums Sheffield.

One of the objects which had captured the attention of both Armstrong and (he hoped) of the construction workers was, as we have seen, a large key 'neatly ornamented and of elegant form', which was 'quite free from rust' and would 'originally have almost the appearance of silver' (Armstrong 1927b; 1930, plate I (no. 1); Figure 2.23). To identify its composition, Armstrong turned to specialists at the University of Sheffield. William George Fearnsides, Professor of Geology, and Cecil Henry Desch, Professor of Metallurgy, examined the key and determined that it was 'almost pure block tin' (Armstrong 1927b; block tin is pure tin - as opposed to tin plate - with only very small quantities of impurities). Their contribution was not only the start of the University's engagement with the archaeology of the castle, which continues to this day, but was part of a long-term relationship with Armstrong, Fearnsides helping him in his work at Creswell Crags (Armstrong 1932, 331; 1942, 50), and Desch with the analyses of bronze axes and palstaves which Armstrong (1926b, 164) oversaw on behalf of the 'British Association Committee on the Distribution of Bronze Age Implements. Their involvement highlights access to specialists who combined their practical skills and knowledge with a passion for understanding the past. Desch's archive in the University of Sheffield's Special Collections contains information on his work with the 'Sumerian Committee of the British Association' in their efforts to determine the origins of the copper used by the Sumerians, as well as his correspondence with some of the world's leading archaeologists - including V. Gordon Childe, Harold Peake, Winifred Lamb, Cyril Fox, and Leonard Woolley (Anon. n.d. (a)). Similarly, not only was Bradbury one of Sheffield's leading silversmiths; he was also author of A History of Old Sheffield Plate (1912), the fundamental work on the subject, elected as a Fellow of the Society of Antiquaries, and an associate member of the British Archaeological Association from 1913. The firm's catalogue, c.1920, lists not only the usual cream jugs, sauce boats and coffee sets but also illustrates historic cutlery for sale, including 'reproductions of Roman Spoons found while excavating Ancient Camps in England' and 'The Bath Spoon ... from a Roman Original found in the District', showing how his interest in the past informed his own craft practice. In a letter to the editor of the Sheffield Daily Telegraph published on Wednesday, $19^{\text {th }}$ October 1927, he wrote about how the discoveries on the ongoing excavations at the castle reminded him of the great feasts once held there, noted (again linking his craft with his historical interest) that the 'display ... of silver plate and pewter on the "Dressors" must have been prodigious', and asked 'where has it all gone?'

Drawing on his professional experience and knowledge of local history, Himsworth was another specialist contributor to the analysis of artefacts from Sheffield Castle. Reports in local newspapers make clear the depth of his knowledge, which was never merely 'local', with his public lectures ranging from 'Florentine guilds' $\left(9^{\text {th }}\right.$ December 1924$)$ to 'Beauty and interest in North-East Notts' $\left(16^{\text {th }}\right.$ November 1931$)$. A two-page note written to Armstrong on $29^{\text {th }}$ May 1930 illustrates how he brought this knowledge to bear on some of the artefacts from the excavations. It concerns single blades from two different pairs of shears (no. 9 on plate I (Figure 2.23) in Armstrong's 1930 paper, dated to the 16th century from 'its position in the ditch', and no. 10 on plate III (Figure 2.22), 'from the lower levels of the ditch' and dated to between the 13th and 15th centuries). Having outlined the basic dimensions and appearance, one set being more 'gothic' in shape, Himsworth (1930c) then described how he cleaned (!) 'until the bright steel appeared', allowing him to observe that they were composed of solid steel, not 'iron welding, with steel facing for the cutting edge, as has been said is the case in this period work'. His tests demonstrated the same 'steel hardness all over the blade', though the material itself was 'very coarse' - a product, he thought, of 'great variation in or lack of homogeneity in the steel' rather than of overheating in forging. He concluded that 'the general shape, lightness with strength and the proportions of both [examples] compare favourably with the best modern productions' (also Armstrong 1930, 26-7, for how this memo was used in the final excavation report).

Himsworth seems to have examined a range of objects, supplying Armstrong with a stream of information in the build-up to the publication of the excavation report. In a letter of $13^{\text {th }}$ May 1930, in which he recorded the return of various metal objects ('from the Co-op collection'), ${ }^{9}$ offering some thoughts on conservation, Himsworth (1930b) told Armstrong that 'it would be a very congenial task to describe the knives as you suggest' (emphasis added; Figure 2.24; also Himsworth 1930d). In his 1935 lecture he recounted that Armstrong 'gave [him] the job of preparing a detailed description' of the knives found during the excavations (Himsworth 1935, 7), which appears at the end of Armstrong's (1930, 25-6) report on the excavations. In his '500 years of

9 'Iron key, 2 small knife blades, 1 large knife blade, paper of 4 pins, 2 large flat buttons, 1 small round bean shaped button.' 


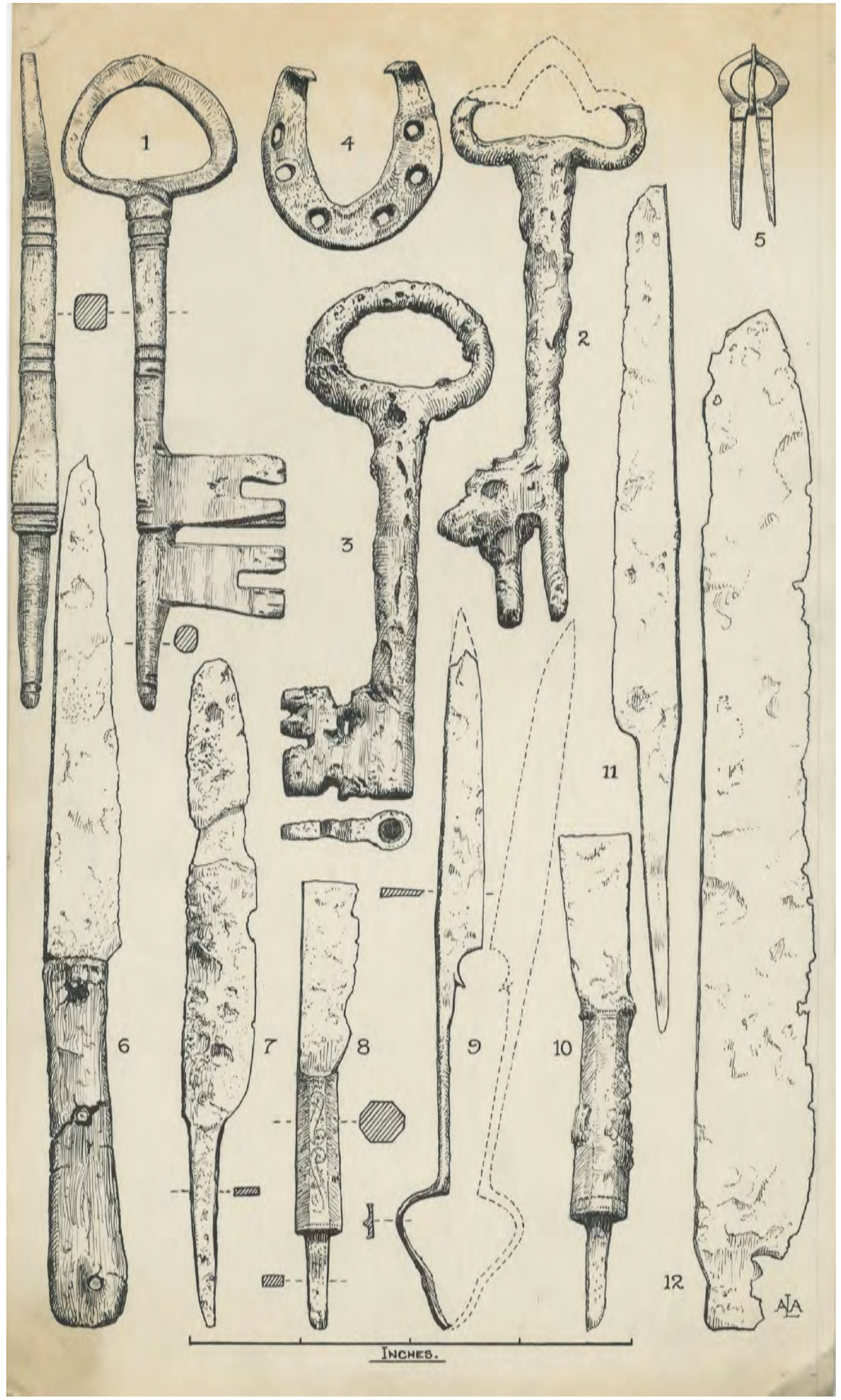

Figure 2.23: Plate I from Armstrong's 1930 paper on Sheffield Castle, illustrating some of the other significant finds, including keys, knives and shears. Hunter Archaeological Society. 


\section{QhetiII.}

10 13. (Promial number)

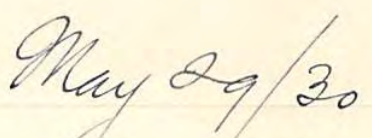

Ino freces of shear style sersar, matimig uf ne lelade unth shante and hant of bow.

Iotal length of the tio heeces $=6 \frac{3}{8}$ inches.

In cleaving away monstation and must, exterswe fatches of "Ime" Whe hation were first removed to reveal suact shafe. The thickest hant of blade is the track, a little ketno where the blade Hrstry joins the shank, and is $3 \mathrm{M} / \mathrm{M}$. The undth of blade at the same flace is $\frac{Y}{16}$ " on $11 \mathrm{M} / \mathrm{M}$ and the bevel on the cuttungedge here is $4 M / M$. troad(sichoded in the $11 M / M$ )

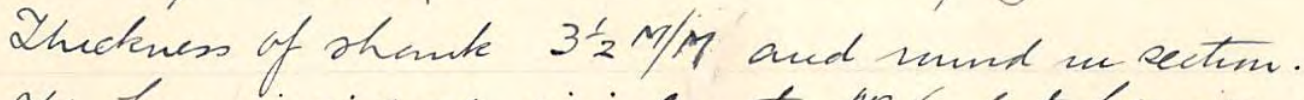

The tow is ridged similur to 106 but heaver and Dimflew in sectim and $3 \mathrm{M} / \mathrm{M}$ thotest hat. The fow whew cunflete was furbably sund mi cuttene, not giother. 106 biw is flat an the siside; and on the outride, a reed, udge a nember surs unind it with a hollow on either ack of it. AN 13? bow is hypamidal m sectom. The base of frypanid benig the flat inside and the tow sides sleightly minded a frell! The apex than fours the center vidige

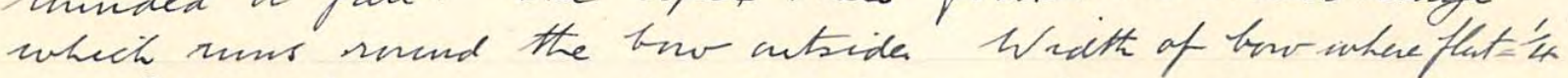
After cleanmi until the bright sted affeaned, there is no endence of im woddrig, usth sted facmin for the cutting edge, as has hea said is the case me thes lerod unk. Iny ofumin is that torls of suek suade hoofntion.

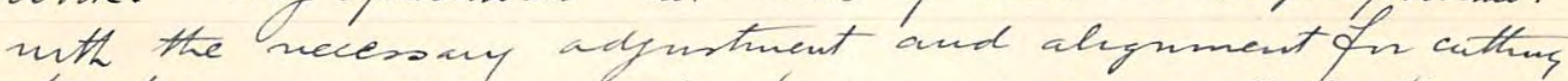
hurtises conld sut he froduced so woll hy the use of the tur metulo as if only soled ated were nsed. Pugh tests gure sted harduess all wer the blade. The ingitt fracture stumin where hlade has heen hroken fin shank (endently sunce the artude was discuered) duws ven crarse sturcture of material.

Figure 2.24: Note written by Joseph Himsworth to Leslie Armstrong in late May 1930 (page 1). In this Himsworth provides detailed metallurgical information on the finds that he had been analysing. Courtesy of Museums Sheffield. 


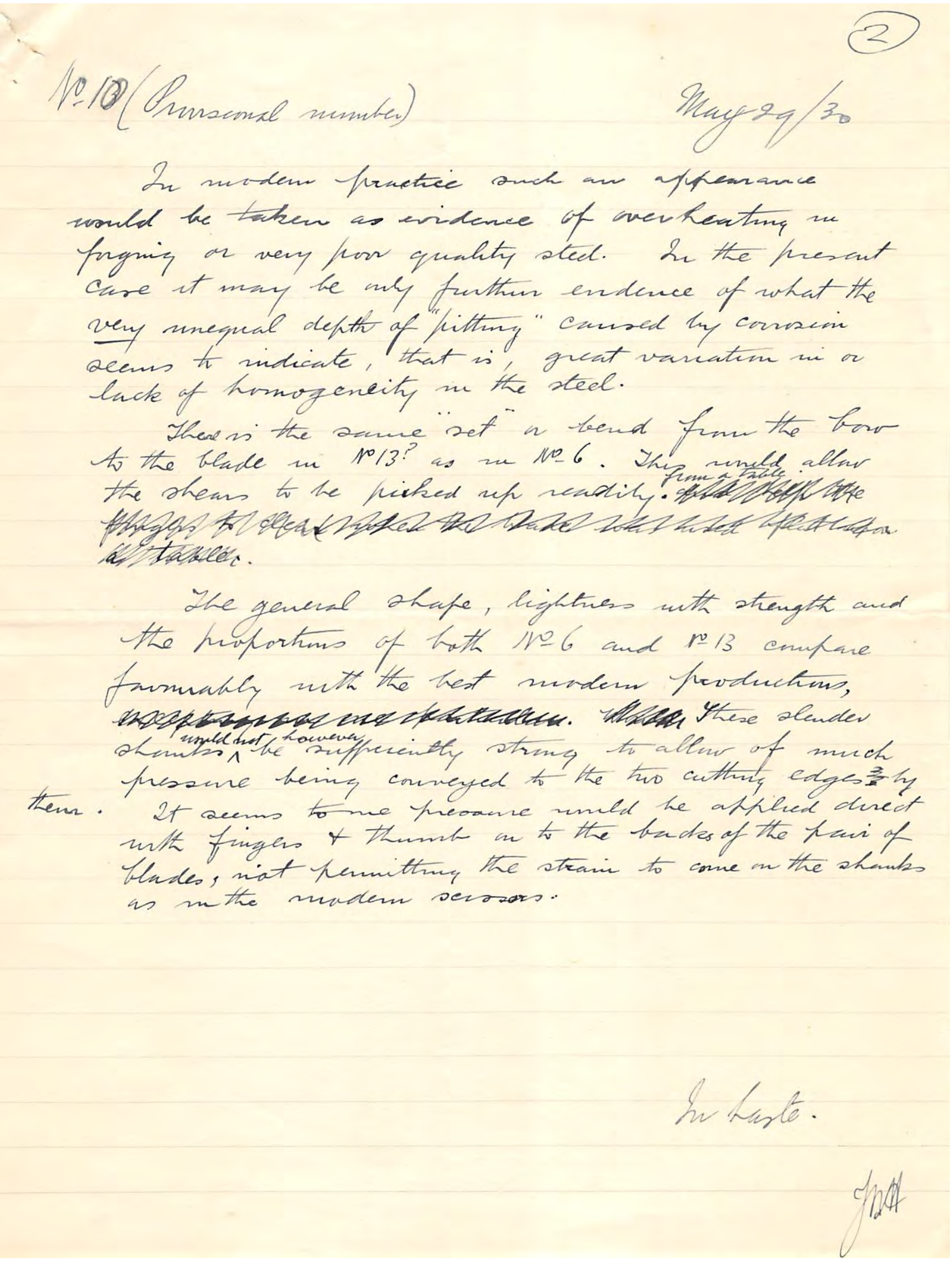

Figure 2.24 (continued): Note written by Joseph Himsworth to Leslie Armstrong in late May 1930 (page 2). Courtesy of Museums Sheffield. 
Sheffield trade and Sheffield castle' lecture, Himsworth $(1937,3)$ reminded his audience that 'one knife found in Sheffield Castle moat had damaskening in gold and had a chased, that is, a punched design upon it' (also Armstrong 1930, 25-6 and no. 8 on plate I; Figure 2.23). Himsworth (1930b) clearly looked at other objects too - the letter of $13^{\text {th }}$ May contains his thoughts on 'a small round bean shaped button', and Armstrong's paper includes his description and analysis of one 'half of shear style scissor' (Armstrong 1930, 27, also plate III (no. 10)). He was also keen to do more; he finished his letter by assuring Armstrong '[i]t is a pleasure - so please don't hesitate to give me other matters to deal with when I can be of use' (Himsworth 1930b). In his analysis of these artefacts, Himsworth was encountering the archaeological traces of craft working, and of the common man that he seems to have been so interested in; as we will see in Chapter 6, the traces of the servants, craftworkers and merchants who supplied and facilitated the daily routines of the castle emerge very strongly from the wider material record.

It is as well that Armstrong engaged these specialists, as our examination of the archives revealed that some artefacts recovered from the castle site have sadly been subsequently lost, and so the accounts in his 1930 paper and in the archived correspondence provide the only surviving records. The most dramatic factor in this depletion was the bombing of Sheffield in December 1940, causing the loss of those items at the Brightside and Carbrook Co-op Society building, which was destroyed (Himsworth 1927-42, 21; 1944, 1; Figure 4.1). As these items were on public display, it seems likely that they included some of the more significant and visually striking finds. The Society's report for 1969 describes 'a cabinet of relics (cannon balls, tobacco pipes, leather, sword pieces etc.)' having formerly been on view there (Anon. 1969, 11), but there is no surviving inventory of what this contained. Lost in the bombing may have been some of the items illustrated by Armstrong in his 1930 paper that could not be traced in the archive, including some of the gold pins, two leather shoe soles (nos 40,42) and a shoe vamp (no. 142) (Mould 2017a). The written accounts of the 1927-30 excavations also document the removal of items from the site. For example, in a handwritten amendment at the end of the typed version of his diary, Himsworth $(1927-42,21)$ notes that he then had 'a few objects taken from the moat in his possession viz: an early shoe sole and several blades depicted by Armstrong in his report', all of which seem to be missing from the museum archive, and may never have been deposited. His diary also records his acquisition from the excavations of 'an antler and Tudor shoe sole', and 'some fragments of Midhope pottery' (Himsworth $1927-42,3,11,39)$. Some items found in the 1920s were even given away, including 'a terra-cotter ornament dug up on the site' presented by the Clerk of Works, Reg Loughran, to Himsworth's mother when she visited the excavations in November 1928 (Himsworth 1927-42, 9), while one of Himsworth's relatives has told us that he had 'bestowed a box of archaeological treasures' on her brother (Hutten pers. comm.). In sum, while there was undoubted concern to see the finds from the castle recorded, there was not necessarily an expectation that the City Museum was the appropriate place for all of them to end up.

\section{The enduring legacy of Leslie Armstrong}

This correspondence between Armstrong and a range of specialists highlights his pivotal role in the accumulation of knowledge about Sheffield Castle, and it was to him that requests for information were directed. For example, the secretary of the Brightside and Carbrook Co-op wrote to him to ask for help with the souvenir brochure planned to mark the opening of their new premises on the castle site (Forster 1928; 1929). Despite the growing importance of Himsworth in recording the castle excavations, it seems that in this respect not much changed even after Armstrong left Sheffield for a new job in Warrington (Cheshire). Thus, W. G. Davies (1930a), the City Architect, wrote to him in Warrington on $20^{\text {th }}$ June 1930 providing a 'ground floor and foundation plan of the new market with the vestiges of walls remaining of the Sheffield Castle. He wrote again on $12^{\text {th }}$ August providing a plan 'showing the new market with relation to the surrounding streets at present, and before the street widening' (Davies 1930b). It is likely that Armstrong asked for this information to assist with the preparation of the excavation report. He received the proofs of this from the publisher, J. W. Northend, on $30^{\text {th }}$ August, with a request, among other things, to provide figure numbers and captions, and with the (very familiar) warning that 'publication is now being held up for this article' (Northend 1930b). So, when Davies (1930c; see also 1930d) wrote to him again on $17^{\text {th }}$ November 1930 to provide 'a tracing shewing a further section of walling which has been uncovered by the City Engineer's workmen when excavating the new Road, ${ }^{10}$

${ }^{10}$ Significantly, Davies also told him that '[a]t the corner of Lady's Bridge, a foundation stone was discovered in which was a cavity containing brown fragments of paper, which has also been preserved'. 
it would seem likely that this was to inform some other project. Correspondence between Armstrong and Northend provides us with an insight into what this might have been.

On $31^{\text {st }}$ October 1930 Himsworth wrote to Armstrong telling him that the Hunter report was 'easily the most important local thing of its kind for many years', and urged him to give it a 'wider circulation' (Himsworth 1930c). ${ }^{11}$ It is not clear that Armstrong needed this encouragement; he had already asked Northend for 200 copies of the Transactions report, and his archived correspondence has numerous replies, and thanks, from those to whom he had sent them (Northend 1930b; Edwards 1930). Nevertheless, on $13^{\text {th }}$ November, he wrote to Northend with an idea for a book on Sheffield Castle. Northend's reply of $22^{\text {nd }}$ November provides more detail on what the proposed book was to contain: Armstrong's Transactions paper, an 'additional chapter', and 'Mr. Drury's article on the "History of the Castle"' - '500 copies, bound full red cloth, stiff boards' (Northend 1930c). ${ }^{12}$ Unfortunately for Armstrong (and us!), Northend (1930c) added that, while they would have been pleased to print it, they 'cannot undertake the financial responsibility of publishing the book'. And there the matter seems to have ended. The point here, however, is that, although not present in Sheffield while the last phases of these interventions on the castle site were taking place, it was to Armstrong that people turned when they wanted something written on the castle. Prehistorian, and resident in Warrington, he may have been, but such was his experience and stature that Armstrong remained the person with the authority to write the 'official' narrative of Sheffield Castle, a narrative upon which (until now) all subsequent understandings have been anchored.

\section{Conclusion}

While the 1930 report on the remains of Sheffield Castle published by Armstrong is the best-known insight that we have into what was found on the site, it is clearly not the complete account, nor does it fully do justice to the circumstances of the recording undertaken. Armstrong was a very experienced excavator, and his recording methods were typical of the period, but while he was the 'great man' who provided a figurehead for the excavations it was the comparatively unknown Himsworth who was more frequently on the ground, liaising with the workmen and continuing to record what was emerging after Armstrong had moved on. While Armstrong may have been regarded at the time - and ever since - as the expert on the excavations, his interest in the site had clearly dwindled by early 1930, if not earlier, and his plans to write a book on the castle progressed no further than handwritten drafts. In fact, it was Himsworth, with his range of intellectual interests, political sensibilities and interest in hunting out the common man who kept the story of Sheffield Castle alive through his public lectures. The account presented in this chapter has only passing resemblance to the way in which early castle studies have been characterised recently, with Matthew Johnson $(2002,4)$ writing that

A generation of scholars working on castles were military men. They chose to pursue historical interests in retirement; and the obvious place to look for evidence of changing medieval techniques of warfare was the castle. Castles, then, were understood in military terms almost by definition (see also Stocker 1992).

This hardly does justice to men like Armstrong and Himsworth, whose approach was deeply embedded in local society and the urban landscape, little interested in matters of war and defensibility but concerned with local placemaking and traditions; it was this that drove them on, and, as we will see in Chapter 3, shaped the narratives about the castle that they created.

\section{Bibliography}

The full bibliography is available at the end of this volume, or at: https://doi.org/10.22599/SheffieldCastle.k.

${ }^{11}$ Note that the entry for $31^{\text {st }}$ October 1930 in the extracts from Himsworth's original diary reads as follows: ' 25 Reprints from JRW [Wigfull] to send on to ALA [Armstrong]' (Himsworth 1927-30).

${ }^{12}$ The latter is probably that published the previous year, with a comment by Armstrong, in Drury's posthumous collected essays A Sheaf of Essays by a Sheffield Antiquary. The proofs of Drury's posthumous volume survive in the Museums Sheffield archive, and were presumably supplied to Armstrong by Northend, as the publisher's stamp appears on the text (Drury 1929a). 



\title{
CHAPTER 3
}

\section{The Origins of Sheffield Castle}

\author{
Sheffield Castle, once so massive and strong, has become a tradition and nothing more (Leader \\ $1872,362)$
}

In the last chapter we explored the process through which Leslie Armstrong and Joseph Himsworth came to record the archaeology of Sheffield Castle, as Castle Hill was redeveloped between 1927 and 1930. We now turn to the archaeological remains encountered and interrogate the interpretations they placed on them. This has previously mainly rested on Armstrong's 1930 publication (even his 1928 interim publication has been overlooked), but here we incorporate the full range of archival material discussed in the previous chapter. These records reveal that some of the published interpretations are questionable, a product of the conditions and the era in which the two men were working, and the influences on them of contemporary debates about the heritage of Sheffield. In common with others at the time, they were unduly influenced by the written record relating to the castle and especially by the ongoing local debate about the location of the hall of Waltheof, the last Anglo-Saxon lord of Sheffield (see Chapter 1). This debate had been (and, for some, remains) central to Sheffield's sense of its origins, and is therefore an appropriate place to begin our exploration of what F. E. P. Edwards (Sheffield City Architect from 1908 to 1926) $(1930,1)$ referred to as 'the most notable local building historically and such as Sheffield is never likely to possess again'.

\section{Civic pride and the search for Waltheof}

In his diary entry for $22^{\text {nd }}$ March 1929 , Himsworth $(1927-42,15)$ recorded that 'A.L.A [Armstrong] rang up to say that he had been fetched down to the castle site to see what was probably the most important find yet made, viz. Saxon posts and floor made of twigs rammed with earth' (Figures 3.1, 3.2). As the ongoing construction work exposed further remains, Himsworth (1927-42, 15, underlining and strikethrough in the original) provided additional details:

March 26th. 1929. Much more has been done by clearing, which now exposed two post stumps. One split in two as though it had been riven by levering outwards when it was much longer. The loose stump was square. The split one in situ was roughly round. The two posts were eight 12 feet $[3.66 \mathrm{~m}]$ apart. One of the posts taken out of position was apparently adze dressed at the bottom (see also Figure 2.16).

How to cite this book chapter:

Moreland, J. and Hadley, D. (with A. Tuck and M. Rajic). 2020. Sheffield Castle: archaeology, archives, regeneration, 1927-2018, pp. 69-103. York: White Rose University Press. DOI: https://doi.org/10.22599/SheffieldCastle.c. CC BY-NC 4.0, https://creativecommons.org/licenses/by-nc/4.0 
On $4^{\text {th }}$ April 1929, he recorded that he saw:

a number of spars varying from three to six feet long much splintered. They were blackened and watersoaked [?waterlogged]. One or two pieces spotted with bright blue mould, others crozzled [burnt/ blackened] by fire. Diameter mostly about $4 "$ to $6 "[c .10 \mathrm{~cm}-15 \mathrm{~cm}]$. All very splintry, split irregular shapes, but all with spring in the fibre when bent. All appeared to be of oak, and black right through.

Continuing this entry, Himsworth wrote that 'an excavator' who had originally uncovered these 'spars' 'said they were the first pieces to come to light before they found the two posts. He described them as being in a horizontal position between, and approximately level with, the posts.

As we established in the last chapter, while the Himsworth manuscript is not a diary in the sense of a contemporary, daily record of events, it was nevertheless constructed from such records, and so provides us with fairly immediate access to this potentially very important discovery. The photographs Himsworth took at the moment of discovery are even more immediate, and together they constitute powerful testimony of what he and Armstrong were in no doubt was 'the most important [Saxon remains] yet discovered locally' (Himsworth 1937, 5), constituting 'actual proof ... of the existence [on Castle Hill] of a pre-Conquest Saxon building of timber' (Armstrong 1930, 7). This building was aligned north-south, measured $23 \mathrm{ft}(7.01 \mathrm{~m})$ in length, and comprised two complete bays, and part of a third. It was constructed of 'massive crutches, or "crucks" of oak', of which the lower portion of two -13 in by 14 in $(33 \mathrm{~cm} \times 36 \mathrm{~cm})$ and 12 in by 13 in $(30 \mathrm{~cm} \times 33 \mathrm{~cm})$, respectively remained in position, with traces of a third which had largely been destroyed by an 18th-century building (perhaps the Georgian 'scale-cutting [part of the process of making bone knife handles] establishment' Armstrong $(1930,14)$ refers to as having been built on this part of the site). The principal timbers, which Armstrong (1930, 22 ) thought had been shaped with an axe, were spaced at $9 \mathrm{ft}(2.74 \mathrm{~m})$ intervals and set in postholes $1-1 \frac{1}{2} \mathrm{ft}$ $(0.30-0.46 \mathrm{~m})$ deep with a padstone at the base.
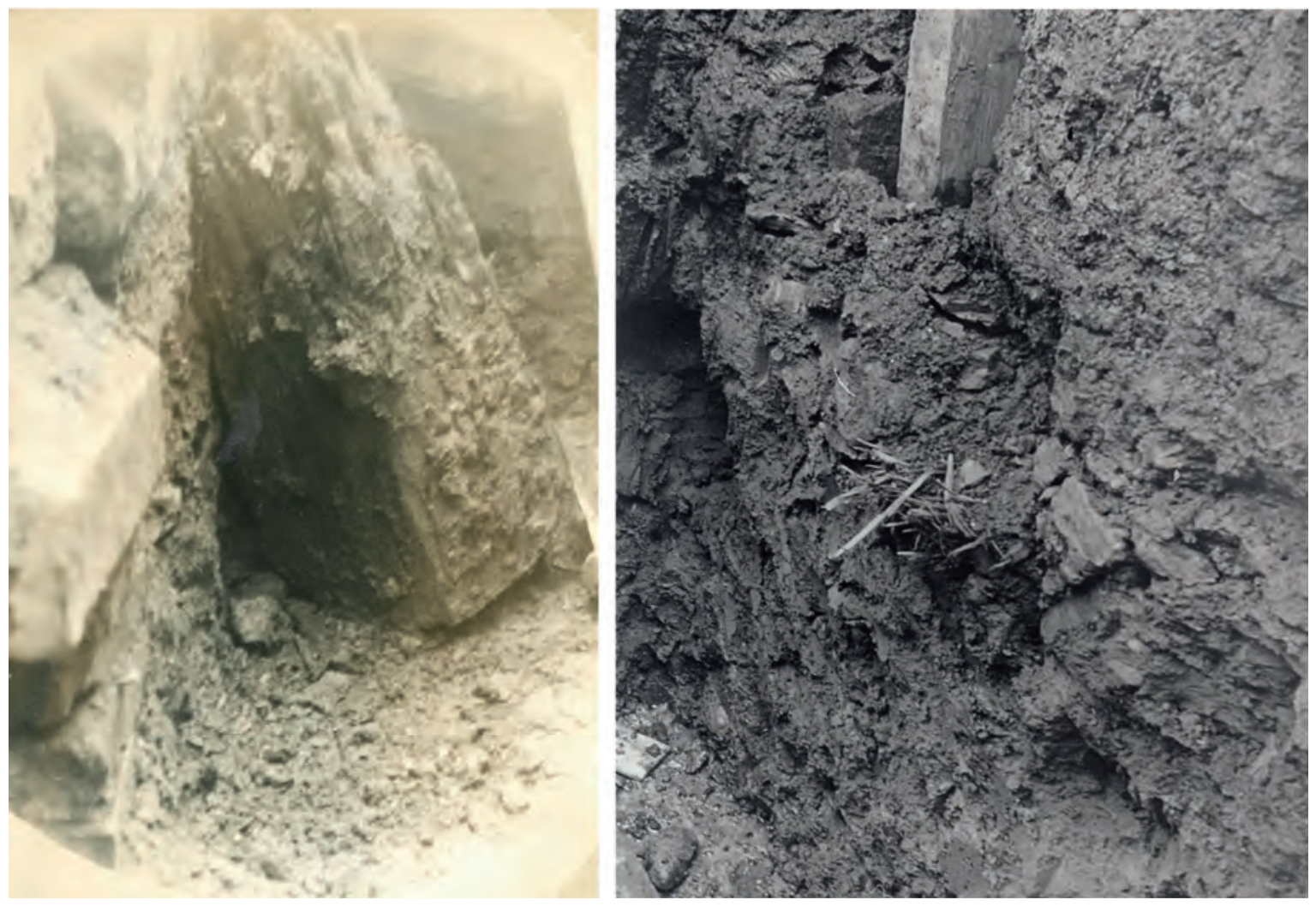

Figure 3.1: Remains of the putative 'Saxon' building. Joseph Himsworth's photographs show (left) a post he described in his diary as 'adze dressed at the bottom' and (right) the floor of the building (see also Figure 2.16). Courtesy of Museums Sheffield. 


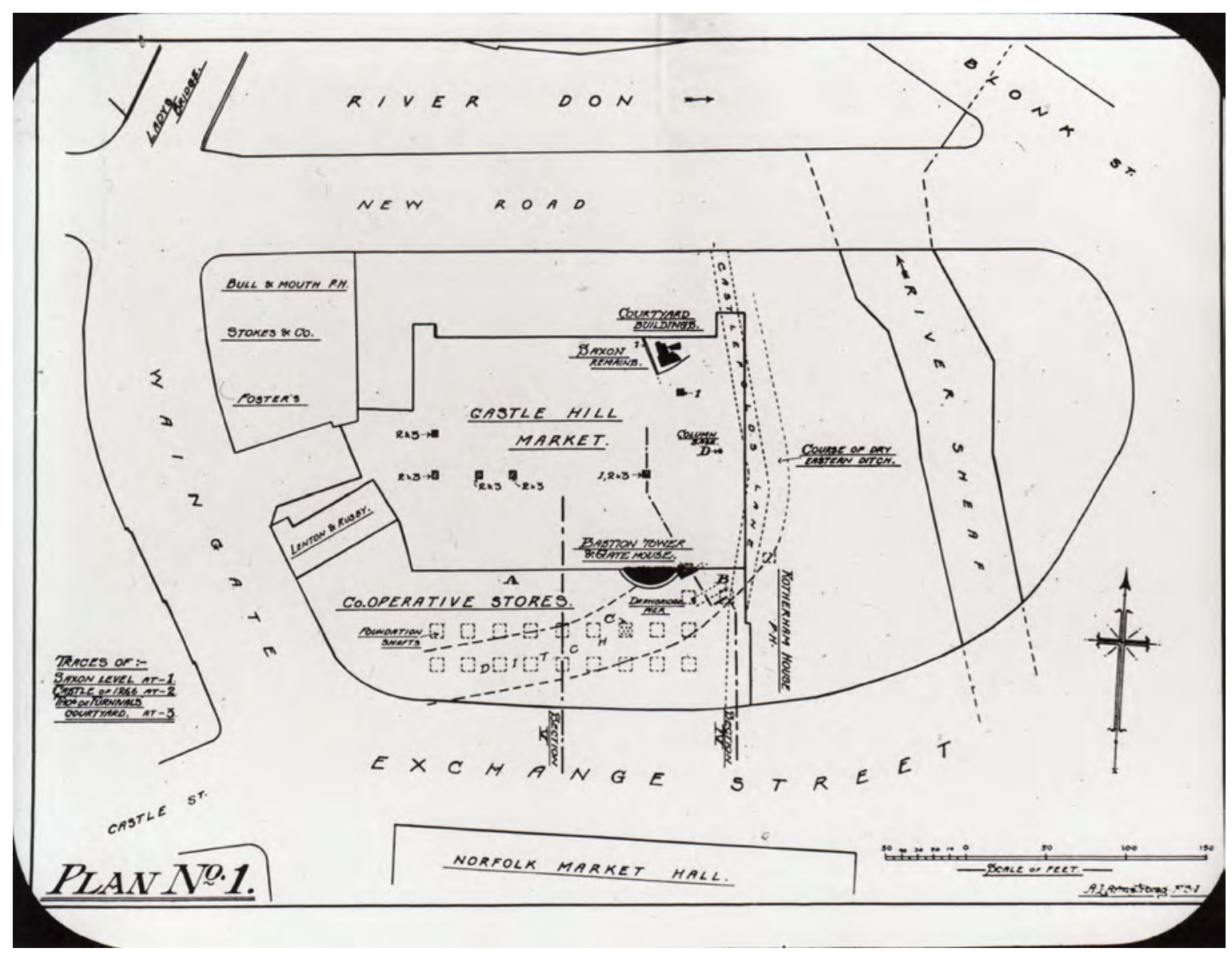

Figure 3.2: Plan 1 from Armstrong's 1930 paper on Sheffield Castle. The locations of the archaeological remains he recorded are plotted in the context of new developments on the site. Hunter Archaeological Society.

Running between the surviving oak posts was an oak sill beam 9in $(23 \mathrm{~cm})$ square, to the west of which were floor levels consisting of a layer of earth and clay $2-3$ in $(5-8 \mathrm{~cm})$ thick. Immediately below this deposit were wattle hurdles of birch and hazel, placed on a 6-9in $(15-23 \mathrm{~cm})$ layer of hard packed clay 'very black and tenacious' (Armstrong 1930, 22). The wattle was interpreted as reinforcement for the floor, as the branches were laid at right angles to the sill beam and partially overlapped it, and were overlain by a surface of padded earth and clay (Armstrong 1930, 22-3, plate V; 1927-28, 6; Figure 3.3). Efforts were made to save the remaining traces of this timber structure, and Himsworth's diary entry for $12^{\text {th }}$ August 1929 reports that the Clerk of Works, Loughran, 'showed me how they had preserved the Saxon floor [and] the posts ... in situ, by making a basement' (Himsworth 1927-42, 15; also 1935, 9; 1937, 5; 1944, 6). These remains survive, albeit in an 'advanced state of decay' and, while they have seen subsequent recording (e.g. Latham and Atkinson 1994, 10; Richardson and Dennison 2014a, 65; Anon. 1987), they have not been subject to modern scientific analysis (e.g. dendrochronological dating). Since the chamber in which they are housed is currently inaccessible to researchers, and our analysis of the archive suggests that none of the timbers curated by Museums Sheffield derives from this building (Mepham 2017), interpretations of this putative Anglo-Saxon phase must rest entirely on the written accounts and photographs of the excavations.

Armstrong $(1930,22)$ felt that this timber structure was 'essentially Saxon' (being 'far too primitive to have been erected by the first Norman Lords of Hallamshire'; Armstrong 1929c), and that stratigraphic evidence demonstrated that it predated buildings constructed, he believed, in the 12th and 13th centuries. As we noted earlier, Himsworth $(1927-42,15)$ refers to evidence for burning on the timbers, while Armstrong $(1930,22-3)$ argued that the presence of charcoal and wood ashes over the 'floor' surface confirmed that the Anglo-Saxon structure had been destroyed by fire, 'probably' when William the Conqueror 'ravaged the north in 1069' 

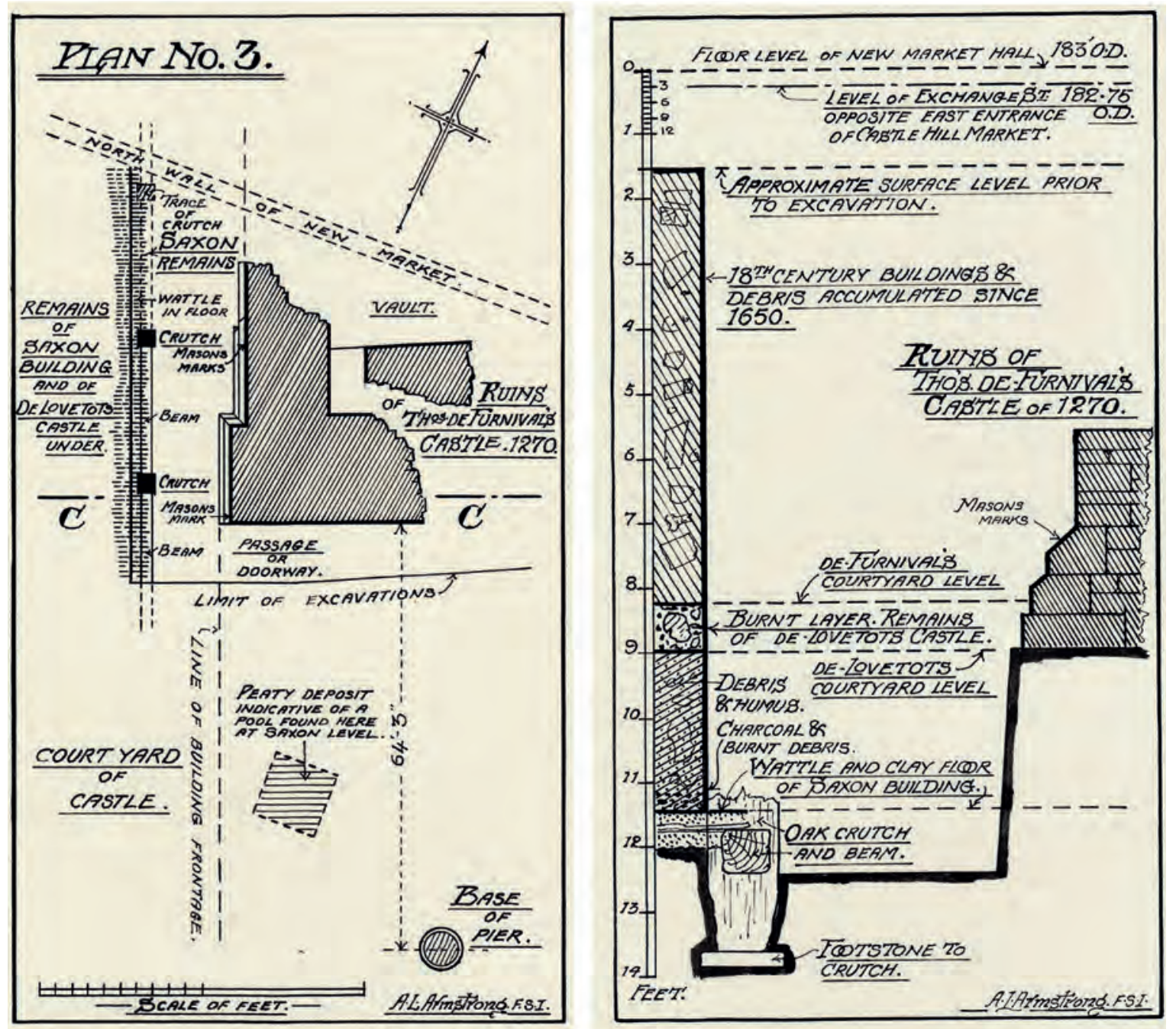

Figure 3.3: Plan 3 and Plate V from Armstrong's 1930 paper on Sheffield Castle. This shows the locations of the buildings encountered in the courtyard of the castle (left), and a schematic section drawing (right). Hunter Archaeological Society.

(although there is no evidence that William actually visited Sheffield). Armstrong $(1930,23)$ claimed to have found other features belonging to this 'Saxon' phase. For example, $50 \mathrm{ft}(15.24 \mathrm{~m})$ south of the 'cruck-built' timber structure was a band of black earth and clay, which he interpreted as part of the floor ('but without the wattle reinforcement') of a building aligned north-south of 'large size with a wide roof span'. Located $16 \mathrm{ft}(4.88 \mathrm{~m})$ south and $12 \mathrm{ft}(3.66 \mathrm{~m})$ east of this putative building was an area of peaty material enclosing 'remains of reeds ... kitchen refuse, including bones of deer, ox and pig, and indicating the presence there of a shallow pool of water' (Armstrong 1930, 23); it is labelled on Armstrong's plan 3 as being 'AT SAXON LEVEL' (Figure 3.3).

Armstrong also argued that the moat 'considerably' predated the castle and could belong to this Anglo-Saxon phase. This conclusion was based on the fact that 'the castle wall ... was not parallel with the ditch' ('Had it been dug by the twelfth century builders or by Thomas de Furnival, surely this would not have been the case'), and on 'other significant factors' (Armstrong 1930, 16, 23; 1928b, 366). These included three rows of 'riven oak piles', 5 in $(13 \mathrm{~cm})$ square and $5-6 \mathrm{ft}(1.52-1.83 \mathrm{~m})$ long with sharpened ends, driven into the bottom of the moat near the west 'bastion' tower of the gatehouse (Armstrong 1930, 19, 23; marked C on plan 1 (Figure 3.2); Armstrong 1929b). Himsworth documents their discovery in late 1927. On $25^{\text {th }}$ November he recorded 'Two wooden props or stakes in middle of moat photographed' and provides two images of them emerging from 
the mud (one clearly at an angle), and on $9^{\text {th }}$ December reported that 'A.L.A. showed me two oak stakes about $5 \frac{1}{2}$ ' long. Sharp at both ends which had come out of the moat. And which had been fixed pointing outward' (Himsworth 1927-42, 2; Figure 3.4). The significance of these stakes lies in Armstrong's (1930, 12, 16, 22-4) belief that, with the supposed early enclosure ditch, reinforced by 'a stockade on the inner side', they constituted the defences around 'an important Saxon homestead', which was situated at a strategic location, 'the best in the district', where 'precipitous slopes' fell away northwards towards the River Don and eastwards towards the Sheaf. In a lecture delivered in 1937, Himsworth $(1937,5)$ tried to conjure up for his audience a 'mental picture' of this stockaded settlement: the building's timbers 'covered with skins to give some security from fire. It is likely the structure would be on a mound which would have its height increased artificially by throwing up soil and stone. In digging a trench would be made on two sides, the rivers Don and Sheaf protecting it on the other'. Yet, while Himsworth and Armstrong differed on whether there was an encircling moat in this early phase, they agreed that this was one of the most, if not the most, important of the discoveries made on Castle Hill in their time (Armstrong 1929c).

There are, however, very significant problems with the identification of an Anglo-Saxon phase of occupation on the site of the castle, not least the fact that cruck buildings (so central to Armstrong's interpretation) are now generally thought to date from no earlier than the 13th century (Gardiner 2012, 232; Grenville 1997, 59; McCoy and Stenton 2009, 6). Moreover, since Armstrong $(1930,22)$ recorded that the posts had been cut down to almost ground level when the building was destroyed, it is hard to know how he so confidently reconstructed the superstructure. The presence of padstones in the postholes opens up at least two possibilities for the form of the building. Cruck-framed buildings of c.1200-1350 see the weight of the roof carried to the ground through curved crucks sat on padstones, while timber buildings of the 11th to 13th centuries, characterised by jointed
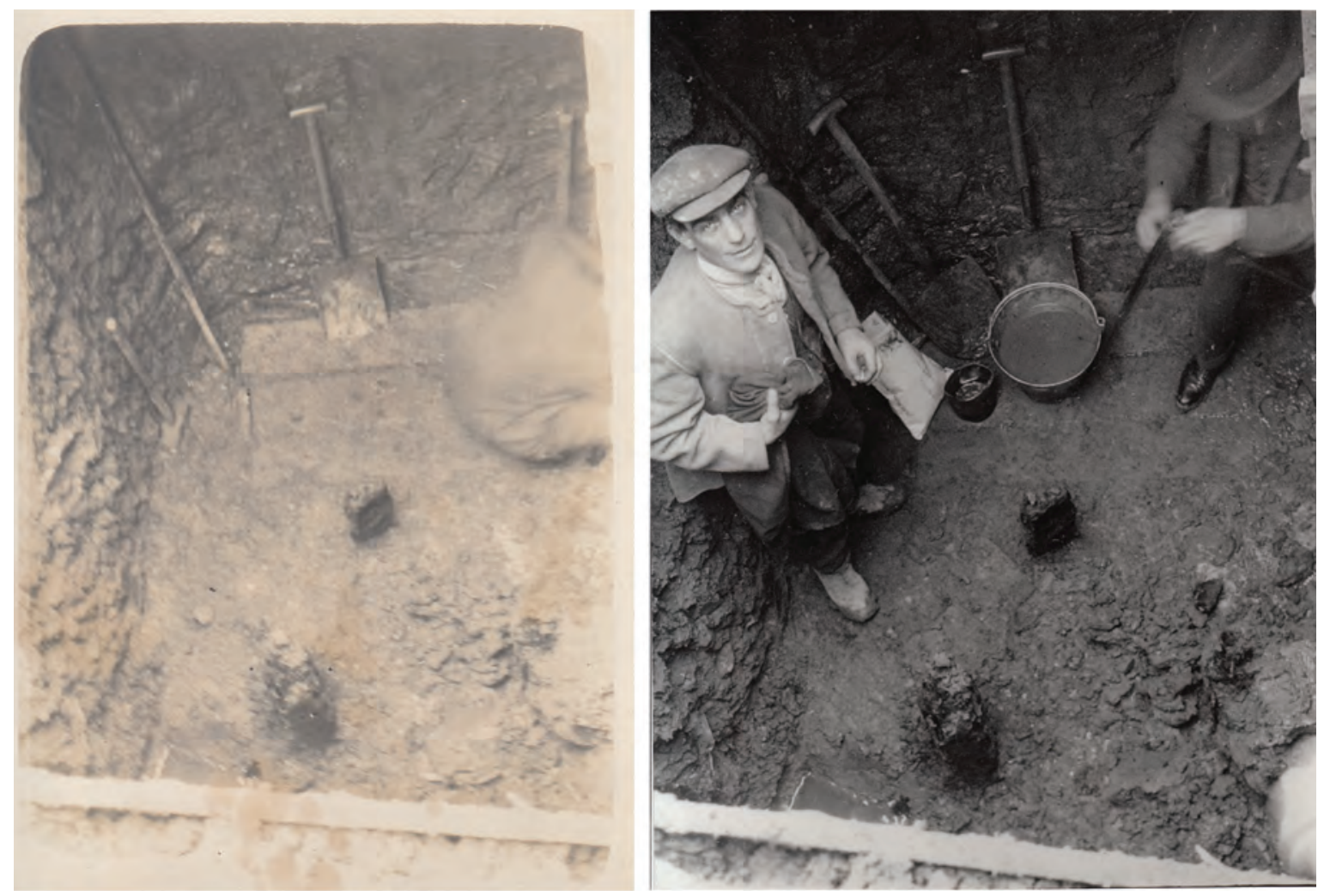

Figure 3.4: Oak stakes in the moat near the west tower of the gatehouse. They were believed by Armstrong and Himsworth to be part of the Saxon defences. The photograph on the left, dated $25^{\text {th }}$ November 1927, is labelled (in pencil, on the back) 'ALA [Armstrong] grubbing in the moat', and was reproduced in Himsworth's diary. The right-hand photograph shows Armstrong, at the rear, setting up the camera, with one of the workmen in December 1927. Courtesy of Museums Sheffield. 
timbers in their superstructure, typically had earthfast foundations, with their principal posts set directly into the ground often on padstones to prevent them from rotting (Grenville 1997, 30-7; for distinctly Anglo-Saxon building traditions, see Gardiner 2012; Blair 2018, 51-60, 71). Richardson and Dennison (2014a, 85) have pointed out that the building recorded by Armstrong and Himsworth is on the same alignment as the 13thcentury stone buildings located just $1.5 \mathrm{~m}$ to the east, and suggest that, rather than the free-standing hall that Armstrong $(1930,23)$ proposed, it may have been a pentice-like construction built up against these structures (also below, Section: Courtyard buildings; as we will see in Chapter 7, evidence from the most recent excavations supports a 13th-century date for these wooden buildings). Armstrong's (1930, 22) capacity to interpret what was uncovered may also have been hampered by wattlework being taken away by 'souvenir hunters', one of several examples of the removal of material from the site of the castle during construction work (Himsworth 1927-42, 3, 9, 11; 1944, 21; also Chapter 2, Section: Joseph Beeston Himsworth: cutler and artist).

Armstrong $(1930,23-4)$ claimed to have recovered Anglo-Saxon pottery from the lowest fills of the south moat, which, if correct, would have reinforced his argument for an early phase of occupation. However, it is notable that he $(1927-28,2)$ initially dated this pottery to the 14 th or 15th century in his site diary $\left(27^{\text {th }}\right.$ October 1927), to between the 12th and 17th centuries in his interim report for the Society of Antiquaries (1928b, 366), and made no reference to Anglo-Saxon pottery in any of the early newspaper articles to which he contributed information. On $20^{\text {th }}$ December 1928 he called Himsworth to tell him that in one of the recently excavated foundation pits he had just recorded 'nine "occupation levels" in ten feet', adding that 'the lowest level would be the stone castle period' (Himsworth 1927-42, 14). It would seem that, at this point, he had no expectation of finding pre-Norman phases. In a diary entry for $18^{\text {th }}$ November 1927 it is, in fact, Himsworth who first refers to 'Saxon, Norman and Elizabethan pottery' (Himsworth 1927-42, 1, emphasis added). We are not to know whether Armstrong was influenced by his 'assistant', but no such pottery was identified during our analysis of his archive, nor among any of the other pottery assemblages recovered during later excavations on the site (see Chapters 6 and 7), and it seems certain that he was mistaken. In short, Armstrong and Himsworth did not find any 'independent' evidence for Anglo-Saxon activity on the site of Sheffield Castle, and the timber structure they documented was probably considerably later in date than they suggested.

That they were keen to find an Anglo-Saxon presence might be deduced from amendments to Himsworth's descriptions of what he observed. In his handwritten diary, Himsworth (1927-30, 8) records the discovery on $26^{\text {th }}$ March 1929 of two posts which were ' 8 feet apart', but in his typescript he $(1927-42,15)$ amended this entry in black ink: 'two posts ... eight 12 feet $[3.66 \mathrm{~m}]$ apart' were found, after further 'clearing' on the site. The typescript record for $9^{\text {th }}$ September 1929 tells us that he photographed the demolished remains of the slaughterhouses which had lined the south bank of the River Don. Among the remains were a number of oak beams ' 12 to 16 feet long X 15" X 9". Some appeared to have been in a severe fire' (Himsworth 1927-42, 16; Figure 3.5). A handwritten amendment to this entry by Himsworth, in the same ink used to amend the $26^{\text {th }}$ March entry, points out that:

The span between the centres of the two crutch butts of the Saxon building foundation was 12 feet. Whether these beams date from Saxon times their size leads one to think them too large to have been made for slaughter house construction.

Did Himsworth 'amend' the typescript entry for $26^{\text {th }}$ March to fit the dimensions of these oak beams? It is striking that he also implies that the beams were reused in (i.e. not made for) the slaughterhouses, and that some were fire-damaged, thereby creating a connection with the 'Saxon' building uncovered earlier in 1929, and supposedly destroyed by fire during William the Conqueror's 'harrying of the North. ${ }^{13}$ We suggest that Armstrong and Himsworth's interest in finding a Saxon presence on the site of Sheffield Castle derived from long-standing, and ongoing, debates about the origins of Sheffield, and tells us much about the way archaeology was used to write history in the early part of the 20th century.

Much of this debate was based on the statement in Domesday Book that Earl Waltheof had an aula, a hall or court, in Hallam (Hunter 1819, 17; Faull and Stinson 1986, fol. 320a; Chapter 1, Section: Elusive

\footnotetext{
${ }^{13}$ If the beams had indeed been part of the castle, one wonders where they had been in the 150 years between its slighting and the construction of the slaughterhouses at the end of the 18th century, and why they had not been appropriated by the good people of Sheffield, as had been the case with much of the rest of the fabric of the castle (see also Chapter 9).
} 


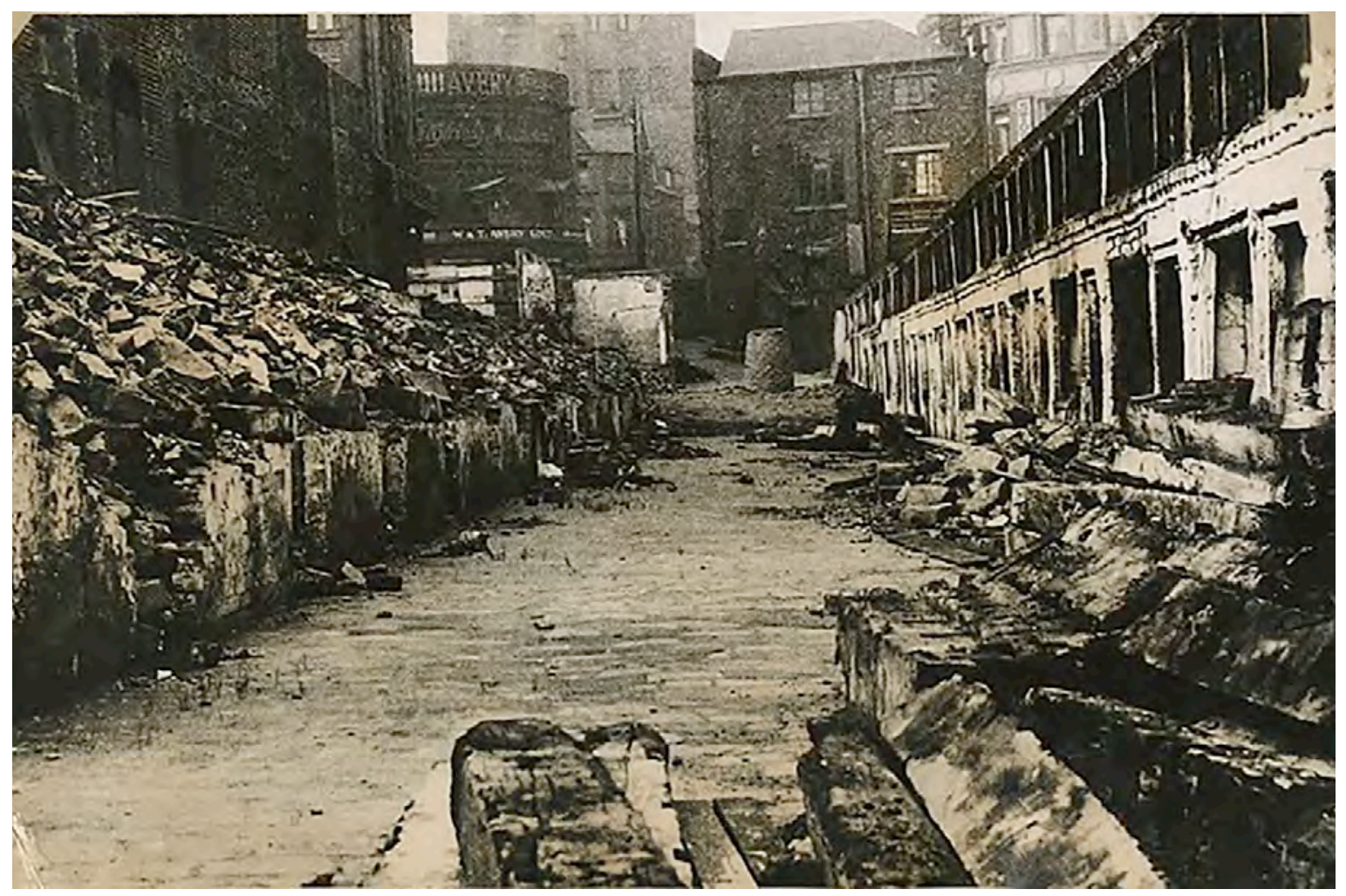

Figure 3.5: Demolition of the slaughterhouses along the bank of the Don. A photograph from the diary of Joseph Himsworth. Their removal allowed him to record the north side of the site. At the bottom right are the timbers that Himsworth believed had been reused from the castle. Courtesy of Museums Sheffield.

antecedents). He was 'the last Anglo-Saxon lord of Hallamshire' (Hey 2010, 14; Hunter 1819, 22), and the 'ubiquitous Waltheof' (Leader 1910,25) and the location of his aula were among the 'hot topics' of late 19thand early 20th-century scholarship in Sheffield - and sold books. Local historian Sidney Addy (1893) had called his collection of essays The Hall of Waltheof even though that subject occupied only six of its 295 pages. In January 1923, Walter Hall (1923) wrote to the Sheffield Daily Telegraph to argue that the recent discovery of a deed, dated November 1562, for Stumperlowe Grange Farm (c.5km to the south-west of the city centre), in which it is described as within the 'precyncte' of Hallam, meant that the aula of Waltheof was situated somewhere on the hillside 'along the crest of which runs the Redmires Road ... and at the foot of which is the river Porter in Whitely Woods' (also Scurfield 1986, 165). Thomas Winder (1923) concluded that 'it is at Burnt Stones [c.5km to the west of the city centre] [that] we should dig for the ashes of the aula'. Studies by other local antiquarians allowed them to locate Waltheof's aula at various places in the district, including at Wincobank hill fort (6km north-east of Sheffield city centre), or close to the ancient church at Ecclesfield (8.5km to the north of the city centre; A. S. M. 1927; Gatty 1927; F. C. 1927). Significantly, this flurry of letters to the Sheffield Daily Telegraph were all written before the excavations began - and so demonstrate a deepseated concern with this issue.

However, like John Leader (1897, ix, xx), most antiquarians believed that 'Waltheof's hall stood on the site in Sheffield now known as Castle Hill', thereby providing 'Sheffield' with pre-Norman, Saxon, origins. In an essay on Sheffield Castle on which he was working 'almost up to the time of his death' on $4^{\text {th }}$ January 1929 , Charles Drury $(1929 b, 177)$ elaborated on the argument for continuity - 'when an important building has been erected or superseded by a stronger one, the site of the previous building has generally been used for the purpose. On this basis, he proposed not only that 'the Hall of Waltheof stood on the same hill as that castle which held for so long as prisoner the hapless Queen of Scots', but also that it might have continued in existence to become part of the castle built by the first of the de Lovetots (Drury 1929b, 178-9; and below, Section: Discussion). Armstrong (n.d. (b), 4), too, was 'inclined to think' that the first de Lovetot 'found one [a castle] already existing' on the 
site. The prevailing view was perhaps put most succinctly by the Rev. W. H. Small, who told the audience at his lecture in Walkley Wesleyan Church in February 1922 that 'Waltheof, the last of the Saxon earls, lived in a house on Castle Hill' ('Old Sheffield', 1922).

Drury $(1929 b, 192)$ had intended to include some account of the ongoing work on the site in his Sheffield Castle paper, but died before the 'most important find' was made. Equally, Armstrong knew of Drury's draft paper, for he wrote to Drury's widow requesting to read it. She replied asking Armstrong if he would finish the paper, stating that 'I am quite sure [Charles] would rather you did it than anyone else' (Bateman Drury 1929). Armstrong undertook the task, and at the end of his short addition to Drury's essay cited the discovery on the castle site, in February 1929, ${ }^{14}$ of 'extensive traces', including the floor and the outer wall, of a timber building of 'typical Saxon construction', finishing with the assertion that this find confirmed 'Mr Drury's opinions ... respecting the coincidence of the Castle site with that of the Hall of Waltheof (Armstrong in Drury 1929b, 193, emphasis added).

It is likely, therefore, that local antiquarian as well as public opinion strongly predisposed Armstrong and Himsworth to the likelihood of Saxon material on Castle Hill - and not just any Saxon material but the hall, the palace, of 'the last Anglo-Saxon lord of Hallamshire' (Hey 2010, 14). Even before the first traces of the hoped-for 'Saxon' phase were unearthed early in 1929, Armstrong was talking publicly about the possibility of finding it. In his lecture to the Hunter Archaeological Society on $11^{\text {th }}$ December 1928 Armstrong speculated about 'the first occupation of the site and the possibility of Waltheof's Aula being there' (Himsworth 1927-42, 12; also 'Sheffield Castle', 1928). In a set of handwritten notes he makes this clear (Armstrong n.d. (b), 3) - 'for me', he originally said, 'Castle Hill is the site of the Hall of Waltheof \& the excavations now in progress have already revealed evidences which go far to establish that assumption'. Even though he then allowed a sliver of uncertainty to enter the argument by inserting 'most probable' before 'site', there can be no doubt about what he really thought - or wanted (see also Armstrong 1929c).

This was a city where antiquarians regularly bemoaned the sacrifice of antiquity and beauty to industry and material gain, and lamented the absence of objects of archaeological interest. For example, in 1903 Robert Leader $(1904 \mathrm{a}, 1,13)$ told the visiting delegates of the British Archaeological Association that the oldest surviving feature 'after our rivers, is probably that "goit" or mill race', which had once fed the lord of the manor's mill but was 'now relegated to the status of a sewer'. In this context, finding the aula of Waltheof would be a major discovery and a significant boost to local pride (see Andrews 2015, 6-7 for the ARCUS excavation of that 'goit'). As David Clarke (forthcoming) has recently argued, 'the destruction of the hall of Waltheof is a key foundation story in the folklore of Hallamshire'. Armstrong and Himsworth needed to find this hall, and find it they did!

Even before the discoveries of 1929, the name of Waltheof was attached to the 'civic' story. On $5^{\text {th }}$ April 1911 the Cutler's Hall hosted the 'consecration' of a new Masonic Lodge, tellingly called the Waltheof Lodge ('New Masonic Lodge', 1911). A letter-writer to the Sheffield Daily Telegraph adopted the pen name 'Waltheof' (1912a; 1912b), perhaps to lend authority to his pronouncements on, for example, the real presence of Christ at the Eucharist. A report in the same paper on $27^{\text {th }}$ June 1924 was the first of several in which the aula of Waltheof (as well as the man himself, and his wife Judith) was presented, in pageant form, as one of the seminal scenes, 'real happenings in the course of Sheffield's origin and growth' ('Sheffield's History', 1924). Waltheof reappeared in pageants in June 1929 and June 1931, the latter in the 'yard' of Sheffield Cathedral in a spectacle which, it was hoped, would have a 'popular appeal to citizens' ('Sheffield of long ago', 1929; 'Sheffield down the ages', 1929; 'The history of Sheffield in pageant', 1931; 'Sheffield Pageant', 1931; Figure 3.6). In 1926, one of the roads in the newly constructed Manor Estate in the former deer park was named after him, though at least one Sheffield Daily Telegraph reader, F. W. Boland, who was estate clerk to the Duke of Norfolk, had to be reminded about how 'their high mightinesses at the Town Hall' had 'evolved such street names' (Boland 1926; with a reply from Ward 1926; see also Odom 1927, 9; and Chapter 9).

For some, this interest in Waltheof was tinged with ethnic or even racial overtones. Belief in what Christopher Hill $(1958,52)$ called 'the Norman Yoke' seems to have persisted in the region in the early 20th century and may have informed the 'Waltheof debate. This was the assumption that before 1066 'the Anglo-Saxon inhabitants of this country [England] lived as free and equal citizens, governing themselves through representative

${ }^{14}$ Note that in his diary Himsworth said that this discovery was made towards the end of March 1929 (see above), which is likely to be true as the first newspaper reports began to appear at that time ('Saxon or Norman?', 1929; 'Current topics', 1929; see also Armstrong's (1929c) own contribution). 


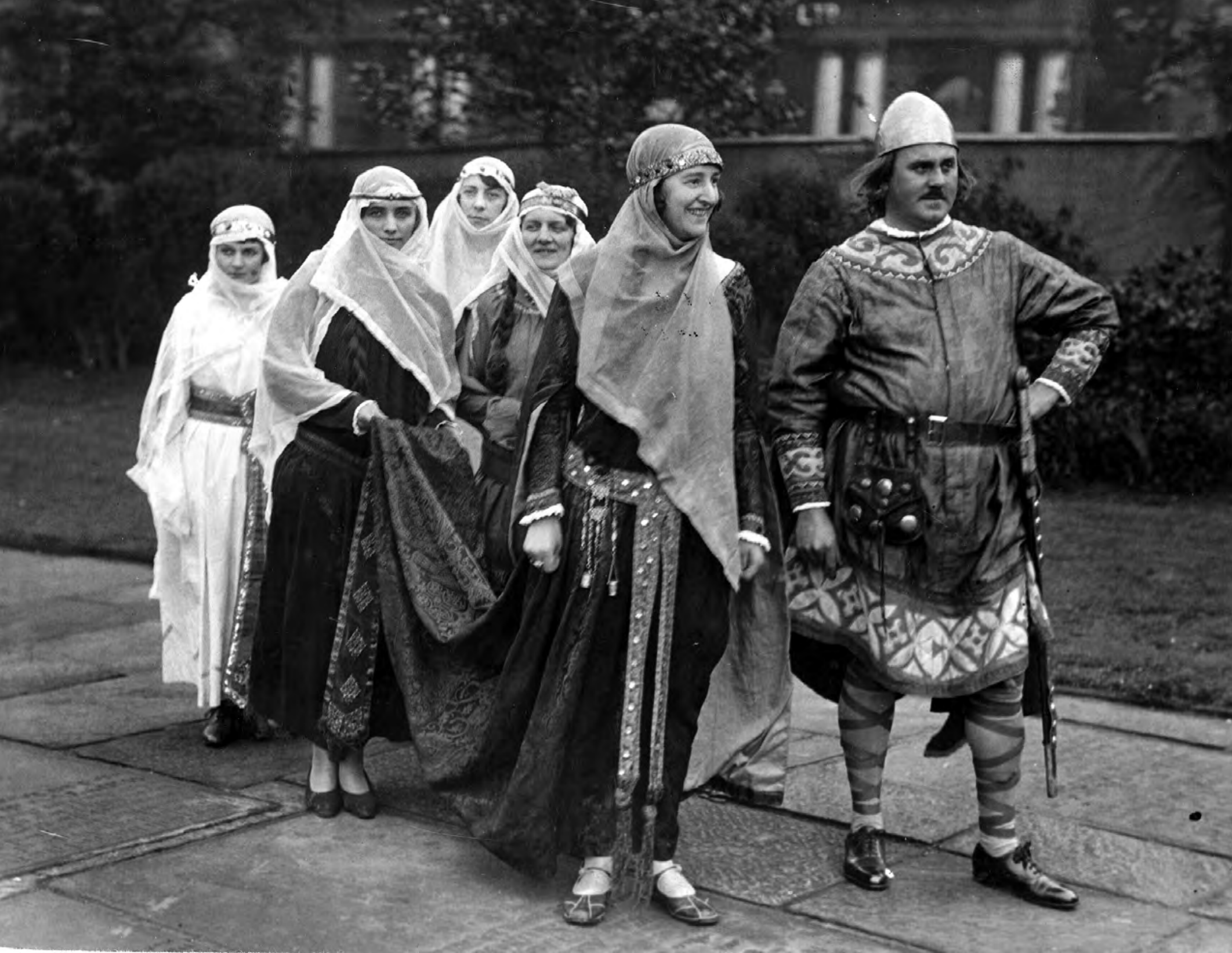

Figure 3.6: Earl Waltheof and his wife Judith attended by Saxon and Norman ladies at the Sheffield Pageant in June 1931. This tableau was set in the year 1075 ('The history of Sheffield in pageant', 1931). Waltheof first appeared in the pageant of 1924, with an array of other historical figures. This pageant was held in the grounds of Rye Lodge, Ashland Road, and 'The story was depicted in six scenes, embracing AD 214, "The Vale of the Rivelin"; 1075, "The Aula of Waltheof, Lord of Hallam"; 1199, "A Glade in Sherwood Forest", "A Room in the First Sheffield Castle" and "Wedding Tableau of Maud de Lovetot and Gerard de Furnival"; 1287, "Sembly Green"; 1530, "The Grounds of Sheffield Manor" and "Wedding Tableau of the Earl of Shrewsbury and Lady Saint Loe", "A Room in Sheffield Castle" and "The Shrewsbury Room in the Turret House". With thanks to www.picturesheffield.com (s03100).

institutions. The Norman Conquest deprived them of this liberty and established the tyranny of an alien King and landlords' (see also Simmons 1990). We hear echoes of it in Robert Leader's (1904a, 7) address to the British Archaeological Association in Sheffield Town Hall on the evening of $10^{\text {th }}$ August 1903, which told delegates that, 'when the Norman invasion burst upon the land', the people of the district, 'benefiting by their seclusion', had been enjoying 'a fair measure of peace and prosperity'. Canon W. Odom $(1927,6)$ is, characteristically, more direct. Earl Waltheof, he writes, having pledged allegiance to William the Conqueror, in the end rebelled, 'his proud spirit ... could not long endure submission to the Norman Yoke'. And finally, even closer to home, Armstrong (n.d. (b), 3), closely echoing the words of Joseph Hunter $(1819,22)$ a century earlier, argued 
that 'Waltheof was a man of outstanding eminence amongst the Saxons \& it is hardly to be expected that he could for long quietly submit to the Norman Yoke'.

Further, in most accounts, emphasis is placed on Waltheof's 'ethnicity' and on the fact that he is the end of a 'line, 'the last Earl of purely English blood, tall, and of more than ordinary strength, matchless as a warrior' (Odom 1927, 4; 1911; also Small 1922; Hall 1923). Himsworth (1937, 5) and Armstrong (n.d. (c), 3) too refer to him, respectively, as the 'last of the Saxon earls' and 'so great a Saxon earl'. For many in the district, the discoveries on Castle Hill meant that Sheffield's origins could now be traced back to the timber 'hall' of this last English or Saxon earl, rather than to the stone castle, and associated planned settlement, of the (foreign, French) Norman conqueror. In this context, the proof of Sheffield's Saxon origins would have contributed to national, English identity as well as to civic pride.

\section{The ashes of 1266 ?}

If we can dismiss the argument that Armstrong and Himsworth uncovered an Anglo-Saxon phase on Castle Hill, what then of the proposition that they found 'traces ... of the De Lovetots' castle' (Armstrong 1930, 10, 21-2)? Although his 1930 paper did not discuss the written sources behind this supposition, his manuscript notes reveal his familiarity with the textual evidence for a castle in Sheffield by the late 12th century, and also with the local tradition that it was built earlier in that century by the first de Lovetot lord, William (Armstrong n.d. (b) and (c); see also Chapter 1). Armstrong $(1930,21)$ deduced that, after the destruction of the alleged Anglo-Saxon settlement, the site lay abandoned 'for a considerable period', leading to a build-up of nearly $2 \mathrm{ft}$ $(0.6 \mathrm{~m})$ of 'debris and humus'; activity post-dating this he placed in the 12th century and later. However, as we have seen, the timber building he found is not of Anglo-Saxon date, and, as McCoy and Stenton $(2009,8)$ have argued, the 'debris and humus' may represent not abandonment but the deliberate levelling-up of the ground surface prior to the redevelopment of the site. As we will see in the course of this volume (and especially in Chapter 7), this levelling-up was a fairly constant process across the history of the site and had a significant impact on both the topography of the hill and the character and preservation of the archaeology. ${ }^{15}$

Above this layer, Armstrong claimed to have identified traces of the destruction of the de Lovetot castle in the late 13th century, annotated on his published section drawing as 'BURNT LAYER. REMAINS OF DE LOVETOTS CASTLE' (Armstrong 1930, 12, plate V; Figure 3.3). Destruction layers, 4-8in (10-20 cm) thick, comprising 'charcoal and wood ash combined in places with calcined rubble and fragments of dressed masonry displaying damage by fire', were found 'at various points' on the site. Beneath the courtyard buildings he recorded 'a layer, from 9 to 12 inches in thickness, of ashes and burnt stones' stratigraphically located above the remains of the supposed Saxon building (Armstrong 1930, 7, 21; 1928, 365). Armstrong (1929c) elaborated in a newspaper report in late March 1929, describing this deposit more vividly as 'a layer six inches to 12 inches thick of red ash, containing an abundance of charcoal and fragments of stone crackled and burnt to a deep red tint by the action of fire. He also describes a stone of 'typical "axed" masonry of early Norman character, which once formed part of a window' and uses this as further evidence for the discovery of the destroyed de Lovetot castle. Himsworth's (1930g) sketch of the section he saw above the River Don in 1930 also records this burnt layer. At one location he labels a layer as 'red ash 8" thick', which is above a '9" black occupation level', west of a layer of 'red ash 12" to 8 " thick'. In an inked-up version of this sketch in his typed diary, these burnt layers have become, simply, 'Ashes 1266' (Himsworth 1927-42, fig. 47; Figure 3.7), and his script for a lecture given in 1944 notes that the section he saw in 1930 had 'revealed red ash of 1266 fire destruction' (Himsworth 1944, 5). Rather like the case for the aula of Waltheof, the evidence for the de Lovetot castle grew in the retelling - but that evidence consists entirely of the burnt layer.

This burnt layer was below the remains of what Armstrong (1928b, 365) assumed to be the "historic castle built by Thomas de Furnival in 1270', and it is quite clearly a text-based assumption that it dates to 1266 . Armstrong and Himsworth had no independent means of dating the burnt layer to the mid-13th century, never mind to a precise year. Although Armstrong had little to say about his reasoning, he was well aware that in 1266 'Johane D'eyvill cum equiis et armis' burnt 'Saffield' during the Barons' War, in which Simon de Montfort led a

${ }^{15}$ As we saw in Chapter 2, Wigfull $(1916,239)$ regretted the decision to abandon a proposal to cut a road through the site. It was replaced with a scheme that 'involves a raising of the site rather than an excavation, and so what remains of the Castle will be placed still further below the surface, [and] it may be for future generations of archaeologists to discover and explore'. 

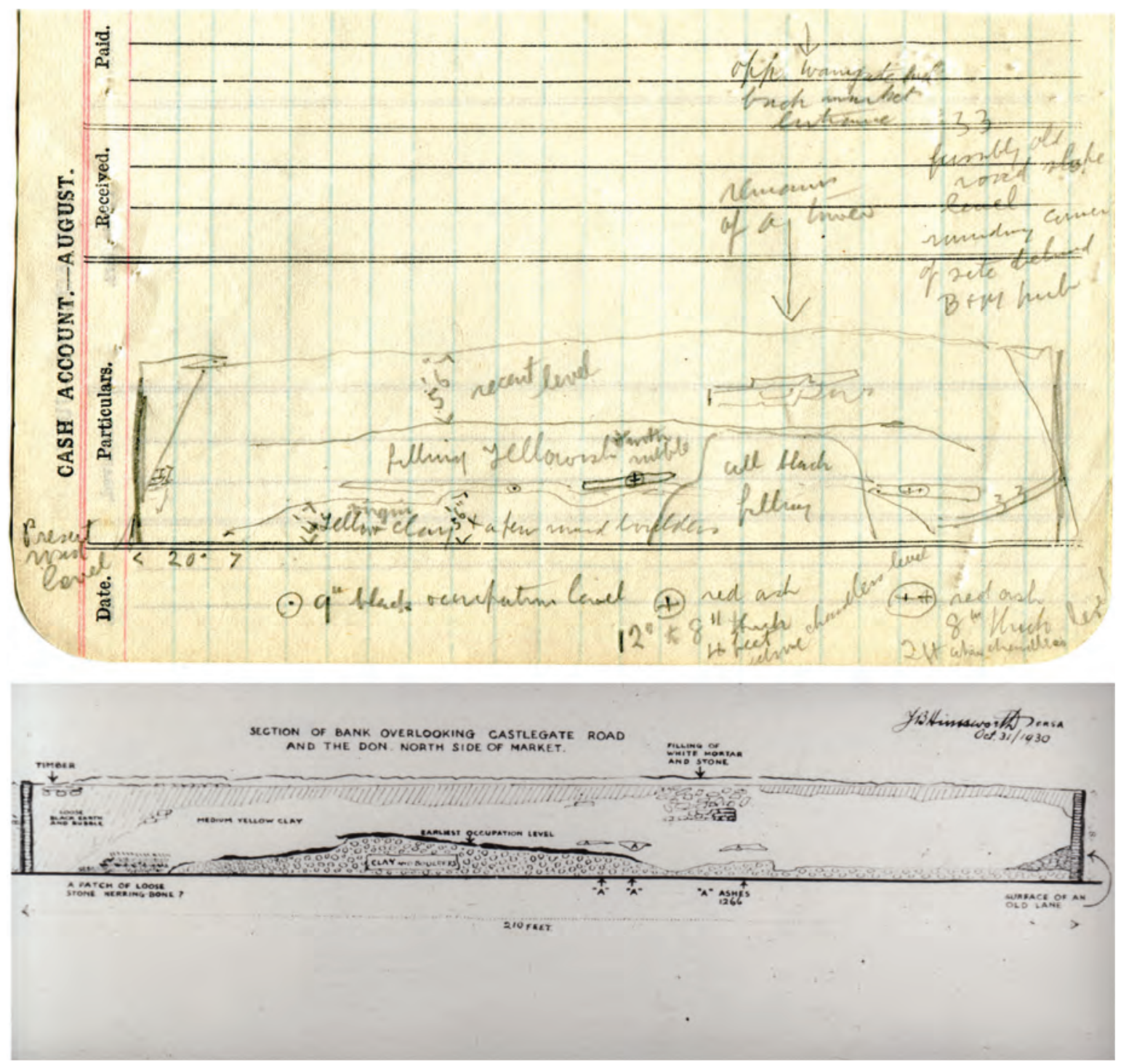

Figure 3.7: The north bank of the site overlooking the Don. Sketch section by Joseph Himsworth found with the original handwritten diary (top). Courtesy of Pat Wagner. The typed copy of the diary contains this inked-up version of the drawing (bottom). Courtesy of Museums Sheffield.

revolt against Henry III (Armstrong 1930, 7, 10). This must be the basis for his statement that the de Furnivals resisted the barons resulting in 'the stronghold itself and the town which looked to it for protection, being alike consumed by fire' (Armstrong 1930, 7). Certainly, in 1270, the second Thomas de Furnival received a licence to 'build a stone castle and fortify and crenellate it' at Sheffield, thought to be a reward for supporting Henry III in the Barons' War (Maddicott 1994; Hart 1989b, 3). However, the extent to which the 'earlier' castle had been damaged is unknown, as is the scale of any rebuilding undertaken as a result of the acquisition of a licence to crenellate (Guy 2005, 205). Further, more recent study has cautioned against interpreting licences to crenellate as secure evidence for the date at which building work was undertaken, with many being acquired long after construction had been completed, or even prior to work that was never undertaken (Coulson 1979; 1993; Creighton 2002, 67).

The interpretation of the burnt layer is problematic in various ways, and even a modern analysis failed to recover any dating evidence from it (Latham and Atkinson 1994, 10). The late 13th-century events do not offer the only context for the burning and rebuilding that Armstrong recorded. For example, a fire documented 
in the Pipe Rolls for 1184-85 saw $£ 66$ spent on rebuilding, although the extent of the damage and reconstruction is unclear (McCoy and Stenton 2009, 10). Referring to Himsworth's section and descriptions, Richardson and Dennison $(2014 a, 73)$ show that his 'Ashes 1266' layer was 3.64m beneath the layer Armstrong associated with the same event. Magnifying the uncertainties masked by an apparently definitive single year, McCoy and Stenton $(2009,11)$ suggest that the 'crozzled' cruck-built building which Armstrong took to be Anglo-Saxon was in fact 'a building that stood within the bailey of the first Sheffield Castle, and which may have been demolished after being damaged by the 1184-85 fire. In sum, the archaeological case for the de Lovetot castle is circumstantial, poorly explained in the 1930 paper and driven by the written sources, which were alluded to rather than fully analysed, and which, in any case, do not adequately support the interpretation offered.

\section{The inner courtyard moat}

In several places on the south, east and - less clearly - west sides of the castle, Armstrong and Himsworth recorded the moat, or 'ditch' as Armstrong generally referred to it. While they disagreed about its date, their observations confirmed the accuracy of the 17th-century documentary sources that describe the monumental scale of the moat (Anon. 1644, 2; Vicars 1646, 7; Ronksley 1908, 47). However, they also observed significant differences between its various sections, and at no point were able to date the cut feature, although they offered dates for some of its fills.

As noted in Chapter 2 (Section: Sheffield Castle: where the two rivers meet), a report in volume 1 of the Transactions of the Hunter Archaeological Society records the discovery, during the construction of a new building, of a ditch which seems to have run parallel with Exchange Street, on the southern edge of the castle site (Wigfull 1916, 239). Despite its location, it was not, Armstrong $(1930,13)$ insisted, 'part of the main ditch of the building' as 'plainly shown' by his recent excavations, though he does not tell us precisely how this was shown, or how he associated it with the Civil War phases instead (see also Chapter 5). In Armstrong's published accounts, the moat 'proper' was first encountered on what turned out to be the south-east corner of the inner courtyard, close to the west tower of the gatehouse, and its upper portion was filled with mid- to late 17th-century demolition debris. However, the bottom $13 \mathrm{ft}(3.97 \mathrm{~m})$ comprised a 'black tenacious sludge, none too fragrant' containing many finds, including 'cannon-balls and stone ballista-balls, knives, keys, personal ornaments, coins, glass, $\ldots$ and leather ... kitchen refuse such as potsherds, animal bones, antlers of red deer, roe and fallow deer, and oyster shells' (Armstrong 1930, 15). This was the only point at which the bottom of the moat was reached, with Armstrong's recording elsewhere stopping at the base of the foundation shafts for the Co-op (Johnson 1927b). He reported that the moat extended down to ' 14 feet 6 inches $[4.45 \mathrm{~m}]$ below the plinth course of the gatehouse, a total depth of 33 feet [10.06m] below the level of Exchange Street' (Armstrong 1930, 15; Himsworth 1927-42, 3). On his plan 1, Armstrong (1930) depicted the south moat running parallel to Exchange Street and as c.30ft (c.9m) wide (Figure 3.2; see also Himsworth 1927-42, 3), and on plate VII he presents it as having a uniform profile with a consistent depth along its length (though we need to note that these sections are further examples of Armstrong's tendency to produce 'typical', schematic, sections; Figure 3.8; Chapter 2, Section: Albert Leslie Armstrong: more than just the 'gifted amateur').

A foundation shaft, located in the centre of the former Castle Folds Lane (marked B on his plan 1; Figure 3.2), ${ }^{16}$ exposed the south side of the moat as it curved sharply to the north-east and ran beneath the buildings to the north of the Rotherham House Hotel. This revealed that the bottom $7 \mathrm{ft}$ of the moat had been cut through rock, with the south face almost vertical (Armstrong 1930, 18). This foundation shaft also encountered brownish peat, $8 \mathrm{in}(20 \mathrm{~cm})$ thick, which included reeds and aquatic plants, and lay between layers of black sludge, 7 to $8 \mathrm{ft}(2.1-2.4 \mathrm{~m})$ below, and 4 to $5 \mathrm{ft}(1.2-1.5 \mathrm{~m})$ above (Armstrong 1930, 19; Figure 3.8). Sphagnum moss, reeds and rushes were identified at the top of the upper black sludge layer, leading Armstrong $(1930,19)$ to conclude that there was only a moderate depth of water in the moat by the 17th century, covering a bottom of 'mud, deep and treacherous'. He felt that his evidence suggested that the south moat had formerly held a large body of water but that the depths had fluctuated over time. There was, again, some difference of opinion with Himsworth. On $18^{\text {th }}$ November 1927 Himsworth $(1927-42,1,7)$ tells us that, while Armstrong 'was quite

${ }^{16}$ This is the name they use for the lane which ran from Castle Folds, or Exchange Street as it was to become, northwards through the site to the Don. It is also the name which appears on the 1888 Goad Fire Insurance Map, but on the 1853 Ordnance Survey Map it is called Shambles Lane. 


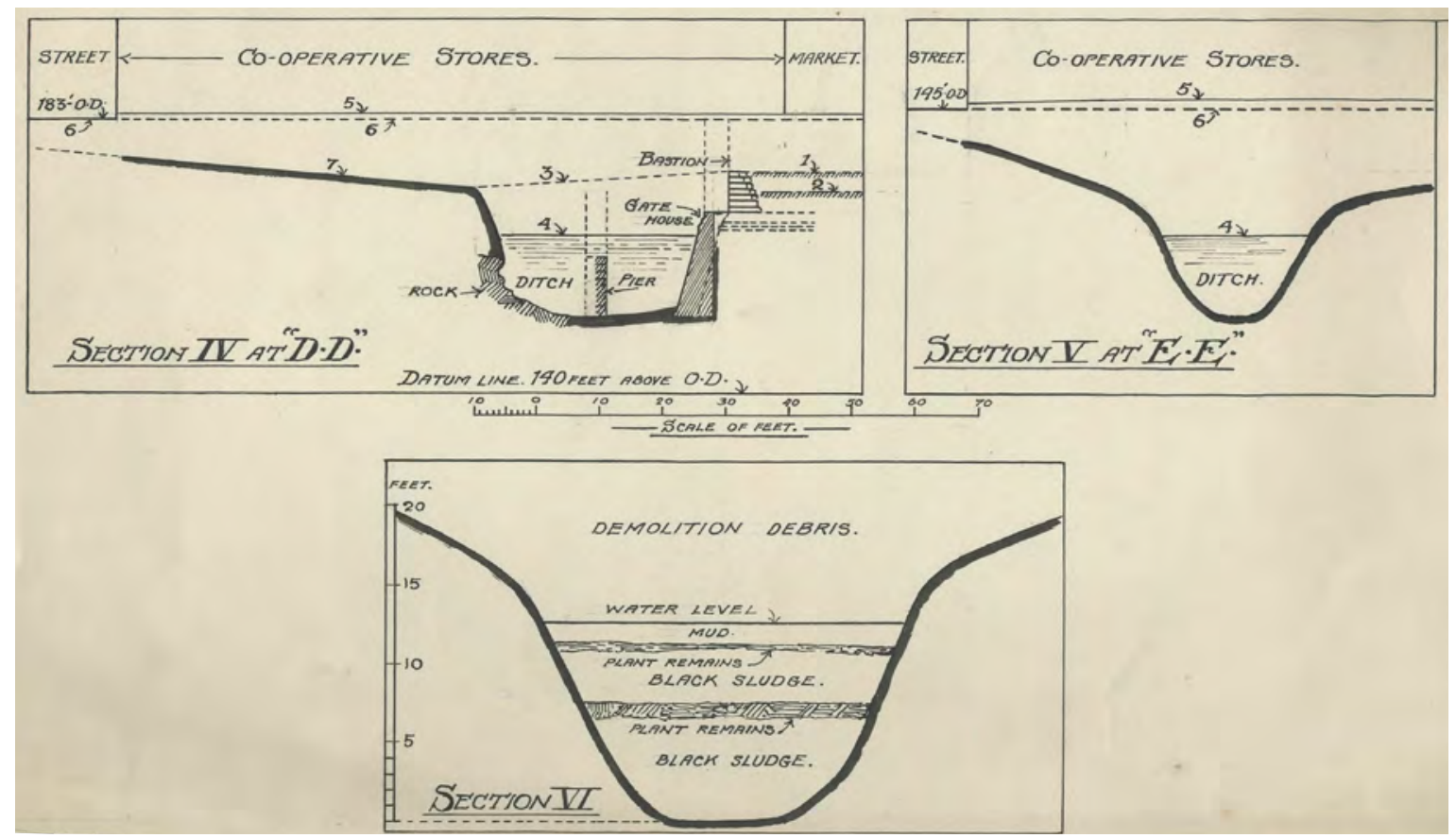

Figure 3.8: Plate VII of Armstrong's 1930 paper on Sheffield Castle. This shows three schematic sections through the moat. Their locations are shown on plan 1 (Figure 3.2). Hunter Archaeological Society.

positive' that the water in the castle moat had been stagnant, he himself 'thought it possible ... that the moat was fed by a stream of water still known to be running under property in High Street' (for a resolution to this argument, see Chapter 7).

Armstrong $(1930,11)$ proposed that, from the gatehouse, the moat 'curved round sharply east of north, towards the Sheaf', its alignment later followed by the steep and narrow Castle Folds Lane, and he argued that the silts encountered in a foundation pit at the northern end of this lane indicated that it followed the centre of the east moat. In his site diary, on $18^{\text {th }}$ and $19^{\text {th }}$ November 1927 , Armstrong $(1927-28,3)$ recorded, in both plan and section, the appearance of the moat in a series of nine-foot-wide stanchion holes running northwards from the Rotherham House Hotel (Figure 3.9). Himsworth (1927-42, 3), in his diary entry for $19^{\text {th }}$ January 1928, noted that during the clearance of buildings along Castle Folds Lane "black sludge showing a "section" of the moat is very clearly defined against the yellow clay forming the foundation or subsoil of the old lane. Armstrong concluded that the moat on the east side of the inner courtyard was rather shallower than that to the south and suggested that it did not generally hold water, but conceded that water may sometimes have flowed into it from the south moat. He was of the opinion that the Sheaf may have run further west, and so closer to the castle, than it currently does and would, therefore, have provided additional defences - 'the river and its high bank and the dry ditch surrounding it [the castle] and the steep glacis ... would provide a strong defence on that [east] side' (Armstrong n.d. (f); Armstrong 1930, 18; see Chapter 7 for further discussion and Figure 7.16 for an illustration).

The evidence for the western section of the moat is much less clear. In his interim report for the Society of Antiquaries, Armstrong (1928b, 366) suggested that the south moat continued westward 'across Waingate' in the direction of Castle Street, but in his 1930 publication he was adamant that the western 'ditch' 'was certainly not encountered in any of the excavations I was privileged to examine' (Armstrong 1930, 12). Nonetheless, he was 'informed' about 'a considerable depth of black sludge-like material' in the basement of a property south of the Bull \& Mouth public house (Armstrong 1930, 13); similarly, Himsworth (1927-42, 8) heard about the 'deep black ditch sludge' encountered on the site of R. J. Stokes's shop, at the northern end of Waingate (Armstrong 1930, plan 1; Figure 3.2). All this led Armstrong to conjecture that the line of the west moat roughly followed the course of the old Waingate, but ran west of it at the 'top' (south) and to the east of it as it approached Lady's Bridge. After Armstrong's paper had been completed (Northend 1930a), Himsworth (1927-42, 20) recorded in 


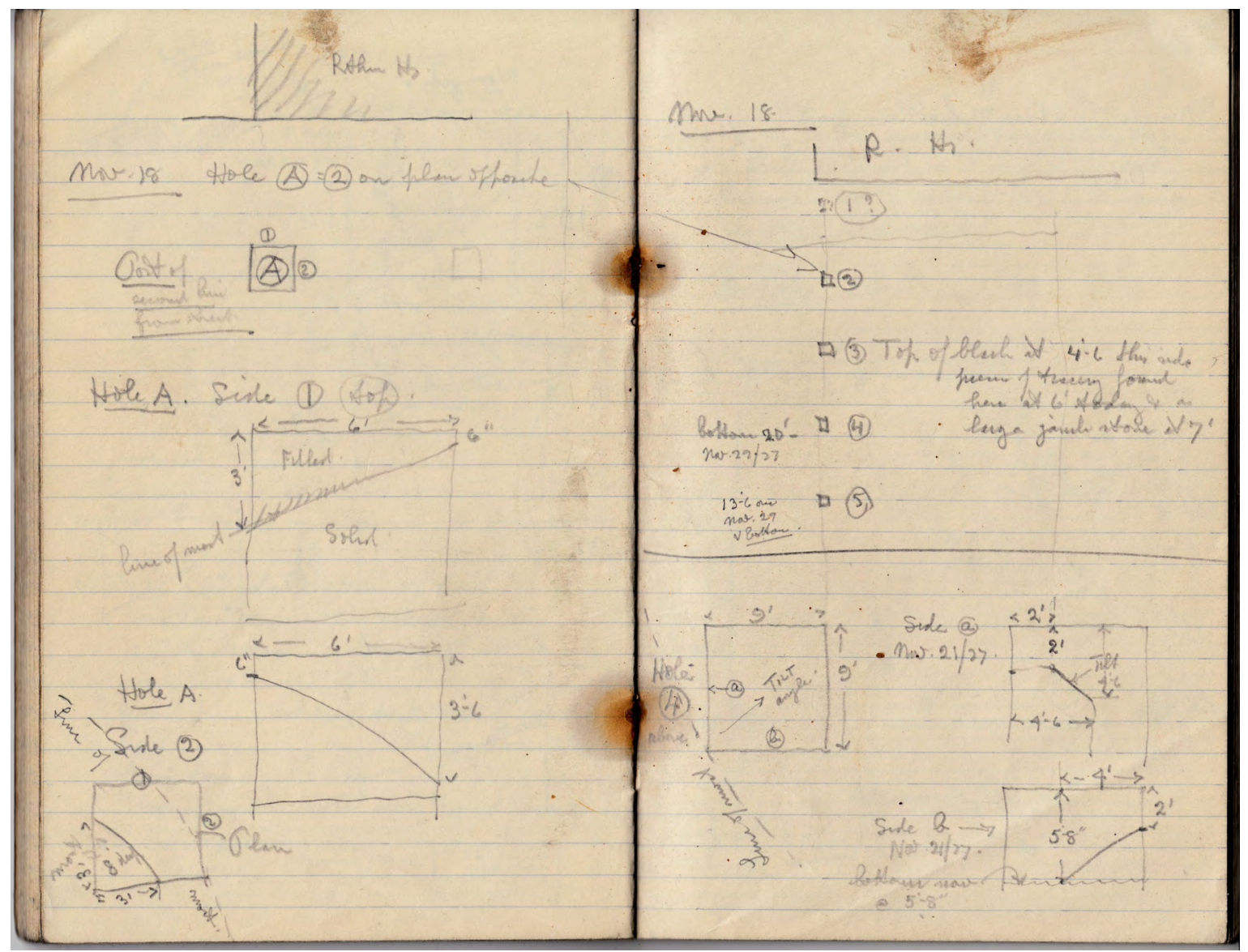

Figure 3.9: Pages from Armstrong's site diary. Here he records the appearance of the moat in a series of foundation shafts running north from the Rotherham House Hotel. Courtesy of Museums Sheffield.

his diary entry for $18^{\text {th }}$ November 1930 a 'peaty strip of soil' running south along the back of the Bull \& Mouth pub, speculating that this was where the moat emptied into the Don.

There is other evidence for the west moat that Armstrong's publications omits. On Tuesday, $13^{\text {th }}$ September 1927, the Sheffield Daily Telegraph announced the discovery, after the removal of $12 \mathrm{ft}(3.66 \mathrm{~m})$ of 'made ground', of what (unnamed) 'experts' believed to be the site of the castle moat, which 'appears to have run along a portion of Exchange Street, and then branched away towards the top of Waingate' ('Castle moat find', 1927). The description is not entirely clear - 'the definite demarcation of the "made" and natural ground and its contour lead to the belief that the south-westerly section of the moat was situated at this spot' - but, in the light of the most recent excavations in this area (see Chapter 7), it seems certain that this was indeed part of the moat.

There are other, equally inexplicable, examples of what we might call this 'under-reporting. Thus, on $21^{\text {st }}$ September 1927, again in the early weeks of Armstrong's involvement, and before anything of what he regarded as of significance was found, the Sheffield Daily Telegraph reported the discovery, 'late yesterday afternoon', of 'a very old skeleton' ('Castle relics', 1927). It was buried about $8 \mathrm{ft}(2.44 \mathrm{~m})$ down and about $20 \mathrm{ft}(6.10 \mathrm{~m})$ north of Exchange Street (so in or close to the moat) and was reckoned 'so old that it may be that of a man who saw Sheffield Castle in its pride and glory'. We do not know how they established the date of the skeleton or, for that matter, how they knew it was male. Neither do we know what happened to it subsequently - other than that the bones were placed in a shed on the site. What we do know, and what makes this as curious as the section of moat discussed above (if not more so), is that neither Armstrong nor Himsworth makes any reference to it in any of their papers (published or unpublished) (see Munby et al. 2019, 33, 143 for evidence that at 
Oxford Castle, by the late 15th or early 16th century, 'the silting-up ditch was being used for the burial of executed prisoners').

Himsworth's (1927-42, 16-17) diary entry for $1^{\text {st }}$ July 1930 suggests that he may have recorded, but not recognised, part of a dam at the point where the west moat met the Don. He had observed holes being filled with concrete near Lady's Bridge (to 'stiffen the ground at the edge near the river bank'), exposing what he believed to be a 19th-century wall, underneath which were 'heavy worked stones that looked like much earlier work'. A contemporary description of the siege of Sheffield Castle in 1644 reveals that a dam controlled the flow and level of water between the east moat and the Don. Thus, on $4^{\text {th }}$ August, 'at night', 'the Major Generall [Crawford] ... went to view a sluce that was stopt to keep the water deep about the east side of the Castle, which he thought to draine the more to facilitate his businesse. The next night, 'the Major generall attempted to break up the Sluce through the Dame, to let out the water of that corner against the Orchard, on the east side of the Castle, which could not take effect' (Anon. 1644, 3). If what Himsworth observed in 1930 was part of a similar structure, it would imply that the western arm of the moat entered the Don c.10m to the east of Lady's Bridge (City Architect's Department 1930; see Chapter 5 for Butcher's important conclusions about these structures).

\section{The de Furnivals' monumental entrance}

Similarly, we now know that the construction work uncovered more of the monumental entrance to the castle at its south-eastern corner than Armstrong recorded in his 1930 paper. On the morning of Tuesday, $20^{\text {th }}$ September 1927, about 40-50ft (12.19-15.24m) north of Exchange Street, a south-facing wall said to be 'undoubtedly a section of the old castle' was reported in the Sheffield Daily Telegraph:

Strongly resembling the letter ' $V$ ', but running inwards instead of outwards, the facing wall is about $3 \mathrm{ft}$. high and some $12 \mathrm{ft}$. thick. There were three layers of stone, and each stone was 14 inches thick and weighed about $2 \mathrm{cwt}$... The mortar between the stones has a hard gritty feel, almost like wet sand ('Castle relics', 1927).

This wall was so impressive that it was thought to be one of the buttresses on the outer wall of the castle. Yet, the detailed newspaper report is hard to match with anything in Armstrong's published accounts, or unpublished notes and drafts, even though he must have been at work on the site at the time of its discovery. He must have known about it - there is even a photograph in Yorkshire Telegraph and Star. His silence might be because it was quickly demolished, as contemporary newspaper reports record ('Part of Sheffield castle, 1927; 'Castle relics', 1927). As we stressed in Chapter 2, this was an active construction site with its own priorities, when attitudes towards archaeological remains were quite different. Himsworth $(1927-42,3)$ frequently lamented (and photographed) the destruction of what was being uncovered (see also Chapter 9).

It is just possible, given the reported size of the masonry and the thickness of the walls, that this 'demolished' fragment was part of the monumental entrance to the inner courtyard, which in its scale and grandeur matched the section of moat which ran past it. Armstrong's site diary for $7^{\text {th }}$ October 1927 records the discovery of a stretch of wall, 15 yards $(13.72 \mathrm{~m})$ long, comprising five courses of dressed masonry $(24 \mathrm{in} \times 14 \mathrm{in} \times 12 \mathrm{in}(61 \mathrm{~cm} \times$ $36 \mathrm{~cm} \times 30 \mathrm{~cm})$ ), with a rubble backing at least $12 \mathrm{ft}(3.66 \mathrm{~m})$ thick. On $11^{\text {th }}$ October, he recorded and sketched a curved wall, with a radius of $20 \mathrm{ft}(6.10 \mathrm{~m})$, comprised of 'ashlar very well worked \& jointed backed with flat bedded rubble' (Armstrong 1927-28, 1-2; Figure 3.10). Himsworth was now also involved and in his diary he too records, almost day by day, the uncovering of these massive structures. On $11^{\text {th }}$ October he met Armstrong and Wigfull on site to view the 'walling, both straight and round in plan; both sections having a good plinth [which] had been uncovered when a trench was excavated for the back wall foundations for business premises [the Co-op]'. On $10^{\text {th }}$ and $11^{\text {th }}$ November, he returned to photograph these structures, and on $5^{\text {th }}$ December met Armstrong on site 'to view more masonry which is evidently a portion of a bastion ... Photographed it three courses high.' He went back the next day - 'Photos taken of more courses' (see Figure 2.2) - and in his surviving photographs we can still see this beautifully coursed stonework as it emerged from the earth. Armstrong phoned him at $9.30 \mathrm{am}$ on $9^{\text {th }}$ December to tell him to go down to the site - 'There were nine courses including plinth of tower or bastion now uncovered' (Himsworth 1927-42, 1-2, photos 8 and 9; also Figure 3.10 (2)). 

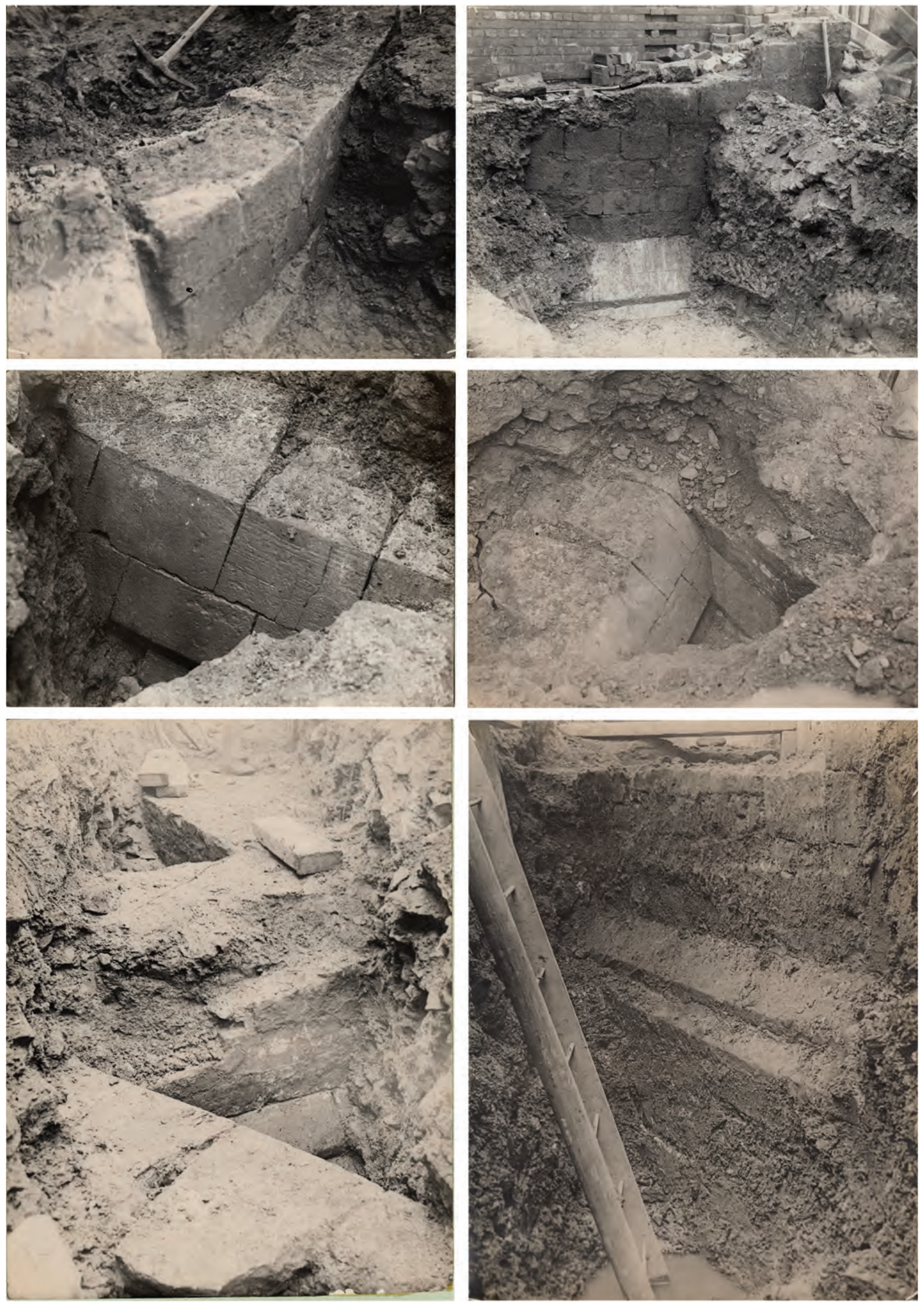

Figure 3.10: Photographs from Armstrong's 1930 paper on Sheffield Castle. These show the west tower of the gatehouse, plinth and walls of the forestructure. Courtesy of Museums Sheffield. 
From what they had found, Armstrong $(1930,17)$ declared it 'easy to picture the strength and massive dignity of the entrance to the castle in the days of its pride' (Figure 3.11).

Published plans and discussions of this tower, and of the monumental entrance more generally, tend to draw on the evidence uncovered on the site of the Co-op, with Armstrong's plan 2 showing the plinth course and the rubble backing projecting southwards from under the 'outer wall of the new building. However, Armstrong $(1930,11)$ also tells us that on the north side of this wall, on the site of Castle Hill Market, they encountered '[a] further portion of the large circular bastion, a continuation of that uncovered upon the site of the Co-operative Stores'. He does not provide any further details - but Himsworth (1927-42, 11-12) records the discovery, again in both text and image. Thus, he tells us that on $7^{\text {th }}$ December 1928:

The plinth where it comes through the Co-op. brick wall, was reached in digging a pillar hole about 12 feet deep [he later (18 ${ }^{\text {th }}$ December 1928) corrected this to $18 \mathrm{ft}$ 6in from the Co-op floor level to the top of the plinth]. It was in a perfect state. A very handsome piece of masonry, in clay ... Loughran gave me the measurements. Some of the stones are about 10" X 20" on face.

Loughran cursed the delay caused (above, Chapter 2, Section: Doing archaeology in Sheffield 1927-30) but, embodying the tension at the heart of the whole process between recording the past and building the future, he nevertheless, that very day, provided Himsworth with a (signed!) measured drawing of the profile of this plinth (Himsworth 1927-42, fig. 40; also Armstrong 1927-28, 7). Himsworth picks up the story on $14^{\text {th }}$ December 1928, when he tells us that Loughran had instructions (he does not say from whom) to 'bring up ... the best or largest piece of plinth for preservation as it could not be left in situ'. He photographed the process, and his photo 39 (Figure 2.14) shows those involved at the bottom of a deep shaft with a piece of the plinth. By $18^{\text {th }}$ December 'Loughran had got a complete section of the large plinth out and set it up on the surface' - we can see it in Himsworth's photos 41 and 42 (1927-42, 13-14). It is clear, both from these pictures and Loughran's drawing, that it has the same profile as that supporting the west tower on the Co-op site (see Armstrong 1930, plate VI - 'Bastion plinth. Section I at "A.A"'; Figures 2.14, 3.12).

Neither Armstrong nor Himsworth tell us the location of this portion of the tower plinth - only that it was on the Castle Markets site. It could therefore have lain anywhere along the continuation of the arc of the plinth
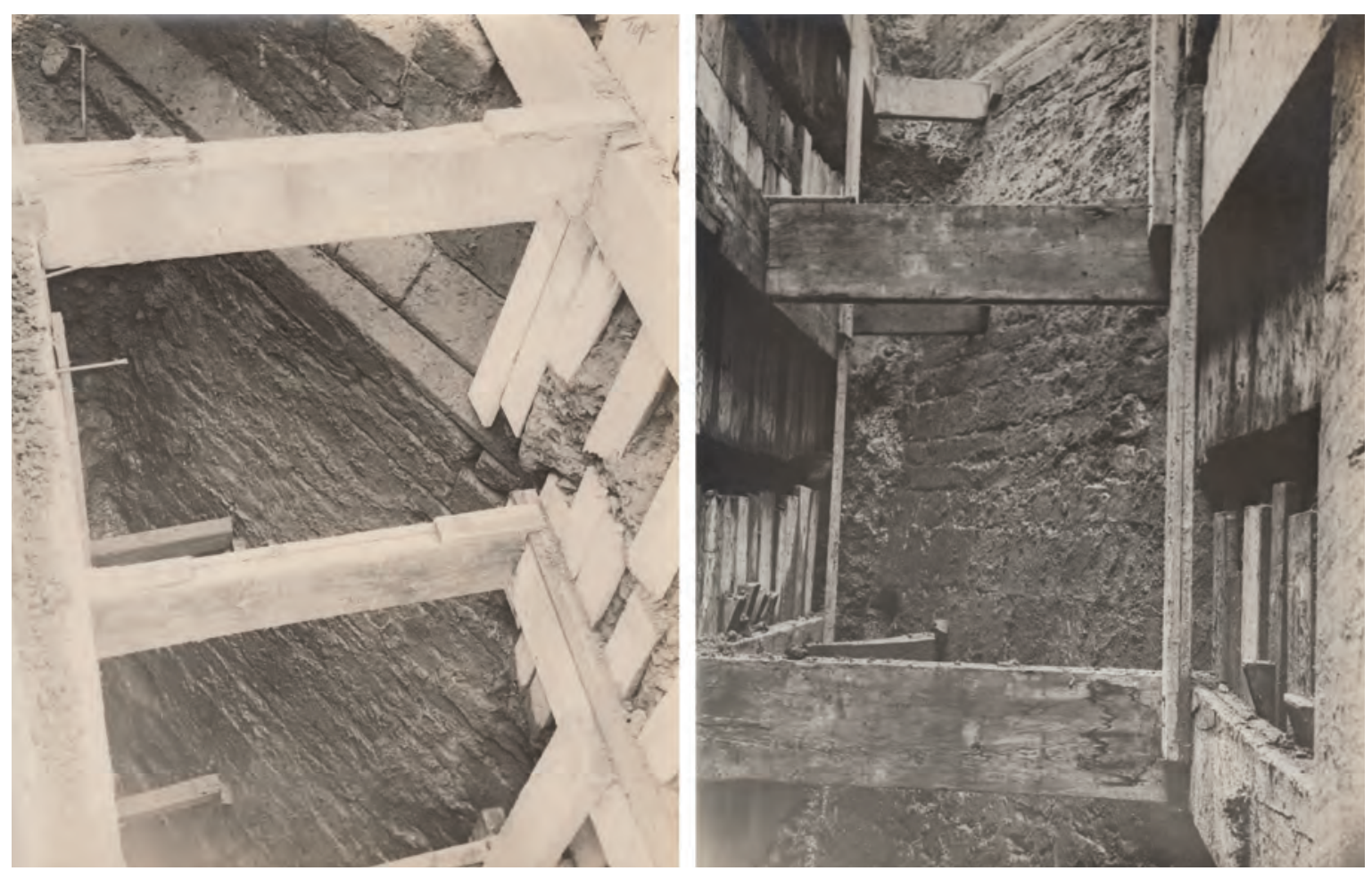

Figure 3.11: The lower walls of the gatehouse projecting into the moat. Signs of cannonball impact can be seen at the lower left of the right-hand image. Courtesy of Museums Sheffield. 

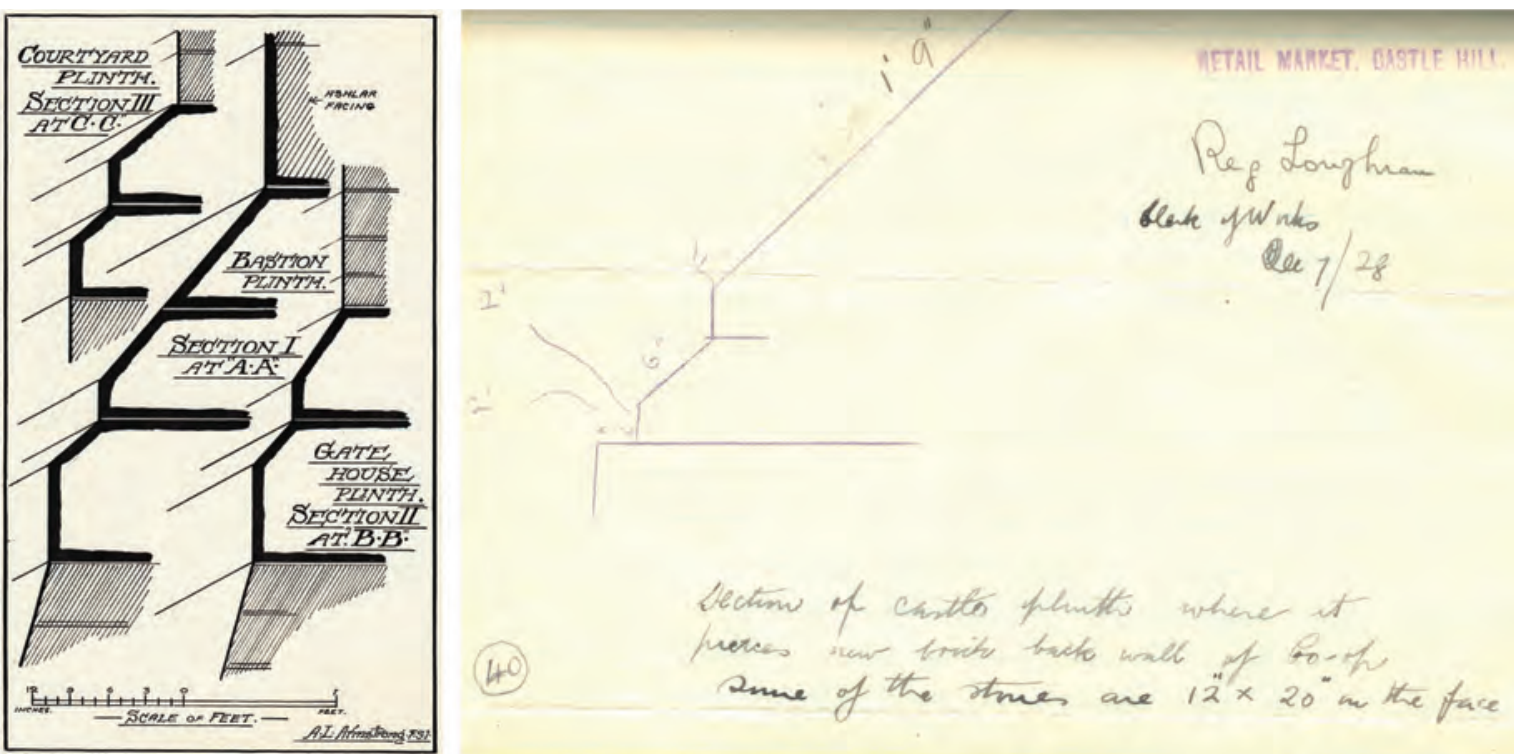

Figure 3.12: Plinth courses from Sheffield Castle. Plate VI from Armstrong's 1930 paper (left) depicts sections of plinth courses from the courtyard building and the gatehouse. Hunter Archaeological Society. On the right is a scrap of paper on which Clerk of Works Reg Loughran had drawn the courtyard plinth. He provided this to Himsworth, who included it in his diary. It was the discovery of this plinth that caused Loughran to curse delays in strong 'Builders language'! Courtesy of Museums Sheffield.

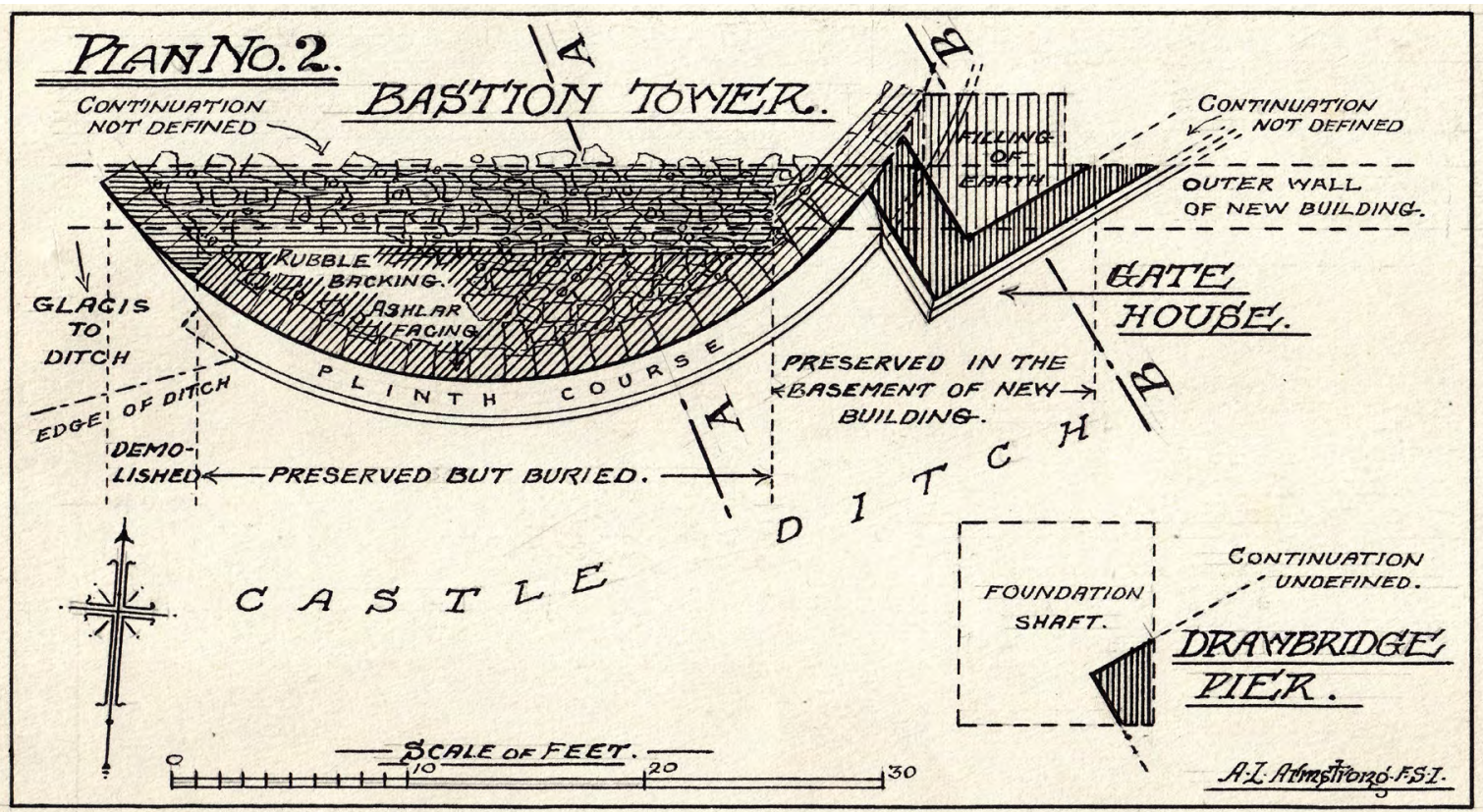

Figure 3.13: Plan 2 from Armstrong's 1930 paper on Sheffield Castle. This shows the gatehouse west tower, forestructure and drawbridge pier. Hunter Archaeological Society.

course shown on Armstrong's plan 2. However, one possibility is that it was located on the eastern side of this west tower, where a gatehouse was later added (see below). On Armstrong's plan 2, a rectangular cut (labelled 'filling of earth') is shown at this point, and this seems to extend into the Castle Markets site (Figure 3.13). Leslie Butcher's $(1961,32)$ statement that Armstrong removed a 'section' of the plinth of the forestructure (gatehouse), where it met the tower and had it preserved, 'but he never recorded the position on his published plan', might be taken as supporting this suggestion (but see Chapter 5, Section: Gatehouse; this section of plinth is currently among the fragments of the castle residing in the chamber built around the courtyard remains). 
In his published accounts Armstrong drew on these notes and observations to describe a monumental entrance consisting of circular towers on either side of a fortified gateway. The exposed remains of the west tower had a radius of $20 \mathrm{ft}(6.10 \mathrm{~m})$ and was described by Armstrong $(1930,14)$ as being of excellent workmanship, with an ashlar face of fine jointed masonry 'laid in courses 12 and 14 inches [ $30-36 \mathrm{~cm}]$ on bed backed with flat-bedded rubble, only partially grouted in mortar. Although the full extent of the tower was not ascertained, the rubble core extended $12 \mathrm{ft}(3.66 \mathrm{~m})$ from the ashlar face, and the total width of the gateway recorded by Armstrong $(1930,10)$ was $40 \mathrm{ft}(12.19 \mathrm{~m})$ from east to west, with walling to a total height of $20 \mathrm{ft}(6.10 \mathrm{~m})$. The massive ashlar base course of the tower had a tooled ashlar plinth $24 \mathrm{in}(0.96 \mathrm{~m})$ in height splayed outwards in two bold chamfers. At the centre of the tower seven courses of stonework, standing to $6 \mathrm{ft} 6 \mathrm{in}(2.01 \mathrm{~m})$ from the plinth course, survived, while only three courses stood on the western side, and on the east only the plinth remained. Below the plinth, the footings for the tower were splayed at an angle of $75^{\circ}$ into the ditch. The plinth did not extend beyond the western side of the tower, where the ground sloped steeply from the glacis towards the moat cut (Armstrong 1930, 16-17; see above).

A rectangular gatehouse was partially uncovered which projected $6 \mathrm{ft}(1.83 \mathrm{~m})$ from its junction with the west tower, 'added for the accommodation of the drawbridge machinery and to increase the strength of the main entrance of the castle' (Armstrong 1930, 17). Its walls, $2 \mathrm{ft} 6 \mathrm{in}(0.79 \mathrm{~m})$ thick on the sides and $1 \mathrm{ft} 6 \mathrm{in}(0.49 \mathrm{~m})$ at the front, were of 'roughly chiselled masonry in irregular and narrow courses' and, Armstrong $(1930,17)$ thought, were 'much inferior' to those of the tower. Like the tower, the gatehouse had a plinth course below which the walls splayed $75^{\circ}$ into the moat. The space between the gatehouse and the west tower was filled with earth and clay, and the pottery recovered from the filling was thought by Armstrong (1930, 17, plan 2) to date to the 14th century (although none of the pottery within the archive could be related to this deposit in our analysis). Armstrong $(1930,16)$ says little about the materials from which the gatehouse and tower were constructed, noting only that the latter was built from 'a fine grained freestone, slightly grey in colour when fractured ... believed to have come from the vicinity of Handsworth', where there were sandstone quarries. Himsworth $(1927-42,2)$ provides us with more information when he tells us (25 th $N o v e m b e r ~ 1927)$ that 'most of the castle building now uncovered appears to be of Handsworth stone', although pieces of window tracery found in the moat were 'rather yellow' and were probably, he thought, of 'magnesium' [magnesian] limestone (see Himsworth 1927-42, photo 7; also Chapter 7). In his 1930 paper, Armstrong (1930, 20) referred to the recovery of demolition debris from the moat, including chamfered stone mullions, window jambs and tracery, probably from the windows of the chapel or hall, but in one of his draft manuscripts, he commented that the windows were of 14th-century date, and so were probably insertions having been 'modernised' at that date (Armstrong n.d. (d)).

Himsworth records further elements of the entrance complex discovered on $18^{\text {th }}$ January 1928 . While sinking a foundation shaft, the construction workers encountered 'a square pier in the middle of the moat'; it was 'in an exceptional state of preservation, clean cut stone, angle (only one preserved) perfect, not a stone out of place' (Himsworth 1927-42, 2-3; also Armstrong 1930, 17, and plan 1). We can still see that 'perfect angle' in Himsworth's photos 11 and 12 (Figure 3.14). The sinking of another foundation shaft, just $5 \mathrm{~m}$ to the east in the middle of the former Castle Folds Lane (marked B on Armstrong's plan 1), encountered a stretch of masonry deemed to be 'of similar character to that of the drawbridge pier' (Armstrong 1930, 18). This was $12 \mathrm{ft}$ (3.66m) high and had been partially demolished, but Armstrong was sure that it was either the eastern end of the pier we have been discussing, or that it was a second pier. He believed that the former, and presumably the latter, occupied a free-standing position within the moat, and was so placed 'to receive the movable portion of the drawbridge' (Armstrong 1930, 17, 11; 1928b, 366). Himsworth (1927-42, 3) concurred - the pier in the middle of the moat was 'probably for a drawbridge to fall upon from the castle gateway'. Armstrong (1930, 17; 1928b, 366) believed, perhaps because of the quality of the masonry/construction, that it was 'contemporary in date with the bastion tower. That would, of course, make the pier earlier than the gatehouse, which, as we have seen, Armstrong $(1930,17)$ said, was 'clearly of more recent date'. We would therefore have to assume that it was originally intended to support an earlier drawbridge than that raised and lowered by the new mechanism installed (so Armstrong assumed) in the gatehouse.

However, the actual location of this 'pier' was, and (to some extent) remains, a matter of debate. Although Armstrong and Himsworth both placed it in the middle of the moat, there are signs that the former (at least) was not entirely sure. Armstrong toyed with an alternative interpretation in a draft of his published paper, where he described the portion found in foundation shaft B as part of the abutment 'on the outer side of the bridge', although the word 'landward' had first been used before being overwritten (Armstrong n.d. (d), 22), and in another draft stated that it was 'obviously part of the abutment of the southern half of the bridge' 


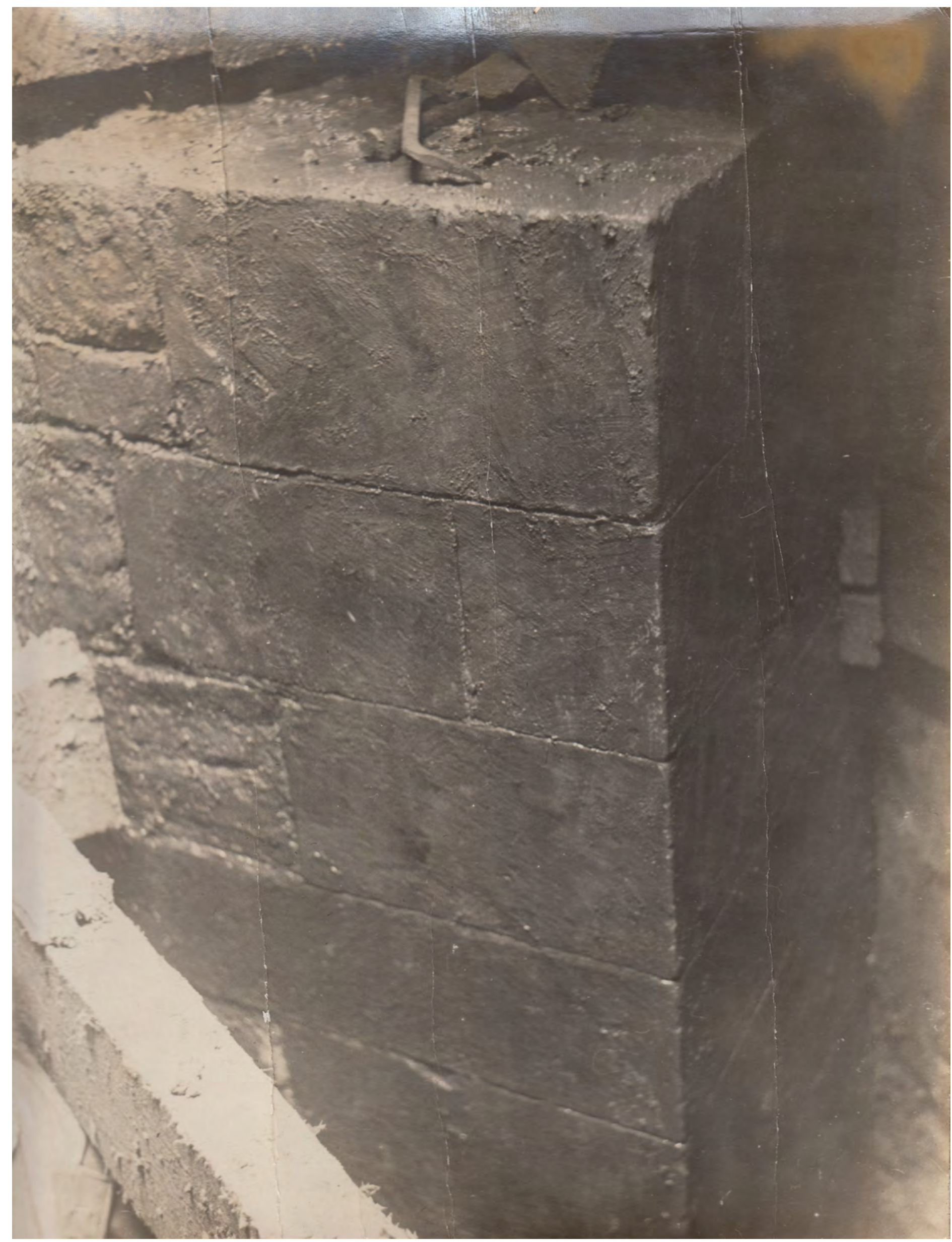

Figure 3.14: The drawbridge pier. Photograph taken by A. Senior. Himsworth $(1927-42,3)$ described the pier as 'perfect, not a stone out of place'. Courtesy of Museums Sheffield. 
(Armstrong n.d. (e), 6). In this scenario, the drawbridge would cross the moat in a single span, without the need for support in the middle, with both the 'first' pier and the masonry in shaft B forming the southern, landward platform on which it rested. Clearly, Armstrong struggled to interpret what he had seen, before deciding that it was a free-standing pier (for further discussion, see Chapter 5, Section: Gatehouse).

The east tower is noticeable by its absence from detailed descriptions of this monumental entrance, although Armstrong (1928b, 366) clearly assumed it was there and makes repeated reference to it (Armstrong 1930, 11, 16-17). In fact, Armstrong and Himsworth may have seen more of these entrance structures than they realised for parts of the east tower plinth and eastern angle of the forebuilding were visible in some of the site photographs, although the latter was partially obscured by 'trench timbers' (Butcher 1972a, 17; Richardson and Dennison 2014a, 58; see Chapter 5, Section: Gatehouse). Himsworth's $(1927-42,11)$ diary entry for $3^{\text {rd }}$ December 1928 supports the possibility that they encountered (and recorded) part of the east tower:

three men digging a hole for a market pillar. Expected they might 'pick up' the plinth where it comes through the back wall of the Co-op., and I hope, the bastion or tower I expect to balance the other side of the castle entrance.

Four days later he describes, as we have seen, the plinth 'coming through' the Co-op wall (see also Butcher 1961, 32). The significance of Himsworth's report of $3^{\text {rd }}$ December is that it places the discovery of $7^{\text {th }}$ December in the context of the east tower, the one which would 'balance the other side of the castle entrance'. All this implies, of course, that he and Armstrong had seen both the east tower and the eastern corner of the gatehouse structure, but Armstrong had not included them in his final report or marked them on his plans. Armstrong and Himsworth associated these structures with the rebuilding of the castle in 1270 when, as we have seen, Thomas de Furnival II was awarded a licence to crenellate. Thus, Himsworth $(1937,6)$ told the audience at his '500 Years of Sheffield Trade and Sheffield Castle' lecture that ' $t$ the finely worked stone remains uncovered in 1927-29 are undoubtedly those of de Furnivals [Furnival's] 13th century castle'.

\section{Himsworth discovers the curtain wall above the Don}

The numerous foundations dug west of the gatehouse failed to identify the curtain wall surrounding the inner courtyard. However, Armstrong $(1930,11)$ thought it unlikely that this wall had been entirely demolished (he reasoned that the ashlar facing might have been robbed, but not the foundations and rubble core), and so assumed that its remains lay to the north of the rear wall of the Co-op building, but the lack of foundations dug on the site of the new market hall meant that there was no opportunity to investigate this hypothesis. There seems to have been rising ground along the northern edge of the moat cut, as shown on William Fairbank's Correct Plan of the Town of Sheffield (Figure 1.8; Fairbank 1771a), and which Armstrong referred to as the glacis, and the southern line of the curtain wall may have run along the top of this slope (see Chapter 5, Section: Curtain wall). On the eastern side, the buildings along Castle Folds Lane (Shambles Lane, see above) were 'backed against the glacis'; that they were 'built of castle material was amply demonstrated during their demolition' (Armstrong 1930, 21). Armstrong does not say how this was demonstrated, but we can reasonably assume that he saw the large masonry blocks which had, in the past, been mistaken for the actual walls of the castle. Here again, Himsworth's $(1927-42,6)$ record is invaluable. On $28^{\text {th }}$ September 1928 he photographed, on the north-east of the site, a set of stone steps leading down to some brick-built basements, 'the floor of which rests upon some good stone walling in Castle Folds Lane below' (see also his photos 21, 22, 23; Figure 2.11). On $26^{\text {th }}$ November he recorded that men were 'digging away some of the bank (west) of Castle Folds Lane [i.e. into Castle Hill] ... the debris in the bank side was largely composed of old mortar (lime and sand) such as was seen in one or two places near the south moat' (Himsworth 1927-42, 10). And on $30^{\text {th }}$ November he refers to the discovery, 'near the edge of the bank in Castle Folds Lane', of a 'base of what appears to be remains of a Norman pillar' (Himsworth 1927-42, 11, also his photos 36 and 37; Figure 3.15).

After Armstrong had completed his paper, by the summer of 1930 (Northend 1930a), traces of the north curtain wall seem to have been uncovered on top of the river cliff above the Don, known from at least the later 18 th century as 'the precipice' (see Chapter 1; Fairbank 1769). This discovery was made during the demolition of the late 18th-century slaughterhouses, which took place prior to the construction of the new road along the south bank of the Don - 'Castlegate'. Again, it is the diary of Joseph Himsworth that is crucial for providing 

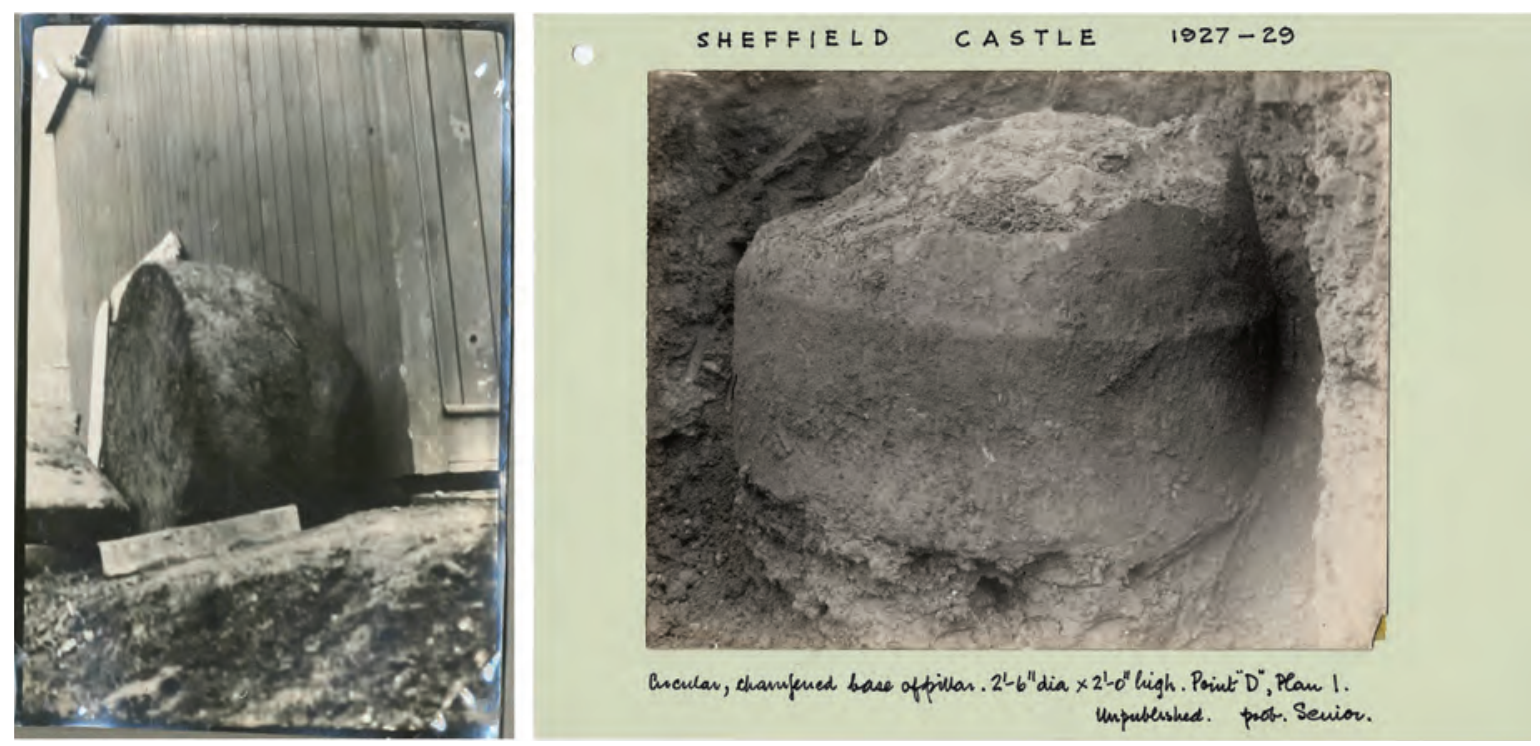

Figure 3.15: The 'base of what appears to be remains of a Norman pillar'. On the left is the photograph that appeared in Himsworth's diary showing the pillar on its side leaning against a site hut, and on the right a photograph of the pillar in the ground taken by A. Senior, mounted on card and annotated by Leslie Butcher during his research on the castle. Courtesy of Museums Sheffield.

evidence of this part of the castle. On $1^{\text {st }}$ July he noted that underneath what he took to be a 19th-century wall 'were heavy worked stones that looked like much earlier work' (Himsworth 1927-42, 17), and then in his diary entry for $4^{\text {th }}$ September 1930 he records:

About 50 feet $[c .15 .2 \mathrm{~m}]$ from N.E. corner some squared rubble masonry appears; also at about 100 feet $[c .30 .5 \mathrm{~m}]$ along the Don front facing the river, like buttresses, both about four feet $[c .1 .3 \mathrm{~m}]$ wide. These are approximately about five feet $[c .1 .5 \mathrm{~m}]$ back from the old brick wall and about seven feet $[c .2 .10 \mathrm{~m}]$ below the present market level (Himsworth 1927-42, 18).

Further tantalising glimpses of masonry appeared on $10^{\text {th }}$ October, when Himsworth $(1927-42,18)$ records that he visited the site at $2.15 \mathrm{pm}$ just in time to stop workmen destroying 'masonry almost six feet [1.8m] by four feet $[1.2 \mathrm{~m}]$ high overlooking the Don and parallel with it. This wall was at a similar level to the courtyard buildings to the east and located about $9 \mathrm{ft}(c .2 .7 \mathrm{~m})$ back from the brick retaining wall along the Don. Himsworth speculated that it may have formed the rear, or inner, wall of a tower, since a section of walling extended from it towards the Don.

At the western end of this section overlooking the Don, and 'at a higher level', Himsworth (1927-42, 18-19) also noted the destruction of part of a square building, which had a wall comprised of stones that were '12" X 9" $[30 \mathrm{~cm} \times 23 \mathrm{~cm}]$ and $10^{\prime \prime} \mathrm{X} 6 "[25 \mathrm{~cm} \times 15 \mathrm{~cm}]$ '. It was $13 \mathrm{ft}(3.96 \mathrm{~m})$ long and bonded with white lime mortar (with very little sand); the top of this lay 'about five feet $[1.52 \mathrm{~m}]$ below market site'. A roughly measured drawing of the section is included in his typed diary, where a 'Filling of White Mortar and Stone' is noted towards the east end (Himsworth 1927-42, fig. 47; Figure 3.7); the unpublished sketch in his manuscript diary labels it 'remains of a tower', presumably one of the towers on the castle's curtain wall (Himsworth 1930g). Above this, Himsworth $(1930 \mathrm{~g})$ wrote 'opp. Waingate and back market entrance', which helps to locate this tower more precisely. In a letter written to Armstrong on $30^{\text {th }}$ November 1930, Himsworth (1930e) noted that these observations tended to support a suggestion that had been made by the City Architect, Edwards, concerning the likely location ('but not just as he plans them') of the principal apartments of the castle along its northern edge. Edwards (1930) had drawn a 'conjectural' plan of the castle layout in response to the publication of Armstrong's findings, in which he made use of the written sources, although his supposition about the location of the principal buildings was simply based on a belief that that might be expected to have been 'at the least vulnerable position' of the castle (Figure 3.16; also Himsworth 1930f, and for an alternative perspective, see below). 


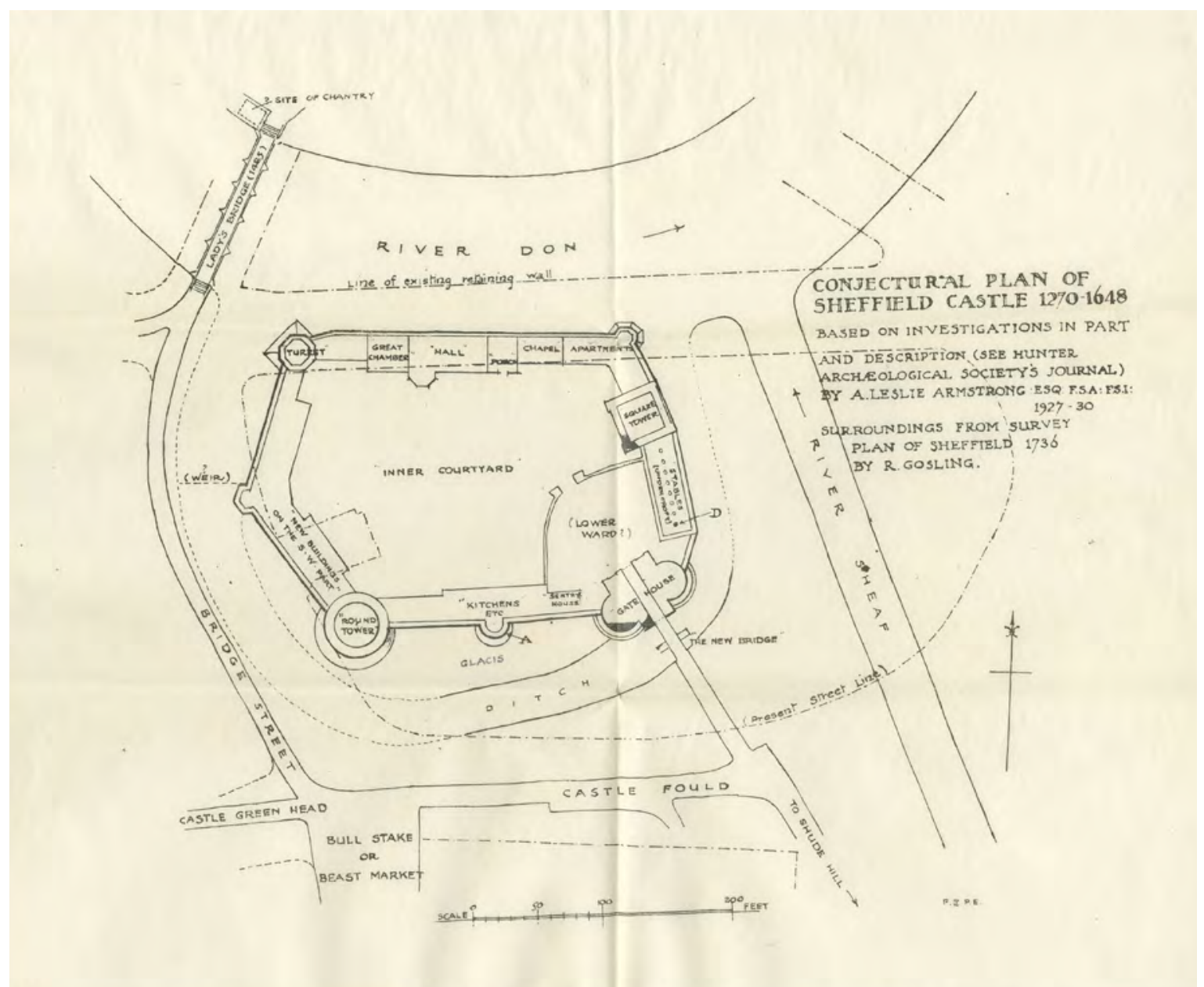

Figure 3.16: Conjectural plan of Sheffield Castle. Drawn by City Architect F. E. P. Edwards in November 1930. This was sent to Armstrong in a letter dated $15^{\text {th }}$ November 1930, after his paper had been published in the Transactions of the Hunter Archaeological Society. Courtesy of Museums Sheffield.

Remains of this tower may have been identified c.1868 during construction of a tunnel for a new sewer running under the site of the castle, from the weir on the Sheaf at the rear of the Alexandria Hotel westwards to the end of Bridge Street (Leader 1872, 362-3). A shaft excavated in the yard of Messrs C. Chambers \& Co. (shown on the 1896 Goad Fire Insurance map as located in the middle of Castle Hill, at the north-western end of Castle Folds Lane), cut through a 'subterranean passage', which reignited old stories about underground links between the castle and the hunting lodge (stories that had been dismissed by Hunter $(1819,193)$ half a century earlier as 'palpably absurd'). Another was excavated 'near to Waingate' and, at a depth of about $20 \mathrm{ft}(6.10 \mathrm{~m})$, it encountered three walls, one $12 \mathrm{ft}(3.66 \mathrm{~m})$ thick and probably an outer wall, while the second was $4 \frac{1}{2} \mathrm{ft}(1.37 \mathrm{~m})$ thick and the third $3 \mathrm{ft}(0.91 \mathrm{~m})$ thick. Significantly, the structure was built of 'large rubble with dressed quoins' (Leader 1872, 363; Leader 1880, 146). It seems that there was a substantial tower located on the north-western edge of the promontory, perhaps exploiting the slope towards the Don and Waingate.

In his diary entry for $20^{\text {th }}$ October 1930, Himsworth $(1927-42,19-20)$ recorded that 'There now appear four patches of rubble filling on edge, and lead me to suggest there were probably four towers with a sloping glacis in between, overlooking the Don, about $10[c .3 \mathrm{~m}]$ to 12 feet [ $3.6 \mathrm{~m}]$ wide'. Sadly, the photos he took of this were already lost by the time his diary was typed (the handwritten word 'lost' has been inserted beside 'Photos'). On $18^{\text {th }}$ November he was able to confirm his observations - 'The long N. face of the bank under the market facing the Don having been washed by the recent rains shows the rubble fillings, behind what I assume were the four towers, to advantage.' Himsworth $(1927-42,17)$ identified this corner as being the highest on the north side of the 

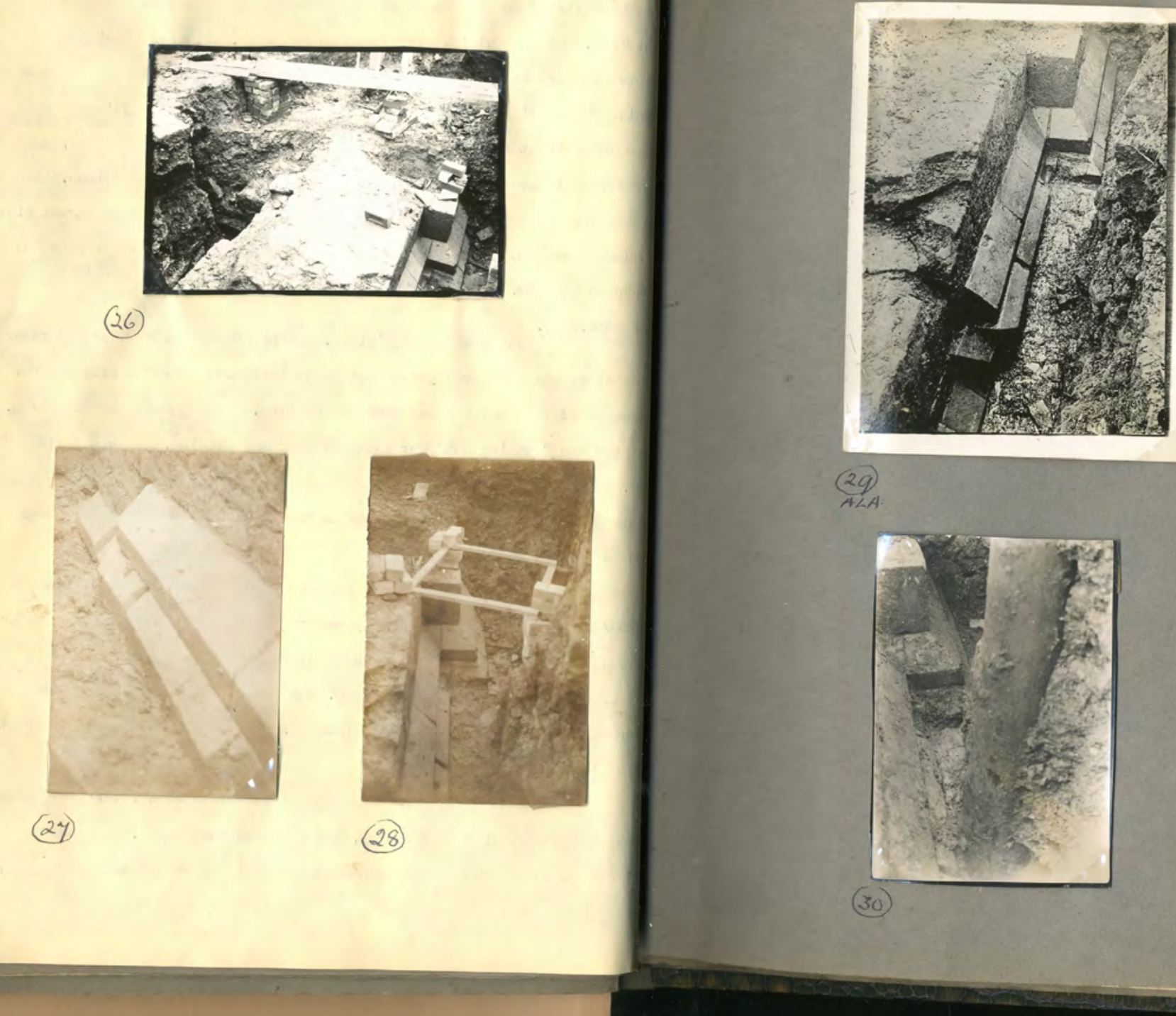

Figure 3.17: Two pages of photographs of the plinth course from Himsworth's diary. Photograph 28 shows a planning frame for the 'setting out' of Castle Hill Market. Courtesy of Museums Sheffield.

site, and the place where the largest perimeter tower was likely to have been situated. He felt that these sections of walling along the Don, along with the evidence for the original edge of the promontory, established the extent of the castle site (see also Chapter 7). It is clear from his diary entries that Himsworth was far more concerned with recording the topography of the site than was Armstrong in his published work (Butcher 1972a, 8).

\section{Courtyard buildings}

Structures probably associated with the hall and domestic accommodation of the castle were encountered at what is likely to have been the north-east corner of the inner courtyard. Stone walls - now encased in the chamber beneath the former market - were located $c .6 \mathrm{ft}(1.83 \mathrm{~m})$ to the north-east of the putative Saxon timber structure, and Armstrong (1930, 20-1; plate V, plans 1 and 3; Figures 3.2,3.3) argued that they were part of Thomas de Furnival's castle built after 1270. The first signs of the remains appeared on $15^{\text {th }}$ October 1928, and, alerted by the City Architect, Armstrong, Himsworth and Wigfull met on the castle site at 12.00 to view, about 'four or five feet below the present ground level', 'walling with a double plinth ... There was a corner or return in the plinth which was presumably a courtyard wall with a filling or backing of loose mortar and pebbles to the east' (Himsworth 1927-42, 6-7). Wigfull later (23 $3^{\text {rd }}$ October) told Himsworth $(1927-42,8)$ that the plinth was of 'sandstone, perhaps from Sheffield Park or Arbo[u]rthorne' (Figure 3.17).

Himsworth $(1927-42,7)$ returned on $18^{\text {th }}$ October to see that more of the walls had been uncovered, observing that 'A young man from the City Arch. Office was "setting out" for parts of the new building' - i.e. Castle 


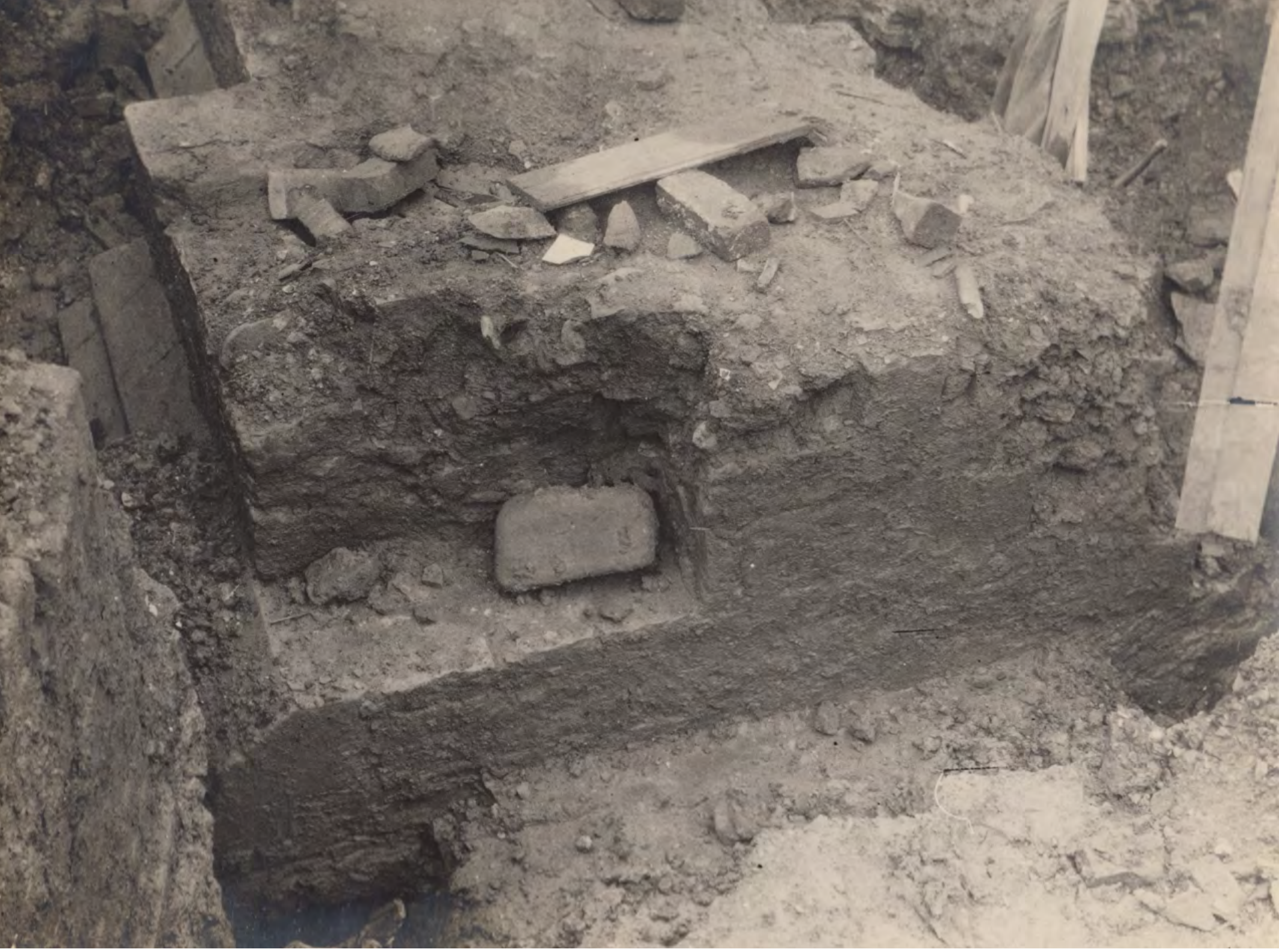

Figure 3.18: The return wall of the courtyard building. Photograph taken by Joseph Himsworth. Courtesy of Museums Sheffield.

Hill Market. Himsworth captured the moment in his photo 28, in which the 'frame' for one of the pillars for the new building, precariously held in place and levelled with bricks, sits on top of the wall and plinth which is still in the process of being exposed (Figure 3.17; see also his photo 38 for a close-up). This juxtaposition says much about the pressured conditions under which Armstrong and Himsworth went about their task, and so, more broadly, about the relationship between archaeology and development at the end of the 1920s.

Himsworth's diary entries for $23^{\text {rd }}$ and $31^{\text {st }}$ October 1928 reveal that work continued to uncover more of this structure, with Reg Loughran very helpfully 'putting' two men to 'test the wall for continuation to the south'. Significantly, Himsworth (1927-42, 8) noticed at the south end of this wall 'a return towards the east' comprising 'roughly dressed good squared rubble', with no plinth (Figure 3.18). In his diary, Armstrong $(1927-28,5)$ provides a detailed sketch plan of the walls 'as exposed 25th Oct 1928' (Figure 3.19), and this seems to have been the basis for the plan he published (as plan 3) in 1930 (Figure 3.3). On this, Armstrong shows the remains as consisting of two walls at roughly right angles to each other, one aligned from north-east to south-west, the other from south-east to north-west, and the measurements on plate $\mathrm{V}$ show that the top of the walls was at $177 \mathrm{ft}(54.10 \mathrm{~m})$ above ordnance datum (AOD) and their base at $174 \mathrm{ft}(53.03 \mathrm{~m})$ AOD. The north-east to southwest wall (the one described and photographed by Himsworth; Figure 3.18 ) survived for $15 \mathrm{ft}(4.57 \mathrm{~m})$ and was $5 \mathrm{ft}$ 3in thick $(1.61 \mathrm{~m})$, and was interpreted by Armstrong $(1930,20)$ as the external wall of a building facing the courtyard (also Himsworth 1927-42, 6). Its western elevation was faced with hammer-dressed stone built in narrow courses rising from a double-chamfered ashlar plinth course. At the north-eastern end of this wall, the plinth changed to a single chamfer, while at the south-western end the 'roughly dressed good squared rubble' noted by Himsworth $(1927-42,10)$ was taken by Armstrong to mark either a doorway or passage through the 


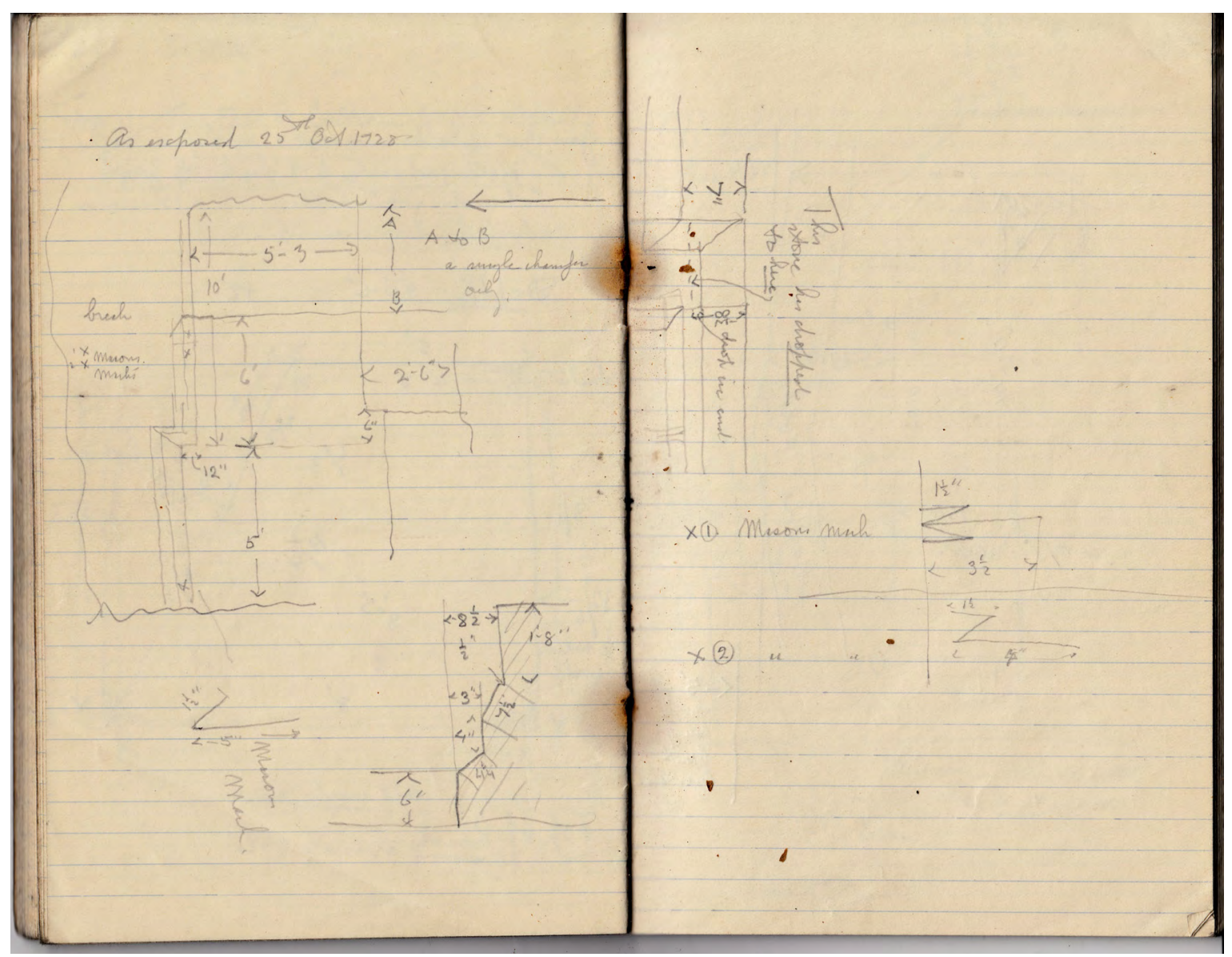

Figure 3.19: Sketches of the courtyard building. A record in the site diary of Leslie Armstrong of features exposed on $25^{\text {th }}$ October. This sketch formed the basis of plan 3 in his 1930 paper. Note also Armstrong's sketches of the masons' marks, and their location on this structure (see also Figure 3.21). Courtesy of Museums Sheffield.

wall. The south-east to north-west wall was dressed with similar stone, and was, Armstrong $(1930,20)$ argued, an internal division within a set of apartments.

On $30^{\text {th }}$ November 1928 workmen discovered, at the northern end of this structure, the 'remains of a stone vaulted room or dungeon'; the vaulting, Himsworth $(1927-42,10)$ noted, 'suggested a large span' (also his photos 33 and 34; Figure 3.20). Armstrong $(1930,20)$ argued that it was a cellar or dungeon. He may well have favoured the latter interpretation, which is what appears in one of his drafts (Armstrong n.d. (e)), while the caption to the published photograph (his fig. 13) labels it as the 'remains of a vaulted apartment, probably a dungeon. There seems to be no basis for this interpretation other than, perhaps, the fact that dungeons are what castles have (see also Himsworth 1935,$8 ; 1937,5,7 ; 1944,6$ ). There was apparently a narrow passage giving access to this room, but there were no surviving remains of any steps (see Chapter 7 for further detailed discussion).

Armstrong $(1930,21)$ also recorded the circular base of a stone pier or pillar, which measured $2 \mathrm{ft} 6 \mathrm{in}$ in diameter $(0.79 \mathrm{~m})$ and stood $2 \mathrm{ft}(0.60 \mathrm{~m})$ high, and was marked on his plan 1 at point $\mathrm{D}$ (see also plan 3$), 64 \mathrm{ft}(19.5 \mathrm{~m})$ to the south-east of the remains of the stone courtyard buildings (a rough pencil sketch appears in his diary; Armstrong 1927-28, 7). He thought it was of 13th-century date (or perhaps earlier) and associated with either the hall or the chapel, and he believed that it was in situ. He described the top as chamfered, but partly hacked away 'as it interfered with the foundations of a 19th century building erected there' (Armstrong 1930, 21). Himsworth also recorded and photographed this base, but in his diary for $30^{\text {th }}$ November 1928 disagreed with aspects of Armstrong's assessment: 


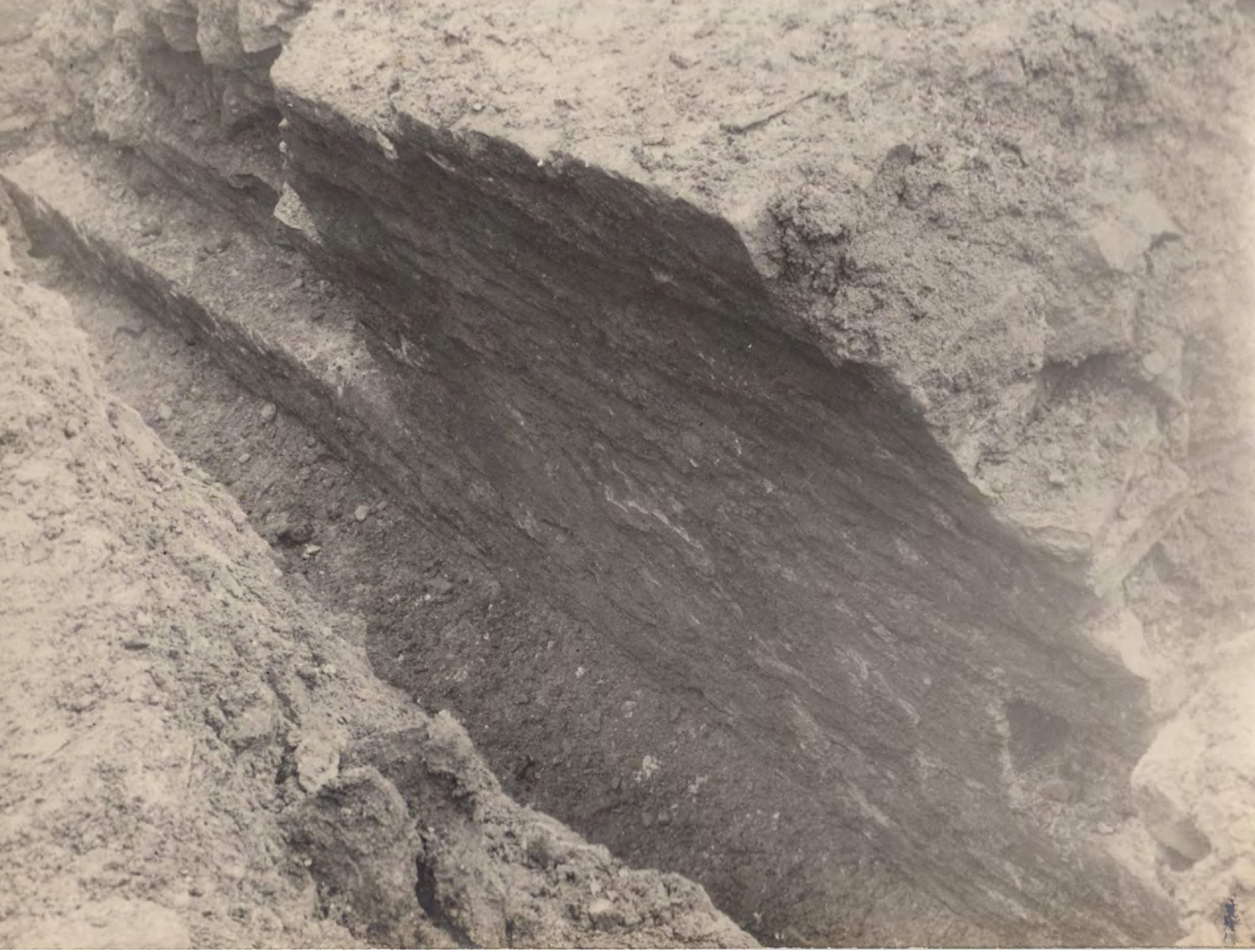

Figure 3.20: The vaulted courtyard 'apartment' during excavation. Photograph by A. Senior (Armstrong 1930, fig. 13). Courtesy of Museums Sheffield.

Considerably to the S.E. near the edge of the bank in Castle Folds Lane, a base of what appears to be remains of a Norman pillar. A.L.A. thought it was in situ, but Loughran and I think otherwise as there was no setting. It was in a clay bed very near the surface. A.L.A thinks it a very likely spot for the Chapel or perhaps the Great Hall (Himsworth 1927-42, 11).

Unfortunately, by the time his photographs of this base were taken (his photos 36 and 37; see also Senior 1928; Figure 3.15), it had clearly been moved as it was on edge leant against what appears to be a site hut (perhaps that in which the skeleton found on $20^{\text {th }}$ September 1927 ended up? This base too is currently in the chamber enclosing the courtyard remains).

Neither Armstrong's nor Himsworth's analysis of these structures makes it certain that the walls are contemporary, and therefore represent a single phase of construction. Nor was the modern study of the walling by Latham and Atkinson (1994) able to establish the relationship between the two walls, which had been unsympathetically reconstructed in more recent times as part of their display (Figure 3.21). This is an aspect of a more general problem - the lack of phasing information, and detailed, context-specific, dating evidence, about the remains uncovered in the process of constructing the Co-op and Castle Hill Market. This means that we can rarely date structures or establish relationships between them. It also results in an 'unhealthy' dependence on written sources 

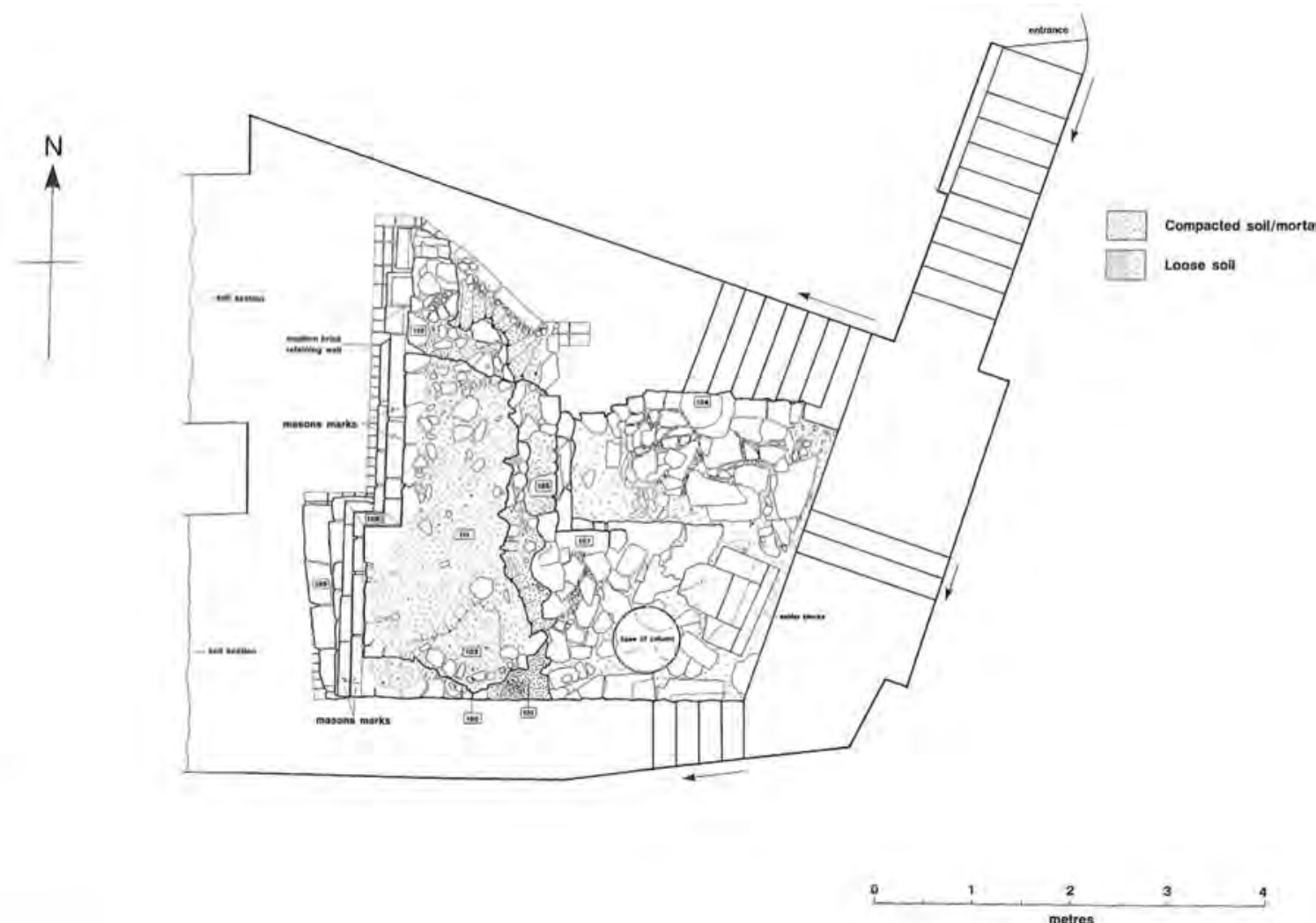

Figure 3.21: The remains of the courtyard building. Drawn by Ian Latham and Simon Atkinson in 1994. @ South Yorkshire Archaeology Service.

to date and, by extension, affects how we interpret the archaeological evidence (see below, Section: Discussion). Nonetheless, in this case we do have some indications that these courtyard buildings were built at roughly the same time as the gatehouse structures, and so may have been part of a restructuring of the castle (for further discussion of this, see Chapter 7). They have similar masonry, and Armstrong (1927-28, 5; 1930, 23, plate IV) recorded three masons' marks on the outer plinth of the courtyard structure, one of which was identical to a mason's mark on the plinth course of the west gatehouse tower (see also Himsworth 1927-42, 13). Armstrong (1930, 12) predicted that the range of buildings on the eastern side of the courtyard would extend to the north of the remains he recorded, and Himsworth's observation $(1927-42,18)$, on $9^{\text {th }}$ October 1930, of a 'piece of plinth' (as well as 'a piece of window tracery'), in the section overlooking the Don supports his argument. These substantial stone buildings may have formed part of either the Great Hall or domestic accommodation ranged along the north wall of the castle.

Himsworth's diary provides us with indications that traces of other buildings in, or close to, the courtyard might have been revealed during the construction work. On $1^{\text {st }}$ January 1929 he recorded the discovery of 'about three courses of very fine masonry suggesting a large doorway and two smaller ones'. Armstrong thought that, while the stonework derived from the castle, it had been 're-erected' - i.e. possibly after the Civil War 'slighting'. Himsworth (1927-42, 14), and Loughran, disagreed ('the jointing was ... too good') and believed it to be in situ. Unfortunately, the photographs Himsworth took do not survive (Richardson and Dennison 2014a, 49), but, given the date of discovery, it is likely that this structure too was in the north-eastern corner of the castle.

Himsworth also records that in or close to Castle Folds Lane 'big pockets of old lime and sand mortar' were found, 'evidently castle debris'. In one place, having dug down about $4 \mathrm{ft}(1.22 \mathrm{~m})$, they found 'large blocks of rubble, apparently for rough foundation work. Himsworth $(1927-42,13)$ goes on to tell us that these blocks, which measured 18 in by 9 in $(45.72 \mathrm{~cm}$ by $22.86 \mathrm{~cm})$, showed 'no signs of discolouration from exposure at any time'. It is not easy to understand exactly what he means here, but one might suggest that this rubble derives from the castle wall (and/or courtyard buildings) pushed into the moat in the context of its Civil War slighting (see also Armstrong 1930, 8, 14; Tuck and Rajic 2019, 29; and Chapters 5 and 7). 
Finally, we should note Himsworth's reference to the uncovering of a 'square sandstone pillar ... about $4 \frac{1}{2}$ feet high', to the south-east of the vaulted room of the courtyard building; this pillar had an iron rod embedded in it and was thought to be either part of the battlements or a railing of the 18th-century bowling green (Himsworth 1927-42, 11, photo 35; 1937, 9; Figure 3.22 and 3.23). As Himsworth notes, this bowling green is depicted as the central feature of the site in Thomas Winder's (1907) T'Heft an' Blades O'Shevvield. More to the point, it is at the heart of a plan of Castle Hill produced by the Fairbank family in 1769 (Figure 3.24; also Figure 9.4; Hall 1932) and features as one of the focal points in depictions of the site from the early part of the 18th century - for example, on Ralph Gosling's 1736 Plan of Sheffield (Figure 1.6), in Thomas Oughtibridge's 1737 North Perspective View of the Town of Sheffield (just above and to the left of the Lady's Bridge on the lefthand side of the picture, two people can be seen playing bowls; Figure 8.26), and in Nathaniel Buck's 1745 East Prospect of Sheffield, in which it is depicted as surrounded by a high wall. If Himsworth is correct that the pillar and iron rod were part of this complex, it would serve, along with these images, to confirm that significant activity took place on the site after it was slighted, some of which was every bit as important, socially and culturally, as what happened in the castle 'in the days of its pride' (Armstrong 1930, 17); see Chapters 7 and 9 for a further in-depth discussion).

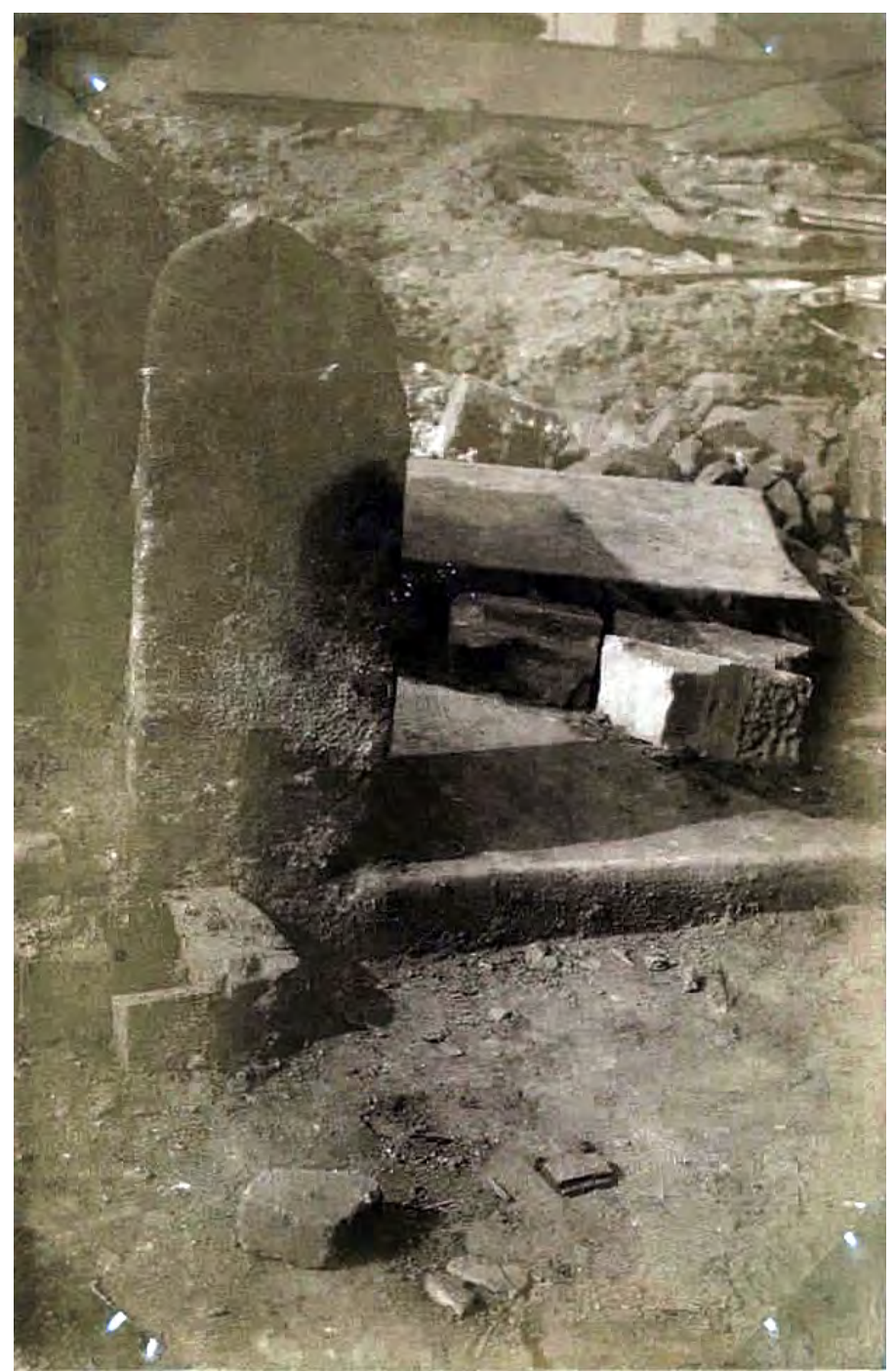

Figure 3.22: A sandstone pillar with an iron rod embedded in it. Photograph from Himsworth's diary. He thought it was either part of the battlements or a railing of the 18th-century bowling green. Courtesy of Museums Sheffield. 


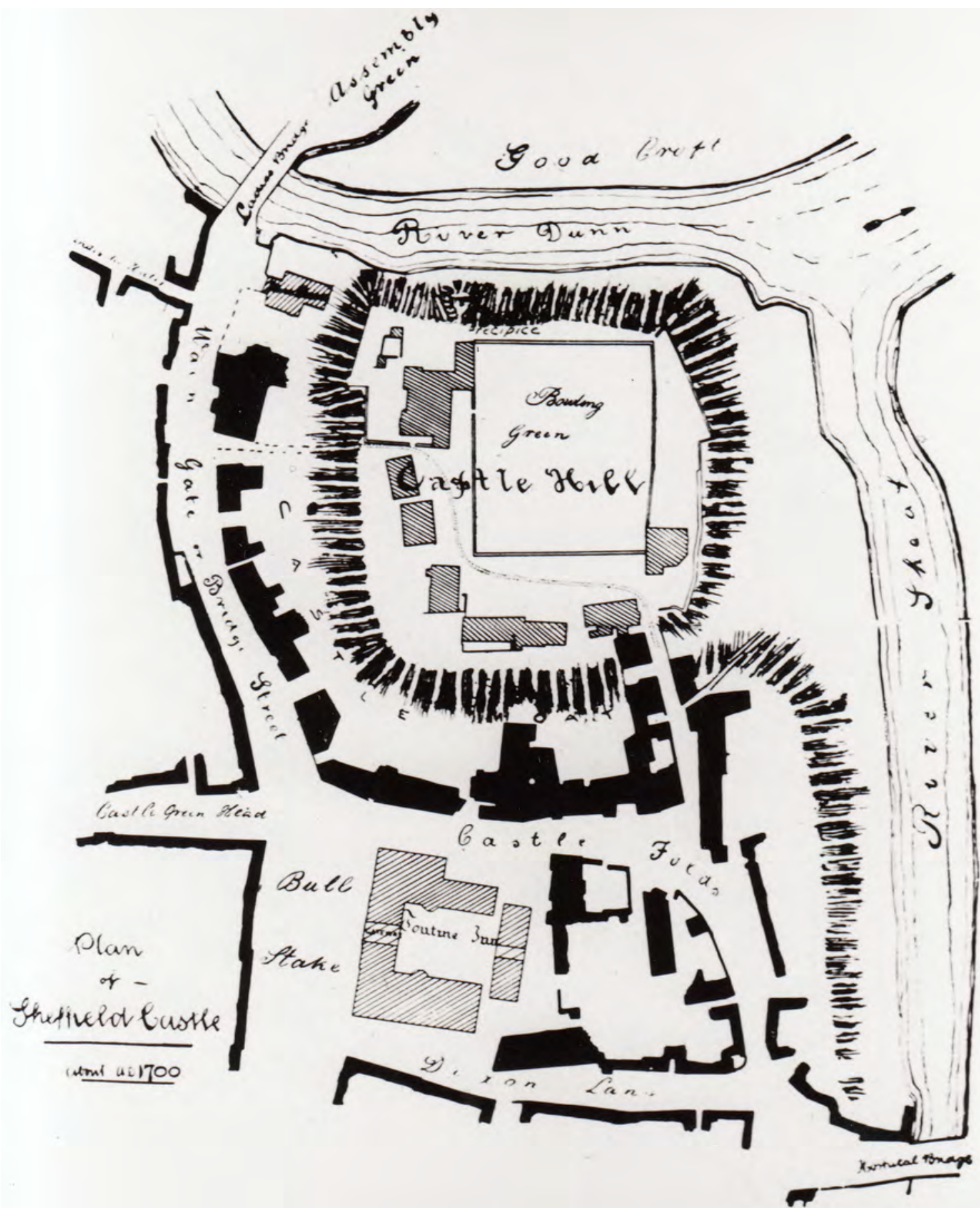

Figure 3.23: Plan of Castle Hill as it was believed to have appeared around 1700. From T'Heft an' Blades O'Shevvield, by Thomas Winder from 1907. Himsworth drew attention to this plan in his diary when trying to make sense of the pillar depicted in Figure 3.22. This plan is almost certainly based on detailed surveys of the site, on behalf of the Duke of Norfolk, by William Fairbank in 1769 and 1771 (see Figures 3.24 and 9.4). Winder had been architect and surveyor of the Duke of Norfolk's Yorkshire and Derbyshire estates. Public Domain. 


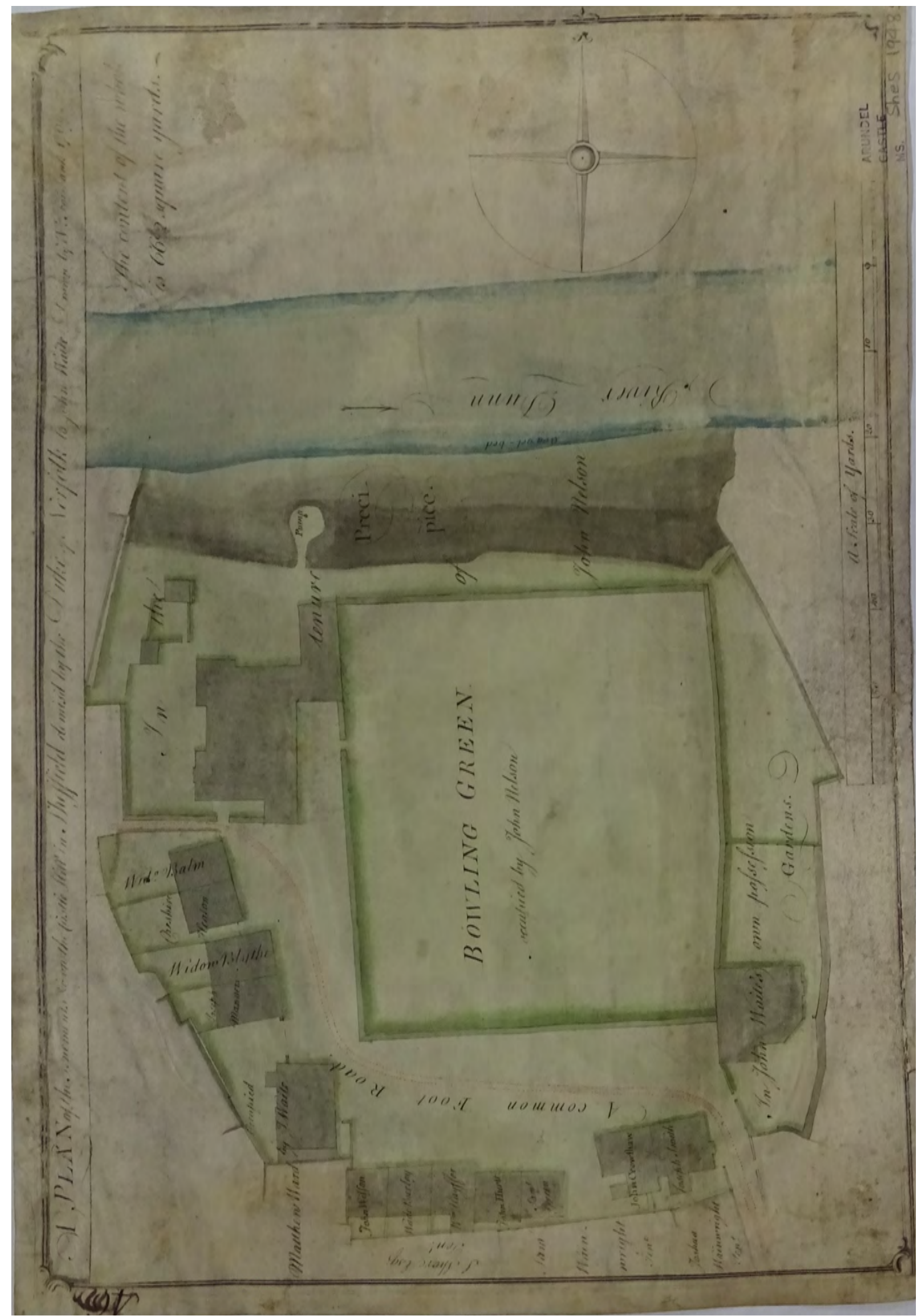

Figure 3.24: A Plan of the Tenements etc. on the Castle Hill in Sheffeld demised by the Duke of Norfolk to John Waite. Prepared and drawn by William Fairbank, 1769, illustrating multiple occupation of what had been the inner courtyard of the castle, and the centrality of the bowling green. Reproduced with permission from His Grace the Duke of Norfolk, DL and Sheffield City Council. 


\section{Discussion}

Archaeologically, what did Armstrong and Himsworth 'observe' on Castle Hill between 1927 and 1930? In very broad terms, they found one or more timber structures, the moat, layers of burning, the courtyard buildings, the gatehouse towers, the drawbridge pier, the gatehouse, and buildings along the north wall overlooking the Don. Before we can consider what these mean historically, we have to be able to date them (even relatively), and this is where the interpretations of the two pioneers are, in some respects, questionable. On-site working conditions hampering their ability to recover contextual information, and their limited knowledge of, for example, ceramic chronology, undoubtedly made dating features difficult, and Armstrong's efforts to do so were based largely on a combination of stratigraphy and text-based assumption. His conclusions are summarised in his plate V (our Figure 3.3), in which he shows the 'three successive buildings which have occupied the site' (Armstrong 1930, 22). The stratigraphic sequence, as presented, is as follows (from bottom to top) - wooden building, debris and humus, burnt layer, courtyard/stone castle. Similarities in construction style and in materials allowed Armstrong to extend this sequence horizontally (from the north-east corner of the site) to include the gatehouse towers (and drawbridge pier), an argument reinforced by the fact that the same mason's mark (the M-shaped one seen in Figure 3.19; also Armstrong 1930, plate IV) was found on the plinth course of the tower and on the courtyard buildings. The gatehouse added to the monumental entrance (in the 14th century?) would thus come at the end of this sequence which incorporates all the major features observed by Armstrong and Himsworth, apart from the moat. As we noted earlier, Armstrong (but not Himsworth) placed that at the beginning of this sequence, but there is, in fact, no stratigraphic connection between it and the timber buildings (and the 'Saxon' ceramic evidence, if it ever existed). We'll come back to consider the 'absolute' dates within this sequence, but now have to return to the stratigraphic relationships - i.e. can we be sure that the features and structures appeared in the sequence set out in Armstrong's plate V?

The earliest elements in this sequence were discovered 'at the eleventh hour', in one of the last excavations on the site - to create the chamber that would house the remains of the courtyard buildings. That 'last trench', Armstrong (1929c) says, produced 'clear evidence of three successive buildings on the site':

First a Saxon structure, which there is every reason to think is part of the Hall of Waltheof; secondly, traces of a building of early Norman date which was subsequently destroyed by fire, and which must be the castle of the first Norman Lords, the De Lovetots; and finally, the magnificent dressed masonry and massive walls of the great castle of Thomas De Furnival, erected in 1270, or soon after (also Armstrong 1930, 21).

The impression here (and in Armstrong 1930, plate V) is that a clear stratigraphic relationship was established between all of these structures. And at first sight this is reinforced by the notes and drawings Armstrong made while the excavation/construction was taking place. Thus, at the base of a measured sketch of the plinth of the courtyard buildings (labelled 'Market piece') is a note which says 'This is level with the burnt layer', and below this is another - ' $3 \mathrm{ft}$ to bottom of Saxon layer'. Importantly, however, there is another note, again level with the base of the plinth but with an arrow pointing to the left, which reads ' $5 \mathrm{ft}$ to the face of burnt layers' (Armstrong 1927-28, 6; Figure 3.25). From this, and from the fact that the earlier note said 'level with', not 'on top of', the burnt layer, we can deduce that there is no stratigraphic relationship between the 'burnt layer' and the courtyard buildings above (see also Armstrong 1930, 21). There do seem to be physical, stratigraphic, relationships between the timber buildings, the humus/debris, and the burnt layer, but even here Armstrong's $(1927-28,6)$ sketch drawing leaves room for some doubt since it suggests that the 'Saxon' layers lay c. $3 \mathrm{ft}(c .0 .91 \mathrm{~m})$ below the courtyard plinth - with the burnt layer $5 \mathrm{ft}(1.52 \mathrm{~m})$ away. Crucially, it seems that the section depicted in 1930 , plate $\mathrm{V}$ is one of Armstrong's typical, schematic, sections (above, Section: The inner courtyard moat) - not what was actually observed at that 'eleventh hour'.

And, if the stratigraphic situation is not clear, we are on even shakier ground when it comes to assigning dates to each of the layers and structures. Chronologically, the sequence is anchored in the belief that the timber buildings are of Saxon date, which, as we have seen, rests almost entirely upon textual references to Waltheof, and assumptions about the 'primitive' character of cruck-built structures. It now seems that this ascription of a Saxon date was an exercise in wish-fulfilment rather than having any relationship to past reality. There may be an early medieval phase on the castle site, but the timber structures discovered in March 1929 do not belong to it. Nor is there any strong evidence for Armstrong's putative early moat (but see Chapter 7). If there was 


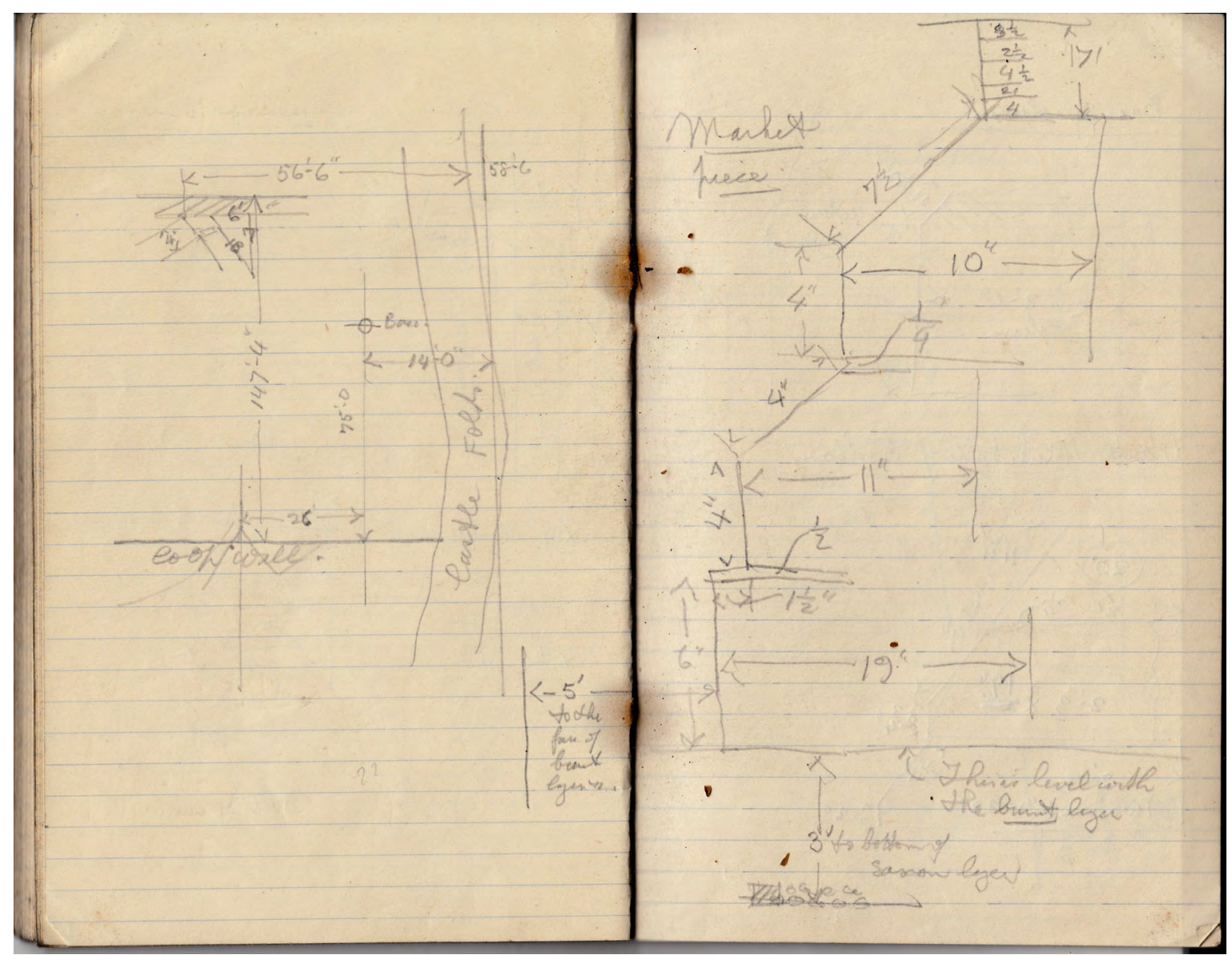

Figure 3.25: The plinth of the courtyard buildings (labelled 'Market piece'). From Armstrong's site diary. There is a note which says 'This is level with the burnt layer', and below this is another - ' $3 \mathrm{ft}$ to bottom of Saxon layer'. Another note, again level with the base of the plinth, has an arrow pointing to the left, which reads ' $5 \mathrm{ft}$ to the face of burnt layers.' Courtesy of Museums Sheffield.

an early medieval settlement it is possible that it was surrounded by a ditched enclosure; it is now clear from the work of Steve Bassett (2007) and John Blair (2018), for example, that such enclosures were a feature of the early medieval landscape of England (also Squatriti 2002). But the only 'evidence' for it are the fragments of Saxon pottery apparently found at the base of the south moat, and the fact that the (later) castle walls did not run parallel with it (Armstrong 1930, 16, 19, 23). The latter is at best circumstantial, and, as for the pottery, as Leslie Butcher (1972a, 8) pointed out, Armstrong identified it himself, it is not illustrated in his report, and he (Butcher) could not find it in the Museum - nor could we (see Chapter 6). Moreover, as we will see in Chapter 7, modern excavations have also failed to find any securely pre-Conquest pottery. If Waltheof was ubiquitous to Robert Leader, he remains elusive to us.

Next in the sequence is the layer of humus/debris, nearly $2 \mathrm{ft}(0.61 \mathrm{~m})$ deep. Again, there are no 'independent' dates, and Armstrong $(1929$ c; 1930, 21) dates and interprets it with reference to what he assumes comes before and after. In essence, he sees it as a product of the passage of time after William's supposed destruction of the aula of Waltheof. However, as we noted above, it is just as likely, if not more so, that this deposit was created rather rapidly through what McCoy and Stenton $(2009,8)$ called 'landscaping works', carried out to create the surface on which the site's next phase would be constructed. One of Armstrong's $(1930,13)$ abiding impressions of the site is of the "enormous depth of "made ground" covering it. Much of this, he believed, accumulated or was deposited in the 18th and 19th centuries ('as indicated by the pottery and coins'), but there had also been significant interventions in the Middle Ages. Thus he suggested that, when building his castle, Thomas de Furnival 'slightly raised the whole area of his courtyard and rendered it level by the addition of considerable 
material on the west and north', and that, before him, the de Lovetots 'had raised the ground in various places and partially levelled it' (Armstrong 1930, 8, 12); further evidence for this building up of the site emerged from the recording undertaken by Butcher, discussed in Chapter 5, and in the results of the 2018 evaluation, discussed in Chapter 7. Armstrong does not provide evidence (or locations) for any of this, but it is notable that the last suggestion could contradict his own argument that the layer of 'debris \& humus' accumulated over decades (Armstrong 1930, 23). This constant levelling-up was a product of both the topography of the hill and (we will argue later in the book) its earlier usage, had a significant impact on the character and preservation of the archaeological remains, and could affect the ways in which the heritage of the site can be deployed in its future regeneration (see Chapters 7 and 9). It also means that, in fact, no significant amount of time need have passed between the demolition of the wooden buildings and the creation of the 'humus' layer, or between that and the building represented by the burnt layer above.

Armstrong $(1929 \mathrm{c} ; 1930,12)$ is unequivocal in reading this thick layer of 'charcoal and wood ash', which, in places, also included 'fragments of stone crackled and burnt to a deep red tint by the action of fire', as the remains of the 'first' Sheffield Castle, built, perhaps, in the early 12th century, and destroyed by fire, supposedly, in 1266. This destruction layer is, in fact, his only evidence for the de Lovetot castle. But is it really the remains of that castle? Nothing dates the structures which burnt down to the 12th century, apart, perhaps, from the 'piece of typical "axed" masonry of early Norman character' referred to earlier (Armstrong 1929c) - but we do not know what this piece actually looked like, and it is not mentioned in Armstrong's (1930) published account. It is simply an assumption that the layer itself can be associated with any of the documented fires discussed earlier in the chapter, let alone that deriving from the actions of Johane D'Eyvill in 1266. The label 'Ashes 1266' and the description 'destroyed by fire in 1266' (Himsworth 1927-42, fig. 47; Armstrong 1930, 10) mask, then, considerable uncertainty in the apparent fixity and objectivity of a date (see also Chapter 7). Continuing this text-based approach, Armstrong immediately assumed that the gatehouse towers (and therefore the courtyard buildings) were 'remnants of [the] castle which Thomas de Furnival built in 1270', the date a direct link with another text, the licence to crenellate issued to Thomas de Furnival by Henry III (Armstrong 1930, 7, 10; 1928b, 365; Gatty 1869, 48; 1873, 13; Tucker 1874, 240; Drury 1929b, 180; Butcher 1972a, 8). And, while the towers might well belong to the later 13th century, as we will see in Chapter 5 it is possible to make a case for a date early in that century. The 14th-century pottery reportedly recovered from a deposit associated with the construction of the later gatehouse might have provided us with an independent means of dating the last element in our sequence but none of the pottery in the Museums Sheffield archive could be associated with this context (see Chapter 6).

In the unpublished draft of his proposed book on the castle, Armstrong extended his text-based archaeological framework into the early modern period. In an account of the 1644 siege of Sheffield Castle by Parliamentarian forces, during the English Civil War, the castle itself is described as strongly fortifyed with a broad and deep Trench of eighteen foot [5.5m] deep, and water in it, a strong [brest]-work [pallisadoed], a wall round of two yards $[1.83 \mathrm{~m}]$ thick' (Vicars 1646, 7). These details, Armstrong argued, 'were confirmed' by the excavations he oversaw. In this case it looks like the archaeology is providing the objective account against which the texts are measured. That the reverse is true, however, can be gleaned from the fact that Armstrong associated the phrase 'a strong brest-work pallisadoed' with the archaeological discovery of 'a series of stout oak "pallisadoes", which were an average of 5 feet $(1.52 \mathrm{~m})$ in length $\&$ had their ends sharpened. These were found driven into the bottom of the moat in three parallel lines, in eschelon' (Armstrong 1929b, 2). The 'breastwork' is, of course, a raised fortification, and so the palisade referred to in the text can hardly be the same as, or help explain, the sharpened posts found in the moat, but Armstrong used it to explain an aspect of the archaeology he observed. The fact that he would later, in his published account, place these stakes at the beginning of the archaeological sequence as part of a Saxon defensive system highlights the uncertainty about the dating of the moat, and about the way it and its fills seem to 'float' in the sequence.

The first page of one of the manuscripts in the Museums Sheffield archive, handwritten by Armstrong, contains a list of names and dates of the great men (and some women, including Judith, widow of Waltheof, whom he thought 'appears to have been a proto Mrs. Pankhurst and stood for women's rights!') who made the history of Sheffield Castle. They provide the framework around which the subsequent draft for a lecture or book chapter was constructed (Armstrong n.d. (b)), and exemplify a core element in Armstrong's approach to writing history. While his use of specialists to extract information from the finds speaks of a 'modern' approach which few suspected existed in the 1920s (see Chapter 2), it is nevertheless clear from the foregoing discussion that the objects would only be allowed to speak within a framework structured by texts, and as the product of an historical process driven by the 'great men' of history. This is an approach which would have been very normal 
in Armstrong's day, and which also informed the culture-historical approach which framed his writing of prehistory (see Chapter 2). Himsworth too, despite his instinct to seek out the 'common man', his deployment of empathy to engage with the past, and his leanings towards environmental determinism (see Chapter 2), nevertheless read the archaeological sequence at Sheffield Castle through the lens of great men. In the 'Saxons remains' we have, he argues

the Aula of the last of the local Saxon earls, Earl Waltheof ... The Conqueror ravaged the North in 1069, possibly banning [recte burning] this Saxon building the ashes of which came to light during recent excavations about two feet below the level of de Lovetots Castle which was destroyed by the rebellious Barons along with the town in 1266 (1937, 5; also Himsworth 1935, 8).

It is also one which has structured much subsequent understanding of the castle, and of Sheffield (for example, Hey 2010, 15-16). The new scientific dates produced as part of Wessex Archaeology's excavations in 2018 help us clarify and amend this sequence, and break the hold of 'great men' (see Chapter 7).

\section{Conclusion}

In this chapter we have elucidated the events that led to the first and hitherto only publication of the excavations at Sheffield Castle, revealing how interwoven became the actual historical realities of the castle's architecture, with the struggles of Armstrong and Himsworth to record and make sense of what they had seen, and the demands of inter-War concerns about Sheffield's heritage. Armstrong's paper set the agenda for all future work, with even modern excavations adopting its dating horizons (e.g. Davies and Symonds 2002, 9), but it has never previously been subject to critical analysis. For the first time, we have uncovered the circumstances and set out the process by which the published account emerged, identified the documentary and cultural influences on what Armstrong (and also Himsworth in his lecture scripts and diary) wrote, and traced what he omitted. The 1930 paper has repeatedly been misunderstood and undervalued because of a failure to appreciate the recording methods employed and the intellectual and cultural contexts within which Armstrong and Himsworth were working. While the texts on which it relied are certainly important to enhancing our knowledge of what happened at Sheffield Castle from the 12th century onwards, they are also partial (in the sense that they derive from, and tend to relate to, elites), and they can serve to limit our understanding, by reducing the range of scenarios we might consider, when imposed on archaeological sequences, and that is what had happened in the 1920s. Armstrong phased the castle remains on the basis of the characters around which Sheffield's early history had been constructed - Waltheof, de Lovetot, and de Furnival. In doing so, he created a long chronology for the site, back into late Saxon times, when, given the elusiveness of Waltheof and the scanty evidence for the 'de Lovetot castle', a short chronology, and one focussed on the 13th century, is equally possible (Hunter 1819, 26; Drury 1929b, 179), if just as unlikely. As we will see in subsequent chapters, our reanalysis of the evidence from earlier excavations, and the results of those recently carried out by Wessex Archaeology, have freed us from the constraints of the historical framework, have provided us with greater chronological precision, and have thereby helped to dilute some of the agency conventionally attributed to these great men.

The prominence of Waltheof, William de Lovetot and Thomas de Furnival in the work of Armstrong and Himsworth is heightened when we consider those elite actors who are absent. By comparison with the way in which the castle is discussed in the early 21st century, Mary, 'the unfortunate Queen of Scots' (Armstrong 1930, 8), is muted here, as are the Earls of Shrewsbury and Dukes of Norfolk. This is in no small part because Armstrong and Himsworth were in search of the origins of Sheffield and its castle; theirs was a history with local horizons. In the last two chapters we have shown how the means by which the archaeological sequences were constructed were, despite the pressurised circumstances of commercial construction, not all that different from then normal archaeological practice, and have used our awareness of the theoretical and conceptual perspective within which Armstrong and Himsworth worked to 'liberate' the evidence gathered from the framework imposed upon it. For all its undoubted shortcomings, our detailed analysis reveals a valuable record of the archaeology of Sheffield castle, and a unique insight into how it was uncovered and its story unlocked.

\section{Bibliography}

The full bibliography is available at the end of this volume, or at: https://doi.org/10.22599/SheffieldCastle.k. 



\title{
CHAPTER 4
}

\section{Post-War Rebuilding: A New Battle for the Castle}

\author{
To him must go the honour of pioneer discoveries on the site, as of course did the thrill of \\ first discovery which was largely denied to me. To him, alas, as to all turners of first furrows \\ must also go some criticism (Butcher 1961,7)
}

A new opportunity to record the remains of Sheffield Castle emerged at the end of the 1950s in the wake of post-War rebuilding. The Brightside and Carbrook Co-op's store at the corner of Waingate and Exchange Street was destroyed during the bombing of Sheffield on the night of $12^{\text {th }} / 13^{\text {th }}$ December 1940 (Figure 4.1). In 1949, following the compulsory purchase of their bombed headquarters by the City Council, the Co-op moved their city-centre store to temporary prefabricated premises on nearby Angel Street, before receiving planning permission for a new, more imposing, headquarters in 1958 (Figure 4.2). ${ }^{17}$ While the Castle Hill Market buildings to the north of the Co-op store 'largely escaped damage' (Himsworth 1927-42, 20), and temporary structures (socalled Bailey bridges) were used to ensure continued access to them (Zasada 1996, 32), parts of the Castlegate area remained derelict into the late 1950s (Butcher 1972c, 5). In 1958 the Sheffield Corporation began construction of Castle Market on the site of the former Co-op, with the intention of incorporating the Castle Hill Market into a single market-complex (Butcher 1972a, 5; Richardson and Dennison 2014a, 36; see their fig. 3 for the main elements of this complex). The new Castle Market building was intended to rehouse traders from the 100-year-old Norfolk Market Hall to the south of Exchange Street, and Castle Hill Market was refurbished and provided with new access from Castlegate (see Figure 1.15). New buildings were constructed or rebuilt fronting onto Waingate from the junction of Exchange Street to the Bull \& Mouth public house at the corner of Castlegate (Zasada 1996, 32; Butcher 1972a, 10). As in the late 1920s, a formal programme of archaeological investigation was not required in advance of this regeneration of the area, but the castle remains encountered in the course of construction works were recorded by Leslie Butcher from Sheffield City Council's Architect's Department and John E. Bartlett, Deputy Director of the City Museum. In this chapter we discuss the nature of the recording undertaken and the resulting archive, which is an essential prelude to analysing what was found in the next chapter.

${ }_{17}$ This new home, Castle House, is now a Grade II listed building (ref. 1393220); English Heritage 2009; Anon. 1950 (see Epilogue).

\footnotetext{
How to cite this book chapter:

Moreland, J. and Hadley, D. (with A. Tuck and M. Rajic). 2020. Sheffield Castle: archaeology, archives, regeneration, 1927-2018, pp. 105-133. York: White Rose University Press. DOI: https://doi.org/10.22599/SheffieldCastle.d. CC BY-NC 4.0, https://creativecommons.org/licenses/by-nc/4.0
} 



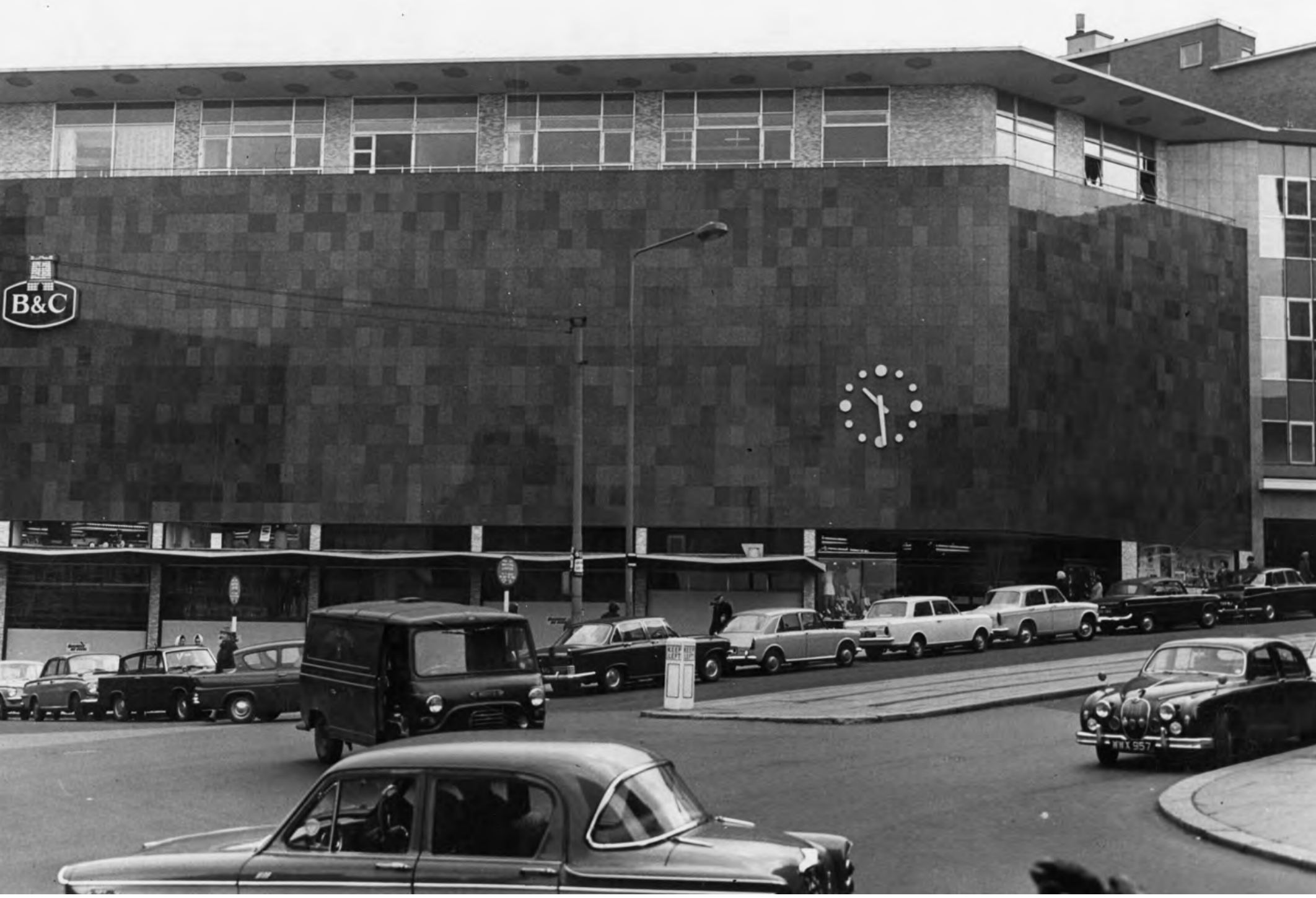

Figure 4.2: Castle House. The new home of the Brightside and Carbrook Co-op opened in 1964. With thanks to www.picturesheffield.com (s30254).

At first glance, our efforts here might appear forlorn. Over 20 years ago, Julien Parsons $(1997,1)$, then Keeper of Archaeology and Ethnography at Sheffield City Museum, bemoaned that 'some of Sheffield's most important archaeology has been destroyed with inadequate recording', while a review of previous investigations of Sheffield Castle dismissed the work undertaken by Butcher as having been conducted under 'restricted circumstances, taking the form of watching briefs with little opportunity for detailed recording' (Belford 1998, 6; for similarly pessimistic views see Davies and Willmott 2002, 6-9, 26; McCoy and Stenton 2009, 26). However, as with Armstrong and Himsworth in the late 1920s, while the circumstances under which Butcher and Bartlett operated were certainly restricted, their recording was nevertheless very detailed, and the character of the archaeological intervention was neither inadequate nor unusual for its time, and has been unjustly neglected in subsequent work. Although the two men shared responsibility for observing, recovering and recording the archaeology encountered during construction work, our greatest debt remains to Leslie Butcher (Figure 4.3) - his diligence and perseverance in recording the castle remains and trying to make sense of what he saw in the context of the earlier work of Armstrong and Himsworth is crucial to our knowledge and understanding of Sheffield Castle. This chapter accordingly begins with an outline of his archaeological career, which helps to explain why Butcher was charged with the Sheffield Castle 'watching brief'. We will also discuss his efforts to publish what he found, on which he had made considerable progress before his sudden death after a short illness in 1975. What emerges from this chapter is recognition of the quality of the work he, and Bartlett, 


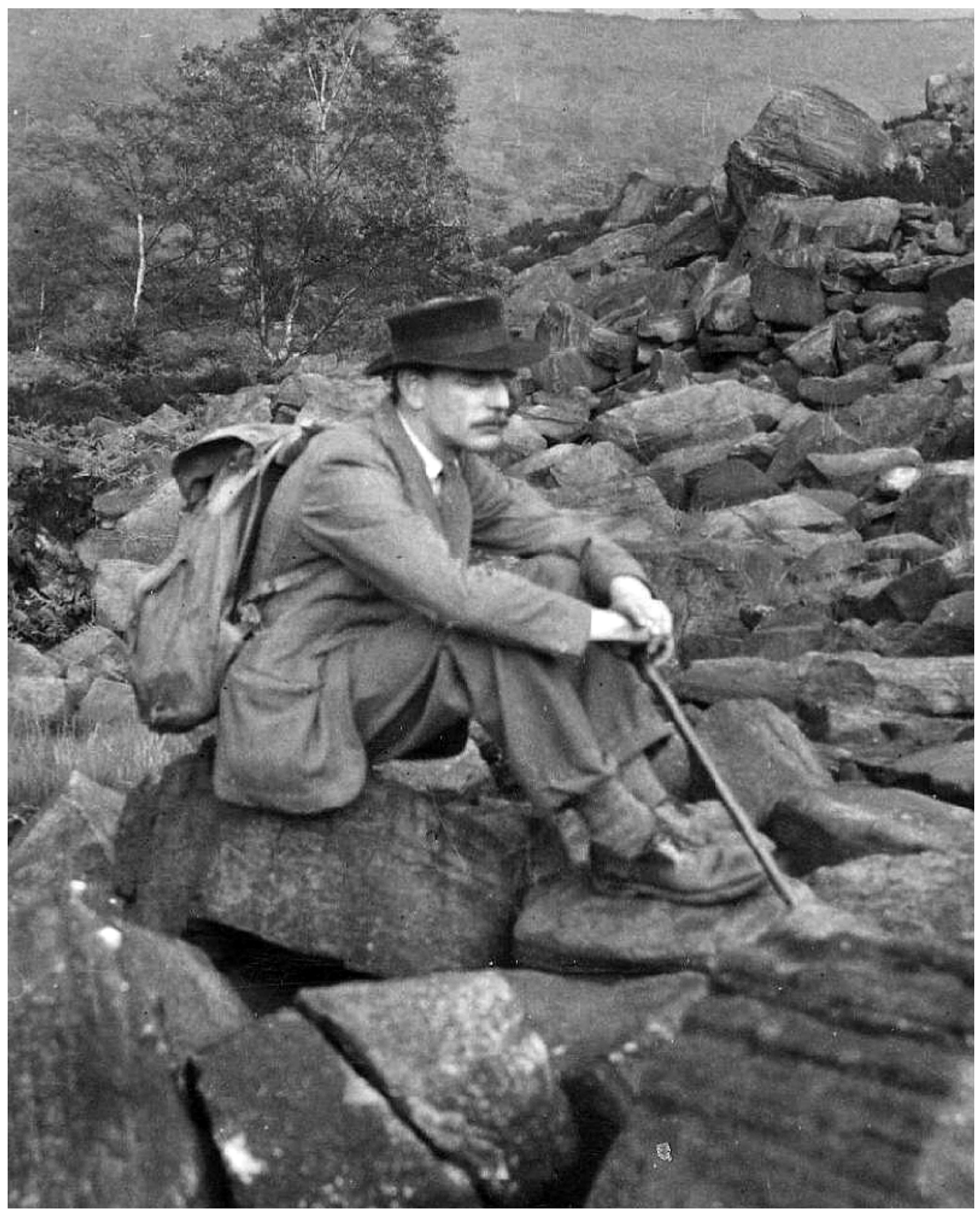

Figure 4.3: Leslie Butcher. A photograph taken at the Wharncliffe quern production site, Sheffield in the 1950s. Courtesy of Museums Sheffield.

carried out, and the immense value of local archaeological societies and museums in fostering widespread public enthusiasm in recording and championing the past in the mid-20th century, without which our knowledge of this major medieval and post-medieval site would have been immeasurably reduced. Leslie Butcher may have been unusual in the range of skills he possessed, in his determination, and in the opportunity he was 
granted to record Sheffield Castle, but the circumstances that led to the production of a valuable archaeological archive owe more to structural opportunities than to mere serendipity.

\section{Leslie Butcher: stalwart of local archaeology}

The various previous accounts of the excavations of Sheffield Castle outlined in Chapter 1 accord Leslie Butcher very little attention, but while he was not a full-time archaeologist - and, according to his son Nick (pers. comm.), was 'always very conscious of not being a formally trained archaeologist' - he was far from inexperienced. He was a highly skilled practitioner of archaeological field survey and illustration, was a key figure in the local archaeological scene, and operated in a context framed by national concerns about the archaeological heritage of the post-War decades. He trained as a mining surveyor, had a background in geology and was a long-time member of the Hunter Archaeological Society, spending much of his leisure time recording archaeological features in the countryside around Sheffield. His training led him to a particular interest in geological formations and soil development (Beswick and Merrills 1983, 17), and he was regarded among the local archaeological fraternity as having a very keen eye for landscape, with considerable abilities for distinguishing natural from man-made features (Bartlett 1977; Hart 1981, 53, 57, 63; Clayton 2012, 38). His differentiation of Bronze Age from Roman landscape features has been described as 'radical' for the time, and proven correct by subsequent fieldwork (Beswick and Merrills 1983, 16; Hart 1981, 53; Pearson and Oswald 2000). He also developed an interest in the relationship between distributions of prehistoric artefacts and varying soil types, but had not completed this work when he died.

Beyond short notes, very little of his work was published (Beswick and Merrills 1983, 17), apparently because, as his obituary by John Bartlett (1977) in the Transactions of the Hunter Archaeological Society puts it, 'he had a passion for perfection which prevented him all too often from achieving publication'. One exception was his excavation, conducted with Fredric (Freddie) Preston, a bank employee and lifelong member of the Hunter Archaeological Society (Jones 2012; Beswick 1997), of a section of the 'Roman Rig', or Ridge, an earthwork north-east of Sheffield, which had been identified as either an Iron Age defensive earthwork or a Roman road, although they principally encountered evidence of 19th-century tipping and quarrying (Preston and Butcher 1956). The other exception was a paper published in 1957 on quern working at Wharncliffe in north-west Sheffield (Butcher 1957). But, despite having published little, Butcher had a significant impact on the compilation and understanding of the archaeological record of the region. Particularly important was his collaboration with Preston, who was the local correspondent for the Ordnance Survey from 1949 to 1967, a voluntary position in which he provided the OS with details of the archaeology of the region so that they could include them on their maps (Beswick, pers. comm.; also Phillips 1980, 46-55). Together Butcher and Preston developed what became known as the 'Scheme for Archaeological Research' in the region around Sheffield, comprising a detailed inventory of archaeological monuments and finds, producing site records and distribution maps (Beswick 1997, 102-5). In this respect, Preston and Butcher ensured that the Hunter Archaeological Society was one of the first to respond to the initiative of the Council for British Archaeology, founded in 1944, which encouraged local archaeological societies to collect data that might otherwise be lost during post-War reconstruction (Beswick 1997, 102). The Scheme resulted in an index of sites, which was maintained by the Hunter Archaeological Society. It was hoped that local archaeology enthusiasts would consult the index and then be inspired to conduct their own fieldwork; this record eventually formed the basis for the South Yorkshire Sites and Monuments Record (Preston 1955; Bartlett 1977; Beswick 1995, 77; 1997, 103; Jones 2012, 35; Cockrell 2016, 59). As Pauline Beswick $(1997,105)$ has observed, the recording methods proposed in Butcher and Preston's Scheme 'predated the issue of the CBA's official record card [and] are so far-sighted as to foreshadow the County Sites \& Monuments Records, begun officially only in the 1970s' (Figure 4.4).

Butcher was responsible for mapping the archaeological remains recorded through the Scheme and his skills as a draughtsman were already recognised in the mid-1950s, when he was asked to provide maps and plans for the volume published following the hosting of the British Association for the Advancement of Science in Sheffield in 1956 (Linton 1956), comprising chapters on the natural history, prehistory and history of the region. Butcher illustrated the chapter on 'Prehistory' in which the section on the 'Palaeolithic, Neolithic and Bronze Ages' was written by Leslie Armstrong, while that on the 'Iron Age and Roman Period' was by Bartlett 
and Preston. Butcher was, thus, well connected with both local and national figures in archaeology before he took on the recording of Sheffield Castle, a fact that has been overlooked by previous reviews of the history of excavation of the site.

After Butcher's death, members of the Hunter Archaeological Society undertook 'The Butcher Project' to bring his work to publication. This involved examining in the field all of the sites that Butcher had recorded,

The Hunter Archaeological Soclety, Researah Sub-Committee.

\section{SCHEMT FOR ARCHAEOLOGICAL RESEARGH,}

I. Objects. The objects of the Scheme are:-

(1) to encourage and co-ordinate individual and collective archaeological research within the Society;

(2) to index and to record on period maps the archaeological sites and finds within the agreed area;

(3) to correlate the archaeological evidence with the natural features of the area; and

(4) to seek further archaeological evidence.

II. Area. The Scheme shall cover the area approximately contained by a line joining Woodhead, Edale, Baslow, Eckington, the YorkshireDerbyshire boundary as far as the Nottinghamshire boundary, Maltby, Adwick-upon-Deame and Woodhead.

III. Period. The Scheme shall cover all periods up to and including the Nedieval.

IV. Evidence. The evidence to be indexed and recorded shall comprise:-

(1) published sites and finds;

(2) sites and finds resulting from the Scheme; and

(3) unpublished sites and finds with the consent of those having knowledge of then.

v. Maps. The maps shall be transparencies based on the 1-in. O.S. maps, and shall include:-

(1) maps showing the natural features; and

(2) archaeological distribution maps.

VI. Method of Research. Each specific line of Research shall be undertaken by an individual or by a small group, in order to preserve the personal association of the individual(s). with the work.

The individual or the gxoup leader shall be responsible for seeing that all necessary permissions have been obtained.

VII. Results of Research. The Index and Maps shall be the property of the Society and shall be kept by the Sub-Committee.

The Index and Maps may be consulted by nembers of the Society, by members of other archaeological bodies and (at the Sub-Comittee's discretion) by other persons.

Provided that the use in any form of publication of information: obtained from the Index and Maps shall require the prior approval of the Society (to be given in such manner as the Committee shall direct).

The results of each specific line of rusearch may be published separately and pending publication may be kept by the Sub-Committee in the same way and under the same conditions as the Index and Maps.

(Adopted by the Hesearch Sub-Committce, 1949; revisad by the Kesearch Sub-Committee, 1967)

Figure 4.4: The Scheme for Archaeological Research in the region around Sheffield. Devised by Freddie Preston and Leslie Butcher in 1949; it was revised in 1967. Hunter Archaeological Society. 
collating and, where necessary, updating his notes and using these to draw up plans for publication (Beswick and Merrills 1983, 17). However, only two papers ensued. His former collaborator Graham Makepeace (1985) wrote up the Romano-British settlement Butcher had surveyed and excavated at Whitley, Wharncliffe, while Pauline Beswick and Dariel Merrills (1983) published a summary of his various surveys of mainly prehistoric and Romano-British settlements and field systems in North Derbyshire and South Yorkshire, accompanied by examples of his many plans and maps. This paper described him as 'a pioneer landscape archaeologist whose achievements deserve to be more widely known' (Beswick and Merrills 1983, 16). He had been planning a book on his surveys at the time of his death, and his archive reveals his systematic approach to recording earthworks. Butcher was clearly influenced by a Council for British Archaeology method statement from 1948 concerning the recording of Bronze Age features, which stated that

field systems and enclosed areas should be not merely photographed or roughly mapped, but precisely surveyed and measured. Only by this means will it be possible to evaluate the size and subsistence economics of the inhabitants, and so obtain a realistic picture of the mode of life and social organization; in other words, to make prehistory live (Hawkes and Piggott 1948, 91; Beswick and Merrills 1983, 16; Heath 2003, 30).

His early work, using compass and pace to measure features, was recorded on 6in base maps, but in his later work he used the 1922 edition of the 25in Ordnance Survey Map (Beswick and Merrills 1983, 17); here, as in his work on Sheffield Castle, his training as a surveyor clearly influenced his archaeological practice. Unfortunately, despite the hope expressed by Beswick and Merrills $(1983,17)$ that Butcher's work on Sheffield Castle 'may eventually be published', this was not to come to fruition until the present volume.

\section{Sheffield Castle in 1958: the threat of post-War redevelopment}

In the post-War decades the threat to archaeological remains in Britain, especially in cities, was severe (Biddle 1972, vi). Reconstruction and redevelopment, including major infrastructure projects (such as city ring roads), dramatically altered, and in many cases obliterated, the topography of medieval towns and damaged or destroyed the archaeological evidence for human activity within them. This was as true of Sheffield as it was elsewhere, most famously London, where between 1946 and 1962 the Roman and Mediaeval London Excavation Council, led by Professor W. F. Grimes, despite some supposedly 'valuable links' with individuals in the City, managed to raise only $£ 46,000$ to record the destruction of the city’s archaeological heritage (Shepherd 1998, vii; Gerrard 2003, 95-6). As Barri Jones $(1984,122)$ notes, 'the scale of its financial support [was] wholly inappropriate to the archaeological problems posed by the City of London'. In London, as in Sheffield, those linked processes of reconstruction and destruction did not come to an end immediately after the War (contra Jones 1984, 20), and, in Sheffield too, very limited resources were available to counter this threat to its medieval heritage. As Stuart Bryant and Jan Wills $(2016,4)$ point out, during this period archaeological intervention, even on sites threatened with destruction by development/regeneration, was by no means guaranteed. In many, perhaps most, cases, any response to such threats was dependent on voluntary effort and good will, on 'tolerant developers allowing access to sites in advance of the commencement of work?. More typical than not is the situation described by Barri Jones $(1984,48)$ for Perth (Scotland) in 1974, in which requests to gain archaeological access to an important site prior to development came to nothing despite the fact that all that was being asked was 'simple access for observation by persons who were adequately insured and professionally competent'. The Minister of State, in a reply to Perth Civic Trust, made the position clear - if the developer cannot be persuaded to allow time for archaeological examination of a site no power exists to compel him' (Jones 1984, 49; Biddle 1972, vi).

In comparison, the situation in Sheffield in 1958 seems relatively benign. Leslie Butcher wrote several accounts of the process which led to him being asked to record the structures and strata encountered in the course of excavation of the foundations for the new Castle Market building (Butcher 1972a; 1972b; 1972c; 1961; Figure 4.5). Although they vary slightly, these accounts are consistent in reporting that Butcher was 'appointed'

or 'instructed' by the City Architect, (John) Lewis Womersley (Figure 4.6), to record 'all structures of archaeological interest' found during those excavations, and that John Bartlett 'undertook the recovery and conservation of loose finds' (Butcher 1972b, 2; 1972c, 14; 1972a, 5; Nick Butcher pers. comm.). 


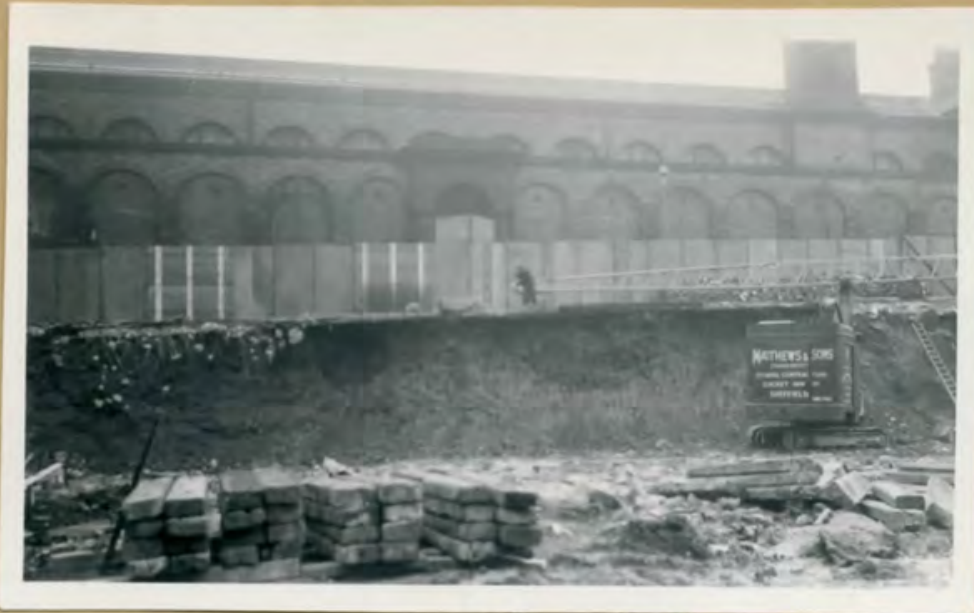

15) Lubsid deteh, Exehange At, hue 8 .
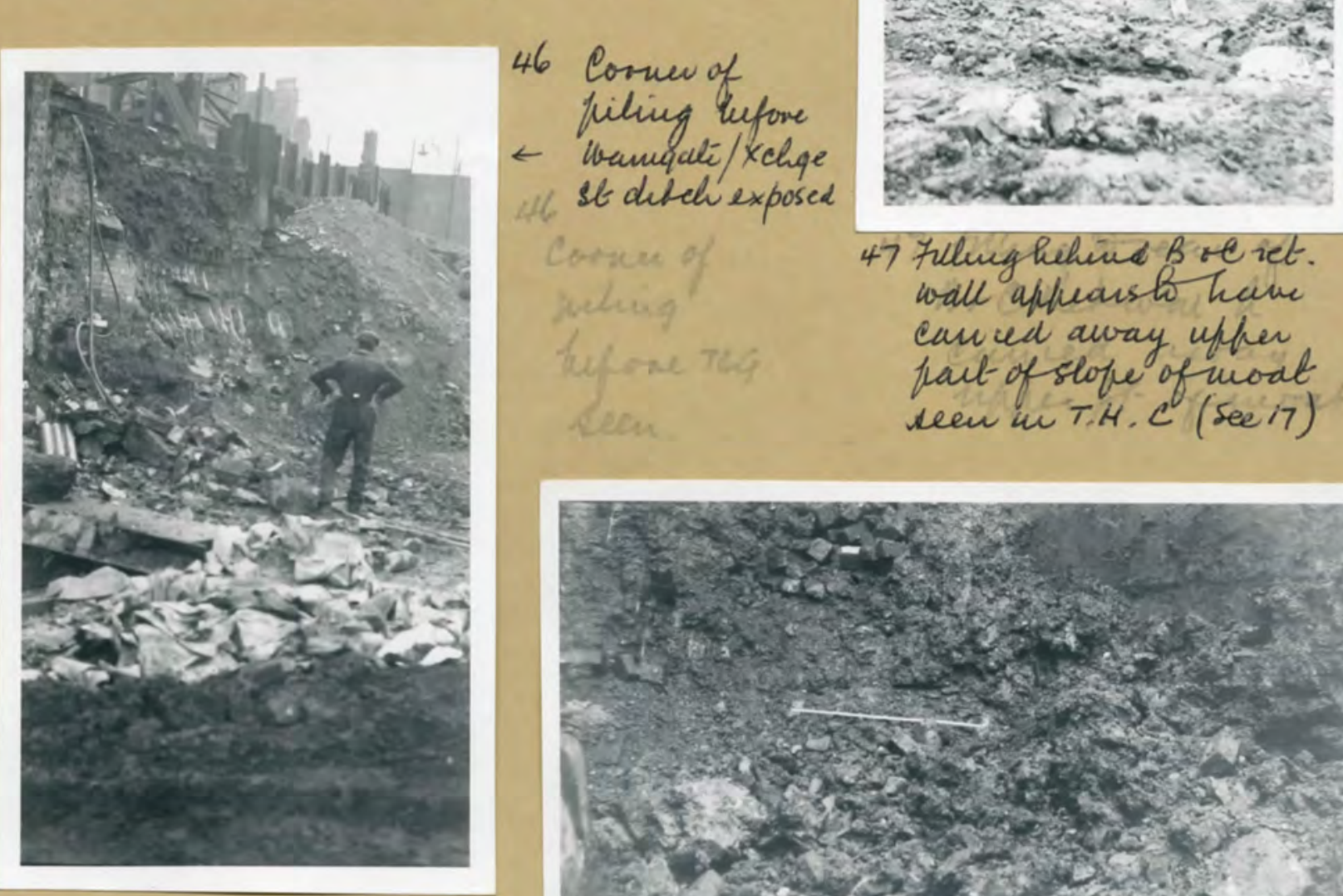

47 7dlug hihind B re iet. wall apfears b have canced away upfer part of slofe of wo at seew wi T.H. C (See i7)

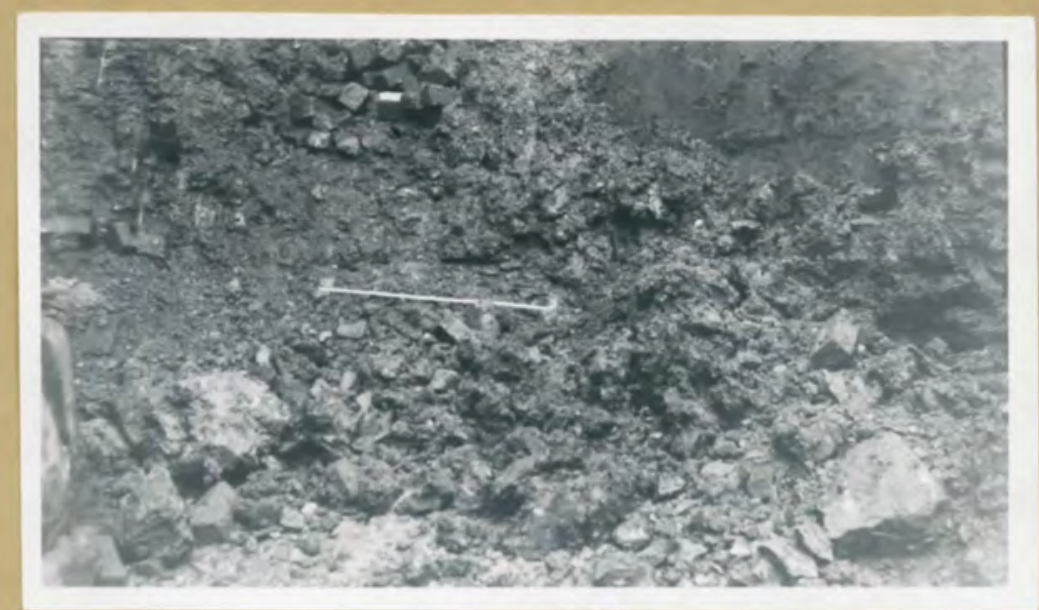

$48 \uparrow$ as 4\%, latu.
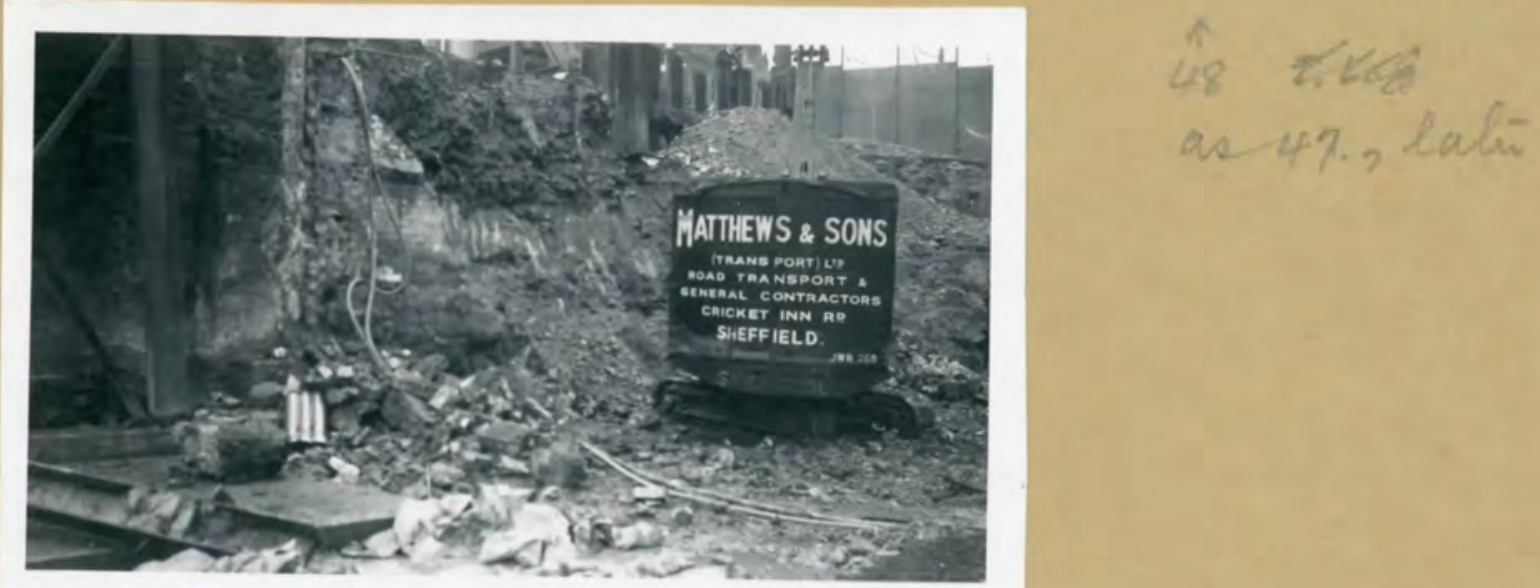

45. Cos 46.46 
The impression that the need for an archaeological input was recognised, and welcomed, at the highest level among those who planned and delivered the Castle Market project is confirmed in the details of some of Butcher's papers. In a handwritten account he stated that Womersley appointed him to the task 'as a result of representations' (Butcher 1972b, 2). One might suspect that those 'representations' were made by the Hunter Archaeological Society, of which Butcher was a member, and which had played such a pivotal role both in securing Armstrong's involvement in the excavations of the late 1920s and in preserving the remains uncovered (see Chapter 2). Had it been them, however, we might have expected Butcher to mention this in a lecture on the excavations which he delivered to Hunter Society members on $10^{\text {th }}$ January 1961 - especially given that a report on the lecture in the next day's Sheffield Daily Telegraph ('New light', 1961), told readers that Butcher had 'recorded the excavations for the corporation and the society' (emphasis added). Instead, in the handwritten text of this lecture, he singled out for thanks 'the council committees \& chief officers of the Corporation who between them decided to have a record and appointed me to do it' (Butcher 1961, 8), suggesting, perhaps, that the impetus (and the 'representations') came from 'high up' in the local authority.

While the decision of the Corporation and the City Architect to make a record of the archaeology on Castle Hill was clearly not driven by any legal requirement to do so, it equally might not have been entirely the product

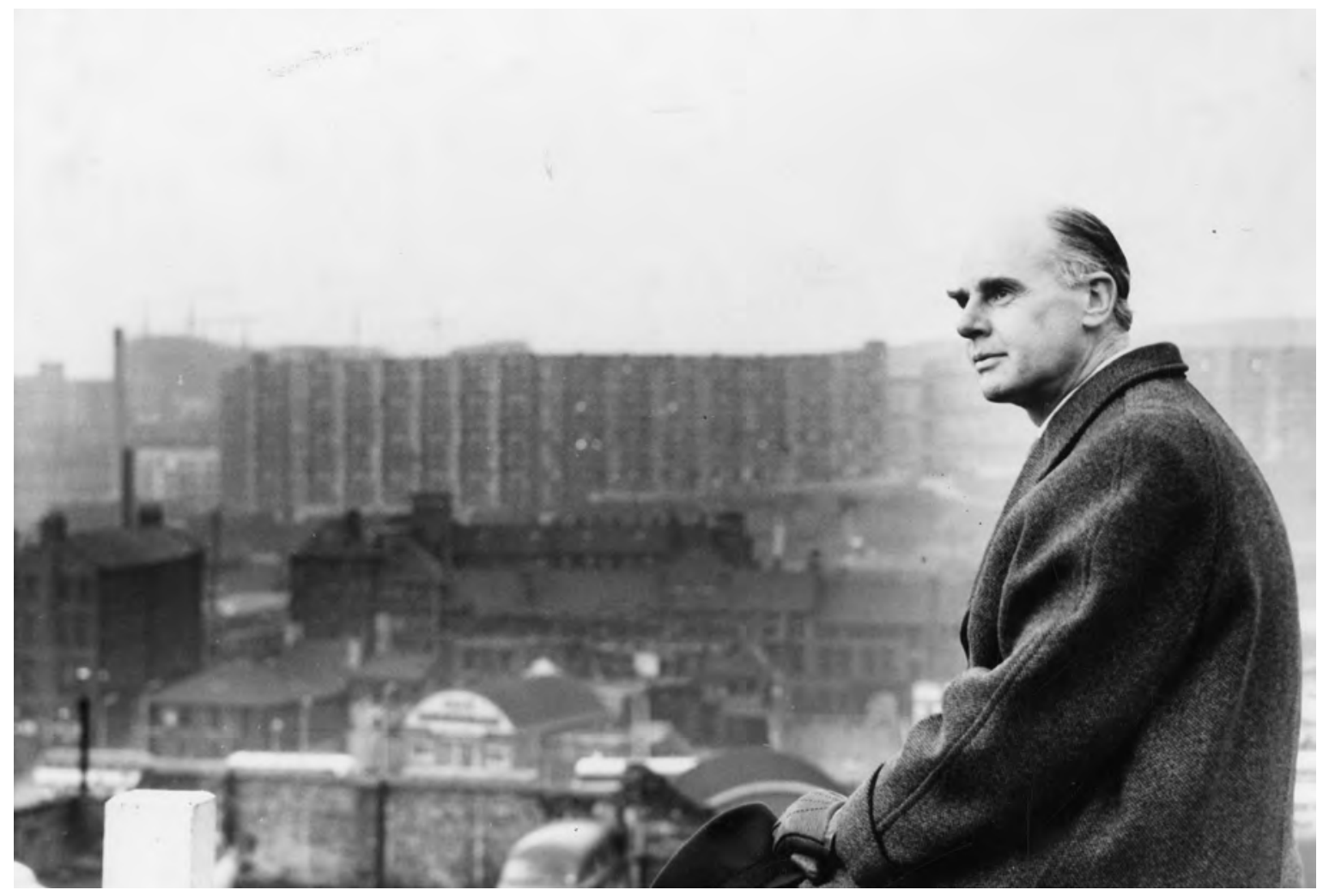

Figure 4.6: J. Lewis Womersley, Sheffield City Architect (1953-64). He was responsible for the building of Castle Market on the site of Sheffield Castle and the high-rise Park Hill and Hyde Park flats on the edges of the former deer park. The Hyde Park flats can be seen on the horizon, in a photograph taken in 1964. With thanks to www.picturesheffield.com (s34943).

Figure 4.5 (page 112): Photographs taken during building work on Castle Hill in the late 1950s/early 1960s. These show the circumstances in which Leslie Butcher and members of the City Museum were working to record archaeological remains. These photographs were all taken at the corner of Exchange Street and Waingate, and the top left photograph shows the pair of ditches that he recorded there in the section. Courtesy of Museums Sheffield. 
of a desire to uncover and understand the city's heritage. From Armstrong's (1930) published account, council records, and the memories of those involved, there will have been awareness of the constructional difficulties encountered by those who built the Brightside and Carbrook Co-op building in the late 1920s, caused by the presence both of substantial stone structures and deep, waterlogged moat deposits. In a telling comment in the typescript of a paper he was preparing for publication in the early 1970s, Butcher reveals that his involvement began even before excavations started on site; he was asked by Womersley ' when design work started on [the new Castle Market building] to assist in defining the shape and extent of the moat for design and contract purposes' (Butcher 1972a, 5, emphasis added). Thus, in contrast to what seems to have been happening in other parts of the country, those involved in creating Sheffield's new market building drew on Butcher's considerable archaeological experience not only to record the remains of the past but also to assist in the pre-construction, design phases of the future building.

This spirit of collaboration continued during the construction process, with Butcher (1972a, 6) emphasising the 'interest, cooperation and assistance of those primarily concerned with building the market' (also Butcher 1972c, 14). This extended to changing construction methods to facilitate archaeological recording. Nick Butcher (pers. comm.) recalls that his father was instrumental in persuading the contractor to use handtimbered foundation shafts at a time when piling was increasingly the norm. This decision was critical in allowing detailed recording and the recovery of a wide range of artefacts. Indeed, in one of his handwritten accounts, Leslie Butcher thanked the Markets Committee, 'the contractors, and the City Architect for supporting the change we advocated in the redesign of the chamber protecting part of the gate structures' (Butcher 1972c, 14, emphasis added). He provided the audience at his Hunter Archaeological Society lecture with further details. Having uncovered the foundations of the towers, the gatehouse forebuilding, and the edge of the inner face of the moat, 'I pressed for these new discoveries to be left permanently open \& both the City Architect, contractor and all concerned finally agreed to lower the sub basement floor a little further' (Butcher 1961, 29). Butcher, therefore, was not only involved, as an archaeologist, in the pre-construction phases of the Castle Market project; he also influenced the mode of construction and the final form of a part of the building - the developers and contractors were evidently willing to listen to him.

Among the details of Butcher's accounts, however, are signs that not all was 'plain sailing. For example, might not the fact that, in the course of his lecture to the Hunter Archaeological Society, he thanked Andrew Derbyshire, the project architect, for 'much sympathy' (subsequently edited to 'understanding \& help') suggest that he too had experienced something of the frustration (and perhaps resistance) which Armstrong records of his dealings with those building the Co-op? Furthermore, Butcher (1972a, 6; 1972c, 14) made a point of noting that during the recording of the archaeological remains on Castle Hill 'lay assistance was not officially encouraged. There were clearly limits to the level of archaeological presence acceptable on site, and (beyond Butcher and Bartlett, and some colleagues from the Museum) this seems to have been confined to those who assisted with photography (Butcher 1972c, 14). There are implications in all this about public access to the city's past, with no sense here that the archaeological remains belonged to 'the people' of Sheffield as part of their patrimony and heritage - and this at a time when community involvement, led by the Hunter Society, in recording (and preserving) that heritage was flourishing (see above and below, Section: John E. Bartlett, the City Museum and the flowering of local archaeology; also Chapters 7 and 9 for how much has changed in this respect since 1958).

Despite the comparatively effective collaboration between archaeologists and developers, in terms of control, finance and resources, the former were still very much second-class (and impoverished) citizens. Butcher's friend Cyril James assisted with photography, and 'took score upon score of colour photographs at his own expense \& in his own time' (Butcher 1961, 8, emphasis added). It is not evident from his written accounts how Butcher's own time and effort were funded - and, to judge from the large number of sections, plans, isometrics and other reconstructions he produced, he spent a vast amount of time on the project. We need to remember that, like his predecessors Armstrong and Himsworth in the role of recording the castle remains on a site 'under active commercial excavation' (Butcher 1972c, 4), he was not a professional archaeologist - there were still very few of them. He had a full-time job as a surveyor, and his son Nick (pers. comm.) reports that his father's involvement on the castle site during the construction process was 'mostly confined to his lunch breaks', with his office conveniently located nearby in Fitzalan Square. Although he was only 12 when the excavations began, Nick well remembers 'our daily discussions of his observations from each day's lunchtime inspections of the foundation shafts'. So, although Womersley may have 'appointed' him to the task of recording the castle 
remains, it seems that neither was he 'seconded' to that role nor were significant (any?) resources placed at his disposal to help him complete the task. As Nick Butcher (pers. comm.) told us, 'I am not aware that ... he had any in-work time allotted to this work. Rather my impression was that if he was a little late returning from his "dinner break", due to some especially interesting situation, he had backing from a very high level'. In this context it is very telling that, at the beginning of his 1961 lecture to the Hunter Archaeological Society, Butcher thanked the 'senior members of the OUR Committee who produced cash when my funds ran low' (Butcher 1961, 8, emphasis and correction in the original). Perhaps Andrew Derbyshire's 'sympathy' was for the straitened circumstances in which Butcher had to work?

\section{John E. Bartlett, the City Museum and the flowering of local archaeology}

We know much less about John Bartlett's involvement in the Castle Hill excavations that began in 1958 (Figure 4.7). He is not mentioned at all in some reviews of the archaeology of the site (e.g. Parsons 1997, 1; Belford 1998) and only once in others where he is merely noted as having assisted Butcher (e.g. Davies and Willmott 2002, 6; Richardson and Dennison 2014a, 55). This negation of Bartlett's involvement is, to some extent, understandable. First, unlike Butcher, he did not produce any written account of the project or of his involvement in it - so we simply know much less about what he thought or did. Second, his involvement was comparatively brief as he left Sheffield on $1^{\text {st }}$ March 1959 to take up an appointment as Director of Museums at Kingston upon Hull (East Yorks) (Museums Sub-Committee 1960). However, we have established that his participation was as part of a partnership with a defined and accepted division of responsibilities: Butcher, with his extensive surveying and archaeological field experience, and background in geology, took charge of recording and mapping the structures uncovered and the local topography; Bartlett, also an experienced field archaeologist but with a museum background, took on responsibility for the finds (Butcher 1972a, 5-6; also 1972b, 2; 1972c, 14). It is not clear from the archival material who asked Bartlett to take on this role, but it was probably the Museum Director, H. Raymond Singleton. Moreover, as we will see, Bartlett was one of the driving forces behind local archaeological enthusiasts, and had worked closely with Butcher for some years through their involvement in the Field Research Section of the Hunter Archaeological Society.

Bartlett was notably more visible than Butcher in the early newspaper reports on this phase of the uncovering of the castle. On $25^{\text {th }}$ April 1958 the Sheffield Daily Telegraph reported that 'Sheffield City Museum authorities have been carefully watching [the excavations], since the market work started some months ago' (Hopkinson 1958a), and on $2^{\text {nd }}$ May noted that 'Mr John Bartlett, Deputy Director of Sheffield City Museums, is watching the site excavations on the Museums' behalf' (Hopkinson 1958b). In neither case is there any mention of the involvement of Butcher or the Sheffield Corporation. This just might be a product of the personalities involved, with Butcher being somewhat 'retiring' and Bartlett not averse to the limelight (Pauline Beswick, pers. comm.; Armstrong 2001, 4) - Nick Butcher (pers. comm.) recalled that 'my father was not a committee man and did not fit into administrations easily. Rather he preferred to work alone or rather with his close group of associates'. Butcher (1972a, 6) described his work with Bartlett as a 'very enjoyable collaboration', and his son Nick (pers. comm.) told us that it was his impression that 'the relationship was one of mutual respect with the work undertaken being collaborative and complementary, rather than overlapping'. He also said that he thought that his father 'gradually drifted away' from the Hunter Archaeological Society after John Bartlett left the Museum, perhaps confirming our impression of the close relationship between the two. Expanding on the working relationship between his father and the Museum staff, Nick provided some fascinating insights into the practice of archaeology on a mid-20th-century construction site:

My father's role was principally as surveyor producing [foundation-]shaft stratigraphy sections, finds locations (at least in terms of depth) and measuring up the castle foundations and moat profiles to the extent they were revealed. My understanding was that each day's moat diggings (by one man) was stacked off to one side or in a series of kibbles ${ }^{18}$ by the contractor and worked through by the museum staff [presumably including Bartlett] and volunteers by the next day (Nick Butcher pers. comm.; Figure 4.8).

${ }^{18}$ The word 'kibble' derives from mining - a large wooden or (later) iron bucket, for conveying ore or rubbish to the surface' (O.E.D.). 


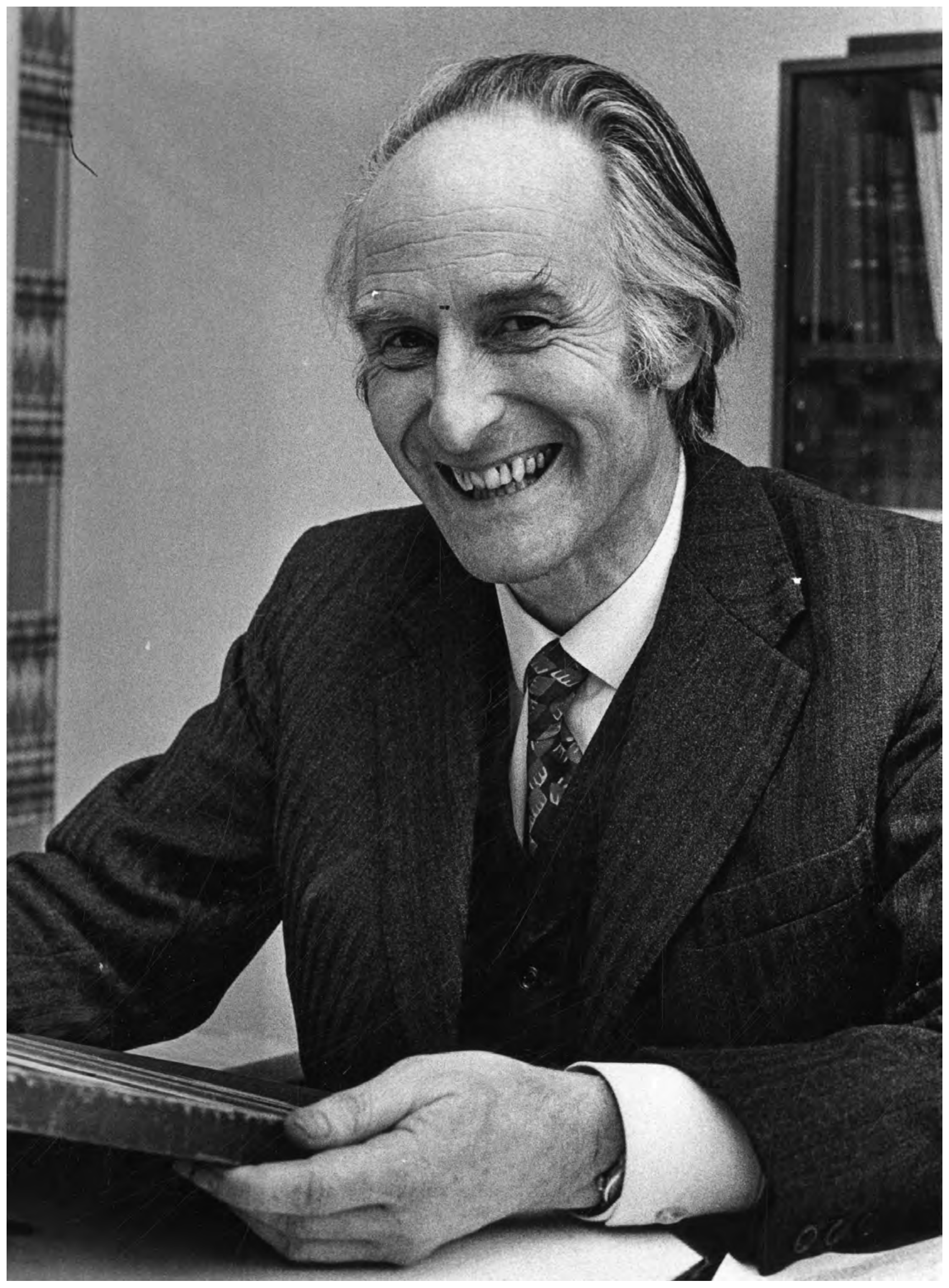

Figure 4.7: John Bartlett. Photographed in 1972, after he returned to Sheffield from Hull Museum to take up the post of Director of the City Museum. Courtesy of Sheffield Newspapers Ltd. 


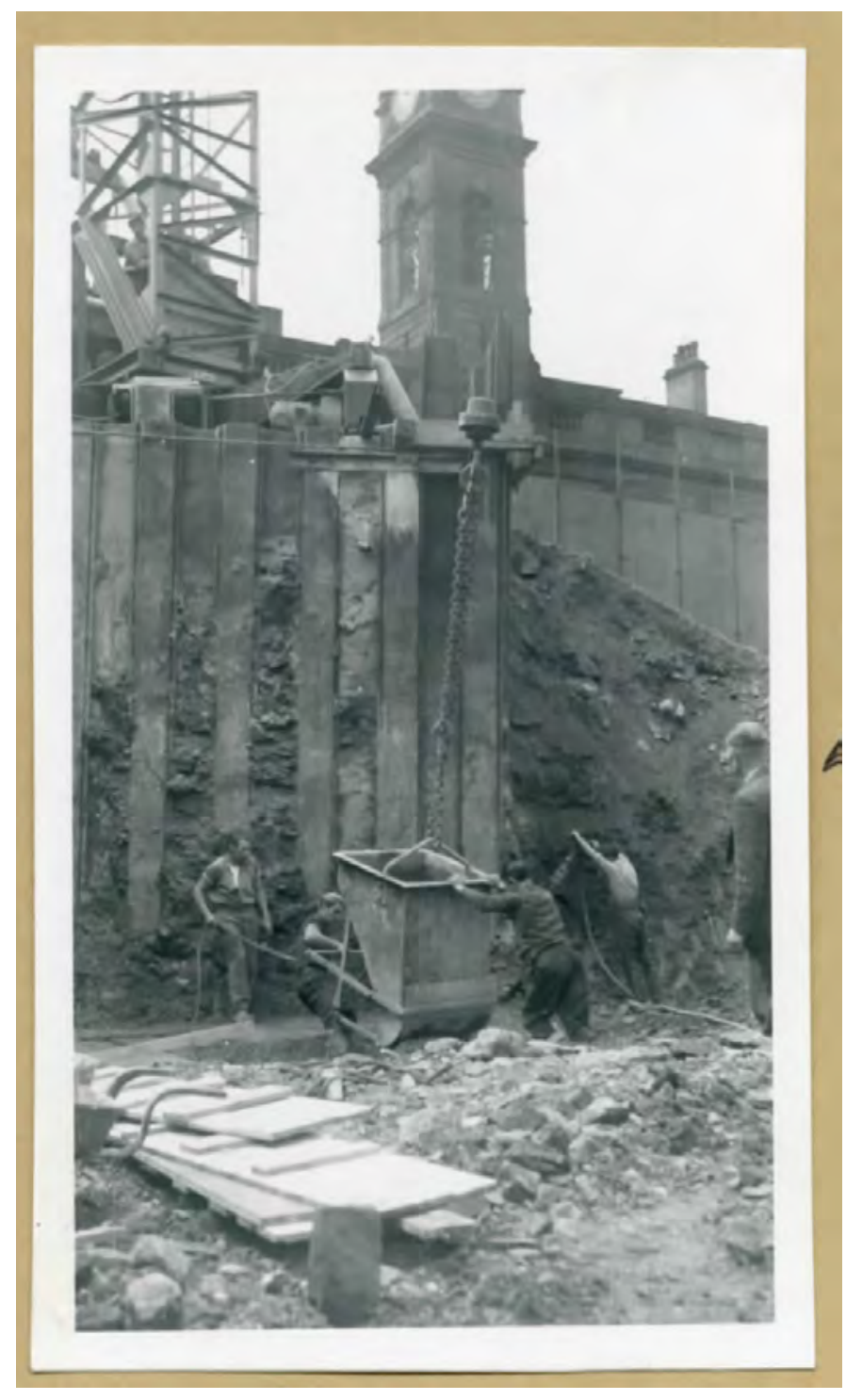

Figure 4.8: Workmen filling a bucket - or kibble as it was known in mining parlance - during construction work on Exchange Street. Courtesy of Museums Sheffield.

It is clear that, before his departure for Hull in early 1959, John Bartlett was central to overseeing, and disseminating information about, the castle excavations. His involvement was also critical in making the discoveries on Castle Hill accessible to the people of the city and region. In 1958-59 Sheffield City Museum planned to reorganise its Saxon and medieval material into three new displays - showcasing Anglo-Saxon jewellery and metalwork (including the famous 7th-century helmet from Benty Grange (Derbs)), medieval pottery and sculpture (including material from Beauchief Abbey), and medieval metalwork, respectively. However, while these displays were being created, 'the excavation of the site of Sheffield Castle ... brought to light sufficient new material, mostly of mediaeval date, for a fourth case of items illustrating that particular period in the city's history' (Museums Sub-Committee 1960; Figure 4.9). At a time when direct lay participation in the excavation and recovery of archaeological material was not 'encouraged', yet visitor numbers to the Museum were growing (Museums Sub-Committee 1960, 5), this display would have been as close as many people were able to come to the process of discovery then unfolding as the new market building was erected over the site of the castle.

Finally, it is important to highlight that Bartlett, through force of personality and passion for the past, acted as a catalyst for the study of archaeology in Sheffield. Indeed, it was his arrival at the City Museum in 1954 that 


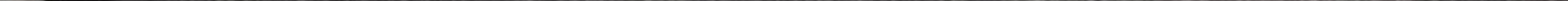


saw the Scheme for Archaeological Research developed by Preston and Butcher finally begin to have an impact on the local archaeological fraternity, as he facilitated access to the Scheme's index at the museum. Moreover, he was instrumental in encouraging the creation of a new Field Research Section of the Hunter Archaeological Society in early 1955, becoming its Field Director; a series of excavations was then organised to train local enthusiasts directed by Bartlett, Preston and Butcher, the latter working at Wharncliffe and Grenoside (Beswick 1997, 105-6). Recollections by those who knew Bartlett in his role as Director of Hull Museum provide insights into both his character and his impact on people. Peter Armstrong $(2001,4)$ remembered him as 'an inspirational character' with an 'unstoppable combination' of 'irrepressible energy and irresistible persuasiveness'. He is said to have possessed a 'uniquely flamboyant, close-up style ... able to charm you into feeling that for that one receptive moment nobody else in the whole universe mattered more than you'. Such was the force of his personality that he attracted interested people to him, and made things happen. Thus, an editorial in the East Riding Archaeological Society News, celebrating the Society's 25th anniversary, suggested that

it was the drive and enthusiasm of John Bartlett, the newly arrived Director of the Museum, who was the catalyst that brought the Society into existence [in the autumn of 1960] and stimulated so much interest in the subject. For there were a number of others already immersed in archaeology at that time, but one feels that a vital spark was lacking (Hampel 1985, 1).

There is evidence that Bartlett had had the same impact in Sheffield prior to his move to Hull. Nick Butcher (pers. comm.) told us that his father's interest in archaeology had been sparked in the early 1950s when, as a surveyor for a road project, he cut through the 'Roman Rig' east of Wincobank Iron Age hill fort in north-east Sheffield, and he subsequently attended lectures organised by the Hunter Archaeological Society at Sheffield University, and at the Museum by Singleton and Bartlett. Through these classes with Bartlett, Butcher met Cyril James, an engineer with 'a very good knowledge of the limestone area of Derbyshire and its lead mines and caves'; James was crucial in introducing Butcher to the archaeology of Derbyshire, not least because he had a car, since Butcher never drove (Nick Butcher pers. comm.). Moreover, as we saw earlier, James took many of the photographs of the castle excavations preserved in the Butcher archive, and along with his wife Pat was among those who retrieved finds from the kibbles of sediment excavated from the foundation shafts. James, Butcher, and Gordon Hunter, one of the latter's work colleagues, 'spent most Thursday evenings in summer surveying the Bronze Age field systems of the gritstone dipslopes/edges west of Sheffield' (Nick Butcher pers. comm.). They also worked with Freddie Preston to systematically survey the landscape around Sheffield, contributing to the Hunter Index (Jones 2012, 35). Inspired by his classes with Bartlett, Butcher went on to teach his own archaeology classes with the Workers' Educational Association, which were taken by Gordon Hunter and another later collaborator Graham Makepeace along with members of the Peak District Mines Historical Association. Bartlett looks to have been one of the inspirations, if not the inspiration, behind this remarkable flowering of archaeological activity in Sheffield in the late 1950s, which undoubtedly contributed much, in terms of personnel and skills, to the recording of Sheffield Castle.

It is easy to overlook the importance and contribution of local archaeological societies, and of the meetings and activities they have been organising for a century or more, but it is clear that without their input much more of the British archaeological record would long have been lost, especially in the wake of 20th-century urban development. Today it is the contributions of metal detectorists, recording their finds through the Portable Antiquities Scheme, that tend to come to the fore when professional archaeologists acknowledge the input of amateur enthusiasts (Lewis 2016), but this is just the latest manifestation of the significance of ordinary people in shaping the archaeological record. It is, indeed, surprising that so little scholarly attention has focussed on the work of local archaeological groups in Britain, given the extensive discussion of the importance of archaeologists acknowledging communities and their beliefs and sensitivities about their heritage in many countries, and of working together with communities to use archaeology for social benefit in the modern world (e.g. Sabloff 2008). Throughout this book we have been demonstrating that the history of archaeology matters just as much in northern English cities like Sheffield as it does in the more glamorous, and sunny, places on which many archaeologists prefer to focus their efforts.

Figure 4.9 (page 118): Finds from Sheffield Castle. This new display was created following refurbishment of Sheffield City Museum in 1958-59. Courtesy of Museums Sheffield. 


\section{New foundations for Sheffield Castle}

Although the plans for the new market building meant that the stanchion supports, and thus the excavations, largely avoided those of the late 1920s Co-op structure, and had deeper foundations, Butcher later observed that 'with few exceptions, the ground gone over in 1958-1960 is that gone over in 1927-30', and lamented that he was thus denied the 'thrill of first discovery' experienced by Armstrong (Butcher 1961, 6, 11, 29; also opening quotation of this chapter). Yet, the fact that the new foundation works overlapped, and in some cases extended beyond, the earlier trenches, presented Butcher with the opportunity both to check the recording undertaken by Armstrong and Himsworth and also to record more of the remains in the areas that had been investigated before, particularly parts of the gatehouse, moat and courtyard surfaces.

Perhaps unsurprisingly, given the brief set by Womersley, the majority of the unpublished records of the castle in the Butcher archive focus on the (constructionally problematic) south moat and the gatehouse area, where some of the foundations and service trenches were dug by hand, providing the opportunity to record the excavated features in detail (Butcher 1972a, 5-6; 1972b, 18; Davies and Willmott 2002, 6). Butcher recorded each of the foundation trenches and pits meticulously: 'all four sides of each stanchion base, each side of each trench \& so on ... were measured fully ... all were photographed in bl \& white, \& some in both bl \& wh and colour' (Butcher 1961, 12, 18; also 1972a, 24; Figure 4.10), and the location of each photograph marked on a plan of the site (Ove Arup \& Partners and Butcher 1957; Figure 4.11). Where features could not clearly be seen they were usually omitted from his drawings rather than projected; this is a practice that he had long since adopted in his field survey (Beswick and Merrills 1983, 17).
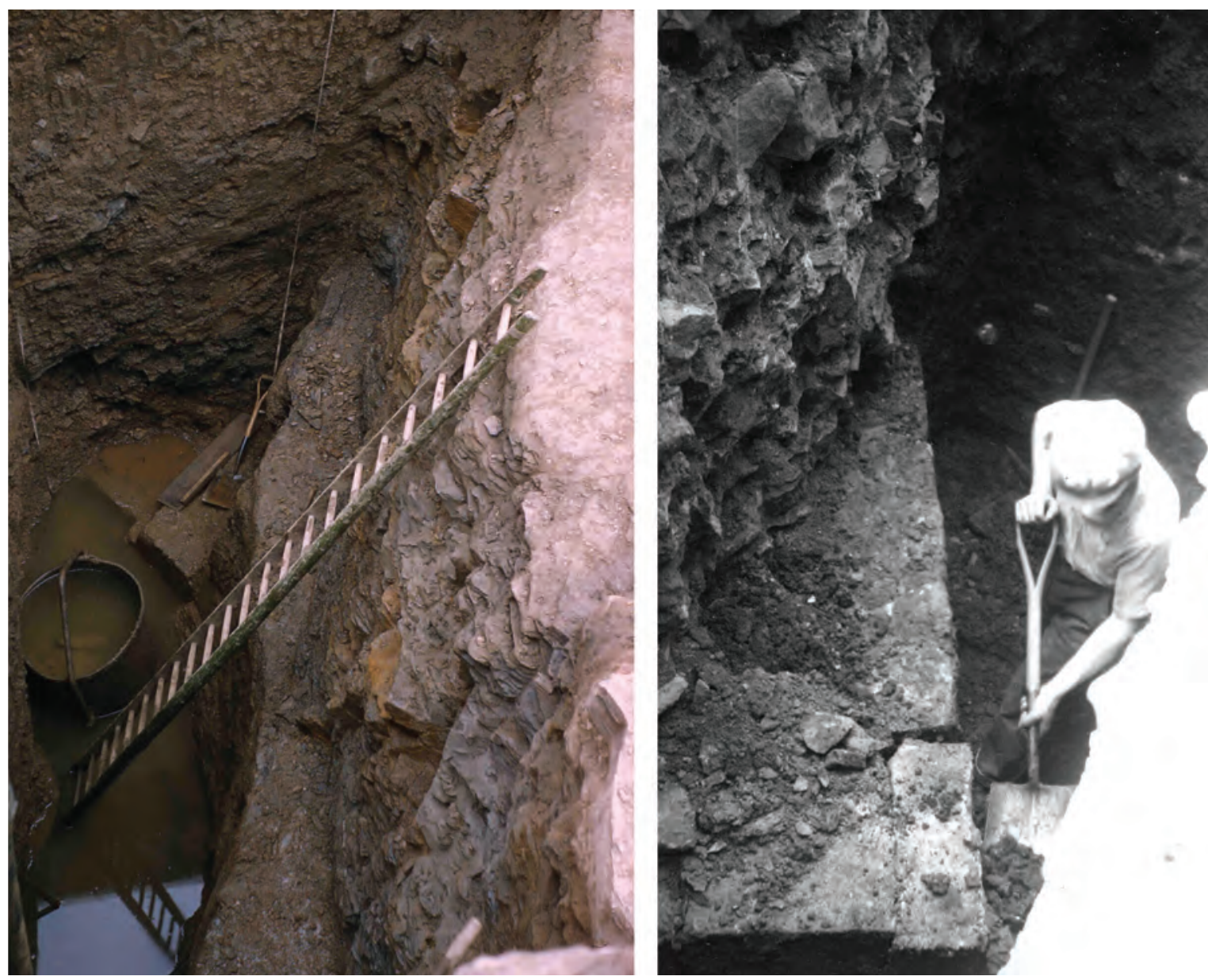

Figure 4.10: Photographs of foundation shafts taken on site in the late 1950s. The Butcher archive contains a wide array of both colour and black and white photographs, taken by Cyril James, Ray Newton and Leslie Butcher. Courtesy of Museums Sheffield. 


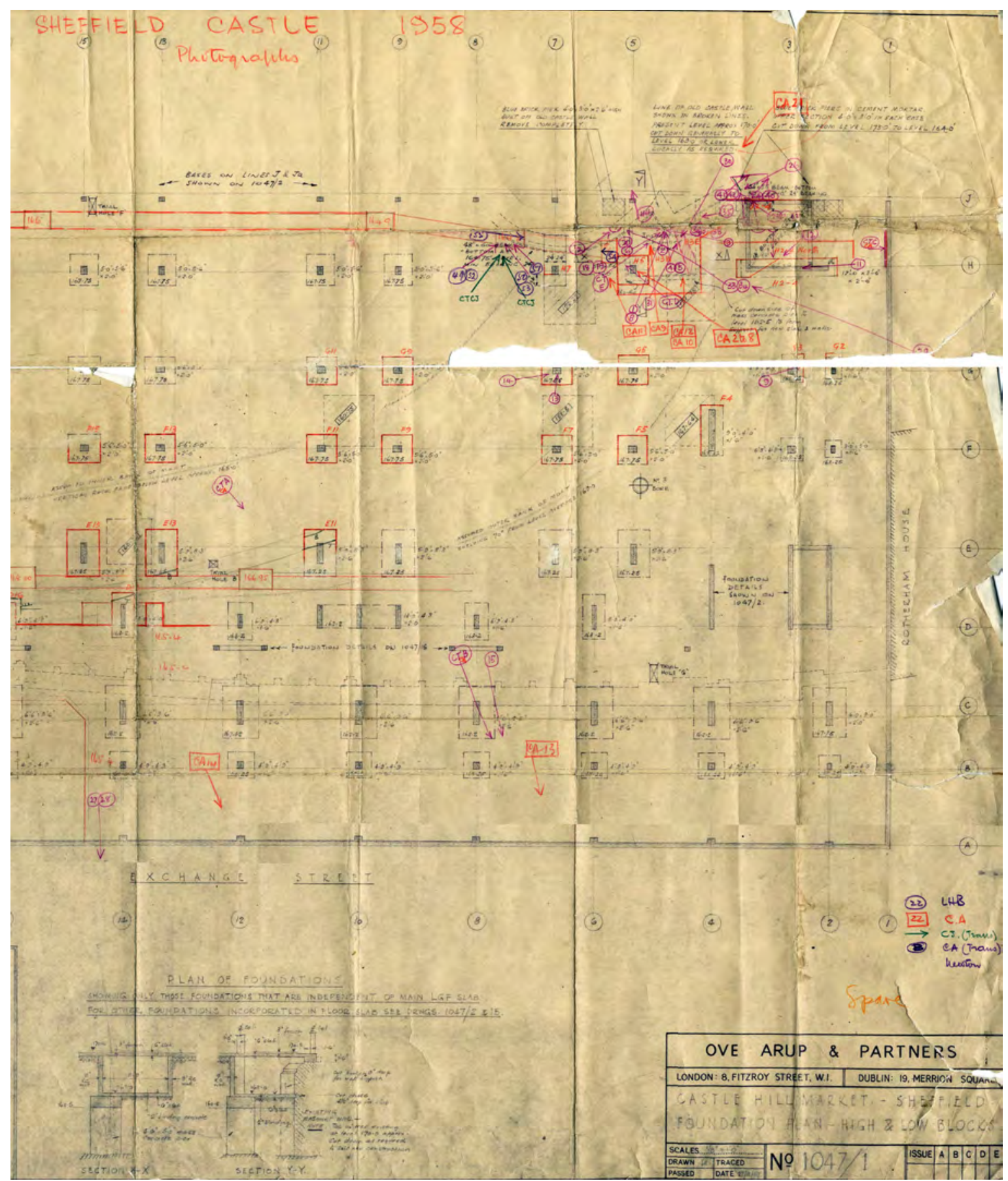

Figure 4.11: Leslie Butcher's record of the photographs taken in the area of the gatehouse. The photographer and the direction from which the picture was taken, are also marked on this copy of the Ove Arup \& Partners foundation plan for Castle Market. Courtesy of Museums Sheffield.

The excavation and recording of discrete squares would have been familiar to Butcher (Figure 4.12). What evidence we have for his own archaeological practice, albeit on rural sites, suggests that he deployed the same box system (the so-called Wheeler-Kenyon method) discussed in Chapter 2. This is seen most clearly in the posthumous publication of his work at Whitley, Wharncliffe, which was excavated (c.1958-60) through a grid of $20 \mathrm{ft}(c .6 \mathrm{~m})$ squares, separated by $5 \mathrm{ft}(1.52 \mathrm{~m})$ wide baulks (Makepeace 1985, fig. 4; Figure 4.13). As we saw in Chapter 2, the aim of the box system was to effect the excavation of the whole site while at the same time 


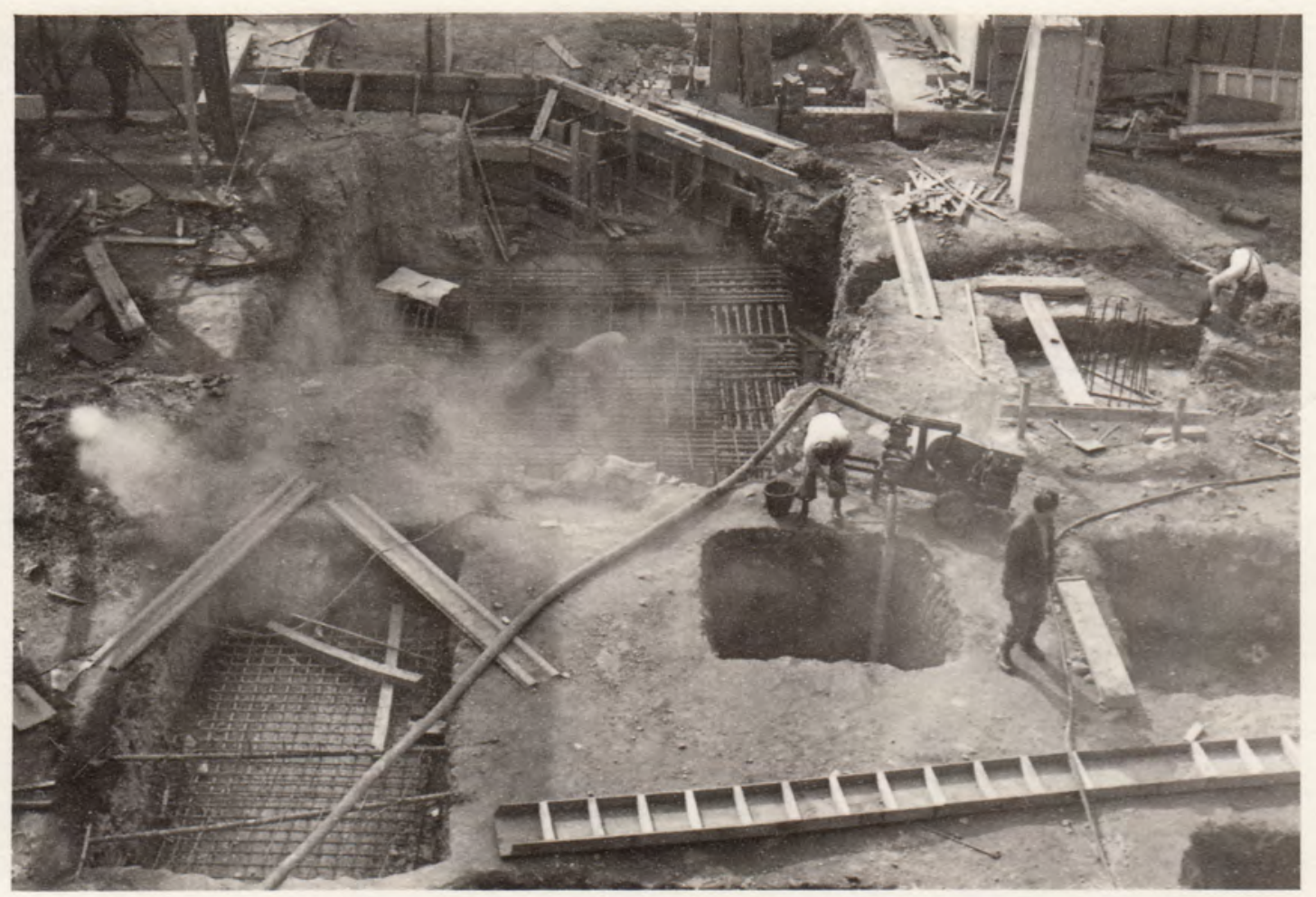

\section{SEP 1958}

Figure 4.12: Foundation shafts being dug by construction workers. This is the 'excavation grid' that Butcher recorded. Courtesy of Museums Sheffield.

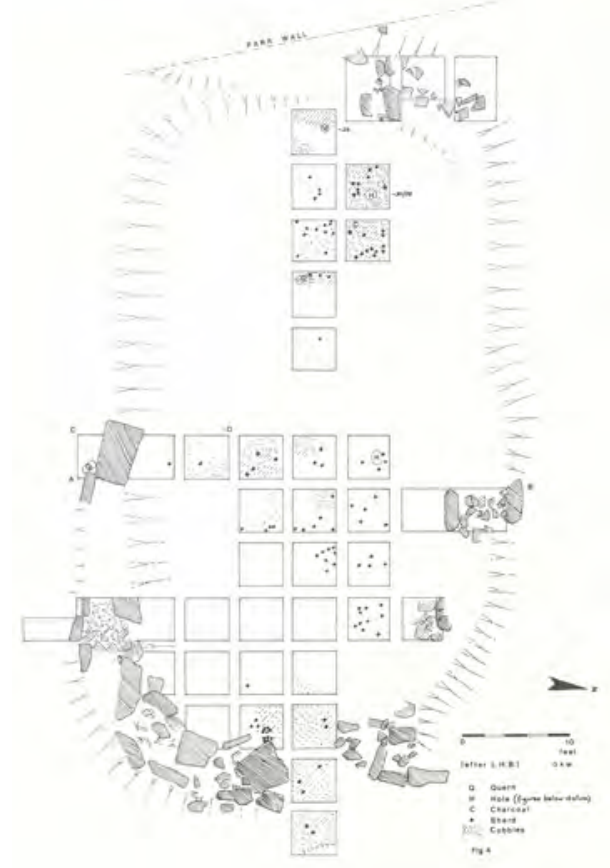

Figure 4.13: Plan of the excavation grid used by Butcher at the Romano-British settlement at Whitley, Wharncliffe (South Yorks). From Makepeace 1985; reproduced courtesy of the Hunter Archaeological Society. 
retaining chronological control through multiple sections. At Whitley, Butcher achieved this not by removing the baulks (as Wheeler recommended) but by 'joining together' a series of sections to create a profile across the site (Makepeace 1985, fig. 5). As Gavin Lucas $(2001,52)$ notes, by the beginning of the 1960 s very little had changed in terms of excavation technique from the time of Wheeler, and Martin Carver $(1987,105)$ links the prevalence in British urban archaeology of 'the efficient Wheeler system of standing boxes' to the 'sondages' long used on the much more ancient urban sites of the Middle East. So, like Armstrong, Butcher would have been very familiar with the practice of viewing the archaeology of the castle site through a grid - of the foundation shafts excavated for the market buildings. The shallow stratigraphy of sites like Whitley would not have prepared Butcher for the deep sections of these foundation shafts, but no doubt his surveying and roadbuilding experience did. And, as at Whitley, at Sheffield Castle too he 'joined together' the sections of adjacent foundation shafts to create profiles across large areas of the site (see Chapter 5).

In contrast, the foundations for the west side of the new building along Waingate were driven piles (Butcher 1972a, 24; n.d. (g)), which provided fewer opportunities for observing archaeological remains, although Butcher was, nonetheless, able to record the position of the 'vertical and sloping parts of the inner rock-cut face' of the moat and its depth (Butcher 1972a, 24; 1958-62b; 1958-62d; 1958-62e). The limited interventions during construction work on the east side of the site were mostly service trenches and manholes, although one of these revealed part of the moat (Butcher 1958-62d). During alterations to the east wall of the 1930s market building, Butcher (n.d. (r)) was able to draw sections of the exposed archaeology, which revealed a clear sequence of deposits associated with the courtyard surfaces and building that had been recorded by Armstrong $(1930,12,20-1)$, as well as deposits immediately behind the retaining wall overlooking Castlegate and the Don, and the natural topography of the site. The demolition of the buildings along Exchange Street was also monitored, revealing further ditches outside the moat around the inner courtyard (Butcher 1972a, 9).

\section{Making sense of the archaeological record}

Only a single short account of the late 1950s work at Sheffield Castle was ever published, in the annual roundup of excavations in Britain and Ireland for 1959 in the journal Medieval Archaeology. It is reproduced here in full:

Builders' excavations watched by L. Butcher have allowed re-examination of the moat and gatehouse first revealed in 1927 (A. L. Armstrong, 'Sheffield Castle, Trans. Hunter Archaeol. Soc., IV (1929-30), 7-27). A SW. angle and N. return in the moat (not observed 1927) have been defined. The moat, perhaps $35 \mathrm{ft}$. wide at original ground level, splays inwards to $18 \mathrm{ft}$. in the first 10-20 ft. of depth; below, vertical rock-cut walls carry it to depths between $30 \mathrm{ft}$. and $40 \mathrm{ft}$. Pottery and small finds of the 13th to the 17th century confirm the documented military occupation of the site; a few sherds of coarse heavily shell gritted ware of the late 11th century (Armstrong's 'Saxon') indicate earlier occupation (Hurst 1959, 308).

The focus in this published note was on comparing what had been uncovered with Armstrong's earlier findings, and it is telling that Butcher identified the pottery from the supposed 'Saxon' phase as being of late 11thcentury date, indicating that very early on in his work on the castle he disagreed with the earlier interpretation.

Butcher intended to publish a more detailed account of his work on the castle. In April 1970, he proposed that 'a comprehensive report be made on the known archaeological facts of the area of the Castle and its immediate environs', noting that this could be relatively easily achieved on the basis of the records he had kept during construction of Castle Market and the rebuilding of the Woolworth's building at 34-36 Haymarket just to the south (Butcher 1970). He commenced writing up what he had recorded, and the archive contains various handwritten drafts (Butcher n.d. (a); 1972b; 1972c; 1972d), and a typed copy of that paper dated to around 1972, to be submitted to the Transactions of the Hunter Archaeological Society. The handwritten drafts contain more detail, and he seems initially to have been intending to publish it in two parts - as one draft refers to a 'Part I' and 'Part II' to appear in different volumes of the Transactions (Butcher 1972c, 1, 14-15) - but then seemingly changed his mind, and someone other than Butcher had annotated the handwritten manuscripts with instructions about passages to be omitted (e.g. Butcher 1972c, 15; 1972g; 1972h). The typescript therefore seems to be in the format that he intended to publish his findings and other than a few missing measurements 
looks largely complete. Butcher could not type (Nick Butcher, pers. comm.) and so it was prepared for him, and there are a number of instances of the typist misreading Butcher's handwriting. The typescript summarises the key findings across the site, and provides a list of intended illustrations (Butcher 1972a, 25-7). It reveals that the main focus for Butcher was to determine the date of the earliest phases of activity at the castle, to establish the form and extent of the gatehouse, to trace the position and profile of the moat, and to identify how it was fed with water, a question undoubtedly informed by his background in geology. It also sets out at length Butcher's thoughts on the topography of the site, reflecting his interest in landscape, as evidenced in his other archaeological work. He was clearly far less interested in the people who had occupied the castle; in this respect his approach is very different from that of Armstrong and Himsworth a generation earlier.

The unpublished typescript and handwritten notes reveal that Butcher had studied closely the work of Armstrong and Himsworth, as he summarised their findings, both published and unpublished, and attempted to relate them to his own. Butcher $(1972 a, 1)$ realised that the new work on the site had both 'extended and in some parts corrected Armstrong's "Account", and that while it had largely confirmed Armstrong's views of the stone structures it had, on the other hand, 'the effect of rendering obsolete most of his views of the moat' (Butcher 1972a, 3). In his 1961 lecture, for example, he told his audience 'you will have noticed already on this slide that contrary to ALAs [Armstrong's] surmisal, the moat does not cross Waingate and go under the courthouse but turns northward, barely cutting into Waingate and procedes [proceeds] squarely under the Styring property' (Butcher 1961, 13; see Figure 1.11 for the location of this building, where it is marked as Lenton \& Rusby - Charles P. Styring was an optician there; also Armstrong's plan 1 Figure 3.2). Butcher (1972a, 24) also tells us that he had access to 'not only the late Leslie Armstrong's observations of 1927 and 1929 ... but also [to] records kept by the Clerk of Works during the original 1927 development of the southern part of the site, which Armstrong either never saw, or used very selectively'.

Butcher (1972a, 4) acknowledged use of what he calls 'Himsworth's "Notes on Sheffield Castle", a photographically illustrated typescript', which he says he accessed in Sheffield City Library. His discussion establishes that this was Himsworth's diary, and, indeed, we found a photocopy of it in Butcher's archive, along with two pages of photographs (labelled '1958') from his own excavations, two copies of an Ordnance Survey map of the Castlegate area, on one of which the excavated remains of the castle, the moat and other features are sketched, and two sketches of the same area. Intriguingly, this is not a copy of the version typed out by Harry Lea that we discussed in Chapter 2, as it has been updated to include the content of handwritten annotations by Himsworth on the first typed version; it contains a Sheffield City Libraries bookplate recording that it was 'Presented by Bequest of Mr C. H. Lea July 1965', suggesting that Lea had typed out a second version (Himsworth n.d. (b) and (c)), and that the diary was taking on a life of its own in the history of the castle. Having stressed the importance of Himsworth's 'Notes on Sheffield Castle', Butcher (1972a, 4) went on to emphasise that 'Himsworth's profile of the slope between Castlegate and the Market car park ... is ... the only record we have of what was revealed when the "New Road" was made, and it has proved invaluable. Butcher (1972a, 3) realised the significance of the work of Himsworth to record the remains, some of which was not included in the 1930 publication as we saw in Chapter 3, and also that Armstrong had relied greatly on him when preparing his paper.

While omitted from the typescript, some of his handwritten drafts explain the approach Butcher (1972c, 4) took to the work of his predecessors: 'If the present reporter appears over-conscious of clearing rubble from Armstrong's report \& redressing Himsworth's Notes he trusts that in the process he has revealed \& conserved the soundest parts of each before incorporating them in a new monument to the labours of two pioneers'. Butcher collated the records of earlier work on the site, including the surviving engineers' plans for the construction of the Brightside and Carbrook Co-op building in 1927-30 (Johnson 1927b; 1927c; Davies 1928; Anon. 1922). For example, during the clearance of Chandler's Row (the lane which ran between the slaughterhouses) in July 1930, Himsworth $(1927-40,17)$ had recorded walling near the bank of the River Don, and in his diary had noted that 'a plan was furnished of these by the City Architect', a copy of which is retained within Butcher's archive (City Architect's Department 1930; Figure 5.8). Butcher also drew many new plans which associate the features he encountered with those seen in the earlier investigations and also with the modern buildings in the area. For example, a plan of the gatehouse, forebuilding and drawbridge pier was colour-coded to show the areas recorded by Armstrong (green) and his own new observations (red) (Butcher 1958a; Figure 5.15). Butcher used Ordnance Survey maps and Himsworth's photographs to enable the locations of the 1920s findings to be 'accurately fixed'. This much is to be expected when one considers his posthumously published regional landscape surveys, in which it can be seen that he took a methodical approach to drawing landscape 
features on the 1922 edition of the 25in Ordnance Survey map, often resurveying features as he refined his methods (Beswick and Merrills 1983, 17).

The archive is also invaluable in highlighting an aspect of Butcher's methodology in which he explicitly differed from Armstrong and Himsworth: Butcher placed a greater emphasis on visual recording, through maps, plans, isometric drawings and reconstructions. Indeed, he complained that Armstrong's and Himsworth's observations on the moat were 'unfortunately only recorded in words' (Butcher 1972b, 6), although our analysis in the previous two chapters suggests that Butcher rather overstated his case and misrepresented the work of Himsworth, in particular, given the extensive photographic record created in the course of the 1927-30 work. Nonetheless, it remains true that Butcher's archive mainly comprises drawn, rather than written, records; and that he placed a greater emphasis on the image (both graphic and photographic) than on the word. In particular, his isometric drawings, with deposits and features annotated and coloured, testify to his great skill as a draughtsman and are the most visually striking component of his archive. These are mainly based on his section drawings of the foundation shafts (Butcher n.d. (k)) but also feature the gatehouse and moat (Butcher n.d. (b); n.d. (c); n.d. (d); n.d. (e); Figure 4.14). He produced interpretative drawings including a reconstruction

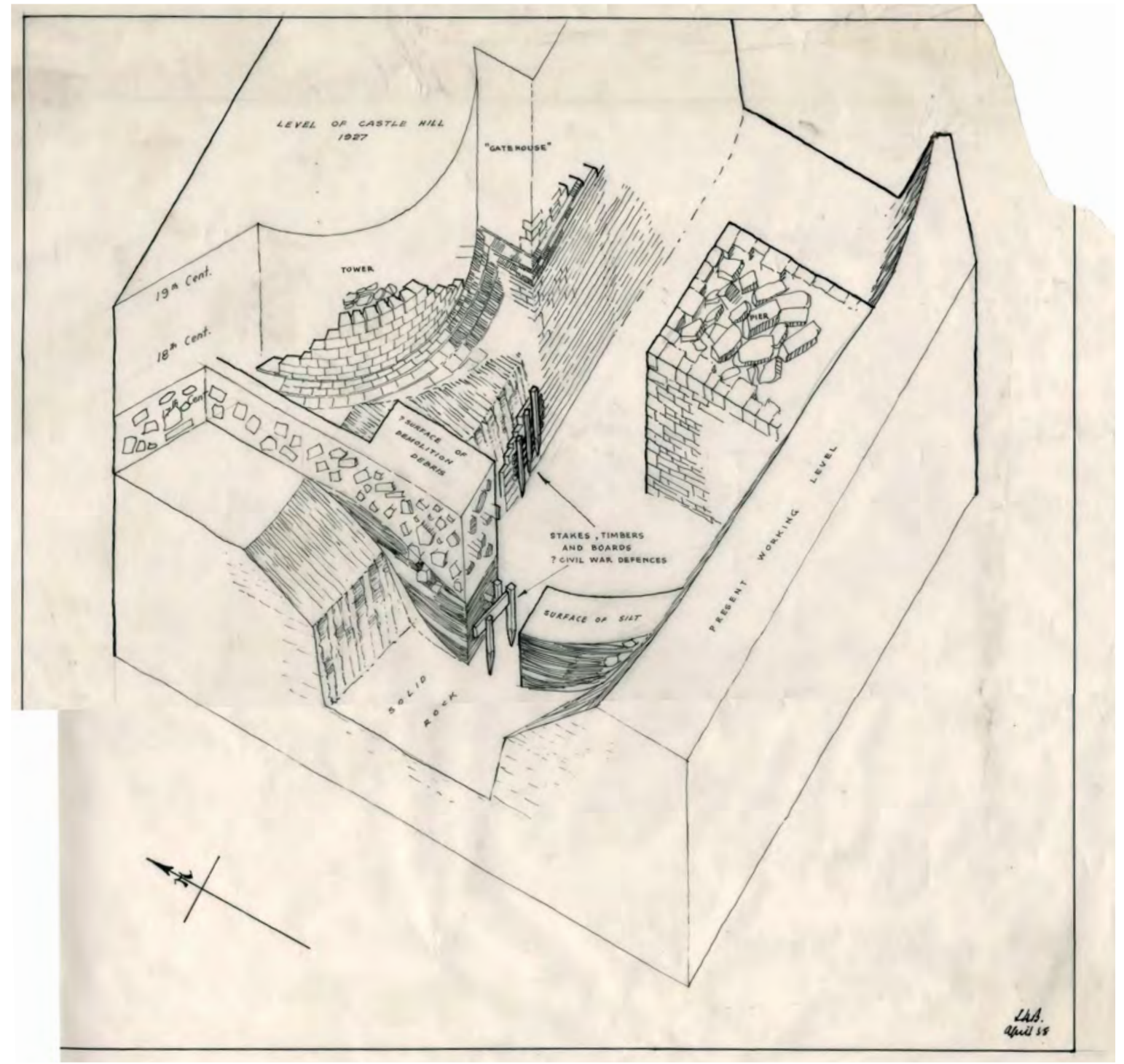

Figure 4.14: Draft isometric drawing of the area in front (south) of the castle gatehouse. Courtesy of Museums Sheffield. 
of the gatehouse (Butcher 1958b; 1958c; Figure 5.18), and a high-quality elevation drawing of the surviving masonry (Figure 5.13), which provides considerably more detail than appears in the drawn and photographic records produced by Armstrong and Himsworth. It is apparent from his lecture text that Butcher regarded his illustrations as an important means of communicating what he had recorded to the general public.

He annotated copies of the 1:1250 Ordnance Survey map (1953) of the Castle Market area showing the position of the gatehouse, the courtyard building, the moat, and the ditches on the south side of Exchange Street (e.g. Figure 4.15; Butcher n.d. (h)), and used the depths of a series of boreholes that crossed the lines of the south and west moat to overlay contour lines showing the underlying topography of the site (Butcher n.d. (i);

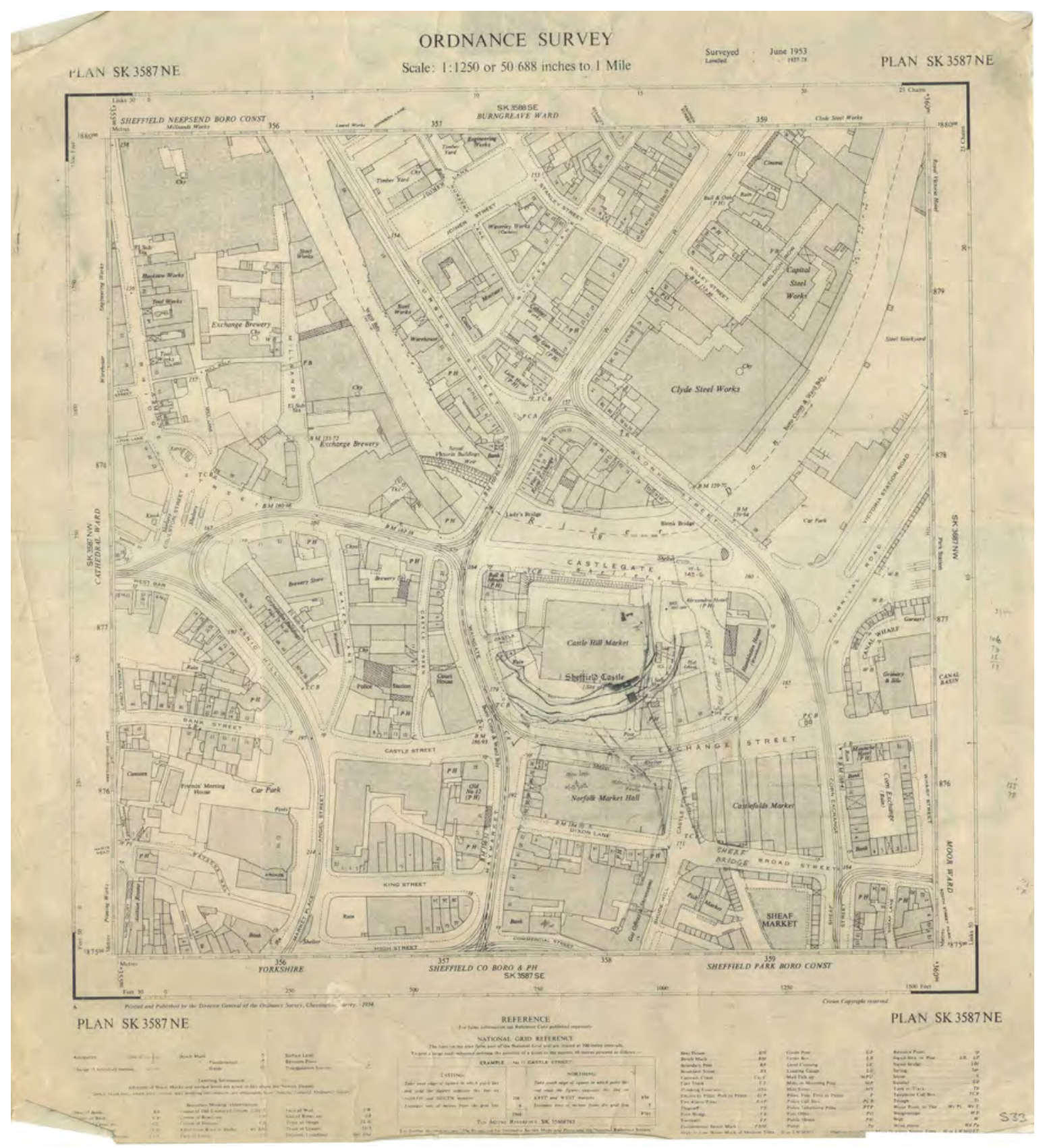

Figure 4.15: Ordnance Survey 1:250 map of Sheffield. Annotated by Leslie Butcher during his recording of the archaeological remains on Castle Hill. Courtesy of Museums Sheffield. 
Figure 5.23). Unusually in his drawing practice, his plans of the moat projected its course from the recorded positions of the moat cut and also showed both the width as excavated and the projected width allowing for the truncation of the site due to later construction work (Butcher n.d. (j)).

Another contrast with the work of Armstrong and Himsworth is that the artefactual record seems not to have influenced Butcher's thinking about the castle to any great extent, accentuating the impression that he may have been more interested in geology and geomorphology, and the formation processes operational on the site, than in the history of the people who lived there. His handwritten drafts and typescript make no reference at all to any of the artefacts he had recovered, and the typescript contains just a single comment about the AngloSaxon pottery Armstrong claims to have found, noting that he had been unable to locate any such pottery in the Armstrong archive (Butcher 1972a, 8). It is only in the short note for Medieval Archaeology in 1959 that Butcher refers to artefacts, and then only the pottery is explicitly mentioned, even though in the handwritten notes for that report there are other artefacts listed that he tellingly had deleted, including knives, a silver-inlaid spur, copper gilt pins, a minute die and a plaited rope of polytrichum commune, kitchen refuse, leather shoes and clay pipes (Butcher 1972b, 5). In another set of handwritten notes, as well as in the typescript (Butcher 1972a, 8), he wrote '[?dating material]', at the end of a section on the 'pre-1266' layers (Butcher 1972c, 9), suggesting that he intended to incorporate information from analysis of the finds, or at least recognised the importance of doing so. In a summary of planned future work outlined at the end of his 1961 lecture to the Hunter Archaeological Society (Butcher 1961, 4), he told his audience that 'All pottery - and small finds to be studied', and near the beginning of this typescript he (1972a, 3) commented that since the recording undertaken by Armstrong, 'Inevitably, too, new identifications and interpretations of portable artefacts have become necessary'. However, no such analysis was included in his text, even though in the 1960s there had been some attempts to catalogue at least the pottery from his excavations, as the museum archive contains a series of pottery drawings of this date ('Pottery illustrations', 1964-66); also from this period are likely to be a typed list of the boxes containing the artefacts, with information on which foundation shaft they were from ('Artefacts list', n.d.), and a collection of handwritten index cards containing descriptions of each sherd of pottery, including fabric and surface appearance by David Crossley (n.d.). Moreover, as we will see in Chapter 5, John Bartlett had acquired reports on environmental remains, but, again, Butcher made no use of these, and we have no evidence for other specialist reports. It is likely that the departure of Bartlett from Sheffield, followed by the Director, Singleton, who left to set up the Department of Museum Studies at the University of Leicester in 1966, weakened Butcher's links with the museum, just as he distanced himself from the Hunter Archaeological Society. Perhaps also Butcher simply left the finds analysis to the museum staff, regarding himself insufficiently expert to undertake this study (Nick Butcher pers. comm.) and changes in personnel saw the project fall by the wayside.

Whatever the case, we have one of the fundamental differences with the work carried out in the late 1920s, in which, as we saw in Chapter 2, what we might call 'finds specialists' played a role in extracting information from the materials recovered and fed it to Armstrong to allow him to tell the history of Sheffield Castle and its people. Tellingly, Butcher $(1961,8)$ told his Hunter Archaeological Society audience that the 'defects' in Armstrong's report on the 1920s excavations were perhaps 'merely those of another generation of archaeologists a generation preoccupied with objects qua objects'. It is difficult to avoid the conclusion that Butcher had a preference for those traces of the past that derive from, and inform us about, the longer-term processes of what has become known as 'deep history' (Gamble 2014; Shryock and Smail 2011), traces which, in their very nature, have less to tell us about people and the shorter-term, historical processes within which they operated. Indeed, although Butcher undertook research on the documentary evidence for the development of the castle, this does not feature in his draft typescript - his must be one of the only pieces on Sheffield Castle not to mention Mary, Queen of Scots! His focus is, however, recoverable from his handwritten notes on the medieval sources, which reveal that he seems to have been particularly interested in what the Civil War demolition accounts reveal about water management at that time (Butcher n.d. (a)). Again, it is processes rather than people that interested him. This preference for rooting explanation for change in natural forces might well derive from Butcher's geological background. However, it is notable that in British archaeology it coincides with the beginnings of the replacement of culture-historical perspectives (see Chapter 2) with ecological and economic approaches, exemplified by the work of Grahame Clark (Fagan 2001, 138-41), who had a run-in with Armstrong earlier in his career (Chapter 2, Section: Albert Leslie Armstrong: more than just the 'gifted amateur'). This privileging of the archaeological record over written sources was also in keeping with wider trends in the development of medieval archaeology in the mid-20th century. As Chris Gerrard $(2003,98)$ has argued, 
the range of excavations in British towns between the mid-1950s and 1970 'did much to break down the perception that historical documentation held all the answers'.

While Butcher did not live to publish the manuscript on which he was working in the early 1970s, he nonetheless played an important role in the dissemination of knowledge about the castle as some of the material he recovered went on display in Sheffield City Museum, following its aforementioned 1958-59 reorganisation. An enlarged version of his reconstruction drawing of the gatehouse was featured alongside a number of the items that he had found including four reconstructed pottery vessels, clay pipe fragments, an iron knife with bone handle, an iron spur with silver inlay, and a selection of pottery and iron finds from both his work and that of Armstrong (Museums Sub-Committee 1960, 12-13; Butcher 1958b; Figures 4.9, 5.18).

\section{Decoding the archive}

Although his typescript was seemingly close to being ready for publication, it cannot form the basis alone for an understanding of what Butcher recorded. It does not, for example, refer in detail to the findings from specific trenches and foundation shafts, and a good deal of the focus is on summarising the findings from the 1927-30 work. It also contains much less detail than can be found in the many handwritten drafts of the paper, which had clearly been trimmed out to prepare it for publication (e.g. Butcher 1972b; 1972c; 1972d; 1972e; 1972f). The typescript does not contain any illustrations, although it does list those he intended to incorporate, including numerous plans, elevations and isometrics, and photographs taken both during his own observations of the construction work and those of Armstrong (Butcher 1972a, 25-7), although it is not always easy to decipher specifically to which of the illustrations in the archive his list refers. Hence, one of the major tasks for our project was to integrate the findings summarised in this unpublished manuscript with the detailed information provided on the many plans, drawings and photographs in the archive, and the results of the first comprehensive analysis of the artefactual record (see Chapter 6). As we have seen, some of the areas investigated during the two periods of construction work recorded by Armstrong, Himsworth and Butcher overlapped, and this has allowed us to compare the findings. Key observations by Butcher relate to the east tower of the gatehouse, the make-up of the courtyard deposits, and the alignment and profile of the moat. Importantly, having analysed Harrison's 17th-century survey of the castle (see Chapter 1) and Ordnance Survey maps, he also highlighted the fact that the excavated area represented only the inner courtyard of the castle, and that a second courtyard, or outer bailey, lay to the south of Exchange Street (Butcher 1972a, 2).

In undertaking his work, Butcher utilised a recording system that was much more systematic than Armstrong's, with its heavy reliance on sketched (if measured) sections and plans, and notes in field diaries. It was based on the Ove Arup \& Partners (1957) engineering site plans, which show the locations of the service trenches, foundation shafts and manholes. As we have seen, the foundation shafts were arranged in a grid, and assigned a unique number/letter, which Butcher adopted in his recording. The grid was labelled from $\mathrm{A}$ at the south of the site to $\mathrm{K}$ at the north, and from 1 at the east to 24 at the west. There are several City Architect's Department plans in the archive that incorporate the original grid on which Butcher had made notes and sketches about the archaeology (Womersley and Butcher 1957a; 1957b; Figure 4.16). These annotated plans also show where shaft numbers have been altered, and where foundation shafts were combined into one during construction work. They are essential to our ability to locate the positions from which artefacts were retrieved, as these are generally marked with numbers that are derived from the grid. However, the location of a few of the foundation shafts cannot be precisely identified as they are assigned letter and number combinations not found on the grid.

The collection and recording protocol employed for the finds is represented on a flow diagram preserved in the archives bearing the names of both Bartlett and Butcher (n.d.), although it is uncertain who devised this (Figure 4.17). This shows the stages involved in recording the foundation shafts, in which three separate visits by the pair were envisaged, and indicates that the sections of the foundation shafts were to be labelled according to the depths that had been excavated. Artefacts would be identified by the letter 'P' and a number which would be recorded on the section drawings to identify the precise location (i.e. depth, face of the trench) from which they had been recovered. The finds would then be dated, and either boxed for further study, displayed or reconstructed. Unfortunately, however, analysis of the archive reveals that this system was not followed consistently, and on some section drawings the presence of artefacts is noted but these are not assigned a 


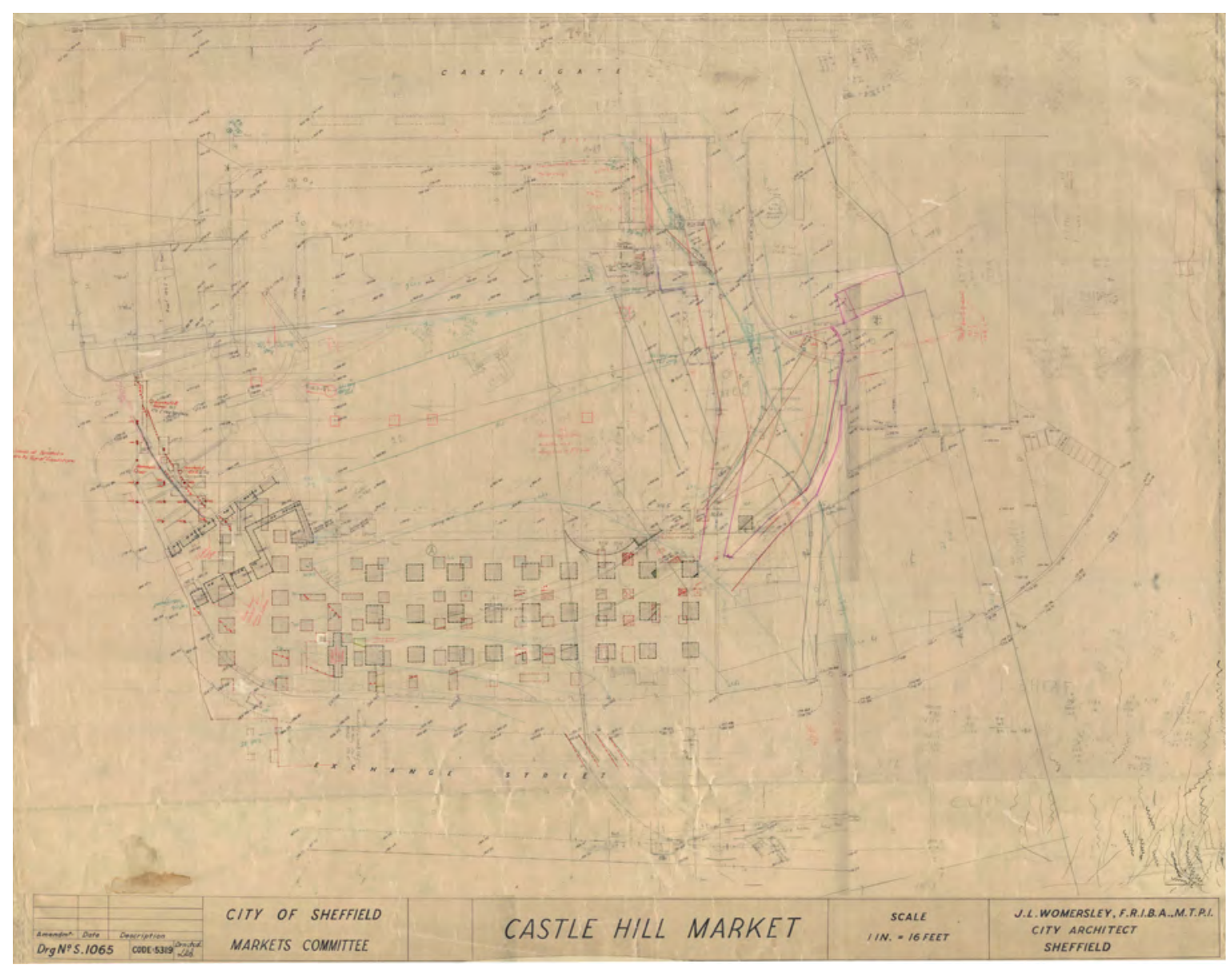

Figure 4.16: Plan of Castle Hill Market. Drawn up by City Architect J. Lewis Womersley and annotated by Leslie Butcher to show the locations of foundation shafts and boreholes. Courtesy of Museums Sheffield.

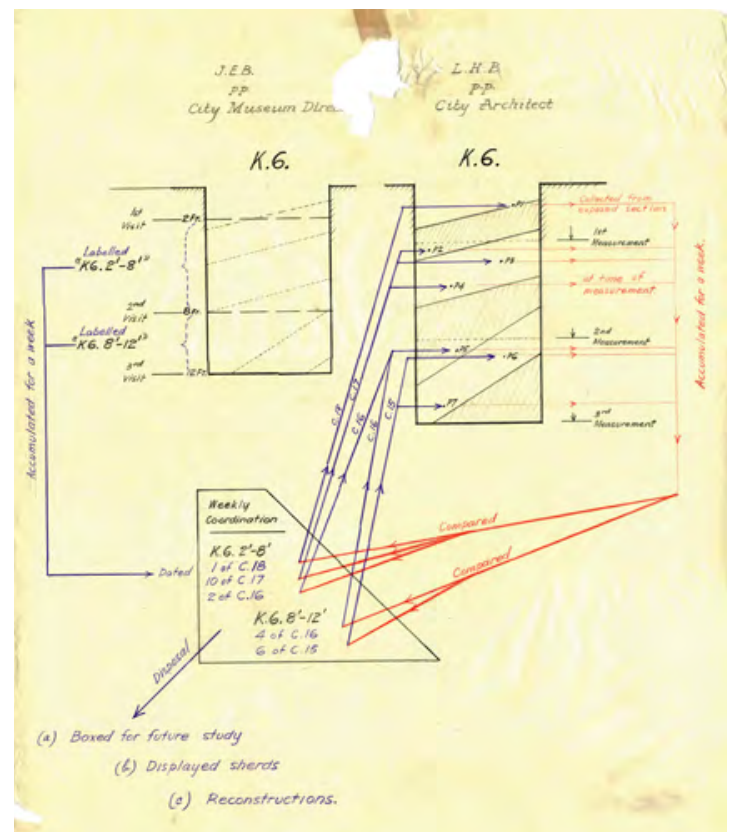

Figure 4.17: Finds processing flow diagram. This was created by John Bartlett and Leslie Butcher for their recording of the castle excavations. It is, however, apparent from our analysis of the archive that this model workflow was not consistently followed. Courtesy of Museums Sheffield. 
$\mathrm{P}$ number, or the letter $\mathrm{P}$ appears alone without a number, suggesting that the recording was incomplete. The methodology diagram suggests that $P$ numbers would run sequentially from the top of the foundation shaft on the first section drawing produced and that the numbering would continue through the other sections, but it is apparent from the most detailed section drawings that this was not carried through consistently and so it is not possible to guess at what depth and on which section any given P number might have been located if it does not appear on a section drawing. Even among the material recovered from the same foundation shaft, the extent to which P numbers and other context information are provided vary, and the references on the section drawings to finds are rarely sufficiently specific to identify individual objects (saying only, for example, 'bone', 'slag', etc). The result is that a significant proportion of the assemblage (up to $50 \%$ for some categories of object) must be regarded as essentially unstratified. We should also remember the circumstances of excavation on site and the limitations on recording. We know that the foundation shafts were hand dug - we can even see the individual pick marks on photographs of some of them - and that the kibbles were filled by hand, while Nick Butcher (pers. comm.) recalls the museum staff with Cyril and Pat James sifting through the previous day's kibble row, which must have been laid out on the ground (see the annotation to this effect on Butcher 1958-62d; Figure 5.14). So the idealised version of finds collection and reality did not fully accord.

Some of the items described on section drawings by Butcher could not be traced in the museum archive (e.g. leather annotated on the section drawings for foundation shafts G5, G7 and F21). While this is doubtless sometimes due to loss of context information in the archive, we also suspect that much, in particular the architectural fragments, was left in situ, although even some artefacts catalogued as recently as 2002 (Davies and Willmott 2002) have subsequently been misplaced. The assemblages from individual shafts vary greatly in size, and, while this may reflect meaningful differences in use or deposition of material culture across the site, other factors were also probably relevant to these differences. In particular, different recovery strategies must have been a factor, such as in the cases of foundation shafts F9, which produced just four sherds of pottery and no other finds, and F11, which produced five sherds of pottery and a medieval floor tile. Both of these shafts have some of the most limited recording on their section drawings, with those for F11 noting that it had been sheet piled and only the east section was drawn in detail (see Figures 5.29 and 5.30). There are also some finds from contexts for which we have no other information (e.g. foundation shaft E18), and there is uncertainty over the provenance of finds labelled as coming from ' $5 \mathrm{H}$ ', as this is not the standard format for identification of foundation shafts, which otherwise always have the letter first. This is probably a transcription error for H5, perhaps during rebagging/reboxing of the material in the early 1990s (Davies and Willmott 2002, 8; Dennison 2014, 3-5). Indeed, some of the finds are recorded as being from ' $5 \mathrm{HX}$ ' and '5HY', which corresponds with information on the $\mathrm{H} 5$ section drawing, where Butcher uses a large ' $\mathrm{X}$ ' and ' $\mathrm{Y}$ ' to differentiate the lowest levels of the moat deposits close to the gatehouse, and the types of finds listed in the archive as being from $5 \mathrm{H}$ accord with those annotated on the $\mathrm{H} 5$ section drawing (Butcher 1958-62g).

The drawings contain many useful annotations about the nature of the deposits exposed, and the finds they contained, although some of the sections were not able to be recorded due to the use of shuttering, or have minimal information suggesting they simply could be completed in detail. The section drawings of foundation shafts produced by Butcher (1958-62a; 1958-62b; 1958-62d; 1958-62e) must often have necessitated him scaling long builders' ladders (Figure 5.2), and there is photographic evidence for him stringing up sections and measuring them amid the construction work (Figure 4.18). However, he may sometimes have drawn the foundation shafts off site on the basis of photographs; indeed, some of the photographs in the archive have been annotated with descriptions of layers that appear intended to inform his drawings (e.g. Butcher n.d. (s), no. 282; Figure 4.19). A handwritten legend for his plans and section drawings is contained within the archive showing the conventions he followed for drawing features, in which he distinguished what he had been able to record from 'probable' and conjectural features (Butcher 1972e). Details of the many photographs of the archaeology and construction work on the site, mostly taken by Cyril James, were annotated on an engineer's plan with the letters CA and a number written in red or green (e.g. CA12-1) or just a number written in purple associated with an arrow indicating the foundation pit to which they relate; the initials appear to relate to the person who took the photograph for which there is a key on the plan (e.g. 'LHB' for Butcher, 'CJ' for Cyril James, 'Newton' for Dr Ray Newton, whom Butcher thanked in one of his draft manuscripts; Ove Arup \& Partners and Butcher 1957). These numbers are replicated on the back of the photographs, as well as on a series of sheets onto which the photographs had been mounted and annotated by Butcher allowing them to be located precisely on the site plan (Figure 4.11). 


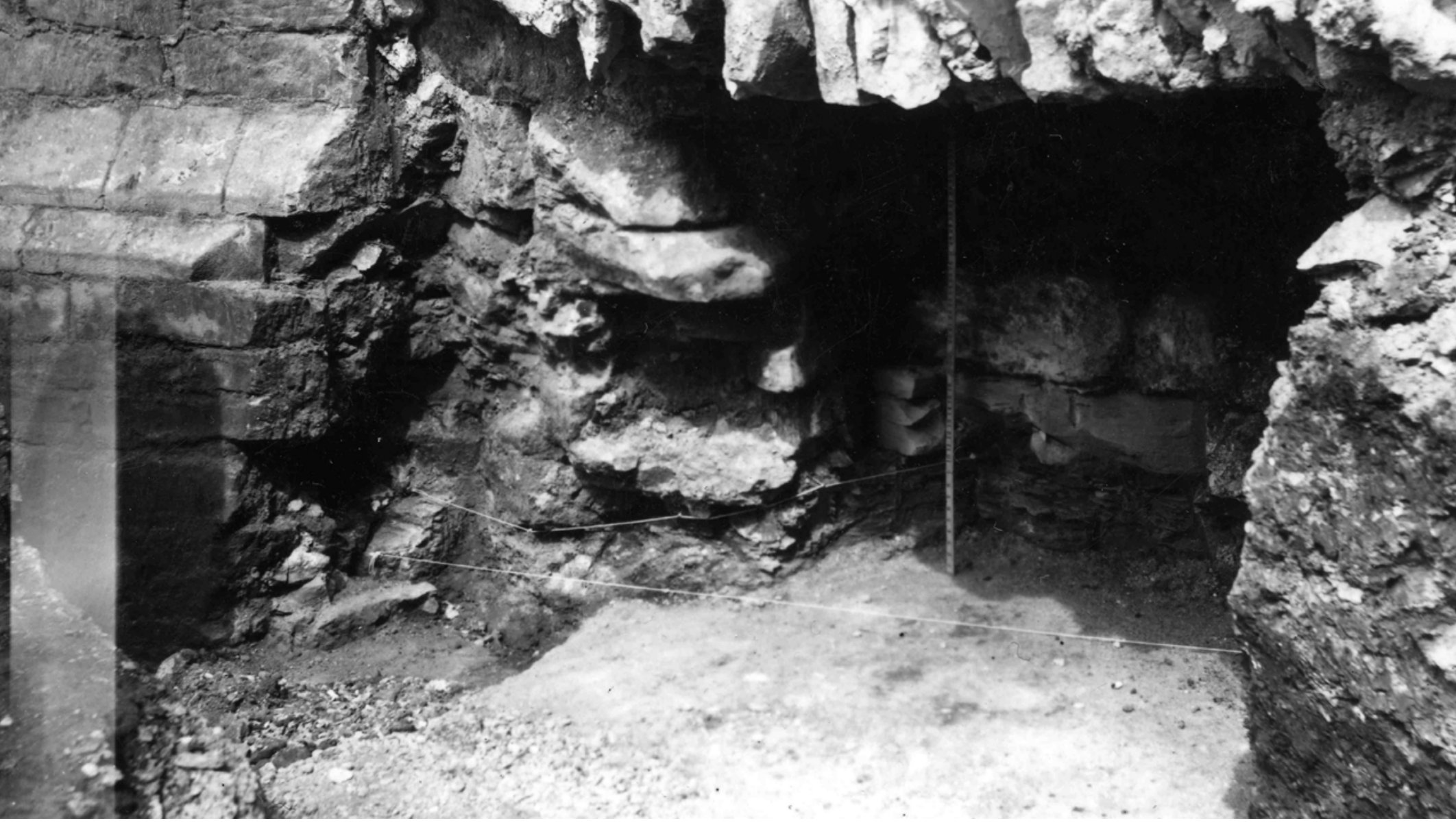

Figure 4.18: Photograph taken near the gatehouse showing how the foundation shafts were strung up for recording. Courtesy of Museums Sheffield.

A few of the section drawings do not contain information about which side of the shaft they record, although this can generally be surmised by reference to the features depicted. Butcher's section drawings of foundation shafts do not all have a scale on them, but this can, nonetheless, be calculated from the known scale of other drawings, which was roughly 1:50 (Butcher's 1972a, 24). Other measurements are annotated on many of the drawings to note the depth at which features were seen or the height AOD of given features or finds, but this is sporadic. While there is generally information about the height AOD of the top of foundation shafts recorded on the construction plan, we cannot use this instead of a height on the section drawings, because layers had been removed from the site before the recording of the foundation shafts commenced; we can demonstrate this from the inconsistency in the heights in cases where they are recorded on both the plan and the section drawings. On many section drawings, the drawn deposits were annotated with descriptions of their colour, composition and inclusions - as one might expect from someone practised in mining surveying and with a geological background. The annotations were usually in an abbreviated form, for which there is no key, but we were able to use the coloured isometric drawings produced by Butcher as a guide to determine their likely meaning and to interpret the composition of the different deposits within the moat. Butcher used geological terminology, such as 'beds' to denote the interface between deposits or 'bind' for mudstone. The drawn sections have allowed us to construct a broad deposit sequence for each of the foundation pits, and these are discussed in Chapter 5. Although it is not clear from the archival sources how aware Butcher was of wider developments in urban archaeology, his work to plot archaeological deposits in the context of the natural topography was consistent with recording undertaken earlier in the decade in Norwich (e.g. Jope 1952) and Bristol (Marshall 1951; Gerrard 2003, 97). Annotations on the section drawings also reveal that Bartlett was on site recording some of them. For example, the section drawing for the north side of F22 says both 'Pottery etc J.E.B.' and 'Lower 12' J.E.B.' revealing that Bartlett recorded it. A comment on the west section drawing states 'Not described by J.E.B but cf blocks in other holes', which confirms that Butcher was drawing up the section from Bartlett's notes (which do not survive in the archive; e.g. Butcher 1958-62b; Butcher 1958-62a; Figure 5.30). These drawings, thus, also reveal something of the processes by which the two men collaborated in the recording of the castle. 


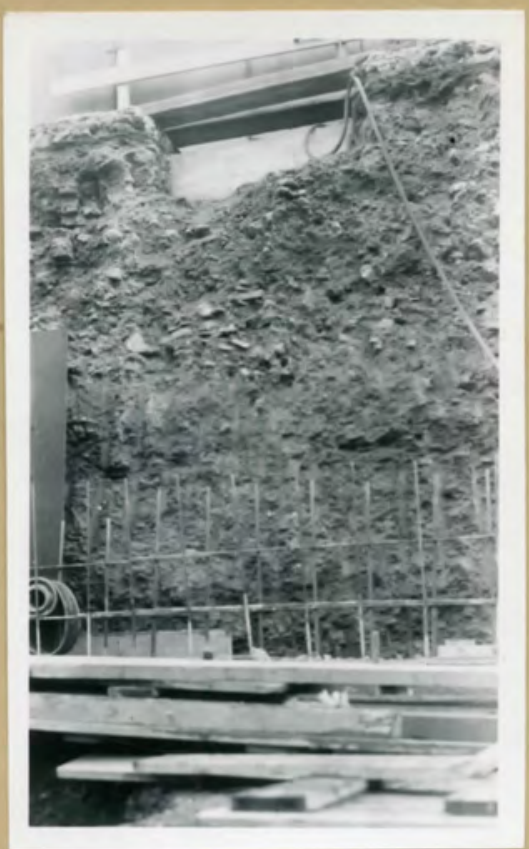

28

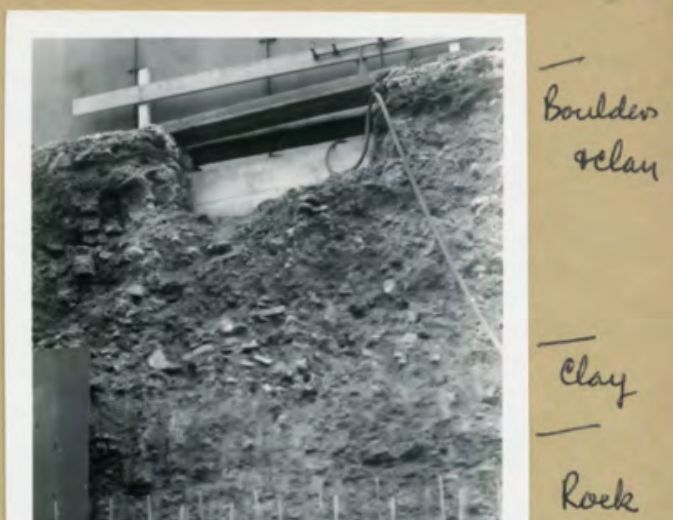

27

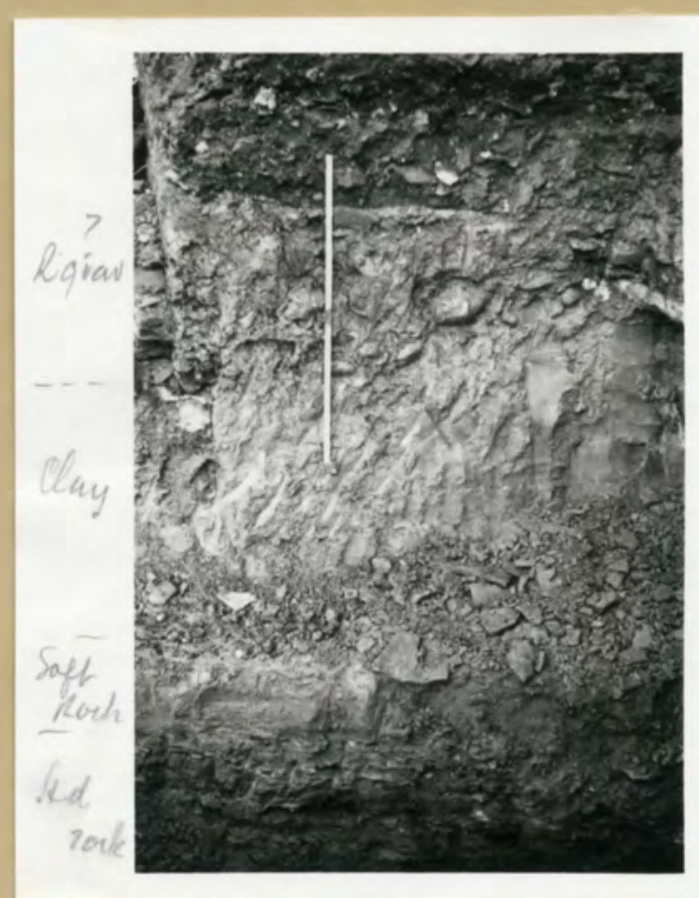

$$
\begin{aligned}
& \text { CA } 24 \text { Ia } 21 . \\
& \text { Watural quand helow } \\
& \text { later fiul. }
\end{aligned}
$$

Figure 4.19: On-site photographs of exposed archaeology. These were subsequently annotated by Leslie Butcher, showing that, in these cases at least, he produced his drawings off site using photographs. The top two photographs also capture the building work amid which Butcher undertook his recording. Courtesy of Museums Sheffield. 


\section{Conclusion}

The circumstances in which Leslie Butcher and John Bartlett found themselves recording the archaeological remains of Sheffield Castle in the 1950s and 1960s were not radically different from those faced by Leslie Armstrong and Joseph Himsworth a generation earlier. Personal commitment to the heritage of the site, a recognition that 'something had to be done' and toleration if not active support from the local authorities were common to both eras, and given that little had changed in terms of archaeological procedure the opportunities presented for recording were similarly largely limited to a chequerboard view. The work undertaken on Sheffield Castle from 1958 was not located in a purely local context. As we have seen, Butcher had been closely involved in developing recording protocols through his work with Freddie Preston that responded to a growing national requirement to preserve information about heritage that was being lost to post-War development, and the galvanising force of Bartlett among the local archaeological fraternity had been a critical element in ensuring that endeavour succeeded. While Butcher may not have had the international profile of Armstrong, or his experience of a range of archaeological sites, in many respects his extensive understanding of geology and landscape made him extremely well equipped to record the moat and topography of the site, as we will see in the next chapter. Butcher was acutely aware of the importance of the work on the castle that he undertook, and with limited, if any, resources he, and a small group of volunteers, recorded what they could in difficult circumstances, and he worked doggedly over the following years to write it up. For him, however, it was not the famous inhabitants of the castle who were to be the focus; rather, it was the castle as a landscape feature and as a topographical conundrum to be resolved.

\section{Bibliography}

The full bibliography is available at the end of this volume, or at: https://doi.org/10.22599/SheffieldCastle.k. 



\title{
'Long before Castles Were Thought of': Sheffield Castle and Deep History
}

\author{
Castles, with their moats \& the hills they stand on are 3 dimensional. Plans \& sections are \\ not everyone's cup of tea \& so I have introduced a number of 3 dimensional drawings giving \\ a sort of bird's eye view effect (Butcher 1961, 1)
}

In the text of a lecture delivered to the Hunter Archaeological Society in January 1961, Leslie Butcher $(1961,18)$ expressed his view that it would be a time-consuming task to write up what he had recorded on the site of Sheffield Castle:

Interpretation of such a complex of moat sludge, clay with rubble, burnt stone, pottery bone \& leather, recurrent layers of different qualities of rubble, flagstone, the occasional tree root, stakes, ashes, slag and the rest, is going to take a long, long time.

We doubt he expected it would take 60 years! Indeed, over the following decade Butcher made much progress on writing up his findings and comparing them with those of Leslie Armstrong and Joseph Himsworth a generation earlier, but died before this work could be published. This chapter sees this work of reporting and interpretation finally completed, integrating the written, drawn and photographic record with evidence from our new analyses of the surviving artefacts, which played no discernible part in Butcher's interpretations. A typescript of a planned publication survives in his archive, but it lacks detailed references to specific excavated features, and so we set out to reconstruct the basis of Butcher's arguments, integrating discussion from his handwritten manuscripts which provide greater detail.

The chapter also compares Butcher's findings with those of Armstrong and Himsworth and examines what this more complete picture of the remains enables us to say about the form of Sheffield Castle. In writing up what he had recorded, Butcher $(1972 c$, 4) clearly developed much sympathy with Armstrong and Himsworth as fellow practitioners 'each labouring under his own difficulties' who had 'sought the truth where it is most likely to elude anyone: on an archaeologically unknown city centre site under active commercial excavation'. What emerges from Butcher's archive is not simply informative about the medieval

\footnotetext{
How to cite this book chapter:

Moreland, J. and Hadley, D. (with A. Tuck and M. Rajic). 2020. Sheffield Castle: archaeology, archives, regeneration, 1927-2018, pp. 135-184. York: White Rose University Press. DOI: https://doi.org/10.22599/SheffieldCastle.e. CC BY-NC 4.0, https://creativecommons.org/licenses/by-nc/4.0
} 
castle and its afterlife, but it allows us to trace his struggles to make sense of what he had seen, and is also of critical value for future construction on the site presenting essential information about its topography and stratigraphy. Finally, we complete the work that Butcher had started on the relationship of the castle to the townscape. In Chapter 7 we will situate his conclusions in the context of the results of the most recent excavations on the site.

\section{The remains uncovered}

During the construction work on Castle Hill that began in 1958, more accurate information about the course, depth and profile of the moat was recorded, principally to the south of the inner courtyard of the castle, but new insights were also gained into the moat on the east and west sides. The chamber in which some of the remains of the gatehouse had been encased since the late 1920s was rebuilt, permitting more of the gatehouse structures to be recorded, and short sections of the south curtain wall were also identified. The removal of the east wall of the 1930 market hall re-exposed the cobbled surfaces and courtyard building recorded by Armstrong, which had been preserved within the other chamber, and a complete profile of this side of the castle was drawn. Butcher integrated information he gathered at the north end of the site with the records made by Himsworth in 1930, but which had not been included in Armstrong's paper published that year. The demolition of buildings along Exchange Street was monitored and Butcher was able to record further ditches beyond the moat, two of which may be related to the earliest phases of activity on the site, while another may have been an outwork, or barbican, around the gatehouse.

Butcher also expended much effort on examining the topography of the site, showing how it had been transformed during the medieval period, following the demolition of much of the castle in the mid-17th century, and through the construction and subsequent demolition of industrial buildings and the late 18th-century slaughterhouses (although, as we will see in Chapter 7, he was not able to record all such significant changes). The topography of the site had been transformed further during 20th-century building work, and Butcher (1972a, 15) estimated that the 1958 formation level for construction was 'cut some 2 feet $[0.60 \mathrm{~m}]$ lower' than that for the Brightside and Carbrook Co-op building recorded by Armstrong, which had been at c.174ft $(53.04 \mathrm{~m}) \mathrm{AOD}$; this accounts for some of the discrepancies between the estimations that the two offered for the depth of the moat. In his lecture notes, Butcher $(1961,13)$ estimated that the original ground level had been $c .183 \mathrm{ft}(55.78 \mathrm{~m}) \mathrm{AOD}$, and noted that $c .15 \mathrm{ft}(c .4 \mathrm{~m})$ had been removed from the site of the Co-op building without record during the construction work in 1927.

\section{The moat}

Butcher recorded 35 excavations (foundation shafts, trial trenches, manholes) that were dug completely or partially through the moat (Butcher 1961, 18): no mean achievement for a man doing this in his lunch breaks. The foundation shafts were mainly between $6 \mathrm{ft}(1.83 \mathrm{~m})$ and $8 \mathrm{ft}(2.44 \mathrm{~m})$ square and up to $c .20 \mathrm{ft}$ (c.6m) deep (Ove Arup \& Partners and Butcher 1957; Butcher 1972b, 18). Their locations are depicted on the foundation plan produced by Ove Arup \& Partners, a copy of which Butcher annotated, and were also marked by him on a copy of a plan drawn up by City Architect Lewis Womersley (Womersley and Butcher 1957b; Figure 5.1; see also Figure 4.11). It was specifically those foundation shafts dug through the moat in which Butcher was interested, and these were marked in red on the Ove Arup plan. There is little evidence in the archive that he recorded the foundation shafts excavated elsewhere on the site in any detail; certainly, there are no drawings of them although some feature in photographs (Richardson and Dennison 2014a, 57). The drawn and photographic record captures the archaeological recording that took place at the centre of a busy construction site, and highlights the challenges of building the new market hall over a medieval moat. Butcher (1972b, 15; 1972d, 14; Figure 5.2) seems to have had more opportunity to record sections than had Armstrong, who had been hampered by an 'older and more cautious practice' of excavating foundation shafts, leading to them being close-boarded, 'which would obscure the complex stratification of the moat fill'; indeed, this is clear from the photographs taken on site by Himsworth and Senior (for example, Armstrong 1930, fig. 7). Butcher was also sometimes impeded by this practice (e.g. 1972b, 21; 1958-62d; Figure 5.3) but the drawn and photographic record suggests that he generally had a clear view of the sections, albeit that on occasion this was from the top of the foundation shafts or precariously positioned on long builders' ladders (Figure 5.4). 


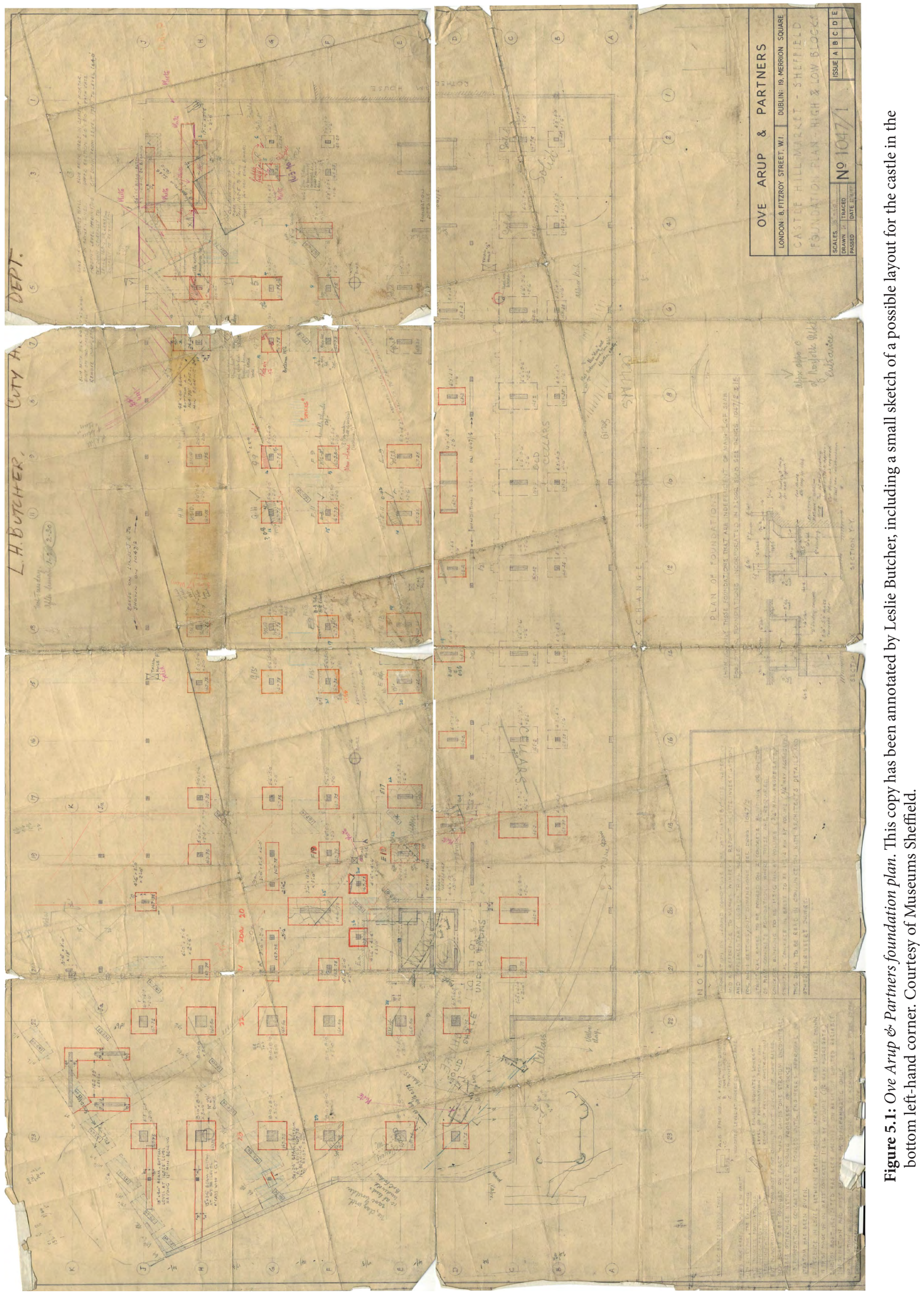



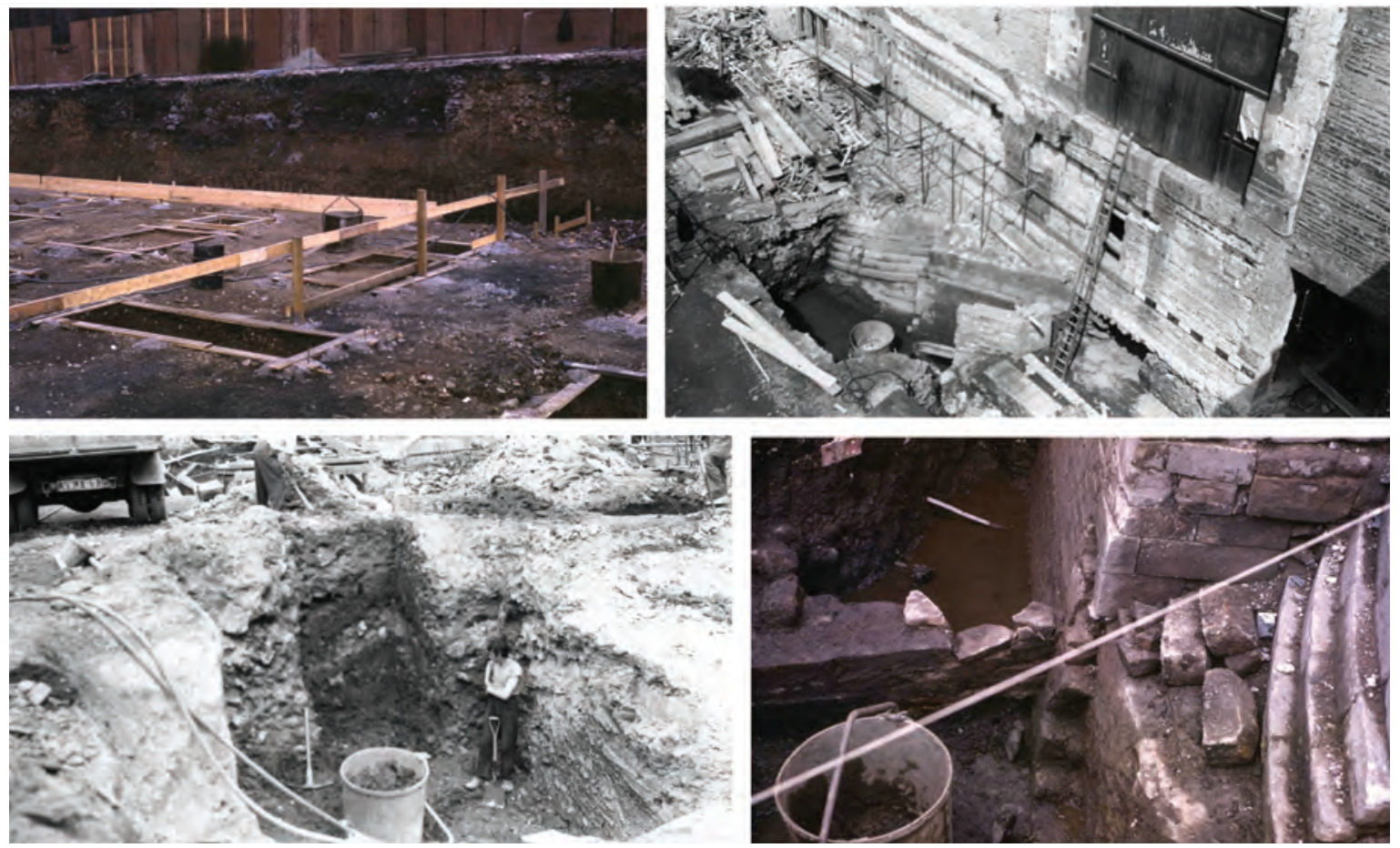

Figure 5.2: Photographs taken during construction work on the site of Sheffield Castle between 1958 and 1962. They are reminders that Leslie Butcher, John Bartlett and staff from the City Museum were recording the castle amid a very 'active' construction site. Courtesy of Museums Sheffield.

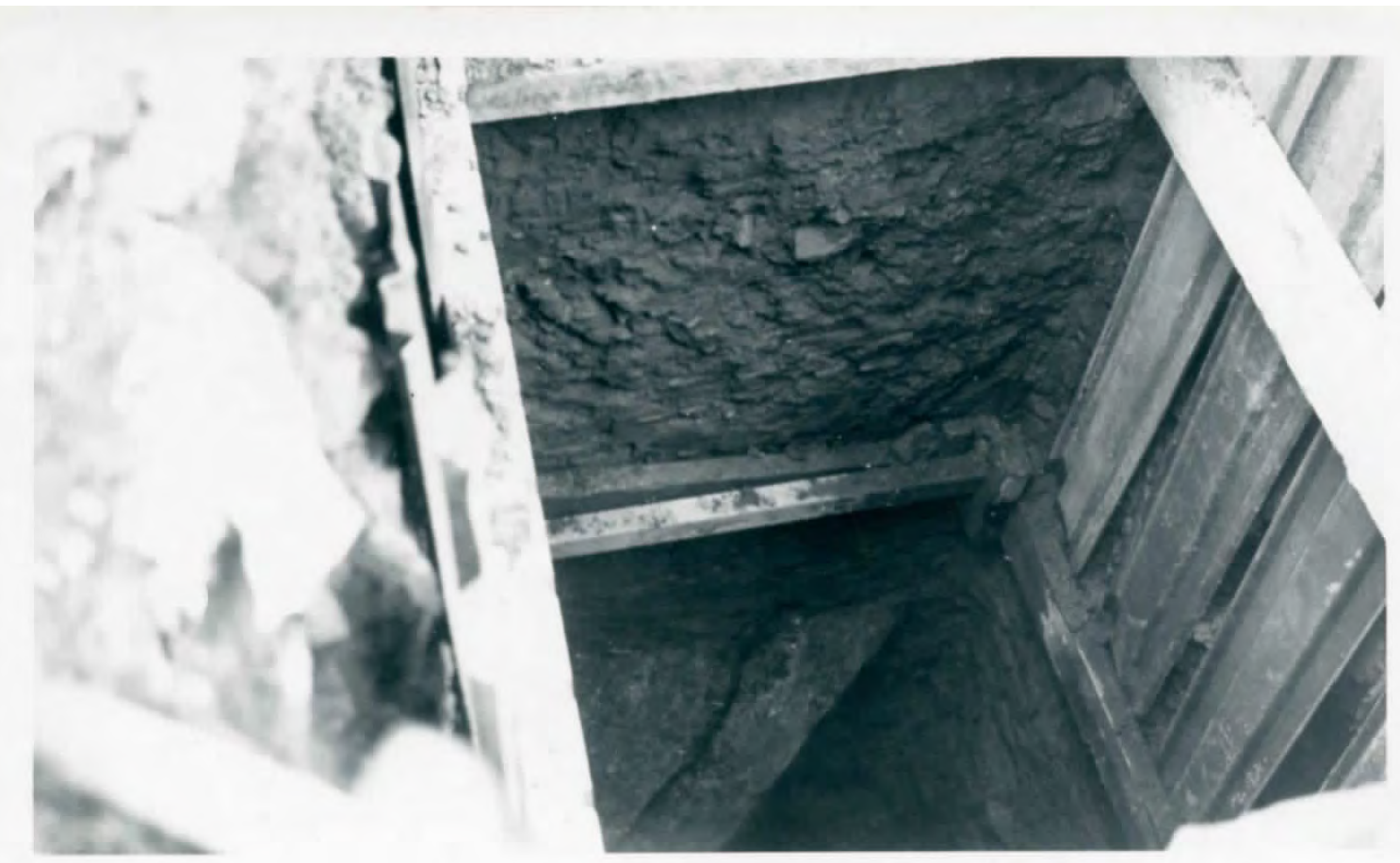

Figure 5.3: Looking down foundation shaft E19 from the north-east. This photograph shows the use of shuttering by the construction workers. Courtesy of Museums Sheffield. 


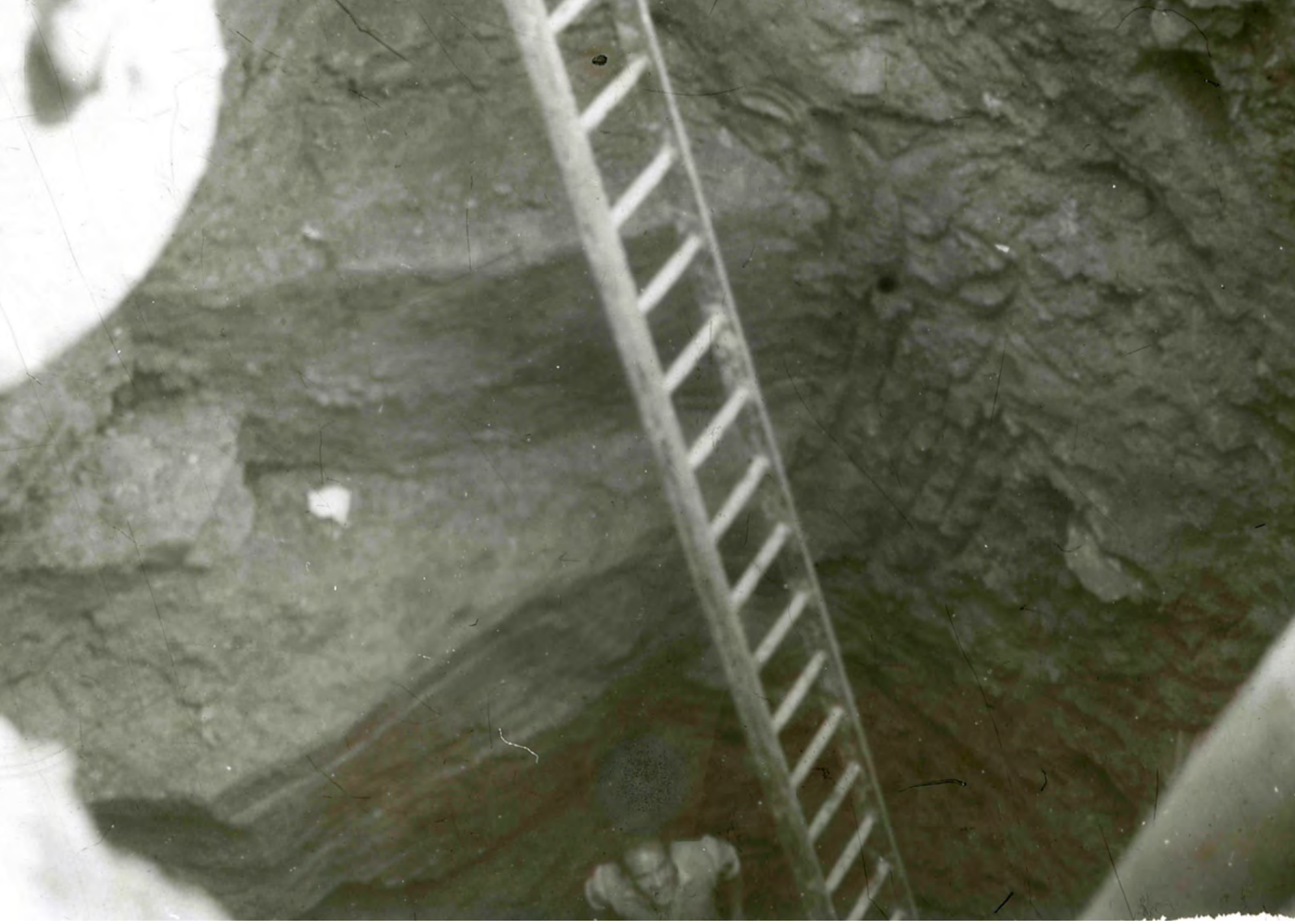

Figure 5.4: Foundation shaft H23 photographed from the south-west with a view of the moat cut. A workman is visible at the bottom giving an indication of working conditions on site that were faced by archaeologists as well as construction workers. Courtesy of Museums Sheffield.

Butcher's drawings provide a wealth of information on the deposit sequences within the moat (for details see the appendix at the end of this chapter). The 1958 construction work saw the bottom of the moat reached in many of the foundation shafts, and Butcher demonstrated that this had generally not been the case 30 years earlier (Butcher 1961, 17; 1972a, 23), despite the impression conveyed by Armstrong (1930, plate VII). His recording of those foundation shafts enabled him to produce a contour map of the base of the moat (Butcher n.d. (u); Figure 5.5), a plan of its course and width (Butcher n.d. (j); Figure 5.6), and a profile drawing to show its depth and composition (Butcher n.d. (m); Figure 5.7). He recorded the base of the south moat at $157 \mathrm{ft}$ $(47.85 \mathrm{~m}) \mathrm{AOD}$ at its west end (e.g. E17), and $152 \mathrm{ft}(46.33 \mathrm{~m}) \mathrm{AOD}$ at its east end near the gatehouse (e.g. in shafts G5, G7; Butcher 1972a, 14; 1972b, 19). The published note in Medieval Archaeology reported that the south moat would have been between 30 and $40 \mathrm{ft}(c .9-12 \mathrm{~m})$ deep in the medieval period (Hurst 1959, 308). However, in his later analyses Butcher argued that the key issue was the height AOD of the bottom of the moat rather than its depth, since neither the modern roads nor the medieval ground surface were level; giving depth beneath those levels 'would in a number of cases obscure the important fact that the bottom of the moat lies at three distinct altitudes above sea level (\& hence above river level) in its three different reaches' (Butcher 1972b, 19). Butcher showed that Armstrong $(1930,18)$ was wrong in his view that the south moat was 'considerably deeper' than the east moat; as we will see, the opposite was true. Butcher initially estimated the moat to be 35 feet $(10.67 \mathrm{~m})$ wide just to the west of the gatehouse structures, although truncation of the archaeological deposits meant that he did not encounter the original top of the moat, and in later drawings he differentiated between the width he recorded $(c .9 \mathrm{~m})$ and the conjectured width at original ground surface $(c .15 \mathrm{~m})$ (Hurst 1959, 308; Butcher 1972a, 13-14; 1972b, 18; Figure 5.6). 


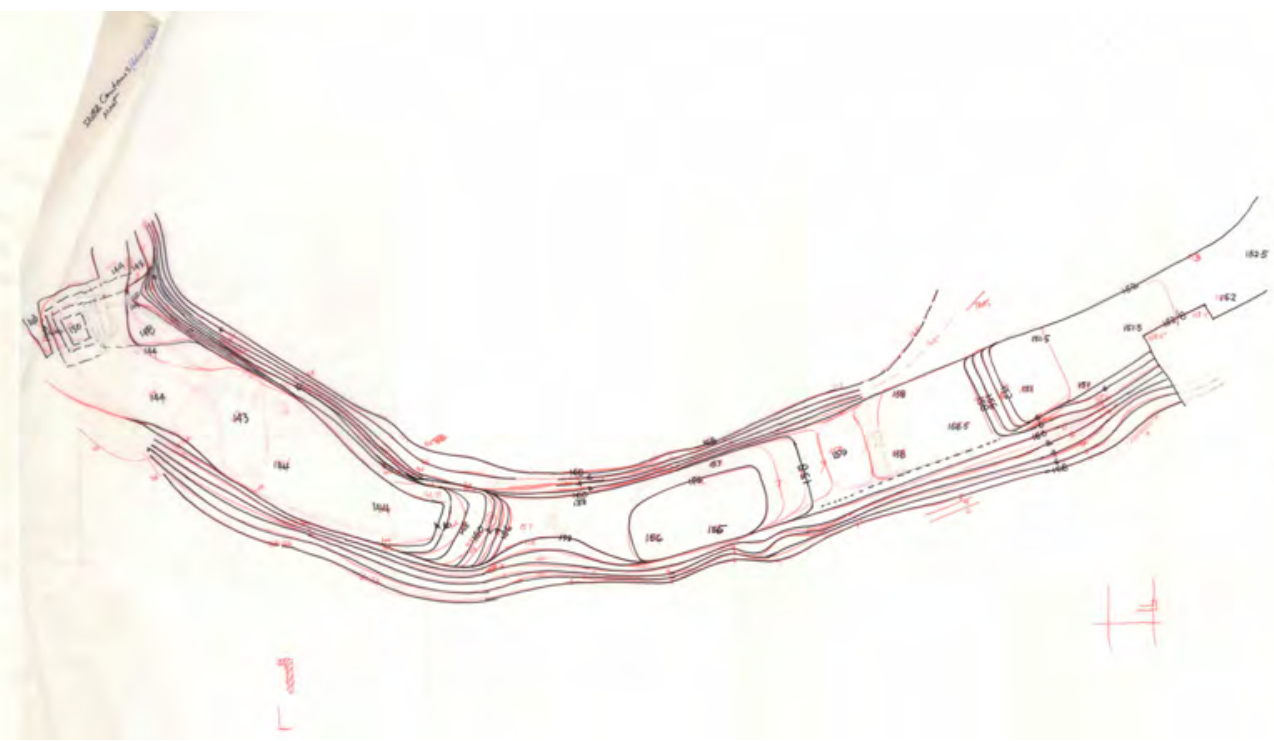

Figure 5.5: Contour map of the base of the moat. Drawn by Leslie Butcher, this reveals that the south moat (centre) was not as deep as the moat on the west and east sides of the castle. Courtesy of Museums Sheffield.

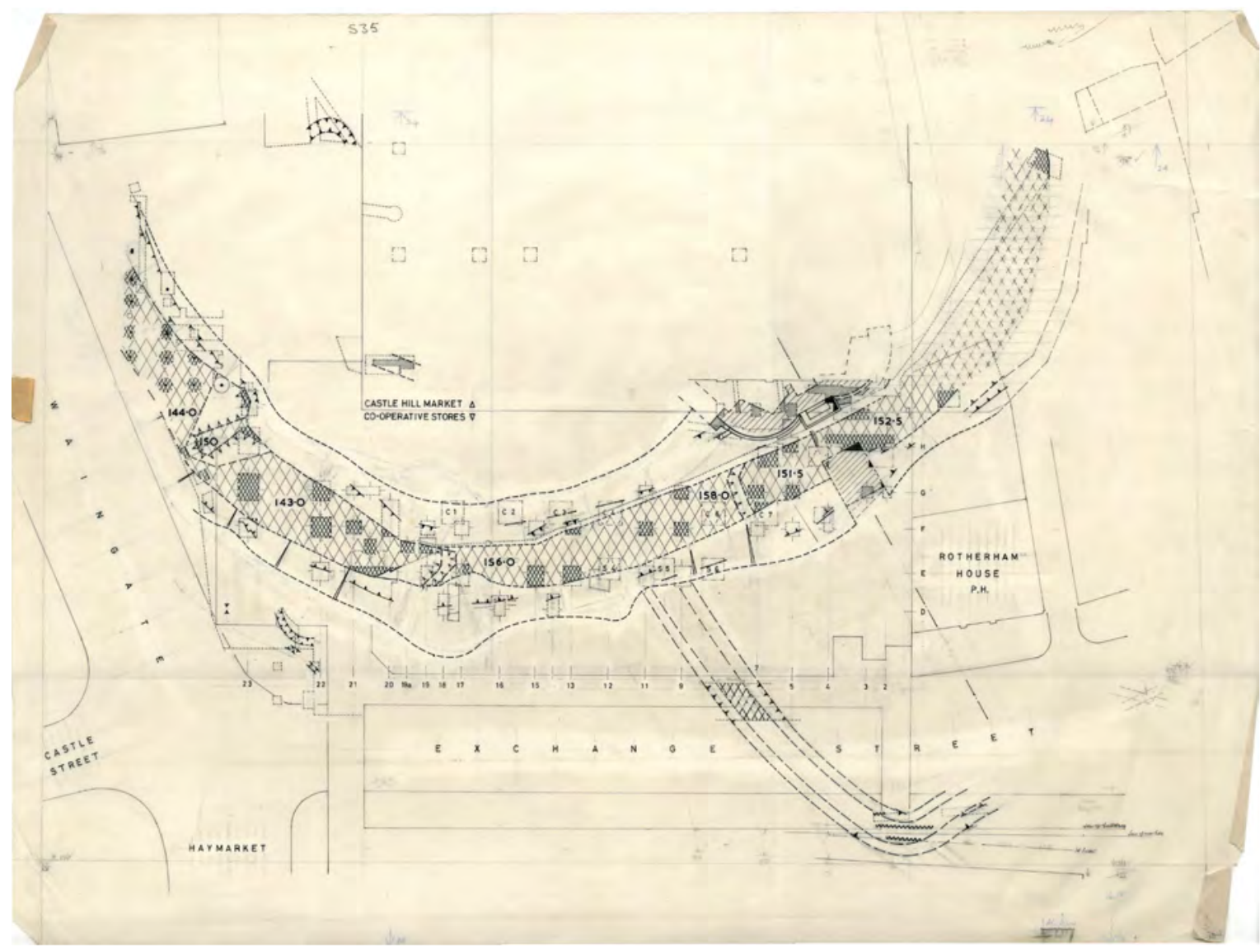

Figure 5.6: Leslie Butcher's plan of the locations of foundation shafts and boreholes. The foundation shafts (hatched squares/rectangles) were dug through the south and west moats and the boreholes (circles with dots) were dug through the west moat. The locations of ditches on Exchange Street are also depicted, as well as the gatehouse and associated structures, and a ditch in the inner courtyard (top left), which Butcher thought to be one of the earliest features on the site. Courtesy of Museums Sheffield. 


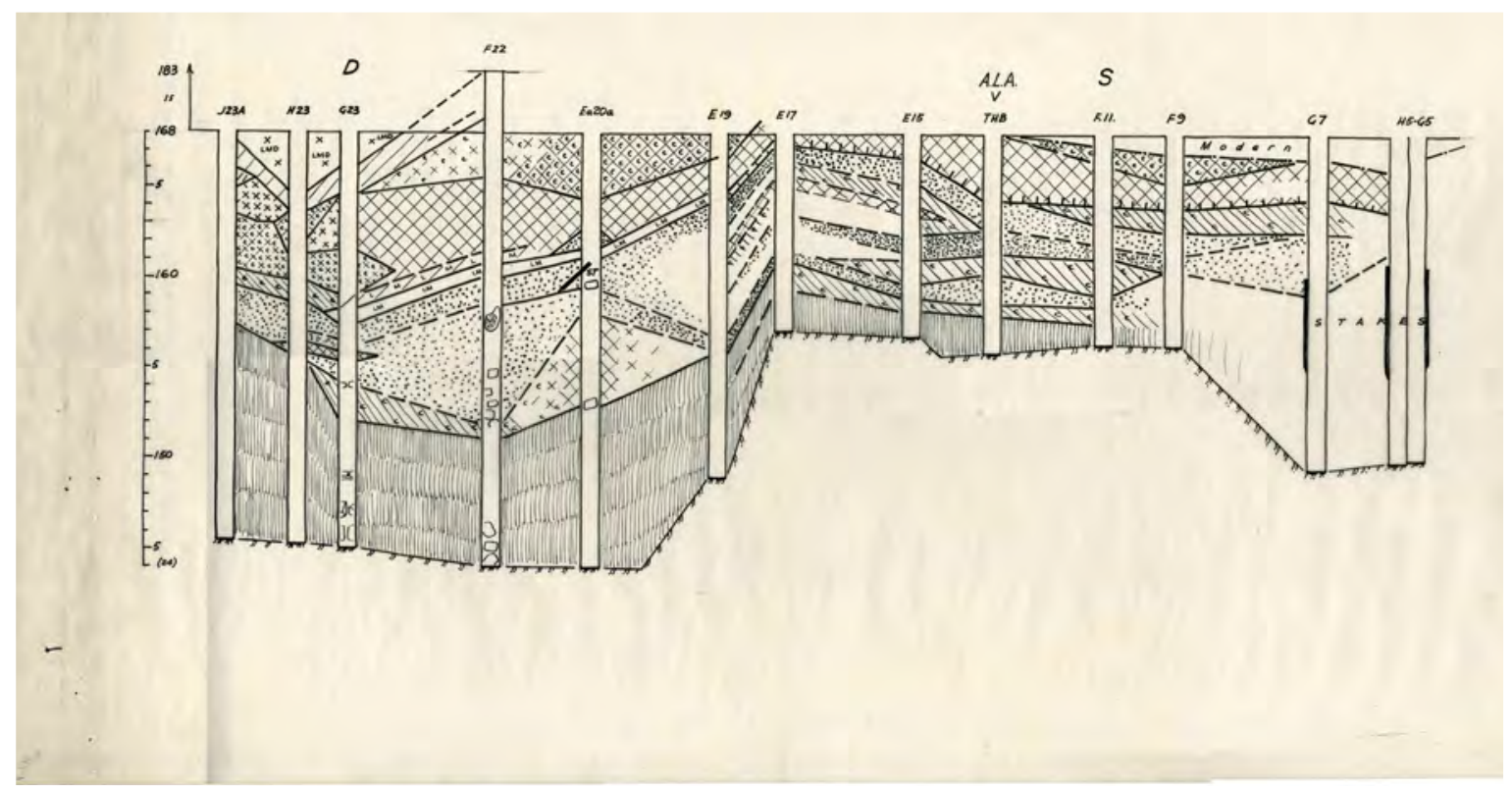

Figure 5.7: Profile drawing of the moat. Drawn by Leslie Butcher based on his recording of the foundation shafts. Courtesy of Museums Sheffield.

The foundation shafts dug along the line of Exchange Street broadly confirmed the alignment of the south moat that Armstrong had suggested, but the recording challenged the earlier deductions about the moat on the west and east sides of the castle. The foundation shafts near the junction of Exchange Street and Waingate (in particular, E19, F20, F21, F22, F23, G22, G23, H23 and J23; see Ove Arup \& Partners and Butcher 1957) revealed a stepped transition from the south moat to the deeper west moat, and also suggested that from here the moat made 'a slow quadrantal turn $\left[90^{\circ}\right]$ and continues northward, nearly parallel to Waingate ... where less than half of its width lies under the present street' (Butcher 1972a, 7; n.d. (u)). Butcher (1972a, 8; 19722c, 10) suggested that the moat joined the Don to the east of Lady's Bridge (Butcher 1972a, 8-9). He believed that there may have been a dam nearby, because he recorded the base of the moat to the south of Foster's store virtually at river level (144ft (43.9m) AOD), which was a level sustained all along the west moat; to maintain an adequate level of water in the south moat, he deduced that a $20 \mathrm{ft}(6.10 \mathrm{~m})$ high dam would have been needed (Butcher 1961, 46; 1972a, 9; 1972c, 10). Indeed, an anonymous Civil War siege description reveals that there was a dam with a sluice to the moat on both the west and east sides of the castle: 'The water deep in the West and East sides of the Castle, slackered [controlled by sluices] on all sides' (Anon. 1644, 2; see also Chapter 3). Butcher pointed out that ' $[\mathrm{m}]$ asonry encountered in 1930 at river level in a pit? [the measurement is missing, but see below] feet east of the present east parapet [of Lady's Bridge] shows a contrast in construction which may relate to the debouchement' into the Don (Butcher 1972a, 8-9). This must be the stonework Himsworth (1927-42, 16-17) recorded in his diary for $1^{\text {st }}$ July 1930 (see Chapter 3, Section: The inner courtyard moat). A plan of the wall drawn by the City Architect in 1930 survives in Butcher's archive (Anon. 1930a), which shows it to be almost on the line of Castlegate, located c.9m east of the southern end of Lady's Bridge, and c. $1.4 \mathrm{~m}$ south of the then extant parapet wall above the Don (Figure 5.8).

The construction work provided only limited opportunity to record the east moat (Butcher 1972a, 10; 1972d), but insights from manhole 3 and boreholes 3, 7, 8 and 70 enabled Butcher (n.d. (r); 1961, 19-20, 27) to suggest that east of the gatehouse the moat ran north-eastwards in the direction of the Sheaf rather than curving round the tower northwards towards the Don as shown on Armstrong's plan 1. He argued that this explained why Armstrong had not encountered organic deposits typical of moat fills in the foundation shafts he had examined (Butcher 1972b, 21). ${ }^{19}$ Butcher (1972b, 20-1) disagreed with Armstrong that the east

\footnotetext{
${ }_{19}$ Although, as we saw in Chapter 3, in his unpublished site diary Armstrong $(1927-28,3)$ did in fact record the appearance of the moat in a number of foundation shafts running northwards from the Rotherham House Hotel, and in one of them notes the 'top of black' - a probable reference to organic layers.
} 


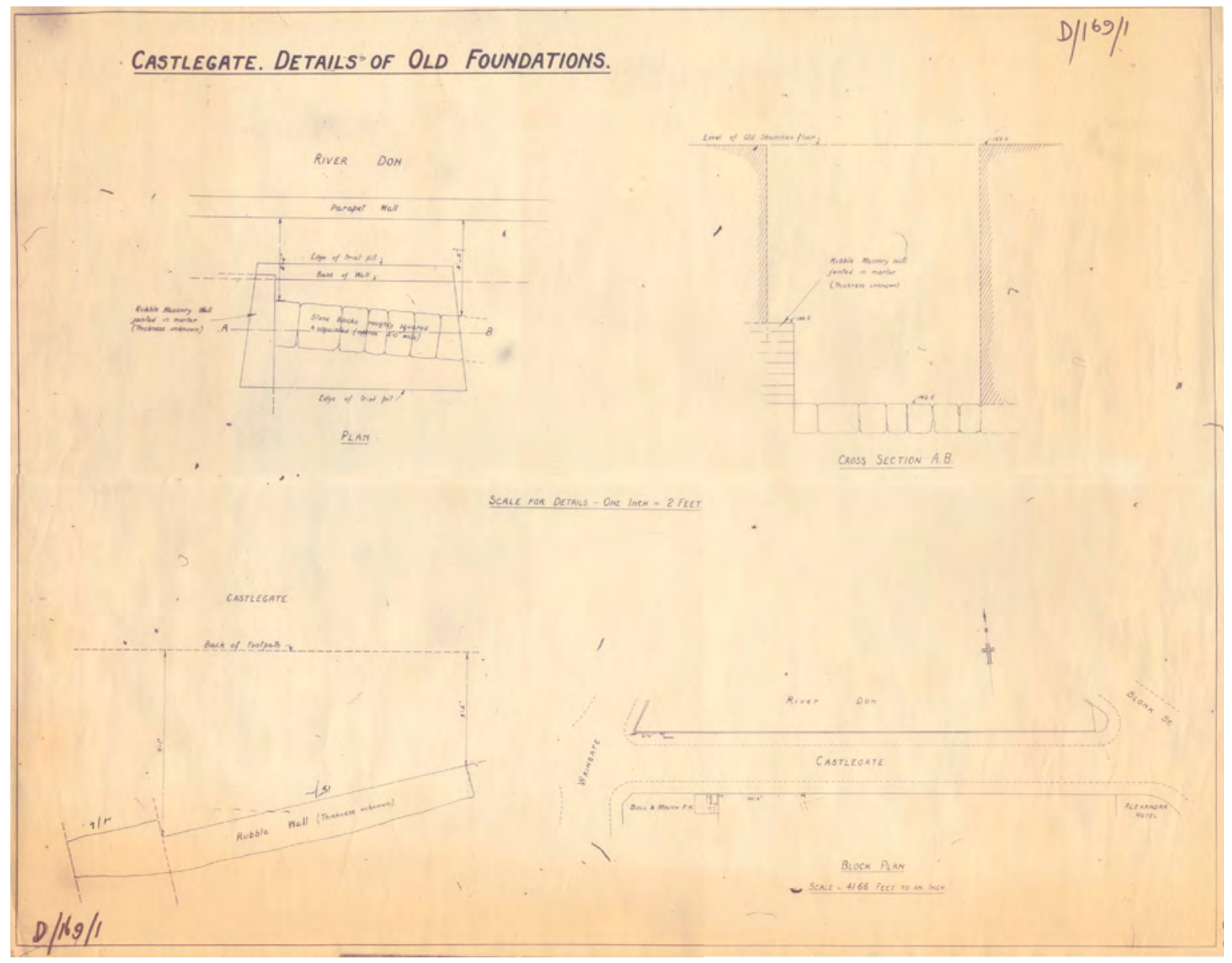

Figure 5.8: Drawing of old foundations on Castlegate. This plan from 1930 is contained in the Butcher archive, and records stone features uncovered during the building of the road. Courtesy of Museums Sheffield.

moat had followed the line of Castle Folds Lane, proposing instead that the east curtain wall ran along this line, with the moat lying further to the east. A sketch which summarises his thinking about the 'shape' of the castle, and its place in the landscape, clearly shows the east wall running along 'CFL' (Castle Folds Lane) (Butcher 1972e, 3; Figure 5.9). Describing the lowest deposits in manhole 3 as stagnant, Butcher argued that these were the lower fills of the moat, not an earlier channel of the Sheaf, which ran still further to the east (Butcher 1961, 45; see also 1958-62d). These deposits also contradicted Armstrong's $(1930,18)$ deduction that the east moat had been dry, for which he had provided what Butcher $(1972 b, 19)$ described as 'no positive supporting evidence' (see also Butcher 1972d, 19). In manhole 3 Butcher (1972a, 13; 1972b, 19) recorded the depth of this section of the east moat as being the same as that of the west moat (144ft $(43.9 \mathrm{~m})$ AOD - a measurement that was later confirmed in the work undertaken by both ARCUS (Davies 2000, 7-9) and Wessex Archaeology (see Chapter 7) - and concluded that there must have been a stepped transition down to it from the south moat, as was the case where the south moat turned to form the west moat. While the excavations did not throw any new light on the matter, the dam on the east side was probably situated where the moat met the Don, which 'echoed' the proposed arrangement on the west side (Anon. 1644; Butcher 1972c, 10). However, Butcher (1972b, 23) remained uncertain, listing among his 'Unresolved problems' the issue of how the water level was maintained in the moat (and this is an issue we will return to in Chapter 7). On the sketch which appears to summarise his thinking about the location and shape of the castle (Butcher 1972e, 3), a dotted line running south from the Don and overlapping with the course of the Sheaf suggests that he (at least) toyed with the idea that the confluence of the two, and hence of the moat with the Don, lay significantly further south than currently. And he marks a '?sluice' not far north of the point where the moat 


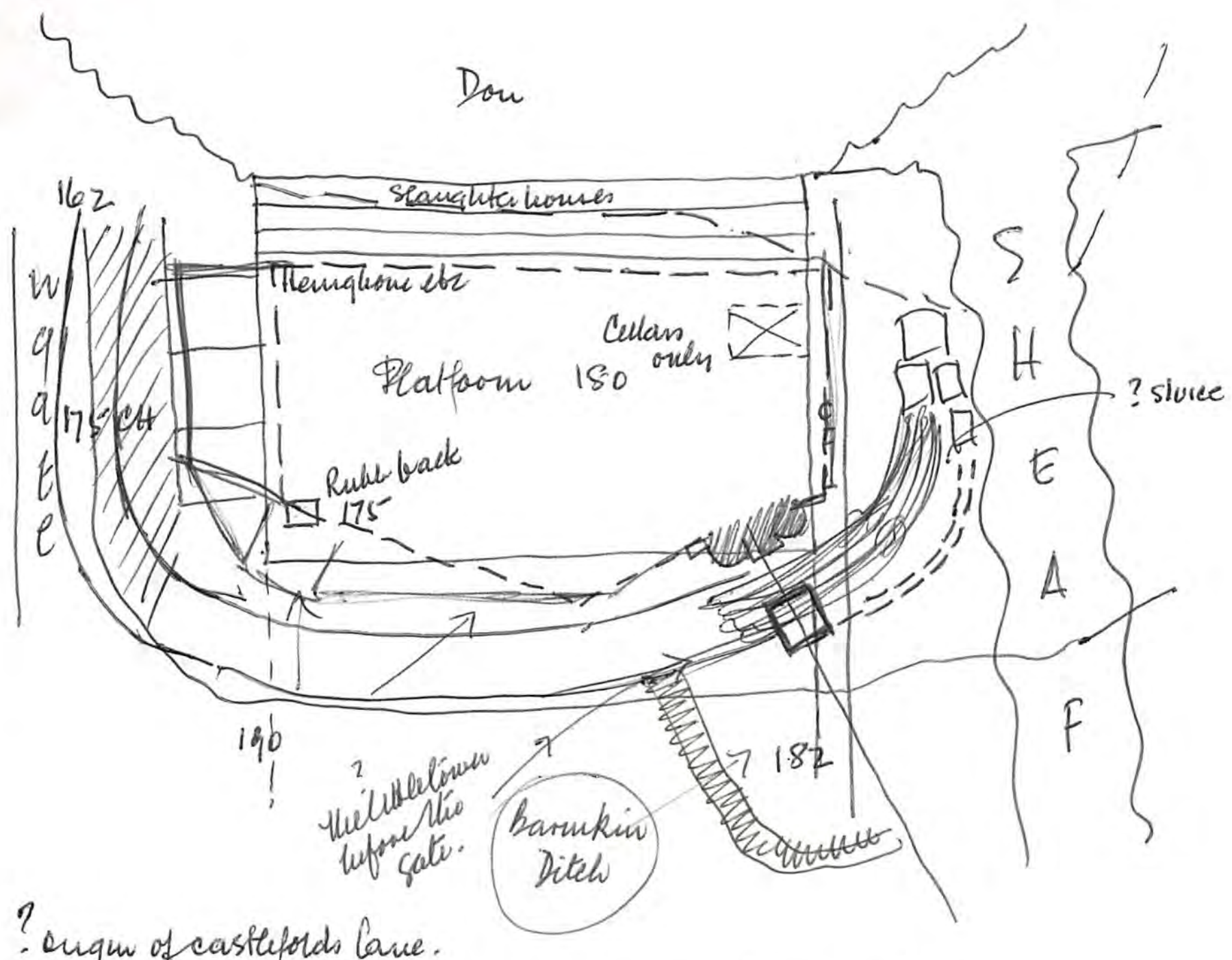

? onque of casitefords lave.

NOT nalinal ontgrowik of caste defences (nutersects)

VSTRACHET

Hugh ret wall ouly west

Quly struchua of w sude = cellars to cit poperty

Aurevorles steps = precip slope

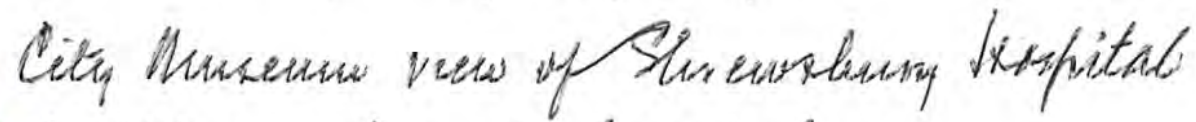

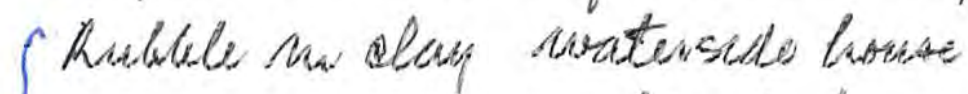

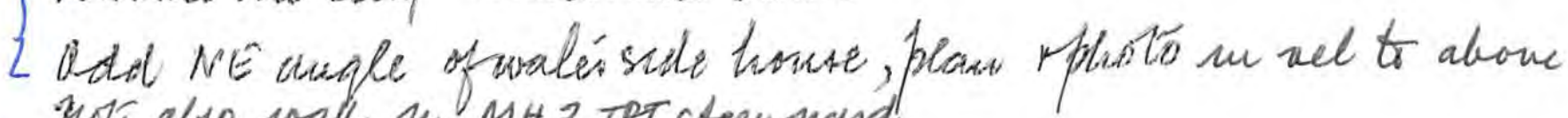
note also wall m MH 3 TPT cteen yand

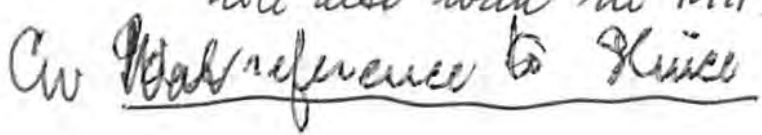

Figure 5.9: Sketch by Leslie Butcher showing his thoughts about the 'shape' of the castle, and its place in the landscape. The ditched enclosure in front of the gatehouse is here described as the Barmkin Ditch. He also notes illustrations that he anticipated might be included in his planned publication. Courtesy of Museums Sheffield. 


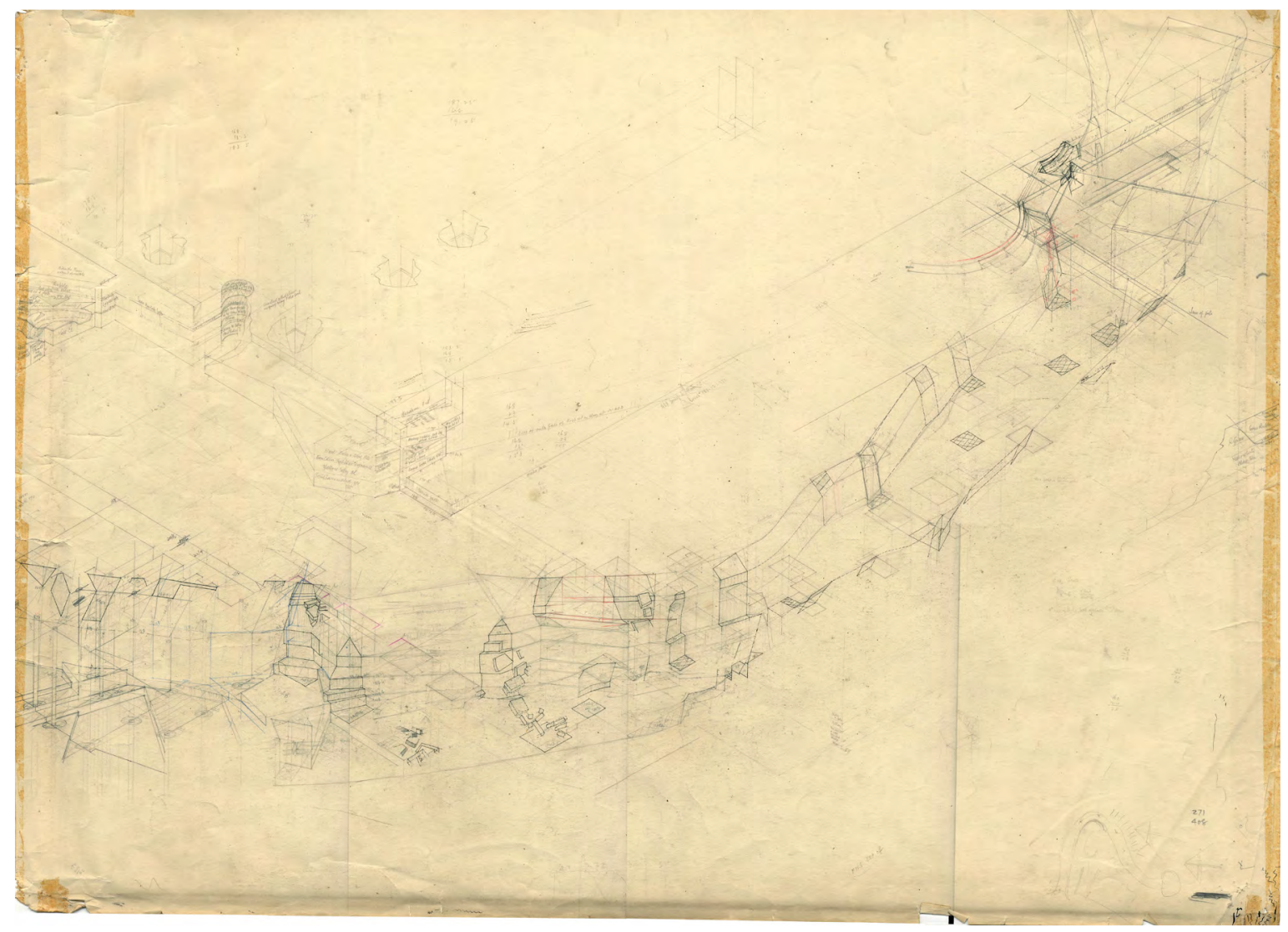

Figure 5.10: Draft isometric drawing of the gatehouse and south and west moats. Drawn by Leslie Butcher. Courtesy of Museums Sheffield.

turns past the gatehouse, although the actual distance is hard to measure as the sketch is not to scale. Butcher also suggested that the dams/sluices may have acted as causeways, providing a means of access to the castle; while we have no firm evidence for entrance gates into the castle at those points, it is notable that Castle Hill Lane crosses from Waingate to the site of the castle at roughly the point where Butcher thought the west dam was located (Butcher 1961, 46).

In recording the foundation shafts, Butcher (1972a, 13) identified three recognisable profiles of the moat based upon a broadly ' $Y$ '-shaped cut (Figure 5.10). The outer edge of the south moat had the greatest variety in profile in the upper slope descending to a rock shelf of varying widths. The upper part of the visible moat cut typically splayed outwards, although as we have seen its original top had been lost through truncation (Butcher n.d. (j)). Below this, the moat became more or less vertical to its base. Butcher suggested that the ' $\mathrm{Y}$ '-shaped profile owed much to the underlying geology, and given his background it is not surprising that he spent some time discussing this in his various unpublished manuscripts. Typical is the following description of the south moat, wherein the solid geology was determined as the key factor in the form of the moat cut:

A marked upward transition from compact, sandy mudstone, to a more friable shaley variety takes place along a plane rising from a foot or two below, 168' A.O.D. [51.21 $]$ ] at the gate structures to a foot or two above 168' A.O.D. at the S.W. angle of the moat. This divide is the most practicable place above which to cut back the friable to obviate collapse and minimise weathering, and below which to cut 'vertical' self-supporting walls down to moat bottom (Butcher 1972a, 15-16).

Butcher contrasted his observations with the rounded profile drawn by Armstrong, and these were confirmed by more recent investigation by ARCUS (Davies 2000, 8). In the light of our discussion of Armstrong's 


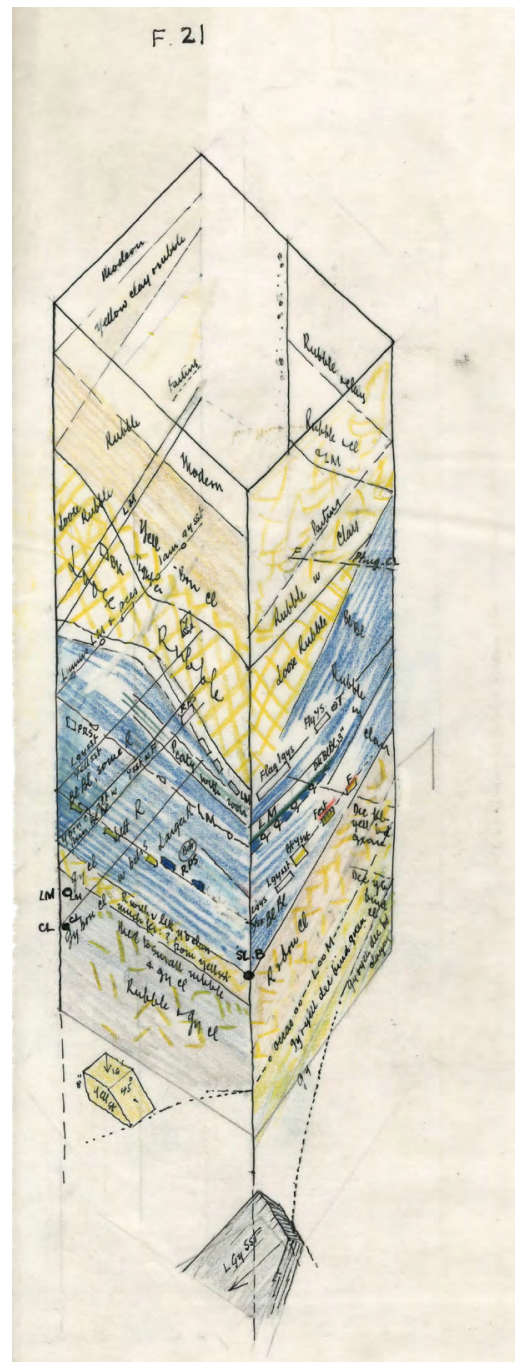

Figure 5.11: Isometric drawing of foundation shaft F21. Drawn by Leslie Butcher. Courtesy of Museums Sheffield.

methods in Chapter 2, it can be seen that Butcher's $(1961,14)$ frustration with Armstrong's recording was a consequence of the latter's presentation of a typical schematic profile through the moat. Having said that, it is also apparent that Armstrong placed the shoulders of the moat cut too far below the original ground level (Butcher 1961, 16).

Butcher's records reveal that the lowest moat deposits visible in the south and west 'arms' largely comprise weathering of the stone from the sides of the moat cut, and above this in many of the foundation shafts are silting deposits, described as primarily blue-black or blue-grey, colours which must have resulted from chemical changes in soils exposed to water, which confirms that they contained water (Butcher 1961, 17-19; for comparison, see Munby et al. 2019, 33). He described these silts as 'accumulations of black organic mud, blue black in colour, containing many plant remains - reeds from the moat, immense amount of small twig and branch timber' (Butcher 1961, 19; Figure 5.11). Some deposits had remained waterlogged into the 1950s, resulting in organic preservation of artefacts, including wood and leather (e.g. in shafts F21, F22, G5, G7, G23, G/H24, H2-4, H5 and manhole 3; see Chapter 6). Correspondence preserved in the Museums Sheffield archives reveals that, although the working conditions were hardly propitious, Bartlett managed to recover some plant remains from the moat, which he sent to a local specialist, T. L. C. Bottomley, who, at various points throughout the late 1940s and 1950s, was President, Secretary and Treasurer of the Sorby Natural History Society, and a Fellow of the Royal Entomological Society. Bartlett passed the latter's brief report (in a letter dated $22^{\text {nd }}$ January 1959) on to Butcher. Bottomley recorded a large number of wood fragments, which he deemed mainly too small to identify, but reported that the larger pieces all appeared to be oak (see Chapter 8 for a discussion of 
the trees in nearby Sheffield park). He also identified oak and grass leaves, moss of the genus Brachithecium (recte Brachythecium), and said that there were a dozen seeds which he had not yet identified. On the basis of the identifiable material, he concluded that 'the local vegetation was pretty much the same as it is now' (Bottomley 1959a). Unfortunately, the absence of any further contextual information means that we are not able to say when the vegetation was the same as now. On $9^{\text {th }}$ February 1959, Bottomley (1959b) wrote to Butcher with further information on 'the seeds which I extracted from the mud of the Castle Moat', reporting that he had now identified some of the seeds as 'small Composites' or sedge, which grow in damp and shady environments (Champness 2008, 13).

The 17th-century written sources reveal that the castle was dismantled and sold off rather than simply being demolished and pushed into the moat (see Chapter 9, Section: Reduced to fragments - embedding the castle in the community), and so the quantities of stone recorded on the section drawings of the foundation shafts represent what was left behind. However, we must remember that earlier 20th-century construction on this part of the site had seen $c .15 \mathrm{ft}(4.57 \mathrm{~m})$ of deposits removed and the ground level reduced (Butcher 1961, 18), and so the comparative lack of demolition debris in some sections of the moat may partly be accounted for by the fact that Butcher was only able to record its lower levels (Richardson and Dennison 2014a, 56; see also Armstrong 1930, 14). From the information recorded on the section drawings, particularly the angle of slope of the deposits, we can sometimes identify the direction from which the moat was infilled (see, in particular, shafts E17, E19, F11, F21 (Figure 5.11), F23, G7, G22, H23, H5 and J23), and since the dating evidence for the upper fills is largely of the 17th century it is often possible to distinguish the post-Civil War fills from those of the medieval period (a good example is provided by foundation shaft F22; see Appendix). Butcher $(1961,19)$ also argued that all of the constructional rubble fill he saw derived from the site and probably from the moat cut.

In the south moat Butcher $(1961,22-4)$ recorded seven wooden stakes in foundation shafts G5, G7 and H5, some with oak boards fastened between them, while twigs and branches had been placed between the stakes and the inner face of the moat cut (Figure 5.12). Several of these stakes were reused timbers with mortice holes (see, for example, the west face of G7), and the section drawings and isometric drawings reveal that they had been driven into the lowest silting deposits within the moat, and that subsequent silt deposits had built up around them. Discussion of these was omitted from Butcher's 1972 typescript, but occurs in his handwritten texts, where he suggested that the sharpened appearance of the stakes was caused by the decayed ends snapping off (Butcher 1961, 23); in this respect he contradicted the view of Armstrong (1930, 19) and Himsworth $(1927-42,15)$ who believed that similar stakes had been deliberately sharpened. The stakes seem to have been acting as a revetment to consolidate the inner moat cut rather than being the defensive feature Armstrong and Himsworth had imagined. Near the gatehouse, foundation shaft $\mathrm{H} 5$ revealed that the inner, steeply inclined face of the moat was clad in masonry as far as a rock-cut shelf which stepped up behind the gatehouse structures (Butcher n.d. (k); n.d. (1); 1958-62c; 1958-62g; 1972a, 13; Figure 5.13). Although the outer face of the moat was not observed near the drawbridge pier, Butcher $(1972 a, 13)$ thought that it may also have been stepped in this way to accommodate the drawbridge; it was certainly stepped further west.

Our archival research revealed that the vast majority of the artefacts surviving from the excavations recorded by Butcher derive from moat deposits. The foundation shafts excavated in the south and west moat mainly produced mixed late medieval and post-medieval pottery assemblages, although the latter had a lower proportion of medieval pottery. In contrast, the greatest concentration of medieval pottery was recovered from foundation shafts and trenches dug through the moat close to the gatehouse. Thus, foundation shafts F9 and F11, located adjacent to each other in the middle of the moat to the west of the gatehouse, contained small and exclusively medieval assemblages. Analysis of the pottery recovered in $\mathrm{H} 2-4$, when differentiated through contextual information (depths, and P numbers), suggests that it may have cut into surviving medieval strata beneath the 17thcentury deposits. This is supported by the fact that the base of the section drawing for $\mathrm{H} 2-4$ bears the annotation 'early Saxon-Norman [pottery] from x + y buckets from ditch bottom' (Butcher 1958-62d; Figure 5.14).

\section{Gatehouse}

The gatehouse was recorded by Butcher in foundation shafts $\mathrm{H} 2-4, \mathrm{H} 3$ and $\mathrm{H} 5$, and manholes 1,2 and 5 . A sketch by Butcher distinguished what he had seen (in red) from what Armstrong had recorded (in green) (Butcher 1958a; Figure 5.15). Butcher recorded more of the west tower, part of the east tower, the full width of 


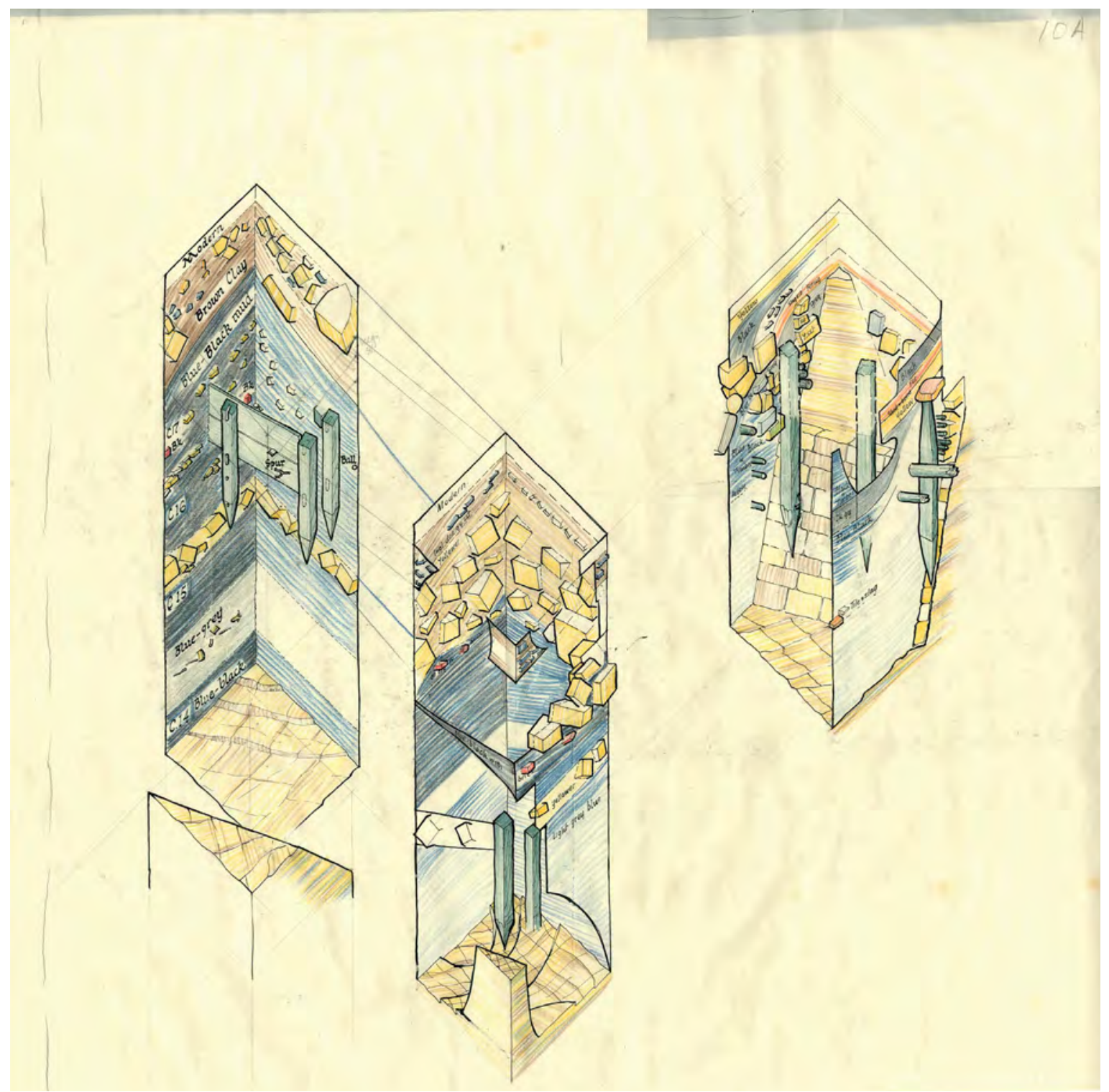

Figure 5.12: Isometric drawings of foundation shafts. This depicts G5 (centre), G7 (left), and H5 (right), and highlights the presence, and survival, of wooden features within the moat. Drawn by Leslie Butcher. Courtesy of Museums Sheffield.

the drawbridge pier, further details of the gatehouse forestructure added between the towers and the full depth of the moat, and produced multiple profile and reconstruction drawings.

The excavation of manhole 5 exposed a short section of wall set at right angles and bonded to the footings of the west tower. Butcher $(1961,33)$ argued that, if this was the junction of the curtain wall and the gatehouse tower, the foundations of the former must have stepped up, for they did not extend even as much as $3 \mathrm{ft}$ $(0.91 \mathrm{~m})$ across the trench. A cross-section of the west tower showed its stepped foundations, offset one course at a time as they rose from the moat cut until they reached the lowest chamfer of the plinth (Butcher n.d. (q); 1961, 33; Figure 5.16). It was also revealed that the footings were deeper on the west side of the tower than on the east side. Records made during work that Butcher (1972a, 17) described as 'in the floor of the "tunnel" under the Castle Hill Market' indicated that the softer upper layers of the natural geology, which were problematic when cutting the moat, also affected the construction of the gatehouse (Butcher n.d. (r); for the 


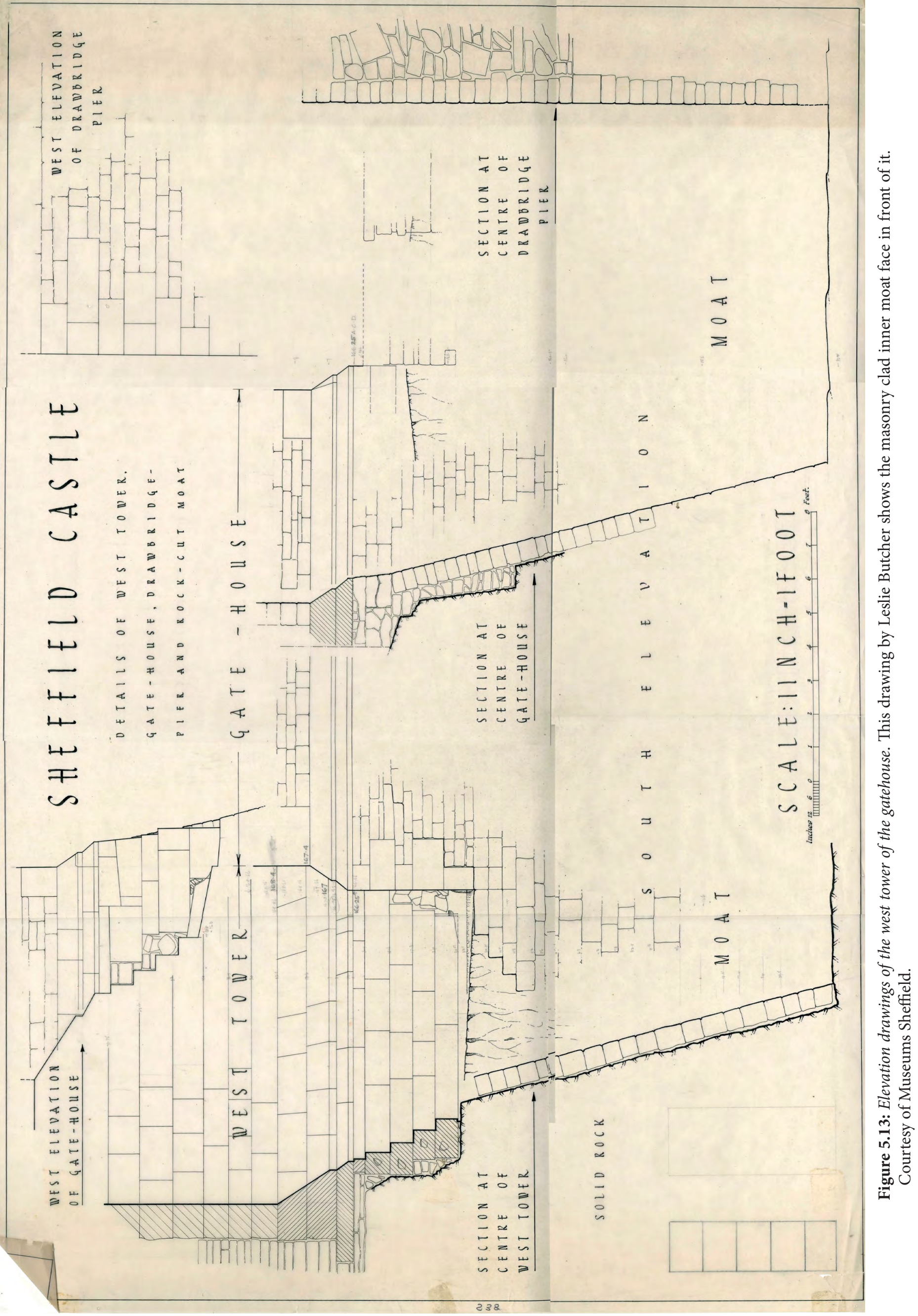




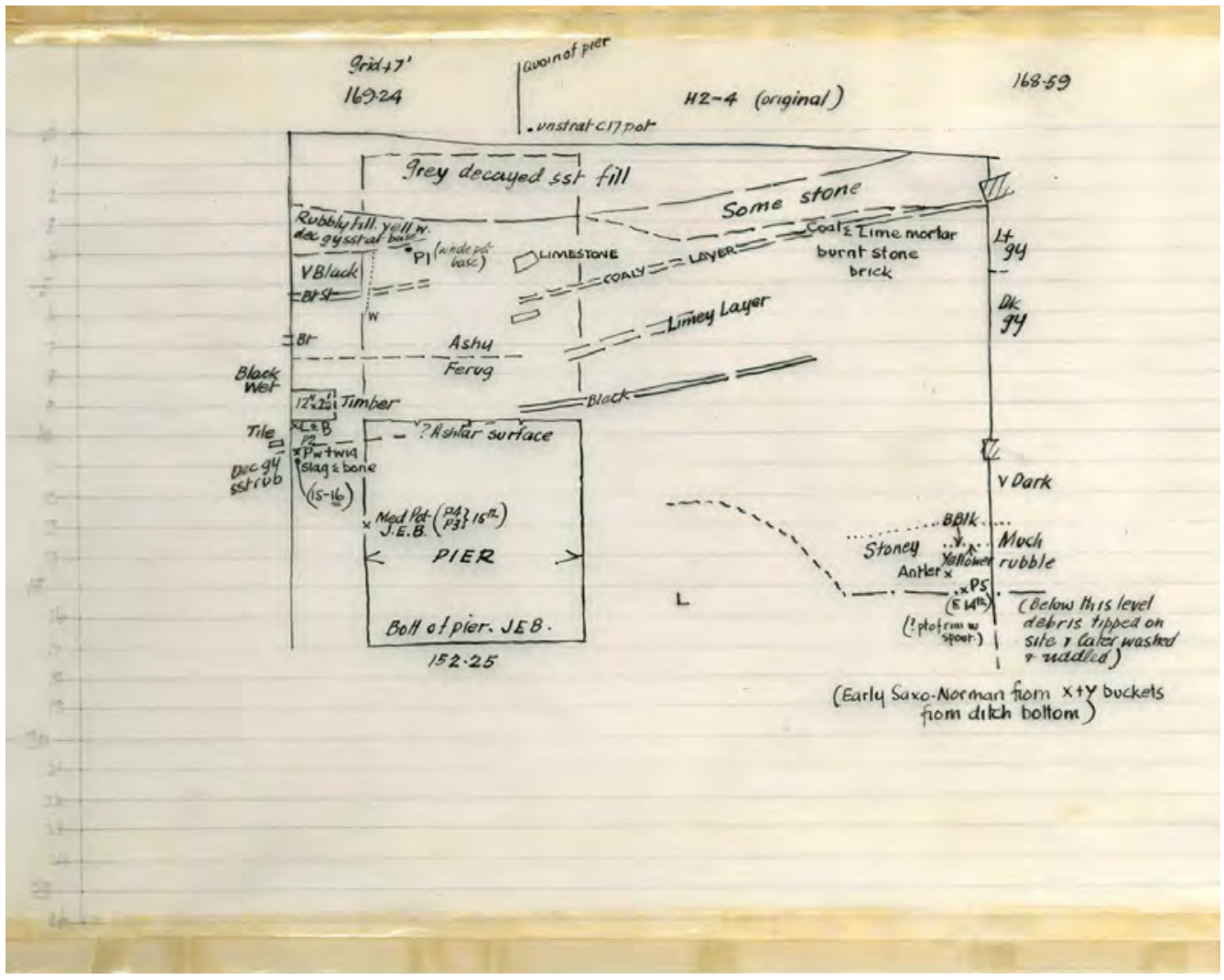

Figure 5.14: Section drawing of foundation shaft H2-4. This drawing, on lined paper with a scale in feet, details some of the finds recovered, including early Saxo-Norman material, which must be pottery. It also refers to findings made by 'JEB', John Bartlett. Courtesy of Museums Sheffield.

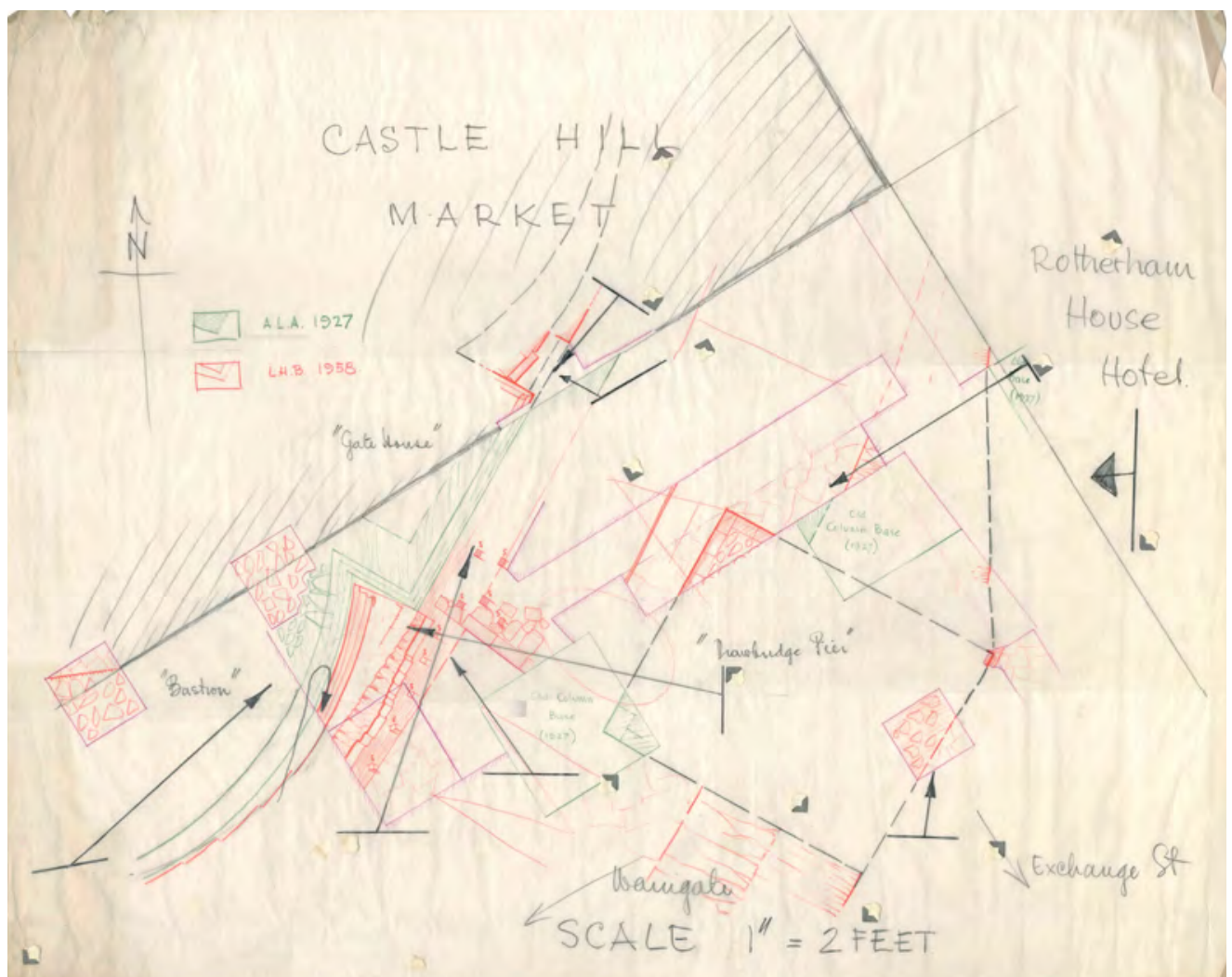

Figure 5.15: Sketch of the gatehouse area by Leslie Butcher. This shows the differences between what Leslie Butcher and Leslie Armstrong had recorded of the castle's monumental entrance (in red and green, respectively). Courtesy of Museums Sheffield. 


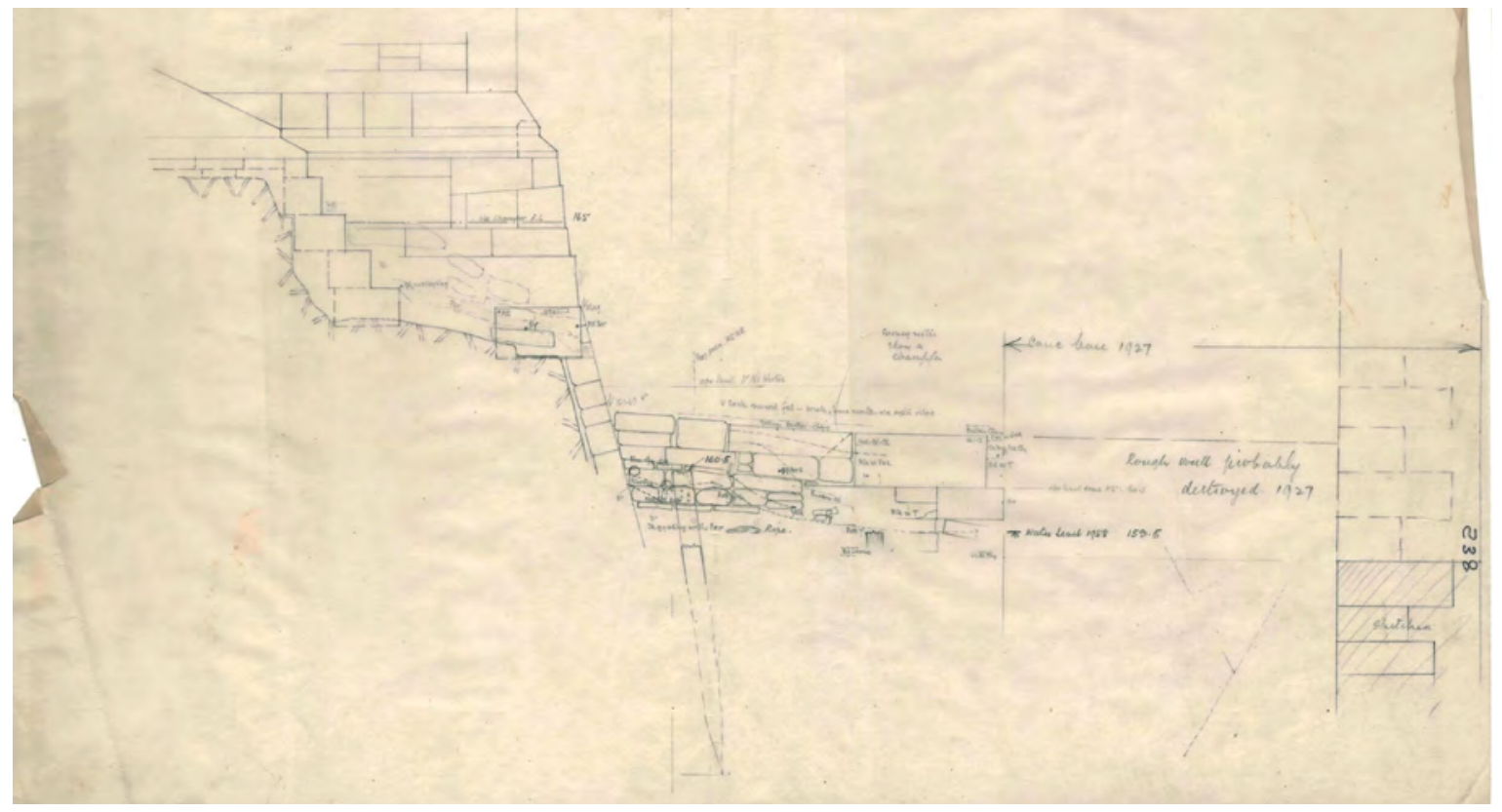

Figure 5.16: Leslie Butcher's profile drawing of the gatehouse, 'late' wall, and drawbridge pier. Courtesy of Museums Sheffield.

tunnel, see f.n. 20, below). The loose, upper strata of natural appeared to have been cut away and replaced by layers of irregular sandstone flags, held together with wedges of sandstone and covered with a thin binding of blue clay, and they 'extended "inwards" from the irregular inner ends of the ashlar facing blocks of the towers and gatehouse' (Butcher 1972a, 17-18). This was presumably to provide a firm footing for the tower foundations (Figure 5.13).

The east tower was recorded immediately below the south-east corner of the Castle Hill Market building, and is shown in plan (Butcher n.d. (n); n.d. (o); n.d. (p)) and on an isometric drawing (Butcher n.d. (d); 1972a, 17). It appeared to have been more extensively robbed of stone than the west tower, especially the ashlar and chamfered plinth, where steps in the rubble core of the wall indicated the former position of some of the plinth stones (Butcher 1961, 32), but a slightly curved 10ft $(3.05 \mathrm{~m})$ section of the tower plinth, which had a rubble core set in clay, could nonetheless be discerned 'under dem. [olition] rubble' (Butcher 1961, 32). As we saw in Chapter 3, Armstrong $(1930,11)$ mentions discovery of another part of the gatehouse structure on the site of the Co-op, a section of plinth described and photographed by Himsworth (1927-42, 11-12; Figure 2.14). Butcher $(1961,32)$ suggested that this section of plinth was part of the east tower.

More of the gatehouse forestructure was recorded, and Butcher (1972a, 17) pointed out that Armstrong had, in fact, uncovered its east edge but had appeared not to notice. It was just visible in his figure 7 but obscured by trench timbers (see Figure 3.11), as Butcher explains:

From the bottom right corner a timber slopes up into the picture making an angle of $30^{\circ}$ with the right edge. The corner of the plinth course is at the upper end of the timber: immediately below it, two ashlar quoins have been slightly displaced in fixing the timber, whilst above the top of the plinth another large quoin can be seen through the angle formed by two more timbers: these ashlar blocks amongst rougher masonry should have prompted closer scrutiny.

Butcher $(1972 \mathrm{a}, 15)$ reported that the plinth course was around $12 \mathrm{ft}(c .3 .7 \mathrm{~m})$ above the bottom of the moat at $152 \mathrm{ft}(46.33 \mathrm{~m})$ AOD. His $(1961,29)$ records show that the gatehouse was built partly on the solid rock and partly on the masonry lining of the moat. The ashlar plinth was similar to that of the west tower, and abutted, but was not bonded to it.

Butcher $(1972 \mathrm{a}, 18)$ contradicted the views of Armstrong $(1930,10-11,17)$ about the character of the pier, arguing that 'the whole concept of a free standing "drawbridge pier" located in mid-moat must be abandoned. 


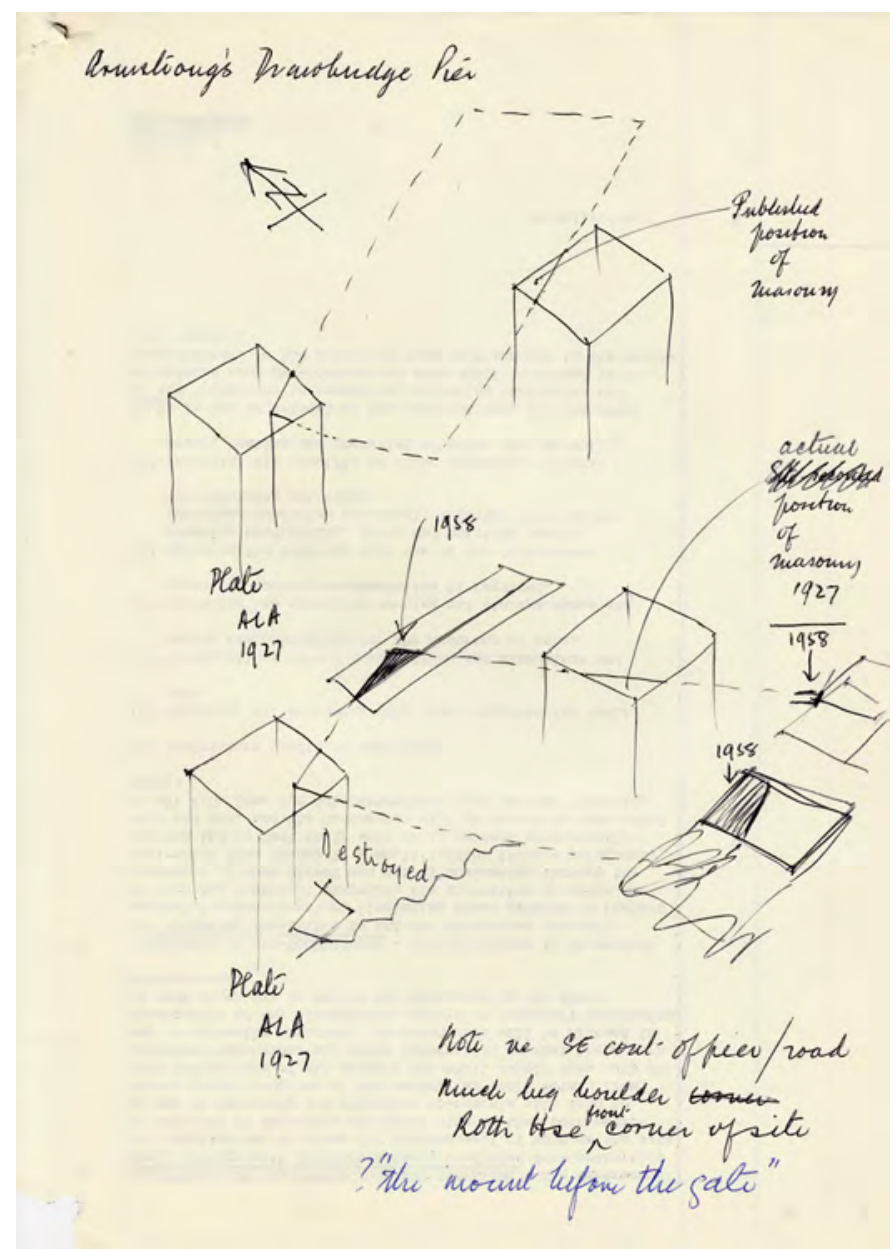

Figure 5.17: Leslie Butcher's sketch of the drawbridge pier. This shows how he worked out the error made by Armstrong in locating what had been recorded of the pier in the moat in front of the gatehouse. Courtesy of Museums Sheffield.

Butcher (1972b, 22; see also 1972a, 18; 1973c, 6) was able to show that Armstrong had been misinformed about the location of what had been exposed of this structure in the late 1920s. A corner of the pier is shown in Armstrong's photograph 10 (see Figure 3.14 ), measuring $3 \mathrm{ft}(0.91 \mathrm{~m})$ on the north side and $2 \mathrm{ft} 8 \mathrm{in}(0.81 \mathrm{~m})$ on the west side (see also Armstrong 1927-28, 4). On Armstrong's plan 1 this is depicted as its north-west corner. Armstrong also thought he had identified another section of the pier on the west side of shaft B (about $5 \mathrm{~m}$ to the east). This is depicted as being on the south side of the pier on his plan 1, suggesting that the pier was narrow and wide, set parallel to the forestructure, and in the middle of the moat. However, Butcher recorded the north-east corner of the pier rather closer to its north-west corner, and he deduced that Armstrong must have depicted this second section of masonry in the wrong position. Accordingly, in a draft reconstruction sketch Butcher (1972b, 22) shows it at right angles to the position in which Armstrong had depicted it, placing it on the west side of shaft B. Butcher (1958-62f; 1961, 27-8) consequently argued that the pier was a narrower structure than Armstrong had proposed, and that it ran from the outer face to the middle of the moat. He recorded that the pier was faced with 'coursed rubble [he meant "ashlar"]' behind which were water-worn boulders grouted in lime mortar, and that it had ashlar quoins (Figures 5.16, 5.17, 5.18).

Butcher (1972a, 18) also recorded 'a comparatively late rough wall' across the moat between the west corner of gatehouse forestructure and the pier, and constructed from stones (including ashlar blocks) robbed from the pier (shown in Butcher n.d. (q); n.d. (s); Figures 5.16, 5.19). This late addition was positioned above the moat fill and the stakes in front of the gatehouse, providing 'a useful link in the chronology of the moat's structures and accumulations' (Butcher 1961, 30-1). This suggests that the stakes were not a Civil War era feature, as they are evidently not among the latest additions to the moat. The wall may have been as late in date as the 17th century and represent a significant remodelling of the entrance to the castle, perhaps following its slighting 


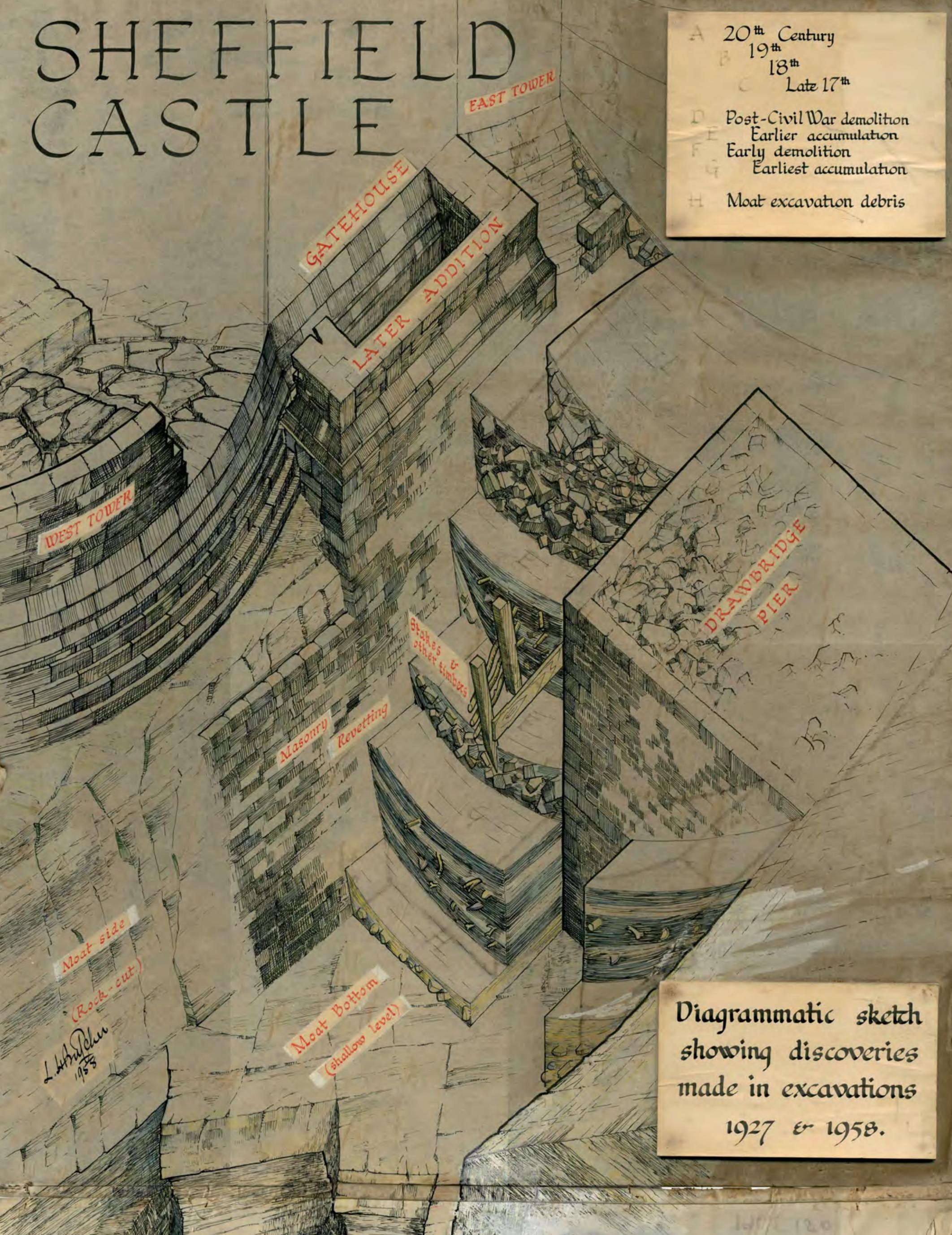


architectural forms, the operation of 'immaterial networks of social power between mobile elites' (Swallow 2014,308 ), and symbolic representations of lordly or royal power (Liddiard 2005, 47-9, 54-8; Goodall 2012, 10; Nevell 2012, 263-5).

The very partial view of the remains of the gatehouse of Sheffield Castle resulting from the circumstances in which Butcher was working mean that we cannot be entirely sure of its form. However, it is probable that here too the entrance passage ran between D-shaped towers, with a chamber above (see Figures 1.20 and Epilogue v). Our limited view makes it difficult to date the original towered structure (as we saw in Chapter 3, the forestructure was added later, probably in the 14th century), and, while the evidence cited above makes an early to mid-13th date possible, it is perhaps more likely that it dates to the later part of that century. This has implications for the dating of other structures on the site. It is notable that in his 1961 lecture to the Hunter Society Butcher $(1961,34)$ drew parallels between Sheffield and Rhuddlan - 'it would be foolish', he argued, 'to attempt further reconstruction above plinth level but this picture of Rhuddlan gatehouse may suggest original appearance of Sheffield gatehouse'.

\section{Curtain wall}

As we saw in Chapter 3, Armstrong $(1930,11)$ failed to find any trace of the curtain wall to the west of the gatehouse tower. Therefore, he assumed that it lay to the north of the rear wall of the Brightside and Carbrook Co-op, where 'unfortunately no foundation pits were required to be sunk'. In contrast, in a sewer trench near the south-west corner of Castle Hill Market, Butcher (1958-62d; 1972a, 7; 1972c, 7-8) found what he believed was the 'last remnant of the southern curtain wall. ${ }^{20}$ This consisted of sandstone rubble set in blue clay, similar, Butcher argued, to the 'rubble-backing' behind the ashlar of the gate structures (Butcher 1972a, 7; 1972c, 7). He recorded it in plan, section (Butcher 1958-62d; Butcher n.d. (j); Ove Arup \& Partners and Butcher 1957), and photographs (Butcher n.d. (s), 13). Significantly, he went on to point out that it aligned with a short length of 'rough masonry' which Armstrong had uncovered in September 1927, and marked as point 'A' on his plan 1 - but which he did not believe was 'contemporary with, or formed any part of, the main building [i.e. the castle]' (Armstrong 1930, 14). If we include the short stretch of wall bonded to, and running at right angles from, the west tower, we can suggest that three short, very denuded, stretches of the south curtain wall survived. In a letter written to Armstrong in November 1930, City Architect F. E. P. Edwards (1930) commented on the stretch of wall that Armstrong had recorded at point 'A': 'I was rather struck with that portion of the excavation when I saw it, \& greatly regretted it had to be destroyed', and he believed it was part of a projecting 'bastion' to protect the castle at its south-west corner. Edwards clearly had greater belief that it was part of the castle than did Armstrong, who thought it had only been constructed of material derived from the castle. Significantly, in his summary sketch of the shape of the castle (1972e, 3; Figure 5.9), Butcher appears to mark, on the southwest corner of the 'platform', both the sewer trench and the remains of the wall ('Rubb. back'), with hints of a square building running off it to the south-west.

In his 1961 lecture, Butcher (1961, 17-19) used foundation shaft G22 as an example of one of those dug through the moat, which provided further evidence for the curtain wall. The shaft was close to the inner face of the moat at the south-west corner of the central courtyard, where the moat turned north-west to head towards the Don. Within the layers depicted on the section drawings are numerous pieces of ashlar, described as both 'tooled' and chamfered, and tracery, and his lecture script also refers to a 'complete section of wall facing which has fallen into the moat'. To the south-east of shaft G22 is shaft F21, which also contained pieces of ashlar, one of which is annotated 'cf gatehouse', suggesting he saw similarities with the form of the gatehouse, although there is no indication he believed this to be the site of another entrance to the castle. It seems that Butcher thought, rather, that he had identified another tower at this part of the site because on the Ove Arup foundation plan he sketched a drawing of the castle showing a tower at this corner (Ove Arup \& Partners and Butcher 1957; Figure 5.1).

${ }^{20}$ The prospect of discovering other sections of this wall were, he argued, limited by the fact that 'in the late 1930s a "tunnel" was driven along the entire length, destroying, without any known record, whatever may have lain in its path' (Butcher 1972a, 7). 


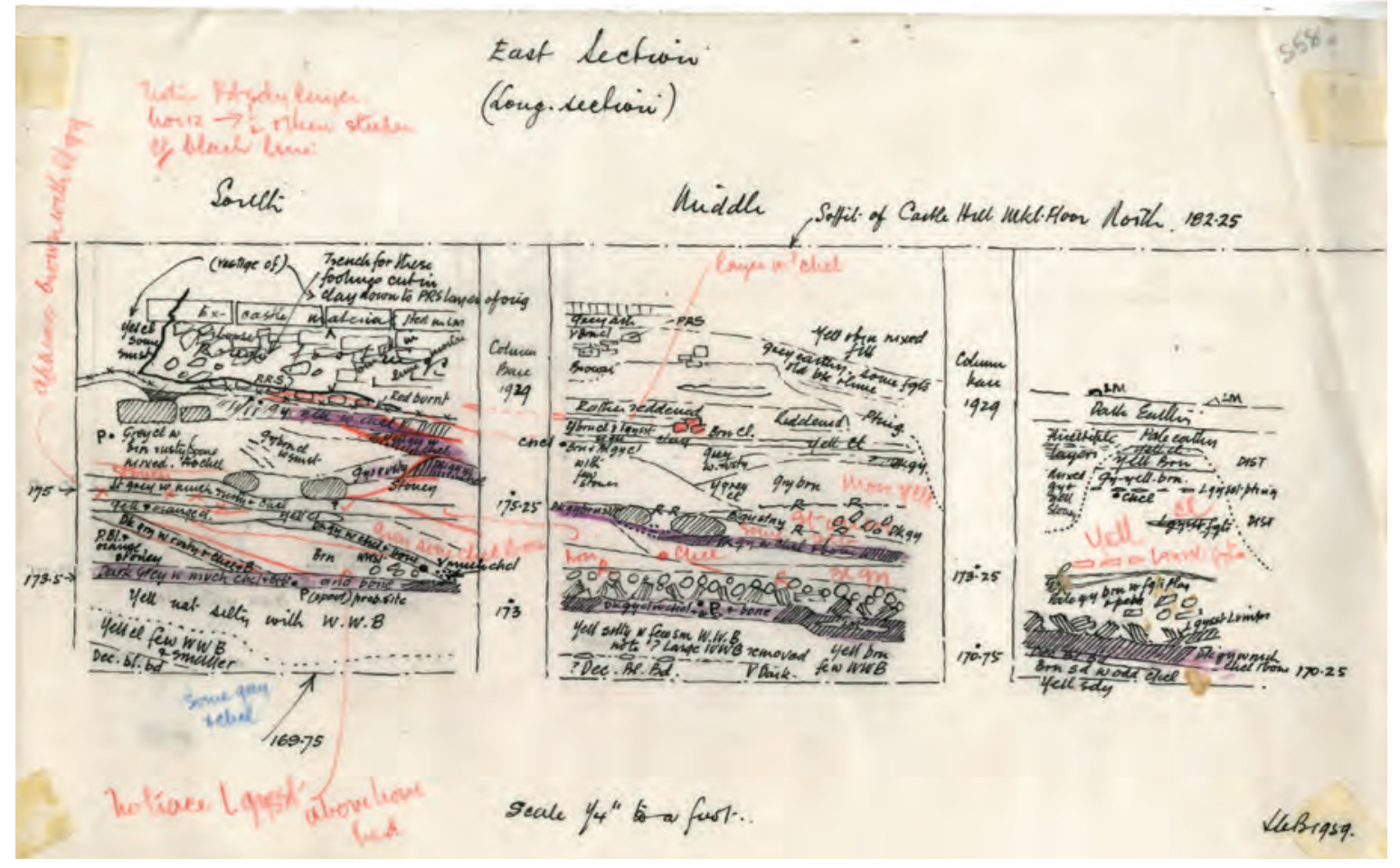

Figure 5.20: Two section drawings of the east side of Castle Hill. These drawings by Leslie Butcher provide a detailed record of the foundation shafts dug on this side of the site, as well as boreholes about which we otherwise have no information. The hand drawn section (bottom) records the surfaces revealed between the column bases for the 1929 market building. The inked-up drawing (top) provides an interpretation of what was recorded along the full section between the Exchange Street ditches and the Don, including the gatehouse and drawbridge pier, the pit containing wattlework, a 'patch of loose stone herring-bone' recorded by Joseph Himsworth (see Figure 3.7), and the wall recorded by Pauline Beswick in 1972 when the paved slope above the Don collapsed (see Figure 1.16). Courtesy of Museums Sheffield.

\section{East side of the castle and courtyard buildings}

Some of the most important insights to emerge from the Butcher archive concern the east side of the castle. These allow us to draw comparisons with the recording undertaken in 1927-29, and throw new light on the castle courtyard and what Butcher thought were the earliest phases of occupation. In particular, there are several detailed section drawings, based on Butcher's recording of manhole 3, various boreholes about which we otherwise have no information (their locations are marked on Butcher n.d. (r)), foundation shafts near the gatehouse, the documentation of Armstrong and Himsworth, and the record of a section of wall above the Don made by Pauline Beswick in 1972 (Butcher n.d. (g); n.d. (r); 1958-62e; 1959; Figure 5.20). One section draw- 
ing spans the southern end of the Castle Hill Market, the chamber constructed around Armstrong's courtyard building, and the edge of the cut-back slope overlooking Castlegate (Butcher n.d. (g); n.d. (r); 1959). This section is partially obscured by four column bases for the 1929 market building, but Butcher was able to make detailed records of the 'bays' between them (Figure 5.29). At the south end, the top of the section (marked as 'soffit of eld Castle mkt floor') is at $182.25 \mathrm{ft}$ ( $55.55 \mathrm{~m}$ ) AOD (from A to C), while at the north-east corner of the 1929 building (C-D) the top of the section is formed by the Castle Market car park, and although not labelled with a height AOD it appears to be $c .3 \mathrm{ft}(c .0 .91 \mathrm{~m})$ lower, and in one of his typescripts Butcher $(1972 \mathrm{~b}, 12)$ refers to the car park level being at $179 \mathrm{ft}(54.56 \mathrm{~m})$ AOD. The lowest height AOD is recorded at the base of the slope above the Don, by that time covered in 'crazy paving', at $161.25 \mathrm{ft}(49.15 \mathrm{~m}) \mathrm{AOD}$. This section drawing contextualises the courtyard deposits, including the supposed Anglo-Saxon phase recorded by Armstrong, and their relationship to the underlying topography of the area, revealing a clear south-north slope towards the Don. What Butcher interpreted as the earliest occupation level is shown at $172.5 \mathrm{ft}(52.58 \mathrm{~m})$ at point $\mathrm{A}, 167.3 \mathrm{ft}$ $(50.99 \mathrm{~m})$ at borehole 3 and dropping to $160 \mathrm{ft}(48.77 \mathrm{~m})$ AOD above the Don (Butcher n.d. (r)).

The upper deposits of the bays between each of the column bases had clearly been disturbed during construction of Castle Hill Market in the late 1920s, and include clay, stone, and fragments of old brick and lime mortar. At the top of the southern bay is a deposit described as 'Ex-castle material jointed in LM [lime mortar]', with 'rough footings' jointed in lime mortar. These remains of a structure that made use of some of the demolished castle fabric provide an insight into developments after the Civil War, for which there are hints in contemporary documents. The estate accounts for 1649 note the use of lime to repair parts of the castle alongside carpentry, masonry and glass working, suggesting that building work was continuing on parts of the site even while much of it was being destroyed (Wilson MSS, 295/223, Book 15, fols 33-4; Askew 2017, 201-2; also Chapter 9). Immediately below this was a red burnt layer incorporating a purple reddish stain which extended north into the second bay, and, while it is not apparent in the third bay, which had been heavily disturbed, a corresponding burnt layer is noted in the fourth bay. Butcher (n.d. (g)) labelled this 'De Lovetot burnt layer A.L.A. 1929', which he described in his typescript as 'a 3"-4" layer of bright pink debris' (Butcher 1972a, 20). On the schematic interpretative drawing of the section (Butcher n.d. (r)), this is labelled as 'D'Eyville destruction layer' (Butcher 1972a, 8). This is linked by Butcher to the recorded burning of Sheffield in 1266 during the Barons' War, to which Armstrong $(1930,10)$ had assigned the destruction of the de Lovetot castle. These annotations, seemingly intended to link his drawings to those of Armstrong, were a rare foray for Butcher into matters concerning the historical actors who occupied the site in the medieval period.

Towards the base of the section in the south bay at $c .173 .5 \mathrm{ft}(c .52 .88 \mathrm{~m}) \mathrm{AOD}$ is a layer described as dark grey with much charcoal and burnt stone in which bone and the 'probable' location of a pottery spout are noted; this layer extends through the second and third bays, sloping down to $c .170 .25 \mathrm{ft}(51.89 \mathrm{~m}) \mathrm{AOD}$, and seems to be what was interpreted by Butcher (1972a, 7-8; n.d. (r)) as 'the early occupation level on the original natural surface. Looking at his schematic drawing (Butcher n.d. (r)) this layer begins at c.172.5ft AOD at 'A' and slopes downwards towards the Don where it is labelled as 'Original natural surface'. Butcher (n.d. (g); 1972a, 8) equates it with the layer Armstrong believed to be Saxon (and labels it as such - "Saxon wattle floor ALA 1929", with the quotation marks already signalling his doubt about the dating), but while he clearly did not accept Armstrong's date he stopped short of assigning his own. It is notable, however, that on the section drawings this layer seems to be a little deeper than the surfaces Butcher labelled as Armstrong's 'Saxon wattle floor'.

At the top of the northern end of the section, just before the 'crazy paved slope' down to the Don, Butcher recorded a '?? masonry wall in L.M. [lime mortar]'; this may be a section of the wall recorded by Himsworth in 1930 (1927-42, 17-18, fig. 47) and again by Pauline Beswick in 1972 since they seem to be at the same height (Butcher 1972b, 12; also Butcher n.d. (f) and n.d. (r)). Towards the bottom of the section is a 3in deep grey sandy surface, which is described as 'rusty' with lime mortar powder, charcoal and burnt stone, and below this was a pit cut into the underlying yellow-brown clay. The fills in the pit are described as sticky grey clay with twigs and rushes, hazelnut shells, yellow-grey clay, silty clay, blue-black with timber and pale blue clay. The pit was lined with a deposit described as a 'thin "proto" hard pan', a term that refers to a hard subsoil layer impervious to water, which helps to explain the evidence for waterlogging. Butcher (1972a, 8; 1972c, 9) described this pit as containing 'natural and wrought timber including "wattle-work" similar to that found in 1930 near the "Courtyard Buildings"' (see also Butcher n.d. (s), no. 299; Figure 5.21). He also noted that excavations immediately east of the Bull \& Mouth public house, at the northern end of Waingate, revealed a similar pit, while 


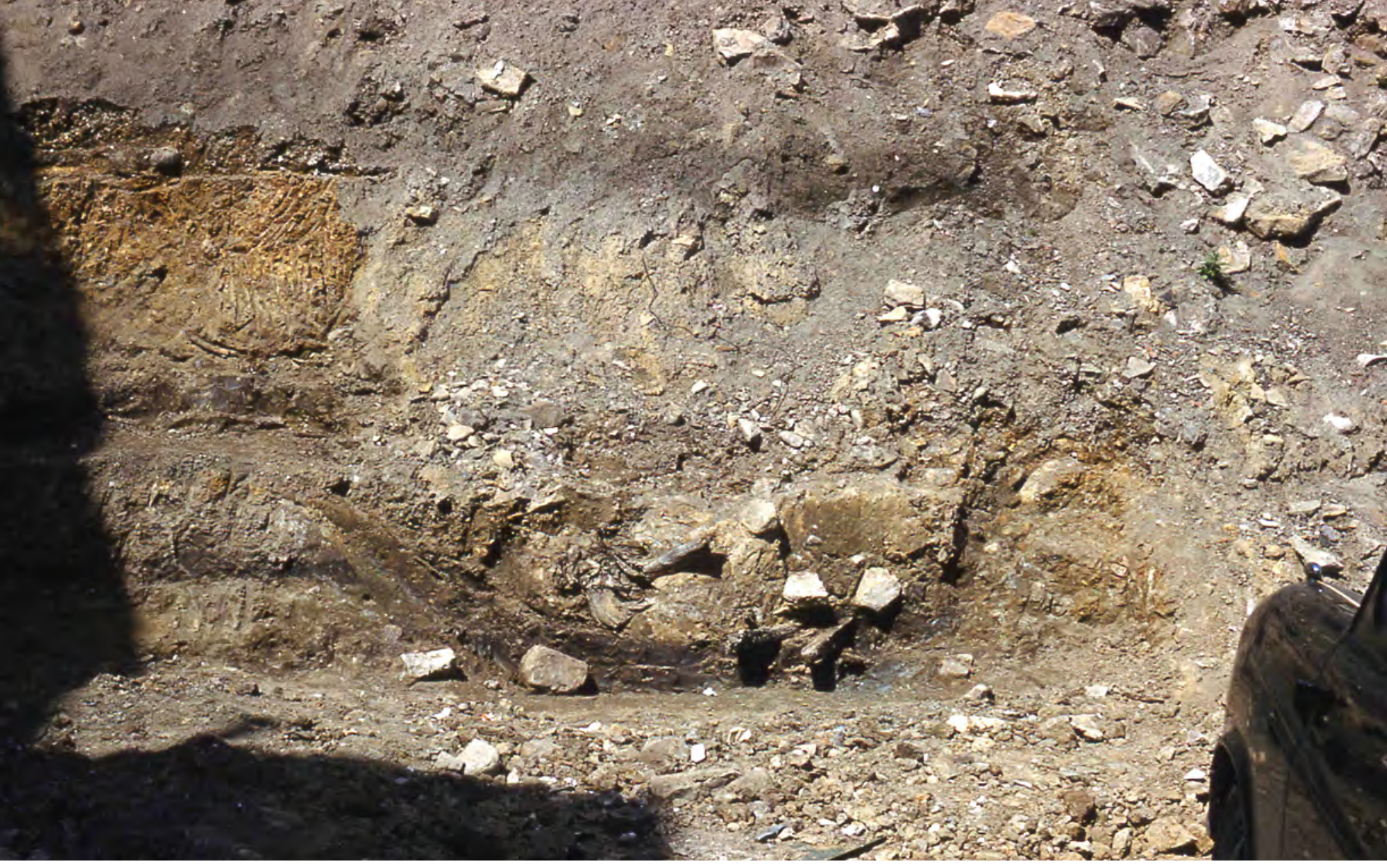

Figure 5.21: Photograph of an early pit. Described by Leslie Butcher as containing 'wattle-work' similar to that found in 1930 near the courtyard buildings, this pit can also be seen in the long section in Figures 5.20 and 5.29. Courtesy of Museums Sheffield.

at the same horizon 'a narrow curving ditch' was located in the service yard to the west of the market', which appears to be the ditch marked on his plan of the site (Butcher n.d. (j)). In the absence of any surviving artefacts from these early features, or any other dating evidence, it is difficult to establish a date for them, or the sort of occupation they represent (but see Chapter 7).

\section{Exchange Street ditches}

As we saw in Chapter 2 (Section: Sheffield Castle: where the two rivers meet), a ditch identified along Exchange Street in 1916 was thought to be one of the earliest archaeological traces of the castle (Wigfull 1916, 239), although as we noted in Chapter 3 (Section: The inner courtyard moat) Armstrong $(1930,13)$ disagreed and thought it unrelated to 'the main ditch', in other words the moat. Butcher (1972a, 8) identified two sections of ditch at the corner of Exchange Street and Waingate, and one of these may be related to what was reported earlier in the century. These ditches are shown on an isometric drawing (Butcher n.d. (v)) and on several of Butcher's plans of the site (e.g. Butcher n.d. (j); Figure 5.22). Butcher adduced no dating evidence for these ditches, which contained organic material, but it seems significant that they are mentioned in his typescript following a discussion of the earliest occupational levels on the site. This suggests that he thought they had similarities to other early features, albeit that he was evidently unsure of their dating: 'It is not clear if two further ditches intersected near the Exchange Street/Waingate corner, the tops of which were not located, represent much deeper ditches of the same occupation' (Butcher 1972a, 8). Ditch I was the closest to the surface and most heavily truncated, with the top of the exposed fill recorded at $176.5 \mathrm{ft}(53.8 \mathrm{~m})$ AOD and described simply as an 'organic deposit' (Butcher n.d. (v)). This ditch was intersected at two points and appeared to be curving away from the moat. The less truncated Ditch II was $2 \mathrm{~m}$ lower down (the top measured at $174.5 \mathrm{ft}(53.19 \mathrm{~m})$ AOD) and is shown cut into the underlying orange sandy mudstone and curving towards the moat, with the lowest fill described as organic from which was recovered leather, pottery and timber, although none of this could be found within the archive. 


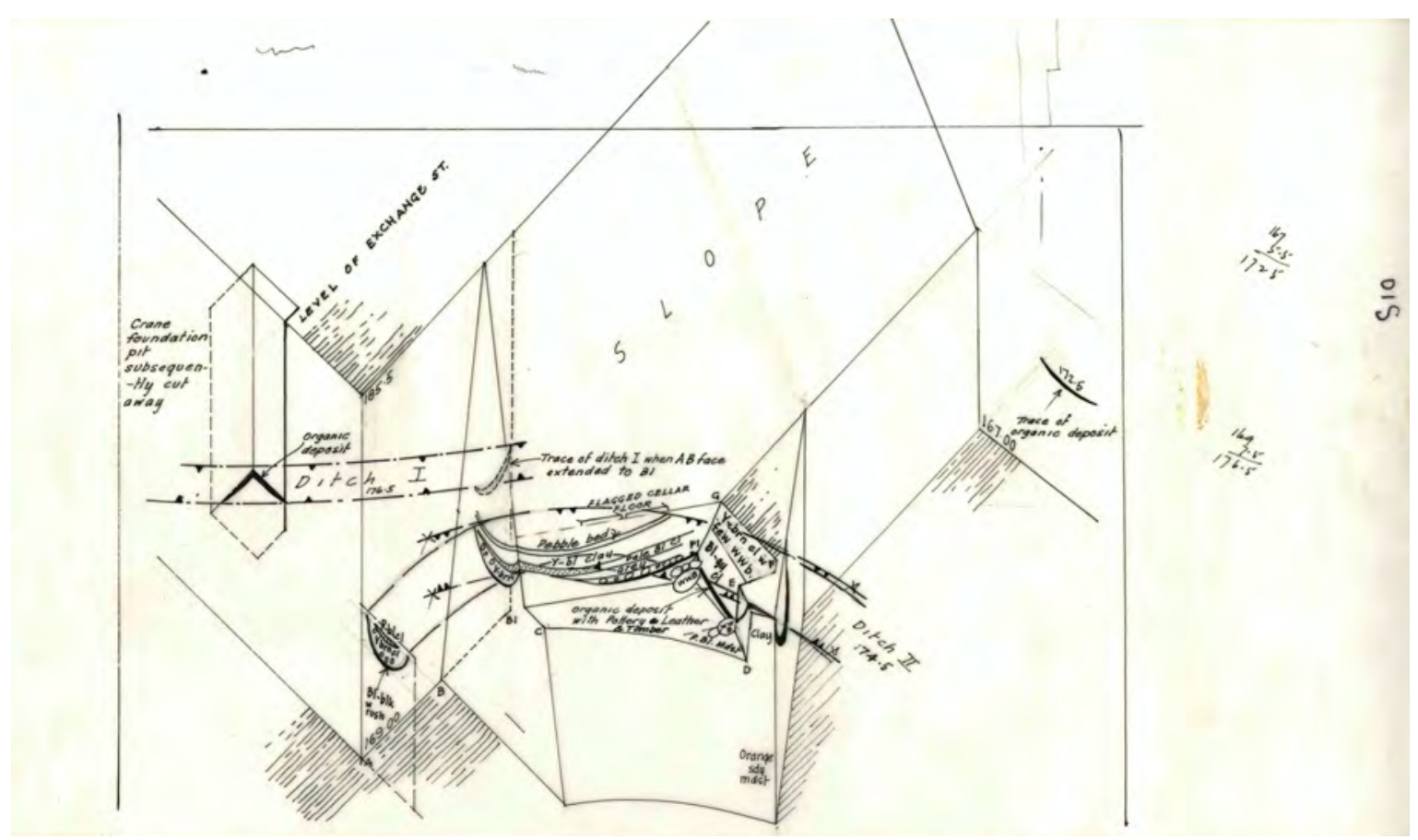

Figure 5.22: The ditches recorded at the junction of Exchange Street and Waingate. Isometric drawing by Leslie Butcher. Courtesy of Museums Sheffield.

This was overlain by a series of deposits that seem to represent weathering or gradual silting in the ditch, and these are described as water-worn boulders, grey, pale blue clay and yellow-blue clay. The ditch is sealed by a layer of pebbles which were immediately below a 'modern' cellar floor. A further patch of organic material is noted on the isometric drawing at a similar level to Ditch II, but it is unclear whether it constitutes another ditch parallel to Exchange Street. In an electricity trench in Exchange Street, the east side of the cut was exposed, and it was thought to be turning to the east, but the feature was heavily disturbed (Butcher 1961, 35).

Further east along Exchange Street, closer to the gatehouse, Butcher recorded another ditch, which ran south-eastwards from the Co-op building towards the north-east corner of the 19th-century Norfolk Market Hall, and which contained organic material (Butcher 1961, 35-6; see Figures 4.16). If it had been connected to the earlier discovery made in this area by Armstrong $(1930,13)$, Butcher $(1972 a, 9)$ speculated that the two sections of ditch, which related well 'to the axis of the gate structures', may have been part of 'a long term "outwork" rather than being a temporary feature connected with the Civil War siege, as some commentators had claimed (e.g. Armstrong 1930,13). Clive Hart (1989b, 4) was later unequivocal in seeing them as part of a 'D-shaped barbican' similar to that at Pembroke Castle (Wales). On his summary sketch of the castle site, Butcher (1972e, 3; Figure 5.9) refers to this feature as the 'Barmkin Ditch'; barmkin is a Scots term referring to an outer fortification or barbican. His alternative suggestion was that they were a feeder for the moat from 'the Ponds' on the Sheaf, something that it was impossible to explore further due to the built-up nature of the area (Butcher 1972a, 9) but to which we will return in Chapter 7 with the benefit of new archaeological evidence.

\section{Topography of Castle Hill}

Although he followed Armstrong in assigning significant moments in the archaeology of the castle site to key historical figures (de Lovetot, de Furnival, D'Eyvill etc.), by and large Butcher preferred his history 'deep'. As we saw in Chapter 4, geology and landscape are the forces really driving the historical process as far as he was concerned. Several pages of his unpublished 1972 typescript were devoted to discussion of the 'physique' or topography of Castle Hill, in which he provided a detailed account both of its 'deep history' - its geology and geomorphology - and of the changes that it had undergone during and since the medieval period. Sheffield 


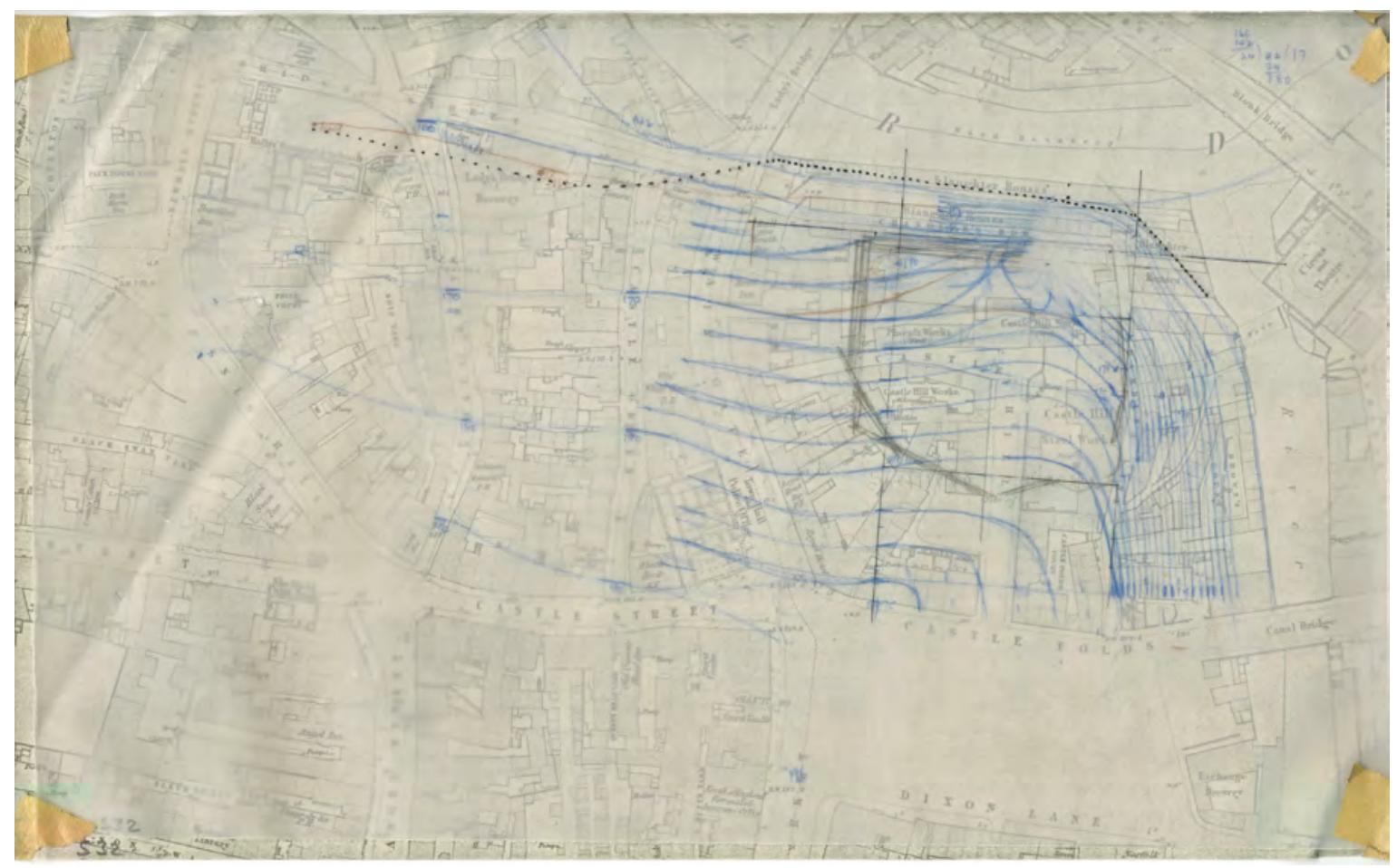

Figure 5.23: Contour map of Castle Hill. Overlain by Leslie Butcher on the Ordnance Survey 1:1250 map. Courtesy of Museums Sheffield.

Castle was built on a promontory, defined by low cliffs, at the confluence of the rivers Don and Sheaf. Butcher's many section drawings provide clear insights into the underlying geology, which is Lower Coal Measures (Upper Carboniferous or Silesian deposits), with the bulk of the site resting on an outcrop of the Silkstone Rock sandstone, through which the rivers had eroded channels (Davies 2000, 2). Butcher (1972a, 20) described the undulations of the underlying sandstone, of the mudstone that overlay it, and of the clay, silt and rounded boulders deposited, 'in similarly remote geological antiquity', to a depth of $10 \mathrm{ft}(3.05 \mathrm{~m})$ by the two rivers. He deduced that its 'obvious natural defences', with low cliffs running alongside the Don and Sheaf, and shallow 'valleys' on the line of Waingate and Dixon Lane, explain why it was chosen as the site at which to build the castle (Butcher 1972a, 19; also Hart 1989b, 1).

As we will see in Chapter 7, Butcher's geological training, observation skills and detailed recording enabled him to make some very significant observations about changes in the level of the ground surface of Castle Hill in the Middle Ages. He (1972a, 21) drew a plan to show the contours of the castle at the time of the building of the Furnival Castle c.1270', for which he used records made during the construction work between 1927 and 1930, including Himsworth's diary, bore holes and trenches dug between 1958 and 1972, Ordnance Survey maps and construction drawings (Ove Arup \& Partners and Butcher 1957; Butcher n.d. (i); Figure 5.23). Some of the details of his deductions only occur in handwritten drafts, one of which describes the profile of the site:

Excavations at various points along the eastern \& western sides of Castle Hill market show a gentle northward slope of the original surface towards the river as far as the south side of Castlegate, where it stood at about $168[51.21 \mathrm{~m}]$ AOD. Waingate occupies a shallow hollow running down towards the river which in the area around eastern Bridge Street \& the [Exchange] Brewery had a terrace six or eight feet above river level. Near the south end of Lady's Bridge this terrace gives way to solid rock but it reappears, to the east of the bridge \& widens as it approaches the mouth of the Sheaf. Here the river terrace appears to have been present on the west side of the Sheaf \& may have been as much as [measurement missing] yards wide (Butcher 1972b, 7-8). 
Butcher also drew profiles through the market site, revealing that on the western and eastern sides of the castle the ground sloped steeply down by up to $4-5 \mathrm{~m}$ from the level of the inner courtyard to the edges of the moat cut (Butcher n.d. (f); n.d. (g); Figures 5.20), creating what was referred to by Armstrong as the glacis (1930, passim). Butcher's fullest description of the topography of the site, reflecting his training in geology and geomorphology, is found only in one of his handwritten accounts:

The oldest representation [of Castle Hill] appears on Gosling's Town map of 1736 where it appears as a square platform with slopes to the cardinal points, northwards to the R. Don, eastwards to the R. Sheaf with those westwards and southwards towards the town. Presumably these latter reflect the mass of post Civil War demolition debris declining into the moat with the following century's build-up on its levelled top.

The northward slope, which we may call the Don Cliff must have presented the usual raw appearance of any active meander scar to the foot of which the Don's maximum erosive power gravitated as the river swung from a SE to a NE course resulting in a constant nibbling and occasional biting at the toe of the slope. At its western end the gentler uneroded slope would attract N-S travellers to ford and later bridge the Don.

On the east the River Sheaf probably offered less of a threat to slope stability but long before any human occupation of the site similar action on its part had produced a series of intercutting meander scars along its western side the smoothed outline of which we can call the Sheaf Cliff ... At Dixon Lane some easing of the cliff must have attracted westward travellers to ford, and later bridge, the Sheaf here. Thereafter the cliff must have resumed its height to join the Don Cliff at the confluence (Butcher 1972b, 27).

Here, the historical actors are the river ('nibbling and biting') and the landscape, the latter encouraging and facilitating human action. Nonetheless, this analysis of the topographical setting of the castle, and its relationship to other aspects of the medieval town offers important insights into the motivations for its foundation and its ensuing impact on Sheffield. The site near the confluence of the Sheaf and the Don afforded a good but far from ideal position for the castle, if topographical considerations had been the only factor (see Pounds 1990, 69-70). The 1771 Fairbank Correct Plan of the Town of Sheffield shows the raised area on which the inner courtyard was positioned, exploiting a naturally available defensible setting (Figure 1.8). The site was protected by the rivers on two sides, but, nonetheless, as we have also seen, there was evidently a feat of engineering required, not only to dig the moat but also to construct dams where it met the Don to enable it to hold water. The cartographic evidence shows that on the east side of the inner courtyard the ground fell sharply down to the River Sheaf; the later Castle Folds Lane that ran north-east from Exchange Street had a steep slope, although the gradient around the lane had been modified by later infilling (Armstrong 1930, 19). Nonetheless, there was a need over time to build up the site on which the castle was located, especially towards the Don, to create a broader platform on which to extend the castle. As we will see in Chapter 7, the 2018 excavations, along with our analysis of Butcher's archive, have provided further evidence for just such a remodelling of the site.

\section{The morphology of the town plan}

The position of the castle within the medieval townscape has largely been obscured by modern development (Davies and Symonds 2002, 17), but can be teased out by analysis of cartographic evidence. Indeed, Butcher drew attention to a block of irregular medieval layout that could still be discerned on the 1853 OS map between the Castle Hill Steel Works and the weir on the Sheaf, framed around a narrow curving alley (Figure 5.24). In his typescript, Butcher described a photograph that he said dated to 1917 and which apparently showed an 'irregularly shaped house' on this lane, which was brick-built and seemingly of 18th-century date but had what appears to be a masonry wall at its north-east corner. The photograph that he was describing has not been traced in the Museums Sheffield archive, but Richardson and Dennison (2014a, 28; 2014b, plate 12) suggest that Butcher may have been referring to the building painted white visible on another early 20th-century photograph showing buildings adjacent to the Sheaf (Anon. 1900-19; Figure 5.25). Butcher reported that

Figure 5.24 (page 161): 1853 OS (1:1056; 5ft to a mile) map of Castle Hill. Source: University of Sheffield map collection. 


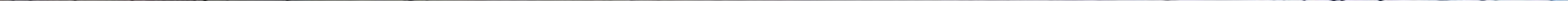



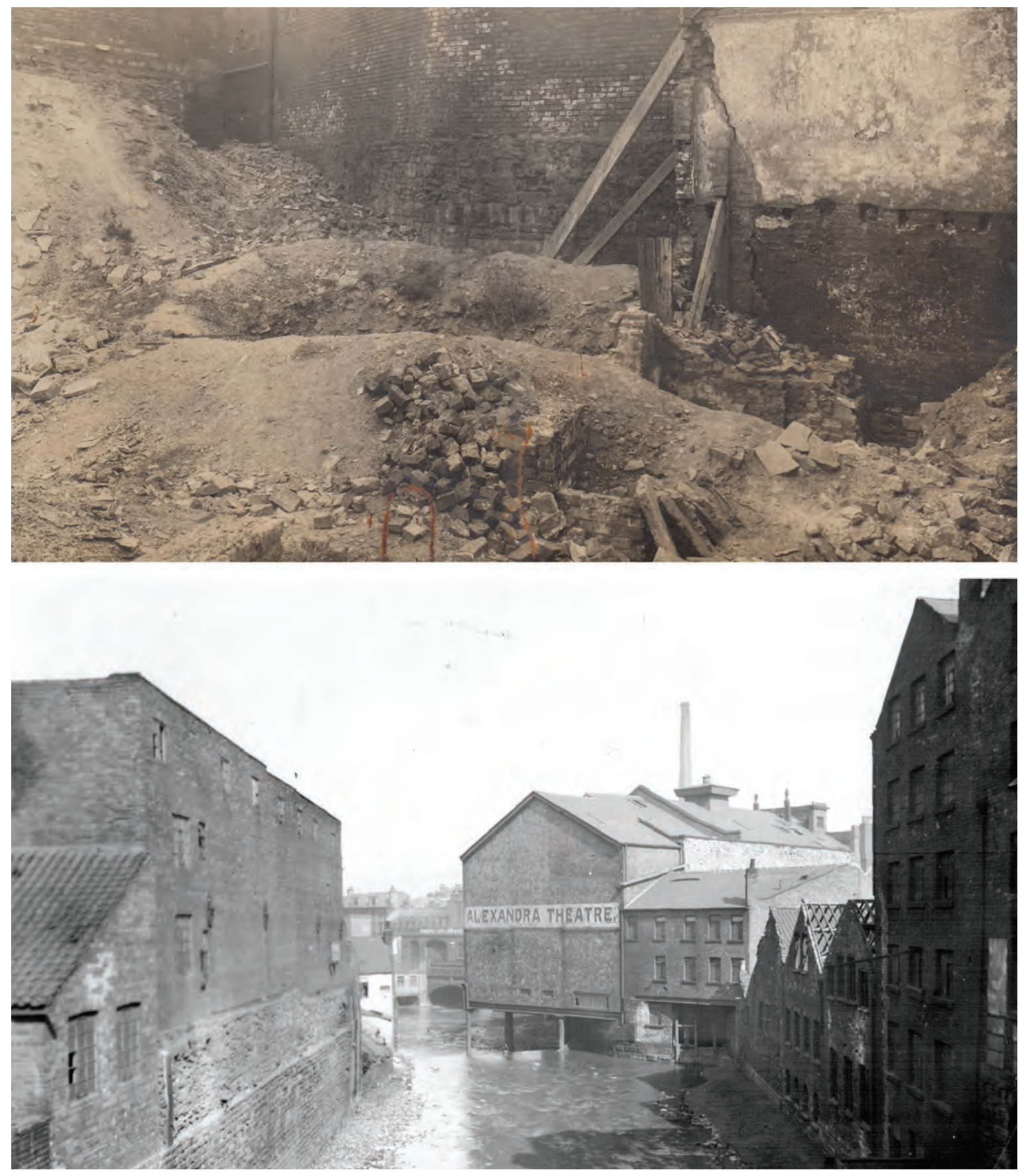

Figure 5.25: Early 20th-century photographs of the east side of Castle Hill. A photograph (top) from 1918 labelled 'West wall of passage, but East of Castle site ... composed of stone, part dressed, part rubble, set in lime mortar'. It is noted that the wall was used 'as a foundation for a building, now used as a slaughter house.' Another photograph in the archive, which is a close-up of the right-hand end of this wall, is labelled 'Part of Sheffield Castle wall, discovered while pulling down old house, built in 1666, on the site of Sheffield Castle moat', and it is said to be located opposite the weir on the Sheaf. Courtesy of Museums Sheffield. An early 20th-century photograph (bottom) showing the Alexandra Theatre and, on the opposite bank of the Sheaf, a white building which may be what Butcher described in his 1972 typescript as an "irregularly shaped house" ... which is brick-built and seemingly of 18 th-century date but has what appears to be a masonry wall at its north-east corner. With thanks to www.picturesheffield.com (s12223). 
among photographs in the City Museum he saw one with a caption describing 'ancient walling, flag in clay, said to be part of Sheffield Castle', which had been revealed during demolition of the 'irregularly shaped house', and two other photographs showing the alley curving steeply away from Castle Folds Lane to the demolished house. Again, these photographs do not seem to survive, but others from 1918 in the Museums Sheffield archive record a building that fits Butcher's (1972a, 11) description of a brick-built structure with lower levels in stone, adjacent to a steep, narrow, curving lane; the lower part of the building contained what appears to be a window, quoined jambs and a doorway with a massive stone lintel (Lees 1918; Richardson and Dennison 2014b, plates 13-15; Figures 1.9, 5.25). While it is possible, indeed likely (especially in view of the results of the most recent excavations discussed in Chapter 7), that much of this was reused rather than in situ castle material, Butcher's (1972a, 11) conclusion that the 'survival of this patch of irregularity ... suggest[s] a "medieval" rather than a "neo-classical" origin' seems reasonable. He also used these photographs to suggest that the ground level outside the house was c.150ft $(45.72 \mathrm{~m}) \mathrm{AOD}$, which is the level at the top of the river gravels near the confluence of the Sheaf and Don, showing that there had not been much modification of the area near the house since the medieval period. There was a block of buildings located at the level of the weir, just below $150 \mathrm{ft}(45.72 \mathrm{~m})$ AOD, which Butcher (1972a, 12) noted 'again partake of the more archaic "evolved" development being limited to the drier predictable conditions of the $150 \mathrm{ft}$ Terrace' - these may appear on his summary sketch of the site (1973e, 3; Figure 5.9) as four squares at the end curving lane. This contrasted with the slaughterhouses, which were part of a development that saw buildings 'pushed adventurously onto the more geologically recent, waterlogged gravels lying at the current level of the Don some six feet below the 150ft. terrace. This, he argued, would account for the steep incline down to the river from the east end of Chandlers Row.

Butcher (1972a, 10-11) also identified a relic of the medieval townscape in the irregular street layout to the west of Waingate, which follows its curve and, hence, the west moat. This, he observed, contrasted with the post-medieval regular 'precisely planned' layout, or 'tidy post Civil-War parcelling out', on Castle Hill, including the Duke of Norfolk's 'regular rows of slaughterhouses, screened by a mock-Gothic facade'. This regular parcelling out largely stopped at what was then known as Shambles Lane (known later as Castle Folds Lane; Butcher 1972a, 10), other than at its north end where the slaughterhouses projected further east towards the confluence of the Sheaf and Don. Cartographic analysis also suggests that the Exchange Street ditches had a lasting impact on the street layout to the south of the inner courtyard, reinforcing his argument that it was part of the medieval entranceway into the castle. Gosling's 1736 map of Sheffield shows an 'L'-shaped alley running west off Shude Hill and turning north towards 'Castle fould' Lane, although it does not connect through to it as it appears to have encountered a wall at that point (Figure 1.6).

While most discussions of Sheffield Castle have focussed on the inner courtyard, in 1637 Harrison recorded 'an outward Court or Fould builded round with diverse houses of office as an armory a Granary, Barnes Stables \& divers Lodgeings' on the south side of the castle (Ronksley 1908, 47; Scurfield 1986, 169). An earlier reference to the outer courtyard may occur in the 15th-century Account Rolls describing buildings as being outside the castle', including the Exchequer Chamber, where dues and fines were received and wages and service payments were made, a stone and timber grange, a cowhouse and stables (Thomas 1920-24, 68-72). Adjacent to the stables was said to be a tower, and this may be the same one as that referred to as the 'ould tower wher the stables ar' in a letter from Major Carter on $30^{\text {th }}$ May 1649 concerning the demolition of the castle (Hunter 1819, 14). There has been little archaeological investigation of this area of the city centre, and so we do not know anything of the form the outer courtyard took or even whether it was enclosed with a wall (Davies and Symonds 2002, 14-15). Some of the buildings within the outer bailey may, however, have remained standing until the later 18th century. For example, Fairbank notebooks from 1784 record a barn at the 'castle stable' at the corner of Exchange Street, Waingate and the marketplace; it is, thus, intriguing that on the 1797 Fairbank map what had been called 'Castle fould' on the 1771 map was now named Barn Street (Figures 1.7 and 1.8; see also Hall 1926, xix). And it is just possible that castle remains were encountered during the construction of Castle Square in 1965, focussed on the affectionately remembered 'Hole in the Road' underpass and shopping complex, at what would have been the southern edge of the outer bailey on High Street. A photograph taken at the time seems to show stone structures, but it is impossible to date them at this remove.

We are fortunate to have several 18th-century maps of Sheffield which reveal a clearly defined block of streets and property boundaries to the south of Castle Hill, which may reflect the location of the outer courtyard. This is in the form of a narrow strip of land delineated on Ralph Gosling's 1736 map by Beast Market (later renamed Haymarket) and Jehu on the west, Castle Fould on the north, Shude Hill on the east and Baker's Hill to the south (Hart 1989b, 1; Hey 2005, 17; Figure 1.6). This block of land is also clearly marked on the 1771 Fairbank 
map of Sheffield (Figure 1.8), which depicts a steep slope on the east side down towards the Sheaf, echoing that to the east side of Castle Hill. We have no archaeological evidence for any surrounding wall or ditch, which we would normally expect (Thompson 1991), but the morphology of the streets and plot boundaries suggest the locations of access points into the outer courtyard, with the principal west-east route represented by Dixon Lane. Since routeways often preserve the location of gates, there may have been gates at either end of the lane, providing access to the marketplace to the west and the bridge across the Sheaf to the deer park to the east (see Chapter 8). It is unclear whether this outer courtyard had direct access to the inner courtyard, perhaps through the putative barbican. The aforementioned reference to a tower next to the stables may suggest that this was part of the defences around the outer bailey at its north-west corner.

\section{Conclusion}

Leslie Butcher had very different interests in the past than did Leslie Armstrong and Joseph Himsworth and his approach to recording and interpreting the archaeological evidence on Castle Hill reflects this. Butcher seems to have had little concern with the people who occupied the castle; rather, it was the place of the castle in the longer-term history of the site that fascinated him. The geological make-up of the site, and the natural forces that shaped it, are accordingly to the fore in his recording and draft manuscripts, while his discussion of the occupants of the castle is largely limited to their modification of the topography underlying the castle. Above all, he was interested in the geology of the site, and he criticised Armstrong for not having had much understanding of this (Butcher 1972c, 3). While he did not live to bring his work to publication, from the almost complete typescript (Butcher 1972a) we get a clear sense of his priorities and interpretative framework. This text lacks the flourishes of Armstrong's 1930 paper, or the historical imaginings of Himsworth's various lectures, and is a much more sober account of the profile of the site. Butcher left us an account that focusses on the form of the castle and the site on which it was built, and on setting the castle in its immediate landscape context. And, as we will see in Chapter 7, while Butcher was not himself particularly interested in the short term, in what Fernand Braudel $(1975,21)$ referred to as 'the event', his keen eye and meticulous records have allowed us to link some of his geomorphological observations with a key moment in the history of the site, a moment which demanded the labour of many, and without which Sheffield Castle in its 'mature' form could not have existed.

\section{Bibliography}

The full bibliography is available at the end of this volume, or at: https://doi.org/10.22599/SheffieldCastle.k.

\section{Appendix: foundation shafts}

This appendix provides detailed summaries of what Butcher and Bartlett recorded of the foundation shafts dug through the moat, largely derived from the section drawings in the archive, supported by the supplementary information provided on the isometric drawings. As we saw in the last chapter, Butcher seems not to have been greatly interested in the artefacts recovered when writing up his findings in draft manuscripts, but the nature of the recording system he and Bartlett devised means that we have been able to integrate some of them into our discussion of what was revealed during the construction work. In most cases we can assign finds to particular foundation shafts, if not always to depth or section, although many of the artefacts described on the section drawings cannot be confidently identified among the collections in the Museums Sheffield archive. A full account of the range of artefacts recovered, including information on dating and provenance, appears in Chapter 6, but in this appendix the finds assemblages from each foundation shaft are examined for crucial dating evidence. The supporting data from the finds reports can all be accessed in the digital archive (Cumberpatch 2017; Mould 2017a; Mepham 2017; Young 2018).

\section{Extensions to the chamber around the gatehouse}

Foundation shaft H2-4 was associated with reconstruction of the chamber around part of the gatehouse structures, and was dug to a greater depth than during the work recorded by Armstrong. There are surviving drawings of two of the sections (Butcher 1958-62d; Figure 5.26); on one of Butcher's sheets of multiple section 


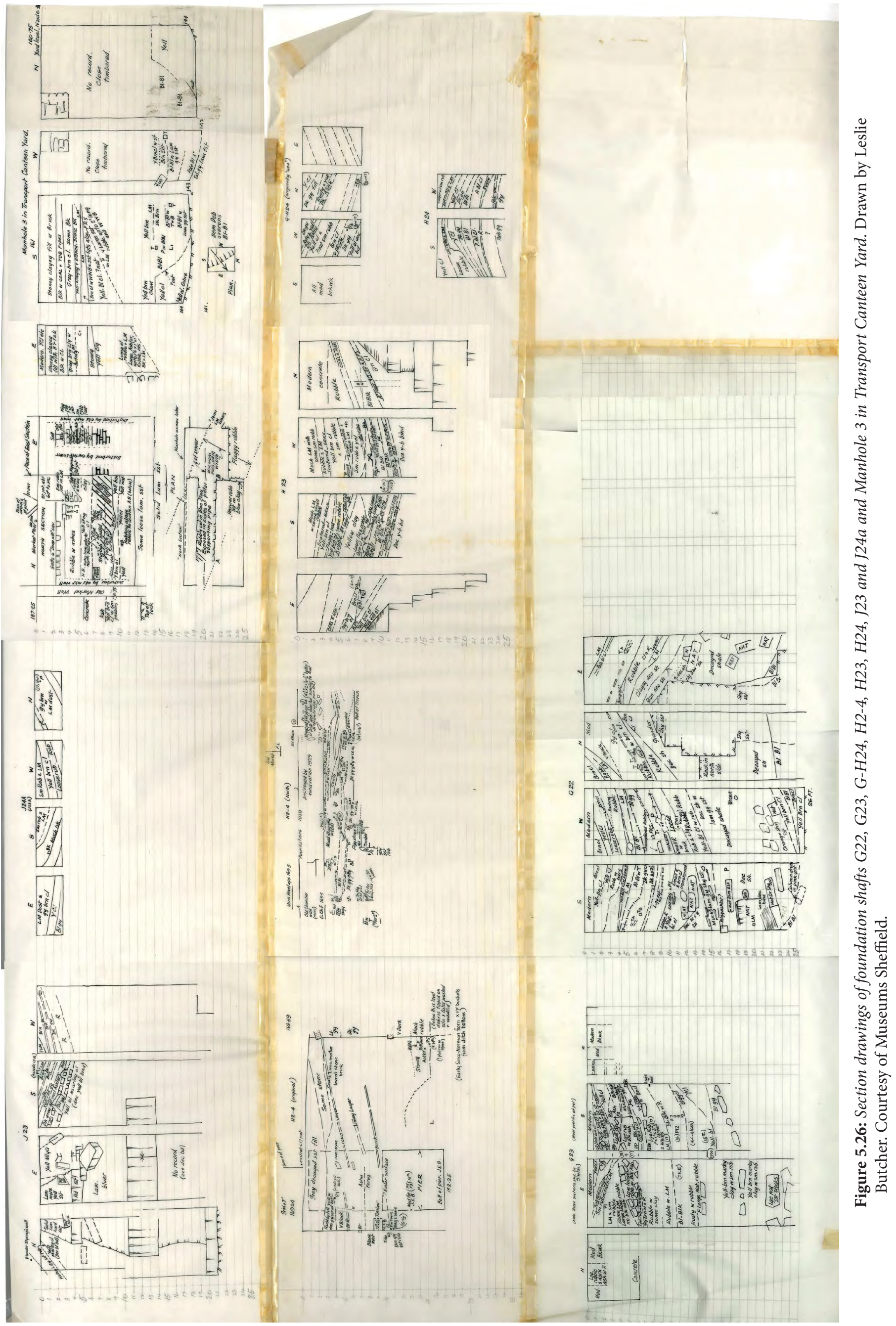




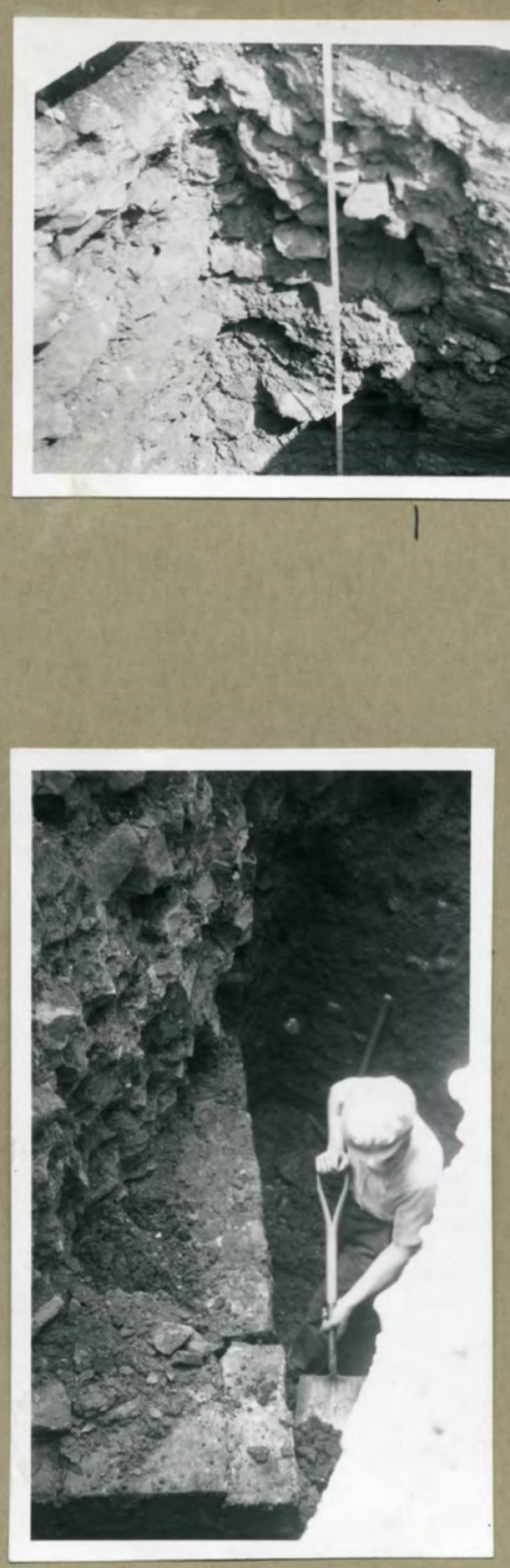

H.2-4. from N.E NE angle of dvawbudge fiev, destioyed lo astilar coarse Rubble frllng above
9. 93 Eart rhorth

Dawbodye frier (SE end abitting ou soled wele. Rubble fre $L$. It 1 Rubble

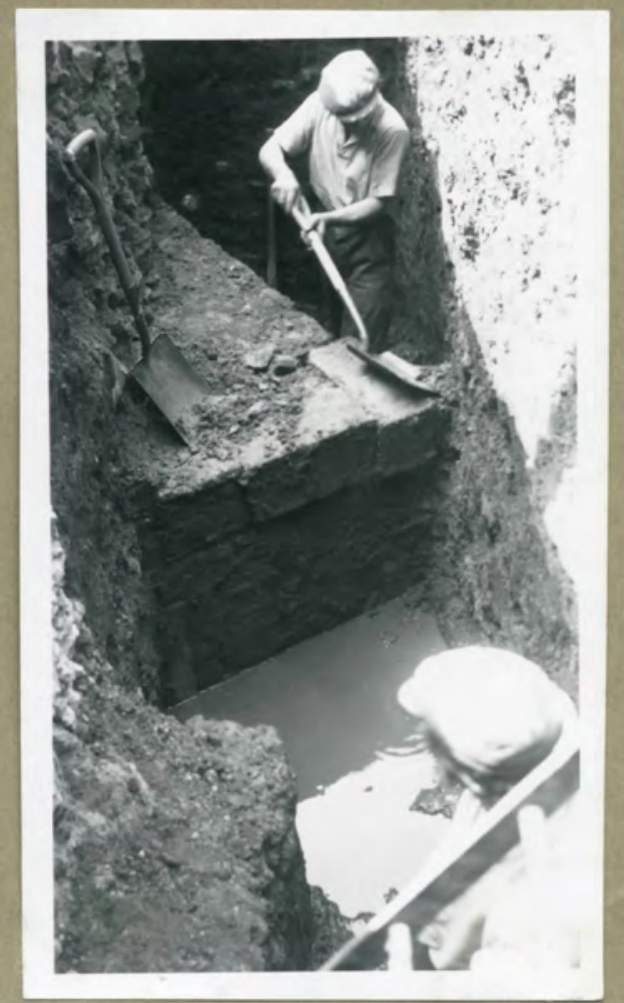

H.2-4. from $E$. Rnwhinge fuev: X ashion face, E.

10. H2-4 from $N$ Rubble fill (includ - ng waitio worn boulders) behud astilar face (nemuanb heyoud head of figune.)

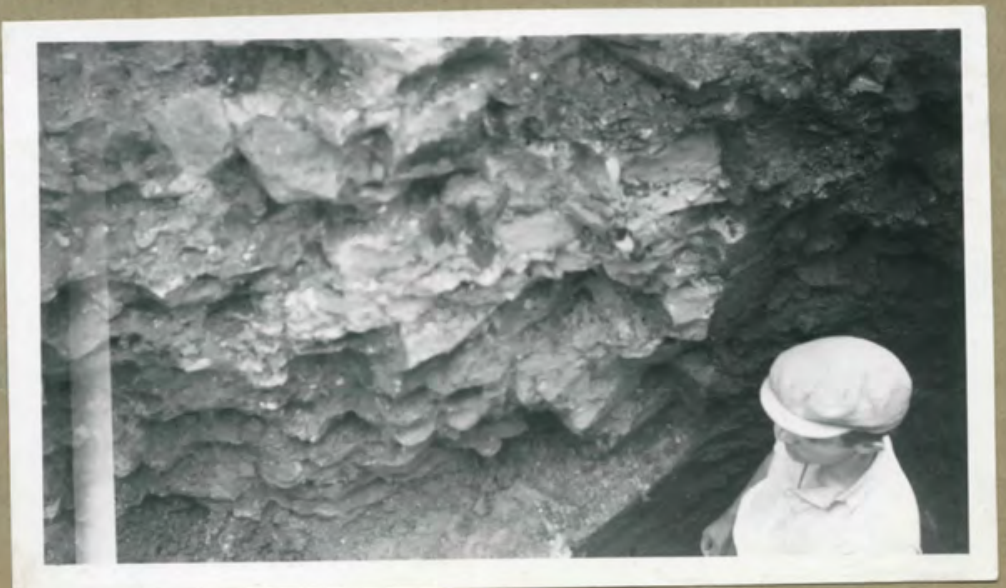


drawings is one of the north face, and another described as 'original' but apparently of the south section given that it shows the stone drawbridge pier (see Womersley and Butcher 1957b). Two heights AOD are recorded at the top of the left $(169.24 \mathrm{ft} ; 51.58 \mathrm{~m})$ and right $(168.59 \mathrm{ft} ; 51.39 \mathrm{~m})$ sides of the 'original' section drawing, which records a sequence of moat deposits. Beneath a layer of grey decayed sandstone is a rubble fill, yellow with decayed grey sandstone 'at base' on the left (east) side, and a layer of 'some stone' on the right (west) side. Below this is an episode of silting in the moat from a depth of $5 \mathrm{ft}$ to $6 \mathrm{ft} 6 \mathrm{in}(c .1 .5-2 \mathrm{~m})$, within which is findspot P1, annotated as a whole pot base. The underlying fills are light grey (containing coal and lime mortar, burnt stone and brick), then dark grey (with a 'limey layer' and an 'Ashy/Ferug' (presumably ferruginous) layer running through it), then very dark. Butcher's depiction of the drawbridge pier takes two forms - intermittent dashed lines down to about $9 \mathrm{ft} 6 \mathrm{in}(c .2 .9 \mathrm{~m})$, and then, below a level marked '? Ashlar surface' bolder, more solid lines. The distinction, and the reference to 'ashlar surface', is explained by Butcher's $(1961,30)$ reference to the fact that the pier had been robbed of its ashlar quoins, down to a level $7 \mathrm{ft} 6 \mathrm{in}(c .2 .3 \mathrm{~m})$ from the bottom, exposing the rubble core. The ashlar facing was then used to construct a late wall in the moat (see above, Section: Gatehouse; Butcher n.d. (s), 7; Figures 5.14, 5.27). Importantly, in the section drawing all of the fills above the level marked '?Ashlar surface' seem to have accumulated against the rubble core, and so after the robbing of the ashlar facing. While these fills are shown to have built up around the 'denuded' pier, the sequence to the east of the latter is differentiated by the fact that the layers are described as 'very black' and 'black wet', the latter containing a timber measuring $12 \mathrm{in} \times 2^{1 / 1} / 4 \mathrm{in}(30 \mathrm{~cm} \times 6 \mathrm{~cm})$. Beneath this is another black deposit with a P2 findspot (labelled ' $15-16$ ', presumably meaning ' 15 th-16th-century pottery') and leather, twigs, slag and bone annotated on the section drawing, and then a layer of decayed sandstone rubble.

Below this, and the '?Ashlar surface' level, the deposits are recorded as largely uniform ('v dark'), apart from on the west side of the pier, and towards the base of the moat, where there were stonier deposits ('much rubble') differentiated as 'blue black' on top and 'yellower' underneath. Roughly $3 \mathrm{ft} 6 \mathrm{in}(c .1 .1 \mathrm{~m})$ below the 'ashlar surface' are findspots $\mathrm{P} 3$ and P4, which are noted as producing 15th-century pottery. Findspot P5 lies at the base of the 'yellower much rubble' deposit (at a depth of $16 \mathrm{ft}(4.88 \mathrm{~m})$ ) and was annotated as '(E 14th) (? part of rim with spout)'. The contents of the bottom $2 \mathrm{ft} 9$ in $(0.84 \mathrm{~m})$ of the moat are described as having been 'tipped on site \& later washed \& riddled', and early Saxo-Norman (pottery?) is recorded as being recovered from the $\mathrm{x}$ and $\mathrm{y}$ buckets 'from ditch bottom'.

The top of the H2-4 north section drawing is recorded as 'Foundations 1929' at a height of $168.59 \mathrm{ft}(51.39 \mathrm{~m})$ AOD, with the upper part of the west side of the section formed by the inner wall of the old gatehouse chamber, the floor level of which is given as $165.5 \mathrm{ft}(50.4 \mathrm{~m})$ AOD. The east side of the section has a deposit of mixed sandstone and some brick batter $\left(4 \frac{1}{2} / \mathrm{in} \times 2^{1 / 1} / 2^{1 / 4} / 4 \mathrm{in} ; 11 \mathrm{~cm} \times 6 \mathrm{~cm}\right)$, with decayed mortar 'similar to that in the drawbridge pier fill', and which may represent material disturbed in 1929. Indeed, the area between this and the inner wall of the old chamber to the west is recorded as having been destroyed during the 1929 excavation. Below the 1929 chamber floor are c.4ft (c.1.2m) of moat deposits ('black-grey, dark grey') that seem to be associated with post-Civil War infilling, and which contain bands of clay, coal and stone. At the top is findspot P16, which is recorded as 17th century. The presence of blue-black material throughout the section suggests the presence of water within the moat where material accumulated. At a depth of between $6-7 \mathrm{ft}(c .1 .8-2.1 \mathrm{~m})$ blueblack silting deposits are underlain by a dark grey gritty layer, with a lens of thin flag and light pale blue clay. Just above the gritty layer is a P number, labelled as ' 1 st $1 / 2$ C16?', and below it is further silting described as blueblack, yellow and coal, with a timber at a depth of about $7 \mathrm{ft}(c .2 .1 \mathrm{~m})$ along with findspot P2. 'Pier 2' is recorded at the bottom of the west side of the section - this is the name originally given to the late wall built from the robbed ashlars of the drawbridge pier recorded in the south section (Figure 5.14 and Butcher n.d. (s), 1, 11).

The pottery assemblage from H2-4 comprises 213 sherds representing a maximum of 164 vessels. The majority of sherds are unstratified, but a few are labelled with information on the depth or the location in the moat deposits (e.g. 'Bottom') from which they were recovered, and there are several sub-groups, identified as 'J2-4 East End', 'North Extension', or through letters (X, Y, L, E) and number-letter combinations (4X, 4Y). A sherd of the rim of a bowl or pancheon in a medieval Buff Sandy fabric is labelled E6', presumably indicating that it

Figure 5.27 (page 166): Leslie Butcher's record shots of excavation of the drawbridge pier exposed in foundation shafts $G 3$ and H2-4. The bottom photograph shows the rubble core exposed after the ashlar facing had been removed to build the late wall in the moat. Courtesy of Museums Sheffield. 
was recovered from the east section at a depth of $6 \mathrm{ft}(1.83 \mathrm{~m})$. The assemblage from the $11 \mathrm{ft}$ level consists principally of Coal Measures wares dating to between the late 13th and 16th centuries. In contrast, the assemblage from the $12 \mathrm{ft}$ level is more diverse, although it also includes a substantial group of Coal Measures wares. This group includes the only jug spout from $\mathbf{H 2 - 4}$ but it is not necessarily the sherd described on the section drawing as part of a rim with a spout, since this was at a depth of $c .4 \mathrm{ft}(1.22 \mathrm{~m})$ deeper. The $12 \mathrm{ft}$ level also includes sherds of Reduced Sandy ware fabrics of 14th- to 15th-century date, including a pancheon rim, glazed lid and base of a baluster jug labelled P4 and described as 'Beside Pier' - which corresponds with information provided on the 'original' section drawing, where 'J.E.B' [Bartlett] dated P3 and P4 to the 15th century. Sheffield ware, dating to between the late 13th and 15th centuries, is also present at this $12 \mathrm{ft}$ level and the latest datable sherds are the rim and body of a jar in a 15th- or 16th-century Coal Measures Purple ware and a small piece of a post-medieval Sandy ware, possibly a late Humberware type. The $13 \mathrm{ft}$ level produced just three sherds including the rim and handle of a jug in Sheffield-type ware, also designated as coming from findspot P5, which on the 'original' section drawing is annotated at a depth of a little over $15 \mathrm{ft}(4.57 \mathrm{~m})$, and in the archive have the additional mark ' $9 \mathrm{E}$.' On the section drawing these sherds are described as being of 14th-century date, but our recent analysis suggests a wider date range of between the late 13th and mid-15th century, based on new work on this fabric. A single sherd, part of a lid in a Reduced Sandy ware, labelled ' 16 ', is of particular note as ceramic lids are unusual finds; wooden lids were more commonly used with lid-seated rim vessels. Such vessels are perhaps more likely to be associated with the storage of food or drink than its consumption and as such might be expected to be found in assemblages derived from kitchens or pantries rather than from places associated with the consumption of food or drink. A group of small sherds of North Lincolnshire Shell-tempered ware dating to the late 12th to 14th century are from the 'Bottom' context, and these are presumably the fabrics misidentified on the 'original' section drawing as 'Early Saxo-Norman', which had been recovered from the ' $x+y$ buckets. The mode of recovery ('below this level debris tipped on site \& later washed \& riddled') may help to explain the otherwise anomalous post-medieval sherd (a very small chip of 17th-century Redware labelled as ' $y$ ') from this context.

Sixteen sherds of pottery bear P numbers alone and two sherds (labelled P4 and P5) also have a depth figure recorded, while three sherds of post-medieval pottery have P numbers (P1 and P2) followed by '2.5.58', presumably the date of recovery. In one case two P numbers (P1 and P4) relate to a single piece of pottery, the base of a 17th-century Redware jar which consists of 12 joining sherds; on the 'original' section drawing at P1 a 'whole pot base' is noted. Four sherds of Coal Measures Purple ware are labelled P3, which appears on the 'original' section drawing adjacent to the pier. Seven sherds spanning the 14th to 16th centuries are labelled P4, which is marked near P3 on the 'original' section drawing.

Two sherds from H2-4 are also marked J2-4 and seven as J2-4 East End (presumably an error, using the next grid line north), and there is a diverse group of post-medieval wares, including two imports: a sherd of Frechen-Köln stoneware and another of Low Countries Redware. The group marked North Ext comprises 47 sherds representing a maximum of 44 vessels, among which medieval and early modern pottery is notably absent (a single sherd of 19th-century pottery is intrusive). Fifty-three sherds representing a maximum of 47 vessels are either unmarked or bear only letters $(\mathrm{X}, \mathrm{Y})$ or combinations of letters and numbers $(4 \mathrm{X}, 4 \mathrm{Y})$, suggesting that they may have been from the bottom of the moat along with other sherds labelled in this manner (see above). Although the group includes a small number of early modern and recent sherds, the majority are of medieval and post-medieval date and consistent with the period of occupation of the castle.

Few other finds can be confidently associated with foundation shaft H2-4. A single 16th- or 17th-century leather heel-lift is labelled $\mathrm{H} 2-4 \mathrm{X}$, which suggests that it was recovered from one of the buckets that contained fill from the bottom of the foundation shaft. Also probably from the bottom of the moat are wood fragments and a piece of slag labelled $\mathrm{H} 2-4 \mathrm{Y}$, stone items, some of which may have been roof tiles, and iron - mainly nails but also a bar labelled as being from 'near bottom' - as well as animal bone and oyster shell from H2-4Y and H2-4X. Finds from the northern extension of $\mathbf{H 2 - 4}$ include a clay pipe bowl, window glass and animal bone. Window glass derives from several other locations in the trench including P2, which is marked on the left-hand edge of the 'original' section drawing, although glass is not among the finds listed there. There is also a ceramic floor tile labelled P2, which corresponds to the annotation of tile next to P2 on the 'original' section drawing. Animal bone, including red deer antler, comes from both the $6 \mathrm{ft}$ level and from P2 - although antler is also recorded on the section at $c .15 \mathrm{ft}(c .4 .5 \mathrm{~m})$, close to P5.

The archive contains drawings of the west and east sections of $\mathbf{H 5}$, which was extended to incorporate H3 and was also an extension of the original chamber around the gatehouse structures (Butcher 1958-62g; Figure 5.28). The east section drawing does not provide a height AOD at the top, but at a depth of $6 \mathrm{ft} 6 \mathrm{in}$ 


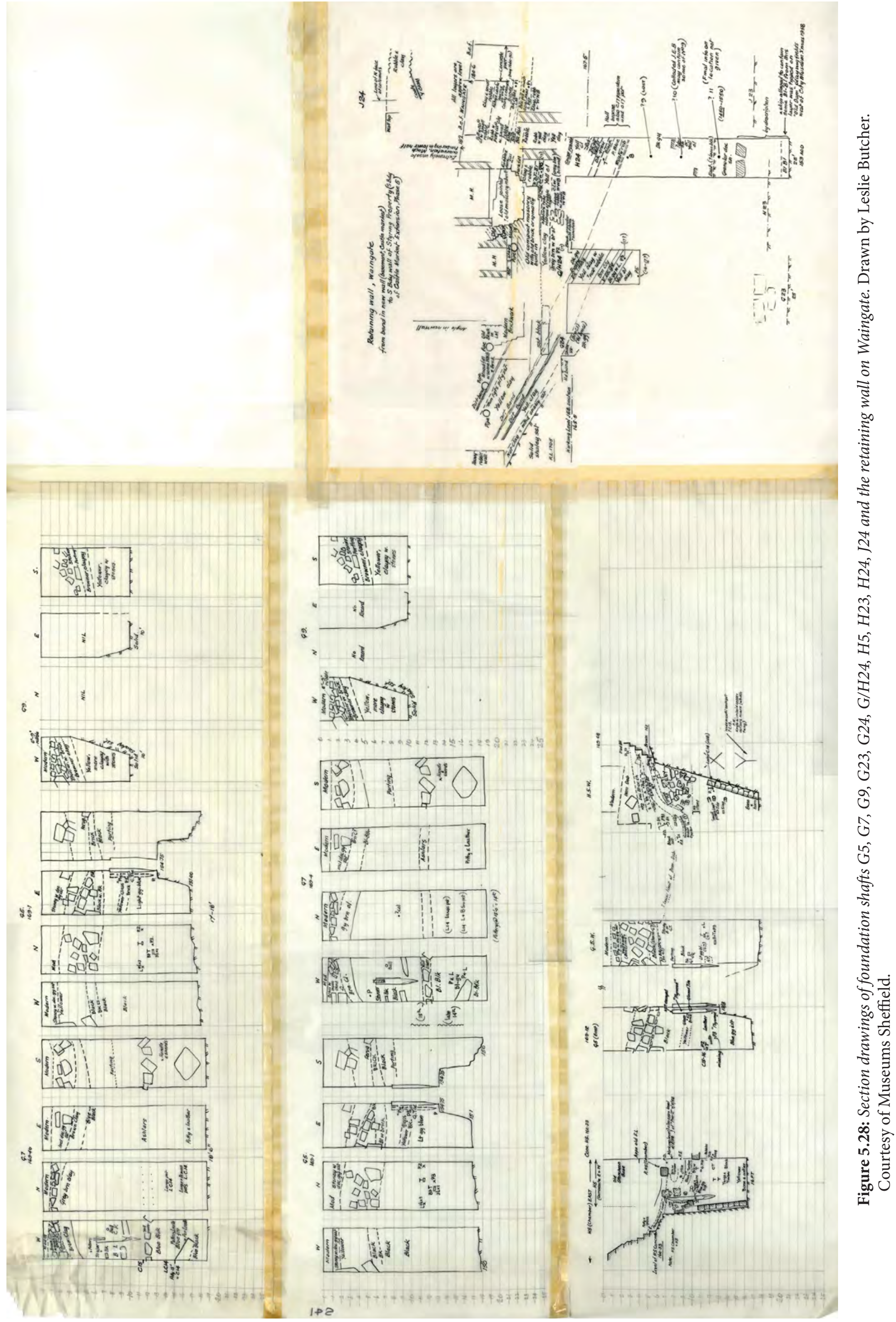


(1.98m) 'Level of H5 Concrete 160.33' (48.86m AOD) is noted, indicating that the top of the section is at $166.83 \mathrm{ft}(50.85 \mathrm{~m})$ AOD. The top of the west section is over $2 \mathrm{ft}(0.61 \mathrm{~m})$ higher at $169.08 \mathrm{ft}(51.5 \mathrm{~m})$ AOD. The top $4 \mathrm{ft}(1.22 \mathrm{~m})$ of the east section drawing is annotated as comprising an 'old stancheon base', to the north of which is the base of the west gatehouse tower, beneath which is the near-vertical edge of the stone-lined moat cut (photographs in Butcher n.d. (s), 18, 20). Since everything above would have been destroyed in 1929 in the construction of the chamber to preserve/display some of the remains (see Chapter 9), detailed recording of deposits commences at 'Level of H5 Concrete. 160.33', where a 'ferugenous' layer containing pottery and glass overlaps the footings of the tower, beneath which is a timber stake $(1.52 \mathrm{~m}$ long) adjacent to the moat cut. A number of $c .1 \mathrm{ft}(c .0 .30 \mathrm{~m})$ deep mixed deposits from $c .7-11 \mathrm{ft}(c .2 .1-3.4 \mathrm{~m})$ in depth appear to represent silting episodes within the moat, described as black with timber, a layer noted as containing brick and tile, and another as black with tile, twigs and small branches. The lowest deposits on this section drawing, from c.11-16ft (c.3.4-4.9m), are described, in turn, as blue-grey silt, black, and 'yellower'. Finds annotated on the section drawing include tile, antler, bone, twigs, timber and slag, while the stone cladding of the north, inner, face of the moat cut is depicted (as it is on the west section drawing), with twigs and branches between it and the wooden stake mentioned above.

The drawing of the west section contains more detailed information about the sequence of moat deposits. Down to $2 \mathrm{ft}(0.61 \mathrm{~m})$, deposits had been disturbed by the stancheon, and below this are a series of stony dump deposits that include brick, tile and sandstone. These deposits slope from north to south, and were clearly associated with the clearance of the site and the infilling of the moat (the annotations 'dem deb' and '?lower limit of dem. deb. [demolition debris] make it clear Butcher thought so too) - finds include a pin, honeycomb slag, tile, and mussel and oyster shell. Beneath the demolition layers is a layer $(c .10-11 \mathrm{ft} ; c .3 .1-3.4 \mathrm{~m})$ noted as containing 'no stone' and beneath that are deposits (of another $c .7 \mathrm{ft} ; c .2 .1 \mathrm{~m}$ ) associated with silting within the moat, with the only descriptor being 'small pebble layer' at a depth of around $13 \mathrm{ft}(3.96 \mathrm{~m})$. This section drawing records that artefacts collected from this lowest layer included tile, slag, bone and horn. A 13th-century 'wide-mouth cookpot' and a whittle-tang knife with 'inlaid' copper cutlers mark' were retrieved from the ' $y$ ' bucket (see Chapter 6 for more details), and it is noted that Bartlett thought some of the finds recovered from the ' $\mathrm{x}$ ' bucket (at $12 \mathrm{ft} 6 \mathrm{in} ; 3.81 \mathrm{~m}$ ) were of later 14 th-century date, but without specifying what these were; the findspot is recorded as 'P.J', but this does not occur on any of the finds bags or labels associated with this foundation shaft.

There is limited contextual information for the small collection of finds that survive from $\mathbf{H} 5$ and $\mathbf{H} 3$, concerning either depth or P number, while some of the abbreviated identifications cannot be reconciled with information recorded on the section drawings. The pottery assemblage from $\mathbf{H 3}$ consists of 34 sherds representing a maximum of 29 vessels. The medieval pottery is principally 14 th- to 16 th-century Coal Measures wares, among which there is at least one jug or cistern and one pancheon, along with a series of local 13th- to 14th-century Sandy wares. Post-medieval pottery includes Cistercian ware, Blackware, a range of utilitarian wares, and a single sherd of German stoneware, possibly Frechen-Köln type. The pottery assemblage from $\mathbf{H} 5$ is smaller, comprising just 11 sherds, among which medieval pottery is notably absent. The context information reveals three sub-groups in H5: two sherds of Blackware and one of Cistercian ware are distinguished as coming from 'Upper west 163 aod'; a larger group, consisting primarily of 16th-/17thcentury coarsewares, are identified as 'MH (manhole) 1 West', which was located north of $\mathbf{H} 5$ over the west bastion tower (Womersley and Butcher 1957b; Butcher n.d. (s), 23), while a single sherd of 17th-century Yellow Glazed Coarseware is labelled P1, but cannot be located as the findspot does not appear on either of the section drawings.

Other finds from $\mathbf{H} 3$ and $\mathbf{H} 5$ include wood, animal bone (including evidence for bone working), ceramic floor tile, a whelk shell (from 17ft) and window glass, one piece of which is labelled as 'kon layer', which presumably corresponds to the label 'Level of H5 Concrete 160.33' on the east section drawing. A series of finds labelled $\mathbf{5 H}$ are probably also from this foundation shaft and include glass, wood, animal bone, stone, and medieval ceramic floor tile, some of which is also labelled $\mathrm{X}$ and $\mathrm{Y}$, indicating that it was retrieved from the buckets that removed the fill from the base of the moat fill as is noted on the west section drawing. A context labelled ' $5 \mathrm{H}$ Moat Exchange Street' produced a great deal of both medieval and post-medieval leather, and seems most likely to have been from context H5 (discussed in Chapter 4, Section: Decoding the archive). 


\section{Foundation shafts dug through the moat near to the gatehouse}

Two well-recorded foundation shafts with substantial surviving collections of artefacts provide useful information about the moat fills in the immediate vicinity of the gatehouse. Foundation shaft G5 was located in

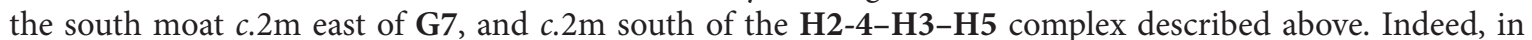
the archival drawings Butcher placed versions of the sections for G5 East and G5 West between those for H5 East and H5 West, as if to suggest that together they constituted a composite profile through the moat - he even drew a dotted lined (labelled '? Lower limit of Dem. Deb.) between layers in G5W and H5W (Butcher $1958-62 \mathrm{~g})$. The top of G5 is recorded at $169.12 \mathrm{ft}(51.55 \mathrm{~m})$ AOD with a base between $152.1 \mathrm{ft}(46.36 \mathrm{~m})$ and $151.1 \mathrm{ft}(46.06 \mathrm{~m})$ AOD. The section drawings record the incline of the base of the moat, dug into the underlying sandstone, sloping from north-south and east-west. A step down towards the base of the moat is recorded on the east and south section drawings; the top of the step is recorded at $154.75 \mathrm{ft}(47.17 \mathrm{~m})$ AOD with the moat base on the east section drawing at $151 \mathrm{ft}$ (46.02) AOD and $150 \mathrm{ft}(45.72 \mathrm{~m})$ AOD on the south section drawing (Butcher 1958-62g; Figure 5.28). On both the west and north section drawings the topmost fills of the moat are labelled as modern, and the same may have been the case for the other section drawings, which have dashed lines drawn at roughly the same heights as these modern layers are depicted. Beneath this on all four section drawings down to a depth of $c .7 \mathrm{ft}(c .2 .1 \mathrm{~m})$ are layers containing much brick and stone, with the remainder of the fills to the base of the moat roughly to a depth of $18 \mathrm{ft}(5.45 \mathrm{~m})$ described as black, with bluegrey silt recorded at the bottom of the east section. Two timber stakes $c .5 \mathrm{ft}(c .1 .5 \mathrm{~m})$ long are recorded against the south edge of the east section, one of which is described as 'NOT decayed' and "plywood"'(it is not entirely clear what Butcher meant by this term as plywood is not a medieval artefact), and there are two other stakes, on the adjoining east edge of the south section, and the south edge of the west section, respectively. The tops of each of these are at a depth of 7.5-8ft $(c .2 .3-2.4 \mathrm{~m})$. Various artefacts are notated on the north, west and east section drawings in the base fill of the moat, including tile, leather, glass and brick, with $\mathrm{P}$ numbers marked on the north (P2, P3), west (P3) and east (P2, P3, P5) section drawings.

Foundation shaft G5 produced an assemblage of 33 sherds of late medieval and early post-medieval pottery representing a maximum of 25 vessels. Two joining sherds of 16th- or 17th-century Purple Glazed Whiteware are labelled P1. Although this number is not recorded on any of the section drawings, we can identify their provenance since they are also recorded as coming from $13 \mathrm{ft} 9 \mathrm{in}$, where several other sherds of this fabric were found. A sherd in a 15th-/16th-century Fine Coal Measures Purple ware fabric was found at P2, which is marked on both the north and east section drawings just below $11 \mathrm{ft}(3.35 \mathrm{~m})$ in depth, with the date ' $\mathrm{C} 15-16$ ' annotated on the east section drawing. Cross-context joins link six sherds of Coal Measures Purple-type ware from both the $8 \mathrm{ft}(2.44 \mathrm{~m})$ level and the unstratified group. Vessel types include cups/tygs in Cistercian and Blackware (one sherd at $8 \mathrm{ft}$ ), a jug in Sheffield-type ware (at 11ft $(3.35 \mathrm{~m})$ ) and jugs/cisterns in Coal Measures Purple ware (at $13 \mathrm{ft} 8 \mathrm{in}(4.16 \mathrm{~m})$ and $10 \mathrm{ft}(3.05 \mathrm{~m})$ ). The pottery assemblage from this foundation shaft is one of the most chronologically discrete among the moat deposits recorded by Butcher, all dating to the latter period of the occupation of the castle and largely derived from the black and silty lower moat fill. Even though various other finds are notated on the section drawings, there is only a single fragment of unidentified bone in the archive that can be assigned to this shaft.

G7 is located to the south of the west tower of the gatehouse; the top of the section drawings is at $169.4 \mathrm{ft}$ $(51.63 \mathrm{~m}) \mathrm{AOD}$, and the shaft is $18 \mathrm{ft} 7 \mathrm{in}(5.67 \mathrm{~m})$ deep (Butcher 1958-62g; Figures 5.12, 5.28). On all four section drawings the uppermost deposit is described as modern. On the west section drawing, which has the most detailed deposit descriptions, immediately below this is a layer of brown clay containing 'much stone' (6in-3ft $21 / 2 \mathrm{in} ; 0.15-0.99 \mathrm{~m}$ ), with an underlying brown clay layer (2ft-4ft $6 \mathrm{in} ; 0.61-1.37 \mathrm{~m})$. Both deposits slope steeply north-south, suggesting that they reflect the direction from which the demolished castle was pushed into the moat. The other deposits shown on the section drawing relate to silting and dumping within the moat. The uppermost of these is described as black ( $3 \mathrm{ft}-11 \mathrm{ft} 6 \mathrm{in} ; 0.9-3.5 \mathrm{~m})$ and there is a timber stake, with a vertical board inserted into its top, located at a depth of between $6 \mathrm{ft}$ and $11 \mathrm{ft}(1.8 \mathrm{~m}$ and $3.35 \mathrm{~m})$. Photographs of the excavations, and the isometric drawing reproduced as Figure 5.12, suggest that this was one of three stakes found in this shaft (Butcher n.d. (s), 8). The section drawing and annotations reveal that the deposit contained rock and brick, and there is an arrow pointing downwards beneath the word 'stonier' suggesting the composition of the lower part of the fill. Artefacts from this deposit noted on the section drawing are a 'ball' (possibly 
a cannonball or musketball) and 15th-century pottery. A line of stones at $11 \mathrm{ft} 6 \mathrm{in}-12 \mathrm{ft} 2 \mathrm{in}(3.50-3.70 \mathrm{~m})$ in a deposit described as yellower, continued as a layer of ashlars and large stones in the east and south section drawings, respectively. The blue-black deposit beneath this (12ft $2 \mathrm{in}-15 \mathrm{ft} ; 3.70-4.57 \mathrm{~m}$ ) is annotated as containing pottery and leather, and dated to the late 14th century, and the same range of finds was recovered from an underlying blue-grey deposit at a depth of $15-17 \mathrm{ft}(4.57-5.18 \mathrm{~m})$. The deepest deposit, at $17 \mathrm{ft}-18 \mathrm{ft} 7 \mathrm{in}$ $(5.18-5.35 \mathrm{~m})$ is described as blue-black. On the north, east and south section drawings the deposits accord with the levels shown on the west section drawing, although they contain fewer deposit descriptors. Finds are recorded on the section drawings in the lowest fills on the north (large and small pots of late 14th-century date, and leather), east (pottery and leather) and south (handle and sherds) sides. However, none of these is linked with a P number; a lone ' $\mathrm{P}$ ' without a corresponding number is noted on the west section drawing.

Foundation shaft G7 produced an assemblage of 52 pottery sherds, representing a maximum of 41 vessels. The assemblage comprises three distinct groups of sherds: unstratified; those identified to depth; and those assigned a $\mathrm{P}$ number. The three groups are mutually exclusive, with just one exception, a sherd of late 15thor 16th-century German stoneware assigned both a depth (16ft) and a P number (P3), although P3 does not appear on any of the section drawings. The assemblage is notable for including one of the few examples of cross-shaft joins (with G9 $c .6 \mathrm{~m}$ to the west), with three sherds of probable 15th-/16th-century Cistercian ware labelled 'G7 \& G9' and 'RP3' joining to form part of a small cup or tyg. A small group of largely medieval wares (including single sherds of later Rhenish stoneware and Cistercian ware) were recovered from defined levels (10ft; $13 \mathrm{ft} 7 \mathrm{in} ; 14 \mathrm{ft} ; 15 \mathrm{ft} ; 16 \mathrm{ft} ; 18 \mathrm{ft}$ ), while the sherds with $\mathrm{P}$ numbers are mostly post-medieval wares, largely of the 17th or very early 18th century. There are two examples of cross-joins between the $\mathrm{P}$ numbered groups (P1 and P2; P3 and P8), but unfortunately, there is no information recorded on the finds bags, or the section drawings, to reveal precisely where in G7 these sherds were recovered. The foundation shaft produced a range of other material, although little of this can be assigned to a depth. This includes metal slag, 17th-century clay pipe and wooden laths (all labelled P1), window glass of probable post-medieval date (P3), medieval floor tile (from 12ft; 18ft; P3; P5; P7), animal bone and antler (from 10-11ft/P5; 6ft 6in; P1; 16ft 6in), a post-medieval copper-alloy lace, iron wire, an iron collar (P1) and an oyster shell. While the section drawings indicate that leather was recovered from this shaft, none of the leather in the Museums Sheffield archive can be assigned to it.

\section{The centre of the south moat}

Six foundation shafts (G9, F9, F11, E13, E15 and E17) located in the south moat to the south-west and west of the gatehouse provide insights into its cut and its fill, although recording was restricted in all cases and most of the sections produced limited finds. Foundation shaft G9 encountered part of the inner edge of the south moat cut, and the upper fills of the two sections recorded - on the south and west sides - contained many pieces of large rubble from the demolition of the castle, but produced few other finds, comprising just 12 sherds of pottery, a piece of glass and an animal bone (Figure 5.28). No height AOD is given for the top of the sections but it is notable that the bottom, comprised of 'solid shaley sandstone', was reached only 10 feet down, reflecting its position on the edge of the moat cut. Foundation shafts F9 and F11 were dug through the centre of the south moat and largely comprise clayey deposits and blue-black layers indicative of silting in the moat (Figures 5.29, 5.30). The only finds from $\mathbf{F 9}$ are four sherds of medieval pottery. Here too no height AOD is given but bedrock was reached at a depth of $10 \mathrm{ft}$ 6in $(3.2 \mathrm{~m})$. Foundation shaft F11 was sheet piled and only the east section was recorded in detail, with the tip lines of its layers of clay and rubble sloping from north to south, showing the direction from which it had been filled. The south section drawing notes the recovery of a large stone with 'flat faces', presumably architectural, in the bottom quarter of the fill. There are few finds that can be associated with this foundation shaft, just four medieval pottery sherds and two fragments of a medieval ceramic floor tile.

Foundation shaft E13 encountered the lower cut of the southern edge of the south moat (Figure 5.30). This is recorded on the east section drawing, which shows that, beneath a 'modern' layer, the uppermost deposit comprises demolition and levelling material including ashlars, brick and brown clay, beneath which a yellow-brown clay deposit abuts brown and yellow deposits representing weathering against the moat cut. Deposits towards the bottom of the section drawing are separated by the decayed remains of a timber post, to the north of which are deposits of clay and sandstone, with decayed natural on the south side of it. The only finds surviving from 


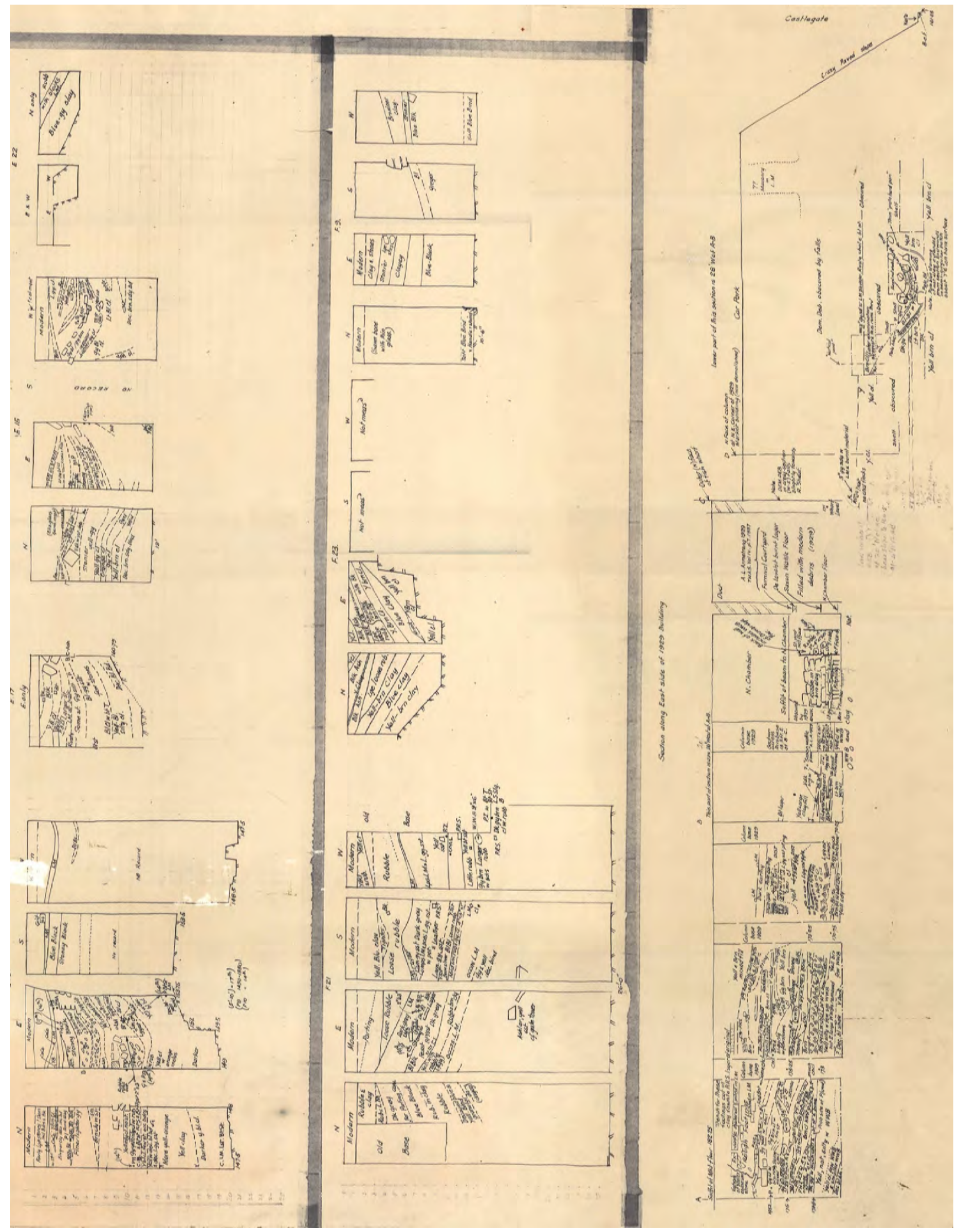

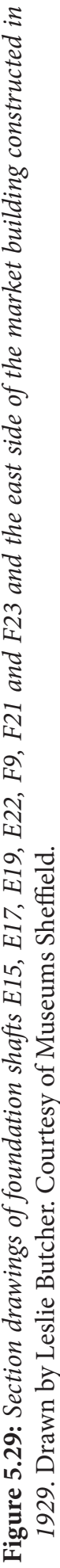



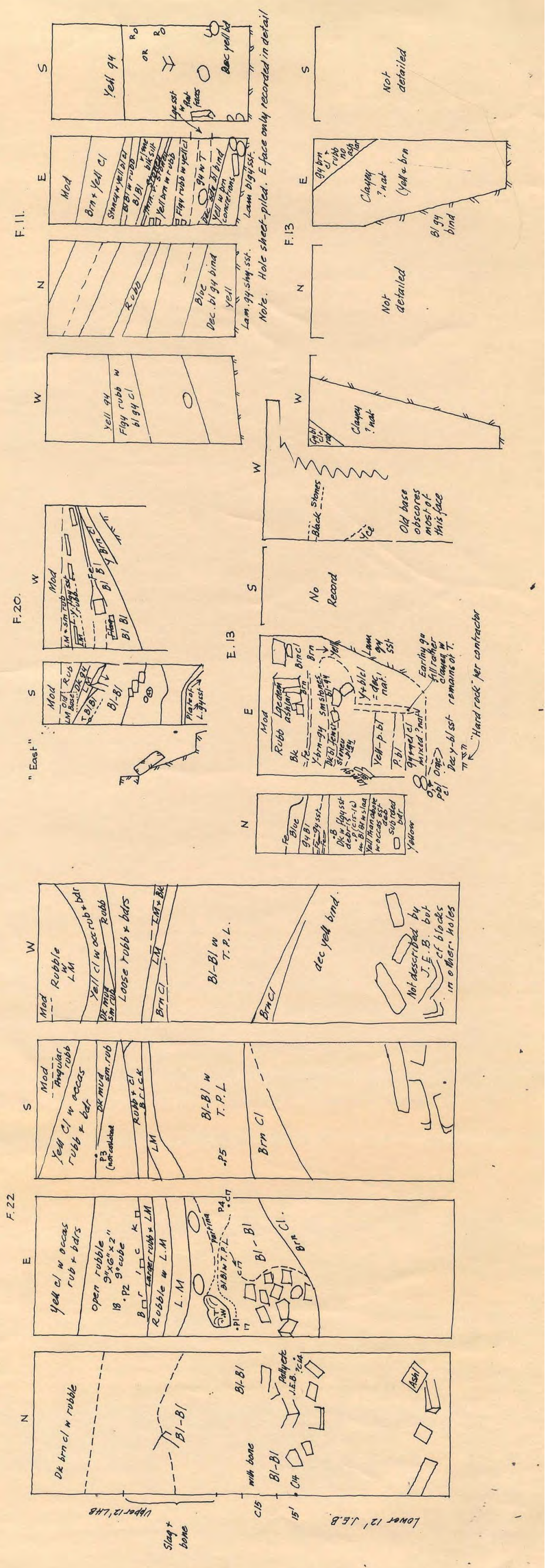

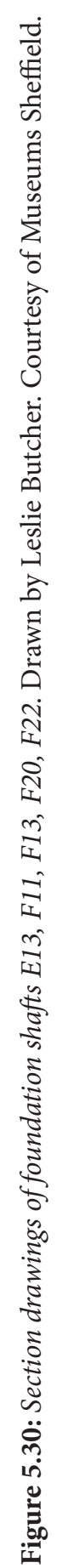


this shaft are 23 sherds of pottery. The earliest sherds are of late 15th- or 16th-century Coal Measures Purpletype ware (one of which was a pot disc), while the remainder of the assemblage largely comprises late 15th- to 17th-century fabrics, including Yellow ware, Unglazed Redware, Coarse Blackware and Midlands Purple ware. Foundation shaft E15 also exposed moat deposits, and the drawings of the north, east and west sections reveal a series of thin clay and stoney layers (Butcher 1958-62e). Finds annotated on the section drawings include plant remains, a mid-17th-century clay pipe and imported German glass of Elizabethan date. Foundation shaft E17 was located in the southern moat $c .5 \mathrm{~m}$ to the west of E15, with its north-western corner overlapping a footing from the buildings constructed in the late 1920s (Ove Arup and Butcher 1957). Only the east section of this shaft was drawn (Butcher 1958-62e), and its deposits comprise a sequence of layers containing clay, brick and stone which slope from north to south at the top and may represent backfilling after demolition of the castle. The bottom of the shaft comprises silty and clay layers sloping from south to north, with a decayed blue bind (shale) overlying the bedrock of the cut of the moat. No finds recovered from this foundation shaft are identifiable in the Museums Sheffield archive.

\section{The junction of the south and west moat}

Foundation shaft E19 was located at the point where the south moat begins to turn to the north to form the western section of the moat (Figures 5.29; Butcher n.d. (s), 27). The shaft was up to $20 \mathrm{ft}$ (6.10m) deep (compare, for example, G9 and F9 in the south moat), and detailed recording was undertaken of the north and east sections, which show the moat base cut into the underlying bedrock. The top of the shaft is described on the east section drawing as modern, and is between 1 and $2 \mathrm{ft}(0.30 \mathrm{~m}$ and $0.6 \mathrm{~m})$ thick towards the south. Immediately below this deposit is a sequence of clay and silt deposits that slope from south to north, which shows that the moat was filled in from the south. The drawing of the north section of the trench records a series of yellow and brown clay layers, and mixed deposits that appear to be demolition layers from the castle, including tips of crushed sandstone, grey silt, lime mortar, grey-yellow marly clay and burnt flagstones. At the bases of both the north and east section drawings are dark layers, which are probably silting deposits within the moat, and on the east section drawing decayed bind represents weathering of the moat cut. The two section drawings also record the base of the moat, which on the north section drawing slopes east to west from $148 \mathrm{ft}(45.11 \mathrm{~m})$ to $147.5 \mathrm{ft}(44.96 \mathrm{~m}) \mathrm{AOD}$, but on the east side slopes from $153.75 \mathrm{ft}(46.85 \mathrm{~m})$ to $152 \mathrm{ft}(46.33 \mathrm{~m})$ AOD, before a step down to $149.5 \mathrm{ft}(45.57 \mathrm{~m})$ and then sloping to the north at $149 \mathrm{ft}(45.42 \mathrm{~m})$ AOD (the step down can be seen in Butcher n.d. (s), 27).

Foundation shaft E19 contained a diverse pottery assemblage consisting of 35 sherds representing a maximum of 32 vessels. The assemblage is distinguished by the presence of some of the earliest sherds from the site as a whole. Most of the material comes from the 5-10ft and $6 \mathrm{ft} 3$ in levels, while two joining sherds of Coal Measures Purple ware link levels $6 \mathrm{ft} 3 \mathrm{in}$ and $9 \mathrm{ft}$ 9in. The unstratified pottery also bears the mark ' $5 \backslash 3-10 \backslash 2$ ', although the significance of this is unclear. Four medieval sherds and two post-medieval sherds bear P numbers: P7, P8, P10, P11 and P13. The earliest sherds are two joining fragments in the Stamford ware A fabric, dating to between the mid-10th and late 11th century; they are labelled P11, which reveals that they were recovered from the north section of the foundation shaft, just below a depth of $10 \mathrm{ft}(3.05 \mathrm{~m})$. The section drawing at this point is annotated ' $14^{\text {th' }}$, suggesting that they were thought to be later in date at the time of excavation. A small sherd of an unidentified Reduced Sandy ware, probably of 12th- to 14th-century date, is labelled P13, which reveals that it was recovered from the east section of the shaft at roughly the same depth as the Stamford ware (again annotated '14th'). Other medieval sherds include unstratified Sheffield-type ware labelled P10, which is annotated on the east section drawing, as is a sherd of 14th- or 15th-century Coal Measures White ware. Two sherds of 14th- or 15th-century Coal Measures Fineware type are among the unstratified material, while the remainder of the pottery is of late 16th- to 17th-century date with one sherd of probable 18thcentury Slipware from the $6 \mathrm{ft}$ 3in level. The post-medieval wares are of types common across the site including Yellow ware, Redware, Midlands Purple ware, Blackware and Early Brown Glazed Coarseware. Other finds from this foundation shaft include a piece of window glass (from P13), a piece of unworked sandstone and a pebble (annotated ' $5 / 3-10 / 3$ '), five pieces of slag ('between $5 / 3 \& 10 / 6$ '), iron, possibly a nail (P10), and animal bone (' $5-10$ ', ' $5 / 3-10 / 3$ ' and ' $5 / 3-10 / 6$ unstrat'). 
Foundation shaft F21 seems to have been close to the centre of the moat, and excavated to a depth of $26 \mathrm{ft}$ $(7.92 \mathrm{~m})$. Drawings survive for all four sections (Butcher 1958-62e; Figure 5.29). The upper sequences in this foundation shaft suggest the deliberate tipping and dumping of material to backfill the moat, while the lower deposits appear to represent phases of silting and weathering. On the north and west section drawings, parts of the upper fill are obscured by a foundation base extending to a depth of $10 \mathrm{ft}(3.05 \mathrm{~m})$. The first $1 \mathrm{ft}(0.30 \mathrm{~m})$ of deposit on all the sections is described as modern. Beneath this, on the east half of the north section drawing, is a layer of rubble and clay and then five deposits sloping east to west and comprising rubble and lime mortar, a dark grey deposit with coal inclusions, a blue-black layer, rubble in clay, and decayed blue and yellow bind. On the south section drawing the deposit immediately below modern is described as yellow-blue clay, beneath which is loose rubble containing brick and a lens of material annotated as 'tighter'. Beneath this is a thin deposit of lime mortar and light grey sandstone which overlies a dark grey deposit with laminated grey sandstone, and lumps of lime mortar. The underlying deposit has limestone inclusions and contains pottery and leather, and this is underlain by three more layers comprising sandstone, rubble and clay. The bottom $13 \mathrm{ft}(3.96 \mathrm{~m})$ of the trench is described as decayed bind and it contains a large piece of ashlar. The deposits recorded on the east section are very similar to those on the south section, aside from the layer below modern, which is described as 'parting', an example of Butcher drawing from geological terms to refer to a contrast in deposits. The bottom of the section also produced ashlars of yellow sandstone and it is notable that on this drawing Butcher has annotated it with 'cf gatehouse. He seems to have believed that there was another tower at this corner of the castle, and, indeed, on the Ove Arup \& Partners foundation plan he sketched a drawing of the castle showing a tower at this corner (Ove Arup \& Partners and Butcher 1957; Figure 5.1). On the west section drawing, similar clay and rubble layers are recorded, but there is a little more information provided about the finds recovered, which included burnt tile and stone, and slag at findspot P1. This foundation shaft was also represented by Butcher in one of his isometric drawings (Figure 5.11), and was one of those that was critical in assisting the interpretation of the various abbreviations he used.

Foundation shaft F21 produced an assemblage of 48 sherds of pottery representing a maximum of 38 vessels, the bulk of which comes from level ' $\mathrm{C} 8$ '. The assemblage largely dates to between the late 15th and 17th centuries. There is little evidence of any stratigraphic succession within this group, which includes the familiar mix of Coal Measures Purple ware, Cistercian ware and Yellow ware alongside Blackware, Coarse Blackware and Early Brown Glazed Coarseware. Vessel types include a cistern, pancheons, a bowl and a cup or tyg, the latter in Cistercian ware. All three sherds of pottery marked P1 or P2 (which is not annotated on any of the section drawings) are of late medieval date, as are two sherds from the $18 \mathrm{ft}$ level (Coal Measures Purple ware types). The unstratified pottery includes a sherd of Cistercian ware, three sherds of Blackware, the rim of a Midlands Purple ware jar and the handle of a jug or cistern in Early Brown Glazed Coarseware. Other finds from F21 include plaster and slag (P1), and animal bone (one fragment from P1) including a red deer metapodial, boneworking waste and sawn bone.

Foundation shaft $\mathbf{G 2 2}$ was located adjacent to the inner moat cut, and $c .10 \mathrm{~m}$ north-west of foundation shaft F21. In addition to the section drawings of this shaft (Butcher 1958-62d; Figure 5.26), it is one of a series of shafts (with F23, G22 and H22) used to construct a profile drawing of this part of the moat and the underlying geology (Butcher n.d. (t)) and described in Butcher's (1961, 17-19) lecture script, where it is used as a detailed example of what he recorded of the moat. The upper deposit on the south section drawing is annotated as modern, beneath which is a deposit comprising brown clay, yellow clay, rubble with boulders, and lime mortar, which slopes from east to west in common with most of the fills recorded on this section drawing. Beneath this are a series of deposits described as blue-black, and dark grey clay containing brick and tile. A 'P' without a number is marked on the west side of the section drawing. Below this is a deposit of light grey sandstone, and then a dump deposit described as loose red and yellow-blue clay, small rubble and brown clay iron stained. Findspot P1 is recorded at the top of this deposit and the drawing notes the recovery of a set of shears. A further sequence of weathering deposits of decayed blue shale and laminated grey sandstone was recorded immediately below this dump, and the underlying deposit is suggestive of silting within the moat, with occasional dumping of material, described as blue-grey, fragments of ashlar, decayed shale, decayed laminated bind, and shaley sandstone. Another $\mathrm{P}$ without a number is annotated within this deposit. At the base of the moat is a silting deposit described as blue-black with a 'column drum in pink grit' marked on the section drawing. The west section drawing records very similar deposits sloping from north to south, including more examples of architectural stones, including chamfered ashlar and tracery. Other finds recorded include tile, pot and two 
whittle-tang knives. Again, the information recorded at the base of the moat suggests weathering and silting. On the north section drawing, below the modern deposits is grey clay, which includes tile at the interface with the underlying rubble and clay deposits. Again, deposits at the base of the moat suggests weathering of the underlying natural sandstone into the moat fills. The cut of the moat recorded on the east side of the north section has a chamfered edge recorded between $8 \mathrm{ft}$ and $9 \mathrm{ft}(c .2 .4$ and $2.7 \mathrm{~m})$, which then dropped vertically to $11.5 \mathrm{ft}(3.51 \mathrm{~m})$, then stepped back to the west and dropped vertically again to $c .17 .7 \mathrm{ft}(c .5 .4 \mathrm{~m})$. Very similar deposits are recorded on the east section drawing, sloping from north to south, and with the edge of the moat cut also recorded on the northern edge. Overall, the records of the foundation shaft show dumping of material into the moat which had already silted up to a level of between $10 \mathrm{ft}$ and $12 \mathrm{ft}$ from its base.

The pottery assemblage from foundation shaft G22 comprises 186 sherds representing a maximum of 170 vessels. Only three sherds lack any context information, and this renders the assemblage the best recorded of those from the foundation shafts. The assemblage from the $8 \mathrm{ft}$ level is, with the exception of a single sherd of Cistercian ware and two sherds of Coal Measures Purple-type ware, of late 16th-/17th-century date, with a large quantity of Blackware, Early Brown Glazed Coarseware and Midlands Purple ware. Only two vessels are identifiable to type: a cup or tyg in Cistercian ware and a bowl or dish in Coarse Blackware. The group from the $10 \mathrm{ft}$ level is considerably larger and includes a much higher proportion of medieval and early post-medieval pottery alongside 17th-century wares. The earliest sherds identified are of Hallgate A type, currently dated to the 13th century, while a sherd of White-slipped Sandy ware probably dates to the period between the later 12th and early 14th century. Coal Measures Whiteware was represented by three sherds including the base of a jar, jug or cistern. However, these earlier sherds appear to be residual in this deposit as the bulk of the assemblage is of later medieval and post-medieval date with particularly large groups of Coal Measures Purple ware, Midlands Purple ware, Cistercian ware and Early Brown Glazed Coarseware and smaller quantities of Coarse Blackware. With the exception of the Cistercian ware, from small cups or tygs, the majority of vessels are of utilitarian types with jugs, jars and cisterns the commonest identifiable forms. The group also includes a sherd from a Martincamp-type flask and the rim of a mug or jug in Frechen-Köln stoneware. The latest sherd is a small piece of 18th-century Slipware, which might be considered to be intrusive. The $12 \mathrm{ft}$ level (including one sherd labelled ' 12 ' 11') produced just three sherds of pottery, all of 17 th- or, at the latest, early 18th-century, type. Similarly small groups of sherds come from the 12-15ft and 12-16ft levels, the former including a sherd of medieval Sheffield-type ware alongside smaller sherds of Slipware and Coarse Blackware. The pottery from the $17 \mathrm{ft}$ level, and so from the silting layers at the base of the moat, was, with the exception of a sherd of Unglazed Redware, exclusively of medieval date, with two sherds of Brackenfield ware, various kinds of Coal Measures ware (including two jug or cistern handles) and a sherd of Sheffield ware. Three body sherds are labelled P1: two of Coarse Blackware and one of Early Brown Glazed Coarseware. A single small sherd from a 17th- or early 18th-century Yellow Glazed Coarseware pancheon, is labelled P2.

Foundation shaft G22 produced a range of other finds, including part of a wooden lath from the $24 \mathrm{ft}$ level, suggesting waterlogging in this silted up deposit, coal, smelting slag and animal bone from the $17 \mathrm{ft}$ level, boneworking waste including evidence for handle manufacture, and oyster shells from the 10ft level. Confirming an annotation on the west section drawing, a medieval whittle-tang knife survives in the archive which has a bone handle made from a single medium mammal long bone, and while the blade is now in very poor condition it appears to have a straight back and convex blade (see Chapter 6, Section: Domestic and personal items; Figure 6.8). A fragment of a polished bone handle was recovered from the $8 \mathrm{ft}$ level, which is a little shallower than where the knives are annotated on the west section drawing.

Foundation shaft $\mathbf{G} 23$ was located $c .7 \mathrm{~m}$ to the west of G22. Construction work limited recording of the north and west sections of the shaft (Butcher 1958-62d; Figure 5.26). The east and south section drawings have more detailed records, and a note at the top of the latter states it was 'most prolific of pot'. G23 is one of the few shafts in which Butcher detected, or at least recorded, a clear chronological sequence, with annotations (mostly on the south section drawing) running from '(15th)' and '1500' at 15-14ft, '16C' glass at 11-10ft '(17)' at 10-9ft, and '(17) $\rightarrow(18)$ ' at $6-4 \mathrm{ft}$. The upper deposits on both recorded sections are very similar, with a modern layer above a series of layers containing yellow clay, rubble, ash and lime mortar. Below this on the east section drawing, a deposit of lime mortar and small rubble is recorded along with findspot P1. On the south section drawing, the corresponding deposit is recorded as yellow clay, black ash, loose rubble, and large rubble with black ash, along with findspot P2. From this point on the section drawings the deposit descriptions vary, but probably represent similar deposits. On the east section drawing there is a succession of dump deposits described as some lime 
mortar, large loose rubble with black ash, large rubble black greasy and grey-brown rubble and clay, and rubble with lime mortar. On the south section drawing, the corresponding deposits are described as rubble and yellow clay, brick, and very loose rubble at base, and containing findspot P6. The underlying deposit is described as brown clay, large rubble, water-worn boulders, lime mortar, and brick, and it contains findspot P5. It seems likely that these extensive dump deposits are associated with the post-Civil War demolition, clearance and levelling of the site.

Below these deposits, silting within the moat is recorded. On the east section drawing, this is described as blue-black and rusty with rubble, and as containing tile. On the south section drawing, the corresponding deposit is blue-black and contains findspots P7, P8, P9, P10, and P12 as well as a leather sole (with heel), which suggests waterlogging. In the east section, a rubble and clay deposit is beneath this silting, but is not recorded on the south section drawing. The bottom deposit on the east section drawing suggests weathering and silting within the moat, and is described as mixed, yellow-brown marly clay with small rubble and large natural sandstone blocks. On the south section drawing are deposits suggesting silting and described as blue-grey and yellow clay which produced glass noted as being of 16th-century date. The bottom two deposits in this section are described as yellow clay and blue-grey.

As suggested by the annotation on the south section drawing, the pottery assemblage from G23 is one of the largest recovered from the site, comprising 616 sherds representing a maximum of 542 vessels. Context information is generally good with depth information on all but 38 sherds. Pottery sherds from the upper sections of the shaft include information about the depth from which they were recovered, although several of the depth ranges overlap, perhaps revealing that they were collected from different sections, although this is not specified. The depths concerned are $0-3 \mathrm{ft}, 0.6 \mathrm{ft}, 1 \mathrm{ft}, 3-6 \mathrm{ft}$ and the slightly confusing ' 4 ' 6 ', which may mean either 4-6ft or $4 \mathrm{ft} 6 \mathrm{in}$. The 0-3ft layer produced just two sherds, both different types of Midlands Purple ware of probable 16th- to 17 th-century date. The $0.6 \mathrm{ft}$ level contained a small mixed group consisting of Cistercian ware, Blackware and Early Brown Glazed Coarseware. A mug or tyg and a handled bowl are among the Blackware vessels and a cup or tyg among the Cistercian wares. The $1 \mathrm{ft}$ level produced just one sherd, which is of probable 18th-century date (Mottled Coarseware), and early modern pottery is also present in the much larger and very mixed assemblage from the 3-6ft level which includes Slipware, Mottled ware and Creamware. Later still are the sherds of Colour Glazed ware (including the base of a teapot), transfer-printed Whiteware (with the popular Asiatic Pheasants design) and plain Whiteware. Earlier pottery includes Blackware, Midlands Purple ware and Early Brown Glazed Coarseware. The group also includes a sherd of Low Countries Redware dating to between the late 14th and 16th centuries.

The '4' 6" level produced just two sherds; a very small sherd of 15th- or 16th-century Cistercian ware and a larger sherd of later Yellow Glazed Coarseware. A cross-context join, in the form of two sherds of transferprinted Whiteware, links the 3-6ft and 10-12 1/2ft levels, and a second join links the $12 \mathrm{ft}$ and $10-12 \frac{1}{2} \mathrm{ft}$ levels through two sherds of Purple-glazed Sandy ware of 16th- to 17th-century date. The group from the 10-121/2ft level itself contains a substantial group of late medieval to late post-medieval wares with small quantities of earlier and later wares. Tablewares are represented by small numbers of 15 th- and 16 th-century Cistercian ware and 17th-century Blackware sherds (cups/tygs and a probable jug) but these are a minority element when compared with the much more substantial numbers of sherds of utilitarian type. Medieval wares include Sheffield ware and various types of Coal Measures ware but post-medieval wares are commoner and more diverse with Midlands Purple types, Coarse Blackwares, Redware and late Sandy wares. Early Brown Glazed Coarsewares constitute a significant part of the group. The range of vessel types includes cisterns, jugs, cups/tygs, bowls, a pipkin and a handled bowl.

The assemblage from the $10 \mathrm{ft}$ level is, with the exception of a single sherd in an unidentified but probably local Sandy ware, of 17th-century date with one or two sherds of probable 18th-century date (Slipware, and Mottled Coarseware). The assemblage from the $11 \mathrm{ft}$ layer is dominated by Early Brown Glazed Coarseware with vessel types including cisterns, jugs, pancheons and jars, but also includes a wide range of other types including a small quantity of later medieval sandy wares, Coal Measures Purple ware and Cistercian ware. Post-medieval types include Blackware, Coarse Blackware, Redware (glazed and unglazed). The latest types are of 18th-century date including Slipware and Mottled ware. The assemblage from the 11-13ft layer is smaller and less diverse than that from the $11 \mathrm{ft}$ layer but appears to span a similar date range, with Coal Measures Purple ware, Coarse Blackware and Early Brown Glazed Coarseware the principal types. Vessel forms include cisterns and at least one jug. The 11-15ft layer produced just one sherd, the handle of a jug or cistern in Coal 
Measures Purple ware. The assemblage from the $12 \mathrm{ft}$ level closely resembles those from the $10-12 \frac{1}{2} \mathrm{ft}$ and $11 \mathrm{ft}$ levels, with small quantities of Cistercian ware and Coal Measures Purple ware alongside a much larger group of post-medieval wares including various Midlands Purple and purple-glazed wares and Early Brown Glazed Coarsewares. The range of vessel types is also similar to that seen elsewhere in the shaft, with cisterns, jugs, jars and bowls common among the utilitarian types and cups and tygs among the Cistercian and Blackwares. The only sherd from the depth $12^{1 / 2} \mathrm{ft}$ is the rim and handle of a jug or cistern in Early Brown Glazed Coarseware, and the $13 \mathrm{ft}$ level also contains just one sherd of Blackware, the rim of a mug or tyg.

The assemblage from the 13-14ft level is smaller than those from the $10-12 \frac{1}{2} \mathrm{ft}$ and $11 \mathrm{ft}$ levels but otherwise resembles them in all major respects. A small, presumably residual, medieval element is accompanied by a larger quantity of Midlands Purple ware, Coarse Blackware and Early Brown Glazed Coarseware. Vessel types include a cistern, a pancheon, an open jar and a jug or cistern. A cup or tyg in Cistercian ware is also present. The 14-15ft and 14-15ft layers produced a range of similar post-medieval wares but with a higher proportion of late medieval wares, including Sheffield ware, Coal Measures Purple ware and Buff Sandy ware. A smaller quantity of early modern wares are also present. The assemblage from the $14 \mathrm{ft}$ level is primarily of later medieval to early post-medieval date but includes sherds of Coarse Blackware and Early Brown Glazed Coarseware. How far the varying proportions of medieval as opposed to post-medieval and/or early modern wares in these contexts is significant is open to question. It seems probable that the earlier material is residual in later deposits but whether it represents material dumped in the moat during the later medieval period and disturbed during the demolition of the castle or whether it was derived from deposits elsewhere in the castle or its environs and moved before being dumped along with the post-medieval material is unclear. Layers $14-16 \mathrm{ft}, 14 \mathrm{ft}, 18 \mathrm{ft}$ and 19ft contain individual sherds or pairs of types familiar from the larger groups: Yellow ware, Coal Measures Purple ware, Coarse Blackware and early Brown Glazed Coarseware. Despite the fact that the south and east section drawings record numerous P numbers, only two sherds are designated with a P number: P1 (annotated towards the top of the east section drawing) is a sherd of Early Brown Glazed Coarseware, while P5 (at a depth of just over $6 \mathrm{ft}$ on the south section drawing) is a piece of Midlands Purple ware. Forty-four sherds representing a maximum of 38 vessels are not identified to a specific level or spit or by $P$ numbers, although many bear obscure or illegible marks, with four dated $18^{\text {th }}$ November. Vessel types include cisterns, jars, dishes and a handled vessel. Finally, the pottery assemblage from $\mathbf{G} 23$ presents one of the rare examples of cross-pit joins, as seven sherds forming the base of a Midlands Purple ware jug or cistern are labelled as coming from G23 and G25, the latter a context not otherwise represented in the archive, nor does it appear on the construction plan annotated by Butcher (Ove Arup \& Partners and Butcher 1957).

Other finds that can be assigned to G23 include three 17th-century shoes and another of post-medieval date; it is notable that the heel and sole of a leather shoe is annotated on the south section drawing (see Chapter 6, Section: Working with leather - cobblers, saddlers and harness-makers). Also recovered were three fragments of animal bone (from $12 \mathrm{ft} 11 \mathrm{in}, 11 \mathrm{ft}$ lin and $10-12 \frac{1}{2} \mathrm{ft}$, respectively), a fragment of a medieval ceramic floor tile (10ft), the bowl of a mid-17th-century clay pipe (11ft), two fragments of window glass (10ft), the base of a 17 th- or 18th-century glass phial (11ft 1in), an oyster shell (3-6ft), a roof slate (12ft) and a whetstone (labelled $12 \mathrm{H}$, the meaning of which is unclear).

Foundation shaft F22 was located $c .5 \mathrm{~m}$ to the south of $\mathbf{G 2 2}$ in the west moat, and was $c .24 \mathrm{ft}(7.32 \mathrm{~m})$ deep. Beneath the top layer of dark brown clay with rubble on the north section drawing is a layer that is not described; there is a note 'upper 12' LHB', indicating that Butcher recorded it but we have no further details (Figure 5.30). Slag and bone are reported as having been found in both this layer and the one below, which is described as blue-black to the base of the moat. The lowest $12 \mathrm{ft}(3.66 \mathrm{~m})$ of deposits are noted as having been recorded by Bartlett ('J.E.B'), and bone, pottery and ashlars are depicted, with annotations indicating that the some of the finds dated to the 14th century. There are similar sequences (but more fully annotated) on the east section drawing, with clay and rubble layers containing brick and the P2 findspot, layers containing lime mortar and the middle fill of the moat again a blue-black deposit, the upper part of which is labelled ' $\mathrm{C} 17$ ' and contains the P1 and P4 findspots. The base of the moat fill is labelled as brown clay, suggesting weathering from the moat edges. The south section drawing has corresponding upper layers of clay and rubble, and the annotation 'P3 (not collected)'. As on the other section drawings, the next deposits are associated with demolition comprising rubble and clay with brick, and lime mortar. The blue-black silting within the moat is recorded at $6-11 \frac{11 / 2 \mathrm{ft}}{}$ $(1.23-3.51 \mathrm{~m})$ and findspot P5 is annotated in this deposit. The lowest deposits $\left(c .11-23 \frac{1}{2} \mathrm{ft} ; c .3 .35-7.16 \mathrm{~m}\right)$ of brown clay with rubble are indicative of weathering and dump deposits. On the west section drawing, there 
is, again, a clay and rubble layer, and lime mortar, beneath which is a blue-black layer containing tile, pottery and leather. The lowest moat fill comprises a decayed yellow bind, suggesting weathering, and it includes what appear to be architectural stones; the section drawing notes 'Not described by J.E.B but cf blocks in other holes'.

Foundation shaft F22 produced a pottery assemblage consisting of 61 sherds representing a maximum of 52 vessels, and a further four sherds representing a maximum of three vessels are labelled ?F22. Excluding the ?F22 group, the pottery from F22 can be divided into three groups: those with depth information recorded (much coming between the $10 \mathrm{ft}$ and $15 \mathrm{ft}$ levels); sherds assigned a P number; and pottery labelled BWT, the significance of which is unknown. There is some indication of a stratigraphic succession within the pottery assemblage, with that from the $15 \mathrm{ft}$ level being of exclusively medieval date and comprising sherds of Brackenfield 01 ware, Sheffield ware and Coal Measures wares. In contrast, the pottery from all other contexts, which appear to be in higher deposits (P1, P4,12-14ft, 10ft, 10ft 8in, 10ft 4in, 10ft 9in), largely dates to the late 17th or early 18th century and includes Midlands Purple wares, Early Brown Glazed Coarseware and Redware with smaller quantities of Yellow ware and Blackware-type sherds. The range of vessel types is broadly similar to that from elsewhere on the site, with utilitarian vessels (jugs, jars, pancheons etc.) much commoner than tablewares. Three sherds (one Cistercian ware and two of Coarse Blackware) all bear the ambiguous mark '12/- to 14/-' and the code ?F22, and while it is unclear how these relate to the rest of the assemblage they would not be out of place in the $12 \mathrm{ft}$ to $14 \mathrm{ft}$ level.

Among the other material recovered from foundation shaft F22 are 17th-century leather turnshoe fragments, including a rand, a fragment with lasting margin, and another with butted edge/flesh seam; while there is no information concerning the place from which these were recovered, it may have been from the $c .11 \mathrm{ft}$ level as leather is here recorded in the east, south and west sections. The remainder of the finds from this foundation pit are twigs, perhaps wattle, and animal bone, some indicative of bone working, and much of this material is from the $12 \mathrm{ft}$ to $14 \mathrm{ft}$ level - generally just above the 'brown clay' lower fills. From the $10 \mathrm{ft} 9 \mathrm{in}$ level is bone-working debris and a red deer metapodial.

Foundation shaft $\mathbf{H} 23$ was located in the west moat about $10 \mathrm{~m}$ to the north-west of F22. The most detailed records are for the south and west sections, although the north and east sections provide important records of the lower rock-cut edges of the moat, showing a steeply chamfered upper slope before regular steps with vertical faces (Butcher 1958-62d; Butcher n.d. (s), 29; Figure 5.26). On the north section drawing, the upper $3 \mathrm{ft}(0.91 \mathrm{~m})$ consists of concrete, while on both the south and west section drawings there is a deposit of lime mortar and small rubble at the top, while there is no description of the top layers of the east section. In all sections, the succeeding deposits consist of sloping dumps - the west and east section drawings demonstrate that the pit was infilled from the north - comprising rubble and lime mortar, yellow-brown clay, coal and ash, with findspot P1 annotated on the west section drawing. On both the south and west section drawings, below these dumps are deposits $\left(7^{1} \frac{1}{2}-10^{1 / 2 \mathrm{ft}} ; 2.29-3.2 \mathrm{~m}\right)$ described as mixed coal, peaty, yellow, blue and dark grey clay, and blue-black. Tile was recovered from these deposits in the south section, and the drawing is annotated with a date of 15th to 16th century at the bottom of this deposit, while brick is recorded on the west section drawing. Deposits associated with silting within the moat are recorded below these dump deposits, comprising a mixed, lensed blue-black deposit, which on the west section drawing includes tile, yellow-grey sandstone fragments and peaty material, and this is where findspot $\mathrm{P} 4$ is recorded. On the north section drawing, below this deposit is a 4in layer of yellow clay, sandstone with a reddish-purple stain. On the west and south section drawings beneath the silting is a deposit of rusty yellow and grey sandstone fragments, and a 3in layer of blue clay. The bottom deposits in this foundation pit comprise decayed yellow-blue bind in both the south and west sections, brown clay in the north section, and blue-yellow clay in the east section.

Foundation shaft $\mathbf{H} 23$ produced a pottery assemblage consisting of 40 sherds representing a maximum of 39 vessels. Depth data is provided for a substantial part of the assemblage. The earliest sherd is a piece of Hallgate A ware, labelled P1 (so from quite high up in the shaft), while two sherds of 15th- or 16th-century Coal Measures Purple ware and the base of a Midlands Purple ware jar or cistern bear the letters BL, suggesting they came from a black layer. An unstratified sherd of 17th-century Type 1 Slipware is numbered ' 46 '; it is unclear what this means, unless it is an error for ' $4-6$ ', which would identify it to the rubble layers at the top of the shaft. The material with depth information is diverse and includes early modern pottery in the form of a small sherd of hand-painted Pearlware, a sherd of late Blackware and of Stoneware, alongside the ubiquitous postmedieval wares (e.g. Midlands Purple type ware, Blackware, Early Brown Glazed Coarseware). The identifiable vessel types include bowls, jars and jugs/cisterns with the handle of a small cup/tyg in Cistercian ware. One 
sherd, the base of a 17th- or 18th-century Unglazed Redware vessel, bears the code $\mathbf{H 2 3 / H 2 4}$. A cross-shaft join is represented by two sherds of a tripod vessel in 16th- to 17th-century Yellow ware from $\mathbf{H 2 3}$ (17ft) and H25 (6-7ft), located $c .3 \mathrm{~m}$ to the west. A range of other finds survive from $\mathbf{H} 23$ including bone-working waste in the form of a scale handle fragment from $4 \mathrm{ft} 6 \mathrm{in}$ and sawn bone from ' $9-10$ ' black', which must be the silting layer recorded on both the south and west section drawings (see also Chapter 6, Section: Domestic and personal items). Part of a desiccated squared wooden post survives from a context labelled as 'C10/-', the bowls of mid-17th-, 18th- and 19th-century clay pipes are labelled C6 and two conjoined fragments of plaster are from P2 which is recorded on the west section drawing at the top of the black silting layer but has been crossed out.

Three other foundation shafts (F20, F23, J23) dug at the southern end of the west moat provide only limited insights, but are worth briefly summarising (Figures 5.26, 5.29, 5.30). Foundation shaft F20 (east of F21) was dug to a depth of $c .9 \mathrm{ft}(2.74 \mathrm{~m})$; no heights AOD are recorded on the section drawings (Butcher 1958-62b). It encountered part of the moat cut in the east section, showing that it was stepped, although no details about the moat fill at this location are recorded (Ove Arup \& Partners and Butcher 1957; Butcher 1958-62b). The south section drawing shows that beneath a top modern layer is an 'old base' from an earlier building abutted by deposits of rubble and lime mortar probably associated with its construction. Beneath this are deposits associated with the moat, comprising a blue-black deposit which contains fragments of tile. The underlying deposit has no descriptor with the bedrock described as a plate of light grey sandstone. On the west section drawing, the top layer is labelled as modern and beneath this is a similar series of rubble and lime mortar deposits as shown on the south section drawing. Beneath this is a blue-black moat deposit annotated as containing flag (presumably flagstone), and Fe (iron; probably iron-staining). The lowest deposit recorded comprises yellowbrown clay. No finds from this foundation shaft survive in the archive. To the west of the better recorded F20 and F21 was F23, which seems to have been located near the outer edge of the moat (Butcher n.d. (t)); the north and east section drawings record a series of deposits sloping steeply from west to east, and south to north, respectively (Butcher 1958-62e). The upper three fills consist of yellow clay, black ash and rubble and probably relate to demolition and clearance of the site, while the lower comprise yellow-brown clay and blue clay, which may represent weather and silting of material from when the moat was open. In the east section, the deposits were largely the same, with minor changes in inclusions within the deposits. The southern edge of the east section drawing shows that the top of the moat was stepped. Foundation shaft F23 yielded just five sherds of 17th- or early 18th-century pottery, and pieces of sawn bone indicative of bone working. J23 was located $6 \mathrm{~m}$ to the north of $\mathbf{F 2 3}$, and while all four sections were drawn they contain limited deposit descriptors. At the top of the north section drawing it is noted that findspot P1 came from 'under Styring's wall' (Butcher 1958-62d) - this almost certainly refers to Lenton \& Rusby opticians, where, as we noted in Chapter 4, Charles P. Styring worked (see Figure 3.2 for the location). On the east side of the north section drawing is the edge of the moat cut through the natural, solid laminated, hard sandstone (see also Butcher n.d. (s), 30 for photographs). The other deposits recorded on this section drawing seem to derive from weathering or silting, and comprise fragments of platey light grey sandstone and yellow marley clay, with decayed blue bind, and similar deposits are recorded on the east section drawing. Slightly more detail is provided for the south section, with the upper $3 \mathrm{ft}(0.91 \mathrm{~m})$ consisting of alternating bands of brown, dark and yellow dark grey, which is similar to corresponding, but less well annotated, deposits on the west section drawing. Beneath this on the south section drawing is a dump of material probably associated with the demolition and clearance of the castle site, as it is described as dark grey, with sandstone including ashlar. Beneath this demolition material is a deposit suggestive of silting within the moat, comprising yellow-blue marley clay and decayed yellow-blue bind. J23 produced just two sherds of pottery, one of which, a sherd of Early Brown Glazed Coarseware, is identified as P1, revealing that it was recovered from the demolition layer at the top of the south section (where it is marked as 'handle 15-16'). The other sherd, the handle of a late medieval Coal Measures Purple ware jug or cistern, is recorded as coming from the 'South Extension'. No other finds from this foundation shaft can be identified in the archive.

\section{Waingate}

Construction of a retaining wall on Waingate, at the northernmost part of the Castle Market buildings, saw several foundation shafts recorded which provide further detail on the west moat (Butcher n.d. (w); 1958-62g; Figures 5.28, 5.31). The work is recorded in one of the largest surviving section drawings, providing a southnorth profile, the upper parts of which record deposits disturbed by a cellar, concrete pier and two manholes, 


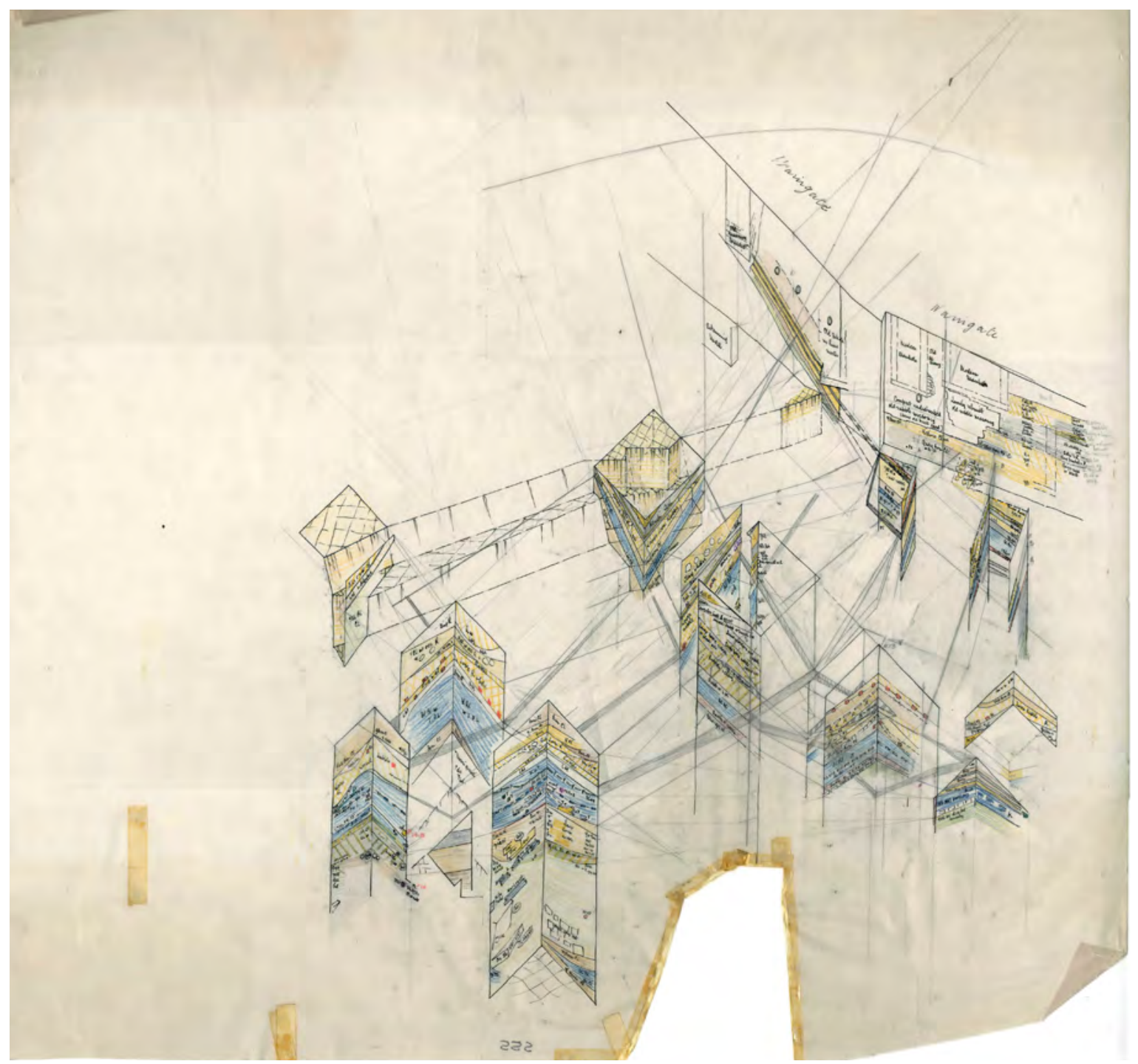

Figure 5.31: Isometric drawing of the foundation shafts dug at the corner of Exchange Street and Waingate. Drawn by Leslie Butcher. Courtesy of Museums Sheffield.

while the lower part records three foundation shafts (G24, G-H24, H24) (see also Butcher n.d. (s), 28, 33 for photographs). The only heights AOD given are for Waingate $(182 \mathrm{ft}(55.47 \mathrm{~m})$ and $180.6 \mathrm{ft}(55.05 \mathrm{~m})$ ), a recording line annotated 'Working Level JEB. section' at $168.5 \mathrm{ft}(51.36 \mathrm{~m})$, another, not annotated, at $167.5 \mathrm{ft}(51.05 \mathrm{~m})$, and the base of shaft $\mathbf{H 2 4}$ at $153 \mathrm{ft}$ (46.63m) AOD. The upper deposits on the south side of the section drawing consist of sections of modern brick work, sandstone slabs, masonry and pipes that cut through make up levels which overlay a sequence of deposits associated with the west moat. There are two manholes at the top centre of the section, and the upper deposits on the north side of the manholes (and running under Waingate) comprise dumps of clay, rubble, ash and coal, among which were recovered pantile and pottery; findspot $\mathrm{P} 1$ is notated in these layers. Above the foundation shafts G24, G-H24 and $\mathbf{H 2 4}$ at this location is a layer of yellow clay and (in G-H24 and H24) what are described as 'vestiges of rubble layer', and beneath this a brown-grey layer containing stone and rubble. On the south side of the manholes the deposits slope from south to north; some of them continued down through the foundation shafts to the north. These deposits comprise alternating 'dirt band' and yellow clay, overlying the moat cut, described as natural clay with decayed shaley sandstone, which represents weathering of the underlying geology, described as solid shaley sandstone. These deposits continue 
to the north in foundation shaft G-H24, at the top of which is findspot P2 (labelled as '17'), with layers of brown clay and blue-brown clay overlying deposits of shaley sandstone, suggestive of silting within the moat.

Foundation shaft G-H24 also has a sequence of deposits sloping steeply south-north. The upper layers again suggest silting and weathering of deposits within the moat, consisting of bands of material described as dark grey, rusty, dark ashy, yellow clay with '?natural' rubble, brown clay, very dark grey, dark grey and yellowblue clay. Artefacts were collected from the bottom two deposits, including leather, and findspots P3 and P5 are noted, and dated 17th century and 16th to 17th century, respectively. Just four sherds of pottery in the archive are labelled as deriving from G-H24, representing a maximum of three vessels. None of it predated the 17 th century. Only one sherd bears any indication of context, an elaborately decorated sherd of 18th-century Slipware noted as being 'Unstratified. However, there is some pottery in the archive listed as coming from G24 which clearly come from G-H24, because G24 is not deep enough to have been the source of it; the section drawing, indeed, records that G-H24 was 'originally "G24"' and the latter label seems to have been retained during bagging of pottery. This includes 17 sherds of pottery representing a maximum of 16 vessels. Only one sherd, the rim of a 17th-century Redware vessel, is identified by a depth measurement (15-19ft). The rest comprise Blackware, Redware, Early Brown Glazed Coarseware and a single sherd of Mottled ware, subsumed under finds numbers P1, P3 and P4, with only P3 marked on the section drawing. The whole assemblage is of 17 th- to early 18 th-century date with medieval and early post-medieval pottery notable by its absence, in contrast to the majority of the assemblages from the site. The only other surviving find from this deposit is a piece of possibly architectural terracotta, with a chamfered edge labelled P4.

H24 is the deepest foundation shaft excavated in this section, being $25 \mathrm{ft}(7.62 \mathrm{~m})$ deep at the base at $153 \mathrm{ft}$ $(46.63 \mathrm{~m}) \mathrm{AOD}$. The uppermost deposits within the shaft again slope steeply from south to north, and are suggestive of dumping or backfilling comprising layers of rubble, dark grey and yellow clay. Beneath these are four deposits similar to those in G-H24, indicating silting, weathering and perhaps dumping within the moat, and described as dark grey, black, pale blue and rusty rubble. Several finds are annotated on these deposits, including 'holl' (hollow?) bronze, and 17th-century clay pipe stem and pottery. The number 7 appears in the black layer. The lower deposits in the foundation shaft are also suggestive of silting and weathering of material into the moat, and annotated here are the numbers 8, 9 (which is said to be lost) and 10, labelled as 'collected J.E.B may contain some of № 9'. Below this is a deposit described as loose black and a deposit of granular decayed shale, in which the number 11 is noted with the comment 'final info on location not given', adjacent to which is the date 1450-1550. The final deposit in the sequence is described as blue-black, and there is an annotation that records 'a skip alleged to contain some Bl-Bl from this layer was tipped on "Old Dam" playing fields west of City Museum Xmas 1958.

H24 produced 59 sherds of pottery representing a maximum of 51 vessels. A considerable part of the assemblage was recorded as coming from the 15-19ft level (the same level as recorded in the case of G24), with a smaller quantity from the 7-8ft level. Two sherds, both examples of Early Brown Glazed Coarseware, are identified with findspots P1 and P3, respectively, although neither of these numbers are recorded on the section drawing. One sherd, a piece of Blackware, is labelled as coming from the ' $3{ }^{\text {rd }}$ Pit'. The remainder of the assemblage is unmarked. Cistercian ware is present in both main groups, as is Early Brown Glazed Coarseware, but the disparity in quantity makes useful comparison difficult and the overall picture is of a 17th- to early 18th-century assemblage with a small quantity of earlier, residual, wares. Midlands Purple ware and Unglazed Redware are both prominent in the 15-19ft level, while the 7-8ft level includes the rim of a bowl of Yellow ware. The range of vessel forms is unremarkable, with utilitarian wares (jugs/cisterns, bowls etc) commoner than the tablewares (cups or tygs) represented by the Cistercian wares.

\section{The east moat}

The principal insight into the east moat comes from manhole 3 in the Transport Canteen Yard (Butcher 1958$62 \mathrm{~d}$; Figure 5.26), located beneath ' $\mathrm{A}$ ' on the section drawing of the east side of the castle. The top of manhole 3 was $161 \mathrm{ft}(49.07 \mathrm{~m})$ AOD on the south section, and it was excavated to a depth of $142 \mathrm{ft}(43.28 \mathrm{~m})$ AOD. A series of boreholes at the northern end of the projected line of the east moat indicated that the base was at $144 \mathrm{ft}(43.89 \mathrm{~m})$ AOD (Butcher n.d. (r)), a level that corresponded with the base of the west arm of the moat F). A small plan alongside the section drawings of manhole 3 shows the moat cut running diagonally from northwest to south-east across the manhole, with a note that 'Dem [demolition] Deb [debris] overruns bl-bl [blue- 
black]'. Limited records were made of the west and north sections, as they were obscured by close timbered shuttering. The top of the north section is at $160.75 \mathrm{ft}(49 \mathrm{~m})$ and its lowest levels comprise a blue-black layer above the yellow natural, while the base of the west section comprises a deposit of yellow-brown clay with stone, a brown silt overlying a deposit described as blue-black with laminated grey sandstone. An annotation above the cut of the moat records 'pale blue 3"' at a depth of about $142 \mathrm{ft}(43.28 \mathrm{~m})$. On the south section drawing the top of the manhole is recorded as $161 \mathrm{ft}(49.07 \mathrm{~m})$, and the top layer is a stoney clayey fill with brick. Underlying this are three deposits labelled as black with coal and tobacco pipes, grey-brown clay with brick and a yellow clayey and stony layer with brick, and then demolition dumps comprising lime mortar, brown clay with water-worn boulders and sandstone fragments, purple reddish stain and lime mortar. A possible silting deposit underlies this, described as yellow-blue clay, and then the lower part of the pit comprises very large sandstone rubble 'up to 2 ' long' and water-worn boulders. The annotation ' $\mathrm{P}$ in lime mortar' refers to pottery. Above the cut of the moat and at the base of the rubble is yellow-brown clay, and lime mortar, and immediately overlying the cut is a blue-black silting deposit, which includes pottery, tile and bone. Within this deposit are lenses of dark brown and laminated grey sandstone. The top of the east section drawing records almost identical layers to the south section, and the lowest part of the fill comprises rubble, brick and lime mortar with pieces of ashlar 'up to 1' 6 x 1' $x 1^{\prime}$ '.

Manhole 3 produced a small pottery assemblage consisting of 25 sherds. Pottery assigned to the $8 \mathrm{ft}$ level comprised a group of post-medieval and early modern wares, including the base of a Cistercian ware cup or tyg and two sherds from 18th-century Slipware vessels. The $12 \mathrm{ft}$ level produced a larger assemblage of later post-medieval and early modern date, among which Blackwares were prominent, along with Early Brown Glazed Coarseware and Redware. Later types included Brown Salt Glazed Stoneware, Late Blackware and Mottled Coarseware. Identifiable vessel types were limited to a cup or tyg and a bowl or open jar rim in Blackware and a dish or bowl in Redware. A number of sherds bore the letter P but lacked any number; no $P$ numbers are marked on the section drawings. All of the sherds with marked depth information also bore the letters CY (Courtyard?). Butcher recorded the presence of leather within the deposits, and Box BS784 in the museum stores, accompanied by a loose label, handwritten in purple crayon on scrap paper, which reads 'M.H.3 (Tpt Canteen Yard) L1. In Black-w-timber C17/- assoc. bone (chopped) oyster shell, twigs + P.I.', contains predominantly 14 th- and 15 th-century leather shoe parts, with only one piece datable to the 17 th century. Other finds include oyster shell, animal bones, some of which are indicative of bone working, and nine pieces of 17th-century clay pipe. 


\title{
CHAPTER 6
}

\section{Pots, Pins and People}

\begin{abstract}
And paid to the wife of Henry Roworth for washing the linen and napery belonging to the stock of the Castle on divers occasions this year 14d... And paid to Henry Roworth, carpenter, for working within the Castle for 4 days and a half this year, in performance of carpentry work in the stable there ... receiving $5 d$. a day (Account Rolls of 1442-3, cited in Thomas 1920-24, 235)
\end{abstract}

This chapter presents the first detailed analysis of the artefacts recovered during construction work on the site of Sheffield Castle in the early and mid-20th century, incorporating new research undertaken for this book by Chris Cumberpatch (medieval and post-medieval pottery), Jane Young (shell-tempered pottery), Quita Mould (leather), and Lorraine Mepham (all other small finds). ${ }^{21}$ These objects are mainly curated in the stores of Museums Sheffield, although some are currently on display in the city's Weston Park Museum (the former City Museum) and the 16th-century Bishops' House in Meersbrook Park. Despite the undeniable challenges posed by the state of the physical archive, we have been able to generate important new information about activities on the site, especially craft working, while the pottery assemblage, in particular, enables us to place Sheffield Castle in the context of local and regional economic networks and cultural preferences.

We took the decision to incorporate the results of the specialist finds reports in the main body of the book, rather than relegating them to appendices as so often happens in archaeological publications (a tendency highlighted in Bayley and Watson 2009). We read this material culture alongside the documentary record, and focus on the labourers, craftworkers and servants who built, repaired, provisioned and maintained the castle. We have been told in recent scholarship of the importance of looking 'behind the castle gate' and of exploring the 'lived experience' of the ordinary people of castles (Johnson 2002, 161-75; Johnson 2017a; Dempsey 2019, 783), but such analyses have hitherto been conducted and presented in largely abstract terms, dominated by historical sources, limited to castles with extensive surviving architecture (e.g. Gilchrist 1999; Johnson 2017b), or with a focus on acts of resistance to elite power. ${ }^{22}$ Here we offer a new approach, grounded in the material remains of the most mundane activities, all of which, nevertheless, were implicated in the construction and maintenance of the household.

${ }^{21}$ Their archive reports and the associated data tables are deposited in the digital archive hosted by the Archaeology Data Service (https://doi.org/10.5284/1074899).

22 We should also note that the study of castles is male-dominated. As Oliver Creighton (2002, 6) pointed out, Ella Armitage (1841-1931, in honour of whom a building at the University of Sheffield was recently named), was a 'rare female castellologist'.

How to cite this book chapter:

Moreland, J. and Hadley, D. (with A. Tuck and M. Rajic). 2020. Sheffield Castle: archaeology, archives, regeneration, 1927-2018, pp. 185-214. York: White Rose University Press. DOI: https://doi.org/10.22599/SheffieldCastle.f. CC BY-NC 4.0, https://creativecommons.org/licenses/by-nc/4.0 


\section{Living with pots}

The circumstances in which Armstrong and Himsworth were working, and the documented disinterest among the construction workers in finds recovery (see Chapter 2, Section: Doing archaeology in Sheffield 1927-30), partly explain why the surviving pottery collection from 1927 to 1930 is much smaller than that deriving from Butcher's work and commensurately less informative. Only 79 sherds survive in the Armstrong assemblage, in contrast to 1812 sherds in Butcher's. At the time of our analysis, a further 21 sherds were on display in Weston Park Museum and 18 in Bishops' House, some of which had been subject to restoration. Site context information survives for $89 \%$ of the pottery in the Butcher assemblage, which is often quite detailed with respect to location and depth of recovery; in contrast, the only context we have for pottery in the Armstrong assemblage is the year it was recovered or that it was from the moat. There had been previous attempts to catalogue the pottery assemblage recovered by Butcher (see Chapter 4), but these do not conform to modern recording standards and were undertaken before the development of the current widely used fabric series. In our analysis the medieval and early post-medieval pottery was recorded using the regional medieval ceramics reference collection by Cumberpatch (2004) as a guide, while the later wares were reported on using similar principles. The shelltempered pottery was recorded using the fabric codenames of the City of Lincoln Archaeology Unit, which pioneered the analysis of such fabrics through the work of Jane Young and the late Alan Vince (Young et al. 2005).

It is important to recognise that pottery production, and hence the dating that emerges from pottery assemblages, does not map directly on to the chronological brackets used by studies of other types of evidence, in particular with respect to where the divide between 'medieval' and 'post-medieval' lies. In the following discussion, the term 'late medieval' refers to pottery dating to between the mid-11th and mid-15th century, while 'early post-medieval' pottery dates to between the mid-15th century and early 18 th century. The majority of the pottery in both the Butcher and Armstrong archives belongs to these periods, largely deriving from 17th-century deposits, and is the focus in this chapter; the much smaller assemblages of early modern and recent date are discussed in the digital archive (Table 6.1; see also Chapter 7 for the more extensive collections of this date from the 2018 excavations).

Table 6.1: Proportions of pottery according to broad date range in the Armstrong and Butcher archives.

\begin{tabular}{|l|c|}
\hline \multicolumn{1}{|c|}{ Period } & \% of total \\
\hline Medieval & 28.5 \\
\hline Post-medieval & 65.1 \\
\hline Early modern & 5.8 \\
\hline Recent & 0.45 \\
\hline Total & 99.85 \\
\hline
\end{tabular}

\section{The earliest pottery from Sheffield Castle}

As we have seen throughout this book, there has been speculation about Anglo-Saxon occupation on the site of Sheffield Castle since the 19th century. Armstrong $(1930,19,22-4)$ claimed to have identified traces of as many as two timber structures of that date and to have recovered from the moat Anglo-Saxon pottery, which he described as being ' $[t] h i n$, dark grey ware, polished surface, one fragment shows trace of spiral ornament. Portions of body of large vessel and base of a smaller one. Unfortunately, he provided no illustrations of this pottery and none matching this description survives in the archive, nor did it when Butcher (1972a, 8) checked c.50 years ago, and in any case it is likely, as discussed in Chapter 3, that Armstrong had been mistaken about the date of this pottery. There are, however, two sherds of different fabric that may be of late Anglo-Saxon date: a single sherd of Stamford-type ware in the Butcher assemblage (from foundation shaft E19), and a similar unstratified sherd, although its finish is atypical of Stamford ware and so is catalogued as Medieval Whiteware. The slightly sandy fabric of the identifiable sherd is similar to Stamford ware Fabric A, which dates to between the mid-10th and late 11th century (Kilmurry 1980, 130-3). However, it is not unequivocal evidence for late Saxon-period activity on the castle site, given the wide date range of the type and the fact that it was found fairly 
high up in the shaft deposits (marked as P11 on the north section of E19; Butcher 1958-62e; Figure 5.29). The lack of any clearly pre-Conquest pottery should not be a surprise given that pottery of the Anglo-Saxon period is extremely rare in South Yorkshire (Cumberpatch 2016; Cumberpatch and Young n.d., 3).

Shell-tempered wares comprise the majority of the earliest fabrics from the castle, with 69 sherds, representing no more than 15 vessels. Four unprovenanced sherds were found by Armstrong, but most were recovered by Butcher from the bottom of the south moat in foundation shaft $\mathrm{H} 2-4$ in front of the gatehouse; one of his section drawings notes the recovery of 'early Saxon-Norman [pottery] from $\mathrm{x}+\mathrm{y}$ buckets from ditch bottom' (Butcher 1958-62d). Two shell-tempered sherds come from handmade Lincolnshire Fine-shelled ware jars or bowls of 11th- to 12th-century date (Young et al. 2005, 81-8). These vessels would have been manufactured in central Lincolnshire, but the type was traded to much of the East Midlands and south, west and east Yorkshire, and 12 sherds were recovered in early excavations at Conisbrough Castle (Cumberpatch and Young n.d., 4, 6). A single sherd is from a medium-sized jar in Lincolnshire Early Medieval Shelly ware; in Lincoln, this fabric has been dated to between the mid-12th and first quarter of the 13th century (Young et al. 2005, 113; Cumberpatch and Young n.d., 6). As we will see in Chapter 7, these sherds may provide some indication of when this section of the moat was cut.

The remaining 66 sherds come from just 12 vessels of North Lincolnshire shell-tempered ware, mainly jars of varying size, and at least one large bowl. Most of the vessels have external soot deposits, suggesting their use for cooking over an open fire (similar deposits coated a number of the pots found at Conisbrough Castle; see Cumberpatch and Young n.d., 4, 6). This ware dates to as early as the late 12th century, but three of the vessels recovered are of 13th- to 14th-century types. The assemblage is the most westerly known occurrence of this ware, which was used throughout northern Lincolnshire and South Yorkshire, and, although no production site has yet been identified, the increasing numbers of finds in Yorkshire suggest that there may have been one (or more) in the region (Young 2018; Cumberpatch and Young n.d., 7). In sum, our analysis of the material available suggests that all of the shell-tempered wares post-date the mid-11th century, and that in the late 11th and 12th centuries the occupants of the site were sourcing their pottery either from Lincolnshire or South Yorkshire.

\section{The late medieval and early post-medieval pottery}

In the only published account of late medieval pottery from Sheffield Castle, Leslie Armstrong $(1930,24)$ summarised the assemblage that he had recovered as follows:

Twelfth to sixteenth century levels provided a large range of wares partially glazed externally with green, yellow and purple slips. The paste is extremely hard, almost metallic, and the whole are of continental origin, believed to be German. Chiefly cooking vessels, jugs and tygs and all incomplete. I saw in 1928 exactly similar fragments of several of these wares in south Sweden amongst material excavated from an early mediaeval site, and which Scandinavian archaeologists considered were imported from north Germany.

As we will see, this view of the late medieval pottery assemblage has been completely overturned by our new work. In this section, we characterise the pottery from the castle and consider what it reveals about pottery use by the site's inhabitants.

\section{COAL MEASURES WARES}

It is unsurprising that the late 13th- to early 16 th-century pottery is dominated by various types of Coal Measures wares, since pottery production in South Yorkshire largely involved exploitation of Coal Measures clays. Coal Measures wares have been identified elsewhere in Sheffield, showing that the town fell within the marketing zone for them, which extended to sites in West Yorkshire and north Derbyshire (Cumberpatch in prep. 1). Two potteries are known in the Don Valley in South Yorkshire: at Rawmarsh, on what is now the outskirts of Rotherham, and at Firsby Hall Farm, near Conisbrough (Hayfield and Buckland 1989; Cumberpatch 2004). Their products have been grouped in our study into two fabrics labelled Coal Measures Whiteware and Coal 
Measures Fineware (Hayfield and Buckland 1989, 10-11; Cumberpatch 2004), with the latter distinguished by their harder fabrics and generally finer texture, although the inclusions in both wares are broadly similar. Whether the two types represent the products of different potteries or changes in manufacturing practice over time (or a combination of both) is unclear, although both types seem to date to the 14th to early 15th century. Coal Measures Whiteware is particularly common in foundation shafts G22, G23 and H2-4, with smaller quantities from F22, H3, H23, H32 and H2, while Coal Measures Fineware is somewhat rarer, with sherds from E19, G22, G5 and H3 (Figure 5.1 for locations of these foundation shafts). The assemblage shows greater variation in the fabrics of these two wares than has been noted on other sites, and may represent the output of an unknown pottery or potteries in the region.

Chris Cumberpatch $(1997,146)$ has argued that up to the mid-15th century the production and use of pottery in medieval Yorkshire and Humberside was characterised by two ceramic traditions - gritty wares and sandy wares - which embody a series of oppositions and contrasts. Thus

green glazed, decorated and brightly coloured vessels [including jugs, pitchers, pipkins (a type of cooking pot), and dripping pans] usually in a sandy fabric, are associated with the more public aspects of cooking, with the serving of food and drink and with the roasting of meat, a higher status form of cooking than stewing or boiling ... Unglazed, undecorated and often discoloured vessels [including jars, cooking pots, bowls and pancheons], normally in gritty fabrics, appear associated with the more mundane boiling and stewing of food, with the preparation of food, notably dairy products, the brewing of ale and the storing of food.

He went on to argue that the glazed, coloured, sandy-textured vessels were associated with more public and prestigious activities, while the duller, unglazed, gritty wares operated within less public, lower-status spheres (Cumberpatch 1997, 146; also 2003, 6). These ceramic forms not only elucidate some of the essential structures of late medieval society; they were the means through which those structures were lived and reproduced. It is significant, therefore, that production of Coal Measures wares seems to have changed some time in the 15th century, with the use of thick purple glaze and higher firing temperatures resulting in harder, denser, dark grey (i.e. reduced) fabrics, which continued in use through the 16th, and perhaps into the 17th, century.

The Don Valley potters were fortunate that the local clay could withstand the temperatures required to produce vessels whose physical characteristics approached the increasingly popular stoneware (Cumberpatch 2003; 2002b, 175-6 for discussion of these wares at Pontefract Castle). This transition from Coal Measures Whiteware to Coal Measures Purple ware does not seem to have been primarily a matter of functionality but was probably linked to changing perceptions of pottery, manifest in the demise of the aforementioned medieval pottery tradition and the emergence of a rather different post-medieval tradition. While these Coal Measures Purple wares can be distinguished from medieval types by their fabrics and glaze colours, they simultaneously show considerable continuity with earlier practices with respect to the kind of vessels produced and the pattern of glazing (Cumberpatch 1996, 64; 2003, 8). The potters may have been consciously adapting their techniques to the requirements of their customers, while retaining elements of their traditional manufacturing practice (Cumberpatch 2003). We recorded 149 sherds of such pottery (including Coal Measures Purple-type wares), and a number of other sherds that were variations around the basic Coal Measures-type fabric (e.g. 10 sherds of Coal Measures Gritty ware). This may reveal that the castle was drawing pottery from other, as yet unidentified, potteries in the local area using such clays, which contain varying quantities and sizes of red grit (appearing as vesicular black grains when fired to a high temperature), quartz and in some cases white rock fragments, possibly mudstone. The paucity of local parallels reflects the lack of excavated medieval sites in Sheffield, but may also reveal that the castle was being supplied by a pottery or potteries making such variants on Coal Measures wares that had few other markets.

The Coal Measures Purple wares show some degree of heterogeneity but are less diverse than the earlier whitewares. The principal distinction identified in the castle assemblage is between the typical Coal Measures Purple wares known from Firsby Hall Farm and Rawmarsh (principally in foundation shafts G22, G23 and $\mathrm{H} 2-4$, with smaller quantities elsewhere in the western moat, and in front of the gatehouse) and a finer-textured variant recorded as Fine Coal Measures Purple ware (with minor variants indicated by the -type qualifier; the sub-type is particularly common in foundation shaft G23 with smaller quantities in E19, F21, F22, G5, G7 and H2-4; Figures 5.26, 5.28, 5.29, 5.30). 


\section{HALLGATE A, DONCASTER}

Among the other medieval wares are 19 sherds from Doncaster, all but one of Hallgate A fabric, conventionally dated to the 13th century (Buckland et al.1979), although it may have originated in the 12th century (Cumberpatch in prep. 2). Most are from the Butcher assemblage, with four sherds from foundation shafts G22, H13 and $\mathrm{H} 23$, but the majority are unstratified; an unprovenanced jug handle survives in the Armstrong assemblage. The scarcity of Doncaster wares from the castle is in striking contrast to the situation at Conisbrough Castle, where they dominated the earlier phases almost to the exclusion of other contemporary wares (Cumberpatch 2013; 2014a; 2016; Cumberpatch and Young n.d., 8-9).

\section{BRACKENFIELD WARES}

Seven sherds of pottery derive from the Brackenfield kilns near Chesterfield (Derbs). The 1972 excavations of these kilns remain unpublished, and much of the site archive has been lost (Cumberpatch 2004), so the industry cannot be dated any more precisely than to the 13th to 15th centuries (Cumberpatch and Thorpe 2002). Our analysis of the castle assemblage has identified the first such fabrics in Sheffield, but their recovery should not be surprising since Brackenfield wares have been found in some quantity at Peveril Castle (Derbs), just over $30 \mathrm{~km}$ to the north-west of Chesterfield, revealing that vessels from the Brackenfield kilns were transported over considerable distances and rough country. Six sherds of Brackenfield ware survive in the Butcher assemblage (F9, F22, G22, H2-4), all but one of them body sherds, the exception being a rod handle from a jug (F9). In the Armstrong assemblage, but lacking any context beyond the date of recovery (1927), is the handle of a pipkin, a vessel type common in the Brackenfield kiln assemblage (Cumberpatch 2004, figs 42, 43, 46, 48, table 22).

\section{HUMBERWARE}

From the late 13th to mid-/late 15th century, Humberware was a highly significant regional type, produced at multiple sites around the Humber, of which the kilns at Holme-on-Spalding-Moor and West Cowick (both in East Yorks) are the best known (Mayes and Hayfield 1980; Hayfield 1988). Humberware is found in very large quantities across Yorkshire and neighbouring counties (Watkins 1987; Hayfield 1992; Cumberpatch 2002b, 181) but only three sherds feature in the Sheffield Castle assemblage: two base sherds in the Butcher assemblage (foundation shafts E18 and H2-4) and an unprovenanced neck and handle from a jug, or cistern, in the Armstrong assemblage (it was similarly scarce at Conisbrough Castle; Cumberpatch and Young n.d., 11-12). Humberware continued to be manufactured into the 16th century, and three sherds of the later variants (Late Humberware (H2-4), Green Glazed Sandy ware (no context) and a reduced version of the latter (labelled NE-NW 4-4', 6")) are also present in the assemblage.

\section{SHEFFIELD WARE}

The late medieval assemblage also includes sherds of pottery made in Sheffield, by an industry that exploited a clay source similar to that used for the Coal Measure wares (Cumberpatch 2011; Vince 2011). In this context it is notable that, in the preamble to his 1637 survey, John Harrison tells us that within 'the Mannor of Sheffield' there is 'very good clay for pots \& bricks' (Ronksley 1908, 3). Excavations by ARCUS in 2006 at Norfolk Row, around $400 \mathrm{~m}$ south-west of the castle, recovered an assemblage of medieval kiln wasters and fragments of kiln structure, suggesting that a medieval pottery kiln was located nearby (Baker et al. 2011, 3.2.1; Baker and Baker 2008). Although it could be dated no more closely than to the 13th to 15th century, this was the first excavated evidence for industry within the medieval core of Sheffield. The sherds found at the castle are the largest known collection of wares from this kiln. In the publication of the Norfolk Row excavations the fabric was given a variety of names describing its appearance, including Oxidised Sandy ware, Oxidised Gritty ware, Glazed Red Earthenware and Northern Gritty ware (Baker et al. 2011; Vince 2011), but here we refer to it as Sheffield ware, describing near-identical fabrics as Sheffield-type wares (Figure 6.1). In total there are 51 sherds of these two wares in the castle assemblage: four in the Armstrong assemblage (three body sherds and a base), all recovered from the moat, while the material in the Butcher assemblage is from foundation shafts $\mathrm{H} 2-4, \mathrm{G} 5, \mathrm{G} 7, \mathrm{G} 22, \mathrm{G} 23$, 


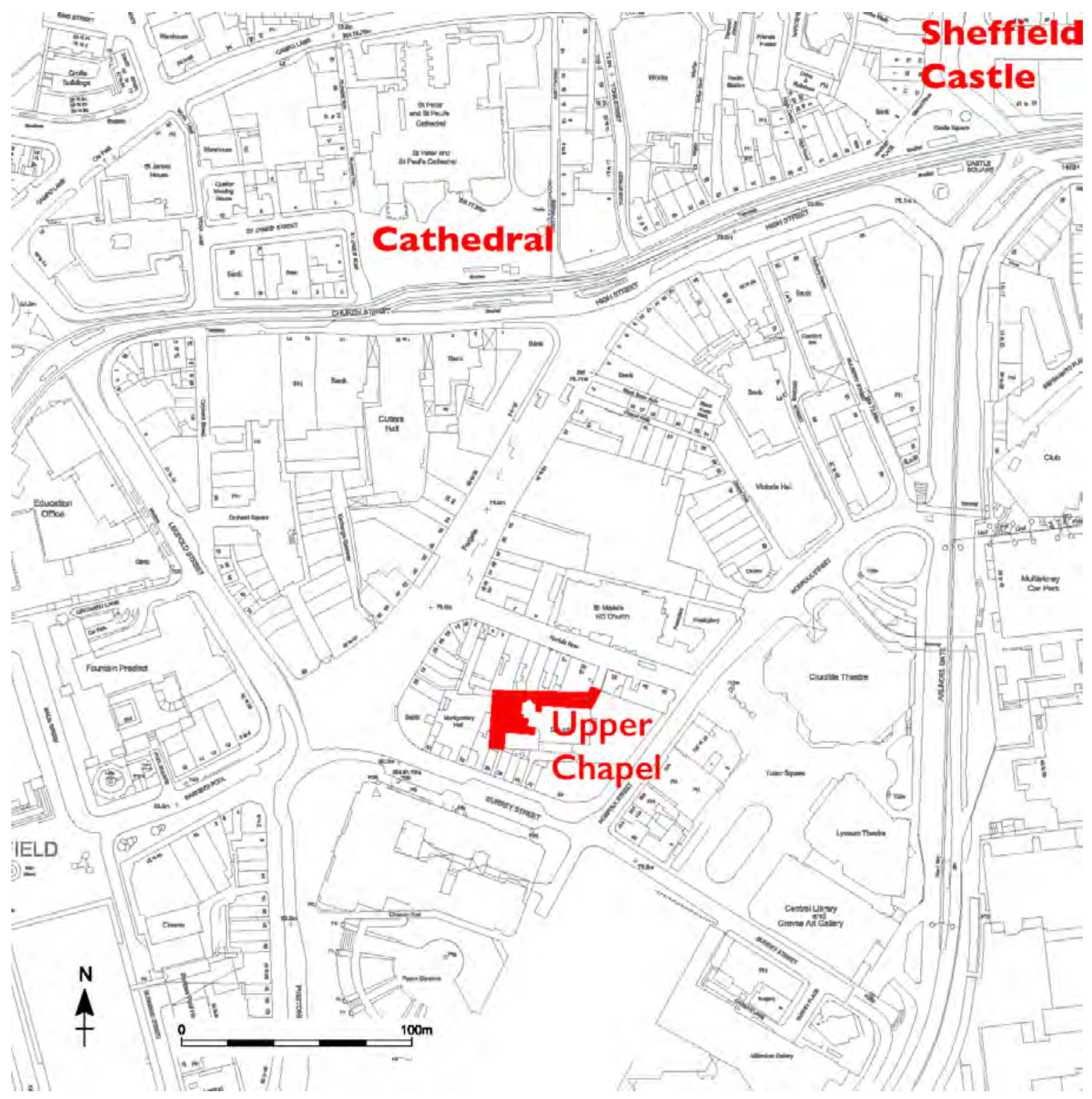

Figure 6.1: Location map of the production site of Sheffield ware pottery at the Upper Chapel south-west of the castle. University of Sheffield.

F9, F22 and E19; Figures 5.26, 5.28, 5.29). They include rims and both rod and strap handles, probably from jugs and a body sherd which may have come from a bowl or a small pancheon (a wide shallow bowl). Decoration is largely limited to glaze (green to brown, often mottled), with just one sherd bearing decoration in the form of parallel incised grooves on the external surface.

\section{SURREY WHITEWARE}

The Armstrong assemblage includes one small sherd identified as either Surrey Whiteware (formerly known as Tudor Green ware) or Border ware. Dated in London to between the mid-13th and later 15th centuries (Pearce and Vince 1988), Surrey Whitewares may continue into the early 16th century, while Border ware dates to the 16th and 17th centuries. Although generally rare in northern England, Border wares were identified in 
castle assemblages at Pontefract (Cumberpatch 2002b, 186), Conisbrough (Cumberpatch 2013; Cumberpatch and Young n.d., 12-13) and Sandal (Moorhouse 1983a, 93).

\section{OTHER MEDIEVAL WARES}

There are a variety of other late medieval fabrics among the assemblage which cannot be identified to specific known types and have, thus, been assigned generic names based on the characteristics of individual sherds or groups of sherds. The relatively large proportion of such unidentified wares is unsurprising given how few medieval and early post-medieval sites have been excavated in Sheffield; there are consequently few pottery assemblages of this date from which more information might be derived. These include 55 sherds of various types of sandy wares. Six sherds in a buff, sandy-textured fabric (Buff Sandy ware) are in the Butcher assemblage (foundation shafts G23, H2-4, and four joining sherds from H3). Buff-firing sandy and gritty wares are a feature of the wider regional medieval tradition which extends from the northern part of South Yorkshire, across West and North Yorkshire and into the North East (Cumberpatch 2002b, 176-7; Cumberpatch and Young n.d., 11 for finds from Conisbrough Castle). Subsumed under the name Reduced Sandy ware is a diverse group of wares from the Butcher foundation shafts D22-23, E19, F21, G23, H2, H2-4, and 5HY, and from the moat and a context labelled ' 1927 ' in the Armstrong assemblage. Three sherds from the Butcher assemblage are described as Fine Reduced Sandy ware; one from G23 is heavily overfired (or perhaps secondarily burnt) but the two from H2-4 bear a resemblance to Scarborough II ware (East Yorks), dated to the late 12th or 13 th century.

Two sherds from the Butcher assemblage (G22 and H3) bear thin white slip coatings on pale orange bodies, a practice that has been identified regionally among Tees Valley B/C ware from north-east England, between the late 12th and early 14th centuries (Didsbury 2010) and in newly discovered late 11th- and 12th-century kilns in Pontefract (Roberts et al.2013). Some potters were attempting to provide buff or white vessels, presumably in response to consumer demand, or possibly influenced by French potters, as even where the clay was iron-rich and tended towards an orange colour the slip coatings have no clear practical or functional value.

The remaining sandy wares include four sherds from the Butcher assemblage (G22, G23, H2-4, H3), classified as Local Oxidised Sandy ware. The combination of quartz and red grit, in some cases with fine white streaks, suggests the use of a Coal Measures clay but the origin of the pottery remains obscure and the later 12th- to 14th-century date range is merely indicative. One sherd from the moat in the Armstrong assemblage is classified as Oxidised Sandy ware, and may also be of local origin. Six sherds classified as Late Oxidised Sandy wares (G23) date to between the late 14th and 17th centuries. With the exception of a strap handle, all the fragments are body sherds. Four sherds from the Armstrong assemblage, all from the moat, are classified as Late Medieval Sandy ware; these comprise two body sherds and two bases, one reused as a pot disc, a common find from many periods, and considered to be gaming pieces or counters (Cumberpatch 2010, 25). Finally, there are three unstratified sherds, classified as Late Medieval Gritty ware, comprising two sherds of lid-seated rims from jars, while the third is a base in a very unusual hard, lumpy fabric containing abundant quartz and voids.

\section{CISTERCIAN WARE, BLACKWARE AND YELLOW WARES}

The assemblage includes 84 sherds of Cistercian ware, which is notable for being closely associated with the transformation of the pottery industry in the mid-15th century and the end of the medieval pottery tradition discussed above (Cumberpatch 2003, 8). Despite the name, the type has no specific association with the Cistercian Order, other than having been recovered from post-Dissolution contexts on a number of religious sites (Cumberpatch 2003; Boyle 2006). Six sherds are listed as Cistercian ware type as they are fabrics which do not conform to the typical characteristics, although some may have been slightly underfired Cistercian ware. Cistercian wares were particularly common in foundation shafts G22 and G23. Vessel forms include bottles or costrels, but the majority of sherds are from small cups or tygs. Applied pipeclay decoration was noted on sherds from contexts G22 and G23 and on one of the three sherds from the Armstrong assemblage. This latter sherd bears a tripartite acanthus leaf motif, one of the symbols which, Janet Spavold (2009, 37-8, fig. 7) argues, had specifically Catholic associations (see also below, Section: Domestic and personal items). 
Cistercian ware remained in use until c.1600 before being replaced by Blackware; the distinction between the two is largely typological, with Blackware vessels generally being larger and produced in a variety of different forms (Moorhouse and Slowikowski 1992). The similarity in their fabric and finish renders it difficult to distinguish the Cistercian ware from Blackware when small body sherds are involved (as was also the case at Pontefract; Cumberpatch 2002b, 186), and, for this reason, 12 sherds from Sheffield Castle are classified as Cistercian/Blackware. Blackwares are one of the commonest types of pottery in the Butcher assemblage, with 126 sherds; there are 11 sherds in the Armstrong assemblage, and a complete reconstructed Blackware jug in the Bishops' House collection. As with the Cistercian wares, a number of sherds fall into an ambiguous 'Blackware-type' category ( 31 sherds from the Butcher assemblage, with two further sherds in the Armstrong assemblage). Although the majority of sherds are unidentifiable to specific vessel types, those that are diagnostic included large cups (tygs), handled bowls and small jugs or jars (Figures 6.2, 6.3). The category of Coarse Blackwares (98 sherds) covers larger vessels, generally with thicker walls such as cisterns, jars, large jugs and larger handled bowls. Inevitably there is some overlap with the Blackwares and for many purposes the two sub-groups can be considered part of the same class, although some of the larger vessels may have been contemporary with late Cistercian wares.

Both Cistercian wares and Blackwares were manufactured widely across the Midlands and northern England, often in villages which in some sense specialised in pottery production, such as Wrenthorpe (West Yorks) and Ticknall (South Derbs) (Moorhouse and Roberts 1992; Spavold and Brown 2005). Yellow wares (33 sherds) were produced alongside both Cistercian ware and Blackware, although in smaller quantities, and are characterised by their fine white fabrics and bright yellow glaze, sometimes applied over a thin layer of white slip (Moorhouse and Slowikowski 1992). They appear in foundation shafts E13, E19, F22, G23, G7, H2-4, H24, $\mathrm{H} 5$ and unstratified in the Butcher assemblage (Figures 5.26, 5.28, 5.29). Forms include a tripod vessel, cups or mugs, dishes, bowls and small pancheons, and one unstratified sherd appears to be part of a tubular leg (Cumberpatch 2003, 9).

\section{OTHER EARLY POST-MEDIEVAL WARES}

A substantial proportion of the assemblage comprises a range of purple and brown glazed utilitarian wares, dating to the 16th and 17th centuries. These have not previously been the subject of detailed typological study of either their form or fabric and there is little comparative reference material. Therefore, as part of our study an attempt was made to devise a scheme that contributes towards a more comprehensive account of the pottery industry, its markets and aspects of its consumption, during a period of fundamental social and economic change. These fabrics include Midlands Purple ware (of which few vessel forms could be identified; 44 sherds) and Midlands Purple-type ware (the range of vessel forms includes cisterns, jugs, jars and a pipkin; 133 sherds), a variety of early post-medieval wares characterised by the use of purple glaze, usually on hard, dense red-to-purple bodies which are often, but not always, semi-vitrified in character. The second major category of post-medieval utilitarian wares, Early Brown Glazed Coarseware, is distinguished by its orangeto-red sandy-textured fabric usually containing quartz and black non-crystalline grit, sometimes with fine white rock fragments ( 408 sherds). Unlike the hard purple glaze of the types described above, its glaze tends to be flaky and brittle. The glazing pattern resembles that of Humberware, particularly on and around the handles of jugs, cisterns and handled jars, but it is unclear whether this reflects continuity in practice. Both the Midlands Purple ware and Early Brown Glazed Coarseware should be regarded as a fabric group rather than a fabric type and may have been the product of more than one pottery operating in the region (Cumberpatch 2002b, 189-90).

The assemblage also contains a few sherds of other types of early post-medieval wares including 10 sherds of Early Brown Glazed Fineware and 18 sherds of post-medieval Sandy ware. There are also small amounts of Brown Glazed Coarseware, Brown Glazed Fineware, and Mottled Coarseware. Seventeenth-century Redware and Fine Redware are common across the site, and there are also two sherds of Low Countries Redware. The latter was imported in significant quantities but is a relatively rare find on inland sites, with only a small quantity similarly identified at Pontefract Castle (Cumberpatch 2002b, 194), most vessels being consumed in ports such as Newcastle (Vaughan 2007), Hull (Watkins 1987), Bawtry (Cumberpatch 1996) and Doncaster (Cumberpatch 2007). Unglazed Redware, Yellow ware and Tin Glazed wares are also probably of this date, as are 11 sherds of various imported stonewares. 


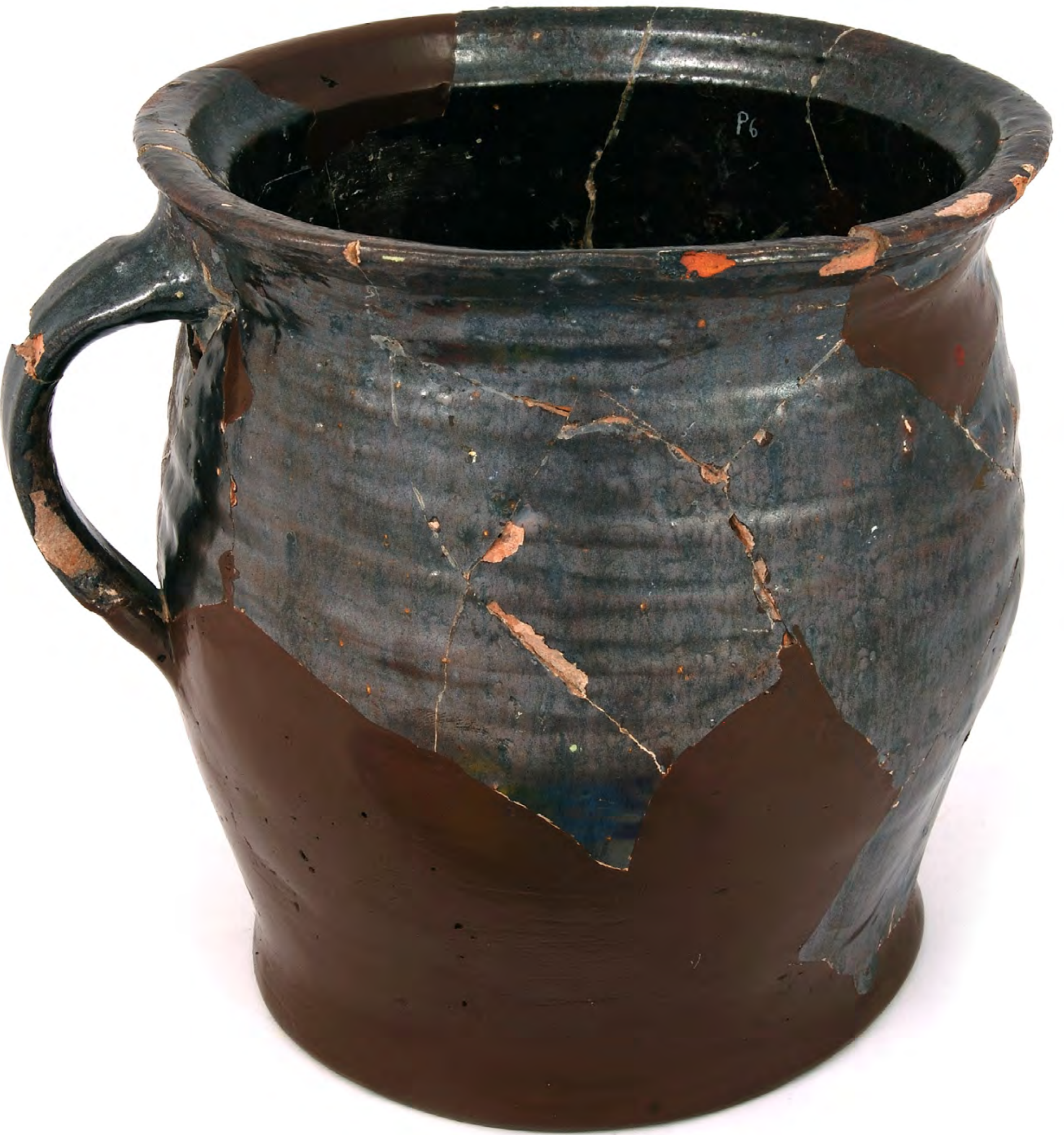

Figure 6.2: Blackware jar. Reconstructed from sherds recovered by Leslie Butcher, and now on display in Bishops' House in Meersbrook Park, Sheffield. Courtesy of Museums Sheffield; accession no. 1995.90.2.5. 


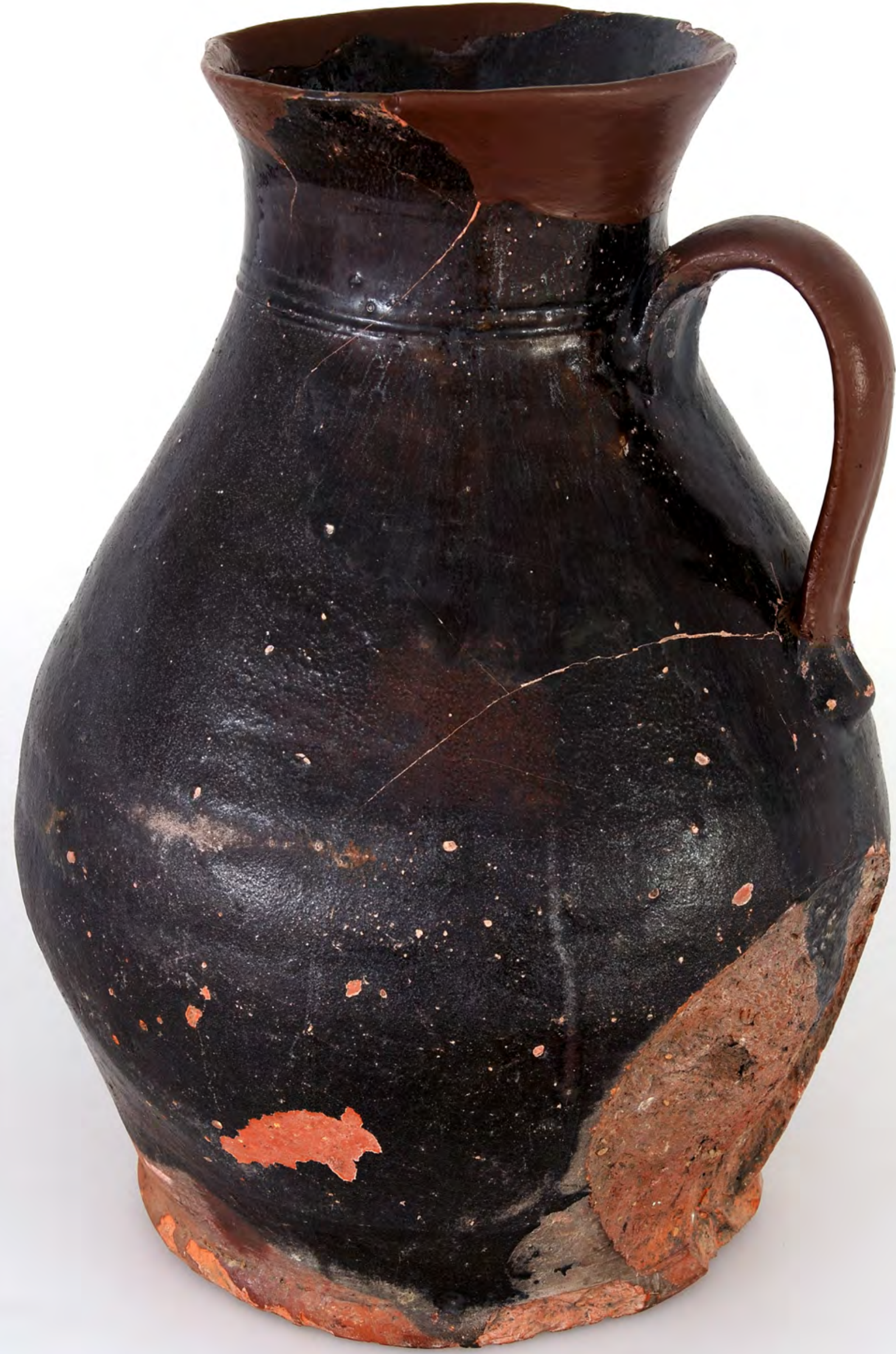

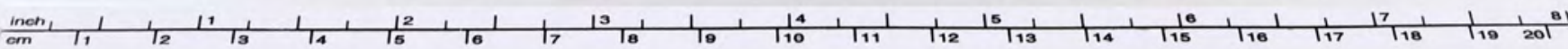


To a large extent, these purple and brown glazed wares define the early post-medieval ceramic tradition that replaced the aforementioned medieval one from the late 15th century. Detailed study of a series of assemblages from across Yorkshire and Humberside has allowed Chris Cumberpatch to elucidate the part this tradition played in structuring daily life. Broadly speaking, he argues, it seems that there was 'an association between black and brown vessels and the storage, serving and consumption of liquids', while the 'preparation and serving of food appears to be linked with lighter coloured wares (Redware, Yellow ware and Slipware)' (Cumberpatch $2002 \mathrm{~b}, 222 ; 2003)$. Although, as we have noted, there was considerable continuity in vessel form between the medieval and early post-medieval traditions, some new types did appear (including single- and multi-handled cups, mugs and beakers, and some vessels associated with food preparation). This suggests that changes in cuisine and consumption accompanied the shift in perceptions of the proper relationship between the colour and texture of pottery and the symbolic qualities of food and drink. This arguably marks not just a 'ceramic revolution' but a transformation of attitudes and everyday social practices (Cumberpatch 1997; 2002b, 222; 2003, 6-7; Gaimster and Nenk 1997).

\section{Supplying the castle with pottery}

When considering the supply of pottery to the castle in the late medieval and early post-medieval periods, the assemblage can be divided into three broad groups. The first consists of wares of local or regional origin, such as the Doncaster Hallgate A, shell-tempered, Sheffield and Brackenfield wares, as well as much of the Coal Measures wares. This suggests that the inhabitants of the castle drew on a number of well-established regional potteries for their everyday requirements, and reveals the supply networks relied upon by those who provisioned the castle. The relative lack of Humberware, in comparison with large quantities of contemporary Coal Measures Whiteware, suggests that Sheffield lay outside its circulation zone. This scarcity of Humberware is in marked contrast to its abundance at Pontefract Castle, where a close connection between the inhabitants of the castle and the potters is documented (Cumberpatch 2002b, 181-2, 218-19). While we have no evidence for the means by which the inhabitants of Sheffield Castle acquired pottery, it is likely that, as Cumberpatch (2002b, 218) has suggested for Pontefract Castle, they either procured much directly from potters (some of whom may have been situated on the castle's estates) or through the local market, particularly that situated just to the west of the castle (see Hey 1991, 40; also Moorhouse 1983a, 126-7 for potters on the estates of Sandal Castle). Perhaps this is where, in 1642 , someone from the castle spent $£ 112 s$. $0 d$. on 'a dozen earthen potts to bake venison in, to send to London ... for my Lo. Arundall' (Hunter 1819, 103).

The second group of wares forms a major element of the castle assemblage, but is more difficult to analyse because it consists of hitherto unknown or poorly documented types, such as Early Brown Glazed Coarsewares, various Midlands Purple and Purple Glazed wares, Redware and Unglazed Red Earthenwares. The Midlands Purple-type wares show some similarities with the utilitarian wares produced at Ticknall but the nature of the fabrics (very dense and in some cases semi-vitrified) means that conventional macroscopic fabric characterisation is not a particularly reliable guide to origin. The fabric of the Early Brown Glazed Coarsewares suggests that they may have been made of Coal Measures clays and their absence from sites outside Sheffield indicates a very local origin, perhaps even within Sheffield itself.

The third category, exotic material, including European pottery and wares from other parts of Britain, seems to have reached Sheffield Castle in only small quantities, perhaps connected with the movement of its peripatetic elite household and of estate officials travelling on business (Moorhouse 1978; 1983b; Cumberpatch 2002b, 170, 217). This is similar to the situation at Pontefract, although the range of wares there is broader. This may be another result of the rather different areas investigated and the nature of the investigations undertaken on the two sites. A scarcity of European wares is not uncommon on inland sites. Indeed, even given the small quantities involved, the presence of several sherds of Low Countries Redware (rarely encountered on sites in South Yorkshire other than the two principal inland ports of Bawtry, on the River Idle, and Doncaster, on the River Don; but see Cumberpatch and Young (n.d., 13) for finds at

Figure 6.3 (page 194): Blackware jug. Reconstructed from sherds recovered by Leslie Butcher. Courtesy of Museums Sheffield; accession no. 1995.90.2.4. 
Conisbrough Castle) might imply a situation outside the norm. Among European pottery, German stoneware is not uncommon on inland sites across South Yorkshire, and in this respect the castle assemblage is not unusual. The wares represented include Frechen-Köln, Raeren and unidentified types, which are common in Hull and occur in smaller quantities in Doncaster and Bawtry and on other inland sites, such as Conisbrough (Watkins 1987; Cumberpatch and Young n.d., 13). The vessel forms, bottles and mugs, are also typical of regional imports. Other possible imports include a sherd of a Martincamp-type stoneware flask, possibly from northern France, although recent work has identified production of identical fabrics at kilns in Ticknall, and it is thought that they may also have been made at other potteries in the Midlands (Brown and Spavold 2019). A single Tin Glazed Earthenware sherd could be of Dutch origin, but may equally have been produced in Britain, as early as the mid-16th century or as late as the mid-19th century. Tin Glazed Earthenware is regularly found, albeit in small quantities, on sites with early modern pottery across Sheffield, but is scarce at the castle, reflecting the overwhelmingly utilitarian nature of its pottery assemblage (see Chapter 8 for the Tin Glazed wares at the hunting lodge).

Chris Cumberpatch has noted that the pattern of pottery procurement at Conisbrough Castle contrasts markedly with that for other Yorkshire castles. Although there were a small number of regional and European imports, the largely homogenous assemblage was heavily dominated by locally manufactured wares, suggesting 'a well-organised and regular system of pottery procurement with local potters supplying a standard rage of wares to the occupants' (in Cumberpatch and Young n.d., 49-50). The assemblage from Pontefract Castle, by contrast, was more diverse, with its pottery supplied from across the region including Doncaster and East Yorkshire (Cumberpatch and Young n.d., 50). The assemblage from Sandal Castle is equally diverse, with local products supplemented by those procured from sources in Doncaster (Hallgate wares), East Yorkshire, and further afield in Norfolk, West Sussex and Oxfordshire (Moorhouse 1983a, 118-30). The evidence suggests that the pattern of procurement for Sheffield Castle was closer to this Yorkshire 'norm' than to the homogeneity of Conisbrough.

The paucity of comparable late medieval pottery assemblages from elsewhere in Sheffield makes it difficult to determine how far the material from the castle is typical of the town as a whole. Comparison with Pontefract suggests that, while the castle was a major consumer of pottery, there was no significant difference in the types of pottery reaching the town and the castle, although it is probable that large consignments of pots reached the castle direct from the manufacturers rather than via local markets. The assemblages from Pontefract and Conisbrough Castles were recovered from a variety of contexts rather than, as is the case with Sheffield Castle, mostly from the moat. This largely accounts for the much smaller quantities of medieval pottery from Sheffield Castle in comparison to Pontefract. Nevertheless, our analysis overturns Armstrong's (1930,24) argument that much of the castle's medieval pottery was 'of continental origin', with 'the first fragments of possibly English manufacture' appearing only from the late 16th century.

\section{Working with leather - cobblers, saddlers and harness-makers}

Of the 200 pieces of leather surviving in the archive, the majority (75\%) are shoe parts, along with a small number of other items and waste leather (Figures 6.4, 6.5; Mould 2017a). The leather is now brittle, often puckered and distorted through shrinkage, and some folded items cannot be opened out or flattened. Some of it had clearly been conserved in the past, but no records of this process survive, while other parts of the assemblage had been air-dried. A shiny surface on some of the artefacts obscures the grain pattern and stitching details, and some surfaces are heavily worn, but, where the grain is visible, animal species are identifiable by hair follicle pattern using low-powered magnification. The grain patterns of sheep and goat skins are difficult to distinguish and so are grouped together when the distinction cannot be made, while the term bovine is used when uncertainty arose between mature cattle hide and calfskin. Shoe bottom components and repairs are of cattle hide unless stated otherwise. Nearly $70 \%$ of the leather records generated (101 out of 145 ) have no stratigraphic information directly associated with them, making it difficult to contextualise most of the pieces. This collection is, nonetheless, extremely important as the more recent excavations by ARCUS (Davies 2000; Davies and Symonds 2002) did not recover any leather, and those by Wessex Archaeology recovered leather only from post-medieval contexts (see Chapter 7). 


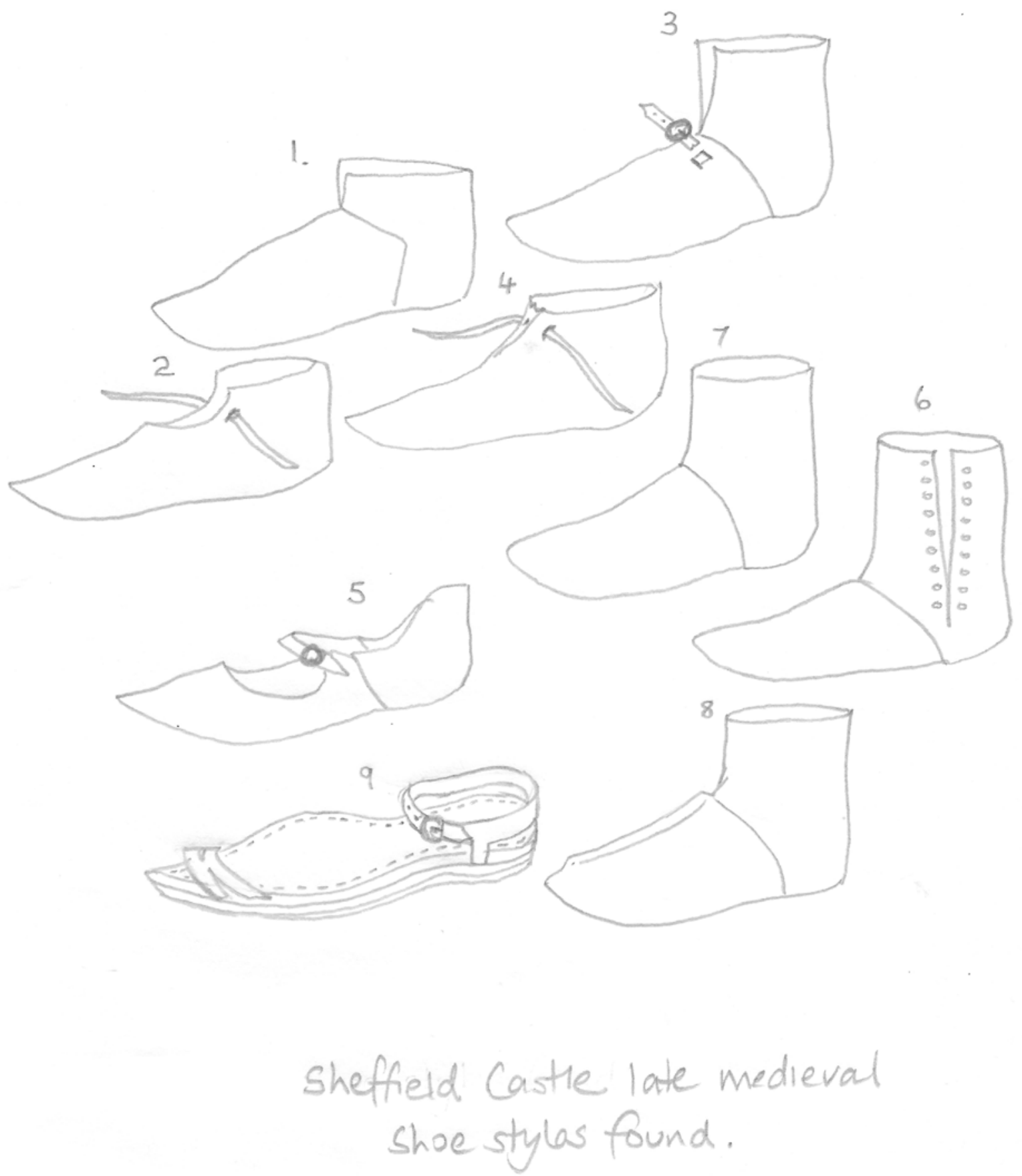

Figure 6.4: Late medieval shoe styles represented by leather fragments found in the moat at Sheffield Castle. Drawn by Quita Mould.

\section{Medieval shoes}

Nearly $65 \%$ of the medieval shoe parts are from types of 15th-century randed turnshoe construction; a 'rand' is a strip of leather sown between the upper and sole of a shoe, while turnshoe forms are made inside out on the last and then turned so that the seams are on the inside (Goubitz et al. 2001, 321, 324). At least 30 turnshoe soles are more or less complete, with additional broken soles suggesting more than 40 in total. 

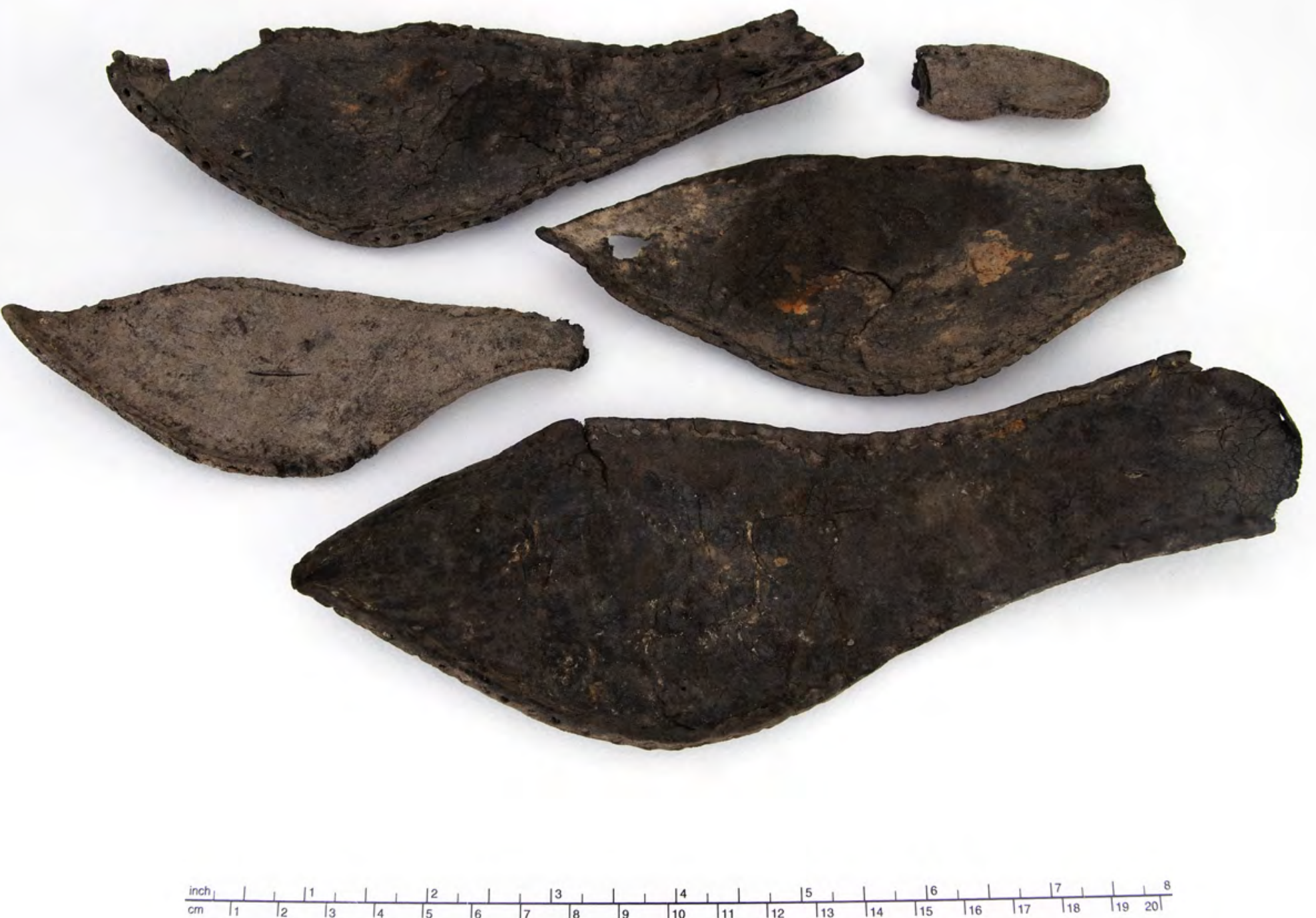

Figure 6.5: Shoe fragments recovered during mid-20th-century excavations at Sheffield Castle. Courtesy of Museums Sheffield; accession no. 1995.90.17.

The soles have narrow waists (the middle part of the shoe corresponding with the instep and the arch of the foot; Goubitz et al. 2001, 324), with $30 \%$ of the 36 soles with complete waists being less than $26 \mathrm{~mm}$ wide, among which the narrowest measures just 16-20mm (nos 108, 141, 135, 137, 51, 146). Seven soles have long toes extending beyond the foot for $20-40 \mathrm{~mm}$. Long, pointed toes, often filled with hair or moss to support the points, were fashionable during the 1460s, a product, Roberta Gilchrist $(2009,249)$ argues, of the belief that penis size was linked to the length of the feet. A sumptuary law passed in 1463-64 in the reign of Edward IV restricted the wearing of the so-called 'pike or poulaine' to two inches $(50.8 \mathrm{~mm})$, as it had been in a previous sumptuary law of 1368 (Swann 1975, 19-20; Goubitz et al. 2001, 321); none of the toes from Sheffield Castle exceed this limit. The pointed toes and distinctly narrow and long waists confirm a late 14 th- to 15 th-century date.

Several shoe styles can be recognised from the surviving parts. These include high shoes - what we would term ankle boots today - with uppers made principally from a single piece of leather that wrapped around the foot, joined with a single seam. Elements from such shoes include a dog-leg side seam (no. 140), upper fragments (nos 23, 83) and an upper insert piece (no. 41), all of bovine leathers, some being calfskin. The front areas of broken uppers with no seams surviving may well come from other such high shoes. Some of these upper fragments and vamps (the front section of the upper, covering the fore part of the foot up to the instep; Goubitz et al. 2001, 324 ) with front openings have stitching for a separate tongue (nos 15, 95), and a tongue of calfskin with a large fastening hole was one of the components of shoe no. 83 (Figure 6.4 (no. 2)). These come from high-throated, front-fastening shoes that either laced, or fastened with a tied toggle or a small metal buckle and strap, across the instep. A well-preserved calfskin vamp (no. 141) certainly fastened at the instep 
with a small metal buckle and strap (Figure 6.4 (no.3)), as the angular tab of the split strap to secure the buckle, and a loop strap keeper, survive, and the latter is characteristic of high, closed shoes with buckle fastening of 15 th-century date.

There are two fragments from lower throated front-lacing shoes (nos 27 and 84; Figure 6.4 (nos 4, 5)), known as 'open shoes' (Goubitz et al. 2001, 31). Side-lacing shoes are also represented (e.g. nos 21, 24 and 29). One (no. 54) fragment of sheep/goatskin is from footwear of uncertain height, having only two lace holes surviving, while another fragment (no. 82), of calfskin, comes from a boot at least $160 \mathrm{~mm}$ high of which nine small lace holes survive (Figure 6.4 (no. 6)). It is consistent with early 15th-century forms popular in the City of London (Grew and de Neergaard 1988, 43, figs 69 and 70). Another calfskin boot (no. 20) has a different form of construction, comprising a vamp and a separate piece that wrapped around the leg, and was seamed to the vamp throat and at centre back (Figure 6.4 (no. 7)). Two vamps (nos 19, 142), of bovine leather, from a boot or shoe, are distinctive in having a raised rib running vertically from the throat down toward the toe, stitched on the interior (flesh side) to maintain its shape. This decorative feature occurs occasionally on 15th-century boots and shoes throughout England, apparently rather popular in Coventry (Warks) (Mould 2017b, 65, 78 and 80, no. 24, fig. 5:16).

There is a single layer (no. 52) from a sandal or patten (footwear with a sole and a foot strap, intended to be worn as overshoes; Goubitz et al. 2001, 249, 321) for the left foot and a piece from its ankle strap (no. 53), of cattle hide. The seat (the back part of the insole on which the heel sits) has been cut from the sole layer so that its original, equivalent shoe size is unknown. Sandals with soles made with multiple layers of leather became popular in the City of London at the beginning of the 15th century (Figure 6.4 (no. 9); Grew and de Neergaard 1988, 101), and this example from Sheffield Castle, with its long, pointed toe extending some $35 \mathrm{~mm}$ beyond the foot, is of a highly fashionable style. However, while such an exhibition of prestige and fashionable footwear might be deemed suited to a layman, Goubitz et al. (2001, 267-70, fig. 3) noted that such sandals are also found in excavations at religious sites and may have been worn by members of religious orders. While the stitching of the seam suggests it comes from a sandal, since it lacks any other sole components, it is possible that this single layer (no. 52) may be the tread sole from a cork-soled patten worn over hose; highly fashionable examples, with very long toes and decorated insoles and toe straps, have been found on the continent (Goubitz et al. 2001, 264-6).

\section{Post-medieval shoes}

A smaller proportion of shoe parts from the castle can be dated to the 16th and 17th centuries. Those of turnshoe construction are distinguishable from late medieval forms due to their distinctive shapes, with oval or round toes (nos $39,58,62,63,64,65,66,73$ ). One turnshoe sole (no. 61) has a wide, almost straight-ended toe, while a clump repair and a vamp (no. 87) have very broad, round toes, both styles fashionable in the first half of the 16th century (Swann 1975, 22). Nineteen shoe parts come from shoes of welted construction, and, although some lack the elements to permit closer dating (nos 109, 101, 110, 14, 128), most date to the 17th century (nos $35,90,91,92,93,98,99,100,129)$. The welted shoe bottoms (soles, midsoles and insoles) are made straight that is, for neither a left nor a right foot. The toes are square, while the tread, waist and seat are relatively wide compared with the medieval shoe soles. At least two (nos 98, 99), however, are notably narrow and may have been worn by women or adolescents. The shoe uppers comprise vamps and two quarters seamed at centre back, but all of the upper parts are incomplete and no fastenings or indication of shoe style survive. There are two examples of shoe uppers with the upper leather flesh outward, what we would term suede today (nos 98, 129), which was a popular feature of 17 th-century footwear. The shoes have separate heels, and, although no complete heels were found, individual lifts from stacked leather heels are present (nos 91, 92), one of which (no. 92) has the central area cut out to lighten the weight, indicating it came from a large, high, stacked leather heel from a man's shoe or boot. A broken sole (no. 100) is moulded to continue down the breast of a separate heel, a feature seen on 17th-century footwear.

\section{Other leather items}

Two straps (nos 36, 80) of bovine leather, $3 \mathrm{~mm}$ and $4 \mathrm{~mm}$ thick respectively, had been cut from larger items, probably a harness. One of these (no. 80 ) is of good quality, approximately $58 \mathrm{~mm}$ wide with tooled and creased edges 
(impressed lines made using a heated tool known as a crease or creaser). A piece of sheep/goatskin (no. 16) with a decorative scalloped edge and a whip stitched seam running at right angles from it may have been torn from the bottom edge of a garment or glove, a horse barding or a decorative leather covering used in the home.

At least 16 fragments of leather (nos 112-126), all recovered from '5H Moat at Exchange Street', share characteristics suggesting they had been broken from the same item (or items). They are of thin leather, 1-2mm thick, mostly of calfskin, with two appearing to be of sheep/goatskin (nos 121,123), all now being black, shiny, brittle and often curling and distorted. One (no. 112) has a small area of whip stitched edge, while others have grain/flesh stitching (nos 115, 122), and one of the largest fragments (no. 113) has five surviving grain/flesh stitches from a seam and two small groups of grain/flesh stitching, each group $10 \times 10 \mathrm{~mm}$, spaced $20 \mathrm{~mm}$ apart, marking where two narrow straps, perhaps a small loop handle, had been attached. However, most have broken edges, lack any features, and so may best be described as 'scrap'. These fragments are stored in a box containing an index card which states 'Parts of 2 black jacks Subsid. Moat from Exchange St. These may have been from Butcher's 'barmkin' ditch (see Chapter 5), although, as noted in Chapter 4, ' $5 \mathrm{H}$ ' is not a standard format for describing the foundation shafts, and some finds labelled as being from this context are consistent with those recorded on the section drawings for $\mathrm{H} 5$ near the gatehouse. Black-jacks are small drinking vessels of moulded and hardened leather (cuir bouilli) and made of cattle hide (Waterer 1950, 7-8, plates XIIa and XIVb) using distinctive waterproof seams. However, no black-jacks are now present among the collection and no record of them has been found, and while the leather in the box is black, shiny and brittle, some with an opaque, brown, wax-like deposit on one or both surfaces, this appears to be the result of previous conservation treatment. Further, the leather is thin, and the stitching is inappropriate for a black-jack. Many of the shoe parts are also black, shiny and slightly sticky; the wax-like material may have been mistaken for a waterproofing substance lining the interior of the vessel, but it would not be present on both surfaces if serving such a purpose. No diagnostic features remain on these fragments, so the item/s from which they have been broken cannot now be identified. They may have been from the leg of a tall boot, but it is very unlikely to have been a black-jack or any other liquid container.

\section{The production and sale of leather}

Many features of the medieval and post-medieval leatherwork indicate that it was not a product of domestic rubbish disposal but rather was cobbling waste (Figure 6.5). Cobblers repaired shoes and bought old shoes for refurbishment and resale, recycling any reusable leather. Many of the later medieval shoe soles had been heavily worn: 13 have holes worn through the soles at the tread or seat, and 18 have repair stitching from the attachment of patches. Discarded repair patches, known as clumps, were also found, some of which had also been completely worn through before being thrown away. One turnshoe sole (no.138) had been made in two pieces, as either an economy measure or a major repair. While 17 turnshoe soles and eight repair clumps are complete, only four of the shoe upper parts are complete, the remainder being broken and often highly fragmented. Several soles and upper parts display secondary cutting (e.g. nos 17, 21, 24, 28, 145) where areas have been deliberately removed, including three shoe upper parts that had clearly been cut off when their shoe soles had been removed (nos 43, 82, 84). Two turnshoe soles (nos 2, 6) and a piece cut from a third (no. 86) appear to have been used as temporary cutting platforms, while a clump repair (no. 87) had been cut and an area removed to make a smaller patch confirming they had come from a cobbler's workshop.

Some of the early post-medieval footwear had been cut up to salvage reusable leather before being discarded. Notable examples are the 17th-century shoe bottom and lasting margin, which had been cut off from the quarters (no. 98), and the left quarters (no. 129) from another 17th-century shoe similarly cut off from its lasting margin when it was removed from the shoe bottom. The larger, more shapeless clump repairs recovered (e.g. nos 102, 103) may also fall into this date range. The clump repair (no. 87) had been cut and an area removed to make a smaller patch again indicating it had come from a cobbler's workshop.

The waste leather probably also derives from cobbling activity. This includes two pieces of primary waste cut from edges of cattle hide (nos 56, 107), while the rest is secondary waste produced when cutting out pattern pieces and trimming them to size during the manufacture, refurbishment and repair of leather goods. Most of the secondary waste comprises narrow trimmings (nos 45, 46, 55, 79, 94, 106, 130); a group of seven trimmings (no. 94) from G23 represent the result of trimming around shoe soles. One piece of secondary waste had been cut from an old shoe sole (no. 86), and two others may have been cut from shoe uppers (nos 89, 105). 
What very limited contextual information we have for the leather suggests that it was found across the site. For example, some of the items of post-medieval cobbler's waste (nos 102 and 103) were recovered from the south moat near the gatehouse, one from near the junction with the west moat (no. 129 in foundation shaft E19) and others from the southern end of the west moat (nos 94 and 98 in foundation shaft G23). It seems likely that this distribution resulted from the clearance (or episodic clearances) of more than one cobbler's workshop. Similar assemblages of late medieval and early post-medieval date have been found in comparable contexts elsewhere, such as in the city ditch at Coventry (Warks; Mould 2017b) and the defensive ditches at Carlisle (Cumbria; Mould 2011). Leather principally comprising cobbling waste has been found in ditches associated with Oxford Castle (Mould 2010; Jones 1976, 275-96), the barbican ditch at Norwich Castle (Norf; Mould 2009a) and the King's Ditch at Cambridge (Mould 2009b). It seems that, not surprisingly, open ditches in urban settings were a common repository for the opportunistic dumping of workshop debris.

Further evidence for leatherworking, albeit not cobbling, comes from an oval wooden object from the lowest deposits in the moat, published by Armstrong (1930, plate III (no. 2)) as a possible 'saddler's palm-board' (Figure 6.6). Palm guards used by leather-workers are usually of cast lead (Bailey 1995, 64-5), but this example, with an off-centre perforation, is reminiscent in form (see, for example, one from Staffordshire recorded by the Portable Antiquities Scheme: WMID-07FF87) and could have been part of a composite object, covering a lead base (palm guards were enclosed in leather or cloth for use). In addition, Armstrong (1930, 20, plate III (no. 9); Figure 2.22) suggested that three fairly crudely fashioned, hemispherical stone objects from 'the deepest portions' of the moat may have been used for dressing and softening leather.

It is noteworthy that Harrison's 1637 survey records two properties just to the south of the castle which contained tanneries: Christopher Capper held a 'Tenement with a dwelling house and a Tann office ... in Sheffield Town next the river called the Little Sheath East, and next the Quarries in part and the Pond Mill in parte South', while Edward Sanderson's 'Tenement with a dwelling house \& Tan office' lay nearby and 'abutteth upon a high way leading from Sheffield Parke to Sheffield towne' (Ronksley 1908, 58). Excavations by ARCUS in 1998 just south of Broad Street West, identified the remains of 17th-century tanneries in what they argued was Sanderson's property, while a medieval pit $2 \mathrm{~m}$ in diameter was tentatively thought to reveal an earlier tannery on the site (Belford 1999, 20, 67-8). The site lay only c.170m from the centre of the castle's inner courtyard, and if it was not incorporated within the outer bailey, it lay just beyond it (Belford 1999, figs 1 and 2). The area west of the outer bailey and north of the Ponds had long been associated with the sale and slaughter of livestock, and the preparation of their hides. A 1581 rental document records that three tanners held stalls in the nearby marketplace (Jones 2004, 31), which, according to Gosling in 1736, also contained the Shambles (Figure 1.6). The 'Beast Market' (now Haymarket) lay just to the east, while the 1771 Fairbank map shows the Swine Market and Slaughter Houses nearby (Figure 1.8; also Hey 2010, 63). Further ARCUS excavations close to the area marked 'Mill Sands' on Gosling's 1736 map, just 300m to the north-west of the castle, uncovered yet another mid-17th-century tanning complex, the animal bones from which revealed that, here at least, leather was produced from sheep/goat skins (Andrews 2015, 11-16). Significantly, at the court of 'the most noble lord George earl of Shrewsbury held on the 24th day of April' 1565, 'Thomas Greves of Waddlesley, John Holland the elder, William Mosseley and Umfrey Baite were chosen as leather searchers and sealers [scrutatores tannatorem]' (Hall 1928, 13-14). Their job was to examine and certify the quality of the products of tanneries. As Roy Thomson (1981, 166; also Minard 2011, 153) noted, the existence of this office, and of the associated bye-laws which determined 'when, where, how, and to whom leather could be sold', speaks volumes for the importance of leather, and leatherworking, in the economy of the period.

\section{Fragments of 'the most notable local building historically'}

The archive contains just 40 fragments of ceramic building material, the majority comprising medieval/early post-medieval floor tile and are from foundation shafts (F11, G7, G23, H2-4, H3, H5, 5HX, 5HY) recorded by Butcher and Bartlett (Figures 5.26, 5.29). The floor tiles are all plain, in coarse sandy fabrics, mostly glazed (a few over a white slip), and probably locally produced; no traces were found of the 'three or four' imported 'Netherlandish' tiles noted in the review of the archive by Davies and Willmott $(2002,13)$. Two tiles recovered by Armstrong from the moat had been roughly trimmed, indicating reuse, for an unknown purpose. There are 15 fragments of plaster (five are identifiable to F21 and H23) including two with lath impressions, of uncertain 


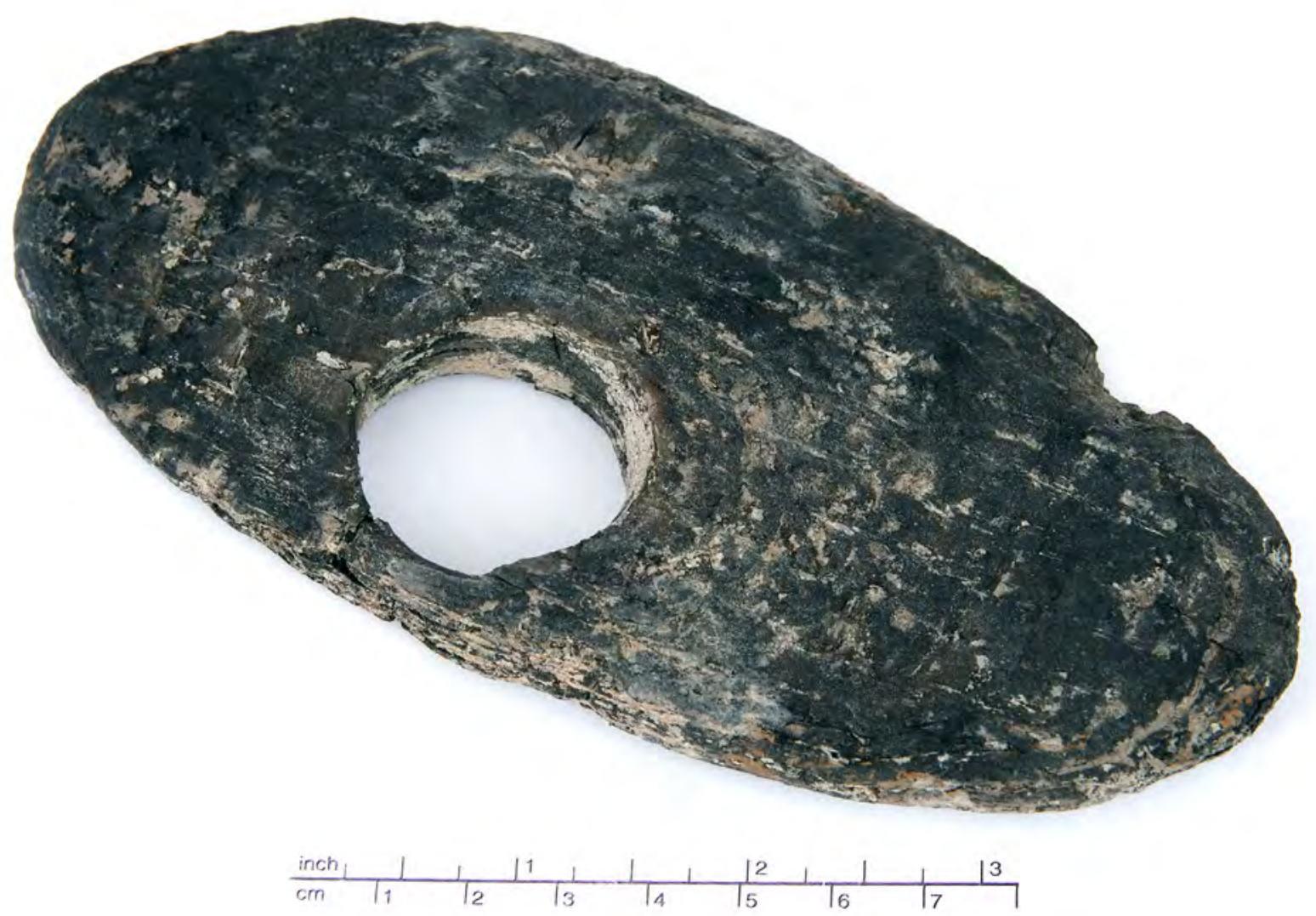

Figure 6.6: Wooden palm guard recovered during the excavations. Recorded by Leslie Armstrong in the late 1920s. He believed this dated to between the 13th and 15th centuries. Courtesy of Museums Sheffield; accession no. 1995.84.2.

date. The 'large piece of moulded plaster ceiling rib' found by Armstrong (1930, 20; plate IV) among demolition debris in the top of the south moat does not survive in the archive. Five mortar fragments labelled as being from a trial hole are of uncertain date and can only have formed a tiny proportion of the mortar that must have been encountered during excavation, suggesting very selective retention. One partial brick and a small fragment of what may be architectural terracotta (from G24) probably date from the post-medieval period.

Armstrong $(1930,22)$ noted the use of wattling to reinforce the floor of what he (wrongly) believed was an Anglo-Saxon timber building, but this could not be correlated with what is held by Museums Sheffield. There are various references in the texts and section drawings by Butcher to structural timbers including posts, and small twiggy fragments, some possibly from wattling or hurdles, some of which may have been part of a revetment of the moat (see Chapter 5), and the archive does contain numerous twigs and thin fragments or laths that are from foundation shafts (F22, G7, G8, G22, H2-4, H3, H5 (manhole 1), 5H). However, the four complete wooden stakes and part of a wooden pile recorded during the assessment of the archive by Davies and Willmott $(2002,19)$, which they reported as having potential for dendrochronological analysis, could not be positively identified within the wood assemblage we examined. The surviving assemblage includes two timber posts, which may have originally been squared (one from G23), and one squared timber with a rectangular slot carved out on one side labelled 'part of pump', along with two other fragments. All surviving pieces of wood are desiccated, but apparently by natural drying rather than freeze-drying, and their condition precludes any detailed comments on possible function, or tool marks, or any dendrochronological analysis; hence their date remains uncertain.

Fifty-nine fragments of window glass survive, 25 from the Armstrong archive and the remainder, where identified, from foundation shafts (E11, E18, E19, G7, G9, G23, H2, H2-4, H3, 5H, J2-4, J4) recorded by Butcher and Bartlett (Figures 5.26, 5.28). Where colour can be discerned, it is greenish; some fragments have been rendered opaque by heavy surface oxidation. Colour and condition indicate domestically produced potash glass. 
Flat window glass is notoriously difficult to date, but this small collection could include some medieval fragments (particularly the heavily oxidised examples), although the majority probably dates to the 16th century or later. There are both grozed (shaped with pliers or a 'grozing-iron') and flame-rounded edges; three pieces preserve acute or obtuse angles (from diamond-shaped quarries (small panes)) and two have right-angled corners (square or rectangular quarries). Diamond leaded lights were used from the later 16th century and, despite the growing popularity of square or rectangular panes from $c .1660$, diamond panes were still commonly used into the 18th century (Hall 2005, 86). It is a relatively small collection for a castle, a product, no doubt, of the context in which much of it was deposited (remember Armstrong's $(1930,15)$ description of the moat fill as 'black tenacious sludge') and the difficult circumstances surrounding its recovery, including less-than-enthusiastic workmen. Nevertheless, we can very tentatively link some of this glass to the refurbishment of parts of the castle in the mid-17th century. As we saw in Chapter 1, attempts were made, following its partial demolition, to restore what was left as 'a fittinge habitation'. Further, in 1649, Major Andrew Carter ordered that new windows be inserted into castle buildings, all of which faced 'towards the Towne' (see also Chapter 9, Section: Reduced to fragments - embedding the castle in the community). This would put the buildings on the south or west sides of the castle, and it might just be significant that several of the foundation shafts from which glass was retrieved lay on the south side of the site (notably E11, E18, E19, G7 and G9).

A few metal objects may have had structural functions, including undated iron nails (from H2-4) and two unprovenanced small fragments of lead window came, which could not be identified to type or date (e.g. Knight 1985). Armstrong published four keys, although he did not recognise one as such, describing it as a 'probable cheek piece from a horse's bit' (Armstrong 1930, plate III (no. 4); Figure 2.22). It is in fact a padlock slide key with an angled bit (Egan 1998, cat. no. 264). This type of slide key is the most common nationally, having a pre-Conquest origin and continuing in use into the post-medieval period (Goodall 1990, 1005-6, type A). Padlocks were used to secure items of furniture as well as doors and shutters, and sometimes human and animal limbs. Of the other three keys, Armstrong (1930, plate I (nos 1,2)) dated two to the 14th century, one of which was the aforementioned example of block tin (see Chapter 2, Section: The finds specialists), and the third to the 16th century (plate I (no. 3); Figure 2.23). However, only one (no. 3), with a hollow stem and integral bit in line with the end of the stem, is definitely medieval (Goodall 1990, 1007, type 3 ). The others, which apparently have solid stems, one with the stem ending in line with the bit and the other with the stem projecting beyond the end of the bit, are of forms which began in the Middle Ages but continued into the postmedieval period (Goodall 1990, 1007, types 6 and 8, respectively).

This range of building material is clearly only a tiny fraction of what had once been on the site, providing accordingly limited insight into the appearance of the castle. However, it does bring us close to the craftworkers and estate officials whose labour provisioned and maintained the castle, which can be contextualised by the mid-15th-century Account Rolls. For example, they record that the aptly named John Plumber (one of several such in the following discussion) and his assistant received $6 d$. and $5 d$. a day respectively to repair the lead on the 'Great Tower' and the tower next to the bakehouse, maintain the gutters that led into the inner courtyard and those of the Exchequer Chamber in the outer courtyard, and provide a lead pipe for bringing water into the castle from an outside well (Thomas 1920-24, 68, 236). Geoffrey Botery received 10d. a day for using his wagon and oxen to convey mud from the park to the castle to be used by the plumber, and for bringing stone and timber to repair the grangehouse and stable in the outer courtyard (Thomas 1920-24, 157). Carpenters including Henry Roworth and Robert Swyfte were paid $5 d$. a day for carpentry work in the stable, and for making racks and mangers in the cowhouse and in other buildings outside the castle, while two unnamed sawyers provided timber for the cowhouse for $4 d$. a day (Thomas 1920-24, 236-7, 239). The stonemason Richard Waller repaired the walls of the grange for $5 d$. a day, assisted by John Mulner, who made mortar, and John Abbeney, who plastered the walls, and we are also told of repairs to the roof of the kitchen by a tiler (Thomas 1920-24, 68-9, 236). The roof of the bakehouse was repaired by the tiler Nicholas Sklatter, while 'divers windows' were repaired by carpenter Robert West and glazier John Glasier; a payment was made to John Swynok for 200 boards for repairing the chapel, nails were bought from John Smyth and Richard Greve, lead from Thomas Moldeclyff, and 1000 laths from William Gotson (Thomas 1920-24, 351-5). The Account Rolls also record the reconstruction of a battlement above the hall, the rebuilding of one of the kitchen walls, and the work by two masons from Tickhill (South Yorks) to demolish and replace 'the old tower' next to the chapel (see Chapter 1, Section: Sheffield Castle and its elite occupants). One hundred and twenty people brought stone from Roche Abbey (South Yorks, c.22km to the east of Sheffield) in 60 wagons for the task, suggesting the new tower was 
built of limestone, which was extensively quarried on the abbey's lands (McCoy and Stenton 2009, 16). In this context it is worth noting Himsworth's $(1927-42,2)$ observation that some of the window tracery recovered on $25^{\text {th }}$ November 1927 was of magnesian limestone, the kind of rock quarried at Roche. We should also remember Wigfull's assessment that most of the fabric of the castle uncovered during the late 1920s was comprised of local sandstone, probably from Arbourthorne in the park (see Chapter 3, Section: Courtyard buildings). John Hanson was paid $5 s .6 d$. for felling 60 oak trees in the deer park to provide timber for this building work, and the path that ran from the hall to the gate was repaired at this time, for which John Michell used his wagon and oxen to bring stone and cinder from the park (Thomas 1920-24, 68, 71, 355-7).

Sixteenth-century records provide further details of building work. For example, in July 1578 the $6^{\text {th }}$ Earl wrote from Sheffield to his servant Thomas Baldwin about building work he was at that time carrying out on the castle, ordering him to buy pitch, tar, and other materials that could be got 'good chepe' (LPL, MS 697, fols 171). Finally, as we will see in Chapter 9, there were building works and acts of demolition in the mid-17th century, carried out by the Earl of Arundel's servants and town labourers. In sum, it is easy to disregard a small collection of plaster, mortar, glass and nails as providing any insight into as substantial a building as a castle, but if we do so we are unwittingly glossing over the activities of a multitude of people whose labour constructed and maintained this building over several centuries.

\section{Domestic and personal items}

The few personal items recovered mainly comprise clothing accessories, and are all from the 1920s excavations. Armstrong $(1930,24)$ noted gold pins from what be believed to be 14th- and 15th-century levels of the moat (see Chapter 2, Section: The finds specialists). His Figure 16 shows 13 pins, of which six appear to have wire-wound heads. Five pins (with heads) and two longer objects are included in his plate III (Figure 2.22) - it is unclear whether some of the 'pins' appear in both illustrations. Our study of the material in the archive located three pins with wire-wound heads and three lengths of wire, the latter perhaps for pin manufacture, and the longest of which had a pointed end. Pins could have been used as head-dress ornaments or to secure items of clothing; they are usually of copper alloy (three further examples were found by ARCUS in 1999; Davies 2000, 58), but, as we saw in Chapter 2, Thomas Bradbury's analysis in 1930 claimed these were gold, suggesting they were high-status accessories. We cannot know where they were acquired from, but it is intriguing that among the Earl of Shrewsbury's 15th-century properties in Sheffield was a townhouse called Goldsmytheplace, whose tenant in 1442-3 was Katherine Goldesmyth (Thomas 1920-24, 235, 239). However, the pins that survive in the archive are gold-plated copper alloy (Mepham 2017; Figure 6.7). Drawn wire pins with spiral-wound heads are commonly thought to have been introduced from the continent in the 16th century, but evidence from, for example, Winchester (Hants) shows that they appeared in this country around three centuries earlier (Biddle and Barclay 1990).

A small cast single-loop form of buckle with integral forked spacers (which would have held sheet metal plates) dates to the later 14th or early 15th century (Armstrong 1930, plate I (no. 5); Figure 2.23; Egan and Pritchard 1991, 80; Whitehead 1996, 36-7). Such buckles were more suited for use with finer woven fabrics rather than leather - perhaps pointing to a slightly higher-status wearer. A second buckle (Armstrong 1930, plate III (no. 3)) is a square double-loop type of 16th- or 17th-century date (Whitehead 1996, 74). A rectangular gold object with interlaced repoussé decoration, probably originally jewelled at the centre, is described by Armstrong (1930, 26, plate II (no. 5)) as a 'brooch front' and dated to the 16th or 17th century as it came from the upper levels of the moat, but below the demolition debris. However, he offers no parallels, and none have been found, and the form could equally well have functioned as some form of mount. A lace end is of 16th- or 17th-century type, made from rolled copper-alloy sheet with both long ends bent inwards (Margeson 1993, 22, type 2). Six buttons were published by Armstrong (1930, plate II (nos 6-10), plate III (no. 6); Figure 2.22; also Chapter 2, Section: The finds specialists, and Figure 2.20 for Frederick Bradbury's analysis), five of post-medieval disc form and one of medieval domed form - it is uncertain whether it is cast or made from sheet metal (Egan and Pritchard 1991, 272-7). There is also a mother-of-pearl button from Armstrong's investigations.

Six whittle-tang knives were recovered. This form constitutes the sole type found in medieval England until c.1300 and, even after the introduction of scale-tang handles in the 14th century, remained the most common type until the early 15th century (Cowgill et al. 1987, 25). The knives from the castle are not closely datable on morphological grounds, although two carry cutlers' marks, one in the form of a cross (Cowgill et al. 1987, 20), which do not seem to have become common until the 13th century. These knives could have been used at the 

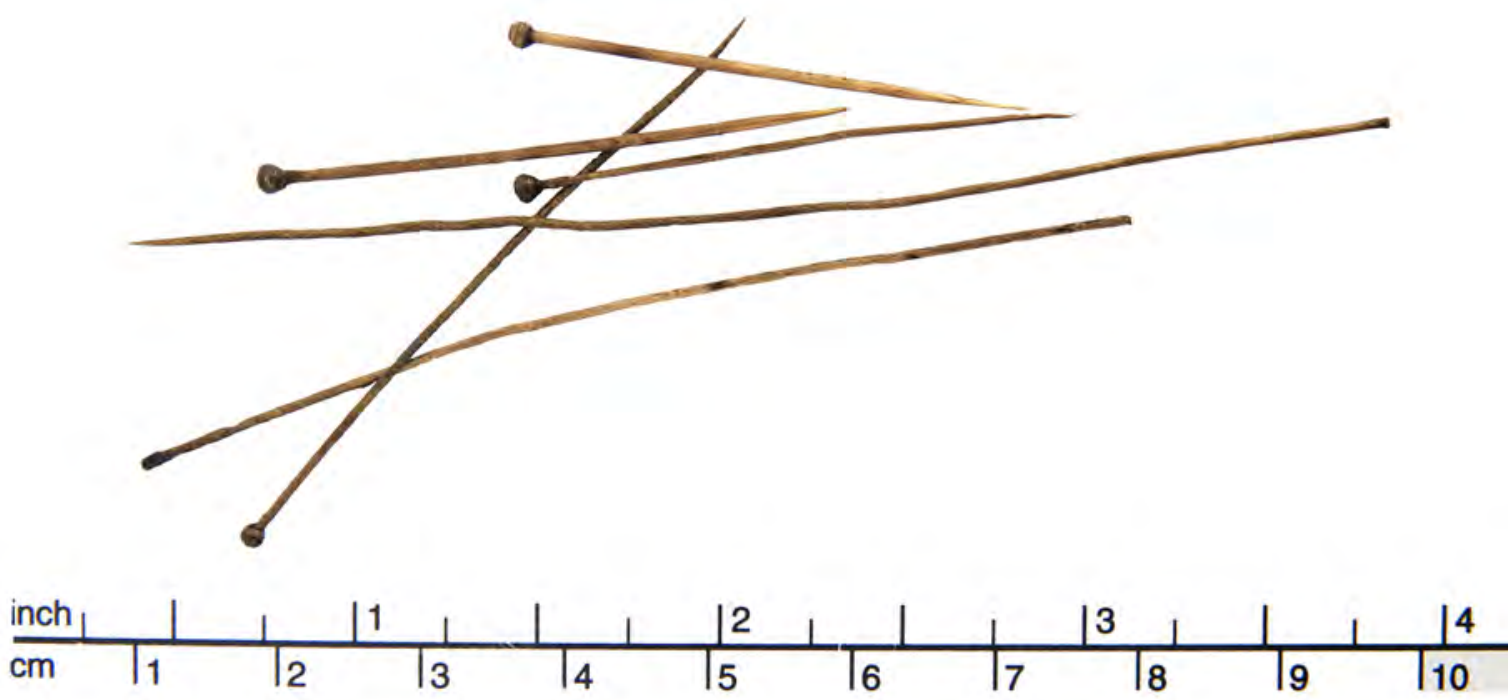

Figure 6.7: Medieval pins from Sheffield Castle recovered during the excavations. Recorded by Leslie Armstrong in the late 1920s. Courtesy of Museums Sheffield; accession no. 1995.84.7.

table, for craft work, or, as Himsworth $(1953,48)$ pointed out, for defence. Two, which were not traced in the archive, were published by Armstrong (1930, plate I (nos 7, 11); Figure 2.23; also Himsworth 1930b). Two bone whittle-tang handles were also found. No longer surviving in the archive are three knives of scale-tang form published by Armstrong, including one unusual example with an elaborately decorated bolster (Armstrong 1930, plate I (nos 6-8); Himsworth 1937, 3), and a fourth, possibly a carving knife, which is of uncertain whittletang or scale-tang form (Armstrong 1930, plate I (no. 12)). Himsworth $(1953,49,50)$ tells us that the knife with the decorative chasing on the bolster was also gold-damascened; he dated it to the 16th century, assumed it was made in Sheffield and argued, reasonably, that it demonstrated that 'some of the early Sheffield products were of more than "provincial" quality'. A knife with a bone handle was recovered by Butcher; although it is labelled both G22 and F21 (Figure 6.8), it is likely to be from the former as two whittle-tang knives are annotated on the west section drawing of this foundation shaft (Figure 5.26). Important to the use of knives were whetstones for sharpening, and two were found: a square-sectioned stone with one pointed end, pierced for suspension (Armstrong 1930, plate III (no. 8); Figure 2.22), and one with a sub-rectangular section from foundation shaft G23 recorded by Butcher.

Medieval Sheffield was famed for its cutlery industry, and the knives from the castle site represent not just personal items but the products of local labour. Geoffrey Chaucer, who in the 1350s had spent some time at Hatfield, near Doncaster, referred in his late 14th-century The Reeve's Tale to 'A Scheffeld thwittel [knife] baar he [the miller of Trumpington] in his hose' (1. 3933), suggesting it would have been a familiar reference to the products of the town's metalworking industry. A 1297 list of Sheffield taxpayers includes one 'Robertus le Cotelear' (Brown 1894, 76), and the town was at the heart of a region renowned for its cutlery production. There are references to 'cutlers' in the Poll Tax returns for 1378-79 in the surrounding villages of Ecclesfield, Tinsley and Handsworth (Leader 1904b, 118-19; also Jones 2013, 69), while the antiquarian John Leland, in his Itinerary in England and Wales, c.1535-43, was struck by the fact that 'ther be many good smithes and cuttelars in Halamshire' (Smith 1909, 14). However, as Himsworth $(1935,8)$ proudly announced to the Sheffield Trades Technical Society in November 1935, 'the very earliest knives of local origin that are known, are what we found in the moat of Sheffield Castle.

Other items that probably belonged to individual craftworkers include the half pair of shears found by Armstrong (1930, plate III (no. 10)), which are more likely to have been used as fullers' shears than sheep or cloth shears, which were larger (Cowgill et al. 1987, 58; also Himsworth 1930c and Chapter 2, Section: The finds specialists for Himsworth's metallurgical analysis). Shears were also marked by Butcher (1958-62d) on the south section drawing of foundation shaft G22, but were not located in the archive during our analysis. One other possible textile-working tool was found, in the form of a short length of wood, circular in cross- 


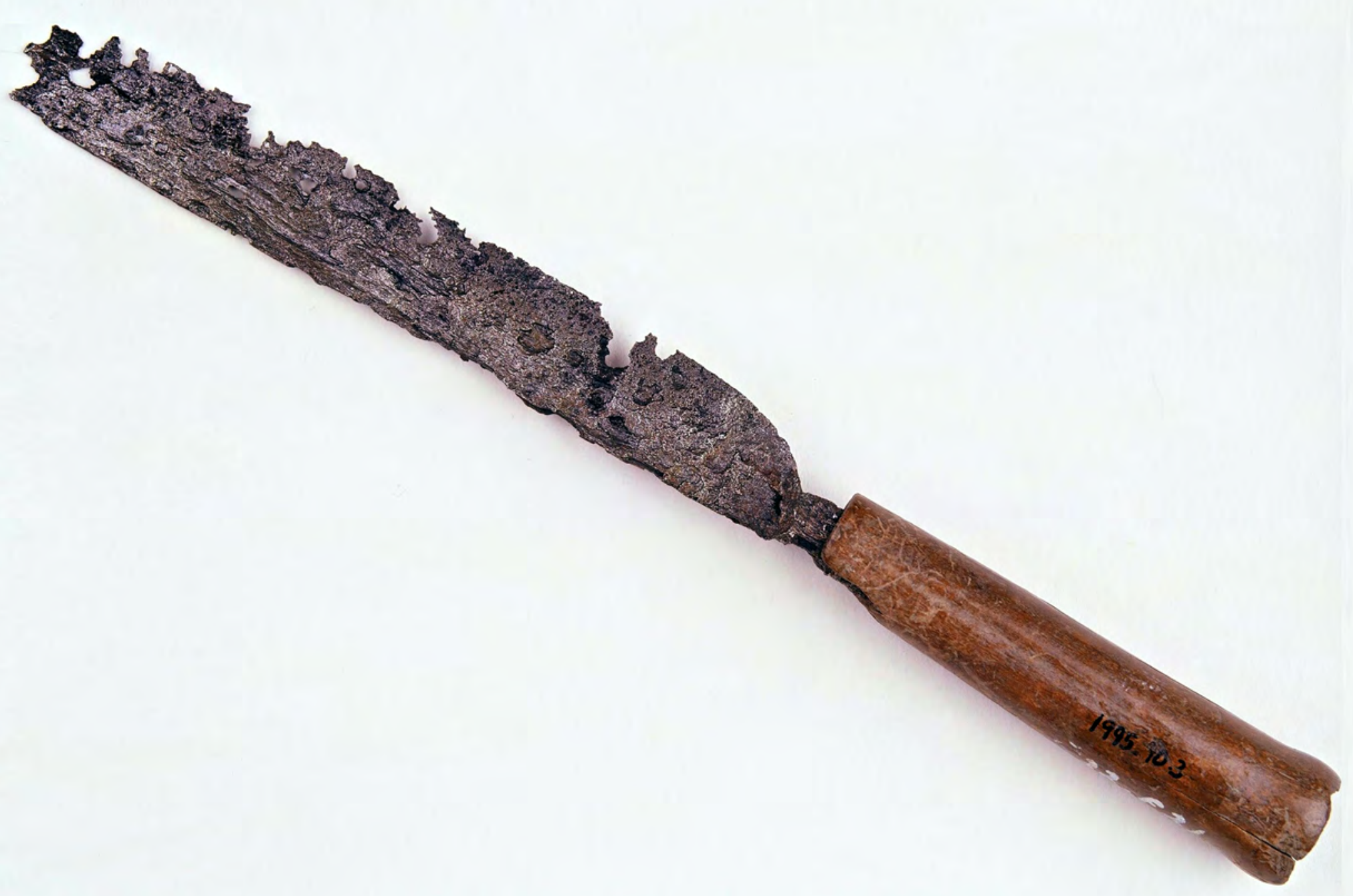

Figure 6.8: Whittle-tang knife recovered in the mid-20th-century excavations. This was probably found in foundation shaft G22. Courtesy of Museums Sheffield; accession no. 1995.90.3.

section and roughly worked to a point at each end (Armstrong 1930, plate III (no. 5); Figure 2.22), possibly a weaving tool of some kind (for use with a two-beam or horizontal loom), of a type more usually found in bone (e.g. Brown 1990, cat. no. 213).

As might be expected in a centre of cutlery manufacture, bone-working waste, apparently primarily for the manufacture of handles, is much in evidence in the assemblage ( 52 pieces recorded). This includes offcuts in the form of sawn ends of cattle metapodials, the sawn metapodials ready for use, and the rectangular plates cut from them (Figure 6.9). A significant proportion of this waste came from foundation shafts recorded by Butcher (E19, F21, F22, F23, G22, H2-4, H3, 5H, H23, manhole 3; Figures 5.26, 5.28, 5.29). Armstrong $(1930,14)$ tells us that he found evidence, at the north-east of the site, for a 'scale-cutting establishment where ivory, bone and stag antler were worked for knife handles' in the 18th century, and so some is likely to have been post-medieval in date.

The mid-15th-century Account Rolls reveal how partial is the surviving material culture, as they record many purchases of items for use in the household including wax for making candles and tapers for the chapel, parchment, paper and red wax for the office of the Receiver, 11 yards of linen cloth of canvas for covering one feather bed and one bolster, and 'Curtaynecordez' (cords) for hangings and preparing beds, all of which were

Figure 6.9 (page 207): Bone-working debris retrieved by Leslie Butcher. Courtesy of Museums Sheffield; accession no. 1995.90.10. 
delivered to Richard Wode, janitor (Thomas 1920-24, 235-6, 350-1). These are all items unlikely to survive in the archaeological record but clearly essential to the running of the household.

The documentary evidence also enables us to see something of the resonances of household items in the context of personal relationships and the demands placed on servants to sort matters out. In the late 16th century, we have records of the $6^{\text {th }}$ Earl, George, asking his servant Baldwin to procure a great copper pan, feathers for beds, and four silver flagons 'to replace gilt ones given him by his wife'. This was in response to his wife, Bess, having removed from the castle items she considered to be her own, as she had brought them to the marriage, and the Earl grumbled about how 'grete tormoyle dothe ij houses brede' (Folger Shakespeare Library, X.d.428 (95)). In November 1581, as Shrewsbury prepared Sheffield Castle to receive Mary, Queen of Scots again, he commanded Baldwin to send wax lights, torches and table linen for her, and complained that lack of ready money would force him to sell his ship The Talbot (LPL, MS 3198, fols 92, 193). In June 1583 the Earl instructed Baldwin to buy taffeta, damask for a counterpoint to furnish the castle and lodge, and plates for fruit while in London (LPL, MS 3198, fols 208). One of the most informative written sources to survive is a partial inventory of the household goods and furniture of the $6^{\text {th }}$ Earl and his royal prisoner, in both Sheffield Castle and the hunting lodge (LPL, MSS 694-710, LPL, MSS 3192-3206; see Chapter 8, Section: The captivity of Mary, Queen of Scots). It is not clear what the purpose was of the inventory, undertaken on $18^{\text {th }}$ June 1582 by John Dickenson and William Kettelicke, nor can we always determine in which of the households the recorded items were found, but it reveals that both the castle and the hunting lodge were furnished in a manner appropriate to one of the wealthiest peers in the realm (Leader 1874, 44-5; ICOSSE 2005, 57). The inventory lists carpets and tapestries, rich bed furnishings including counterpanes, testers, sheets and pillows, many of which were elaborated with embroidery or silk fringes, feather beds, bolsters and mattresses, altar cloths, candlesticks of brass, pewter and iron, chests, stools, bedsteads, tables, chairs covered with velvet and silk, bibles and other books, and clocks, and there were pantries and bakehouses well stocked with pans, vats and tuns (Leader 1872, 366-9). The household was reluctant to dispose of objects, as demonstrated by the listing of eight chairs, four stools, five feather beds, and two pillowcases said to be 'past service' (Tucker 1874, 255-6). The worn stools may have been among those for which the $6^{\text {th }}$ Earl requested gilt nails and other upholstery materials in May 1583 (Lodge 1838, 242).

The written accounts reveal the castle as a place where craftworkers and labourers came to receive payments, for such activities as the pannage of the pigs, cropping of the oaks, hay crops, leases for grazing, pasture, felling wood in the park, and 'the mine of sea-coal at the Stobbynge' in the park, and for cinders sold to 'divers dyers of Chesterfield' (Thomas 1920-24, 157). However, traces of this in the archaeological record are, perhaps not sur-
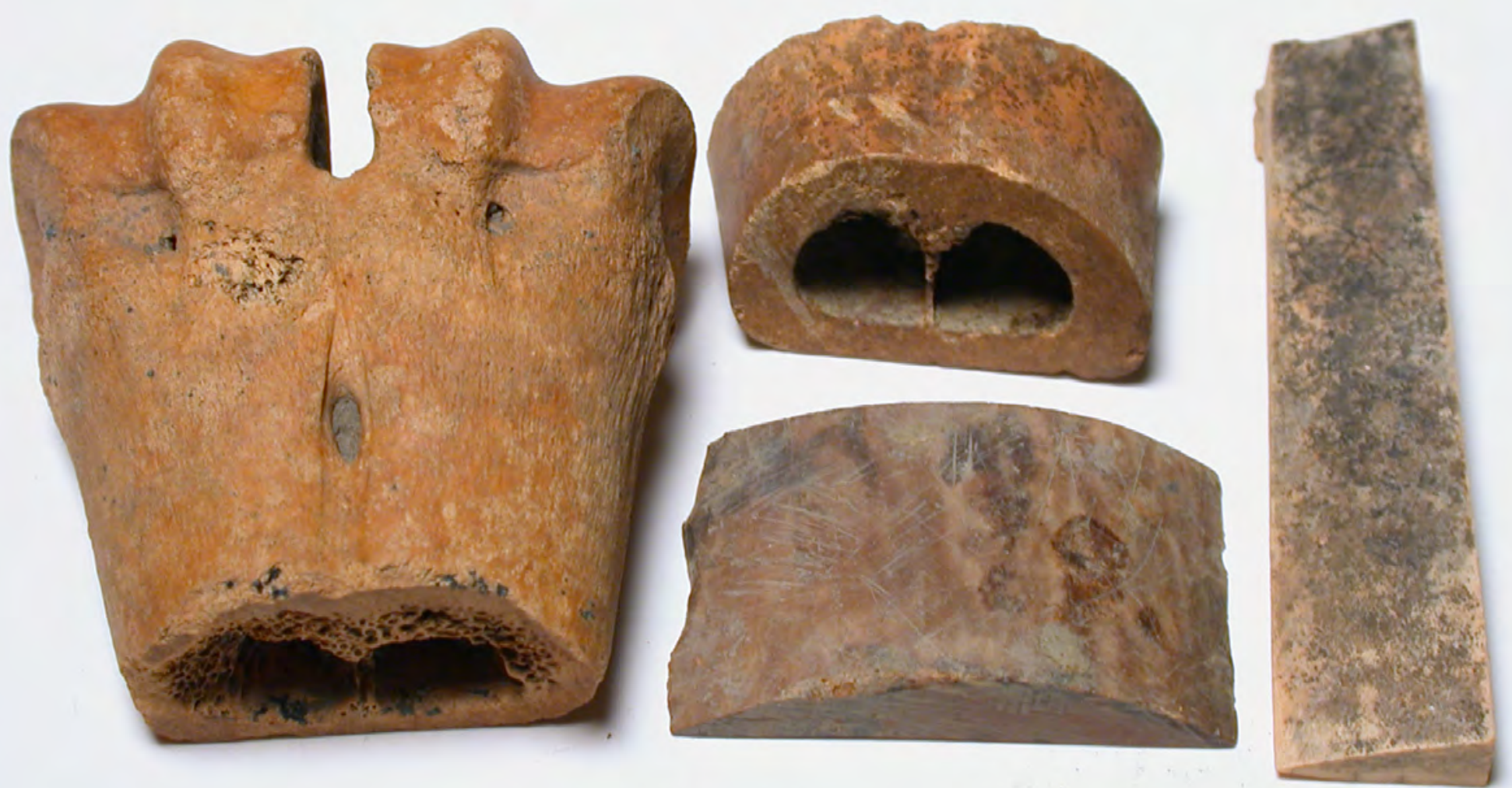
prisingly, thin. Excavations have recovered just one 13th-century coin (a long-cross silver penny of Henry III), three 17th- or 18th-century coins (of James II (1686), William III (1698) and George II (date worn)), a French 14th-century 'crown' jeton, and three Nuremberg Rose/Orb tokens of mid-16th- or 17th-century date; some of the coins and counters listed by Armstrong $(1930,25)$ are no longer with the archive. The Account Rolls also record something of the material culture associated with financial transactions, such as the purchase of purses of white leather and canvas in which to carry the lord's money (Thomas 1920-24, 235).

The archive contains 31 clay pipe fragments, which have been studied by Susie White (2015); the limited numbers suggest selective retention. Armstrong $(1930,19-20)$ reported that the earliest clay pipes occurred in what he believed were the Elizabethan levels of the moat, but no pipes of this date survive in the archive. Seventeen of the clay pipe bowls were dated by White to the 17th century (the earliest from 1610-30), a period which is not well represented in Sheffield (e.g. White 2015, figs 11, 139-40), and at least seven of these could potentially belong to the Civil War period, or that of the castle's destruction soon after (see Chapter 7, Section: Clay pipes).

Two other objects published by Armstrong are of intrinsic interest: a wooden 'playing card' and a wooden/ brass crucifix (Armstrong 1930, plate II (nos 1, 4); Figure 2.21). The 'card' is, in fact, a small block of wood into which a brass diamond has been inlaid, and the letter ' $K$ ' marked by brass pins (hence the King of Diamonds). No parallels can be found for this as a 'playing card' and it has been suggested that it might be a craft 'trial piece' (Mark Hall, pers. comm.). Thomas Ellin, a former Master Cutler, who examined the piece for Armstrong, thought it the work of a local cutler, a proposition confirmed when a local boy gave Armstrong some similar ones belonging to his grandfather (Armstrong 1930, 26; also 1930, plate II, 2 for the grandfather's Queen of Hearts; Figure 2.21). This suggests a late date, and provides valuable insights into craft activities and leisure pursuits among Sheffield's working people (Figure 6.10). There is also a small bone die (context unknown), of medieval or post-medieval date. The wooden crucifix (Armstrong $(1930,26)$ says ebony) is enclosed in brass, and was found in the upper levels of the moat, below the demolition debris. This makes a late 16th- to early 17th-century date very likely (Figure 6.11). Armstrong $(1930,24)$ also found a series of 16th-century brass 'counters' (which do not appear to have survived in the archive) inscribed 'in Tudor lettering' with 'Ave Maria Gracia [Gratia] Plena' on one side, and emblems of the apostles or a fleur-de-lys design on the reverse. Armstrong mentions the appearance of 'the abacus in the centre', which makes little sense until we realise that these 'counters' may have been jetons (see Munby et al. 2019, 257-9 for several examples of jetons bearing an 'Ave Maria' legend from Oxford Castle). In 1858, Albert Way (1858, 259-60), speaking of other 'elegantly designed counters' which Mary, Queen of Scots received as a gift in 1579 while in custody in Sheffield, noted that they 'were very probably used [by the Queen] with a kind of Abacus for casting accounts'. Armstrong's 'counters' are not the jetons the Queen received in 1579 (the design is different), but we can take them to stand both for a continued Catholic presence in a town in the process of Reformation (Moreland and Gorman 2019, 11-12; also above for a pottery sherd bearing a Catholic motif), and the importance of commercial transactions in the castle (even, it seems, to a captive Queen).

\section{Feasts and refuse}

Armstrong $(1930,19)$ noted the plentiful occurrence of animal bone (including deer antler) and oyster shell among 'refuse' found in the area of the drawbridge, and concluded that the kitchens were located on the south side of the castle. However, he does not seem to have retained more than a very few examples. More bone was retained by Butcher, and survives from virtually every foundation shaft he recorded, but the overall quantity still seems small for this kind of site. Among the bone analysed, the major domesticates (cattle, pig and deer) were clearly predominant, but only two horse bones were noted, and just one fish vertebra, but working conditions must have precluded the recovery of fish bones. The bone probably included both butchery and consumption waste, but, given the relatively small quantity present, and the likely recovery and retention bias inherent to it, little more can be made of the assemblage. We are not in a position to assess Armstrong's suggestion about the location of the kitchens, but it is worth noting that deer bones are plentiful, which is not surprising given the ready supply of venison from the adjoining deer park (Hunter 1819, 189). It was probably the source for the 'fifty does and twenty nine red deere' killed and cooked for the 'great dinner' that followed the funeral of Francis Talbot on $21^{\text {st }}$ October 1560 (Hunter 1819, 57). Frederick Bradbury (1927) made this connection while the 


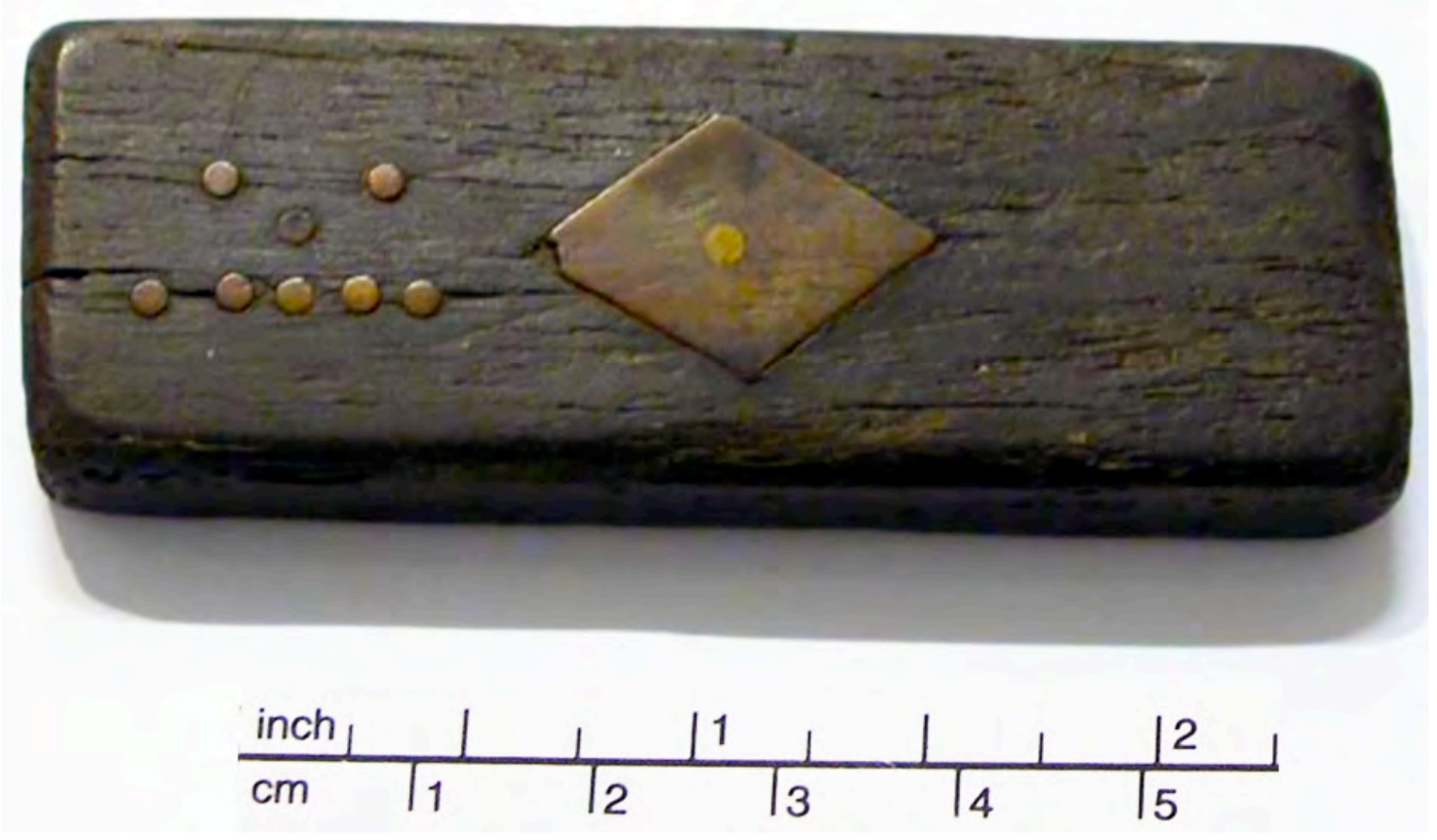

Figure 6.10: An item identified by Leslie Armstrong as a 'playing card'. This was probably the work of a 19th-century craftsman. Courtesy of Museums Sheffield; accession no. 1995.84.18.

excavations were taking place, and wrote to the Sheffield Daily Telegraph to marvel that so many deer would be served up at one feast and, silversmith that he was, to remark that the accompanying 'display of silver plate and pewter ... must have been prodigious'. In the late 16th century, the $6^{\text {th }}$ Earl's servant Robert Bradshaw wrote to him about supplies to the castle, including wine, fish, pasties, venison, and pheasants, to be laid in at Sheffield for the coming Christmas-tide (LPL, MS 705, fol. 144). Later records provide further occasional snapshots of this supply process. Stewards accounts record the delivery to the castle, 'when the surveiors and other gentlemen were there' in 1633, of 34 quarts (c.38.6 litres) of white wine, three quarts of sack, and one quart of claret (Hunter 1819, 102). This is an apposite reminder that even the humblest of remains can sit on a spectrum of social display for which only traces survive in the archaeological record.

The relative scarcity of wine bottle glass of 17 th-century date or later suggests selective retention; there is only one bottle neck, and one bottle seal with the initials CP (see Chapter 8 for bottles from the hunting lodge). There are parts of up to four drinking vessels of 16 th-/17th-century date, all of potash glass. Three are represented by bases only; two are rigaree-decorated (a feature which disappears in the mid-17th century; one from Armstrong's archive, the other from foundation shaft E15), and probably belong to cylindrical beakers (Willmott 2002, type 1), while the third may belong to a pedestal beaker (Willmott 2002, type 4; from foundation shaft H2-4). The example from E15 may correlate with a piece of 'Elizabethan glass, German import' marked in a deposit of dark silt on the north section drawing (Butcher 1958-62e), one of the few instances where Butcher's finds other than pottery can be related to his written records. There is also an unprovenanced small body fragment which shows traces of possibly optic-blown wrythen (twisted or coiled) decoration; this may represent a fourth drinking vessel, of unknown form but of similar 16th- or 17th-century date. None of the beakers are necessarily 'German imports'; all these forms were made at English glasshouses such as Hutton, Rosedale (both Yorks) and Haughton (Lancs) (Crossley and Aberg 1972; Hurst-Vose 1994). While the castle vessels may have belonged to the elite household, Willmott $(2002,21-2)$ identifies the second quarter of the 17th century as the point at which glass tablewares became available to the 'middling sort' living in urban environments. 


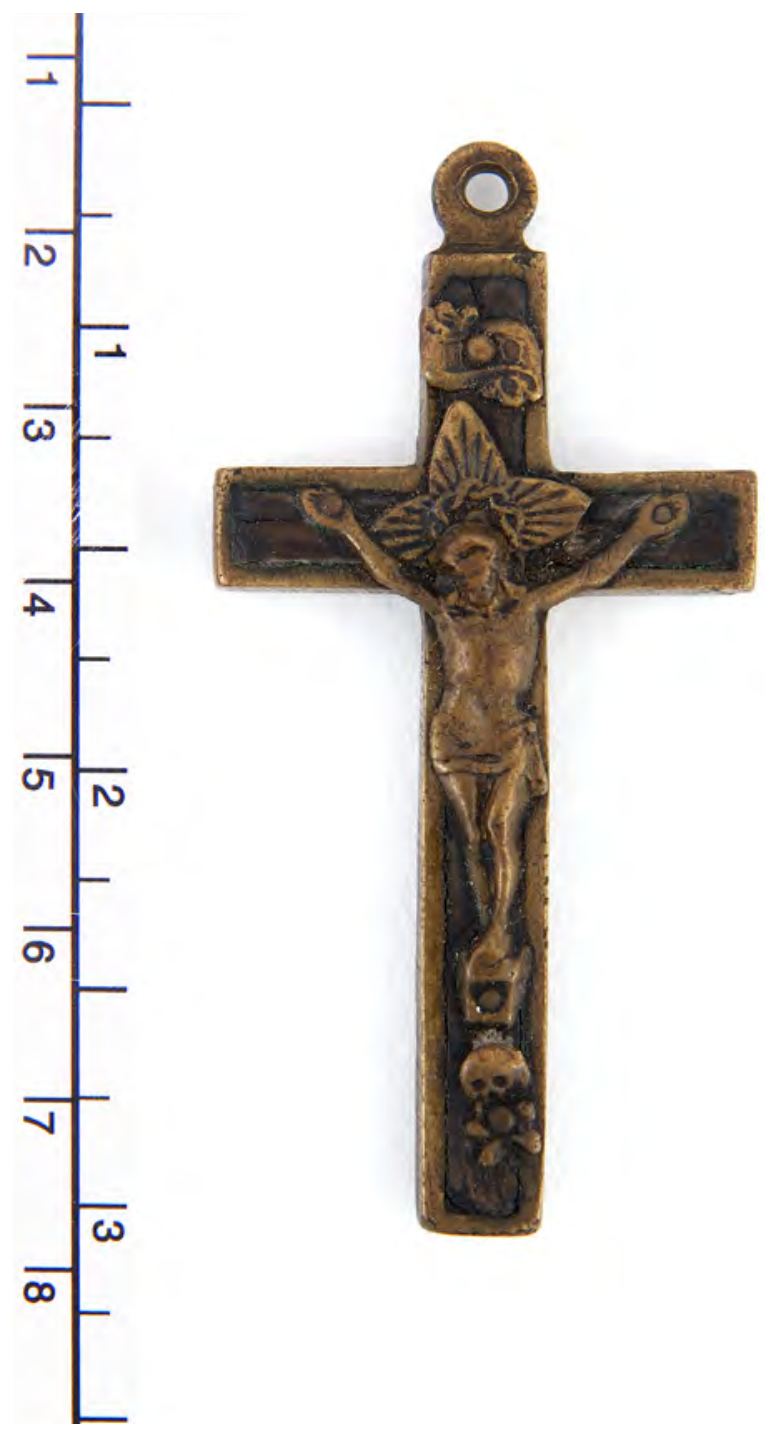

Figure 6.11: Wooden and brass crucifix of late 16thor early 17th-century date. Recovered from the site of Sheffield Castle in the late 1920s. Courtesy of Museums Sheffield; accession no. 1995.84.12.

The archive contains comparatively little material that can be related to eating and drinking, but this is clearly unrepresentative of the range of activities that took place at the castle. As Collinson $(1987,18-19)$ has observed of Mary's household after she had been transferred to the 'more straitened' custody of Sir Amyas Paulet:

the sums expended in these final months, up to the very moment of execution, give some indication of the scale of the custodial operation. Mary and her people consumed, or at least had placed on their tables, 353 tuns of beer, costing $£ 706.13 .5$... Twenty-eight tuns of white wine from Gascony cost $£ 480.7 .12$. The meat bill came to a colossal $£ 2,279.2 .4$., including 158 carcasses of beef, 1341 sheep, 497 calves, 398 lambs, almost a thousand pigs of different kinds, 1829 pounds of lard and $£ 617$ worth of sundry poultry, pigeons and rabbits. The fish bill, for $£ 1,569.5 .11$., covered 721 codfish, 489 ling, and salmon, turbot, salt eels, white herrings, red herrings, sprats, pike, barbel, chub, tench and perch. Forty gallons of olive oil were required to dress the salads.

The remains of refuse from feasting and other aspects of daily living should also serve to remind us that elite households are very high-maintenance, also requiring much cleaning. The Account Rolls record several payments for cleaning, some of which doubtless resulted in the deposition of material in the moat from where it was recovered centuries later during archaeological investigation. For example, in 1442-43 John Mulner was 
paid $4 d$. a day over a period of nine days to 'clean the stable and other houses and chambers within the said castle', and Henry Roworth's unnamed wife was paid 14d. on several occasions for washing the castle linen and napery (Thomas 1920-24, 235-6). These are very rare insights into a domestic economy, much of it female, that underpinned elite posture and display.

\section{'The Frenchmen's only scourge'}

Unusually for a castle, we might think, very few finds have any association with military activity. A spearhead found by Armstrong (1930, plate III (no. 1); Figure 2.22) is described as of small, light type, but in form it falls within Jessop's (1996, type M9) military category of arrowheads, an armour-piercing type dated to the 13th to 15th century. The only shot in both metal and stone was recorded by Armstrong (1930, 14), who noted 'arquebus and musket balls of lead' found among the demolition debris from the castle, although something similar may have been meant by the word 'ball' on the west section drawing of foundation shaft G7 recorded by Butcher (n.d. (k); 1958-62g). Four lead pistol or musket balls are extant, along with one iron and one stone cannonball. The diameter of the iron shot $(46 \mathrm{~mm} / 13 / 4$ inches) would fit it for use in a falconet, while the stone shot (diameter $120 \mathrm{~mm} / 43 / 4$ inches) would have fitted a demi-culverin (Scott 2001, table 5.1). The excavated castle walls bear the imprint of cannonballs and of musket balls (Armstrong 1930, 16, figs 7 and 8; Figure 3.11), and iron cannonballs were found at various levels within the moat (Armstrong 1930, 15, 20). A prick spur was found by Butcher in foundation shaft G7. The end of the goad is missing, but the body is finely decorated with an inlaid silver design. The form would place it no later than the 13th century (when prick spurs were replaced by rowel spurs), or in the 17th century, when they enjoyed another period of popularity (Figure 6.12). A recent study of gender and medieval castles has observed that such objects

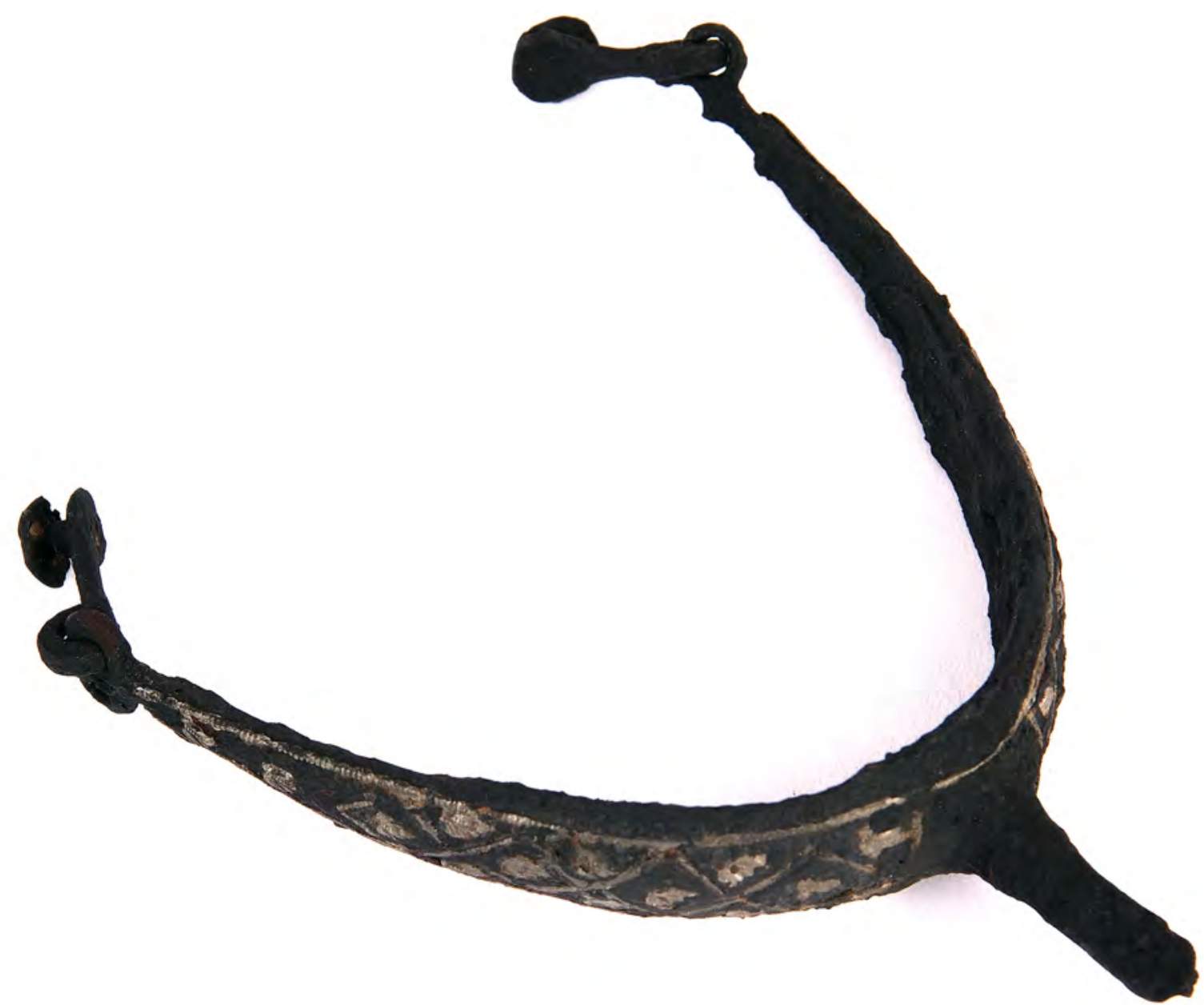

Figure 6.12: Silver-inlaid prick spur. Recovered from foundation shaft G7. Courtesy of Museums Sheffield. 

relate to particular aspects of masculinity, typically being 'ornate and designed to be visible', with spurs often presented to lords as gifts, and sometimes 'given in "homage" to lords from people lower down the social scale' (Dempsey et al. 2019, 3).

While we have to be cautious about accepting any of the artefact assemblages as fully representative of the range of activities on the site, it is striking that items with any potential military significance are so spare, despite the likelihood that they would have been preferentially sought out and retained during the excavations. This absence also appears to contrast with an inventory of the 'armour' in Sheffield Castle on $16^{\text {th }}$ November 1586 (Hall and Thomas 1914, 260-1; Figure 6.13). However, a closer look at the latter reveals that, while 24 muskets are recorded, so too is 'complet armorre for my Lo. [Lord] gilded and another black gilded for my Lo. boothe for hors and foote', suggesting that much here was for display rather than for war. The inventory of arms belonging to the town of Sheffield in 1615 - ' 3 corslets, 8 headpieces, 4 musketts, 1 caliever, 9 swords' (Hunter 1819, 105) - also serves to contextualise the material from the castle. Military activities were a small, occasional part of the lifecycles of castles, and for this reason alone it is certainly time to move beyond militarist and masculinist approaches, which tend to emphasise them (Dempsey et al. 2019, 2-3; Dempsey 2019, 782-3).

\section{Discussion}

The task of archaeologists is to write history from material remains. What survives to us from the past is a product of a range of circumstances. In this respect, Leslie Armstrong's initial account, published in a local newspaper as construction of the Co-op was bringing to light the remains of the castle, is very illuminating, for it highlights the partiality of the material record from Sheffield Castle. The task of doing archaeology on an active construction site meant that much was missed, and Armstrong (1927b) points out that the variety and number of objects recovered stand testimony to 'the extensive collection which could have been obtained had the excavated material been systematically searched. But the castle assemblage is partial in another way too. In the same report, Armstrong refers to the key, which 'had the appearance of silver' and which he linked with Mary, Queen of Scots. As we argued in Chapter 2, this association with the captive Queen was almost certainly strategic, designed to encourage the reluctant workmen to look out for and retain objects of archaeological interest. What it highlights here is the fact, while much material was 'being carted away to the tip' (Armstrong 1930, 15), this kind of object, of precious metal, with presumed historical associations, was much more likely to be recovered and preserved in our archive. The circumstances of discovery, and decisions about what is important and should be retained, have thus affected the traces of the past available to us.

On the other hand, the particular character of certain deposits means that some objects, especially ordinary, everyday things that archaeologists would not normally expect to find (Dempsey et al. 2019, 3), have survived the rigours both of time and of inattentive workmen. In this same first report Armstrong (1927b) bemoaned the 'very wet and unpleasant ... sticky black sludge' through which the foundation shafts were being dug, but it was this waterlogging of moat deposits that preserved a range of organic objects which would not normally have survived and so contributed to the special character of the finds assemblage from the castle. Thus, Armstrong (1927b) described, and illustrated for the readers of the Sheffield Daily Telegraph, the discovery of a stout leather shoe in an astonishingly good state of preservation. The upper is cut from one piece of leather, and has been secured to the sole by stitching. The shoe was fastened by means of a leather thong, which was still in place' (Figure 2.17). It was, he suggested, 'a typical leather shoe such as the retainers of the Earl would wear'. As Armstrong recognised, the moat deposits preserved the world of the ordinary, or at least more of it than is normally the case.

So while there are exceptions, the bulk of our assemblage does not resonate with images of commanders in the Hundred Years War, of the greatest earls in the land, or of siege and warfare, and this will be a disappointment only if we fall into the trap of privileging the elite occupants of castles, if we believe that only they made history. We also need to remember that the castle would not have continuously been occupied by its lords and

Figure 6.13 (page 212): An inventory of armour in the castle taken in 1586. It is entitled 'A note takenn of all my L. Armorre by Mr Whyat wch came from Yor Lp from Aurtoun Lang-feld when Yor Lp Lyed their the xvi th of November 1586 as followethe. With thanks to www.picturesheffield.com (arc02599). 
their families, who had properties across the region including the hunting lodge in the park; moreover, many of the lords were regularly engaged in affairs of state or other endeavours, which took them far from Sheffield (see Chapter 1, Section: Sheffield Castle and its elite occupants), leaving behind retainers, cooks, servants and craftworkers. These elite peripatetic households would have removed many of the high-status items when not in residence, many of which are anyway far less likely to end up discarded in the moat, from which the bulk of our finds derive. The assemblages that survive from the early and mid-20th-century excavations, therefore, largely reflect the mundane activities of all the inhabitants of this substantial building, rather than the set-piece rituals of the elite.

\section{Conclusion}

In this chapter we have finally brought to publication all of the surviving artefacts recovered during construction work on the site of Sheffield Castle in the early and mid-20th century. Only a small selection of these had previously been discussed in print, in Armstrong's 1930 paper, and some of the identifications there required updating. The surviving material record is overwhelmingly of late medieval to 17 th-century date; in this respect it is rather different from the assemblage recovered during the 2018 excavations by Wessex Archaeology, as we will see in the next chapter. What has emerged from this chapter is an alternative narrative to the popular and widely repeated accounts of Sheffield Castle that emphasise dukes, earls and the shenanigans attendant on the incarceration of Mary, Queen of Scots; here we have an archaeology of the ordinary men and women of Sheffield. We have discussed an array of mundane items in the archaeological record, such as nails, shears, timbers, twigs, and leather offcuts, which are the remnants of the work of the multitude of men and women mentioned in the written sources, and countless unnamed and undocumented others. Furthermore, even the items of more obviously elite material culture, such as dressed stone and plaster recovered from the moat fills, represent the work of a host of labourers and servants. These were the people who provided the labour for the elite displays required for the production and articulation of elite power and the concomitant subordination of the ordinary people of the town. These were also the people who made the castle and, as we will discover in Chapter 9, whose descendants probably also helped to unmake it in the 17th century.

\section{Bibliography}

The full bibliography is available at the end of this volume, or at: https://doi.org/10.22599/SheffieldCastle.k. 


\title{
Modern Excavation and Regeneration, 1999-2018
}

\author{
Ashley Tuck and Milica Rajic
}

Of course whenever a motte was thrown up, the first castle upon it must have been a wooden one. A stone keep could not be placed on loose soil. The motte, therefore, must always represent the oldest castle (Armitage 1912, 82)

It was not until the turn of the 21 st century that any systematic archaeological excavation was undertaken on the site of Sheffield Castle; all previous investigations had only been able to examine construction trenches and shafts. Two campaigns of archaeological evaluation were carried out by ARCUS in the PPG16 era: a single trench across the castle's east moat was excavated in 1999 (Davies 2000; Figure 7.1), while in 2001 two trenches were dug within its projected northern edge (Davies and Symonds 2002; see Chapter 1, Section: Sheffield Castle rediscovered: 1927-2001). Although there were brief summaries of this work in the annual report on archaeology in the region by South Yorkshire Archaeology Service (SYAS) (Saich and Matthews 2005; 2006) and the excavations were reported on in the Castle Studies Group Bulletin (Guy 2005), these remain unpublished. In 2018 Sheffield City Council commissioned Wessex Archaeology to undertake a comprehensive scheme of evaluation of the site, comprising 11 trenches and 21 geoarchaeological boreholes strategically positioned across Castle Hill and the line of the moat (Figures 7.2 and 7.3). This fieldwork was undertaken between $13^{\text {th }}$ August and $20^{\text {th }}$ October 2018, and was the first large-scale investigation of the archaeological remains on the site. Unlike the archaeological recording carried out in the early and mid-20th century, this project was not conducted principally out of personal commitment to heritage, nor was it undertaken on an ad hoc basis over lunch breaks (see Chapter 4, Section: Sheffield Castle in 1958: the threat of post-War redevelopment). It was, in contrast, a commissioned piece of modern excavation, whose methodology and quality were standardised, closely monitored and reviewed by SYAS, advisers to Sheffield City Council, and a wider Project Board, comprising representatives from Wessex Archaeology, Sheffield City Council, the University of Sheffield, Historic England and the Friends of Sheffield Castle.

In this chapter the results of the excavations undertaken by ARCUS and Wessex Archaeology will be synthesised and set in the context of the work on the site carried out in the early and mid-20th century. The chapter

How to cite this book chapter:

Moreland, J. and Hadley, D. (with A. Tuck and M. Rajic). 2020. Sheffield Castle: archaeology, archives, regeneration, 1927-2018, pp. 215-250. York: White Rose University Press. DOI: https://doi.org/10.22599/SheffieldCastle.g. CC BY-NC 4.0, https://creativecommons.org/licenses/by-nc/4.0 

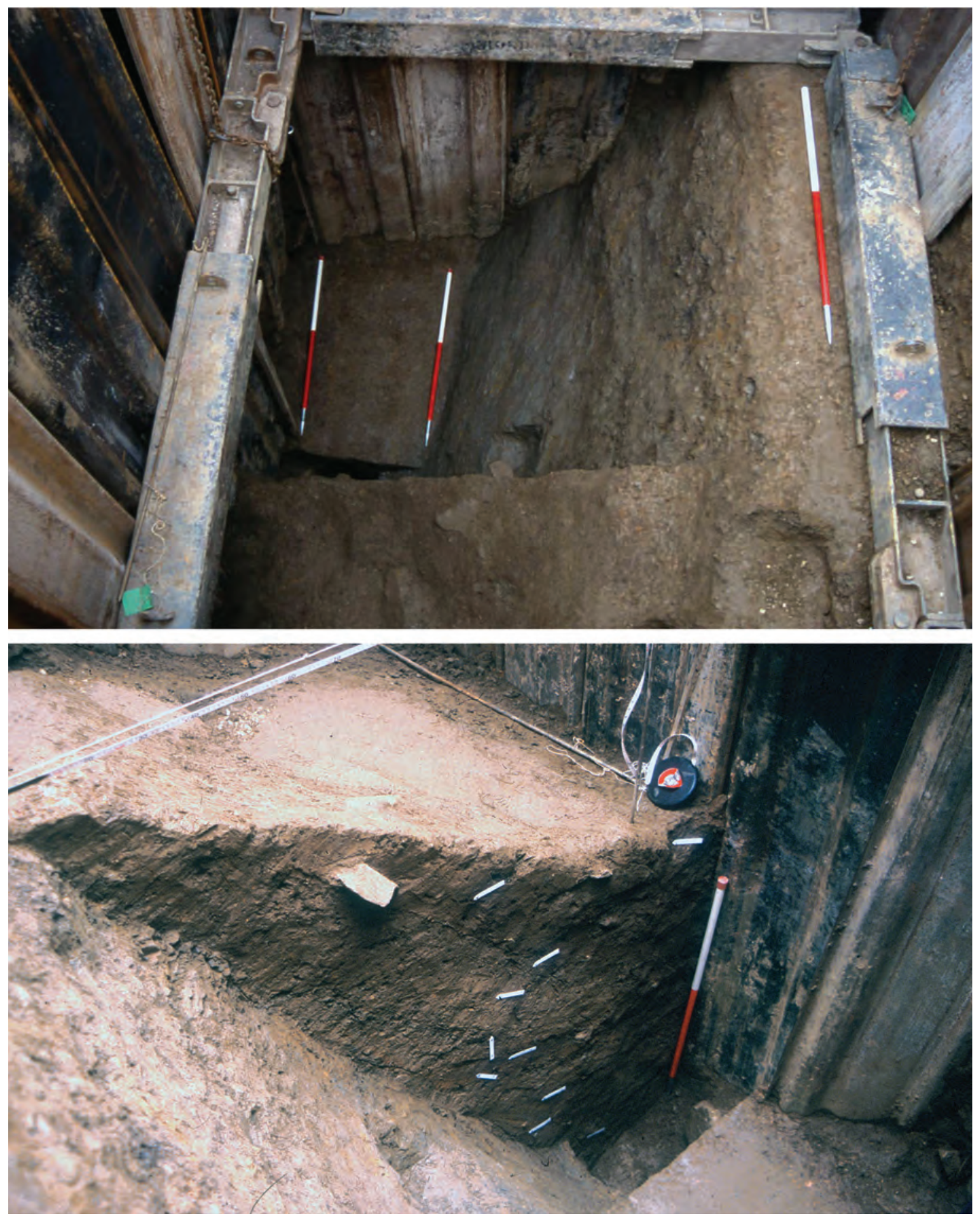

Figure 7.1: The east moat of the castle as exposed in the excavations conducted by ARCUS in 1999. These photographs show the metal shoring used in modern excavations, which is a great contrast with the ways in which the walls of trenches were braced in the early and middle decades of the 20th century, when timber, sometimes just reused doors, was used, if anything. University of Sheffield.

Figure 7.3 (page 217): Aerial photograph of the site showing the locations of the trenches excavated in 2018. Wessex Archaeology. 


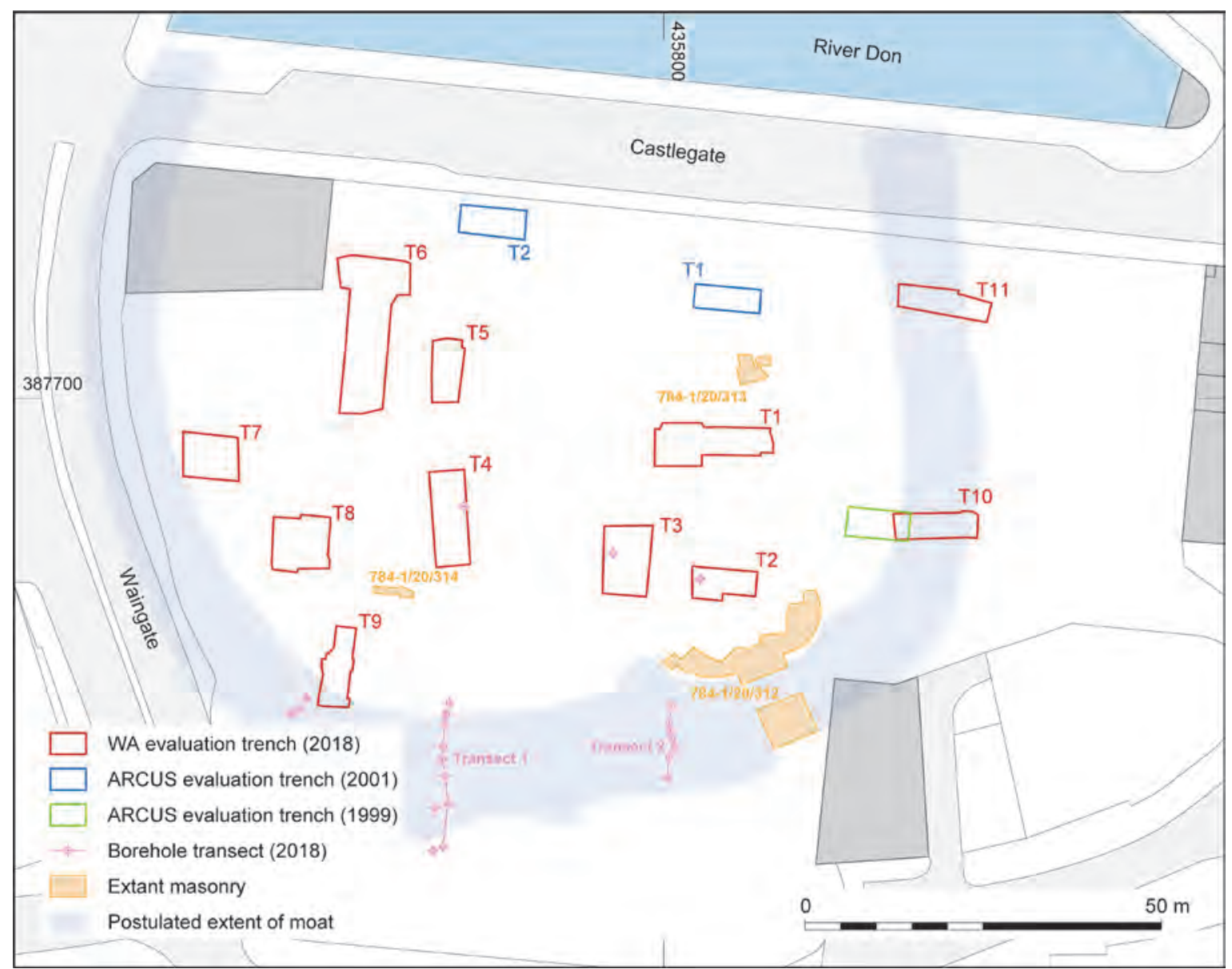

Figure 7.2: Excavations on Castle Hill. This plan shows the location of the trenches excavated by ARCUS in 1999 and 2001 and by Wessex Archaeology in 2018, as well as the probable line of the moat and the castle remains uncovered in the 1920s and 1950s. Wessex Archaeology.

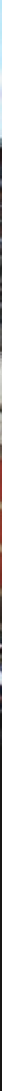


will first outline the excavation methodologies, some of which were used for the first time in the history of archaeological investigation of the site; these have resulted in considerable improvements to our understanding, not least concerning chronology. We will then describe the results of the excavations, including the artefactual assemblages, and compare them with the findings of earlier archaeological investigations.

These modern excavations (1999, 2001 and 2018), along with the 2018 borehole survey, have reinforced our ideas about the scale and form of Sheffield Castle, and have shown that in places more is preserved than was previously expected. The 2018 evaluation confirmed many of the findings of earlier generations of archaeologists, albeit that, as we will see, we have been able to refine the dating of phases of activity. It also provided significant new information relating to the castle's origins, and was the first detailed study of the post-medieval remains of the site. The Wessex Archaeology excavations, in other words, were the first investigations of Castle Hill to explore the deep history of this locale (including, but not limited to, the castle), with significant implications for how to deploy its heritage in the interests of regeneration.

\section{Old practices and new technology}

Unlike the excavations undertaken in the early and mid-20th century - for which no formal brief was issued and the context and aims of which we have had to reconstruct from interrogation of their archives - those conducted by both ARCUS and Wessex Archaeology had a clear mandate and strategy. As plans for the future of Castle Market were being explored by the City Council in the late 1990s, ARCUS was commissioned to undertake a programme of archaeological and cultural heritage assessment. As noted in Chapter 1, a deskbased assessment was produced in 1998 by Paul Belford and three evaluations were conducted (Belford 1999; Davies 2000; Davies and Symonds 2002). Their principal aims were to assess the potential survival of archaeological remains, of both the castle and subsequent developments on the site. Belford's $(1998,1)$ desk-based assessment was intended to accompany a planning application, and to provide a strategy for future archaeological work. It was written in accordance with the Institute for Field Archaeologists' $(1994,1)$ definition of a desk-based assessment as a collation of existing written and graphic information in order to identify the likely character, extent, quality and worth of the known or potential archaeological resource in a local, regional or national context.

The desk-based assessment was largely informed by the South Yorkshire Sites and Monuments Record, maintained by SYAS, historical sources held by Sheffield Archives, and a limited range of secondary sources, including Armstrong's 1930 paper. Belford (1998, 10-24) argued for the potential for surviving archaeological remains beneath modern development on the site, particularly where they had not been disturbed by deep foundations, and recommended that future work 'should sample as wide a range of deposits as possible across the site' (Belford 1998, 35). He also drew attention to PPG16 paragraph 12, which required developers to prepare 'sympathetic designs' where important archaeological remains were known or suspected, by positioning foundations to avoid them, raising ground levels of any new structures on the site, and careful siting of landscaping. While highlighting the possibility of exposing some of the remains, which 'would be of considerable interest to the people of Sheffield ... an excellent and far-sighted long-term solution', he recognised that the other solution recommended by PPG16, in paragraph 25, would be more likely, which was to preserve the remains 'by record' (in other words, in the detailed plans, sections, photographs and notes made during excavation) (Belford 1998, 25, 36).

The ensuing ARCUS excavations were not the wide-ranging assessment that Belford's report advocated, as buildings were still in use and access was limited. In 1998 an evaluation was conducted to the east of Shude Hill in the Broad Street car park, in advance of a proposed large-scale development of the wider markets area, on behalf of Tarmac Development Management. SYAS had agreed that 'an ad hoc programme of archaeological evaluation [was] acceptable, with trial trenching being undertaken as and when open space becomes available' (Belford 1999, 1). Thus, despite the recommendations of Belford's desk-based assessment, financial reality and logistics determined that a piecemeal approach would be adopted to the recommended 'preservation by record'. Two trenches, each $10 \mathrm{~m}$ by $22 \mathrm{~m}$, were excavated on either side of the Sheaf. Trench 1 , on the west side of the river, was intended to explore 18th- and 19th-century activity on the site, while Trench 2, on the east side, was positioned to investigate 19th-century and earlier tenements. As well as the tanning pits referred to in Chapter 6, the excavations succeeded in demonstrating that the archaeology on the west side of the river, 
closer to the location of the castle, was varied and included traces of medieval activity which had survived 19th-century industrial construction (Belford 1998, 36-7). The following year, ARCUS evaluated the area of the Castle Market lower loading bay on the east side of Castle Hill, targeting the moat with a single trench $(9 \mathrm{~m} \times 4 \mathrm{~m})$ and four boreholes, which concluded that it was dry but acknowledged that the bottom had not been reached as deeper excavation was not possible. The excavations in both years sought to gather information about the 'character, extent, state of preservation and date of any archaeological deposits' (Davies 2000, 3; also Belford 1999, 9). Both excavations saw the value of collecting environmental samples, although insights from them were, in the end, limited. In 2001, ARCUS was commissioned to undertake additional evaluation while plans for Castle Market were further considered. A specific aim was to assess the survival of castle remains at the north of the site (Davies and Symonds 2002, 6). All three campaigns were conducted by small teams of professional archaeologists. Despite the limited scale of the excavations, they were instrumental in convincing the City Council to move the markets to a new site in the city centre (Minutes 2008; Chapter 1, Section: Sheffield Castle rediscovered: 1927-2001).

The 2018 investigations by Wessex Archaeology were commissioned by the City Council in the context of discussions about the regeneration of the area after the markets were moved in 2013, and required the excavation and recording of 11 evaluation trenches accompanied by a geoarchaeological borehole survey (Figures 7.2 and 7.3). The requirements of the evaluation were set out in a specification prepared by Ed Dennison Archaeological Services in 2014 (see Chapter 1, Section: The excavation archives and the city), updated by SYAS in 2017. This was then used by the Council in the tender process for the work to be undertaken, and, once commissioned, Wessex Archaeology addressed them in a Written Scheme of Investigation (Tuck and Rajic 2018, 13-15), based on guidance issued by the Chartered Institute for Archaeologists (2014) and agreed in advance of fieldwork with SYAS. Seven aims were identified, including:

to establish the presence/absence, nature, date, quality of survival and importance of any archaeological deposits ... to determine the profile of the [east] moat ... to gather information on the nature of the foundations of the former Castle Markets ... and, to inform the formation of a mitigation strategy and management strategy.

To achieve these aims, 20 objectives were established, supplemented by detailed rationales for each trench. In brief, the trenches were positioned to investigate the location and preservation of the remains of all phases of the castle and its fate at the end of the Civil War. More than this, however, there was an explicit focus on the recovery of information about periods largely ignored by the earlier investigations, for example the 18th and 19th centuries, when the site was occupied by a bowling green, slaughterhouses and the iron and steel industry. Further, the trenches were positioned to investigate areas where the level of preservation was uncertain, to fill in the 'blanks on the map' of our understanding of the archaeology and geoarchaeology of Castle Hill.

The 2018 archaeological team comprised four members of staff from Wessex Archaeology (Sam Birchall, Amy Derrick, Milica Rajic and Ashley Tuck), with two more (Liz Chambers and Richard Payne) conducting the borehole survey. However, reflecting the circumstances in which the excavations were devised, with a focus on public engagement and the wider regeneration debates within the city, there were also four students on placements from the University of Sheffield (James Chapman, Georgina Goodison, Paul Harrison and Isabelle Sheriff) and five volunteer members of the public each day. A further five volunteers were based each day at Wessex Archaeology's Sheffield offices - located in a converted industrial building in Heeley on the western edges of the former deer park (see Chapter 8) - cleaning finds and undertaking other post-excavation tasks. In total, over 350 volunteers participated in the project.

The site has been shaped over the last 90 years by extensive construction, and now consists of several platforms on varying levels, which reflect the locations of the former markets and other buildings, with the highest platform in the centre of the site, and lower platforms surrounding it to the east, south and west. Castlegate, constructed in 1930, lies at the lowest level to the north of the site, parallel to the River Don (see Chapter 3). Although the River Sheaf is not visible, it still runs in a culvert beneath the modern streets from south to north along the eastern edge of the site. The 11 trenches distributed across Castle Hill were up to $7 \mathrm{~m}$ wide and up to $20 \mathrm{~m}$ long. Trenches $1-6$ and Boreholes $1-3$ were strategically positioned to investigate the largely unexplored upper platform (54.39-55.80m AOD), while Trenches 7-11 and Boreholes 4-21 were positioned to provide more information about the remaining archaeology of the lower platforms (48.90-52.37m AOD; Figures 7.2 
and 7.3), especially the location and form of the castle moat. All trenches were excavated using a machine with a $1.8 \mathrm{~m}$ wide toothless bucket to remove concrete and overlying rubble, followed by hand excavation of all archaeological layers. The trenches were hand-cleaned to identify and clarify complex deposits and structures, all of which were recorded in section and plan. Levels within each trench were then further reduced by hand and machine to investigate deeper layers.

Recording was carried out by standard methods including the use of context numbers and pro forma sheets, extensive digital and film photography, and both drone and video filming. The site was drawn digitally using Global Navigation Satellite System (GNSS). Contextual evidence was collected for all artefacts and environmental samples. In addition to Wessex Archaeology's digital record, volunteers, students and visitors were encouraged to take and share photographs of the site. Volunteer Paul Rowland (2019), a member of the local Harthill with Woodall Archaeology Group, captured a particularly comprehensive and valuable photographic archive, which was initially made available online on the Flickr image sharing site but subsequently published in a book. Here we see a very different type of public engagement with the archaeology of the site than during earlier generations of excavation, when the local community was largely kept at a distance, and lay assistance was not officially encouraged' (Butcher 1972a, 6). With a few exceptions, such as Joseph Himsworth's mother, who was presented with a souvenir of the finds by the Clerk of Works Reg Loughran (Himsworth 1927-42, 9), most interested members of the public had to wait for newspaper articles and queue to see museum displays in the months and years afterwards ('Old Sheffield', 1929). In 2018, in contrast, members of the public were on site and encouraged to disseminate information about what had been found.

The artefactual assemblage comprised medieval, post-medieval and modern material. Assessments of each category of artefact have been carried out by a relevant specialist. The use, where possible, of the same specialists who studied the material from the late 1920s and 1950s excavations (see Chapter 6) ensured consistency of approach and interpretation, and allowed knowledge gained from the study of the legacy archives to feed into the study of the new material. A bulk sampling strategy was also implemented to secure critical environmental and dating information, with a minimum of 40-litre samples taken from targeted secure archaeological contexts, and further samples taken from the most significant deposits. The boreholes were extracted using a window sampler - a cylindrical tube driven into the ground to extract soil samples enabling laboratory testing for microfossil assessment and dating evidence on different deposits across the upper and lower platforms.

\section{The first castle}

Despite the lack of any evidence at that time, in her 1949 history of Sheffield Mary Watson $(1949,24)$ assured us that 'the castle itself would be of the Norman "motte and bailey" type, partly of stone, but mainly of wood' (see also Jones 2004, 27; Belford 1998, iv, 20-1). It is unclear how she arrived at this conclusion; it was probably simply an assumption that this was the sort of fortification that Normans built. Subsequent reviews of the archaeological record have consistently pointed to the absence of any archaeological evidence for a motte and bailey on this site (Richardson and Dennison 2014a, 8, 86; McCoy and Stenton 2009, 8). However, the 2018 excavations have turned this debate on its head.

In 2018 Wessex Archaeology recorded a substantial mound of redeposited alluvium at an elevation well above the floodplain levels in Trenches 2 and 3 in the south-east and south, respectively, of what would become the inner courtyard of the castle. The surviving top of this mound is at $51.68 \mathrm{~m}$ AOD (Figure 7.4). This orange/ brown silty alluvial clay differs from the underlying, natural, alluvium through the presence of tiny fragments of charcoal. Iron accumulations were also identified throughout the deposit, either deriving from later fluctuations in water level or included within the deposits when they were laid down to form the mound. In addition, the upper levels of the mound had sandstone inclusions, which dipped to the south-east, and in places the redeposited alluvium contained layers of blue clay (Figure 7.5). Prior to construction, ground preparation works had been undertaken, removing soil and the upper layers of natural alluvium, producing (in Trench 2) a 'step' with the ground surface sloping away at a $45^{\circ}$ angle towards the gatehouse $c .14 \mathrm{~m}$ to the south (Tuck and Rajic 2019, 30-1). This is reminiscent of the situation at Oxford Castle, where the motte was constructed as a series of steps which were subsequently filled with a clay/gravel mix, the whole being then capped with a layer of grey-blue clay (Munby et al. 2019, 135). 


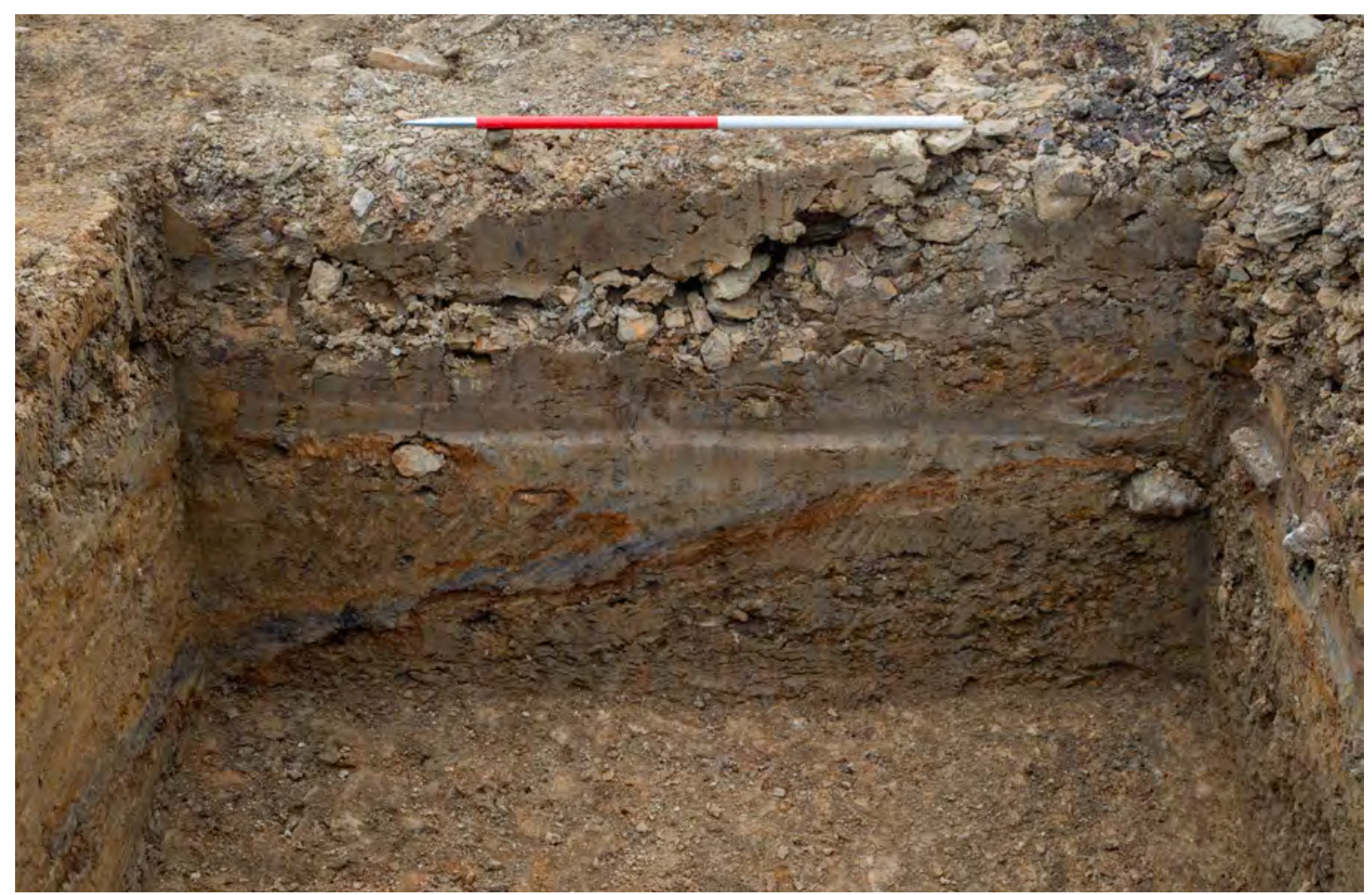

Figure 7.4: Section through Trench 2. This shows the make-up of the probable motte. Wessex Archaeology.

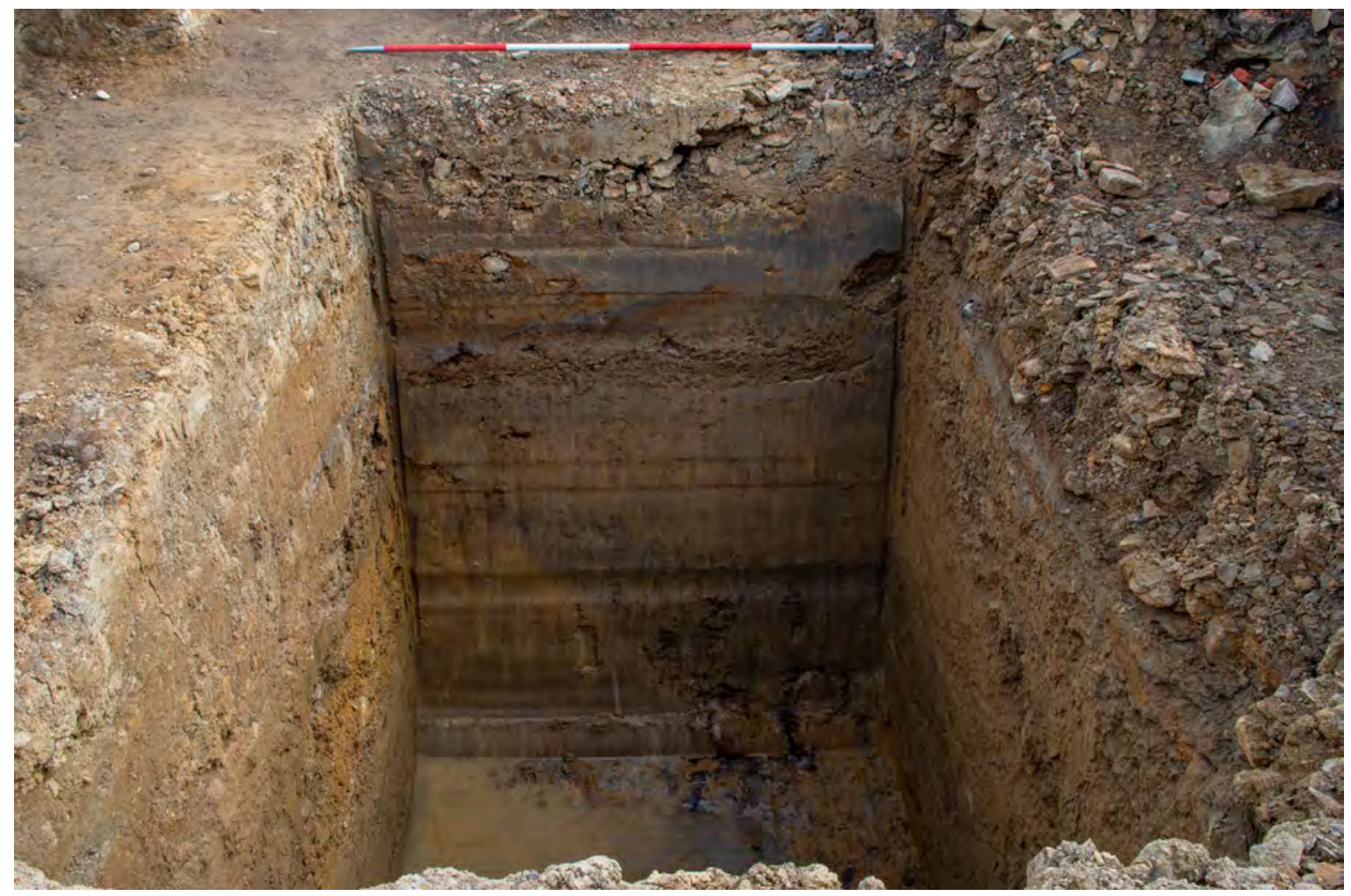

Figure 7.5: Soil profile in Trench 2 after deeper excavation. This reveals the upper levels of the motte, which had sandstone inclusions, which dipped to the south-east, and in places the redeposited alluvium contained layers of blue clay. Wessex Archaeology. 

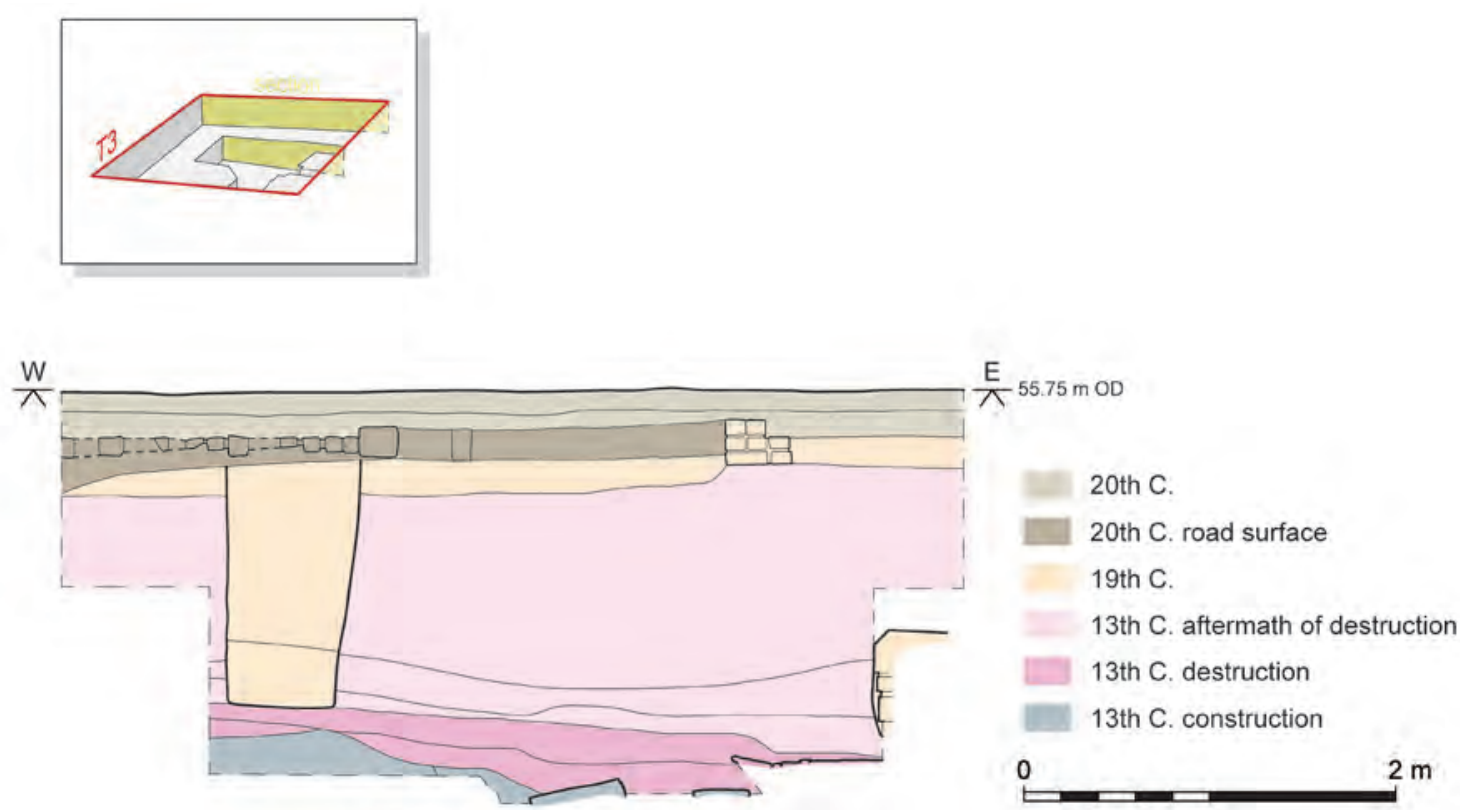

Figure 7.6: Section of Trench 3. This depicts a linear feature, $0.52 \mathrm{~m}$ wide, comprising two courses of large unworked flat stones and associated deposits (labelled '13th C. construction' in the key), which capped the demolition layers of the early castle. Wessex Archaeology.

Excavation to a depth of $52.1 \mathrm{~m}$ AOD (3.65m below ground level) in Trench 3 recorded further layers of redeposited alluvium with varying levels of charcoal inclusions (1-5\%) and redoximorphic states (some layers were yellow, others blue; one of the layers had brown soil mixed into the alluvial material). A $0.52 \mathrm{~m}$-wide linear feature of large unworked flat stones capped these layers. It ran from south-east to north-west, surviving to two courses, and appears to have been constructed in a single phase (Figure 7.6). After it was built, clay layers continued to accumulate (Tuck 2020). It is noteworthy, in this context, that elsewhere there is evidence that mottes were 'clad with wooden boards or stone slabs to prevent soil wash and make [them] more difficult to climb' (Pounds 1990, 17).

It is difficult to determine a date for the creation of this mound, due to the sterility of the deposits from which it was originally formed - there were no artefacts securely within that context (but see below). Therefore, we needed to rely on scientific dating methods, and so optically stimulated luminescence dating (OSL) and portable optically stimulated luminescence dating (pOSL) samples were taken from the mound deposits. Luminescence techniques enable dating of inorganic materials by measuring the length of time since they were last exposed to light. Our intention was to assess whether the quartz sand within the alluvium had been 'reset' (i.e. exposed to light) at the time of the construction of the motte, which would help to date it. However, the analysis of the luminescence samples from Trench 2 produced a range of dates from the first to the 15th centuries $\mathrm{AD}$ and so it was clear that the grains analysed had not been fully reset during construction (Tuck 2020). Despite the absence of supporting evidence from the OSL dating, the motte seems unlikely to be any later than the mid-12th century, as none are known to have been constructed in England after $c .1170 .{ }^{23}$ Thirteenthcentury pottery (Reduced Sandy ware, North Nottinghamshire Quartz \& Shell ware and Hallgate A-type ware; Cumberpatch 2020; Young 2020) found in association with the mound in the Trench 3, and perhaps the stone capping, suggest continued modifications to the structure.

Given the nature of our archaeological encounters with the motte (in separate trenches in the south-east corner of the site, and in a machine-cut section in one of those) it is difficult to estimate its size - but something of the order of $c .25 \mathrm{~m}$ across looks likely (see Figure 7.2 for the position of these trenches), and this would put it

${ }^{23}$ We are grateful to one of the anonymous manuscript reviewers for updating Pounds's argument that none were built after the accession of Henry II in 1154 (1990, 21). As they rightly point out, 'textual evidence for motte builds is rarely available, in fact, and future archaeological research might well push the building of mottes to an even later, rather than an earlier, date'. 


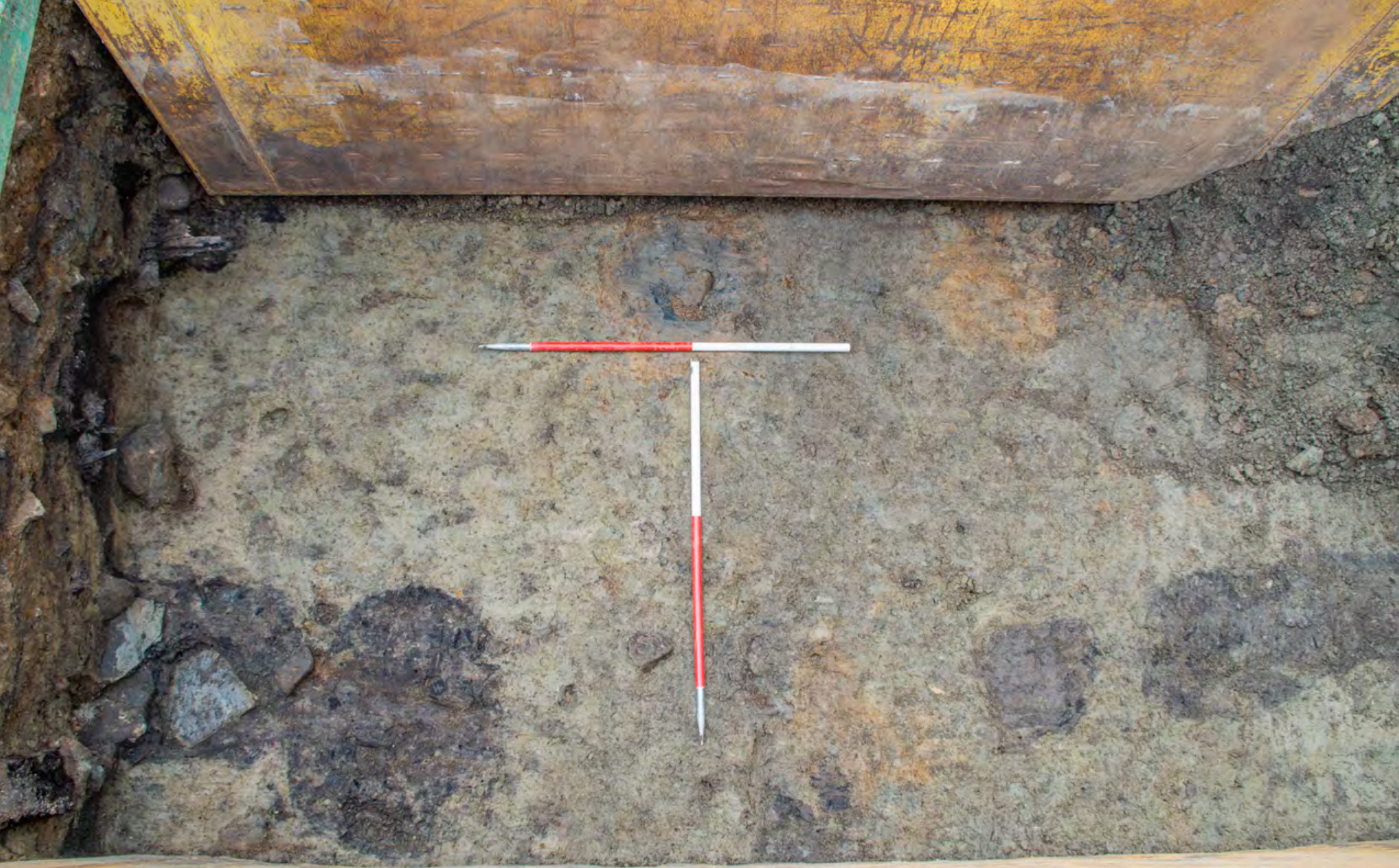

Figure 7.7: Some of the earliest features on the site. Two gullies or beam slots terminate adjacent to a posthole in Trench 6. Wessex Archaeology.

at the smaller end of the range of medieval mottes (Pounds 1990, 15-17). The material for the construction of the motte could have come from anywhere in the surrounding area. Usually, the surrounding ditch provided at least some of the material (Pounds 1990, 18; Munby et al. 2019, 32; Higham and Barker 1992, 198), and the same might be true here. We have on several occasions remarked on the difference in depth between the south moat and the sections of moat on the east and west sides of the castle - might the south moat be all that survives of the ditch which surrounded the 'first Sheffield castle'? If it is, we need, once again, to acknowledge the insights of Leslie Armstrong $(1930,16)$, the 'pioneer' archaeologist of Sheffield Castle (Butcher 1961, 6), who argued that 'the ditch considerably antedates the castle.' In this context, it might be significant that Leslie Butcher recovered fragments of 12th-century pottery from the base of the moat (in shaft $\mathrm{H} 2-4$ ) close to the (future) gatehouse.

The 2018 excavations in the area to the north and north-west of the motte produced further evidence for structures and surfaces which were roughly contemporaneous (and therefore probably associated) with it. In Trench 6, in the north-west corner of the site, a complex sequence of deposits and cut features were identified at $50.39 \mathrm{~m}$ AOD, only $0.7 \mathrm{~m}$ above the present level of the modern Castlegate road to the north. The earliest features were two gullies or beam slots, each terminating adjacent to a posthole (Figure 7.7). These are stratigraphically the deepest features within the area of the upper platform. A radiocarbon date of cal AD 1030-1200 at the $95 \%$ confidence rate was acquired from waterlogged plant remains in the form of a hazelnut shell (Corylus avellana; Tuck 2020). Furthermore, dendrochronological analysis suggests that the oak timber from a layer associated with the postholes and beam slots 'is unlikely to be much later than the mid-12th century' (Tyers 2020). Above these gullies was a sequence of two layers and small pits dug into them, which were overlain by two levelling deposits or 'made ground. These contained no datable evidence, but were cut by a pit which yielded a single sherd of pottery of unknown type, but broadly dated to the medieval period, as well as a primary fill of dense, reddish-black slag. The slag is from a secure medieval context, and of similar character to 
slag recorded in other trenches on the upper platform, and provides evidence of medieval industrial activity in, or close to, the castle (Andrews and Mackenzie 2020).

Sealing these deposits in Trench 6 was a stone rubble layer through which another pit had been dug, and which contained a long rough block of magnesian limestone (Tuck 2020). As we saw in Chapter 6, 15th-century Account Rolls record that stone was transported to the castle from quarries at Roche Abbey (South Yorks) for the construction of a Great Tower in 1445-46 (Thomas 1920-24, 71), although the large stone found in Trench 6 shows no evidence of use. Redeposited alluvium overlying this complex sequence of medieval features contained 11th-/12th-century Hand Made White Sandy ware and 12th- or 13th-century White Sandy ware pottery (Cumberpatch 2020). These sherds are some of the earliest dated artefacts from the site from a secure context.

Just to the north-east of Trench 6, in their 2001 Trench 2, ARCUS recorded a pair of square pits, which they interpreted as part of the 'de Lovetot' castle, although this was on the basis of a single sherd of shell-tempered pottery, which could only be broadly dated to between the late 12th and 15th centuries (Davies and Symonds 2002, 11-12, 31). Nonetheless, this interpretation can now be broadly supported by reconsidering the stratigraphic position and levels of these features. The pits were cut into redeposited alluvium, which at the time of the ARCUS excavation was assumed to be natural (Davies and Symonds 2002, 11, 29). The bases of the pits identified in 2001 were at $51.70 \mathrm{~m}$ and $51.55 \mathrm{~m} \mathrm{AOD}$, respectively, and are within the range of the features identified in Trench 6 in 2018 at 50.39-53.0m AOD. It is arguable, therefore, that they belong to one of the 11th- to 12th-century phases of activity recorded by Wessex Archaeology in 2018.

And here we might return to a series of features noted by Leslie Butcher. The first is a pit at the northern end of the east section across Castle Hill (Butcher 1972a, 8; 1972c, 9; n.d. (s), no. 299; Figures 5.20, 5.21), close to where Joseph Himsworth (1927-42, 17-18, fig. 47) had seen masonry in 1930. The pit contained a series of clay fills, as well as twigs, rushes and hazelnut shells. We have no dating evidence from this pit, but its position on the section should make it 'early' and it is in rough alignment with those in Wessex Archaeology's Trench 6 and the ARCUS Trench 2, although this does not necessarily imply a structural connection. Butcher also noted that a similar pit was exposed during excavations close to the Bull \& Mouth public house, which lies at the north-west corner of the site, close to Wessex Archaeology's Trench 6, while at the same horizon 'a narrow curving ditch' was located in the service yard west of the market (Butcher 1972a, 8). Finally, on the south side of Castle Hill there are the two 'Exchange Street ditches', which, we have argued, Butcher believed to be among the earliest features on the site.

At the west end of Wessex Archaeology's Trench 1 further evidence of the early castle comprised five layers of redeposited alluvial clay (starting from 51.5m AOD), containing 13th- or 14th-century Oxidised Sandy ware pottery (Cumberpatch 2020), sealed beneath a much-disrupted cobblestone surface (Tuck 2020). This surface had been disturbed, with the upper interface rising from $52.2 \mathrm{~m}$ to $52.8 \mathrm{~m}$ AOD. At roughly the same depth $(53.09 \mathrm{~m} \mathrm{AOD})$ and $35 \mathrm{~m}$ to the east, in Trench 5, a better-preserved cobblestone surface was encountered (Figure 7.8). The base of the surface contained three sherds of 13th-century Hallgate A-type ware (Cumberpatch 2020), plus a few charred cereal grains and seeds of plants associated with both food storage and processing, as well as scrubby vegetation (Simmons and Jones 2020). A 13th-century copper-alloy toiletry item (an ear scoop and fingernail cleaner) was found between the stones (Figure 7.22), while charred plant remains (spelt wheat, Triticum spelta) from the matrix between them produced a radiocarbon date of cal AD 1170-1260 at the $95 \%$ confidence rate (Tuck and Rajic 2019, 85, 96, 194). Although patchy in places and with indication of repairs, all our evidence points to this being a 13th-century courtyard associated with the early castle. Further traces of this courtyard may have been encountered during ARCUS excavations nearby, but the remains in Trenches 1 and 5 are the most extensive yet exposed, and the only ones to be firmly dated.

Within one of the layers of redeposited alluvium recorded in both Trenches 1 and 5 there was a dark red deposit containing iron smelting slag and tap slag. As noted above, a small amount of similar slag was also recovered from medieval deposits in Trench 6. The slag seems to have been used to repair or replace an earlier cobblestone surface, and although we do have to accept the possibility that it might have come from elsewhere - note the cinder brought from the deer park to repair the path from the great hall to the gate, as recorded in mid-15th-century Account Rolls (Thomas 1920-24, 71; Chapter 6, Section: Fragments of 'the most notable local building historically') - it nevertheless suggests that ironworking had taken place in the vicinity of the castle. Radiocarbon dates acquired from organic remains in these levelling layers suggest that they date to the 12th or 13th centuries: one from Trench 1 was from charred remains of rye grain (Secale cereal; cal AD 1170-1260; Tuck 2020); a second from this trench, in a deeper layer, was from the charred remains of a 
Armstrong, Himsworth and Butcher (see Chapters 3 and 5). What the material culture and the scientific dates from the 2018 excavations also make clear is that there is no evidence of an 'Anglo-Saxon' phase. When this is combined with a similar absence of evidence from the ARCUS investigations in 1999 and 2001, the lack of any finds from that period identified in our analysis of the archives from the late 1920s and 1950s excavations, and the re-dating of Armstrong's 'Saxon' building to the 13th century, we can be reasonably confident (but not certain) that there was no Anglo-Saxon settlement - whether belonging to Waltheof or anyone else - on Castle Hill.

\section{Destruction}

In Trench 3 both the stone linear feature and mixed clay deposits of the motte were sealed by two demolition layers comprising dark brown, humic silt clay and containing a rich environmental assemblage including both charred and uncharred seeds and wood. Charred cereal grains recovered from the lowest layer included oats, hulled barley, rye and free-threshing wheat. The taxa in the uncharred seed assemblage includes plants commonly associated with disturbed fertile soils and cultivation, such as redshank (Persicaria maculosa), knotgrass (Polygonum aviculara agg.) and black bindweed (Fallopia convolvulus). Scrub-type vegetation was represented by bramble (Rubus fruticosus), alder (Alnus glutinosa) and elder (Sambucus nigra), as well as a particularly high concentration of hazelnut shell (Corylus avellana) (Tuck and Rajic 2019, 84-5; Simmons and Jones 2020).

The lower of the two demolition layers was blue in hue, with vivianite present throughout the deposit as a result of the chemical reaction of phosphates, iron, water, and a dearth of oxygen. The upper layer had a red hue, also with vivianite throughout. Within this latter deposit a series of parallel unburnt pieces of wood were also found, representing a collapsed fence or wall. At least one of the pieces was of small hazel roundwood; others were thin pieces, perhaps cut from oak timbers (Tuck and Rajic 2019, 34). Burnt material, including wood, seeds and hazelnut shells, was recovered from these layers, and is consistent with the evidence for burning reported by Armstrong $(1930,22-3)$. As we saw in Chapter 3, on $4^{\text {th }}$ April 1929, Himsworth $(1927-42,15)$ described a number of 'spars' as 'blackened and water-soaked' or waterlogged. He noted that some were 'spotted with bright blue mould', which we can now identify as vivianite. He also noted that others were 'crozzled by fire ... in horizontal position as though they might have been thrown down'. In sum, we have been able to confirm, and explicate, the archival accounts of the earlier excavations, which once again show themselves to be reliable - if occasionally overwrought - accounts of the archaeology on Castle Hill.

In general, the position and composition of these layers are consistent with Armstrong's (1930, 22) observations concerning the presence of rich organic and burning deposits, which, as we saw in Chapters 2 and 3, he associated with his 'wished-for' Saxon structures. Twelve sherds of 13th-century pottery were recovered from the two demolition layers in Trench 3, comprising Reduced Sandy ware, North Nottinghamshire Quartz \& Shell ware and Hallgate A-type ware pottery (Tuck and Rajic 2019, 34; Cumberpatch 2020; Young 2020). While some burning had clearly taken place, it was much later (13th century) than Armstrong and Himsworth hoped for. As noted in Chapter 3 (Section: The ashes of 1266?), we know from written records that in 1266 'Johane D'eyvill cum equiis et armis' burnt 'Saffield' during the Barons' War, and it would be tempting, as Armstrong did, to read the archaeology recorded in 2018 as a product of the events described in texts. As we have emphasised throughout this book, however, this text-driven approach is problematic, not least because it discourages us from seeking other explanations for what we see in our trenches - there had probably been many destructive fires in the castle. Further, this 'burning of Saffield' is one of the key moments in the narrative history of the town, and one wonders whether an awareness of that historical event encouraged Armstrong to read layers which were a mixture of burning and processes of organic decay (both resulting in 'blackness') as evidence of 'destruction'? On the other hand, it would be churlish to dismiss the possibility that this is, in fact, a product of the actions of John D'Eyvill and that these layers represent the remains of 'Saffield'. One of the timbers from Trench 3 has been dendrochronologically dated to at least the first half of the 12th century, so if the layers in which it was incorporated were created by D'Eyvill and his retinue then the structure of which it was a part was already a century old - and perhaps, therefore, from the first castle.

\section{New beginnings}

The 2018 Wessex Archaeology excavations found evidence for landscaping across the site, probably in readiness for a programme of construction; our analysis of the archives suggests that Himsworth and Butcher may have 


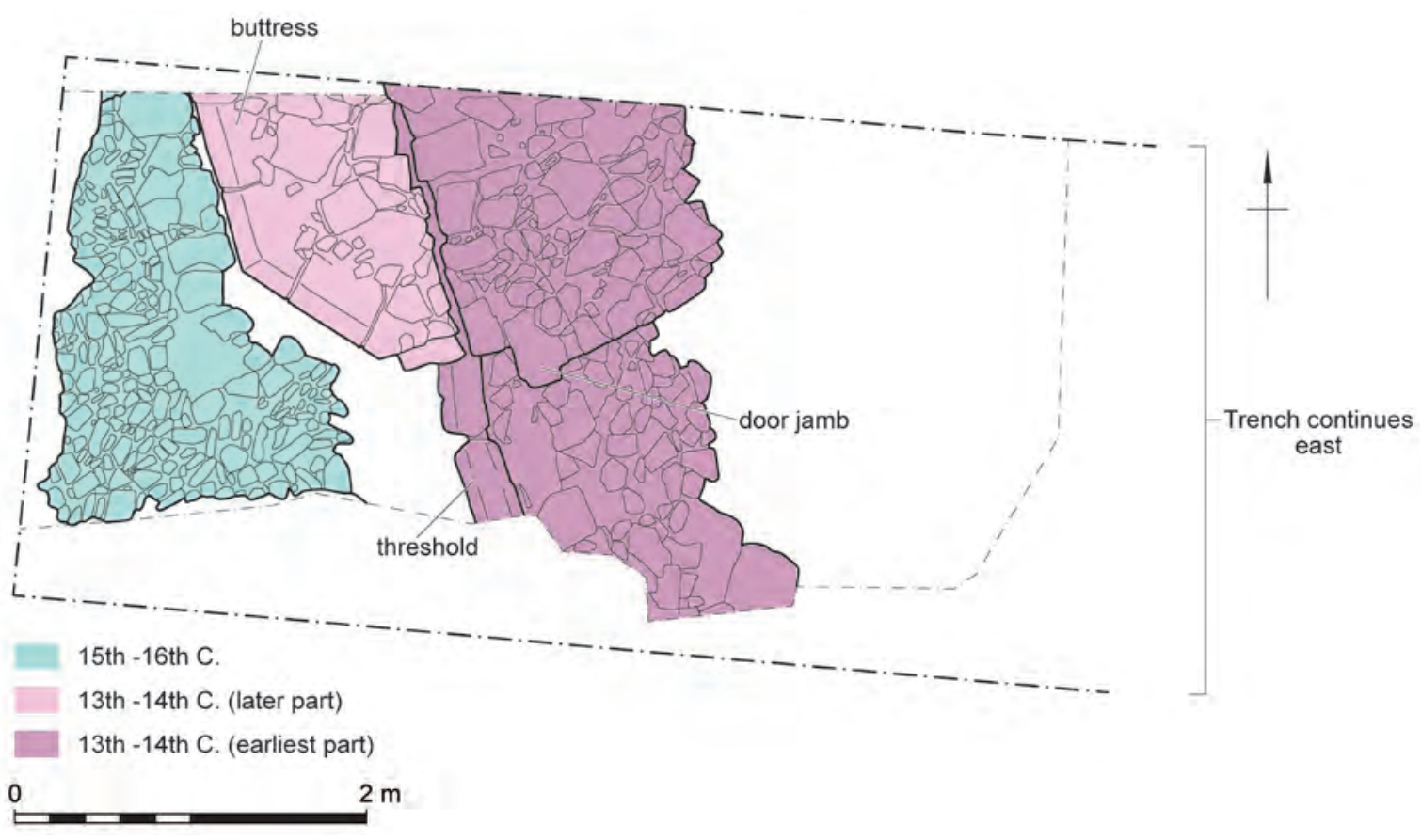

Figure 7.9: Plan of medieval structures excavated in the 2001 ARCUS Trench 1. Wessex Archaeology.

witnessed the same phenomenon. The two aforementioned organically-rich demolition layers in Trench 3 were sealed by redeposited alluvial clay mixed with a little of the demolition material. This sequence was truncated and a further layer of redeposited alluvium was laid down, presumably to level the site (Tuck and Rajic 2019, 34-5) - a perennial process on Castle Hill (and one to which we will return shortly). An additional layer of organicrich demolition material, probably sourced from the earlier destruction contexts, was sealed by yet another layer of redeposited alluvium. These levelling deposits contained five sherds of 13th- or 14th-century pottery. The sequence points to intense reuse and redistribution of the existing deposits within the inner courtyard at this time.

In 2001, in Trench 1 at the north-east corner of Castle Hill, ARCUS recorded a 1.6m-wide stone wall on a roughly north-west/south-east alignment comprising a rubble core with dressed stone blocks bonded with lime mortar (Figure 7.9). This, they argued, formed a continuation of the western side of the substantial stone courtyard building first recorded by Armstrong $(1930,10)$ and since preserved in a chamber below the Castle Markets (Davies and Symonds 2002, 9-11). If so, and there is no reason to doubt it, then it belongs to the phase of the significant restructuring of the castle of which the gatehouse is now, and probably was then, the iconic structure. As we argued in Chapter 3 (Section: Courtyard buildings), the gatehouse and the courtyard building belong to the same phase of construction, as revealed by the presence of identical masons' marks on the plinths of both structures (Armstrong 1930, 20, plate IV). At the southern end of this wall there was a doorway with a simple chamfered surround, on which patches of plaster had survived. Two large chamfered stones formed a threshold at $53.85 \mathrm{~m}$ AOD. Inside the doorway (i.e. to the east) was a robbed-out staircase, of which only the rubble steps and some of the stone flags survived, and which once led to an undercroft or cellar (Davies and Symonds 2002, 9-10). Here one immediately thinks of the 'vaulted apartment' recorded just to the south-east by Armstrong (1930, 20, figs. 12 and 13). Himsworth (1927-42, 10, fig. 34) importantly recorded the following on $30^{\text {th }}$ November 1928: 'the vaulting suggested a large span and must have crossed the space cut into by the market brick foundation'. The 2001 ARCUS excavation lay just on the other side of this. A few stones may tentatively be interpreted as evidence of a courtyard associated with this wall (Davies and Symonds 2002, 10).

A buttress faced with chamfered ashlar blocks was later added to the outside of the wall to the north of this doorway, and slightly overlapping the stones of its threshold. Fragmentary remains of a stone flagged/ cobbled surface were associated with this buttress, demonstrating that a courtyard surface had certainly been constructed in this phase. Twenty-five metres to the north-west, the ARCUS Trench 2 revealed two further 


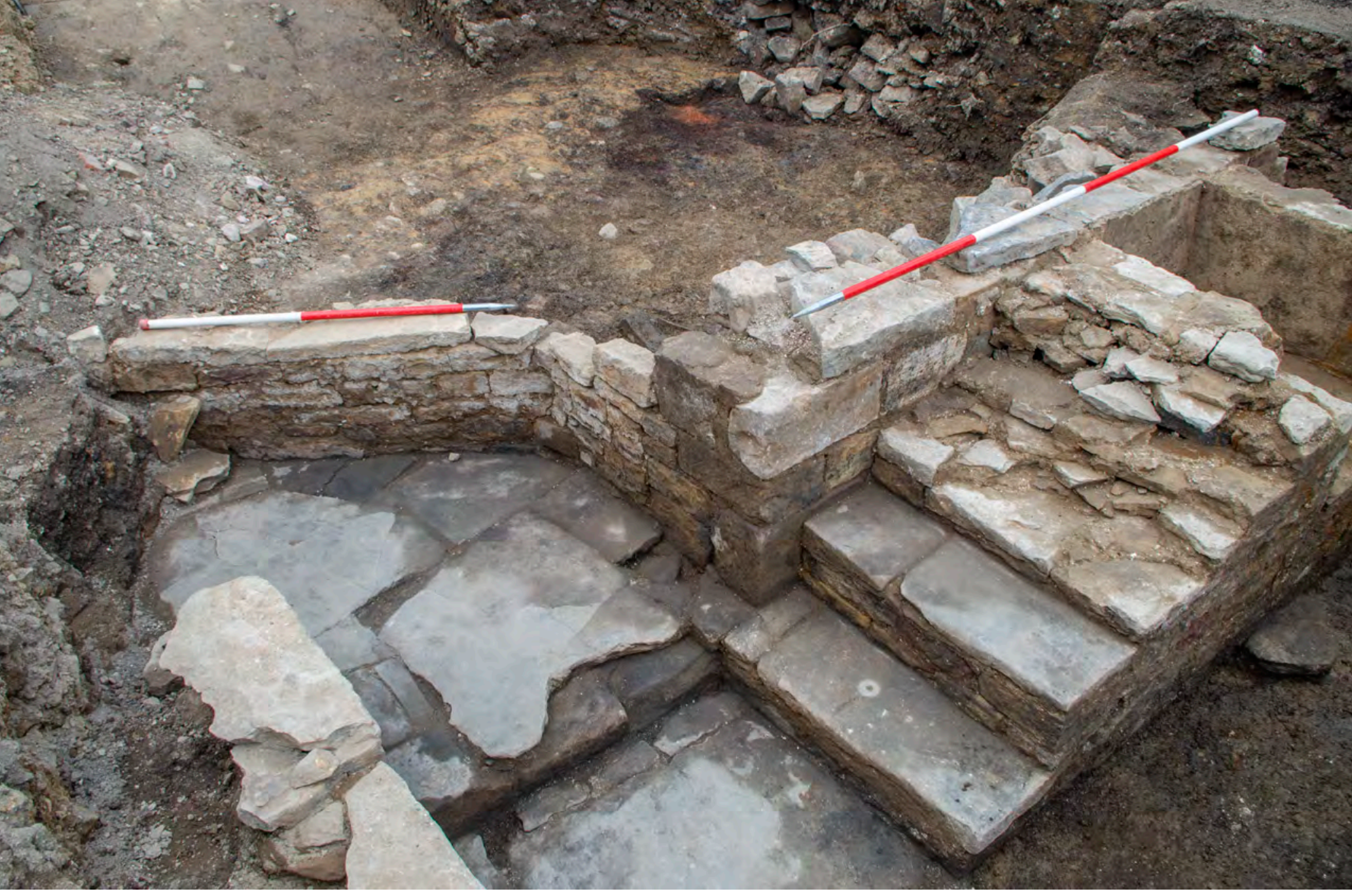

Figure 7.10: Walls and staircase excavated by Wessex Archaeology in Trench 6. They comprise a wall nearly $1 \mathrm{~m}$ wide oriented north-south and formed of sandstone blocks and lime mortar. It retained earlier redeposited alluvium to the east. This wall turned $90^{\circ}$ to the east before turning again $45^{\circ}$ to the north-east, at which point it was only $0.4 \mathrm{~m}$ wide. Wessex Archaeology.

structures between $51.6 \mathrm{~m}$ and $53.41 \mathrm{~m}$ AOD. The first comprised a small drystone wall oriented north to south, and thought to have been part of a small lean-to structure built against the north wall of the castle. Redeposited alluvial clay underlying and banked up against this wall contained pottery dating to the 13th or 14th century. Later disturbance made interpretation difficult, but it seems to have been a large structure of sandstone blocks which incorporated a set of rough steps, and had a raised internal level (Davies and Symonds 2002, 12-13).

Importantly, further excavations along the northern perimeter of the site by Wessex Archaeology in Trench 6 located walls and a staircase at 52.02 to $53.93 \mathrm{~m}$ AOD. A north-south-oriented wall nearly $1 \mathrm{~m}$ wide comprised sandstone blocks and lime mortar, and served to retain earlier redeposited alluvium to the east. This wall turned $90^{\circ}$ to the east before turning again $45^{\circ}$ to the north-east, at which point it was only $0.4 \mathrm{~m}$ wide (Figure 7.10). It may represent an outer wall of a building, dug into an earthen mound on the north side of the castle. A staircase adjacent to the west face of the north-south-oriented section comprised flagstone treads, and had a rendered keeping hole (a small 'cupboard') with iron stains. A flagstone surface formed the floor from the bottom of the staircase through a doorway evidenced by a carved indentation further to the east (Tuck and Rajic 2019, 50, plate 10$).^{24}$

We suggest that, despite being revealed during two separate excavations, the structures identified in 2001 and 2018 were contemporary. This suggestion is based on their appearance and the similarity of the levels at which

${ }^{24}$ A single sherd of 18th-century Mottled ware was pulled out from beneath one of the flagstones forming part of the structure in Trench 6. In addition, a fragment of brick, perhaps of 18th-century type and with industrial-era slag bonded to it, was recovered from the disturbed rubble core of the wall (Tuck and Rajic 2019, 50). These artefacts may indicate that these structures, although originating in the 13th or 14th century, were reused and maintained in the 18th. 
they were identified. Furthermore, in 2001, contexts surrounding these structures produced pottery of 13th- to 14th-century date. Together they provide good evidence for the partial survival of a large building, or, more likely, series of buildings, along the north side of the site overlooking the Don. It is also possible that they are the remains of some of the structures seen by Joseph Himsworth in October and November 1930. Himsworth $(1927-42,18)$ explicitly noted that one of these was 'about the same level as the "dungeon"', his interpretation of Armstrong's 'vaulted apartment'. He went on to tell us that he thought the remains he had seen were those of 'four towers with a sloping glacis in between', pronouncing that they 'settle the extent of the castle area to my mind' (Himsworth 1927-42, 19). In this he was probably right. He clearly thought that these structures were part of, or attached to, the north wall of the castle. We have no secure dating evidence for these structures, but note that those in ARCUS Trench 1 probably belonged to the same phase as both the gatehouse and courtyard buildings, one of the structures in ARCUS Trench 2 was associated with 13th-or 14th-century pottery, and the building remains in Wessex Archaeology's Trench 6 were at the same level. It is just possible, therefore, to argue that they belong to the same phase (or phases) of the castle.

\section{Preparing the ground}

As we saw at the beginning of the previous section, in 2018 Wessex Archaeology found evidence across the site for a series of levelling deposits, containing 13th- to 14th-century pottery. These deposits, it is suggested, were preparatory to a new building programme. Our study of the archival material from the early to mid-20th century excavations might just provide further valuable insights into the character and scale of those preparations. As we saw in Chapter 5, Leslie Butcher was particularly interested in the 'physique' or topography of Castle Hill, and he recorded his ideas and findings both in diagrammatic form and in his unpublished texts (e.g. Figure 7.11). Particularly important here is his understanding, and dating, of the various phases of 'levelling-up' on Castle Hill during the Middle Ages (Butcher 1972a, 20). Armstrong (1930, 12, 14) too recognised the significance of this process, and had suggested that the construction of the de Lovetot (so early 12th-) and de Furnival (late 13th-century) castles led to the progressive raising of the courtyard above the natural, and referred to 'subsequent accumulations of eighteenth- and nineteenth-century date', but provided little detail, and so for the purposes of understanding these critical phases of the site's development Butcher's record is crucial.

Butcher $(1972 b, 6)$ argued that the earliest occupation - 'at an early, but undetermined, date' - was on the river gravels, into which, as we have seen, pits and ditches had been dug and later filled in with 'thicker accumulations of the part organic deposit which covers at least the northern part of the site. Later phases of occupation, which Butcher (1972b, 6) believed dated up to the mid-13th century, saw the accumulation of 'successive layers of inert \& organic matter. While his notes do not record the depth of this build-up, section drawings along the east side of the castle suggest that it was between $3 \mathrm{ft}$ and $6 \mathrm{ft}(0.91 \mathrm{~m}$ and $1.83 \mathrm{~m})$ (e.g. Butcher n.d. (g); n.d. (r); Figure 5.20).

A critical observation concerned the transformation of the site through the subsequent addition of made ground, on top of a destruction layer comprising ' 3 " -4 " layer of bright pink debris' - a sequence paralleling that found by Wessex Archaeology in Trench 3. Butcher (1972a, 20; 1972b, 12) saw the deposition of this 'made-ground' as an effort to 'level and extend the northern part of the site', and as 'deliberate vertical planning along the northern perimeter as part of a scheme to raise the level here by back filling. He also linked his findings with observations Himsworth made in October 1930 when he drew the section exposed above the River Don. Butcher deduced that there had been 'lateral as well as vertical filling' of the site, particularly in the north-east corner, where Himsworth (1927-42, fig. 47) recorded 'A patch of loose stone herring-bone' (see Figures $3.7 ; 5.20 ; 7.12$ ). Himsworth's profile drawing showed the natural ground surface sloping steeply eastwards towards the Sheaf 'with a mass of "herringbone fill" rising above it to a level of 173.5 A.O.D.' (Butcher 1972b, 12). Butcher did not himself see any of this 'herringbone' fill when recording the east section along Castle Hill, but noted that it was 'obscured by a mantle of grey dusty fill', which he regarded as 'the dry weather' version of the 'dark fill' above the herringbone deposit recorded by Himsworth. However, he did note that more herringbone filling had been recorded in 1961 at the north-west corner of the site, but at a higher level (Butcher 1972b, 6, 12).

This herringbone filling occurred in what Himsworth (1927-42, fig. 47) had described on his section drawing as medium yellow clay. Butcher $(1972 b, 12)$ recorded a similar layer, characterised as a homogenous depth 


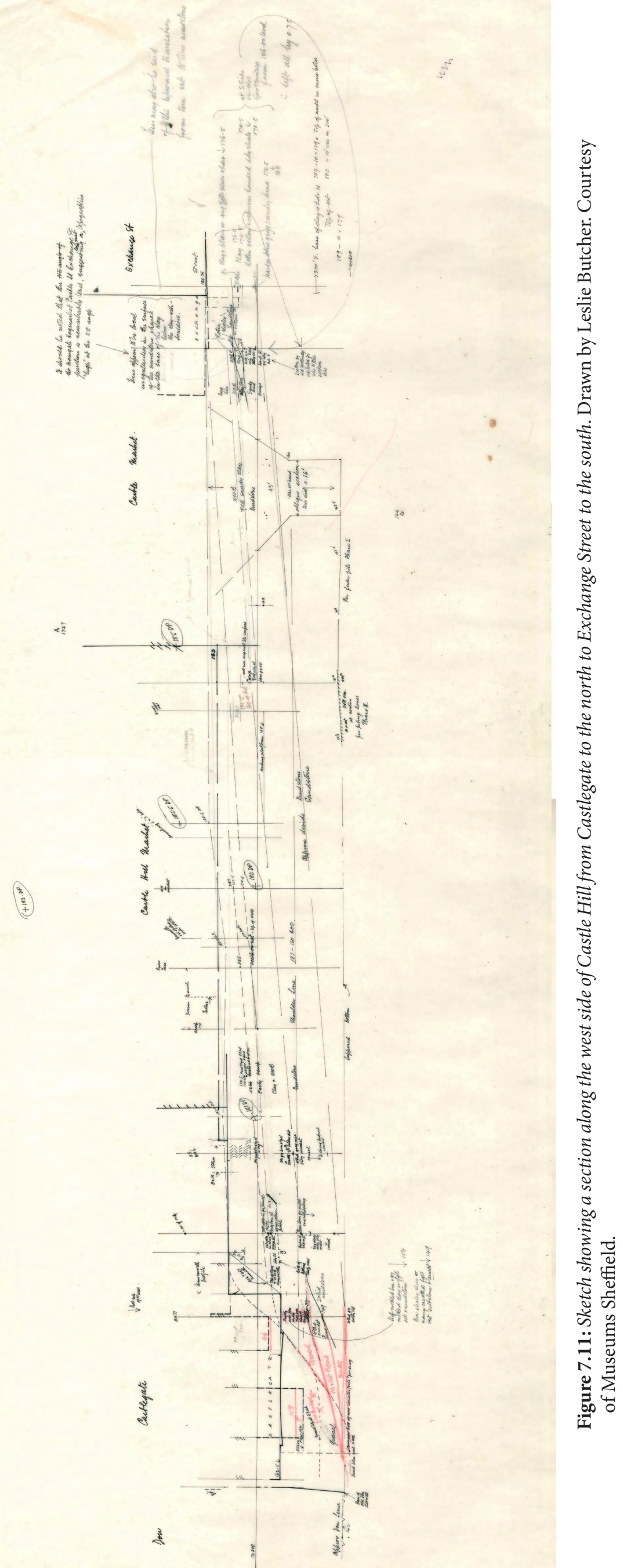




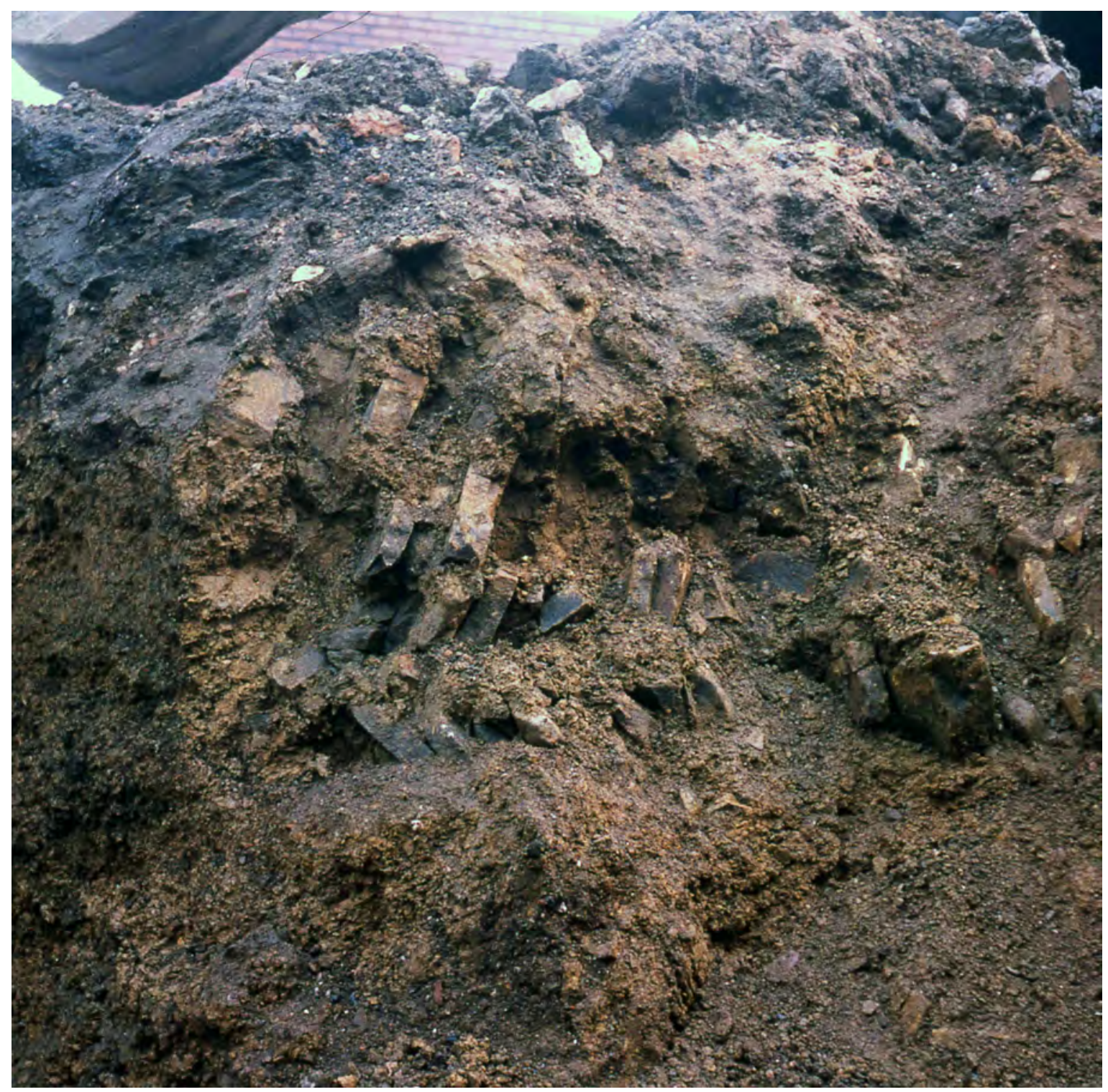

Figure 7.12: The 'herringbone fill' that Butcher recorded at the north-west corner of the site. Courtesy of Museums Sheffield.

of sandy clay lacking water-worn boulders', and deduced that it was a deliberate deposit introduced to extend and raise the hill on which the castle was located at the north-west and north-east corner of the site. 'Newly deposited', it would not, he thought, support substantial structures, and before such were constructed, pits and trenches would have to be dug down 'to the earlier, compacted, level' and then 'filled with stronger material, systematically placed to give a locally stronger foundation. The rubble-fill masses, "herringbone" or otherwise may well be the result of such processes' (Butcher 1972b, 13).

In essence, Butcher envisaged a process in which, preparatory to building/rebuilding, the site was 'extended' by laying down layers of redeposited natural, especially at its northern end where it overlooks the Don. Since this would not, he suggests, have been strong/stable enough to support the major stone buildings he envisaged, special foundations were prepared - a variant of 'rubble trench' foundations which provided both support and good drainage and was commonly used in the construction of secular buildings in, for example, the City of London up to the middle of the 13th century (Schofield 1991, 5). Butcher (1972a, 20) explicitly linked this process to construction of 'the Furnival stone castle' in the late 13th century. We have no dating evidence from these herringbone fills, other than that they are deposited in trenches cut into redeposited natural dated, in 
Wessex Archaeology's Trench 3, to the 13th or 14th centuries. ${ }^{25}$ Accepting as always the caveat that explanations other than those provided in the texts are possible, and that this feat of preparatory landscape engineering need not be linked to Thomas de Furnival's licence (1270) to 'build a stone castle [at his manor of Sheffield] and fortify and crenellate it' (Lyte 1913, 447), the evidence suggests that it just might.

\section{The 'great ditch'}

Both ARCUS (in 1999) and Wessex Archaeology (in 2018) investigated parts of the east moat by trial trenching, while Wessex Archaeology also sought to confirm the line of the west moat, and conducted three borehole transects, two across the south moat and a smaller third across the south-west corner of the moat.

\section{The west and south moat}

Records of the early and mid-20th-century excavations of the south moat indicate that it contains well-preserved, waterlogged deposits. The line of the west moat has always been less clear, although there is good evidence that it contained similar fills (see Chapters 3 and 5). Wessex Archaeology Trenches 7, 8 and 9 were specifically located to end the uncertainty about its line and nature. Although Trenches 7 and 8 were heavily truncated and/or contained modern features, the south-west corner of Trench 9 clipped the edge of the moat. Here the moat was rock-cut, with a steep inner profile at an $80^{\circ}$ angle; the boreholes across this south-west corner showed that it was $5.6 \mathrm{~m}$ deep with its base set at about $46 \mathrm{~m}$ AOD. A thick mixed clay backfill was encountered above the bedrock (Tuck 2020). This fill was sealed by a sandstone rubble and a brown mixture of sand and clay containing late 13th- to early 15th-century pottery (Coal Measures Whiteware type, Reduced Sandy ware and Sheffieldtype ware; Cumberpatch 2020), uncharred plant seeds (Simmons and Jones 2020), and a rich assemblage of land snails (Tuck and Rajic 2019, 192). Bricks and other debris had been pushed into the top fill of the moat from 20th-century construction works, probably those associated with building the Brightside and Carbrook Co-op store in 1927. The orientation of this part of the moat confirms the accuracy of plans drawn by Butcher (n.d. (j); n.d. (m); n.d. (u)), which show it heading towards (and probably partially under) Waingate.

The two borehole transects across the southern moat were designed to confirm the profile and to take detailed palaeoenvironmental and dating samples. The boreholes confirmed the records of Butcher (n.d. (j); see Chapter 5, Section: The moat) that it was $10.5 \mathrm{~m}$ wide with both profiles steeply cut into the bedrock (Figures 7.13 and 7.14). The transect closest to the gatehouse (Transect 2) revealed a flat base, again as Butcher had recorded. The base of the moat towards Waingate is at $49 \mathrm{~m} \mathrm{AOD}$, and is slightly lower on the eastern side near the gatehouse, with the base at $45.5 \mathrm{~m}$ AOD. Here, the moat was up to $6 \mathrm{~m}$ deep, with multiple fills relating to natural sediment accumulation and demolition rubble, all composed of different clays, rubble and made ground (for Butcher's records of the foundation shafts through the moat, see Chapter 5).

Boreholes from the three transects were subjected to detailed palaeoenvironmental assessments of pollen, ostracods and diatoms, with samples for dating taken from several levels (Brown 2020; Cameron 2020; Whittaker 2020). Only Transect 1 contained well-preserved pollen grains of elm, hazel and alder, which were found in the basal fills, and cereal pollen, meadowsweet and the rose family in the upper fills (Simmons and Jones 2020) - here we might remember that in 1699 Richard Richmond committed to 'plant or sett or cause to be planted or sett three oakes ashes or elmes upon every acres length of fences and walls' on the land he leased within the park (Scurfield 1986, 153-4). The presence of ostracods (a crustacean, often known as seed shrimp) and diatoms (algae) suggests that this section of the moat was only filled intermittently with still, shallow water, with seasonal dry periods (Cameron 2020; Whittaker 2020). Furthermore, the presence of diatoms tells us that the water was heavily polluted with heavy metal contamination (Cameron 2020). These are major findings and show that earlier suggestions that the moat was fed either from the Sheaf (Butcher 1972a, 9), or from 'a stream of water still known to be running under property in High Street' (Himsworth 1927-42, $1,7)$ are incorrect. Certainly, there must have been dams at the junction with the Don - as we have seen, they are referred to in Civil War accounts (Anon. 1644, 2-3), and if they had not existed there would be no water at all in the south moat. However, the moat itself would have been filled from the heavens and through run-off

${ }^{25}$ Although an argument could be made that these herringbone fills represent 'post-depositional' modification of natural deposits (Historic England 2015, 23-4), we would note that Butcher, a former mining surveyor and highly experienced in dealing with geology and geomorphology, was confident that they were contained within redeposited layers. 


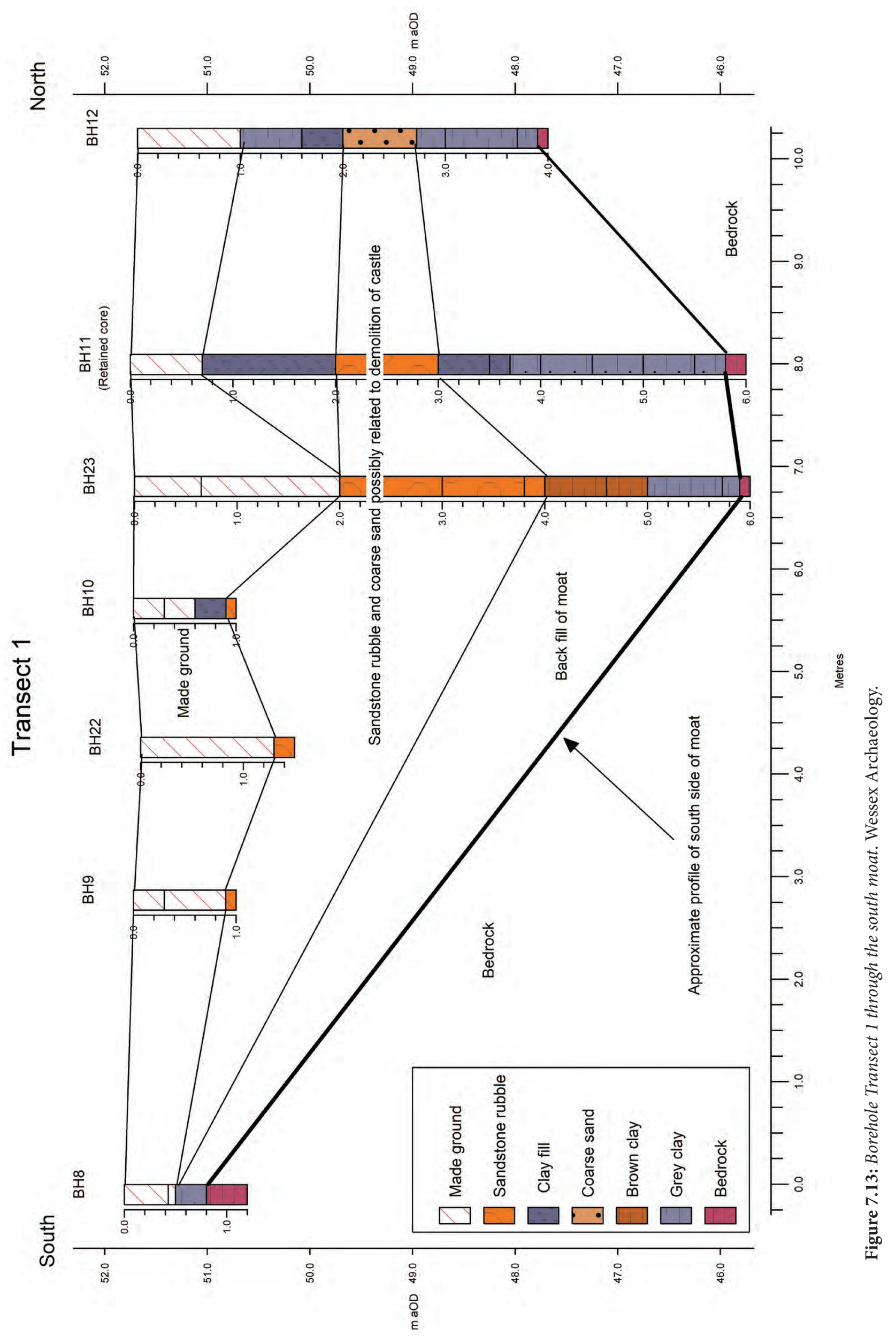




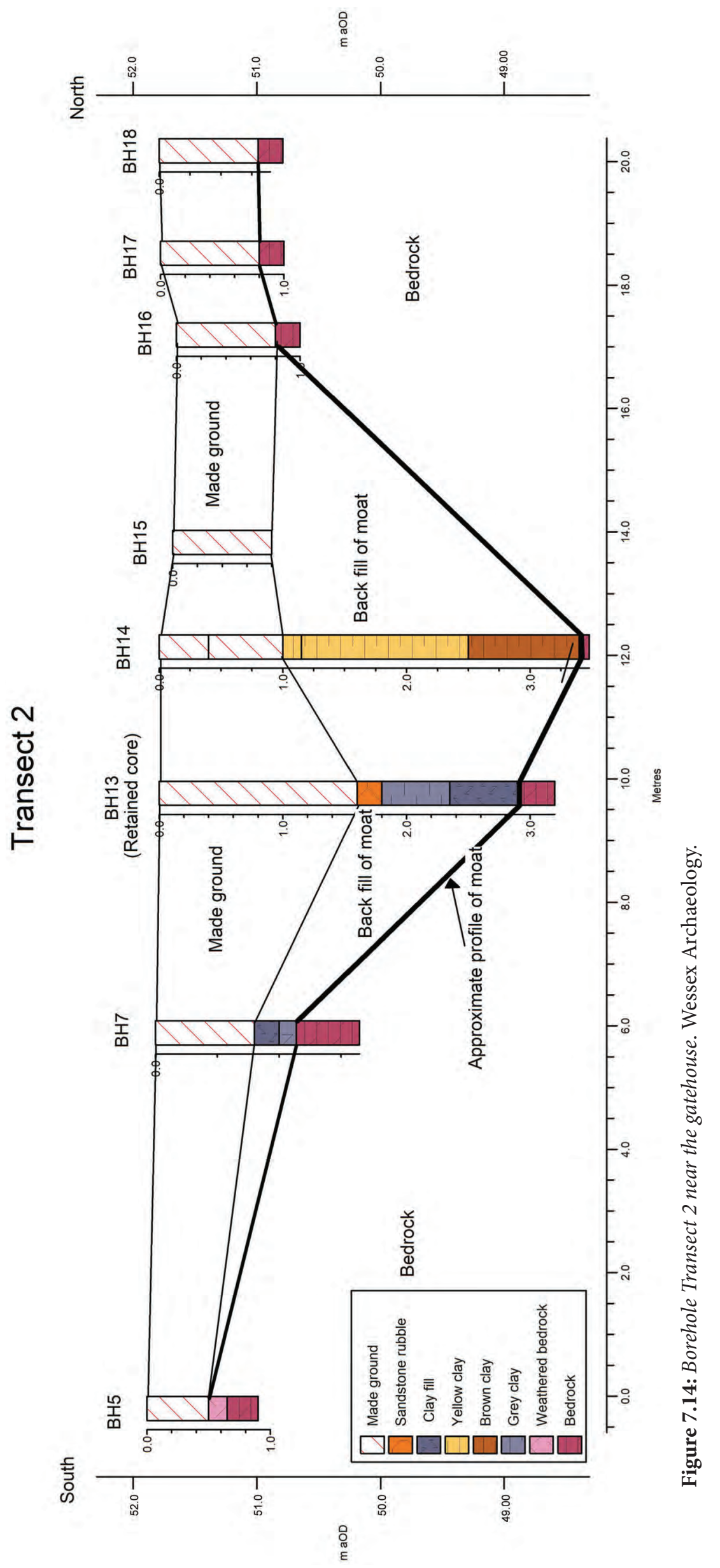


from the surrounding landscape and from the town - no doubt explaining the heavy metal contamination. It is likely that the town drains also emptied into the moat, adding to the miasma - and, as David Templeman $(2016,71)$ suggested, to the discomfort to Mary, Queen of Scots.

Recent work at Oxford Castle reveals a similar situation. There the insect fauna from the basal fills of the moat point to 'slow flowing or still water', while the diatoms may 'indicate a closed-moat system' (Munby et al. $2019,143)$. There it was further argued that the recovery of early medieval material from the moat suggests that rubbish was being dumped in it shortly after its construction, and there is no evidence that it was ever scoured out (Munby et al. 2019, 33). The result was that over the course of the Middle Ages it (and possibly that in Sheffield too) slowly filled up and became increasingly dry (Munby et al. 2019, 143).

One curious outcome of the analysis of the fine-grained organic sediment from the boreholes through the south moat of Sheffield Castle is that the radiocarbon dates extended from Late Glacial through to the Bronze Age: $2920-2880 \mathrm{cal} \mathrm{BC} ; 19520-18990 \mathrm{cal} \mathrm{BC} ; 8540-8280 \mathrm{cal} \mathrm{BC} ; 830-770 \mathrm{cal} \mathrm{BC} ; 6480-6270 \mathrm{cal}$ вC, all at the $95 \%$ confidence rate (Tuck 2020). This dating evidence reveals the inclusion of older sediments, which were probably washed or eroded into the moat. This sediment is likely to have derived from multiple sources and to have accumulated over the life of the moat, including its initial cutting, and during later phases of erosion or mixing, particularly if/when it was recut.

\section{The east moat}

In 1999 ARCUS recorded the western face of the east moat, cut into bedrock, close to its south-east corner as it turned towards the gatehouse (Davies 2000). In 2018 this trench was extended in Trench 10 to uncover the full profile of the east moat. This excavation showed that the east side of the east moat was not as steep-sided as either its west side or both sides of the south moat. The east moat was $9.5 \mathrm{~m}$ wide and around $2.5 \mathrm{~m}$ deep, buried beneath up to $4.5 \mathrm{~m}$ of later material (for some of which, see below). The east moat was narrower, and shallower than the south moat, but its base was deeper. The 2018 trench into the moat was $6 \mathrm{~m}$ deep, and required shoring of the plate and waling type. The base of the trench was at $44.53 \mathrm{~m} \mathrm{AOD}$, but, even then, the bottom of the moat was not reached and its lower fills went unexplored. However, extrapolating from the two evaluation trenches the base of the moat is likely to be at around 44.0m AOD (6.5m below ground level; Tuck and Rajic 2019, 58). As in other sections of the moat, the higher fills were almost certainly deposited during the Civil War.

Excavation of Trench 10 also revealed that the east face of the east moat is a gently sloping clay bank (Figure 7.15). This moat bank comprises at least three layers of clean redeposited alluvium, similar in composition to that from which the motte was constructed (above). Although these layers are distinguished by colour, ranging from blue-yellow to orange-yellow, to grey-yellow, it seems likely that they were deposited at the same time (Tuck and Rajic 2019, 57-9). One sherd of Humberware and another of Sheffield ware were found within the make-up of the bank, suggesting a 13th- to 15th-century date (Cumberpatch 2020). Two sherds of pottery (one of 11th- to 13th-century Splash Glazed Gritty ware and another of 13th- to 14th-century Local Coarse Sandy ware) recovered by ARCUS in 1999 from the earliest observed fills of the moat push the date of the east moat into the earlier part of this range (Davies 2000, 31, 41). In 2018 it had been hoped that Trench 11 (30m to the north) would confirm the alignment of the moat, but it was not, however, possible to excavate deeply enough in this location, and so the presence or absence of the moat there remains unconfirmed (Tuck and Rajic 2019, 63-5). However, the line of the east moat, as recorded in the 1999 excavation and Trench 10 in 2018, is traced by a minor lane depicted on 19th-century maps running north-east from Castle Fold's Lane (Belford 1999, 22; contra Armstrong 1930, 11; see also below for discussion of the upper levels of Trench 10), and this perhaps provides an insight into the line it took as it progressed northwards towards its confluence with the Don (Tuck and Rajic 2019, 60).

One of the intriguing questions about the east moat relates to the nearby River Sheaf. In short, why dig a moat on this side of the castle when a river defence was already available? Armstrong noted the phenomenon in a sketch on which the high walls of the castle are set on top of a steep slope which ends in a shallow dip/ ditch and bank; below this the moat is separated from the Sheaf by a stretch of open ground (Figure 7.16). This 'doodle' is not entirely accurate as it shows a bank inside (i.e. to the west) of the moat. More significantly, as we saw in Chapter 3, Armstrong believed that the east moat was shallower than the other sections, and that it was generally dry. Both of these facts, he believed, were a product of the presence of the Sheaf - 'a strong defence would be provided on that side by the river and its high bank surmounted by the dry ditch, from which the glacis sloped steeply upwards to the castle walls' (Armstrong 1930, 18). We now know that the base of the east 

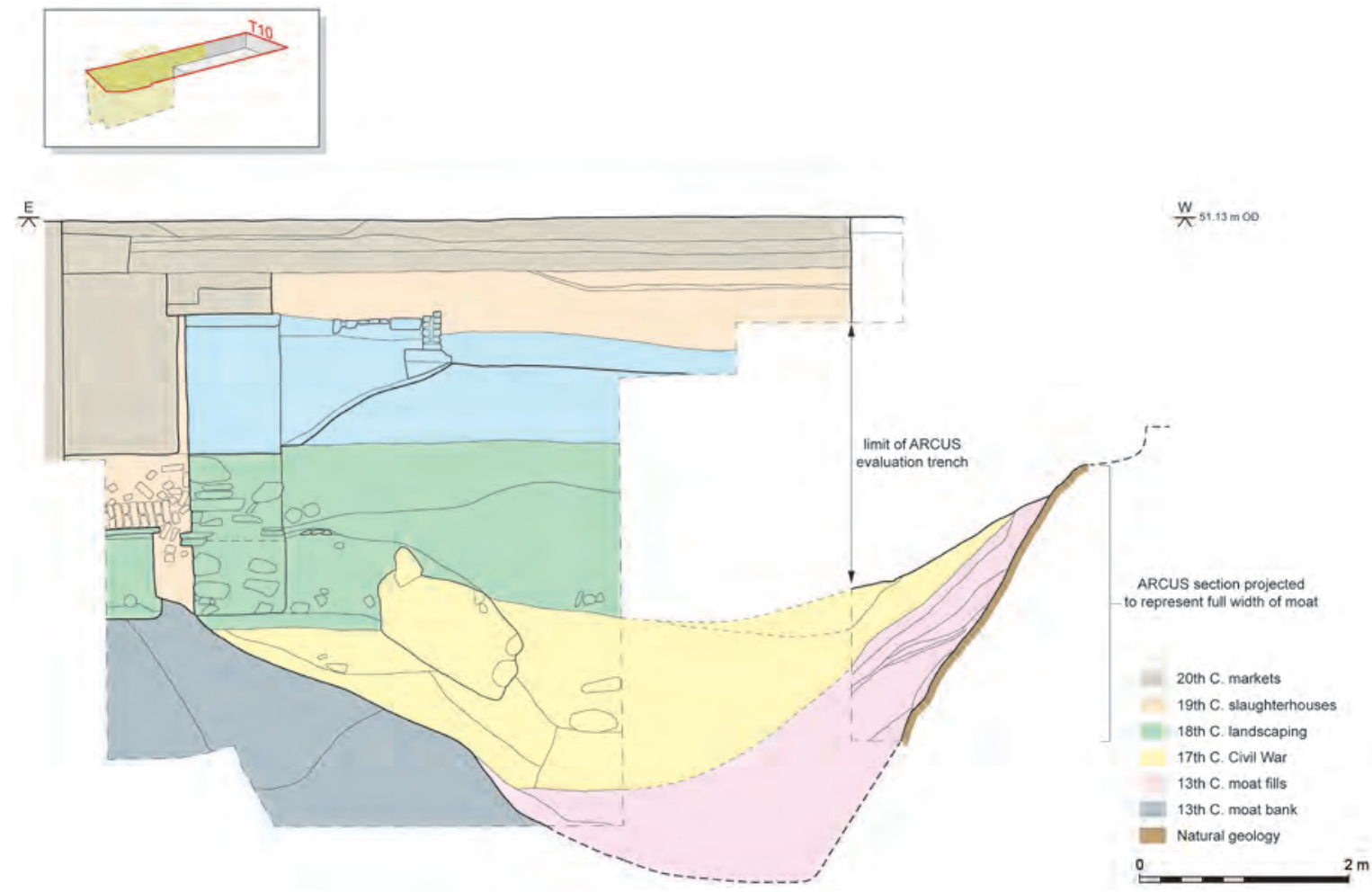

Figure 7.15: Section through Trench 10 showing the east moat. This figure relates what was recorded in 2018 with that part of the moat excavated by ARCUS in 1999. Wessex Archaeology.

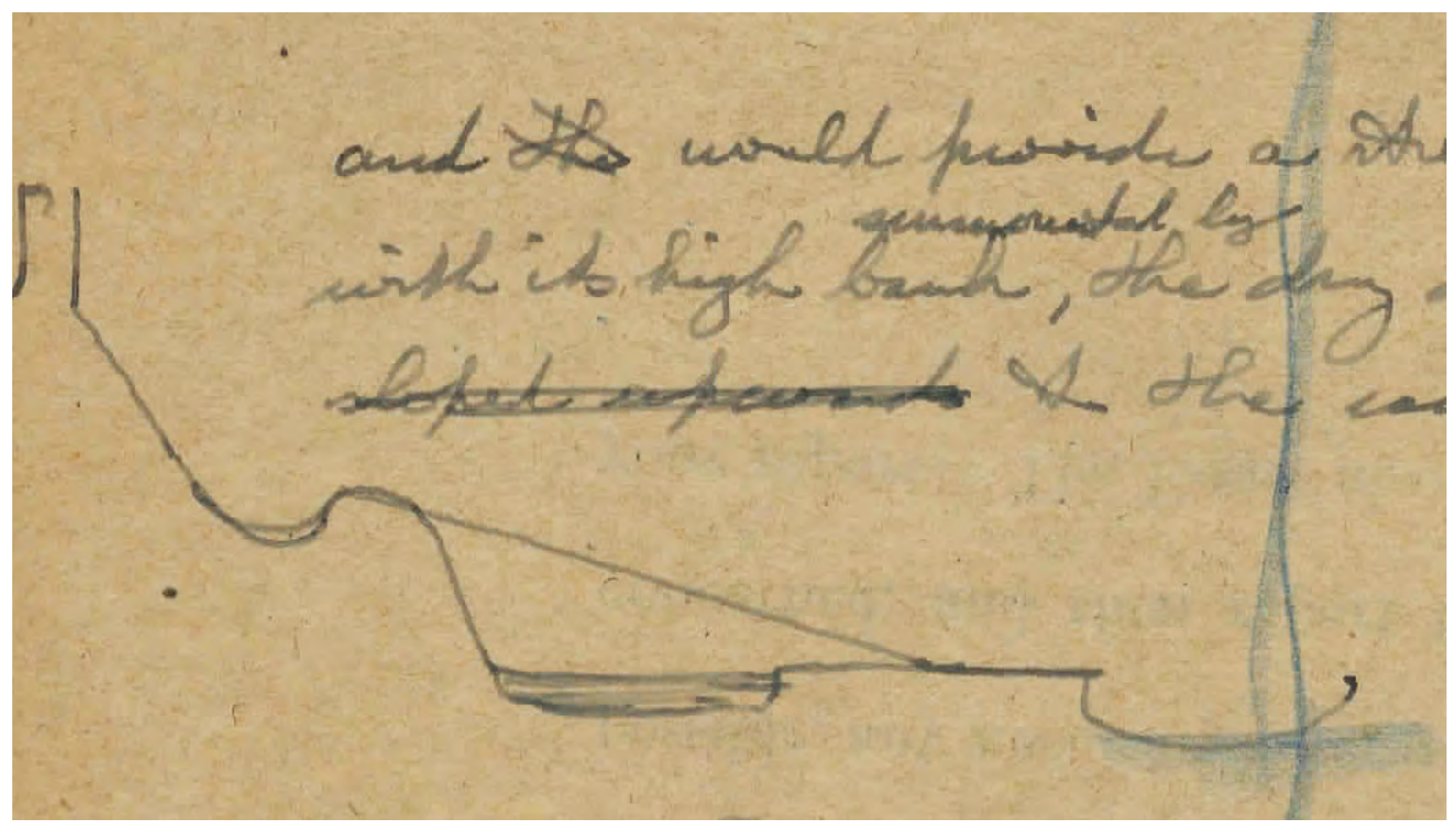

Figure 7.16: Sketch showing the east side of the site including the moat and the River Sheaf. In this 'doodle' Leslie Armstrong set out his thoughts on the castle's eastern 'defences'. Courtesy of Museums Sheffield. 
moat was lower than that of the south moat and that it must have contained water - how else do we explain the 'black sludge' recorded by Himsworth $(1927-42,3)$ or the fact that on $5^{\text {th }}$ August 1644 Parliamentarian forces tried (and failed) to 'break up the Sluce through the Dame, to let out the water of that corner against the Orchard, on the east side of the Castle' (Anon. 1644, 4). So Armstrong's practical argument does not hold. Instead, we suggest, the rationale for the impressive, repeated marking of the eastern side of the castle lies in the realm of perception, of the symbolic. As we will argue in Chapter 8, our understanding of Sheffield Castle is significantly enhanced by viewing it within its wider seigneurial landscape, by seeing it as one of two focal points around which that landscape was articulated, and by remembering that the other lay on the hills of Sheffield park to the east. In other words, Sheffield Castle was designed to be seen from the east - its best, most 'impressive' face looked in that direction. Thus, even though the castle and its wider landscape setting are now obscured by urban sprawl, we have been able to tease out of its remains something of the cultural context in which it was constructed (Liddiard 2005 and 2007 for discussions of castles in their landscape context).

\section{The late medieval castle}

The evidence from the 2018 excavations for late medieval activity at Sheffield Castle is limited to one cobblestone surface in the south-east corner of Trench 1 (Tuck and Rajic 2019, 25-7). This possible courtyard, at about $54.5 \mathrm{~m}$ AOD, was made of small cobbles and is dated to the 15th to early 16 th centuries through pottery of Late Medieval Sandy ware type found between the cobbles (Cumberpatch 2020). In 2001 ARCUS recorded a similar feature $20 \mathrm{~m}$ to the north in Trench 1 , and this might well be a continuation of the same surface. That surface was at $53.2 \mathrm{~m} \mathrm{AOD}$, and was also associated with 15th- to 16th-century pottery, in this case Midlands Purple ware (Davies and Symonds 2002, 10). At this point it is worth pausing to reflect on the fact that the 15th and 16th centuries were when Sheffield Castle was at the apex of its power, when its lords operated at the highest levels of society and politics. This is the time of George Talbot, the richest man in England, Bess of Hardwick, and the unfortunate Queen of Scots, while inventories from this period reveal a castle expensively furnished (LPL, MSS 694-710; LPL, MSS3192-3206; LPL, MSS 3192-3206; Leader 1874, 44-45; see Chapter 6). Its archaeology is, by contrast, impoverished.

\section{The Civil War}

At various points in this book we have seen how the archaeological record, especially in the upper layers of the moat, was a product of the documented clearance of castle buildings (see especially Chapter 5). Although the 2018 excavations demonstrate that parts of some medieval buildings survived into the 18th century or later (see discussion of Trench 6, above), there is also evidence for this mid-17th century slighting. For example, overlying the late medieval cobblestone surface recorded in Trench 1 , there was a $0.15 \mathrm{~m}$-thick layer of orangered sand with stone and brick rubble inclusions (Tuck and Rajic 2019, 26). Pottery within this demolition and levelling layer was of various types and dates, but none post-dated the 17 th century. The evidence was more extensive in ARCUS Trench 1 , where a $1.9 \mathrm{~m}$ deep sequence of 17 th-century demolition deposits filled the stairs leading to the undercroft of the vaulted building discussed above. These layers were composed of sandy silt with sandstone blocks, and contained fragments of medieval and early post-medieval pottery, ceramic floor tiles, animal bones, window glass and lead cames (Davies and Symonds 2002, 10-11).

In addition, a series of mixed 17th-century layers filled the top of the moat in Trench 10 (Figure 7.15). These deposits are composed of redeposited alluvium, probably representing the upcast from slighting works and therefore redeposited for a second time (Tuck and Rajic 2019, 59). Datable artefacts in these upper moat fills were sparse, and included just two sherds of 17th-century pottery along with residual 14th- and 15th-/16thcentury pottery (Blackware and Blackware-type ware, Coal Measures Purple ware and Coal Measures-type ware; Cumberpatch 2020). Two large pieces of the lime mortar-bonded rubble core of walls were also found in the 17th-century moat fills (Tuck and Rajic 2019, 59).

\section{The 18th century}

A further 're-landscaping' occurred when Castle Hill shifted from an aristocratic space to a public arena, albeit one still owned by the earls. As we saw in Chapter 3, cartographic evidence reveals that by the early 18 th century 


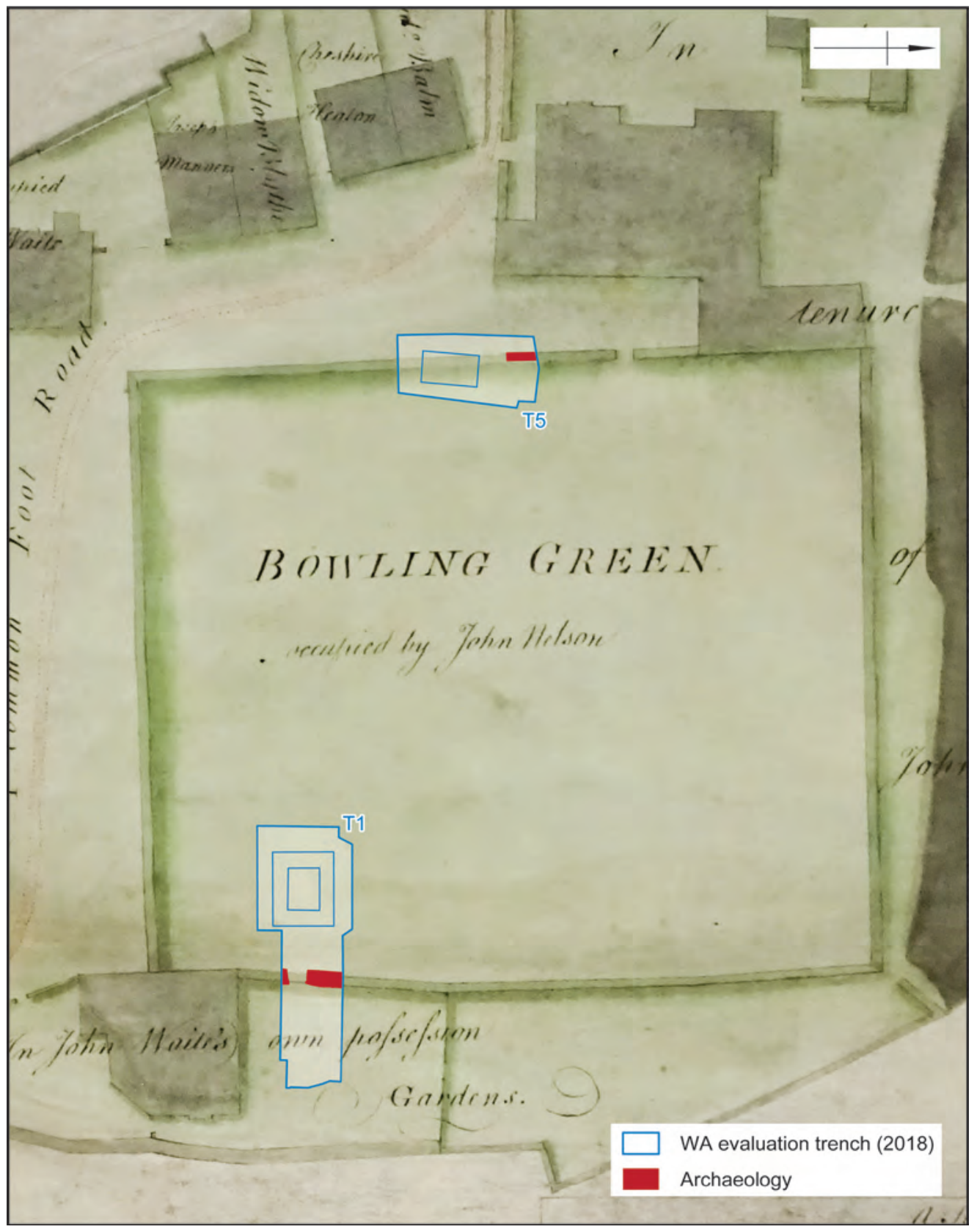

Figure 7.17: The locations of Trenches 1 and 5 superimposed on the 1769 Fairbank plan of the site (see Figure 3.24). Wessex Archaeology.

there was a bowling green and associated buildings in the centre of what had been the castle courtyard (Gosling 1736; Fairbank 1769; see Chapter 9 for detailed discussion). Joseph Himsworth (1927-42, 11, fig. 35; 1937, 9) thought that a square sandstone pillar with an iron rod embedded in it, which he saw being excavated in early December 1928, might be a railing from around this green. Much more substantive evidence emerged in 2018. Levelling material, which, again, was redeposited alluvium, had been laid down to bury the remaining medieval structures (although in Trench 5 the courtyard of the castle was directly overlaid by 18th-century deposits). This levelling material contained residual medieval pottery along with 18th-century pottery, clay pipes, slag and clinker, and intrusive 19th-century material (Tuck and Rajic 2019, 27). In Trenches 1 and 5, two parallel stone walls, $40 \mathrm{~m}$ apart and each running north-south, were built on top of this levelling deposit, and on either side of the expected position of the bowling green (Figure 7.17). The walls were made of rough sandstone blocks, perhaps quarried from the castle remains, bonded with lime mortar (Tuck and Rajic 2019, 


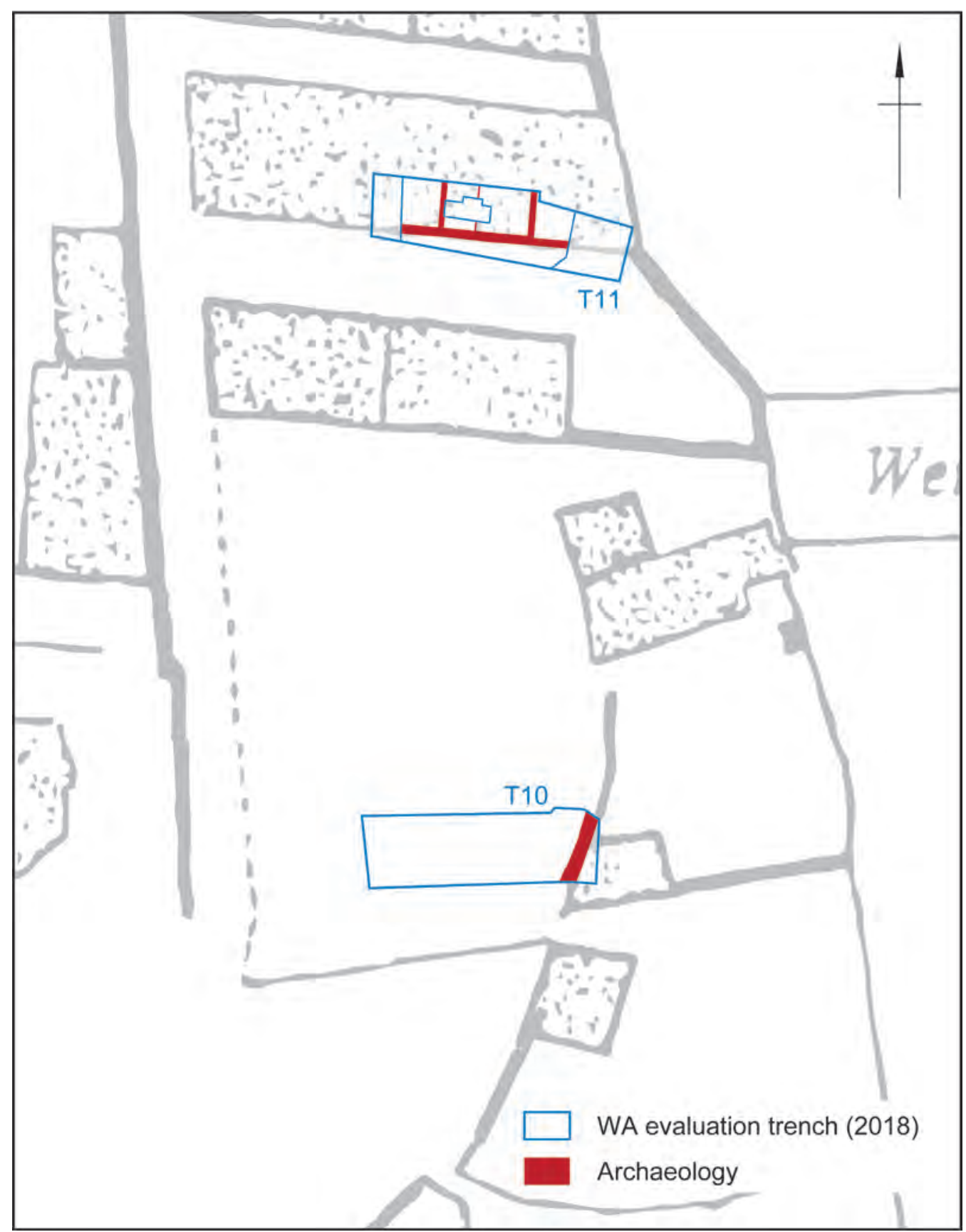

Figure 7.18: Location of Trenches 10 and 11 superimposed on a detail of the 1853 OS map. Wessex Archaeology.

$27,46)$. Comparison of the excavated remains with the Fairbank 1769 plan make it highly likely that the walls are those of the bowling green, perhaps even those visible on Thomas Oughtibridge's 1737 North Perspective View of the Town of Sheffield (see Figure 8.26).

The restructuring of market provision in Sheffield following the 1784 Act of Parliament (see Chapter 1) brought radical changes to the area. If the bowling green had not already gone out of use by then (see Chapter 9), its fate was sealed by the construction of a series of slaughterhouses along the south banks of the River Don (Figure 1.10). Three of these were excavated in 2018 in Trench 11, and it was revealed that their foundations were dug into levelling layers composed of alluvial clay which contained 18th-century pottery and clay tobacco pipes (Tuck and Rajic 2019, 64-5; Figure 7.18). The foundations were constructed of rough 
sandstone blocks (perhaps reused from the castle) and lime mortar, and there was a sandstone threshold at the west end of the south side of each room, indicating the position of the former doorways. The floors were made of high-quality, probably imported sandstone flags, and the walls were built of handmade red brick and lime mortar. An interesting feature was the presence of sloping floors in each slaughterhouse, which drained toward the river, producing the 'streams of ink' into the Don reported in advance of a royal visit in 1875 (see Chapter 9). These slaughterhouses were used up until 1928, and had several modifications during the 130 years of their use; their demolition was recorded by Himsworth, as we saw in Chapter 3, Section: Civic pride and the search for Waltheof.

In Trench 10, the eastern bank of the moat was capped with the flagstone surface of the narrow lane mentioned above as indicating the course of the eastern moat. The area of the east moat itself was buried beneath 2.5m (47.23-49.53m AOD) of redeposited alluvium and rubble containing large blocks of worked sandstone probably derived from castle structures. Nineteenth-century OS maps (1853 and 1892) depict the area as occupied by a yard and excavation revealed this to have had a cobbled surface (Figure 7.19). The yard and the lane were divided by a substantial $0.9 \mathrm{~m}$-wide sandstone wall, oriented north-south and bonded with lime mortar in the lower courses (Tuck and Rajic 2019, 60). When the slaughterhouses expanded into this area in the mid-19th century, the wall was partially rebuilt and reused as the east wall of a slaughterhouse (Tuck and Rajic 2019, 60-1).

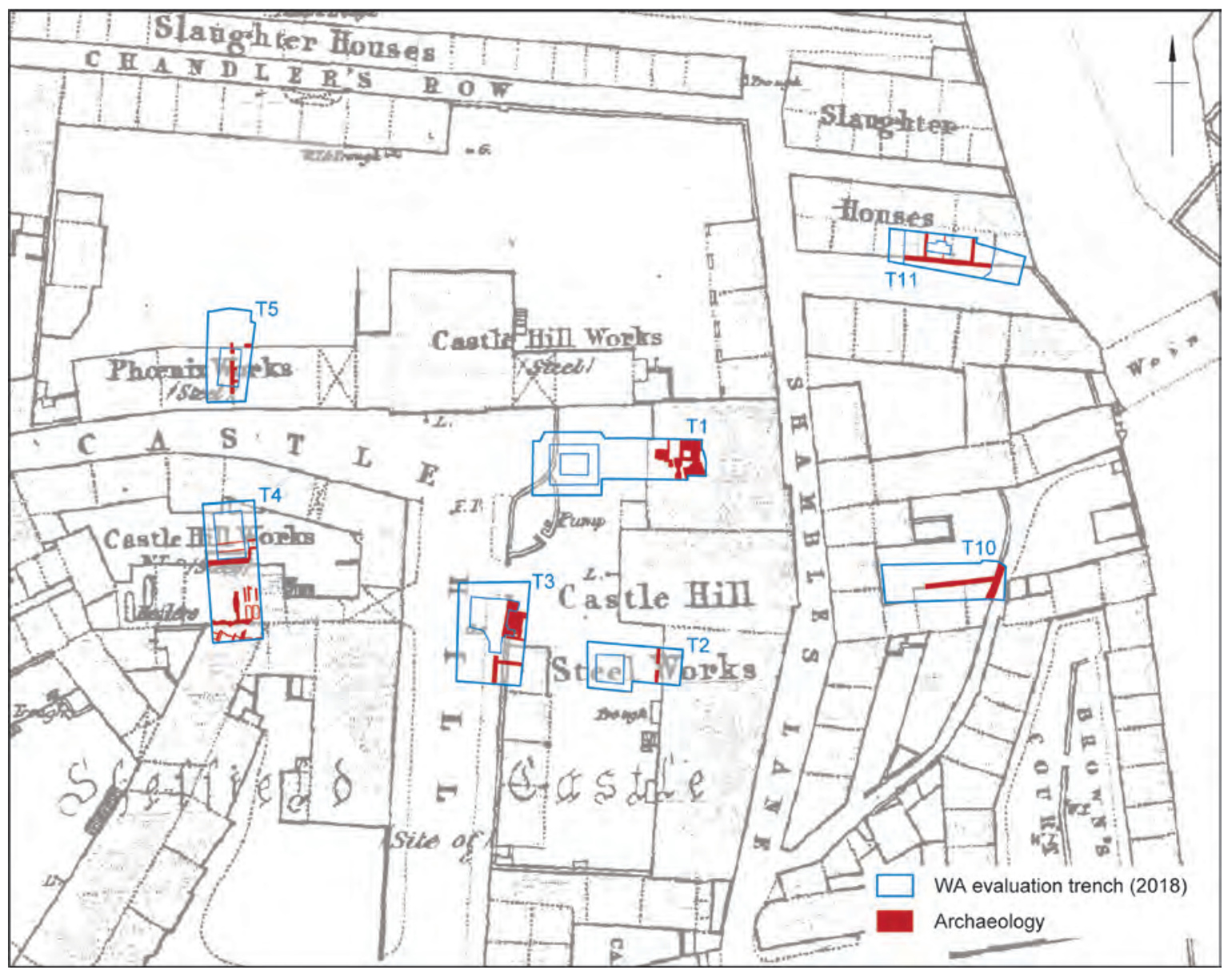

Figure 7.19: Trenches dug by Wessex Archaeology in 2018 superimposed on the 1853 OS map. Wessex Archaeology. 


\section{Steel City}

The 1853 OS map (at a scale of five feet to one statute mile) shows a series of small steel works (Castle Hill Works, Castle Hill Steel Works and Phoenix Works) on Castle Hill (Figure 5.24), with hotels, public houses, and the slaughterhouses around its edges. In Trench 4, in the south-west of the upper platform, at 53.42m AOD, was an exhaust gas flue, perhaps associated with a boiler or some other industrial process (Tuck and Rajic 2019, 39-40; Figure 7.20). The sides of the flue were constructed of firebricks and the base comprised handmade red bricks covered in a refractory sand. A series of belt power transmission line shafts were located to the south-east of the flue and may have been contemporary, although any relationship between the two had been substantially truncated. The line shafts were evidenced by fragments of three parallel single-skin handmade brick and lime mortar walls.

Nineteenth-century OS maps indicate the layout of the steelworks, and further detail was provided by the excavations in Trench 4. A series of brick walls, some with sandstone foundations, were bonded with both lime mortar and ash mortar, indicating at least two phases of construction (Tuck and Rajic 2019, 42-3). Both the exterior walls of the steelworks and interior divisions were excavated. In the south-east of Trench 4, a large cut respected the walls of the works but truncated the earlier line shafts. The cut was made for the installation of a pair of large, reused sandstone blocks $(0.9 \mathrm{~m}$ by $0.4 \mathrm{~m}$ by $0.3 \mathrm{~m})$. The blocks were probably used as a base to support something heavy (perhaps a machine), and fittings on the underside of the blocks indicated that they had previously been used for this purpose in another setting. We take these blocks to be reused parts of the castle because of their size and geological type (Coal Measures sandstone). The north part of Trench 4 was depicted as a yard on the 1853 Ordnance Survey map, and two phases of reused brick structures excavated in this area probably represent minor buildings within the yard. The southern end of the trench contained the remains of a second major range of 19th-century buildings visible on the 1853 map, this time on a north-east to south-west alignment. The excavations uncovered a handmade brick and lime mortar wall and a series of kerbs, flagstone, cobblestone and sett surfaces (Tuck and Rajic 2019, 43).

In other trenches (1, 2, 3 and 5) across the upper platform evidence for the steelworks was generally limited to boundary walls and culverted drains in former yard areas. The remains of a weighbridge, with a significant

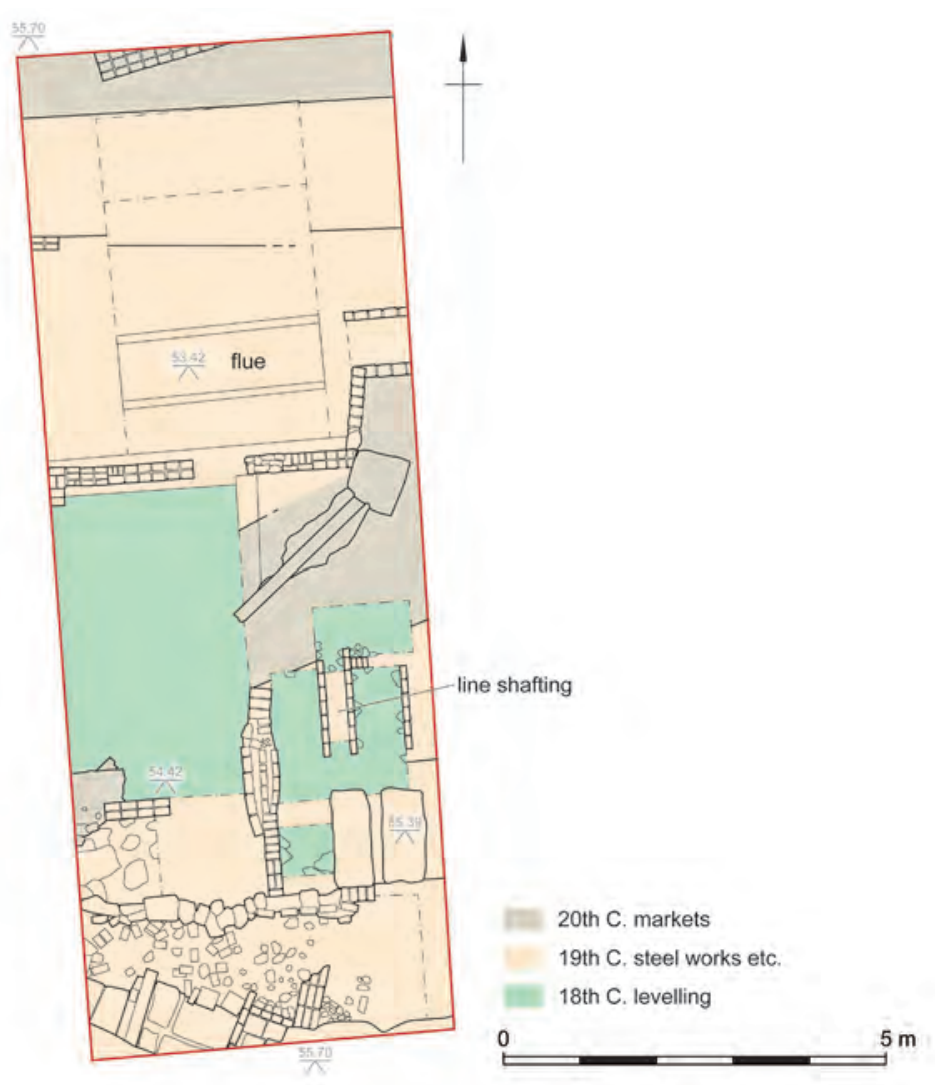

Figure 7.20: Industrial archaeology, and the perennial levelling-up, in Trench 4. Wessex Archaeology. 
impact on several medieval layers, were uncovered in Trench 3. This was recorded on the 1892 Ordnance Survey map by the letters 'W.M.' (weighing machine). The weighbridge comprised a brick-lined pit with sandstone corner stanchions and a maintenance access passage. Fragments of the cobbled Castle Hill Road, depicted on the 1853 OS map, were also preserved in Trench 3 (Tuck and Rajic 2019, 33, 36-7; Figure 7.19).

A large construction cut recorded in Trench 1 contained a series of structures associated with a cementation furnace. It was built primarily of sandstone, again perhaps sourced from the castle, with interior structures of handmade brick. A north chamber was just large enough to permit access for maintenance of the south chamber, which likely acted as a fire or ash pit for the furnace. Iron bars were built into the structure and helped to carry the load of a flagstone floor over the north access chamber. The backfill of the construction cuts and chambers comprised brown and reddish-purple sandy silt, representing redeposited ash and heataffected materials from a furnace. Lumps of rubble were recovered comprising ganister - a refractory grade of sandstone obtained locally in Sheffield and elsewhere - with bonded crozzle, the lining of the furnace chest. Although the furnace chest itself had been removed, the excavated remains are identical to those found in cementation furnaces excavated elsewhere in Sheffield, such as at Hollis Croft (Tuck et al. 2019). Superimposing the plan of Trench 1 on the Goad Fire Insurance plan of 1896 suggests that this furnace was on the premises of R\&J Smith. As we noted in Chapter 2, on $30^{\text {th }}$ March 1915 the Sheffield Daily Telegraph reported the demolition of a furnace which stood in what was 'formerly the yard of Messrs. Smiths' Steel Works', and which was portrayed in Thomas Winder's $(1907,80)$ T'Heft an' Blades o' Shevvield (Figure 7.21). The same cone, we have

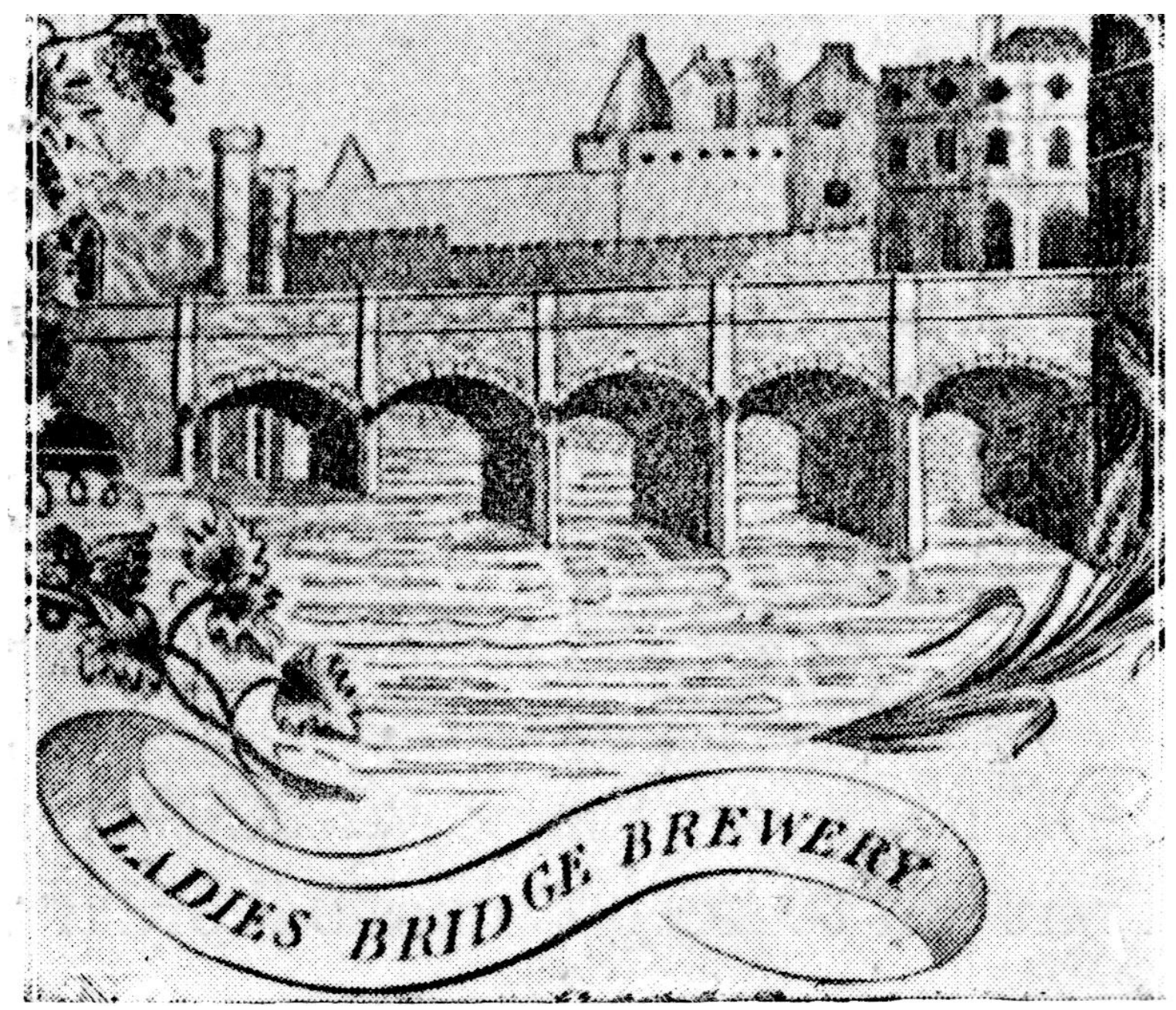

Figure 7.21: This advert for 'Ladies [sic.] Bridge Brewery' contains a depiction of Castle Hill and the Bridge. From T'Heft an' Blades O'Shevvield, by Thomas Winder (1907). Behind the slaughterhouses the cone of a furnace is visible. Public Domain. 
argued, can be seen in early 19th-century paintings (see Chapter 2, Section: Doing archaeology in Sheffield 1927-30; also Chapter 9, Section: New uses for Castle Hill).

These, then, are the material traces of Steel City on Castle Hill - and it could be argued that they are among the most significant of the remains uncovered by the 2018 excavations. This is not because of their association with Sheffield's era of industrial greatness, or because they were largely ignored during the 1920s and the 1950s investigations - though both are true. Rather, we contend that their importance stems from the fact that they lie at the top end of a stratigraphic sequence that encapsulates the history of Sheffield. This history is not one obsessed with the search for Waltheof, or one blinded to the significance of earlier periods by the furnaces of industrial might. It is, rather, a long-term history in which the castle, the bowling green, and R\&J Smith's cementation furnace all have a voice. And, as we will see in Chapter 9, that raises questions about just how such voices can be articulated in a process of regeneration.

\section{Finds assemblage}

In Chapter 6 we discussed the assemblages recovered from the site of the castle in the early and mid-20th century, including the provenance of the material and what it revealed about activities on the site. We also highlighted apparent evidence for selective retention, although what was recovered was also determined by the circumstances of investigation, and sometimes hampered by the actions of construction workers. Where the builders' foundation shafts were dug also determined what was recovered. The circumstances faced by ARCUS were different in terms of the retention policies adopted, but similar in as much as the locations of their trenches were dictated by access considerations. The Wessex Archaeology excavations were similarly conducted with potential future development in mind, but there was greater freedom to position the trenches for the furtherance of a research-based understanding of the site. During the 2018 excavations, all artefacts were removed from site to be examined with no on-site selection other than for obviously very modern material. In this section, we will discuss the finds recovered during these excavation campaigns and compare the findings with those discussed in Chapter 6. The specialist finds reports that underpin the following discussion are available through the Archaeology Data Service (https://archaeologydataservice.ac.uk/).

\section{Pottery}

The 1999 ARCUS trial trench $(9 \mathrm{~m} \times 4 \mathrm{~m})$ recovered an assemblage of 142 sherds of pottery, dating to between the late 11th/12th century and the 18th century; no material certainly of 19th-century or later date was found. With the exception of a single sherd of Low Countries Redware, all of the pottery was of local or regional manufacture, and hence very similar to the material recovered in the 1920s and 1950s/1960s and discussed in Chapter 6 (Davies 2000, 28-50). The lowest fills (but still not the bottom) of the moat encountered during these excavations yielded only two sherds of medieval pottery, but the higher fills produced a mixture of medieval and post-medieval fabrics; hence the ceramic material from these moat deposits was very similar to that recovered earlier in the century. The two 2001 trenches $(9.2 \mathrm{~m} \times 3.3 \mathrm{~m}$ and $9 \mathrm{~m} \times 4 \mathrm{~m})$ produced 84 sherds of pottery, and as in 1999 the medieval pottery was largely residual in post-medieval contexts. One of the pits contained a single sherd of a large jar of North Lincolnshire shell-tempered fabric, dating to between the late 12th and mid-14th century (Davies and Symonds 2002, 30-5). More than $40 \%$ of the assemblage by sherd count dates to the 19th or 20th centuries, which is a considerably higher proportion than survives in the Armstrong and Butcher archives, where it is a little over $6 \%$ of the assemblage. The difference can be accounted for by the fact that the excavations in Trench 2 encountered modern dumping levels, while the earlier excavations were in parts of the site that had been considerably truncated prior to excavation.

The 2018 Wessex Archaeology excavations recovered an assemblage of 1488 sherds of pottery, and the range of wares is very similar to those recovered in the early and mid-20th century; the assemblage was principally reported on by Chris Cumberpatch (2020), while Jane Young (2020) analysed the shell-tempered wares. As with the 2001 ARCUS assemblage, there was a greater proportion of modern material, while medieval wares formed a higher proportion of the Butcher assemblage than of the 2018 assemblage: $28.5 \%$ as opposed to $10.1 \%$. The finds do not challenge the impression that emerges from the earlier assemblages that there is no evidence for any activity on the site predating the late 11th or early 12th centuries. Four sherds of Handmade White Sandy ware - which were slab-built rather than wheel-thrown - date to this period, and are of a type not previously 
found on the site. Three sherds were from Trench 6, while one was from Trench 4; the latter contained red and black iron-rich grit similar to that seen in Coal Measures wares. Such handmade wares have been found across the region at sites in Doncaster (South Yorks), Duffield (Derbs) and Wetherby and Ripon (North Yorks), but the nature of this industry is poorly understood, in comparison to the high-quality wheel-thrown pottery produced in West Yorkshire at around the same time, including wares produced in Pontefract (Roberts et al. 2013) and the wheel-thrown Yorkshire Gritty wares, made at unknown sites (Cumberpatch 2002a). More abundant than the handmade wares are wheel-thrown products of the Doncaster Hallgate potteries represented by a small quantity of Hallgate B ware (two vessels, jug and hollow ware) both from Trench 4, one from the made ground and one from the rubble of redeposited lime mortar, and Hallgate A wares (32 vessels; jugs and hollow ware) from the levelling layers in Trenches 1, 3 and 4, but also from under a cobbled yard in Trench 5.

As was the case with the pottery assemblage recovered in the early and mid-20th century, the later medieval pottery was dominated by Coal Measures wares, including Coal Measures Purple wares (two sherds), Coal Measures Whiteware (one sherd) and Coal Measures Fineware (one sherd). These were recovered from across the site, including made ground in Trench 1, and the fills of the south and east moat in Trenches 9 and 10, respectively. Just one sherd of Brackenfield ware, a strap handle from a jug, came from made ground in Trench 1. Similar to the assemblages from earlier excavations discussed in Chapter 6, there were just five sherds of Humberware, representing five vessels, from made ground in Trenches 1 and 4, and from the bank to the east of the east moat. A total of 52 sherds of Sheffield-type ware, representing 39 vessels, was recovered. As with the assemblages discussed in Chapter 6, there were many sherds of late medieval pottery that could only be assigned generic names, including various sandy wares, such as White Sandy ware (two sherds), Splash Glazed Sandy ware (one sherd), Buff Sandy ware (four sherds), Reduced Sandy ware (10 sherds), Oxidised Sandy ware (six sherds), and Chalk-tempered Sandy ware (one sherd). Three sherds of North Nottinghamshire Quartz and Shell ware from Trenches 1 and 3 date to between the 12th and mid-13th centuries and three other sherds of shell-tempered pottery are from a single vessel found in Trench 4 and probably date to between the mid-12th and mid-14th centuries (Young 2020). A single sherd of Gritty ware from Trench 4 was from a dripping tray or pan, intended to catch the fat dripping from an animal carcass while it was being cooked on a spit. While not common on most medieval sites, a number have been identified at Conisbrough Castle (South Yorks; Cumberpatch 2013; 2014a; 2015b; 2016).

As with the assemblage analysed in Chapter 6, the post-medieval pottery of the mid-15th to early 18 th century was dominated by Cistercian ware (eight sherds) - two of which bear white pipeclay motifs - Blackware (13 sherds) and Coarse Blackware (three sherds) - while other fabrics were present in smaller amounts, such as Yellow wares (four sherds), Surrey Whiteware (one sherd), Midlands Purple ware (two sherds), Brown Glazed Coarseware (171 sherds), Early Brown Glazed Coarseware (four sherds), Brown Glazed Fineware (two sherds), Redware (one sherd) and Slipware Type 1 (10 sherds). There was little imported pottery. The few examples of imports include a sherd of Westerwald stoneware found in an early 20th-century demolition deposit in Trench 6 , 25 sherds of Martincamp-type ware found in made ground in Trench 1, and four sherds of Tin Glazed Earthenwares. Westerwald stonewares, distinguished by the use of dark blue cobalt decoration on a pale grey stoneware body, are relatively common on post-medieval and early modern sites (Gaimster 1997), but this is the first example from the castle site, although it is too small to identify to a specific vessel type. As we saw in Chapter 6, Martincamp-type flasks and Tin Glazed Earthenwares are of a type that may have been imported but equally well could have been manufactured in Britain. Post-medieval wares, notably those from the 17th century, were considerably commoner in the assemblages from the earlier excavations (over $65 \%$ of the total) than in the 2018 assemblages (3.8\%). This suggests that the areas of the site investigated by Butcher, in particular, were among those pertaining to the final phase of the castle's existence and to deposits relating to the Civil War and its aftermath.

The 2018 assemblage contained far more early modern and recent wares than the assemblage discussed in Chapter 6: $5.8 \%$ and $0.45 \%$, respectively, of the latter, and $48 \%$ and $37 \%$, respectively, of the 2018 material. The 18th century saw a major change in the pottery industry with the appearance of White Salt Glazed Stoneware (c.1720-c.1780; seven sherds; see Edwards and Hampson 2005) and, slightly later, the first refined earthenwares: Creamware (c.1740-1820; 164 sherds) and Pearlware (c.1780-c.1840; 34 sherds), all closely connected with the industrialisation of the pottery industry. Often linked specifically with Staffordshire, they were in fact manufactured very widely, including in Yorkshire (Griffin 2012), although it is difficult to attribute them to 
specific potteries unless the sherds bear makers' marks or, more rarely, unique decorative designs. The character of these wares distinguished them from both earlier types and contemporary vernacular tablewares, with their fine, thin profiles and hard, bright, white finish. The wider social significance of the wares, which reflect the importance of the cult of 'civility' (Thomas 2018) in the 18th century, has been discussed by numerous authors (e.g. Kowaleski-Wallace 1997; Richards 1999). They were much cheaper and more readily available than imported porcelain, and as such were highly desirable objects, eminently suitable as part of the move towards formal dining which was an important element in the rise of the 'Georgian Order', a central part of 18th-century society and sensibility. As we will see (Chapter 9), bowling greens in 18th-century England were frequently linked with dining clubs (Hornby 2015, 86), perhaps explaining this element of the ceramic assemblage. Bone China is a common element in the assemblage (152 sherds), and found throughout the site, with plain, hand-painted, moulded and transfer-printed examples all common. First developed in the late 18th century, Bone China rapidly became the commonest type of porcelain body used by British manufacturers (Barker and Ford 1999), which was well suited to moulding (although not to wheel throwing) and was used for a wide variety of tablewares distinguished by their thin walls, bright white colour and delicate appearance. The examples from the 2018 assemblages include a wide range of tablewares, but also include kitchenwares such as pie dishes. Decoration includes overglaze painted designs (mainly floral motifs) and gold lines, and underglaze transfer prints (of both the Willow and Two Temples schemes).

A range of 18th- and 19th-century utilitarian wares were also recovered, including kitchen vessels made of Cane Coloured wares (62 sherds) and Slip Banded Cane Coloured wares (14 sherds), and teapots made of Colour Glazed wares ( 25 sherds), many of which bear the shiny brown 'Rockingham'-style glaze developed in the late 18th century by the Brameld family, who operated the pottery at Swinton (South Yorks; Cox and Cox 2001, 116-20). Unglazed Red Earthenwares (11 sherds) are mainly from flowerpots, perhaps reflecting the importance of allotments in Sheffield (Flavell 2005).

\section{Claypipes}

The 2018 excavations produced a total of 662 clay tobacco pipe fragments, consisting of 73 bowls, 569 stems and 20 mouthpieces, and were analysed by Susie White and David Higgins (2020). Most of the stems are plain, but there are a number of 18th-century roll-stamped name marks that can be attributed to makers from Rotherham (South Yorks), such as William Wild, Thomas Wild, Benjamin Marsden and Richard Scorah (White 2015). A small number of the plain bowls from the excavations have makers' initials stamped on the bowl facing the smoker, including the initials TW, which is almost certainly Thomas Wild (fl. c.1777). The majority of the finds date from the 18th century and include some bowls of $c .1710-50$ with long surviving stems suggesting fresh and little disturbed deposits of this date. It might be significant, as we saw earlier, that the site became a more publicly accessible space at this time. The group also contains a number of different 18th-century rollstamped stems and a very early glazed mouthpiece, supporting the suggestion from other excavations that the use of glazed tips originated in this area. Many of the 18th-century pipes are finely burnished, showing that good-quality pipes were in use on the site at this time.

Among the 17 decorated bowl fragments, some simply have a band of leaves along the seams, but others are more elaborately decorated, such as the Armorial bowl, which bears the name of the maker WILL WILD (William Wild). The earliest mould-decorated bowl from the site bears a series of enclosed scallops with a stag's head on the seam, facing the smoker. Pipes decorated with this particular motif appear throughout Yorkshire, and this is a design that is known to have been produced by Samuel Lumley of Doncaster c.1790 (White 2015).

\section{Glass}

The glass assemblage comprises 452 fragments, all of post-medieval/modern date, analysed by Lorraine Mepham (2020a). The earliest glass recovered comprises 51 fragments from free-blown or mould-blown green wine bottles. One neck fragment could belong to a bottle of 'onion' or 'mallet' form of late 17th- to mid-18thcentury date, and one base is from a mid-18th- to early 19th-century cylindrical form, but otherwise these fragments can only be broadly dated as mid-17th to early 19th century. These fragments are in an abraded 
condition, with surface oxidation, and were found in association with later pieces, suggesting that they are residual. There is also one free-blown pale green phial base of 18th- or early 19th-century date. Other bottles are 19th-/20th-century machine-made forms, and include containers of carbonated and alcoholic drinks, foodstuffs (e.g. condiments) or pharmaceutical preparations, reflecting the tastes and needs of those who worked in, for example, the Phoenix Works or the Royal Hotel.

Drinking vessels are limited to a clear wine glass stem and fragments of two others, one etched. A significant proportion of the assemblage (152 fragments) consists of opaque glass in a range of colours (white, pale green, pale turquoise, blue and pink); these were concentrated in Trench 5 (in a levelling deposit and a modern construction cut in the west of the site) and appear to belong to lampshades with fluted edges. Window glass (95 fragments) includes one piece of blue/green 'crown' glass and at least nine other fragments in pale greenish glass which could predate the 19th century, but the majority are clear sheet/plate glass, some thick and frosted or reinforced and of more recent date.

\section{Metalwork}

The metalwork assemblage, reported on by Mepham (2020b), includes only one certainly medieval item, a copper-alloy toiletry implement comprising a small ear scoop at one end, while the other end is bifurcated and possibly functioned as a nail cleaner (Figure 7.22). The range of specialised toilet implements increased in the later medieval period (Margeson 1993, 63-4, fig. 32). Other copper-alloy artefacts are post-medieval or modern in date, and include a small safety pin, five buttons, a lid fitting from a Kilner jar, a figure-of-eight chain link, two knob handle fittings, four short lengths of narrow piping, two with crimped ends, several other miscellaneous fittings, a plated disc, seven short lengths of wire, and various bar and strip fragments. Four coins were also recovered, one is a 1978 penny, and while the others are too corroded for identification they are almost certainly also 20th-century issues - from the site's most recent incarnation as Sheffield's Castle Markets.

Sixteen pieces of post-medieval and modern lead were found, mostly scrap fragments of sheet and plate, but there were also two window cames. Iron objects were subject to X-radiograph, but they remain difficult to identify. A nail and a strip/bar came from 13th-century demolition levels in the south of the site, with four more unidentifiable objects from a late medieval deposit found between the cobbles of the surface in Trench 1. Among the later material are some structural items, including nails, a section of narrow pipe, a window fastener and a possible hinge, as well as tools, including files, knife blades and at least one punch. Some of the blades may be unfinished objects, and these and the other tools could have been either used on the site or represent products in various stages of manufacture, for example from the steelworks. There is one large annular buckle, of a size appropriate for use on horse harness, two S-hooks and a large chain link. Much of the ironwork, however, consists of miscellaneous bar, rod and sheet fragments of uncertain function. Some of this may represent manufactured bar for sale, or material brought in for further processing. The other metal objects, all of 19th-/20thcentury date, include a teaspoon (stamped with the mark of Arthur Price), a small fork, a container lid with an oily residue, and a squeezed tube of Gordon Moore's Cosmetic Toothpaste.

\section{Leather}

The leather assemblage comprises 23 objects, in 152 fragments, the majority of which are small scraps, reported on by Quita Mould (2020). All but one fragment of the leather came from the south-west part of the upper platform in Trench 4 . No complete items were found, and the leather comprises principally highly fragmentary shoe parts. There is also the discarded junction from machine belting and a fragment of horse harness strap. This material is too fragmentary to date closely but cannot be earlier than the second half of the 19th century. The assemblage, thus, differs considerably from that discussed in Chapter 6. Substantial shoe parts were found in Trench 4, and what remains of them reveals that they were of brass riveted construction, heavily hobnailed and front-lacing, which suggests that they were working boots. The brass riveted junction of a machine belt and small fragments broken from belting were also found in Trench 4, perhaps deriving from the industrial machinery housed in buildings comprising the 19th-century steelworks. 


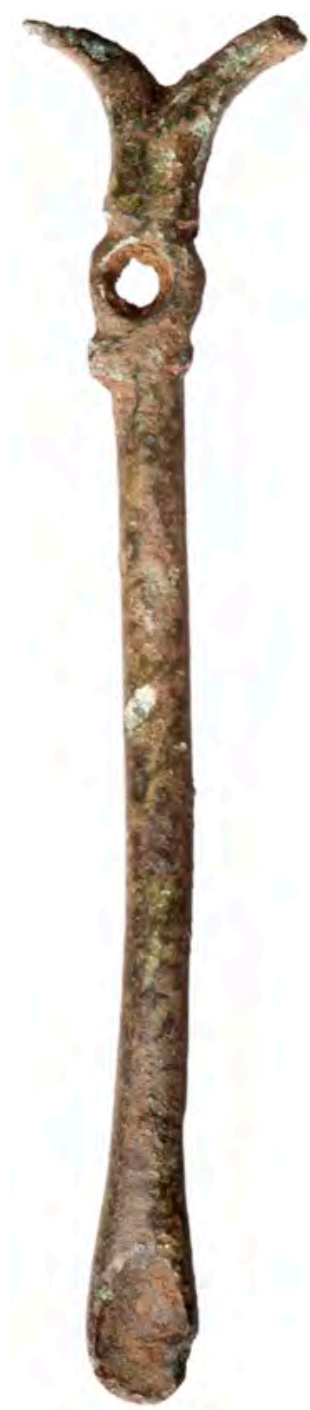

0

$25 \mathrm{~mm}$

Figure 7.22: Medieval copper-alloy ear scoop found between the cobblestones in Trench 5. Wessex Archaeology.

\section{Wood}

Thirty-five pieces of wood were recovered from the site, in Trenches 3, 4 and 6, and reported on by Lucy Allott and Erica Macey-Bracken (2020), with dendrochronological dating undertaken by Ian Tyers. The largest piece is part of a large rectangular oak beam from a medieval demolition deposit in Trench 3, which is broken at both ends and appears to have been burnt, giving it a twisted appearance; as noted above, it was dated dendrochronologically to the late 11th to early 12th century (Tyers 2020). A fragment from another large timber was also recovered from the same context; again, this is broken at both ends and very little of the original surface remained, although this piece does not appear to have been burnt. A section of a large oak beam that had been cut down and subsequently reused was recovered from a medieval levelling deposit in Trench 6 - it too has been dendrochronologically dated to the late 11 th to early 12 th century (Tyers 2020). There is evidence of a face lap with a large peg on one side, and a deep groove has been cut into the side of the beam, although subsequent 
reduction of the width left this groove on the edge of the timber. In later reuse the piece had also been chamfered into a chisel point with a flat facet at one end, while the other end was more crudely cut back. Nine other fragments of wood were recovered from this context; these pieces are broken fragments from larger timbers. One has possibly been sawn at one end but no other tool marks are visible.

Another major piece of timber is the broken end of a large squared-off oak timber post from a medieval pit in Trench 6. This piece has lost most of its original surface, and no tool marks are visible. The flat base of the post has a sub-rectangular depression in the base that may have come from being pressed up against a large stone, and, indeed, it was set on a stone post-pad. In Trench 3, three further pieces of wood were recorded from a redeposited natural levelling deposit. These pieces comprise a broken fragment from a large oak timber, with possible cut marks and a notch on one side; a short section from an alder roundwood stake, which seems to have been chopped off diagonally at one end; and a broken hazel branch. The remainder of the assemblage consists of three small lath or plank fragments, all from Trench 4, two broken fragments from a sawn timber recovered from the medieval fill of a pit in Trench 6, and two small fragments from a post-medieval levelling deposit in Trench 4.

\section{Animal bone and shell}

The evaluation of the faunal remains by Morgan Windle and Umberto Albarella (2020) yielded a very small assemblage consisting of 1,074 fragments, although, once joins are considered, this falls to 235 bones. Little animal bone was recovered from medieval contexts, but this did include species such as fallow deer and woodcock, which are likely to have come from the deer park (see Chapter 8). Canid (i.e. dog/fox) species and horse are also present in the medieval bank layers to the east of the east moat. Analysis of the post-medieval/modern assemblage was limited by the low proportion of identifiable bones, but it includes deer (Cervidae) post-cranial bones, which must be residual, while the three main domesticates (cattle, sheep and pig) are represented by post-cranial bones and teeth in all phases. Evidence for sawing and cutting on a variety of post-cranial bones, a worked antler, working debris and incomplete or broken implements associated with the 19th-century layers indicates bone working (for knife handles?) was taking place on site. The 20th-century levelling deposits in the north-west of the site yielded Galliformes (probably chicken) and levelling deposits in the west of the site yielded Gadidae (cod) species in addition to cattle, sheep and pig.

Sixteen shells were recovered from 18th- to 20th-century deposits, comprising oyster (six), whelk (seven), cockle (two) and mussel (one) (Mepham 2020c). Among the oyster, where valve side could be determined, all are left valves, which reveals that they are consumption waste. There is also a small fragment of mother-ofpearl, which could represent button-making waste.

\section{Building material}

The assemblage of ceramic building material, reported on by Mepham and Alvaro Mora-Ottomano (2020), is small (40 fragments), and is entirely of post-medieval/modern date. The roof tiles include both flat peg tile (11 fragments from a bedding layer in Trench 1) and pantile (one fragment from a construction cut for a 20th-century drain in Trench 5). All 15 pieces of floor and wall tiles in Trenches 1 and 4 are of 19th-/20th-century date. Three bricks are heat-affected, with two fused together, and probably derive from furnaces. A red, handmade half-brick $(110 \mathrm{~mm} \times 60 \mathrm{~mm})$ from a wall in Trench 6 was examined in detail. It is of general 18th-/19th-century appearance, and its fabric is coarse and mixed with slag inclusions. Prior to reuse of the brick as part of the rubble core of the wall, it had been exposed to intense heat and had been heavily blistered on one of the bed faces, perhaps from use in a steel furnace or similar. In 1776, Parliament fixed brick sizes at $8^{1 / 2} \times 4 \times 2^{1 / 2}$ inches $(216 \mathrm{~mm} \times 102 \mathrm{~mm} \times 63 \mathrm{~mm})$ and in 1784 introduced a tax on each brick used, in response to which some bricks were made larger, up to $10 \times 5 \times 3$ inches $(254 \mathrm{~mm} \times 127 \mathrm{~mm} \times 76 \mathrm{~mm})$ (Brunskill 1997, 38; Cunnington 2002, 147; Iredale and Barrett 2002, 22). The size of the half-brick from Trench 6 is broadly consistent with the fixed brick size of 1776 . Other building material was recovered in the form of small quantities of mortar (53 small fragments) and plaster (one fragment), which is painted red and is from a medieval levelling deposit at the base of the stratigraphic sequence in Trench 6 . 


\section{Stone}

Among the 50 fragments of stone recovered, and analysed by Peter Ryder (2020), most are unworked, but 21 pieces were building material, portable objects or had industrial uses. The only medieval find was part of a voussoir from a large arch at least $3 \mathrm{~m}$ wide, which measured $460 \mathrm{~mm} \times 350 \mathrm{~mm} \times 260 \mathrm{~mm}$. It was of buff medium-grained sandstone, quite badly weathered, and at least some of this weathering may have taken place when the stone was in a secondary context. Despite erosion, patches of light diagonal tooling are still discernible. The voussoir is moulded with a square step and two hollow chamfers, and stylistically appears to be of 14th- or 15th-century date and it came from the east moat in Trench 10 (Figure 7.23). Also from this trench was a rectangular block $(440 \mathrm{~mm} \times 350 \mathrm{~mm} \times 240 \mathrm{~mm})$, with a broad chamfer on one angle. This may well be medieval, although there is nothing really diagnostic; it could have formed part of the plinth of a substantial building, although where undamaged the faces are relatively unweathered.

A fragment of window tracery in fine-grained buff sandstone $(143 \mathrm{~mm} \times 125 \mathrm{~mm} \times 68 \mathrm{~mm})$ found in Trench 7 is the head of a bifurcating mullion between two lights or sub-lights. It is chamfered on one side and hollowchamfered on the other; cusping to the lights on both faces. In form it appears medieval, perhaps late 14th to early 16th century, but it is completely unweathered. Although it could have been part of an internal feature such as a screen, it seems unlikely that this is a genuinely medieval piece as it was found with relatively modern material in a 20th-century context. On balance, it is more likely to be a piece of 19th-century Gothic Revival work (Figure 9.10). We discuss the medieval revivalism evident on the site in Chapter 9.

Other stone items recovered include six fragments of grindstone, most from Trench 4 A segment $(12 \mathrm{~mm}$ long and $97 \mathrm{~mm} \times 80 \mathrm{~mm}$ in section) of well-finished moulded stone ring was recovered from Trench 6 . It has a level top, an outer face with a sophisticated moulding of Classical nature, and an inner face with fine grooving,
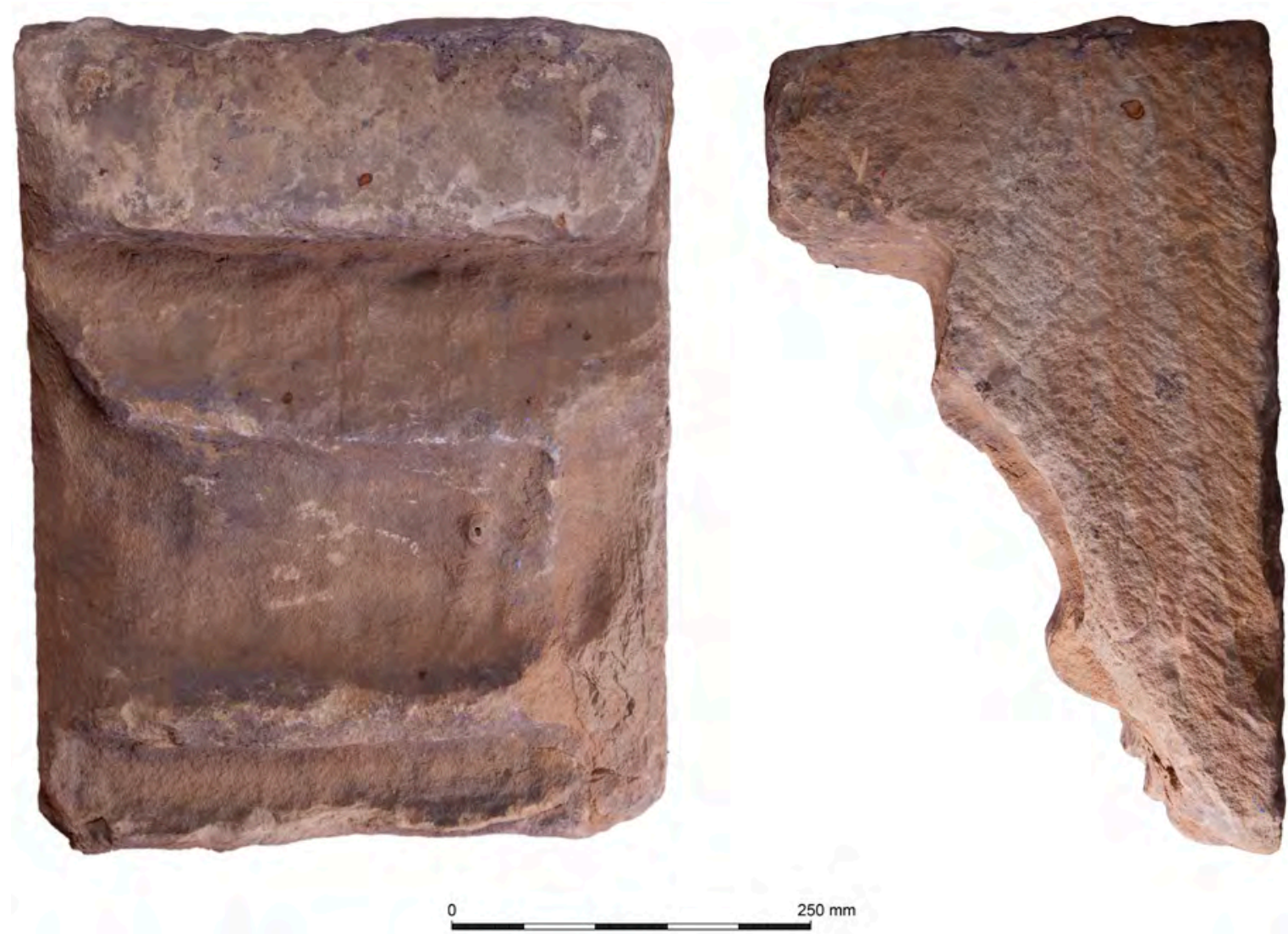

Figure 7.23: Voussoir of 14th- or 15th-century date found in Trench 10. Wessex Archaeology. 
possibly produced by friction. It is not clear what this stone is, but it has the feel of being post-medieval rather than medieval. Other fragments include eight pieces of stone roof tile and four pieces of slate, probably Welsh slate, which only came into common use with the development of the railway network in the mid-19th century.

\section{Conclusion}

The excavations on Castle Hill in 1999, 2001 and 2018 were conducted in a very different set of circumstances than those faced by Leslie Armstrong, Joseph Himsworth and Leslie Butcher. In the modern era the excavations were framed by planning legislation and represented an intentional sampling strategy, with trenches located to examine both known features and the state of preservation of archaeological deposits across the site. In the early and mid-20th centuries, in contrast, the archaeological recording was a by-product of the circumstances of construction. In all eras public interest in the findings was considerable, but only in 2018 was the involvement of the local community designed into the excavation process. The regeneration dynamic and heritage enthusiasm in the city has required community engagement and it was in this context that facilitating public participation in the uncovering of the archaeology of Castle Hill emerged. While the modern excavations have thrown new light on our knowledge of the castle, the 2018 work, in particular, has also provided insights into the less archaeologically well known developments from the 18th century onwards. In this chapter the working classes of Sheffield have been to the fore, albeit much later generations than we read about in Chapter 6. Through the remains of their boots, teapots and tools it has been the industrial workers of the 19th century who have emerged centre stage, as they inherited the site of the castle for manufacturing. Through the presence of the slaughterhouses, Castle Hill witnessed far more bloodshed between the late 18th century and 1930 than it ever did in the medieval period. As we will see in the following chapters, this new phase in the history of the site, while economically beneficial to the individuals concerned and to the city itself, was also inimical to the image that the city's elite wanted to portray, and we will show that the medieval allure of Castle Hill has continued to resonate even after the castle was demolished in the 17th century.

\section{Bibliography}

The full bibliography is available at the end of this volume, or at: https://doi.org/10.22599/SheffieldCastle.k. 


\title{
CHAPTER 8
}

\section{Beyond the Pale}

\author{
Lone wreck of antient splendour! where are they, \\ Whose perish'd forms outsripp'd thy slow decay? \\ No longer heard in this once princely haunt \\ The festal merriment nor bridal chaunt; \\ Through roofless chambers and slow-crumbling halls, \\ Viol and song unheard, and midnight balls; - \\ Now the patch'd cottage in the pile is seen, \\ And poverty resides where wealth has been (Holland 1820, 7)
}

A deer park once occupied the area of Sheffield that today spans the aptly named districts of Manor Park, Manor Top, Wybourn, Park Hill, Norfolk Park and Arbourthorne, stretching from near the Ponds Forge sports centre as far as Heeley to the south-west, and Gleadless and Handsworth to the south-east (Figure 8.1). However, it is not as a historic landscape that this area of Sheffield has recently been known; rather, it has tended to appear in the news in connection with the social issues that flow from economic deprivation and austerity (McCaffrey 2007; Lee 2016; Sheffield City Council 2017). The substantial working-class housing complex of the Manor Estate built on the site of the former deer park in the 1920s and 1930s was blighted by unemployment and high levels of crime by the 1980s, leading to it periodically being dubbed the worst estate in Britain and a police 'no-go' area. At the foot of the hill near the city centre the Corbusier-inspired Park Hill flats and high-rise Hyde Park blocks, constructed in the late 1950s and 1960s, have also had chequered histories (Bryant and Knowles 1974; Hollow 2010) - the latter eventually demolished in 1992-3, the former the subject of active regeneration efforts under the aspirational strapline 'it's Corb with less sun and more soul' (Urban Splash 2019).

This chapter presents a rather different perspective on this part of the city, where the capacity to construct large-scale 20th-century social housing was, to a very large extent, made possible by the residual open spaces of the former deer park. When we look out over some of the great parks of England today, not all is what it seems. Much that looks ancient, like the park at Chatsworth (Derbs), is really 'an 18th-century imposition', while Graves Park, the largest public park in Sheffield, created in 1925, is 'overlaid onto a medieval deer park

How to cite this book chapter:

Moreland, J. and Hadley, D. (with A. Tuck and M. Rajic). 2020. Sheffield Castle: archaeology, archives, regeneration, 1927-2018, pp. 251-287. York: White Rose University Press. DOI: https://doi.org/10.22599/SheffieldCastle.h. CC BY-NC 4.0, https://creativecommons.org/licenses/by-nc/4.0 


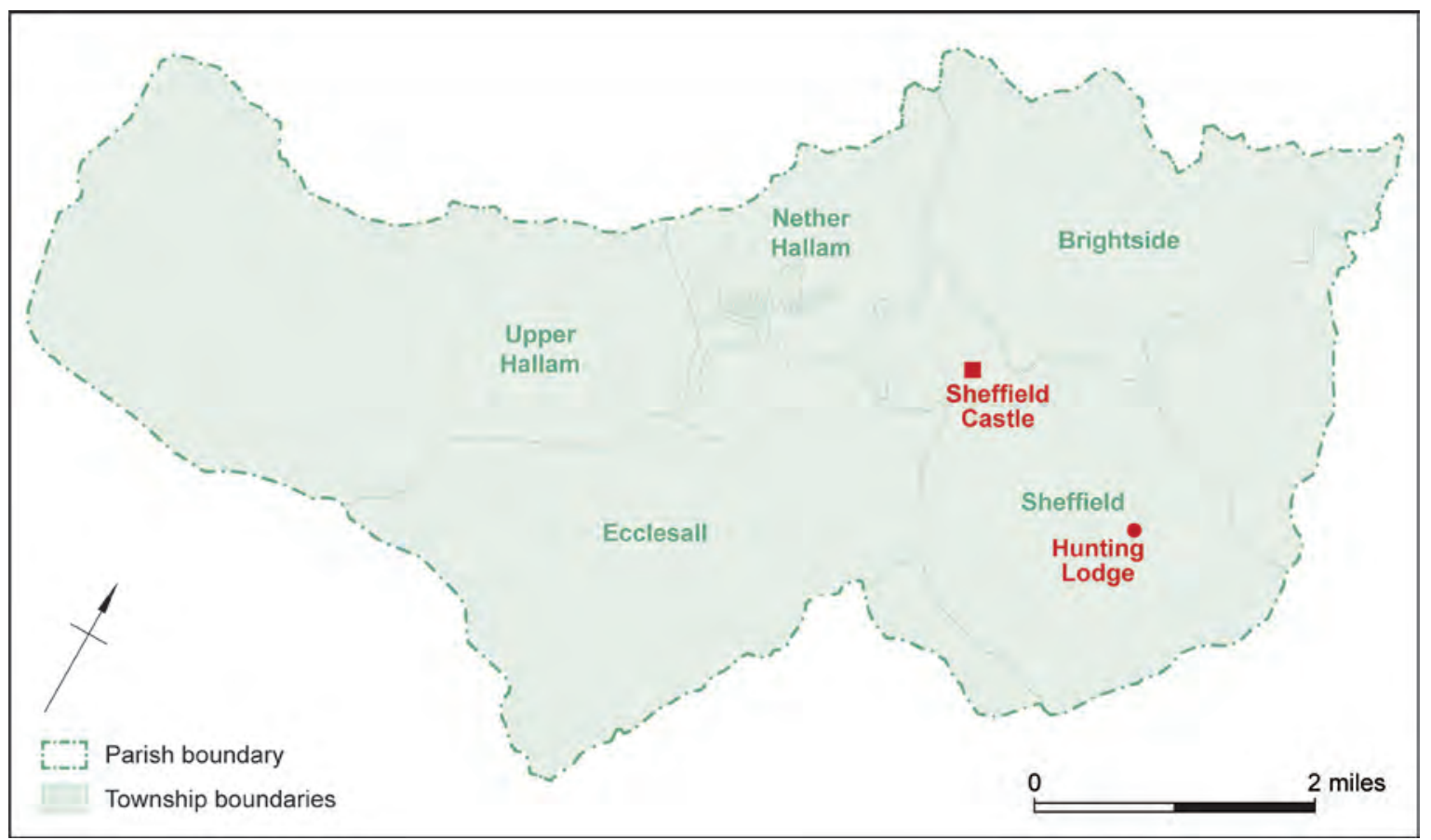

Figure 8.1: The parish of Sheffield showing the location of the park and the hunting lodge (Manor Lodge) to the east of the castle. Wessex Archaeology.

with early ponds and other features' (Rotherham 2007a). Sheffield Park, ${ }^{26}$ on the other hand, is no longer visible but has significantly influenced the present cityscape - and, like the castle, it echoes down to us in the place names of the district.

Hunting was a central element in medieval elite identity. The aristocracy had become a 'self-conscious "predatory" class; skill in the art of hunting came to define the knight par excellence' (Pluskowski 2007, 63). The availability of hunting resources could influence the location, and subsequent development, of castles (Creighton 2002, 187-8). The deer park and hunting lodge located immediately to the south-east of Sheffield Castle were integral to the medieval and early post-medieval seigneurial landscape, which also included great hunting reserves, with associated lodges, such as Rivelin Chase, which covered 6,863 acres (2777.36ha) of the Rivelin valley, and Stannington to the west (Hey 2013, 271-2; Jones 2004, 35-8; Jones 2013, 26). The lords of the manor divided their time between the castle and the lodge when resident in the town, which was not often for much of the period. However, continuing the theme developed in Chapter 6, the deer park was a place of daily work and economic production as well as of elite display. It was in existence by at least the 13th century, and remained in use into the 17th century, after which it was divided into tenant farms and coal pits. Later still, its open spaces had a significant impact on the topography of the townscape, inhibiting any notable development until the early 20th century (see Coates 1967; Simmons 1997, 406); yet, despite its acknowledged large size, it has received only passing mention in recent discussions of medieval parks (e.g. Creighton 2002, 185-6; Mileson 2009, 161). Excavation has revealed a hunting lodge on one of the highest points of the park from at least the 15th century, although its surviving standing remains (and most of our written sources) largely date to the 16th. While the lodge did not share the post-Civil War 'slighting' of the castle, continuing to be used as a residence into the early 18 th century, its presence in the landscape was nevertheless much reduced. It was subsequently rented by a potter and then became home to a mining community until the turn of the 20th century - the 'patch'd cottage and poverty' of the poet John Holland's (1820) early 19th-century lament with which we opened this chapter. Our focus here is on tracing the development of the hunting lodge and deer park into the 17 th century, and situating that within its changing social, economic and political contexts.

${ }^{26}$ While there were other medieval deer parks in Sheffield, for example in what is now known as Ecclesall Woods in the west of the city (Hart 1993; Rotherham 2007a; Hey 2010, 19-20), that which lay to the east of the castle is known as Sheffield Park. It is thus referred to in Harrison's 1637 survey (Ronksley 1908, 2; Hall 1930, 99). 


\section{A lordly landscape}

Deer parks sit at the 'more intense' end of a spectrum of animal/landscape management which also included wood pasture, wooded commons and forests (Rotherham 2007b). The practice of keeping wild animals in parks has deep roots, with breeding populations of fallow deer kept in 'parks and pleasure gardens' in parts of Roman Britain (Sykes and Carden 2011, 139-40; Madgwick et al. 2013). Fallow deer apparently died out with the end of the Roman Empire in Britain, and until recently it was believed that they were reintroduced around the time of the Norman Conquest, as part of a suite of changes which included 'new hunting landscapes', such as deer parks (e.g. Sykes and Carden 2011, 156; Sykes 2014, 72-3). However, new scientific evidence, including radiocarbon dating, genetic analyses, and carbon and nitrogen isotopes within deer bones, now suggests that 'fallow deer had been established in England for some time by the "Saxo-Norman" period' (Sykes et al. 2016, 118). In this context, Carole Hough's $(2001,2,6,10)$ argument, based on the toponymic association between deer and 'leaping places, ${ }^{27}$ that deer parks existed in Anglo-Saxon England appears compelling, but we need archaeological evidence to determine the nature of such parks. Importantly, the study of the age profile of the herds reveals that the earliest medieval examples had been kept to an older age than would be the case later. These early arrivals were, it is suggested, 'rare exotica, more important to be maintained and displayed in life than consumed in death', and so early medieval deer parks should be viewed 'more as menageries than hunting reserves' (Sykes et al. 2016, 122). The association with elite display was there from the beginning; the hunt as part of that display and performance would come later.

There is some evidence that Sheffield deer park was 'early'; none to suggest that it was Anglo-Saxon (as tentatively proposed by Jones 2013, 27; also Rotherham 2007a). In South Yorkshire more generally, there are many examples where the fencing of demesne land to create a park followed a royal grant of free warren, which was the right to hunt certain animals such as hare, badger and game birds (Turner 1901; Crook 2001), and from the early 13th century landowners were meant to obtain a royal licence to create a park (Jones 2013, 27; see Rotherham 2007b for baronial parks). However, no such textual evidence exists for Sheffield deer park, and, since archaeology does not yet help, we are therefore reliant on circumstantial evidence for its origins. Hunter $(1819,195)$ suggests that the 'great antiquity' of this park is demonstrated by the fact that its boundary forms the division between the townships of the parish (also Hey 1991, 19; Creighton 2002, 26-7, 112, 188 for parallels). He argues that it might have been in existence by the mid-12th century, when Richard de Lovetot - son of the William de Lovetot about whom we have heard a good deal in this book - in augmentation of alms, granted a tithe of venison to the monks of Ecclesfield Priory (South Yorks), demonstrating that deer were being hunted in the woods around Sheffield (Hunter 1819, 189). However, as Walter Hall $(1930,98)$ cautions, this does not necessarily mean that they were then 'emparked', and still less is this evidence that Sheffield Park yet existed (although it might have done). In 1281 Thomas de Furnival II was asked by a royal enquiry, under the writ of quo warranto, by 'what right' he claimed to have free warren in his Sheffield manor; he replied that his family had held such rights since the Conquest (Hunter 1819, 38). In 1297 a royal charter acknowledged this claim to hunting rights, and the Inquisition Post Mortem of 1332 following the death of his son, Thomas de Furnival III, notably mentions possession of a deer park and an associated wood, while the Inquisition following the death of William de Furnival in 1383 refers to 'a certain park with deer living in the same together with hunting for the same and with parks, woods and pastures in the same' (Curtis 1914, 48).

Our only detailed description of Sheffield deer park comes late, in John Harrison's 1637 survey, when it covered 2,461 acres, 3 roods and 11 perches, and contained 1,000 fallow deer and 200 stags (Ronksley 1908, 3; Sheffield Archives ACM/S/75). The associated map does not survive, but Gordon Scurfield (1986) created a detailed plan of the park as it may have appeared in the early 17th century, by plotting the places and features the survey describes on 18th- and 19th-century maps (Figure 8.2). At that time the park was demarcated by a fence eight miles long (Hunter 1819, 7, 189; Jones 2009, 4-5; 2013, 30).

In England, the 'great age of park creation' was between 1200 and 1350, and in South Yorkshire most of the grants of free warren were issued between 1250 and 1325 (Jones 2013, 27; also Bowen 2013, 196 for Shropshire). Parks were characteristically pear- or egg-shaped, most often, as in Sheffield, appended as a 'lobe' directly onto one side of a castle (Creighton 2002, 188-9; Bowen 2013, 195). They were:

compact acres of land enclosed by robust timber palings, ditches, or walls, with the landscape comprising large areas of grazed Lawn [from 'laund', a treeless area where deer would graze], pollarded rather

${ }^{27}$ OE hlyp-geat - 'a gate in a fence over which deer and other animals can leap but which restrains others such as sheep and cattle' (Hough 2001, 10; also Moorhouse 2007, 105). 


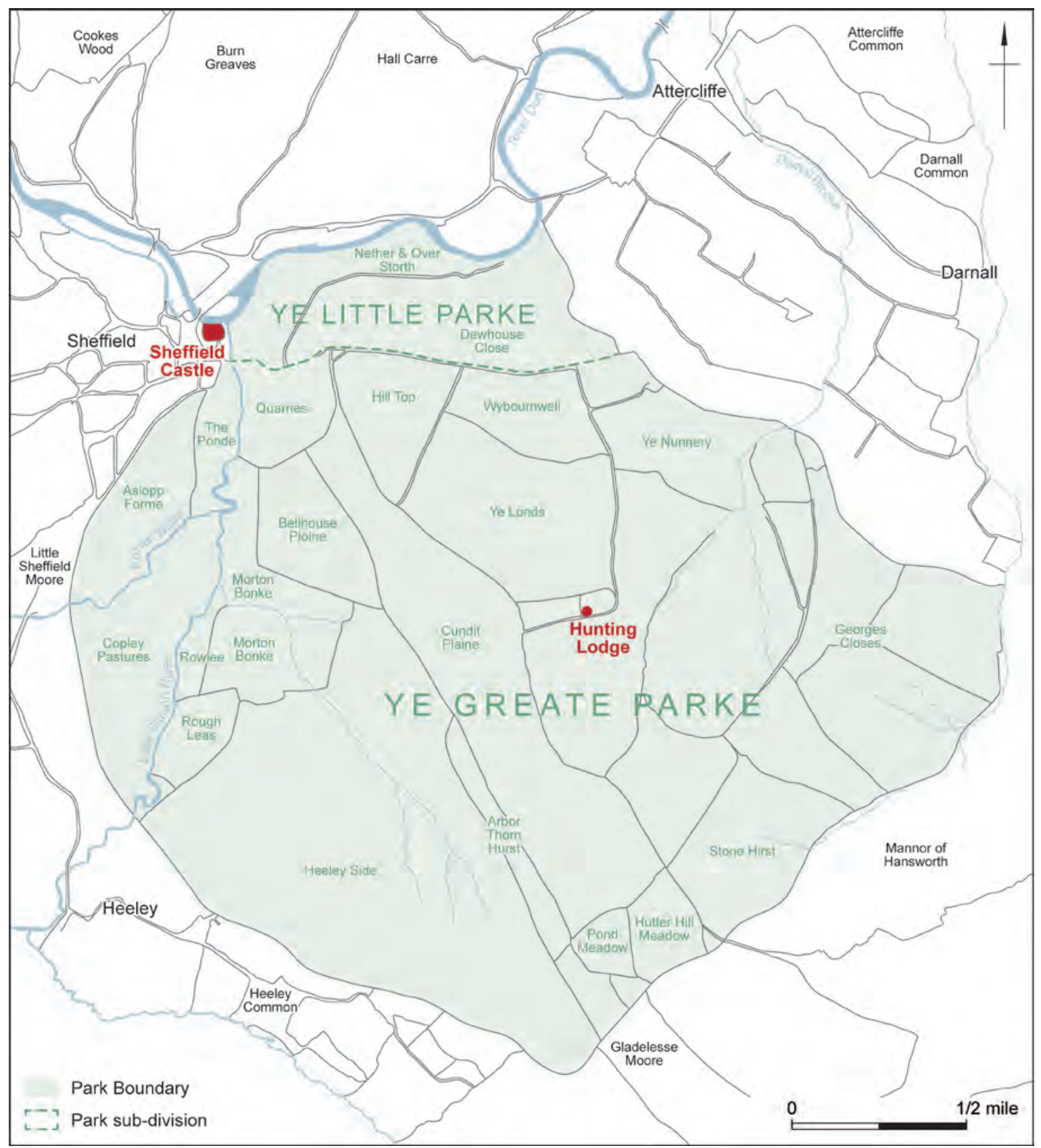

Figure 8.2: Map of Sheffield Park based on Harrison's 1637 survey. Wessex Archaeology, after Scurfield 1986.

than coppiced trees, as well as groves and larger patches of unimproved woodland (Bowen 2013, 195; Jones 2013, 28).

There may have been as many as c.3,000 parks (Rotherham 2007b, 80; Pluskowski 2007, 76), which varied greatly in size, with an average of about 100 acres (40.47ha) (Rotherham 2007b, 80). Sheffield park was enormous by comparison. The intimacy of the relationship between castles and deer parks makes their presence in the lordly landscapes of the Middle Ages seem almost natural. Yet emparkment, the process of their creation, required careful planning and modification of the landscape to meet the needs of the deer and other species and came at a significant cost (Pluskowski 2007, 64). 
Deer parks are now regarded as integral to lordship in the medieval period, with their landscape setting used to impress lordly status on visitors (Taylor 2000, 39, 44, 46; Herring 2003, 38-41; Liddiard 2005). Sheffield was no exception, with the park constructed adjacent to the castle, in a widely found juxtaposition, with an elaborate hunting lodge complex at its heart (Moorhouse 2007, 107-11; Mileson 2009, 86-91). By the 15th century, many lords had constructed new homes in their parks, often in the form of tower houses, such as the stone and brick structure at Fulbrook (Warks) built for the Duke of Bedford (Mileson 2009, 88). The developments at Sheffield mirror wider trends, then, with the hunting lodge becoming a favoured residence of the Earls of Shrewsbury as the 16th century progressed. David Hey $(1998,20)$ has suggested that they preferred its elevated setting to the 'old-fashioned castle set low in the smoky town', while Joseph Hunter $(1819,49)$ also noted that the site of the lodge 'commanded a glorious prospect of the well cultivated and inhabited country around, a great portion of which acknowledged him for its lord'. But it seems that only certain kinds of wealth and ownership visibly enhanced lordship - 'the town of Sheffield', Hunter continues, 'was not in view'. Further, while it was common for the gatehouses of urban castles to face towards the town (Creighton 2002, 138; see also the depictions of Pontefract Castle in Roberts 2002, 424), at Sheffield it is oriented, instead, south-east towards the deer park; from at least the 13th century the seigneurial focus was, then, on the surrounding elite landscape rather than the town.

Travel between the castle and park was via a bridge across the Sheaf and through the Park Gate, and 18thcentury maps reveal that this route persisted after the demolition of the castle (e.g. maps by Gosling (1736; Figure 1.6), and Fairbank (1769; 1771; Figures 1.8 and 9.4)). The 1771 Fairbank map indicates that access to the promontory on which the castle was located was via a narrow causeway leading to the gatehouse, but, from a defensive perspective, the main entrance to the inner courtyard could as effectively have been positioned at the south-west corner of the promontory facing towards the town (Figure 8.3). Thus its orientation towards

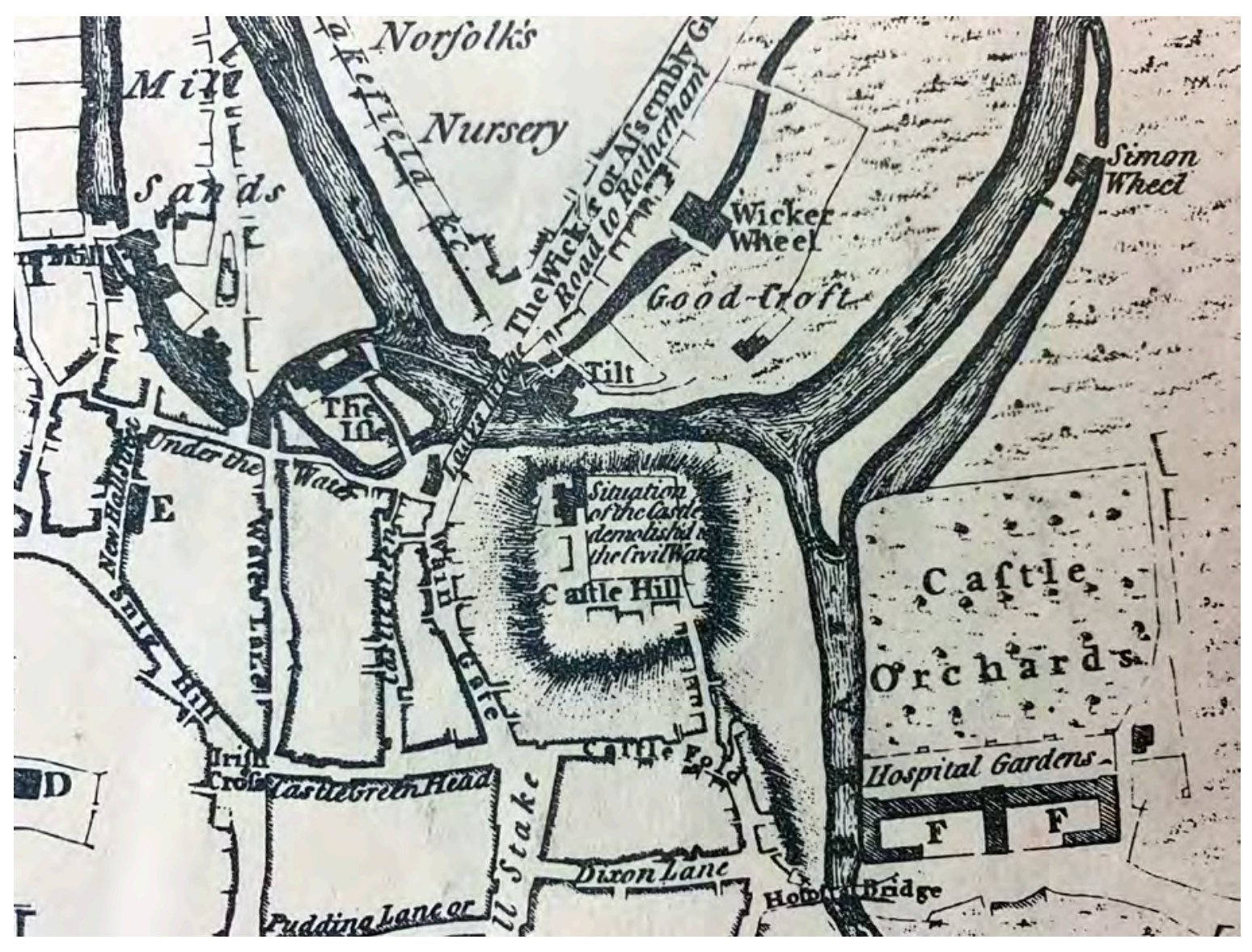

Figure 8.3: Detail from the Fairbank map of 1771. This shows the access to Castle Hill, from which a lane leads to the bridge over the Sheaf into the park (see also Figure 1.8). Reproduced with permission from Sheffield City Council. 
the park was a deliberate choice designed to display the principal entrance to the inner courtyard to visitors approaching from the deer park; it was, of course, also of considerable convenience to those labourers who regularly transported resources from the park to the castle. That many of the castle's illustrious owners spent little time in Sheffield, and on those occasions when they were present spent much of their stay at the hunting lodge, suggests that the interests of these lords lay in the seigneurial display attendant on possession of the deer park, as well as its concomitant leisure pursuits. The focus here seems specifically to have been on the local landscape, the aristocratic community and their visitors, rather than in making a political statement of wider import, of the sort that Phil Dixon (1990) has discussed in his work on Knaresborough Castle (North Yorks), which he argues was the 'stage setting' for royal authority in the north of England, at a time of baronial unrest over the role of Piers Gaveston at the court of Edward II.

Developing this argument, it also seems clear that the east side of the castle was intended to provide views to the higher ground of the park, and to present a more impressive prospect on the side from which elite visitors were mainly expected to approach. Fragments of window tracery, mullions and glass, a massive circular pier and the scale and character of the remains recorded by Armstrong indicate important buildings on this side of the courtyard (see Chapter 3). These probably included the hall and great chamber, which appear to have been adjacent to each other according to the description of the castle included in the burial account of Francis Talbot, $5^{\text {th }}$ Earl of Shrewsbury (d. 1560) (Hunter 1819, 56; Armstrong 1930, 11-12). Fifteenth-century Account Rolls record a hedge between the walls of the castle near to the Great Tower and 'the stream, which is probably a reference to the Sheaf on the east side rather than to the much wider Don (Thomas 1920-24, 71). Even if the Don had been 'the stream', the Great Tower would still have looked out towards the orchards and park to its north-east (which is where Edwards (1930) thought it was located; Figure 3.16). Furthermore, as we saw in the last chapter, the bank constructed between the east moat and the Sheaf - perhaps in the 13th century - seems designed to enhance the impression of defensibility and monumentality on the east side of the castle.

Harrison's survey differentiates the 'great park' from the contiguous 'little park', which allows us to suggest that they had different purposes within the lordly landscape. For example, he describes Horse Close, a piece of arable land, as 'being parte of ye little Parke lying next unto Dewhouse Close east \& abutteth upon ye Storth North \& ye Great Parke South' (Ronksley 1908, 54). Citing the example of the 'Great Park' and the 'Little Park' at Fotheringhay (Northants) - where, of course, Mary, Queen of Scots, having departed Sheffield Castle, would be tried and executed - Creighton $(2002,190)$ suggests that 'small parks closely appended to castles' may have been dedicated to entertainment activities, including tournaments. These 'little parks' could contain woodland and grazing - the one in Sheffield included some arable and pasture (Ronksley 1908, 53-4) - but, in some cases at least, their primary function seems 'more closely related to gardens and served as private and ornamental environments associated with recreation and pleasure' (Liddiard and Wells 2008, 89). The topographical and toponymic indicators provided by Harrison reveal that 'ye little Parke' was close to the castle along the banks of the Don, and its gardens and 'Three Orchards thereto adjoyneing ye first whereof ... lyeth Betweene ye River called ye little Sheath [Sheaf] on ye West \& ye little Parke on ye East' (Ronksley 1908, 47; Figure 8.2). The 'Great Parke' stretched away over the hills to the south and east (Jones 2004, 38). Sheffield Castle, therefore, was situated within a 'constructed' (i.e. contrived, designed) landscape wherein, looking eastwards, one moved from the cultured and cultivated to the - apparently at least - natural and wild. Amanda Richardson $(2007,42)$ has noted that such landscapes might be seen, and in fact might have been consciously designed as, 'chivalric landscapes' embodying the journey from routine social space to wilderness and back (also Pluskowski 2007, 69-77). With the 'wilderness' of the great park stretching over the horizon to the south and east, was there was an implied claim to boundless ownership and control, over both Nature and property?

The 'pale' both defined the edges of the park and kept deer within its confines; accordingly, its maintenance was a matter of some importance. In 1441-42 John Legge and William Gotson were paid a total of $46 \mathrm{~s}$. $4 \mathrm{~d}$. for mending the paling and constructing a hedge around Loggeclose, a task that took 139 days (Thomas 1920-24, 157), and on this basis it has been suggested that much of the medieval park boundary comprised a high 'cleft-oak paling fence' (Jones 2004, 39). However, here we might be being overly influenced by the kind of information that gets recorded in texts, and there are, in fact, indications that the boundary took other forms too. Hunter (1819, 190) refers to 'some old walling that seems to have been part of the ancient inclosure' near Newfield Green, where the South Yorkshire Sites and Monuments Record (03008/02) interprets an earthen bank and ditch $2 \mathrm{~m}$ wide and $1.5 \mathrm{~m}$ high in Buck Wood as part of the 'medieval deer park boundary'. Walls that survived into the early 20th century at Arbourthorne are believed to have been part of the park boundary (Lea n.d.; Figure 8.4). Prior to 


\section{DDeer Park Wa11. Sheffield Manor. I945.}

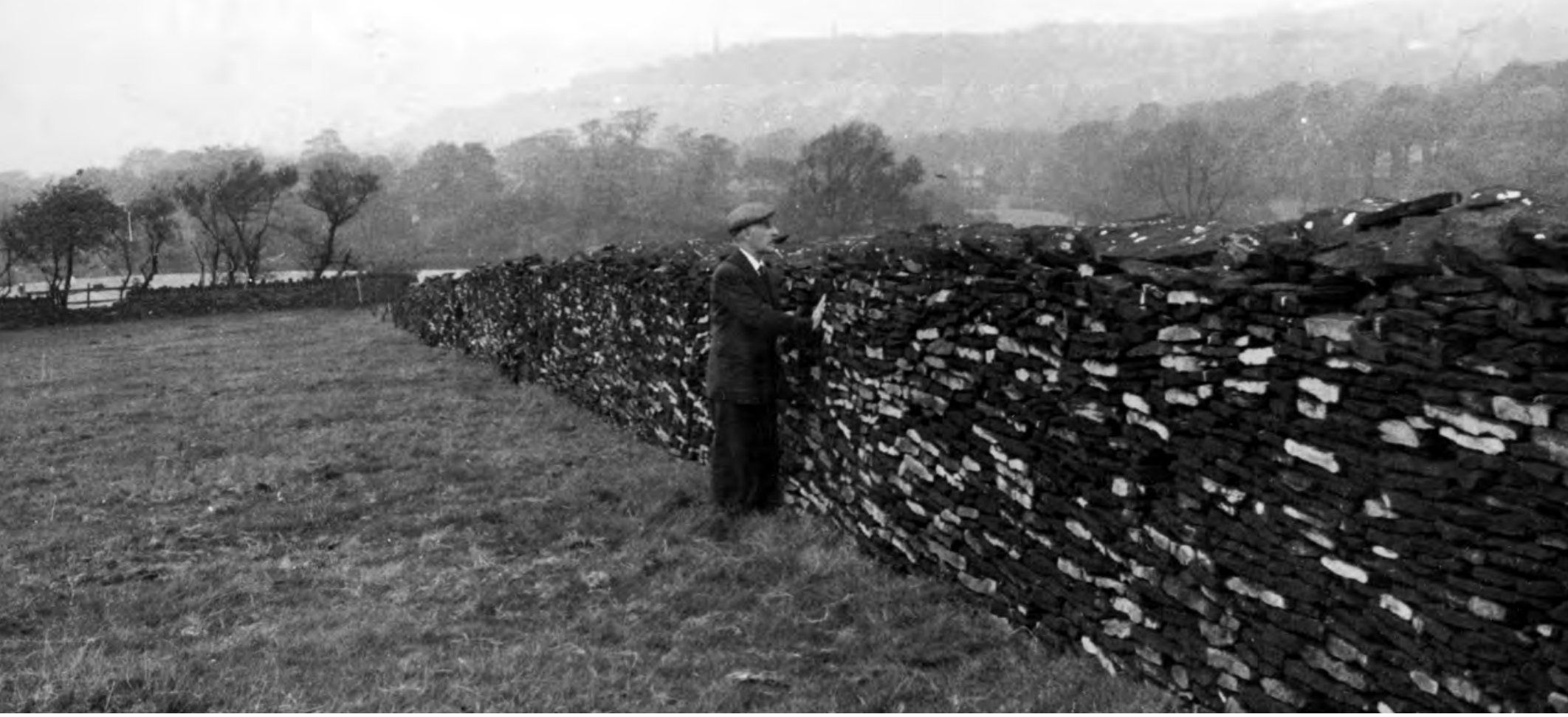

Figure 8.4: Wall at Blackbank, Arbourthorne. Said to be part of the boundary of the deer park of Sheffield; photographed by Harry Lea. With thanks to www.picturesheffield.com (s08135).

redevelopment of what would eventually become the new home of Sheffield Markets (see Chapter 1), excavation in 2007 located two short stretches of ditch (one $15 \mathrm{~m}$ long, the other $3 \mathrm{~m}$ ), which were heavily truncated but are probably pre-18th century. Here the boundary between the park and Little Sheffield Moor ran along the line of (the former) Porter Street, and continued north-east along what are now Union Street and Norfolk Street (see Ronksley 1908, 52, 57; Scurfield 1986, fig. 2; Hey 2010, 19). Both ditches follow that alignment, leading to the suggestion that they 'represent features associated with the late medieval deer-park boundary' (Gregory 2009, $3,16-17,37)$. In places the park boundary seems to have comprised a bank with an internal ditch, topped with a hedge, timber palisade or stone wall, presenting a more formidable barrier to the animals inside (Moorhouse 2007,104 ), and in that context it is worth noting a late 17th-century reference to the planting of trees along Sheffield park's fences and walls (see below, Section: The landscape and woodland resources).

However, this pale did much more than confine animals. As a barrier, it would have had a significant impact on pre-existing patterns of settlement, work and movement through the landscape. Although there were four gates into the park (Winder 1913,112), access was controlled by means of two main entrances: the aforementioned one facing west towards the castle and the other opening onto Gleadless Moor to the south (Hunter 1819, 189; a watergate was also recorded in 1441-42 (Thomas 1920-24, 157)). The park boundary was, in fact, a statement of control. As Oliver Creighton $(2002,191)$ has argued, 'deer parks were miniaturised landscapes of exclusion, reflecting directly the coercive power and status of castle lords'. In sum, they did not just reflect that power; they were among the means through which it was exercised.

\section{A noble residence}

Medieval deer parks contained a variety of lodges, from comparatively humble abodes for park keepers to elaborate complexes of royal and noble residences. In the case of Sheffield park, Harrison refers to lodges for three park keepers, one occupied by 'widdow' Elizabeth Skelton at the exit onto Gleadless Moor to the south, 

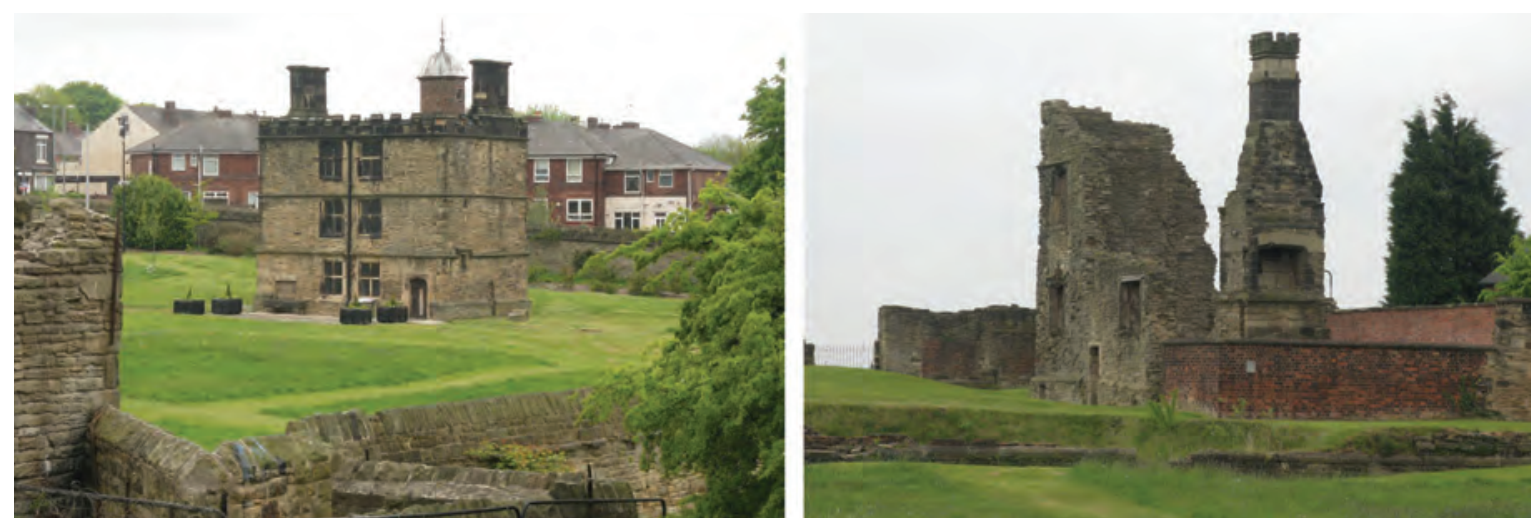

Figure 8.6: Sheffield Manor Lodge. This is the name by which the Tudor hunting lodge has come to be known locally. The photograph on the left is of the late 16th-century Turret House, which was probably a banqueting house with a viewing platform on the roof affording extensive views of the park; to the rear is mid-20th century social housing which grew up around the lodge in the post-War period. The photograph on the right is of part of the range of buildings on the south side of the inner courtyard. Photographed in 2013, (C) Dave Pickersgill and licensed for reuse under a CC BY-SA 2.0 licence; https://www.geograph.org.uk /photo/3465199; https://www.geograph.org.uk/photo/3465208.

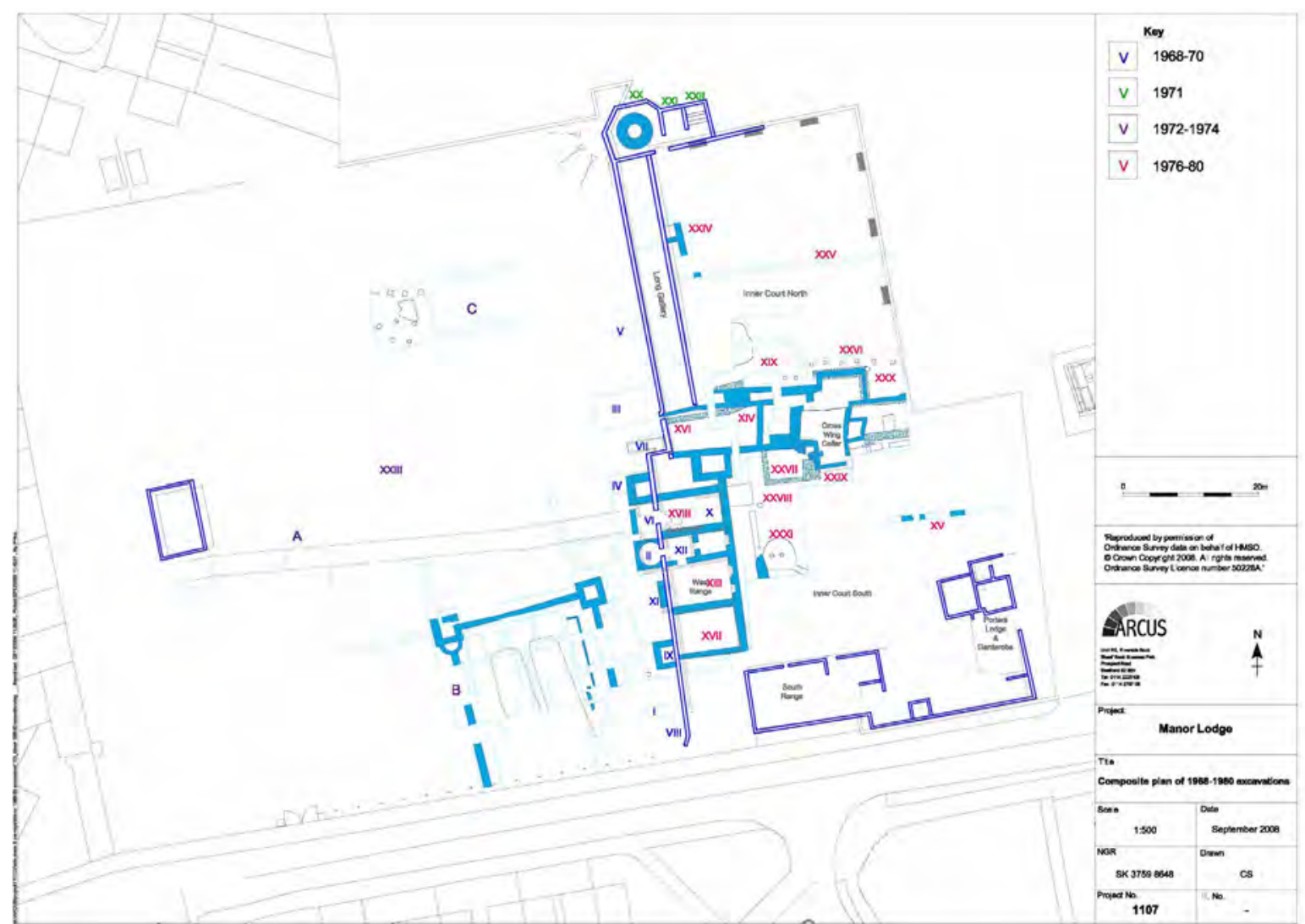

Figure 8.7: Plan of the trenches excavated by Sheffield City Museum between 1968 and 1980. The trenches are numbered with Roman numerals, colour-coded to indicate in which year they were excavated, which is shown on the key. University of Sheffield.

Figure 8.5 (page 258): The Hall in the Ponds, now the Old Queen's Head public house. Photographed in 1971 by H. Mann. With thanks to www.picturesheffield.com (s05471). 
(e.g. Cherry 1972; 1973; 1974; 1977; Moorhouse 1971; 1977; 1978; Beswick 1980). In this chapter we have drawn on the archive housed by Museums Sheffield (synthesised in Hadley and Harlan 2011). An analysis of the standing fabric was commissioned in 2002 from Field Archaeology Services of York in preparation for a Heritage Lottery Fund application (Clark and Jack 2002; see Chapter 9), and between 2007 and 2009 ARCUS conducted new excavations in advance of the construction of a visitor centre and the opening of the site as a heritage attraction (McCoy 2007a; 2007b; 2009; see Chapter 9, Section: Archaeology and social enterprise in Sheffield Park). Over the following two years a University of Sheffield knowledge exchange project was directed by Dawn Hadley, in collaboration with Wessex Archaeology and the Derbyshire-based Archaeological Research Services Ltd, and this saw excavations in both the inner and outer courtyard, and a survey of the standing fabric of the long gallery (Mepham and Powell 2010; Burgess et al. 2011; Crewe and Askew 2012). In the following discussion, we present the first published account of the archaeological evidence for the hunting lodge during the medieval and early post-medieval periods, which helps to place the long-term history of the castle in its contemporary context. We trace the earliest excavated phases of the lodge, examine evidence for its rebuilding and enhancement in the late 15th and 16th centuries, and chart its decline as the landscape around it saw hunting give way to industrial activities.

\section{'A house in the Lord's Park'}

As we have seen, we have written references to the deer park from the late 13th century, but documentary evidence concerning the lodge is largely confined to the period after the late 15th century, and most of the standing fabric appears to be of 16th-century date. However, excavation and buildings analysis has identified earlier phases of occupation. Excavation in the outer courtyard in 1972 and 1973 revealed a stone building at least $25 \mathrm{~m}$ in length; its full dimensions could not be ascertained as it continued under the modern road to the south (Beswick 1974; Figure 8.8). At the north-west and north-east corners were square towers with flagged floors (4m square); a semi-circular feature of uncertain function was added to the north-west tower in a later phase (Beswick 1972a; 1972b; 1972c; 1972d; 1973a; 1973b; Bonsall 1972; Bartlett 1973; 1974). There were ephemeral traces of internal partitions (Bartlett 1974; Thorp 1974; Crewe and Askew 2012, 34-5) and drainage channels that distributed rainwater away from the towers, while external channels, another of which was excavated in 2011, may have been associated with garderobes (Bartlett 1974; Hadley and Harlan 2011, 10-12; Crewe and Askew 2012, 20,34). It was clearly a substantial building as glass, lead and slates were recovered from the inside (Bartlett 1974). Its alignment is different from that of the surviving 16th-century buildings, which suggests that it belongs to an earlier phase of the hunting lodge, a deduction reinforced by the 15thand 16th-century date of the pottery recovered from the backfill of the robbed-out walls (Hadley and Harlan 2011, 12; Crewe and Askew 2012, 34, 136). It has been suggested that it might have been a tower (Bartlett 1974; ICOSSE 2005, 38-9), of a type common to medieval hunting lodges, with an upper room to allow viewing of the hunt (Girouard 1978, 76-7; Rackham 1986, 26-7; Pluskowski 2007, 76). The limited range of finds recovered include deer bones and iron knives, as well as pottery, which has led to the suggestion that it was a building that fulfilled dining and kitchen activities (Bartlett 1974), consistent with the socialising offered to those who partook of the hunt.

The towers and west wall of this building had been reduced to two or three courses of stone, while the other walls had generally been reduced to robber trenches, suggesting a very careful and deliberate demolition, perhaps to recover stone for reuse at the time of the documented remodelling of the site in the late 15th or early 16th century (see below; Bartlett 1974; Beswick 1973a; 1973b; Hadley and Harlan 2011, 11; Crewe and Askew 2012 , 34). In 1973 a pit $(10 \mathrm{~m} \times 6 \mathrm{~m} \times 1.5 \mathrm{~m})$ was partially excavated in the west half of the building; it was dug into the clay subsoil and contained building debris including brick fragments (Beswick 1974). The following year a second pit $(12 \mathrm{~m} \times 5 \mathrm{~m} \times 1.5 \mathrm{~m})$ was encountered in the east half of the building, and it was tentatively suggested that the pits may have been part of a clay-lined ornamental water feature (Beswick 1974; Hadley and Harlan 2011, 12). However, re-examination in 2011 revealed that the pits were not as large as had been conjectured in the 1970s and that the clay was natural (Crewe and Askew 2012, 35), which suggested that, as originally argued in 1973, it had been dug out for use in construction.

Figure 8.8 (page 261): The medieval building in the outer courtyard of the hunting lodge during excavation in 1972. Courtesy of Museums Sheffield. 


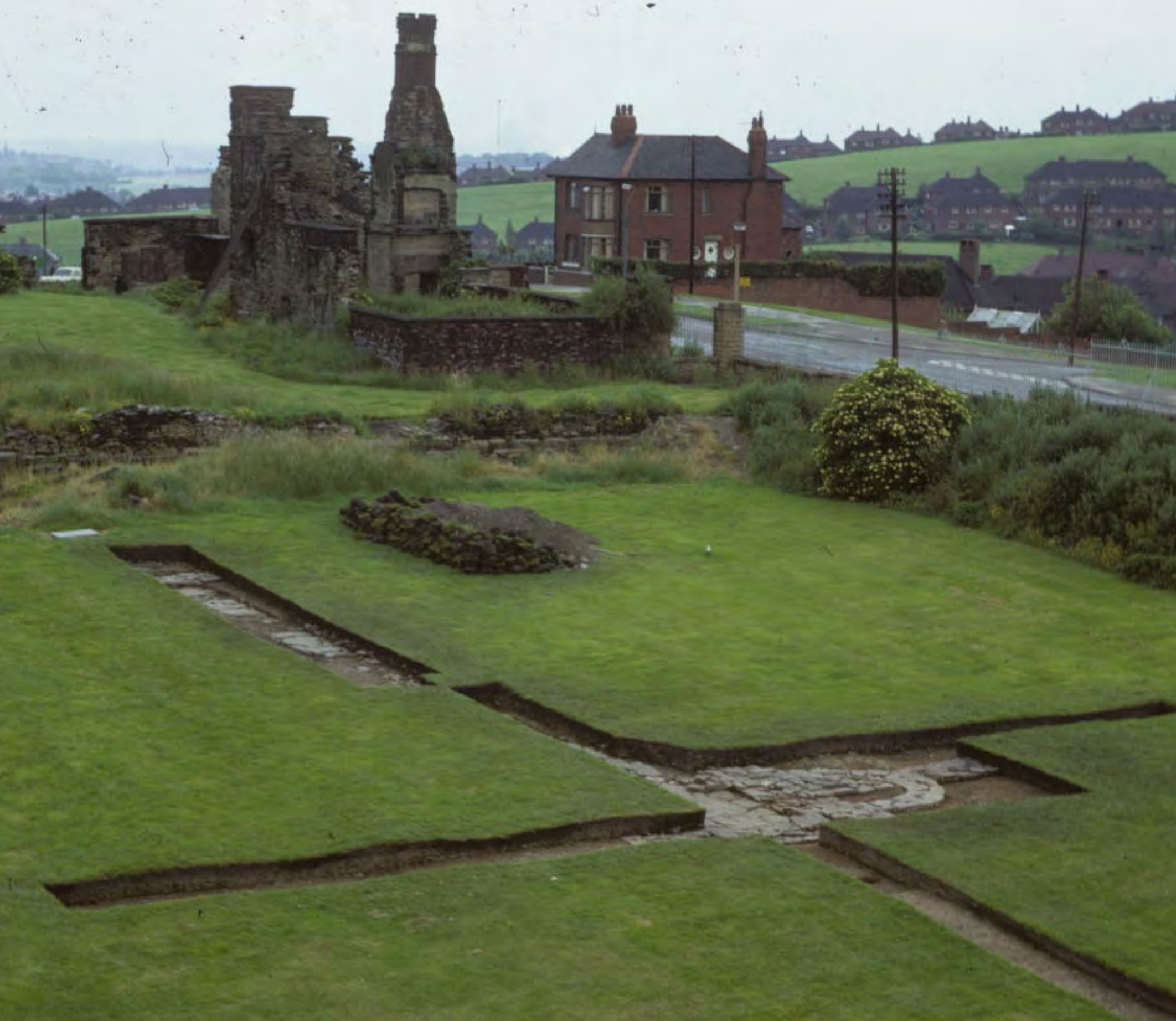


A partially surviving building on the eastern side of the hunting lodge complex, with walls still standing to c. $1.5 \mathrm{~m}$ in height, incorporates a timber cruck blade which has prompted speculation that it was a medieval building (Winder 1913, 112; Beswick 1980, 468; Grade II listed building, no. 1246612; Figure 8.9). Excavation in 1990 revealed that it had formerly comprised two bays with three pairs of cruck blades, but architectural fragments derived from the 16th-century phases of the lodge were reused in the walls, demonstrating that it was constructed at a later date than had long been supposed. Beneath the floor surface the remains of steps led down to an oven or kiln, adjacent to a contemporary cellar, and it was concluded that the building was probably constructed in the 18th century. Internal drainage channels and two troughs set into the west wall reflected its conversion into a stable or cowshed, probably in the 19th century, after which it was used as a garage (Merrony 1990-91). Nonetheless, the cruck building is on the same alignment as the building with corner towers in the outer courtyard, suggesting that it may have been rebuilt on the site of a medieval building (Beswick 1980, 468; Clark and Jack 2002, 22; ICOSSE 2005, 38).

In the inner courtyard, traces of clay-bonded stone footings for walls on various alignments were excavated beneath the 16th-century cross-wing of the lodge in the 1970s (Beswick 1976a; 1976b; Hadley and Harlan 2011, 15). A fragmentary wall of weathered boulders (running east-west) was the earliest feature discovered, with traces of an associated clay floor (Bartlett and Beswick 1979; Beswick 1979; 2002; Moorhouse 1977). Only the south-east corner of this building remained, along with evidence for an internal partition wall. Burnt clay in the foundation suggested the location of a fireplace, while postholes in the corners of the building indicated that there had been an above-ground timber-framed structure (Beswick 1979; 1980; Hadley and Harlan 2011, 15-16). Two further walls were found to the south, which appeared to form part of a building $5.5 \mathrm{~m}$ wide, sealed below the sandy under-flooring of a 16th-century flagged area. Dating evidence was inconclusive, but located nearby in a disturbed area was a penny of Henry V dated to 1420-22 (Beswick 1979; Hadley and Harlan 2011, 17). This building was on a similar alignment to that of both the building with the corner towers in the outer courtyard and the cruck building, and they may all have been part of a substantial later medieval hunting lodge complex (Beswick 2002; ICOSSE 2005, 38).

In 2010, a detailed structural analysis by Wessex Archaeology revealed further evidence for an early phase of the lodge (Figure 8.10). This comprised the lower levels of the long gallery's west and north walls and

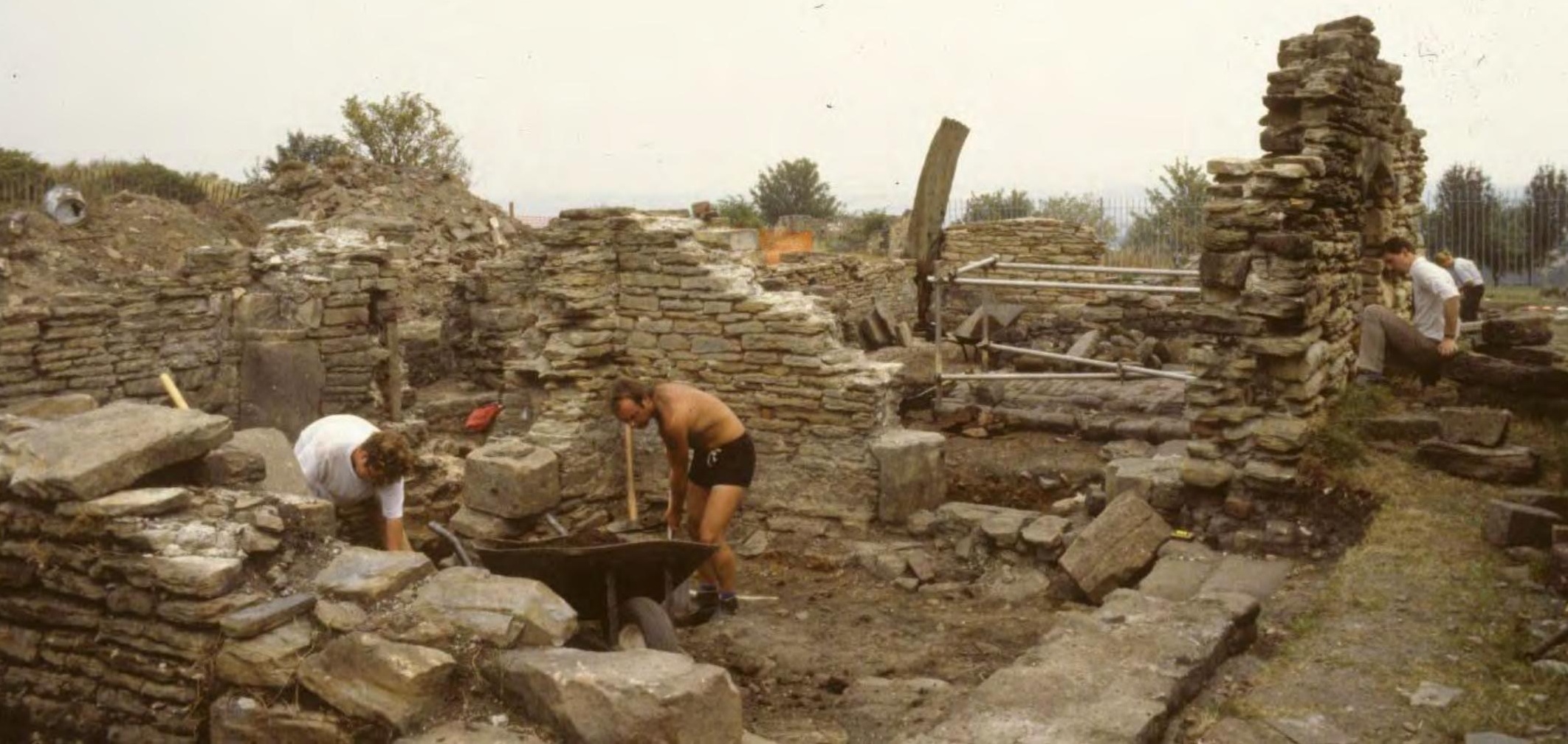




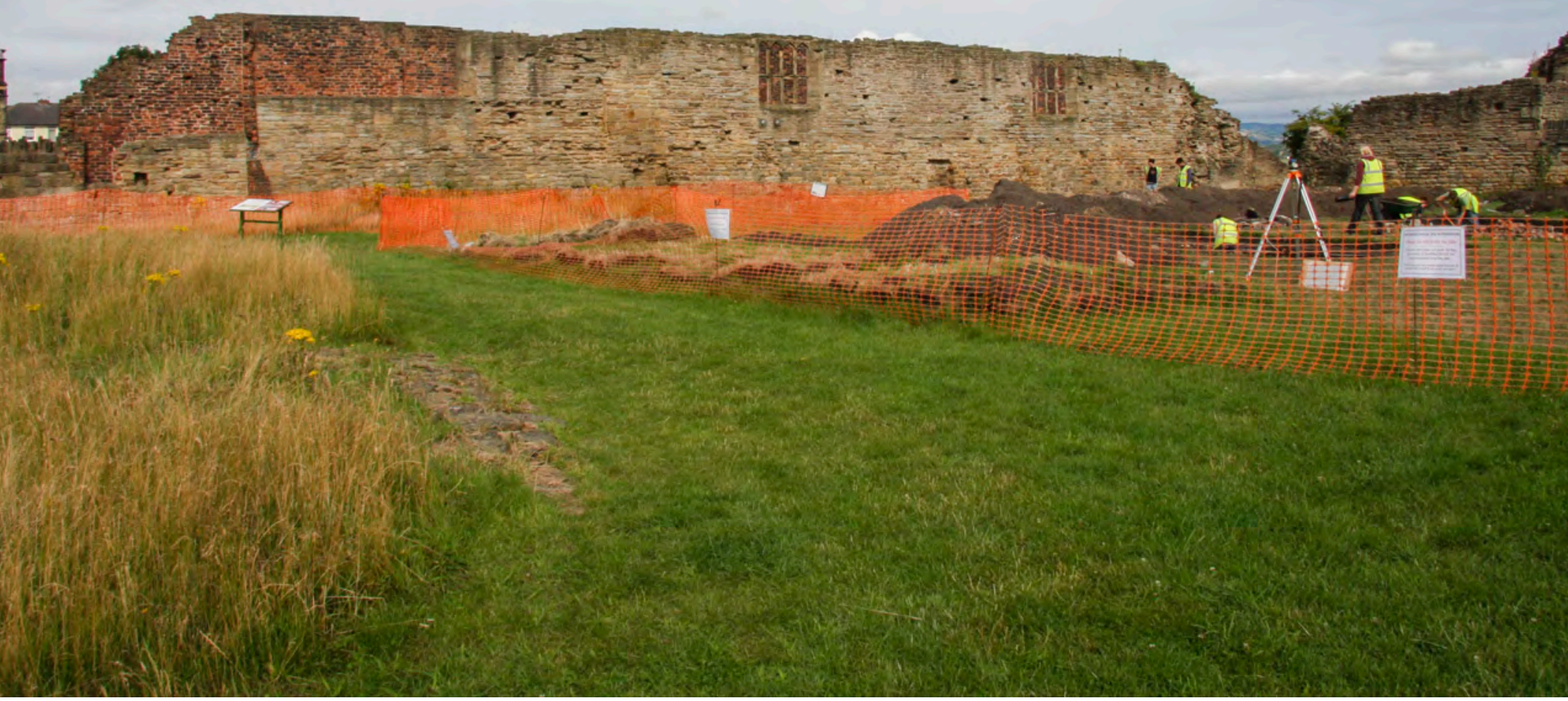

Figure 8.10: The east face of the long gallery wall photographed from the south-east during the 2010 excavations in the inner courtyard. On the right-hand side of the photograph is part of the north courtyard wall. Wessex Archaeology.

the north wall of the inner courtyard, which were all constructed of large sandstone blocks (Figure 8.11). Several now-blocked window and door openings in the lower west wall of the long gallery appear to belong to this phase, and suggest the locations of earlier buildings of uncertain function (Burgess et al. 2011, 11-12; Figure 8.12). Excavation in the inner courtyard suggested that it had contained trees and vegetation in the late medieval period, as burnt deposits related to the removal of tree roots were identified, which were overlain by levelling deposits associated with the 16th-century construction of the long gallery (Burgess et al. 2011, 23, 56).

Excavation has produced little medieval material culture, beyond some Coal Measures wares and a handful of pieces of painted window glass, and so it is difficult to say anything more of the nature of late medieval occupation at the lodge. Nonetheless, we have been able to show the importance of the archaeological evidence for this phase, which reveals something of the investment of earlier lords such as John Talbot in their lands in Sheffield.

Figure 8.9 (page 262): The cruck-framed building on the east side of the inner courtyard during excavation in 1990. University of Sheffield. 


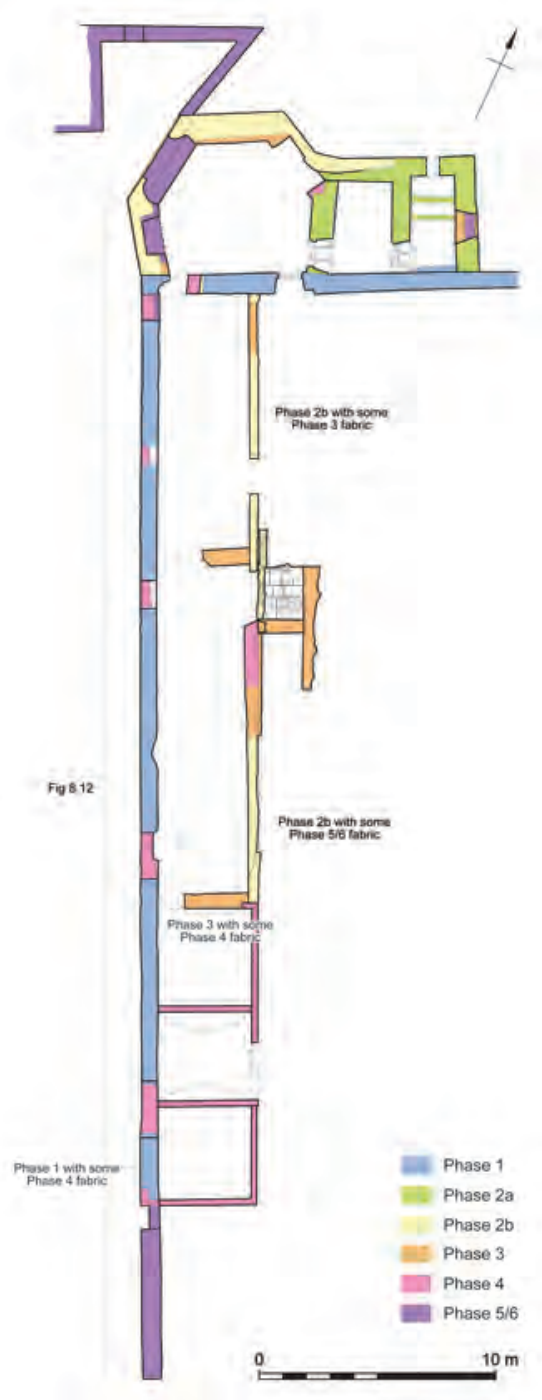

Figure 8.11: Phased plan of the long gallery. Wessex Archaeology.

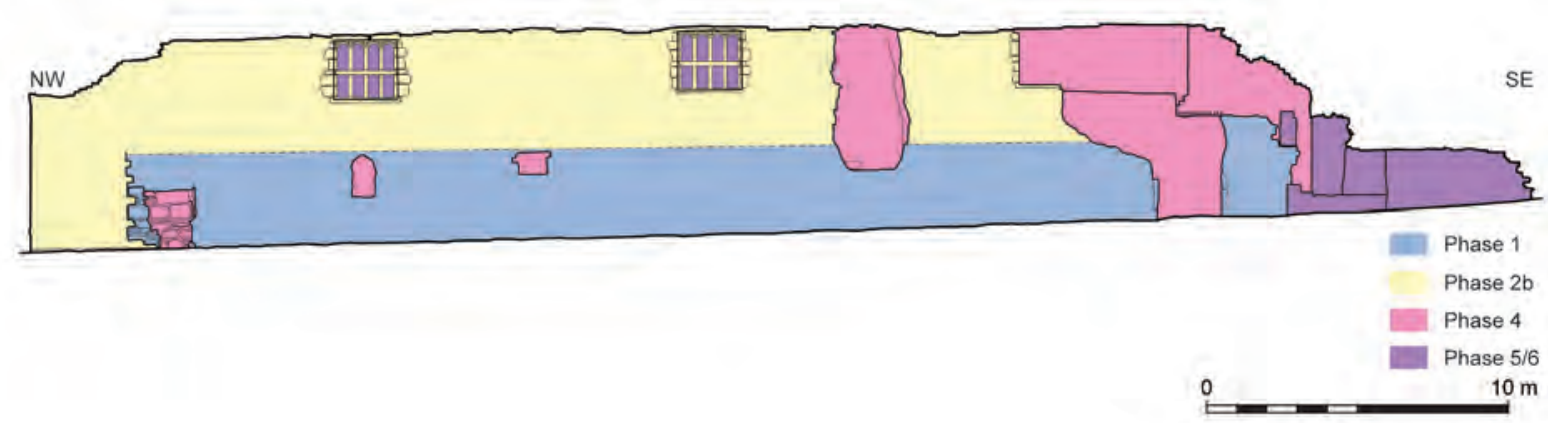

Figure 8.12: Phased drawing of the west elevation of the inside (east-facing) wall of the long gallery. Wessex Archaeology.

Figure 8.13 (page 265): The 16th-century timber framing in the hunting lodge long gallery. Photographed at the end of the 19th or beginning of the 20th century. Courtesy of Museums Sheffield. 


\section{'A faire house pleasantly, very scituated upon a hill'}

The first detailed documentary references to the hunting lodge come from an Account Roll of 1478-80, during the lifetime of George Talbot, $4^{\text {th }}$ Earl of Shrewsbury, the first of the earls to make Sheffield his principal residence (Potter and Walton 1950; ICOSSE 2005, 14). It details the rebuilding undertaken at 'a house in the Lord's Park', confirming that a building was already in existence at the lodge. This refurbishment necessitated the purchase of lathes and over 400 boards, and saw $£ 50 s$. $1 \mathrm{~d}$. spent on labour, stone foundations, wood, nails and food for the workmen, as well as transporting and dressing 14 wagonloads of stone roof tiles from Shiregreen (c.7km to the north) (Hunter 1819, 49; Potter and Walton 1950, 19, 21; Beswick 1980, 468). Further work was undertaken in the early 16th century. As John Leader $(1874,43)$ put it, 'George ... found himself ... with a fine estate, money in hand, and a taste for building. Selecting the most elevated spot in his park [he] proceeded to change the hunting lodge of his forefathers into a mansion, covering with its courts and gardens more than four acres'. Hunter tells us that it was 'furnished in a style of magnificence corresponding to the rank of its noble inhabitant, and notes a payment of 240 crowns in 1516 for 'hangings', possibly tapestries, to be brought from Tournai (France) for use in the lodge (Hunter 1819, 49; Burgess et al. 2011, 3). Given the overwhelming ethos of the place, one wonders if they depicted hunting scenes (see Pluskowski 2007, 77).

The visit of the captive Cardinal Wolsey in 1530 was recorded by his gentleman usher, George Cavendish, who noted that the gallery and tower were then 'newly built'. Cavendish also reports that the long gallery was divided by a curtain ('a travers of sarcenett' - a fine, soft silk material), allowing the cardinal and the Earl their own separate space (Singer 1825, 295). The antiquarian Thomas Winder $(1919,10)$ identified the position of this screen from a moulded oak corbel still in place in one of the 19th-century cottages built into the Tudor ruins (Figure 8.13). In 1666 the herald and antiquarian Sir William Dugdale recorded the long gallery's armorials,

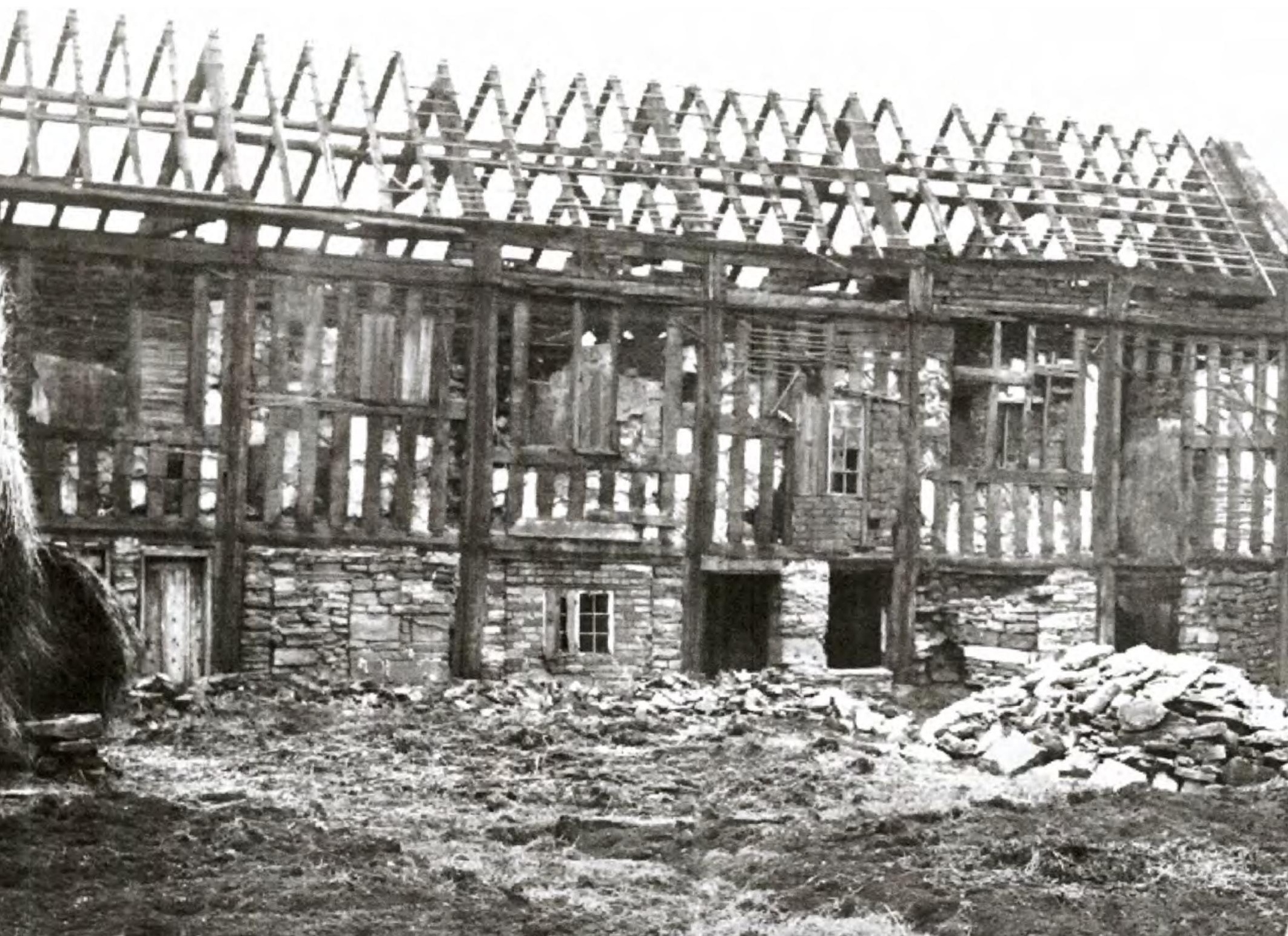


which included the Talbot arms combined with those of the $4^{\text {th }}$ Earl's second wife, Elizabeth Walden of Erith (Kent), whom he married in the early 1520s, while the inclusion of the royal arms impaling those of Spain is unlikely to have occurred after the breakdown of the marriage of Henry VIII and Catherine of Aragon, which became widely known in 1527 (Hunter 1819, 192; Leader 1874, 43). This suggests that the decorative schema recorded by Dugdale was created in the early to mid-1520s (Leader 1880, 149-50; ICOSSE 2005, 41).

The lodge was extended during the time of the $5^{\text {th }}$ Earl, Francis; a letter dated $15^{\text {th }}$ June (but year unknown) from his wife, Grace, Countess of Shrewsbury, informed her husband that the construction work at the lodge was going well (Batho 1971, 324). Francis died at the lodge in 1560 and was laid out in its chapel prior to his burial in the parish church (Hunter 1819, 55; Hey 2010, 28); this is the only mention of a chapel, and its location is unknown (ICOSSE 2005, 43). The lodge was substantially altered again by the ${ }^{t^{\text {th }}}$ Earl, George, and his wife, Bess of Hardwick, who invested heavily in the buildings and surrounding landscape. There has been debate about whether these alterations were motivated by a desire to make the hunting lodge their principal residence in Sheffield (instead of the castle) or to provide a fitting residence for Mary, Queen of Scots (Clark and Jack 2002, 4); perhaps both were factors.

These documented periods of refurbishment cannot easily be related to the standing fabric and excavated remains, and it is, anyway, clear that there were multiple episodes of 16th-century construction. For example, the standing fabric of the tower at the north end of the long gallery reveals two distinct phases. First, a threestorey tower was built against, and, above, the aforementioned north wall of the inner courtyard, with new walls constructed from rubble sandstone coursing with sandstone quoins. This tower contained two rooms at ground- and first-floor levels, and scars on the west walls of the tower indicate that a timber staircase once led to a single large chamber on the second floor with a large oriel window looking north across the park, as depicted in several 18th- and early 19th-century drawings and paintings (Burgess et al. 2011, 12-13; Figures 8.14 and 8.15 ). The east room of this tower housed a garderobe, which survives as a low stone arch; a groove

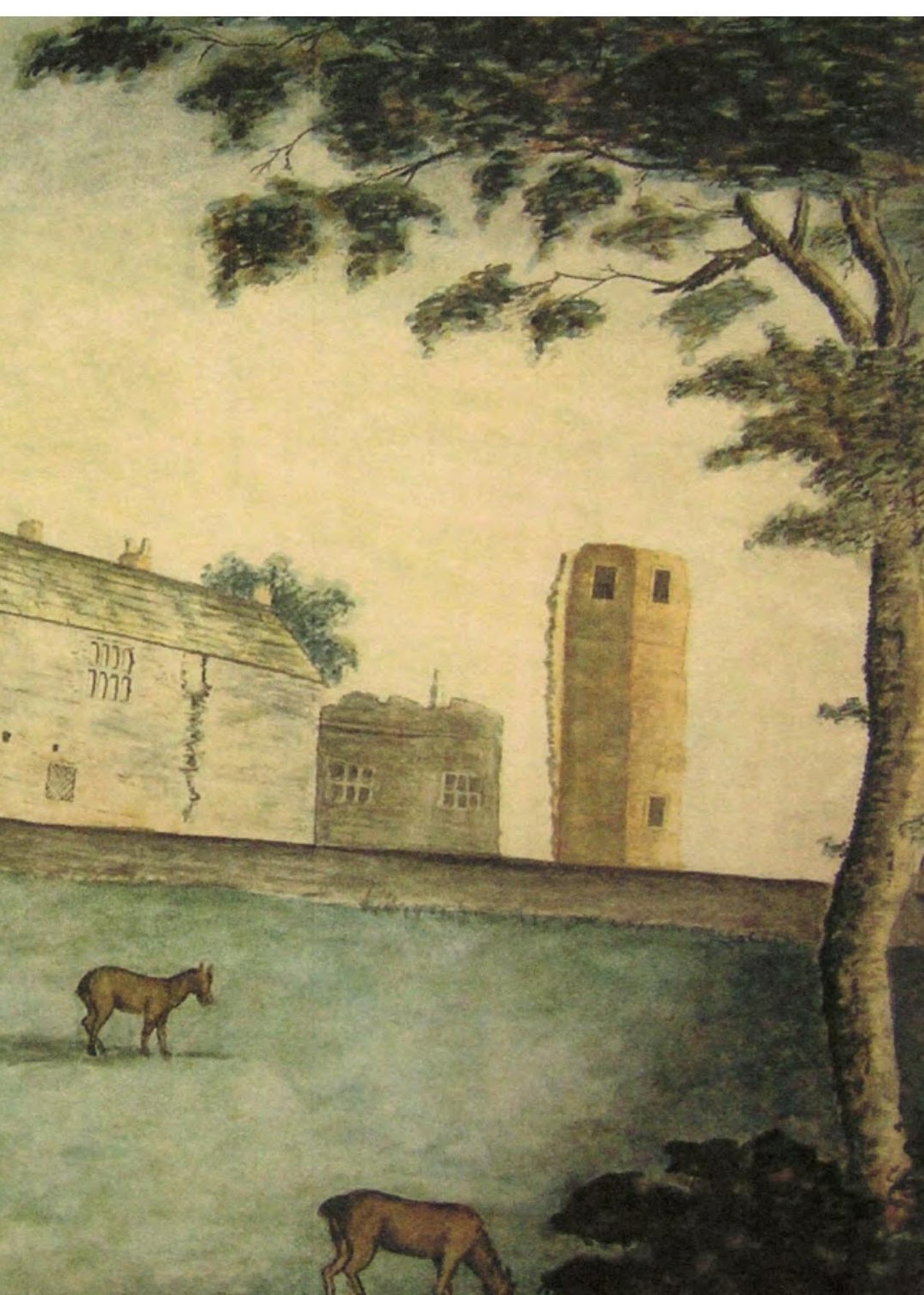




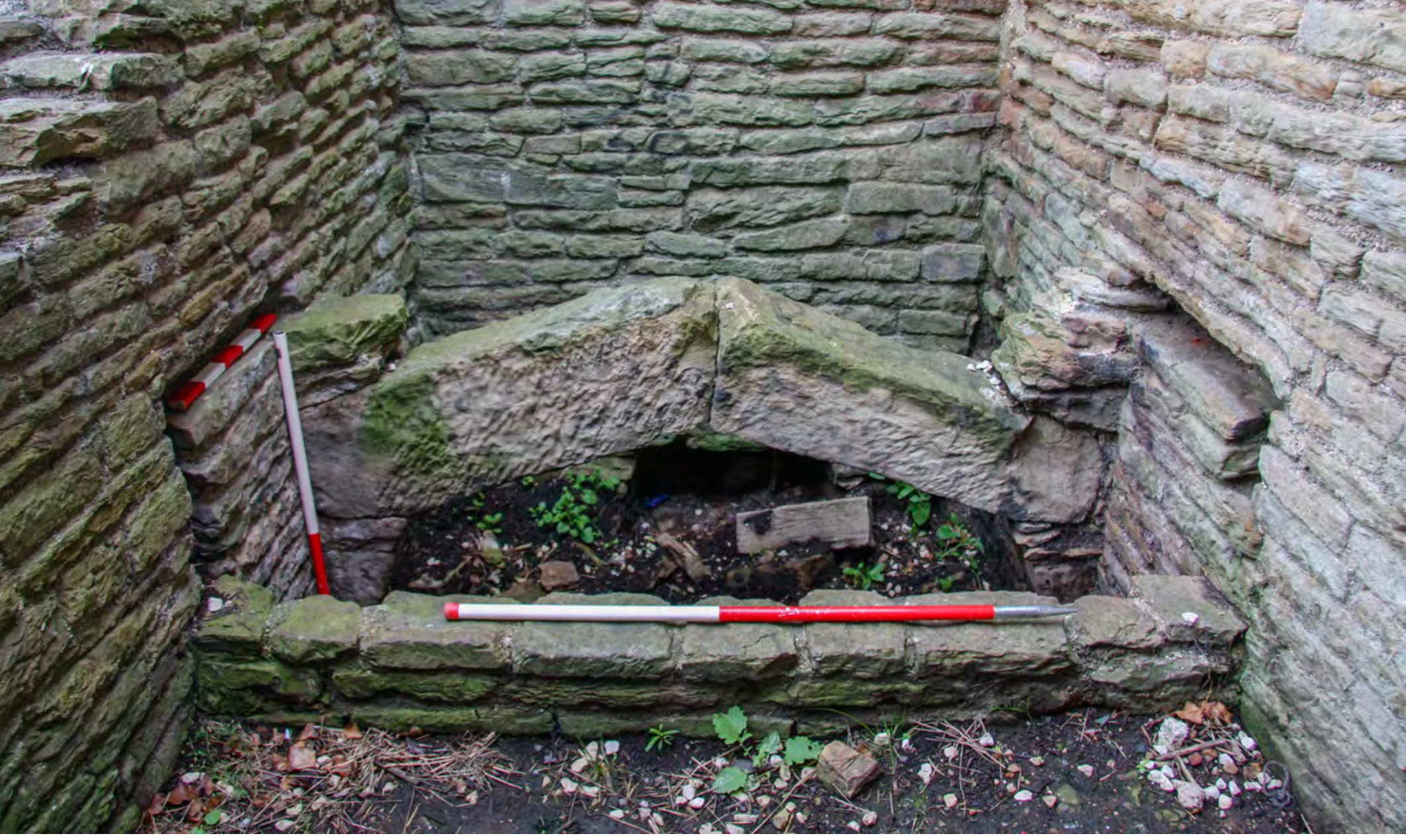

Figure 8.16: The garderobe in the three-storey tower. It takes the form of a low stone arch across the room; there was an associated timber structure and a drain leading through the north wall. Wessex Archaeology.

The long gallery was a long $(38.5 \mathrm{~m})$ and narrow $(5 \mathrm{~m})$ two-storey structure (Figure 8.10$)$. It utilised the earlier single storey boundary wall as the lower part of its west wall, and above this it was constructed of sandstone rubble coursing. At first-floor level this wall contained two stone mullioned and transomed windows; the upper four lights have four-centred arched heads with sunk shouldered spandrels, indicative of late 15th- or early 16th-century date. At the south end of the first floor the remains of a third window survive in the form of its north jamb and part of the sill. These windows would have enabled occupants of the long gallery to look out towards the entrance to the hunting lodge, across the park and towards the town, although this was critically hidden from view, thus preserving the 'sylvan' illusion. A large area of blocking to the north of the windows extends from the ground floor to the top of the wall and suggests the former position of a chimney stack or projecting wall. The east-facing elevation includes a horizontal scar at the same height as the change in stonework, which is the product of former joist holes for the first floor of the long gallery. Numerous small holes in the elevation at first-floor level are indicative of it having been wood panelled (Beswick 2002; Burgess et al. 2011, 13-14; Figures 8.11, 8.12).

The east side of the long gallery was constructed of a timber frame resting on stone pads, laid on a low stone wall (Winder 1919, 11; Figures 8.13, 8.18). While the last remaining timber framing was removed in the early 20 th century, part of the low stone wall remains in situ, capped with a chamfered stone plinth. Two of the original stone pads on which the timber framing rested have been retained elsewhere on site (Burgess et al. 2011, 15). A trench was excavated in 2010 to investigate the foundations of this east wall, which revealed they had been cut into natural clay deposits. The ground level outside the long gallery had been raised by the deposition of sandy clay layers, seemingly in preparation for the new phase of the hunting lodge, which also involved, as noted above, clearance of vegetation in the centre of the inner courtyard (Burgess et al. 2011, 20).

Figure 8.17 (page 269): The two-storey tower at the north end of the long gallery. Wessex Archaeology. 


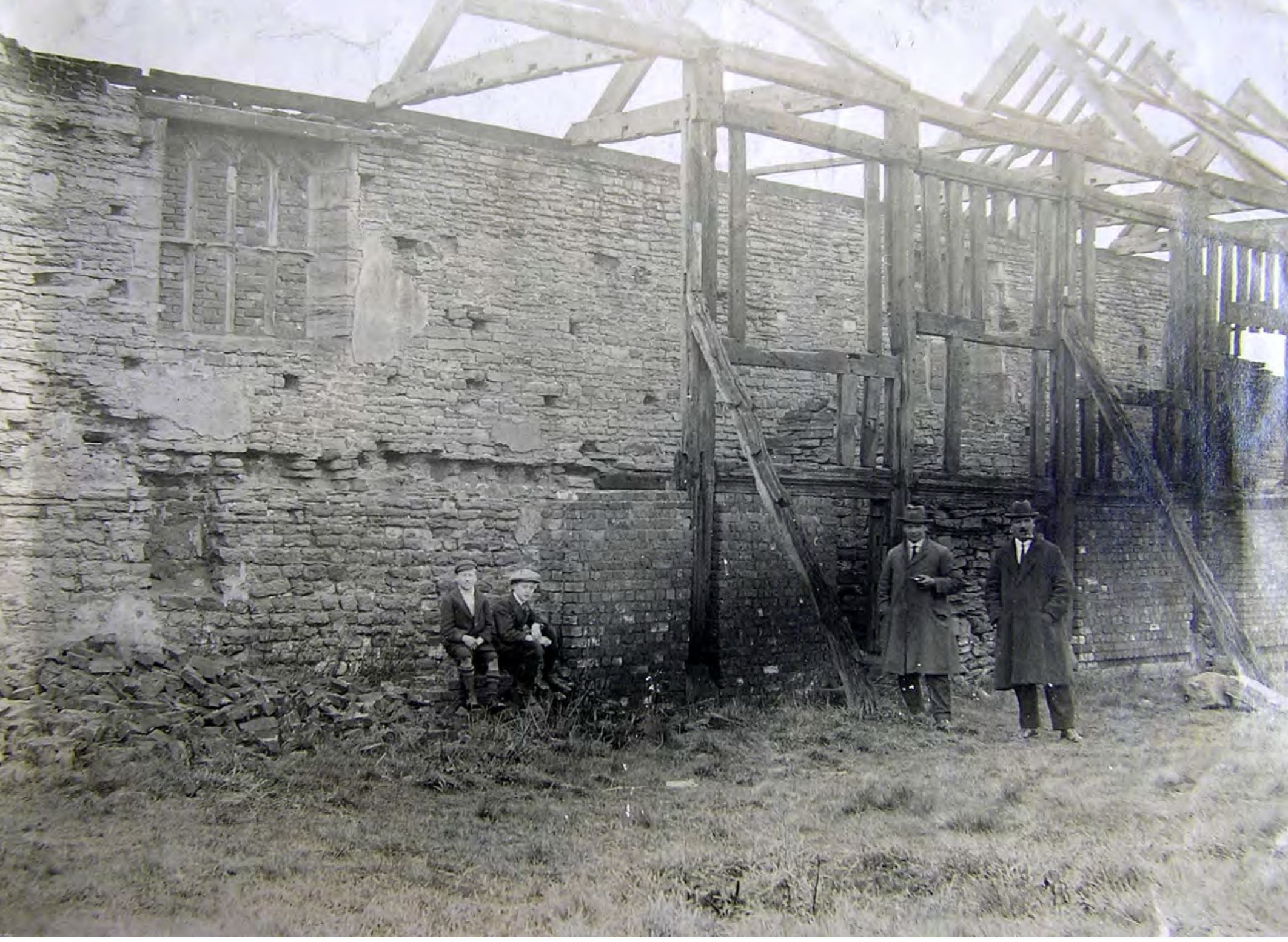

Figure 8.18: Remnants of the long gallery in the early 20th century. Courtesy of Museums Sheffield.

In the later 16th century, perhaps during the period of refurbishment by the $6^{\text {th }}$ Earl, the southern end of the west wing was rebuilt, creating an impressive entrance with octagonal brick towers (Beswick 1980, 469; Figure 8.14). As Hey $(1998,20)$ notes, this is the earliest known use 'of this then prestigious material' in Sheffield. The towers stood into the 18th century, but the last one fell during a great storm of $2^{\text {nd }}$ March 1793; Hunter $(1819,191)$ described them as 'two lofty octagonal towers about sixty feet $[c .18 \mathrm{~m}]$ apart, built of stone but cased with brick ... Between these was the principal entrance to the court, where a noble flight of steps led to the door which opened into what was called the great gallery' (Figure 8.19). Excavation between 1968 and 1970 focussed on the tower remains still visible on the surface (which turned out to be the south tower) and on locating the other one (Radley 1970; Butler 1971; Moorhouse 1971). Contrary to Hunter's claims, the towers, each $c .5 \mathrm{~m}$ in diameter, were found to be $c .5 \mathrm{~m}$ apart. The mortared stone foundations of the south tower were externally rectangular but with a circular interior, which would have housed a staircase. Traces of paving remained on the original floor level, and five stone-packed postholes outside the tower were interpreted as being from the scaffolding that would have been required during construction of the tower. The excavated remains of the north tower lay beneath destruction layers, and were different from those of the south tower, comprising three sides of a massive octagonal structure of mortared stone, with a rectangular internal form. This was consistent with the appearance of the last standing tower depicted in 18th- and 19th-century paintings and drawings of the lodge, although these show it on the south side of the entranceway into the inner courtyard. 


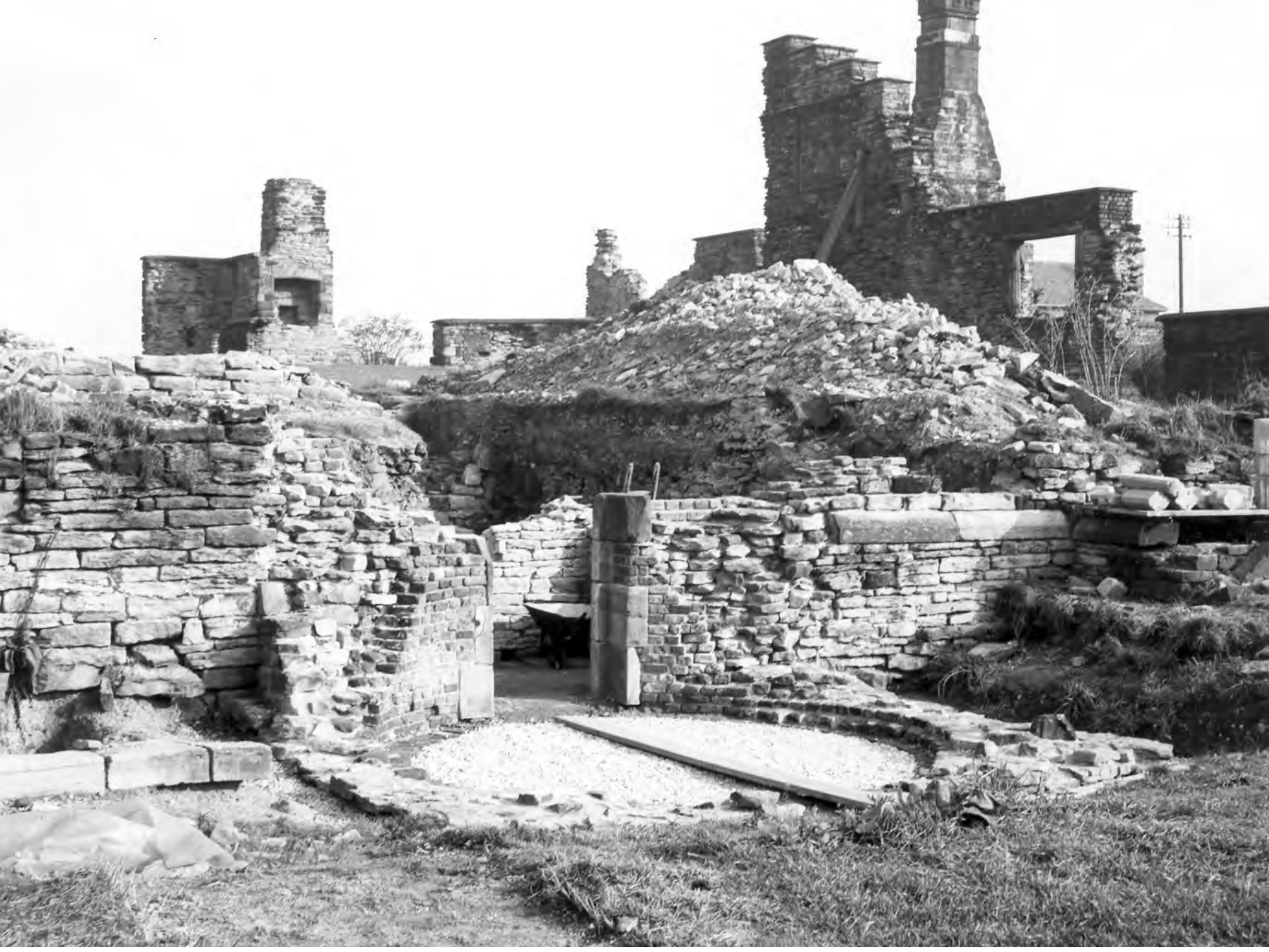

Figure 8.19: Excavation in 1970 of the south tower at the entrance into the inner courtyard. Behind it is one of the storage rooms. Compare with Figure 8.14, which shows the tower before it collapsed in 1793. Courtesy of Museums Sheffield.

One flight of stone steps survived at the entrance, which was approached from across the outer courtyard by a kerbed and cobbled pathway (Beswick 2002) and led into the inner courtyard, with its fashionable gardens. Investigation of four rooms behind the south tower revealed one to have plastered walls and a window onto the inner courtyard, while another contained a well from which were recovered leather, bones, and a coin dated to the 1550s. A third room survived to over $2 \mathrm{~m}$ in height and had two windows looking out into the inner courtyard, while a covered drain extended into the fourth room, which had traces of a newel staircase in its south-west corner (Hadley and Harlan 2011, 4-6). The lack of fireplaces suggested that these rooms were used for storage, but the fragments of mullion windows among the debris in their fills indicate that the rooms above were for higher-status accommodation (Beswick 2002; Hadley and Harlan 2011, 4-6). Just beyond the monumental entranceway excavation revealed a paved area that seems to have been a walkway round the inner courtyard. An adjacent area of clay-grouted sandstone slabs incorporated a substantial stone-built drain and a shallow gully that may have once carried a pipe; this was interpreted as a fountain (Hadley and Harlan 2011, 17; Figure 8.20).

Excavation in 2009 revealed remains of a tower at the southern end of the west range, comprising five courses of sandstone topped with an ashlar plinth, above which was a double layer of bricks. At its southern end this wall was keyed into a brick wall, which turned outwards at a $35^{\circ}$ angle to the south-west, and then after $0.4 \mathrm{~m}$ 


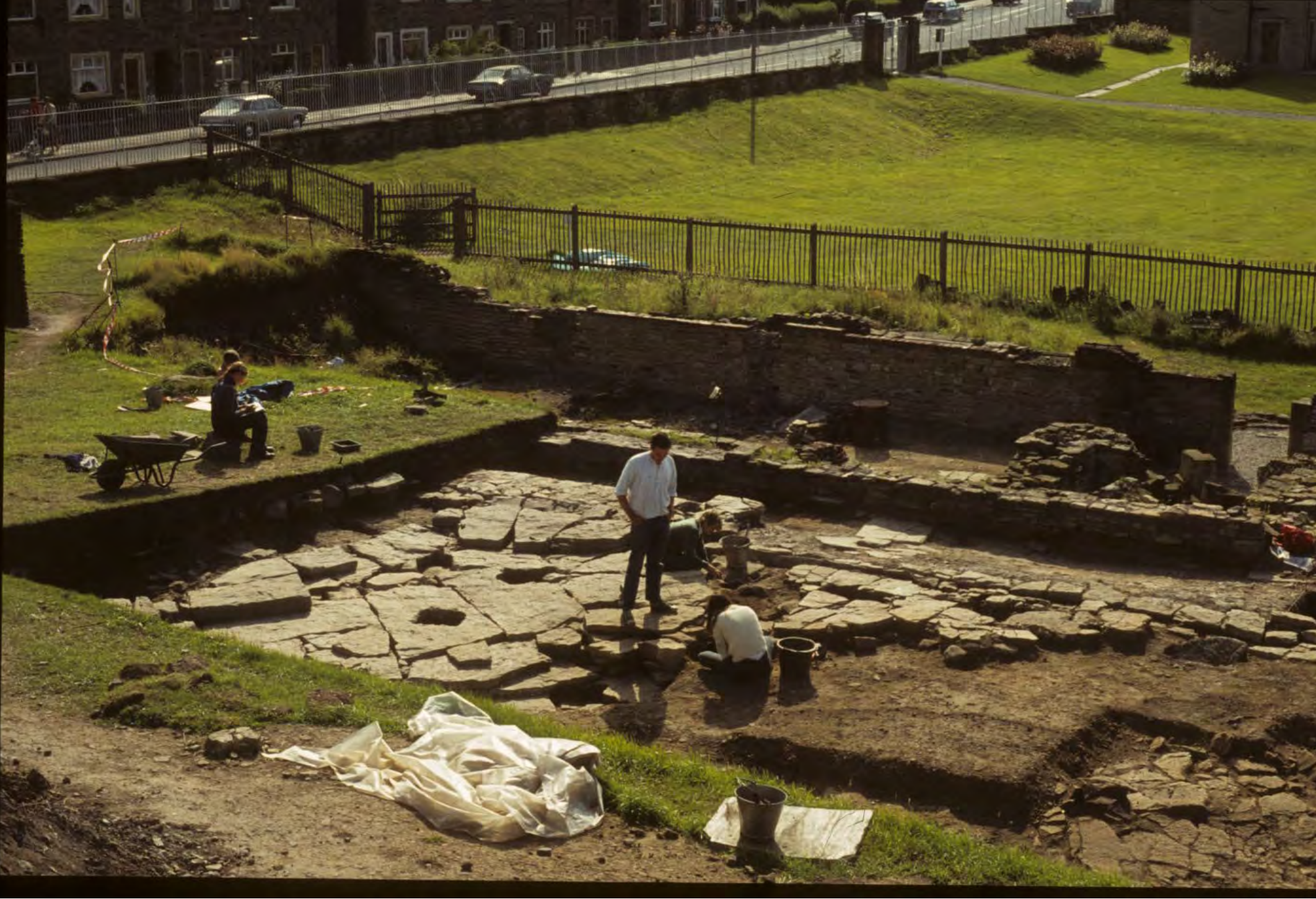

Figure 8.20: Excavations conducted in the inner courtyard in 1980 (looking south-west). Immediately behind the entrance from the outer courtyard, a possible foundation base was excavated. Courtesy of Museums Sheffield.

turned west to a similar degree. The exact nature of this angled structure is unclear - it may be a polygonal tower or an angled buttress (Mepham and Powell 2010, 13-15; Figure 8.21).

Across the centre of the inner courtyard was a range of buildings running west-east. They were not bonded to the long gallery, suggesting that they were a later addition (Figure 8.22). The room immediately south of the long gallery contained a southwards projection interpreted as a garderobe. The room to the east of this contained the remains of a substantial fireplace in its north wall, while pitched stonework on the bedrock formed an internal floor surface. Sealed beneath an 18th-century pathway were the remains of at least two further rooms to the east, which had probably been built consecutively given that their north walls were on slightly different alignments. Numerous substantial postholes excavated to the north of the cross-wing were interpreted as being either related to scaffolding used during building work or the bases of supports for unstable walls; either way, they are humble reminders of the construction work that occurred on the site. An extensive cellar complex was excavated in the eastern half of the cross-wing; it had been cut into the bedrock, walls survived up to $2 \mathrm{~m}$ in places, and were of two distinctive forms of construction - clay-grouted, rough-cut stonework, and ashlar masonry - indicating two separate campaigns of building work. The remains of two staircases were also revealed. The cellar fill comprised moulded plaster, carved stonework and fine dressed masonry from 16th-century fireplaces and chimneys, presumably from the rooms above, suggesting that the cross-wing had provided further high-status accommodation. 

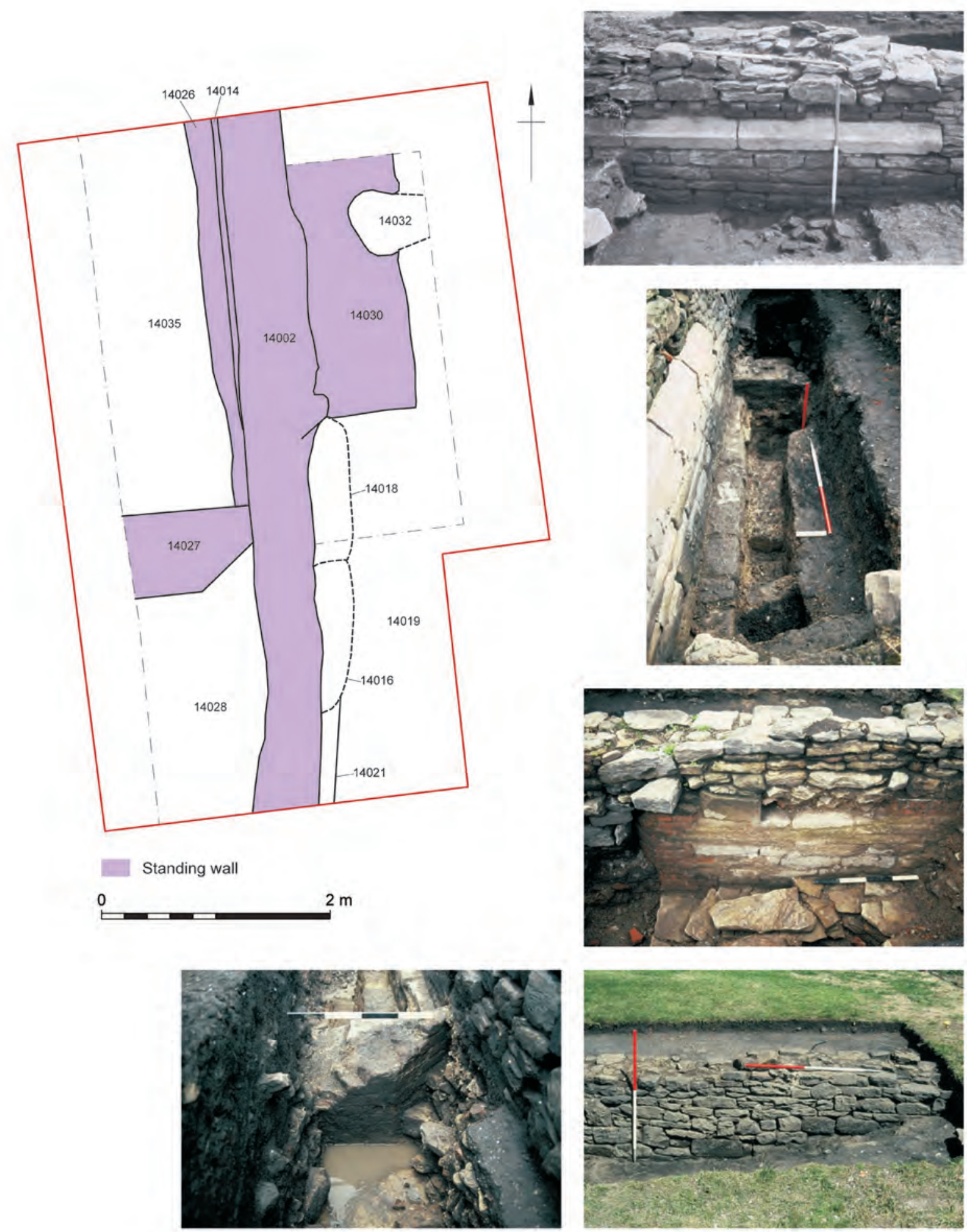

Figure 8.21: Plan and photographs of excavations conducted in 2009. At the south end of the west side of the main hunting lodge complex were the remains of an angled tower, similar in form to the better surviving example at the north end of the long gallery. Wessex Archaeology. 

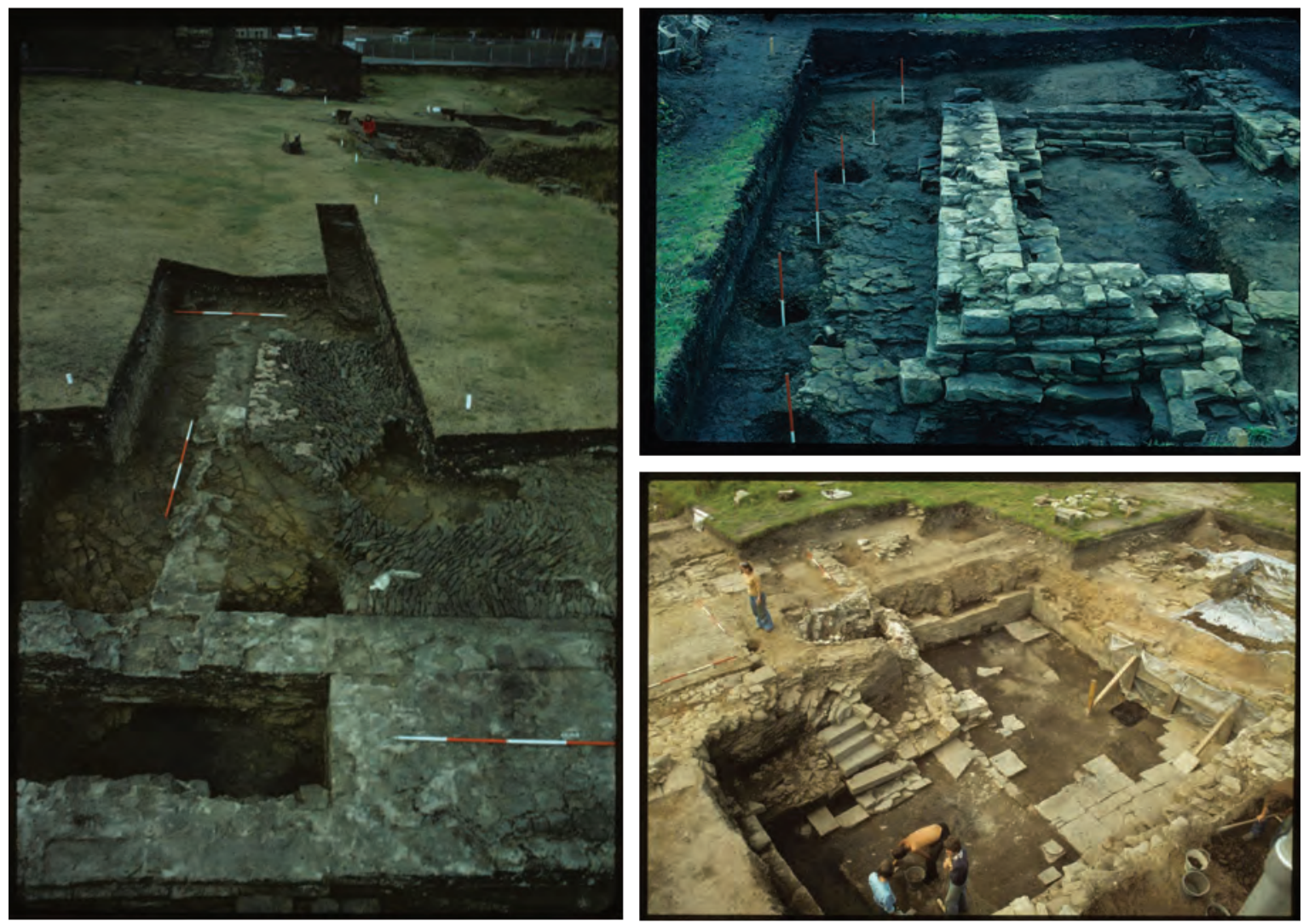

Figure 8.22: Sections of the cross-wing of the hunting lodge. On the left is the room closest to the long gallery, with the remains of a substantial fireplace in the north wall, and pitched stonework on the bedrock forming an internal floor surface. Top right is a room in the middle of the cross-wing which projects northwards from the range; postholes are visible on the north side of this room. On the bottom right is one of the cellared rooms of the cross-wing during excavation. Courtesy of Museums Sheffield.

\section{The service range}

Along the south side of the inner courtyard is a range of partially surviving service buildings (Figure 8.23). At the east end is a two-storey structure, comprising a chamber with fireplaces in the east wall at both groundand first-floor levels, and a first-floor garderobe (Clark and Jack 2002, 19). To the west of this is a narrow two-storey building with a chimney stack, and fireplaces at ground and first floors; the finely moulded jambs suggest a late 15th- or early 16th-century date. To the west of the chimney stack are two small apartments at ground and first floor, each with fireplaces, and with a garderobe at the south-west corner. It has been proposed that these were lodgings for servants (Clark and Jack 2002, 20). At the west end of the range is a three-storey building, which may also have provided lodgings, with six rooms on each floor. Windows on the second and third floor are similar to those in the Turret House (below), suggesting a late 16th-century date for this building (Winder 1919, 14; Clark and Jack 2002, 21). The only excavations in the south range occurred in 2009 prior to the transformation of part of it into a herb garden as a feature of the new visitor attraction. Three trenches each encountered cellars of differing construction, perhaps suggesting that they were not contemporary, although all are probably of 16th-century date (Mepham and Powell 2010, 3-15; Figure 8.24). These cellars and the servants' lodgings in the upper floors, as well as the storage rooms behind the entrance into the inner courtyard, are reminders of the work required to maintain a lavish lifestyle at the hunting lodge, much of which would have been unseen by elite visitors. The lodge may have been an elite residence but its occupants traversed the social spectrum. 


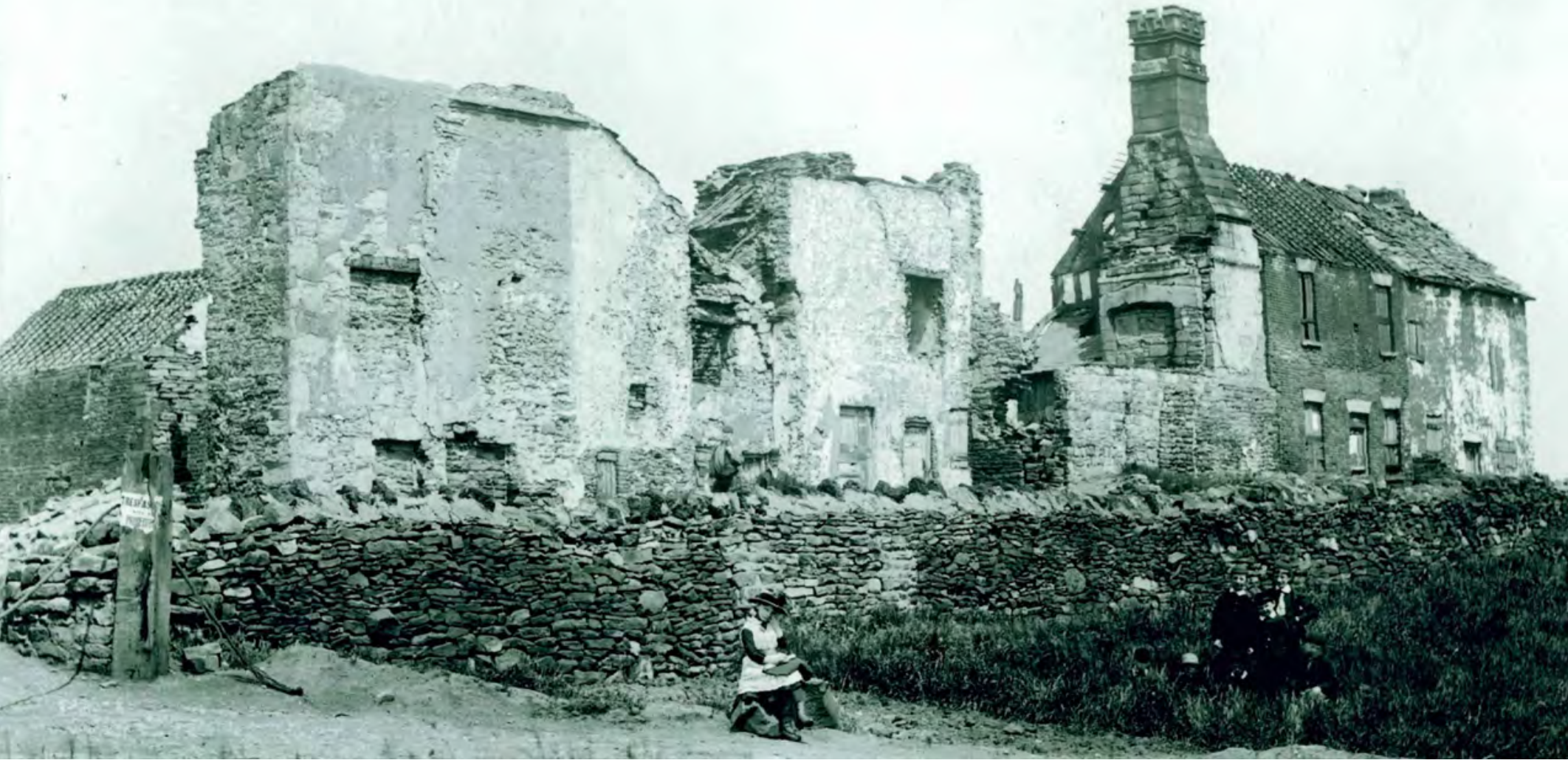

Figure 8.23: The south service range photographed in the late 19th century. It had once housed cottages for workers in the mining industry and the Norfolk Arms pub. The pub had been in the second cottage from the right; above the door are traces of its licencing information, and the hole visible higher up the wall was where the signage was formerly fixed. The roof next to the large tower had collapsed, and a first-floor fireplace is visible. The photograph has been annotated to suggest it was part of a series of postcards issued by a company called JWM and RPS; by now the former hunting lodge was becoming a local curiosity. Courtesy of Museums Sheffield.

\section{The Turret House: visitors and views}

The time of the $6^{\text {th }}$ Earl, George, and his wife, Bess, saw the construction of the Turret House, which seems to have served as a combined banqueting house, hunting tower and gatehouse, in a position commanding wide views of the surrounding park (Crossley 1990, 69; Beswick 2002, 1.4.3.2; Hey 2010, 32; Grade II listed building, no. 1271283; Figure 8.6). Known by contemporaries as the 'Tyrrett', it is one of the few structures for which building accounts have survived, in the account book of William Dickenson, the Earl's bailiff, dating to between 1574 and 1577 (Wigfull 1920, 191-2; ICOSSE 2005, 45-6; Sheffield Archives, Miscellaneous Documents 12). This notes the dimensions of the building and the price of the stone used in its construction by two masons, Turner and Rodes; it seems that much of the tower had been constructed by the time of this 1574 entry (ICOSSE 2005, 45-6). The building measured 54 roods, 4 yards and 1 foot, with 6 roods of doors and windows (Wigfull 1920, 191); as a linear unit, a rood measured between 5.0 and 7.3 metres; as a measurement of area it comprised $1,012 \mathrm{~m}^{2}$. It appears to have been surrounded by a boundary wall of capped and uncapped stones measuring 74 roods, which also used 2 roods of 'the olde stone', presumably taken from a nearby building (Wigfull 1920, 192).

The Turret House is a rectangular three-storey structure, with a chamfered plinth around the base, and string courses defining the first and second floors, although these, and the crenellated parapets, were reconstructed in the 19th century (Clark and Jack 2002, 10; Leader 1874, plate 4). Walls scars c.2.5m and c.4m high can be seen on the north and south elevations, respectively, suggesting that the documented enclosure wall had been substantial. Remnants of a stone jamb indicate that there was a gateway adjoining the south side of the Turret House (Clark and Jack 2002, 12). There are three chimneys on both the north and south sides of the building. Centrally located on each floor are pairs of 16th-century square-headed two-light windows, although they now incorporate 19th-century glass; they are of decreasing size higher up the elevation which enhances the impres- 

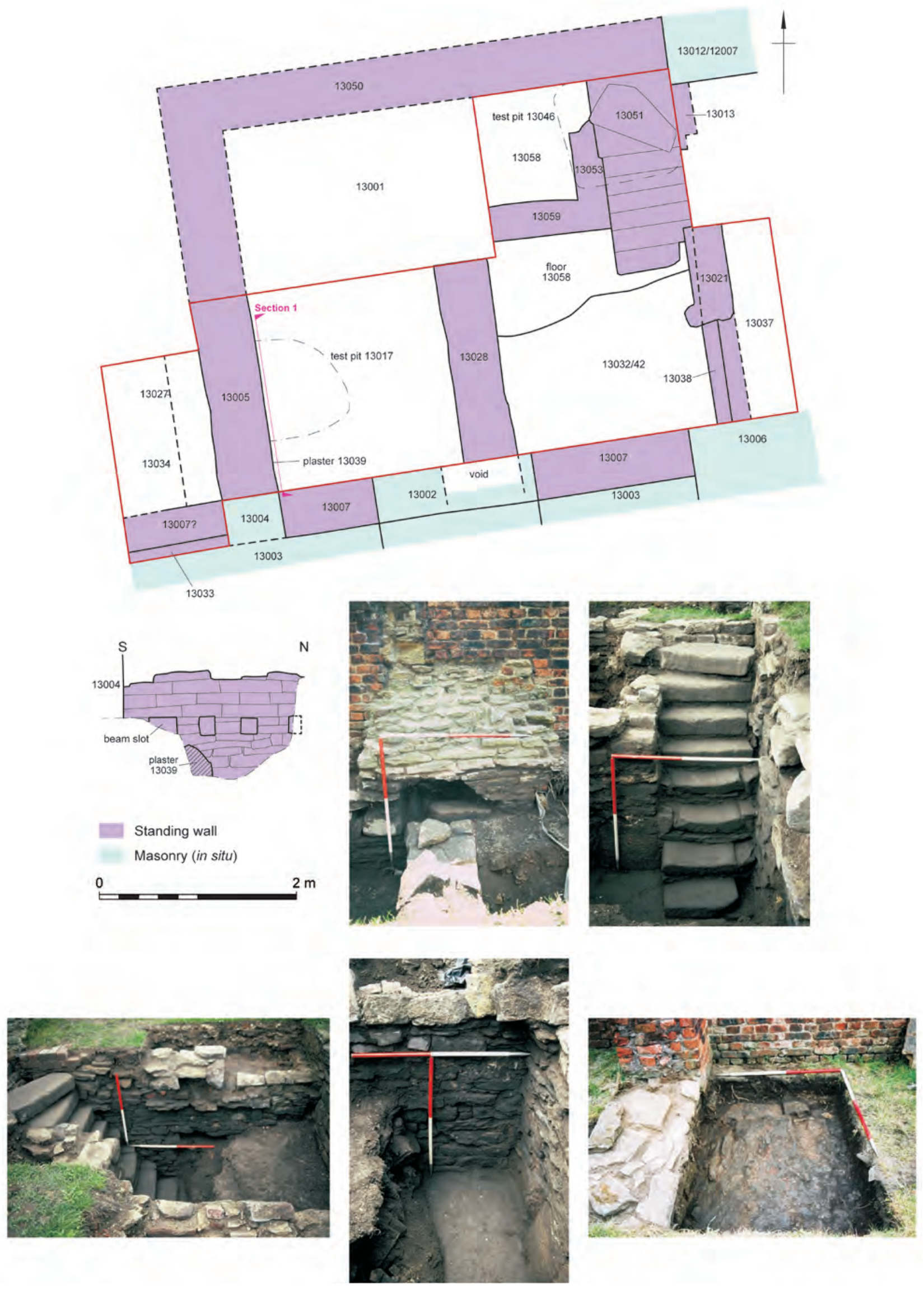

Figure 8.24: Excavations in 2009 at the west end of the service range to the south of the inner courtyard. They revealed evidence for cellars. Wessex Archaeology.

Figure 8.25 (page 277): Overmantle and ceiling on the second floor of the Turret House. Photograph taken in the early 1970s prior to modern restoration. Courtesy of Museums Sheffield. 

sion of the height of the building (Clark and Jack 2002, 10). A newel staircase leading up to the roof in the north-east corner of the Turret House is illuminated by two small windows in the north elevation. The current entrance, at the north end of the east elevation, is a 19th-century reconstruction, when a small vestibule was added; an original blocked doorway is located at the south end (Clark and Jack 2002, 12). Each floor is divided into two chambers, and while an original arrangement, the doorways were replaced in the 19th century, when a narrow corridor running through the northern chamber of the first floor was also constructed. On the first floor, the southern chamber contains a 16th-century plaster ceiling of geometric design. The plaster overmantel of the fireplace in the southern chamber of the second floor is decorated with the coat of arms of the $6^{\text {th }}$ Earl of Shrewsbury, George Talbot, and two inscriptions in Old French reading HONY SUIT OVI MAL Y PENSE ('Evil be to him who evil thinks') and PREST D'ACCOMPLIR ('Ready to accomplish') (Figure 8.25). The ceiling of this room is richly decorated with similar motifs intertwined with vines, thistles and roses (Clark and Jack 2002, 14).

This building has come to be associated with Mary, Queen of Scots - and was being shown off to visitors as housing her chambers in the 19th century (Leader 1872, 364; 1874, 49), consistent with tendencies elsewhere to associate historic buildings with elite figures (e.g. Swallow 2019, 173). The Turret House is, however, more likely to have been used as a place for guests to enjoy the hunt, perhaps from the roof, and for banqueting, in both senses consuming the 'wild' world over which they claimed to exercise command (Collinson 1987, 2; Clark and Jack 2002, 4; Moorhouse 2007, 117-19). The location of the Turret House adjacent to the entrance to the lodge reinforces its role in providing views of the seigneurial landscape as well as approaching visitors coming from the direction of the castle and the town; it was also a visible symbol of the lord's status.

\section{The captivity of Mary, Queen of Scots}

Between 1570 and 1584, the hunting lodge and castle were used for the incarceration of Mary, Queen of Scots, much to the $6^{\text {th }}$ Earl's increasing distress (Hey 2010, 32). Patrick Collinson $(1987,2,13)$ has suggested that the proximity of two such 'habitable' houses was one of the main reasons for Mary's 'long residence' in Sheffield, the others being its distance from the sea, the Earl's great wealth, and the fact that he was a Protestant, 'but only just'. However, the lodge was not the preferred choice of prison, with Mary initially using it only occasionally while the castle was being cleansed, as the castle was deemed to be safer. Indeed, her removal to the lodge with its comparatively weaker security was the source of some consternation at court, with the Earl's son, Gilbert, having to provide reassurance in 1573 that the Queen was so securely guarded that, 'unless she could transform herself to a flea or a mouse, it was impossible that she should escape' (Lodge 1838, 19; Leader 1880, 290). Nonetheless, her presence at the lodge is recorded not only in spring 1573 but also April and September 1574, March 1576, January to July 1577, June 1578, October to November 1578, June, September and October 1578, May and September 1580, January 1581 and September 1582 (Leader 1874, 46-9; Batho 1971, 95, 364; Templeman 2016, 101-103, 132). The added burdens of hosting a separate household, and a royal one at that, - Collinson $(1987,19)$ argues that, apart from the royal court, this was 'the largest (joint) household in England at the time' - compounded more mundane inconveniences, such as those recorded in a letter dated $14^{\text {th }}$ August 1580 from William Dickenson to the Earl documenting the repair of floors and windows at the lodge as well as the catching of rats within the building (Jamison and Bill 1966, 150). In addition to these tribulations, the Earl also had to deal with robbery. A letter dated $8^{\text {th }}$ December 1577 to William Cecil, Lord Burghley, a long-standing adviser to Queen Elizabeth, documents how thieves broke a window in the Earl's study at the lodge and stole plate worth between two and three hundred pounds. Given the conspicuous nature of their haul, it is unsurprising the thieves were quickly apprehended and the goods retrieved, one of the culprits being subsequently identified as a former, presumably disgruntled, servant (Birch 1874, 319; Batho 1971, 376).

An inventory made during Mary's incarceration in 1582, now preserved among the Talbot Papers in Lambeth Palace, lists many of the rooms in the lodge and their contents (LPL, MS 3198, fol. 150; Leader 1872; 1874, 44-5; Tucker 1874, 251-63). It reveals that the lodge contained all the buildings necessary for the maintenance of a household of the Earl's standing, with rooms specifically set aside for the Queen - a hall, great chamber, Queen's chamber, tower chamber, lord's chamber, Queen's gallery, Queen's 'utter' chamber, nursery, garden gallery, stables, chamber over the stables, porter's lodge, lord's kitchen and larder, Queen's kitchen and larder, bakehouse, wash-house, salting house, brewhouse, pantry, saddler's chamber, and workmen's chamber (Leader 1872, 370). Several other rooms mentioned in this account - not least the individual chambers of the Queen's servants - cannot be securely attributed specifically to the lodge rather than the castle, which is also included in 
the inventory. In Chapter 6, we discussed some of the furnishings recorded in this inventory, but these too cannot be assigned specifically to the lodge or castle and were probably moved between them according to where the elite household was based. Other objects, however, were more permanent, such as the corded bedstead in the lodge's tower chamber and a carved press (Tucker 1874,256). The inventory also provides an insight into more mundane aspects of the Earl's household; for example, in the lodge's nursery was a chest made for his young son Francis Talbot, with bone inlays of Talbot arms and the initials F.S., although the chest was in poor condition, having been roughly treated by the room's occupants (Leader 1872, 368; Tucker 1874, 257). And then there is the complete alchemical set, including tin stills, alembic and serpentine, and glasses (Leader 1872, 369), a material pointer to an interest in, and practice of, science in this world of the hunt. Gilbert Talbot, the $7^{\text {th }}$ Earl, was one of the patrons of William Gilbert author of De Magnete (1600), a treatise which 'demonstrated that the Earth was a magnet, ... drew out navigational applications ... [and] argued that terrestrial magnetism rotated the Earth in Copernican orbits' (Pumfrey and Dawbarn 2004, 165-6). This interest in science was passed on to Gilbert's daughter Alethea (born in Sheffield in 1585), who later (1655) published Natura Exenterata: or Nature Unbowelled one of the 'first printed books of technical and scientific material in England to be attributed to women' (Hunter 1997, 89). Interestingly, Lynette Hunter $(1997,100)$ argues that, in the late 16th and early 17th centuries, women were among those who were 'buying the books of household and alchemical secrets, and turning them to commercial uses', especially in medicine.

The 16th-century pottery from excavations at the lodge has largely been found in residual contexts and cannot in any case easily be distinguished from that of the 17th century. Nonetheless, it is still possible to deduce that the material is dominated by Cistercian ware and Blackwares, and so the lodge appears to have been supplied with similar ranges of pottery, and from the same range of kilns, as the castle. Some more exotic and highstatus ceramic items of 16th-century date were, however, recovered from the lodge, including 25 majolica tiles and a few fragments of continental stove tile (Beswick 2002, 2.3). There is a glass 'linen smoother' of probable 16th-century date, of a type usually assumed to have been used for ironing cloth and other fabrics, although the small size of this example suggests it could have been used for finer materials (Mepham and Powell 2010, 31).

While the marriage of George Talbot to Bess of Hardwick was originally affectionate, the strain of acting as jailor to Mary, Queen of Scots and other contributing factors led to its demise, and letters from the time reveal various details about the hunting lodge, including those arising from the first documented serious disagreement between George and Bess in 1577 over work there (Lovell 2005, 268-71). The Earl's Keeper of the Wardrobe, John Dickenson, refused lodging to workers commissioned by Bess to repair the lodge's many textiles, including furniture and tapestries, probably due to strict instructions from Elizabeth I's court regarding persons allowed to have access to the same house as the Scottish Queen. The Earl, although absent, supported Dickenson's decision and, according to Bess, who was then in Sheffield, communicated his displeasure to her in the strongest of terms. Bess took affront, stating that 'she truly thought that your Lordship [was] gladder of her absence than her presence' and departed Sheffield for her house at Chatsworth, which she had inherited through her second marriage to Sir William Cavendish: a visible slight to the Earl, which he took badly (Folger X.d.428 (111); Lovell 2005, 270). The breakdown of the marriage led to similar ructions between the Earl and his sons Gilbert, Henry and Edward, with the former stating that he 'must either forsake [the Earl], or hate his wife [Bess's daughter]' (Lodge 1838,244 ; Leader 1880, 587). To try to appease them, articles were drawn up to divide the Earl's estates between the sons, with the father retaining the land and property, Handsworth and Sheffield, including the lodge. The fact that the $6^{\text {th }}$ Earl was willing to part with lands in many counties, including Yorkshire, Nottinghamshire, Derbyshire, Shropshire and Herefordshire, yet retain those around Sheffield is indicative of the wealth held in the park, town and its environs (Batho 1971, 136). From these written accounts, we can also appreciate the buildings at the lodge not just as structures to be dated and phased archaeologically but as places of lives lived and focal to both harmonious living and interpersonal disputes. The Turret House is similar in style to the hunting tower at Chatsworth, which Mary will also have seen, and both were probably designed by the great Elizabethan architect Robert Smythson, who went on to design a new hall for Bess at Hardwick (Derbs; Hey 2010, 32).

\section{The animals of the park}

Parks typically contained not only deer but also rabbits, hares, wild boar, pigs, game birds, cattle, sheep and fish (Rotherham 2007b, 83-5; Moorhouse 2007, 114-22; Pluskowski 2007, 66-8), and it required extensive management to maintain the diverse (and sometimes conflicting) ecological preferences of these faunal resources. As a very large aristocratic park, it is not surprising to discover that Sheffield park contained a similarly wide array 
of resources. Our written sources, again not surprisingly, confirm that it was a source of venison. For example, a letter from Francis Talbot, $5^{\text {th }}$ Earl of Shrewsbury, records the supply of bucks from the park to the court of Henry VIII in 1541 (Hunter 1819, 55), while in the early 17th century the $7^{\text {th }}$ Earl, Gilbert, had bucks driven to an area near the town where all the parish butchers were allowed to kill as many as they were able; Hunter $(1819,189)$ wondered if this was the origin of the 'Cutler's venison feast', given by the newly elected Master Cutler on the first Thursday and Friday in September. However, it is the animal bone evidence from excavations undertaken between 1971 and 1974 that provides the real insights, especially into the changing 'role' of deer in the park. These bones were studied by Mark Maltby (1980) and are one of the few categories of material recovered from the earlier excavations to be fully analysed. In particular, Maltby was able to study 16th- and 17 th-century deposits from features excavated within the aforementioned building in the outer courtyard. The remains of cattle and sheep, many showing signs of butchery, comprised between $c .70$ and $80 \%$ of the assemblage according to number of fragments, which does tend to privilege identification of larger animals. While a high percentage of the deer bones from 16th-century deposits were hind limb fragments, representing the highest-status meat cut, and typical of a high-status residence, fallow and red deer represented only between $8 \%$ and $20 \%$ of the mammal fragments. It is the comparative paucity of deer bones, even in a deer park, in the 1971-74 assemblage that potentially gives us the most significant insights into both the 'economy' of Sheffield park and into changing perceptions of the deer within it.

As we saw at the beginning of this chapter, the earliest fallow deer in medieval England are likely to have been 'trophy animals', exotics in menageries. Over the course of the Middle Ages, the numbers of deer, and deer parks, increased, and the higher percentage of sub-adults in faunal assemblages suggests that parks had become 'farms for the production of venison' (Sykes et al. 2016, 123). As Jean Birrell $(1992,113)$ pointed out, some of this meat might have been for elite household consumption, but it would also have featured in feasts when guests were entertained, and there are many records of it being gifted to mark, and reproduce, social relationships - the importance of feasts and gifts, she concludes, 'should not be underestimated in a society where largess and patronage were crucial attributes of lordship' (see above for the supply of Sheffield deer to the court of Henry VIII). By the end of the Middle Ages, however, the 'place' of deer in deer parks seems to have shifted away from this 'mass-produced' social currency and returned to something like the 'menagerie-style management' seen several centuries before. Written records from the 15th century onwards point to a rise in the number of cattle being grazed in parks, while the later assemblages of deer bones demonstrate a 'return to the maintenance of older animals' (Bowen 2013, 205-6; Sykes et al. 2016, 124; Pluskowski 2007, 67) - tendencies which might also find expression in ratio of deer to cattle and sheep in the faunal assemblage from Sheffield park.

Within the same faunal assemblage, other domestic animals - pig and dog - were poorly represented, and other wild animals - roe deer, rabbit and pine marten - were found only in very small numbers. Domestic fowl predominated among the bird bones, although a number of game birds were also identified, such as woodcock. More recent excavations have not identified faunal deposits that can be securely dated to the period when the site was in use as a hunting lodge, although the deer bones, grouse and partridge recovered from mixed deposits in 2009 may date to the 16th or 17th centuries (Mepham and Powell 2010, 36). Other sources of evidence confirm the diversity of animal species in the park. The area to the north of the lodge was known as the Warren, suggesting the management of rabbits or hares. If rabbits, it would have involved the construction of an artificial warren, which elsewhere have been shown to have varied greatly in size, and an enclosed area to contain the rabbits (Williamson 2007; Moorhouse 2007, 113; but see Sykes 2007 for 'rabbiting as a distinctly low activity'). However, since the term 'coneyger' was more typically used for rabbits, here 'warren' might well refer to hares, which shelter in shallow depressions and were left to roam more widely (Pluskowski 2007, 67-8). Indeed, in 1578 six local men were prosecuted for 'huntinge the hare within my Lordes Parke'. The 1441-42 Account Rolls note that $2 s .10 \mathrm{~d}$. was raised by pannaging pigs within the park boundaries (Thomas 1920-24, 156). The presence of cattle is revealed by references to a dairy, and in 1441 a substantial sum was paid to repair its walls (Thomas 1920-24, 158). During the same period, Master John Talbot's foals were housed in the park over the winter, with Isabella Bailly paid $2 s .8 d$. for feeding them (Thomas 1920-24, 157). There were also fishponds on the western edge of the park (Jones 2009, 4). A Dog Kennel Lane ran south-east from the hunting lodge on 19th-century maps (May 2008, 11), one of many dog-related place names associated with deer parks in Yorkshire (see Moorhouse 2007, 115-17). 


\section{The landscape and woodland resources}

The landscape of a medieval deer park was varied, containing areas of wood pasture, heaths, moors and commons, with an array of species of trees, used for fuel, timber, fodder for the animals it contained (Rotherham 2007b, 85-7) and the construction of buildings, ships, gates, palings and stiles (Thomas 1920-24, 143, 157; Scurfield 1986, 157; Moorhouse 2007, 111-12). Some of the species growing in Sheffield park are recorded in 17 th-century accounts. Harrison, for example, tells us that in 1637 it was 'very well adorn'd with great store of very Stately Timber' (Ronksley 1908, 3), while in 1664 John Evelyn marvelled at the number, size and value of the great oaks then to be found in Sheffield park. His Silva: Or a Discourse of Forest-Trees and the Propagation of Timber was designed to encourage landowners to plant trees to service the English navy:

In Sheffield-Park, An. 1646, stood above one hundred Trees worth a thousand Pounds ... In the same Park, two Years since, Mr. Sittwell. with Jo. Magson, did choose a Tree, which after it was cut, and laid aside flat upon a level Ground, Sam. Staniforth, a Keeper, and Edw. Morphy, both on horseback, could not see over the tree one anothers Hat-crowns ... In the same Park, near the old Ford, is an Oak-tree yet standing, of ten Yards Circumference (Evelyn 1729, 201).

In 1699 Richard Richmond, who leased 477 acres of the park, was committed to 'plant or sett or cause to be planted or sett three oakes ashes or elmes upon every acres length of fences and walls' (Scurfield 1986, 153-4). Much of the park's woodland was managed. Harrison's 1637 survey tells us, for example, that the greatest part of the area known as Morton Banke, to the south of the Ponds, was spring wood; in other words, it was coppiced (Ronksley 1908, 51). In the 19th century there was still a local memory of an avenue of walnut trees running from the park gate near the Sheaf to the main entrance to the hunting lodge (Hunter 1819, 7; Leader 1880, 147), and fields to the west of the lodge were then known as Great and Little Walnuts (May 2008, 10). It is possible that this tree-lined avenue (if not the walnut trees themselves) is captured running 'uphill' through the Park, and away from the castle site, on Thomas Oughtibridge's (1737) North Perspective View of the Town of Sheffield (Figure 8.26). The 'blackened trunks' of some of these trees survived into the early 20th century (Winder 1904, 44).

Evergreen holly was a source of year-round fodder, and Richard Richmond had 'liberty to fell all hollins [holly], except the hollins upon Stonehurst', on the park's boundary with Gleadless Moor (c.1.6km south-west of the lodge) (Scurfield 1986, 154; also Jones 2013, 32-3). Trees in the park were also a source of fuel (Hunter 1819, 7; Scurfield 1986, 154, 157). A surviving Account Roll running for a year from $29^{\text {th }}$ September 1441 provides a detailed record by the park keeper, Geoffrey Botery, which notes that he was paid 10d. a day to carry fuel and charcoal (primarily from oak and ash) by ox and cart from the park to the castle to prepare for the arrival of Christopher Talbot, son of the $1^{\text {st }}$ Earl of Shrewsbury Sir John Talbot (Thomas 1920-24, 67, 143). Other natural resources within the park were mud used for plumbing and tiles, while 'Walstone' was transported by Botery to repair the castle's stable and grangehouse, as well as Goldsmytheplace, a house in Sheffield's market place (Thomas 1920-24, 157; see Chapter 6, Section: Domestic and personal items). Stone and wood were provided for repairing the corn and fulling mills, it was the source of wood for carpenters repairing Deyhous house at Roueley, and cinder was sold at $6 d$. a stone to dyers in Chesterfield (Derbs), while improvements to Sheffield Castle in 1446 required stone and cinder from the park to improve a path leading across the courtyard from the Great Gate to the hall (see also Chapter 7). Around the same time, 60 oaks within the park were felled for use in the rebuilding of the old tower, John Hanson receiving $5 s .6 d$. for undertaking the task (Thomas 1920-24, $69,71,355,357)$.

In 1441, a number of pastures in the park were already being rented out to tenants for substantial sums. For example, Gopelypasture was rented by William Kilton for 53s. 4d. per annum (Thomas 1920-24, 155), and other pastures mentioned by the mid-15th-century Account Rolls include Roule, Myddelstubbynge, Rouleleys, Middlepasture, Bienlonde, Smytheclos, Great Stubbynge, Walkemullekerre, Neuparke, Backehouseyorde, Coltclos, Juterelle and Bruggende, so named as it lay near the bridge leading to the castle (Thomas 1920-24, 155-6). However, pastures were not let on a permanent basis; for example, Langalte, which would normally have an income of 30s., had been reserved in 1441 for feeding the Earl's deer, and thus produced no income, as was the case with Blakewell and Loggeclos (Thomas 1920-24, 155). The locations of many of the fields are now unknown, although some are mentioned by Harrison and can be identified using later maps, which reveal that Roule and Rouleleys were in the west of the park adjacent to the River Sheaf. Bienlonde may have been 


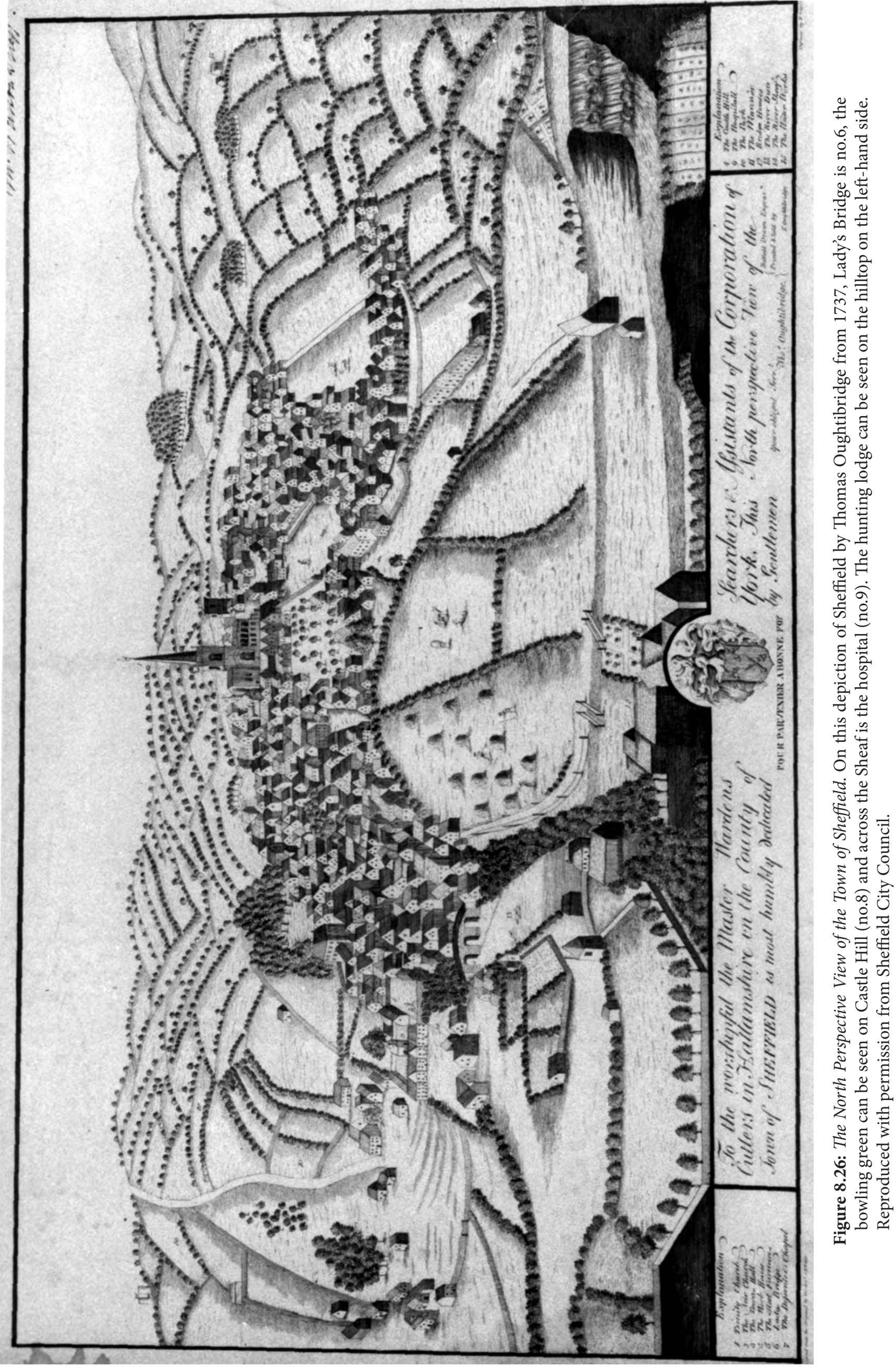


incorporated into the Londs, immediately to the north of the lodge; Londs may derive from laund, which, as we have seen, refers to a treeless grassy area (Scurfield 1986, 152; Jones 2009, 5). In total, park rentals for 1441-42 totalled $£ 226 s$. $8 d$., a not inconsiderable sum at the time, although not all the income from the park went to the lord; in 1442-43 a tithe of pannage, meadows and pastures 'both within the Park as well as without' was paid to the vicar of Sheffield, an income that amounted to $5 \mathrm{~s} .6 \mathrm{~d}$. (Thomas $1920-24,156,235$ ). The importance of the park as a source of revenue, and its comparative lack of agriculture, can be seen within the 1637 survey; compared to other areas of Sheffield, there were few subdivisions within the park, despite 971 acres having been let (Scurfield 1986, 164). However, over the course of the later 17th century, much of the park was broken up into tenant farms. A 1663 letter to the agent for the estate recorded that the Duke of Norfolk had been 'Farming out Shefeild Parke into severall farmes', while in 1707 the vicar of Sheffield wrote in a letter that the hunting lodge had become 'ruinous and naked, by disparking as much ground about it' (Hey 1991, 21-2; Hunter 1819, 7). As we will see, this 'disparking' affected social relationships as well as the physical fabric of the lodge and the park.

\section{Industry in the park}

As John Harrison noted in 1637, 'if you look into ye bowels of this Parke, you will find ye inside correspondent to the outside, being stored with very good coales and Iron stone in abundance' (Ronksley 1908, 3; Scurfield 1986, 153; and Moorhouse 2007, 123 for the Yorkshire Coal Measures more generally). As the 1441 Account Rolls show, coal was being exploited in the park from at least the mid-15th century, with William Hynes paying 20s. for the area known as Colputtes, while another mine, le stobbynge, was then said to be vacant (Thomas 1920-24, 143). In 1579 a single deep pit was in operation in the park, and might well have been of some antiquity as it was in need of repair; the dangers of gas prevented work in the mine for much of the year, and new shafts had to be dug (Stone 1950,98). The remedial work clearly paid off, because from July 1579 to December 1582 between 1,200 and 1,300 tons of coal were taken from Sheffield Park Colliery, the largest coal output in Sheffield during this period (Stone 1950; 1965, 341; Medlicott 1983, 51; Scurfield 1986, 168). Further coal mines were sunk across the park as the Talbot family patronised the Sheffield cutlery trade - demonstrated by the presentation to William Cecil of a case of knives in 1590 by the $6^{\text {th }}$ Earl, 'being such fruits as my country affordeth with fame throughout this realm' (Lodge 1838, 389; Hey 2010, 32). Nonetheless, in the 16th century there were only ever a handful of miners recorded as working in the park, supported by casual labourers, and the market for their output was largely restricted to the town (Stone 1950, 99; 1965, 341). The records reveal many occasions when the mines were not in operation, either due to the miners participating in festivities or otherwise being absent, perhaps engaged in other forms of work (Stone 1950,102). Mining may have had only a limited impact on the landscape of the park, as contemporary records reveal that the pitheads comprised a portable thatched hut (Stone 1950, 99). Remains of beehive-shaped pits were recorded at the northern end of the park at Woodbourn in 1934 and identified as being medieval, although they may have been early postmedieval (May 2008, 18).

Lawrence Stone $(1950,104-5)$ stressed the 'modesty of ... scale and simplicity of ... operations' of the Earl of Shrewsbury's mine in Sheffield Park, and has referred to its use of 'exceptionally out of date methods. However, he dispelled the assumption that this is all one might expect from a member of the old aristocracy by pointing to the fact that his lead-mining activities were on a large scale, and suggests that his servants would have had 'at least a nodding acquaintance with new techniques of drainage and administration' (Stone 1950, 105). Stone might have gone further. George Talbot was one of the wealthiest men of his age and has been described as its 'leading aristocratic industrialist' (Stone 1965, 382). Francis Bacon was probably thinking of him when he spoke of a nobleman of his acquaintance who was 'a great grazier, ... a great timber man, a great collier ... a great lead-man and so of iron' (Stone 1965, 375; Goldring 2015, 3) - but it seems that, within his park, between his two Sheffield residences, coal production at least was limited. Like the town of Sheffield itself, collieries were not among landscape elements deemed to enhance lordship.

\section{Absentee lords and new priorities}

After the death of the $6^{\text {th }}$ Earl in 1590, his son, Gilbert, continued to make alterations to the lodge, as noted in a letter of 1594 from Richard Mason concerning warrants and payments for workmen, plaster and stone to 
carry out work there (ICOSSE 2005, 60). However, Gilbert's death in 1616, followed only a year later by that of his younger brother Edward, saw the Talbot estates shared between Gilbert's three daughters. The manor of Sheffield descended through his youngest daughter, Alethea (whom we have already met), to the Earls of Arundel and Surrey, later Dukes of Norfolk. The town's new lords were largely absentee - Hunter suggesting that Sheffield could not 'vie with Arundel' (Sussex) - but for at least another 50 years the lodge was maintained for periodic use. The pottery evidence confirms continued occupation. The range of wares is similar to that from the castle, being dominated by Cistercian ware and Blackwares, with few traces of imported pottery (Beswick 2002, appendix 1; Mepham and Powell 2010, 15-28; Burgess et al. 2011, 24-38; Crewe and Askew 2012, 24-8), although there were more sherds of Tin Glazed Earthenware, which was the first European pottery to offer any sort of competition to imported Chinese porcelain (Mepham and Powell 2010, 19; also Gaimster and Nenk 1997, 175-6). There are rather more glass vessels from the 16th and 17th centuries than from the 15th (although the limited nature of the assemblage means that we probably should not read too much into that), and domestically produced types include pedestal beakers, bowls and flasks. Higher-status items include the stem from a very early lead crystal wine glass of the late 17th century (Mepham and Powell 2010, 29-31), imported Venetian vetro a retorti and fili goblets, façon de Venise tablewares from Antwerp (Belgium), and an extremely rare diamond-point engraved bowl, quite possibly from the Antwerp workshop of Giacomo Verzelini (Beswick 2002, 2.9). Seventeenth-century wine bottles were found in the cellars of the cross-wing (Beswick 2002, 1.4.3.5).

Bills from 1632 demonstrate that the lodge's steward was still active, and a staff of servants and labourers must have been employed, as alms were dispersed to the poor, coaches maintained, and a blind harpist hired to entertain the lord of the manor on one of his rare trips north, while beer brewed at the lodge was sent to his household in London. The 'bull-beters' paid $£ 1$ may have provided their 'entertainment' at the Bull Stake, situated close to the castle. A delivery of ' 6 quarts [6.8 litres] of sherry sack, 5 quarts of white wine, 1 gallon of vinegar, 3 ounces of cloves and mace, 2 oz. of nutmegs, $1 \mathrm{lb}$ of sugar, \& 1lb of currants, [and] $1 \mathrm{oz}$ of cinnamon' on $23^{\text {rd }}$ September 1633 shows that the lodge was still the base for fine eating and drinking (Hunter 1819, 102) - no doubt from some of the vessels recovered during excavation, and courtesy of England's far-flung imperial possessions. Hunter $(1819,102)$ records that in August 1636 Lord Maltravers (Henry Howard, the future $22^{\text {nd }}$ Earl of Arundel and Surrey; see Chapter 9) was at 'the Manour', and that 'at the great leet, ${ }^{28} 1$ quart of sherry, and 1 pint of canare, 1 bottle of claret and 1 quart of white wine with sugar' were consumed.

The garden was being maintained, as demonstrated by a gardener's bill of 1633 for 'seeds sowne at the Manner' (Hunter 1819, 102; Addy 1893, 164-7). Repairs were carried out at the lodge in 1644, including pointing, plastering, glazing and plumbing (Winder 1919, 18), and during the demolition of the castle in the late 1640s wood and lead were sent to the hunting lodge presumably for building or repair work (Askew 2017, 196-7). When Sir William Dugdale visited in 1666 he recorded heraldic devices in the windows, which show that the long gallery, at least, was in a good state of repair, although he also noted that the rooms at the lodge were half deserted.

Hunter $(1819,49)$ tells us that when the castle had been 'dismantled and destroyed' after the Civil War, its archives were removed to the lodge. Some may, in fact, have been transferred earlier, as we have a record from 1644 of the payment of $£ 03 \mathrm{~s} .2 \mathrm{~d}$. 'for packinge and cayringe 4 packes of writings from castle to the manner' (Hunter 1819, 103); Walter Hall (1926, xiv) suggests Lord Maltravers may have ordered them to be moved away from the risk of 'fire and sword' to the comparative safety of the hunting lodge. The archives remained there for several years, 'exposed to much injury from wet, and from the depredations of mice, those tiny but potent foes of antiquarianism. In 1671, the antiquarian Nathaniel Johnston visited the lodge to consult these records, bemoaning the conditions in which they were being kept, and used them to write his lives of the Earls of Shrewsbury between 1692 and 1694, although these were never published (Hunter 1819, 116; Martin 1956, 22). ${ }^{29}$ The lodge was clearly the hub for the remaining operations of the lords of the manor,

${ }^{28}$ In the introduction to his survey, Harrison tells us that 'Within this Mannor is kept a Court Barron once every three weekes \& a Court Leet twice every yeare, whereof ye Chiefest Court is kept upon every Easter Tuesday (which is there called Sembly Tuesday)' (Ronksley 1908, 2).

${ }^{29}$ The papers were subsequently acquired by various archives, including the College of Arms (LPL MSS 3192-3206), Lambeth Palace Library (LPL MSS 694-710), Sheffield Archives (Bacon Frank Collection) and the Folger Shakespeare Library in Washington, DC (Cavendish-Talbot Collection), and collectively form one of the best records of a 16th- and 17th-century noble household at the height of its powers. 
now elevated as Dukes of Norfolk, in Sheffield, but the fact that at least some of it was open to the elements, and the estate records were no longer cared for, speaks of a slippage into decay. As late as 167221 hearths were taxed at the lodge but by the early 18th century it was no longer required as a residence for the dukes (Hey 2005, 57; 2010, 57). In 1708 Thomas Howard, $8^{\text {th }}$ Duke of Norfolk, received consent from Parliament to demolish the lodge, although, as we will see in Chapter 9, parts of it remained standing and were used for industrial activities.

As the 17th century progressed, new coal mines had been constructed in the park, including one at 'Parke hill topp' in 1636 (Hunter 1819, 103). Coal was becoming increasingly profitable for the dukes. According to Harrison, in 1637 'Coalpits' on the Heeley side of the park 'yeildeth great profit unto the Lord' (Ronksley 1908, 51), while in 1642 Francis More paid $£ 200$ to lease 'colepitts in Sheffield Parke' from the duke (Scurfield 1986, 168; Jones 2009, 5). More also provided coal for the lodge, castle and kilns in Sheffield (Scurfield 1986, 154-7, 168). The coal mines created a demand for 'punch-wood' as support timber; the lessee of coal mines in the park had an allowance there 'for punch-wood' (Scurfield 1986, 157; also Stone 1950, 102-3).

On the other hand, it might be that the related processes of industrialisation and 'disparking' rendered the park, and so the lodge, less congenial to the Talbots - and then the Howards - contributing to the decision to move away, first to Worksop (Notts) and ultimately to Arundel (Hey 2010, 57). Joseph Hunter $(1819,191)$ captured this transformation in what he admits is a lament for a time - one populated by 'the chieftain of the age of the eighth Henry', 'the fallen Wolsey', and '[Mary] the victim of the lawless power of Elizabeth' - 'when a state of society existed at Sheffield essentially different from that which now prevails there. Thus he describes how 'at the time of Harrison's survey ... or soon after' coal and ironstone pits were opened in the park; it was divided into farms, both arable and pasture; and the lodges that had once housed park keepers were turned into farmhouses - the latter an echo of the process we observed in the faunal evidence. And it is in this context that Harrison's survey was commissioned. The Duke, aware of the momentous changes happening around him, wanted an assessment of the current state of affairs. As such the text, Harrison's survey, is part of that process.

Some have contrasted the differing fates of Sheffield Castle and the Manor Lodge, the twin poles of the seigneurial landscape, in the turbulent years of the mid-17th century. Thus, Hunter $(1819,116)$ argued that, despite the slighting of the castle in the late 1640s,

Still the Manour existed: an edifice less extensive, less splendid, but sufficient to display the magnificent spirit of those by whom it was erected and inhabited. This place had suffered nothing in the late contentions. It does not appear that either party had thought of placing a garrison in it, or that it was ever a military post: and the Park, the spacious and noble park, which spread around it was still unenclosed.

Almost a century later, Thomas Winder $(1913,113)$ shared this view. Its secluded position, he believed, had made 'the Lodge ... immune during the Civil War', its essential continuity marked by the fact that it 'was even used at that time for the safe custody of documents removed from Sheffield Castle. And there is clearly something in the argument, in the sense that significant traces of the lodge remained for both to see, while the castle persisted only in the names of 'the streets and places thereabouts' (Goodwin 1764, 157). However, it is also clear that Hunter's view is much too rosy, and, while the lodge might indeed have been 'a habitable residence forty or fifty years after the castle had perished' (Hunter 1819, 116), the park was utterly transformed and its scale reduced. This much is clear in documents, dated $c .1692$, relating to a dispute between the Duke of Norfolk and some local men in which 'Sheffeild Parke' is described as 'about three miles in compass, [and] enclosed with a high wall' (Hall 1930, 99). A circle with a three-mile circumference contains c.458.4 acres and so, acknowledging that the park would not have been a perfect circle, it is clear that it had been very significantly reduced since Harrison's survey in 1637 (when it was recorded as 2,461 acres). Its diminished scale is well illustrated on John Warburton's 1718-20 Map of Yorkshire (see Hey 2010, 56). Sheffield park was an integral element in the seigneurial landscape, and local networks of power; its reduction speaks of changes in those networks.

The dispute to which we have just referred was about whether the road to Sheffield from the south which ran through the park was a public highway. Importantly, it seems to have had its origins $c .1650$ during the Commonwealth, but came to a head in 1692 when Henry Howard, $7^{\text {th }}$ Duke of Norfolk, accused several individuals including 'Randolfe Ashenhurst, John Woodrove, Alexander Fenton etc.', of wilful and persistent trespass (Hall 1930, 99-102; Hunter 1819, 190; Clark and Jack 2002, 5). The Duke's case was that the 'normal' routes 
to Sheffield actually ran round the edge of the park, and that while he had allowed people from Handsworth, Intake and Gleadless passage through the park, this was because the normal routes were 'very dirty in winter' and because he wanted to benefit Sheffield market (Hall 1930, 99-102). In support of his case, several elderly men drew on their long memory, back to the time 'before the unhappy Civil Wars broke out', to recall that the gate onto Gleadless Moor was 'stopped up' four times a year 'to prevent the same being claimed as a highway' (Hunter 1819, 190). The outcome of the case is not recorded in these papers, but, as Walter Hall pointed out, 'if on the strength of the evidence of these old people the duke got rid of the trespassers on Park Hill', it was only a temporary victory as the road in question has long been one of the main roads into Sheffield (Hall 1930, 99). The lords of the manor had always tried to restrict access to the park (see Moorhouse 2007, 124 for efforts to control movement through parks elsewhere in Yorkshire). The fact that these legal proceedings were necessary makes it clear that the Duke's authority was being challenged, that this particular challenge emerged in the same political and ideological context that brought down Sheffield Castle, and that men of all social classes were involved - those listed in the 1692 Chancery papers included John Woodrove, gentleman; Alexander Fenton, gentleman; John Bradbury, yeoman; John Jenkinson, carpenter; Richard Simon, gardener; and William Downe, saddler (Hall 1930, 101).

There had, of course, long been resistance. As we saw earlier, in 1578 five local men were fined five shillings 'for huntinge the hare within my Lordes Parke ... to the disturbance of my Lordes game there, \& killed one deare \& dyd hyte an other deare, and poaching was reported in a letter written to the Earl on $28^{\text {th }}$ January 1595 by William Dickenson the Younger, then a park keeper (Jamison and Bill 1966, 84). On $1^{\text {st }}$ March 1598 William Craven confessed to hunting in the park, a practice in which he claimed he was joined by several local men including Abraham Milnes, who was charged with taking deer in February 1599. Milnes was a servant of William Cavendish, the son of Bess of Hardwick's second marriage to Sir William Cavendish and hence both step-brother and brother-in-law of the $7^{\text {th }}$ Earl, who was married to his sister Mary Cavendish; the fact that these offences occurred at a time of discord between the two noble households of Talbot and Cavendish may have had some influence on them (Jamison and Bill 1966, 143, 150). But it is significant that Sheffield park was repeatedly targeted by poachers in the 1640 s and 1650s. On $17^{\text {th }}$ December 1657 , local poachers Daniel Bingley and James Bromley fixed a deer's head on the cross in Sheffield marketplace, an act that has been interpreted as deriving from their frustration that laws concerning hunting had not been relaxed as they had hoped; attached to the deer's head was a note pronouncing their hunting as legal and lamenting that 'there was once a Parliam[en]t engaged to root out \& suppress all the Lords of Mannors with all the Norman Blood' (Hopper 2007, 112). This reference to the 'Norman Yoke', as well as prefiguring the local origin myth prevalent at the time the castle was 'rediscovered' in the 1920s (see Chapter 3), is a sign that these incursions into the seigneurial landscape were 'acts of defiance' by a 'middling sort' radicalised by the Civil War rather than desperate attempts by the poor, ordinary people of the region to obtain food for their families (Hopper 2007, 112-13; Simmons 1990, 16-17; also Sykes 2007, 56 for the spate of 'park breaking' during the Peasants' Revolt of 1381).

\section{Conclusion}

The deer park and hunting lodge were part of the wider seigneurial landscape of Sheffield, and we have shown the ways in which the natural advantages of the castle's surroundings were exploited and manipulated to provide a stage setting for the exercise of lordship. The castle was located in one of Sheffield's many valleys, surrounded by much higher ground; this is consistent with many castles of the Anglo-Norman period, which are to be found not on the highest ground of a district. This has led to the conclusion that military factors were only a part of the rationale for the siting of castles, with tenurial, social, economic and political factors also relevant (e.g. Creighton 2018; Johnson 2017b; Liddiard 2000a, 169; 2005, 24-6). Sheffield park provided a landscape of elite display, which was physically delineated from the town and through a distinction between its managed orchards and gardens and the 'wild' of hunting grounds made manifest the authority of the lord to the local community and visitors alike. Numerous campaigns of building work at the lodge can be traced in both the archaeological and historical sources, and this reveals the efforts that were undertaken to remodel the residence to meet changing elite requirements. To the fore in this chapter, however, has been the household of the $6^{\text {th }}$ Earl of Shrewsbury and two formidable women, Bess of Hardwick and Mary, Queen of Scots, and those events 
that, above all else, placed the elite buildings of Sheffield at the centre of events of international significance. As we have stressed, however, the park was also a working landscape, with trees and other vegetation to be managed, and animals to be cared for, as well as being processed for consumption and sale. And while the building complex at the heart of the park was certainly the venue for aristocratic hunting and feasting - as well as royal incarceration - it was also a workplace, with cellars, storage rooms, kitchens, bakehouse, washhouses, stables and so on, all of which will have required a large household staff.

The lodge and park remained as powerful manifestations of the authority of the lord of the manor even after the castle was being dismantled in the mid-17th century (see Chapter 9). However, over the course of the century that authority was increasingly challenged, and the park was transformed from a landscape for deer to one in which agriculture and industry operated alongside the hunt, to one in which industrial uses dominated. It speaks volumes for the changes we have charted in the course of this chapter that our first image of Sheffield, Thomas Oughtibridge's 1737 North Perspective View of the Town (Figure 8.26), places the (now Protestantised) church and the town hall at its centre, the site of the castle is inconspicuous down to the left, the park is patterned with fields and hedges (but devoid of forest and deer), and 'The Mannor' is barely visible over the hills - thus, just about inverting the position which had it held throughout the Middle Ages.

\section{Bibliography}

The full bibliography is available at the end of this volume, or at: https://doi.org/10.22599/SheffieldCastle.k. 



\section{The Persistence of Place}

On the one hand we're trying to bring out the history, which most people are not aware of at all, but at the same time we see this area as a place where the jobs and economy of the future can find a home. It's not reliant on one big project or developer; it's going to be the work of many hands (Ogden 2018)

In this book we have analysed the archaeological record for Sheffield Castle, the contexts in which it was uncovered during investigations reaching back almost a century, and the varying ways in which it has been interpreted, disseminated and displayed. As we have seen, until this current volume much of this archaeological evidence has languished largely untapped, whether for research into the history of the city, the presentation of its heritage to the public, or informing its future regeneration. In this chapter we show how the presence of a castle in Sheffield - even in its absence - has had a profound impact on its development, despite the city, as we noted in the Preface, not being renowned for its medieval heritage. We will demonstrate that from the moment the castle was ordered to be demolished in the mid-17th century its political and mnemonic capital were exploited, and this persisted in the face of the growing industrialisation of Sheffield into the 19th century and beyond. As soon as the remains of the castle were uncovered in the 1920 s, a debate commenced about what was to be done with them, an issue and an opportunity that remain today. During multiple regeneration plans for the site since the 1920s, there have been missed opportunities and misunderstandings about both the castle remains and also the potential for the site's medieval heritage to make a positive contribution to the vitality of this part of the city centre, and to the identity and image of Sheffield more generally. The castle and its attendant seigneurial landscape have shaped Sheffield's history, and can be harnessed to play a positive role long into its future, and the chapter concludes with a discussion of how this can be achieved in the early 21 st century in the context of a City Council-led regeneration partnership.

\section{Reduced to fragments - embedding the castle in the community}

Throughout this book we have emphasised the continued importance of the castle for Sheffield long after its demolition, and in this section we show that the seeds for this were sown in the very processes by which the

\footnotetext{
How to cite this book chapter:

Moreland, J. and Hadley, D. (with A. Tuck and M. Rajic). 2020. Sheffield Castle: archaeology, archives, regeneration, 1927-2018, pp. 289-332. York: White Rose University Press. DOI: https://doi.org/10.22599/SheffieldCastle.i. CC BY-NC 4.0, https://creativecommons.org/licenses/by-nc/4.0
} 
castle was torn down. Many castles were damaged during the English Civil War, ${ }^{30}$ and some were destroyed in the years after fighting had ended. Many, however, retained some habitable buildings - as was the case at, for example, Belvoir (Leics) (Johnson 2000, 196; Rakoczy 2007, 87-90), Kenilworth (Warks), and Alnwick (Northumb) - some were converted to other uses - such as prisons, as occurred at Lancaster (Lancs) (Cox 1896) and Flint (Clwyd) (Rakoczy 2007, 390) - or at least partly preserved as 'romantic' follies in the grounds of country houses - as was the case for Beeston Castle (Ches) (Mowl 2000,6) and Cartington Castle (Northumb) (Pettifer 1995, 179). Many that were eventually to disappear or become entirely uninhabitable only did so in the 18th or 19th centuries. The reasons that have been offered for why castles were slighted (razed, or dismantled) during and after the Civil War include a move to prevent their military reuse (e.g. Porter 1994; Hutton and Reeves 1998; Newman et al. 2001), or a political act by the 'middling sorts' seeking to destroy symbols of lordly oppression (Johnson 2002, 173-5). Sheffield was unusual in being a large castle in the heart of an urban settlement that was almost entirely demolished.

Analysis of the slighting of castles during the Civil War has been dominated by historians (e.g. Thompson 1987), although a few recent archaeological studies have sought to redress the balance. In these accounts the Parliamentarian forces are increasingly being depicted as encountering complex local circumstances, and they have also begun to reveal that detailed analysis of specific case studies incorporating archaeological evidence presents a new perspective on Civil War destruction, and nuances the national picture as traditionally presented through historical sources (Rakoczy 2007, 30-4; Askew 2017; Nevell 2020). Historical narratives have tended to focus on slighting as acts derived from principally military and fiscal concerns, with less consideration of local, small-scale decisions, actions and motivations (Rakoczy 2007, 35). However, these archaeological studies have tended to focus on the short-term acts of slighting, and where longer-term implications have been addressed these have been restricted to the survival and reuse of parts of castles (e.g. Rakoczy 2008). Moreover, despite being approached from an archaeological perspective most remain dominated by the historical records. Sheffield Castle offers a unique opportunity to integrate and contrast demolition accounts, town records, contemporary letters and estate rentals with the archaeological evidence, to discover the specific circumstances of demolition, and to explore the longer-term consequences of a demolished castle which continues to be directly relevant to the fate of the urban landscape in which it was located. What will become clear is that the castle remained embedded in the society and political culture of Sheffield even as it was disappearing stone by stone, while the influence of its Royalist owner, the $22^{\text {nd }}$ Earl of Arundel, Henry Howard, remained largely undimmed in the town even as the major symbols of his authority were taken apart. This is especially striking given the high profile of the Earl in supporting the king; prior to inheriting the earldom he had fought on the king's side at the Battle of Edgehill on $23^{\text {rd }}$ October 1642 and later joined his court at Oxford (Howarth 1985, 213). This Royalist support was probably decisive in prompting the order to demolish the castle after Henry Howard had inherited it from his father, Thomas Howard, $21^{\text {st }}$ Earl of Arundel, in October 1646 (Askew 2017, 192). It should also be noted that Yorkshire was one of the main regions, along with Wales, in which slightings were ordered in the period up to and including 1647, probably because of their extensive support for the king (Thompson 1987, 179-85; Rakoczy 2007, 48-9). However, Sheffield is among a small number of castles in Yorkshire, along with Helmsley and Knaresborough (both North Yorks), on which there was additional Parliamentary attention in 1648 (Rakoczy 2007, 51).

As we saw in Chapter 1, there were Parliamentary orders to disgarrison and slight the castle in April 1646 and July 1647, but the main stages by which Sheffield Castle was demolished occurred between $16^{\text {th }}$ October 1648 and the end of January 1649. In a declaration issued by William Blythe and John Crooke in February 1649 it was reported that the Earl of Arundel had offered to carry out the demolition at his own expense, 'to save the Country from that burthen' - a situation paralleled in the slighting of Montgomery Castle (Powys) by Lord Herbert (Askew 2017, 192-4). The Earl's servants, especially John Griffith, John Staniforth and Robert Rawson, not the Parliamentary representatives, were responsible for its demolition, and although it was overseen by Major Andrew Carter for Parliament he only occasionally visited to monitor progress. The demolition accounts reveal that $£ 208$ 8s. $8 d$. was spent on demolishing the castle, while $£ 2256 s$. $7 d$. was gained through the sale of materials (Askew 2017, 193). These are small sums compared, for example, to the $£ 7774 s$. $6 d$. for demolishing Pontefract Castle and the $£ 1779$ 17s. 4 . received for the sale of its lead, timber, iron and glass (Roberts 2002,

${ }^{30}$ While recognising the 'English Civil War' is a misnomer, as in reality it involved multiple phases of combat across the British Isles, it is used here in recognition of the fact that it is the term most commonly applied to this period of history. 
442). Much of the difference is down to the fact that lead sales - which accounted for over $£ 1,540$ of the income at Pontefract - are not included in the Sheffield accounts, but it might also reflect 'the extent of the demolition' (Askew 2017, 186, 201). What small profit there was, however, went to the Earl, and this contrasted with the situation at Pontefract, where the urban populace benefitted more widely from the sale of parts of the castle, which was intended to fund rebuilding of the parish church, although the plans did not come to fruition (Martin 1956, 27; Askew 2017, 197; Roberts 2002, 422). The Earl also ensured that some materials, including 'the beste sheetes of leade etc.', were transferred to the 'Mannr' (Wilson MSS, 295/145, fol. 31; Askew 2017, 196), thereby maximising the benefits of his offer to carry out the demolition himself, and providing further evidence for continuing investment in his other Sheffield home (see Chapter 8).

The demolition accounts also reveal much about the technicalities of tearing down such a substantial edifice. For example, in November 1649 Edward Maiknie, together with Richard Claiton and his son, was paid 3s. 6 d., for 'cutinge the timb[er] from the walle at Castle for the fallinge of an oute[r] walle', which suggests that the walls had been undermined, leaving behind timbers as props which could then be removed to bring down sections of wall (Wilson MSS, 295/57, fol. 12; Askew 2017, 194; see also Rakoczy 2007, 64-6 for a discussion of how undermining may have been carried out). Maiknie and Clayton were clearly more successful than Major General Crawford had been during the war; on $5^{\text {th }}$ August 1644, using a combination of 'threates, promises and money', he got together some 'colliers' - perhaps including some from the Park - 'to myne the Castle, which they found not to feasable, it being builded on a rock' (Anon. 1644, 3). However, on the whole the accounts suggest that the castle buildings were dismantled more carefully and removed from the site to be reused elsewhere in the town. This is also consistent with our findings from the archaeological record; while some architectural stone and rubble was recorded in the upper levels of the moat fills, this appears insufficient to suggest that the moat was infilled with castle demolition debris. The stone was clearly too valuable, and an entry in the demolition accounts for $10^{\text {th }}$ September 1649 records a payment from Joseph Capper 'for certaine stone taken by him forth of the castle ditches' (Hunter 1819, 114; Askew 2017, 206). Nor is there any clear evidence for burning on any of the stone recovered, or any of the stonework surviving in the chambers beneath the former Castle Market, suggesting that the destruction of parts of the castle by burning was not a method employed at Sheffield (for documented examples of the use of fire to effect demolition at other castles, see Rakoczy 2007, 69-73).

The records of Sheffield's Town Trust provide further insights into the process by which the castle was fragmented and dispersed. The only building in this area drawn on Gosling's 1736 map is the 'almshouses' which lay just below the castle (Figure 1.6). These almshouses, for four poor widows according to Goodwin (1764, 157), had their origin in the suppression of the chantry 'Chappel of Our Blessed Lady of the Bridge', the latter certainly referring to Lady's Bridge, constructed in the late 12th century and rebuilt in the late 15th (Hunter 1819, 194; Gatty 1869, 337; Wigfull 1914, 59; Figure 9.1). By c.1572 the former chapel was being used by the Earls of Shrewsbury as a wool warehouse (David Hey $(1991,42)$ tells us that the $4^{\text {th }}$ Earl, George Talbot, saved it from demolition after dissolution by converting it to this use), and was first referred to as an almshouse in 1589 (Leader 1897, 60; Wigfull 1914, 57). In 1656 the Town Trustees paid several men, including 'Shawres, Heathcote, Firth and Atkinson', to carry out a range of work there. They were paid 'for preparing a way to tumble stones for the Almeshouse', and for 'tumbling and carrying stones'. Supplies purchased included 'six baskettes for carrying earth' and - critically - 'a rope to drawe stones out of the Dungeon', and Leader $(1897,165)$ is surely correct to read this as the 'dungeon of the now destroyed castle'. So here we have an account of the removal of stonework from the castle site, and its transportation down a prepared path to the almshouses below. In 1657 or 1658 further payments were made to 'Showres, Ronckesley and others for getting stones, building, and worke done by them at the Almeshouse'. Leader $(1897,167)$ argued that, while the Town Trust paid for the labour and supplies, the Earl of Arundel donated the material (i.e. the fragments of the castle).

The documentary evidence records individual architectural elements being cut out of the walls and sold off. For example, in January 1648 a small stone window was sold to Edward Wood for $4 s$. and buttresses were sold for $£ 1$ each to three other individuals (Wilson MSS, 295/57, fol. 4.). The demolition was carried out by local craftsmen who can have had little or no experience of dismantling such major structures. They seem to have been rewarded for their work by being given parts of the castle fabric or by being allowed to make a small payment for whole rooms or sections of wall and were then responsible for hiring other workers to remove the materials (Wilson MSS, 295/57, fol. 8; Askew 2017, 199). The entries in the demolition accounts which record payments to workers to carry out specific acts of dismantling are typically for individual walls next to particular buildings, such as 'a wall next the dungan' and the 'crosse walles' (Wilson MSS, 295/57, fol. 8; Hunter 1819, 


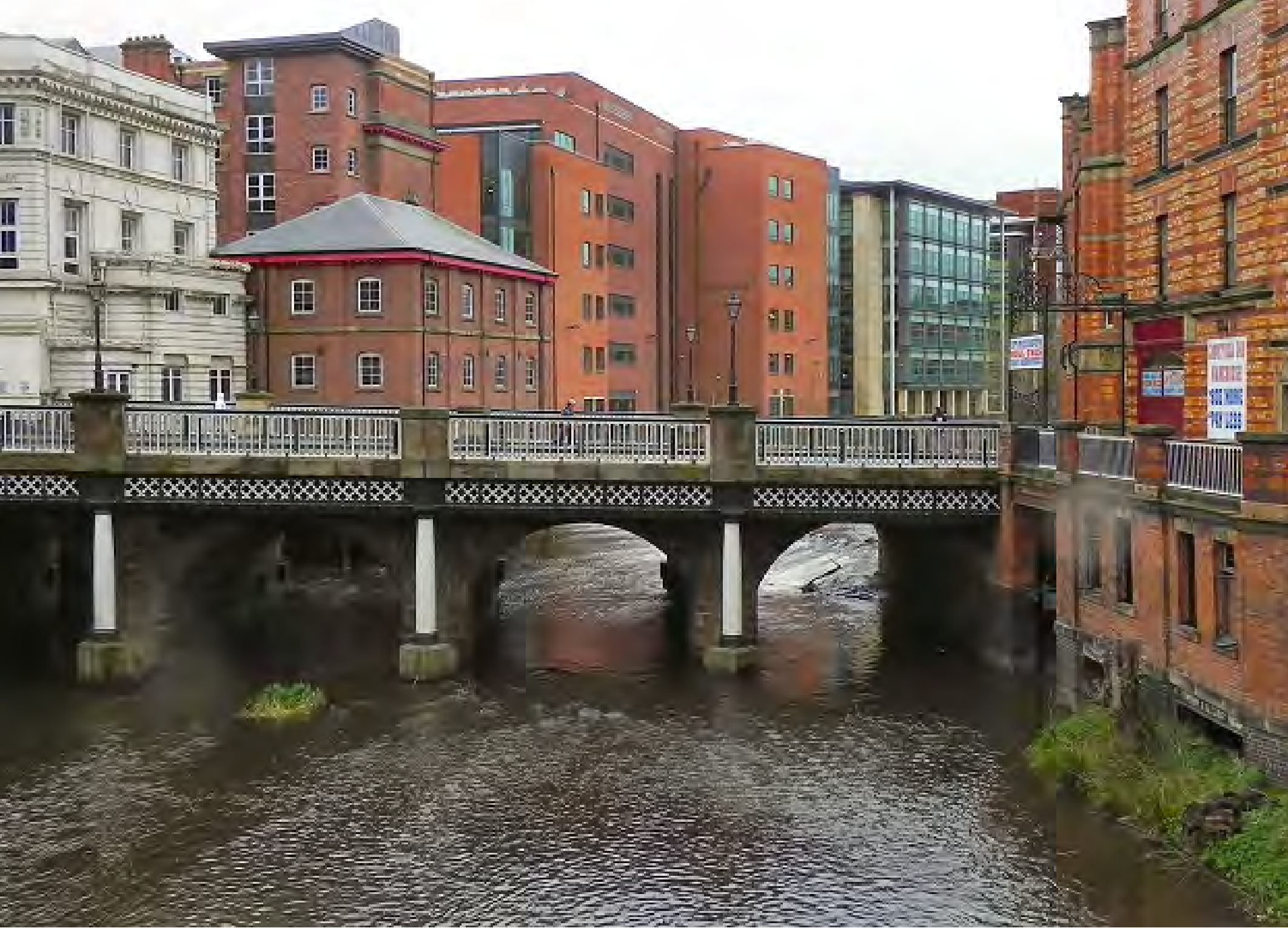

Figure 9.1: The medieval Lady's Bridge over the River Don. This survives beneath the modern road bridge, photographed in 2012. Copyright David Dixon; reproduced under a CC BY-SA 2.0 licence; geograph.org $. u k / p / 2889725$.

114-15; Askew 2017, 208. Walls would have required labour to remove, but profit would be limited because unlike covered buildings they would not have yielded highly saleable items such as slates. Other payments made in January 1648 were $£ 91 s$. $6 \mathrm{~d}$. 'for dimollishinge the Round of either sid[e] [of] the gatehouse' (probably the towers which flanked the gatehouse; see Chapter 3), £8 10s. $0 d$. for 'dimollishinge al the walle after the watersid[e]', and $£ 70$ s. 0 d. for 'dimollishinge the halle'- all to the Shore brothers - and $£ 111 \mathrm{~s}$. $0 \mathrm{~d}$. to Michael Wright to demolish 'the end of the Chappell \& one pillar' (Wilson MSS, 295/57, fol. 8; Hunter 1819, 114; Askew $2017,208)$. In such cases, the payments to workmen were necessary inducements to take these parts of the castle away. Rather than being a centralised activity organised by the Earl's representatives, the demolition process seems to have required workmen to bring their own tools, given the limited records of equipment, such as paniers, pickaxes, crowbars and mattocks being purchased by the Earl's servants and officials to facilitate the demolition (Wilson MSS, 295/57, fol. 11; Hunter 1819, 114; Askew 2017, 199-200). The demolition of the castle was, then, a collective activity that involved members of the gentry and artisan classes of Sheffield - though the reference of multiple payments to, for example, the Shore brothers show that some were more heavily involved. As Rachel Askew $(2017,201)$ concluded, 'a significant proportion of Sheffield's middling sort profited from the castle's demise'; as we will see later in this chapter, this was not the only time this class benefitted from the repurposing of the castle and its landscape. 
The demolition accounts list a wide range of items sold to the local community from the castle in January 1648. These include 18 hundredweight of 'ould Ironne' for $£ 10$; all the wood, including joists, roofs, partitions, floors and furniture for $£ 644 s$. $2 d$.; stone for $£ 20$ 8s.; and slates from the hall and the bakehouse for $£ 110 s$. and $£ 113 s$. $4 d$., respectively (Wilson MSS, 295/57). Numerous Sheffield residents acquired fixtures and fittings from the castle, even 'ould' or 'bad' items. Therefore, even though it had largely disappeared as a monument, it lived on as fragments dispersed throughout the city, in domestic households and public buildings for years, if not decades. For example, in 1648 a frame, piece of plank and two table planks from the hall (16s.) and a table from the sentry house (8s.) were purchased by Edward Wood, Leonard Wood acquired ' 2 dresser tables in the ould kichen' (10s.), the 'square room at the hall end' was sold for $£ 110 s$., John Crooke purchased 'the Territ' for $£ 510$ s., William Saunder 'the little kichen' $(£ 3)$ and Nicholas Hicke 'et socios' paid $£ 36$ 'for all the mater-ialls of the Ould Kichenn, savinge lead', while ' 2 bad dores 2 peices of wood \& one dore' were purchased for 10s. 'for the schoole' (Wilson MSS, 295/57, fols 3-4; Askew 2017, 198). Some items seem, however, to have been acquired for purposes other than structural, to judge from their state; presumably Thomas Skargel intended to burn ' 4 loads of broken timb[er] from the s[ta]b[1]e', for which he paid $£ 4$ (Wilson MSS, 295/57, fol. 7). Stone, especially ashlar, must have been greatly prized within the town but it would have been difficult to remove and transport, and this probably accounts for the comparatively low levels of sales of stonework recorded in the demolition accounts (Askew 2017, 198-9).

The Earl's representatives sometimes paid workmen to remove items ready for sale. For example, the sum of $£ 559 s$. $5 d$. was paid out for the removal and smelting of lead, including $£ 19 s .4 d$. in March 1649 to workmen to remove lead pipes in the castle and a total of $£ 414 \mathrm{~s}$. $9 d$. was 'paid at sev[er]all times to workmen for takinge up the lead pipes in the Parke \& the Orchards' (Wilson MSS, 295/42, fol. 143; Askew 2017, 196). In contrast, we have records for only a little over $£ 77$ in sales of lead, which is a paltry figure in comparison to the $£ 1,540$ raised by sale of lead at Pontefract Castle (Yorks) (Roberts 2002, 442; above). The reason for this is partly that the Sheffield lead was largely smelted into pigs by John Pearson and sold at Bawtry (South Yorks), for which we have no records, but partly because some was retained by the Earl for use at the hunting lodge in Sheffield park (Wilson MSS, 295/42, fol. 143; Wilson MSS, 295/145, fol. 31). Timber was also taken to the hunting lodge: 'to the Mannor one load of bords' (Wilson MSS, 295/57, fol. 6). Other local residences that benefitted from acquisition of materials from the castle include Carbrook Hall (c.4km to the north-east), for which Colonel Bright purchased '2 flores and 10 great Joysts' (Wilson MSS, 295/57, fol. 5), while fellow Parliamentarian Captain Blithe purchased plaster and boards for his house in Sheffield, which is now known as the Bishops' House, and where some of the surviving plasterwork may be that which he acquired (Wilson MSS, 295/57, fol. 5; Figure 9.2). Plasterwork is fragile and it must have been regarded as particularly desirable to have taken the trouble to transport (Askew 2017, 197). It is noteworthy that local tradition holds that tapestries which until recently adorned the walls of the dining room at Norton Hall, Sheffield, came from the castle (Christian 1968, 24). This is among the many such traditions which associate 'antique' objects with the castle (see below for Mary, Queen of Scots' bed), but is more plausible given that Norton Hall was the home of Edward Gill, colonel in the Parliamentarian Army, brother-in-law of Colonel Bright, and governor of the castle between 1645 and 1646 (Hunter 1819, 112, 250). Sheffield's emerging gentry were acquiring parts of the castle and incorporating them into the fabric of their own homes. On the one hand, the antiquity of these material remains, their association with power and lineage, helped to legitimise their newly won positions of authority. On the other, the very fact that these were pieces of the castle served to emphasise the fragmentation of the old order, and the triumph of the new.

From the mid-17th century, fragments of the castle, its stones, architectural elements, fixtures and fittings, were clearly distributed throughout many properties across Sheffield. That this has scarcely been traced is the result of three main factors. First, extensive rebuilding in the city during the 18th and 19th centuries saw many earlier wooden buildings demolished and replaced with brick or stone structures (Hey 2010, 71-3). For example, a 16th-century timber-framed house for the Earl's bailiff, William Dickenson, on the corner of High Street and Change Alley is recorded in a photograph of 1886 but was demolished when the High Street was widened shortly afterwards (Hey 2010, 41; see also Skill n.d.). The rapid industrialisation of the town centre during the 18th century is evident from the maps produced by the Fairbank family, and this doubtless also contributed to the destruction of earlier buildings. Second, limited modern excavation within the city centre has restricted opportunities to document fragments of the castle incorporated in its buildings, although recording of brickbuilt industrial buildings has often revealed large sandstone foundations which may be from the castle, as we saw in Chapter 7. Third, the Blitz and the extensive damage done to the city centre during World War II 

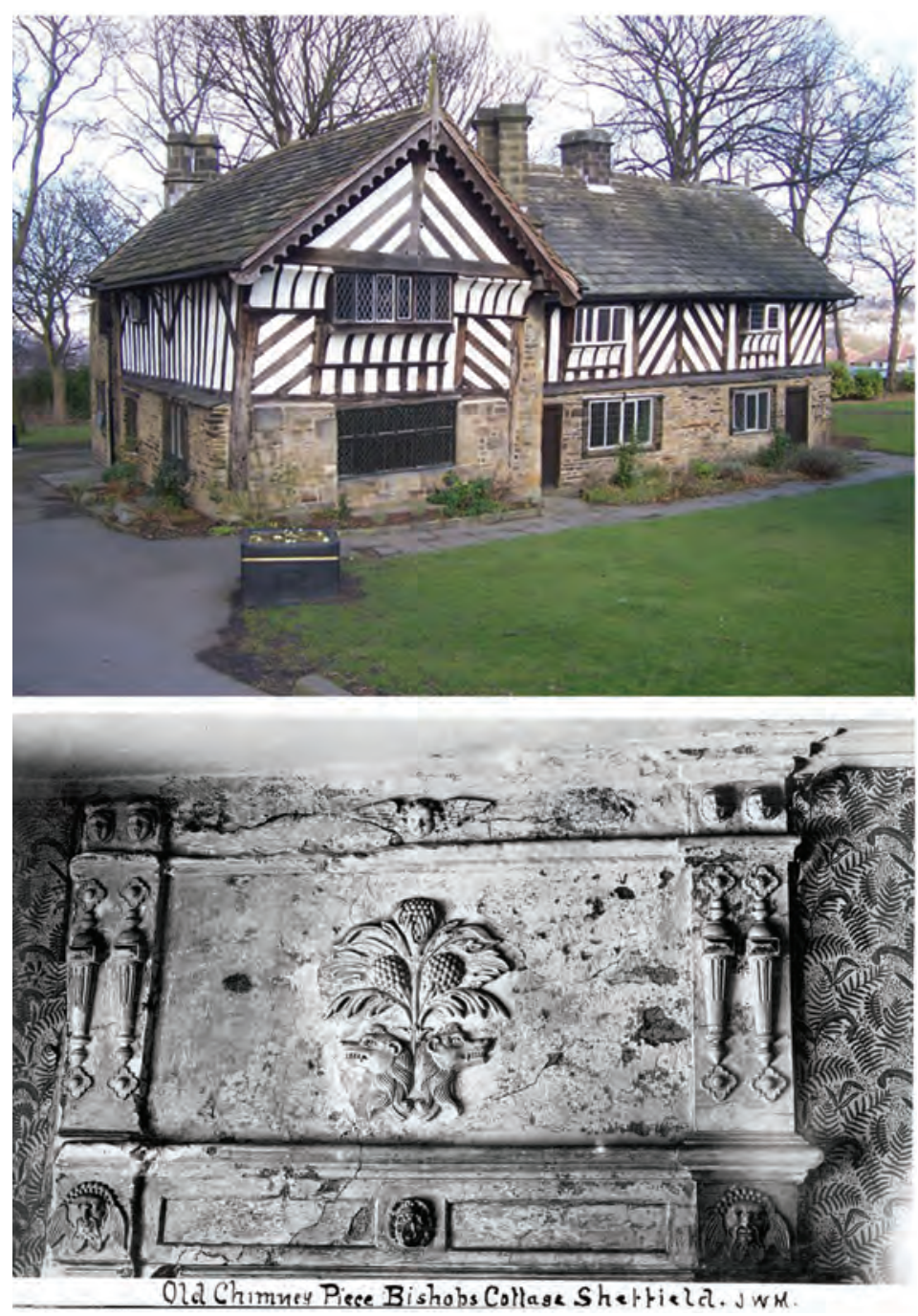

Figure 9.2: The 17th-century Bishops' House in Sheffield's Meersbrook Park. This is where Parliamentarian Captain Blithe took plasterwork from Sheffield Castle. (c) Martin Speck and licensed for reuse under creativecommons.org/licenses/by-sa/2.0; geograph.org.uk/p/1208861. The surviving plasterwork at the Bishops' House may be from the castle. With thanks to www.picturesheffield.com (s09441).

accounts for the destruction of many buildings in the immediate vicinity of the castle, with the effects compounded by urban planning in the mid-20th century unaccompanied by archaeological investigation.

It is striking that while the Earl's castle in Sheffield was being demolished he nevertheless maintained a major residence at the nearby hunting lodge, which was evidently being improved through the acquisition of new materials from the castle remains. As Askew $(2017,203)$ has pointed out, while the demolition accounts support the argument that the slighting of the castle was partially a product of 'Sheffield's middling sort rising up against the elite' and, as we have seen, they certainly profited from it, it is not a complete explanation. Even though the Earl was a Royalist, local Parliamentarians clearly engaged with him and his servants in the process of demolition and redistribution, which, as we have seen, he had offered to carry out 'att his owne charge'. A major concern for the Earl was to protect the castle from theft; indeed, following the theft of lead in November 1649 the Shore brothers, Humphrey, John and Robert, were paid 10s. 'for waitinge by the Castle 8 weekes \& lyinge there'; in addition a further $5 \mathrm{~s}$. was paid to ' 3 men' (presumably the Shores again) and Thomas Rawson was paid for 'lyinge forth one night to waite an opportunity to search for lead' (Wilson MSS, 295/57, fols 12-13; see also Wilson MSS 295/223, Book 15, fol. 28). The thieves, possibly local men, were quickly apprehended and bound over to the next Quarter Sessions, and the incident reveals that retribution was swift to those who sought to undermine the process of selling off the lord's chattels (Wilson MSS, 295/57, fol. 13). The demolition

Figure 9.3 (page 295): The Shrewsbury Hospital, built in the former orchards of the castle in the late 17th century. Sketch by Edward Blore from the early 19th century. With thanks to www.picturesheffield.com (s07452). 
accounts reveal that the Earl continued to exert considerable authority over the people of Sheffield, who were generally Parliamentarian in their leanings, as his tenants were employed in the erasure of the castle from the townscape, in particular filling in of the ditch (Askew 2017, 194, 200). The written accounts suggest that both the Earl and many of the inhabitants of the town, the middling sort and the lesser gentry alike, benefitted from the demise of the castle. It could be argued, therefore, that the demolition, by removing a physical manifestation of the recent turbulent past, helped smooth over the social divisions and loyalties within the town while at the same time leaving the Earl with his hunting lodge in the park on the hills to the east (though, as we saw in Chapter 8, there too his authority was to be challenged and, ultimately, diminished).

Despite the orders to disgarrison and slight the castle in April 1646 and July 1647, there is evidence to suggest that the Earl of Arundel was in a position to retain parts of the castle as habitable. When Major Andrew Carter came from York in 1649 to inspect the 'rema[i]ning part of Shiffeld Castle now standing', he reported in a letter that it was still 'in part teanable' (Wilson MS 295/24, fol. 2 ). Accounts from 1649 show that the Earl ordered repairs to be made at the castle, including payments for carpentry, plumbing, glazing, stone masonry and the purchase of new supplies of lime (Wilson MSS, 295/223, Book 15, fols 33-4). In the same letter by Major Carter it emerges that some castle buildings in the south range were to be retained, and four new $8 \mathrm{ft}(2.44 \mathrm{~m})$ square windows were to be inserted 'three foot and a half from the ground', and three $6 \mathrm{ft}(1.83 \mathrm{~m})$ by $8 \mathrm{ft}(2.44 \mathrm{~m})$ windows inserted in the second storey. Windows were also to be inserted in the 'ould tower wher the stabls ar', and he proposed that 'all the battlements' should 'bee not above one Foot and a halfe' (Wilson MS 295/24, fol. 2; Hunter 1819, 113-14). The implication, of course, is that parts of the castle still stood to at least the second storey, and some of the towers remained, as did at least some of the battlements (see also Richardson and Dennison 2014a, 20).

It is significant that the works proposed by Carter were to be undertaken with a view not to the erasure of the castle but 'to mak the said bilding unservesable for warr and to be imployed for an Hospetall' (Wilson MSS, 295/57, fol 2; Hunter 1819, 113-14; also Askew 2017, 192-3). The need for a hospital in Sheffield had been recognised in the will of Gilbert, $7^{\text {th }}$ Earl of Shrewsbury, who left provision after his death in 1616 to found an institution catering for 20 'poore personnes' (DD/4P/46/6; Hunter 1819, 76; Figure 9.3). However, a dispute over the will and then the Civil War meant a delay of nearly 50 years to his wishes being carried out, and in the end the hospital was completed in 1673 across the Sheaf on the site of the castle orchards (Hey 2010, 42-3).

The remaining buildings on the castle site are notably said to all be facing 'towards the Towne' (Wilson MSS, 295/24, fol. 2; see also Chapter 6). The windows may have been intended to weaken any defensive capabilities of the castle (Askew 2017, 193) but the specific request that they faced towards the town is striking in the context of a castle that had, as we saw in Chapters 5 and 8 , been oriented towards the deer park for the previous 400 years. 
That there were symbolic resonances in this reorientation of the castle at the time when it was being dismantled buttress by buttress, wall by wall is unlikely to have been lost on the inhabitants of the town. And we should not lose sight of the fact that the moment of the town's 'capture' of the castle also marks the beginning of the major changes in the park, which we discussed in Chapter 8. In this context, it is also notable that the bulk of the 17thcentury Blackware, Blackware-type, Coarse Blackware and Coarse Blackware-type sherds recovered from the site was retrieved from foundation shafts located in the moat at the south-west corner of the site (152 out of 191 sherds for which a provenance is recorded), mainly in F21, F22, G22 and G23. A similar pattern emerges from the Early Brown Glazed Coarseware of the 17th and 18th centuries, and this would correspond with the continued use of this part of the site through the 17th century (see also Chapter 6 for clay tobacco pipes from this period).

It seems that the death of Henry Howard in April 1652 was critical to the fate of what remained of the castle. His heir was his eldest son, Thomas, who spent much of his adult life in an asylum in Italy, although this did not prevent the newly restored King Charles II from reviving the Dukedom of Norfolk for him in 1660. With Thomas abroad and incapable of undertaking his duties, and his grandmother Alethea Talbot, through whom Sheffield had come to the Howards (see Chapter 1, Section: Sheffield Castle and its elite occupants), still alive but residing in the Netherlands, there was no English interest in the fate of the castle. It seems that any plans to convert the remnants of the castle into a hospital or a habitable dwelling place for the lord of the manor were abandoned, although the Earl continued to own the site of the castle. In some respects, then, the demise of the castle was settled with a whimper. Only the hunting lodge was retained as a habitable residence, and it was here that the principal documentation of the estate was taken by the Earl's officials from the castle prior to it being dismantled (Martin 1956; Askew 2017, 197; also above Chapter 8).

\section{New uses for Castle Hill}

Following the demolition of the castle we can trace the developments on Castle Hill through maps and written sources, particularly rate books, which recorded the rates being levied to pay for poor relief, highways, street lighting, sewers and so on. In 1736, when Ralph Gosling produced his plan of Sheffield, much of Castle Hill appears extensively built up, although there is little information provided about the types of buildings that occupied the site by then, or about who owned them (Figure 1.6). On 18th-century maps, Castle Hill is, in fact, dominated by a bowling green (e.g. Gosling 1736; Fairbank 1769; 1771; Figure 3.24), traces of which were recently identified during excavation as we saw in Chapter 7 (see also Chapter 3, Section: Courtyard buildings, for the possibility that it had also been encountered in the 1920s). The Fairbank map of 1769 records John Waite and John Nelson as the main property-holders on Castle Hill. But, while the house and land (marked 'gardens') to the east of the bowling green, and another property to the south, were 'in John Waite's own possession', much of the northern and western part of the Hill, including an enclosed complex of buildings with outhouses, courtyards and access to a pump, was in the tenure of John Nelson'. The bowling green too was 'occupied by John Nelson'.

The early modern period saw the emergence of sports and leisure facilities that were intended as meeting places for gentlemen and citizens, alike, in informal settings but where, as Angela Schattner $(2014,212)$ has recently argued, 'issues of belonging to a specific status group were still in force' while bowls was being played. The Castle Hill bowling green is the earliest representation of a purpose-built sports facility to appear on maps of the city (Hornby 2015, 53). It was one of at least four in Sheffield in the 18th century. Leader $(1901,46)$ argues that the evident popularity of bowls owed much, for some, to the opportunity it provided for 'betting and heavy drinking. He seems to have been thinking specifically of 'cutlers and grinders', suggesting that, as in the rest of the country, the sport was becoming increasingly popular across social classes (Hornby 2015, 86). Therefore, the two people seen playing bowls on the Castle green in Oughtibridge's 1737 depiction need not have been gentlemen. Elsewhere in the country, bowling greens were associated with inns and dining clubs, providing an opportunity for social activities and were financially lucrative (Schattner 2014, 211-2; Hornby 2015, 86). In 163920 gentlemen from Lewes (Sussex) wrote this petition to the Justices of the Peace, 'Wee ... conceive John Standinge of Lewes to be a very fitt man to keepe the bowlinge greene and sell drinke in the hosue wheer he dwelleth' (Hornby 2015, 59) - did John Nelson do the same in Sheffield?

Interestingly, the green at Lewes comprises the bailey of the former castle (Hornby 2015, 59-61), pointing to an association between bowling greens and castles, perhaps especially former castles (see also Cattell 2016 for Halton Castle (Cheshire); Russell 2017 on Carisbrooke Castle (Isle of Wight); Whittle 1989 on Raglan Castle (Monmouths); Hynd and Ewart 1983 on Aberdour (Fife)). It may be that the flat area of the former courtyard was perfectly suited to the needs of the sport, but one wonders if there was something more calcu- 
lating in bringing an increasingly popular sport, one which in 1541 had been outlawed for anyone worth less than $£ 100$ per year (Hornby 2015, 49), into the heart of the former seat of power? Was this another step in the democratisation of this space which began in tumult of the middle of the previous century, a subversion of the ideology and structures of power that had underpinned the castle for half a millennium? That the locale, nevertheless, retained an association with power, politics and justice can be detected in the fact that by at least the late 18th century public outdoor meetings were held on Castle Hill. Robert Leader $(1875,12-13)$ tells that one such, in April 1794, 'had passed strong resolutions and spoken fierce words against the Government', resulting in the issue of warrants and the flight of Mr Joseph Gales, editor of the Sheffield Register, first to Germany, and then to America, to pursue the cause he had espoused - 'peace, liberty and justice' (also Kay and Kay 2017).

The open space of the bowling green was in contrast to the activities that were developing around Castle Hill over the course of the 18th century. For example, the 1774 Sheffield Trade Directory lists among traders on Waingate a silversmith, wheelwright, coach maker, gunsmith, baker and confectioner, while a file maker, raff or timber merchant, and a pen and pocketknife cutler were trading on Castle Fold, the road that later became known as Exchange Street (Sketchley 1774; SA/RB1; SA/RB2; Clark 2019, 34). Over the course of the 18th and 19th centuries the Dukes of Norfolk, who still owned the site - as part of a 12,000 acre (4,856ha) estate in and around Sheffield - leased it out for a variety of industrial and commercial uses (Simmons 1997, 405). A Fairbank plan of 1771 depicts the houses and yards along Waingate and Castle Fould, encircling what was probably still the bowling green (Figure 9.4; also Figure 3.24). The list of those leasing these properties from the Duke include Sam and Joseph Wainwright and Samuel Shore. Documentary sources reveal that one of the buildings on the site in the first decade of the 18th century was a steel works founded by Shore, who was probably a descendant of the Shore brothers who had helped to dismantle and guard the castle some 50 years earlier. It is not surprising that an available centrally located block of land such as the castle site would be targeted by industrialists, in a town in which around $60 \%$ of men recorded in the parish registers of the mid-17th century are described as cutlers (Hey 2005, 91, 93). Shore built a cementation factory shortly afterwards to the west of Castle Hill at what is now known as Furnace Hill, and which at that time was on the northern edge of the town (Gardner and Frudd 2015, 13-14). The rate book of 1755/6 lists, however, just a handful of properties on Castle Hill, including three houses described as 'new', a tan yard, garden, Manor farm and Turners farm, suggesting some agricultural or horticultural activity on the site (SA/RB1; SA/RB2). The range of buildings remains similar in later rate books, but the names of individuals holding properties there expands, albeit that we do not know what type these were (SA/RB 6, 21, 22, 24, 25; Clark 2019, 103-5).

The large open space on the 1771 Fairbank map might still be the bowling green, but it is now labelled 'Situation of the Castle demolished in the Civil War' - clearly the memory of the castle, and its fate, persisted and marked the place (Figure 1.8). However, by the time of the 1797 map it had been built on. The changes made to the town centre to improve access to the market places following an Act of 1784 (see Chapter 1) saw the bowling green and many of the houses on Castle Hill swept away and replaced with the Killing Shambles and, eventually, a range of industrial premises as the Duke sought to maximise the return from his Sheffield properties (Simmons 1997). However, in a Trade Directory of 1787, the only resident listed on Castle Hill was Samuel Broadbent, factor and agent to the Lombard Street Fire Office (perhaps the Phoenix Fire Office, in Lombard Street, London; Gales and Martin 1787, 5, 52). The 1787 and 1797 directories list a range of occupations in the area of the former castle: John Eyre, dealer in flour, Castle Green; Edward Foster, hackney keeper, Castle Green; William Gray, victualler, Castle Fold; John Greaves, dealer in hay, Castle Fold; Francis Hallam, butcher, Castle Fold; Charles Law, victualler, Castle Fold; Matthew Hall (plasterer), William Heffor (victualler) and Benjamin Taylor (smith and farrier) (Robinson 1797, 50). However, the only reference to metal workers or metal production is to Joseph Hawksley, file manufacturer on Castle Fold (Gales and Martin 1787, 7, 62).

The 1797/8 rate book names more traders and landholders on Castle Hill, including Widow Broadbent, who sublet 13 dwellings, and J. Bettany and J. Birks, who both had four properties (Clark 2019, 39-40, appendix 2). The early 19th-century rate books name a Castle Street, and comparison with trade directories suggests that this is, in fact, Castle Hill; by c. 1807 the company Weldon and Furniss was manufacturing saws and edge tools on Castle Hill, and by 1810 had also built a furnace there (Barraclough 1984, 103). The firm would go on to become Furniss, Cutler and Stacey, listed in a directory of 1833 as owners of Castle Hill Works, marked on the 1853 OS map as occupying the centre of the former castle site (Clark 2019, 41). The 1817 trade directory names a pen and pocketknife manufacturer, James March and Company, and a carpenter and builder, John Senior, operating on Castle Hill, along with Weldon and Furniss and the aforementioned blacksmith Benjamin Taylor (Brownell 1817, 40-66). By the 1820s Castle Hill also had a wheelwright's shop, three milliners and dressmakers, a draper, timber merchant, furniture brokers, and the company of Steers 


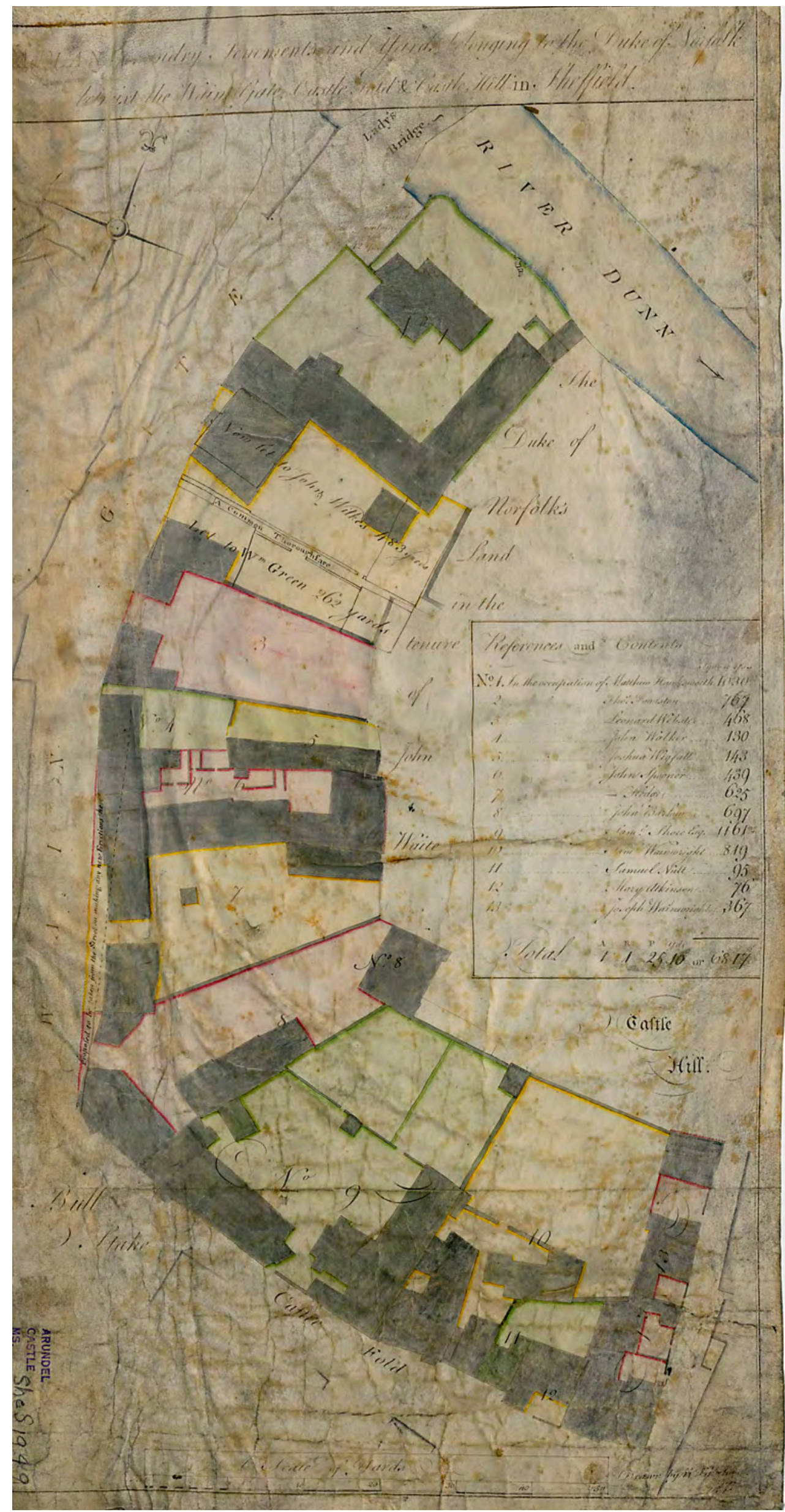

Figure 9.4: Plan of Sundry Tenements and Yard belonging to the Duke of Norfolk betwixt the Wain Gate, Castle Fold and Castle Hill in Sheffield. Drawn by William Fairbank, 1771. Reproduced with permission from His Grace the Duke of Norfolk, DL and Sheffield City Council. 


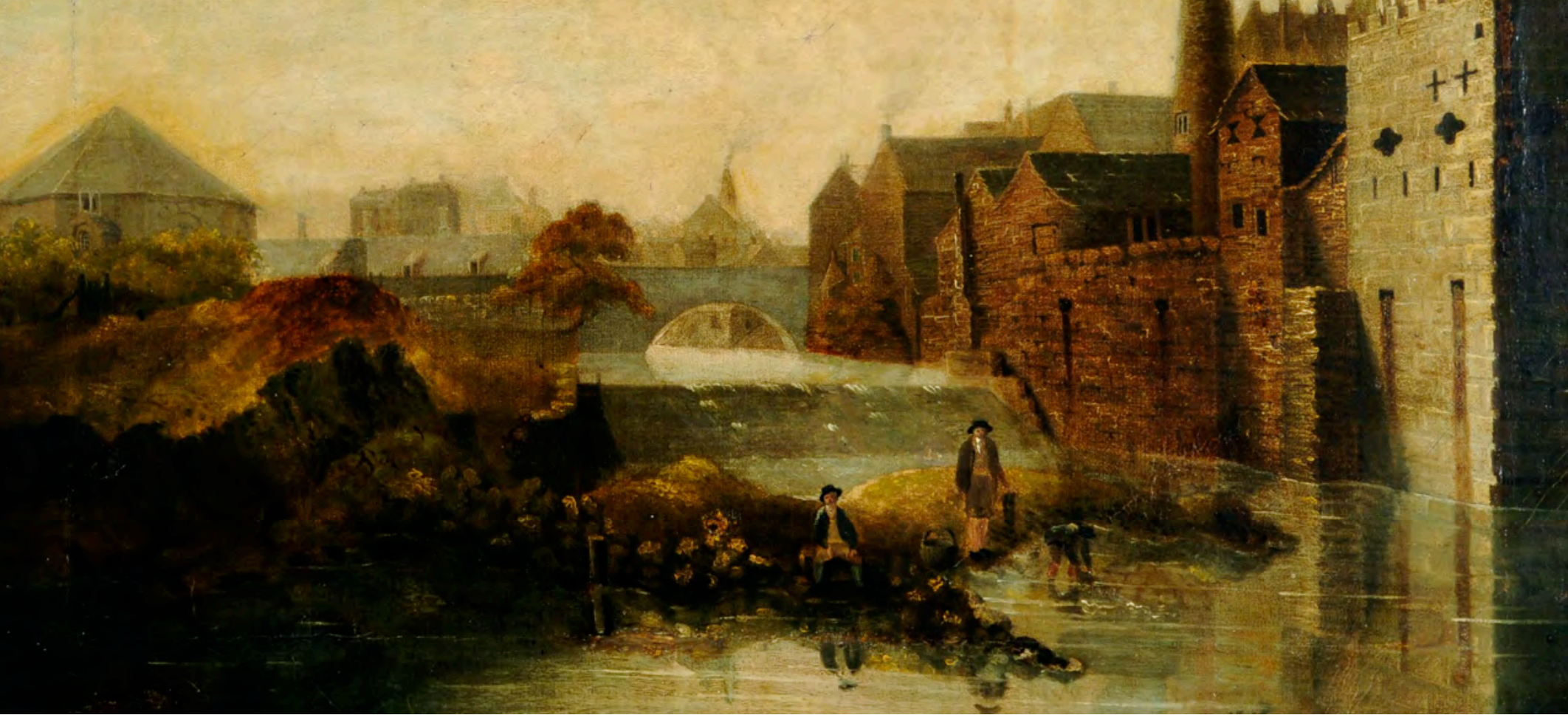

Figure 9.5: The River Sheaf and the Shrewsbury Hospital on the left of the bridge. Unknown artist, 1825. This appears to show what is labelled the Hospital Bridge on the 1771 Fairbank map (see Figure 1.8). On the right is the corner of the crenellated slaughterhouses, behind which are various factories that then occupied Castle Hill. Courtesy of Museums Sheffield.

and Wilkinson, which manufactured scissors, nail nippers and table knives (Baines 1822, 325-95; Gell 1825; Blackwell 1828, 89).

Following the late 18th-century construction of the Killing Shambles, the number of butchers and related trades on Castle Hill increased significantly, with around 90 recorded in the 1814/15 rate book (SA/RB148). Clearly the 19th century saw an intensification of activity on Castle Hill, and the Ordnance Survey 6in map of 1853 gives a clear impression of a tightly packed, promiscuous (and almost certainly noxious) mixture of public houses/hotels (including the Bull \& Mouth, the Anvil Inn, the Rose and Crown and the Royal Hotel (formerly the Reindeer Inn)), industry (steel works such as the Phoenix Works and Castle Hill Works) and slaughterhouses, as well as Castle Folds Court and Browns Court at the south-east of the site.

Developers and industrialists were not simply attracted to newly available space in the town, but the resonances of this place were also important to the buildings of the 18th and 19th centuries. This can be seen in the names assigned to many of the buildings, and in particular in the architecture of the factories and slaughterhouses. A painting of $c .1825$ depicts three men at the junction of the Rivers Sheaf and Don, with the Shrewsbury Hospital behind them and chimneys rising from the site of the castle. Just to their left, however, is a building constructed to look like a castle tower, complete with castellations and arrowslits. Its location 
suggests this must have been part of the slaughterhouses (Anon. c.1825; Figure 9.5), what Butcher (1972a, 21) described as the Duke of Norfolk's "'Gothickised" slaughterhouses. Photographs from the late 19th and early 20th centuries confirm the use of turreted walls and towers on the buildings constructed on and adjacent to Castle Hill ('The royal visit' 1875, 5). For example, the late 18th-century tilt hammer forge known as Huntsman's Tilt and later the Wicker Tilt was built on the opposite banks of the Don to the slaughterhouses in a mock medieval style (Figures 9.6, 9.7). The Tower Grinding Wheel constructed in the mid-19th century on Blonk Street was adorned with battlements and turrets (Earl 1844; Figure 9.8). Similarly, the scheme of development that took place $c .1900$ to construct the Royal Exchange Buildings, comprising shops and flats, a veterinary surgery and dogs' home, as well as the adjacent Castle House, which belonged to the veterinary surgeon, also incorporated castellations (Harman and Minnis 2004, 154); it is reputedly the place where mushy peas were invented, as Batchelors had a factory here from 1931. The 2018 excavations recovered a piece of neo-Gothic window tracery that derives from the sort of architectural forms we can see in photographs and artistic representations of Castle Hill in the 19th century (Ryder 2019; Figure 9.9). With many of the buildings on the site of

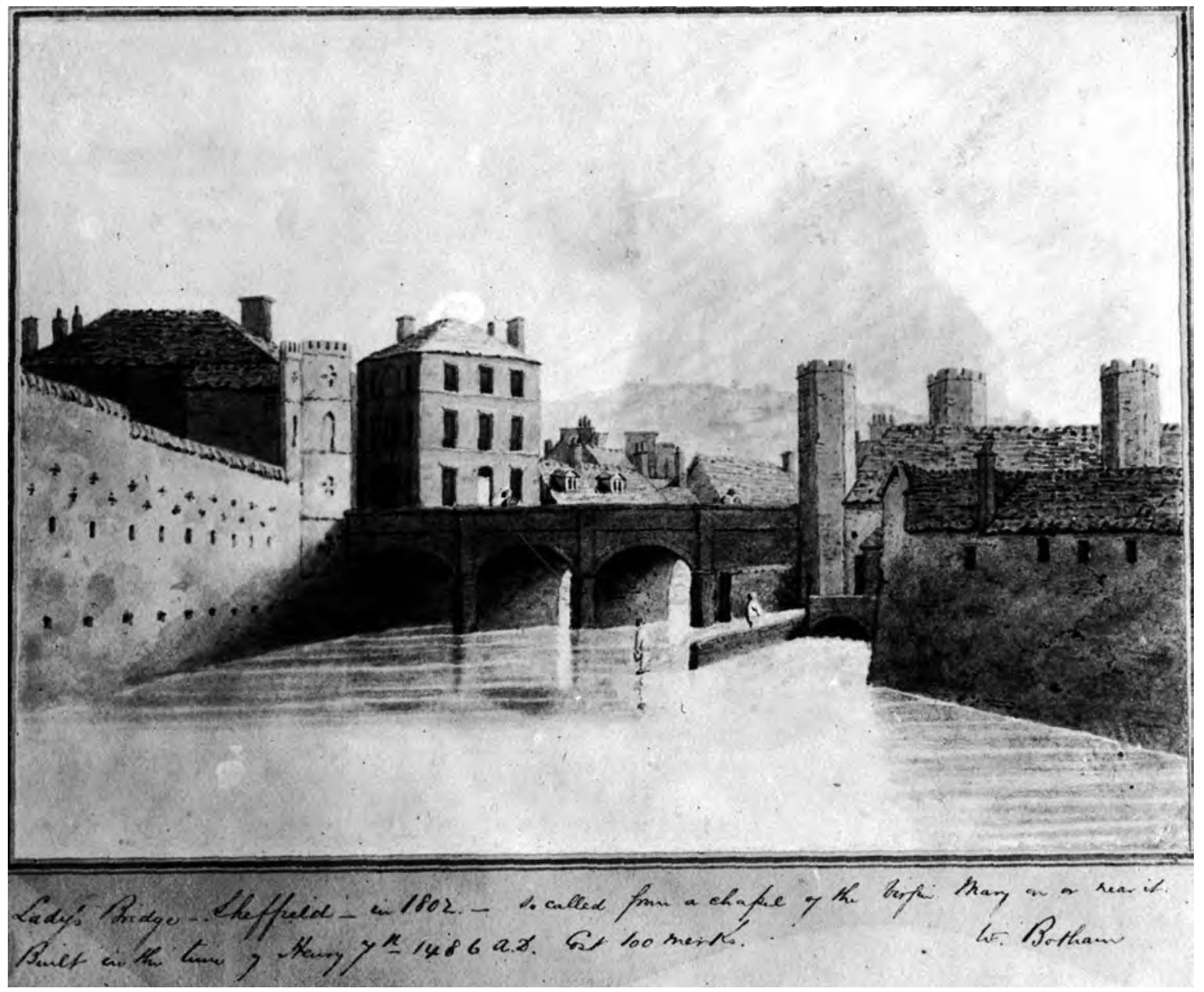

Figure 9.6: Lady's Bridge in 1802. The Wicker Tilt is on the right and slaughterhouses on the left. Note the crenellations and turrets. With thanks to www.picturesheffield.com (s07499).

Figure 9.8 (page 301): The Wicker Tilt and the Tower Grinding Wheel. Photograph from 1896 with the Wicker Tilt on the left in the foreground and the Tower Grinding Wheel to the rear beyond the Blonk Street bridge. With thanks to www.picturesheffield.com (s12220). 


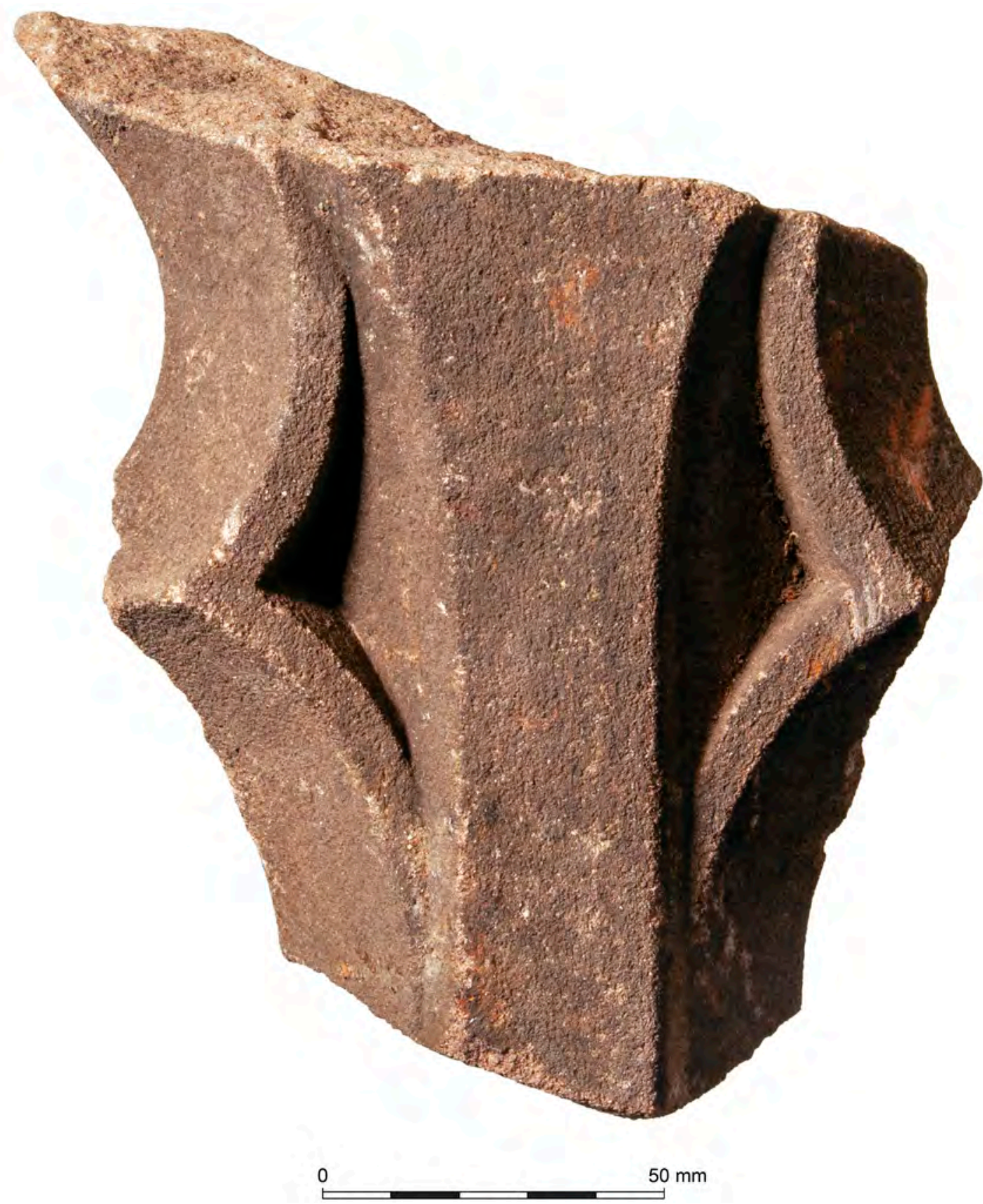

Figure 9.9: A fragment of window tracery of Gothic Revival type. This probably dates to the 19th century, and was recovered during excavations in 2018. Wessex Archaeology.

the castle, and its immediate vicinity, referencing the castle in their architectural design, a strong sense of the heritage of the site persisted in the centuries following the Civil War slighting and into an industrial era. And its diminished physical presence was deemed important enough to mark on maps - the 1888 Goad Fire Insurance Plan recorded 'Part of the Old Castle' among the warehouses of R\&J Smith Bros. Iron Merchants. In the late 19th century, workmen in the factories on Castle Hill commented that the ground sounded hollow beneath their feet and thought that this revealed the presence of dungeons or undercrofts from the castle (Leader 1875, 218). The castle was clearly on their minds, and they were surrounded by structures inspired by it. In this con- 
text, it is particularly mystifying why, at the beginning of the 20th century, some antiquarians had entered into such debate over the location of the castle (see Chapter 2, Section: Sheffield Castle: where the two rivers meet). It was clear in memory, in place names and in architecture. It infused the place.

\section{Lamenting the loss of the past}

Some 200 years ago, Joseph Hunter reflected on the demise of the castle and what it said about Sheffield's priorities at the time he was writing, lamenting that the ruins had not been

left to time, the slow destroyer; and that we still might have been allowed to trace out the foundations at least of that suite of apartments where the royal captive [Mary, Queen of Scots] pined away the years of her long seclusion; or the hall where the honoured chieftain of former days held his wassel, or the chapel in which he prayed: and that Sheffield, like its neighbour Pontefract, might still have had its ruined towers to attract, delay, and delight the curious traveller. But an active and industrious manufacturing population makes few sacrifices to taste, and does not long endure the near neighbourhood of plots of ground not occupied by what immediately concerned itself (Hunter 1819, 116, emphasis added).

Hunter was not alone in this awareness that the disappearance of the castle from the urban landscape had a negative impact on perceptions of Sheffield. A poem written in 1882 by Francis Buchanan (b.1825), a poet originally from Perth (Scotland) who later moved to Sheffield, was a wistful reflection on the lost castle:

I cannot hail thee, tho' thou liv'st in story,

Thy turrets and thy towers are all gone.

Little is left to indicate thy glory

But old tradition, and this little song.

Spectre of time! Where are thy relics resting?

Where are thy battlements and lordly hall?

Nor vestage here, nor stone with noble crest in,

Nor remnant of a buttress or a wall.

No effigy supreme, however broken.

No tottering gable in the sunlight glow,

No grey remembrance that would be a token

To take us back to ages long ago.

For others, however, the castle was now a valuable marketing commodity. This emerges from a poem published in 1868 in White's Directory of the Borough of Sheffield, Doncaster and Chesterfield, where the ancient glories of the castle have been replaced by 'forests of chimneys [which] make murky the air / With smoke and with smuts that pervade everywhere'. But 'compensation' is nevertheless to be found in the presence of the latest fashionable building nearby:

For hard by the site of the Castle that's gone,

There's a TEA MART as good as the sun hath shone on ...

Haste then thither and cheer, ye! - ye brave sons of toil,

Ye matrons and maids! - all who fret and who moil,

And quiet your spirits, and gladden your lot,

With 'the cup that can cheer and inebriates not!'

The powerful appeal of the castle in the late 19th century was reinforced when the Prince and Princess of Wales visited Sheffield in August 1875 to open Firth Park (a public park about 4km from Sheffield city centre, gifted to the city by the industrialist Mark Firth). Their host, the $15^{\text {th }}$ Duke of Norfolk, Henry Fitzalan-Howard, while willing to accept the profits from his Sheffield properties, seems to have been unwilling to let some of them be seen by royalty. A newspaper report on the visit describes the Don at Lady's Bridge as a 'stream of ink', a 
result of industrial production and waste from the slaughterhouses which poured from the openings of the walls of these Shambles ... poisoning the river and rendering the atmosphere in this vicinity at times almost pestilential' ('The royal visit', 1875, 6); the drains from which some of this waste discharged into the Don were excavated by Wessex Archaeology in 2018 (see Chapter 7). Substantial efforts were made to hide such offensive sights from royal eyes and simultaneously enhance the links of the area, and the city more generally, with the medieval past; this was an interesting approach in an industrialising city, on a royal visit hosted by one of its leading industrialists. The royal procession from the railway station through the town saw triumphal arches constructed at several locations, including Lady's Bridge. Here the Duke commissioned an arch in the form of the turrets and outworks of a castle constructed from wood and canvas, while 'a 30 foot high wall of painted canvas representing an "old baronial castle" was erected at the bottom of Waingate to hide 'the unsightly walls' of the slaughterhouses - some of which, as we have seen, had themselves been built to resemble a castle (Zasada 1996, 27; Figure 9.10). The Lady's Bridge triumphal arch was even to be distressed to appear old, with the Telegraph announcing that it

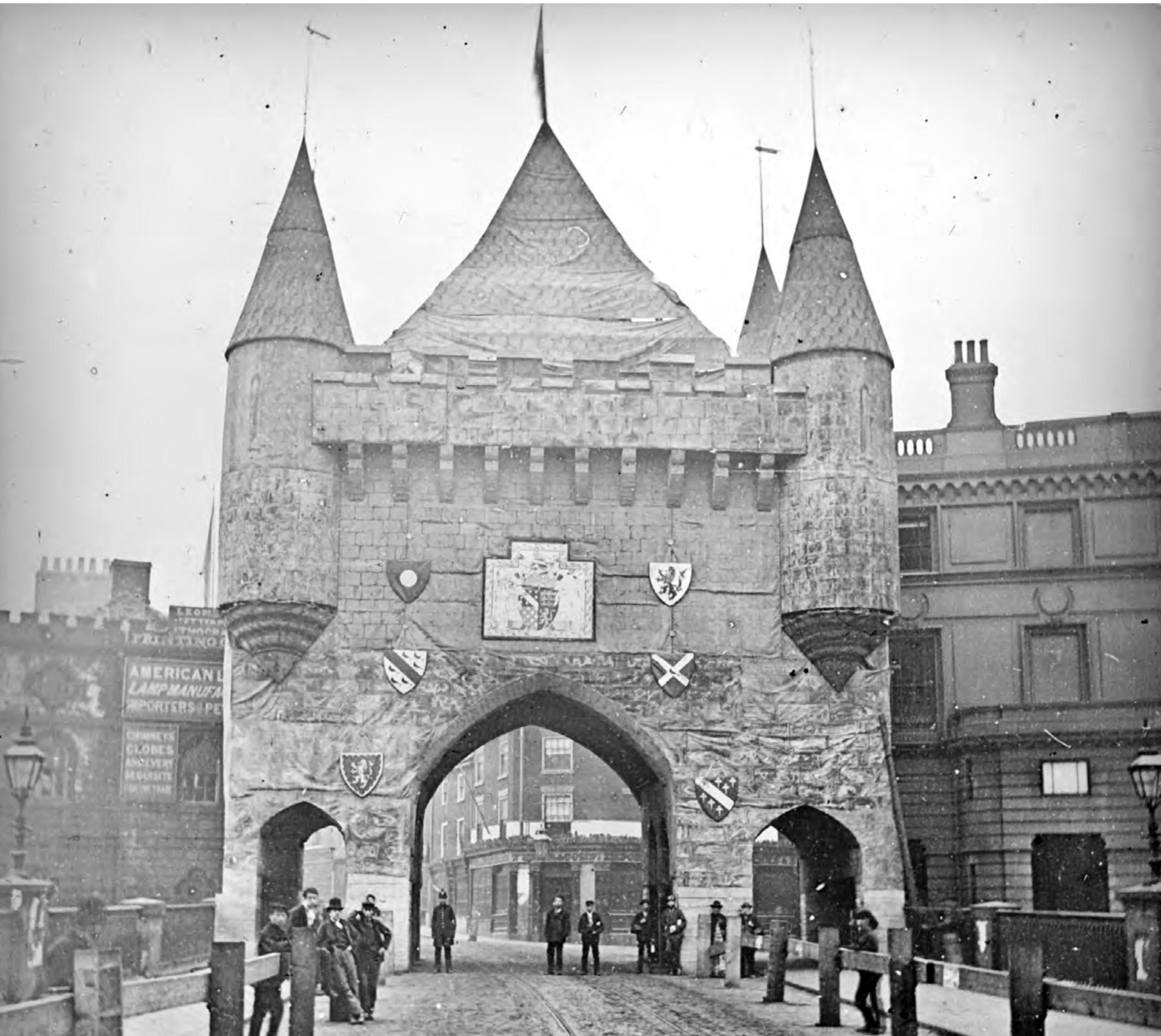


will appear as the bulwark of a castle, or as though the walls from some old fortifications had been transplanted to this spot. It will represent the defences of a castle of the middle ages ... Extending along the upper portions of the arch will be battlements so painted as to appear worn by time and bearing upon their walls the defacing effects as it were of exposure to the elements.

Fountains were constructed on either side of the bridge, with cascades of water pouring down from $30 \mathrm{ft}(9.14 \mathrm{~m})$ above the level of the Don, to distract visitors from the murky water of the river.

The Sheffield Daily Telegraph reported that the decorations were 'characteristic of the architecture of the feudal times when the staple trades of Sheffield were in their infancy, and when the foreign refugees who brought the industries to this locality were protected and cared for by the resident lords' ('The royal visit' 1875, 5). This was a very conscious appropriation of the past, and a recasting of the role of the lords of the manor as a patrician of the community. This was occurring at the very time when the Duke's place in that community was being further questioned as Sheffield Corporation, empowered by the Public Health Act of 1875, began the process of acquiring the centuries-old market rights from him (Zasada 1996, 27; Chapter 1, Section: The castle 'made untenable').

While the castle had long since disappeared from Sheffield's skyline, it continued to fascinate and in 1875 proved to be a valuable tool in both propaganda and regeneration, albeit of the most temporary type during the royal visit. This need for a sanitised version of the medieval past that was represented by the wooden and canvas facade extended beyond the castle, to the hunting lodge, which was simultaneously undergoing renovation that prioritised tearing down of traces of the industrial present (see below, Section: The deer park and hunting lodge: from mining to medieval revival).

\section{Saving the castle remains}

While Armstrong's and Himsworth's archaeological endeavours at the end of the 1920s settled any remaining doubt about the location of Sheffield Castle, they did raise another question - 'once you have found a castle, what do you do with it?' (paraphrased from an article in the Yorkshire Telegraph and Star, 13 $3^{\text {th }}$ October 1927). Leslie Armstrong and the Hunter Archaeological Society played a vital part in preserving the remains of the courtyard buildings and gatehouse, and used local newspapers to highlight the importance of doing so (Himsworth 1927$42,4)$. It was not, in fact, obvious to all that the remains should be preserved, and we know much was lost in the process of construction - 'there has been more destroyed or covered up with concrete that will ever be seen by the public' (Himsworth 1927-42, 4). One local newspaper noted the possibility that all the remains 'should be broken up and carted away' ('A matter of preservation', 1927, 6; see also 'Survey of Sheffield Castle remains', 1927). The Telegraph 'emphatically' rejected this proposal, but others, it seems, did not. Joseph Himsworth had canvassed local opinion about what should happen to the castle remains and was dismayed to find that:

everywhere the reply was, 'we must clear the site quickly as possible and build a market cheaply. Conditions of trade are so bad we can spend neither time nor money and can brook no delay' (Himsworth 1927-42, 5).

However, local pressure, galvanised by Armstrong's advocacy, led to a suspension of 'the threatened demolition for a few days to see if a feasible scheme is forthcoming for [their] preservation' ('Castle site', 1927; 'Sheffield Castle', 1927). Two suggestions were considered at a special meeting of the Hunter Archaeological Society on $14^{\text {th }}$ October:

The first is to preserve the relic in situ, and this could be accomplished by building piers at each end of the site, with girders over, and thus form a sort of alcove in the basement of the new Co-operative premises ... The second is to number all the stones and remove them for re-erection in one of the public parks of the city ('Castle site', 1927).

Figure 9.10 (page 304): Wooden and canvas castle at Lady's Bridge. This was made for the visit of the Prince and Princess of Wales to Sheffield in August 1875. With thanks to www.picturesheffield.com (w00347). 
While one correspondent to the Sheffield Mail argued the merits of the latter scheme - 'it would make the relics more accessible to members of the public' ('Transferring relics', 1927) - The Yorkshire Telegraph and Star disagreed, saying that 'no one with any feeling for history would care for that unless the alternative were the total disappearance of the relics', and summoned the epitaph of Shakespeare in support of the argument - 'Blest be the man that spares these stones'. On $15^{\text {th }}$ October 1927, J. R. Wigfull (1927a; 1927b), Honorary Secretary of the Committee of the Hunter Archaeological Society, wrote to Mr John E. Forster, Secretary of the Brightside and Carbrook Co-op, and to the Mayor of Sheffield, informing them of the following resolution:

This Committee is strongly of opinion that the remains of Sheffield Castle discovered upon the site of the Societies new premises in Exchange Street, should be preserved in situ, and desires to submit a plan showing a definite proposal for carrying out such a scheme without detriment to your building. The Hunter Archaeological Society will guarantee the cost up to sum of $£ 100$ (Figure 9.11; also 'Sheffield Castle relic', 1927).

This 'definite proposal' (or a copy of it), drawn by Armstrong, survives in the Museums Sheffield archive (see Figure 9.12) and shows (in plan and elevation) the gatehouse remains in a sub-basement, accessed by a staircase which opened out onto viewing areas adjacent to the western tower and the gatehouse forestructure. The

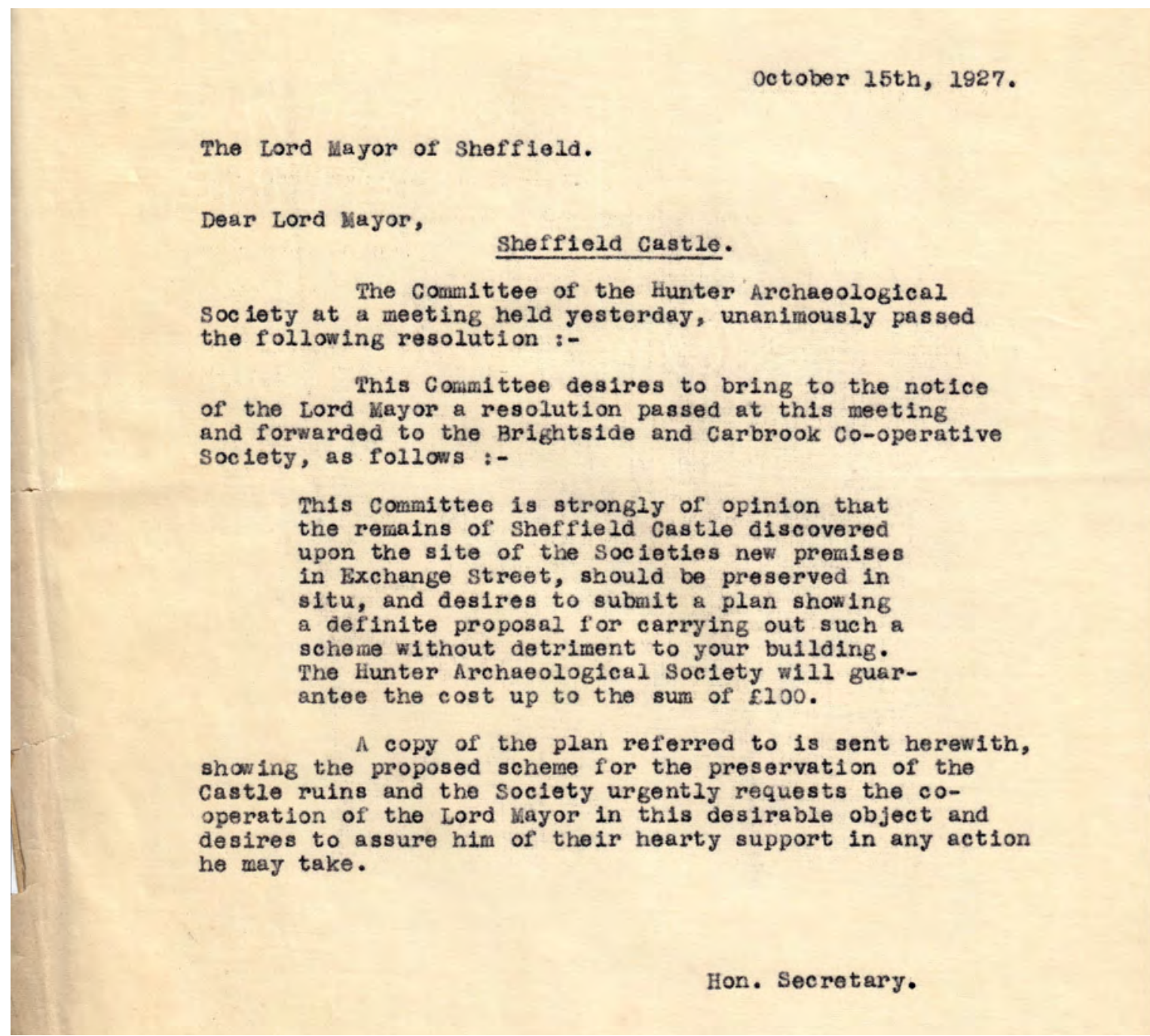

Figure 9.11: Letter written to the Lord Mayor of Sheffield by the Hunter Archaeological Society on $15^{\text {th }}$ October 1927. This advocated for the preservation of the remains of the castle which had been uncovered just days before. Courtesy of Museums Sheffield. 


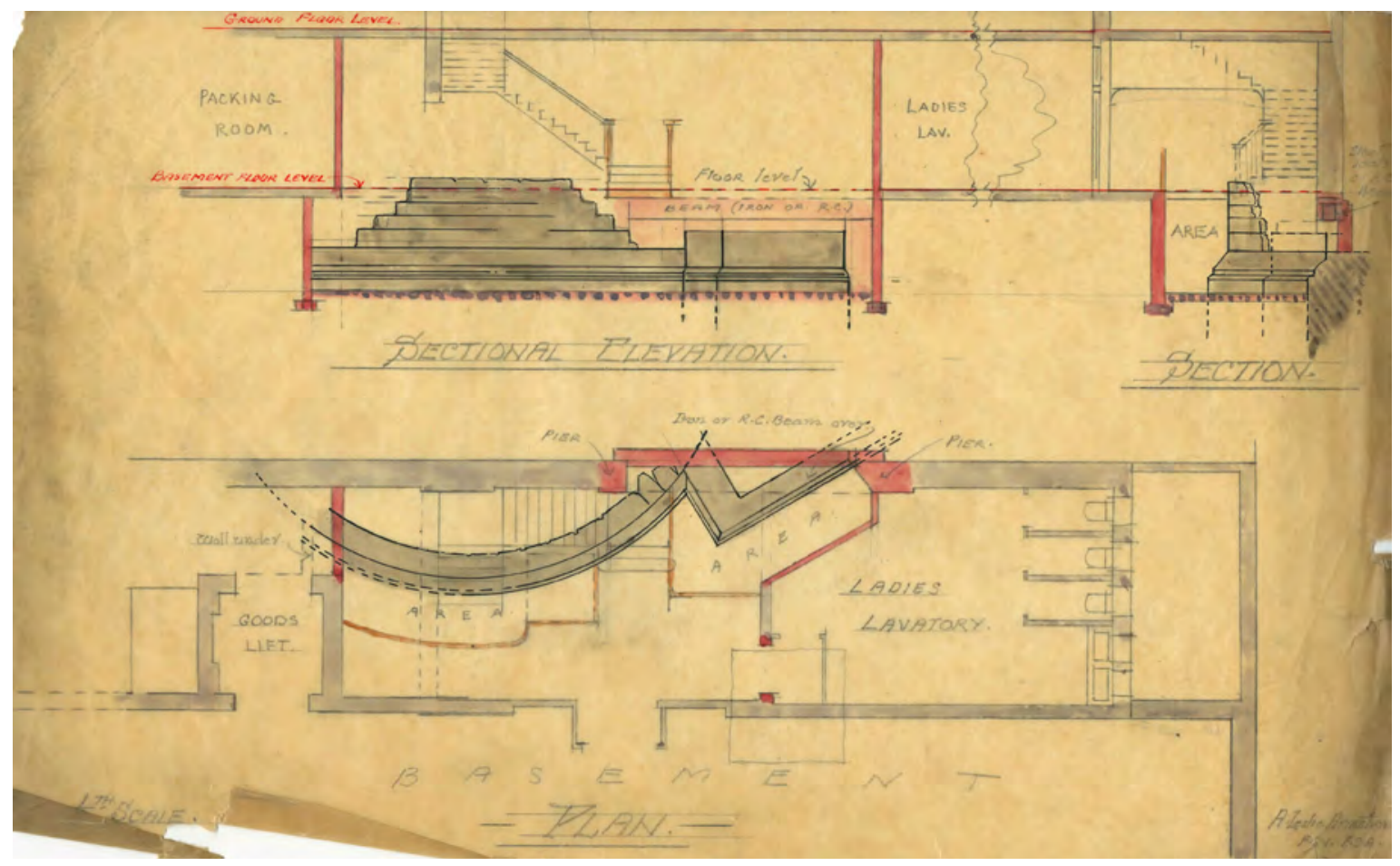

Figure 9.12: Leslie Armstrong's proposal for how to display the gatehouse remains beneath the Co-op building. There were to be viewing areas and it appears that some of the masonry would have projected through the sub-basement of the building. Courtesy of Museums Sheffield.

elevation suggests that some of the masonry of the tower would have projected through the sub-basement floor to be visible as one came down the stairs from the ground floor. If carried out, Armstrong's proposal (while placing the remains at a level below the ladies' lavatory and the packing room), would have made the gatehouse more accessible to the public than anything considered to date. However, this was not to be. In a letter of $10^{\text {th }}$ December 1927, William Johnson, the Co-op's architect (1927a), told Armstrong that he regretted that 'owing to the relative position of the Bastion and the staircase walls and passenger and good lifts ... it will not be possible to leave this portion of the Bastion wall permanently exposed to view'. Essentially rejecting his (and the Hunter Society's) proposal to facilitate public access, Johnson went on to tell Armstrong that 'the remains are to be preserved beneath our basement floor level and their exact position indicated by means of lines on the floor. In his publication, Armstrong noted that 'only such portions were pulled down as actually interfered with the plan of the Stores' (Armstrong 1930, 16), and on his Plan 2 (Figure 3.13) he marked the position of the (comparatively small) section of the excavated remains 'preserved in the basement of the new building' - most of the western tower was 'preserved but buried'; some of it was demolished. As we saw in Chapters 2 and 3, a chamber around the courtyard building was also created beneath Castle Hill Market, and this became the repository for architectural fragments that had been collected during this and subsequent development work (Anon. 1930b, 3; Richardson and Dennison 2014a, 63-5; Himsworth 1935, 8-9; Latham and Atkinson 1994).

The souvenir brochure issued by the Co-op in 1929 portrays their 'palatial' New City Stores as a 'worthy successor' to the castle. But they are also more than that - 'a new Palace', we are told, 'more beautiful than the old castle, has been reared to make new history for Sheffield' (Bingham 1929, 5). Here the Co-op, having rendered the actual castle remains largely inaccessible, appropriated the heritage and tradition of 'the most historic [site] in Sheffield', as well as the actual place itself, for the needs of 20th-century merchandising. And that process of association and appropriation continued. Thus c.1948 G. A. Hampshire, the Brightside and Carbrook Co-op's advertising manager, redesigned the Society's logo to incorporate a 'one tower heraldic symbol' harking back to the 'bastion' towers discovered in the late 1920s (Denton 1946). And when the Co-op moved to their new premises in 1964 they not only called it 'Castle House'; they also commissioned noted Sheffield artist Kenneth Steel (1964) to paint an imaginative reconstruction of Sheffield Castle to hang at its core, in their boardroom, from which they would have been able to see the site of the original (Figure 9.13). 


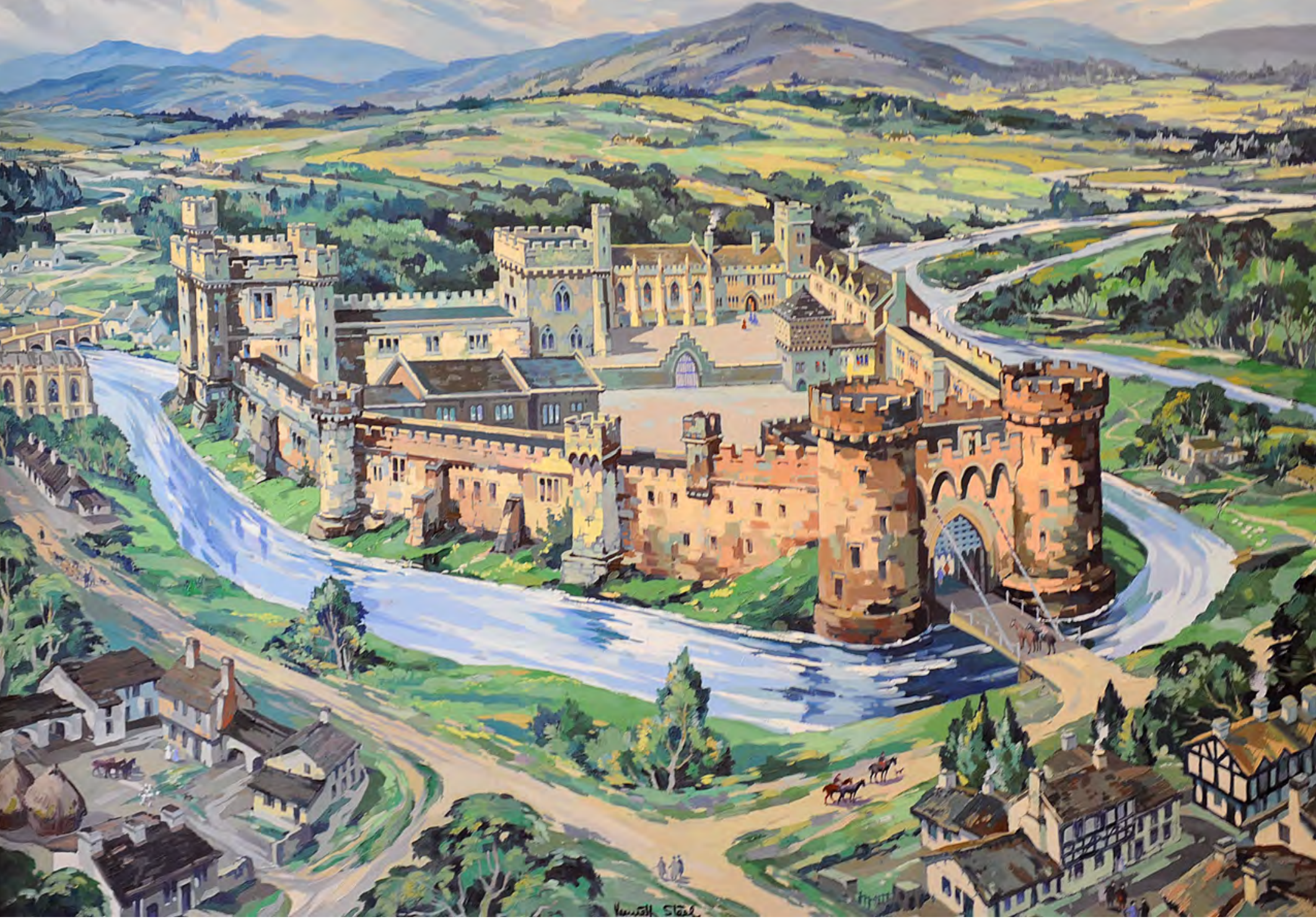

Figure 9.13: Sheffield Castle as imagined in the early 1960s. This painting by Kenneth Steel was commissioned by the Brightside and Carbrook Co-operative Society for the boardroom of their new city-centre building, Castle House. Courtesy of the Co-operative Group.

The rediscovery of the castle generated considerable interest in the medieval and Tudor history of Sheffield. As we saw in Chapter 2, one of the local experts to whom Armstrong turned in analysing finds from the castle excavations was Joseph Baggaley, curator of Sheffield City Museum. Baggaley's involvement with material from Sheffield Castle seems to have sparked his interest in its history, as he went to great lengths to authenticate, and then purchase for the city, a bedstead said to have been that of Mary, Queen of Scots during her imprisonment in the castle. He contacted several organisations to try to establish provenance and raise the necessary funds, including the London art dealers the King's Galleries, which were offering it for sale (Baggaley 1929a and 1929b; Fredericke 1929), the auctioneers and valuers Hadsley \& Co., which assured him that 'there is no question at all, but that the bedstead came from "Sheffield Castle" (Taylor 1929), the Librarian of the British Museum (Baggaley 1929c; Sharp 1929), the Director of the Victoria and Albert Museum (Baggaley 1929d), Sir George Sitwell (1929) in Florence (Bradbury 1929), Birmingham Public Libraries (Anon. 1929a), and the Sheffield Cutlers' Company (Evans 1929). His efforts ultimately came to naught, perhaps because the Victoria and Albert Museum was not able to offer a grant to help meet the purchase price, and he could not be absolutely sure of the bed's authenticity (Baggaley 1929e; Figure 9.14).

It is worth noting that this bedstead was already associated with Mary in 1848 when George Shaw saw it at Brougham Hall, near Penrith (Cumbria), and that, to judge from notes and sketches made (by Baggaley?) on a visit to see the bed, on $14^{\text {th }}$ March 1929, it did bear the Talbot crest (Shaw 1848, 371-2; Gatty 1869, 146, n. 2; 


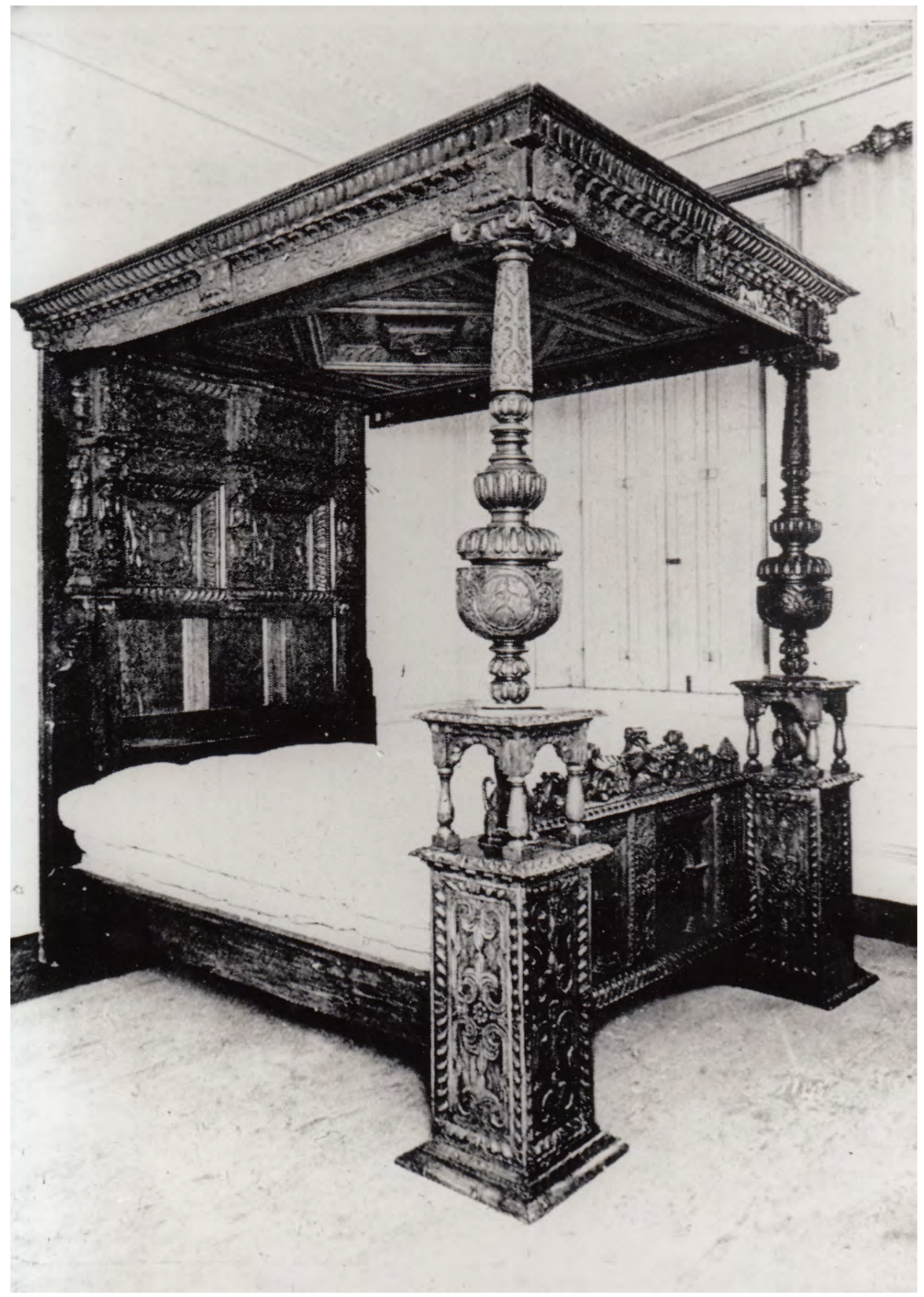

Figure 9.14: A bedstead in which Mary, Queen of Scots may have slept while imprisoned at Sheffield Castle. It is unclear where this was photographed, but it was included among the collection of photographs contained in the Armstrong archive and may have been taken by either Himsworth or Senior. This is the bedstead advertised for sale in The Connoisseur at the King's Galleries, King's Road, Chelsea, London on $28^{\text {th }}$ October 1928, and which Joseph Baggaley was interested in purchasing for the City Museum. Courtesy of Museums Sheffield. 
Anon. 1929a, b). Gatty $(1869,146)$ tells us that the bed was presented to Lord Brougham by James Watt, the famous inventor and engineer. Shaw $(1848,372)$ describes the bed as

a magnificent, ponderous, old bedstead of carved oak, covered thick and thicker with all the heraldries of all the Talbots. It came originally from Sheffield Castle, through various possessors, until purchased by Mr. Watt of Aston Hall, Birmingham, and presented by him to his lordship. How many a tale of romance does this frowning old bed seem cognizant of, perhaps occupied by Mary, Queen of Scots during her long confinement under the Earl of Shrewsbury; her eyes fixed upon the heraldic pomp of her lordly keeper, but her heart far away in her own land of blue mountains, or in gay and regretted France (Anon. 1928; Moreland and Gorman 2019, 11).

In an article published in the Transactions of the Hunter Archaeological Society early in 1929, Charles Drury (1929c) was convinced of its authenticity based on a detailed analysis of the heraldic devices depicted on it.

It might be argued that the discovery of the castle remains and the debates about if or how they should be preserved mark the high point in Sheffield of late 19th- to early 20th-century medievalism - an interest in, and a desire to appropriate, the medieval past. We see this in the medieval triumphal arches that spanned the city streets not only during the royal visit of 1875 but also during Queen Victorias visit in 1897 (Anon. 1897). We see it in the, at times, fevered debate about the location of the aula of Waltheof, in the use of medieval pen names, in the quest to acquire authentic relics, in the appropriation of the castle to the commercial needs of the city (whether a modest tea shop or a 'palatial' store), and in the portrayal of scenes from medieval history on the streets of the city. ${ }^{31}$ As we saw in Chapter 3, this interest stemmed from, and further fed, questions of civic and national identity. But in the decades to come new economic, political and military realities, not least the continued expansion and industrialisation of the city as well as the impact of war, meant that Sheffield's medieval past no longer served the needs of its present, and its physical remains were further destroyed in the construction of Steel City.

\section{The deer park and hunting lodge: from mining to medieval revival}

To place the Castlegate regeneration debate in context, we need to examine the fate of the other main parts of the seigneurial landscape: the hunting lodge and deer park. Both were absorbed into an increasingly industrial landscape during the 18th and 19th centuries, but the medieval heritage of the lodge, in particular, came to be of interest in the late 19th century. More recently, the opportunities offered by the medieval heritage of the lodge and the open spaces afforded within the relict landscape of the park have provided a focal point for an ambitious programme of social welfare and employment creation led by a social enterprise, that is, a business whose profits are reinvested to create positive social change (Social Enterprise UK 2019). As we will see, the history of the lodge and park have rendered them contested spaces into the 21 st century.

\section{The industrialisation of the hunting lodge}

By the early 18th century the hunting lodge had ceased to be a residence for the Dukes of Norfolk, with parliamentary consent for demolition acquired in 1708 (see Chapter 8, Section: Absentee lords and new priorities). Excavation of the rooms behind the south tower of the gateway revealed that they were filled with rubble sealed

\footnotetext{
${ }^{31}$ A series of street names in the western part of the city centre, including Furnival Street, Howard Street, Earl Street, Matilda Street etc., might also be taken as part of this phenomenon. However, they were part of a planned street system created by the $10^{\text {th }}$ Duke of Norfolk between 1771 and 1778 and are more about personal, dynastic memory than civic identity. The names stretch from the Duke himself (who was also Earl of Surrey), through the Furnivals, to the de Lovetots (via Matilda; see Chapter 1) (Walton 2011, 18-19; Harvey 2001).
}

Figure 9.15 (page 311): Etching by unknown artist of the Turret House from the early 19th century. The buildings attached to its north and south sides were removed during restoration in the 1870s. Courtesy of Museums Sheffield. 
by 18th-century deposits, suggesting that the upper parts of these rooms were demolished at this time (Hadley and Harlan 2011, 6). Yet, parts of the hunting lodge clearly remained standing and some of the original structures were reused by the site's 18th-century occupants. The 'Turret House' was converted into a farmhouse, with a series of associated barns constructed between the house and Manor Lane to the south, and a kitchen and other outbuildings to the north (Hadfield 1875) (Figure 9.15). There was also a farm building constructed in the outer courtyard, revealed during excavations in 1972 (Hadley and Harlan 2011, 12-13). By 1738, the potter John Fox (1682-1738) had leased the 'late gallery of the Manor' from the Dukes. An item found in one of the rooms behind the south tower was the base of a 'Dutch Oven' - which would have been set in front of a fire and used to reheat food - inscribed with the initials of Fox and his wife Elizabeth and the date 1715, suggesting that the pottery was set up a couple of decades before it is first documented (Hadley and Harlan 2011, 6; Figure 9.16). The foundations of a large, circular, multi-flued kiln were excavated in the hexagonal tower at the north end of the long gallery in 1971 (Beswick 2002; Burgess et al. 2011). They comprised stone, brick and floor tile from the ruined buildings of the hunting lodge, and were set into the original floor of the tower, and in places the kiln foundations overlay fallen plasterwork from the partial demolition of this building (Hadley and Harlan 2011, 7). The close confines of the room would have been ideal for allowing control of both the draught through it and the temperature to ensure successful firing. The kiln probably had either a clay dome-shaped roof with vent holes, or a chimney, to let the heat escape. The pottery it produced was mottled ware, characterised by its distinctive honey-coloured glaze with dark mottling resulting from the inclusion of manganese or iron oxide in the glaze, and it is one of the most distinctive of local 18th-century vernacular tablewares. It was produced widely from the early part of that century, and the pottery kiln at the hunting lodge is one of the earliest documented such production sites (Beswick 1978; Hadley and Harlan 2011; Cumberpatch 2014b). Clinker - a form of slag produced by the burning of coal - was found over parts of the foundation, indicating that the kiln was fuelled by coal, which is likely to have been locally sourced; as we saw, coal sources are known to have been exploited within the medieval park (Jones 2009, 13; above Chapter 8). Moreover, coal was also

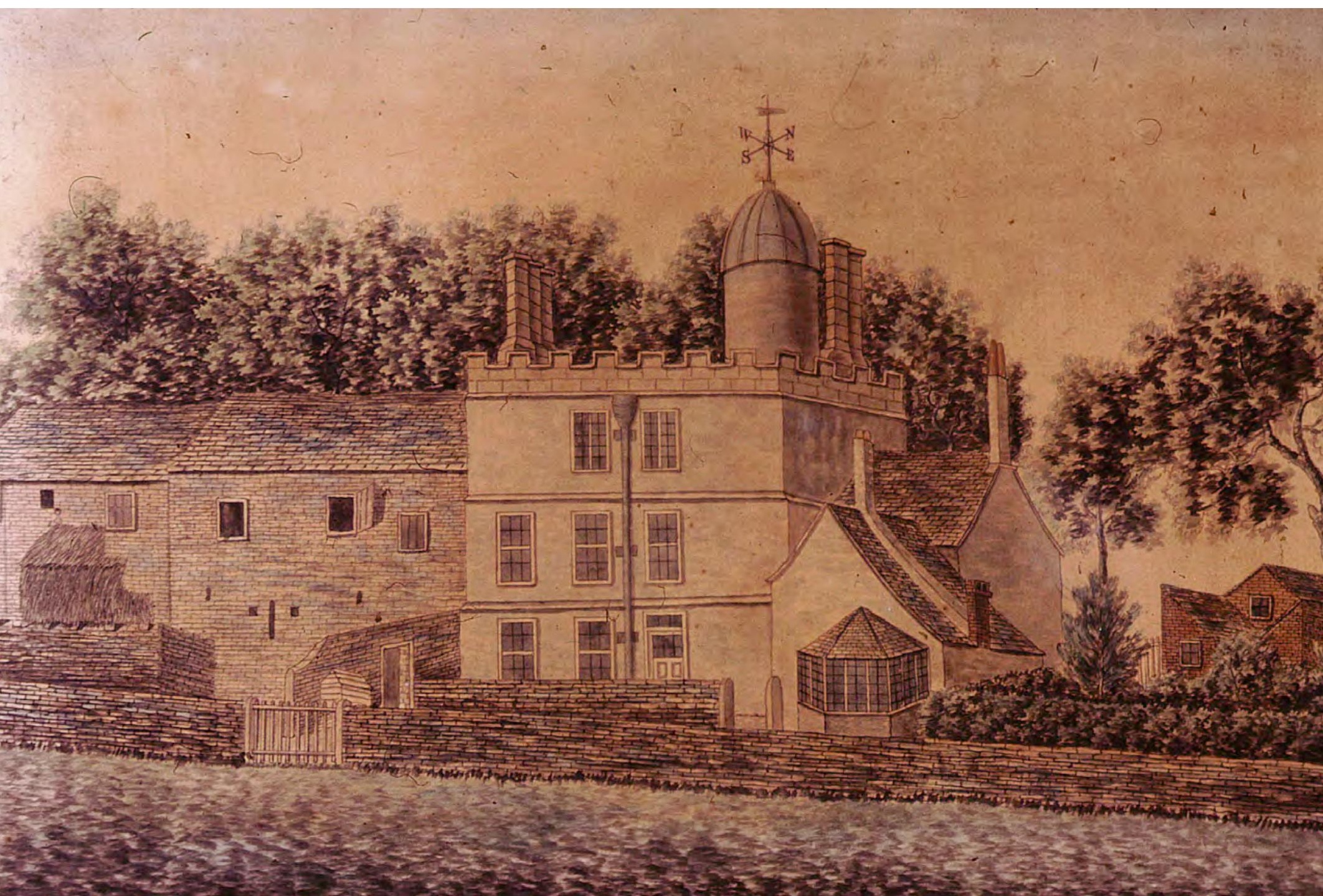



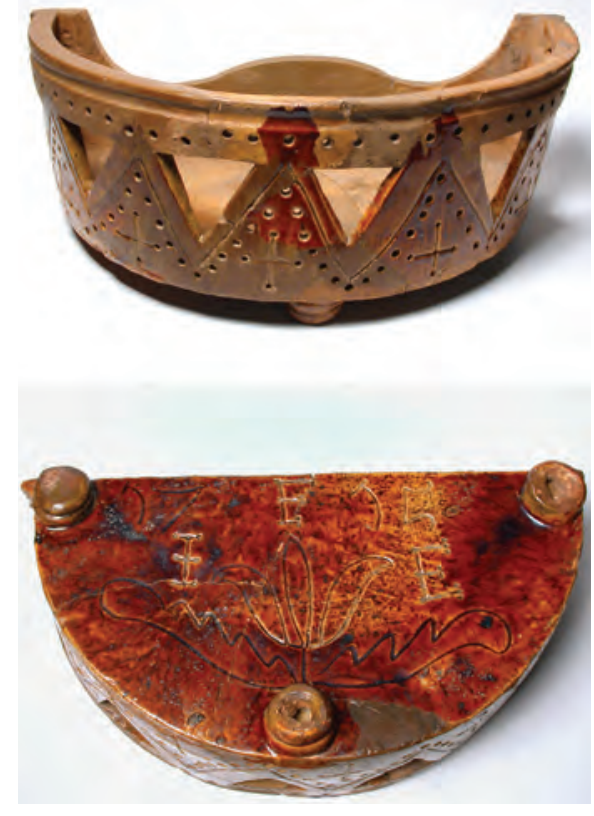

Figure 9.16: Early 18th-century Dutch oven. The remains of a pottery kiln owned by John Fox were excavated in 1971 in the tower at the north end of the long gallery. A Dutch oven, bearing the initials of John and Elizabeth Fox and the date 1715 was found in the remains of one of the storage rooms behind the entrance way into the inner courtyard. Courtesy of Museums Sheffield.

extracted within the lodge itself, as excavations in the inner court in 2010 identified pits dug into coal deposits (Burgess et al. 2011, 59).

Excavations in the long gallery conducted in 1971 and 2010 recovered large numbers of kiln saggars, suggesting that it had been used for associated activities, including perhaps drying the ceramics prior to firing, and storing the fired pots at other stages of manufacture and decoration. In order to adapt the long gallery for use as workshops, parts of the open ground-floor loggia were infilled with stone and brick, and a workshop was added to its eastern side, containing a small brick open-hearth furnace (Burgess et al. 2011, 60; Figure 9.17). Splashes of glaze on the stonework nearby suggest that the furnace was used for the manufacture of glazes.

Cottages were subsequently constructed amid the ruins to provide housing for workers in the expanding mining industry in the park (McCoy 2009; Burgess et al. 2011; Figure 9.18). The nature of these working-class houses, and the activities that took place within them, can be recovered from late 18th- and 19th-century artistic representations, the photographic record from the mid-19th century onwards, architectural analysis and archaeological evidence (Mepham and Powell 2010; Burgess et al. 2011; Crewe and Askew 2011; Crewe and Hadley 2013). A few cottages were free-standing in the inner courtyard, but most were built in to the Tudor long gallery, the service range on the south side of the inner courtyard, or above the gatehouse, while the inner courtyard was divided in to gardens and allotments (Figures 9.19; Hadfield 1875, 110; Crewe 2012, 333-4). A Methodist chapel and school were founded c.1810 (Graham 1914, 42-4), initially occupying one of the cottages but by 1818 were in a building constructed above the remains of the gatehouse, while a pub, the Norfolk Arms, was opened in the service range in 1819 (Hudson 1874, 37). Joseph Hunter $(1819,191)$ lamented the incursion of the 'poorest of the poor', what he called 'a new species of inhabitant', and the consequent proliferation of buildings that had so altered the layout of the site that it was impossible to recover the exact arrangement of [the Lodge's] various apartments' or to determine 'the particular appropriation of some which remain entire'; photographs, drawings and paintings of the 19th century confirm the extent to which the former lodge had been appropriated. The three brick cottages built against the south end of the long gallery west wall were of two storeys, one with two rooms on each floor, the other two comprising just a single room at each level, although there is also evidence for an attic room. Fireplaces had been constructed in the cottages, the largest of which had a brick cellar. Further north in the long gallery brick walls had been constructed between the bays of the ground-floor loggia, making use of the Tudor timber framing. There is little indication from architectural analysis of staircases in the smaller cottages, and the upper floors were therefore probably accessed via ladders (Burgess et al. 2011, 61-2). 


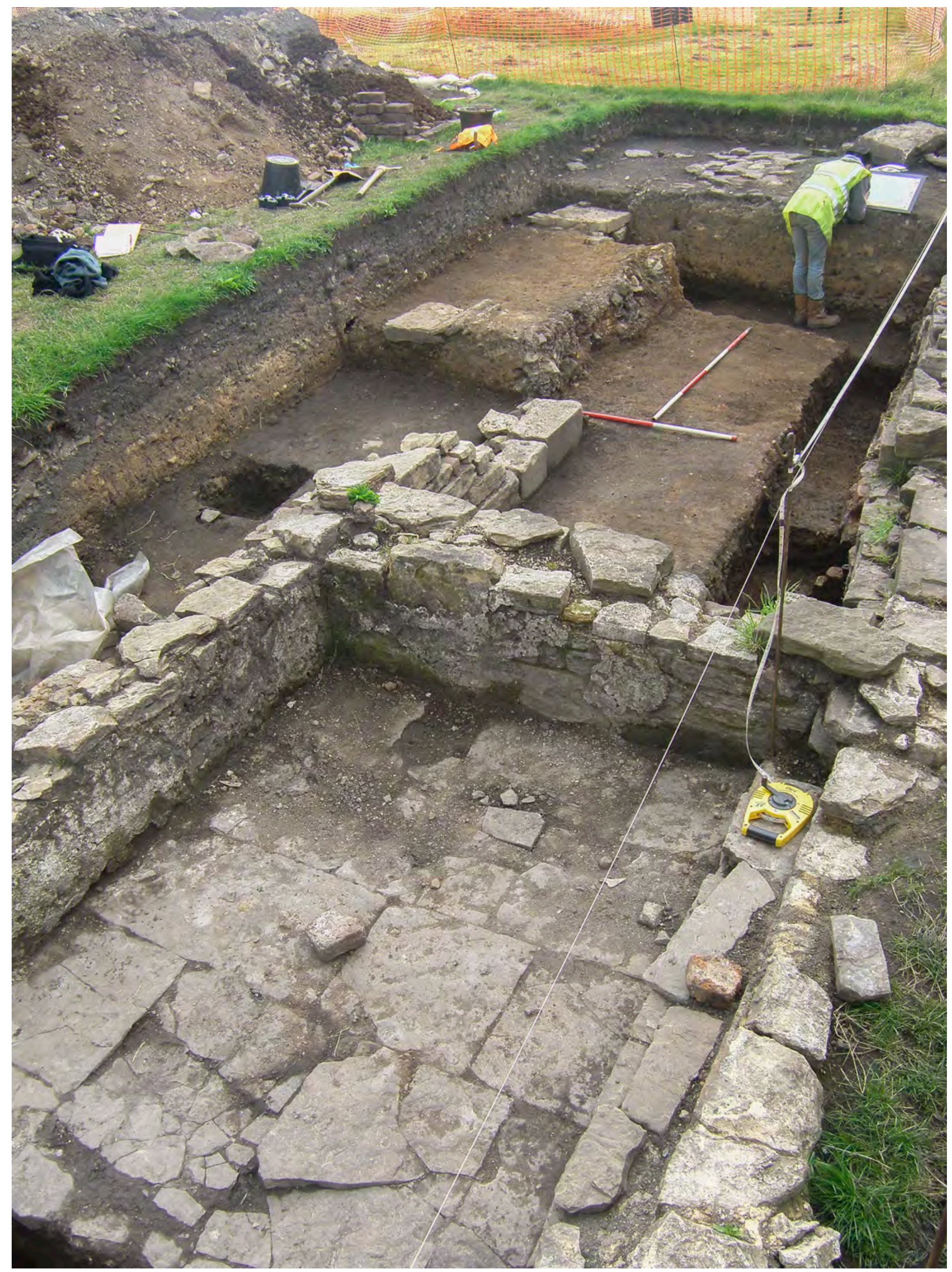

Figure 9.17: Workshop added to the east side of the long gallery in the 18th century for use in pottery manufacture. Wessex Archaeology. 
Excavated assemblages and census returns reveal the range of activities that were undertaken at the former hunting lodge in the 19th century, when the community typically comprised around 20 households. For example, the occupations listed in the census returns for 1861 are mainly miner, coke burner, colliery engine tenter, labourer, blacksmith, white metal smith, table knife cutler, shoe maker and blade joiner (Crewe and Hadley 2013, 90), and metalworking debris and evidence for bone working was recovered from the cottages during excavation (e.g. Crewe and Askew 2012, 23, 33). It was a community infamous for engaging in such vices as 'Sabbath-breaking, swearing, drunkenness and cock-fighting' (Staniforth 1858, 48) and castigated as 'a godless and cursing rabble' (Tyerman 1856, 11). The occupants of the lodge became a focal point for competing social dynamics, with the Methodist preachers and publicans vying for influence over the occupants; this is ironic given that their landlord was the most prominent Roman Catholic member of the English aristocracy.

\section{Restoration of the lodge: return to the days of the Earls of Shrewsbury}

The 19th century witnessed increased antiquarian interest in the historic buildings of the hunting lodge, but this was often to its detriment. For example, in the 1830s local cutlery magnate and 'admirer' of Mary, Queen of Scots Samuel Roberts took stone from the hunting lodge to build 'Queen Mary's Bower' in the grounds of his house. This was known as the Queen's Tower, built in the park in Tudor Gothic style in 1837. From the lodge he took part of a wall and a mullioned window said to have been associated with Mary, Queen of Scots, doubtless to enhance the prestige and historical associations of his home (Thomas 1844, 43; Pawson and Brailsford 1971, 23; Lea 1945; Clark and Jack 2002, 6-7; ICOSSE 2005, 70; Figure 9.20). By the 1870 s the $15^{\text {th }}$ Duke of Norfolk, Henry Fitzalan-Howard, appears to have had a change of mind over how to use the site of the hunting lodge, and the process of removing the labourers who occupied the site commenced. In 1872 the tenants of the Turret House were removed after the Duke appointed the architect Charles Hadfield to oversee the restoration of the building, including the removal of later structures and restoration of the plaster ceilings (Hadfield 1875, 111; Clark and Jack 2002, 7; ICOSSE 2005, 72-3). Hadfield commented on the difficulty of the task, complaining that the cottages, 'squalid and rickety ... like parasites', had obscured much of the original fabric, thereby making it almost impossible to distinguish from later developments on the site, although John Leader (1874, 50) asserted that 'only where absolutely necessary has new material been introduced' (see also Hadfield 1875, 111; Crewe 2012, 335). The work involved restoring the timber partitions within the Turret House, those on the ground floor being replaced with brick to bear the weight of the upper floors. Other work included bricking up an additional entrance to the tower, although parts of the door jamb were left in situ (Hadfield 1875, 111-12). Many of the fireplaces had survived, merely being concealed by later development, but the plaster ceilings, damaged by rainwater and lime wash and attached to rotten beams, were carefully restored to what was perceived to be their original condition (Hadfield 1875, 112; Figure 9.21).

While this restoration is clearly another aspect of the medievalism discussed earlier, the immediate context seems to have been the impending visit of the British Archaeological Association in 1874, for which the Duke was invited to act as President. The members of that organisation were brought on a visit to the site, led by local historian John Leader; here they must have been faced with the peculiar juxtaposition of one of the oldest and most high-status buildings in Sheffield just yards from a pithead and the ramshackled houses, chapel and public house of the mining community (Burgess et al. 2011, 5). This was not lost on Leader. In his published report, which presumably reflects the tenor of his guided tour and the everyday racism of the time, he decried that

Figure 9.19 (page 314): Cottages amidst the ruins of the hunting lodge in the late 19th century. In the range of buildings above the former entranceway into the inner courtyard was a Methodist chapel (in the white building). The pithead is visible on the left-hand side of the photograph, beyond the long gallery. Courtesy of Museums Sheffield. 


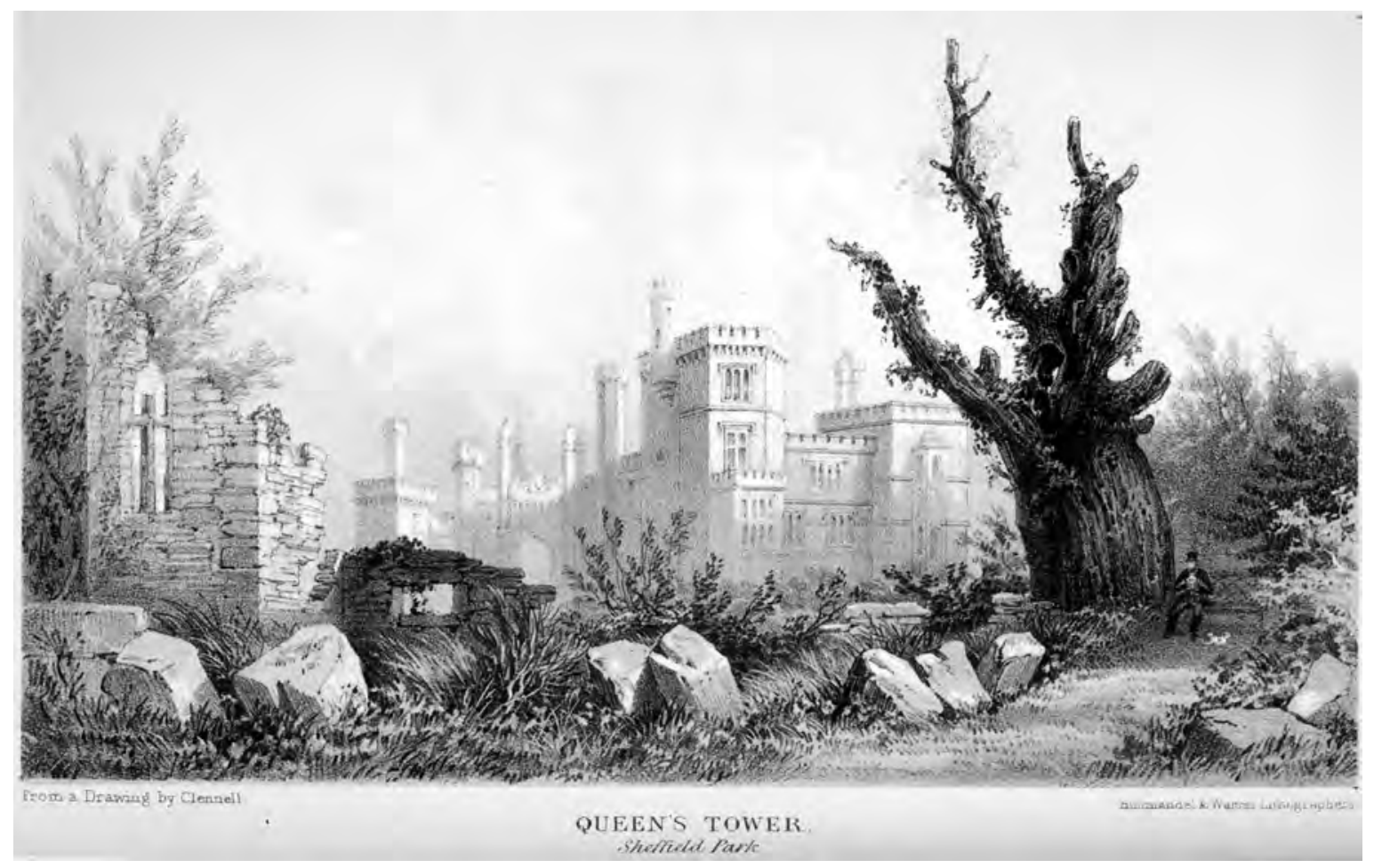

Figure 9.20: Queen's Tower. The home of Samuel Roberts, built in the 1830s. A window said to have been associated with Mary, Queen of Scots was brought here from the hunting lodge. This drawing shows the juxtaposition of the house and the ruins in the garden, a proximity through which 'ancestry' was constructed. With thanks to www.picturesheffield.com (y01107).

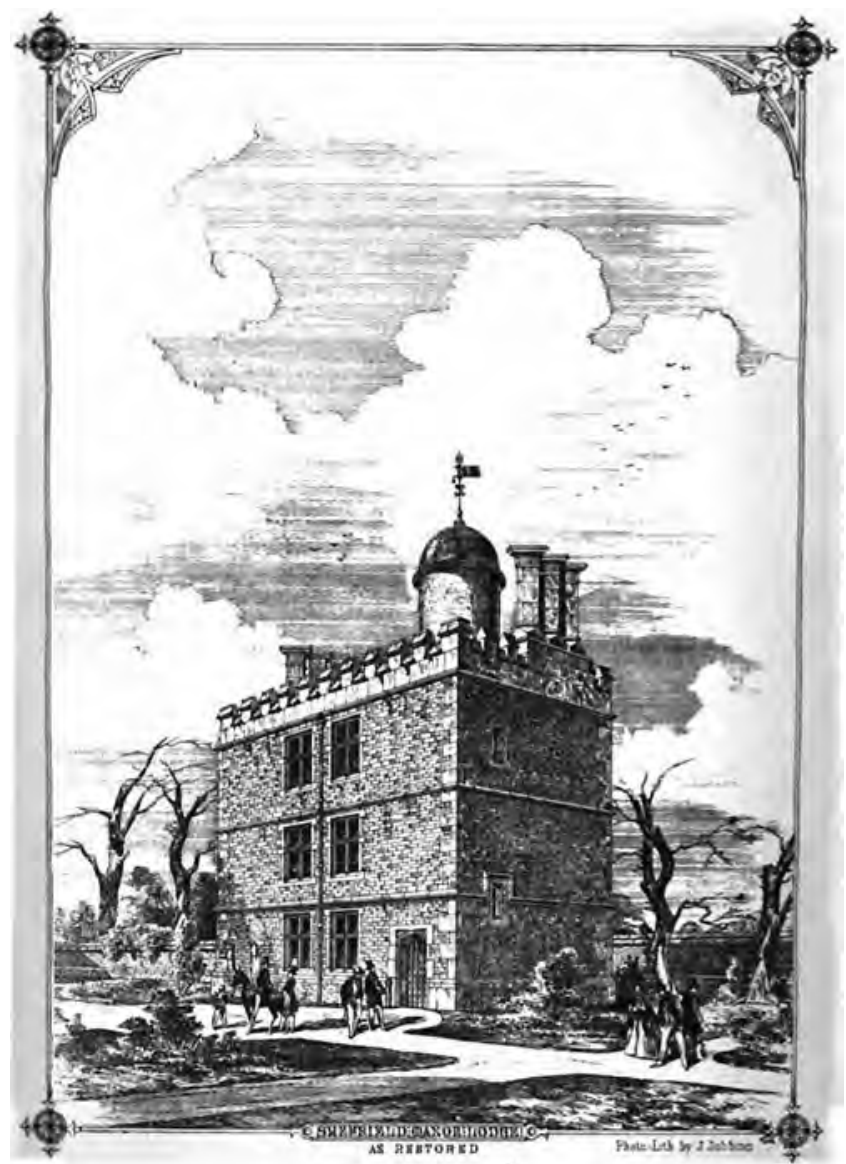

Figure 9.21: The Turret House. As it was to appear following refurbishment by the Duke of Norfolk's architect Charles Hadfield. Source: Hadfield 1875. 


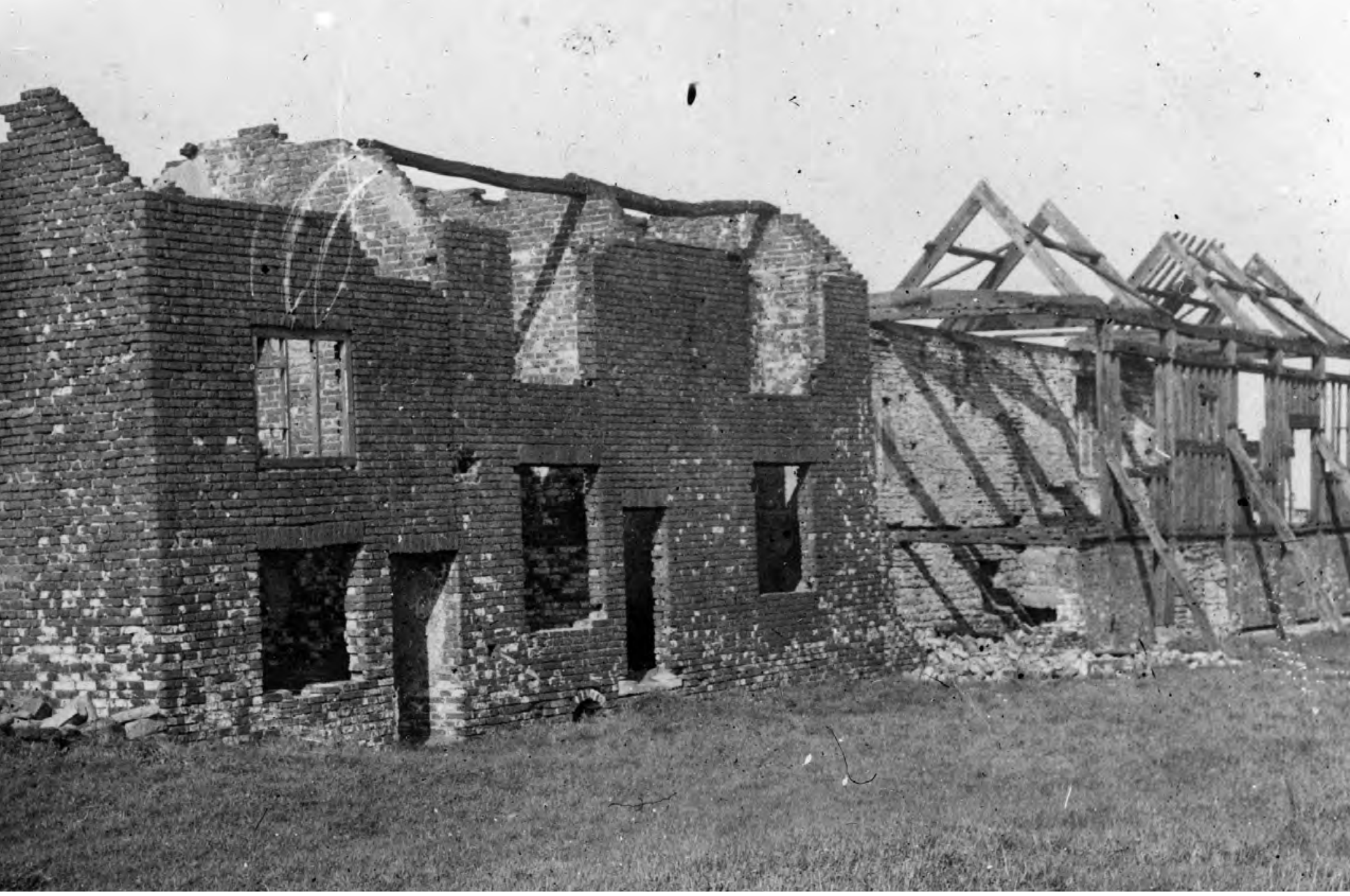

Figure 9.22: Cottages built into the ruins of the long gallery. Within a few years the brick cottages on the left were demolished and the Tudor timber framing to the right was removed. With thanks to www.picturesheffield .com (s05244).

anything more squalid, more wretched, or more dangerous than the dwellings that have been formed out of its remains it would be difficult to conceive. Its smells excel those of Cologne in strength and variety, while the association of ancient luxury with modern filth is quite Egyptian in its character and thoroughly Irish in its details (Leader 1874, 42).

It is pretty clear from this what the learned attitude in Sheffield was to the current occupation of the lodge at the end of the 19th century.

Over the coming years the rest of the tenants were removed and any structure not deemed to be associated with the Shrewsbury occupation was demolished; the Norfolk Arms closed in 1902, and by 1907 a fence had been erected around the site to restrict access (Clark and Jack 2002, 7; ICOSSE 2005, 74-5; Figure 9.22). The 'restoration' of the site was doubtless hastened by the closure of Manor Colliery in 1896 (ICOSSE 2005, 75). Again, however, a visit by the British Archaeological Association in 1903 may have been the prompt to this repair and 'restoration' of some of the buildings at the hunting lodge. This emerges from Robert Leader's (1904, 48) report, in the proceedings of the British Archaeological Association, on the visit to the lodge, updating members on what had transpired since their visit:

It will be gratifying to the members of the Association who recently visited the ruins of the Manor House, to learn that their condition having been brought to the notice of the Duke of Norfolk by his agent, Mr. Henry Coverdale, his Grace has decided on the removal of the modern additions, and the conservation of so much of the ancient buildings as can be preserved. This work is now being carried 
out under Mr. Coverdale's instructions by the writer, his Grace's local architect and surveyor. The whole of the modern additions are being removed, and where there are gaps in the stone walls they are being built up in brickwork, so that there may be no fear of their being mistaken for old work. In two or three cases, the removal of modern chimney-breasts have disclosed the existence of ancient fireplaces in situ, and in one case an ancient doorway and a small window were found behind a chimney-breast.

Paradoxically, the desire to restore the lodge to its original state seems to have resulted in much medieval and Tudor fabric being torn down; whether this was through ignorance of the antiquity of the features is unclear. However, the dismantling of the timber framing of the long gallery can hardly have been accidental; lack of resources or skills to maintain it may have been a factor. Since the ground-floor loggia had been filled in with brick walls to create workers' cottages, perhaps this confused the 'restorers' into tearing it down. Many of the remaining oak timbers around the east gate, south front and long gallery, were also removed during this period (Beswick 2002, 1.4.4.3). It is a profound irony that, while professing their interest in preserving them, the combined influence of archaeologists, architects and the custodians of the medieval heritage of Sheffield in the guise of the Norfolk estate succeeded in destroying some of the most important historic remains in the city. But we should also note that the Duke's 'restorers' did not work in isolation. Across the country, the desire to return medieval, and later, buildings (especially churches) to their original form resulted in what the great antiquarian and architectural historian, the Reverend J. Charles Cox $(1897,239)$ called 'the shocking and irreparable destruction of much that is ancient, brimful of interest, and fragrant with the memories of the past'.

\section{Changing priorities for the former deer park}

Not only did the lodge become home to a working-class community, but as we saw in Chapter 8 the former parkland around it was increasingly devoted to agricultural and industrial activities. A 1795 map of Sheffield parish by William Fairbank junior reveals that the park that had been subdivided into numerous smaller closes (May 2008, 11; Fairbank 1795), and the late 17th and 18th centuries saw several new farmsteads constructed. For example, Ash House Farm, on the south-west side of the park, is of 18th-century date but associated with two barns dendrochronologically dated to the late 17 th century, which were contemporary with a cellar located beneath the farmhouse, suggesting that it also had late 17th-century origins (Lee 2007). Manor Oaks Farm, located $c .1 .5 \mathrm{~km}$ north of the lodge, comprises buildings dating to the late $17 \mathrm{th}$ and $18 \mathrm{th}$ centuries; it was constructed in the area described by Harrison as the Warren and is recorded on a 1794 map as Warren House (Douglas and Jessop 2007). As already noted, the Turret House at the lodge was converted into a farmhouse in the 18th century, with outbuildings built up against either side of it, while excavation in 1972 revealed a substantial farm building, perhaps a barn, in the outer courtyard, dated by associated finds to the 18th century (Hadley and Harlan 2011, 12-13).

Coal mines recorded in the 18th century were the Sheffield Park Colliery, from a which a wagon-way of oak and beech was laid running $13 / 4$ miles $(2.82 \mathrm{~km})$ into the town, and Manor Colliery, where the renowned mining engineer John Curr was employed from 1778 (Medlicott 1983; Figure 9.23). Curr highlighted the financial perils faced by the mining operation there: transport costs had increased, geology meant that the coal was now more expensive to mine and the quality of coal had also decreased, and, as a result, he forecast that in just two years the mine would be operating at an annual loss of $£ 250$. With such heavy losses, the lease was surrendered back to the Earl on $25^{\text {th }}$ March 1781, and over the next 24 years there was investment in new mines and equipment to return mining to profitability; such was their success, many of the innovations adopted by Curr were later employed at other coalfields (Medlicott 1983, 52-3). The opening of an iron furnace in 1784-5 by Booth and Company further increased coal production, from just over 16,000 tons in 1783-4 to over 20,500 tons in 1784-5 from Sheffield Park Colliery alone. However, the overall trend during this period was for a decline in revenue as wages and materials increased, a series of wars disrupted trade and coal decreased in popularity (Medlicott 1983, 55-7).

Following their lease to the Sheffield Colliery Company in 1805, the mines of the former deer park continued in operation for the next century, contributing to the Duke of Norfolk's estate's 'virtual monopoly of coal supplies to the town before 1819' (Simmons 1997, 409). Shafts were sunk across the park, and around 1840 the commencement of Manor Castle Colliery led to a 142m shaft being opened to the rear of the lodge near Wolsey's Tower, probably initially for ventilation rather than coal extraction (Bayliss and Hague 1997; Clark and 


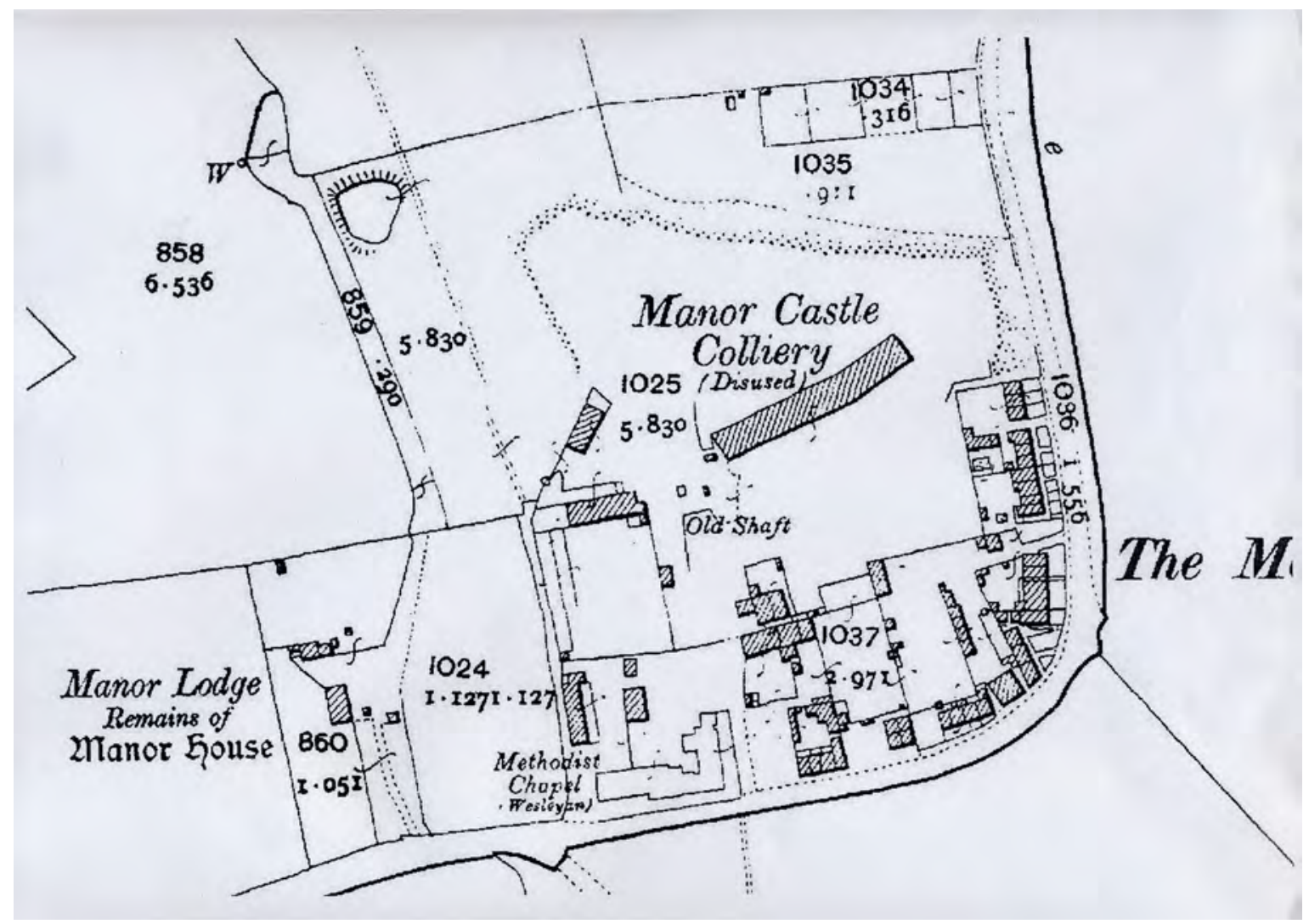

Figure 9.23: The site of the hunting lodge on the 1903 OS map. The disused Manor Castle Colliery is depicted behind. Source: University of Sheffield map collection.

Jack 2002, 6; ICOSSE 2005, 69). The colliery continued in operation for just over 50 years, closing in 1896, at which point the last of the workforce that lived at the remains of the lodge transferred their labour to Nunnery Colliery at the north end of the former park (Clark and Jack 2002, 7).

Some indication of the transformation of the park into an industrial landscape emerges from the 1820 poem by John Holland, which we introduced in the last chapter. This celebrates the park as it may once have appeared - or as he would have liked it to have been - but juxtaposes the ancient splendour with the current industrial usage. Aside from writing that 'poverty resides where wealth has been', Holland $(1820,7)$ also captures the mixed usage of the park at the start of the 19th century:

The woodland, waving o'er the landscape's pride;

The mansions scatter'd o'er its sloping side;

The cornfields, yellow with autumnal wealth;

The meadows, verdant with the hues of health;

The lifeless walls which intersect the fields;

The quick-thorn hedge, which now its fragrance yields;

Yon neighbouring town, capp'd with its cloud of smoke;

The ceaseless sound with which the calm is broke (Holland 1820, 4)

The poem mentions mines, a furnace near the Don, a foundry used to make cannon and coke ovens situated on the western edges of the park (Holland 1820, 10, 16, 31). Holland $(1820,17)$ also recalled that hops had once been grown in the park, a practice that had ceased since his boyhood but which had been memorialised in cottages known as the Hop-houses. Throughout the 19th century, the park continued to be exploited for its natural resources; a geological map of 1855 depicts small sandstone quarries for extracting building material 


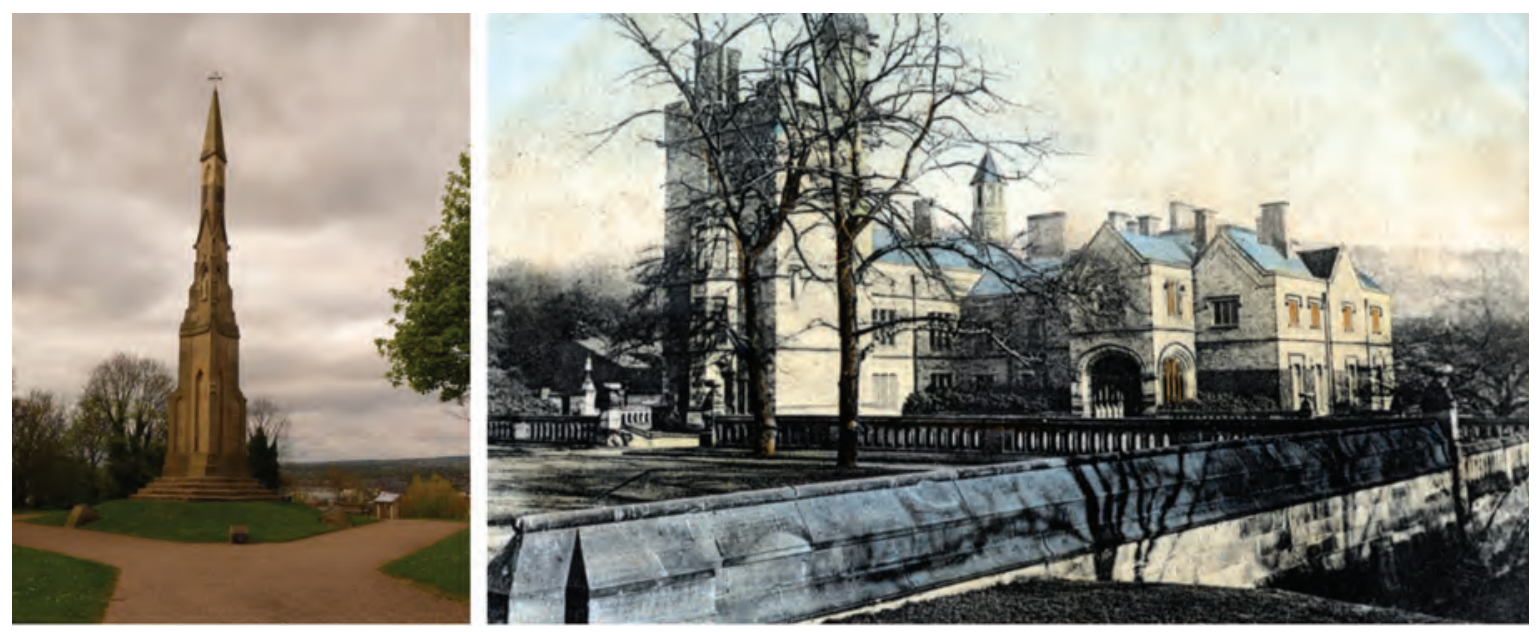

Figure 9.26: The cholera monument and The Farm in Norfolk Park. The plaque erected at the cholera monument (left) reads: 'This monument was erected to the memory of 402 persons who died from Asiatic Cholera during the epidemic of 1832 \& were buried in these grounds. The total number of persons attacked by the disease was 1347 - and among those who died was The Master Cutler for the year Mr John Blake. The foundation stone was laid by James Montgomery, the poet 11th Dec 1834. The Monument was completed and the top stone placed in position 11th April 1835. @ Chris Downer; reproduced under a CC BY-SA 2.0 licence geograph.org.uk/p/1903709. On the right is The Farm, the home of the Duke of Norfolk, when resident in Sheffield, built on Granville Road in the former deer park. With thanks to www.picturesheffield.com (s05291).

to build new homes (Malpass 2000). Sheffield City Corporation was encouraged to improve the poorest quality housing in the city, which included the areas around Lady's Bridge and the Wicker in the immediate vicinity of the former castle, and in the park (Hey 1998). And this locale inspired not just the name of the estate but many of the street names as well - Queen Mary Road, Wulfric Road, and (as we saw in Chapter 3) Waltheof Road (see Harvey 2001). Initially proposed as a development of 3,754 houses, schools and two shopping centres, the Manor Estate was extended after World War II, when the area surrounding the lodge was purchased by the Sheffield City Corporation from the Duke of Norfolk in order to build further houses (ICOSSE 2005, 75-6; Figure 9.27).

The new homes were taken up enthusiastically, and the space and views afforded by building in the former deer park were greatly desired. However, no sooner had communities moved in than they were faced with problems arising from insufficient employment opportunities or school places for families. Unemployment hit this estate hard in the 1980s, and by then it was the most impoverished district in Sheffield and one of the most disadvantaged in the UK (McCaffrey 2007).

\section{Archaeology and social enterprise in Sheffield Park}

A renewed desire to restore the hunting lodge, explore its archaeological remains and open it to the public began after 1955, when Sheffield City Council obtained the site from the Duke of Norfolk's estate on a 999-year lease. A stone mason was commissioned to conserve and consolidate the ruins; from 1965 he lived on site in a house constructed especially for his convenience (Beswick 2002, 1.1). Over five years from 1966 houses surrounding the site were acquired and demolished to try to provide the lodge with something of its original rural setting (Beswick 2002, 1.1; Clark and Jack 2002, 7; ICOSSE 2005, 77). This is the period when the archaeological investigations discussed in Chapter 8 were instigated by the City Museum, and when local interest in the site's heritage began to be revived, although little was to come of this at the time (Anon. n.d. (b)). A critical development was the foundation in 1997 of the Manor and Castle Development Trust, a community initiative 

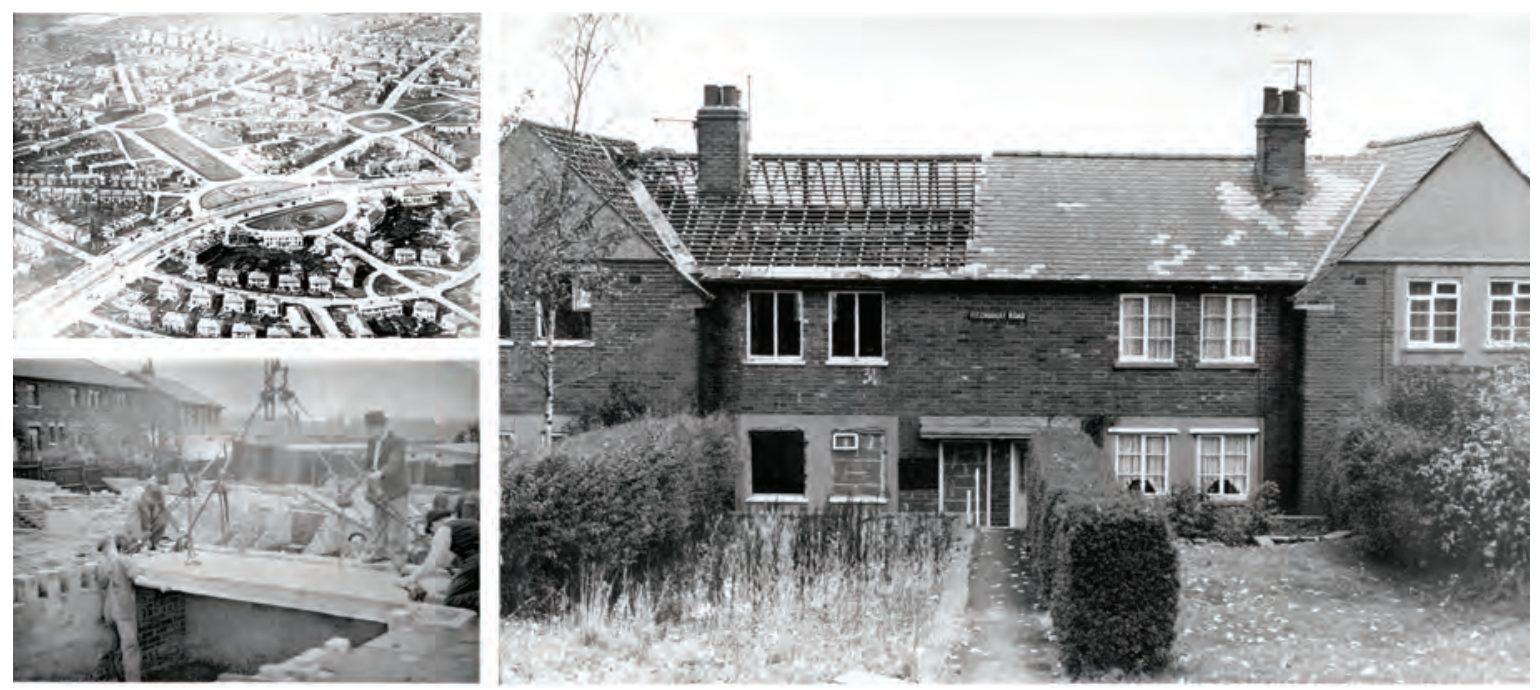

Figure 9.27: The Manor social housing estate. Photographed from the air (top left). Resumption of house building after World War II in 1946 (bottom left). Council house awaiting demolition in the 1980s (right). With thanks to www.picturesheffield.com (w00513; s12635; u04953).

to promote regeneration of the Manor, which has successfully managed projects funded by the City Council, private organisations, the European Union and the Heritage Lottery Fund. In its own words, it has fostered a variety of initiatives 'to improve the lives of people who live and work in our area', by raising aspirations, creation of employment opportunities and training, improvements to services and to the physical environment (Manor and Castle Development Trust 2019).

One of the key initiatives to emerge from the work of the Manor and Castle Development Trust was the creation of Green Estate, set up in response to one of the seven strategic initiatives of the Trust, focussing on environment and heritage, and was a collaboration with Sheffield City Council and the Sheffield Wildlife Trust (France 2006, 6). Initially supported by government funding (the Single Regeneration Budget (SRB) scheme), the aims were to address issues deriving from poor-quality open space and social exclusion and to re-build social capital in a way that would create a lasting legacy after grant funding' (Green Estate 2019). In 2004, Green Estate was reconstituted as a social enterprise, focussing on urban space regeneration. Aside from improving the quality of the open spaces of the former deer park through an initiative called Pictorial Meadows in collaboration with Prof. Nigel Dunnett of the University of Sheffield's Department of Landscape Architecture, Green Estate set out to transform the hunting lodge ruins as a visitor attraction and as a basis for providing training and education. In this, their aims coincided with those of a community heritage group, the Friends of Sheffield Manor Lodge, which had also been striving to promote the history of the site, and secure funding to preserve and promote it since 1996. Both the Friends (in 1997) and Green Estate (2003) tried, and failed, to secure funding from the Heritage Lottery Fund (HLF), with the unsuccessful applications foundering on the scale of the task and the perception that it was too ambitious for the nature of the organisations involved. However, thanks to the SRB funding a range of investigations were able to be carried out on the condition of the historic remains (e.g. Clark and Jack 2002) and an ecology survey (Rotherham et al. 2001). With all of the necessary preparatory work conducted, a successful HLF application was submitted in 2006, which secured $£ 1.5 \mathrm{~m}$ of funding to develop the site as an educational and community resource and to develop it as a visitor attraction.

A visitor centre was built, opening in 2007, and a programme of renovation and landscaping commenced, with archaeological work conducted by ARCUS and the University of Sheffield providing the required recording prior to development and also presenting new information for the visitor centre (also Chapter 8). The creation of two Virtual Reality models based on our recording of the buildings at the lodge presented views of its appearance in both the Tudor period and the 19th century and featured in the early years of the visitor 
This study emphasised the impact that austerity has had, on an international scale, on regeneration initiatives since the global financial crisis of 2008, noting that this has made community-based initiatives ever more vital

in addressing deprivation in the future and in stimulating recovery, given that central and local governments' ability to support economic and social improvement is increasingly compromised by budgetary stringency. And so society looks to the third sector, via a cocktail of social enterprise, community businesses and charitable organizations, or hybrids of these variants, to plug the gap where market and state have failed [or been unwilling] to address manifest need. At the same time, of course, financial stringency impacts also on these types of organization ... and on their ability to offer adequate provision (Bruce and Clarson 2017, 90).

This account resonates closely with developments in that other nodal point in Sheffield's medieval seigneurial landscape. The need for local initiatives has characterised the efforts to regenerate the Castlegate district of Sheffield, home to the castle, and this is the focus of the remainder of this chapter.

\section{Back to the future: Castlegate}

If the regeneration of the former deer park has been something of a success and has shown how heritage can play a key role in this, the same has not yet been true for the site of the castle. As we saw in Chapter 1, ever since the City Council began to plan for the redevelopment or relocation of Castle Market in the 1990s there have been attempts to develop strategies for the regeneration of the Castlegate area. Funding has been difficult to come by, and the remains of the castle have repeatedly been cited as both an aid and an impediment to future development. While there were multiple reviews of the archaeological archives between 1998 and 2014, often with a view to supporting regeneration initiatives, the resources and wherewithal to analyse and publish the evidence from the earlier excavations could not be found until the present volume. This book has not been undertaken in an academic vacuum but rather has emerged in the context of a growing local effort to formulate regeneration possibilities and to make them manifest, with heritage and the castle remains at their heart.

The book has its origins in 2013, when the Castle Markets were closed (prior to demolition in 2015) and the University of Sheffield set up the Castlegate Steering Group to coordinate its research on the Castlegate area, and to liaise with Sheffield City Council providing access to research expertise in animal and plant sciences, archaeology, architecture, history, landscape design, civil and structural engineering, and town and regional planning. The aim was to deliver on the University's wider civic engagement mission, in which practice-led research, embedded within strategic partnerships, would contribute to addressing key regional problems and challenges, the impact of which was exacerbated by years of austerity and reduced local authority funding. Central to this team were Prof. John Moreland, then Head of the Department of Archaeology and Chair of the Steering Group, Prof. Vanessa Toulmin, the Director of City and Cultural Engagement at the University, Prof. Richard Jones, then Pro-Vice Chancellor for Research and Innovation, and Simon Ogden, then Head of City Regeneration at Sheffield City Council. A series of events followed to showcase ways in which Castlegate could be regenerated. These included the Sheffield Bazaar in September 2014 in Castle House - the city-centre home of the Brightside and Carbrook Co-op from 1962 - which saw art commissions including projection, digital media, poetry, films and illustration, co-curated by Vanessa Toulmin and Felicity Hoy of social enterprise Common People and co-funded by the Arts Council for England (Castlegate News 2014). The focus was on demonstrating how empty city-centre buildings could be utilised for cultural events, and on raising awareness about the castle and the potential of Castlegate, and the Bazaar was visited by c.11,000 people over eight days (University of Sheffield 2015, 11; Figure 9.29). The Castlegate Festival followed in June 2015, showcasing how artists and academics could collaborate to shape the city, through a pop-up collective, the Castlegate Open Community of Artists. This was funded by an Arts \& Humanities Research Council Connected Communities grant and Yorkshire Artspace, one of the first studio groups of artists to be founded outside London in 1977. Part of the ensuing discussion focussed on the castle ruins, with members of the public calling for them to be 


\section{$1+\frac{1}{3}=$ SHOWS OF SHEFFIELD}

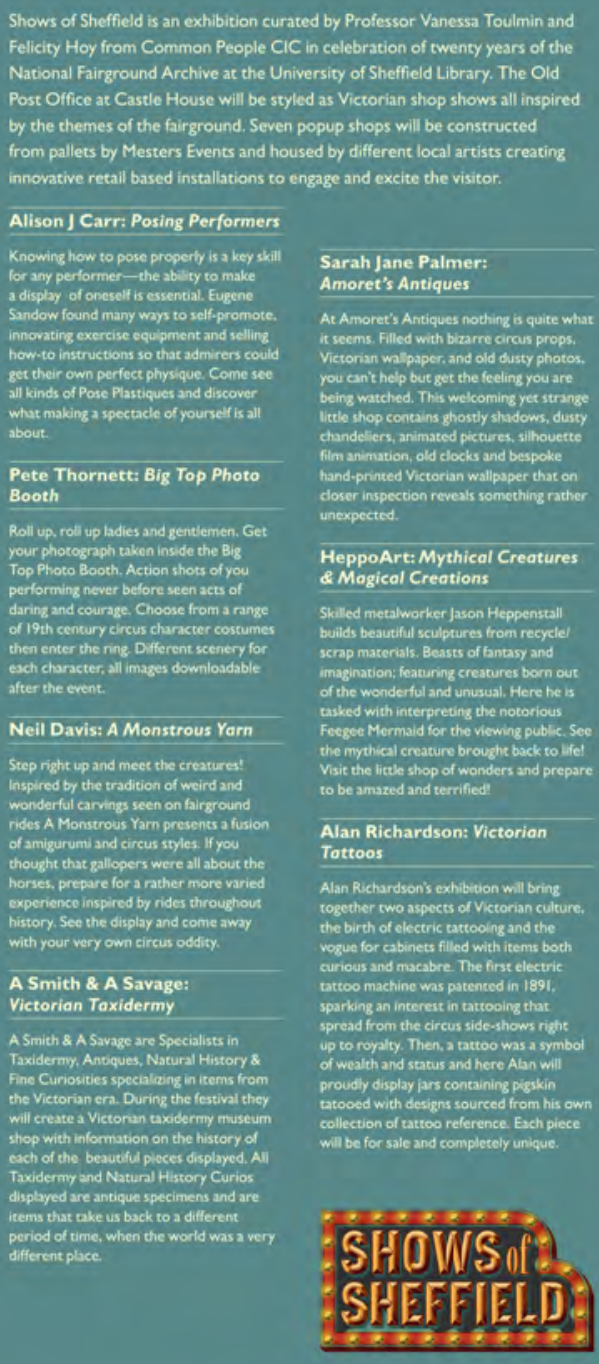

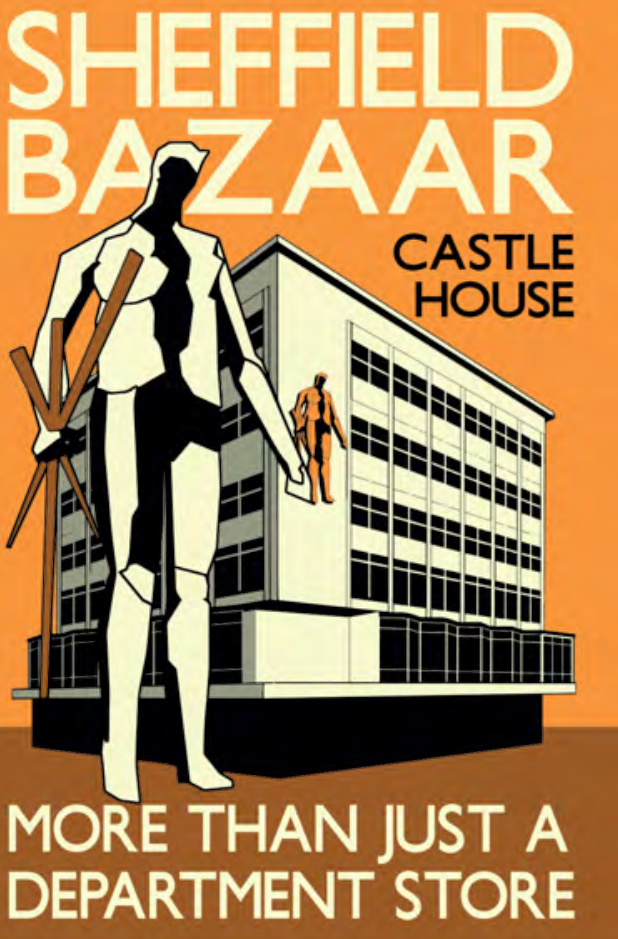

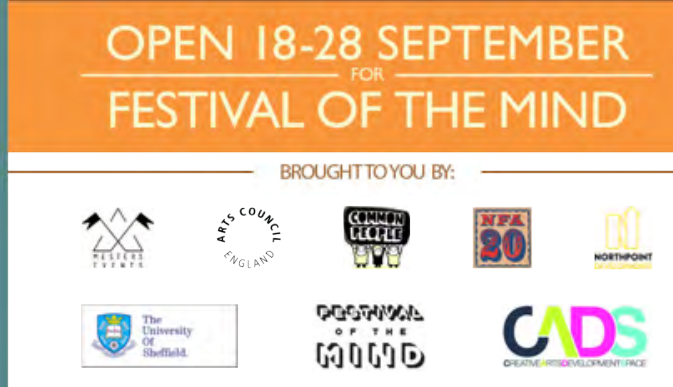

TT Travel wellcometrust
Sheffield

Figure 9.29: The Sheffield Bazaar. Held in Castle House, the former home of the Brightside and Carbrook Co-op in September 2014. University of Sheffield.

used to inform future developments on the site (University of Sheffield 2015, 13-15; Figure 9.30). Meanwhile, the creation by the City Council Regeneration department of the Castlegate Partnership Steering Group in 2013 saw academics from both Sheffield and Hallam Universities come together with the City Council, community groups the Friends of Sheffield Castle and the Friends of the Old Town Hall, hoteliers, retailers and the city's Culture Consortium to plan coordinated action to transform the Castlegate area.

Between 2014 and 2017 students from the University of Sheffield's School of Architecture focussed on Castlegate, working with local organisations and residents to develop 70 research and design projects for this area of the city centre; this was directed by Carolyn Butterworth. The first stage of this residency was the production of a large model, in collaboration with local residents and organisations, to present a co-designed future vision of Castlegate that was informed by its rich social and cultural heritage. One of the projects also saw a team of students work with the City Council, effectively acting as a 'client' for the project, to develop ideas for creative engagement of local people in the regeneration of the Castle site (University of Sheffield 2015, 21-9). This was part of an annual programme by the School of Architecture called Live Projects, which 'provide valuable tools, ideas and built designs to community clients that would otherwise be unable to obtain them. These projects are public and accountable and make a clear difference to the clients and communities they work with' (http://live-works.org).

Through this project, all stages of the history and built environment of Castlegate were explored from the medieval castle through to the mid-20th-century market halls. With respect to any future plans to uncover historic remains on the site, the students asked questions about how buildings can help to preserve the character 

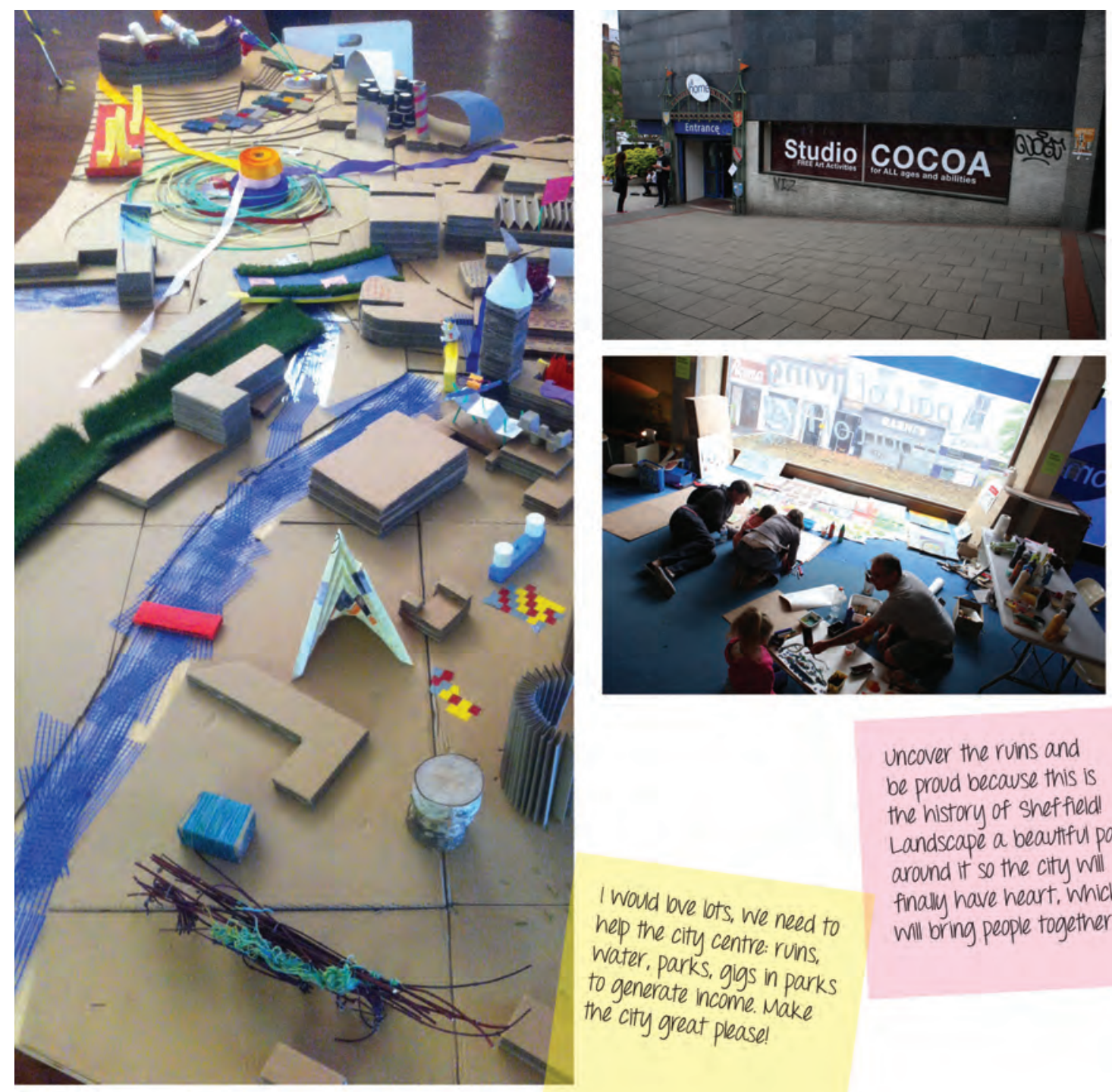

uncover the ruins and be proud because this is the history of shef field! Landscape a beauttful park

I would bve lots, we need to help the city centre: ruins, around it so the city will finally have heart. Which to gener, parks, gigs in parks will bring people together the city great income. Make

Figure 9.30: The 2015 Castlegate Festival. This showcased how academics and creative organisations could work together to inspire regeneration of the area. Images from the festival booklet, with Post-it notes to record the feedback received from members of the public. University of Sheffield.

of both an area and its community, what decisions have to be taken about what is preserved, conserved and restored, and, critically, about how to 'embrace heritage without stifling progress' (University of Sheffield 2015, 49). In 2016 John Moreland secured AHRC funding for a Cultural Engagement Fellow (Rachel Askew), working in collaboration with Llama Digital, a local web and mobile app company, to produce a free walking app of medieval and early modern Sheffield. The aim was to disseminate our enhanced understanding of its archaeology and history, and to facilitate engagement with Castlegate's deep heritage, an understanding and engagement that is vital to informed decisions about regeneration (AHRC 2016, 33; https://situate.io/sheffieldlives).

Over the same period of time, students from the University's Department of Landscape Architecture, led by Nigel Dunnett, were working with Sheffield City Council on design ideas for Castlegate. The students were 'encouraged to respond to the unique history of the site and community whilst also meeting the challenges that the city faces today including climate change, loss of habitat and an increased likelihood of flooding', and to use vegetation and landform 'to create dynamic, robust and ecologically rich landscapes' (University of Sheffield 
2015, 97). Influenced by the medieval heritage of the site, some of the design ideas included planting poplar trees along the highest parts of the site to emphasise the former stronghold, within which further elements of planting would demarcate a 'system of intimate strongholds', and the use of concrete and timber hard landscaping in the park walls will create 'a structure that not only pays homage to its ancestral palisade heritage, but will visually form the park's iconic structural element of defence' (Muller 2015). Some of the design ideas developed during this project informed the City Council's highly successful and internationally acclaimed 'Grey to Green' strategy for transformation of the public realm in Castlegate, which emphasises the conversion of redundant roads into attractive new linear public spaces underpinned by sustainable urban drainage systems (SUDS; Sheffield City Council 2016), and making the riverside areas more attractive to pedestrians, cyclists, workers and developers (University of Sheffield 2016, 97; Figure 9.31).

In 2016, the School of Architecture's Live Projects programme turned again to Castlegate, and this time worked with the community heritage group the Friends of Sheffield Castle, which had been set up in 2013 'to protect and promote the archaeological site of Sheffield Castle for the benefit of the people of Sheffield and surrounding areas and for future generations', on a project called Revealing the Castle. As part of the project, John Moreland was seconded from the University of Sheffield to the Friends, who acted as a 'client' for the Live Project, with Moreland providing the critical link between detailed archaeological knowledge of the castle remains, the communitydriven heritage agenda, and the regeneration dialogue being driven by the Castlegate Partnership Steering Group, on which he represents the University. The brief given to the Masters students was 'to use creativity and research to formalise an alternative vision for the Sheffield Castle site and the surrounding area', and to devise a proposal that would 'not only conserve the physical and historical fabric but to also "build purposefully" for the benefit of local communities and the wider city landscape.' It was further requested that 'the vision should not be bland or corporate but show creativity and celebrate the qualities of Sheffield' (University of Sheffield 2016).

In collaboration with the Friends of Sheffield Castle and other local organisations, the students developed a vision for the castle site which addressed key practical considerations concerning the topography of the site
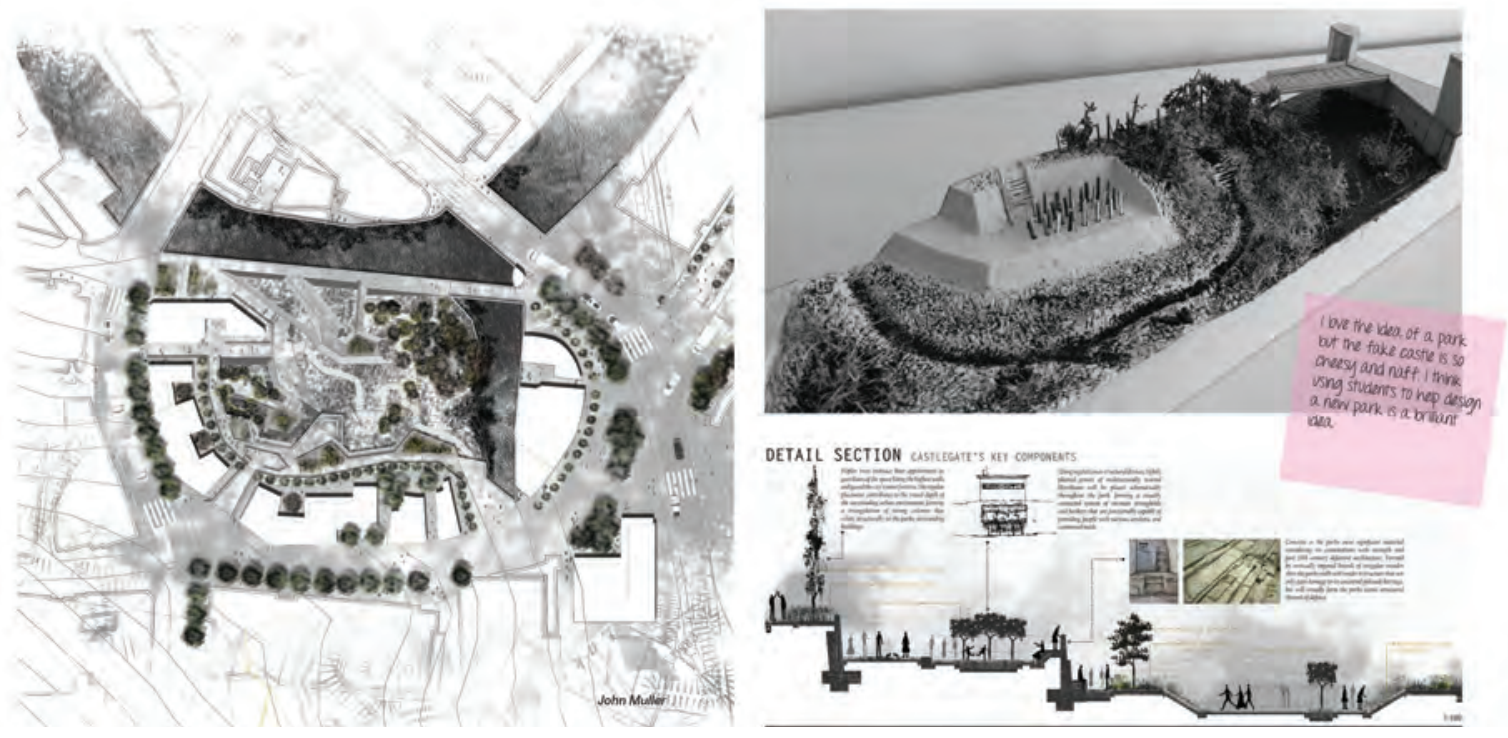

Figure 9.31: Design ideas for Castlegate. A student in the Department of Landscape Architecture at the University of Sheffield, John Muller, explored 'how the site's rich history as a defensive stronghold and a landscape that was once shaped by the rivers Don and Sheaf can be used to generate new spatial forms, articulated through sculpted landform and the careful selection and positioning of trees. This was included in the Revealing the Castle, Live Project 2016 booklet. University of Sheffield.

Figure 9.32 (page 329): Incremental development in Castlegate - excavation, meanwhile use, regeneration. Postgraduate students in the School of Architecture at the University of Sheffield developed a series of regeneration scenarios during the Live Project of 2016. They drew on the heritage of Castlegate and the possibilities and interest that they envisaged that would emerge from ongoing excavations on the site. University of Sheffield. 
of the former castle, transport routes, flooding risk, current building use, and the presence of listed buildings. In order to build resilience in the area to support a community-led development, the students proposed the formation of the Castlegate Collective, comprising a wide array of stakeholders, including the Council, local businesses, community groups, academics and creative organisations. The role of the 'creative classes' in the development of under-used urban areas is now well-established in the UK, influenced by work in the United States, where the importance of 'human creative capital' to regenerate cities had been identified (e.g. Florida 2014). However, the students and local stakeholders were critical of the way in which this model of development too often results in gentrification and the marginalisation of existing communities. The proposal for a community-led collective to steer the development of Castlegate was a direct response to this concern and was intended to embed local agency and ownership at the heart of Castlegate's future. The Revealing the Castle vision builds on existing creative community assets to propose ideas for both temporary and permanent development, integrated throughout the site with generous public spaces (Figures 9.32, 9.33).

In the imagined Castlegate of the future, a new creative quarter would emerge out of the existing networks of local creative individuals and organisations, building a critical mass in the process. Here the influence of this sort of initiative on a global scale was referenced, highlighting examples such as the emergence of Tianzi Lane in Shanghai (China) as a hub for artists who moved into abandoned workshops. Through these sorts of initiatives, Revealing the Castle envisaged Castlegate becoming a destination for visitors as well as the heart of Sheffield's creative community. This was not wishful thinking, because there were already moves towards such a transformation, with the opening of new artists' studios in 2013 in the empty Exchange Place building on Exchange Street. Thanks to funding from Arts Council England, this 1920s Art Deco building was taken on and transformed by Yorkshire Artspace, and now offers workspace to over 60 artists and makers (Yorkshire Artspace 2019).

But the history and memory of the castle, and the longer-term heritage of the site, underpinned all. Influenced by the work of Richard Hodges at Butrint (Albania), which is a UNESCO World Heritage Site, the potential for the archaeology to lead the regeneration initiatives was stressed. The archaeological remains of Butrint have been central to what Hodges $(2017,5)$ calls placemaking - 'the practice of either creating or lend-

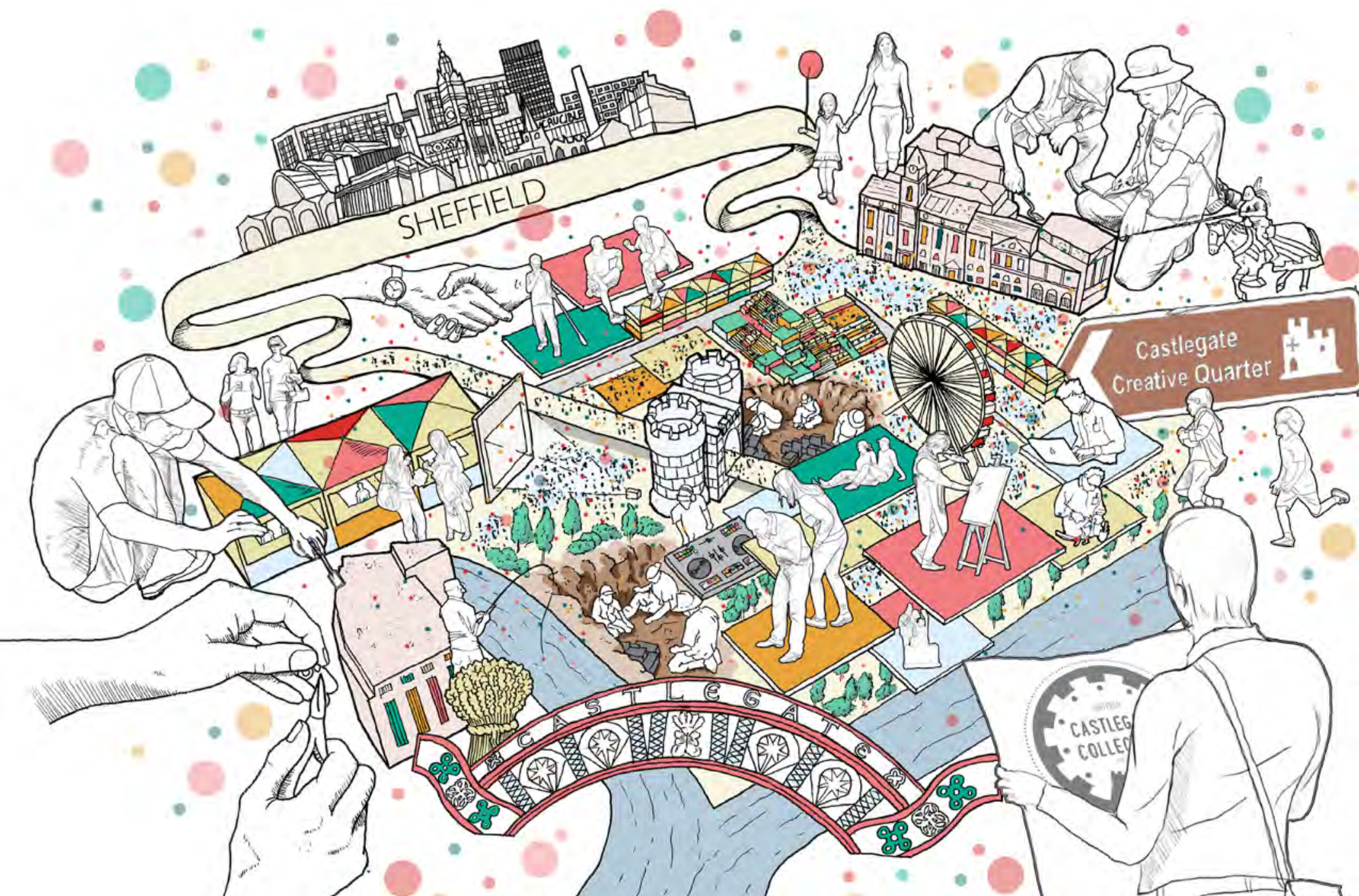




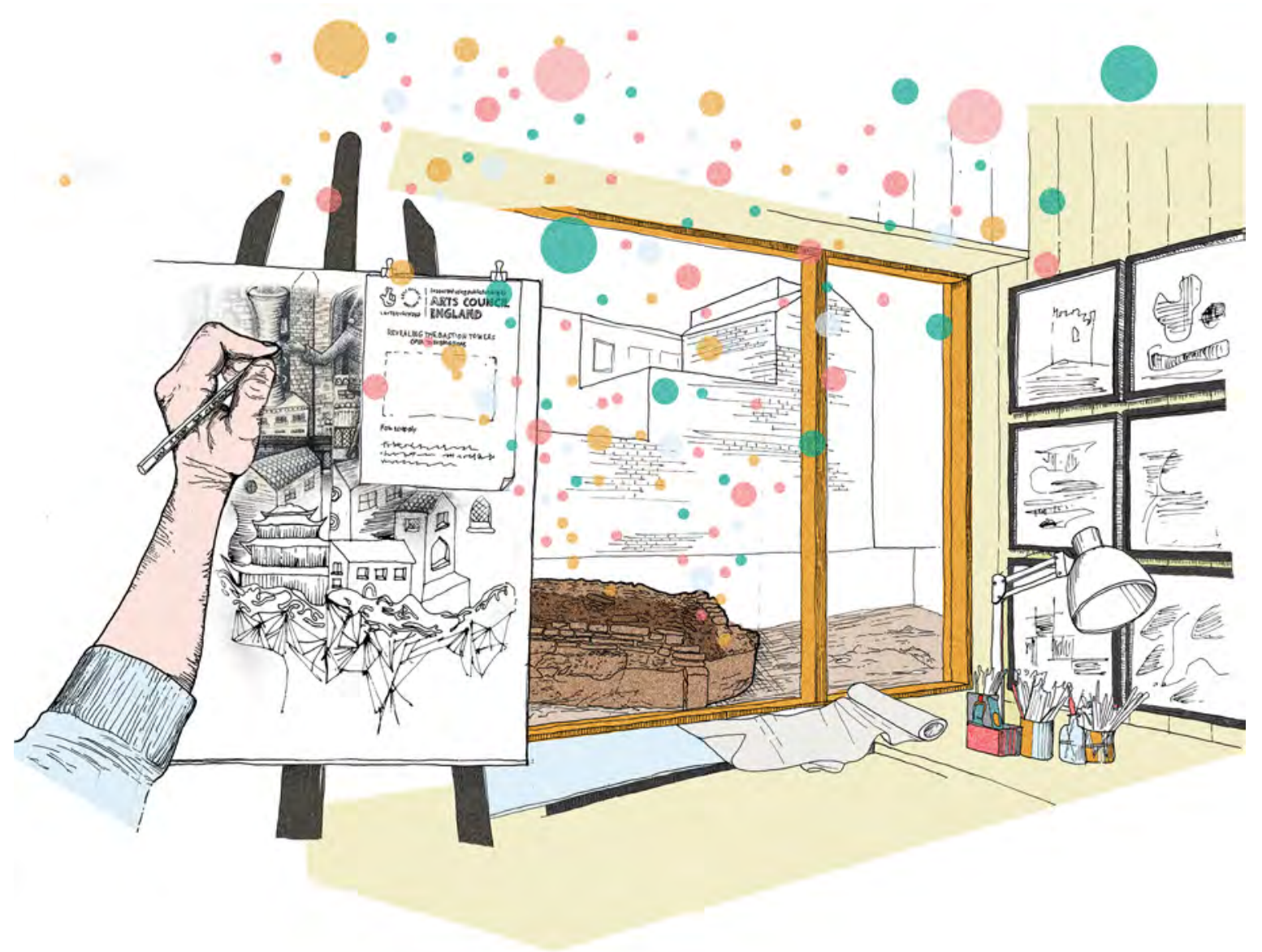

Figure 9.33: Heritage-led regeneration. The Revealing the Castle project envisaged that archaeological investigation of the castle site would generate excitement in the area and lead to an influx of creative organisations leading to funding bids for regeneration. University of Sheffield.

ing a place ... an identity that, with strategic management of conservation and presentation, attracts visitors whose support helps sustain it.' And as Hodges went on to note, the very practice of archaeology, the 'theatre of excavation with the drama of discovery', provides a further dimension to this placemaking. The Revealing the Castle team recognised the importance of archaeological investigations to generate a buzz around Castlegate and a series of hypothetical scenarios for capitalising on this were generated, including events such as festivals and markets, outdoor cinema screenings, sculpture and other art installations, including the re-creation of the medieval towers of the castle in the manner of sculptor Edoardo Tresoldi (Figure 9.34). And in some ways this latter captures the ethos of the project. Tresoldi's monumental sculptures, often of iconic buildings, are made of wire mesh, providing them with both a presence and a sense of impermanence, or absence; he is known as 'the artist of absent matter' (Tresoldi 2019). This dialogue between presence and absence mirrors the desire for a Castlegate regeneration informed by, but not dominated by or subservient to, the heritage of the site. The other key aspect of the Revealing the Castle project, again a product of a dialogue between archaeology and architecture, was the adoption of an 'incremental strategy' to development in which excavation on one part of the site would be carried out in tandem with meanwhile use, such as pop-up festivals and events, and longterm developments on others (University of Sheffield 2016,35). The castle was not to be seen as an impediment to development but as a resource (including the excavation process itself) which would inform, and add to, regeneration options. Heritage would add to the cultural, as well as the economic, value to development. As a recent Historic England $(2018,3)$ report concluded, 'heritage generates demand and a property price premium'. 


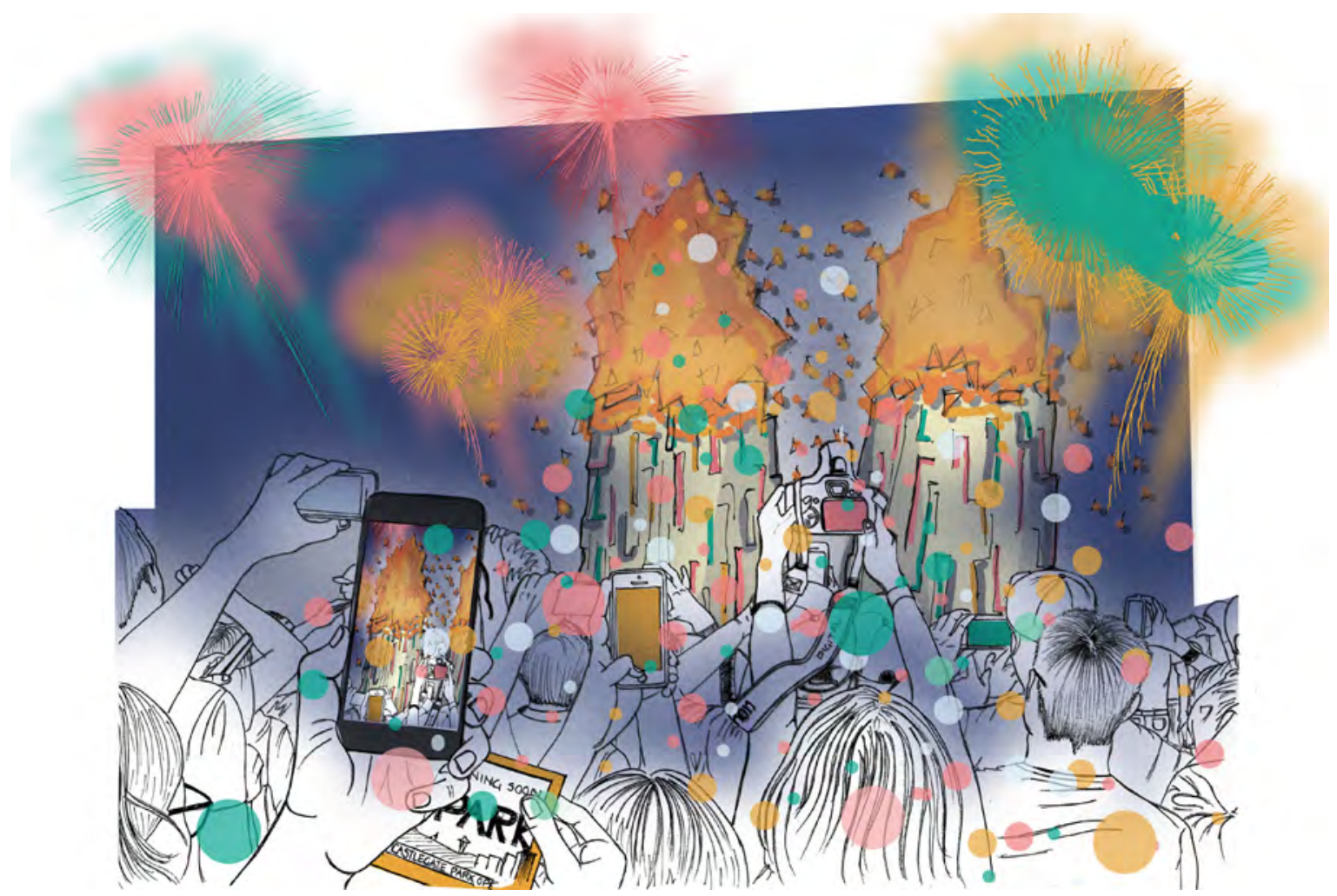

Figure 9.34: Imagined arts festivals. Inspired by the art installations of Edoardo Tresoldi, the students envisaged that the gatehouse towers of the castle would be built in wood and then set on fire as part of an arts festival to raise the profile of the site. University of Sheffield.

This was, of course, an imagined future, but through the role of John Moreland, Carolyn Butterworth, and the Friends of Sheffield Castle on the Castlegate Partnership these ideas were presented to the City Council's regeneration department. Following the award of local government kickstart funding for development of Castlegate, they have informed the Council's plans. Indeed, they have featured in presentations given by Simon Ogden (2018), former Head of City Regeneration and now the programme leader of Castlegate Kickstart, under the strapline 'Castlegate Kickstart: back to the future!' Placemaking through heritage is at the heart of these new aspirations, with the Revealing the Castle project's findings incorporated into the concept design plans. The excavations that this kickstart funding enabled took place over nine weeks in the summer of 2018, and encouraged by the Project Board public access to the excavations was at their heart. As we saw in Chapter 7, students from the University's Archaeology department, many of them from Sheffield, were part of the core excavation team, while members of the public participated in the excavations and helped with post-excavation processing. Wessex Archaeology held four open days, which attracted 480 visitors, gave 20 talks to over 1,000 members of the public, maintained a blog which had 15,600 hits, received nearly 18,000 emails enquiring about the castle over the course of the project, and had students from Sheffield Hallam University creating street art on the hoardings surrounding the site inspired by the castle's history. The contrast with what happened in the 1920 s and in the 1950s could hardly have been greater. In 2018, the people of Sheffield were involved from the offset in the investigation and interpretation of a site which for decades had dominated, even in its absence, antiquarian debate and the form of local architecture. And one of their most significant discoveries was that the heritage of the site transcends the castle. Sheffield's deep history is here and, with the castle remains buried under at least four metres of deposit accumulated from subsequent occupation and use of the site, the question of how to present that history, and which stories to tell, became much more complex than simply displaying the ruins of the castle in a park. 


\section{Conclusion}

From the moment that the Parliamentary order was given to slight Sheffield Castle in 1646, it was subject to reconstruction, both physical and symbolic. As the stones, walls, buttresses, windows, walls and internal fixtures and fittings of the castle were taken away by members of the local community, the building moved quickly into the realms of the imagination, becoming a resource for expressions of status, particularly among the middling sorts of Sheffield's community. Castle Hill was partly transformed into a public space in the form of the bowling green but was soon given over to new types of dwelling place and work. Over the coming centuries, Castle Hill became increasingly industrial in its outlook, sound and smell, mirroring wider developments in the community as the Steel City began to take shape and Sheffield's global reputation for steel and cutlery manufacture emerged. Its role in the politics of the realm diminished as it no longer possessed a major symbol of political authority, although, as we have seen, the Dukes of Norfolk continued to be major landowners, a fact that continues to the present day. Meanwhile, the parkland to the east of the castle was transformed into an industrial landscape, albeit that new pockets of elite residence, social display and charitable benefaction emerged in the area of Norfolk Park. Demands for working-class housing eventually, however, caught up with this open space close to the heart of the city and in the early 20th century council housing began to transform the landscape of the park. It was an exciting time for the former medieval park, couched with promises of a bright future for those who moved there, only to be let down by the political choices and rhetoric of the 1980s. The desperate need to improve the situation on the Manor Estate was recognised by the mid-1990s and since then, tentatively and with plenty of setbacks along the way, this has been achieved and the heritage of the place has been a central driver. Castle Hill, in contrast, was at the vibrant heart of the city from the 1930s with the opening of Castle Hill Market and remained so until 2013, despite the competition presented by the Meadowhall shopping centre on the edges of the city, which has unquestionably had a negative impact on the vitality of the city centre and its retail offer. The future is an uncertain one for Castlegate, but through the work of partner-

ship between the University, the Friends of Sheffield Castle, the City Council and local businesses a vision of what the future could comprise and the stages by which regeneration can be achieved has been mapped out. At the heart of this is Sheffield Castle, a place that no longer exists but which retains a powerful hold on the city.

\section{Bibliography}

The full bibliography is available at the end of this volume, or at: https://doi.org/10.22599/SheffieldCastle.k. 


\section{Epilogue}

Our blueprint [for the site of Sheffield Castle] seeks to combine the history and heritage of the site with the contemporary regeneration of Sheffield in the 21st century... Some of the most exciting cities in the world are those that adapt, change and grow. This is the opportunity for Sheffield now (Friends of Sheffield Castle 2019, 3)

In this book we have presented a biography of Sheffield Castle, built around the intertwined histories of the building, the landscape in which it was located, the changing needs, interests and involvement of the local community, and the priorities of successive generations of archaeologists. We tend to think of castles as places where the great lords and ladies of the Middle Ages lived, but the heroes of our book have scarcely been the Earls of Shrewsbury or Dukes of Norfolk but rather a tax collector, a cutler and a local authority surveyor. We have seen the castle through their eyes, and analysed their struggles to understand what they encountered, their priorities in interpretation and public dissemination, their achievements and disappointments and the obstacles that were placed in their way. We have also situated our analysis of the archaeological archives and of the modern excavations in the context of a long-running regeneration debate, and we have used them to contribute to this both by dealing with a major impediment to the City Council securing much-needed funding, and also to inform and inspire future developments. In this final section of the book we reflect on what we have achieved, and on the lessons to be learned from our efforts to use the archaeology of Sheffield Castle to add an important new dimension to the history of Steel City, and to put that archaeology to work in the service of the city's future.

\section{Working with early archives}

Had we simply wished to write a book about the form and chronological development of Sheffield Castle, the Armstrong, Himsworth and Butcher archives would certainly have enhanced our understanding of broad phases of development, the topography of the moat, and the state of preservation across the site. This is all valuable information but is actually among the least interesting of the many uses to which these archaeological archives can be put. Certainly, in the context of aspirations to redevelop the site and to attract investment in this deprived district of the city centre, it is critical to scrutinise the records of earlier excavations to understand something of the logistical challenges that a construction company will encounter during groundworks on the site, to encourage their investment through presenting what can reasonably be known of the archaeological record, rather than what is feared by funding bodies distracted by worst-case scenarios. Such study also helps to inform plans for

\footnotetext{
How to cite this book chapter:

Moreland, J. and Hadley, D. (with A. Tuck and M. Rajic). 2020. Sheffield Castle: archaeology, archives, regeneration, 1927-2018, pp. 333-340. York: White Rose University Press. DOI: https://doi.org/10.22599/SheffieldCastle.j. CC BY-NC 4.0, https://creativecommons.org/licenses/by-nc/4.0
} 
preservation and recording of the archaeological remains during future development, albeit, as we pointed out in the Preface, that modern requirements for developer-funded initiatives exclude analysis of legacy archives from the requirements placed on developers. Here we have been able to facilitate interpretation of the findings from recent excavations by incorporating them into a volume that has also seen the legacy archives written up. Together they provide an enhanced understanding of the history of the heart of the city from the Middle Ages right through to the demolition of the Markets in 2015, a knowledge that provides a significant resource for developers seeking both to respect the character of the place and to benefit from the fact that heritage 'pays'.

Throughout the book we have focussed on how we can use early legacy archives to understand the archaeological process and the development of historical knowledge over the course of a century. By engaging in what might be called source criticism of the archives, we have shown how we can understand them as repositories of information about the archaeological record but also of the circumstances in which archaeological investigation and interpretation were conducted over a period of almost a hundred years. As such, we have been able to offer invaluable insights into the development of the discipline, and its practice at a local level - in a world far removed from Leonard Woolley's excavations at Ur or the search for Homeric and biblical cities in the east Mediterranean (see Chapter 2; Carver 1987, 101-3). The recent archival turn in the humanities has moved from an approach that uses 'archives as a primary source to studying them as a topic in themselves, considers how the archive is constructed, and its implications in knowledge formation' (Baird and McFadyen 2014, 14). There has been a constant theme throughout the book of archaeology being conducted against a backdrop of building construction, with varying levels of local government intervention, and in response to contemporary public interest and expectations, and we have seen the impact that this had on the creation of the archaeological archive. For example, in Chapters 2 and 3 we saw the ways in which the archive of Armstrong and Himsworth was shaped by a growing sense of Sheffield's history, and how this sometimes led to archival information being modified. In the case of the former, he was presenting schematic results in his drawings as a means of delivering what was, for those times, a modern archaeological pastiche of what had been found. Himsworth, in contrast, can be shown to have gone back to his records and amended them in the light of new findings. It would be unfair to claim that he falsified what he had seen; rather, what emerges is an attempt to make sense of what was being recorded as new findings emerged. It is too easy to dismiss archives from nearly a hundred years ago as unreliable; while there are inevitable shortcomings in terms of how findings were recorded, in all other respects it is difficult to deny that Armstrong and Himsworth between them kept as good a record as they could in the circumstances in which they were working. What is also striking about the way they worked is that they sought at every step to interpret what they had seen, typically in the framework of the historical accounts concerning some of the earliest lords of the manor, Earl Waltheof, William de Lovetot and Thomas de Furnival II. And, while we have been critical of their tendency to rely on texts in this way, we also acknowledge that much of the history they wrote from the archaeology they saw has stood the test of time, and has been confirmed by modern excavations with their scientific dates and more refined understandings of artefact chronologies. It is also important to recognise, as we discussed in Chapters 2 and 3, that while they were recording the archaeology the two men were actively engaged in research about the site, and worked closely with local finds specialists and historians. Such examples of research-based interpretation during the process of excavation have seemingly been overlooked in the context of 21st-century arguments about the need to inculcate a research culture in modern developer-funded excavations where the emphasis on excavation as record has resulted in the central role of historical enquiry being denied in much of the legislative and policy frameworks established by the curatorial sector of British archaeology' (Andrews et al. 2000, 527). The desire to embed research in all practice is laudable, but it is one of the considerable strengths of the 1920s 'castle project' that it was already doing so and we suspect that this is as often true as not in the longer-term history of urban excavation.

Leslie Butcher was closely embedded in the local archaeological scene when he was tasked by the City Architect with recording the remains of the castle during construction work from the late 1950s. While he did not have the profile of Leslie Armstrong, he was unquestionably 'the right man for the job'. Butcher's motivation seems to have lain in his long-standing commitment to recording the archaeological record of Sheffield and its region, and his capacity to both capture and present archaeological information through the drawn record was exceptional. In contrast to Armstrong and Himsworth, who largely interpreted the archaeological record through the written record, Butcher contextualised what he saw through consideration of the natural topography of the site, its physical modifications and the townscape. While we have little evidence for Butcher's knowledge of wider archaeological discourse, it is striking that the draft papers he wrote in the early 1970s, focussing on long-term processes and geology, with little attention to historical actors, mirror the trends more broadly in archaeology at that time following the processualist turn of the 1960s. Butcher's emphasis was on environmental factors and long-term change, with 
apparently limited interest in human agency or social and cultural factors. The premature death of Leslie Butcher deprived the city of the publication of what he had recorded, which was clearly close to being ready to submit.

The examination of archaeological personalities, their collaborators and the experiences they had during their research can be of considerable value for understanding the development of the discipline. As Richard Bradley (1997) has noted of a habit of his when reading archaeology publications:

I have become an aficionado of the Acknowledgements, for these often explain much of the main text ... It tells us which field archaeologists worked together at different times, and sometimes it indicates the tasks that they performed.

In this book we have situated earlier archaeological investigations in the context of the local collaborations, personalities and available resources to reveal how archaeological knowledge was created and disseminated. We have also identified the impediments placed in the way of earlier generations of archaeologists and the considerable efforts they made to overcome them. In doing so we have shown how important insights can be recovered from early legacy archives, both about the past and about how knowledge of that past was created. We have also documented how important 'amateur' archaeologists have been in the creation of local knowledge, both feeding off and fuelling local beliefs about heritage and identity. But we seriously underestimate their efforts and devalue their contribution if we see their framework of enquiry as 'merely' local. Armstrong, Himsworth and Butcher may have been interested in the history of their place, but the ways in which they explored and understood it was informed by broader (national and international) perspectives and practices. Wessex Archaeology is a national organisation, but they, more than anyone, have engaged the people of Sheffield in the recovery of Castlegate's history.

\section{Urban regeneration and community action}

In Chapter 9 we discussed the slow progress that has been made towards improvement of the social and economic conditions of some of Sheffield's most deprived regions using heritage as an element in the regeneration process. Considerable achievements over the last decade in using the local heritage to improve conditions on the housing estates built within the former deer park have yet to be matched in efforts to regenerate Castlegate. The former was achieved by a combination of efforts involving a community-based charity, a social enterprise and local volunteers, assisted by local government and European and charitable funds, which, among other things, facilitated the building of a visitor centre at the hunting lodge ruins. In the case of Castlegate, however, the regeneration initiatives are made more complex by the variegated pattern of land use and property ownership, by the fact that its buildings are at different stages in their lifecycle - some newly built, some recently demolished - and by the need to excavate on Castle Hill in advance of future construction. Further, as we saw in the Preface, the unpublished archaeological archives have been a significant impediment to the council's capacity to acquire funding and attract investors. In the view of such funding bodies they constituted a serious 'known unknown'. Through this volume, and the research that underpins it, they have become 'known', a significant resource both for understanding the past and informing the construction of its future.

Heritage-led urban regeneration is a global phenomenon, albeit approached very differently across the world, according to levels of state intervention, availability and sources of funding, and attitudes to heritage assets (Pendlebury and Porfyriou 2017). In the UK, in the current economic climate, community-based initiatives, in which local government works with third sector and voluntary organisations, have become commonplace as the means to achieve regeneration. In a 2017 joint report by the Local Government Association, the Chief Cultural \& Leisure Officers Association and Arts Council England (2017) it was argued that community engagement should lie at the heart of successful 'placemaking', and that this requires strong partnership working. This was a response to the 2016 Culture White Paper, setting out the government's vision and strategy for the cultural sectors, including heritage, which placed councils at the forefront of leading local action. For their part, local councils have frequently turned to community engagement to improve services, infrastructure and opportunities, and the 2017 report on placemaking identified successful case studies which were embedded in local heritage, culture and traditions, noting that '[e]ffective placemaking cannot be done by councils alone, and strong partnership working is a feature of all the case studies featured here'. While one can see the positives in this, as communities are empowered to have a say about developments in their local environment, it is nevertheless apparent that these developments have been driven by serious cuts in the central funding available 
to local authorities. The University of Sheffield's 'Engaged University' initiative was developed in response to the deficit thus created, and the ongoing Castlegate collaboration between the Departments of Archaeology, Architecture and Landscape Architecture has been cited as an instance of the 'power of academics to influence urban development and discourse which is not subjugated to commercial and capital interests' (Shtebunaev $2018,41)$. In this context too, community groups no longer see their role simply as sounding boards for plans led by local authorities or universities. The Friends of Sheffield Castle (2019, 3 11), following wide-ranging consultation, have produced their blueprint for the future development of the castle site. This foregrounds its long history in a set of options to meet the needs of 'current and future Sheffield' and create an 'inspirational and dynamic district' of the city centre. Local businesses are also playing their part in investing in the Castlegate area and creating an exciting vibe. The creative industries sector is now populating the district and there have been frequent meanwhile uses of the site, including the pop-up festivals and cultural events; this is exactly what was envisaged, and encouraged, by the Revealing the Castle project that we discussed in Chapter 9. These have been important steps forward, underpinned by our academic research into the history and archaeology of the site, but the future remains precarious and the risks to the new momentum of lack of funds remain real.

\section{Future directions}

A new dimension to the regeneration debate, and a new way of presenting the history of the site, emerged in 2018 through the creation of a Virtual Reality (VR) model of the castle. This was courtesy of funding awarded to Dawn Hadley, Steve Maddock and Carolyn Butterworth by the Arts \& Humanities Research Council and the Engineering and Physical Sciences Research Council, as part of a joint initiative to foster research into immersive experiences (Figure v). Informed by the archaeological research for this book, a VR model of the castle was created by local creative agency Human, which used specialist computer packages, including Maxon Cinema $4 \mathrm{D}$ and Unity game engine software. While this shows among other things just how far visualisations of the castle have come since the sketches of Leslie Armstrong and Joseph Himsworth, it is not so far removed from their intentions of bringing the castle to public attention using the latest techniques available to archaeologists, or from the aims of Leslie Butcher with his 'bird's eye view' of the castle and his isometric drawings. It is hard to say if this model takes us closer to the reality of the appearance of Sheffield Castle in the late 15th century,

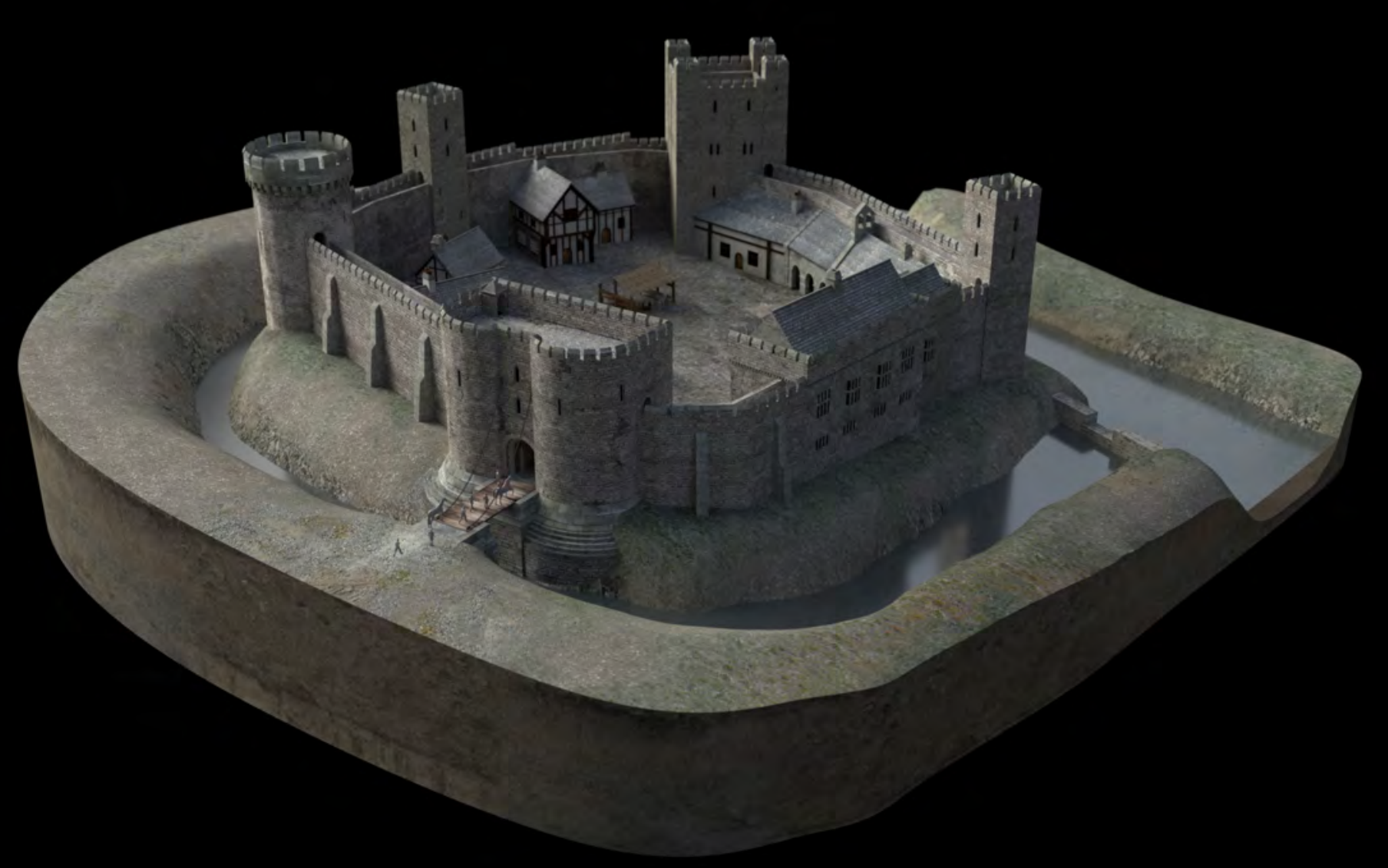



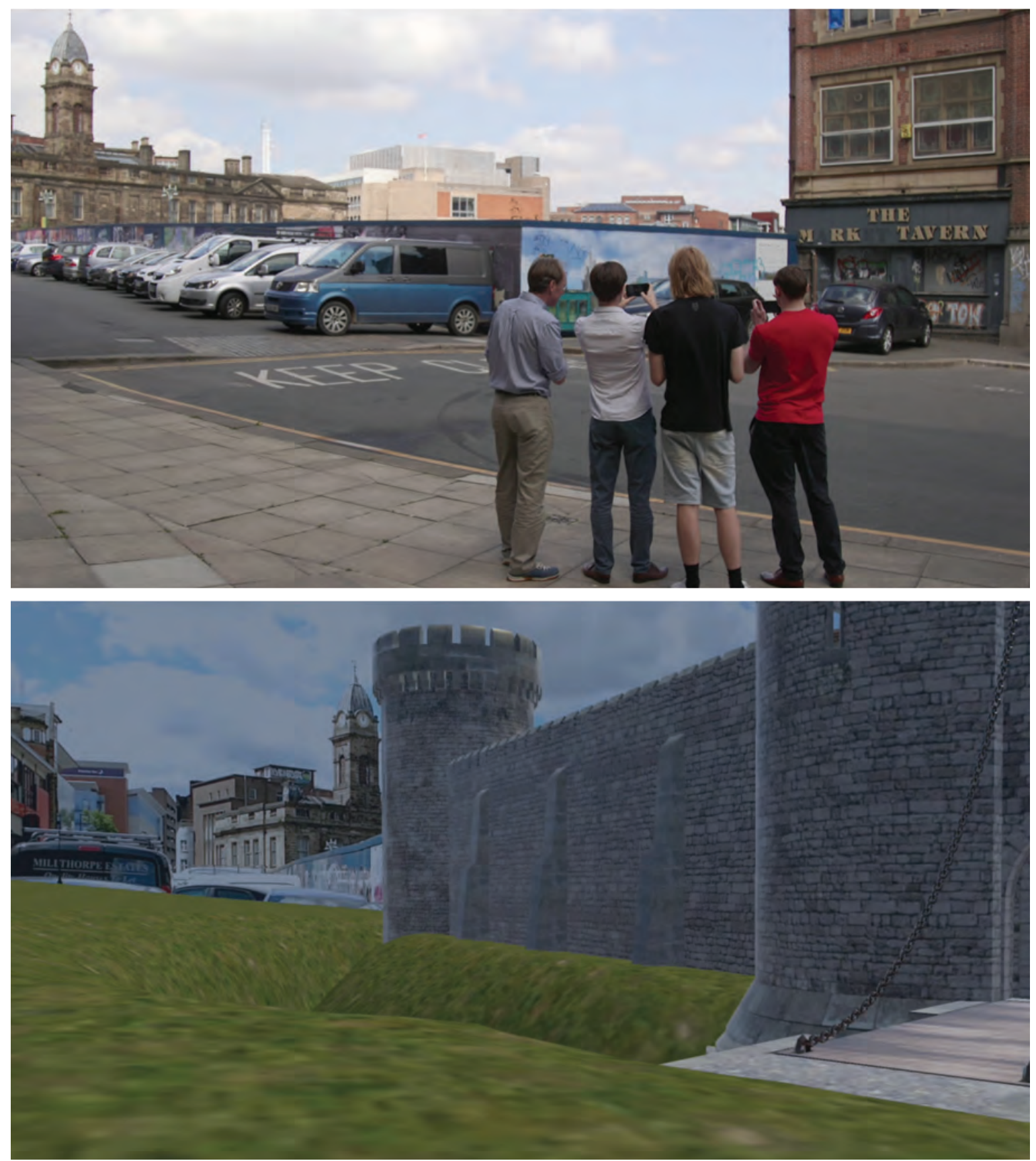

Figure vi: Augmented Reality experience. The virtual reality model was used by Dr Steve Maddock and Matt Leach of the Department of Computer Science at the University of Sheffield to create an Augmented Reality experience for smartphones to be used on site. The team developing the app on site (top) and the castle returned virtually to its place in Castlegate amid the modern cityscape (bottom). University of Sheffield.

Figure $\mathbf{v}$ (page 336): Virtual Reality model of the castle. Created by Sheffield creative agency Human, using Maxon Cinema 4D (3D software), Unity (realtime 3D/AR/game engine software), Adobe Photoshop and Adobe Illustrator. Created by Human, copyright University of Sheffield. This is a still from a video, which can be seen here - https://doi.org/10.15131/shef.data.12302429. 


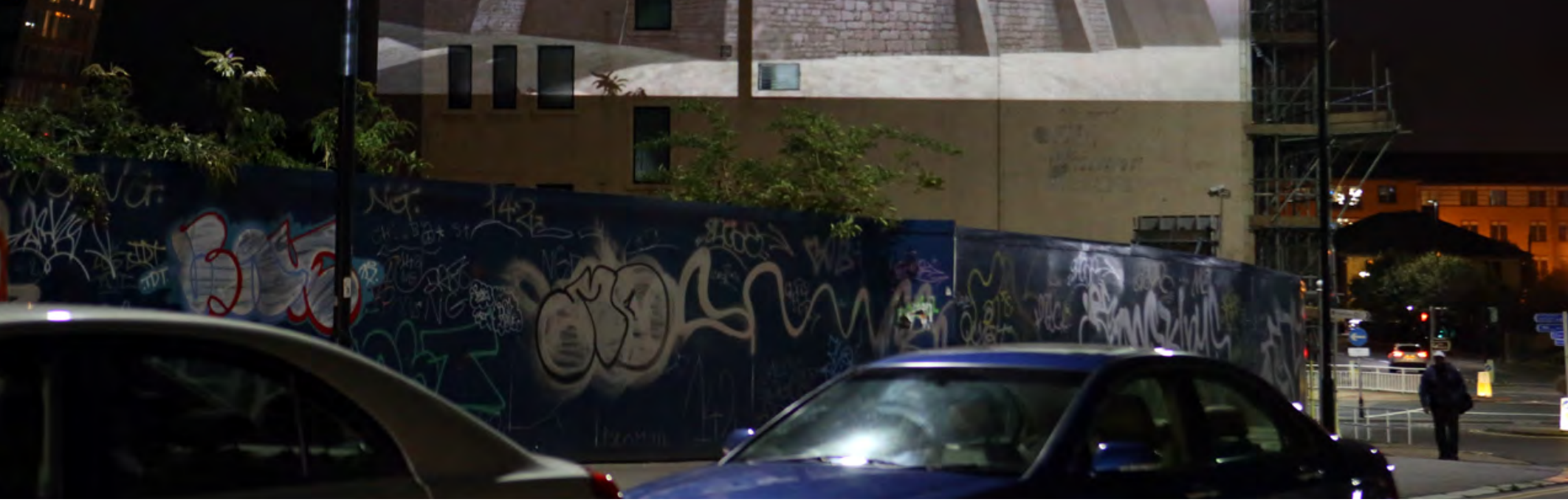

Figure vii: Putting the castle back in Castlegate. The virtual castle projected onto the side of the Yorkshire Artspace building on Exchange Street during the Festival of the Mind, September 2018. For the first time in over 350 years the castle towered over the town; for one night only! Photograph Steve Pool, copyright University of Sheffield. This is a still from a video of the event. The video can be seen at https://doi.org/10.15131/shef.data.12311684. A video of a flythrough of the virtual castle can be seen at https://doi.org/10.15131/shef.data.12341186.

but there is no question that the format we chose for presenting a model of the castle captured the imagination and translated the archaeological evidence into a medium that is up to the moment and culturally relevant. Our work gave Sheffield Castle a new visual identity in the context of the regeneration debate (Burn 2018).

We also transformed the VR model into an Augmented Reality (AR) application. This was initially produced for smartphones, so that it could be used on site in Castlegate, allowing the user to see the castle at real size in its exact location amid the modern buildings, and it produced some arresting images (Figures vi and vii). However, rolling this out for wider public use was a challenge, with respect to the technological limitations of using AR on mobile devices in an outdoor setting (Leach et al. 2018). Therefore, we repurposed the model into an app for iPad, and launched it at the University of Sheffield's Festival of the Mind in September 2018 in an installation in the city centre's Millennium Galleries (University of Sheffield 2018). The app was used in conjunction with a 1:150 scale wooden model of Castlegate as it is now (constructed by the School of Architecture at the University of Sheffield), and was presented alongside images of some possible futures for Castlegate to emerge from the Revealing the Castle project (University of Sheffield 2016). Under the strapline of 'Experience Castlegate' we asked visitors 'What if you could see the past, present and future of our city all at the same time?', encouraging debate and discussion about what the future might entail, and what place the remains of the castle might play in that. Over eight days, there were over 7,000 visitors, with the installation garnering a great deal of media attention including an appearance on the BBC regional news programme Look North (Figure viii; 'Sheffield Castlegate', 2018).

At the time of completing this book the AR app and wooden model have been installed in the National Videogame Museum (NVM) in the city centre, where it is being seen and explored by hundreds of schoolchildren and their families. It is apposite that this is how the castle is now being consumed, because the NVM is based in a rejuvenated Castle House, the city-centre store of the Brightside and Carbrook Co-op from 1958. This building is now also home to Kollider, an incubator for digital and tech companies and start-ups, and to a range of restaurants, bars and social spaces. The castle has found a temporary virtual home in a building which is the successor to the one on the corner of Exchange Street and Waingate, whose construction in 1927 led to the

Figure ix (page 339): The gatehouse of Sheffield Castle in a Virtual Reality model. The 21st-century visual identity for this historic site. University of Sheffield. 

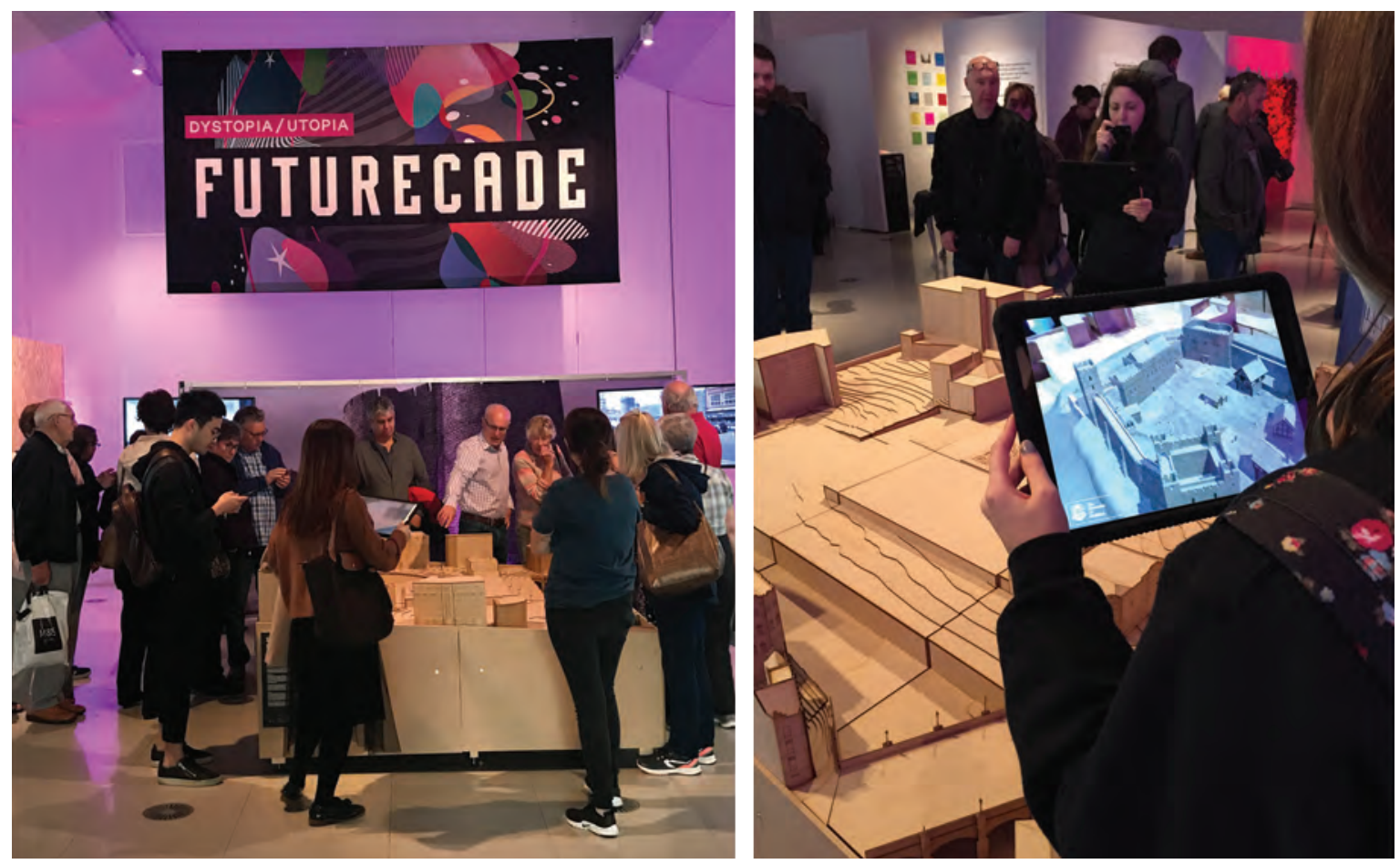

Figure viii: The past, the present, and the future of Castlegate. The castle went on display in Sheffield's Millennium Gallery in September 2018 as part of the University of Sheffield's Festival of the Mind. The castle was able to be viewed in Augmented Reality on tablets in the context of a wooden scale model of Castlegate as it appears today. The installation attracted $c .7,000$ visitors over eight days. University of Sheffield.

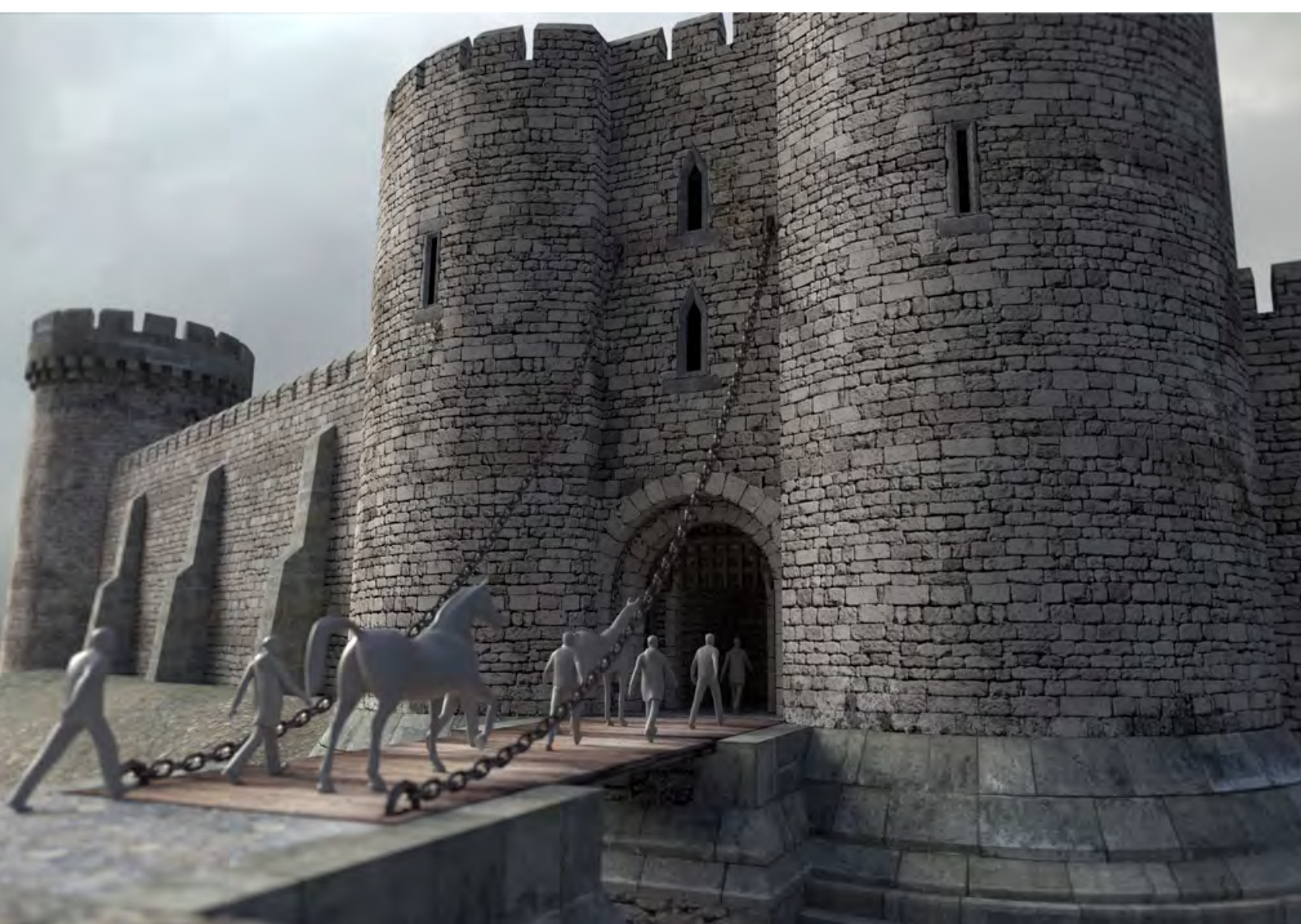


involvement of Leslie Armstrong and Joseph Himsworth, and the subsequent first serious debate about how to preserve and present the heritage of the site. The use of VR and AR allows us to create and display multiple instances from the histories of Castlegate, but the actual remains of the castle (and/or the bowling green, the cementation furnace etc.) must also have a role to play in the presentation of the heritage of this persistent place, allowing, as they do, people to encounter and engage with the materiality of the past, and with the buildings and objects experienced by those who lived then (Figure ix).

The Castlegate district is seeing an influx of new businesses and the landscape around the site of Sheffield Castle is beginning to thrive once again. Community action groups, the Friends of Sheffield Castle and the Friends of the Old Town Hall, which is nearby, are working hard, and in collaboration with the University and the Council, to preserve and promote the heritage and especially the material remains of this place. ${ }^{32}$ But the heart of Castlegate, the former heart of the city, remains empty. We very much hope that the knowledge of the past, and the lessons to be learned from it, contained in this book will help to fill that space with an iconic development that contributes to the future vitality and identity of the city, as the castle itself once did.

\section{Bibliography}

The full bibliography is available at the end of this volume, or at: https://doi.org/10.22599/SheffieldCastle.k.

${ }^{32}$ The University of Sheffield has worked with Sheffield City Council, The Friends of Sheffield Castle, and Wessex Archaeology to produce a video which captures the essence of that collaboration and our vision for the future - 'Castlegate, Sheffield - Excavating the Past; Building the Future' can be seen here - https://doi.org/10.15131/shef.data.12361838. 


\section{Bibliography}

Archival material held by Museums Sheffield has been digitised and made available in our online archive hosted by the Archaeology Data Service (https://doi.org/10.5284/1074899); in this bibliography we have provided the file names to facilitate ease of access.

\section{Manuscript sources}

Anon. n.d. (a). Catalogue of Desch manuscripts. Sheffield: Special Collections, University of Sheffield Library Anon. n.d. (b). Sheffield Manor. Programme of excavations. Outline of the potential for conducting excavations at Sheffield Manor Lodge (dating to the late 1960s). Sheffield: Museums Sheffield

Anon. 1929a. Copy of the report from Birmingham Public Libraries (Reference Department) about furniture at Brougham Hall dated $15^{\text {th }}$ March 1929 (SHEFFIELD_CASTLE_PROJECT_FILE_025-49_ Correspondence)

Armstrong, A. L. n.d. (a). Sketch on the back on an Inland Revenue envelope (AL_ARMSTRONG _1995_85_028-29_Sketches)

Armstrong, A. L. n.d. (b). Notes on written sources about Sheffield Castle, including what appears to be a chapter of the draft manuscript of a book (AL_ARMSTRONG_1995_85_118-132_Historic_Research_Notes)

Armstrong, A. L. n.d. (c). Notes written during research on Sheffield Castle (AL_ARMSTRONG_1995_85_233-242_Drafts_Synthesis)

Armstrong, A. L. n.d. (d). Draft manuscript of the paper published in the Transactions of the Hunter Archaeological Society in 1930 (AL_ARMSTRONG_1995_85_250-286_Publication_Manuscript)

Armstrong, A. L. n.d. (e). Draft manuscript of the paper published in the Transactions of the Hunter Archaeological Society in 1930 (AL_ARMSTRONG_1995_85_097-109_Publication_Draft_Manuscript)

Armstrong, A. L. n.d. (f). Draft manuscript of the paper published in the Transactions of the Hunter Archaeological Society in 1930 (AL_ARMSTRONG_1995_85_091_Publication_Draft_Manuscript)

Armstrong, A. L. 1927a. Annotation on the back of a photograph of artefacts from Sheffield Castle (BUTCHER _1976_1064_140)

How to cite this book chapter:

Moreland, J. and Hadley, D. (with A. Tuck and M. Rajic). 2020. Sheffield Castle: archaeology, archives, regeneration, 1927-2018, pp. 341-366. York: White Rose University Press. DOI: https://doi.org/10.22599/SheffieldCastle.k. CC BY-NC 4.0, https://creativecommons.org/licenses/by-nc/4.0 
Armstrong, A. L. 1927-28. Site diary detailing excavations on the site of Sheffield Castle in 1927 and 1928 (ARMSTRONG_ALA_4_001-8_NOTES)

Armstrong, A. L. 1928a. Manuscript of a lecture delivered to the Hunter Archaeological Society on $11^{\text {th }}$ December 1928 (Box_File_Written_Text_180-183_manuscript)

Armstrong, A. L. 1929a. Chapter III of a draft manuscript of a book on Sheffield Castle (AL_ARMSTRONG_1995_85_052-68_Manuscript)

Armstrong, A. L. 1929b. Chapter IV of a draft manuscript of a book on Sheffield Castle (AL_ ARMSTRONG_1995_85_070-73_Manuscript)

Artefacts list, n.d. Notes on finds recovered by Leslie Butcher and John Bartlett during excavations on the site of Sheffield Castle (BUTCHER_1976_1064_060-62_Typed_Pottery_Notes)

Baggaley, J. W. 1929a. Letter to The King's Galleries, London, $11^{\text {th }}$ January 1929 (SHEFFIELD_CASTLE_ PROJECT_FILE_025-49_Correspondence)

Baggaley, J. W. 1929b. Letter written to M. Fredericke, The King's Galleries, London, $22^{\text {nd }}$ February 1929 (SHEFFIELD_CASTLE_PROJECT_FILE_025-49_Correspondence)

Baggaley, J. W. 1929c. Letter to The British Museum, London, $11^{\text {th }}$ March 1929 (SHEFFIELD_CASTLE_ PROJECT_FILE_025-49_Correspondence)

Baggaley, J. W. 1929d. Letter to the Director and Secretary of the Victoria and Albert Museum, London, $9^{\text {th }}$ March 1929 (SHEFFIELD_CASTLE_PROJECT_FILE_025-49_Correspondence)

Baggaley, J. W. 1929e. Letter to M. Fredericke, $28^{\text {th }}$ March 1929 (SHEFFIELD_CASTLE_PROJECT_FILE_ 025-49_Correspondence)

Baggaley, J. W. 1930a. Letter to A. L. Armstrong, $9^{\text {th }}$ May 1930 (AL_ARMSTRONG_1995_85_306_Finds_ Correspondence)

Bateman Drury, S. 1929. Letter to A. L. Armstrong, 16 ${ }^{\text {th }}$ January 1929 (AL_ARMSTRONG_1995_85_092-93_ Correspondence)

Beswick, P. 1971a. Sheffield Manor Site Records, Vol. II. Sheffield: Sheffield City Museum

Beswick, P. 1971b. Sheffield Manor Site Records, Vol. III. Sheffield: Sheffield City Museum

Beswick, P. 1972a. Sheffield Manor Site Records, Vol. IV. Sheffield: Sheffield City Museum

Beswick, P. 1972b. Sheffield Manor Site Records, Vol. V. Sheffield: Sheffield City Museum

Beswick, P. 1972c. Sheffield Manor Site Records, Vol. VI. Sheffield: Sheffield City Museum

Beswick, P. 1973a. Sheffield Manor Site Records, Vol. VIII. Sheffield: Sheffield City Museum

Beswick, P. 1973b. Sheffield Manor Site Records, Vol. IX. Sheffield: Sheffield City Museum

Beswick, P. 1976a. Sheffield Manor Site Records, Vol. XIII. Sheffield: Sheffield City Museum

Beswick, P. 1976b. Sheffield Manor Site Records, Vol. XIV. Sheffield: Sheffield City Museum

Beswick, P. 1990. Note regarding works to chamber below Castle Hill Market building (Box_File_Written_ Text_001_notes)

BL Add MS 6671. Lincolnshire Genealogical Collections and Papers. London: British Library Manuscript Collections

Bonsall, J. C. 1972. Sheffield Manor Site Records, Vol. VII. Sheffield: Sheffield City Museum

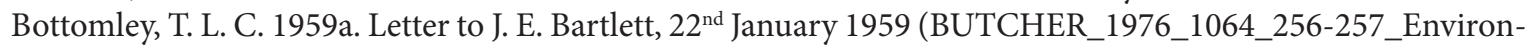
mental_Correspondence)

Bottomley, T. L. C. 1959b. Letter to L. H. Butcher, $9^{\text {th }}$ February 1959 (BUTCHER_1976_1064_256-257_Environmental_Correspondence)

Bradbury, F. 1929. Letter to J. W. Baggaley, $19^{\text {th }}$ March 1929 (SHEFFIELD_CASTLE_PROJECT_FILE_02549_Correspondence)

Bradbury, F. 1930a. Letter to A. L. Armstrong, 11 ${ }^{\text {th }}$ June 1930 (AL_ARMSTRONG_1995_85_288-294_Finds_ Correspondence)

Bradbury, F. 1930b. Letter to A. L. Armstrong, 17 th June 1930 (AL_ARMSTRONG_1995_85_046-47_ Finds_Correspondence)

Bradbury, F. 1930c. Letter to A. L. Armstrong, $8^{\text {th }}$ July 1930 (AL_ARMSTRONG_1995_85_094-96_Finds_ Correspondence)

Butcher, L. H. n.d. (a). Notes on historical sources about Sheffield Castle (BUTCHER_1976_1064_222-239_ Notes)

Butcher, L. H. 1958-62a. Geological summary of foundation shafts (Drawer_8_027_notes_drawing_metadata) 
Butcher, L. H. 1961. Recent discoveries at Sheffield Castle. Text of a lecture delivered to the Hunter Archaeological Society, 10 ${ }^{\text {th }}$ January 1961 (BUTCHER_1976_1064_063-110_Lecture_Notes)

Butcher, L. H. 1970. Memo written to J. Dean in the Sheffield City Department of Planning and Architecture, $3^{\text {rd }}$ April 1970 (Butcher_Planning Memo_1970)

Butcher, L. H. 1972a. A report on the discoveries made during various excavations on the site between 1927 and 1972. Unpublished typescript (BUTCHER_1976_1064_166-192_Sheffield_Castle_-_Summary)

Butcher, L. H. 1972b. Sheffield Castle. Draft manuscript (BUTCHER_1976_1064_193-220_Draft_publication)

Butcher, L. H. 1972c. Sheffield Castle. A report on the discoveries made during various excavations on the site between 1927 and 1972. Draft manuscript (BUTCHER_1976_1064_019-33_Notes)

Butcher, L. H. 1972d. Sheffield Castle. Draft manuscript (Box_File_Written_Text_087-114_manuscript)

Butcher, L. H. 1972e. Notes for a publication on Sheffield Castle (BUTCHER_1976_1064_005-7_Notes)

Butcher, L. H. 1972f. Notes for a publication on Sheffield Castle, including a legend showing the drawing conventions used by Leslie Butcher for his excavation plans and sections, and handwritten notes by Joseph Himsworth (Butcher_1976_1064_242_252_Notes)

Butcher, L. H. 1972g. Notes for a publication on Sheffield Castle (BUTCHER_1976_1064_053-59_Notes)

Butcher, L. H. 1972h. Notes for a publication on Sheffield Castle including a sketch of the castle (Box_File_ Written_Text_059-61_manuscript)

College of Arms RR 20/D. Dethick's Funerals of Nobility 1586 to 1603. Volume 1. London: College of Arms

Crossley. D. n.d. Descriptions of pottery recovered during excavations on the site of Sheffield Castle (Box_File_ Finds_Related_Materials_012-135_Pottery_Index_Cards)

Davies, W. G. 1930a. Letter to A. L. Armstrong, 20 ${ }^{\text {th }}$ June 1930 (AL_Armstrong_1995_85_312-314_Correspondence)

Davies, W. G. 1930b. Letter to A. L. Armstrong, 12 ${ }^{\text {th }}$ August 1930 (Box_File_Written_text_016-26_correspondence)

Davies, W. G. 1930c. Letter to A. L. Armstrong, $17^{\text {th }}$ November 1930 (AL_Armstrong_1995_85_312-314_ Correspondence)

Davies, W. G. 1930d. Letter to A. L. Armstrong, 30 th $^{\text {th }}$ November 1930 (AL_Armstrong_1995_85_312-314_Correspondence)

DD/4P/46/6. Probate will of Gilbert, Earl of Shrewsbury, aged 62 yrs. and more. Nottingham: Nottinghamshire Archives

Drury, C. 1929a. Proofs of a paper entitled 'Sheffield Castle' supplied to A. L. Armstrong by J. W. Northend publishers (AL_ARMSTRONG_1995_85_079-82_Proof_parts)

Edwards, F. E. P. 1930. Letter to A. L. Armstrong, $15^{\text {th }}$ November 1930 (AL_ARMSTRONG_1995_85_298-305_ Correspondence)

Evans, D. 1929. Letter to J. W. Baggaley, $11^{\text {th }}$ March 1929 (SHEFFIELD_CASTLE_PROJECT_FILE_025-49_ Correspondence)

Folger Shakespeare Library, Washington, DC, Cavendish-Talbot Correspondence (X.d.428)

Forster, J. E. 1928. Letter to A. L. Armstrong on behalf of the Brightside and Carbrook Co-operative Society, $2^{\text {nd }}$ May 1928 (AL_ARMSTRONG_1995_85_158-159_Correspondence)

Forster, J. E. 1929. Letter to A. L. Armstrong on behalf of the Brightside and Carbrook Co-operative Society, $13^{\text {th }}$ February 1929 (Box_File_Written_Text_169-179_Correspondence)

France, S. 2006. Sheffield Manor Lodge Business Plan. Unpublished report

Fredericke, M. 1929. Letter to J. W. Baggaley, $11^{\text {th }}$ February 1929 (SHEFFIELD_CASTLE_PROJECT_FILE_02549_Correspondence)

Harley MS 2076. Coats of the Nobility; Knights of the Garter; and Lord Mayors of London, \&c. London: British Library, Harleian Collection

Harrison, J. 1637. An Exact and P[er]fect Survey of the Manoor of Sheffield. Sheffield: University of Sheffield, ARCH MS.11

Hart, C. 1989a. Sheffield Castle and borough. Memo from the Director of Museums to Councillor M. Buckley, $21^{\text {st }}$ September 1989 (Hart_Sheffield Castle and Borough_1989)

Hart, C. 1989b. Sheffield Castle draft paper (Box_File_Written_Text_434-449_report)

Himsworth, J. B. n.d. (a). Notes made for A. L. Armstrong on the content of volume 1 of the Transactions of the Hunter Archaeological Society, Hunter's Hallamshire and Harrison's survey of 1637 and incorporated in Himsworth 1927-30. Sheffield: private ownership (Pat Wagner) 
Himsworth, J. B. n.d. (b). Sheffield Castle Excavations. Records of an Eye Witness. Typed and abbreviated version of Himsworth 1927-42, Presented to Sheffield City Libraries by bequest of Mr C. H. Lea, July 1965 (Box_File_Written_Text_661-690_report)

Himsworth, J. B. n.d. (c). Sheffield Castle Excavations. Records of an Eye Witness. Typed and abbreviated version of Himsworth 1927-42, Presented to Sheffield City Libraries by bequest of Mr C. H. Lea, July 1965 (Box_File_Written_Text_691-715_report)

Himsworth, J. B. n.d. (d). Undated note recording a visit to the site of Sheffield Castle (AL_ARMSTRONG_1995_85_026_Note)

Himsworth, J. B. 1927-30. THE UNCOVERING OF SHEFFIELD CASTLE SITE. Handwritten diary. Sheffield: private ownership (Pat Wagner)

Himsworth, J. B. 1927-42. Record by an eye-witness of the uncovering of SHEFFIELD CASTLE (typed by C. H. Lea) (HIMSWORTH_JB_1995_89_001-41_Record_By_an_Eye_Witness_of_the_Uncovering_of_ Sheffield_Castle)

Himsworth, J. B. 1930a. Draft response to W. G. Davies written on a letter from Davies, $27^{\text {th }}$ October 1930. Sheffield: private ownership (Pat Wagner)

Himsworth, J. B. 1930b. Letter to A. L. Armstrong, 13 ${ }^{\text {th }}$ May 1930 (AL_ARMSTRONG_1995_85_046-47_ Finds_Correspondence)

Himsworth, J. B. 1930c. Notes on shears for A. L.Armstrong, 29 $9^{\text {th }}$ May 1930 (AL_ARMSTRONG_1995_85_288-294_Finds_Correspondence)

Himsworth, J. B. 1930d. Letter to A. L. Armstrong, 21 ${ }^{\text {st }}$ May 1930 (AL_ARMSTRONG_1995_85_288-294_ Finds_Correspondence)

Himsworth, J. B. 1930e. Letter to A. L. Armstrong, 31 ${ }^{\text {st }}$ October 1930 (AL_ARMSTRONG_1995_85_298-305_ Correspondence)

Himsworth, J. B. 1930f. Letter to Leslie Armstrong in response to suggestions made about the layout of the castle by F. E. P. Edwards, 30 th November 1930 (AL_ARMSTRONG_1995_85_298-305_Correspondence)

Himsworth, J. B. 1935. Some old Sheffield stories, discoveries \& art. Script of a lecture given to the Sheffield Trades Technical Society, $20^{\text {th }}$ November 1935 (Box_File_Written_Text_456-467_lecture_notes)

Himsworth, J. B. 1937. 500 years of Sheffield trade and Sheffield castle. Text of a lecture delivered in 1937 (Box_File_Written_Text_006-15_manuscript)

Himsworth, J. B. 1944. Eye Witnesses of Sheffield Castle. Text of a lecture delivered to the Hunter Archaeological Society (Box_File_Written_Text_526-544_lecture_notes)

Himsworth, J. B. 1964. Biographical Account of Members or Associates of the Original City of Sheffield Artcrafts Guild and their Associates. Unpublished manuscript. Sheffield: University of Sheffield, Western Bank Library ARCH (Archives) (MS.414)

Himsworth, J. B. 1965. Supplement to The Story of Cutlery, unpublished note in the copy of this book presented to the University of Sheffield by the author. Sheffield: University of Sheffield

HLF 2014. Rejection letter to funding application submitted by Sheffield City Council (https://www.what dotheyknow.com/request/413276/response/1008202/attach/html/2/SF4\%20Standard\%20reject\%20letter \%20for\%20first\%20round\%20pass\%20Redacted.pdf.html)

Johnson, W. A. 1927a. Letter to A. L. Armstrong by the Architect of the Co-operative Wholesale Society Limited, Manchester, 10 $0^{\text {th }}$ December 1927 (AL_Armstrong_1995_85_295_Correspondence)

LPL Miscellaneous Papers of the Earls of Shrewsbury and their Household. London: Lambeth Palace Library (cited according to manuscript numbers)

Minutes 2008. Minutes of The Remains of the Sheffield Castle Working Group, $18^{\text {th }}$ September 2008. Sheffield: Sheffield City Council

National Archives E372/30. Exchequer Pipe Roll for Michaelmas 1183 to Michaelmas 1184 (30 Henry II)

Northend, J. W. 1930a. Letter to A. L. Armstrong, $16^{\text {th }}$ August 1930 (AL_ARMSTRONG_1995_85_307-311_ Correspondence)

Northend, J. W. 1930b. Letter to A. L. Armstrong, 30 th $^{\text {th }}$ August 1930 (AL_ARMSTRONG_1995_85_307-311_ Correspondence)

Northend, J. W. 1930c. Letter to A. L. Armstrong, 22 ${ }^{\text {nd }}$ November 1930 (AL_Armstrong_1995_85_296-297_ Correspondence) 
Parsons, J. 1997. Letter to the Directorate of Planning and Economic Development, Sheffield from the Keeper of Archaeology and Ethnography, Sheffield City Museum, 14 $4^{\text {th }}$ May 1997 (Sheffield_Castle_Project_File_05054_Correspondence)

SA/RB1 1775. Rate Books, microfiche 1. Sheffield: Sheffield Archives

SA/RB2 1776. Rate Books, microfiche 2. Sheffield: Sheffield Archives

Sharp, R. F.1929. Letter to J. W. Baggaley, 13 ${ }^{\text {th }}$ March 1929 (SHEFFIELD_CASTLE_PROJECT_FILE_025-49_ Correspondence)

Sheffield City Council 2014. Rediscovering Castlegate Sheffield. Application to the Heritage Lottery Fund (https://www.whatdotheyknow.com/request/413276/response/1008202/attach/3/Sheffield\%20Castle \%20application\%20form\%20Redacted.pdf?cookie_passthrough=1)

Sitwell, G. 1929. Letter to F. Bradbury, 13 ${ }^{\text {th }}$ March 1929 (SHEFFIELD_CASTLE_PROJECT_FILE_025-49_ Correspondence)

Sheffield Archives, Miscellaneous Documents 192. William Dickenson's account book for 1574-1577

Sheffield Archives, ACM/S/75. John Harrison's Survey of the Manor of Sheffield, 1637 (late 17th-century copy)

Taylor, T. H. 1929. Letter to M. Fredericke, The King's Galleries, London, $18^{\text {th }}$ February 1929 (SHEFFIELD_ CASTLE_PROJECT_FILE_025-49_Correspondence)

University of Sheffield 2016. Revealing the Castle, Live Project 2016. Sheffield: School of Architecture, University of Sheffield

University of Sheffield 2017. The Great Pier Exhibition, Castlegate, Live Project 2017. Sheffield: School of Architecture, University of Sheffield

University of Sheffield 2018. Festival of the Mind 20-30 September 2018. Programme. Sheffield: University of Sheffield

Walton, M. 2011. Street Names of Central Sheffield. Study Guide. Sheffield: Sheffield Libraries, Archives and Information

Wigfull, J. R. 1927a. Letter written on behalf of the Hunter Archaeological Society to Mr Forster, Secretary of the Brightside and Carbrook Co-operative Society, 15 ${ }^{\text {th }}$ October 1927 (AL_ARMSTRONG_1995_85_038-45_ Correspondence)

Wigfull, J. R. 1927b. Letter on behalf of the Hunter Archaeological Society to the Lord Mayor of Sheffield, $15^{\text {th }}$ October 1927 (AL_ARMSTRONG_1995_85_038-45_Correspondence)

Wilson MS 295. Miscellaneous Papers collected by John Wilson (1719-83). Leeds: Brotherton Library, University of Leeds

\section{Maps, plans, drawings and photographs}

Anon. c.1825. River Sheaf and the Shrewsbury Hospital, Sheffield (Museums Sheffield; accession no. K1930.30)

Anon. 1897. Photograph of Queen Victoria's visit to Sheffield, Blonk Street, decorative arch (s01540; http://www.picturesheffield.com/)

Anon. 1900-19. Rear view of the Alexandra Theatre, showing stilts over the combined flow of the Rivers Don and Sheaf, from Exchange Street Bridge (s12223; http://www.picturesheffield.com)

Anon. 1922. Plan of proposed new developments on Castle Hill. Drawing no.4927. Tracing from plan loaned from Improvement Surveyor, 30 $0^{\text {th }}$ October 1922 (Drawer_9_012_construction_plan)

Anon. 1929b. Sketch of the bedstead associated with Mary Queen of Scots on $14^{\text {th }}$ March 1929 possibly by J. W. Baggaley (SHEFFIELD_CASTLE_PROJECT_FILE_025-49_Correspondence)

Anon. 1930a. Castlegate. Details of old foundations (Drawer_10_065_construction_drawing)

Anon. 1950. Sketch of the Brightside and Carbrook Co-operative Society's new store, Angel Street (y08993; http://www.picturesheffield.com)

Anon. 1987. Sheffield Castle remains of large oak beam (s45020; http://www.picturesheffield.com)

Bartlett, J. E. and Butcher, L. H. n.d. Diagrammatic methodology plan (Drawer_9_009_methodology_diagram) Beswick, P. 1972d. Sketch of Castlegate retaining wall, May 1972 (Drawer_8_025_plan)

Buck, N. 1745. The East Prospect of Sheffield in the County of York. Sheffield: Sheffield Archives

Butcher, L. H. n.d. (b). Draft of an isometric drawing of the gatehouse and adjacent section of south moat (Drawer_10_034-35_draft_isometric) 
Butcher, L. H. n.d. (c). Isometric drawing of the west tower, gatehouse and pier (Drawer_6_111_draft_isometric) Butcher, L. H. n.d. (d). Isometric drawing of the east tower (Drawer_10_057_drawing)

Butcher, L. H. n.d. (e). Draft isometric drawing of the gatehouse and south and west moats (Drawer_10_062-63_ isometric)

Butcher, L. H. n.d. (f). Sketch of features recorded in the section above the Don by Joseph Himsworth, Pauline Beswick and Leslie Butcher (Drawer_10_025_section)

Butcher, L. H. n.d. (g). Section along the east side of Castle Hill (Drawer_8_006_section)

Butcher, L. H. n.d. (h). Ordnance Survey 1:1250 map of Castle Market annotated by L. H. Butcher (Drawer_8_014_map)

Butcher, L. H. n.d. (i). Contour map overlain on Ordnance Survey 1:1250 map of Castle Hill (Drawer_8_022_ map_overlay)

Butcher, L. H. n.d. (j). Plan of the moat showing locations of foundation shafts overlain on map of Castle Hill (Drawer_6_076_plan)

Butcher, L. H. n.d. (k). Isometric drawing of foundation shafts G5, G7 and H5 (Drawer_7_004_isometric)

Butcher, L. H. n.d. (l). Elevation drawings of Sheffield Castle gatehouse (Drawer_6_075_drawing)

Butcher, L. H. n.d. (m). Drawing showing the profile of the south moat and southern end of the west moat (Drawer_7_001_section)

Butcher, L. H. n.d. (n). Plan of the gatehouse, forebuilding and pier as revealed during construction work (Drawer_9_020_plan)

Butcher, L. H. n.d. (o). Plan and elevation drawing of the gatehouse, forebuilding and pier (Drawer_6_074_ drawing)

Butcher, L. H. n.d. (p). Plan of the gatehouse, forebuilding and pier (Drawer_9_010_plan)

Butcher, L. H. n.d. (q). Profile drawing of the gatehouse (Drawer_6_073_drawing)

Butcher, L. H. n.d. (r). Drawings of the east side of the castle site (Drawer_6_078-80_drawings)

Butcher, L. H. n.d. (s). Photographs mounted on card of the foundation shafts and sections recorded by Leslie Butcher (SC2_3_DONE)

Butcher, L. H. n.d. (t). Profile of the south moat at the west end of Exchange Street (Drawer_7_002_section)

Butcher, L. H. n.d. (u). Contour map of the base of the moat (Drawer_8_040_topographic_plan)

Butcher, L. H. n.d. (v). Isometric drawing of the ditches at the junction of Exchange Street and Waingate (Drawer_6_103_drawings)

Butcher, L. H. n.d. (w). Isometric drawing of foundations shafts dug through the moat at the junction of Exchange Street and Waingate (Drawer_7_003_Isometric)

Butcher, L. H. 1958a. Sketch of Castle Hill Market showing the excavations by A. L. Armstrong and L. H. Butcher (Drawer_6_112_plan)

Butcher, L. H. 1958b. Isometric drawing of the gatehouse used in the Sheffield City Museum display from 1958 (Drawer_2_1_isometric_drawing)

Butcher, L. H. 1958c. Isometric drawing of the gatehouse (Drawer_6_111_draft_isometric)

Butcher, L. H. 1958-62b. Section drawings of foundation shafts E13, F11, F13, F20, F22 (Drawer_6_101-101a_ drawings)

Butcher, L. H. 1958-62c. Elevation of the gatehouse visible in foundation shaft H5 (Drawer_8_001_section)

Butcher, L. H. 1958-62d. Section drawings of foundation shafts G22, G23, G-H24, H2-4, H23, H24, J23, J24a, and Manhole 3 in Transport Canteen Yard (Drawer_9_018_sections)

Butcher, L. H. 1958-62e. Section drawings of foundation shafts E15, E17, E19, E22, F9, F21 and F23 and the east side of the 1929 building (Drawer_8_028_sections)

Butcher, L. H. 1958-62f. Plan of the moat and a cross-section through the south moat including the gatehouse (Drawer_6_002_plan)

Butcher, L. H. 1958-62g. Section drawings of foundation shafts G5, G7, G9, G23, G24, G/H24, H5, H23, H24, J24 and the retaining wall on Waingate (Drawer_9_019_sections)

Butcher, L. H. 1959. Section drawing of the east side of the castle site (Drawer_8_002_section)

City Architect's Department 1930. River Don street - details of old foundations, 17 $7^{\text {th }}$ October 1930 (BUTCHER_1976_1064_254-254a_Drawing)

Davies, W. G. 1928. Castle Hill Market, Castle Hill. Plan of Section C. C. DWG No. 7269 (Drawer_8_024_ annotated_section) 
Denton, E. 1946. Drawing of the Brightside and Carbrook Co-operative city centre stores (s11202; http://www .picturesheffield.com)

Earl, H. E. 1844. Lady's Bridge, Wicker, Tower Grinding Wheel in background, Wicker Tilt in foreground (s07500; http://www.picturesheffield.com)

Fairbank, W. 1769. A Plan of the Tenements etc. on the Castle Hill in Sheffield demised by the Duke of Norfolk to John Waite. Sheffield: Sheffield Archives

Fairbank, W. 1771a. A Correct Plan of the Town of Sheffield in the County of York. Sheffield: Sheffield Archives

Fairbank, W. 1771b. A Plan of Sundry Tenements and Yards Belonging to the Duke of Norfolk betwixt the Waingate, Castle Fold and Castle Hill in Sheffield. Sheffield: Sheffield Archives

Fairbank, W. 1781. Plan of Land and Tenements in Sheffield Park. Sheffield: Sheffield Archives

Fairbank, W. 1795. A Map of the Parish of Sheffield. Sheffield: Sheffield Archives

Fairbank, W. 1797. A Plan of the Town of Sheffield in the County of York. Sheffield: Sheffield Archives

Gosling, R. 1736. A Plan of Sheffield. Sheffield: Sheffield Archives

Ordnance Survey 1853. 6 inch:1 mile map sheets Yorkshire 294 and 295. London: Ordnance Survey

Oughtibridge, T. 1737. North Perspective View of the Town of Sheffield. Sheffield: Sheffield Archives

Goad Fire Insurance Map 1888. Sheffield: Sheffield Archives (http://www.bl.uk/onlinegallery/onlineex /firemaps/england/yorkshire/mapsu145ubu21u1uf006r.html)

Goad Fire Insurance Map 1896. Sheffield: Sheffield Archives (http://www.bl.uk/onlinegallery/onlineex /firemaps/england/yorkshire/mapsu145ubu21u2uf006r.html)

Himsworth, J. B. 1930g. Sketch of a section of archaeology exposed above the River Don in 1930. Sheffield: Private archive of Pat Wagner

Johnson, W. A. 1927b. Brightside and Carbrook Co-operative Society Ltd. New central premises. Foundation plan (Box_File_Drawings_Plans_Maps_007_foundation_plan)

Johnson, W. A. 1927c. Brightside and Carbrook Co-operative Society Ltd. New central premises. Foundation sections (Drawer_9_013-13a_construction_sections)

JWM n.d. The oldest furnace in Sheffield on the site of Sheffield Castle; photographed c.1851-99 (s10000; http://www.picturesheffield.com)

Lea, C. H. n.d. Wall at Blackbank, Arbourthorne. Part of the old deer park of Sheffield Manor House (y01807; http://www.picturesheffield.com)

Lea, C. H. 1945. Photograph of a portion of wall 'rescued' by Samuel Roberts and re-erected in grounds of Queen's Tower, Norfolk Park (y01796; http://www.picturesheffield.com)

Lees, C. E. 1918. Photograph of an eighteenth-century brick-built building with lower parts built in stone next to a narrow lane to the east of Castle Hill (lent to the Mappin Art Gallery) (SHEFFIELD_CASTLE_ PROJECT_FILE_001)

Ove Arup \& Partners 1957. Castle Hill Market - Sheffield. Foundation plan - high \& low blocks (Drawer_7_014_construction plan)

Ove Arup \& Partners and Butcher L. H. 1957. Plan of Castle Hill Market annotated by L. H. Butcher (Drawer_6_083-86_photographic plans)

Pottery illustrations, 1964-66. Drawings of pottery recovered during excavations on the site of Sheffield Castle (Drawer_6_004-72_pottery_illustrations)

Skill, E. C. n.d. Timber framed building (formerly a large town house), High Street at the corner of Change Alley (s00362; http://www.picturesheffield.com)

Senior, A. 1928. Chamfered base of pillar found on the site of Sheffield Castle in November 1928 (BUTCHER_1976_1064_306)

Smith, P. 1987. Sheffield Castle remains - charred remains of a wooden post within the remains of an 11th century building (s45026; http://www.picturesheffield.com)

Steel, K. 1964. Painting of Sheffield Castle (v04204; http://www.picturesheffield.com)

Womersley, J. L. and Butcher, L. H. 1957a. Castle Hill Retail Markets extensions. Plan showing ducts \& drainage. Taken immediately before lower G. F. level. Annotated by L. H. Butcher (Drawer_7_013_annotated_plan)

Womersley, J. L. and Butcher L. H. 1957b. Plan of Castle Hill Market by J. L. Womersley and annotated by L. H. Butcher (Drawer_6_003_plan) 


\section{Newspaper articles, online news reports and websites}

A matter of preservation, 1927. Sheffield Daily Telegraph, $13^{\text {th }}$ October 1927

Ancient furnace on the site of Sheffield Castle, 1915. Sheffield Daily Telegraph, 30 ${ }^{\text {th }}$ March 1915

Anon. 1928. Advertisement from The Connoisseur featuring a bedstead for sale at the King's Galleries, King's Road, Chelsea, London, on $28^{\text {th }}$ October 1928 (SHEFFIELD_CASTLE_PROJECT_FILE_025-49_ Correspondence)

AHRC 2016. The impact of AHRC research April 2015-March 2016 (https://ahrc.ukri.org/documents/project -reports-and-reviews/the-impact-of-ahrc-research/2015-16)

A. S. M. 1927. The hall of Waltheof. Sheffield Daily Telegraph, $11^{\text {th }}$ May 1927

Armstrong, A. L. 1927b. Relics of old Sheffield Castle. Discovery of interesting links with Queen Mary's days. Yorkshire Telegraph and Star (late October/early November 1927) (AL_ARMSTRONG_1995_85_160-175_ Newspaper_Cuttings)

Armstrong, A. L. 1929c. Discovery on site of Sheffield Castle. Is it Waltheof's hall? Latest find may settle agelong controversy. Sheffield Daily Telegraph, 30 $0^{\text {th }}$ March 1929 (AL_ARMSTRONG_1995_85_033_Newspaper_Cutting)

Beauty and interest in North-East Notts, 1931. Sheffield Daily Telegraph, 16 ${ }^{\text {th }}$ November 1931

Boland, F. W. 1926. Letters to the Editor. Sheffield street names. Sheffield Daily Telegraph, $5^{\text {th }}$ October 1926

Bradbury, J. 1927. Letter to the Editor. Sheffield Daily Telegraph, 19 ${ }^{\text {th }}$ October 1927

Burn, C. 2018. How Sheffield Castle excavation holds key to area's regeneration hopes. Yorkshire Post, $8^{\text {th }}$ October 2018

Castlegate: Tonight the streets are ours, 2019. Sheffield City Council News, $3^{\text {rd }}$ May 2019 (https://sheffieldnews room.co.uk/news/castlegate-tonight-the-streets-are-ours)

Castlegate News. 2014. Newsletter of the Castlegate Partnership Group, 2. September 2014

Castle moat find, 1927. Sheffield Daily Telegraph, $13^{\text {th }}$ September 1927

Castle relics. Ancient skeleton found in Sheffield, 1927. Sheffield Daily Telegraph. $21^{\text {st }}$ September 1927

Castle site. Fate of Sheffield relic in balance, 1927. Yorkshire Telegraph and Star, $13^{\text {th }}$ October 1927 (Box_File_ Newspapers_001-8_newspaper_cuttings)

Current topics: the hall of Waltheof, 1929. Sheffield Daily Telegraph, $1^{\text {st }}$ April 1929

Deaths, 1928. Sheffield Daily Telegraph, $21^{\text {st }}$ January 1928

English Heritage 2003. Listing Report for Monument Grounds, Sheffield (https://historicengland.org.uk/listing /the-list/list-entry/1000284)

English Heritage 2009. Appendix 1: English Heritage Listing Report, Castle House, 1 (https://historicengland .org.uk/listing/the-list/list-entry/1393220)

F. C. 1927. The hall of Waltheof. Sheffield Daily Telegraph, $14^{\text {th }}$ May 1927

Florentine guilds. Where football, cricket and tennis originated 1924. Sheffield Daily Telegraph, $10^{\text {th }}$ December 1924

French art craftsmanship, 1922. Sheffield Daily Telegraph, $27^{\text {th }}$ January 1922

Gatty, I. 1927. The hall of Waltheof. Sheffield Daily Telegraph, $13^{\text {th }}$ May 1927

Green Estate 2016. In the beginning (http://greenestate.org.uk/about/history-of-green-estate; last accessed $20^{\text {th }}$ February 2019)

Hall, T. W. 1923. Long-lost Hallam. Sheffield Daily Telegraph, 8th January 1923

Himsworth, J. B. 1924. Sheffield castle next? Sheffield Daily Telegraph, $1^{\text {st }}$ July 1924

Himsworth, J. R. 1936. Peace and friendship with Russia. Daily Independent, $8^{\text {th }}$ December 1936

Hopkinson, G. 1958a. History unearthed by market excavations. Sheffeld Telegraph, $25^{\text {th }}$ April 1958 (BUTCHER_1976_1064_261-263_Newspaper_Cuttings)

Hopkinson, G. 1958b. Relics found in excavations: Civil War spur and ancient knife. Sheffield Telegraph, $2^{\text {nd }}$ May 1958 (BUTCHER_1976_1064_261-263_Newspaper_Cuttings)

Jackson, J. 2016. Sun removes inaccurate article claiming Sheffield estate 'worst in Britain. Guardian, $22^{\text {nd }}$ March 2016

Lee, C. 2016. Sheffield's estates show us the perils of half-baked regeneration. The Guardian, $30^{\text {th }}$ March 2016

Local Government Association 2017. (https://www.local.gov.uk/people-culture-place-role-culture-place making) 
McCaffrey, J. 2007. This our Manor. What life is really like on one of Britain's worst no-go estates. The Mirror, $27^{\text {th }}$ April 2007

Manor and Castle Development Trust 2019. (https://manorandcastle.org.uk)

Museums Sheffield 2019a. The Sheffield Cutlery Map (http://www.sheffieldcutlerymap.org.uk/location /b-worth-sons/; last accessed $19^{\text {th }}$ February, 2019)

Museums Sheffield 2019b. Online collections catalogue (http://collections.museums-sheffield.org.uk; last accessed $19^{\text {th }}$ February, 2019)

New light on city castle. Society told of finds, 1961. Sheffield Telegraph, $11^{\text {th }}$ January 1961 (BUTCHER_1976_1064_261-263_Newspaper_Cuttings)

New Masonic Lodge in Sheffield. Consecration at Cutlers' Hall, 1911. Sheffield Daily Telegraph, $6^{\text {th }}$ April 1911

Odom, W. 1911. Restful days in Northumbria. Sheffield Daily Telegraph, $31^{\text {st }}$ August 1911

Old Sheffield, 1922. Sheffield Daily Telegraph, $7^{\text {th }}$ February 1922

Old Sheffield. Many thousands visit the exhibition 1929. Sheffield Daily Independent, $28^{\text {th }}$ February 1929

Part of Sheffield castle wall unearthed, 1927. Yorkshire Telegraph and Star, $20^{\text {th }}$ September 1927

Saxon or Norman? More discoveries on site of Sheffield castle 1929. Sheffield Daily Telegraph, $27^{\text {th }}$ March 1929

Sheffield Art Society and Sketching Club, 1896. Sheffield and Rotherham Independent, $15^{\text {th }}$ August 1896

Sheffield Castle, 1927. Sheffield Daily Telegraph, $13^{\text {th }}$ October 1927 (Box_File_Newspapers_001-8_newspaper_ cuttings)

Sheffield Castle: another relic, 1908. Sheffield Daily Telegraph, 24 $4^{\text {th }}$ November 1908

Sheffield Castle. Mr Armstrong's lecture on recent finds, 1928. Sheffield Daily Telegraph, $12^{\text {th }}$ December 1928

Sheffield Castle relic. Lord Mayor favours scheme for preservation, 1927. Sheffield Daily Telegraph, $14^{\text {th }}$ October 1927 (Box_File_Newspapers_001-8_newspaper_cuttings)

Sheffield Castlegate: Virtual model of castle recreated, 2018. BBC news online, $20^{\text {th }}$ September 2018 (https:// www.bbc.co.uk/news/uk-england-south-yorkshire-45587064)

Sheffield City Council 2016. Work on $£ 5.8 \mathrm{~m}$ Grey To Green Phase 2 begins (https://sheffieldnewsroom.co.uk /news/grey_to_green_phase_two)

Sheffield City Council 2017. Manor Castle Ward (https://www.sheffield.gov.uk/content/dam/sheffield/docs /your-city-council/facts-figures/ward-profiles/Manor\%20Castle.pdf)

Sheffield down the ages, 1929. Sheffield Daily Telegraph, $28^{\text {th }}$ June 1929

Sheffield of long ago, 1929. Sheffield Daily Telegraph, $22^{\text {nd }}$ June 1929

Sheffield pageant, 1931. Sheffield Daily Telegraph, 24 $4^{\text {th }}$ June 1931

Sheffield's history; story told in pageant form, 1924. Sheffield Daily Telegraph, $27^{\text {th }}$ June 1924

Sheffield's oldest furnace (photograph), 1915. Sheffield Daily Telegraph, 30 $0^{\text {th }}$ March 1915

Sheffield's streets. Old names and their origin explained, 1922. Sheffield Daily Telegraph, $13^{\text {th }}$ December 1922

Small, W. H. 1922. Old Sheffield. Sheffield Daily Telegraph, $7^{\text {th }}$ February 1922

Social Enterprise UK 2019. Website of the national body for Social Enterprise (https://www.socialenterprise .org.uk)

Survey of Sheffield Castle remains. Suggestion for the preservation of the relics, 1927. Yorkshire Telegraph and Star, October 1927 (AL_ARMSTRONG_1995_85_035_Newspaper_Cutting)

The History of Sheffield in Pageant, 1931. Sheffield Daily Telegraph, 22 ${ }^{\text {nd }}$ June 1931

The royal visit to Sheffield. The whole arrangements, preparations, decorations and illuminations, 1875. Sheffield Daily Telegraph, $12^{\text {th }}$ August 1875

Torr, G. 2016. Community in focus: Manor is on the up after MP's 'worst estate in Britain' comments. Sheffield Star, $27^{\text {th }}$ October 2016

Transferring relics, 1927. Sheffield Mail, $14^{\text {th }}$ October 1927

Tresoldi, E. 2019. (https://www.edoardotresoldi.com/concept)

Urban Splash 2019. Park Hill Sheffield (https:/www.urbansplash.co.uk/regeneration/projects/park-hill)

W. 1914. Sheffield castle. Sheffield Daily Telegraph, $1^{\text {st }}$ July 1914

Waltheof. 1912a. Letters to the Editor. Sheffield Daily Telegraph, 29 ${ }^{\text {th }}$ March 1912

Waltheof. 1912b. Letters to the Editor. Sheffield Daily Telegraph, 30 $0^{\text {th }}$ March 1912

Ward, S. A. 1926. Sheffield street names. Sheffield Daily Telegraph, $17^{\text {th }}$ February 1926

Winder, T. 1923. Hallam or Hallamshire. Sheffield Daily Telegraph, $16^{\text {th }}$ January 1923

Yorkshire Artspace 2019. (http://artspace.org.uk) 


\section{Unpublished reports, theses and booklets}

Allott, L. and Macey-Bracken, E. 2020. Wood. In A. Tuck, Sheffield Castle, Sheffield, South Yorkshire: archaeological evaluation final archive report. Unpublished client report. Sheffield: Wessex Archaeology

Andrews, P. and Mackenzie, R. 2020. Slag. In A. Tuck, Sheffield Castle, Sheffield, South Yorkshire: archaeological evaluation final archive report. Unpublished client report. Sheffield: Wessex Archaeology

Anon. 1930b. Castle Hill Market. Official opening by the Minister of Health (The Right Hon. Arthur Greenwood, M.P.). Souvenir copy. Friday 9th May 1930. Sheffield: City of Sheffield Printing and Stationery Department (Box_File_Printed_Article_Copies_059-67_Castle_Hill_Market_Official_Opening)

Anon. 1969. Report and Balance-Sheet - Half Year Ended January 27 1969. Sheffield: Brightside and Carbrook Co-operative Society

Atkinson, S. 1994. Archaeological Desktop Assessment of Land off Angel Street, Sheffield. Sheffield: South Yorkshire Archaeology Service

Baker, K. and Baker, S. 2008. Archaeological Works at the Upper Chapel, Norfolk Street, Sheffield. Report 732f.3(1). Sheffield: ARCUS (https://doi.org/10.5284/1003656)

Banham, J. 2011. Politeness in Eighteenth-Century Sheffield: practices, accoutrements and spaces for sociability. Unpublished PhD Thesis, University of Sheffield (http://etheses.whiterose.ac.uk/id/eprint/2238)

Barker, D. and Ford, D. 1999. Data sheets produced to accompany an English Heritage sponsored course on post-medieval and early modern ceramics. Stoke-on-Trent

Bartlett, H. and Brien, M. 2013. Castle Market Sheffield: archaeological ground penetrating radar survey. Report 11912/173-2. Leeds: Met Geo Environmental

Bartlett, J. 1973. Excavations at Sheffield Manor, 1972. Interim report. Sheffield: Sheffield City Museum

Bartlett, J. 1974. Excavations at Sheffield Manor, 1973. Interim report. Sheffield: Sheffield City Museum

Bartlett, J. and Beswick, P. 1979. Excavations at Sheffield Manor, 1979. Interim report. Sheffield: Sheffield City Museum

Bayliss, D. and Hague, G. 1997. Manor Castle Colliery Coke Ovens, Sheffield. Sheffield: South Yorkshire Industrial Society Field Recording Group

Belford, P. 1998. An Archaeological Desk-Based Assessment of the Sheffield Markets Site, Sheffield, South Yorkshire. Report 413. Sheffield: ARCUS

Belford, P. 1999. An Archaeological Field Evaluation at the Broad Street Car Park Sheffield. Sheffield Markets evaluation phase 1a. Report 413b.2. Sheffield: ARCUS

Beswick, P. 1974. Excavations at Sheffield Manor, 1974. Interim report. Sheffield: Sheffield City Museum

Beswick, P. 1979. Excavations at Sheffield Manor, 1979. Interim report. Sheffield: Sheffield City Museum

Beswick, P. 2002. Excavation and Research at Sheffield Manor 1968-1980. Post-excavation assessment and project design. Sheffield: Sheffield City Museum

Boyle, A. 2006. Cistercian Ware Pottery in Yorkshire and the East Midlands. Unpublished PhD thesis, University of Nottingham

Brown, A. 2020. Pollen. In A. Tuck, Sheffield Castle, Sheffield, South Yorkshire: archaeological evaluation final archive report. Unpublished client report. Sheffield: Wessex Archaeology

Burgess, A., Dawson, L. and Harrison, C. 2011. Manor Lodge, Sheffield, South Yorkshire. The long gallery \& inner court excavations and building recording. Sheffield: Wessex Archaeology

Cameron, N. 2020. Diatoms. In A. Tuck, Sheffield Castle, Sheffield, South Yorkshire: archaeological evaluation final archive report. Unpublished client report. Sheffield: Wessex Archaeology

Cattell, S. 2016. Community Archaeology Excavation. Halton Castle, Runcorn. Unpublished client report 24/2015. Salford: Salford Archaeology

Chartered Institute for Archaeologists [CIfA] 2014. Standard and Guidance for Archaeological Field Evaluation. Reading: CIfA

Champness, C. 2008. Fletching Mill, Fletching, Sussex. Oxford Archaeology Geological Assessment Report 4225. Oxford: Oxford Archaeology

Clark, J. and Jack, S. 2002. Conservation Statement, Manor Lodge Farm, Sheffield. Report for Manor Castle Development Trust. York: Field Archaeology Specialists

Clark, M. 2019. Castle Hill, Sheffield - life after death. Unpublished undergraduate dissertation, University of Sheffield 
Cockrell, T. 2016. The Don Valley in Prehistory: upland and lowland developments and interactions. Unpublished $\mathrm{PhD}$ thesis, University of Sheffield

Crewe, V. and Askew, R. 2012. Excavations in the Long Gallery and Outer Court at Manor Lodge, Sheffield, June-July 2011. Sheffield: University of Sheffield

Cumberpatch, C. G. 2002a. Medieval and later pottery. In G. Davies and J. Symonds, Archaeological Evaluation of the Upper Loading Bay, Castle Market Sheffield. Report 413h. Sheffield: ARCUS, pp. 30-5

Cumberpatch, C. G. 2004. South Yorkshire and North Derbyshire Medieval Ceramics Reference Collection. York: Archaeology Data Service (https://doi.org/10.5284/1000242)

Cumberpatch, C. G. 2007. Pottery from Excavations in Church Walk, Doncaster 'Askew's Print Shop'. Report for West Yorkshire Archaeological Services

Cumberpatch, C. G. 2010. Pottery. In L. Mepham and A. Powell, Manor Lodge, Sheffield: interim report on the 2009 excavation. Sheffield: Wessex Archaeology/University of Sheffield, pp. 15-28 (https://doi.org/10.5284 /1038876)

Cumberpatch, C.G. 2013. Medieval and Later Pottery from Excavations at Conisbrough Castle: a report on the material from excavations undertaken in the 1960s and 1970s. Report for English Heritage

Cumberpatch, C. G. 2014a. Medieval and Later Pottery from Excavations at Conisbrough Castle, July 2014. Unpublished archive report for English Heritage

Cumberpatch, C. G. 2016. Pottery from the community archaeology project at Conisbrough Castle, 2016. Unpublished archive report for English Heritage

Cumberpatch, C. G. 2017. Pottery from excavations by A.L. Armstrong and L.H. Butcher on the site of Sheffield Castle (https://doi.org/10.5284/1074899)

Cumberpatch, C. 2020. Pottery. In A. Tuck, Sheffield Castle, Sheffield, South Yorkshire: archaeological evaluation final archive report. Unpublished client report. Sheffield: Wessex Archaeology

Cumberpatch, C. G. in prep. 1. Appendix 2. In Pottery from sites excavated on the line of the Sheffield Inner Ring Road (602). Archive Report for Wessex Archaeology

Cumberpatch, C. G. in prep. 2. Medieval and later pottery in Doncaster: a review of the evidence

Cumberpatch, C. G. and Young, J. n.d. Medieval and Later Pottery from Excavations at Conisbrough Castle: a report on the material from excavations undertaken in the 1960s and 1970s. Unpublished archive report for English Heritage

Cumberpatch, C. G. and Thorpe, R. 2002. The Archaeology of Chesterfield: a report on the results of a pilot study. English Heritage Project Report no. 3184. London: English Heritage

Davies, G. 2000. An Archaeological Evaluation Sheffield Markets: phase $1 \mathrm{~b}$ trial trenching of Sheffield Castle, Castlegate, Sheffield. Report 413c. Sheffield: ARCUS

Davies, G. and Symonds, J. 2002. Archaeological Evaluation of the Upper Loading Bay, Castle Market Sheffield. Report 413h. Sheffield: ARCUS

Davies, G. and Willmott, H. 2002. Excavation and Research at Sheffield Castle 1927-1960: an assessment and project design. Sheffield: ARCUS

Dennison, E. 2014. Sheffield Castle, Sheffield, South Yorkshire Specification of Work for Post-excavation Assessment of 1927-1990 Archives. Report 2013/460.R03. Beverley: Ed Dennison Archaeological Services

Douglas, M. and Jessop, O. 2007. Archaeological Building Recording and Watching Brief: Manor Oaks Farm, Manor Lane, Sheffield, South Yorkshire. Report 873b.3. Sheffield: ARCUS

EDAW 2005. Castlegate - A New Vision. London: EDAW

English Heritage 2018. Heritage and the Economy 2018. London: English Heritage (https://historicengland.org .uk/content/heritage-counts/pub/2018/heritage-and-the-economy-2018)

Friends of Sheffield Castle 2019. Our Blueprint for the Site of Sheffield Castle. Sheffield: FOSC

Gardner, C. and Frudd, A. 2015. Furnace Hill, West Bar, Sheffield. Unpublished client report 2009-10/972. Oxford: Oxford Archaeology

Gregory, R. 2009. Blocks 6 and 11, The Moor, Sheffield. Report L9919. Oxford: Oxford Archaeological Unit (https://doi.org/10.5284/1011738)

Hadley, D. and Harlan, D. 2011. Excavations at Sheffield Manor Lodge 1968-1980. Sheffield: University of Sheffield

Heath, A. 2003. Prehistoric Settlement and Agriculture on the Eastern Moors of the Peak District. Unpublished $\mathrm{PhD}$ thesis, University of Sheffield 
Historic England 2015. Geoarchaeology. Using earth sciences to understand the archaeological record. London: Historic England

Historic England 2018. Heritage and the Economy. Heritage counts. London: Historic England

ICOSSE. 2005. Sheffield Manor Lodge Archaeological Desk Study. Sheffield: ICOSSE

Institute of Field Archaeologists 1994. Standard and Guidance for Archaeological Field Evaluation

Latham, I. D. and Atkinson, S. 1994. Report on an Archaeological Investigation of Some Structural Remains of Sheffield Castle, Castle Market, Sheffield. Report for Sheffield City Markets Department. Sheffield: South Yorkshire Archaeology Field and Research Unit

Lee, D. 2007. Ash House Farm, Arbourthorne, South Yorkshire. Archaeological Investigations, 2 volumes. Client report no. 1653. Wakefield: Archaeological Services WYAS

McCoy, M. 2007a. Interim Statement on Archaeological Evaluation on Land Immediately to the East of the Manor Lodge, Manor Lane, Sheffield, South Yorkshire. Report 1107.2. Sheffield: ARCUS

McCoy, M. 2007b. Assessment Report on Archaeological Evaluation at Manor Lodge, Manor Lane, Sheffield, South Yorkshire. Report 1107.3. Sheffield: ARCUS

McCoy, M. 2009. Manor Lodge, Sheffield. Archaeological evaluation. Report 1107.8. Sheffield: ARCUS

McCoy, M. and Stenton, M. 2009. Sheffield Castle, Sheffield. Archive scoping review. Report 669b(1). Sheffield: ARCUS

Maltby, J. M 1980. The Faunal Remains from the Sheffield Manor Excavations 1971-1974. Sheffield: University of Sheffield

Martin, J. B. 1956. The Antiquarian Collections of Nathaniel Johnston (1629-1705). Unpublished BLitt thesis, University of Oxford

May, R. 2008. Archaeological Desk-Based Assessment for the Pennine Village Sites, Manor Lane, Sheffield. Report 1239.1(1). Sheffield: ARCUS

Mepham, L. 2017. Miscellaneous finds from Sheffield Castle (https://doi.org/10.5284/1074899)

Mepham, L. 2020a. Glass. In A. Tuck, Sheffield Castle, Sheffield, South Yorkshire: archaeological evaluation final archive report. Unpublished client report. Sheffield: Wessex Archaeology

Mepham, L. 2020b. Metalwork. In A. Tuck, Sheffield Castle, Sheffield, South Yorkshire: archaeological evaluation final archive report. Unpublished client report. Sheffield: Wessex Archaeology

Mepham, L. 2020c. Shells. In A. Tuck, Sheffield Castle, Sheffield, South Yorkshire: archaeological evaluation final archive report. Unpublished client report. Sheffield: Wessex Archaeology

Mepham, L. and Powell, A. 2010. Manor Lodge, Sheffield: interim report on the 2009 excavation. Sheffield: Wessex Archaeology/University of Sheffield (https://doi.org/10.5284/1038876)

Mepham, L. and Mora-Ottomano, A. 2020. Building material. In A. Tuck, Sheffield Castle, Sheffield, South Yorkshire: archaeological evaluation final archive report. Unpublished client report. Sheffield: Wessex Archaeology

Merrony, C. J. 1990. 27/29 High St Sheffield: evaluation report. Sheffield: South Yorkshire Archaeology Service

Mould, Q. 2009b. The leather from the Grand Arcade, Cambridge. Typescript submitted to Cambridge Archaeological Unit

Mould, Q. 2010. The leather from Oxford Castle and Paradise Street. Typescript submitted to Oxford Archaeology April 2010

Mould, Q. 2017a. The leather from Sheffield Castle (https://doi.org/10.5284/1074899)

Mould, Q. 2020. Leather. In A. Tuck, Sheffield Castle, Sheffield, South Yorkshire: archaeological evaluation final archive report. Unpublished client report. Sheffield: Wessex Archaeology

Muller, 2015. Landscape architecture on the site of Sheffield Castle. In University of Sheffield 2015, Imagine Castlegate, (https://www.sheffield.ac.uk/polopoly_fs/1.519960!/file/ImagineCastlegate_25mb.pdf), pp. $98-9$

Munby, J., Norton, A. and Poore, D. 2010. Excavations at Oxford Castle, Oxford's Western Quarter from the Mid-Saxon Period to the Late 18th Century. Oxford Archaeology Excavation Report. Oxford: Oxford Archaeology

Museums Sub-Committee of the Libraries Art Galleries and Museums Committee 1960. Sheffield City Museum. Annual Reports. For the two years ending 31st March 1960. Sheffield: City of Sheffield Printing Department (Box_File_Printed_Article_Copies_081-94_City_Museum_Annual_Reports_1958-1960)

Ogden, S. 2018. Castlegate Kickstart. Back to the future! (http://sheffieldcivictrust.org.uk/wp-content /uploads/2018/04/Castlegate-Vision-Mar-18-pdf2.pdf) 
Rakoczy, L. 2007. Archaeology of Destruction: a reinterpretation of castle slightings in the English Civil War. Unpublished PhD thesis, University of York

Richardson, S. and Dennison, E. 2014a. Archaeological Evaluation Strategy for Sheffield Castle, Sheffield, South Yorkshire. Volume 1: Data Gathering, Synthesis and Assessment of Potential. Volume 1a: Textand Appendices. Report 2013/460.R01. Beverley: Ed Dennison Archaeological Services (https://doi.org/10.5284/1028655)

Richardson, S. and Dennison, E. 2014b. Archaeological Evaluation Strategy for Sheffield Castle, Sheffield, South Yorkshire. Volume 1: Data Gathering, Synthesis and Assessment of Potential. Volume 1b: Figures and Plates. Report 2013/460.R01. Beverley: Ed Dennison Archaeological Services

Rotherham, I., Spode, F. and Jones, M. 2001. Manor Castle Home Farm Project: report on the historic landscape, geology and ecology of the area. Sheffield: Hallam Environmental Consultants

Ryder, P. 2019. Lapidary material from Sheffield Castle excavation. In A. Tuck and M. Rajic, Sheffield Castle. Archaeological Evaluation Assessment Report, July 2019. Unpublished client report 201540.03. Sheffield: Wessex Archaeology, pp. 238-48

Ryder, P. 2020. Architectural stone. In A. Tuck, Sheffield Castle, Sheffield, South Yorkshire: archaeological evaluation final archive report. Unpublished client report. Sheffield: Wessex Archaeology

Simmons, E. and Jones, G. 2020. In A. Tuck, Sheffield Castle, Sheffield, South Yorkshire: archaeological evaluation final archive report. Unpublished client report. Sheffield: Wessex Archaeology

Spode, F. 2001. The geology, geomorphology and minerals exploitation of the project area. In I. D. Rotherham, F. Spode and M. Jones. Manor Castle Home Farm Project: report on the historic landscape, geology and ecology of the area. Sheffield: Hallam Environmental Consultants, pp. 7-14

Swann, J. M. 1975. Shoe fashions to 1600. In P. S. Doughty (ed.), Transactions of the Museum Assistants Group for 1973, 12. Belfast: Museum Assistants Group at the Ulster Museum, pp. 14-27

Tuck, A. and Rajic, M. 2018. Sheffield Castle, Sheffield, South Yorkshire: Written Scheme of Investigation for Castlehill Archaeological Survey. Unpublished client report 201540.01, Sheffield: Wessex Archaeology

Tuck, A. and Rajic, M. 2019. Sheffield Castle, Sheffield. Archaeological evaluation assessment report. Unpublished client report 201540.03. Sheffield: Wessex Archaeology

Tuck, A. 2020. Sheffield Castle, Sheffield, South Yorkshire: archaeological evaluation final archive report. Unpublished client report. Sheffield: Wessex Archaeology

Tyers, I. 2020. Dendrochronology. In A. Tuck, Sheffield Castle, Sheffield, South Yorkshire: archaeological evaluation final archive report. Unpublished client report. Sheffield: Wessex Archaeology

University of Sheffield 2015. Imagine Castlegate (https://www.sheffield.ac.uk/polopoly_fs/1.519960!/file /ImagineCastlegate_25mb.pdf)

Waddington, C. 2009. Discovering Sheffield Castle: a prospectus for excavating and presenting Sheffield's lost castle. Report 2009/1. Sheffield: Archaeological Research Services Ltd

Wagner, P. n.d. Joseph Beeston Himsworth. President of the Hunter Archaeological Society 1958-1968. Unpublished typescript: private ownership (Pat Wagner)

Tuck, A., Bromage, S., Carter, E. and Rajic, M. 2019. Hollis Croft, Sheffield, South Yorkshire: strip, map and record, evaluation and watching brief. Unpublished client report 116361.09

White, S. and Higgins, D. 2020. Clay tobacco pipes. In A. Tuck, Sheffield Castle, Sheffield, South Yorkshire: archaeological evaluation final archive report. Unpublished client report. Sheffield: Wessex Archaeology

Whittaker, J. 2020. Ostracods. In A. Tuck, Sheffield Castle, Sheffield, South Yorkshire: archaeological evaluation final archive report. Unpublished client report. Sheffield: Wessex Archaeology

Windle, M. and Albarella, U. 2020. In A. Tuck, Sheffield Castle, Sheffield, South Yorkshire: archaeological evaluation final archive report. Unpublished client report. Sheffield: Wessex Archaeology

Young, J. 2018. The shell-tempered pottery from Sheffield Castle (https://doi.org/10.5284/1074899)

Young, J. 2020. In A. Tuck, Sheffield Castle, Sheffield, South Yorkshire: archaeological evaluation final archive report. Unpublished client report. Sheffield: Wessex Archaeology

\section{Published works}

Addy, S. O. 1893. The Hall of Waltheof, Or, The Early Condition and Settlement of Hallamshire. Sheffield: William Townsend and Son

Allsworth-Jones, P. 2012. Albert Leslie Armstrong 1879-1958. In History Makers. A biographical introduction to the Hunter Archaeological Society, 1912-2012. Sheffield: Northend, pp. 30-1 
Allsworth-Jones, P. 2014. Albert Leslie Armstrong: life and work. Prehistoric Yorkshire 51: 8-16

Andrews, G., Barrett, J. C. and Lewis, J. S. C. 2000. Interpretation not record: the practice of archaeology. Antiquity 74 (285): 525-30

Andrews, P. 2015. Riverside Exchange, Sheffield: Investigations on the Site of the Town Mill, Cutlers' Wheel, Marshall's Steelworks and the Naylor Vickers Works. Salisbury: Wessex Archaeology

Anon. 1644. A Journall, Or, A true and exact Relation of Each dayes passage, of that party of the Right Honourable The Earle of Manchesters Army, Under the command of the ever honoured Major Generall Craford, From the first of August to the end of the same Month. London: Printed for Hugh Perry

Armitage, E. 1912. Early Norman Castles of the British Isles. London: J. Murray

Armstrong, A. L. 1923. Further evidences of Maglemose culture in East Yorkshire. Man 23: 135-8

Armstrong, A. L. 1924. Discovery of a new phase of early flint mining at Grime's Graves, Norfolk. Proceedings of the Prehistoric Society of East Anglia IV: 113-25

Armstrong, A. L. 1925. Excavations at Mother Grundy's Parlour, Creswell Crags, Derbyshire, 1924. Man 55: $146-75$

Armstrong, A.L. 1926a. The Grime's Graves problem in the light of recent researches - Presidential Address. Proceedings of the Prehistoric Society of East Anglia 5: 91-136

Armstrong, A.L. 1926b. Analyses of bronze implements and foundry metal. Man 26: 164-7

Armstrong, A. L. 1928b. Sheffield Castle. Antiquaries Journal VIII(3): 365-7

Armstrong, A.L. 1929d. Excavations at Creswell Crags, Derbyshire, 1924-26, The Pin Hole Cave. Transactions of the Hunter Archaeological Society 3: 116-22

Armstrong, A. L. 1930. Sheffield Castle. An account of the discoveries made during excavations on the site from 1927 to 1929. Transactions of the Hunter Archaeological Society 4: 7-27

Armstrong, A.L. 1931. Rhodesian archaeological expedition (1929): excavations in Bambata Cave and researches on prehistoric sites in southern Rhodesia. Man 61: 239-76

Armstrong, A.L. 1932. Excavations in the Pin Hole Cave, Creswell Crags, Derbyshire. Proceedings of the Prehistoric Society of East Anglia 6: 330-4

Armstrong, A.L. 1936. The antiquity of man in Rhodesia as demonstrated by stone implements of the ancient Zambezi gravels, south of Victoria Falls. Man 66: 331-48

Armstrong, A.L. 1942. Palaeolithic man in the north Midlands. Derbyshire Archaeological Journal 63: 28-60

Armstrong, A.L. 1956. Prehistory: Palaeolithic, Neolithic and Bronze Ages. In Linton, D. L. (ed.), Sheffield and Its Region. Sheffield: British Association for the Advancement of Science, pp. 90-110

Armstrong, P. 2001. Forty years on. East Riding Archaeological Society News 50: 4

Askew, R. 2017. Sheffield Castle and the aftermath of the English Civil War. Northern History 54: 189-210

Atkinson, R. J. C. 1946. Field Archaeology. London: Methuen and Co.

Austin, D. 1984. The castle and the landscape: annual lecture to the Society for Landscape Studies, May 1984. Landscape History 6: 69-81

Austin, D. 2007. Acts of Perception: a study of Barnard Castle in Teesdale. Architectural and Archaeological Society of Durham and Northumberland Research Report 6 (2 Vols). Durham: English Heritage and the Architectural and Archaeological Society of Durham and Northumberland

Baggaley, J.W. 1938. Bronze Age instruments found in Sheffield and district. Transactions of the Hunter Archaeological Society 5: 99-100

Bailey, G. 1995. Detector Finds 2. Chelmsford: Greenlight

Baines, E. 1822. History, Directory and Gazetteer of the County of York. Leeds: Edward Baines

Baird, J. A. and McFadyen, L. (2014). Towards an archaeology of archaeological archives. Archaeological Review from Cambridge 29: 14-32

Baker, K., Baker, S. and Symonds, J. 2011. Archaeological investigations at the Upper Chapel, Norfolk Street, Sheffield, UK. Internet Archaeology 29 (https://doi.org/10.11141/ia.29.4)

Ball, C. 2012. James Ragg Wigfull. In History Makers. A biographical introduction to the Hunter Archaeological Society, 1912-2012. Sheffield: Northend, pp. 24-5

Bahn, P. and Pettitt, P. 2009. Britain's Oldest Art. The Ice Age cave art of Creswell Crags. Swindon: English Heritage 
Barber, S. C. 1931. Excavations at Knaresborough Castle 1925-1928. Yorkshire Archaeological Journal 30: 200-24

Barker, G. 2007. Changing roles and agendas: the Society of Antiquaries and the professionalization of archaeology, 1950-2000. In S. Pearce (ed.), Visions of Antiquity: The Society of Antiquaries of London 1707-2007. London: Society of Antiquaries, pp. 383-413

Barraclough, K. 1984. Steel Making before Bessemer, volume 1. Boca Raton: CRC Press

Bartlett, J. 1977. Leslie Butcher - obituary. Transactions of the Hunter Archaeological Society 10: 301

Bassett, S. 2007. Divide and rule? The military infrastructure of eighth- and ninth-century Mercia. Early Medieval Europe 15: 53-85

Batho, G. R. 1971. A Calendar of the Shrewsbury and Talbot Papers in Lambeth Palace Library and the College of Arms. Volume II: Talbot papers in the College of Arms. Derbyshire Archaeological Record Series 4. London: Her Majesty's Stationery Office

Bayley, J. and Watson, J. 2009. Emerging from the appendices: the contributions of scientific examination and analysis to medieval archaeology. In R. Gilchrist and A. Reynolds (eds) Reflections: 50 years of medieval archaeology, 1957-2007. Leeds: Maney Publishing, pp. 363-81

Bernard, G. W. 2004. Talbot. Francis, fifth earl of Shrewsbury (1500-1560). Oxford Dictionary of National Biography (https://doi.org/10.1093/ref:odnb/26926)

Bernard, G. W. 2012. Talbot. George, fourth earl of Shrewsbury (1468-1538). Oxford Dictionary of National Biography (https://doi.org/10.1093/ref:odnb/26927)

Beswick, P. 1978. The Sheffield Manor products from the Peacock Inn. In P. Borne, T. Courtney and P. Dixon (eds), The Peacock Inn, Chesterfield. Derbyshire Archaeological Journal 98: 47

Beswick, P. 1980. Sheffield Manor. The Archaeological Journal 137: 468-9

Beswick, P. 1995. F.L. Preston 1905-1994. Transactions of the Hunter Archaeological Society 18: 76-8

Beswick, P. 1997. Fredric Preston and the Hunter Archaeological Society. Transactions of the Hunter Archaeological Society 19: 101-11

Beswick, P. and Merrills, D. 1983. L. H. Butcher's survey of early settlements and fields in the southern Pennines. Transactions of the Hunter Archaeological Society 12: 16-50

Biddle, M. 1972. Preface. In C. Heighway (ed.), The Erosion of History. Archaeology and planning in towns. London: Council for British Archaeology, pp. vi-vii

Biddle, M. and Barclay, K. 1990. Sewing pins and wire. In M. Biddle (ed.), Artefacts from Medieval Winchester Parts $i$ and ii: object and economy in medieval Winchester. Winchester Studies 7. Oxford: Clarendon Press, pp. 560-71

Bingham, J. 1929. Souvenir. The Sheffield Castle and Brightside and Carbrook Co-operative Society Limited, 1100-1929. Manchester: Co-operative Society

Birch, W. De G. 1874. Original documents relating to Sheffield, principally in connection with Mary, Queen of Scots. Journal of the British Archaeological Association 30: 308-24

Birrell, J. 1992. Deer and deer farming in medieval England. The Agricultural History Review 40: 112-26

Blackwell, J. 1828. The Sheffield Directory and Guide. Sheffield: John Blackwell

Blair, J. 2018. Building Anglo-Saxon England. Princeton, NJ: Princeton University Press

Bostwick, D. 1985. Sheffield in Tudor and Stuart Times. Sheffield: Sheffield City Museum

Bowen, J. P. 2013. From medieval deer park to an enclosed agricultural and developing industrial landscape: the post-medieval evolution of Lilleshall Park, Shropshire. Midland History 38(2): 194-212

Bradbury, F. 1912. A History of Old Sheffield Plate. London: Macmillan and Co.

Bradley, R. (1997). 'To see is to have seen'. Craft traditions in British field archaeology. In B. L. Molyneaux (ed.) The Cultural Life of Images: visual representation in archaeology. London: Routledge, pp. 62-72

Braudel, F. (1975) The Mediterranean and the Mediterranean World in the Age of Philip II. London: Harper Collins

Brown, D. 1990. Weaving tools. In M. Biddle (ed.), Artefacts from Medieval Winchester Parts $i$ and ii: object and economy in medieval Winchester. Winchester Studies 7. Oxford: Clarendon Press, pp. 225-32

Brown, R. A. 1954. English Medieval Castles. London: Batsford

Brown, S. and Spavold, J. 2019. Excavation at Staunton Lane End Cottage, Ticknall, Derbyshire. Ticknall: Ticknall Archaeological Research Group 
Brown, W. 1894. Yorkshire Lay Subsidy 25 Edward I. Yorkshire Archaeological Society Record Series XVI. London: Yorkshire Archaeological Society

Brownell, W. 1817. Sheffield General Directory. Sheffield: W. Brownell

Bruce, A. and Clarson, D. 2017. Assessing the potential and limits of community-based initiatives in urban regeneration: three decades of experience on Sheffield's Manor estate. Regional Studies, Regional Science 4(1): 80-93

Brunskill, R. W. 1997. Brick Building in Britain. London: Victor Gallancz

Bryant, D. and Knowles, D. 1974. Social contacts on the Hyde Park Estate, Sheffield. The Town Planning Review 45(2): 207-14

Bryant, S. and Wills, J. 2016. Before, during and after: PPG16, its impact after 1990, and the current struggle to retain its legacy. The Archaeologist 98: 4-8

Buchanan, F. 1882. Sparks from Sheffield Smoke: a series of local and other poems. Sheffield: Leader

Buckland, P., Dolby, M., Hayfield, C. and Magilton, J. 1979. The Medieval Pottery Industry in Hallgate, Doncaster: the archaeology of Doncaster. Doncaster: Doncaster Museums and Arts Service

Burkitt, M. 1963. A brief account of the life and work of Albert Leslie Armstrong. In J. Kitching, Bone, Tooth and Horn Tools of Palaeolithic Man. Manchester: University of Manchester, pp. xi-xiv

Butcher, L. H. 1957. Archaeological remains on the Wharncliffe-Greno upland, South Yorkshire. Transactions of the Hunter Archaeological Society 7: 38-9

Butler, L. 1971. Sheffield Manor. Yorkshire Archaeological Journal 43: 199

Carver, M. 1987. Underneath English Towns. Interpreting urban archaeology. London: Fitzhouse Books

Cathcart King, D. J. 1983. Castellarium Anglicanum: an index and bibliography of the castles in England, Wales and the Islands, 2 vols. Council for British Archaeology Research Report 53. London: Council for British Archaeology

Cathcart King, D. J. 1988. The Castle in England and Wales: an interpretative history. London: Routledge

Champion, T. 1996. Protecting the monuments: archaeological legislation from the 1882 Act to PPG 16. In M. Hunter (ed.), Preserving the Past. The rise of heritage in Modern Britain. Stroud: Sutton Publishing, pp. 38-56

Cherry, J. 1972. Post-medieval Britain in 1971. Post-Medieval Archaeology 6: 219-21

Cherry, J. 1973. Post-medieval Britain in 1972. Post-Medieval Archaeology 7: 109

Cherry, J. 1974. Post-medieval Britain in 1973. Post-Medieval Archaeology 8: 128

Cherry, J. 1977. Post-medieval Britain in 1976. Post-Medieval Archaeology 11: 96

Christian, R. 1968. Oakes-in-Norton. Derbyshire Life and Countryside July 1928: 22-5

Clarke, D. forthcoming. The last earl of Hallamshire. Legend, landscape and identity in South Yorkshire. In M. Cheeseman and C. Hart (eds) Nation and Fascination. London: Routledge

Clayton, R. 2012. Leslie H. Butcher 1916-1975. In History Makers. A biographical introduction to the Hunter Archaeological Society, 1912-2012. Sheffield: Northend, p. 38

Coates, B.E. 1967. Parklands in transition - medieval deerpark to modern landscape park. Transactions of the Hunter Archaeological Society 9: 132-50

Coldstream, N. 2003. Architects, advisers and design at Edward I's castles in Wales. Architectural History 46: $19-36$

Collingwood, R. G. 1994. The Idea of History (revised edition; originally published 1946). Oxford: Oxford University Press

Collinson, P. 1987. The English Captivity of Mary Queen of Scots. Sheffield: University of Sheffield

Collis, J. 2001. Digging up the Past. Stroud: Sutton

Conroy, R. 2008. The work and legacy of the Sheffield Artcrafts Guild. Silver Studies 23: 47-52

Coulson, C. 1979. Structural symbolism in medieval castle architecture. Journal of the British Archaeological Association 88: 73-90

Coulson, C. 1993. Specimens of freedom to crenellate by licence. Fortress 18: 3-15

Coulson, C. 2000. Fourteenth-century castles in context: apotheosis or decline? Fourteenth-Century England 1: $133-51$

Coulson, C. 2003. Castles in Medieval Society: fortresses in England, France, and Ireland in the central Middle Ages. Oxford: Oxford University Press

Cowgill, J. de Neergaard, M. and Griffiths, N. 1987. Knives and Scabbards. Medieval finds from excavations in London 1. London: Her Majesty's Stationery Office

Cox, A. and Cox, A. 2001. Rockingham 1745-1842. Woodbridge: Antique Collectors Club 
Cox, J. C. 1896. Lancaster castle. Transactions of the Historic Society of Lancashire and Cheshire 48: 95-122

Cox, J. C 1897. The treatment of our cathedral churches in the Victorian Age. The Archaeological Journal 54: $239-74$

Craven, S. 2001. The British Speleological Association (1935-73) and its founder, Eli Simpson. Cave and Karst Science 28: 99-112

Creighton, O. 2002. Castles and Landscapes: power, community and fortification in medieval England. London: Equinox

Creighton, O. 2018. Overview: castles and elite landscapes. In C. Gerrard and A. Gutierrez (eds), The Oxford Handbook of Later Medieval Archaeology. Oxford: Oxford University Press, pp. 355-70

Creighton, O. and Higham, R. 2004. Castle studies and the 'landscape' agenda. Landscape History 26: 5-18

Crewe, V. 2012. Ancient luxury and modern filth: new insights into 19th century life at Sheffield Manor Lodge. Post-Medieval Archaeology 46(2): 333-66

Crewe, V. and Hadley, D. M. 2013. 'Uncle Tom was there, in crockery': material culture and a Victorian working-class childhood. Childhood in the Past 6(2): 89-105

Crook, D. 2001. The 'Petition of the Barons' and Charters of Free Warren, 1227-58. In P. R. Coss and M. Prestwich (eds), Thirteenth Century England VIII. Woodbridge: Boydell, pp. 33-48

Crossley, D.W. 1990. Post-Medieval Archaeology in Britain. Leicester: Leicester University Press

Crossley, D. and Aberg, A. 1972. Sixteenth century glassmaking in Yorkshire: excavations at the furnaces of Hutton and Rosedale, North Riding, 1968-71. Post-Medieval Archaeology 6: 107-59

Cumberpatch, C. G. 1996. The pottery. In J. A. Dunkley and C. G. Cumberpatch (eds), Excavations at 16-20 Church Street, Bawtry, South Yorkshire. British Archaeological Reports British Series 248. Oxford: Tempus Reparatum

Cumberpatch, C.G. 1997. Towards a phenomenological approach to the study of medieval pottery. In C. Cumberpatch and P. Blinkhorn (eds) Not So Much a Pot, More a Way of Life. Oxford: Oxbow Books, pp. $125-51$

Cumberpatch, C. G. 2002b. The pottery. In I. Roberts (ed.), Pontefract Castle Archaeological Excavations 198286. Yorkshire Archaeology 8. Leeds: West Yorkshire Archaeology Service/English Heritage, pp. 169-226

Cumberpatch, C. G. 2003. The transformation of tradition: the origins of the post-medieval ceramic tradition in Yorkshire. Assemblage 7: 52-85

Cumberpatch, C. G. 2011. Analysis of the medieval and later pottery. In K. Baker, S. Baker and J. Symonds (eds), Archaeological Investigations at the Upper Chapel, Norfolk Street, Sheffield, UK. Internet Archaeology 29 (https://doi.org/10.11141/ia.29.4)

Cumberpatch, C. G. 2014b. Tradition and change: the production and consumption of early modern pottery in South and West Yorkshire. In C. Cumberpatch and P. W. Blinkhorn (eds), The Chiming of Crack'd Bells: current approaches to artefacts in archaeology. British Archaeological Reports International Series 2677. Oxford: Archaeopress, pp. 73-97

Cumberpatch, C. G. 2015b. Pottery. In P. Andrews (ed.), Riverside Exchange, Sheffield: Investigations on the site of the Town Mill, Cutlers' Wheel, Marshall's Steelworks and the Naylor Vickers Works. Wessex Archaeology Occasional Paper. Salisbury: Wessex Archaeology

Cunnington, P. 2002. How Old is Your House? (reprinted from 1980 1st edition). Yeovil: Marston House

Curtis, E. 1914. Sheffield in the 14th century - two Furnival Inquisitions. Transactions of the Hunter Archaeological Society 1: 31-53

Dart, R. 1973. Recollections of a reluctant anthropologist. Journal of Human Evolution 2: 417-27

Darvill, T., Barrass, K., Constant, V., Milner, E. and Russell, B. 2019. Archaeology in the PPG16 Era. Investigations in England 1990-2010. Oxford: Oxbow

Defoe, D. 1724-27. A tour thro' the whole island of Great Britain, divided into circuits or journies (1927 edition). London: J. M. Dent and Co.

Dempsey, K. 2019. Gender and medieval archaeology: storming the castle. Antiquity 93(369): 772-88

Dempsey, K., Gilchrist, R., Ashbee, J., Sagrott, S. and Stones, S. 2019. Beyond the martial façade: gender, heritage and medieval castles. International Journal of Heritage Studies (https://doi.org/10.1080/13527258 .2019.1636119)

Didsbury, P. 2010. Medieval pottery. In R. Daniels (ed.), Hartlepool: an archaeology of the medieval town. Tees Archaeology Monograph series 4. Hartlepool: Tees Archaeology, pp. 218-46 
Dixon, P. 1990. The donjon of Knaresborough: the castle as theatre. Château-Gaillard 14: 121-39

Drury, C. 1929b. A Sheaf of Essays by a Sheffield Antiquary. Sheffield: J. W. Northend

Drury, C. 1929c. A relic of Sheffield castle. Transactions of the Hunter Archaeological Society 3: 343-6

Edwards, D. and Hampson. R. 2005. White Salt-Glazed Stoneware of the British Isles. Woodbridge: ACC Art Books

Egan, G. 1998. The Medieval Household, Daily Living c.1150-c.1450. Medieval finds from excavations in London 6. London: Her Majesty's Stationery Office

Egan, G. and Pritchard, F. 1991. Dress Accessories c.1150-c.1450. Medieval finds from excavations in London 3. London: Her Majesty's Stationery Office

Evelyn, J. 1729. Silva: or a discourse of forest-trees and the propagation of timber (5th edition, first published in 1664). London: Walthoe

Fagan, B. 2001. Grahame Clark. An intellectual biography of an archaeologist. Cambridge: Westview Press

Faulkner, P. A. 1963. Castle planning in the 14th century. The Archaeological Journal 120: 215-35

Faull, M. L. and Stinson, M. 1986. Domesday Book - 30: Yorkshire, part 1. Chichester: Phillimore

Fine, D. 2003. Sheffield. History and guide. Stroud: The History Press

Flavell, N. 2005. Eighteenth century allotment gardens in Sheffield. Transactions of the Hunter Archaeological Society 23: 19-30

Florida, R. 2014. The Rise of the Creative Class, Revisited. New York: Basic Books

Fradley, M. 2015. Urban castles in the Middle Ages: Wallingford in context. In K. S. B. Keats-Rohan, N. Christie, and D. Roffe (eds) Wallingford: the castle and town in context. British Archaeological Reports British Series 621. Oxford: Archaeopress, pp. 20-7

Gaimster, D. 1997. German Stoneware. London: British Museum Press

Gaimster, D. and Nenk, B. 1997. English households in transition c.1450-1550: the ceramic evidence. In D. Gaimster and P. Stamper (eds), The Age of Transition. The archaeology of English culture 1400-1600. Oxford: Oxbow Books, pp. 171-95

Gales, J. and Martin, D. 1787. The Directory of Sheffield. London: G. G. J and J. Robinson

Gamble, C. 2014. The anthropology of deep history. Journal of the Royal Anthropological Institute 21: 147-64

Gardiner, M. 2012. An early medieval tradition of building in Britain. Arquelogía de la Arquitectura 9: 231-46

Gatty, A. 1869. Hallamshire. The history and topography of Sheffield by Joseph Hunter. A new and enlarged edition. Sheffield: Pawson and Brailsford

Gatty, A. 1873. Sheffield Past and Present, Being a Biography of the Town during Eight Hundred Years. Sheffield: Thomas Rodgers

Gell, R. 1825. A New, General, \& Commercial Directory of Sheffield and its Vicinity. Manchester: Albion Press

Gerrard, C. 2003. Medieval Archaeology. Understanding traditions and contemporary approaches. London: Routledge

Gilchrist, R. 1999. Gender and Archaeology: contesting the past. London: Routledge

Gilchrist, R. 2009. Rethinking later medieval masculinity: the make body in death. In D. Sayer and H. Williams (eds) Mortuary Practices and Social Identities in the Middle Ages. Exeter: University of Exeter Press, pp. 236-52

Girouard, M. 1978. Life in the English Country House. New Haven/London: Yale University Press

Goldring, E. 2015. Talbot, George, sixth Earl of Shrewsbury (c.1522-1590). Dictionary of National Biography. Oxford: Oxford University Press

Goodall, I. H. 1990. Locks and keys. In M. Biddle (ed.), Artefacts from Medieval Winchester Parts i and ii: object and economy in medieval Winchester. Winchester Studies 7. Oxford: Clarendon Press, pp. 1001-36

Goodall, J. 2012. The English gatehouse. Architectural History 55: 1-23

Goodwin, E. 1764. Natural history of Sheffield. The Gentleman's Magazine 34: 157-61

Goubitz, O., van Driel-Murray, C. and Groenman-van Waateringe, W. 2001. Stepping Through Time: archaeological footwear from prehistoric times until 1800. Zwolle: Stichting Promotie Archeologie

Graham, J. 1914. A History of Wesleyan Methodism in Sheffield Park, Sheffield. Sheffield: W.C. Leng and Co.

Grenville, J. 1997. Medieval Housing. Leicester: Leicester University Press

Grew, F. and de Neergaard, M. 1988. Shoes and Patterns 2. Martlesham: Boydell \& Brewer

Griffin, J. 2012. The Yorkshire Potteries. Leeds: Leeds Arts Collection Fund

Guy, N. 2005. England's lost castles: Sheffield. Castle Studies Group Bulletin 18: 202-21 
Hadfield, C. 1875. On the restoration of the lodge at Sheffield Manor. Papers Read at the Royal Institute of British Architects. 1874-75: 109-18

Hall, L. 2005. Period House Fixtures \& Fittings 1300-1900. Newbury: Countryside Books

Hall, T. W. and Thomas, T. H. 1914. Descriptive Catalogue of the Charters, Rolls, Deeds, Pedigrees, Pamphlets, Newspapers, Monumental inscriptions, Maps, and Miscellaneous Papers forming the Jackson Collection at the Sheffield public reference library. Sheffield: J. W. Northend

Hall, T. W. 1926. A Descriptive Catalogue of Sheffield Manorial Records, Volume 1. Sheffield: J. W. Northend Hall, T. W. 1928. A Descriptive Catalogue of Sheffield Manorial Records, Volume 2. Sheffield: J. W. Northend

Hall T. W. 1930. Yorkshire. A Descriptive Catalogue of Land-Charters \& Court-Rolls from the Bosville and the Lindsay Collections. Sheffield: J. W. Northend

Hall, T. W. 1932. The Fairbanks of Sheffield 1688 to 1848. Sheffield: J. W. Northend

Hall, T. W. 1934. A Descriptive Catalogue of Sheffield Manorial Records, Volume 3. Sheffield: J. W. Northend

Hallam, R. L. 2015. Saxon remains at Castle Hill, Sheffield: a review of archaeological findings. Transactions of the Hunter Archaeological Society 28: 29-31

Hampel, P. 1985. The story so far. East Riding Archaeological Society News 20: 1-5

Harman, R. and Minnis, J. 2004. Sheffield. Pevsner architectural guide. New Haven: Yale University Press

Hart, C. 1981. The North Derbyshire Archaeological Survey. Leeds: The North Derbyshire Archaeological Trust

Hart, C. 1993. The ancient woodland of Ecclesall Woods. Sheffield. In P. Beswick and I. D. Rotherham (eds), Landscape Archaeology and Ecology 1: 49-66

Harvey, P. 2001. Street Names of Sheffield. Sheffield: Sheaf Publishing

Hawkes, C. and Piggott, S. 1948. A Survey and Policy of Field Research in the Archaeology of Great Britain. London: Council for British Archaeology

Hayfield, C. 1988. The popularity of medieval vessel forms in Humberside. Medieval Ceramics 12: 57-68

Hayfield, C. 1992. Humberware: the development of a late-medieval pottery tradition. In D. Gaimster and M. Redknap (eds), Everyday and Exotic Pottery from Europe. Oxford: Oxbow, pp. 38-44

Hayfield, C. and Buckland, P. 1989. Late medieval pottery wasters from Firsby, South Yorkshire. Transactions of the Hunter Archaeological Society 15: 8-24

Herring, P. 2003. Cornish medieval deer parks. In R. Wilson-North (ed.), The Lie of the Land. Aspects of the archaeology and history of the designed landscape in the South West of England. Exeter: The Mint Press, pp. $34-50$

Hey, D. 1991. The Fiery Blades of Hallamshire: Sheffield and its neighbourhood 1660-1740. Leicester: Leicester University Press

Hey, D. 1998. A History of Sheffield. Lancaster: Carnegie Publishing

Hey, D. 2005. The South Yorkshire steel industry and the Industrial Revolution. Northern History 42: 91-6

Hey, D. 2010. A History of Sheffield (3rd edition revised). Lancaster: Carnegie Publishing

Hey, D. 2013. The commons of the ancient parish of Sheffield. In I. Rotherham (ed.), Cultural Severance and the Environment. Dordrecht: Springer, pp. 263-74

Higham, R. and Barker, P. 1992. Timber Castles. London: Batsford

Hill, C. 1958. The Norman Yoke. In C. Hill, Puritanism and Revolution. Studies in the interpretation of the English Revolution. London: Secker and Warburg, pp. 46-111

Himsworth, J. B. 1953. The Story of Cutlery. From flint to stainless steel. London: Ernest Benn

Hodges, R. 2017. The Archaeology of Mediterranean Placemaking. Butrint and the global heritage industry. London: Bloomsbury

Holland, J. 1820. Sheffield Park. A descriptive poem. Sheffield: Montgomery

Holland, J. 1824. The Picture of Sheffield; or an Historical and Descriptive View of the Town of Sheffield, in the County of York. Sheffield: George Ridge

Hollow, M. 2010. Governmentality on the Park Hill estate: the rationality of public housing. Urban History 37(1): $117-35$

Hopper, A. 2007. The Wortley Park poachers and the outbreak of the English Civil War. Northern History 44(2): 93-114

Hornby, H. 2015. Bowled Over. The bowling greens of Britain. Swindon: Historic England

Hough, C. 2001.Place-name evidence for an Anglo-Saxon animal name: $\mathrm{OE}^{*}$ pohha/ ${ }^{\star}$ pocca fallow deer. AngloSaxon England 30: 1-14 
Howarth, D. 1985. Lord Arundel and His Circle. London: Yale University Press

Hudson, W. 1874. The Life of John Holland of Sheffield Park. London: Longmans Green and Co.

Hughes, H. 1904. Aberystwyth Castle: excavations carried on in the year 1903. Archaeologia Cambrensis (6th series) 4: 317-23

Hunter, J. 1819. Hallamshire: the history and topography of the Parish of Sheffield in the County of York. London: Lackington, Hughes, Harding, Mavor and Jones

Hunter, J. 1828-31. South Yorkshire: the history and topography of the Deanery of Doncaster. London: J. B. Nichols \& Sons

Hunter, L. 1997. Women and domestic medicine: lady experimenters, 1570-1620. In L. Hunter and S. Hutton (eds), Women, Science and Medicine 1500-1700. Mothers and sisters of the Royal Society. Stroud: Sutton Publishing

Hurst, J. G. 1959. Note on Sheffield Castle. In D. M. Wilson and J. G. Hurst (eds), Medieval Britain 1958: postConquest. Medieval Archaeology 3: 308

Hurst-Vose, R. 1994. Excavations at the 17th century glasshouse at Haughton Green, Denton near Manchester. Post-Medieval Archaeology 18: 20-42

Hutton, R. 1997. The Neolithic great goddess: a study in modern tradition. Antiquity 71(271): 91-9

Hutton, R. and Reeves, W. 1998. Sieges and fortifications. In J. Kenyon and J. Ohlmeyer (eds), The Civil Wars: a military history of England, Scotland and Ireland 1638-1660. Oxford: Oxford University Press, pp. 195-223

Hynd, N.R. and Ewart, G. 1983. Aberdour castle gardens. Garden History 11(2): 93-111

Ickowicz, P. 1993. Martincamp ware: a problem of attribution. Medieval Ceramics 17: 51-60

Iredale, D. and Barrett, J. 2002. Discovering Your Old House. Princes Risborough: Shire Publications Ltd

Jamieson, E. 2019. The siting of medieval castles and the influence of ancient places. Medieval Archaeology 63: $338-74$

Jamison, C. and Bill, E. G. W. 1966. A Calendar of the Shrewsbury Papers in the Lambeth Palace Library. Volume 1: Shrewsbury MSS in Lambeth Palace Library (MSS. 694-710). London: Derbyshire Archaeological Record Series

Jessop, O. 1996. A new artefact typology for the study of medieval arrowheads. Medieval Archaeology 40: 192-205

Johnson, P. 1998. R.G. Collingwood. An introduction. Bristol: Thoemmes Press

Johnson, P. 2000. Castles of England, Scotland and Wales. London: Seven Dials, Cassell and Co.

Johnson, M. 2002. Behind the Castle Gate: from medieval to Renaissance. London: Routledge

Johnson, M. (ed.) 2017a. Lived Experience in the Later Middle Ages. Studies of Bodiam and other elite landscapes in south-eastern England. St Andrews: Highfield Press

Johnson, M. 2017b. Discussion: elite sites, political landscapes and lived experience in the later Middle Ages. In M. Johnson (ed.), Lived Experience in the Later Middle Ages. Studies of Bodiam and other elite landscapes in south-eastern England. St Andrews: Highfield Press, pp. 183-201

Jones, B. 1984. Past Imperfect. The story of Rescue Archaeology. London: Heinemann

Jones, B. 2012. Frederic Loxley Preston, 1905-1994. In History Makers. A biographical introduction to the Hunter Archaeological Society, 1912-2012. Sheffield: Northend, pp. 34-5

Jones, J. 1976. The leather. In T. G. Hassall (ed.), Excavations at Oxford Castle, 1965-1973. Oxoniensia XVI: 275-96

Jones, M. 2009. Sheffield's medieval park: a re-examination of its role. Transactions of the Hunter Archaeological Society 24: 4-15

Jones, M. 2004. The Making of Sheffield. Barnsley: Wharncliffe Books

Jones, M. 2013. Woods, trees and animals. A perspective from South Yorkshire, England. In I. Rotherham (ed.), Trees, Forested Landscapes and Grazing Animals. A European perspective on woodlands and grazed treescapes. London: Routledge, pp. 24-34

Jope, E.M. 1952. Excavations in the city of Norwich, 1948. Norfolk Archaeology 30: 287-322

Kay, S. and Kay, M. 2017. How Great a Crime - to Speak the Truth. The story of Joseph and Winifred Gales and the Sheffield Register. Sheffield: 1889 Books

Kenyon, J. 1990. Medieval Fortifications. Leicester: Leicester University Press

Kenyon, K. 1952. Beginning in Archaeology. London: Phoenix House Ltd 
Kilmurry, K. 1980. The Pottery Industry of Stamford, Lincolnshire C.AD 850-1250. British Archaeological Reports British Series 84. Oxford: BAR

Kitching, J. 1963. Bone, Tooth and Horn. Tools of Palaeolithic Man. Manchester: Manchester University Press

Knight, B. 1985. Cames. In J. N. Hare (ed.), Battle Abbey: the eastern range and the excavations of 1978-80. London: Historic Buildings and Monuments Commission for England, pp. 154-6

Kowaleski-Wallace, E. 1997. Consuming Subjects. New York: Columbia University Press

Larkin, F. C. 1927. Excavations on the site of Liverpool Castle. Transactions of the Historic Society of Lancashire and Cheshire 79: 175-97

Leach, M., Maddock, S., Hadley, D., Butterworth, C., Moreland, J., Dean, G., Mackinder, R., Pach, K., Bax., N., McKone, M. and Fleetwood, D. 2018. Recreating Sheffield's medieval castle in situ using outdoor Augmented Reality. In P. Bourdot, S. Cobb and V. Interrante (eds), Virtual Reality and Augmented Reality. EuroVR2018. Cham: Springer, pp. 213-29

Leader, J. D. 1872. Sheffield Castle and Manor Lodge in 1582: a paper read before the Sheffield Architectural and Archaeological Society. Yorkshire Archaeological Society Papers 1850-1901 2: 361-89

Leader, J. D. 1874. The remains of Sheffield Manor. Journal of the British Archaeological Association 30: 42-51

Leader, J. D. 1880. Mary Queen of Scots in Captivity. Sheffield: Leader and Sons

Leader, J. D. 1897. The Records of the Burgery of Sheffield, commonly called the Town Trust. Sheffield: The Sheffield Independent Press

Leader, R. E. 1875. Reminiscences of Old Sheffield, Its Streets and Its People. Sheffield: Leader and Sons

Leader, R. E. 1901. Sheffield in the 18th Century. Sheffield: The Sheffield Independent Press

Leader, R. E. 1904a. Inaugural address. Papers and Proceedings of the Sixtieth Annual Congress Held at Sheffield August 10th to August 15th, 1903. London: British Archaeological Association, pp. 1-14

Leader, R. E. 1904b. Sheffield cutlery and the poll-tax of 1379. Papers and Proceedings of the Sixtieth Annual Congress Held at Sheffield August 10th to August 15th, 1903. London: British Archaeological Association, pp. 116-23

Leader, R. E. 1910. Antiquities of Sheffield. In W. Porter (ed.), British Association Handbook. Sheffield: Independent Press, pp. 1-25

Leakey, L. 1931. The Stone Age Cultures of Kenya Colony. Cambridge, Cambridge University Press

Lewis, M. 2016. A detectorist's Utopia? Archaeology and metal-detecting in England and Wales. Open Archaeology 2: 127-39

Liddiard, R. 2000a. Castle Rising Norfolk: a landscape of lordship? Anglo-Norman Studies 22: 169-86

Liddiard, R. (ed.) 2002. Anglo-Norman Castles. Woodbridge: Boydell

Liddiard, R. 2005. Castles in Context. Power, symbolism and landscape, 1066 to 1500. Macclesfield: Windgather Press

Liddiard, R. (ed.) 2007. The Medieval Park: new perspectives. Macclesfield: Windgather Press

Liddiard, R. (ed.) 2016a. Late Medieval Castles. Woodbridge: Boydell

Liddiard, R. 2016b. Introduction. In R. Liddiard (ed.), Late Medieval Castles. Woodbridge: Boydell, pp. 1-17

Liddiard, R. and Wells, F. 2008. The Little Park at Castle Hedingham, Essex: a possible late medieval pleasure ground. Garden History 36(1): 85-93

Lilley, K. and Lloyd, C. 2009. Mapping the realm. A new look at the Gough Map of Britain (c.1360). Imago Mundi 61: 1-28

Linton, D. L. 1956. Sheffield and Its Region. Sheffield: British Association for the Advancement of Science

Lodge, E. 1838. Illustrations of British History, Biography, and Manners, in the Reigns of Henry VIII, Edward VI, Mary, Elizabeth, \& James I: exhibited in a series of original papers selected from the MSS of the noble families of Howard, Talbot, and Cecil. Volume II. London: Chidley

Lovell, M. S. 2005. Bess of Hardwick: First Lady of Chatsworth. London: Abacus

Lucas, G. 2001. Critical Approaches to Fieldwork. London: Routledge

Lyman, R., O'Brien, M. and Dunnell, R. 1997. The Rise and Fall of Culture History. New York: Plenum Press

Lyte, H. C. M. (ed.) 1913. Calendar of Patent Rolls (1266-72). London: HMSO

Maddicott, J. R. 1994. Simon de Montfort. Cambridge: Cambridge University Press

Madgwick, R., Sykes, N., Miller, H., Symmons, R., Morris, J. and Lamb, A. 2013. Fallow deer (Dama dama dama) management in Roman south-east Britain. Archaeological and Anthropological Sciences 5: 111-22 
Makepeace, G. A. 1985. Report on the Romano-British settlement at Whitley, Wharncliffe excavated by the late L.H. Butcher. Transactions of the Hunter Archaeological Society 13: 34-41

Malpass, P. 2000. Public utility societies and the Housing and Town Planning Act, 1919: a re-examination of the introduction of state-subsidized housing in Britain. Planning Perspectives 15: 377-92

Margeson, S. 1993. Norwich Households: medieval and post-medieval finds from Norwich Survey excavations 1971-78. East Anglian Archaeology 58. Norwich: East Anglian Archaeology

Marshall, K. 1951. Excavations in the city of Bristol 1948-51. Transactions of the Bristol and Gloucestershire Archaeological Society 70: 5-50

Marx, K. 1963. The Eighteenth Brumaire of Louis Bonaparte. New York: International Publishers

Mayes, P. and Hayfield, C. 1980. A Late Medieval Kiln at Holme-upon-Spalding Moor, North Humberside. Hull Old Town Report Series 4. East Riding Archaeological Society 6

Medlicott, I. R. 1983. John Curr and the development of the Sheffield collieries, 1781-1805. Transactions of the Hunter Archaeological Society 12: 51-60

Mercer, R. 2010. Stuart Piggott, Christopher Hawkes and archaeological narrative. In A. Marciniak and J. Coles (eds), Grahame Clark and His Legacy. Newcastle: Cambridge Scholars Publishing, pp. 47-67

Merrony, C. 1990-91. The excavation of the cruck-framed building adjacent to Sheffield Manor Lodge. Archaeology in South Yorkshire 1990-1991: 10-13

Mileson, S. 2009. Parks in Medieval England. Oxford: Oxford University Press

Minard, P. 2011. Micro-economics of quality and social construction of the market: disputes among the London leather trades in the eighteenth-century. Historical Social Research/Historische Sozialforschung 36: 150-68

Moorhouse, S. 1971. Post-medieval Britain in 1970. Post-Medieval Archaeology 5: 209

Moorhouse, S. 1977. Yorkshire archaeological register. Yorkshire Archaeological Journal 48: 16

Moorhouse, S. 1978. Documentary evidence for the uses of medieval pottery: an interim statement. Medieval Ceramics 2: 3-21

Moorhouse, S. 1983a. The medieval pottery. In P. Mayes and L. Butler, Sandal Castle Excavations 1964-1973. Wakefield: Wakefield Historical Publications, pp. 83-212

Moorhouse, S. 1983b. Documentary evidence and its potential for understanding the inland movement of medieval pottery. Medieval Ceramics 7: 45-87

Moorhouse, S. 2007. The medieval parks of Yorkshire: function, contents and chronology. In R. Liddiard (ed.), The Medieval Park: new perspectives. Macclesfield: Windgather, pp. 99-127

Moorhouse, S. and Roberts, I. 1992. Wrenthorpe Potteries: excavations of 16th and 17th-century potting tenements near Wakefield, 1983-86. Yorkshire Archaeology 2. Wakefield: West Yorkshire Archaeology Service

Moorhouse, S. and Slowikowski, A. M. 1992. The Pottery. In S. Moorhouse and I. Roberts, Wrenthorpe Potteries: excavations of 16th and 17th-century potting tenements near Wakefield, 1983-86. Yorkshire Archaeology 2. Wakefield: West Yorkshire Archaeology Service, pp. 59-117

Moreland, J. 2010. Archaeology, Theory and the Middle Ages. London: Duckworth

Moreland, J. and Gorman, M. 2019. Mary Queen of Scots and the archaeology of Sheffield Castle. History Scotland 19: 10-12

Mould, Q. 2009a. Leather shoes and clothing. In E. Shepherd Popescu (ed.), Norwich Castle: excavations and historical survey, 1987-98 Part II: c.1345 to Modern. East Anglian Archaeology 132. Gressenhall: Norfolk Museums Service, pp. 827-33

Mould, Q. 2011. The leather from the medieval defensive ditches. In R. Newman (ed.), Carlisle: excavations at Rickergate, 1998-9 and 53-55 Botchergate, 2001. Cumbria Archaeological Research Reports 2: 38-54

Mould, Q. 2017b. The leather from Hill Street. In P. Mason, D. McAree and I. Soden (eds), Coventry's medieval suburbs, excavations at Hill Street, Upper Well Street and Far Gosford Street 2003-2007. Oxford: Archaeopress Publishing Ltd, pp. 60-81

Mowl, T. 2000. Gentlemen and Players: Gardeners of the English Landscape. Stroud: Sutton Publishing

Munby, J., Norton, A., Poore, D. and Dodd, A. 2019 Excavations at Oxford Castle 1999-2009. Thames Valley Landscapes Monograph No. 44. Oxford: Oxford Archaeology

Murray, T. and Evans, C. (eds) 2008. Histories of Archaeology: a reader in the history of archaeology. Oxford: Oxford University Press

Nevell, R. 2012. Castle gatehouses in North West England. Castle Studies Group Journal 26: 258-81 
Nevell, R. 2020. The archaeology of slighting: a methodological framework for interpreting castle destruction in the Middle Ages. Archaeological Journal 177: 99-139

Newman, R., Cranstone, D. and Howard-Davies, C. 2001. The Historical Archaeology of Britain, c.1540-1900. Stroud: Sutton Publishing

Northend, W. F. 1951. The Hall-in-the-Ponds. Transactions of the Hunter Archaeological Society 7: 11-17

Odom, W. 1927. Historic Personages in Sheffield. From Waltheof to Wolsey. Sheffield: William Townend and Sons

Parliament. House of Commons. 1646 (first published 1802). House of Commons Journal 4. London: Her Majesty's Stationery Office

Parliament. House of Commons. 1647 (first published 1802). House of Commons Journal 5. London: Her Majesty's Stationery Office

Parliament. House of Commons. 1648 (first published 1802). House of Commons Journal 6.

Pawson, H. and Brailsford, J. 1971. Illustrated Guide to Sheffield and Neighbourhood. Originally published 1862. Otley: Amethyst

Pearce, J. and Vince, A. 1988. A Dated Series of London Medieval Pottery Part 4: Surrey whitewares. London and Middlesex Archaeological Society. London: Art Books International

Pearson,T. and Oswald, A. 2000. Quern manufacturing at Wharncliffe Rocks, Sheffield, South Yorkshire. Archaeological Investigation Report Series AI/20/2000. York: English Heritage

Pendlebury, J. and Porfyriou, H. 2017. Heritage, urban regeneration and place-making. Journal of Urban Design 22(4): 429-32

Petrie, W. M. F. 1904. Methods and Aims in Archaeology. London: Macmillan

Pettifer, A. 1995. English Castles: a guide by counties. Woodbridge: Boydell

Phillips, C.W. 1980. Archaeology in the Ordnance Survey 1791-1965. London: Council for British Archaeology

Piggott, S. 1965. Archaeological draughtsmanship: principles and practice. Antiquity 39: 165-76

Platt, C. 1982. The Castle in Medieval England and Wales. London: Scribner

Pluskowski, A. 2007. Breaking and Shaping Beastly Bodies: animals as material culture in the Middle Ages. Oxford: Oxbow

Porter, S. 1994. Destruction in the English Civil Wars. Stroud: Sutton Publishing

Potter, G. R. and Walton, M. 1950. A fragment of the Compotus Roll of the manor of Sheffield, 1479-80. Transactions of the Hunter Archaeological Society 6: 1-24

Pounds, N. P. 1990. The Medieval Castle in England and Wales. Cambridge: Cambridge University Press

Preston, F. 1955. The Scheme for Archaeological Research: a first report. Transactions of the Hunter Archaeological Society 7: 211-14

Preston, F. L. and Butcher, L. H. 1956. Roman Ridge excavation report IV: Grimethorpe Road. Transactions of the Hunter Archaeological Society 7: 96-98

Pumfrey, S. and Dawbarn, F. 2004. Science and patronage in England, 1570-1625: a preliminary study. History of Science 42: 137-88

Rackham, O. 1986. The History of the Countryside. London: J. M. Dent \& Sons

Radley, J. 1970. Yorkshire archaeological register: 1969. Yorkshire Archaeological Journal 42: 393

Rakoczy, L. 2008. Out of the ashes: destruction, reuse, and profiteering in the English

Civil War. In L. Rakoczy (ed.), The Archaeology of Destruction. Cambridge: Cambridge Scholars Publishing, pp. 261-86

Ravetz 2001. Council Housing and Culture. The history of a social experiment. London: Routledge

Richards, S. 1999. Eighteenth-Century Ceramics. Manchester: Manchester University Press

Richardson, A. 2007. 'The King's chief delights': a landscape approach to the royal parks of post-Conquest England. In R. Liddiard (ed.), The Medieval Park: new perspectives. Macclesfield: Windgather, pp. 27-48

Roach, J. 2003. The Shrewsbury Hospital, Sheffield 1616-1975. Borthwick Paper 104. York: Borthwick Publications

Roberts, I. 2002. Pontefract Castle. Archaeological excavations 1982-86. Exeter: West Yorkshire Archaeology Service

Roberts, I., Cumberpatch, C., Young, J., Ixer, R. and Hughes, M. 2013. A Stamford Ware Pottery Kiln in Pontefract. Excavations at Simpson's Malt, Pontefract, West Yorkshire. York: Archaeology Data Service (https://doi.org/10.5284/1012479) 
Robinson, J. 1797. A Directory of Sheffield, Including the Manufacturers of the Adjacent Villages. Sheffield: J. Montgomery

Ronksley, J. G. 1908. Edited Transcription of J. Harrison's. An Exact and Perfect Survey and View of the Manor of Sheffield, 1637. Sheffield: Privately printed for Arthur Wightman

Rose, J. 2001. The Intellectual Life of the British Working Classes. New Haven: Yale

Rotherham, I. 2007a. The ecology and economics of medieval deer parks. Landscape Archaeology and Ecology 6: $86-102$

Rotherham, I. 2007b. The historical ecology of medieval parks and the implications for conservation. In R. Liddiard (ed.), The Medieval Park: new perspectives. Macclesfield: Windgather, pp. 79-96

Rowland, P. 2019. Sheffield Castle - a trench by trench photographic record of the 2018 archaeological excavation. San Francisco: Blurb

Russell, M. 2000. Flint Mines in Neolithic Britain. Stroud: Tempus Publishing

Russell, M., 2017. Excavations in and around the privy garden, Carisbrooke Castle, Isle of Wight, 2006 and 2008-9. Hampshire Studies 72(1): 61-128

Sabloff, J. 2008. Archaeology Matters. Action archaeology in the modern world. Walnut Creek: Left Coast Press

Saich, D. and Matthews, L. (eds) 2005. Archaeology in South Yorkshire 1999/2001. Sheffield: South Yorkshire Archaeological Service

Saich, D. and Matthews, L. (eds) 2006. Archaeology in South Yorkshire Number 11. Sheffield: South Yorkshire Archaeological Service

Shaw, G. 1848. A visit to Brougham Hall. The Gentleman's Magazine 2: 369-76

Schattner, A. 2014. 'For the Recreation of Gentlemen and Other Fit Persons of the Better Sort': tennis courts and bowling greens as early leisure venues in sixteenth- to eighteenth-century London and Bath. Sport and History 34(2): 198-222

Schlanger, N. and Nordbladh, J. (eds) 2008. Archives, Ancestors, Practices: archaeology in the light of its history. New York: Berghahn

Schofield, J. 1991. The construction of medieval and Tudor houses in London. Construction History 7: 3-28

Schofield, J., Carmen, J., and Belford, P. 2011. Archaeological Practice in Great Britain. London: Springer

Scott, I. 2001. The military artefacts and horse gear. In M. Biddle, J. Hiller, I. Scott and A. Streeten. Henry VIII's Coastal Artillery Fort at Camber Castle, Rye, East Sussex. Oxford: Oxford Archaeological Unit for English Heritage, pp. 189-212

Scurfield, G. 1986. Seventeenth-century Sheffield and its environs. Yorkshire Archaeological Journal 58: 147-72

Shakespeare, W. Henry VI, Part 1. Ed. S. McMillin (1991). Manchester: Manchester University Press

Shapland, M. 2019. Anglo-Saxon Towers of Lordship. Oxford: Oxford University Press

Shepherd, J. ed. 1998. Post-War Archaeology in the City of London, 1946-68. A guide to records of excavations by Prof. W. F. Grimes held by the Museum of London. London: Museum of London

Short, B. and Godfrey, J. 2007. 'The Outhwaite controversy': a micro-history of the Edwardian land campaign. Journal of Historical Geography 33: 45-71

Shryock, A. and Smail, D. 2011. Deep History. The architecture of past and present. Berkeley: University of California Press

Shtebunaev, S. 2018. Universities are reshaping our cities. For whom? Here and Now 11: 40-2

Simmons, C. 1990. Reversing the Conquest. History and Myth in Nineteenth-Century British Literature. New Brunswick: Rutgers University Press

Simmons, R. T. 1997. Planning industrial development - the Norfolk Estate, Sheffield, 1800-1914. Planning Perspectives 12: 403-31

Singer, S.W. 1825. The Life of Cardinal Wolsey by George Cavendish, his Gentleman Usher. London: Harding, Triphook and Lepard

Sketchley, W. 1774. Sketchley's Sheffield Directory, Including the Manufacturing Villages in the Neighbourhood. Sheffield: Wilkie

Smith, L. T. 1909. The Itinerary of John Leland in or about the Years 1535-1543, parts VII and VIII. London: G. Bell and Sons

Spavold, J. 2009. Faith made manifest: an interpretation of the decoration on Cistercian wares. Medieval Ceramics 31: 33-48

Spavold, J. and Brown, S. 2005. Ticknall Pots and Potters. Ashbourne: Landmark Publishing Ltd 
Squatriti, P. 2002. Digging ditches in early medieval Europe. Past and Present 176: 11-65

Stacye, J. 1874. The priory and parish church of Worksop or Radford, Nottinghamshire. Journal of the British Archaeological Association 30, 156-7

Staniforth, S. 1858. Memoir of the late William Cowlishaw, of the Manor near Sheffield. The Local Preachers, Magazine and Christian Family Record 7: 46-50

Stocker, D. 1992.The shadow of the general's armchair. The Archaeological Journal 149(1): 415-20

Stone, L. 1950. An Elizabethan coalmine. The Economic History Review 3: 97-106

Stone, L. 1965. The Crisis of the Aristocracy 1558-1641. Oxford: Oxford University Press

Swallow, R. E. 2014. Gateways to power: the castles of Ranulf III of Chester and Llywelyn the Great of Gwynedd. The Archaeological Journal 171: 289-311

Swallow, R. E. 2016. Cheshire castles of the Irish Sea cultural zone. The Archaeological Journal 173: 288-341

Swallow, R. E. 2019. Living the dream: the legend, lady and landscape of Caernarfon Castle, Gwynedd, North Wales. Archaeologia Cambrensis 219: 153-95

Sykes, N. 2007. Animal bones and animal parks. In R. Liddiard (ed.), The Medieval Park: new perspectives. Macclesfield: Windgather, pp. 49-62

Sykes, N. 2014. Beastly Questions: animal answers to archaeological issues. London: Bloomsbury

Sykes, N. and Carden, R. 2011. Were fallow deer spotter (OE ${ }^{*}$ pohha/ ${ }^{*}$ pocca) in Anglo-Saxon England? Reviewing the evidence for Dama dama dama in early medieval Europe. Medieval Archaeology 55: 139-62

Sykes, N., Ayton, G., Bowen, F., Baker, K., Baker, P., Carden, R. F., Dicken, C., Evans, J., Hoelzel, A., Higham, T., Jones, R., Lamb, A., Liddiard, R., Madgwick,R., Miller, H., Rainsford, C., Sawyer, P., Thomas, R., Ward, C. and Worley, F. 2016. Wild to domestic and back again: the dynamics of fallow deer management in medieval England (c.11th-16th century AD). Science and Technology of Archaeological Research 2: 113-26

Taylor, C. C. 2000. Medieval ornamental landscapes. Landscapes 1: 38-55

Templeman, D. 2016. Mary, Queen of Scots. The captive Queen in England 1568-87. Exeter: Short Run Press

Thomas, A. H. 1920-24. Some Hallamshire rolls of the fifteenth century. Transactions of the Hunter Archaeological Society 2: 65-73, 142-58, 229-46, 341-60

Thomas, J. 1844. Walks in the Neighbourhood of Sheffield (second series). Sheffield: Leader

Thomas, K. 2018. In pursuit of civility: Manners and civilisation in early modern England. New York: Yale University Press

Thompson, M. W. 1987. The Decline of the Castle. Cambridge: Cambridge University Press

Thompson, M. W. 1991. The Rise of the Castle. Cambridge: Cambridge University Press

Thompson, M. W. 1997. Castles. In D. Brewer and J. Gibson (eds), A Companion to the Gawain-poet. Cambridge: Cambridge University Press, pp. 119-30

Thompson, M. W. 2008. The Decline of the Castle. Cambridge: Cambridge University Press

Thomson, R. S. 1981. Leather manufacture in the post-medieval period with special reference to Northamptonshire. Post-Medieval Archaeology 15: 161-75

Thorp, F. 1974. Yorkshire archaeological register: 1973. Yorkshire Archaeological Journal 46: 148

Tolley, G. 1999. We, Of Our Bounty. A history of the Sheffield church burgesses. Durham: The Memoir Club

Trigger, B. 2006. A History of Archaeological Thought. Cambridge: Cambridge University Press

Tucker, S. I. 1874. Descent of the manor of Sheffield. Journal of the British Archaeological Association 30: 237-77

Turner, G. J. (ed.) 1901. Select Pleas of the Forest. Publications of the Selden Society 13. London: Bernard Quaritch

Tyerman, L. 1856. Praying William: a memoir of the late Mr William Cowlishaw of Sheffield Manor. Sheffield: J. Cowlishaw

Varndell, G. 1991. The worked chalk. In I. Longworth, A. Herne, G. Varndell and S. Needham (eds), Excavations at Grimes Graves, Norfolk, 1972-1976 (Fascicule 3). London: British Museum Press

Varndell, G. 2005. Seeing things: A. L. Armstrong's flint crust engravings from Grimes Graves. In P. Topping and M. Lynot (eds), The Cultural Landscape of Prehistoric Mines. Oxford: Oxbow Books, pp. 51-62

Vaughan, J. 2007. The pottery. In J. Nolan and J. Vaughan. Excavations at Oakwellgate, Gateshead, 1999. Archaeologia Aeliana (fifth series) 36: 125-249

Vicars, J. 1646. The burning-bush not consumed: or, The forth and last part of the parliamentarie-chronicle. Containing a full and faithfull continuation and exact narration of all the most materiall and most memorable proceedings of this renowned parliament... from Au... Part 4. London: M. Spark 
Vince, A. 2011. Characterisation studies of the medieval pottery. In K. Baker, S. Baker and J. Symonds. Archaeological Investigations at the Upper Chapel, Norfolk Street, Sheffield, UK. Internet Archaeology 29 (https:// doi.org/10.11141/ia.29.4)

Wagner, P. 2012. Joseph Beeston Himsworth. In History Makers. A biographical introduction to the Hunter Archaeological Society, 1912-2012. Sheffield: Northend, pp. 26-7

Walton, M. 1949. Sheffield: its story and its achievements. Sheffield: Sheffield Telegraph

Waterer, J. W. 1950. Leather and Craftsmanship. London: Faber and Faber Limited

Watkins, J. G. 1987. The pottery. In P. Armstrong and B. Ayers (eds), Excavations in High Street and Blackfriargate. Hull Old Town Report Series No. 5. East Riding Archaeologist 8: 53-181

Way, A. 1858. The signet-ring and silver-bell of Mary Queen of Scots. The Archaeological Journal 15: 253-66

Wheatley, A. 2004. The Idea of a Castle. Woodbridge: Boydell

Wheatley, A. 2010. Caernarfon Castle and its mythology. In D. Williams and J. Kenyon (eds), The Impact of the Edwardian Castles in Wales. Oxford: Oxbow Books

Wheeler, M. 1927. History by excavation. Journal of the Royal Society of Arts 75: 814-34

Wheeler, M. 1954. Archaeology from the Earth. Oxford: Clarendon Press

White, T., White, M., Bridgland, D. and Howard, A. J. 2009. Palaeolithic and quaternary research in the Trent Valley (UK): contributions by early collectors. Proceedings of the Geologists Association 120: 223-32

White, S. D. 2015. Clay tobacco pipes. In P. Andrews (ed.), Riverside Exchange, Sheffield: investigations on the site of the Town Mill, Cutlers' Wheel, Marshall's Steelworks and the Naylor Vickers Works. Salisbury: Wessex Archaeology, pp. 20-30

White, W. 1868. Directory of the Borough of Sheffield, Doncaster and Chesterfield. Sheffield: William White

Whitehead, R. 1996. Buckles 1250-1800. Chelmsford: Greenlight Publishing

Whittle, E. H. 1989. The Renaissance gardens of Raglan Castle. Garden History 17(1): 83-94

Wigfull, J. R. 1914. Lady's Bridge, Sheffield. Transactions of the Hunter Archaeological Society 1(1): 57-65

Wigfull. 1916. Notes and queries. Transactions of the Hunter Archaeological Society 1: 237-9

Wigfull, J. R. 1920. Extracts from the note-book of William Dickenson. Transactions of the Hunter Archaeological Society 2: 189-202

Williamson, T. 2007. Rabbits, Warrens and Archaeology. Stroud: Tempus Publishing

Willmott, H. 2002. Early Post-Medieval Vessel Glass in England c.1500-1670. York: Council for British Archaeology

Winder, T. 1904. Notes on Sheffield Manor House. Journal of the British Archaeological Association (new series) 10: $43-8$

Winder, T. 1907. T'Heft an' Blades O'Shevvield. Dialect stories and antiquarian papers. Sheffield: Independent Press

Winder, T. 1910. Sheffield Castle and the Manor Lodge. In W. Porter (ed.), British Association Handbook. Sheffield: Independent Press, pp. 55-61

Winder, T. 1913. Sheffield Manor Lodge and park. Transactions of the Hunter Archaeological Society 1: 112-13

Winder, T. 1919. The Manor Lodge. Sheffield: J. W. Northend

Young, J., Vince, A. and Nailor, V. 2005. A Corpus of Anglo-Saxon and Medieval Pottery from Lincoln. Lincoln Archaeological Studies 7. Oxford: Oxbow

Zasada, K. 1996. A History of Sheffield Castle and Markets. Sheffield: Sheffield City Council 


\section{Index}

Page numbers in bold indicate tables; page numbers in italic indicate figures.

\section{A}

Abbeney, John 203

Abbott, Marcus 23, 25, 324

Aberdour Castle, Fife 296

Aberystwyth Castle, Dyfed 33

Account Rolls, mid- $15^{\text {th }}$ century 9,185

coal mining 283

deer park 256, 280, 281, 283

domestic purchases 207, 208

hunting lodge 265

outer courtyard 163

payments for cleaning 211

payments for maintenance and building work 203, 224

Addy, Sidney 75

Albarella, Umberto 248

Allott, Lucy 247

almshouses 291

Alnwick Castle, Northumberland 290

Andrew, Isaac 320

Andrews, G. xvi

Anglo-Saxon deer parks 253

Anglo-Saxon phase, Sheffield Castle 2

inter-war interpretations of $69,70,72,73,75$, 100,103

lack of evidence in modern excavations 226

Anglo-Saxon pottery 74, 101, 186

animal bone $168,175,176,179,180,184,208,248$, 260, 280 animals, in deer park 279

Antiquaries Journal 18

archaeological practice

inter-war excavations $\quad 33,37$

post-war excavations $121,122,128,129$

Archaeological Research Services Ltd 23, 260

ARCUS (Archaeological Research and Consultancy at the University of Sheffield)

excavations

of castle $21,215,216,217,218$

of hunting lodge 260

reviews of excavation archives 22, 23, 24, 25, 218

Armitage, Ella 215

Armour inventory, Sheffield Castle 213

Armstrong, Leslie $1,2,12,18,20,21,24,29,30,33$, $35,40,51,53,55,56,67,110,114,187,223$, $226,229,235,236,334$

archaeological practice 33,37

enduring legacy of 66

experience and esteem $\quad 31,67$

Himsworth as assistant to 47

lectures $33,35,76$

preservation of remains $305,306,307$

use of finds specialists $57,58,59,60,64,65$

see also inter-war excavations

Armstrong, Peter 119

artefacts $60,61,63,80,127,146,185,213$

bedstead of Mary, Queen of Scots 308, 309

building material fragments 201, 248

metal 168, 175, 203 
artefacts (continued)

mortar 202, 248

plaster $181,202,248$

tile $168,179,201,248,279$

timber and wood 202, 247

window glass $168,175,179,202,246,263$

domestic and personal items 204

bone-working waste $176,177,180,181$, 184, 206

buckles 61,204

buttons $57,58,59,60,61,66,204$

clay pipes $179,181,184,208,238,239,245$

coins 57, 208, 246, 262

crucifix $60,208,210$

glass linen smoother 279

jetons 208

knives $\quad 62,63,177,204,206,260$

pins $57,61,204,205$

'playing card' 60, 208, 209

shears $61,62,63,205$

toiletry item with ear scoop $224,246,247$

feasting and refuse 208

animal bone $168,175,176,179,180,184$, 208, 248, 260, 280

drinking vessel glass 209, 246, 284

wine bottle glass 209, 246, 284

finds specialists $57,58,59,60,64,65$

glass

drinking vessel $\quad 209,246,284$

linen smoother 279

modern excavations 245

opaque 246

window 168, 175, 179, 202, 246, 263

wine bottle 209, 246, 284

hunting lodge excavations $\quad 260,263,279,284$,

311,312

keys $61,62,63,203$

loss of 66

military artefacts 211

cannonballs 211

inventory of armour 213

prick spur 211,213

shot and musket balls 211

spearhead 61,211

post-war recording system 128,129

stone 249

voussoir 249

window tracery $249,300,302$

see also leather artefacts; pottery

Arts Council England 325, 329, 335

Arts \& Humanities Research Council 325, 327, 336

Arundel, Henry Howard, 22 ${ }^{\text {nd }}$ Earl of $\quad 284,290$, 294, 296
Ash House Farm 318

Askew, Rachel 292, 294, 327

Atkinson, Simon 95, 96

Augmented Reality application 337, 338, 339

\section{B}

Bacon, Francis 283

Baggaley, Joseph 57, 308

Bailly, Isabella 280

Baldwin, Thomas 204, 207

Bambata Cave, Rhodesia 36, 37

Barmkin Ditch 143, 158

Barons' War 79, 153, 156, 226

Bartlett, John $19,105,107,109,110,111,115,116$, $127,128,129,145$

see also post-war excavations

Bassett, Steve 101

Batchelors Foods 300

Beale, Robert 8

Beauchief Abbey 30

bedstead of Mary, Queen of Scots 308, 309

Beeston Castle, Cheshire 153, 290

Belford, Paul 22, 23, 107, 218

Belvoir Castle, Leicestershire 290

Bentley, Sir John 9

Bess of Hardwick see Shrewsbury, Elizabeth, Countess of

Beswick, Pauline 20,21, 109, 111, 155, 156,258

Bingley, Daniel 286

Birrell, Jean 280

Bishops' House, Sheffield 293, 294

black-jacks 200

Blackware pottery $170,171,175,176,177,178$, 179, 180, 183, 184, 192, 193, 195, 237, 244, 279, 284, 296

Coarse $175,176,177,178,179,180,192,244,296$

Blair, John 101

Blitz, Sheffield 66, 105, 106, 294

Blore, Edward 294

Blythe, William 290

Boland, F. W. 76

Bone China 245

bone-working waste $176,177,180,181$, 184,206

Booth and Company 318

Border ware pottery 191

Botery, Geoffrey 203, 281

Bottomley, T. L. C. 145

bowling green $10,97,98,99,237,238,239,245$, 282, 296, 297

box grid system of excavation $36,121,122$, 128,129

Brackenfield ware pottery $177,180,189,195,244$ 
Bradbury, Frederick 57, 58, 59, 60, 62, 204, 209

Bradbury, John 286

Bradley, Richard 335

Bradshaw, Robert 209

Breuil, Abbé 31

Brightside and Carbrook Co-operative Society 12 , $16,17,18,30,48,66,105,106,107,232,306$, 307, 308, 338

British Archaeological Association 26, 62, 76, 77, 315

British Association for the Advancement of Science 30, 31, 33, 110

British Museum 57, 308

British Speleological Association 33

Broadbent, Samuel 297

Bromley, James 286

Brougham Hall, Cumbria 308

Brougham, Lord 310

Brown Glazed Coarseware pottery $\quad$ 192, 244

Early $175,176,177,178,179,180,181,183,184$, $192,195,244,296$

Brown Glazed Fineware pottery $\quad$ 192, 244

Early 192

Brown Salt Glazed Stoneware 184

Bruce, A. 324

Bryant, Stuart 111

Buchanan, Francis 303

buckles 61, 204

Buck, Nathaniel $\quad 10,97$

Buff Sandy ware pottery $168,179,191,244$

building material fragments 201, 248

metal $168,175,203$

mortar 202, 248

plaster $181,202,248$

tile $168,179,201,248,279$

timber and wood 202

window glass $168,175,179,202,246,263$

Burghley, William Cecil, Lord 278, 283

burnt layers

inter-war interpretations of $72,78,79,100,101$, 156,226

modern excavations 226

Butcher, Leslie $19,38,50,86,90,105,107,108,109$, $115,119,223,224,229,300,334$

appointment to record post-war excavations 111 archaeological practice $121,122,128,129$

archive 24,123

lecture to Hunter Archaeological Society 113, $114,115,124,127,135,154$

Medieval Archaeology note $\quad 19,123,127$

recording system $128,129,131,132$

Scheme for Archaeological Research in the region around Sheffield 109, 110, 119

see also post-war excavations

Butcher, Nick $109,114,115,119,130$
Butrint, Albania 330

Butterworth, Alan 258

Butterworth, Carolyn $326,331,336$

buttons $57,58,59,60,61,66,204$

C

Cane Coloured ware pottery 245

cannonballs 211

Capper, Joseph 291

Carbrook Hall, Sheffield 293

Carisbrooke Castle, Isle of Wight 296

Carlisle 201

Carpenter, Edward 38

Carter, Andrew 163, 203, 290, 295

Cartington Castle, Northumberland 290

Carver, Martin 52, 123

Castle Hill Market $\quad$ 16, 17, 18, 48, 49, 105, 156

Castle House $\quad 105,107,307,308,325,326,340$

Castle Market $\quad$ xxi, 18, 19, 21, 105, 291, 325

Castle Studies Group Bulletin 22, 215

Castlegate $12,16,20,21,89,105,141,142,219,340$

Augmented Reality application 337, 338, 339

heritage-led regeneration $325,326,327,328$, 330, 331

Castlegate - A New Vision (EDAW Masterplan) 22

Castlegate Festival 2015 325, 327

Castlegate Open Community of Artists 325

Castlegate Partnership (Sheffield City Council) 326, 328, 331

Castlegate Steering Group (University of Sheffield) 325

Catherine of Aragon 266

Cavendish, George 265, 267

Cavendish, Mary 286

Cavendish, Sir William 279, 286

Cavendish, William 286

Cecil, William 278, 283

cementation furnace 54, 242

Chalk-tempered Sandy ware pottery 244

Chantries Act $1547 \quad 3$

Charles II 296

Chartered Institute for Archaeologists 219

Chatsworth, Derbyshire 251, 279

Chaucer, Geoffrey 205

Chief Cultural \& Leisure Officers Association 335

Childe, Gordon 62

cholera 321, 322

Cistercian ware pottery $170,171,172,176,177$, $178,179,180,183,184,191,244,279,284$

Civil War 102, 158, 286

slighting of castle $9,10,96,237,289$

'Clactonian' stone tools 37

Claiton, Richard 291

Clark, Grahame 31, 127 
Clarke, David 76

clay pipes $179,181,184,208,238,239,245$

Clegg, Thomas 12

Coal Measures ware pottery $168,170,171,175$, $176,177,178,179,180,181,187,195,232$, 237, 244, 263

coal mining $\quad 283,285,312,318,319$

Coarse Blackware pottery $175,176,177,178,179$, 180, 192, 244, 296

Cockayne, Sir Thomas 5

coins 57, 208, 246, 262

Collingwood, R. G. 51

Collinson, Patrick 210, 278

Collis, John 33, 36

Colour Glazed ware pottery 245

Committee for the Exploration of Derbyshire Caves 31

Common People (social enterprise) 325

Conisbrough Castle, South Yorkshire 187, 189, 191, 196, 244

construction work, inter-war period $16,17,18,30$

see also inter-war excavations

construction work, post-war period $105,111,113,117$

see also foundation shafts; post-war excavations

cottages, in hunting lodge ruins $264,265,275,312$, $314,315,317,318$

Council for British Archaeology 109, 111

Council for the Preservation of Rural England 38

courtyard buildings

inter-war interpretations of $92,93,94,95,96,97$, 98, 99, 101

post-war interpretations of $136,155,157$

Coventry 201

Cox, J. Charles 318

Craven, William 286

Crawford, Major General $\quad 83,291$

Creamware pottery 244

Creighton, Oliver 256, 257

Creswell Crags, Derbyshire 31, 33, 37, 62

Crooke, John 290, 293

crucifix $60,208,210$

cruck-framed buildings

hunting lodge excavations 262, 263

inter-war interpretations of, at Sheffield Castle $70,72,73,80,100$

Culture Consortium 326

culture-historical paradigm $36,37,103,127$

Cumberpatch, Chris $185,186,188,195,196,243$

cupola furnace 54,242

Curr, John 318

curtain wall

inter-war interpretations of $89,90,91$

post-war interpretations of 136,154
D

Dart, Raymond 31

dating methods

dendrochronological analysis 202, 223, 226, 247

luminescence dating 222

radiocarbon dating $223,225,235$

Davies, Glyn 22, 201, 202

Davies, W. G. 67

Dawkins, William Boyd 31

de Busli, Roger 2

de Furnival, Gerard 2, 77

de Furnival, Thomas, I 2

de Furnival, Thomas, II 2, 72, 78, 89, 92, 100, 101, $102,103,232,253$

de Furnival, Thomas, III 253

de Furnival, William 3, 253

de Lovetot, Richard 253

de Lovetot, William $\quad 2,78,102,103,156$

de Montfort, Simon 79

deer park 251,252, 254, 310, 318

access from castle 255,256

animals 279

cholera monument 321,322

dispute over access through, late $17^{\text {th }}$ century 285

'Great Park' and 'Little Park' 256

Green Estate initiative 323

industry in $283,285,318$

landscape and woodland resources 281, 282

later history of 285

Manor Estate 321, 323, 324

medieval boundary $\quad 256,257$

pastures 281

Pictorial Meadows initiative 323

poaching 286

Shrewsbury Hospital 320,321

trees 281, 282

warren 280

see also hunting lodge

Defoe, Daniel xiii

demolition accounts $10,290,291,293,294$

demolition of castle 226

after Civil War 9, 10, 96, 237, 289

see also burnt layers

dendrochronological analysis 202, 223, 226, 247

Derbyshire, Andrew 114, 115

Desch, Cecil Henry 62

Dethick, William 9

D'eyvill, Johane 79, 102, 226

diatoms 232, 235

Dickenson, John 207

Dickenson, William 275, 278, 286, 293

Dixon, Phil 256 
Domesday Book 2, 74

Doncaster Hallgate A ware pottery $177,180,189$, 195, 222, 224, 226, 244

Doncaster Hallgate B ware pottery 244

Downe, William 286

drawbridge pier

inter-war interpretations of $47,86,87,88$

post-war interpretations of $146,147,150,151$, 155,167

drinking vessel glass 209, 246, 284

Drury, Charles 33, 75, 76, 310

Dugdale, Sir William 266, 284

Dunkley, Sylvia 22

Dunnett, Nigel 323, 327

Dunworth, Arthur 22

Dutch Oven 311,312

\section{E}

East Riding Archaeological Society News 119

east side of castle

deer park and 256

post-war interpretations of $136,155,157$

east tower of gatehouse 89,150

Ecclesfield Priory, South Yorkshire 253

ecological and economic approaches 127

Ed Dennison Archaeological Services Ltd 24, 74, $80,160,219$

EDAW 22

Edward II 256

Edward VI 3

Edwards, F. E. P. $\quad 69,90,91,154$

eighteenth century 10

bowling green $10,97,98,99,237,238,239,245$, 282, 296, 297

maps $10,11,13,14,23,89,97,98,160,163,238$, 239, 253, 255, 285, 291, 293, 296, 297, 298, 318

modern excavations $237,238,239,240$

visible ruins 12

see also industry

Elizabeth I 5

Elizabeth, Lady St Loe

see Shrewsbury, Elizabeth, Countess of

Engineering and Physical Sciences Research Council 336

English Heritage 22

environmental assemblages

modern excavations 225, 226, 232

post-war excavations 145

European pottery $168,195,244,284$

German stoneware pottery $168,170,172,177$, 196, 244

Low Countries Redwares 168, 178, 192, 196, 243

Evelyn, John 281 excavation archives

see Museums Sheffield archives

Exchange Street ditches 136, 140, 157, 158, 163

Eyre, John 297

\section{$\mathbf{F}$}

Fagan, Brian 31, 38

Fairbank, William $12,13,14,23,89,98,99,160$, $163,238,239,255,296,297,298,318$

fallow deer 253, 280

Fearnsides, William George 62

feasting and refuse artefacts 208

animal bone $168,175,176,179,180,184,208$, $248,260,280$

drinking vessel glass 209, 246, 284

wine bottle glass 209, 246, 284

Fenton, Alexander 286

Ferdinand of Aragon 3

Festival of the Mind, University of Sheffield 338, 339

Field Archaeology Services of York 260

finds specialists $57,58,59,60,64,65$

Fine Reduced Sandy ware pottery 191

Fine Redware pottery 192

Firth, Mark 320

Fitzalan-Howard, Henry, $15^{\text {th }}$ Duke of Norfolk 12 , 303, 315

Flint Castle, Clwyd 290

Forster, John E. 306

Foster, Edward 297

Foster, Mary 320

Fotheringhay Castle, Northamptonshire 8, 256

foundation shafts $120,122,164$

E11, finds 202, 203

E13

details 175

pottery 175,192

section drawings 174

E15

details 175

finds 209

section drawings 173

E17

details 175

section drawings 173

E18, finds $189,202,203$

E19

details 175

other finds $175,202,203,206$

photograph 138

pottery $175,186,188,190,191,192$

section drawings 173

E22, section drawings 173 
foundation shafts (continued)

F11

details 172

finds $146,172,201$

section drawings 174

F13, section drawings 174

F20

details 181

section drawings 174

F21

curtain wall 154

details 176

isometric drawing 145

other finds $176,202,206$

pottery $176,188,191,296$

section drawings 173

F22

details 179

other finds $180,202,206$

pottery $180,188,189,190,192,296$

section drawings 174

F23

details 181

finds 181, 206

section drawings 173

F9

details 172

pottery $146,189,190$

section drawings 173

G22

curtain wall 154

details 176

other finds $177,202,205,206$

pottery $177,188,189,190,191,296$

section drawings 165

G23

details 177

other finds $179,201,202,205$

pottery $178,188,190,191,192,296$

section drawings 165,169

G24

details 181,183

section drawings 169

G3, drawbridge pier 167

G5

details 171

isometric drawing 147

pottery $171,188,190$

section drawings 169

wooden stakes $146,147,171$

G7

details 171

isometric drawing 147 other finds $172,201,202,203$

pottery $172,188,190,192$

section drawings 169

wooden stakes $146,147,171$

G8, finds 202

G9

details 172

finds $172,202,203$

section drawings 169

G-H24

details 181,183

section drawings 165,169

H13, pottery 189

$\mathrm{H} 2-4 ; \mathrm{H} 2$

details 164

drawbridge pier 167

other finds $168,201,202,206$

pottery $146,149,167,188,189,190,191$, 192, 223

section drawings 149,165

H2, finds $188,191,202$

$\mathrm{H} 23$

details 180

other finds 181, 202, 206

photograph 139

pottery $180,188,189$

section drawings 165,169

H24

details $\quad 181,183$

pottery 183,192

section drawings $\quad 165,169$

H3

details 168

other finds $170,201,202,206$

pottery $170,188,191$

H32, pottery 188

H5

details 168

isometric drawing 147

masonry clad moat face $\quad 146,148$

other finds $170,201,202$

pottery 170,192

section drawings 169

wooden stakes $146,147,170$

$\mathrm{J} 23$

details 181

section drawings 165

J24, section drawings 169

J24a, section drawings 165

J4, finds 202

locations of $128,129,136,137,140$

at junction of south and west moat 175

in centre of south moat 172 


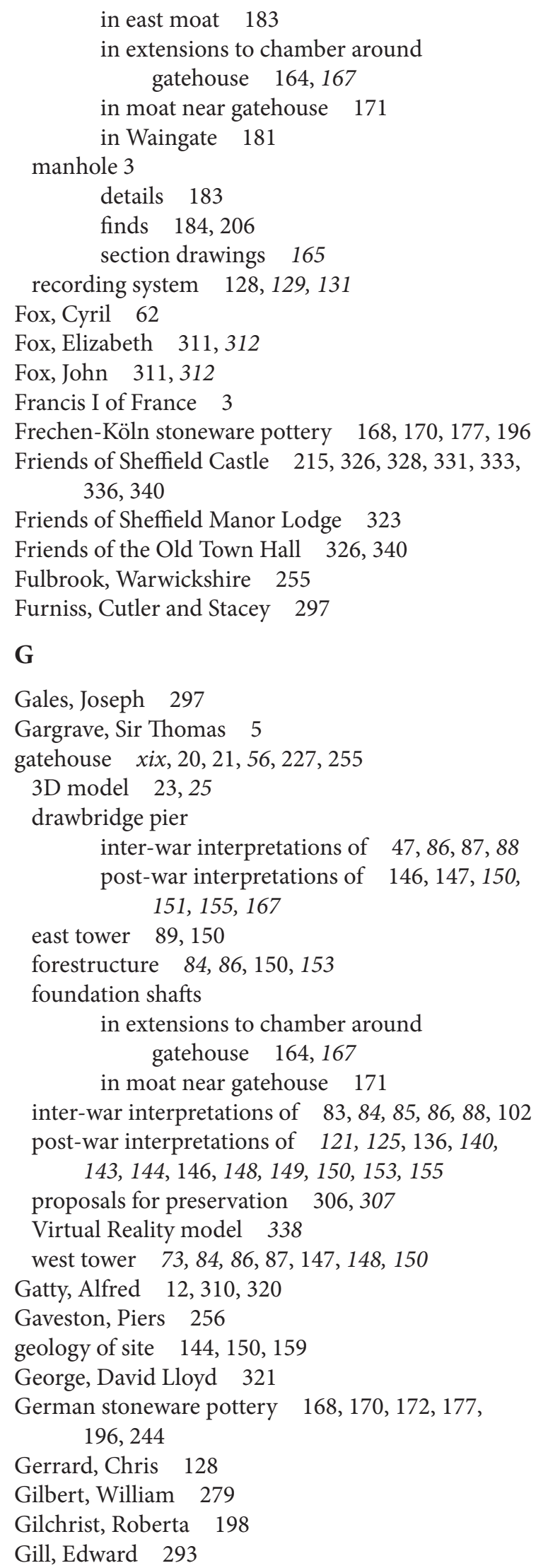

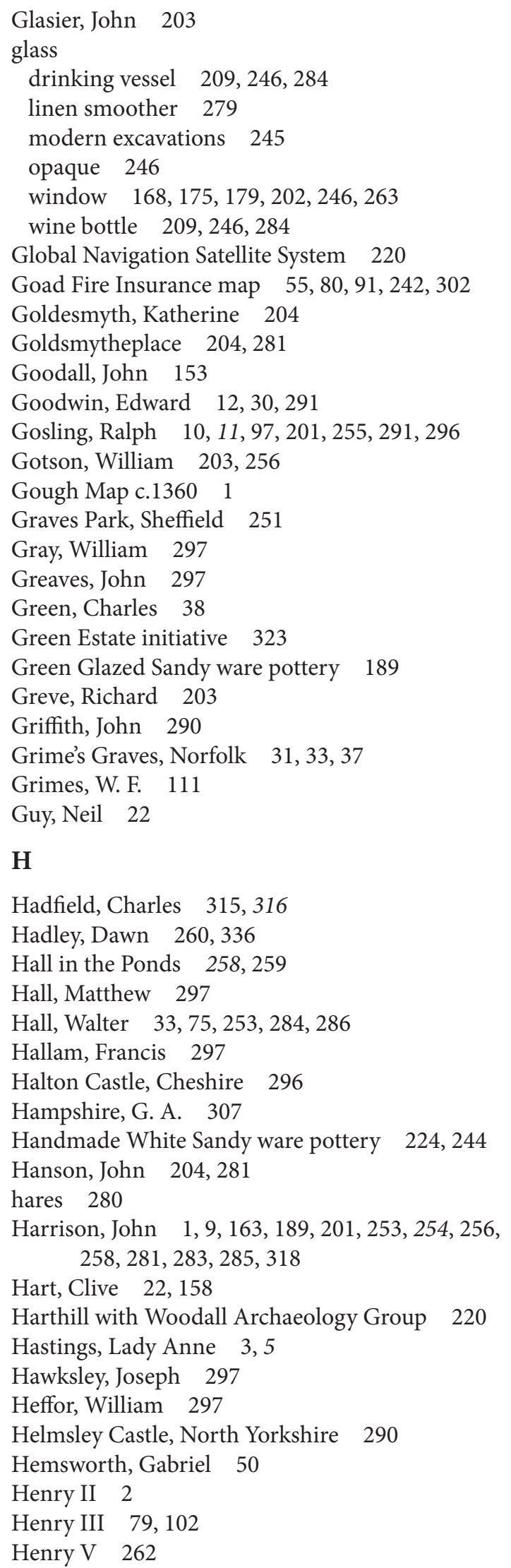


Henry VIII 3, 266, 280

Herbert, Lord 290

Heritage Lottery Fund xvi, 24, 260, 323

heritage-led urban regeneration 335

Castlegate projects $325,326,327,328,330,331$

herringbone fill 229, 231

Hey, David 1, 255, 270, 291

Hicke, Nicholas 293

Higgins, David 245

Hill, Christopher 76

Hilliard, Nicholas 6

Himsworth, Joseph $\quad 18,24,29,30,33,35,38$, $42,48,51,67,155,224,226,229,238$, 305,334

analysis of artefacts $\quad 62,64,65$

artefacts in his possession 66

as Armstrong's assistant 47

diary $33,38,40,41,43,44,45,46,48,52,54$, 55,66

historical perspective 50

lectures 30, 38, 40, 42, 47, 50, 62, 205

see also inter-war excavations

Himsworth, Joyce $38,41,42$

Historic England 215, 330

Hodges, Richard 330

Holland, John 251, 252, 319

Hough, Carole 253

Housing and Town Planning Act 1919321

Howard, Bernard, $12^{\text {th }}$ Duke of Norfolk 321

Howard, Henry, $13^{\text {th }}$ Duke of Norfolk 321

Howard, Henry, $22^{\text {nd }}$ Earl of Arundel 284,290 , 294, 296

Howard, Henry, $7^{\text {th }}$ Duke of Norfolk 285

Howard, Thomas, $1^{\text {st }}$ Earl of Norfolk 9

Howard, Thomas, $5^{\text {th }}$ Duke of Norfolk 296

Howard, Thomas, $8^{\text {th }}$ Duke of Norfolk 285

Hoy, Felicity 325

Hughes, Harold 33

Humberware pottery $168,189,195,235,244$

Hunter Archaeological Society 18, 33, 40, 42, 47, 109, 110, 113, 305, 306

Butcher's lecture to $113,114,115,124,127$, 135,154

Field Research Section $\quad 115,119$

index of sites 109, 119

Scheme for Archaeological Research in the region around Sheffield 109, 110, 119

'The Butcher Project' 111

Transactions of the Hunter Archaeological Society $18,29,30,47,54,80,109,123,310$

Hunter, Gordon 119

Hunter, Joseph $\quad 12,40,42,50,78,91,253,255,256$, $265,270,280,284,285,303,312$
Hunter, Lynette 279

hunting lodge $3,251,252,257,259,282,291,294$, 296, 310

and Mary, Queen of Scots 266, 278

documentary references 265

excavations $258,259,311$

artefacts $260,263,279,284,311,312$

cruck-framed building 262, 263

evidence of pottery manufacture 311 , 312,313

inner courtyard buildings $262,270,271$, $272,273,274$

long gallery $263,264,268,312,313$

outer courtyard building 260

service range 274,276

garderobe 266, 268

Green Estate initiative 323

industrialisation of 310,319

cottages $264,265,275,312,314,315$, 317,318

pottery manufacture $311,312,313$

later history of 283

long gallery $264,266,267,268,270,318$

cottages built in ruins $264,265,312,317,318$

excavations $263,264,268,312,313$

preservation of remains 322

restoration of 315,316

service range $274,275,312,314$

excavations 274,276

three-storey tower $266,267,268$

Turret House $\quad 259,275,276,279,310,311,315$, 316,318

two-storey tower 267, 268

Virtual Reality models 324

see also deer park

Hynes, William 283

\section{I}

industry 293, 297, 299, 304

cementation furnace 54,242

coal mining $283,285,312,318,319$

in deer park $283,285,318$

in hunting lodge ruins 310 cottages $264,265,275,312,314,315,317,318$ pottery manufacture $311,312,313$

modern excavations 241

royal visit and 303, 305

Tower Grinding Wheel 300

weighbridge 242

Wicker Tilt 300, 301

inter-war excavations $\quad x v i i i, x i x, 18,29,33,35,48$, $51,52,56$

archaeological practice 33,37

finds specialists $57,58,59,60,64,65$ 


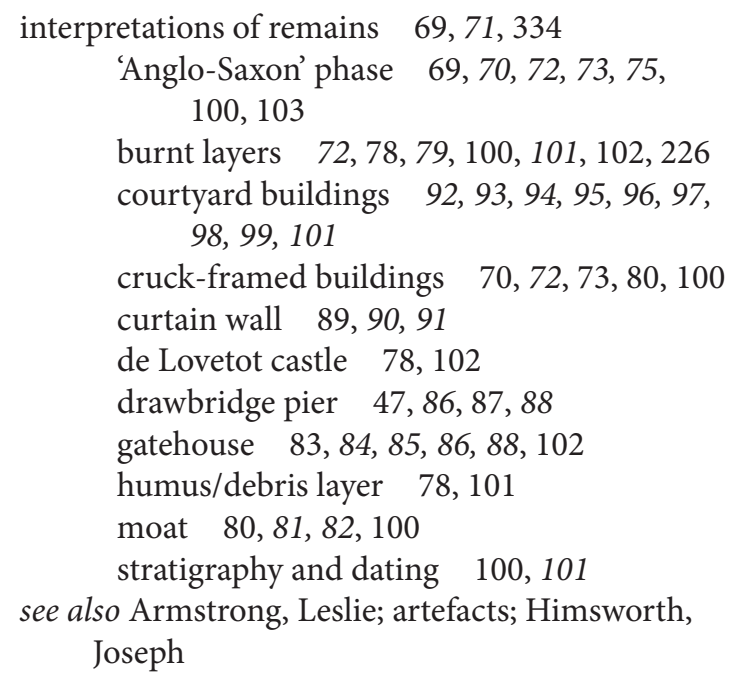

\section{K}

Kenilworth Castle, Warwickshire 290

Kenyon, Kathleen 36

Kettelicke, William 207

keys $61,62,63,203$

Killing Shambles see slaughterhouses

Kilton, William 281

King's Ditch, Cambridge 201

Knaresborough Castle, North Yorkshire 256, 290

knives 62, 63, 177, 204, 206, 260

\section{L}

Lady's Bridge $\quad 55,83,141,242,282,291,292,300$, 301, 304, 305

Lamb, Winifred 62

Lancaster Castle, Lancashire 290

Late Medieval Gritty ware pottery

Late Medieval Sandy ware pottery

Late Oxidised Sandy ware pottery 191

Latham, Ian 95, 96

Law, Charles 297

Lawson, George 9
Lea, Harry $\quad 40,42,47,257$

Leach, Matt 337

Leader, John Daniel xiii, 2, 26, 75, 265, 291, 296, 315

Leader, Robert $\quad 2,76,77,297,317$

Leakey, Louis 31

leather artefacts $168,170,172,196$

black-jacks 200

modern excavations 196, 247

other items 199

production and sale of 200

cobbling 200

palm guard $61,201,202$

tanneries 201

shoes 213

cobbling 200

fragments $180,184,198,200,246$

medieval 197, 200

post-medieval $179,199,200$

Lees, C. E. 15

Legge, John 256

Leland, John 205

'Levalloisian' stone tools 37

levelling-up of ground surface $78,101,227,229$, $231,238,241$

Lewes, Sussex 296

linen smoother, glass 279

Live Projects, School of Architecture 326, 328, 330,331

Liverpool Castle 53

Llama Digital 327

Local Government Association 335

Local Oxidised Sandy ware pottery 191

Lord Leverhulme Fund 31

Loughran, Reg 48, 49, 54, 66, 71, 85, 86, 93, 220

Low Countries Redware pottery $168,178,192$, 196,243

Lucas, Gavin 33, 55, 123

luminescence dating techniques 222

Lumley, Samuel 245

\section{M}

Macey-Bracken, Erica 247

Maddock, Steve 336, 337

Maiden Castle, Dorset 36

Maiknie, Edward 291

Makepeace, Graham 111, 119, 123

Maltby, Mark 280

Maltravers, Henry Howard, Lord 284

Manners, Lady Gertrude 6,9

Manor and Castle Development Trust 322

Manor Castle Colliery 319

Manor Colliery 318 


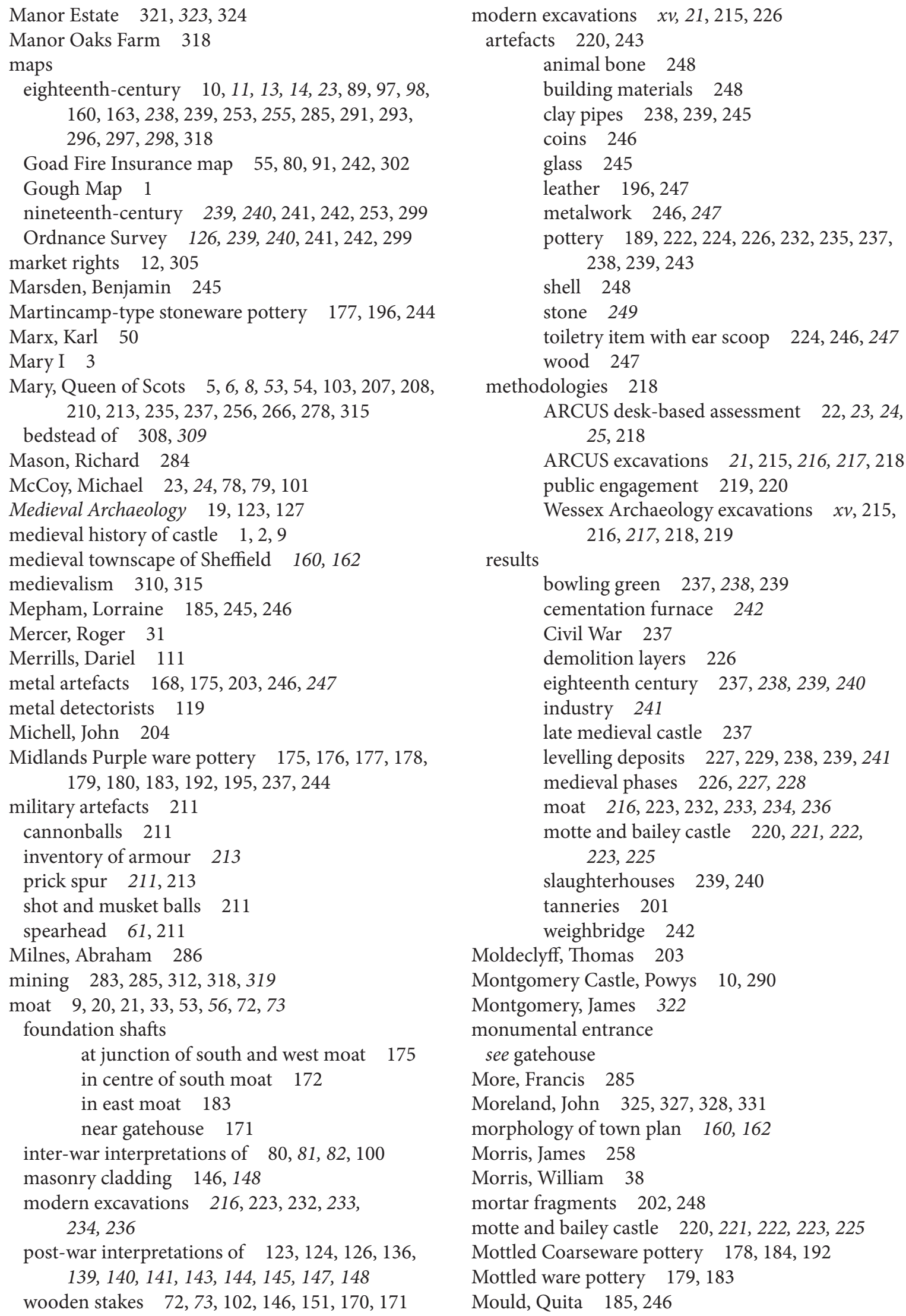


Mower, Arthur 9

Muller, John 328

Mulner, John 203, 211

Murdac, Ralph 2

Museums Sheffield archives $18,22,23,24,25,47$, $145,218,260$

musket balls and shot 211

\section{$\mathbf{N}$}

Nashe, Thomas 3

National Planning Policy Framework xvi

National Videogame Museum 340

Nelson, John 296

Nevell, Richard 153

Nevill, Sir Thomas 3

nineteenth century

development of site $12,14,297$

maps 239, 240, 241, 242, 253, 299

royal visits 1875 and 1897303 , 305,310

visible ruins 12

see also industry

Norfolk, Bernard Howard, 12 ${ }^{\text {th }}$ Duke of 321

Norfolk, Dukes of 9, 10, 283, 284, 285, 297, 298

Norfolk, Henry Fitzalan-Howard, $15^{\text {th }}$ Duke of 12 , 303, 315

Norfolk, Henry Howard, $13^{\text {th }}$ Duke of 321

Norfolk, Henry Howard, $7^{\text {th }}$ Duke of 285

Norfolk, Thomas Howard, $1^{\text {st }}$ Earl of 9

Norfolk, Thomas Howard, $5^{\text {th }}$ Duke of 296

Norfolk, Thomas Howard, $8^{\text {th }}$ Duke of 285

North Lincolnshire shell-tempered wares 168, 187,243

North Nottinghamshire Quartz and Shell ware pottery 222, 226, 244

Northend, J. W. 66

Norton Hall, Sheffield 293

Norwich Castle 201

Nunnery Colliery $\quad 319,320$

\section{O}

Odom, W. 33, 77

Ogden, Simon 289, 325, 331

Old Queen's Head public house 258, 259

open-area excavation 33,38

Ordnance Survey maps 126, 239, 240, 241, 242, 299

ostracods 232

Oughtibridge, Thomas 10, 97, 239, 281, 282, 287, 296

outer courtyard of castle 163

Ove Arup \& Partners site plans 128, 136, 137, 154

Oxford Castle 83, 201, 220, 235
Oxidised Sandy ware pottery $191,224,244$

Late 191

Local 191

\section{$\mathbf{P}$}

padlock slide key 61,203

palm guard 201, 202

Parsons, Julien 107

pastures, in deer park 281

Paulet, Sir Amyas 210

Peak District Mines Historical Association 119

Peake, Harold 62

Pearlware pottery 180,244

Pearson, John 293

Pembroke Castle, Pembrokeshire 158

Percy Sladen Memorial Fund 31

Perth, Scotland 111

Petrie, Flinders 33

Pevensey Castle, Sussex 153

Peveril Castle, Derbyshire 189

Pictorial Meadows initiative 323

Piers, John 9

Piggott, Stuart 31

Pilgrimage of Grace 3

pins 57, 61, 204, 205

Planning Policy Guidance Note 16 xv, xvi, 22, 218

plant remains

modern excavations 224, 225, 226

post-war excavations 145

plaster fragments $181,202,248$

'playing card' 60, 208, 209

Plumber, John 203

poaching 286

Poll Tax returns 1378-79 205

pollen remains 232

Pontefract Castle, West Yorkshire $10,191,192,195$, 196, 255, 291, 293

Portable Antiquities Scheme 119

post-war excavations $19,105,111,113,117,120$, 138,224

archaeological practice $121,122,128,129$

interpretations of remains $123,126,135,143,334$

curtain wall 136,154

drawbridge pier $146,147,150,151$, 155,167

east side of castle and courtyard buildings 136, 155, 157

Exchange Street ditches $136,140,157$, 158,163

gatehouse $121,125,136,140,143,144$, $146,148,149,150,153,155$

moat $123,124,126,136,139,140,141$, $143,144,145,147,148$ 
post-war excavations (continued) morphology of town plan 160,162 outer courtyard 163 plant remains 145 topography of Castle Hill $\quad$ 136, 158, 159, 229,230

preservation of remains $305,306,307$

recording system $128,129,131,132$ for artefacts 128, 129

see also artefacts; Bartlett, John; Butcher, Leslie;

foundation shafts

pottery $146, \mathbf{1 8 6}, 296$

earliest pottery 186

'Anglo-Saxon' 74, 101, 186

shell-tempered wares $168,186,187,195$, 224, 243, 244

Stamford wares 175,186

early modern and recent wares 243, 244

Bone China 245

Cane Coloured wares 245

Colour Glazed wares 245

Creamwares 244

Pearlwares 180, 244

Slip Banded Cane Coloured wares 245

Unglazed Red Earthenwares 245

White Salt Glazed Stoneware pottery 244

foundation shafts

E13 175, 192

E19 175, 186, 188, 190, 191, 192

F21 176, 188, 191, 296

F22 180, 188, 189, 190, 192, 296

G22 177, 188, 189, 190, 191, 296

G23 178, 188, 190, 191, 192, 296

G5 171, 188, 190

G7 $172,188,190,192$

G-H24 183

H2-4 146, 167, 188, 189, 190, 191, 192, 223

$\mathrm{H} 2-4 \quad 149$

H23 180, 188, 189

$\mathrm{H} 24183,192$

H3 170, 188, 191

H5 170, 192

J23 181

manhole $3 \quad 184$

hunting lodge excavations $\quad 260,263,279,284$

Dutch Oven 311, 312

evidence of pottery manufacture 311 , 312,313

inter-war interpretations of $74,87,101,102,186$

medieval and early post-medieval $\mathbf{1 8 6 , 1 8 7}$

Blackwares $170,171,175,176,177,178$, $179,180,183,184,192,193,195,237$, $244,279,284,296$
Border wares 191

Brackenfield wares $177,180,189,195,244$

Brown Glazed Coarsewares 192, 244

Brown Glazed Finewares 192, 244

Brown Salt Glazed Stoneware 184

Buff Sandy wares $168,179,191,244$

Chalk-tempered Sandy wares 244

Cistercian wares $170,171,172,176,177,178$, $179,180,183,184,191,244,279,284$

Coal Measures wares $168,170,171,175$, $176,177,178,179,180,181,187,195$, 232, 237, 244, 263

Coarse Blackwares $175,176,177,178,179$, 180, 192, 244, 296

Doncaster Hallgate A wares $177,180,189$, $195,222,224,226,244$

Doncaster Hallgate B wares 244

Early Brown Glazed Coarsewares 175, $176,177,178,179,180,181,183,184$ 192, 195, 244, 296

Early Brown Glazed Finewares 192

European wares 192, 195

Fine Reduced Sandy wares 191

Fine Redwares 192

German stonewares $168,170,172,177$, 196, 244

Green Glazed Sandy wares 189

Handmade White Sandy wares 224, 244

Humberwares 168, 189, 195, 235, 244

Late Medieval Gritty wares 191, 244

Late Medieval Sandy wares 178, 191, 237

Late Oxidised Sandy wares 191

Local Oxidised Sandy wares 191

Low Countries Redwares $168,178,192$, 196, 243

Midlands Purple wares $175,176,177,178$, 179, 180, 183, 192, 195, 237, 244

Mottled Coarsewares 178, 184, 192

Mottled wares 179, 183

North Nottinghamshire Quartz and Shell wares 222, 226, 244

Oxidised Sandy wares 191, 224, 244

post-medieval Sandy wares 192

Purple Glazed ware pottery $171,178,179$

Purple Glazed wares 195

Reduced Sandy wares $168,175,191,222$, 226, 232, 244

Redwares $168,175,178,179,180,183$, $184,192,195,244$

Sheffield wares $168,171,175,177,178$, $179,180,189,190,195,232,235,244$

Slipware pottery $175,177,178,179,180$, $183,184,244$ 
Splash Glazed Gritty wares 235

Splash Glazed Sandy wares 244

Surrey Whitewares 191, 244

Tees Valley B/C wares 191

Tin Glazed Earthenwares 192, 196, 244, 284

Unglazed Redwares $175,177,181,183$, 192, 195

White Sandy wares 224, 244

Yellow Glazed Coarseware pottery $\quad 170$, 177,178

Yellow wares $175,176,179,180,181,183$, 192,244

modern excavations $\quad 189,222,224,226,232,235$,

$237,238,239,243$

Roman 2

supply of pottery to castle 195

pottery manufacture, in hunting lodge ruins 311, 312,313

PPG16

see Planning Policy Guidance Note 16

prehistoric flints 2

Prehistoric Society 31, 40

preservation of remains $305,306,307$

Preston, Fredric 109, 110, 119

prick spur 211, 213

Proceedings of the Prehistoric Society 31

public engagement, modern excavations 219, 220

Purple Glazed ware pottery $\quad 171,178,179,195$

\section{Q}

Queen's Tower 315, 316, 321

\section{R}

R\&J Smith $\quad 55,242,302$

rabbits, in deer park 280

radiocarbon dating $223,225,235$

Raglan Castle, Monmouthshire 296

rate books 297, 299

Rawson, Robert 290

Rawson, Thomas 294

recording system, post-war excavations 128,129 , 131,132

for artefacts 128, 129

Reduced Sandy ware pottery $\quad 168,175,191,222$, $226,232,244$

Redware pottery $168,175,178,179,180,183,184$, 192, 195, 244

Fine Redwares 192

Low Countries Redwares $\quad 168,178,192,196,243$

Unglazed Redwares $\quad 175,177,181,183,192,195$

Reindeer Inn 12

Remains of the Sheffield Castle Working Group 22
Revealing the Castle project $\quad 328,330,331$

Rhodesian Archaeological Expedition 49

Rhuddlan Castle, Denbighshire $\quad 153,154$

Richardson, Amanda 256

Richardson, Shaun $\quad 24,74,80,160$

Richmond, Richard 232, 281

Rivelin Chase 252

Roach, John 320

Roberts, Samuel 267, 315, 316, 320, 321

Roche Abbey, South Yorkshire 203, 224

Roman and Mediaeval London Excavation Council 111

Roman pottery 2

Rotherham House Hotel $\quad 55,80,82$

Rowland, Paul 220

Roworth, Henry 203, 211

Royal Anthropological Institute 31

Royal Entomological Society 145

Royal Exchange Buildings 300

Royal Society for the Encouragement of Arts, Manufactures and Commerce 38

royal visits 1875 and $1897 \quad 303,305,310$

ruins, visible

in eighteenth century 12

in nineteenth century 12

in twentieth century $12,15,162$

Ruskin, John 38

Ryder, Peter 249

\section{S}

Sandal Castle, West Yorkshire 191, 196

Saunder, William 293

Schattner, Angela 296

Scheme for Archaeological Research in the region around Sheffield 109, 110, 119

Scorah, Richard 245

Scurfield, Gordon 253, 254

Senior, John 297

Shakespeare, William 3

Shaw, George 308

shears $61,62,63,205$

Sheffield Artcrafts Guild $\quad 38,42$

Sheffield Bazaar $2014 \quad 325,326$

Sheffield City Museum 20, 21, 117, 119, 258

Sheffield Colliery Company 318

Sheffield Corporation $12,16,17,105,111,305,322$

Sheffield Daily Telegraph $12,30,54,62,75,76,82$, $83,113,115,209,242,304,305$

Sheffield Hallam University 326,331

Sheffield Independent Press 49

Sheffield Mail 306

Sheffield Manor Lodge

see hunting lodge 
Sheffield park

see deer park; hunting lodge

Sheffield Park Colliery 283, 318

Sheffield Register 297

Sheffield Trade Directory 297

Sheffield Trades Technical Society $\quad 30,40,47,205$

Sheffield ware pottery $168,171,175,177,178,179$, 180, 189, 190, 195, 232, 235, 244

Sheffield Wildlife Trust 323

shell-tempered wares $168,186,187,195,224$, 243,244

Shertcliffe, Robert 10

shoes 213

cobbling 200

fragments 198,200

medieval 197, 200

post-medieval 199,200

Shore, Humphrey 292, 294

Shore, John 292, 294

Shore, Robert 292, 294

Shore, Samuel 297

shot and musket balls 211

Shrewsbury Chapel, Sheffield Cathedral 3, 5

Shrewsbury Hospital 294, 295, 299, 320, 321

Shrewsbury, Edward Talbot, $8^{\text {th }}$ Earl of 9, 284

Shrewsbury, Elizabeth, Countess of 7,207, 237, $266,275,279,286$

Shrewsbury, Francis Talbot, $5^{\text {th }}$ Earl of 5,256 , 266,280

Shrewsbury, George Talbot, $4^{\text {th }}$ Earl of 3,5 , 266, 291

Shrewsbury, George Talbot, $6^{\text {th }}$ Earl of $5,8,9,201$, 204, 207, 209, 237, 265, 266, 275, 278, 283

Shrewsbury, Gilbert Talbot, $7^{\text {th }}$ Earl of $9,278,279$, 280, 284, 286, 295, 320

Shrewsbury, Grace, Countess of 266

Shrewsbury, John Talbot, $1^{\text {st }}$ Earl of 3, 281

Shrewsbury, John Talbot, $2^{\text {nd }}$ Earl of 3

Shrewsbury, John Talbot, $3^{\text {rd }}$ Earl of 3

Simon, Richard 286

Single Regeneration Budget scheme 323

Singleton, H. Raymond $\quad 115,119,127$

Skargel, Thomas 293

Skelton, Elizabeth 258

Sklatter, Nicholas 203

slaughterhouses $12,14,49,74,75,89,239,240$, $297,299,300,301,304$

slighting of castle $9,10,96,237,289$

Slip Banded Cane Coloured ware pottery 245

Slipware pottery $175,177,178,179,180,183$, 184,244

Small, W. H. 76

Smyth, John 203
Smythson, Robert 279

social housing 321,323

Society of Antiquaries $\quad 18,30,31,62,74,81$

Sorby Natural History Society 31,145

South Yorkshire Archaeology Field and Research Unit 21

South Yorkshire Archaeology Service 215, 218, 219

South Yorkshire Sites and Monuments Record 109, 218,256

Spavold, Janet 191

spearhead 61,211

Splash Glazed Gritty ware pottery 235

Splash Glazed Sandy ware pottery 244

spurs 211,213

Stamford ware pottery 175,186

Staniforth, John 290

Steel, Kenneth $\quad 307,308$

Steers and Wilkinson 299

Stenton, Mark 23, 24, 78, 79, 101

Stone, Lawrence 283

stratigraphy $36,37,100,101$

Surrey Whiteware pottery 191,244

Swyfte, Robert 203

Swynok, John 203

$\mathrm{T}$

Talbot, Alethea 9, 279, 284, 296

Talbot, Christopher 281

Talbot, Edward, $8^{\text {th }}$ Earl of Shrewsbury $\quad 9,284$

Talbot, Francis, $5^{\text {th }}$ Earl of Shrewsbury $\quad 5,256$, 266,280

Talbot, George, $4^{\text {th }}$ Earl of Shrewsbury $\quad 3,5$, 266,291

Talbot, George, $6^{\text {th }}$ Earl of Shrewsbury $\quad 5,8,9,201$, 204, 207, 209, 237, 265, 266, 275, 278, 283

Talbot, Gilbert, $7^{\text {th }}$ Earl of Shrewsbury $\quad 9,278,279$, $280,284,286,295,320$

Talbot, John, $1^{\text {st }}$ Earl of Shrewsbury $\quad 3,281$

Talbot, John, $2^{\text {nd }}$ Earl of Shrewsbury 3

Talbot, John, $3^{\text {rd }}$ Earl of Shrewsbury 3

tanneries 201

Tarmac Development Management 218

Taylor, Benjamin 297

Tees Valley B/C ware pottery 191

Templeman, David 235

The Farm 321, 322

Thomson, Roy 201

tile fragments $168,179,201,248,279$

timber and wood

building materials 202, 247

wooden stakes $72,73,102,146,147,151,170$, 171,202 
Tin Glazed Earthenware pottery $\quad$ 192, 196, 244, 284

toiletry item with ear scoop $224,246,247$

topography of Castle Hill 136, 158, 159, 229, 230

see also levelling-up of ground surface

Toulmin, Vanessa 325

Tower Grinding Wheel 300

Town Trust 291

trade directories 297

Trades Technical Preservation of Old Tools Society 38

Transactions of the Hunter Archaeological Society $18,29,30,47,54,80,109,123,310$

trees, in deer park 281, 282

Tresoldi, Edoardo 330, 331

tripartite acanthus leaf motif 191

Tudor history of castle 3

Turret House $\quad 259,275,276,279,310,311,315$, 316,318

Tyers, Ian 247

\section{$\mathrm{U}$}

UNESCO World Heritage Site, Butrint 330

Unglazed Red Earthenware pottery 245

Unglazed Redware pottery $175,177,181,183$, 192, 195

University of Sheffield $23,25,215,260,326$

Castlegate Steering Group 325

Department of Landscape Architecture 323, 328

School of Architecture 326, 328, 330, 331

\section{V}

Vernon, Sir George 5

Vicars, John 9

Victoria and Albert Museum 308

Victoria, Queen 310

Vince, Alan 186

Virtual Reality models

castle $337,338,340$

hunting lodge 324

volunteers, modern excavations $\quad 219,220$

voussoir 249

\section{W}

Waddington, Clive 23

Wagner, Pat 40

Wainwright, Joseph 297

Wainwright, Sam 297

Waite, John 296

Walden, Elizabeth 3, 5, 266

Waller, Richard 203

Waltheof $2,69,74,77,100,103$

Warburton, John 285

Wardlow, James 258 warrens, in the deer park 280

Watson, Mary 220

Watt, James 310

Way, Albert 208

weighbridge 242

Weldon and Furniss 297

Wessex Archaeology $x v, 215,216,217,218,219$, 260,331

see also modern excavations

west tower of gatehouse $73,84,86,87,147,148,150$

West, Robert 203

Westerwald stoneware pottery 244

Wheeler, Mortimer $\quad 36,37,38,121$

White Salt Glazed Stoneware pottery 244

White Sandy ware pottery 224, 244

Handmade 224, 244

White, Susie 208, 245

White's Directory of the Borough of Sheffield, Doncaster and Chesterfield 303

Whitley, Wharncliffe, South Yorkshire 111, 122,123

Wicker Tilt 300, 301

Wigfull, James Ragg $\quad 30,33,35,54,83,92$, 204,306

Wild, Thomas 245

Wild, William 245

William I 2,72

Willmott, Hugh $\quad 22,201,202,209$

Wills, Jan 111

Winder, Thomas $12,30,75,97,98,242,258$, 265,285

Windle, Morgan 248

window glass $168,175,179,202,246,263$

window tracery $249,300,302$

wine bottle glass 209, 246, 284

Wolsey, Cardinal 3, 265, 267, 324

Wolsey's Tower 267, 268, 324

Womersley, J. Lewis $111,113,114,120,129,136$

wood

see timber and wood

Wood, Edward 291, 293

Wood, Leonard 293

Woodrove, John 286

Woolley, Leonard 52, 62

Wright, Michael 292

Y

Yellow Glazed Coarseware pottery $\quad 170,177,178$

Yellow ware pottery $175,176,179,180,181,183$, 192,244

Yorkshire Artspace 325, 329, 338

Yorkshire Telegraph and Star 53, 83, 213, 305, 306

Young, Jane $185,186,243$ 
Sheffield Castle presents an original perspective on an urban castle, resurrecting from museum archives a building that once made Sheffield a nexus of power in medieval England, its lords playing important roles in local, national, and international affairs. Although largely demolished at the end of the English Civil War, the castle has left an enduring physical and civic legacy, and continues to exert a powerful sway over the present townscape, and future development, of Sheffield.

In this volume, we rediscover the medieval castle, explore its afterlife, and discuss its legacy for the regeneration of Sheffield into the twenty-first century. The authors bring to publication for the first time all the major excavations on the site, present the first modern study of artefacts excavated in the mid-twentieth century, and situate both in the context of the published and unpublished documentary record. They also tell the stories of those responsible for re-discovering the castle, the circumstances in which they were working, their archaeological methods, and the scholarly and political influences that shaped their narratives.

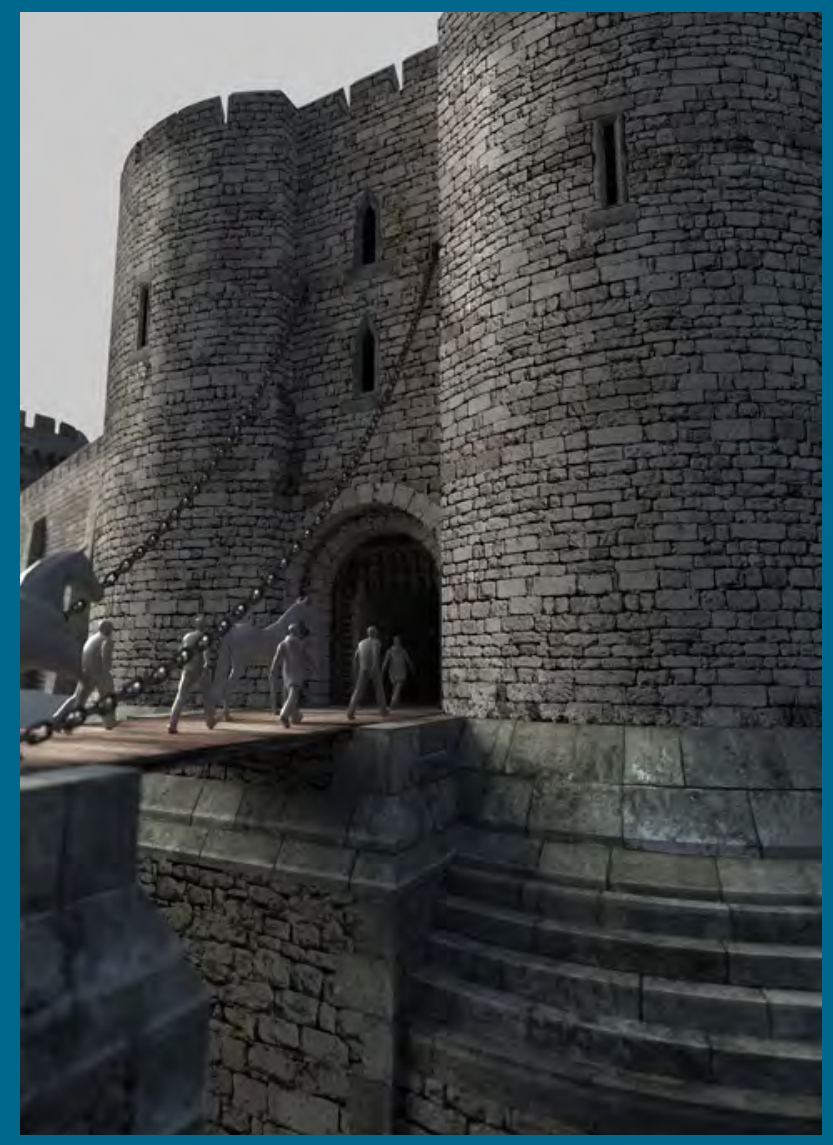

IMAGE: The gatehouse of Sheffield Castle in a Virtual Reality model. The 21st-century visual identity for this historic site. University of Sheffield.

In setting the study within the context of urban regeneration, Sheffield Castle differs from most publications of medieval castles. This regeneration narrative is both historical, addressing the ways in which successive building campaigns have encountered the castle remains, and current, as the future of the site is under active discussion following the demolition of the market hall built on the site in the 1960s. The book explores how the former existence of the castle, and the landscape in which it sat, including its deer park, have shaped the development of the 'Steel City'. We see that the untapped heritage of the site has considerable value for the regeneration of what may now be one of the most deprived areas of Sheffield, but was once at its social, political and cultural heart.

Prof John Moreland (University of Sheffield) and Prof Dawn Hadley (now University of York) led the University of Sheffield's Sheffield Castle project, and worked with colleagues from Wessex Archaeology, Museums Sheffield and the contributors named below. This volume, written with Ashley Tuck and Milica Rajic from Wessex Archaeology, presents the culmination of the findings of this project and is, importantly, accompanied by a digital archive, making all the research materials publicly available.

CONTRIBUTORS: Umberto Albarella, Lucy Allott, Phil Andrews, Rachel Askew, lan Atkins, Mark Bateman, Pauline Beswick, Pippa Bradley, Alex Brown, Alan Bryson, Caitlin Buck, Andrea Burgess, Carolyn Butterworth, Nigel Cameron, Liz Chambers, Vicky Crewe, Chris Cumberpatch, Glyn Davies, Gareth Dean, Deborah Harlan, Chris Harrison, David Higgins, Glynis Jones, Matt Leach, Inés López-Dóriga, Erica Macey-Bracken, Rod Mackenzie, Steve Maddock, Lucy Marston, Lorraine Mepham, Alvaro Mora-Ottomano, Quita Mould, Nicky Mulhall, Richard Payne, Andrew Powell, Paul Rowland, Peter Ryder, Ellen Simmons, James Symonds, lan Tyers, Susie White, John Whittaker, Morgan Windle, Jane Young. 